\title{
Evaluation of Five Sedimentary Rocks Other than Salt for Geologic Repository Siting Purposes
}

Volume 1: Main Report and

Appendixes $A$ and $B$

November 2003

Prepared by
A. G. Croff
T. F. Lomenick
R. S. Lowrie
S. H. Stow

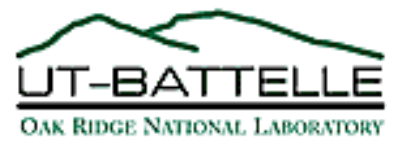


EVALUATION OF FIVE SEDIMENTARY ROCKS OTHER THAN SALT FOR GEOLOGIC REPOSITORY SITING PURPOSES

\title{
VOLUME 1: MAIN REPORT AND APPENDIXES A AND B
}

\author{
A. G. Croff \\ T. F. Lomenick \\ R. S. Lowrie \\ S. H. Stow \\ Date Published: November 2003 \\ PREPARED FOR THE \\ UNITED STATES DEPARTMENT OF ENERGY \\ OFFICE OF CIVILIAN RADIOACTIVE WASTE MANAGEMENT

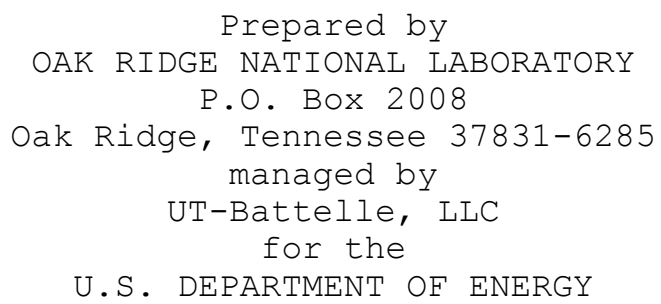


This report was prepared as an account of work sponsored by an agency of the Inited States Covernment. Neither the United States Government nor any agency thereof, nor any of their employees, makes any warranty, express or implied, or assumes any legal liability or responsibility for the accuracy, completeness, or usefulness of any information, apparatus, product, or process disclosed, or represents that its use would not infringe privately owned rights. Reference herein to any specific commercial product, process, or service by trade name, trademark, manufacturer, or otherwise, does not necessarily constitute or imply its endorsement, recommendation, or favoring by the United States Government or any agency thereof. The views and opinions of authors expressed herein do not necessarily state or reflect those of the United States Government or any agency thereof. 
The purpose of this preface is to provide background information concerning a comparative evaluation of five sedimentary rock types performed for the Sedimentary Rock Program (SERP) of the U.S. Department of Energy (DOE) and the quality assurance measures instituted by the Oak Ridge National Laboratory (ORNL) as a part of this program. Planning activities for this evaluation began early in CY 1984 by developing the rock evaluation criteria (RECs) to be employed in the comparative evaluation, identifying the information required to perform the evaluations, and instituting contracts to acquire the information. The information acquisition approach adopted by the SERP was to obtain the services of a number of individuals and organizations having recognized expertise in a parlicular technical area. In many instances, information was acquired for a particular technical area by one individual or organization under the guidance and oversight of an independent consultant. The individuals and organizations participating in the information acquisition phase, their roles, and their affiliations are as follows:

Technical area

Hydrology

Geochemistry

Rock Mechanics

Thermal Response

Geology

Shale

Sandstone

Carbonates

Anhydrock

Chalk

Natural Resources

Repository Cost

Waste Package

Degradation

Decision Analysis
Consuitant

P. Domenico (Texas A\&M University)

D. Brookins (University of New Mexico)

J. Russell (Texas A\&M University)

C. Clalborne (ORNL)

P. Potter (University of Cincinnati)

R. Dott (University of Wisconsin)

K. Walker (University of Tennessee)

K. Johnson, S. Gonzales (Earth Resource Associates)

D. Hattin (Indiana University)

S. Gonzales (Earth Resource As sociates)

RE/SPEC Inc.

J. Griess (ORNL)

P. Gnirk (RE/SPEC Inc.)

\section{Party acquiring intormation}

Berkeley Geosclences Associates

D. Rye, M. Monaghan, P. Dixon (Yale University)

RE/SPEC Inc.

RE/SPEC Inc.

S. Gonzales, K. Johnson (Earth Resource Assoclates)

S. Drlese (University of Tennessee)

K. Walker (University of Tennessee) Earth Resource Assoclates

D. Hattin (Indiana UnIversity) Netherland, Sewell \& Associates

RE/SPEC Inc.

J. Griess (ORNL)

P. Gnirk (RE/SPEC Inc.)

Meetings were held in June of 1984 to plan and coordinate the information acquisition details. Information acquisition took place throughout the summer and early fall of 1984. On October 25-26, 1984, a meeting of most of the above consultants and information acquirers was held at ORNL to review the information base, identify any final information needs, and form preliminary conclusions on the evaluation of the subject rock types. Only minor modifications and additional information requirements were identified in this meeting. The preliminary ranking of the subject rocks, which resulted from a general consensus of the attendees, has remained essentially intact and is reflected in this report. 
Throughout November and early December 1984, manuscripts of reports documenting the data base for the comparative evaluation were submitted to the SERP staff, and the overall evaluation was performed and documented in a first-draft report. Sections of this report were then distributed among the individuals and organizations listed above that had knowledge applicable to the particular section. Reviews were also provided by independent ORNL staff members in the areas of geochemistry, hydrology, and rock mechanics.

Following this review, the report was revised and distributed to the DOE Oak Ridge Operations Office, ORNL management, and the following peer reviewers:

\section{Reviewer and attllliation}

T. Pigford University of Callifornia at Berkeley)

D. Hansen (Lachel Hansen Associates)

J. Handin, N. Carter (Texas A\&M University)

D. Caldwell, J. Rowe (Golder Associates) Hydrology, geochemistry, geology

\section{Areas revlewed}

Geochemistry, hydrology, rock dissolution, general overviow

Hydrology, thermal performance, rock mechanics

Geology, rock dissolution, rock mechanics

These individuals were asked to review the draft report for the technical data base as well as the comparative evaluations in their respective areas. Four of the reviewers (Pigford, Hansen, Carter, and Caldwe11) then met with the SERP staff at ORNL to discuss their comments and views on the report. Their comments were subsequently evaluated and the report revised. At the conclusion of each meeting, each reviewer was asked his opinion concerning the rock rankings in his area of expertise, and all of the rock rankings in this report conform to the expectations of the reviewers.

The resulting report was then submitted to the DOE on February 4, 1985, for review. The comments (both written and oral) subsequently received typically concerned mattero addrcooing the clarification, claboration, or presentation of specific information. These comments were evaluated by the SERP staff, resulting in a modified report being submitted to the DOE on June 21,1985 . Comments were received and incorporated in this version of the report submitted to the DOE on December $11,1985$.

Although many individuals contributed to this report, the SERP staff wish to acknowledge the contribution of Dr. Paul Gnirk, RE/SPEC Inc., who organized and directed the peer review mentioned above. Acknowledgements are also due to Mr. B. G. DeVall, whose Graphic Arts group produced the more than 300 figures of this report; Ms. Ruth Gove, who checked all of the references cited; Ms. Martha Stewart, Ms. Cathy Shappert, and Ms. Donna Reichle for their careful editing of the report; and Ms. Anne Calhoun, who did much of the typing as well as coordinated the typing of Ms. Debbie Brown, Ms. Martha Dawson, Ms. Becky Keever, Ms. Kim Kitts, Ms. Janice Shannon, Ms. Donna Snow, and Ms. Debbie Weaver. 
The report described in the next-to-last paragraph of the preceding page underwent some relatively minor modifications in early 1986 to yield a readyto-publish report in late 1986. However, changing responsibilities for the project within DOE and the eventual cancellation of the second repository program by Congress resulted in DOE direction to cease work on the report without fully reconciling the last set of comments that focused on the evaluation criteria and methodology used to arrive at the draft recommendations in the report.

In 2003 DOE authorized ORNL to proceed with actions necessary to ensure that the information and evaluation constituting the valuable contents of the report. Restructuring the report to make most of it publicly available required resources beyond what could be obtained, so it was decided to create a digital version of the report without any further substantive modification and make it available to others within the DOE system. 
This page intentionally left blank 


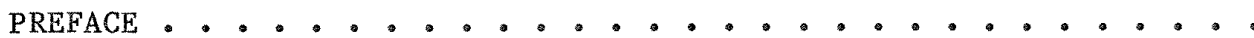

LIST OF FIGURES

EXECUTIVE SUMMARY .......................... . . . xiii

ABSTRACT. .............................. 1

1. INTRODUCTION. . . . . . . . . . . . . . . . . . . . 2

1.1 PERSPECTIVE. . . . . . . . . . . . . . . . . . . 2

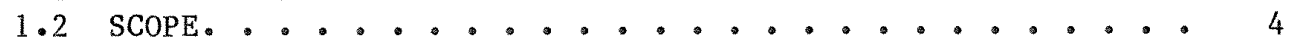

2. ROCK FVALUATION MFTHODOTOCY AND ASSTIMPTTONS . . . . . . . . . 5

2.1 EVALUATION OF ROCK TYPES . . . . . . . . . . 5

2.1.1 Derivation of the Rock Evaluation Criteria. . . . 5

2.1.2 Derivation of Discriminators............ 8

2.1.3 vaca Acquisicion procedure. . . . . . . . . 8

2.1.4 Description of the Rock Evaluation Methodology. . . 8

2.2 BACKGROUND INFORMATION AND ASSUMPTIONS . . . . . . . 9

2.2.1 Reference Information ............. 9

2.2.1.1 Waste Form/Waste Package Information . . 9

2.2.1.2 Reference Repository Description ..... 10

2.2.1.3 Geologic Data........... 10

3. DATA BASE SUMMARY AND COMPARATIVE EVALUATION WITH RESPECT TO

DISCRIMINATORS . . . . . . . . . . . . . . . . . . 11

3.1 GEOLOGY. . . . . ..................... 11

3.1.1 Information Summary and Analysis. . . . . . . 13

3.1.2 Evaluation of the Rock Types for the Geologic

Discriminators. . . . . . . . . . . 17

3.2 GEULHEMLSTKY ...................... 18

3.2.1 Information Summary and Analysis. . . . . . 19

3.2.1.1 Genera1 Data Assessment.......... 19

3.2.1.2 Groundwater Chemistry. . . . . . . 20

3.2.1.3 Petrology and Geochemistry of the Rock

Types............... 20

3.2.1.4 Radionuclide Concentration Limits. . . . 21

3.2.1.5 Radionuclide Retardation . . . . . . 24

3.2.1.6 Reducing Conditions........... 27

3.2.1.7 Potentia1 for Rock Dissolution . . . . . 28

3.2.2 Evaluation of the Rock Types for the Geochemical

Discriminators. . . . . . . . . 28

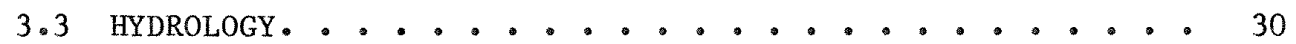

3.3.1 Information Summary and Analysis. . . . . . . 32

3.3.1.1 Data Base............ 32

3.3.1.2 Postclosure Calculations....... 34

3.3.1.3 Preclosure Calculations....... 37 
3.3.2 Evaluation of the Rock Types for the Hydrologic Discriminators. . ............ 37

3.3.2.1 Postclosure.............. 37

3.3.2.2 Preclosure ............. 38

3.4 THERMAL PERFORMANCE. . . . . . . . . . . . 39

3.4.1 Information Summary and Analysis. . . . . . . 39

3.4.2 Evaluation of the Rock Types for the Thermal

Performance Discriminators. . . . . . . . 45

3.5 ROCK MECHANICS ................ 45

3.5.1 Information Summary and Analysis. . . . . . . 46

3.5.1.1 Data Base............. 46

3.5.1.2 Poscclosure Duct111ty......... 49

3.5.1.3 Operational Stability......... 50

3.5 .1 .4 Constructibility .......... 52

3.5.1.5 Postclosure Stability.......... 53

3.5.2 Evaluation of the Rock Types for the Rock

Mechanics Discriminators.......... . 55

3.5.2.1 Postclosure Ductility.......... 55

3.5 .2 .2 operallonal Slablilly......... 56

3.5.2.3 Constructibility ............ 56

3.5.2.4 Postclosure Stability. ........ 56

3.6 NATURAL RESOURCES. . . . . ........... 57

3.6.1 Information Sumary and Analysis. . . . . . . 57

3.6.2 Evaluation of the Rock Types for the Natural

Resource Discriminator... . . . . . . . 59

3.7 WASTE PACKAGE MATERIAL DEGRADATION . . . . . . . . 59

3.7.1 Information Summary and Analysis. . . . . . . 60

3.7.2 Evaluation of the Rock Types for the Discriminator

on Waste Package Material Degradation ....... 62

3.8 REPOSITORY COST. . . . . . . . . . . . . 62

3.8.1 Information Summary and Analysis. . . . . . . 62

3.8.2 Evaluation of Repository Cost Results . . . . . 65

3.9 STSTEMS STUDIES. . . . . . . ........... . 65

3.9.1 Office of Waste Isolation Study . . . . . . 66

3.9.2 Environmental Protection Agency Study . . . . . 66

3.10 FOREIGN ACTIVITIES . . . . . . . . . . 67

4. EVALUATION OF ROCK EVALUATION CRITERIA AND ROCK TYPES . • • . 71

4.1 RANKING AGGREGATION METHODS AND EXAMPLES . . . . . . 72

4.1.1 Averaging Method. . . . . . . . . . 73

4.1.2 Pairwise-Comparison Methods ....... . 74

4.1.3 Weighting Factors and Sensitivity Analysis. . . 75

4.2 EVALUATION OF ROCK TYPES FOR POSTCLOSURE ROCK EVALUATION

CRITERIA ..................... 76

4.2.1 Geohydrology. . . . . . . . . . . . 76

4.2.2 Geochemistry. . . . . . . . . . . . 77

4.2.2.1 Aggregation Using the Averaging Method . 77

4.2.2.2 Aggregation Using the Pairwise-Comparison

Method ............. 79

4.2.3 Rock Characteristics. . . . . . . . . 80

4.2.4 Dissolution .................. 82

4.2.5 Natural Resources ............. 83 
4.3 EVALUATION OF ROCK TYPES FOR PRECLOSURE ROCK EVALUATION

CRITERIA - . . . . . . . . . . . . . . . 83

4.3.1 Rock Characteristics. . . . . . . . . 84

4.3.2 Hydrology ................ 86

4.3.3 other Aspects ............. . . 87

4.3.3.1 Repository Cost........... 87

4.3.3.2 Systems Studies.......... 88

4.3.3.3 Foreign Studies........... 88

4.4 OVERALL EVALUATION OF ROCK TYPES . . . . . . . . . 89

4.4.1 Summary of Rock Rankings by REC . . . . . . . . 89

4.4.2 Postclosure and Preclosure Analyses of the Rock

4.4 Types . . . . . . . . . . . . . . . 89

5. SUMMARY, CONCLUSIONS, AND RECOMMENDATIONS . . . . . . . . 97

5.1 SUMMARY. .................... 97

5.1 .1 Background and Purpose. . . . . . . . . 97

5.1.2 Methodology Employed.............. 97

5.1.3 Information Summary . . . . . . . . . . . 99

5.1.4 Evaluation Results. . . . . . . . . . . 102

5.1 .4 .1 Postclosure Geohydrology ........ 103

5.1.4.2 Postclosure Geochemistry ........ 103

5.1.4.3 Postclosure Rock Characteristics... . 103

5.1.4.4 Postclosure Dissolution........ . 103

5.1.4.5 Postclosure Natural Resources..... . 104

5.1.4.6 Preclosure Rock Characteristics.... . 104

5.1.4.7 Preclosure Hydrology . . . . . . . 105

5.1.4.8 Overall Evaluation........... 105

5.1 .5 Other Aspects.............. 106

5.1.5.1 Repository Cost........... 106

5.1 .5 .2 Systems Studies............ 107

5.1.5.3 Foreign Studies............. 108

5.1 .5 .4 Man Madc Opcnings in Shales...... 108

5.2 CONCLUSIONS. . . . . . . . . . . . . . . 110

5.3 RECOMMENDATIONS. . . . . . . . . . . . . . 112

6. GLOSSARY. . . . . . . . . . . . . . . 115

7. REFERENCES. ......................... 119

APPENDIX A. ROCK EVALUATION CRITERIA AND DISCRIMINATORS GOVERNING THEIR APPLICATION TO ROCK EVALUATION • • . 121

APPENDIX B. BASELINE/REFERENCE INFORMATION FOR THE SEDIMENTARY

ROCK PROGRAM .. . . . . . . . . . . . 133 
This page intentionally left blank

This page intentionally left blank 


\section{LIST OF FIGURES}

Figure

ES.1 Map of the United States showing principal shale deposits by regional geologic province and by general geologic

age. . . . . . . . ................. . xxi

3.1. Groundwater inflow rates into mined openings for the five sedimentary rock types............ . 38

3.2. Temperatures calculated from mean thermal properties for a spent-fuel repository in chalk, shale, carbonate rocks, sandstone, and anhydrock............. 43

3.3. Range of temperatures at the waste-package/rock interface and the near-field/far-field interface for a spent-fuel repository in chalk, shale, carbonate rocks, sandstone, and anhydrock. . . . . . . . . . . . . . 44

4.1. Scnsitivity of averaging method scores to the preclosure REC weighting factor . . . . . . . . . . . . . 92

4.2. Sensitivity of pairwise-comparison scores to the preclosure

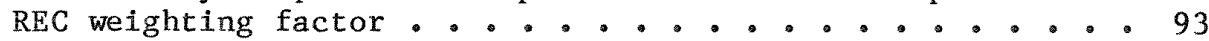

5.1. Map of the United States showing principal shales as distributed according to regional geologic provinces and by general geologic age. . . . . . . . . . . 111

B.1. Reference spent fuel package for borehole emplacement. . . 139

B.2. Reference commercial high-level waste canister . . . . . 140

B.3. Schematic of ourfacc and underground facilitico. . . . . 142

B.4. Generic waste package design for emplacement in boreholes. 143

B.5. Typical stratigraphic section: anhydrock. . . . . . . . 144

B.6. Typical stratigraphic section: cha1k. . . . . . . . . 144

B.7. Typical stratigraphic section: limestone. . . . . . . 145

B.8. Typical stratigraphic section: sandstone. . . . . . . . 145

B.9. Typical stratigraphic section: shale. . . . . . . . . 145 
This page intentionally left blank 


\section{LIST OF TABLES}

Table

ES.1 Summary of rankings for rock evaluation critera (RECs) . . . xvi

2.1 Relationship of rock evaluation criteria (RECs) and their discriminators to the siting guidelines. . . . . . . . 6

3.1 Analysis of geologic information . . . . . . . . . 15

3.2 Evaluation of rock types with respect to thickness and lateral extent discriminator .............. 17

3.3 Rankings of the subject rock types based on geochemical discriminators .................... 29

3.4 Adopted data base for hydrologic properties. . . . . . . 33

3.5 Summary of comparative pre-waste-emplacement groundwater travel times and distances for the five subject rock types. 36

3.6 Mean values and ranges in thermal properties and

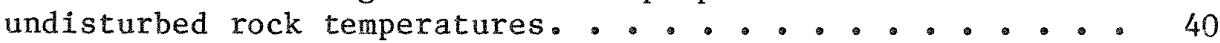

3.7 Summary of mechanical property values. . . . . . . . . 47

3.8 Brittle-to-ductile transition pressures at room temperature. 47

3.9 Preclosure operational stability indices for the subject

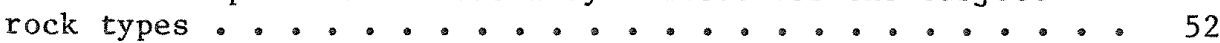

3.10 Constructibility indices for the rock types. . . . . . . 53

3.11 Pootclosure stability indices for the subject rock types. . 55

3.12 Summary of repository costs by rock type . . . . . . . . 64

4.1 Summary of discriminator rankings for the postclosure geochemistry REC . . . . . . . . . . . . . . 77

4.2 Details of applying the averaging method to rock ranking for the geochemistry REC . . . . . . . . . 78

4.3 Details of applying the pairwise-comparison method to rock ranking for the geochemistry REC . . . . . . . . 80

4.4 Summary of discriminator rankings for postclosure rock characteristics REC................... 80

4.5 Rock ranking for the postclosure rock characteristics REC. . 81 
4.6 Summary of discriminator rankings for the preclosure rock characteristics REC. . . . . . . . . . . 84

4.7 Rock ranking for the preclosure rock characteristics REC . . 85

4.8 Summary of rankings for each REC . . . . . . . . . . . 90

4.9 Rock ranking for postclosure and preclosure RECs . . . . . 90

4.10 Overall ranking of the five rock types . . . . . . . . 94

5.1 Summary of rankings for each $\mathrm{KEC} . . . . . . . . . . . .102$

B.1 Characteristics of spent fuel assemblies . . . . . . . 138

B.2 Characteristics of spent fuel elements . . . . .... 139

B.3 CHLW characteristics . . . . . . . . . . . . 140 


\section{EXECUTIVE SUMMARY}

\section{ES.1 BACKGROUND}

The Nuclear Waste Policy Act of 1982 requires the U.S. Department of Energy (DOE) to site two geologic repositories for the disposal of highlevel waste (HLW) and spent fuel. Studies are currently under way to locate sites suitable for a mined geologic repository in tuff, basalt, salt (both bedded and dome), and crystalline rocks. The DOE, in order to increase the diversity of rock types under consideration by the geologic repository program, initiated the Sedimentary Rock Program (SERP), whose immediate objective is to evaluate five types of sedimentary rock [sandstone, shale, chalk, carbonate rocks (1imestone and dolostone), and anhydrock] to determine the potential for locating a geologic repository site in one of these rock types. The evaluation of these five rock types, together with the ongoing salt studies, effectively results in the consideration of all types of relatively impermeable sedimentary rock for repository siting purposes. The results of this evaluation are expressed in terms of a ranking of the five rock types with respect to their potential to serve as a geologic repository host rock. However, it should be noted that the possibility exists that a geologic repository can be located in any of these rock types.

The information generated by this study, which is documented in this report and summarized here, will form the technical basis for any DOE decisions that may be made concerning future investigations of these five rock types.

\section{ES.2 EVALUATION METHODOLOGY}

The evaluation of the five subject rocks was, of necessity, accomplished by means of a non-site-specific (generic) approach, since the purpose was to identify the most promising rock type. The approach adopted was to use the intent of the DOE siting guidelines for geologic repositories [contained in 10 CFR Part 960 (CFR 1984)] to evaluate the subject rock types by the following approach:

1. The postclosure and preclosure provisions of the siting guidelines were analyzed to (a) develop a set of generic rock evaluation criteria (RECs) that formed the basis for evaluating the xiii 
subject rock types, (b) identify the "discriminators" that formed the basis for evaluations against each $\mathrm{REC}$, and (c) identify the information required to address the discriminators.

2. Given the information requirements, technical consultants and subcontractors were used to acquire, collate, and document the data.

3. The information contained in the technical data base was used to evaluate the five subject rock types for each of the discriminators. This comparative evaluation was based on specific technical measures or the preponderance of the evidence (depending on the type of data developed for a discriminator), taking into account the attendant uncertainties, and is expressed as a qualitatively determined rank ordering.

4. The ruck rankings fur each discriminalun were used as lite vasis for evaluating the five rock types against each REC. This twostep process was necessary because some of the RECs include discriminators based on more than one discipline. For RECs having more than one subsidiary discriminator, this evaluation was accomplished by means of the two aggregation methods (averaging and pairwise) employed in the common Chapter 7 of the draft environmental assessments (EAs) for the sites to be nominated for the first DOE repository, along with sensitivity analyses of the results obtained from applying these methods.

5. The rankings for each REC were used as the basis for an overall evaluation of the five rock types with respect to their potential as host rocks for a geologic repository. This comparative evaluation was accomplished by aggregating the rock rankings for individual RECs, using the two methods alluded to above. The ranking of the rock types resulting from this evaluation was primarily derived from the results for the group of postclosure RECs, with the results for the group of preclosure RECs used only to differentiate between rock types having a very similar ranking on the basis of the postclosure RECs. 
The information used in this evaluation was obtained partially from the open literature and partially from unpublished data made available to the SERP. The general philosophy adopted for information acquisition was that the data should be representative of the range of properties typically expected for each rock type. However, in the case of the hydrologic evaluations, the underlying characteristics represent the more promising end of the spectrum for each of the subject rocks. For example, the permeability and porosity data used for evaluating the sandstones and carbonate rocks were representative of those occurrences of these rocks that are reasonably widespread but "tighter" than the typical sandstone or carbonate rocks in the United States. This philosophy was employed because it is these occurrences that would be sought during the siting process, and thus they should form the basis for the evaluation.

Informacton was acquired In the fulluwing aleas ful subsequent use in evaluating the five subject rock types: hydrology, geochemistry, geology/stratigraphy, natural resources, thermal performance, rock mechanics, repository cost, waste package durability, systems studies, and foreign studies.

\section{ES.3 RESULTS}

The process of developing generic RECs from the preclosure and postclosure provisions of the siting guidelines resulted in postclosure RECs for geohydrology, geochemistry, rock characteristics, dissolution, and natural resources. In addition, preclosure RECs were developed in the areas of rock characteristics and hydrology.

The information described in Sect. ES.2 was used to rank the five rock types for each discriminator. These rankings then formed the basis for evaluating the rock Lypes agains each REC.

A preliminary ranking of the five subject rocks was reached by aggregating the postclosure rock rankings in Table ES.1 to yield an overall score for each rock. This aggregation was performed using the averaging and pairwise-comparison methods, as employed in the common chapter 7 of the draft EAs for the sites to be nominated for the first DOE repository. The sensitivity of the preliminary rock rankings to the inclusion of preclusure RECs was lleu exaluited, resulting in the following ranking of 
Table ES.1. Summary of rankings for rock evaluation criteria (RECs)

\begin{tabular}{|c|c|c|c|c|c|c|}
\hline \multirow{2}{*}{\multicolumn{2}{|c|}{$\begin{array}{c}\text { Rock evaluation } \\
\text { criterion } \\
(\text { REC })\end{array}$}} & \multicolumn{5}{|c|}{ Rank order of rock typesa } \\
\hline & & \multirow[t]{2}{*}{ Shale } & Sandstone & Anhydrock & \multirow{2}{*}{$\begin{array}{l}\text { Chalk } \\
\text { ines }\end{array}$} & \multirow[t]{2}{*}{$\begin{array}{l}\text { Carbonate } \\
\text { rocks }\end{array}$} \\
\hline & & & \multicolumn{2}{|c|}{ Postclosure guidelines } & & \\
\hline$A \cdot 1 \cdot 2^{b}$ & Geohydrology & 1 & 2 & 2 & 3 & 3 \\
\hline A. 1.3 & Geochemistry & 1 & 2 & 4 & 3 & 3 \\
\hline A. 1.4 & $\begin{array}{l}\text { Rock character- } \\
\text { istics }\end{array}$ & 1 & 2 & 3 & 3 & 2 \\
\hline A. 1.1 & Dissolution & 1 & 1 & 3 & 2 & 2 \\
\hline \multirow[t]{2}{*}{ A. 1.9} & Natural resources & 1 & 3 & 1 & 2 & 3 \\
\hline & & \multicolumn{4}{|c|}{ Preclosure guidelines } & \\
\hline A.2.3. & $\begin{array}{l}2 \text { Rock character- } \\
\text { 1stics }\end{array}$ & 2 & 2 & 3 & 4 & 1 \\
\hline A. 2.3. & 3 Hydrology & 1 & 2 & 1 & 3 & 3 \\
\hline
\end{tabular}

$a_{A}$ rank of 1 is most favorable and 4 is least favorable. However, the number and the separation of the ranks are not necessarily uniform.

$b_{\text {The }}$ criteria numbers (e.g., A.1.2) correspond to the section in Appendix A where the REC is described. 
the five rock types with respect to their potential for hosting a geologic repository:

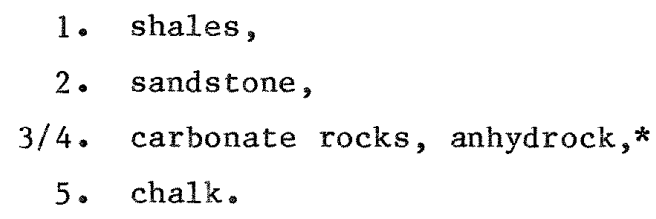

Shales were found to be equal to, or better than, the other four rock types for all RECs. The superior ranking of shales resulted from the following factors:

1. Hydrology - excellent because of very low hydraulic conductivity and relatively high effective porosity;

2. Geochemistry - reducing conditions expected because of the presence of organic matter, thus promoting retardation and insolubility; containo conoidcrablc amounto of clays to retard radionuclide migration;

3. Rock characteristics - widespread occurrence to permit siting flexibility; moderate thermal performance; good mechanical performance because of its ductility;

4. Dissolution - essentia11y insoluble; and

5. Natural resources - generally does not contain economically recoverable natural resources.

Sandstone was ranked a relatively distant second to shale because of the following factors:

1. Hydrology - good because, although the effective porosity is relatively high, even the more promising sandstones generally have higher hydraulic conductivities than shale;

2. Geochemistry - moderately good, but the typically low content of clay and organtc matcer indicates less reducting condtctons and less retardation capability than for shales;

3. Rock characteristics - moderate abundance, moderate thermal performance, and good mechanical performance;

4. Dissolution - essentially insoluble; and

*A combined number (e.g., 3/4) indicates rock types of the same or nearly equivalent ranking. 
xviii

5. Natural resources - sandstones of ten contain natural resources such as gas, oil, and water.

Anhydrock and the carbonate rocks, within the uncertainties of this evaluation, were ranked $3 / 4$. The $3 / 4$ ranking for anhydrock was derived from the following factors:

1. Hydrology - very good, but inferior to shales because anhydrock has a lower effective porosity while having a hydraulic conductivity equal to that of shale;

2. Geochemistry - poor because of the neutral $\mathrm{pH}$ of waters, the lower retardation and increased solubilities resulting from the high salt concentration in the groundwater, and the absence of organic matter to establish reducing conditions;

3. Rock characteristics - very limited occurrence; excellent thermal performance because of high thermal conductivity; poor mechanical performance because of low ductility and high coefficient of therma1 expansion;

4. Dissolution - poor since the primary mineral (anhydrite) is relatively soluble; and

5. Natural resources - generally does not contain natural resources, although it may occasionally be mined for its own value.

The $3 / 4$ ranking for the carbonate rocks resulted from the following factors :

1. Hydrology - fair despite a relatively high effective porosity, because even the more promising carbonate rocks have much higher hydraulic conductivities than shales and sandstones, resulting in high potential water flow rates;

2 - Geochemistry - fair because of the lack of clays to retard radionuclide migration; the low concentration of organic matter, which would establish reducing conditions; and the high concentration of dissolved solids in the waters;

3. Rock characteristics - moderate abundance, intermediate thermal performance, good mechanical performance;

4. Dissolution - fair because of the significant solubility of the principal minerals (calcite and dolomite) in water; and 
5. Natural resources - often contain natural resources such as gas, oil, and water and are mined for their intrinsic value at shallow depths.

The 5 ranking for chalk is based on the following factors:

1. Hydrology - fair to poor: even the more promising chalks have higher hydraulic conductivities than shales and sandstones;

2. Geochemistry - fair because of the lack of clays to retard radionuclide migration; the low concentration of organic matter, which would establish reducing conditions; and the expected high concentration of dissolved solids in the waters;

3. Rock characteristics - limited occurxence, poor thermal perform ance, and poor mechanical performance because of its low strength;

4. Dissolution - fair because of the significant solubility of its principal mineral (calcite) in water; and

5. Natural resources - generally contains minimal extractable resources.

Three other considerations were addressed in the report but did not form the basis for comparatively evaluating the five rock types: systems studies, costs, and foreign waste disposal activities. Meaningful comparison of the rock types on the basis of systems studies was not possible because of the lack of adequate information to predict repository performance. However, two "systems studies" for shale were found in the literature and reviewed: one, by the office of Waste Isolation (predecessor of the office of Nuclear Waste Isolation), predicted radionuclide release rates that were exceptionally low compared with contemporary predictions; the other, sponsored by the U.S. Environmental Protection Agency (EPA), used the rock characteristics of basalt ( $a$ hard, brittle rock of volcanic origin) as a surrogate for shale (a sedimentary rock with an appreciable organic content, distinct bedding planes, and varying properties). The latter systems study is of questionable value in predicting the repository performance of a geologic repository in shale.

Cost estimates were developed for a geologic repository in each of the five subject rock types by adjusting the detailed cost estimates previously developed for a bedded-salt repository. The results indicated 
that the costs of repositories in all rock types were reasonable. A repository in shale or sandstone was predicted to cost slightly more than one in bedded salt. The cost of an anhydrock repository was somewhat higher, because of the reduced thermal loading necessitated by poor mechanical performance. The costs of repositories in chalk and the carbonate rocks were the highest estimated, because of the poor thermal performance of chalk and the higher mining costs and moderate thermal performance of the carbonate rocks.

A survey of foreign activities concerning the subject rocks disclosed that only shalelike rocks are being seriously considered. Shales and/or clays (along with granite) are the geologic media of choice in Belgium, Italy, and Japan. Shales and clays are considered to be alternatives in France, England, and Canada. Clays are also being considered in virtually every country for use as backfill material.

\section{ES. 4 CONCLUSIONS}

On the basis of the evaluations in this report, it is clear that shale is the preferred host rock among the five rock types considered with respect to their potential to serve as the host rock for a geologic repository. The analyses performed indicate that shale ranked highest, since it rated highly on most discriminators and did not rank low on any of them. It should be noted that this conclusion is valid for the shales that are somewhat indurated (i.e., hard or rocklike) and occur extensively in the conterminous United States (see Fig. ES.1). Different (and, perhaps, less favorable) conclusions might be reached if other classes of argillaceous rocks (e.g., clays) were considered.

A brief study of the response of shales to underground excavations was conducted to provide background for subsequent decisionmaking. The excavation records of the Upper Cretaceous Mancos and Pierre shales were examined, and it was found that conventional drill-blast-removal techniques and large-diameter boring machines were both suitable for producing tunnels of the desired diameter. Instability problems in the Pierre Shale are related principally to its high moisture content, reflected by a smectite-dominated mineralogy that allows the rock to absorb water and to be geomechanically affected in the process. The 


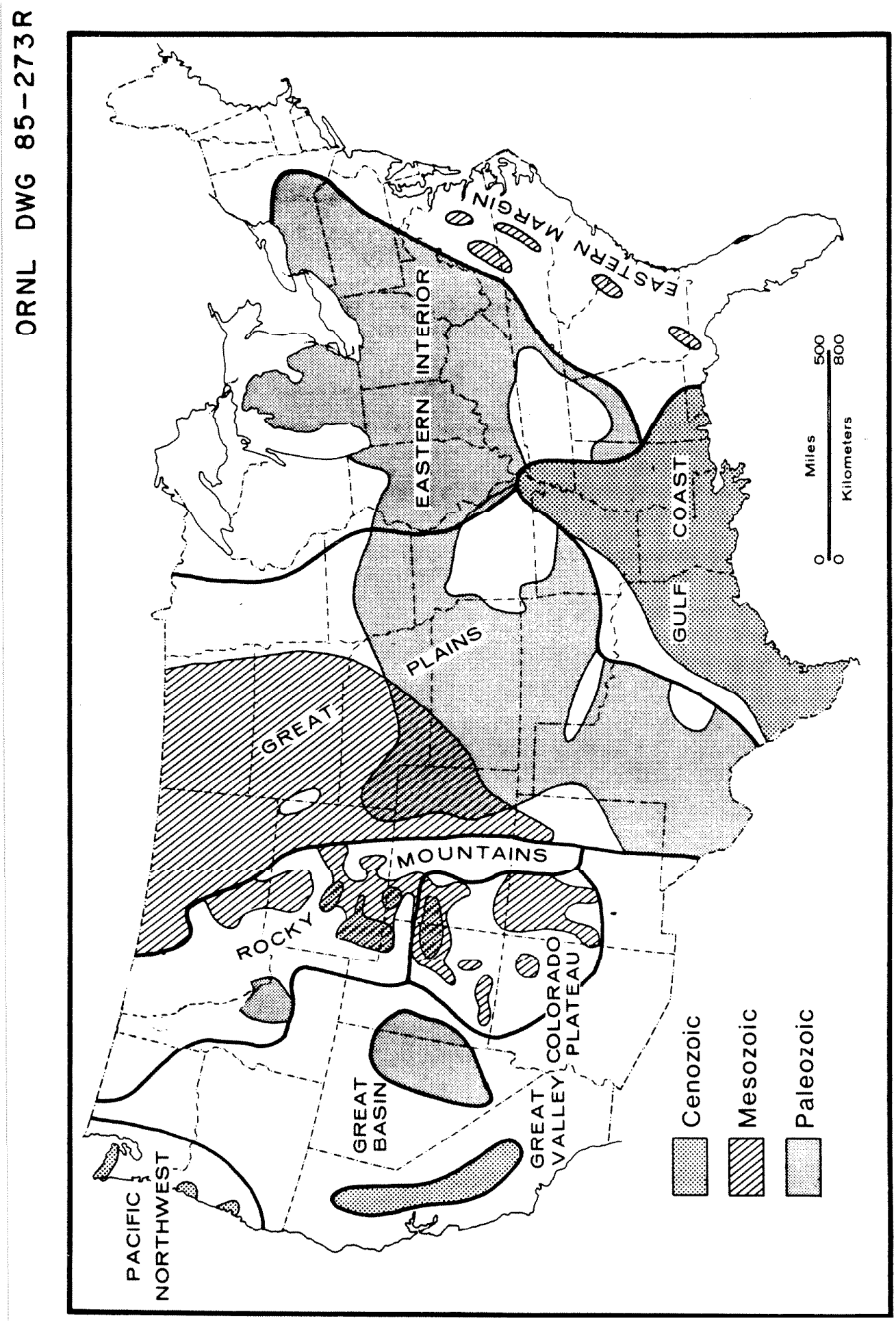

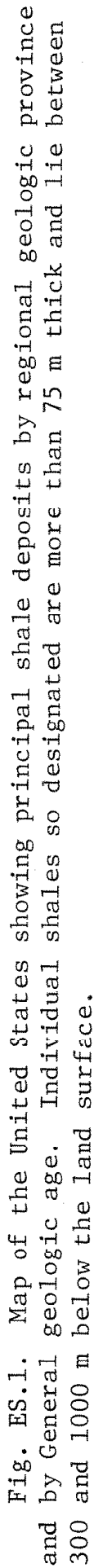


Azotea water-diversion tunnel in southern Colorado and northern New Mexico was driven more than $20 \mathrm{~km}$ through the Mancos Shale at depths of up to $600 \mathrm{~m}$.

Shales commonly are the roof strata in coal mines in the Pennsylvanian coal-bearing sequences mined in the eastern, interior, and mid-continent parts of the country. Failures and/or roof falls are common in some of these coal mines where thin shales in the roof are bounded by well-defined parting planes. Measures to prevent these circumstances must be taken into account in mine design.

The utilization of shales and other rock types for mined storage caverns is discussed at some length in the 1iterature. More underground caverns for storage of petroleum products have been developed in shale than in any other rock type. Although some problems occurred during the conscruction of certatn caverns due to slakily caused by the absorption of water, humidity control can generally arrest this condition. The relatively low strength of shale can be compensated for by good engineering design of the cavern(s), to obtain adequate roof support.

Thermal and mechanical data from the near-surface heater experiment in the Conasauga Formation at Oak Ridge suggest that the shale rocks did not fracture further as a consequence of being heated, but the rocks actually showed a decrease in permeability. In general, these findings reflect favorably on the utility of shale as a host rock for a geologic repository.

From the near-surface heater test in the Eleana Argi11ite, it was observed that the effects of clay contraction cause the opening of preexisting joints in the rocks which could lead to an increase throughout of water and water vapor close to the heat sources. However, no "failure" mechamism was identiried llat would adversely affect the use of argi11a ceous rock for geologic repositories.

As a result of this experience, it is concluded that the construction and maintenance of mined excavations are feasible for the shales considered in this comparative evaluation. However, generalizations concerning the measures that are needed to maintain the openings and provide adequate roof support are not possible because of the variabillly of shale clatalleislics and properties. 
The comparative evaluation in this report also indicates that sandstone could be an acceptable repository host rock, especially if a tight sandstone that was relatively ductile and had a significant clay content could be identified. Although this type of rock has good potential for being an acceptable host rock, it still would not be preferred over the more promising shales, and a site would be considerably more difficult to locate.

The evaluation clearly indicates that establishing a geologic repository in carbonate rocks, chalk, or anhydrock would be less preferable than in either shale or sandstone. However, the possibility exists that a site for a geologic repository could be located in any one of these rock types.

\section{ES.5 RHCUMMENDALIUNS}

The following recommendations are the result of this evaluation:

1. Investigate further the role of shale as a potential host rock for a geologic repository. Investigation of the other four rock types (sandstone, carbonate rocks, anhydrock, and chalk) should be deferred at this time. This recommendation is supported by the evaluation that shale is the most preferred of the five rock types considered with respect to its potential to be an acceptable repository host rock. Even under the best of circumstances. the other four rock types do not have the potential of shale, although it is possible that an acceptable site might be located and developed in any of them. This recommendation is also supported by the following points: (a) further investigation of shales will increase the hydrologic and rock-type diversily of the DOE geologic repository program, (b) shale would offer the possibility of siting a repository in a number of regions in the conterminous United States, and (c) investigation of shales would provide data relevant to the understanding of clays, such as those proposed as backfill and packing material in repositories.

2. Develop a data base that would be adequate to proceed with the ldeultfication of a potencial sice in shale. The objective of 
this work would be to develop a technical data base that would support the screening process leading to identifying a potentially acceptable geologic repository site. Activities in support of this objective should include (a) obtaining laboratory measurements of rock properties (thermal, mechanical, chemical) for a range of potentially relevant shales; (b) establishing a more detalled understanding of the behavior of shales and their components under conditions of heat, stress, radiation, and moisture similar to those expected in a repository (this would also he relevant to understanding bentonite behavior under repository conditions); and (c) performing technical analyses to more precisely identify the desired shale characteristics (e.g., degree of induration, organic content).

3. Escab11sh cooperacion with shale (argillaceous rock) repository programs in other countries. Belgium, Japan, and Italy are considering shale and related rocks (clays) as repository host media. Information exchange and other cooperative programs and facilities would be mutually beneficial and would minimize duplication of effort. Such programs are supported by the Nuclear Waste Policy Act of 1982 .

4. Examine the potential role of shale in the DOE's efforts to establish a geologic repository. The technical merits of shale and its widespread occurrence favor its consideration as a potential host rock for a geologic repository. 


\author{
A. G. Croff \\ T. F. Lomenick \\ R. S. Lowrie \\ S. H. Stow
}

\begin{abstract}
The U.S. Department of Energy (DOE), in order to increase the diversity of rock types under consideration by the geologic disposal program, initiated the Sedimentary Rock Program (SERP), whose immediate objective is to evaluate five types of sedimentary rock sandstone, chalk, carbonate rocks (1imestone and dolostone), anhydrock, and shale - to delerinline the potentlal for sicting a geologic repository. The evaluation of these five rock types, together with the ongoing salt studies, effectively results in the consideration of all types of relatively impermeable sedimentary rock for repository purposes. The results of this evaluation are expressed in terms of a ranking of the five rock types with respect to their potential to serve as a geologic repository host rock.

This comparative evaluation was conducted on a non-sitespecific basis, by use of generic information together with rock evaluation criteria (RECs) derived from the DOE siting guidelines for geologic repositories (CFR 1984). An information base relevant to rock evaluation using these RECs was developed in hydrology, geochemistry, rock characteristics (rock occurrences, thermal response, rock mechanics), natural resources, and rock dissolution. Evaluation against postclosure and preclosure RECs yielded a ranking of the five subject rocks with respect to their potential as repository host rocks. Shale was determined to be the most preferred of the five rock types, with sandstone a distant second, the carbonate rocks and anhydrock a more distant third, and chalk a relatively close fourth. A brief rationale for this ranking is as follows:

Shale - Ranked first on most RECs without any strong negative aspects;

Sandstone - Intermediate ranking on nearly all RECs with the only strong negative aspect being its tendency to contain sought-after resources (oil, gas, water);

Anhydrock - Strong rock with good thermal performance, but with negative characteristics of very limited abundance, low ductility, and poor geochemical/ dissolution attributes;

Carbonate rocks - Strong rock, but relatively poor hydrology, ductility, and geochemistry and commonly contains natural resources such as oil, gas, and water;
\end{abstract}


Chalk - Good ductility, but of 1imited abundance, poor thermal performance, poor hydrology, and low strength.

Other considerations investigated include cost, previous systems studies, and foreign activities. The costs of repositories in all five rock types were determined to be reasonable. The costs of repositories in shale and sandstone were the lowest and were estimated to be slightly greater than that for a bedded-salt repository. The cost of a repository in anhydrock was somewhat higher, and costs for those in the carbonates and chalk still higher. Only two previous systems studies, both generic studies involving shale, were identified. The resuits of both studies were determined to not be useful for the purpose of deriving conclusions concerning the waste-isolation potential of the five subject rock types. A review of foreign studies concerning the subject rocks found considerable interest in shales and related rocks (clays). These types of rocks are primary candidates for geologic repositories in Belgium, Italy, and Japan and are alternatives in France, Fingland, and Canada.

The recommendations resulting from this study are as follows:

1. Investigations of shale as a potential host rock for a geologic repository. Investigations of the other four rock types (sandstone, carbonate rocks, anhydrock, and chalk) should be deferred at this time.

2. Develop a data base that would be adequate to proceed with the identification of a potentially acceptable site in shale.

3. Establish cooperation with the shale (argillarenus rock) repository programs in other countries.

4. Examine the potential role of shale in the DOE geologic repository program.

\section{INTRODUCTION}

\subsection{PERSPECTIVE}

The Nuclear Waste Policy Act of 1982 (the Act) establishes a process and schedule for the siting of two geologic repositories for spent nuclear fuel and high-level waste and assigns the responsibility for 
siting and developing geologic repositories to the U.S. Department of Energy (DOE). The Act further requires that the DOE have a licensed repository in operation by 1998 and that the DOE initiate the process of selecting the site for a second repository through the step of submitting a Presidential recommendation to Congress in 1995. Studies are under way in tuff, salt (both bedded and dome), basalt, and crystalline rocks to locate a geologic repository in these rocks, utilizing the stepwise siting process described in the DOE siting guidelines for repositories (CFR 1984). In order to increase the diversity of rock types under consideration by the geologic repository program, the DOE initiated the Sedimentary Rock Program (SERP), whose objective is to evaluate five Lypes of sedimentary rock - sandslone, chalk, carbonale rocks (1imeslone and dolostone), anhydrock, and shale - to determine the potential for siting a geologic repository (DOE 1984a). Rather than carry each of these rocks through the formal screening phase of the siting process, the DOE has chosen to make use of a prescreening step to narrow the number of sedimentary rocks other than salt that may, at some time in the future, be subjected to screening. In this report, the prescreening step is called "rock evaluation;" its purpose is to identify the particular rock type within a group of rock types that has the greatest potential, on the basis of intrinsic physical and chemical properties, for yielding a geologic repository site during subsequent screening steps. The results of this evaluation are expressed in terms of a ranking of the five rock types with respect to their potential to serve as a geologic repository host rock. The evaluation of these five rock types, along with the current investigation of salt, effectively completes the consideration of all major types of relatively impermeable sedimentary rock for repository siting purposes.

The comparative evaluation presented in this report is based on intrinsic rock properties and characteristics because, by definition of the rock evaluation process, it cannot use site-specific information. The elimination of site-specific aspects at this point enhances the likelihood of success in any subsequent repository siting activity by identifying the rock type that is intrinsically preferable before attempting to find potentially acceptable sites. Only the open literature or unpublished data that were made available to the SERP have been used to obtain 
the needed geotechnical data. This report provides an evaluation of the five sedimentary rocks to serve as the potential host for a geologic repository based on only generic (i.e., non-site-specific) characteristics and features of the rock types.

The information and evaluation developed and presented in this report will provide a technical basis for DOE decisions concerning the future activities of the SERP. These activities might involve (1) initiation of a program leading to the selection of a site for a repository in the preferred rock type; (2) for the preferred rock, planning for the next step in the site screening process - the national survey - as well as initiating studies necessary to enhance the data base for the preferred rock; or (3) a decision to defer further 1nvestigation of any of the rock cypes.

\section{2 score}

The DOE has published siting guidelines in 10 CFR Part 960 (CFR 1984) for evaluating the suitability of a site for the development of a geo$\operatorname{logic}$ repository. For the purposes of this comparative evaluation, these siting guidelines have been utilized to develop a set of rock evaluation criteria (RECs) that are used to evaluate and rank the five rock types. These RECs, along with a description of the logic used to develop them, are summarized in Sect. 2 and discussed in detail in Appendix A.

The evaluation of the rock types uses certain common assumptions (e.g., repository capacity) and technical data (e.g., waste form and canister information). These data are detailed in Appendix B.

Development of the RECs also identified the extent and type of geotechnical data needed for the rock evaluation. A team of consultants and subcontractors assembled, correlated, and reviewed geotechnical data by disctpline (e.g., hydrology, rock mechanics, geochemistry) for the five rock types. The technical reports generated by this effort are presented in Appendixes $\mathrm{C}$ through $\mathrm{K}$. Section 3 summarizes the data and presents a technical evaluation of the data within each discipline.

The method developed to evaluate the potential of the rock types to serve as host media for a geologic repository is described in sect. 2 and implemented in Sect. 4. A summary of this rock evaluation effort and its

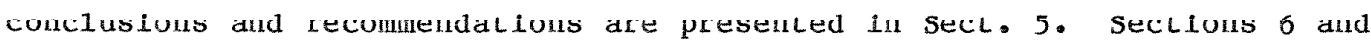
7 present the glossary and the references, respectively. 


\section{ROCK EVALUATION METHODOLOGY AND ASSUMPTIONS}

This section describes the multistep methodology that was employed to evaluate the rock types with respect to their potential as a geologic repository host rock (Sect. 2.1) and provides a summary of the background information and assumptions that formed the common foundation for many of the information gathering and generation activities, especially those involving calculations (i.e., thermal, rock mechanics, hydrology).

\subsection{EVALUATION OF ROCK TYPES}

The approach used by the SERP in evaluating the potential of the five sedimentary rock types to serve as the host for a geologic repository can be outlined as follows:

Step 1: Derivation of rock evaluation criteria (RECs) that form the basis for ranking the subject rock types with respect to their potential for hosting a geologic repository,

Step 2: Derivation of discriminators that constitute the disciplineoriented basis for applying the RECs to the evaluation of the rock types,

Step 3: Acquisition of the technical data necessary for the rock evaluation, and

Step 4: Application of the technical data base to comparatively evaluate and rank the rock typoe ucing the diocriminatoro and RECs as a framework.

These four steps are discussed in Sects. 2.1.1-2.1.4, respectively.

\subsubsection{Derivation of the Rock Evaluation Criteria}

The RECs developed to form the basis for evaluating and ranking the five sedimentary rock types are derived from the siting guidelines. The postclosure and preclosure siting guidelines were reviewed to identify those which required site-specific information, so as to eliminate them from further consideration. Five postclosure siting guidelines and ten preclosure siting guidelines are in this category (see Table 2.1). For each of the remaining technical siting guidelines, an REC was developed. The RECs are not site specific and form the basis for evaluating the rock types with respect to their potential to serve as the host rock for a geologic repository (see Appendix A). 
Table 2.1. Relationship of rock evaluation criteria (RECs) and their discriminators to the siting guidelines

\begin{tabular}{|c|c|c|c|}
\hline $\begin{array}{l}\text { Section in } \\
\text { Appendix A }\end{array}$ & $\begin{array}{l}\text { Section in } \\
\text { siting } \\
\text { guidelines }\end{array}$ & REC title & Discriminator or comments \\
\hline & & \multicolumn{2}{|c|}{ Postclosure guidelines } \\
\hline A.1.1 & $960 \cdot 4-1$ & System & Site specific; not considered \\
\hline A.1.2 & $960 \cdot 4-2-1$ & Geohydrology & $\begin{array}{l}\text { Expected pre-waste-emplacement } \\
\text { gruundwater Lravel Lime }\end{array}$ \\
\hline A. 1.3 & $960 \cdot 4-2-2$ & Geochemistry & $\begin{array}{l}\text { 1. Radionuclide solubility } \\
\text { 2. Radionuclide retardation } \\
\text { 3. Reducing environment } \\
\text { 4. Degradation of canister } \\
\text { materials }\end{array}$ \\
\hline A.1.4 & $960 \cdot 4-2-3$ & $\begin{array}{l}\text { Rock } \\
\text { characteristics }\end{array}$ & $\begin{array}{l}\text { 1. Abundance of rock forma- } \\
\text { tions having adequate } \\
\text { thickness and extent } \\
\text { 2. Ability to transfer heat } \\
\text { 3. Rock ductility } \\
\text { 4. Rock stability under } \\
\text { induced stresses }\end{array}$ \\
\hline A. $1 \cdot 5$ & $960 \cdot 4-2-4$ & $\begin{array}{l}\text { Climatic } \\
\text { changes }\end{array}$ & Site specific; not considered \\
\hline A.1.6 & $960 \cdot 4-2-5$ & Erosion & Site specific; not considered \\
\hline A. $1 \cdot 7$ & $960 \cdot 4-2-6$ & Dissululiun & $\begin{array}{l}\text { Puleulial sulubility of llie } \\
\text { host rock }\end{array}$ \\
\hline A. 1.8 & $960 \cdot 4-2-7$ & Tectonics & Site specific: not considered \\
\hline A.1.9 & $960 \cdot 4-2-8-1$ & $\begin{array}{l}\text { Natural } \\
\text { resources }\end{array}$ & $\begin{array}{l}\text { Extent to which valuable } \\
\text { resources are associated with } \\
\text { the host rock }\end{array}$ \\
\hline A. 1.10 & $960 \cdot 4-2-8-2$ & $\begin{array}{l}\text { Site ownership } \\
\text { and control }\end{array}$ & Site specific; not considered \\
\hline
\end{tabular}


Table 2.1 (continued)

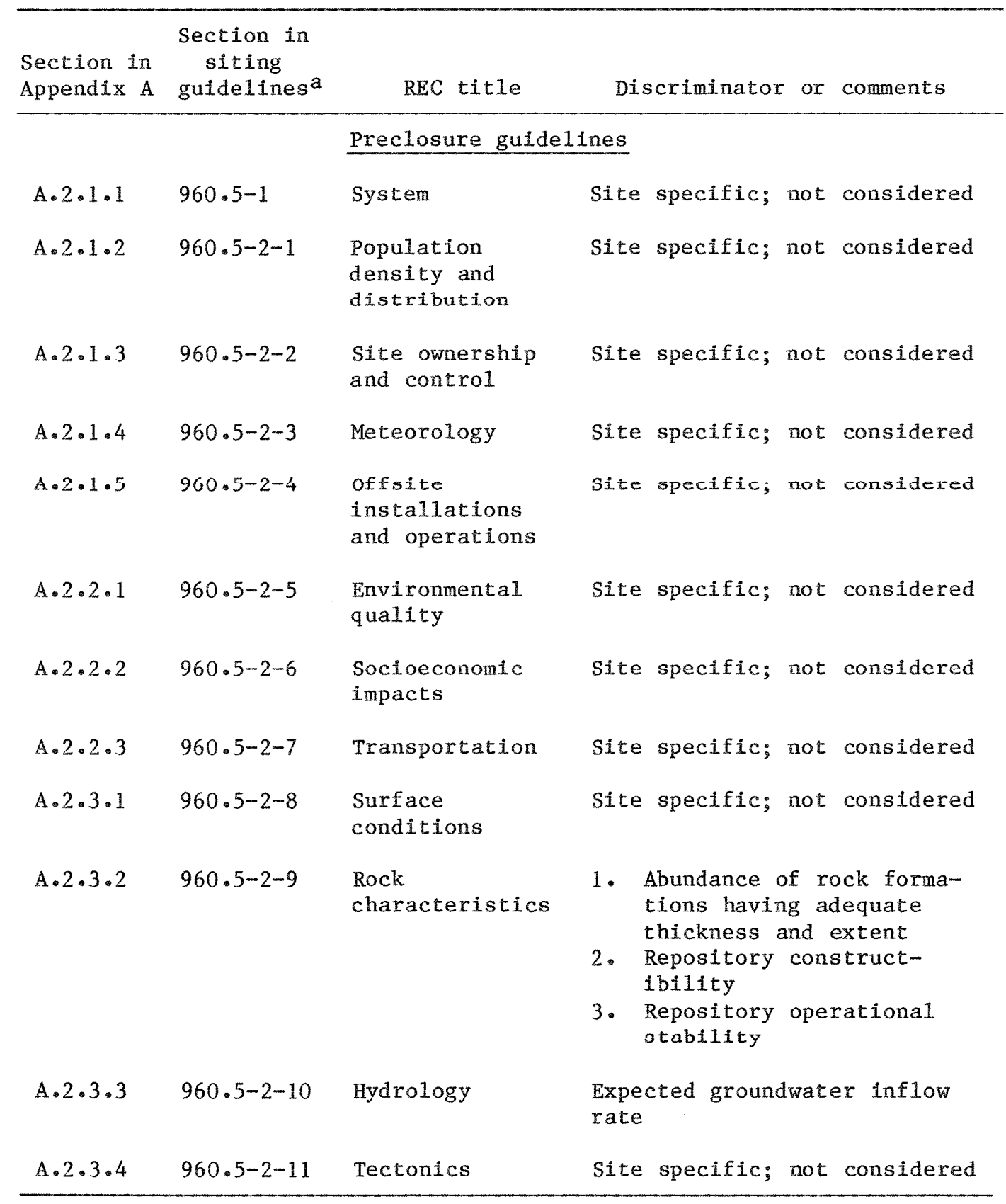

aFrom CFR 1984. 


\subsubsection{Derivation of Discriminators}

The RECs are expressed in the form of a question concerning technical factors that are to be considered. The accompanying discriminators are the technical factors that form the basis for applying the RECs to the evaluation of the rock types. Discriminators were derived from both the favorable and potentially adverse conditions under each relevant technical provision of the siting guidelines. They are defined by the boundaries of scientific (usually geotechnical) disciplines and, within a discipline, by its broad technical concepts as applied to nuclear waste management. The discriminators developed for each REC are summarized in Table 2.1 and precented in detail in Appendix A.

\subsubsection{Data Acquisition Procedure}

Once the RECo and diacriminatoro were derived, the dato required to address the RECs and discriminators were identified, and a generic technical data base was assembled. Specialized technical consultants and subcontractors were utilized to gather, collate, and present the data from a number of technical disciplines (hydrology, geochemistry, rock mechanics). This data base is presented (by discipline) in Appendixes $C$ through $K$. It is summarized and assessed, again by discipline, in Sect. 3 of this report.

\subsubsection{Description of the Rock Evaluation Methodology}

The decircd outcome of the rock evaluation procese is the ranking of the subject rock types according to their potential for hosting a geologic repository under the requirements of the siting guidelines. This was accomplished through a three-phase evaluation methodology. The first phase, discussed in Sect. 3, used the technical data base to rank the subject rock types for each derived discriminator. Evaluation of the rock types for each discriminator is based on specific technical measures (when available) or the preponderance of the evidence (depending on the type of data developed for a discriminator), taking into account the attendant uncertainties.

The second phase of the evaluation was implemented by using the rock rankings developed for the discriminator(s) of a REC as a basis for eva1uating the subject rock types for each REC. This phase is implemented 
in Sects. 4.2 and 4.3 for the postclosure and the preclosure RECs, respectively. Evaluation of the rock types for RECs having more than one subsidiary discriminator was accomplished by using two of the aggregation methods (pairwise-comparison and averaging methods) employed in common Chapter 7 of the draft environmental assessments (EAs) for the potential sites for the first repository (see, for example, DOE 1984b), along with sensitivity analyses of the results obtained by applying these methods.

Finally, the third evaluation phase was accomplished by aggregating the rock rankings for the individual RECs to obtain a ranking of the subject rock types with respect to their potential for hosting a nuclear waste repository. The aggregation was performed using the two methods alluded to above and is discussed in sect. 4.4. In all instances, the results of the evaluations are presented as rank ordering(s) of the rock types.

\subsection{BACKGROUND INFORMATION AND ASSUMPTIONS}

The rock evaluation required certain background information and common assumptions that were used as a technical basis for some of the studies performed to develop the data base. This information is summarized below and reported in detail in Appendix B.

\subsubsection{Reference Information}

The reference information utilized in this report is from three categorles: wasce form/wasce package dald, xeference geulugic tepusiluxy descriptions, and basic geologic data.

\subsubsection{Wacte Form/Waste Package Information}

Two waste package systems that are candidates for use in disposal of nuclear waste in a mined geologic disposal facility were considered: packages containing consolidated spent-fuel elements removed from the fuel assemblies and packages containing high-level waste (HLW) generated by the reprocessing of commercial spent fuel.

Consolidated Fuel Rods

The design of the package containing consolidated fuel elements is the same as that developed for the ONWI salt repository program for borehole emplacement (ONWI 1983). This package onntains fuel olements from 
six fuel assemblies from a pressurized water reactor (PWR). The spent fuel has been aged 10 years, resulting in $3.3 \mathrm{~kW}$ of decay heat. Consolidated PWR fuel was employed in this application because it is usually more limiting because of its higher burnup.

Commercial High-Leve1 Waste

The borosilicate glass/waste matrix and canister developed by the Pacific Northwest Laboratory for commercial HLW is used in this study (SLATE 1981). The HLW is assumed to have been out of the reactor for 10 years, giving a decay-heat level of $2.2 \mathrm{~kW}$ per canister.

\subsubsection{Reference Repository Description}

The reference repository design is typical of many previous conceptual designs consisting of (1) surface facilities for waste receipt, handling, storage, and packaging; (2) an underground facility with horizontal tunnels and waste disposal rooms, with the waste to be placed in vertical boreholes in the floor of the disposal rooms; and (3) vertical shafts connecting the surface and underground facilities. The repository facilities are sized for a maximun capacity of 70,000 MTHM equivalent at a receipt rate of 3000 MTHM per year. All underground facilities are assumed to be located at a uniform depth of $700 \mathrm{~m}$ below the ground surface to provide a common basis for determining groundwater travel times, thermal performance, and rock mechanics performance.

\subsubsection{Geologic Data}

The objective of evaluating rock types, as opposed to specific sites, eliminated the use of actual stratigraphic sections as a basis for the technical studies. Typical stratigraphic sections were developed for the five sedimentary rock types being evaluated (see Figs. B-5 through B-9 in Appendix B). They are intended to he representative of existing occurrences of these rock types, thus permitting data from similar actual rock formations to be utilized in making the evaluations. 


\section{DATA BASE SUMMARY AND COMPARATIVE EVALUATION WITH RESPECT TO DISCRIMINATORS}

As described in Sect. 2.1.4, the first phase of the evaluation process involves gathering technical information for the subject rock types. The necessary information was obtained by using a number of consultants and subcontractors with expertise in disciplines such as hydrology, rock mechanics, and corrosion. The technical data base is presented (by discipline) in Appendixes $\mathrm{C}$ through $\mathrm{K}$. The second phase consists of using the data base to evaluate the rock types with respect to the REC discriminators.

This section serves two primary functions. First, it provides a brief sumnary of the data base for each discipline addressed in this rock evaluation, including a short description of the technical approach, a data summary, a characterization of the data with respect to completeness and uncertainties, and an analysis of the information developed for each discipline. Second, it provides a comparative evaluation of the five rock types (i.e., a rank ordering of the rock types) for each discriminator. For the most part, these comparative evaluations were determined during a caucus of the consultants and subcontractors who participated in the information acquisition and the SERP staff. A few minor modifications were made, in some instances, to reflect information changes and later comments by reviewers. Readers who are not interested in technical details can proceed directly to Sect. 4, which summarizes the results of the evaluation.

\subsection{GEOLOGY}

Before proceeding further with the substance of this report, it is important to establish the nomenclature that will be employed. Each of the five subject rock types is comprised of rocks having a variety of characteristics, and often these rock subtypes have their own names. For example, argillaceous rocks may be comprised of clays, mudstones, and shales - some of which are clearly differentiated from the others and some of which overlap. In the interests of clarity and brevity, a relatively simple nomenclature has been established and will be used 
throughout the main body of this report. Argillaceous rocks will be referred to as shales because (1) these terms are, in some cases, used interchangeably; (2) the focus of the data, analysis, and evaluation in this report centers around those argillaceous rocks that have the characteristics of shale (i.e., significant induration, laminar bedding); and (3) shales are the most abundant of the argillaceous rocks. Limestone and dolostone will be referred to as carbonate rocks. The rock consisting primarily of the mineral anhydrite will be referred to as anhydrock. Chalk and sandstone will be referred to by these names. More precise definitions are given in Sect. 6.

Data on the geologic characteristics of the five rock types are found in Appendix E. Sections E.2 through E.6 contain information on the classification, depositional environment of formation, geometry and dimensium, hand-specimen and field characteristics, nature of bounding lithologies, reaction to external events, and resource association for one of the five subject rock types. A summary of general characteristics by depositional environment is also presented for each rock type. In these reports, reduced emphasis has been placed on the discussion of certain characteristics, such as porosity and permeability, plasticity, and association with natural resources, because they are more fully discussed in other appendixes.

Where possible, rock characteristics are discussed in the context of depositional environments. There are a number of reasons for this. Many of the parameters (such as the typical thickness and extent of a deposit) are related to the depositional environment in which a rock was formed (e.g., whether the rock was deposited in a marine shelf, fluvial, or near-shore environment). Also, because of the gradational nature in composition among sedimentary rocks (which results from the gradational nature of the depositional environments), the separation of the subject rocks into five discrete types is somewhat cumbersome. Considering each rock type as a unique entity would necessitate the development of data for an extensive range of characteristics, because of the gradational nature among rocks. Therefore, it is desirable to subdivide the five rock types more finely, on the basis of depositional environments, to facililate subsequent analysis and evaluation. 
With regard to the RECs that form the basis for the evaluation of the rocks as to their potential to host a geologic repository, the discriminator for geologic evaluation refers to the extent of the rock type; specifically, the host rock should be "sufficiently thick and laterally extensive to permit flexibility in selecting the depth, location, and configuration of the underground facility" (see Appendix A, Sect. A.1.4). Such flexibility is important because it enhances the probability that the subsurface repository workings can be located away from site-specific features that might impair repository construction and operation or degrade postclosure performance. Data relative to this question are, of course, abundant in the geologic literature. For all of the rocks, however, there are certain types of deposits, tormed in well-detined depositional environments, that are not extensive enough for further consideration. Thus, subdivisions of rock types hased on depositional environment will permit the final evaluation to reach more precise conclusions about the overall preference of the five rock types with respect to their potential to serve as a host rock for a geologic repository.

In order to effectively evaluate the data and to focus on those depositional environments with the greatest potential for repository siting, attention has been directed toward deposits that typically are at least $50 \mathrm{~m}$ thick and that occur with reasonable lateral homogeneity over at least $25 \mathrm{~km}^{2}$. In the case of anhydrock, which usually does not form thick deposits, a thickness limit of $30 \mathrm{~m}$ was used.

\subsubsection{Information Summary and Analysis}

A few important points about the geologic aspects of this report deserve emphasis. While each of Sects. E.2 through E.6 of Appendix $E$ is directed toward a specific rock type, it must be recognized that most types grade into one another and that pure end-members of each rock type rarely exist. In addition, there is a general lack of agreement regarding the terminology and unified classification schemes for some sedimentary rocks. Thus, data bases for the reports in Appendix $\mathrm{E}$ are often quite broad and, in some cases, may actually overlap for major rock types. The nature of the data encompassed in the geologic reports is highly variable because it includes results from field, theoretical, and laboratory studies, and virtually all of the data were developed for purposes other than this evaluation of the rock as a geologic repository host. 
As noted, the discriminator to be addressed herein concerns the thickness and lateral extensiveness of each rock type, to allow flexibility in the selection of repository configuration. Knowledge of the rock homogeneity is needed to allow a realistic evaluation of data on the thickness and extent. The fact that a rock type is thick and extensive does not necessarily make it attractive for repository siting. The rock type should also have reasonable vertical and lateral homogeneity so that its characteristics do not drastically change over distances on the order of $25 \mathrm{~m}$. Thus, four major factors are identified that provide input for this determinator: thickness, lateral extent, vertical homogeneity, and 1 ateral homogeneity.

Table 3.1 represents an analysis of pertinent information developed for each of the five rock types, organized by depositional environment. In addition, the relative abundance of each rock type in each depositional environment is given. A qualitative ranking scale, using high, medium, and low values, has been applied so that each depositional environment can be compared with others for the sane rock type. In the cases of shale and sandstone, the environments noted in Table 3.1 are firstorder classifications; more detailed subenvironments are described in detail in Appendix E, Sects. E.2 and E.6, respectively.

The ranking factors in Table 3.1 are based on an overall analysis of the detailed data in Appendix $E$ and do not reflect exceptions that may exist for any particular depositional onvironment. For instance, continental shale deposits are rated "medium" for thickness and "low" for lateral extent. Yet, there is a continental deposit (i.e., the Green River Formation) that is quite thick and extensive. The reader is referred to Appendix E, Sects. E.2 through E.6, for specific, detailed, and quantitative information relative to each rock type and depositional environment.

Examination of Table 3.1 shows that each major rock type contains some depositional environnents that are ranked medium or high with respect to thickness, lateral extent, homogeneity, and relative abundance. It can be seen that some deposits (i.e., marine-shale, basincenter anhydrock) not only have attractive geometric and homogeneity characteristics but also constitute a large percentage of their 
Table 3.1. Analysis of geologic information

\begin{tabular}{|c|c|c|c|c|c|c|}
\hline \multirow{3}{*}{$\begin{array}{l}\text { Rock type and } \\
\text { depositional } \\
\text { environment }\end{array}$} & \multicolumn{6}{|c|}{ Ranking factor $a, b$} \\
\hline & \multirow{2}{*}{$\begin{array}{l}\text { Thick- } \\
\text { ness }\end{array}$} & \multirow[b]{2}{*}{ Extent } & \multicolumn{2}{|c|}{ Homogeneity } & \multirow{2}{*}{\begin{tabular}{l}
\multicolumn{1}{c}{ Relative } \\
abundance of \\
depositional \\
environment
\end{tabular}} & \multirow{2}{*}{$\begin{array}{l}\text { Absolute } \\
\text { abundance }\end{array}$} \\
\hline & & & Vertical & Lateral & & \\
\hline Anhydrock & & & & & & $\mathrm{L}$ \\
\hline Basin-center & $\mathrm{H}$ & $\mathrm{H}$ & $\mathrm{H}$ & $\mathrm{H}$ & $\mathrm{H}$ & \\
\hline Basin-margin & $\mathrm{M}-\mathrm{H}$ & $\mathrm{H}$ & $\mathrm{H}$ & $\mathrm{H}$ & H & \\
\hline Playa & $\mathrm{L}$ & $\mathrm{L}$ & $\mathrm{L}$ & $\mathrm{L}$ & $\mathrm{L}-\mathrm{M}$ & \\
\hline Sabkha & $\mathrm{L}$ & $\mathrm{L}$ & $\mathrm{L}$ & $\mathrm{L}$ & $\mathrm{L}$ & \\
\hline Shelf & M & M & L & L & $\mathrm{L}$ & \\
\hline Chalk & & & & & & $\mathrm{L}$ \\
\hline Shallow water & $\mathrm{L}$ & M & $\mathrm{H}$ & $\mathrm{M}-\mathrm{H}$ & $\mathrm{M}-\mathrm{H}$ & \\
\hline Deep water & $\mathrm{H}$ & $\mathrm{H}$ & $\mathrm{M}-\mathrm{H}$ & $\mathrm{H}$ & $\mathrm{H}$ & \\
\hline Carbonate rocks & & & & & & $M$ \\
\hline Supratidal & $\mathrm{H}$ & $\mathrm{H}$ & $\mathrm{H}$ & $\mathrm{H}$ & $\mathrm{H}$ & \\
\hline Peritidal & $\mathrm{L}$ & $\mathrm{L}$ & $\mathrm{L}$ & $\mathrm{L}$ & $\mathrm{H}$ & \\
\hline Open shelf & M & M & $\mathrm{L}$ & $\mathrm{L}$ & $\mathrm{H}$ & \\
\hline Back bank edge & $\mathrm{M}-\mathrm{H}$ & M & $\mathrm{H}$ & $\mathrm{H}$ & M & \\
\hline Bank edge & $\mathrm{H}$ & M & $\mathrm{L}$ & $\mathrm{L}$ & M & \\
\hline Slope & $\mathrm{H}$ & $\mathrm{H}$ & $\mathrm{L}$ & $\mathrm{H}$ & $\mathrm{L}$ & \\
\hline Sands tone $\mathrm{c}^{\mathrm{C}}$ & & & & & & $M$ \\
\hline Open marine & $\mathrm{H}$ & $\mathrm{H}$ & M & M & M & \\
\hline Terrestrial & M & M & $M$ & M & $\mathrm{H}$ & \\
\hline Transitional & $\mathrm{M}-\mathrm{L}$ & M & $\mathrm{L}$ & M & $M$ & \\
\hline Shale $e^{c}$ & & & & & & $\mathrm{H}$ \\
\hline Continental & $\mathrm{M}$ & $\mathrm{L}$ & $\mathrm{L}$ & $\mathrm{L}$ & $\mathrm{L}-\mathrm{M}$ & \\
\hline Marine & $\mathrm{H}$ & $\mathrm{H}$ & $\mathrm{H}$ & $\mathrm{H}$ & $\mathrm{H}$ & \\
\hline Transitional & $\mathrm{M}-\mathrm{H}$ & $\mathrm{M}-\mathrm{H}$ & M & $\mathrm{M}-\mathrm{H}$ & M & \\
\hline
\end{tabular}

aThe ranking factors reflect thickness, lateral extent, homogeneity, and abundance but do not necessarily imply favorable mechanical or transport properties.

b The ranking factors are relative for each rock type separately (except for absolute abundance) and are defined as follows: $\mathrm{H}=$ high (most

favorable), $M$ = moderate, and $\mathrm{L}=$ least favorable. The specific data on which these rankings are based are found in Appendix E, Sects. E.2 through E.6.

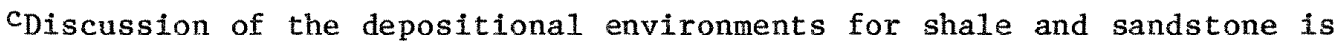
subdivided into topics related to more discrete environments in Appendix $E$, Sects. E. 2 and E.3, respectively. 
respective rock types. On the other hand, the table indicates that there are certain environments for some rocks that do not possess at tractive characteristics, such as the peritidal carbonate rocks. In addition, there are some deposits (slope carbonate rocks) that generally have good physical characteristics but are of low relative abundance.

While the information in Table 3.1 aids greatly in the assessment of the depositional environment for each rock type that will provide suitable strata for further study, it does not provide a complete basis for ranking among the rock types, because all rocks have depositional environments that are potentially suitable. To fully characterize the potential of rock types with respect to providing significant flexibility in the configuration of the repository, one must also consider their absolute abundance. The importance of this aspect cannot be overlooked. A particular depositional environment may have extremely good geometry, homogeneity, and relative abundance characteristics, yet might occur rarely in the conterminous United States. This rock should not be ranked highly with respect to offering flexibility in repository configuration if other rock types or depositional environments with equally attractive characteristics are more widely distributed.

The directly relevant parameter in this instance is the area in the conterminous United States that is underlain by one of the five rock types. Maps showing the general outlines of occurrences of the rock typoe in the United States are given in Appondix $E$. However, in the interests of simplicity and clarity and because the bases of the maps are uneven with respect to the depth and thickness of the included occurrences, the simpler quantitative surrogate discussed below will be employed.

Sedimentary rocks cover approximately $75 \%$ of the earth's land surface. Shale, sandstone, and carbonate rocks constitute over $99 \%$ of all sedimentary rocks. No uniform agreement has been reached as to the relative abundances of these three rocks. Relative abundances may be determined by direct measurements of exposed rock or by calculations based on the proportions of shale, sandstone, and carbonate rocks required to yield the composition of the average igneous rock from which sediments are derived. On the basis of direct measurements, shale, sandstone, and carbonate rocks, respectively, comprise 42 to $56 \%, 14$ to $40 \%$, and 18 to $29 \%$ of all sedimentary rocks. In contrast, calculated abundances are, 
respectively, 70 to $83 \%, 8$ to $16 \%$, and 5 to $14 \%$ (PETTIJOHN 1957). It is generally agreed that the calculated abundances are more realistic. In either case, however, shale is by far the most abundant. Anhydrock is of very minor $(<1 \%)$ abundance. Chalk (chemically equivalent to limestone, although texturally different) is included with the carbonate rocks above but represents a very minor $(<1 \%)$ percentage of all sedimentary rocks. If one assumes that shale constitutes approximate1y $75 \%$ of the sedimentary rocks, then it can be calculated that $50 \%$ of the land surface is underlain by such rocks. The qualitative rankings based on this analysis are contained in the last column of Table 3.1 .

\subsubsection{Evaluation of the Rock Types for the Geologic Discriminators}

The analysis given in Table 3.1 was used to evaluate the five rock types on the degree to which they would permit flexibility in the configuration of a repository. These results are summarized in Table 3.2. In addition, from the relative analysis of depositional environments contained in Table 3.1 , the most promising depositional environments for each rock type are identified in Table 3.2. This ranking reflects the fact that each rock type is represented by depositional environments having suitable characteristics (i.e., cannot be eliminated a priori) and that, within these suitable depositional environments, the absolute

Table 3.2. Evaluation of rock types with respect to the thickness and lateral extent discriminator

\begin{tabular}{|c|c|c|}
\hline Rank $^{\mathrm{a}}$ & Rock type & $\begin{array}{l}\text { Depositional environments of } \\
\text { relatively high abundanceb }\end{array}$ \\
\hline 1 & Shale & Marine; transitional \\
\hline \multirow[t]{2}{*}{$2 / 3$} & Sandstone & Open marine; terrestrial \\
\hline & $\begin{array}{l}\text { Carbonate } \\
\text { rocks }\end{array}$ & $\begin{array}{l}\text { Supratidal; open shelf; back bank edge; bank edge; } \\
\text { slope }\end{array}$ \\
\hline \multirow[t]{2}{*}{$4 / 5$} & Chalk & Shallow water; deep water \\
\hline & Anhydrock & Basin center; basin margin \\
\hline
\end{tabular}

a A rank of 1 is most favorable, and 5 is least favorable. A combined number $(\mathrm{e} . \mathrm{g} \cdot, 2 / 3)$ is used for two rock types of the same or nearly equivalent ranking.

bMore discrete subenvironments for shale and sandstone are described in Appendix E, Sects. E.2 and E.3, respectively. 
abundance of the rock type is the best measure of siting flexibility. on this basis, the $2 / 3$ ranking should be viewed as being relatively close to the first ranking, whereas the $3 / 4$ ranking is substantially lower than the $2 / 3$ ranking.

\subsection{GEOCHEMTSTRY}

Important discriminators in the evaluation of the potential of the five rock types for hosting a geologic repository include the geochemical reactions that might occur after wastes are emplaced. Therefore, significant attention is given to the geochemical interactions that may occur among the rock, its formational water (groundwater), the engineered barriers, and the radionuclides. All of these variables help to establish and control the geochemical environment in the repository area.

The presence of water in the repository is critical to any geochemical consideration. For the purpose of this analysis, it is presumed that water will enter and saturate the repository and therefore will be present after closure. The water represents the medium by which radionuclides could be transported. The geochemical character of this water is of considerable importance because it will, in part, control the mobilization and retardation of the radionuclides. Thus, it becomes important to understand the geochemical nature of groundwaters that might exist at possible repository depths in the five subject rock types.

Likewise, the chemical nature of the host rock is important. The rocks will greatly control the chemistry of the contained groundwater if steady-state conditions are approached, as they may be at depth. Not only does the rock control the aqueous chemistry but it can also serve as a significant barrier to radionuclide migration by acting as a sorbent or a precipitator.

The rocks and waters are of further geochemical importance because adverse conditions may arise after wastes are emplaced. The rock or water composition may be affected such that unfavorable geochemical reactions ensue, thus jeopardizing the isolation of radionuclides by increasing solubility or reducing retardation. In addition, dissolution of the host rock is of concern because it might cause a hydraulic interconnection between the host rock and the immediately surrounding rock 
units and expose waste canisters (i.e., the disposal containers designed to provide long-term containment) to corrosive fluids.

As a result of the above, the RECs contained in Appendix A identify four discriminators to be evaluated on a generic basis:

1. the expected upper concentration limits for the nuclides of interest and adverse conditions that might increase these limits (Appendix A, Sect. A.1.3);

2. the expected retardation factors for the nuclides of interest and adverse conditions that might reduce them (Appendix $A$, Sect. A.1.3);

3. the extent to which the geochemical environment in the host rock is reducing (Appendix A, Sect. A.1.3); and

4. the extent to which the host rock can dissolve in groundwater (Appendix A, Bect. A.1.7).

These four discriminators will be addressed in the following sections, using the detailed information developed in Appendix D. All of these discriminators are intercelated. For instance, the reducing environment affects the solubility and retardation of a radionuclide. Because each discriminator reflects a specific condition of concern constrained in the technical provisions of the siting guidelines, each is discussed separately. A discriminator involving waste package material degradation is discussed in another section of this report (Sect. 3.7), although the relevant groundwater conditions are developed here.

\subsubsection{Information Summary and Analysis}

\subsubsection{General Data Assessment}

The geochemical data are presented in the summary table found in Appendix D.

Discussion of the geochemical data is complicated by the fact that most discriminators draw on the data relative to rock composition, water composition, radionuclide geochemistry, and the effects of waste emplacement on these factors. Available data bases for these factors are neither equivalent nor adequate to allow full evaluation for each discriminator. For instance, there is 1ittle reliable information on the composition of groundwaters from prospective repository depths; analyses, when available, are generally incomplete. Because of gross differences 
in the compositions of deep and shallow groundwaters, it is not realistic to arbitrarily use shallow-water cheristries, for which data are quite abundant. Also, there is scant knowledge of the behavior and speciation of radionuclides in highly saline waters, such as those from deep formations, and little is known of the effects of radiolysis on the geochemistry of the subject rocks and waters.

\subsubsection{Groundwater Chemistry}

In general, deep waters are anoxic, have neutral to moderately alkaline $\mathrm{pH}$ levels, and exhibit high chloride contents. Specific data on deep waters found in the subject rocks indicate the following:

1. Deep waters from sandstones and carbonate rocks are highly variable in their chemistry. Shale and anhydrock waters are less variable but are, nevertheless, locally complex.

2. Anhydrock waters contain very high concentrations of dissolved solids (dominated by chloride and sodium, with substantial amounts of sulfate and smaller, but significant, amounts of magnesium and carbonate). The $\mathrm{pH}$ ranges from 6.2 to 7.8 and averages $\sim 7.0$.

3. Marine shales contain deep waters having a $\mathrm{pH}$ range of 7.0 to 9.0. The total dissolved solids content is variable but averages $\sim 30,000 \mathrm{ppm}$, which is lower than that for most other subject rocks. Dissolved carbonate is substantial, whereas chloride content is relatively low compared with the other rocks.

4. Data on the chemistry of deep waters in chalk are not available. It is assumed that the waters in these rocks are similar to those found in the carbonate rocks, on the basis of the rock types having similar principal mineral constituents.

Note that, because of the variability ohserved in the water compositions for all rocks except anhydrock, it is possible to find locations of each rock type where the total dissolved solids concentration (and the concentration of most other species) is relatively low.

3.2.1.3 Petrology and Geochemistry of the Rock Types

The mineralogic and chemical compositions of the rocks are important factors in determining the groundwater chemistry and the radionuclide 
concentrations and mobility in the water. The five rock types have highly variable compositions, but typical characteristics are described below:

1. Shales - Silica and alumina are the major chemical components. Water, organic matter, and sulfur are commonly present in significant amounts (a few percent of each). Shales usually have a substantial clay content, generally consisting of smectitic or illitic clays. Carbonate minerals may occur in some shales.

2. Sandstone - Silica and alumina are the major chemical components, and silica may constitute almost $100 \%$ of some sandstones. Sulfur and clays are commonly found in sandstones, but organic matter is not generally present in significant amounts. Sandstone-cementing materials are highly variable, but the most common cements are oxides, carbonate rocks, and clays.

3. Anhydrock - Anhydrock is a fairly pure monomineralic rock consisting primarily of anhydrite $\left(\mathrm{CaSO}_{4}\right)$. Generally, it has a low concentration of organic material and clay but may contain large amounts of water.

4. Carbonate rocks - The carbonate rocks (1imestone and dolostone) consist chiefly of the minerals calcite $\left(\mathrm{CaCO}_{3}\right)$ and dolomite $\left[\mathrm{CaMg}\left(\mathrm{CO}_{3}\right)_{2}\right]$. Other constituents are generally of much lesser abundance. Water, sulfur, and organic matter are generally of low abundance. Clays are generally rare also but occasionally occur in significant quantities.

5. Chalk - Chalk is a rock consisting primarily of calcite $\left(\mathrm{CaCO}_{3}\right)$ but having a different texture than does limestone. Its geochemical characteristics are very similar to those of limestone.

\subsubsection{Radionuclide Concentration Limits}

The potential for the solubility of a radionuclide in any groundwater is largely a function of

1. the acidity or the alkalinity of the groundwater,

2. the oxidizing or reducing conditions of the groundwater,

3. the total concentration of dissolved solids and speciation of the groundwater,

4. the presence or the absence of inorganic and organic ligands or complexing species in the groundwater, 
5. the temperature and the dissolved gas content of the groundwater, and

6. the physical and chemical nature of the repository host rock and the waste (form) package.

These factors are not independent. They may act in concert or in opposition (e.g., the presence of a particular organic molecule does not guarantee the solubility of a radionuclide unless other geochemical conditions are also present).

Appendix $D$ addresses the conditions affecting the solubility of the radionuclides in a variety of geochemical environments, with special emphasis on the effects of redox and $\mathrm{pH}$ conditions and interactions between nuclides and chemical complexing species. These data, based on references in the tables, indicate the following:

1. In general, the lower che oxtdacion scace of a polyvalent radionuclide, the greater its insolubility.

2. The common complexing species that cause the radionuclides to become soluble are $\mathrm{HCO}_{3}^{-}, \mathrm{CO}_{3}^{2-}, \mathrm{HPO}_{4}{ }^{2-}, \mathrm{SO}_{4}{ }^{2-}, \mathrm{F}^{-}, \mathrm{Cl}^{-}, \mathrm{OH}^{-}$, and organic species (actinides such as radium may precipitate).

3. At alkaline $\mathrm{pH}$, soluble $\mathrm{OH}^{-}$and $\mathrm{CO}_{3}{ }^{2-}$ complexes dominate.

4. Some of the pentavalent and hexavalent actinides readily form soluble anionic complexes with $\mathrm{CO}_{3}{ }^{2-}$ at $\mathrm{pH}>7$.

5. At $\mathrm{pH}<6$, radionuclide solubility is enhanced.

6. Soluble $\mathrm{F}^{-}$and $\mathrm{SO}_{\mathrm{H}^{2}}{ }^{2-}$ complexes are favored at low $\mathrm{pH}$.

7. Soluble $\mathrm{HPO}_{4}{ }^{2-}$ complexes are favored at neutral $\mathrm{pH}$.

8. In general, a lower concentration of dissolved solids results in lower radionuclide solubility.

These results indicate that reducing groundwaters with pH levels in the range of 6 lo 7 and will low lolal dissolved solids concenlralions favol low solubility of redox-sensitive nuclides.

Analysis of the factors affecting radionuclide concentration limits, in the context of the water and rock characteristics discussed earlier, leads to the conclusions summarized here. Overall radionuclide solubility is expected to be the lowest in shales, primarily because of the relatively low concentration of total dissolved solids in waters that are charactertshlc of shales, the relathely low chloride concent of the 
water, and the reducing conditions expected to result from the presence of organic matter. The low concentration of complexing 1igands is evidenced by the fact that the total dissolved chloride and carbonate concentrations in shale waters are lower than those in other rock types, and, even though total dissolved sulfate can be moderately high in shale waters, sulfate complexes of radionuclides are common only at pH values of 3 or less. The carbonate content in shale waters is moderate and about the same as that in waters of the other rock types; thus, the effect of carbonate complexes on radionuclide solubility does not constitute a basis for differentiating between the rock types. Under shalewater conditions in the far field (ONWI 1984), the elements of concern can be divided into the following groups: (1) very insoluble - Fe, Ni, $\mathrm{Co}, \mathrm{Zr}, \mathrm{Nb}, \mathrm{Pd}, \mathrm{Sn}, \mathrm{Sb}, \mathrm{Sm}, \mathrm{Eu}, \mathrm{Pb}, \mathrm{Po}, \mathrm{Th}, \mathrm{Pa}, \mathrm{U}, \mathrm{Np}, \mathrm{Pu}, \mathrm{Am}, \mathrm{Cm}$; (2) limitcd solubility - Se, Sr, Tc, Ru, Cs; and (J) soluble - I, Kr, Rn. The elements listed in group 1 form insoluble compounds under the redox and $\mathrm{pH}$ conditions expected, while the elenents in group 2 may be fixed by clay minerals or, in some cases, by precipitation ( $\mathrm{Se}, \mathrm{Tc}, \mathrm{Ru}$ ). In group 3, iodine may be partially removed by clay minerals.

The carbonate rocks, sandstone, and chalk would appear to offer the potential of radionuclide concentration limits somewhat higher than those for shale. In the case of the carbonate rocks and sandstone, the total dissolved solids concentration in the groundwater is much higher than that for shale, primarily because of the much higher chloride concentration. The $\mathrm{pH}$ of deep-water samples indicates a higher propensity for acidic conditions, enhancing radionuclide solubility and the complexing importance of the chlorides and sulfates. Organic matter concentrations are generally low, thus offering the possibility of less-reducing redox conditions. Chalk is ascumed to have the same attributcs as the carbonate rocks with respect to radionuclide concentration limits, because of its similarity to limestone.

Radionuclide concentration limits are expected to be the highest in anhydrock waters. These waters have high concentrations of dissolved solids, principally chlorides and sulfates, which act as complexing agents. The $\mathrm{pH}$ range is nearly neutral to very slightly acidic. These rocks are expected to contain virtually no organic mattcr, and redox con ditions are expected to be less reducing than in the other rocks. 
The expected effects of adverse conditions on the various rock types did not form a basis for differentiating between them. In the near field (ONWI 1984), similar adverse conditions would be expected in all rock types because of the effects of increased temperatures and radiationinduced hydrolysis, which may result in local oxidizing and acidic conditions. The higher concentrations of organic matter expected in most shales offer the potential for the production of organic complexing agents through heat- or radiation-induced degradation. However, the rate and effects of this adverse condition are sufficiently uncertain to prevent their meaningful consideration at present.

\subsubsection{Radionuclide Retardation}

It is convenient and conventional to address the problem of radionuclide retardation in terms of laboratory studies of sorption and desorption. The parameter $\mathrm{K}_{\mathrm{d}}$ is usually referred to in such work and is given in units of volume of fluid per mass of element sorbed (i.e., in $\mathrm{mL} / \mathrm{g}$ or $\left.\mathrm{m}^{3} / \mathrm{kg}\right) . *$ The retardation factor, $\mathrm{R}$, is given as

$$
R=1+\left(K_{d} \rho\right) / \Phi,
$$

where $\rho=$ density in $\mathrm{g} / \mathrm{cm}^{3}$ and $\Phi=$ total porosity. The retardation factor is the ratio of the velocity of groundwater to the velocity of the radionuclides, and any value of $\mathrm{R}$ greater than 1 indicates that the radionuclide will move more slowly than does the groundwater. For equivalent values of $\mathrm{K}_{d}$ and density, rocks with a higher total porosity will have lower retardation factors. However, because the variability of $\mathrm{K}_{\mathrm{d}}$ between rock types is large, as compared with that for the total porosity, the $\mathrm{K}_{\mathrm{d}}$ is still the controlling parameter in radionuclide retardation.

Retardation factors have been tabulated for numerous radionuclide species, but usually the data are for oxidizing and dilute-solution experimental conditions. Very few data exist that might be appropriate

*It is recognized that $\mathrm{K}_{\mathrm{d}}$ values are approximations of actual radionuclide sorption behavior, but they are the only available basis for studies such as this and constitute useful information of a relative nalure for the assessment of relardallon. 
for the saline waters encountered at depth in the rocks of interest. However, most R-values can be used for a generic evaluation of the relative ability of the various sedimentary rocks to sorb radionuclides.

Tabulated data suggest that:

1. Radionuclides are usually strongly sorbed onto clays and, to a lesser degree, onto oxides and hydroxides.

2. Smectite sorbs radionuclides better than does illite, which, in turn, sorbs radionuclides better than does kaolinite.

3. Sorption onto clays is most favored in the $\mathrm{pH}$ range of 7 to 8.5 .

4. Minerals such as calcite, dolomite, and anhydrite have poor sorbing characteristics in comparison with clay minerals.

5. The presence of dissolved organic ligands decreases the ability of clays to sorb radionuclides.

6. Sorption of radionuclides onto clays is decreased in high-ionirstrength waters.

7. The higher the charge on the radionuclide, the greater the tendency for the radionuclide to sorb onto clays.

The ability of a rock to retard elements can be estimated in a relative fashion from the $\mathrm{K}_{\mathrm{d}}$ values of its constituent minerals, because $\mathrm{K}_{\mathrm{d}}$ is the principal variable that controls retardation in the subject rocks. Clay minerals typically have $\mathrm{K}_{\mathrm{d}}$ values that are much larger than those for other minerals (see Table D.2.3), while typical total porosity values among the subject rocks vary from only 1 to $10 \%$ (anhydrock, $1 \%$; shale, 3\%; sandstone, $8 \%$; carbonate rocks and cha1k, $10 \%$; data from Sect. 3.3, Hydrology). It is clear, therefore, that clay-rich rocks with relatively low porosity will have a greater retardation ability and that rocks with low clay contents, even though they may have low porosity, will have little ahility to retard elements.

The results also suggest that reducing groundwaters that are nearly neutral to slightly alkaline ( $\mathrm{pH} 7$ to 8 , low total-dissolved-solids concentration, and low organic-ligand concentration) are best for retardation and that aquifers of high ion-exchange capacity, particularly those having a high clay content, are best.

Analysis of these factors and trends affecting radionuclide retardation, in the context of the water and rock characteristics summarized 
earlier, leads to the evaluation of the subject rock types with respect to their ability to retard radionuclide movement. Shales are expected to be the best rock types for radionuclide retardation by virtue of their high clay and organic matter contents, expected reducing conditions, and the relatively low concentration of dissolved solids in the groundwater. The clays in shales are generally smectitic and illitic, with high sorption capabilities.

Sandstones are expected to have moderate retardation capabilities because they generally have a significant clay content and oxides as a cementing material. However, the lower concentration of clays and organic matter and the greater complexing ability of sandstone waters result in less sorption capability for sandstones than for shales. In addition, sandstone waters should have less-reducing conditions and are expected to have a mich higher concentration of dissolved solids than water in shales.

The carbonate rocks, chalk, and anhydrock are all basically monomineralic rocks and are expected to have low retardation capability. The carbonate rocks and chalk usually contain a small amount of clay and organic matter, thus offering some capability in this regard. Clay and organic matter are essentially nonexistent in anhydrock. Also, the total-dissolved-solids concentration in the carbonate groundwater is slightly to greatly less than that for anhydrock. On this basis, the carbonate rocks and chalk are ranked together significantly below sandstone, and anhydrock is ranked slightly lower than carbonate rocks and chalk.

The effects of waste emplacement on retardation characteristics are difficult to evaluate. Temperature increases may produce dehydration of hydrous phases (such as clays), phase changes (with resultant loss of sorptive characteristics), and secondary fracture formation. The relative degree of adversity of these reactions is unknown. However, the maximum temperatures from emplaced waste barely approach those at which clay degrades. Radiation may degrade organic matter and thus reduce sorptive capacity, but such a reaction has not been verified. Products from the degradation of organic matter may be gaseous and produce an adverse condition. The propensity of the subject rocks and groundwaters to form colloids and particulates that muld transport radionuclides 
more rapidly than if they were sorbed is unassessable because of a lack of data. These potentially adverse conditions and reactions could occur only in the near-field to very-near-field (ONWI 1984) portions of the repository since they require (at a minimum) elevated temperatures and radiation levels to proceed.

\subsubsection{Reducing Conditions}

Few reliable data are avallable for the redox conditions that prevail at potential repository depths. The redox conditions will be determined chiefly by the mineral constituents and organic matter content of the host rock at these depths. By examining data for water chemistry and rock mineralogy, it is possible to evaluate in relative terms the redox conditions for the subject rock types.

The presence of a reducing environment in sedimentary rocks is generally fustexed by the presence of urganic mallet and sulfide minerals. Analyses of the reducing propensities of the subject rocks have already been given in preceding sections, and only a brief summary will be presented here.

Shales should provide the most-reducing environment of the five subject rock types. Shales contain significant organic matter and sulfide minerals. Some shales contain extremely large amounts of these constituents, greater than the amounts found in any of the other subject rocks. Sandstones often contain small amounts of organic material, and waters from sandstones often contain $\mathrm{H}_{2} \mathrm{~S}$, which indicates a moderately reducing environment. Carbonate rocks, chalk, and anhydrock (in this order) represent the rocks in which the least-reducing environments should be found. Organic matter is rare in these rocks, although limestones (and chalks) may serve as reservoir rocks for petroleum. Where data are available for groundwaters, $\mathrm{H}_{2} \mathrm{~S}$ is generally reported for all these rocks.

The adverse impacts of heat and radiation on the redox characteristics of minerals are not well documented. It is likely, however, that the greatest effects will be on clays and organic matter, but the degree of adversity with regard to redox potential is unknown. The radiolysis of water, however, may produce a near-field oxidizing condition for all rock types. 


\subsubsection{Potential for Rock Dissolution}

Data for rock solubility, per se, are lacking. There are, however, accurate solubility data for many of the rock-forming minerals. Mineral solubilities are determined by the nature of the solid phase, the composition of the aqueous phase, redox conditions, and temperature. Abundant data exist for a wide range in compositions of both aqueous and solid phases at various temperatures, but there are few data for solubilities in waters typical of repository depths. If a rock at a repository depth is to be dissolved, the solvent must, of course, be undersaturated with regard to the solid phases.

Despite the uncertainties, the available mineral solubility data can, with caution, be extrapolated to depth conditions, and an independent assessment of mineral stabilities under the proposed repository conditions may be attempted. This situation is especially true for rocks that are simple in mineralogy.

In general, anhydrocks tend to be very soluble in the presence of water, and waters from anhydrock contain some of the highest concentrations of dissolved solids reported. Carbonate rocks are also known to be soluble under many conditions in nature, although they are not as soluble as the anhydrocks. Minerals such as quartz and clays are very insoluble under natural conditions; hence, rocks such as sandstone and shale are more resistant to dissolution than are anhydrocks or carbonate rocks. 3.2.2 Evaluation of the Rock Types for the Geochemical Discriminalurs

The data discussed in Sect. 3.2.1 have been comparatively evaluated so that each of the five rock types can be ranked relative to the four geochemical discriminators. Relative rankings are found in Table 3.3.

The data indicate that waters in shale generally have a lower complexing potential and are more reducing than waters in the other subject rocks. Thus, shale is ranked first with regard to radionuclide concentration limits. Carbonate rocks, chalk, and sandstone contain groundwaters that will promote somewhat higher solubility than water from shale because of their much higher concentration of total dissolved solids (especially chloride); thus, they are ranked second. By far the greatest complexing potential is for the salt-laden water from anhydrock; hence, a ranking of 3 is assigned. 
Table 3.3. Rankings of the subject rock types based on geochemical discriminators ${ }^{a}$

\begin{tabular}{lcccc}
\hline Rock type & $\begin{array}{c}\text { Radionuclide } \\
\text { concentration } \\
\text { limit }\end{array}$ & $\begin{array}{c}\text { Radionuclide } \\
\text { retardation }\end{array}$ & $\begin{array}{c}\text { Redox character } \\
\text { of water }\end{array}$ & $\begin{array}{c}\text { Rock } \\
\text { solubility }\end{array}$ \\
\hline Shale & 1 & 1 & 1 & 1 \\
Sandstone & 2 & 2 & 2 & 1 \\
Chalk & 2 & 3 & 3 & 2 \\
$\begin{array}{l}\text { Carbonate } \\
\text { rocks }\end{array}$ & 2 & 3 & 3 & 2 \\
Anhydrock & 3 & 4 & 3 & 3 \\
\hline
\end{tabular}

$\mathrm{a}_{\mathrm{A}}$ rank of 1 is most favorable and 4 is least favorable.

With regard to radionuclide retardation, shale is by far the best because it contains large amounts of sorbing clay and, often, organic matter. Substantially behind shale in the second rank is sandstone, which typically has lower contents of clay and organic matter. Far behind sandstone are the carbonate rocks and chalk, which may have small amounts of clay and organic matter and are, thus, ranked third. Anhydrock is generally devoid of such matter and is ranked fourth somewhat lower than chalk and the carbonate rocks.

The evaluation of the redox character of the rock/water system generally reflects the concentrations of organic matter and sulfide in the rock. Shalc gencrally has a high concentration of organic mattcr and may contain significant amounts of sulfide; it is ranked first. Sandstone may have small amounts of organic matter and is ranked second, substantially below shale. The carbonate rocks, anhydrock, and chalk generally have insignificant to very small amounts of organic matter and are ranked third, significantly below shale.

The presence of organic matter in the rock could have diverse effects. It is expected that the presence of significant amounts of organic matter will enhance radionuclide retardation, reducing conditions, and radionuclide insolubility. On the other hand, the thermal or radiolytic degradation of the organic matter could result in the production of complexing agents that could increase radionuclide solubility 
and decrease retardation. The adverse effects of organic matter are problematic at the present time because of the lack of knowledge in this area.

The evaluation of the potential for rock dissolution is based on the solubility of the rock in unsaturated water; solubilities for all rocks should be greater in the near field than in the far field. Shale and sandstone are ranked first because their principal constituent minerals (clay, quartz) have extremely low solubilities. The carbonate rocks and chalk are ranked second, substantially below shale and sandstone, because their primary minerals (calcite, dolomite) are moderately soluble. Anhydrock is ranked third, significantly below the carbonate rocks, since its principal mincral (anhydritc) is highly soluble.

\subsection{HYDROLOGY}

One of the most important aspects of waste isolation in geologic repositories is the potential for the migration of radionuclides in moving groundwater. This aspect of repository performance is addressed by dividing it into a discussion of factors affecting groundwater travel (presented in this section) and one concerning radionuclide mobility (presented in Sect. 3.2). The postclosure hydrologic discriminator used in this evaluation (Appendix A, Sect. A.1.2) is concerned with the prewaste-emplacement groundwater travel time to the accessible environment, assumed to be located at a distance of $10 \mathrm{~km}$ from the emplaced waste.* The trave1-time objective, from a generic perspective, is a comparative evaluation of the five rock types on the basis of a consistent, standard

*At the time these calculations were made, the "controlled area" was tentatively defined as a "surface location, kept under the effective control of the Department through the maintenance of active institutional controls, extending horizontally no more than 10 kilometers in any direction from the outer boundary of the original location of the radioactive wastes in a disposal system," and the 10-km distance was used in evaluating the rocks relative to groundwater travel times. Subsequently, the EPA defined the "controlled area" to mean a surface area "that encompasses no more than 100 square kilometers and extends horizontally no more than 5 kilometers in any direction from the outer boundary of the original location of the radioactive waste in a disposal system" (CFR 1985). The calculations given in this report have not been changed to reflect the $5-\mathrm{km}$ value because they are of a relative nature, and the resulting ranking would not be affected. 
set of conditions. Such an objective cannot deal with absolutes but with the relative magnitude of the critical parameters. Therefore, the measure used to evaluate the rock types as to relative postclosure hydrologic conditions is the calculated relative pre-waste-emplacement groundwater travel time through each rock type over a distance of $10 \mathrm{~km}$, or, alternatively, the calculated distance traveled by the groundwater during a period of 100,000 years.

preclosure hydrologic factors relevant to repository host rocks involve the expected groundwater conditions that are likely to require engineering measures beyond reasonably available technology in the construction of an exploratory shaft or repository facility. An excessive groundwater inflow rate into the repository during construction and operation is a hydrologic condition often associated with sedimentary rocks that could require such mosures. This concept is therefore adopted as another indicator of performance. Again, from a generic perspective, the results of groundwater inflow analysis cannot deal with absolutes, but rather with the relative responses to a selected, consistent, standard set of conditions. The specific indicator used as a basis for evaluating the preclosure hydrologic favorableness of a rock type is the volumetric rate at which water is expected to flow into the mined openings before closure in a hypothetical geologic repository in each rock type (see Appendix A, Sect. A.2.3.3).

The hydrologic calculations involved in these two discriminators require a variety of data, as discussed below. The calculations also require the specification of a typical stratigraphic section for each rock type, to provide the relevant dimensions of the rock layers. For this reason, the stratigraphic sections given in Appendix $B$ form the basis for these calculations. The typical hydrolngir data used in the calculations are representative of the more promising (less permeable or less fractured) examples of each of the five subject rock types, as depicted in the sections and in the literature. Expert judgment was employed to ensure that this was indeed the case for all rock types and that the data base was internally consistent (e.g., that a low hydraulic conductivity was not associated with an unreasonably high porosity). 


\subsubsection{Information Summary and Analysis}

\subsubsection{Data Base}

The physical characteristics that influence the hydrologic behavior of each rock type are summarized in this section. Detailed information concerning the hydrologic data and their sources is contained in Appendix C. The pertinent structural aspects of each rock type include the fabric, the nature of fracturing, and the variability of occurrence. The hydrologic properties of most concern for this evaluation include both the horizontal and the vertical hydraulic conductivities, the effective porosity, and the specific storage. Of these, the first three are important in groundwater travel-time calculations, whereas the last (specific storage) is required in the transient analysis of potential preclosure flow rates into exploratory shafts and repository excavations. The hydraulic conductivicy and effective porosicy factors are incerrelated in the calculation of groundwater travel time in that, for a simple one-dimensional case, travel time increases linearly as effective porosity increases and hydraulic conductivity decreases. The adopted data base for hydrologic properties is shown in Table 3.4 (see Appendix $C$ for details). The basis for the "typical" value in this table, is defined in Sect. 3.3, and the high and low values represent the approximate range within which the values would be expected to fall with roughly uniform probability.

In arriving at the data base in Table 3.4. several value judgments were necessary. First and foremost was a consideration of a scale of measurement where both laboratory and field conductivities are available. Wherever possible, the field values for the more promising end of the spectrum for each rock type were given preference. For the lowerpermeability rocks, hydraulic conductivitles determined from cores constitute much of the data base and, because of fractures at the field scale, tend to be lower than those obtained in field tests. On the other hand, core data were exclusively relied on for the determination of the total porosity (fraction of the rock that is pore space). Since the effective porosity (fraction of the rock that is interconnected pore space) is not of ten directly measured, in Table 3.4 it is given as an estimate based on compressibility data. Despite the uncertainctes 
Table 3.4. Adopted data base for hydrologic properties

\begin{tabular}{|c|c|c|c|}
\hline Rock type and properties & $\mathrm{High}^{\mathrm{a}}$ & Low $^{\mathrm{a}}$ & Typical \\
\hline \multicolumn{4}{|l|}{ Anhydrock } \\
\hline Horizontal conductivity, $\mathrm{m} / \mathrm{s}$ & $1 \times 10^{-10}$ & $1 \times 10^{-12}$ & $1 \times 10^{-11}$ \\
\hline Vertical conductivity, $\mathrm{m} / \mathrm{s}$ & $1 \times 10^{-11}$ & $1 \times 10^{-13}$ & $1 \times 10^{-12}$ \\
\hline Total porosity & 0.05 & 0.005 & 0.01 \\
\hline Effective porosity & 0.005 & 0.0005 & 0.001 \\
\hline Specific storage, $\mathrm{m}^{-1}$ & $5 \times 10^{-7}$ & $5 \times 10^{-8}$ & $1 \times 10^{-7}$ \\
\hline \multicolumn{4}{|l|}{ Chalk } \\
\hline Horizontal conductivity, $\mathrm{m} / \mathrm{s}$ & $1 \times 10^{-6}$ & $1 \times 10^{-8}$ & $1 \times 10^{-7}$ \\
\hline Vertical conductivity, $\mathrm{m} / \mathrm{s}$ & $5 \times 10^{-7}$ & $5 \times 10^{-9}$ & $5 \times 10^{-8}$ \\
\hline Total porosity & 0.2 & 0.05 & 0.1 \\
\hline Effective porosity & 0.005 & 0.0005 & 0.001 \\
\hline Specific storage, $\mathrm{m}^{-1}$ & $1 \times 10^{-5}$ & $1 \times 10^{-6}$ & $5 \times 10^{-6}$ \\
\hline \multicolumn{4}{|l|}{ Carbonate rocks } \\
\hline Horizontal conductivity, $\mathrm{m} / \mathrm{s}$ & $1 \times 10^{-5}$ & $1 \times 10^{-7}$ & $1 \times 10^{-5}$ \\
\hline Vertical conductivity, $\mathrm{m} / \mathrm{s}$ & $5 \times 10^{-6}$ & $5 \times 10^{-8}$ & $5 \times 10^{-7}$ \\
\hline Total porosity & 0.15 & 0.05 & 0.1 \\
\hline Effective porosity & 0.05 & 0.001 & 0.01 \\
\hline Specific storage, $\mathrm{m}^{-1}$ & $5 \times 10^{-6}$ & $5 \times 10^{-7}$ & $1 \times 10^{-6}$ \\
\hline \multicolumn{4}{|l|}{ Sandstone } \\
\hline Horizontal conductivity, $\mathrm{m} / \mathrm{s}$ & $1 \times 10^{-8}$ & $5 \times 10^{-11}$ & $1 \times 10^{-10}$ \\
\hline Vertical conductivity, $\mathrm{m} / \mathrm{s}$ & $5 \times 10^{-9}$ & $2.5 \times 10^{-11}$ & $5 \times 10^{-11}$ \\
\hline Total porosity & 0.15 & 0.05 & 0.08 \\
\hline Effective porosity & 0.1 & 0.005 & 0.01 \\
\hline Specific storage, $\mathrm{m}^{-1}$ & $5 \times 10^{-6}$ & $5 \times 10^{-7}$ & $1 \times 10^{-6}$ \\
\hline \multicolumn{4}{|l|}{ Shale } \\
\hline Horizontal conductivity, $\mathrm{m} / \mathrm{s}$ & $1 \times 10^{-10}$ & $1 \times 10^{-12}$ & $1 \times 10^{-11}$ \\
\hline Vertical conductivity, $\mathrm{m} / \mathrm{s}$ & $1 \times 10^{-11}$ & $1 \times 10^{-13}$ & $1 \times 10^{-12}$ \\
\hline Total porosity & 0.1 & 0.01 & 0.03 \\
\hline Effective porosity & 0.05 & 0.005 & 0.01 \\
\hline Specific storage, $\mathrm{m}^{-1}$ & $5 \times 10^{-6}$ & $5 \times 10^{-7}$ & $1 \times 10^{-6}$ \\
\hline
\end{tabular}

aThe high and low values represent the approximate range within which the values would be expected to fall with roughly uniform probability.

bThe typical hydrologic data used in the calculations are representative of the more promising (less permeable or less fractured) examples of each of the five subject rock types, as depicted in the geologic sections and in the literature. 
associated with the effective porosity, the range of values is not expected to be as large as the several-orders-of-magnitude ranges associated with hydraulic conductivity. The beneficial effects of the diffusion of radionuclides into rock pores (matrix diffusion) would be enhanced by a higher rock porosity, although this currently evolving concept is not a differentiating factor among the rock types, because of the narrow range of porosity values.

Specific storage is another parameter that is seldom measured. The particular calculation used here was based on the elastic properties of the rocks and their contained fluids. (This method involves a conventional calculation and is thought to be reasonably accurate.) The reported values may be unrealistically high, because the bulk modulus, as opposed to the constrained modulus, was employed in the calculations. However, this assumpliun affects values fur all ruch types essentially equally and is no major source of error.

With respect to the quantity of the hydraulic conductivity data used in the study, sandstone is represented by 30 values, carbonate rocks by 39 values, chalk by 23 values, shale by 21 values, and anhydrock by 13 values, giving a total of 126 values. Of these, 36 represented field measurements, with 13 measurements pertaining to the vertical conductivity. Sources and reasons for using these data are given in Appendix C. The reported "typical" value of Table 3.4 is a value that would be expected to be generally prevalent at a number of field locations in a horizon of sufficient thickness and extent to be considered for radioactive waste disposal. For the more permeable rock units, such as sandstone and the carbonate rocks, only those that are not typically good aquifers are included in the data base values adopted for analysis.

Total porosity data are readily available, and virtually hundreds of measurements were used to support the range of values in the adopted data base of Table 3.4. The same is true for elastic moduli, which are the most important measurements required for the calculation of specific storage.

\subsubsection{Postclosure Calculations}

The pre-waste-emplacement groundwater travel time is estimated by solving the steady-state flow equation. I'ne solution to this equation 
provides data for a spatial distribution of the hydraulic head, from which the water velocity at all points can be calculated. The available pore space in all rock types is assumed to be filled initially with water (i.e., repository saturation is assumed). The details of the calculations are summarized in Appendix C.

The boundary conditions are derived for a two-dimensional vertical cross section of flow, identical to those presented for the typical stratigraphic sections in Appendix B. The upper boundary condition represents the water table where head varies linearly from 20 to $0 \mathrm{~m}$ over a length of $20 \mathrm{~km}$. This provides a regional horizontal component of the gradient of $1 / 1000$ across the sections. This gradient was assumed to be the same for all geologic sections to help provide a uniform basis for compairsons. The other boundary conditions are determined by solving a "boundary conditions" model of the same geometry, where the top boundary is set uniformly to a potential of zero, the lateral boundaries are treated as no-flow boundaries, and the lower boundary is set to some uniform constant potential. The value of the lower boundary is determined by trial and error to provide a potential of $6.5 \mathrm{~m}$ of water head at the repository level. This procedure forces an assumed upward vertical component of the gradient of $1 / 100$ between the repository level and the upper boundary for all geologic sections, thus fixing the boundary conditions for the travel-time model, where both the left and the right vertical profiles from the boundary condition model are employed in the travel-time mode1. Finally, the lower boundary of the travel-time mode1 is simply that of the boundary condition model adjusted for the regional horizontal component of the gradient. In this mannex, each of the rock types under investigation as a potential repository host unit is subjected to the same horizontal (1/1000) and vertical (1/100) gradient components, with a different set of superposed flow fields that force these standard conditions. Although not completely accurate from a theoretical viewpoint, these manipulations provide typical travel times without sitespecific pathways, thereby providing a relative basis for ranking the rocks.

Because the stratigraphic sections considered in this study, and the hydrologic data characterizing them, are selected on the basis of representing the more promising occurrences of each rock type for a geologic 
repository, long pre-waste-emplacement travel times are expected. Analysis indicates that the five rock types fall into two widely separated categories. Anhydrock, sandstone, and shale exhibit very long travel times to the accessible environment (in excess of 100,000 years), whereas chalk and the carbonate rocks show significantly shorter travel times (less than 50,000 years). A summary of the calculated groundwater trave1 times (the groundwater travel distances were calculated for the lowpermeability rock types to eliminate unreasonably long computational times) is given in Table 3.5 .

For shale and anhydrock, all the groundwater travel paths for the first 100,000 years remain in the reference horizon, regardless of the conductivities of the directly overlying beds, primarily because of the small distances the groundwater travels. For the carbonate rocks and sandscone, the groundwacer paths also stay within the reference horizon, mostly because these units are overlain by the lower-permeability rock formations. For chalks, the travel paths typically leave the reference horizon, regardless of the low conductivities of the overlying beds. The groundwater travel times and distances for shale, sandstone, and anhydrock are expected to be quite insensitive to the specifics of the assumed stratigraphic sections and those for chalk and the carbonate rocks only modestly sensitive.

Table 3.5. Summary of comparative pre-waste-emplacement groundwater travel times and distances for the five subject rock types

\begin{tabular}{|c|c|c|c|c|c|c|}
\hline \multirow{2}{*}{ Rock type } & \multicolumn{3}{|c|}{$\begin{array}{l}\text { Groundwater travel distance } \\
\text { in } 100,000 \text { years }{ }^{a}(\mathrm{~m})\end{array}$} & \multicolumn{3}{|c|}{$\begin{array}{l}\text { Groundwater travel time for a } \\
\text { distance of } 10 \mathrm{~km}^{\mathrm{a}} \text { (years) }\end{array}$} \\
\hline & Typical & High & Low & Typical & High & Low \\
\hline Shale & 6 & 40 & 0.3 & $>100,000$ & $>100,000$ & $>100,000$ \\
\hline Sandstone & 30 & 3,000 & 20 & $>100,000$ & $>100,000$ & $>100,000$ \\
\hline Anhydrock & 50 & 300 & 10 & $>100,000$ & $>100,000$ & $>100,000$ \\
\hline $\begin{array}{l}\text { Carbonate } \\
\text { rocks }\end{array}$ & $>10,000$ & $>10,000$ & $>10,000$ & 3,000 & 300 & 30,000 \\
\hline Chalk & $>10,000$ & $>10,000$ & $>10,000$ & 37,000 & 300 & 50,000 \\
\hline
\end{tabular}

acalculated values are generic and should be used only in relation to each other, not in absolute comparisons (e.g., with the qualifying and disqualifying groundwater travel times in the siting guidelines). 


\subsubsection{Preclosure Calculations}

As already explained, the measure of preclosure hydrologic performance is the expected rate at which groundwater flows into mined openings. For the purpose of ranking the five subject rock types addressed in this study, this inflow is estimated as the volume of groundwater that can be expected to enter a very long drift, $5.5 \mathrm{~m}$ in diameter per meter of drift length per unit of time. Because the layout of the repository has not been specified, the effects of flow-field interference associated with multiple drifts cannot be assessed. However, the inflow estimated on the basis of a single drift should provide an adequate measure (for ranking purposes).

The inflow is estimated by a finite-element solution to the transient flow equation. A constant potential at the drift is set equal to $650 \mathrm{~m}$ of water head to represent the 650 m uf saluialed suck above lile repusitory. A line of symmetry passes vertically through the section of the drift and, except at the drift itself, forms a no-flow boundary. The other boundaries have varying boundary conditions to reflect the material properties, but mostly are no-flow in nature.

The results of the groundwater inflow calculations are summarized in Fig. 3.1. The inflows were found to monotonically decline with time, because of the depletion of groundwater sources near the mined openings. All values are considered to be below the range where engineering measures beyond reasonably available technology would be required.

3.3.2 Evaluation of the Rock Types for the Hydrologic Discriminators

\subsubsection{Postc1osure}

Inspection of the results presented in Table 3.5 (and the underlying details in Appendix C) clearly indicates that, on the basis of hydrologic discriminators, shale should be ranked first as a preferred rock type for a geologic repository. The results for sandstone and anhydrock are very similar, and hence they are ranked second, with the ranking order being relatively close to the first rank. The postclosure hydrologic performance of the carbonate rocks and chalk is similar, and thus these rock types are ranked third, considerably below the second rank. 


\subsubsection{Preclosure}

Inspection of the results presented in Fig. 3.1 indicates that the following evaluation is appropriate for the preclosure hydrology discriminators:

1. Anhydrock and shale have low water inflow rates of approximately the same magnitudes and are ranked first.

2. Sandstone is ranked second, with this rank being relatively close to the first.

3. Chalk and the carbonatc rocke are ranked a distant third.

ORNL DWG 85-28

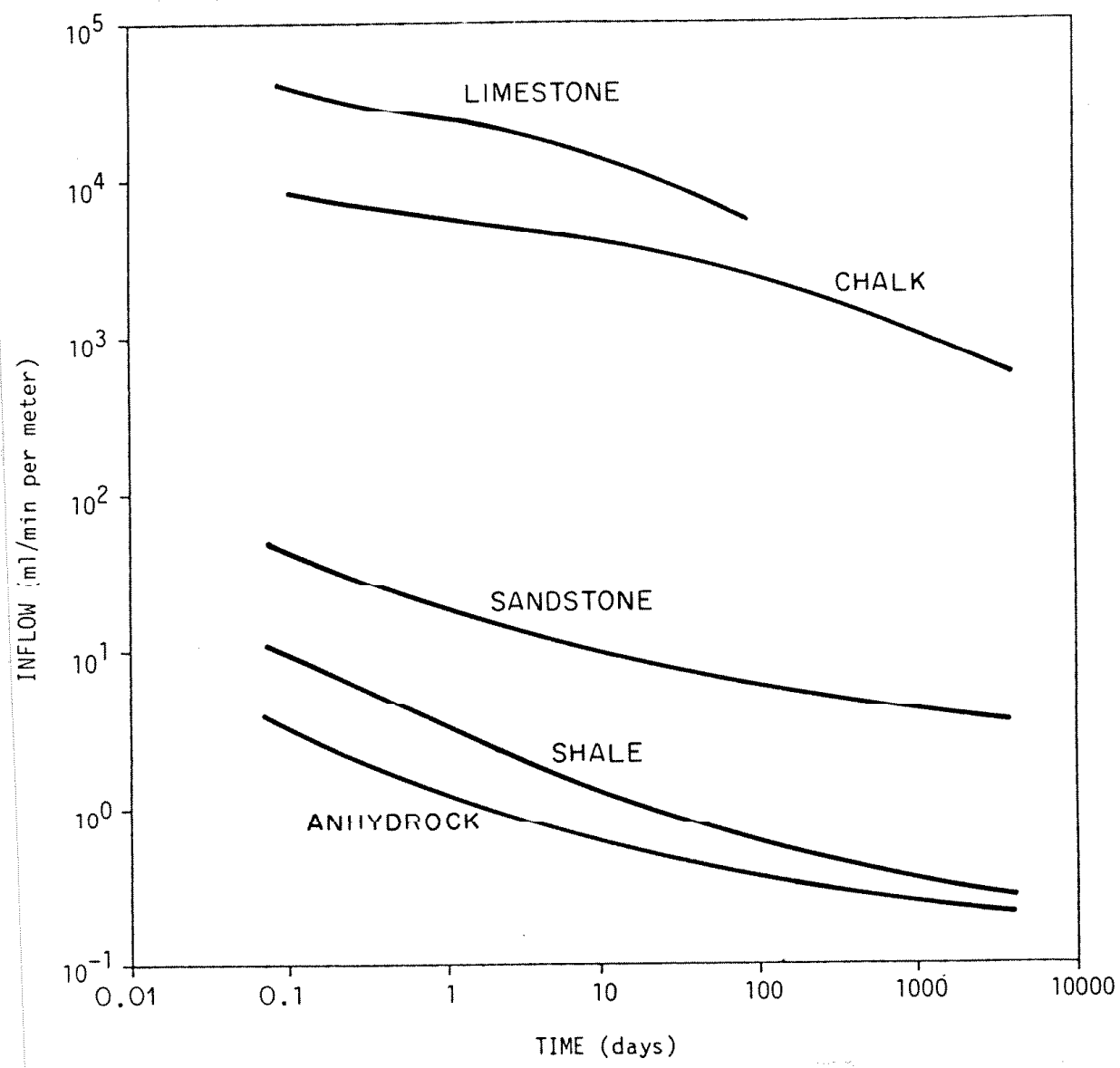

Fig. 3.1. Groundwater inflow rates into mined openings for the five sedimentary rock types. 


\subsection{THERMAL PERFORMANCE}

The thermal performance of a geologic repository, which can be judged by the maximum temperatures attained at various locations and the duration of the elevated temperatures (sometimes called "thermal pulse"), is directly related to the overall performance of a repository since the temperature rise affects the rock mechanics, corrosion rates, geochemical reactions, and, to some extent, the local hydrology. (See Appendix A, Sect. A.1.4.) Consequent1y, the thernal constraints typically imposed on repository design reflect the concern for the effect of higher temperatures on physical, chemical, and mechanical processes: the higher the temperature rise, the more deleterious the effect. As a result of this relationship, the evaluation of the performance of the five subject rock types is based on the calculated temperatures at a variety of locations in and arvund the lepusiluty, with a lower lemperature for the same thermal loading considered more favorable.

\subsubsection{Information Summary and Analysis}

The thermal properties and in situ temperature conditions of the five rock types are summarized in Table 3.6 and discussed in detail in Appendix G. Generally, the values given for each property represent the mean and one standard deviation from the mean for the total data set developed from a very limited search of the literature. Some exceptions are noteworthy. First, anhydrock has been most extensively studied in snutheast New Mexion at the site of the Waste Isolation Pilot Plant (WIPP), and most of the values used in the modeling of anhydrock are extracted from a set of accepted values from that location. Similarly, the shale values are mostly for a "typical" illitic shale. The data for the thermal properties were obtained from tests on both saturated and dry specimens.

Anhydrock generally has the highest thermal conductivity; chalk and shale have the lowest, with the mean values of the latter being a little less than half of the mean value for sandstone. Thermal conductivity values for most sedimentary rocks tend to decrease as temperature increases. However, some shales may show no change or an increase in thermal conductivity with increasing temperature, although the data to support this observation are sparse. The ranges of the temperature 


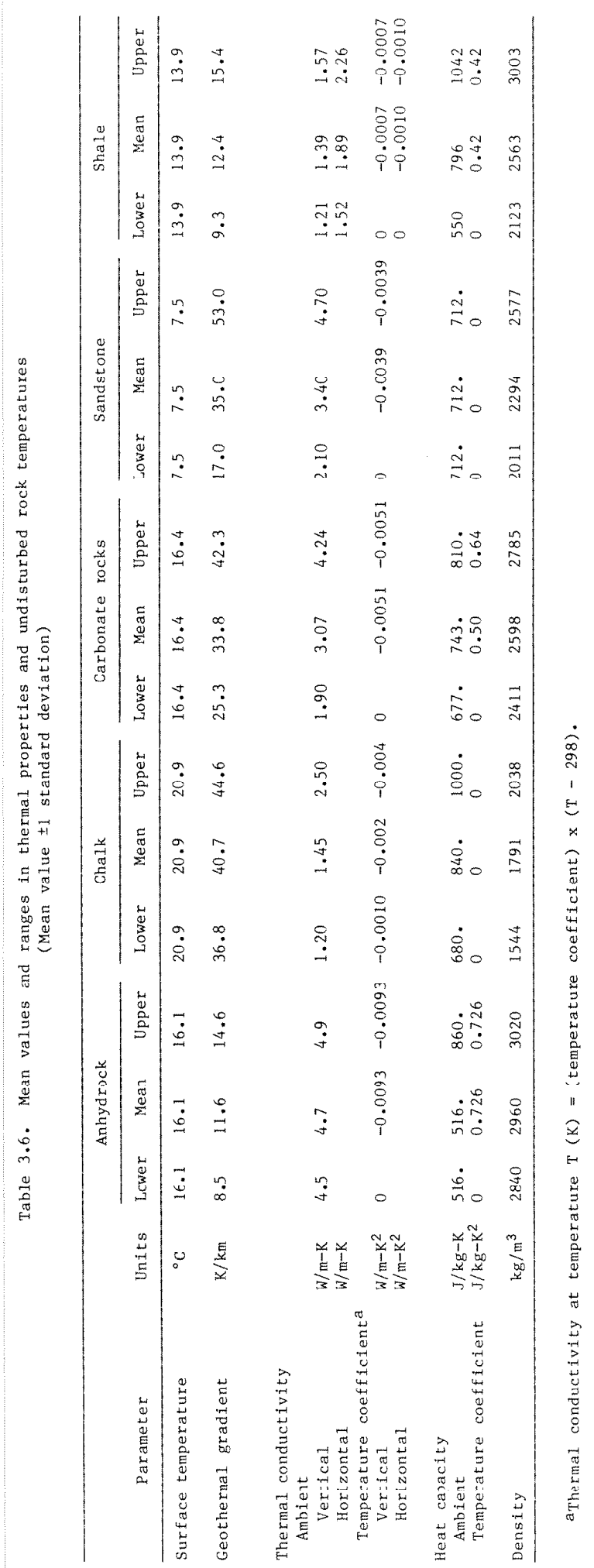


dependence of thermal conductivity (using a linear fit to available data) are shown in Table 3.6. Published values for the heat capacity of these rock types are also given, although the data are very limited.

The initial surface temperature and geothermal gradient are needed to establish the temperature of the undisturbed host rock at the repository horizon. The values given in Table 3.6 for these initial conditions are typical of locations where the reference stratigraphic section might occur. The surface temperature ranges from $7.5^{\circ} \mathrm{C}$, for the typical sandstone location, to $20.9^{\circ} \mathrm{C}$ for the typical chalk location. The geothermal gradient is greatest for a typical chalk location, where the mean value is $40.7 \mathrm{~K} / \mathrm{km}$, and the least for a typical anhydrock location, where the mean value is $11.6 \mathrm{~K} / \mathrm{km}$.

The thermal responses were calculated with finite-element models of a typical repository design that used the generic stratigraphic sections, the data in Table 3.6, and the background assumptions in Appendix B. Each of the thermal responses requires a different degree of detail in the geometric region for which the particular responses are to be determined. To reduce the calculational effort, the underground repository was divided into three different geometric regions: very near field, near field, and far field. The very near field encompasses the waste package and the emplacement borehole as the primary area of investigation and modeling detail. The near field relates to the room-and-pillar system of the repository. The far-field model primarily addresses the behavior of the surrounding rock. This differentiation of geometric regions has been used for the modeling of geologic repositories. The asoumptions uscd in the development of models for each of these geouetric regions differ. The particular aspects of the numerical models are discussed separate1y in Appendix G.

The thermal responses that are addressed for the very-near-field model are the temperatures of (1) the waste form, (2) the overpack, and (3) the borehole surface (rock). The very-near-field model addresses only the magnitude of these responses during the operational and containment periods. Since the temperature gradients in the vicinity of the waste package decrease to a very low value by the end of the containment period ( 300 to 1000 years), the temperatures of the waste package are addressed by the near-field model. 
The responses that are addressed in the near field are the temperatures of (1) the room backfill, (2) the interface of the near field and the far field, and (3) the borehole (rock) over the long term. The room backfill temperature was calculated by taking a volume average of the temperatures within the room. This calculated temperature is reasonably representative of the temperature of the room backfill at any location, since the thermal gradients in the room are very low. The temperature at the interface of the near field and the far field is calculated at a depth of $685 \mathrm{~m}$, or approximately one-half pillar width above the disposal room, assumed to be at a uniform depth of $700 \mathrm{~m}$.

The far-field model is constructed to address the temperatures of (1) Llie shaft sea1; (2) the ground surface ( $5 \mathrm{~m}$ below surface); and (3) $595 \mathrm{~m}$ below surface. The highest temperature of the shaft is assumed to occur at its bottom (i.e.. along the repository horizon $250 \mathrm{~m}$ from the nearest heat-generating waste). The maximum temperatures of the ground surface and the location $595 \mathrm{~m}$ below the surface were both assumed to occur directly over the repository center.

The mean value and range of each of the highest thermal responses described above were calculated for commercial HLW (CHLW) and spent fuel for each of the five subject rock types. The results are presented and discussed in detail in Appendix G. In the interests of simplicity and clarity, only the spent-fuel results and two representative temperature ranges are presented and discussed here, since the trends are the same for other waste forms and temperature ranges at different locations. The thermal responses calculated from the mean thermal properties of the five rock types at several localious are depicled graphical1y in Fig. 3.2. These are the highest temperatures that occur at the indicated location and at the indicated time (if given). For each rock type, the temperatures at the various locations have been connected to make the trends more visible. The mean value and range of the highest temperatures for the five rock types at two representative locations, the waste-package/ rock interface and the near-field/far-field interface, are shown in Fig. 3.3. The input parameters (material properties and initial temperatures) were permuted to result in the minimum, mean, and maximum thermal responses. The term "minimum" is used here to denote the response from 


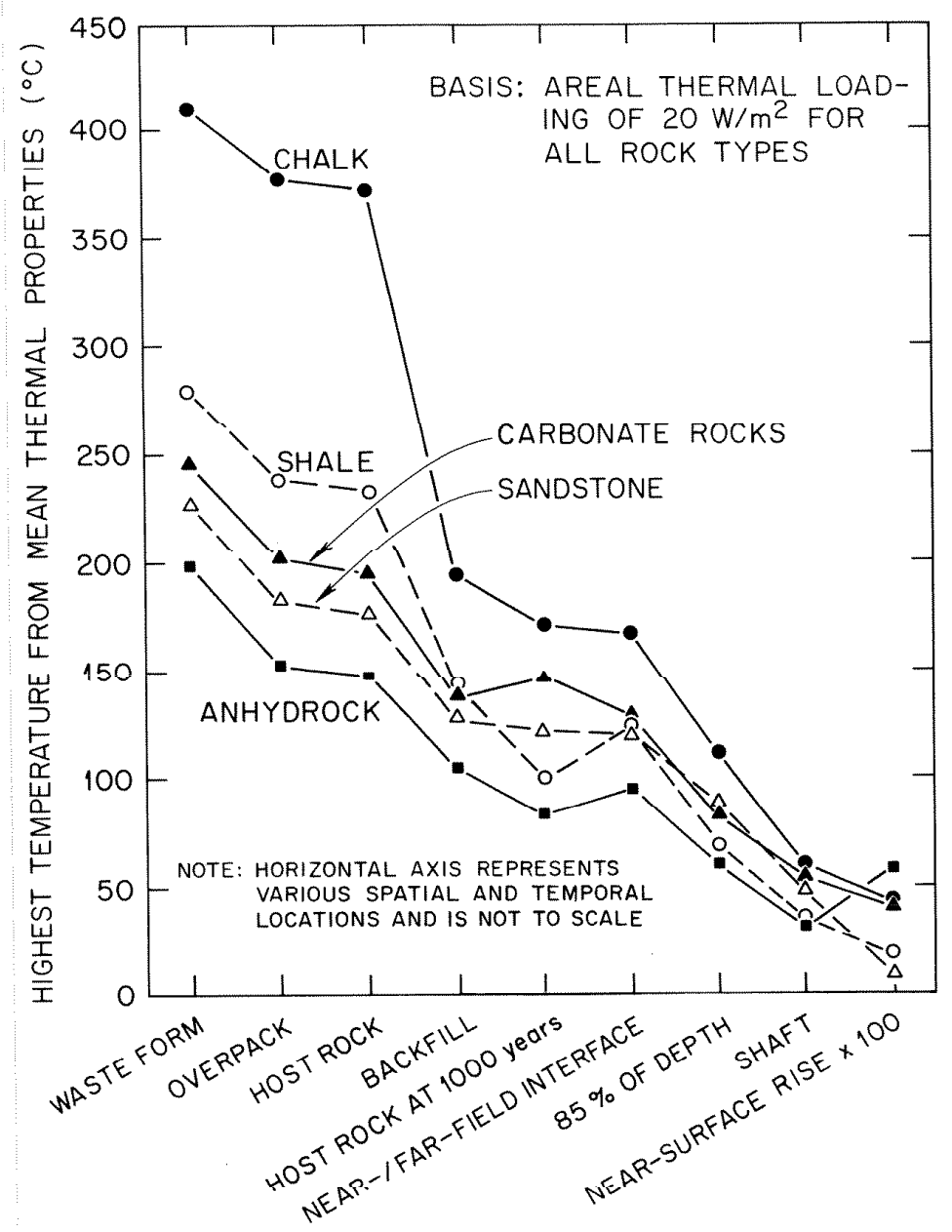

Fig. 3.2. Temperatures calculated from mean thermal properties for a spent-fuel repository in chalk, shale, carbonate rocks, sandstone, and anhydrock.

the permutation of all input parameters for a particular rock type that results in a minimum value for the highest temperature at each location. Similarly, the term "maximum" refers to the maximum value of the highest temperature resulting from permutation of the input parameters. For example, the maximum waste-form temperature results from the lower values of the material properties (i.e., thermal conductivity, heat capacity, and density) and the upper values for the initial thermal conditions (i.e., surface temperature and geothermal gradient). 


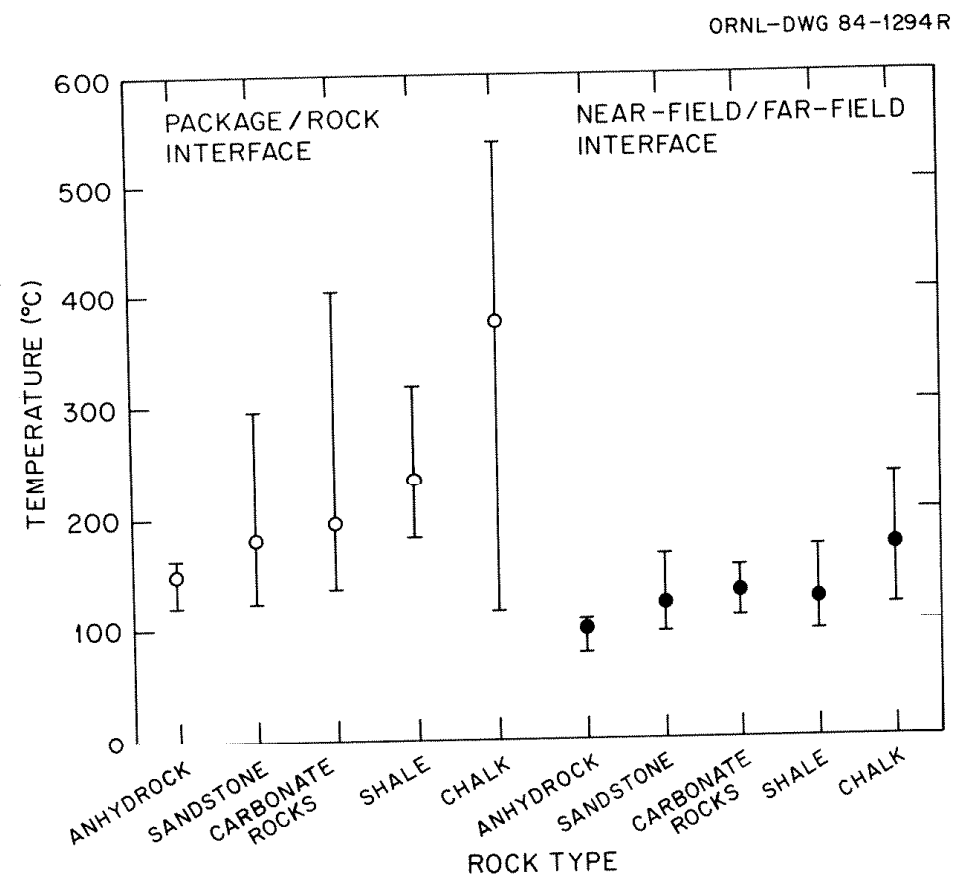

Fig. 3.3. Range of temperatures at the wastepackage/rock interface and the near-field/far-field interface for a spent-fuel repository in chalk, shale, carbonate rocks, sandstone, and anhydrock.

Note that, since the temperatures were calculated only for comparative evalualion and ranking purposes, using an identical areal thermal loading $\left(20 \mathrm{~W} / \mathrm{m}^{2}\right)$ for all rock types, the calculated results may violate the temperature constraints in a repository. Typical temperature constraints are set forth in Appendix G, and the rock types and locations where they are exceeded are noted. The postclosure temperature limit for the five subject rocks was assumed to be $100^{\circ} \mathrm{C}$. However, in an actual repository design, the temperatures would all be forced to remain within the constraints by adjusting the areal thermal loading and the repository design. The areal thermal loadings that would result from having to meet all of the temperature constraints given in Appendix $G$, which are indicative of the overall thermal performance of the rock types, are summarized as follows: 
Rock type

Anhydrock

Shale

Sandstone

Carbonate rocks

Chalk
Areal thermal loading meeting

$\frac{\text { temperature constraints }\left(\mathrm{W} / \mathrm{m}^{2}\right)}{\text { Spent fuel }}$

20.0

15.7

15.5

11.2

8.3
25.0

21.9

21.5

19.0

12.6

The necessity of having different thermal loadings for the various rock types has an impact on costs, which are analyzed further in sect. 3.8 and Appendix J.

\subsubsection{Evaluation of the Rock Types for the Thermal Performance Discriminators}

The results, summarized in Figs. 3.2 and 3.3 and presented in detail in Appendix G, indicate the following cvaluation:

1. Chalk has the worst thermal performance of the five subject rock types for nearly all thermal responses and has the largest range of thermal responses.

2. Anhydrock has the best thermal performance for nearly all thermal responses and has the smallest range of thermal responses.

3. Shale, sandstone, and the carbonate rocks have similar, closely grouped thermal responses and overlapping ranges.

4. The thermal performance of the shale-sandstone-carbonate rock group is similar to that of anhydrock, but much better than that of chalk.

Thus, the result of the thermal performance evaluation is that anhydrock is ranked first, followed closely by shale, sandstone, and carbonate rocks in the second rank and followed more distantly by chalk in the third rank. It is doubtful that any data on impurities that might be associated with each rock type would influence the above evaluation.

\subsection{ROCK MECHANICS}

In general, rock mechanics discriminators are important for two reasons. The mechanical behavior of the host rock and the surrounding rock units after repository closure is related to the degree to which the natural and repooitory-induccd forceo could advcrocly affect repooitory 
performance by creating pathways for water, which can affect the transport of radionuclides. The mechanical behavior of the rocks before closure is related to the cost and occupational safety involved in constructing and operating the repository. The RECs contained in Appendix A identify four rock mechanics discriminators to be evaluated:

1. Postclosure ductility: related to the ability of the host rock to undergo nonelastic deformation without fracture and to seal natural or repository-induced fractures (Appendix A, Sect. A.1.4);

2. Postclosure stability: related to the degree to which the rock is susceptible to fracturing and mineral hydration or dehydration because of natural or repository-induced changes in temperature and stress changes (Appendix A, Sect. A.1.4);

3. Repository constructibility: related to the construction of underground openings and to the artificial support required to maintain the stability of those openings (Appendix A, Sect. A.2.3.2); and

4. Operational stability: related to the stability of the underground openings during repository operation under the thermal stresses induced in the host rock by the decay heat of the emplaced waste (Appendix A, Sect. A.2.3.2).

These four discriminators will be addressed in this section, using the detailed information developed in Appendix G.

3.5.1 Infurmalion Summary and Analysis

\subsubsection{Data Base}

Data on rock mechanics for the five sedimentary rock types were collected by using computerized data bases to find references to the appropriate literature. More detailed information and references are presented in Appendix G. The mechanical properties of interest in evaluating these rock types for their suitability to serve as a host rock for a geologic repository include the unconfined compressive strength, Young's modulus of elasticity, Poisson's ratio, the angle of internal friction, the confinement stress at which a transition from brittle to ductile behavior occurs, and the coefficient of thermal expansion. Values for the mechanical properties are given in Tables 3.7 and 3.8 . 
Table 3.7. Summary of mechanical property values (mean value \pm standard deviation) $a, b$

\begin{tabular}{|c|c|c|c|c|c|}
\hline Rock type & $\begin{array}{l}\text { Unconfined } \\
\text { compressive } \\
\text { strength } \\
\text { (MPa) }\end{array}$ & $\begin{array}{l}\text { Young's } \\
\text { modulus } \\
\text { (MPa) }\end{array}$ & $\begin{array}{l}\text { Poisson's } \\
\text { ratio }\end{array}$ & $\begin{array}{l}\text { Angle of } \\
\text { internal } \\
\text { friction }\end{array}$ & $\begin{array}{l}\text { Coefficient } \\
\text { of thermal } \\
\text { expansion } \\
\left(\mathrm{K}^{-1} \times 10^{-6}\right.\end{array}$ \\
\hline $\begin{array}{l}\text { Carbonate } \\
\text { rocks }\end{array}$ & $\begin{array}{c}107 \cdot 3 \pm 56 \cdot 0 \\
(286)\end{array}$ & $\begin{array}{c}45.8 \pm 22.3 \\
(129)\end{array}$ & $\begin{array}{c}0.27 \pm 0.09 \\
(102)\end{array}$ & $\begin{array}{c}41.9 \pm 11 \cdot 3 \\
(14)\end{array}$ & $\begin{array}{c}6.7 \pm 2.1 \\
(12)\end{array}$ \\
\hline Anhydrock & $\begin{array}{c}92.6 \pm 36.5 \\
(78)\end{array}$ & $\begin{array}{c}64 \cdot 1 \pm 18 \cdot 0 \\
(75)\end{array}$ & $\begin{array}{c}0.34 \pm 0.07 \\
(74)\end{array}$ & $44.8 \pm 8.9$ & $\begin{array}{l}20 \\
(1)\end{array}$ \\
\hline Shale & $\begin{array}{c}69.4 \pm 44.2 \\
(49)\end{array}$ & $\begin{array}{c}20.8 \pm 10.9 \\
(50)\end{array}$ & $\begin{array}{c}0.21 \pm 0.10 \\
(34)\end{array}$ & $\begin{array}{c}32.6 \pm 18.4 \\
(7)\end{array}$ & $\begin{array}{r}7.9 \pm 5 \\
(8)\end{array}$ \\
\hline Sandstone & $\begin{array}{c}65.9 \pm 45.8 \\
(167)\end{array}$ & $\begin{array}{c}20.4 \pm 11.9 \\
(106)\end{array}$ & $\begin{array}{c}0.20 \pm 0.12 \\
(76)\end{array}$ & $\begin{array}{c}41.0 \pm 5.2 \\
(5)\end{array}$ & $\begin{array}{r}10.0 \pm 2 \\
(1)\end{array}$ \\
\hline Chalk & $\begin{array}{c}17.5 \pm 4.5 \\
(28)\end{array}$ & $\begin{array}{c}6.8 \pm 3.9 \\
(9)\end{array}$ & $\begin{array}{c}0.25 \pm 0.09 \\
(6)\end{array}$ & $\begin{array}{r}17.0 \\
(1)\end{array}$ & $\begin{array}{l}c \\
(0)\end{array}$ \\
\hline
\end{tabular}

a Numbers in parentheses are the numbers of data points.

$b_{\text {See Appendix }} \mathrm{G}$ for references.

$c_{\text {No }}$ data available for chalk; carbonate value assumed.

Table 3.8. Brittle-to-ductile transition pressures at room temperature ${ }^{a}$

\begin{tabular}{lcc}
\hline Rock type & $\begin{array}{c}\text { Confining pressure } \\
\text { (MPa) }\end{array}$ & $\begin{array}{c}\text { Young's modulus } \\
\text { (MPa) }\end{array}$ \\
\hline Chalk & $<10$ & $3-11$ \\
Shale (compaction) & $0-20$ & $10-32$ \\
$\begin{array}{l}\text { Sha1e (medium to } \\
\text { high porosity) }\end{array}$ & $<100$ & $10-32$ \\
$\begin{array}{l}\text { Carbonate rocks } \\
\quad(1 \text { imestone) }\end{array}$ & $20-100$ & $24-68$ \\
$\begin{array}{l}\text { Carbonate rocks } \\
\text { (dolostone) }\end{array}$ & $100-200$ & $24-68$ \\
Anhydrock & $50-100$ & $46-82$ \\
\begin{tabular}{l} 
Sandstone \\
\hline
\end{tabular} & $50-150$ & $9-32$ \\
\hline
\end{tabular}

asee Appendix $G$ for references. 
The evaluation of constructibility is based on the unconfined compressive strength and the results of elastic stress analysis for a typical disposal room, which uses Young's modulus of elasticity and Poisson's ratio. This method of evaluating constructibility requires a great number of assumptions, which are described in Appendix G.

Although density is commonly used to calculate the overburden stress for purposes of the elastic stress analysis, an average stress gradient of $27 \mathrm{MPa} / \mathrm{km}$ was assumed to be representative of most sedimentary rock bodies since density variations over most sedimentary rock stratigraphic columns are negligible. Evaluations of operational stability and postclosure stability used the rock strength and elastic properties in conjunction with the coefficient of thermal expansion and the temperature changes previously given in Sect. 3.4. Finally, the evaluation of postclosure ductility is based on the confinement pressure at which a rock experiences a transition from brittle to ductile behavior. The angle of internal friction is simply an indicator of the increase in compressive strength of a rock type under confinement stress. Values of compressive strength as a function of confinement stress and elevated temperature were not collected, because a detailed postclosure stress analysis was not undertaken. Although it is recognized that some of the five rock types, notably chalk and the weaker limestones and shales, will experience creep deformation under expected repository conditions, the available data for each of the five rock types were not adequate for consideration in this comparative evaluation.

A considerable amount of literature exists on the rock mechanics properties of the five sedimentary rock types. However, some difficulties do exist in evaluating these data because of the considerable variability observed. This variability is due to several causes. Most of the data in the literature are presented without petrographic descriptions, and the rocks may have been incorrectly classified. For example, some dolostones may have been incorrectly classified as limestones. Similar problems exist in the classification of shales. Another source of variability in rock properties is that some of the results reported in the literature have not been obtained with standard test methods, a fact that probably adds to the scatter in the data. Also, inadequate 
documentation exists in the 1iterature as to whether the samples were tested wet or dry.

The data on rock properties are given in Table 3.7 in terms of mean values and one standard deviation from the mean (plus or minus). The mean compressive strength of carbonate rocks may be considered high compared with limestone by itself and low compared with dolostone by itself. The rather broad range over plus or minus one standard deviation is representative of the composite collection of data for limestone and dolostone. This also applies to shale and sandstone in the sense of a broad spectrum of compositional and textural variations within each rock type. Conversely, the range over plus or minus one standard deviation is relatively much narrower for anhydrock and chalk, which is indicative of simpler rock compositions.

An additional rock mechanics discriminator relates to the difference between the properties of intact rock samples tested in the laboratory and the properties of rock masses in place. Rock masses tend to be weaker, more deformable, and more permeable than samples of intact rock. The mechanical properties of rock masses are generally controlled by the degree of fracturing of the rock mass, inhomogeneities, and the spacing orientation of fractures. These properties are site specific. On the basis of strength tests on large rock specimens, this size effect can be empirically quantified in terms of a strength-reduction factor and applied to the structural design of underground openings. Generally, the strength-reduction factor for relatively brittle rocks is greater than that for relatively ductile rocks. Because this factor has not been quantified for the five sedimentary rocks under consideration here, it was not considered in the comparative evaluations of either postclosure stability or preclosure constructibility.

\subsubsection{Postclosure Ductility}

Ductility is the ability of a material to undergo large strains while not losing its ability to carry stress. Conversely, more brittle (less ductile) materials tend to fracture at relatively small strains when subjected to high stresses. The ductility of rocks is influenced by confining pressure, temperature, water, and, to a lesser degree, strain rate. At low temperatures (e.g., room temperature), most rocks exhibit 
brittle behavior at low confining pressures, undergo a brittle-to-ductile transition, and then work harden at higher confining pressures. Similarly, for a constant confining pressure, rocks become more ductile with increasing temperature. Thus, the ductility of rocks is a function of the prevailing temperature and confining pressure.

Some degree of ductility is a desirable postclosure property for a geologic repository host rock because the rock will tend to deform inelastically without fracture, and the probability of creating new fractures or opening existing fractures is lower than it is for brittle rock. Furthermore, fractures that do develop in ductile rocks tend to become very tight and effectively seal under continued deformation at elevated temperature and confining pressure. Fractures may become pathways for groundwater and are consequently undesirable.

The usual measure of ductilicy is the given strain (cypically 3 to $5 \%$ ) that a rock can undergo without fracturing or loss of compressive strength. The combination of confining pressure and temperature at which a rock undergoes a transition from brittle to ductile behavior is seldom reported in the literature. In general, rocks with low moduli of elasticity are more ductile than rocks with high moduli. Brittle-to-ductile transition pressures at room temperature for the sedimentary rocks under consideration here are given in Table 3.8. A low transition pressure indicates that the rock is relatively ductile.

The lithostatic stress at a depth of $700 \mathrm{~m}$ is on the order of $19 \mathrm{MPa}$. With an increase in stress due to a temperature rise in the host rock, the resulting confining stress should be sufficiently high for the ductile behavior of chalk, shale, and some limestones. Most dolostones are considerably less ductile than most limestone.

\subsubsection{Operational Stability}

Operational stability relates to the stability of the pillars and rooms during repository operation, when the rocks will be subjected to thermal stresses. During this phase, consideration needs to be given to the magnitude of the thermal stresses and the strength of the rock. In qualitative terms, the potential for the development of fractures in a rock is related to the ratio of the strength of the rock to the thermally induced stress in the rock. The stress induced in an ideal confined rock mass subject to heating is proportional to the quantity 


$$
\frac{E \alpha \Delta T}{(1-\nu)}
$$

where

$$
\begin{aligned}
\mathrm{E} & =\text { Young's modulus of elasticity, } \mathrm{MPa} ; \\
\alpha & =\text { coefficient of thermal expansion, } \mathrm{K}^{-1} ; \\
\Delta \mathrm{T} & =\text { temperature rise, } \mathrm{K} ; \\
\nu & =\text { Poisson's ratio. }
\end{aligned}
$$

Thus, the ratio of strength to thermally induced stress is the dimensionless quantity

$$
\frac{C_{0}(1-\nu)}{E \alpha \Delta T}
$$

where $C_{O}$ is the unconfined compressive strength in MPa. This quantity, defined here as the stability index, is a measure of the operational stability of the rooms and pillars after waste emplacement. The assumptions necessary to use this index as a measure of the operational stability are described in Appendix G.

The indices of operational stability have been calculated for each of the subject rock types using the mean values and one standard deviation (plus or minus) about the mean for the properties given in Table 3.7. The results of these calculations are presented in Table 3.9. The values of temperature rise were taken from Appendix $G$ and correspond to the temperature increase in the host rock at the room periphery at 5 years after waste emplacement. In general, for the five rock types under consideration, the unconfined compressive strength, the modulus of elasticity, and the coefficient of thermal expansion are roughly proportional to density. That is, the relatively higher values of these rock properties would correspond to a relatively high value of mass density for a particular rock type. For this reason, the ranges of the stability indices given in Table 3.9 were calculated on the basis of the values of the rock properties for plus one standard deviation from the mean and for minus one standard deviation from the mean.

Sensitivity of the rock to humidity and moisture changes is also a consideration during the operational phase. Some, but not all, shales 
Table 3.9. Preclosure operational stability indices for the subject rock types

\begin{tabular}{lccccc}
\hline & \multicolumn{2}{c}{ Temperature } & rise $\left({ }^{\circ} \mathrm{C}\right)$ & & \multicolumn{2}{c}{ Stability index } \\
\cline { 5 - 6 } \multicolumn{1}{c}{ Rock type } & Mean & Range & & Mean & Range \\
\hline Shale & 61 & $41-98$ & 5.5 & $2.5-14.8$ \\
Carbonate rocks & 51 & $34-78$ & 5.0 & $2.9-8.7$ \\
Sandstone & 54 & $30-86$ & 4.8 & $2.3-8.8$ \\
Chalk & 73 & $42-112$ & 3.9 & $1.8-14.8$ \\
Anhydrock & 48 & $32-55$ & 1.0 & $0.7-1.8$ \\
\hline
\end{tabular}

exhibit such sensitivity. Shotcrete would probably be used on all excavation surfaces in a repository constructed in a water-sensitive shale. The shotcrete would probably have different thermal expansion properties than the shale, which could cause spalling during the operational phase. However, this spalling would produce only a minor operational problem.

\section{$3 \cdot 5 \cdot 1 \cdot 4$ Constructibility}

As shown in Appendix G, the rock types cannot be ranked on the basis of minability because it is probable that all of these rock types could be efficiently excavated with continuous mining equipment or tunnelboring machines. In Appendix G, it is shown that the primary rock characteristic affecting the constructibility of disposal rooms is the unconfined compressive strength of the rock. Values for the unconfined compressive strength for the rock types are given in Table 3.7. Although these are laboratory-measured values, reduction of the strengths to account for in situ structural effects would involve approxinately the same reduction factor for all rock types (in a generic sense) and thus would not affect the comparative evaluation of the rocks.

The ratio of the unconfined compressive strength to the overburden stress can be used as a comparative measure among the five rock types for indicating the relative ease of excavation construction. This ratio has been calculated for the five rock types on the basis of an overburden stress of $18.9 \mathrm{MPa}$, and the results are summarized in Table 3.10 along with the unconfined compressive strength values. This ratio should be used only for comparing constructibility among different rock types and 
Table 3.10. Constructibility indices for the rock types

\begin{tabular}{lccccc}
\hline & $\begin{array}{c}\text { Unconfined compressive } \\
\text { strength (MPa) }\end{array}$ & & \multicolumn{2}{c}{$\begin{array}{c}\text { Ratio of strength to } \\
\text { overburden stress }\end{array}$} \\
\cline { 2 - 3 } \multicolumn{1}{c}{ Rock type } & Mean & Range & & Mean & Range \\
\hline Carbonate rocks & 107 & $51-163$ & & 5.7 & $2.7-8.6$ \\
Anhydrock & 93 & $56-129$ & & 4.9 & $3.0-6.8$ \\
Shale & 69 & $25-114$ & & 3.7 & $1.3-6.0$ \\
Sandstone & 66 & $20-112$ & & 3.5 & $1.1-5.9$ \\
Chalk & 17.5 & $13-22$ & & 0.9 & $0.7-1.2$ \\
\hline
\end{tabular}

not for determining the feasibility of construction. The failure of rock can be assessed only by considering the three-dimensional state of stress caused by an excavation as well as the three-dimensional failure criterion for the rock, which must naturally include the frictional characteristics of the rock.

On the basis of this general guidance for the evaluation of the expected constructibility in a rock mass, the data of Table 3.10 indicate that rooms could be constructed at a depth of $700 \mathrm{~m}$ in all rock types. Rooms in relatively competent carbonate rocks and anhydrock would require the use of occasional rock bolts for roof support. However, shale and sandstone would probably require rockbolting on a close, regular pattern to ensure stability of the roof and sidewalls of excavated openings. Because of the expected sensitivity of some shales to water, shotcreting of all excavation surfaces could be necessary in order to prevent raveling on drying and slaking during rewetting. Rooms that are excavated in a relatively strong chalk at a depth of $700 \mathrm{~m}$ would require continuous wire mesh and a close, regular pattern of rock bolts as a minimum for rock support.

\subsubsection{Postclosure Stability}

The most important rock mechanics factors during postclosure are related to the potential for creating fractures and/or opening existing fractures in the host rock and surrounding rock units. These fractures could conceivably act as conduits for the transport of radionuclides from the emplaced waste to the accessible environment. The creation of new 
fractures is related to thermally induced stresses in the rock mass, ductility, and rock strength. Thermal stresses in a confined elastic material are proportional to the modulus of elasticity, the coefficient of thermal expansion, and the temperature change.

Opening of existing fractures is probably related to the amount of thermally induced uplift (doming) of the rocks above the emplaced waste. No large-scale thermomechanical analysis of the host rock and surrounding rock units has been made, because of the site-specific nature of the required data. However, it is possible to develop an approximate measure of postclosure stability using the concept previously developed for the evaluation of operational stability. The operational stability index is a measure of the ability of a rock type to withstand the thermally induced stresses within the rock at the periphery of a mined opening, and this index has been adopted as the measure of postclosure stability in this report. This measure, defined here as the postclosure stability index, represents the ability of a host rock to accommodate a onedimensional thermally induced stress and does not account for the interactive effects of the stratigraphic column, the beneficial effects of confinement stress on strength and ductility, or the reduction in strength with elevated temperature. The maximum temperature rise in the host rock is taken as the arithmetic mean of the peak temperature rises in the rock around the emplacement borehole, in the backfilled room, and in the rock at a distance of approximately one room height above the room, for both spent-fuel and CHLW disposal. The temperature rise calculated by this procedure should be conservative because of different times at which the maxima are achieved at the different spatial locations.

The postclosure stability index is the ratio of the unconfined compressive strength to the approximate thermally induced stress in the region of the repository resulting from a temperature rise that is approximately equal to the maximum temperature rise in the vicinity of the repository. This index is useful for comparing one rock to another or for ranking the group of rocks but should not be used for establishing failure in a rock type.

A stability index of less than unity does not imply the failure of the rock. However, an index of less than unity for a given rock implies 
a postclosure rock mechanics behavior less desirable than that for a rock with a postclosure stability index of more than unity. The calculated approximate temperature rises and postclosure stability indices for the five rock types are given in Table 3.11.

The calculations of the range of stability indices are based on the range in host rock temperature rises and the range in the mechanical properties of each rock type given in Table 3.7 .

Table 3.11. Postclosure stability indices for the subject rock types

\begin{tabular}{llrlll}
\hline & \multicolumn{2}{c}{$\begin{array}{c}\text { Peak host rock } \\
\text { temperature } \\
\text { rise }\left({ }^{\circ} \mathrm{C}\right)\end{array}$} & & & Stability \\
\cline { 2 - 4 } \multicolumn{1}{c}{ Rock type } & Mean & Range & & Mean & Range \\
\hline Sandstone & 108 & $69-155$ & & 2.4 & $1.3-3.8$ \\
Shale & 141 & $104-206$ & & 2.4 & $1.2-5.8$ \\
Carbonate rocks & 112 & $78-200$ & & 2.3 & $1.1-3.8$ \\
Chalk & 189 & $96-292$ & & 1.5 & $0.6-6.5$ \\
Anhydrock & 92 & $63-101$ & & 0.5 & $0.4-0.9$ \\
\hline
\end{tabular}

\subsubsection{Evaluation of the Rock Types for the Rock Mechanics Discriminators}

\subsubsection{Postclosure Ductility}

The vasis for evaluathy the postclosure ducllilly of the subject rock types is summarized in Table 3.8. Although the evaluation of this information is difficult because of uncertain and somewhat contradictory data, the following ranking appears to be justified:

1. Chalk and shale are relatively close together and are ranked first because of their higher degree of ductility.

2. The carbonate rocks, anhydrock, and sandstone are also roughly equal and are ranked second because of their lower ductility. The ductility of sandstones is strongly dependent on porosity and the cementing material, which may account for some of the variability evident in Table 3.8 . 


\subsubsection{Operational Stability}

The basis for evaluating the operational stability of the subject rock types is presented in Table 3.9. Evaluation of this information results in the following rock ranking:

1. The carbonate rocks and sandstone are all equal within the uncertainties involved and are ranked first.

2. Although the stability index for shale is greater than that for either the carbonate rocks or sandstone, shale is ranked second becauce of the potential for raveling and slaking under conditions of drying and rewetting during operational humidity changes as well as for roof instability problems in thinly bedded shale members.

3. Chalk is ranked a relatively close third to the second rank.

4. Anhydrock is ranked a distant fourth.

The stability of anhydrock is such that consideration may have to be given to reducing the thermal loading of a repository in this rock to meet constraints on mechanical behavior, as opposed to the more conventional temperature constraints.

\subsubsection{Constructibility}

The basis for evaluating the constructibility of repositories in the subject rock types is summarized in Table 3.10. From this information, the following rock ranking emerges:

1. Anhydrock and the carbonale rucks ale appluximalely equal with respect to both constructibility indices and are ranked first.

2. Shale and sandstone are nearly equal with respect to both constructibility indices, but somewhat lower than the first rank, and are ranked second.

3. Chalk is substantially lower than the second rank and is ranked third.

It should be noted that the comparatively low strength of chalk and its low strength-to-stress ratio indicate that the construction of a repository in this rock may not be feasible.

\subsubsection{Postclosure Stability}

As noted in Sect. 3.5.1.5, the basis for evaluating the postclosure stability of the subject rock types is similar to that for preclosure 
operational stability, with the results given in Table 3.11 . The postclosure stability indices indicate the following ranking:

1. Shale, the carbonate rocks, and sandstone are ranked first.

2. Chalk is ranked second.

3. Anhydrock is ranked a distant third.

\subsection{NATURAL RESOURCES}

In evaluating the five sedimentary rocks as disposal media, the presence or the absence of natural resources is an important discriminator because it affects the likelihood of human intrusion and the long-term integrity of the repository. Natural resource discriminators are present in the siting guidelines and in the RECs (Appendix A, Sect. A.9).

\subsubsection{Information Summary and Analysis}

Sedimentary rocks are by far the most important habitats for natural resources in the United States. It is also noteworthy that $75 \%$ of the rocks exposed at the earth's surface are of sedimentary origin.

In general, economically important resources include oll, gas, coal, groundwater, copper, lead, zinc, gold, and uranium. 0il and gas account for $\sim 80 \%$ of the total value of natural resources mined each year in this country, while coal accounts for $\sim 12 \%$ of the total. The value for groundwater, which is substantial, is difficult to estimate. For the metals, iron and copper have the greatest value but account for $<2 \%$ of the total value of all natural resources that are mined annually. Lead, zinc, and gold together represent $\sim 0.8 \%$ of the value, while uranium accounts for $\sim 1 \%$. Long-term trends also suggest that the value of oil, gas, and coal, in relation to the other minerals, will increase in the future because of energy denands. Therefore, oil, gas, coal, and fresh groundwater are the most important resources to be considered.

$0 i 1$ and gas are found in commercial quantities in most sedimentary rocks; however, the greatest quantities are concentrated in sandstone and the carbonate rocks. This is due largely to the well-developed porosities and permeabilities of these rocks. Although most chalk deposits lack the porosity and permeability needed to serve as reservoir rocks for hydrocarbons, some chalk deposits are locally fxactured and may serve as suitable hosts for hydrocarbons. The impermeability of shale and 
anhydrock deposits normally makes them poor reservoirs for hydrocarbons. Although the so-called oil shales of Colorado, Utah, and Wyoming may in the future provide commercial quantities of oil and gas, it is not now economically feasible to extract petroleum products from them.

Coal deposits are normally found as interbeds in fluvial-deltaic deposits of sandstone and shale in sedimentary basins. Many basins, such as the Illinois Basin, the Appalachian Basin, and the Powder River Basin, contain important accumulations of coal as well as oil and gas.

Although uranium is derived from igneous rocks, it commonly is found in commercially recoverable quantities in sedimentary rocks. Since strong reducing conditions generally are required for the precipitation of uranium, it follows that sandstones containing carbonaceous matter are potential hosts for such deposits.

Carbonate rock (1imeotone) io the principal hoot rock for load and zinc deposits in this country. Indeed, some $90 \%$ of domestic lead production comes from carbonate rocks in southeastern Missouri, while $\sim 60 \%$ of the zinc mined in the United States is found in carbonate rocks in Tennessee and Missouri.

Permeable and porous rocks such as sandstone and carbonate rocks make excellent reservoir rocks for groundwater, which is also a major resource in this country. For the most part, shales, chalks, and anhydrock are too impermeable to store and transmit commercial quantities of water. In summary, natural resources can be associated with all five types of sedimentary rocks evaluated in this report. However, sandstone and carbonate rocks are by far the most prolific resource-bearing rocks. Sandstone was found to be the best host rock for oil and gas reserves as well as for uranium, coal, and fresh groundwater. Carbonate rocks contain large quantitice of oil, gae, and freeh groundwater. In addition, these rocks are noted for their lead and zinc deposits. A few commercial fields of oil and gas are found in chalk, while anhydrock is a source rock for gypsum and sulfur. Some shales are known to contain a few hydrocarbon reservoirs. Certain shales contain significant (but dilute) quantities of heavy metals and "oil shales" that are not economically feasible to mine currently, but may have the potential for exploitation in the future. 


\subsubsection{Evaluation of the Rock Types for the Natural Resource Discriminator}

The relative association of sandstone, shale, carbonate rocks, chalk, and anhydrock with valuable energy and mineral resources was used to develop the following ranking for the extent to which the subject rocks are not associated with natural resources and are thus more favorable as a repository host rock:

1. Shale and anhydrock are about equal and are ranked first.

2. Chalk is ranked second, slightly below the first rank.

3. Sandotone and the carbonate rocko are about equal and are ranked a distant third.

It is recognized that mineral resources may be contained within one sedimentary rock type that is overlain and/or underlain by other types of sedimentary rock and that boreholes and mining shafts may penetrate the non-mineral-bearing rocks to recover these materials with a concomitant altering of the local geohydrology. However, shale remains the least 1ikely host for resources and would probably be the rock type least affected by penetration because of its less permeable nature. These conditions are, therefore, recognized but not dealt with in this report because of the site-specific nature of such occurrences and the complexities of treating such events in this generic study of five sedimentary rocks.

\subsection{WASTE PACKACE MATERIAL DECRADATION}

The performance of waste package constituents is important to a geologic repository, and this postclosure aspect is specifically regulated by 10 CFR Part 60 (CFR 1983). The performance of waste package materials is addressed under the geochemistry REC (Appendix A, Sect. A.1.3), and the discriminator addressing it is concerned with the expected degradation (corrosion) rate of potential waste package metals in the geochemical environment of the repository. The information base developed to evaluate the rock types for this discriminator includes data on the characteristics of groundwaters typical of the five subject rock types, examination of the potential waste-induced alteration of the groundwater characteristics, and the potential corrosion rates of various candidate waste package metals. 


\subsubsection{Information Summary and Analysis}

The characteristics of groundwaters typical of the five subject rocks are presented in Appendix $D$ and are summarized in Sect. 3.2. Although there are substantial variations in their compositions, the groundwaters are typified by high concentrations of chloride, magnesium, and calcium. The concentration ranges of the constituents are very broad in most instances because of the paucity of data on the deep groundwaters for the subject rock types.

The effects of the heat and radiation emitted by the waste on the water compositions are discussed in Appendix $\mathrm{K}$. Their nature and extent are highly speculative, but it is thought that the changes would be relatively moderate, principally because of the expected buffering effect of groundwater carbonates in the subject rocks. However, there are many unknowns concerning the very-near-field alteration of groundwatex; theoc unknowns include water evaporation/salt concentration, the nature and alteration of organic materials, and the formation of nitric and organic acids, and these must be factored into the evaluation.

The potential degradation of various classes of metals (e.g., copperbased alloys and titanium alloys) is analyzed in Appendix $\mathrm{K}$. The key factor in this analysis is that the chloride concentration in all of the groundwaters can be considered to be "high" with respect to metal corrosion. In addition, the temperature of the metals in the waste package is assumed to be the same for all rock types because the areal thermal loading would be adjusted to meet fixed temperature constraints. The result is the following summary of the corrosion of various classes of metals:

1. Iron-based alloys: A high corrosion rate is expected in all groundwaters. The corrosion rate is constant and high at chloride concentrations of $0.1 \underline{\mathrm{M}}(3550 \mathrm{ppm})$ to $0.5 \underline{\mathrm{M}}(17,750 \mathrm{ppm})$. It declines but is still substantial at higher chloride concentrations. The use of iron-based alloys would require massive corrosion allowances.

2. Copper and copper-based alloys: These alloys are subject to significant corrosion rates in the subject groundwaters, partimlarly at elevated temperatures. The significant levels of 
hydrogen sulfide expected in many of the groundwaters would acce1erate the corrosion process.

3. Nicke1-based alloys: These alloys generally have excellent corrosion resistance but are very expensive unless used as cladding on another base metal.

4. Titanium-based alloys: These alloys are highly resistant to chloride solutions at high temperatures, and alloys containing molybdenum and nickel or palladium are resistant even in slightly acid environments. These alloys resist pitting very well under expected conditions and are among the waste package materials proposed for a salt repository. Recent evidence indicates that hydrogen embittlement will probably nut be a problem in repositories.

From this information, it is concluded that iron-based and copper-based alloys should not be used in groundwaters generally containing high salt concentrations, and specifically containing high chloride concentrations, unless large thicknesses are used. Nickel-based alloys are satisfactory but expensive. Titanium alloys are also satisfactory and less expensive. The corrosion rates of the latter two metal classes are expected to be very low in the subject groundwaters. It should be noted that this discussion is based on the assumption that corrosion rates and mechanisms established by relatively short-term experiments (years to a few decades) and often under conditions only approximating those expected in a repository will persist for the long times during which the waste package is to retain its integrity (300 to 1000 years). The validity of this assumption is uncertain but is the best available at this time.

To summarize the above information and analysis, the corrosiveness of the groundwaters typically associated with the five subject rock types toward potential metallic constituents of waste packages is identical within the uncertainties involved: all of the groundwaters are either very corrosive to some metals because of the high chloride content or essentially noncorroding to other metals. Iron-based and copper-based alloys would probably not be satisfactory in this application unless very large corrosion allowances are made, whereas nickel-based and titaniumbased alloys appear promising. 


\subsubsection{Evaluation of the Rock Types for the Discriminator on Waste Package Material Degradation}

The corrosiveness of the groundwaters typically associated with the subject rock types is indistinguishable within the attendant uncertainties in very-near-field geochemistry and long-term corrosion rates because they all are corrosive to metals, such as the iron-based alloys, that are susceptible to chloride corrosion, and they are essentially benign toward alloys that resist chlorides, such as titanium-based alloys. Furthermore, the temperatures in and around the waste packages are expected to be about the same for all rock types when temperature constraints are satisfied, resulting in essentially the same reaction rates. Thus, all of the rock typeo are given the same rank (1) for this discriminator.

\subsection{REPOSITORY COST}

The cost of a repository is not a discriminator for comparatively evaluating the five subject rock types. However, an approximate cost analysis has been performed for informational purposes and to deternine whether the cost of a geologic repository in any of the subject rock types might be unreasonably high relative to bedded salt.

\subsubsection{Information Summary and Analysis}

Because of the generic nature of this evaluation and the paucity of data needed to develop an adequate repository conceptual design for the subject rocks, an analysis of repository costs by conventional means (i.e., costing a detailed design by component) is infeasible. The approach adopted in this work is to take a cost estimate previously deve1oped for a geologic reposicory in bedded salt and adjust the major components of the cost estimates to reflect the differing characteristics of the subject rocks. The details of this undertaking are given in Appendix .T. This summary will only present information concerning the cost of a spent fuel repository because the baseline estimate is more complete for this case. A partial cost basis was also developed for commercial HLW in Appendix J.

The cost of the repository can be divided into two components: a waste preparation system and a repository system. The waste preparation system includes all facilities, equipment, and operations required to 
prepare the waste before emplacing it in the repository. These costs are assumed to be fixed for all repositories at $\$ 2.8$ billion. The second component of the repository cost is a function of the host rock, and these costs are associated with the volume and unit cost of excavation, ventilation, and ground support.

The excavated volume was determined for costing purposes by linearly extrapolating the areal thermal loading (which was assumed to be a constant $20 \mathrm{~W} / \mathrm{m}^{2}$ in the thermal analysis) to (1) reduce the temperature at various locations in the repository to levels within the constraints given in Appendix $G$ or (2) provide adequate operational stability (in the case of anhydrock). The excavated volume was then calculated by determining the length of disposal rooms and tunnels having fixed cross-sectional areas that would be required to meet the thermal loading constraint and then multiplying the disposal room volume by a factor of 1.7 to account for haulageways and ventilation flowpaths.

The basic unit excavation cost was determined by linear interpolation based on the unconfined compressive strength of each rock type. The interpolation points were $\$ 71$ per cubic meter for bedded salt (strength of 24 $\mathrm{MPa}$ ) and $\$ 171$ per cubic meter for tuff (strength of $124 \mathrm{MPa}$ ). A uniform haulage/hoisting/surface storage cost of $\$ 10$ per cubic meter was added to the basic unit cost.

Ground support costs were based on typical properties of the subject rocks. The assumptions employed and the resulting unit costs are summarized as follows:

1. Anhydrock - only spot bolting required at no additional cost;

2. Chalk wire mcsh and rock bolting on a regular pattern at a cost of $\$ 13.50$ per cubic meter;

3. Carbonate rocks - only spot bolting required at no additional cost;

4. Sandstone - long rock bolts on a regular pattern at a cost of $\$ 5.30$ per cubic meter; and

5. Shale - shotcreting of all surfaces plus wire mesh and rock bolting on a regular pattern at an overall cost of $\$ 20.90$ per cubic meter.

The ventilation requirements were assumed to be proportional to repository volume. The capital cost of the ventilation equipment was scaled 
using the 0.6 -power scaling rule typically used in equipment costing. The operating cost of ventilating the repository was assumed to be proportional to the cube of the repository area since the fan power is proportional to the cube of the air volume. The cost of boring the 25,200 waste emplacement holes was based on their volume and the unit excavation costs referred to earlier.

A summary of the information developed in this analysis and the total resulting costs is given in Table 3.12. It should be noted that these costs have significant uncertainties attached to them in an absolute sense; these uncertainties are due to the paucity and variability of the

Table 3.12. Summary of repository costs by rock type

\begin{tabular}{|c|c|c|c|c|c|}
\hline \multirow[b]{2}{*}{ Cost parameter } & \multicolumn{5}{|c|}{ Rock type } \\
\hline & Anhydrock & Shale & Sands tone & $\begin{array}{l}\text { Carbonate } \\
\text { rocks }\end{array}$ & Chalk \\
\hline $\begin{array}{l}\text { Areal thermal } \\
\text { loading, } \mathrm{W} / \mathrm{m}^{2}\end{array}$ & 12.5 & 15.7 & 15.5 & 11.2 & 8.3 \\
\hline $\begin{array}{l}\text { Excavation volume, } \\
\mathrm{m} \times 10^{6}\end{array}$ & 14.3 & 10.2 & $11 \cdot 1$ & 15.9 & 21.7 \\
\hline $\begin{array}{l}\text { Total unit excava- } \\
\text { tion cost, } \\
\text { dollars per } \\
\text { cubic meter }\end{array}$ & 228 & 204 & 196 & 245 & 134 \\
\hline $\begin{array}{l}\text { Total excavation } \\
\text { costa }^{\text {a }}\end{array}$ & 3251 & 2286 & 2186 & 3884 & 2900 \\
\hline $\begin{array}{l}\text { Waste borehole } \\
\text { drilling cost }\end{array}$ & 69 & 61 & 61 & 70 & 50 \\
\hline Ventilation cost & 1325 & 953 & 971 & 1595 & 2860 \\
\hline $\begin{array}{l}\text { Total repository } \\
\text { system cost }\end{array}$ & 4645 & 3300 & 3218 & 5549 & 5810 \\
\hline $\begin{array}{l}\text { Generic (fixed) } \\
\text { cost }^{\mathrm{a}}\end{array}$ & 2847 & 2847 & 2847 & $\underline{2847}$ & 2847 \\
\hline Total costa & 7492 & 6147 & 6065 & 8396 & 8657 \\
\hline
\end{tabular}

acosts are given in millions of dollars. 
data, evolving design requirements, and assumptions made in the analysis. However, the results should be viewed as being adequate in a relative sense and thus applicable for the purpose of ranking each of the rock types on repository cost. This is because one of the primary driving forces for the cost differences is the variation in the permissible areal thermal loading, which is based on thermal calculations that have relatively low attached uncertainties.

\subsubsection{Evaluation of Repository Cost Results}

An inspection of the total repository costs given in Table 3.12 , considering the uncertainties inherent in these numbers, indicates that the following ranking is appropriate:

1. Shale and sandstone have approximately equal costs and are ranked first, with the costs being $\sim 9 \%$ greater than the cost of a bedded oalt repooitory;

2. Anhydrock is ranked second, with costs $\sim 25 \%$ greater than those for shale and sandstone; and

3. Chalk and carbonate rocks are ranked third, with costs $\sim 45 \%$ greater than those for shale and sandstone.

In general, these same results are obtained in the case of an HLW (as opposed to spent fuel) repository, with the notable exception of anhydrock, which has the highest cost in this case. This is because the thermal loading, and thus the excavated volume, for anhydrock cannot be reduced as much as for the other rocks because it is dependent on rock stability rather than on temperature constraints.

\subsection{SYSTEMS STUDIES}

Systems studies techniques are commonly used to assess how a given facility will perform under conditions expected to prevail during its operating lifetime. Such studies are particularly useful in assessing how well a geologic repository will perform in isolating and containing the radionuclides present in the waste because of the very long time involved (thousands of years). The literature search to develop a systems study data base (Appendix I) indicated that, of the five sedimentary rock types under investigation, only shale had been studied in sufficient detail to juotify making a proliminary performance avecement for 
a geologic repository in the preconceptual design stage. Two such studies have been done, one by the office of Waste Isolation (OWI 1978) and one by the Environmental Protection Agency (EPA 1982).

Because of the lack of comparable results for the other rock types and the absence of the necessary input data to calculate these results, the shale results have been included here for informational purposes only.

\subsubsection{Office of Waste Isolation Study}

The OWI study developed generic preliminary performance assessments for salt, granite, shale, and basalt. Although the primary objective of the study was to assess the ability of the rock types to contain and isolate the radionuclides in the waste from the accessible environment, considerable emphasis was also placed on developing a preconceptual design for a geologic repository in each of the rock types. The assumed rock properties data for shale, as well as the stratigraphic section used in the nwT study, are the same as, or very similar to, the baseline data developed in this report. The preconceptual design studies showed that it is feasible to construct a repository in shale using the emplacement technique of putting canisters of waste in boreholes drilled into the floor of the underground storage tunne1s, the technique assumed herein. The hydrologic model used by OWI to show that a repository in shale could isolate and contain the radionuclides for long time periods predicted that radionuclide concentrations in the groundwater leaving the boundaries of the preconceptual repository would be very low, $\sim 10^{-20} \mu \mathrm{Ci} / \mathrm{mL}$ or less. These numbers are much lower than those obtained with a later hydrologic model (SLATE 1981), which range from $10^{-3}$ to $10^{-7} \mu \mathrm{Ci} / \mathrm{mL}$. The reasons for this are unclear because of the lack of documentation for important aspects of the OWI study.

\subsubsection{Environmental protection Agency Study}

The EPA also made a preliminary performance assessment for a generic geologic repository in shale as part of its study to develop acceptable values for the release of radionuclides into the accessible environment. This study utilized the hydrologic properties of basalt to calculate how many health effects would result in 10,000 years from the release of radionuclides from the generic shale repository. The predicted number of hedlli erfecls fur a sliale repostlory was relatively high, abour 10 rimes 
that predicted for salt repositories. The apparent reasons for this are (1) the less favorable hydrologic parameter values for basalt as compared to salt and (2) the assumed higher incidence of intrusion into a shale repository as compared with the basalt repository. The assumption of equivalent hydrologic parameter values for basalt and shale is questionable because of the possibility of self-sealing of fractures and joints in shales, as well as the greater impermeability expected in a massive shale unit compared with the relatively thin basalt units separated by permeable flowtops and interbeds. The assumption of much higher intrusion frequency into a shale repository, as compared with basalt, is also questionable, although it is expected that intrusion frequency would be a function of the particular shale selected and the natural resources associated with the overlying and underlying layers. As a result of these factors, the calculatod impacts from a goologic repository in shale, as given in the EPA report, are not useful in arriving at firm conclusions regarding the ability of such a repository to isolate radionuclides.

\subsection{FOREIGN ACTIVITIES}

This section has been included to provide the reader with some perspectives on the extent to which the subject rock types are being considered in countries other than the United States. A more detailed discussion of the rock types being examined in foreign countries is contained in Appendix $H$. The rock types being investigated in other countries do not form any part of the basis for the rock evaluation contained herein and are included for informational purposes only.

In general, clay, argillaceous rocks, crystalline rocks, and salt deposits are the principal types of rock being considered for geologic disposal in most foreign countries. Clay deposits are preferred by Belgium. Argillaceous rocks are preferred by Italy and are being considered as a primary rock type in Japan and an alternative rock type in Canada, France, and the United Kingdom. Ductility, which accounts for their impermeability and the self-sealing of fractures, boreholes, and other openings, is the principal favorable feature of these deposits. In addition, the high sorptive capacities of the clay minerals contained in these rocks are favorable for a repository. The most significant foreign 
work in clay deposits is in the Mol area of Belgium, where the Boom clay is being studied extensively for its waste-containing potential. A 225-m-deep shaft and underground workings have been excavated in the Boom clay to provide a laboratory for underground tests and evaluations. All investigations to date suggest that these deposits are favorable hosts for the disposal of high-level and other radioactive wastes from the standpoint of isolation. These clays, however, because of their highly plastic nature, require more costly engineering measures to mine and maintain the ohafte, tunnels, and disposal rooms than the more-indurated shales considered herein. The Belgians have nevertheless selected clay because they do not have the less-plastic indurated shales, such as those in the United States, available for use in geologic disposal.

As part of a program funded by the Commission of the European Communities to identify and describe thick and extensive deposits of clay throughout Western Europe, the Italians have compiled geotechnical data on clay formations that may be potentially suitable for the disposal of high-level wastes. More recently, a drilling program has been initiated to characterize more fully the clays underlying several sedimentary basins in Italy. In addition to the drilling program, laboratory and field investigations were made at the Trisaia Centre in southern Italy to study such things as thermal and radiation effects, mine engineering aspects, and risk assessment. Although the Trisaia site is no longer being considered as a potential ropository site, the results of in situ tests conducted near that location are generally applicable to other sites in that country.

At the Nuclear Research Center of Casaccia (ENEA), drilling and other investigations have been initiated to characterize the clay in a nearby quarry. Thermal, rock mechanical, and hydrologic tests are planned in an underground laboratory that was excavated in early 1985 in clay deposits at Pasquasia, Sicily.

Rock salt is considered by several foreign countries (as we11 as the United States) to be an attractive host rock for waste disposal because of its negligible hydraulic conductivity and its high thermal conductivity. The Federal Republic of Germany, the Netherlands, Denmark, and Spain are the countries most interested in utilizing these rocks for 
disposal. By far, the most concerted effort to develop a repository in rock salt is in the Federa1 Republic of Germany, where site exploration work has progressed to the point of sinking shafts for underground facilities at a salt dome near the town of Gorleben in lower Saxony. In addition, in situ tests are being carried out in the Asse II salt mine, and a variety of supporting research is under way in such areas as safety assessments, hydrology, geochemistry, rock mechanics, and thermal behavior.

Because of their high strength and resistance to erosion, crystalline rocks are being investigated as host rocks for geologic repositories by Canada, France, Sweden, Finland, and Switzerland (as well as the United States). Fracture zones are a major concern in the utility of these rocks for waste disposal, and considerable work is under way in several countries to characterize the fracture systems and the flow of water through them. Although site surveys, the drilling of exploratory boreholes, and generic research and development have progressed in many countries, underground test laboratories have been constructed or are being developed in Sweden, Canada, and Switzerland (as well as the United States). Test programs in these facilities are planned to guide the development and operation of ful1-scale repositories in these rocks. 
This page intentionally left blank 


\section{EVALUATION OF ROCK EVALUATION CRITERIA AND ROCK TYPES}

The purpose of this section is to continue and conclude the eva1uation process described in Sect. 2.1 .4 by implementing the second and third phases, using aggregation methods described in sect. 4.1. The second phase uses the rock ranking for each REC discriminator developed in Sect. 3 as the basis for evaluating the five subject rock types for each applicable REC given in Appendix A. The applicable RECs, the discriminators taken into account when evaluating the rock types for each REC, and the section in which the evaluation is discussed are as follows:

\section{Postclosure}

Sect. 4.2.1 Geohydrology

Pre-waste-emplacement rates of groundwater flow in the host rock

Sect. 4.2.2 Geochemistry

1. Expected radionuclide solubility and adverse conditions affecting it

2. Expected radionuclide retardation and adverse conditions affecting it

3. Expected redox conditions

4. Degradation of waste package materials

Sect. 4.2.3 Rock Characteristics

1. Thickness, lateral extent, and homogeneity typical of rock type

2. Ability to dissipate radioactive-waste decay heat

3. Ductility

4. Stability under postclosure conditions

Sect. 4.2.4 Dissolution

Solubility of the host rock in water

Sect. 4.2.5 Natura1 Resources

Natural resources associated with the rock type 


\section{Preclosure}

Sect, 4.3.1 Rock Characteristics

1. Thickness, lateral extent, and homogeneity typical of rock type

2. Constructibility of a repository in the host rock

3. Operational stability under preclosure conditions

Sect. 4.3.2 Hydrology

Rate of water inflow into a repository

The implementation of the third phase of the evaluation methodology, which is the overall evaluation of the five subject rocks with respect to their potential to serve as a host rock for a repository, is discussed in Sect. 4.4. This evaluation is accomplished by summarizing the rock rankings for each REC, aggregating these rankings, and analyzing the results to rank the five rock types.

\subsection{RANKING AGGREGATION METHODS AND EXAMPLES}

In three instances, the rock evaluation for an REC must take multiple discriminators into account, and the subsequent overall evaluation of the five rock types involves aggregating the ranking results from five postclosure and two preclosure RECs. The three aggregation methods employed in the draft environmental assessments (EAs) for the potentially acceptable sites for the first repository (seo, for examplo DOE 1984b) wore considered for this purpose: the averaging method, the pairwisecomparison method, and the utility estimation method. The first two of these were adopted in this evaluation and are discussed in detail below. The utility estimation method was not used because it requires that an acceptable standard of compliance be defined for a site with the full range of qualifying conditions of each technical guideline. The acceptable standards of compliance incorporate the requirements of $10 \mathrm{CFR}$ Part 20, 10 CFR Part 60, and 40 CFR Part 191, as appropriate for preclosure and postclosure repository performance, and the requirements of the nonradiological siting guidelines of 10 CFR Part 960, Subpart D. Evaluations of compliance require performance assessment discriminators, which, in turn, require site-specitic data or assumptions. For the tive rock types of this study, consideration was mainly given to particular 
generic qualities of the rock types in relation to the more general requirements for repository construction and operation and for waste containment and isolation over long periods of time. Thus, although the RECs were derived from the relevant siting guidelines for subsurface conditions and the discriminators related to those RECs were derived from the favorable and potentially adverse conditions for each such guideline, systems evaluations (performance assessments) were not undertaken.

\subsubsection{Averaging Method}

Averaging or weighted averaging is the simplest method for combining the evaluations of alternatives on the basis of competing criteria. It

is sometimes used as an alternative to majority rule in voting as a means of aggregating the preferences of voters (NIEMI 1976). The averaging method was originally proposed in this context in the 18th century by Jean Glarles de Borda and, for Lhls reason, ls somelimes called the Borda standard. The method involves positional weighting whereby the most preferred rock in the preference order is given some maximum number of points, such as 5, the next most preferred is given 4, and so on down to the last alternative, which is given 1 point. The total number of points allocated to each alternative determines the overall preference ordering across all voters (in this instance, the discriminators or RECs).

A useful characteristic for applying the averaging method to rock evaluation is that it requires only the preferential ordering (ranking) of the rock types versus the various criteria (discriminators or RECs) and not absolute measures of performance against those criteria. Preferential orderings are easier to determine than numerical performance measures.

To apply the averaging method in this situation, it is necessary to account proper $1 y$ for those cases where available information is insufficient to justify one rock type as being more or less preferred over another on the basis of some criterion - that is, the cases in which two or more rock types are equally ranked. To handle ties, the averaging method stipulates that an average number of points be given to each rock type. For example, if the preference order of five rock types is

1. $\mathrm{A}$

Z. B, C, D

3. $E$ 
then rock type $A$ would be given 5 points; rock types $B, C$, and D would be given $(4+3+2) / 3=3$ points; and rock type E would be given 1 point. For each rock type, the points are summed over all criteria, and the rock type with the highest total is the most preferred. A specific example of this method in the present application will be given in Sect. 4.2.2.1.

\subsubsection{Pairwise-Comparison Methods}

Although the averaging method is intuitively appealing, it may be difficult to justify the logic by which points are assigned to reflect the position of each rock type in a ranking. For any particular criterion, the influence of a rock type on the overall results is proportional to the points assigned to it. Thus, being ranked first once and fifth once is just as desirable as being ranked third twice. Since a conclusion stemming from such a result might be questioned, it is desirable to use an aggregation method that does not require such assumptions and allows comparison with results from the averaging method. Such a method would be sensitive to the order in which the rock types are ranked, but it would not involve assigning points to the position of a rock type in a ranking. The pairwise-comparison method meets this requirement.

The pairwise-comparison method for ranking alternatives according to weighted criteria is a variation of the Copeland Reasonable Social Welfare Function applied to multicriteria evaluation (GOICOECHEA 1982). In this application of the pairwise-comparison method, the alternatives are the rock types, and the criteria are the discriminators or RECs.

As a simplified example, suppose that there are three rock types ( $A$, $B$, and C) and four criteria (geohydrology, geochemistry, rock characteristics, and dissolution) with the rankings for each criterion as follows:

\begin{tabular}{lcccc}
\hline & \multicolumn{4}{c}{ Rock ranking for each criterion } \\
\cline { 2 - 5 } $\begin{array}{l}\text { Rock } \\
\text { type }\end{array}$ & Geohydrology & Geochemistry & characteristics & Dissolution \\
\hline A & 1 & 1 & 1 & 2 \\
B & 2 & 1 & 2 & 3 \\
C & 3 & 2 & 2 & 1 \\
\hline
\end{tabular}


The pair-wise analysis would be conducted on a worksheet in the following manner:

\begin{tabular}{lcccc}
\hline & \multicolumn{4}{c}{ Rock ranking for each criterion } \\
\cline { 2 - 5 } $\begin{array}{l}\text { Rock } \\
\text { type }\end{array}$ & Geohydrology & Geochemistry & characteristics & Dissolution \\
\hline A vs B & A & T & A & A \\
A vs C & A & A & A & C \\
B vs C & B & B & T & C \\
\hline
\end{tabular}

where the winner of each comparison is given in the body of the table, and $T$ indicates a tie (equal ranking). The results of the analysis are aggregated as fo11ows:

\begin{tabular}{ccccc}
\hline $\begin{array}{l}\text { Rock } \\
\text { type }\end{array}$ & Wins & Ties & Losses & $\begin{array}{c}\text { Score } \\
\text { (wins - losses) }\end{array}$ \\
\hline A & 6 & 1 & 1 & 5 \\
B & 2 & 2 & 4 & -2 \\
C & 2 & 1 & 5 & -3 \\
\hline
\end{tabular}

Thus, if the information basis were absolutely certain, the rock type ranking would be A first, B second, and C third. A specific example of this method in the present application is given in Sect. 4.2.2.2.

\subsubsection{Weighting Factors and Sensitivity Analysis}

In the absence of weighting factors for the discriminators of a particular REC, it is initially assumed that all discriminators are weighted equally. The sensitivity of this assumption is examined quantitatively by considering the extent to which the weighting factors used in the averaging method would have to be altered to affect the order of the rock types.

It is assumed that all postclosure RECs are weighted equally in accordance with the implementation guidelines of the siting guidelines. In addition, the two preclosure RECs are also weighted equally because their parent preclosure siting guidelines are both in the same preclosure subgroup. The aggregation of the rock rankings for the RECs is first 
performed using only the postclosure RECs to reflect the primary emphasis placed on the postclosure guidelines. Then, the sensitivity of this approach is examined by varying the weighting factor for the preclosure RECs from an initial value of zero to $100 \%$ (i.e., ignoring the postclosure RECs).

\subsection{EVALUATION OF ROCK TYPES FOR POSTCLOSURE ROCK EVALUATION CRITERIA}

This section describes the evaluation of the subject rock types for the five applicable postclosure RECs (i.e., geohydrology, geochemistry, rock characteristics, dissolution, and natural resources). This evaluation is based on the rock rankings for each discriminator developed in sect. 3. In those instances where only a single discriminator is involved in addressing the REC, the resulting REC rock ranking is trivial because it is necessarily the same as the discriminator rock ranking. When more than one discriminator is involved in addressing an REC, the rock ranking is more complex, and the discriminator rock rankings are aggregated using the methods described in Sect. 4.1.

\subsubsection{Geohydrology}

As mentioned in sect. 3.3, the postclosure hydrologic discriminator is pre-waste-emplacement groundwater travel time from the expected location of the emplaced waste to the accessible environment. Further, as mentioned previously, the travel time objective from a generic perspective should not deal with absulutes but meiely cumpare lie suck types on the basis of a consistent set of standard conditions. The travel time for each rock type is estimated by solving the steady-state groundwater flow equation for a representative stratigraphy and set of hydrologic properties and characteristics.

Because the calculated pre-waste-emplacement groundwater travel time is the only discriminator involved in evaluating the rock types for the postclosure geohydrologic REC (Appendix A, Sect. A.1.2), the REC rock ranking is the same as the discriminator rock ranking (see Sect. 3.3.2.1):

Postclosure geohydrologic rank

1

$2 / 3$

$4 / 5$

\section{Rock type}

Shale

Sandstone; anhydrock Chalk; carbonate rocks 
The $2 / 3$ ranking is relatively close to the first, whereas the $4 / 5$ ranking is considerably lower than the $2 / 3$ ranking.

These rankings are primarily a function of the hydraulic conductivity of the individual rock types, which is very low for shale and anhydrock, intermediate for sandstone, and relatively high for chalk and the carbonate rocks. The relatively high effective porosity of shales (as compared with anhydrock) is also favorable and results in predicted groundwater flow rates in shales being significantly lower than those for anhydrock.

\subsubsection{Geochemistry}

The REC for geochemistry (Appendix A, Sect. A.1.3) has four discriminators concerning the following aspects of geochemistry: radionuclide solubility, radionuclide retardation (sorption), redox conditions, and waste package degradation. The first three of these are addressed in Sect. 3.2, and the last discriminator is addressed in Sect. 3.6. The rock rankings for the individual discriminators, which form the basis for evaluating the rock types for this REC, are summarized in Table 4.1.

Table 4.1 . Summary of discriminator rankings for the postclosure geochemistry REC

\begin{tabular}{lccccc}
\hline \multicolumn{1}{c}{ Rock type } & Shale & Sandstone & $\begin{array}{c}\text { Carbonate } \\
\text { rocks }\end{array}$ & Chalk & Anhydrock \\
\hline $\begin{array}{l}\text { Radionuclide solubility } \\
\text { Radionuclide retardation }\end{array}$ & 1 & 2 & 2 & 2 & 3 \\
$\begin{array}{l}\text { Redox conditions } \\
\begin{array}{l}\text { Package material } \\
\quad \text { degradation }\end{array}\end{array}$ & 1 & 2 & 3 & 3 & 4 \\
\hline
\end{tabular}

\subsubsection{Aggregation Using the Averaging Method}

The aggregation of the rock rankings for the four postclosure geochemistry discriminators into a single ranking for the geochemistry REC using the averaging method is detailed in Table 4.2. A weighting factor of 0.25 has been used for each discriminator, yielding the total score in the last column. 
Table 4.2. Details of applying the averaging method to rock ranking for the geochemistry $\mathrm{REC}$

\begin{tabular}{lccccc}
\hline & \multicolumn{4}{c}{ Points for each geochemical discriminator } \\
\cline { 2 - 6 } & $\begin{array}{c}\text { Radionuclide } \\
\text { solubility }\end{array}$ & $\begin{array}{c}\text { Radionuclide } \\
\text { retardation }\end{array}$ & $\begin{array}{c}\text { Redox } \\
\text { conditions }\end{array}$ & $\begin{array}{c}\text { Package } \\
\text { degradation }\end{array}$ & $\begin{array}{c}\text { Total } \\
\text { weighted } \\
\text { score }\end{array}$ \\
\hline $\begin{array}{l}\text { Shale } \\
\text { Sandstone }\end{array}$ & 5 & 5 & 5 & 3 & 4.5 \\
$\begin{array}{l}\text { Carbonate } \\
\quad \text { rocks }\end{array}$ & 3 & 4 & 4 & 3 & 3.5 \\
$\begin{array}{l}\text { Chalk } \\
\text { Anhydrock }\end{array}$ & 3 & 2.5 & 2 & 3 & 2.63 \\
\hline
\end{tabular}

\begin{tabular}{ccc}
$\begin{array}{c}\text { The ranking rosulting from this analysis is as follows: } \\
\begin{array}{c}\text { Postclosure } \\
\text { geochemistry rank }\end{array}\end{array}$ & \multicolumn{1}{c}{$\begin{array}{c}\text { Rock type } \\
\text { Total weighted } \\
\text { score }\end{array}$} \\
\hline 1 & Shale & 4.5 \\
2 & Sandstone & 3.5 \\
3 & Carbonate rocks & 2.6 \\
3 & Chalk & 2.6 \\
4 & Anhydrock & 1.8
\end{tabular}

This ranking of the rock types is a function of the concentration of total dissolved solids in the groundwaters (a higher concentration typically correlates with increased solubilities and decreased retardation), the clay content of the rock types (a higher content increases retardation), and the organic matter content of the rock types (a higher content promotes reducing conditions, which promotes precipitation and hence increases retardation). Shale has favorable characteristics for all three of these atrrihutes and thus ranks highest. The concentration of dissolved solids increases, and the content of clays and organic matter decreases steadily as the rock types are ranked lower, thus accounting for the ranking given.

An analysis was undertaken that verified the weighting factors to determine the sensitivity of the rankings, with the following results:

1. A11 of the rock types would rank equally if the first three discriminators were assigned a weighting factor of zero. 
2. With the exception of the above result, sandstone is always ranked significantly lower than shale.

3. Chalk and the carbonate rocks have identical scores for all combinations of weighting factors.

4. Chalk and the carbonate rocks would always rank significantly lower than sandstone unless the last three discriminators were assigned very small weighting factors, but they can never rank higher than sandstone.

5. Anhydrock would always rank significantly lower than chalk and the carbonate rocks unless the first two discriminators were assigned small weighting factors, but anhydrock can never be ranked higher than chalk and the carbonate rocks.

The conclusion is that the rock ranking given above for the geochemistry REC is relatively insensitive to reasonable variations in weighting factors and is therefore appropriate.

4.2.2.2 Aggregation Using the Pairwise-Comparison Method

The aggregation of the rock rankings for the four geochemical discriminators into a single ranking for the geochemistry $\mathrm{REC}$ using the pairwise-comparison method is detailed in Table 4.3. Equal discriminator weighting factors were used, resulting in the following rock ranking:

\begin{tabular}{llcccc}
$\begin{array}{c}\text { Postclosure } \\
\text { geochemistry } \\
\text { rank }\end{array}$ & Rock type & Wins & Ties & Losses & $\begin{array}{c}\text { Pairwise } \\
\text { comparison } \\
\text { score } \\
\text { (wins - losses) }\end{array}$ \\
\hline 1 & Shale & 12 & 4 & 0 & 12 \\
2 & Sandstone & 7 & 6 & 3 & 4 \\
3 & Carbonate rocks & 2 & 9 & 5 & -3 \\
3 & Chalk & 2 & 9 & 5 & -3 \\
4 & Anhydrock & 0 & 6 & 10 & -10 \\
\hline
\end{tabular}

Comparison of these scores with those resulting from application of the averaging method shows that the rock type ranking and the approximate separation between the ranks are virtually identical. 
Table 4.3. Details of applying the pairwise-comparison method to rock ranking for the geochemistry $\mathrm{REC}$

\begin{tabular}{ccccc}
\hline $\begin{array}{c}\text { Rock type } \\
\text { paira }\end{array}$ & $\begin{array}{c}\text { Radionuclide } \\
\text { solubility }\end{array}$ & $\begin{array}{l}\text { Radionuclide } \\
\text { retardation }\end{array}$ & $\begin{array}{c}\text { Redox } \\
\text { conditions }\end{array}$ & $\begin{array}{c}\text { Package } \\
\text { degradation }\end{array}$ \\
\hline SH-SS & SH & SH & SH & T \\
SH-CA & SH & SH & SH & T \\
SH-CH & SH & SH & SH & TH \\
SH-AN & SH & SH & SH & T \\
SS-CA & T & SS & SS & T \\
SS-CH & T & SS & SS & T \\
SS-AN & SS & SS & SS & T \\
CA-CH & T & T & T & T \\
CS-AN & CA & CA & T & T \\
CH-AN & CH & CH & T & T \\
\hline
\end{tabular}

$\mathrm{a}_{\mathrm{SH}}=$ shale, $\mathrm{SS}=$ sandstone, $\mathrm{CA}=$ carbonate rocks, $\mathrm{CH}=$ chalk, $A N=$ anhydrock, $\mathrm{T}=$ tie.

\subsubsection{Rock Characteristics}

The rock characteristics REC (Appendix A, Sect. A.1.4) addresses the extent to which the host rock characteristics/properties and the physical processes operating within the host rock favorably affect the performance of the repository during the postclosure period. The discriminators pertinent to this REC are (1) the extent of the rock formation, (2) ability to transfer heat, (3) ductility, and (4) stability under postclosure conditions. These discriminators were evaluated in Sects. 3.1 (extent), 3.4 (heat transfer), and 3.5 (ductility and stability) and are addressed in detail in Appendixes $E$ and $G$. The results of the rock rankings for the individual discriminators, which form the basis for evaluating the rock types for this REC, are summarized in Table 4.4 .

Table 4.4. Summary of discriminator rankings for the postclosure rock characteristics REC

\begin{tabular}{lccccc}
\hline \multicolumn{1}{c}{ Rock type } & Shale & Sandstone & $\begin{array}{c}\text { Carbonate } \\
\text { rocks }\end{array}$ & Chalk & Anhydrock \\
\hline Extent & 1 & 2 & 2 & 3 & 3 \\
Transfer heat & 2 & 2 & 2 & 3 & 1 \\
Ductility & 1 & 2 & $2^{\mathrm{a}}$ & 1 & 2 \\
Stability & 1 & 1 & 1 & 2 & 3 \\
\hline
\end{tabular}

aFor limestone; dolostone would rank lower. 
Aggregation of the discriminator rock rankings summarized in this table results in the rock ranking and scores given in Table 4.5 for the postclosure rock characteristics REC.

Table 4.5. Rock ranking for the postclosure rock characteristics REC

\begin{tabular}{|c|c|c|c|c|c|c|}
\hline \multirow{2}{*}{$\begin{array}{c}\text { Postclosure } \\
\text { rock } \\
\text { characteristics } \\
\text { rank }\end{array}$} & \multirow[b]{2}{*}{ Rock type } & \multirow{2}{*}{$\begin{array}{l}\text { Score for } \\
\text { averaging } \\
\text { method }\end{array}$} & \multicolumn{4}{|c|}{ Results of pairwise comparison } \\
\hline & & & Wins & Ties & Losses & $\begin{array}{c}\text { Score } \\
\text { (wins - losses })\end{array}$ \\
\hline 1 & Shale & 4.1 & 10 & 5 & 1 & 9 \\
\hline 2 & $\begin{array}{l}\text { Carbonate } \\
\text { rocks }\end{array}$ & 3.1 & 5 & 6 & 3 & 2 \\
\hline 2 & Sandstone & 3.1 & 5 & 7 & 4 & 1 \\
\hline 3 & Anhydrock & 2.4 & 4 & 3 & 9 & -5 \\
\hline 3 & Cha1k & 2.3 & 4 & 2 & 10 & -6 \\
\hline
\end{tabular}

An analysis that varied the discriminator weighting factors used in the averaging method was undertaken to determine the sensitivity of the rock ranking for the rock characteristics REC, with the following results:

1. The score for carbonate rock can never be higher than that of shale, although in the limit where the extent and ductility discriminators are assigned a weighting factor of zero, they are ranked the same.

2. The score for sandstone is identical with that for the carbonate rock for all weighting factor combinations.

3. For anhydrock to have the same score as sandstone, the ratio of the weighting factors for heat transfer:extent:stability, which is $100: 100: 100$ in the reference (equal weighting factor) case, must bc at least 250:100:100 to diminish the effect of anhydrock's relatively poor ductility and stability.

4. For chalk to have the same score as anhydrock, the ratio of the weighting factors for heat transfer:ductility:stability, which is $100: 100: 100$ in the reference case, must be no greater than $87: 100: 100$ to diminish the importance of chalk's poor thermal pexformance. 
The results from these sensitivity studies clearly support the rock rankings given in Table 4.5 because the differences in the scores of the shale, carbonate rocks/sandstone, and anhydrock/chalk ranks are significant and exist over a wide range of weighting factors. Ranking the carbonate rocks the same as sandstone and anhydrock the same as cha1k is also well justified because of the closeness of the scores and the small change in weighting factors required to make the scores identical. The rankings given in Table 4.5 for postclosure rock characteristics are also we11 supported by the results of the pairwise-comparison method.

The highest ranking for shale results from its substantial abundance (permitting flexibility in the configuration of the repository), along with the combination of adequate strength and good ductility. Sandstone and the carbonate rocks rank lower because they are somewhat less abundall and sollewhal to slgntflcanlly less ducltle, while laving higliei strength than shale. Chalk and anhydrock both are ranked third because of their very low abundances, poor thermal conductivity (chalk), and potential instability resulting from the combination of low ductility and high thermal expansion (anhydrock).

\subsubsection{Dissolution}

The REC involving rock dissolution (Appendix A, Sect. A.1.7) is concerned with the possibility that the dissolution of the host rock might adversely affect repository performance by creating significantly more permeable pathways for groundwater migration. There is only one discriminator involved in addressing this REC, and that is the solubility of the host rock in groundwater, which represents the potential for rock disso1ution. Thus, the results of the discriminator rock ranking given in Sect. 3.2 are also appropriate here, and they are summarized as follows:

Dissolution rank

$\begin{array}{ll}1 / 2 & \text { Shale; sandstone } \\ 3 / 4 & \text { Chalk; carbonate rocks } \\ 5 & \text { Anhydrock }\end{array}$

The $3 / 4$ ranking is considerably below the $1 / 2$ ranking, and the fifth ranking is significantly below the $3 / 4$ ranking. This ranking results directly from consideration of the solubility of the constituents of the rock types in unsaturated groundwaters. The principal components of 
sandstones and shales (quartz and clays) are very insoluble. The primary minerals comprising chalk and the carbonate rocks (calcite, dolomite) are somewhat soluble, as evidenced by extensive cave systems in limestones. The principal mineral in anhydrock (anhydrite) is substantially more soluble than the carbonate rocks, and hence the third ranking.

\subsubsection{Natura1 Resources}

The natural resources REC (Appendix A, Sect. A.1.9) is concerned with the possibility that the host rock might be directly associated with valuable resources that fucure generalions could atlempt lo recuver, thus potentially compromising the integrity of the repository. Only one discriminator is used in evaluating this REC, and that is the extent to which each rock type typically is associated with valuable natural resources. As a result, the rock ranking developed for the discriminator evaluation given in Sect. 3.6 is also appropriate here, and it is summarized as follows:

\section{Natura1 resources rank}

$\begin{array}{ll}1 / 2 & \text { Shale; anhydrock } \\ 3 & \text { Chalk } \\ 4 / 5 & \text { Sandstone; carbonate rocks }\end{array}$

The 3 ranking is slightly lower than the $1 / 2$ ranking, whereas the $4 / 5$ ranking is considerably lower than the 3 ranking. The $4 / 5$ ranking for sandstone and the carbonate rocks results from their being common reservolr rocks for wldely soughl resources, such as 011 , gas, and waler. Chalk is occasionally a reservoir rock for oil, gas, and water, especially where fractured, and thus is ranked 3. Shale and anhydrock are not typically reservoir rocks because of their impermeability. Anhydrock and chalk are mined for their intrinsic value but not normally at repository depths. Shale is rarely mined for its intrinsic value, but certain shales (e.g., oil shales and those with somewhat higher metal concentrations) might be mined if economic conditions change.

\subsection{EVALUATION OF ROCK TYPES FOR PRECLOSURE ROCK EVALUATION CRITERIA} This section describes the evaluation of the rock types for the two applicable preclosure RECs (i.e., rock characteristics and hydrology). 
The approach used in this evaluation is the same as that employed in Sect. 4.1 for postclosure RECs. Other discriminators that did not constitute a ranking basis are also summarized in this section.

\subsubsection{Rock Characteristics}

The preclosure rock characteristics guideline (see Appendix A, Sect. A.2.3.2) addresses the extent to which the characteristic properties of the host rock provide for the safe construction, operation, and closure of a repository at the depths of interest. The discriminators used for this ranking include (1) the extent of the rock formation, (2) constructibility, and (3) operational stability. These discriminators were evaluated in Sect. 3.1 (extent) and 3.5 (constructibility and stabi1ity) and are addressed in detail in Appendixes $E$ and $G$. The results of the preclosure rock rankings for the individual discriminators, which w111 be aggregaced Inco a rock rankling for llie REC, are summalized ill Table 4.6 .

Table 4.6. Summary of discriminator rankings for the preclosure rock characteristics REC

\begin{tabular}{lccccc}
\hline & \multicolumn{5}{c}{ Rock type } \\
\cline { 2 - 5 } \multicolumn{1}{c}{ Discriminator } & Shale & Sandstone & $\begin{array}{c}\text { Carbonate } \\
\text { rocks }\end{array}$ & Anhydrock Chalk \\
\hline Extent & 1 & 2 & 2 & 3 & 3 \\
Constructibility & 2 & 2 & 1 & 1 & 3 \\
Operational stability & 2 & 1 & 1 & 4 & 3 \\
\hline
\end{tabular}

Aggregation of the discriminator rock rankings summarized in Table 4.6 results in the rock ranking and scores given in Table 4.7 for the preclosure rock characteristics REC.

An analysis that varied the discriminator weighting factors used in the averaging method was made to assess the sensitivity of the ranking for the preclosure rock characteristics REC, with the following results: 
Table 4.7. Rock ranking for the preclosure rock characteristics REC

\begin{tabular}{cllllll}
\hline \multirow{2}{*}{$\begin{array}{c}\text { Preclosure rock } \\
\text { characteristics }\end{array}$} & & $\begin{array}{c}\text { Averaging } \\
\text { rank }\end{array}$ & Rock type & \multicolumn{4}{c}{ Pairwise comparison results } \\
\cline { 6 - 7 } & score & Wins & Ties & Losses & (wins - losses) \\
\hline 1 & Carbonate & & & & & \\
& rocks & 4.2 & 8 & 3 & 1 & 7 \\
2 & Shale & 3.5 & 7 & 1 & 4 & 3 \\
2 & Sandstone & 3.5 & 6 & 3 & 3 & 3 \\
3 & Anhydrock & 2.3 & 3 & 2 & 7 & -4 \\
4 & Chalk & 1.5 & 1 & 1 & 10 & -9 \\
\hline
\end{tabular}

1. For shale to have the same score as carbonate rocks, the ratio of the weighting factors for extent:constructibility:operational stability, which is 100:100:100 in the reference case, must be at least $233: 100: 100$ to increase the importance of shale's high abundance.

2. Either shale or sandstone, which are cied in the reference rankings, could be ranked higher than the other, depending on the relative weights of the extent and operational stability discriminators. In the limit where the extent discriminator is ignored, the score for sandstone exceeds that for shale by 0.75 , and, similarly, in the limit where the operational stability discriminator is ignored, the score for shale exceeds that for sandstone by 0.75 . 3. Anhydrock would rank the same as sandscone if the racio of the weighting factors for extent:constructibility:operational stability, which is 100:100:100 in the reference case, were at least $100: 275: 100$ to diminish the effects of anhydrock's 1imited abundance and poor operational stability.

4. Chalk would rank the same as anhydrock if the ratio of the weighting factors for constructibility:operational stability, which is 100:100 in the reference case, were at least 100:350 to diminish the importance of chalk's low strength on repository constructibility.

The aggregation results from the reference application of the averaging method and the sensitivity studies support the rock ranking given in Table 4.7 because (a) the difference between carbonate rocks and shale scores is significant with respect to the attendant uncertainties, and 
their ranking could be identical or reversed only with a major change in the weighting factors; (b) the score for sandstone is the same as that for shale, and either rock type could be ranked higher, depending on changes in the weighting factors; and (c) the differences between the scores of sandstone/anhydrock and anhydrock/chalk are significant, and substantial changes in weighting factors would be needed to achieve equality. The preclosure rock characteristics ranking given in Table 4.7 is confirmed in all respects by the results of the pairwise-comparison aggregation method. Shale benefits from its high abundance and moderate ductility, but its constructibility is only fair because of its having lower strength than other rocks. Operational stability is also fair because of the potential for raveling, slaking, and roof instability in thinly bedded shale members. The carbonate rocks are much stronger and have adequate ductility, thus they rank high on discriminators of constructibility and operational stability and, although they are less abundant than shales, they are ranked first. Sandstones are less abundant and have lower ductility than shales but have about the same strength and lack potential stability problems; this results in their being ranked the same as shale. The third ranking for anhydrock and the fourth ranking for chalk result from a combination of characteristics; both have low abundances relative to the other rock types. Chalk has a very low strength, resulting in relatively poor constructibility and operational stability. Anhydrock has excellent strength, but its low ductility and high thermal expansion result in relatively poor stability.

\subsubsection{Hydrology}

As mentioned in sect. 3.3, the preclosure hydrologic discriminator is the expected rate of groundwater inflow during the construction phase. The inflow, for the purpose of ranking the five sedimentary rocks addressed in this study, is estimated as the volume of groundwater that may be expected to enter a very long drift: $5.5 \mathrm{~m}$ diameter per meter of drift per unit of time.

The rock ranking for the hydrologic REC (Appendix A, Sect. A.2.3.3) is the same as that for the preclosure hydrologic discriminator (see Sect. 3.3.2.2), because the calculated preclosure rate of groundwater inflow into the repository is the only discriminator to be addressed: 
Preclosure hydrology rank

$$
\begin{aligned}
& 1 / 2 \\
& 3 \\
& 4 / 5
\end{aligned}
$$

\section{Rock type}

Shale; anhydrock

Sands tone

Chalk; carbonate rocks

The 3 ranking is relatively close to the $1 / 2$ ranking, whereas the $4 / 5$ ranking is considerably lower than the 3 ranking. As with the postclosure hydrology REC, the rankings given here for preclosure hydrology are primarily a function of the hydraulic conductivity of the rock types. Since the effective porosity is of lesser importance here, shale and anhydrock rank about the same. Sandstone, with its somewhat higher conductivity, ranks second, and the markedly higher conductivities of chalk and the caxbonate rocks result in the third ranking.

\subsubsection{Other Aspects}

Tnformation was developed on three other aspects that do not constitute a basis for applying any of the RECs: repository cost, systems studies, and foreign studies. The following paragraphs will briefly describe the results of these studies.

\subsubsection{Repository Cost}

Costs were estimated for repositories (see Sect. 3.10 and Appendix J) in each of the five rock types by analyzing and making appropriate adjustments to a detailed cost estimate for a spent fuel repusilury iu bedded salt (DOE 1984a). The estimated cost of the repositories in each of the subject rock types is primarily dependent on (a) the total excavated volume and (b) the cost per unit volume of excavating the rock. The total excavated volume depends on the maximum permissible thermal loading in the repository for all of the rock types, except anhydrock, where the thermal loading had to be reduced to achieve an acceptable rock stability during operation. The unit cost of excavating the rock is dependent on the strength of the rock, with the mining cost of the rock increasing with rock strength. Costs for ground support (e.g., rock bolting) were taken into account but were found to be relatively small as compared with the excavation costs. 
The results of this analysis showed that spent fuel repositories in shale and sandstone would have about the same total cost, which was only slightly greater than that for the baseline bedded salt repository. The costs of a repository in anhydrock were found to be significantly higher because of a higher excavated volume and a higher unit mining cost. The repository costs for the carbonate rocks and chalk were significantly higher than that for anhydrock. In the case of the carbonate rocks, this was due to the combination of both the total excavated volume and the unit excavation cost being somewhat higher than for anhydrock. In the case of chalk, the unit excavation cost is relatively low, but the excavated volume is very large because of chalk's poor thermal performance. However, the estimated costs for a repository in any of the subject rock types were judged to be "reasonab1e" since the highest of the five costs was on 1 y $\sim 45 \%$ greater than the smallest and $\sim 54 \%$ larger than that for the baseline bedded salt repository.

\subsubsection{Systems Studies}

The data base currently available for the subject rocks is not adequate to permit a meaningful systems analysis (preliminary performance assessment). However, two previous systems analyses for shale were identified and reviewed as part of this evaluation (see Sect. 3.9 and Appendix I). The first systems study predicted radionuclide release rates from a shale repository $\left(<10^{-20} \mu \mathrm{Ci} / \mathrm{mL}\right)$ that were much lower than those resulting from more-recent predictions. The second systems study assumed that the performance characteristics of a shale repository were the same as those for a basalt repository and adopted an existing basalt data base for performing the calculations, except that shale was assumed to have a much higher incidence of undetected boreholes. These assumptions resulted in relatively high calculated radionuclide releases for shale. Because of the broad range in calculated values, it was determined that the results of these studies were not particularly useful in arriving at firm conclusions regarding the performance of a shale repository.

\subsubsection{Foreign Studies}

A study was conducted to provide background concerning the extent to which the subject rock types are being considered in other countries (see Sect. 3.10 and Appendix $H$ for details). The results of this study showed 
that argillaceous rocks, in the form of clay deposits, are the preferred rock type in Belgium and Italy and are being considered on an equal basis with other rocks in Japan. While the clays being considered in these countries have most of the characteristics and advantages of the shales considered herein (e.g., impermeability, excellent geochemical traits), they suffer from the fact that their highly plastic nature requires more costly engineering measures for repository construction. These countries do not have the less-plastic shales like those in the United States, but, nevertheless, have apparently decided that the other favorable attributes (including their availability) of argillaceous rocks outweigh the disadvantages of clay. Argillaceous rocks are also being considered as an alternative rock type in Canada, France, and the United Kingdom.

\subsection{OVERALL EVALUATION OF ROCK TYPES}

This section represents the final step in the multistep methodology used to evaluate and rank the five subject sedimentary rocks with respect to their potential to serve as the host rock for a repository. This is accomplished by (1) summarizing the results of ranking the rock types for each REC (Sect. 4.4.1); (2) using this summary information to aggregate the favorableness of the rock types under preclosure and postclosure conditions separately (Sect.4.4.2); and (3) evaluating these results to determine the overall ranking of the rock types (Sect. 4.4.3).

\subsubsection{Summary of Rock Rankings by REC}

A summary of the rock type rankings developed in Sects. 4.2 and 4.3 for each REC is given in Table 4.8 .

\subsubsection{Postclosure and Preclosure Analyses of the Rock Types}

Given the rock rankings for each of the RECs (Table 4.1), the next task is to aggregate these results in a manner that can be used to evaluate the potential of each rock type to serve as the host rock for a geologic repository. The general approach adopted is to perform the aggregation for the postclosure and preclosure RECs separately using both of the methodologies described above.

The results of aggregating the rankings for the postclosure and the preclosure RECs (Table 4.8) by means of the averaging and pairwisecomparison methndolngies are summariged in Tahle 4.9. The maximum possible 
Table 4.8. Summary of rankings for each REC

\begin{tabular}{|c|c|c|c|c|c|c|}
\hline \multirow[b]{2}{*}{ Rock eve } & \multirow[b]{2}{*}{ uation criterion } & \multicolumn{5}{|c|}{ Rank order of the rock ${ }^{a}$} \\
\hline & & Shale & Sandstone & Anhydrock & Chalk & $\begin{array}{c}\text { Carbonate } \\
\text { rocks }\end{array}$ \\
\hline & & \multicolumn{5}{|c|}{ Postclosure guidelines } \\
\hline$A \cdot 1.2^{b}$ & Geohydrology & 1 & 2 & 2 & 3 & 3 \\
\hline A. 1.3 & Geochemistry & 1 & 2 & 4 & 3 & 3 \\
\hline A. 1.4 & $\begin{array}{l}\text { Rock } \\
\quad \text { characteristics }\end{array}$ & 1 & 2 & 3 & 3 & 2 \\
\hline A. 1.7 & Dissolution & 1 & 1 & 3 & 2 & 2 \\
\hline A. 1.9 & Natura1 resources & 1 & 3 & 1 & 2 & 3 \\
\hline & & \multicolumn{5}{|c|}{ Preclosure guidelines } \\
\hline \multirow[t]{2}{*}{ A. $2 \cdot 3 \cdot 2$} & Rock & & & & & \\
\hline & characteristics & 2 & 2 & 3 & 4 & 1 \\
\hline$A \cdot 2 \cdot 3 \cdot 3$ & Hydrology & 1 & 2 & 1 & 3 & 3 \\
\hline
\end{tabular}

a $\mathrm{A}$ rank of 1 is most favorable and 4 is least favorable. However, the number and the separation of the ranks are not necessarily uniform for different RECs.

bCriterion numbers (e.g., A.1.2) correspond to the section in Appendix A where the REC is defined.

Table 4.9. Rock ranking for postclosure and preclosure RECs

\begin{tabular}{|c|c|c|c|c|c|c|}
\hline Rank & Rock type & $\begin{array}{l}\text { Avcraging } \\
\text { method } \\
\text { score }\end{array}$ & Wins & airwis & e compar & $\begin{array}{l}\text { ison results } \\
\text { Score } \\
\text { (wins - losses) }\end{array}$ \\
\hline & Postclosure & & & & & \\
\hline 1 & Shale & 24.0 & 18 & 2 & 0 & 18 \\
\hline 2 & Sandstone & 17.0 & 10 & 4 & 6 & 4 \\
\hline 3 & Anhydrock & 11.5 & 5 & 3 & 12 & -7 \\
\hline 3 & Carbonate rocks & 11.5 & 4 & 5 & 11 & -7 \\
\hline 3 & Cha1k & 11.0 & 4 & 4 & 12 & -8 \\
\hline & Preclosure & & & & & \\
\hline 1 & Shale & 8.0 & 5 & 2 & 1 & 4 \\
\hline 2 & Anhydrock & 6.5 & 4 & 1 & 3 & 1 \\
\hline 2 & Sandstone & 6.5 & 4 & 1 & 3 & 1 \\
\hline 2 & Carbonate rocks & 6.5 & 3 & 2 & 3 & 0 \\
\hline 3 & Chalk & 2.5 & 0 & 1 & 7 & -7 \\
\hline
\end{tabular}


scores are 25 and 20 for the postclosure averaging and pairwisecomparison methods, respectively, and 10 and 8 for the preclosure averaging and pairwise-comparison methods, respectively. These scores and rankings reflect equal weighting of all five postclosure RECs to obtain the postclosure results; the same holds true for the preclosure results. This is in agreement with the implementation provision of the siting guidelines, which calls for equal weighting of the technical guidelines within a priority grouping (see Appendix A for a discussion of the priorities of the siting guidelines).

\subsubsection{Evaluation of Overall Aggregation Results}

The final remaining task is to collectively consider the rock rankings for the two groups of postclosure and preclosure RECs given in Table 4.9. The implementation provisions of the siting guidelines stipulate that the results of applying the postclosure guidelines be given primary significance as compared to the results for applying preclosure guidelines, but specific guidance on the relative levels of significance is not provided. It is also stipulated that the importance of the three subgroups of preclosure siting guidelines diminishes in the order they are presented (details are provided in Appendix A). In the limiting case, this would necessitate specifying four weighting factors (one for postclosure and three for preclosure), resulting in a complex sensitivity analysis to reconcile the various rankings. However, in this applica-

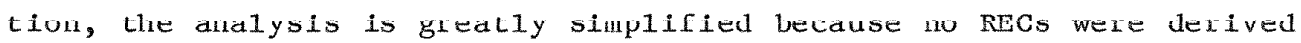
from the two highest-priority preclosure subgroups of the siting guidelines. Thus, only two (complementary) weighting factors (one postclosure and one preclosure) are required.

As an initial position, it is assumed that the overall ranking of the five subject rocks is that given in the upper portion of Table 4.9 for the postclosure RECs, namely:

\begin{tabular}{ll} 
Rank * & \multicolumn{1}{c}{ Rock type } \\
1 & Shale \\
2 & Sandstone \\
3 & Anhydrock; carbonate rocks; chalk
\end{tabular}


The sensitivity of this ranking to the relative importance (weighting factor) of the preclosure RECs will be examined by graphically depicting the total weighted (between 0 and 100\%) score for each of the rocks for preclosure REC weighting factors. The results for the averaging method are shown in Fig. 4.1 , and the results from the pairwise-comparison method are shown in Fig. 4.2. The left and right vertical axes represent the scores for each of the rocks based on only postclosure and preclosure REC groups, respectively. Equal weighting for each of the two groups of RECs occurs at $50 \%$ on the horizontal axis (this is equivalent to a $10 \%$ weighting factor for each of the postclosure RECs and $25 \%$ for each of the two preclosure RECs). Because the postclosure REC group is to be emphasized over the preclosure REC group, the applicable region of these figures is between 0 and $50 \%$.

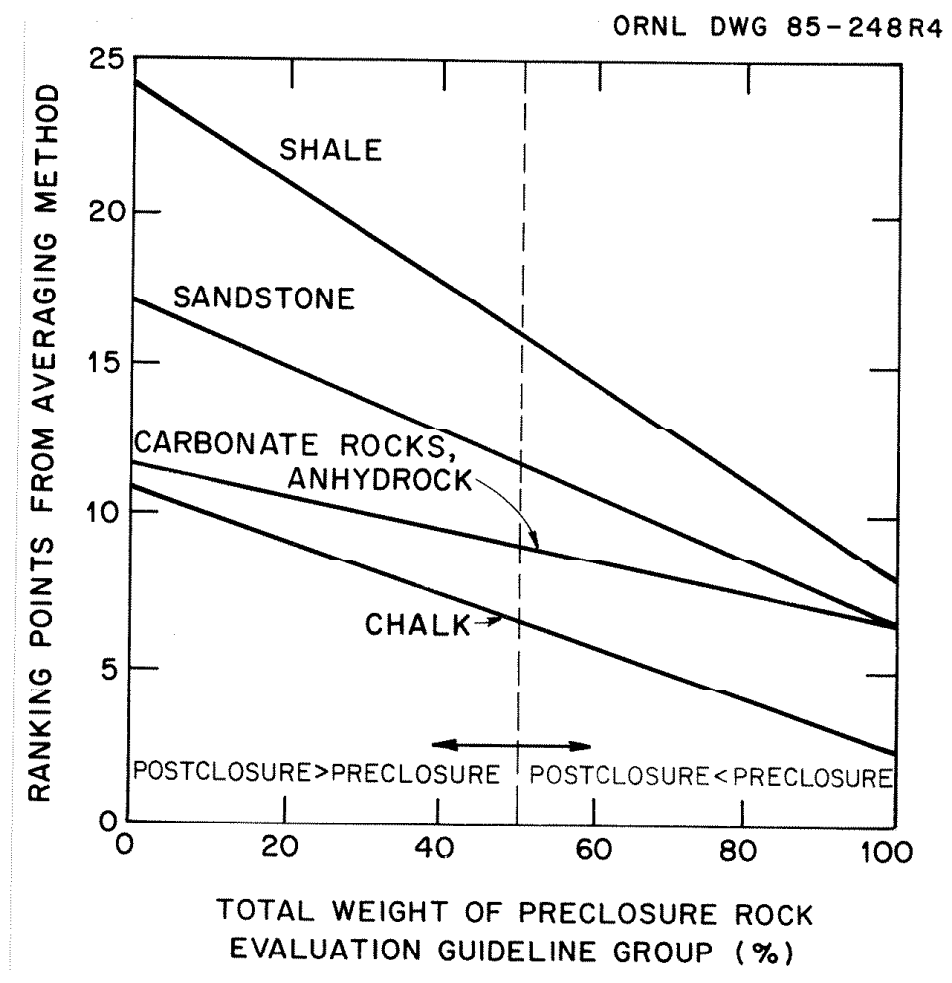

Fig. 4.1. Sensitivity of averaging method scores to the preslnsure RFr weighting factor. 


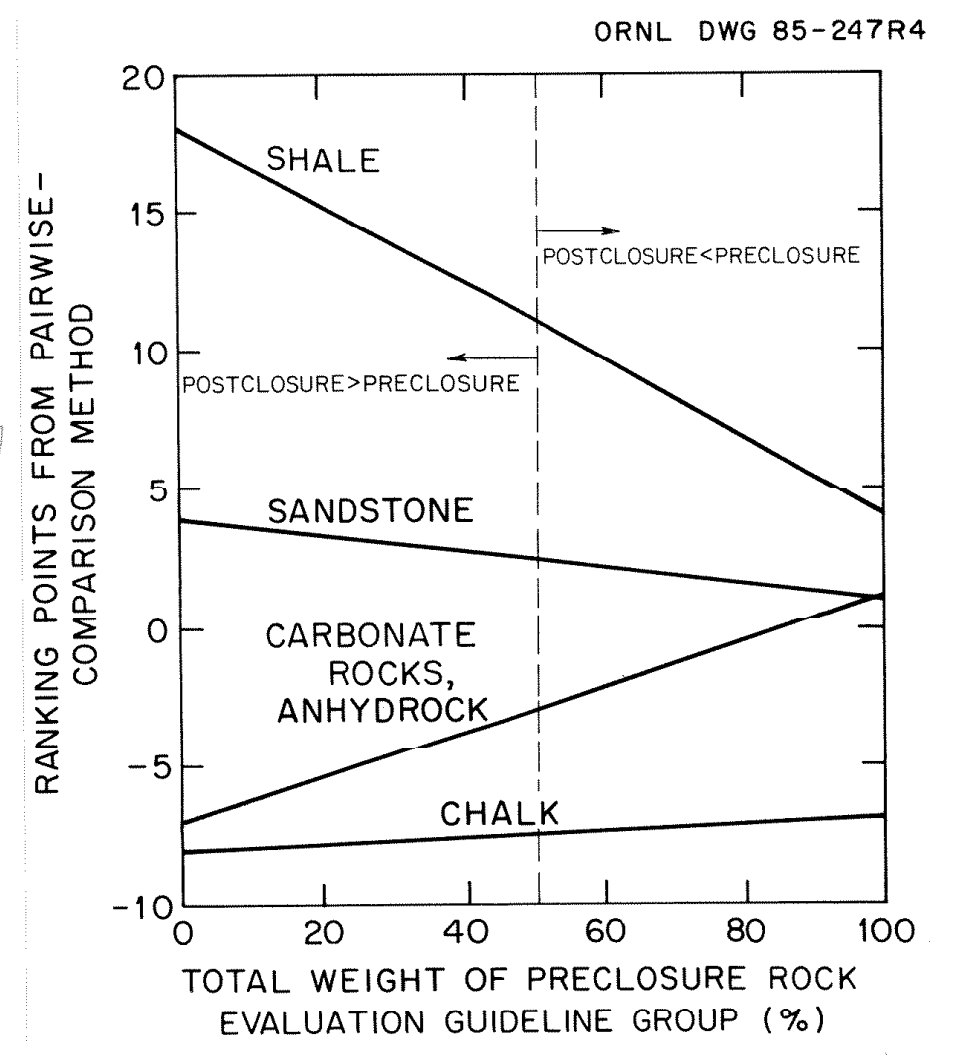

Fig. 4.2. Sensitivity of pairwise-comparison scores to the preclosure REC weighting factor.

The conclusions reached by evaluating the information in these figures are as follows:

1. The score for shale is significantly higher than that for the other rock types for all weighting factors, thus supporting its ranking of first.

2. The score for sandstone generally is significantly higher than that for other rocks except shale. Only if the preclosure REC group is weighted $100 \%$ (i.e., the postclosure RECs are ignored) can the score for sandstone be equalled by that of the carbonate rocks and anhydrocks, justifying a ranking of second for sands tone. 
3. The scores for anhydrock and the carbonate rocks are equal for all values of the weighting factors, indicating that an identical third ranking is appropriate for these rocks.

4. The difference in scores between chalk and the carbonate rocks is sma11 when only the postclosure REC group is considered, thus engendering its initial third ranking. However, the difference in scores becomes quite substantial as the weighting factor for the preclosure REC group is increased. This increasing difference supports the conclusion that a ranking of fourth is justified for chalk.

Thus, the simultaneous evaluation of the postclosure and preclosure scores results in the overall ranking listed in Table 4.10. The overall rock ranking given in Table 4.10 results from the characteristics of the five rock types summarized below.

Table 4.10 . Overall ranking of the five rock types

\begin{tabular}{ll}
\hline Rank & \multicolumn{1}{c}{ Rock type } \\
\hline 1 & Shale \\
2 & Sandstone \\
$3 / 4$ & Anhydrock; carbonate rocks \\
5 & Chalk \\
\hline
\end{tabular}

The superior performance of shales resulted from the following factors :

1. Hydrology - excellent because of very low hydraulic conductivity and relativcly high cffective porosity;

2. Geochemistry - reducing conditions expected because of the presence of organic matter, thus promoting retardation and insolubility; contains considerable amounts of clays to retard radionuclide migration;

3. Rock characteristics - widespread occurrence to permit siting flexibility; moderate thermal performance; moderate mechanical performance bccauoc of ito good ductility and fair otrength; 
4. Dissolution - essentially insoluble; and

5. Natural resources - generally does not contain economically recoverable natural resources.

Sandstone was a relatively distant second preference to shale because of the following factors:

1. Hydrology - good because, although the effective porosity is relatively high, even the more promising sandstones generally have higher hydraulic conductivities than do the more promising shales;

2. Geochemistry - moderately good, but typically low contents of clay and organic matter indicate less-reducing conditions and lcss retardation capability than do shales;

3. Rock characteristics - moderate abundance and thermal performance, good mechanical performance;

4. Dissolution - essentially insoluble; and

5. Natural resources - often contain natural resources such as gas, oil, and water.

Anhydrock and the carbonate rocks, within the uncertainties of this evaluation, were ranked together, 3/4. The 3/4 ranking for anhydrock was derived from the following factors:

1. Hydrology - very good, but still inferior to shales because of the combination of very low hydraulic conductivity and very low effective porosity;

2. Geochemistry - poor because of the neutral $\mathrm{pH}$ of groundwaters, the lower retardation and increased solubilities resulting from the high concentration of ealt in the groundwater, and the absence of organic matter to establish reducing conditions;

3. Rock characteristics - very limited occurrence; excellent thermal performance because of a high thernal conductivity; poor mechanical performance because of brittleness and a high coefficient of thermal expansion;

4. Dissolution - poor, since the primary mineral (anhydrite) is relatively soluble; and

5. Natural resources - generally does not contain natural resources, although may occasionally be mined for its own value. 
The 3/4 ranking for the carbonate rocks results from the following factors:

1. Hydrology - fair performance, despite relatively high effective porosity, because even the more promising carbonate rocks have much higher hydraulic conductivities than do shales and sandstones, resulting in high potential water flow rates;

2. Geochemistry - fair performance because of the lack of clays to retard radionuclide migration, the low concentration of organic matter needed to establish reducing conditions, and the high concentration of dissolved solids in the waters;

3. Rock characteristics - moderate abundance, intermediate thermal performance, yood mechanical performance;

4. Dissolution - fair performance because of the significant solubility of the principal minerals of the carbonate rocks (calcite and dolomite) in water; and

5. Natural resources - often contain natural resources, such as gas, oil, and water and are mined for their intrinsic value at shallow depths.

The 5 ranking for chalk relative to shales is based on the following factors :

1. Hydrology - fair to poor performance because even the more promising chalks have higher hydraulic conductivities than do shales and sandstones while having a very low effective porosity;

2. Geochemistry - fair performance because of the lack of clays to retard radionuclide migration, the low concentration of organic maller needed lo establish reducing condilions, and lle expected high concentration of dissolved solids in the waters;

3. Rock characteristics - limited occurrence, poor thermal performance, and poor mechanical performance because of its low strength;

4. Dissolution - fair performance because of the significant solubility of its principal mineral (calcite) in water; and

5. Natural resources - generally contains minimal extractable resources. 


\section{SUMMARY, CONCLUSIONS, AND RECOMMENDATIONS}

\subsection{SUMMARY}

\subsubsection{Background and Purpose}

The Nuclear Waste Policy Act of 1982 requires that the DOE site two geologic repositories for the disposal of high-level waste (HLW) and spent fuel. Studies are currently under way to locate sites suitable for a geologic repository in tuff, basalt, salt (both bedded and dome), and crystalline rocks. In order to increase the diversity of rock types under consideration by the geologic disposal program, the DOE initiated the Sedimentary Rock Program (SERP). Its immediate objective is to evaluate five types of sedimentary rock - sandstone, chalk, carbonate rocks (limestone and dolostone), anhydrock, and shale - to determine the likelihood of siting a geologic repository in one of these rock types. The evaluation of these five rock types, together with the ongoing salt studies, effectively results in the consideration of all types of relatively impermeable sedimentary rock for repository siting purposes. The results of this evaluation are expressed in terms of a ranking of the five rock types with respect to their potential to serve as a geologic repository host rock. However, it should be noted that the possibility exists that a geologic repository can be located in any one of these rock types. The information generated by this study, which is documented in this report and sumnarized here, will form the technical basis for DOE decisions concerning future investigative activities for these five rock types.

\subsubsection{Methodology Employed}

This comparative evaluation of the five subject rocks was accomplished using a generic approach, since the purpose was to identify the most promising rock type. However, the DOE siting guidelines (CFR 1984) are relevant to the selection of a site and are thus site specific. The approach adopted for this rock evaluation study was to use the relevant siting guidelines as the basis for a comparative evaluation of the subject rock types through the following methodology. 
1. The siting guidelines were analyzed, leading to

a. A 1ist of the technical provisions of the siting guidelines that could be used to evaluate the subject rock types on a generic basis;

b. The development of a non-site-specific rock evaluation criterion ( $R E C$ ) for each technical provision determined to have components that could be meaningfully evaluated on a generic basis;

c. The specification of the "discriminators" that constitute the basis for applying a REC to the evaluation of the rock types. These discriminators, derived from both the favorable and the potentially adverse conditions in the siting guidelines, are defined by the boundaries of scientific and engineering disciplines and, within a diocipline, by ito broad tcchnical concepts as applied to nuclear waste management;

d. The identification of the information that would have to be acquired to address each of the discriminators.

This approach is discussed further in Sect. 2, and the development of the RECs and discriminators is described in Appendix A.

2. Given the identification of the information requirements, the SERP used technical consultants and subcontractors to gather, collate, and document the needed data. This data base is documented in Appendixes $\mathrm{C}$ through $\mathrm{K}$ of this report and briefly summarized in Sect. 3.

3. The information contained in the technical data base was used to evaluate the five subject rock types for each of the discriminators alluded to above. This evaluation, expressed as a rank ordering of the rock types, was qualitatively based on the preponderance of the evidence and considering the uncertainties inherent in the data base. Rock types for which little discrimination was evident were typically assigned the same rank. Thus, although there could be five ranks for each discriminator, in actuality only two or three usually resulted. The separation between the ranks was also characterized qualitatively (e.g., rank 2 could be either a dictant occond or a clooc accond to rank 1). These results are discussed in Sect. 3. 
4. The rock rankings for the various discriminators were used as the basis for evaluating the five rock types for each of the RECs. This two-step process was necessary because some of the RECs include discriminators based on more than one discipline (e.g., the rock characteristics REC has discriminators involving both geology and rock mechanics). The rank ordering of the rock types done for each of the RECs was (a) identical to the discriminator ranking for RECs having only one discriminator or (b) developed by collectively considering rock rankings for multiple discriminators, using aggregation methods described in the draft environmental assessments (see, for example, DOE 1984b) for the sites to be nominated for the firet repoeitory (occ Sect. 4.1). The separation between the ranks was also addressed qualitatively. These results are contained in Sects. 4.2 and 4.3.

5. The rock rankings for the RECs were used as the basis for eva1uating the five rock types with respect to their overall potential as host rocks for a geologic repository. The ranking of the five rock types was determined using the draft EA aggregation methods referced to in item 4 above. Because of the high priority given to the postclosure guidelines, the evaluation was based primarily on the results for the group of postclosure RECs, with the results for the group of preclosure RECs only being used to differentiate between rock types having similar rankings under the postclosure RECs. These results are presented in Sect. 4.4 .

The information used in this evaluation was obtained from literature sources and, in some cases, from unpublished data bases.

\subsubsection{Information Summary}

In general, the overall philosophy adopted for the information acquisition was that the data should be representative of the range of properties typically expected for each rock type. An exception to this is that the typical hydrologic data used in the calculations are representative of the more promising (less permeable or fractured) occurrences of each of the five subject rock types. Expert judgment was employed to ensure that this was the case for all rock types and that the data base was internally consistent. This exception is appropriate because these 
occurrences would be sought during site selection, and thus they should be the basis for the evaluation.

In general, the data base for the five rock types is relatively sparse and not we11 characterized. This is not surprising because, with the exception of shales, these rocks have not been considered previously as hosts for a repository. For example, the literature is replete with data for carbonate rocks and sandstones; however, because the interest in these rocks has been primarily related to petroleum sources or aquifers, the data are relatively more abundant toward the end of the rock hydrology spectrum that is less desirable for repository purposes. Despite these difficulties, the information base acquired in support of this evaluation is thought to be more than adequate for the task at hand: to identify the most promising of the five rocks for geologic repository purposes. The data base for anhydrock is better than that for the other rock types because of anhydrock's typical association with salt deposits, which are currently being considered as a repository host rock. The data bases for shale, sandstone, and the carbonate rocks are adequate for the task. Chalk, which has a relatively narrow range of characteristics, has a small data base. However, it is thought to be adequate for rock evaluation purposes.

The areas for which information was obtained and a brief identification of the types of information developed are listed here.

1. Hydrology - A data baac of values for the parameters used in calculating groundwater flow rates was developed. These values were used to calculate relative pre-waste-emplacement groundwater travel times and the rate at which groundwater might flow into a repository during construction and operation.

2. Geochemistry - A data base consisting of typical groundwater compositions, generic factors affecting radionuclide retardation and solubility, and the dissolution behavior of the rock types was developed and used to analyze the 1ikely geochemical attributes of the rock types.

3. Geology/Stratigraphy - A geologic description of each of the rock types was prepared. This description is principally for background information. However, characterization of (a) the 
thickness, 1ateral extent, and homogeneity of each of the rock types in the contiguous United States and (b) the rock attributes by depositional environment is directly relevant to the rock evaluation process.

4. Natural Resources - An assessment of the degree to which each of the rock types tends to be associated with valuable natural resources, principally petroleum, gas, coal, and water, but including mineral resources.

5. Thermal Response and Rock Mechanics - A data base of values for parameters used to model the thermal mechanical performance of a geologic repository (thermal conductivities, rock strength, etc.) was developed. This data base was used to calculate the temperature responses of each of the five rocks under a fixed thermal loading and indices of the mechanical behavior of the repository during the operational and postclosure time periods.

6. Waste Package Durability - The groundwater composition developed by the geochemists, along with estimates of the likely verynear-field alteration of the groundwater characteristics, was used to examine the performance (degradation rate) of potential waste canister materials in each of the host rock types.

7. Repository Cost Studies - The mechanical properties of the rock types were used as the basis for estimating costs for spent-fuel geologic repositories in each of the five rock types by making adjustments to the portions of an existing cost estimate for vedded sall that depend on rock characteristics (e.g., mining costs).

8. Systems Studies - Existing systems performance studies for the subject rocks were analyzed for information relevant to the rock evaluation.

9. Foreign Studies - Foreign geologic repository programs were surveyed to determine the extent to which there is interest in these rocks in other countries.

The information developed in the last three areas did not constitute a basis for comparatively evaluating the subject rocks. 
As noted earlier, the technical details in the above areas are given in the appendixes of this report and are summarized in sect. 3.

\section{1 .4 Evaluation Results}

The process of developing RECs from the technical provisions of the siting guidelines resulted in five postclosure RECs for the areas of geohydrology, geochemistry, rock characteristics, dissolution, and natural resources. In addition, two preclosure RECs were developed in the areas of rock characteristics and hydrology. The results of the REC rock evaluations are shown in Table 5.1. The following sections will give a brief rationale for the ranking* of rock types based on each REC.

Table 5.1. Summary of rankings for each REC

\begin{tabular}{|c|c|c|c|c|c|c|}
\hline & & \multicolumn{5}{|c|}{ Rank order of the rock } \\
\hline \multicolumn{2}{|c|}{ Rock evaluation criterion } & Shale & Sandstone & Anhydrock & Chalk & $\begin{array}{l}\text { Carbonate } \\
\text { rocks }\end{array}$ \\
\hline & & \multicolumn{5}{|c|}{ Postclosure guidelines } \\
\hline$A \cdot 1 \cdot 2^{b}$ & Geohydrology & 1 & 2 & 2 & 3 & 3 \\
\hline$A \cdot 1 \cdot 3$ & Geochemistry & 1 & 2 & 4 & 3 & 3 \\
\hline \multirow[t]{2}{*}{ A.1.4 } & Rock & & & & & \\
\hline & characteristics & 1 & 2 & 3 & 3 & 2 \\
\hline A.1.7 & Dissolution & 1 & 1 & 3 & 2 & 2 \\
\hline \multirow[t]{2}{*}{ A. 1.9} & Natural resources & 1 & 3 & 1 & 2 & 3 \\
\hline & & \multicolumn{5}{|c|}{ Preclosure guidelines } \\
\hline$A \cdot 2 \cdot 3 \cdot 2$ & $\begin{array}{l}\text { Rock } \\
\quad \text { characteristics }\end{array}$ & 2 & 2 & 3 & 4 & 1 \\
\hline$A \cdot 2 \cdot 3 \cdot 3$ & Hydrology & 1 & 2 & 1 & 3 & 3 \\
\hline
\end{tabular}

$a_{A}$ rank of 1 is most favorable, and 4 is least favorable. However, the number and the separation of the ranks are not necessarily uniform for various RECs.

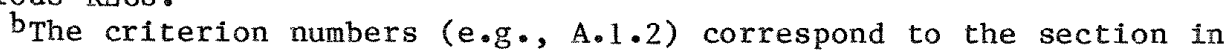
Appendix $A$ in which the REC is defined.

*A rank of 1 is most favorable, and 5 is least favorable. Combined numbers (e.g., 2/3) are used for two rock types with the same or nearly equivalent ranking. 


\subsubsection{Postclosure Geohydrology}

The ranking given in Table 5.1 is based on the calculated pre-wasteemplacement groundwater travel time, which is primarily a function of the hydraulic conductivity of the rock types. Shale and anhydrock are generally known for low hydraulic conductivity, and a tight sandstone that might be considered for a repository also performs well in this regard. However, the higher effective porosity of the shale as compared to anhydrock and the slightly higher hydraulic conductivity of the sandstone as compared to shale result in shale being ranked first and the other two second. The hydraulic conductivities of even the more promising ends of the spectrum for clidk and carbonate rocks are st1ll relarlvely high, and they rank a distant third.

5.1.4.2 Postclosure Ceochemictry

The ranking given in Table 5.1 is a function of the dissolved solids concentration in the groundwaters (a higher concentration tends to increase solubilities and decrease retardation), the clay content of the rock types (a higher content typically increases retardation), and the organic matter content of the rock types (a higher content promotes reducing conditions and increases retardation). Shale has favorable characteristics for all three of these attributes and thus ranks highest. The dissolved solids concentration increases and the content of clays and organic matter decreases steadily as the rock types are ranked lower, thus accounting for the ranking given.

5.1.4.3 Postclosure Rock Characteristics

The first ranking for shale results from its substantial abundance (permitting flexibility in the configuration of the repository), along with the combination of adequate strengll and yood ductility. Sandstone and the carbonate rocks rank second because they are somewhat less abundant and significantly less ductile than shale, while having higher strength than shale. Chalk and anhydrock are ranked third because of their very low abundances, poor thermal conductivity (chalk), and the combination of low ductility and high thermal expansion (anhydrock). 5.1.4.4 Postclosure Dissolution

This ranking results directly from consideration of the solubility of the major constituents of the rock types in unsaturated waters. The 
components of sandstones and shales (quartz and clays) are very insoluble. The primary minerals comprising chalk and the carbonate rocks (calcite, dolomite) are somewhat soluble, as evidenced by extensive cave systems in limestones. The principal mineral in anhydrock (anhydrite) is substantially more soluble than the carbonate rocks, and hence the third ranking.

\subsubsection{Postclosure Natural Resources}

The low ranking for sandstone and the carbonate rocks results from their being common reservoir rocks for widely sought resources, such as oil, gas, and water. Chalk is occasionally a reservoir rock, especially where it has been fractured, and it is ranked second. shale and anhydrock are not typically reservoir rocks, because of their impermeability. Anhydrock and shalk are mined for their intringir value, hut not normally at repository depths. Shale is rarely mined for its intrinsic value, but certain shales (e.g., oil shales and those with somewhat higher metal concentrations) might be mined if economic conditions change.

In certain special environments, oil and gas deposits can occur in sandstone and carbonate rocks overlain by a layer of shale that serves to trap the hydrocarbons in the aforementioned rocks. Such shale formations, to be useful as a repository host rock, would have to meet the conditions, such as depth, thickness, and lateral extent, specified in the siting guidelines. In such a formation, boreholes, to facilitate the recovery of the ofl and gas from the underlying rocks, would penetrate the shale layer. Since shale does not readily undergo dissolution as do salt and carbonate rocks, it would be feasible, using state-of-the-art plugging techniques, to effectively seal the boreholes. However, given the relative abundance of shale formations, it is doubtful that such shale formations would be seriously considered as the host rock for a geologic repository.

\subsubsection{Preclosure Rock Characteristics}

Shale benefits from its high abundance and moderate ductility, but its constructibility is only fair because of its relatively lower strength than that of the other rocks, and its operational stability is fair becauoc of the potential for ravcling, olaking, and roof inctability in thinly bedded shale members. The carbonate rocks are much stronger, 
with adequate ductility, thus ranking high on constructibility and operational stability; although carbonates have a lesser abundance than shales, they are ranked first. Sandstones are in lesser abundance and have a lower ductility than shales but are about the same strength and have no potential stability problems, resulting in their being ranked the same as shale. The third ranking for anhydrock and the fourth ranking for chalk result from a combination of characteristics. Both have low abundances relative to the other rock types. Chalk has a very low strength, resulting in poor constructibility and operational stability. Anhydrock has excellent strength, but its low ductility and high thermal expansion result in very poor stability.

\subsubsection{Preclosure Hydrology}

As with the postclosure hydrology REC, the rankings given in Tah1e 5.1 for preclosure hydrology are primarily a function of the hydraulic conductivity of the rock types. Since the effective porosity is of lesser importance here, shale and anhydrock rank about the same. Sandstone, with its somewhat higher conductivity, ranks second, and the markedly higher conductivity of chalk and the carbonate rocks results in the third ranking.

\subsubsection{Overall Evaluation}

The rock rankings for each $\mathrm{REC}$, as given in Table 5.1 , were aggregated by two of the methodologies employed and described in the draft environmental assessments for the sites to be nominated for the first repository: the averaging method and the pairwise-comparison method (see, for example, DOE 1984b). The ranking of the five subject rocks was first developed using only the postclosure RECs as a basis. The effect of including the preclosure RECs was then examined by depicting the scores from the aggregation methodulogies graplically as a function of the weight placed on the preclosure RECs. The result of this evaluation was a ranking of the five subject rocks with respect to their potential for hosting a geologic repository:

Overall ranking

1

2

$3 / 4$

5

\section{Rock type}

Shale

Sandstone

Amlydruck; casbunale rucks Chalk 
The separations between the 1 and 2 rankings and between the 2 and $3 / 4$ rankings are substantial. The separation between the $3 / 4$ ranking and the 5 ranking is relatively small. The use of preclosure RECs in the evaluation permitted cha1k to be distinguished from anhydrock and the carbonate rocks, but the rank of the rock types other than chalk is relatively insensitive to the weight placed on the preclosure RECs.

A brief rationale for this ranking is as follows:

1. Shale has relatively good performance on most aspects, without having any strong negatives, although it ranked less than first on a few discriminators and on one REC.

2. Sandatone performs moderately well for many discriminators; its only strong negative feature is its association with natural resources.

3. Carbonate rocks are strong rocks, but they have relatively poor hydrology and geochemistry characteristics and are associated with many natural resources.

4. Anhydrock is a strong rock with good thermal performance, but it suffers from very limited abundance, low ductility, and poor geochemica1/dissolution attributes.

5. Chalk has good stability, but it has limited abundance, very poor thermal performance, poor hydrology, and low strength.

\section{1 .5 Other Aspects}

Information was developed for four other areas that do not constitute a basis for the overall rock evaluation. These aspects are included for informational purposes: repository cost, systems studies, foreign studies, and historical experience with man-made openings in shale. The following paragraphs will briefly describe the results of these studies.

\subsubsection{Repository Cost}

Estimated costs were developed for geologic repositories (see Sect. 3.10 and Appendix $J$ ) in each of the five subject rock types by analyzing and making appropriate adjustments to a detailed cost estimate for a geologic repository in bedded salt (DOE 1984a). The estimated cost of a repository in each of the subject rock types is primarily dependent on two factore: the total excavated volume and the unit coot of creavating the rock. The total excavated volume depends on the maximum permissible 
thermal loading in the repository for all of the rock types except anhydrock, for which the thermal loading had to be reduced to achieve an acceptable rock stability during operation. The unit cost of excavating the rock is dependent on the strength of the rock, with the mining costs increasing with rock strength. Costs for ground support (e.g., rock bolting) were taken into account but were found to be relatively small compared with the excavation costs.

The results of this analysis indicate that repositories in shale and sandstone would have about the same total coste, which arc olightly grcatcr than those for the baseline bedded salt repository. The cost of a repository in anhydrock was found to be significantly greater; this increase is due to both a higher excavated volume and a higher unit mining cost. The repository costs for the carbonate rocks and chalk were significantly higher than those for anhydrock. In the case of the carbonate rocks, this was due to the combination of both a higher total excavated volume and a higher unit excavation cost than for anhydrock. In the case of chalk, the unit excavation cost is relatively low, but the excavated volume is very large because of the poor thermal performance of chalk. However, the estimated costs for a repository in any of the subject rock types were judged to be "reasonable" since the highest of the five costs was only $\sim 45 \%$ greater than the smallest and $\sim 54 \%$ larger than that for the baseline bedded salt repository.

J.1.j.2 Systems Studies

The data base currently available for the subject rocks is not adequate to permit a meaningful systems analysis (preliminary performance assessment) to be done. However, two previous systems analyses for shale were identified and reviewed as part of this evaluation (see Sect. 3.9 and Appendix I). The first study predicted radionuclide release rates from a shale repository $\left(<10^{-20} \mu \mathrm{Ci} / \mathrm{mL}\right)$ that were much lower than those resulting from more-recent predictions. The second systems study assuned that the performance characteristics of a shale repository were the same as those for a basalt repository, and an existing basalt data base was adopted for performing the calculations, except that shale was assumed to have a much higher incidence of undetected boreholes. These assumptions resulted in relatively high calculated radionuclide releases for shale. 
Because of the broad range in calculated values, the results of these studies were not considered useful in arriving at firm conclusions regarding the ability of a shale repository to isolate and contain radionuclides.

\subsubsection{Foreign Studies}

A study was conducted to determine the extent to which the subject rock types are being considered in other countries (see sect. 3.10 and Appendix $H$ for details). The results of this study showed that argillaceous rocks, in the form of clay deposits, are the preferred rock type in Belgium and Italy and are being considered on an equal basis with other rocks in Japan. While the clays being considered in these countries have most of the characteristics and advantages of the shales considered herein (e.g., impermeability, excellent geochemical traits), they suffer from the fact that their highly plastic nature requires more costly engineering measures for repository construction. These countries do not have the less-plastic shales found in the United States, but they have apparently decided that the other favorable attributes (including avai1ability) of argillaceous rocks outweigh the disadvantages of clay. Argillaceous rocks are also being considered as an alternative rock type in Canada, France, and the United Kingdom.

\subsubsection{Man-Made Openings in Shales}

There are numerous examples in the literature for geology, engineering geology, and civil engineering that document the slope-stability aspects of shales. The most widely reported problems are along highways, where outcrops of shales have been excavated in roadcuto. Damo and other large civil-engineered structures have also been affected. Landslide problems in such shales can result from the strike and dip of the shale formation, the degree of jointing or faulting, the slope angle, and the degree of interference caused by the construction itself. Failure to properly divert surface runoff or other drainage waters from the shalelined slope has added to the potential for stability problems in some cases.

A more practical aspect of man-made openings in shale is the response of shales to or in underground excavations. Abel and Gentry (ABEL 1975) have discussed the excavation record of the Upper Cretaceous Mancos and 
Pierre Shales and found that conventional drill-blast-removal techniques and large-diameter boring machines were both suitable for producing tunnels of the desired diameter. Instability problems in the Pierre Shale are related principally to its high moisture content, reflected by a smectite-dominated mineralogy that allows the rock to absorb water and be geomechanically affected in the process. The Azotea water-diversion tunnel in southern Colorado and northern New Mexico was driven more than $20 \mathrm{~km}$ through the Mancos Shale at depths of up to $600 \mathrm{~m}$.

Shales are commonly the roof strata in coal mines in the Pennsylvanian coal-bearing sequences mined in the eastern, interior, and midcontinent parts of the country. Failures and/or roof falls are common in some of these coal mines where thin shales in the roof are bounded by well-defined parting planes. A classic study of the relationship between roof 1itho1ogies and roof failures in coal mines is reported by Krause et al. (KRAUSE 1979). Failure of certain shale roofs is to be expected because of depositionally induced structures that are current planes of weakness, reaction to wetting and drying cycles due to the mining activity itself, and the fairly low rock strength of thin shales where they are exposed in essence as lateral beams. Measures to prevent these circumstances must be taken into account in the mine design.

The utilization of shales and other rock types for mined storage caverns is discussed at some length by Cobbs Engineering (COBBS ENGINEERING 1975). More underground caverns for the storage of petroleum products have been developed in shale than in any other rock type. Although during the construction of certain caverns some problems have resulted from slaking caused by the absorption of water, adequate humidity control can generally arrest this condition. Similarly, the relatively low strength of shale can be compensated for by good engineering design of the cavern(s), and thus adequate roof support can be obtained. Thermal and mechanical data from the near-surface heater experiment in the Conasauga Formation at Oak Ridge suggest that the shale rocks did not fracture further as a consequence of being heated, but the rocks actually showed a decrease in permeability. In general, these findings reflect favorably on the utility of shale as a host rock for high-level radioactive waste (KRUMHANSL 1979). 
From the near-surface heater test in the Eleana Argillite, it was observed that the effects of clay contraction resulting from water evolution caused the opening of preexisting joints in the rocks, which could lead to increased amounts of water and water vapor close to the heat sources in a repository situation. However, no "failure" mechanism was identified that would adversely affect the use of argillaceous rock for deep underground waste repositories (MCVEY 1979).

\subsection{CONCLUSIONS}

From the evaluation contained herein and summarized in Sect. 5.1.4.8, it is clear that shale is the preferred host rock among the five rock types considered. In addition, the analyses performed in support of this evaluation gencrally indicate that ohalc has the potential for being an accept able repository host rock, since it rated high on most discriminators and did not rank low on any of them. It should be noted that this conclusion is valid for the general class of shales that are at least somewhat indurated (i.e., hard or rocklike), of which there are extensive occurrences in the conterminous United States (see Fig. 5.1). Different (and most likely less favorable) conclusions might be reached if other classes of argillaceous rocks (e.g., clays) were also being considered.

The evaluation contained in this report also supports the conclusion that sandstone could be an adequate repository host rock, especially if one could identify an impermeable sandstone that was relatively ductile and had a significant clay content. Although this type of rock has the potential to be a repository host rock, it would still be ranked lower than the more promising shales.

The evaluation clearly indicatco that cotablishing a rcpository in carbonate rocks, chalk, and anhydrock would be very difficult. However, the possibility exists that a site for a geologic repository could be located in any one of these rock types.

The conclusions of this evaluation can be summarized in the following statements.

1. Shale is by far the preferred of the five rock types comparatively evaluated, and it has the potential to be a ropooitory hoot rock because of its good performance on most discriminators and its lack of poor performance on any of the discriminators. 


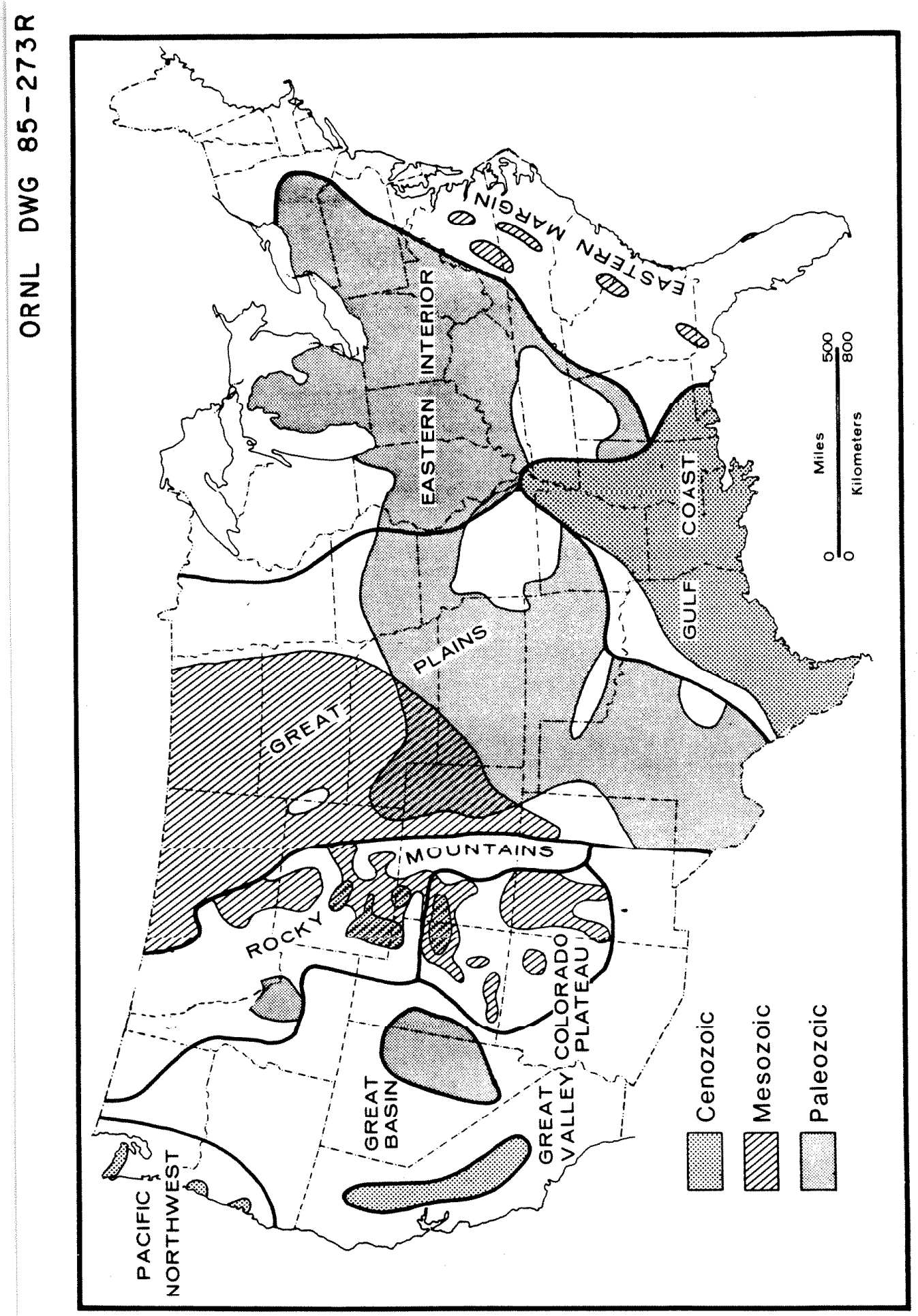

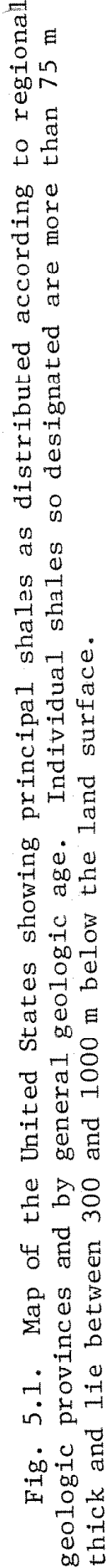


2. A promising sandstone (relatively plastic, with significant clay content) would probably constitute a suitable repository host rock; however, even this type of sandstone does not have as high a potential as the more promising shales because of the lessfavorable hydrologic and geochemical attributes of sandstone and its typical association with natural resources.

3. Carbonate rocks could probably host a repository, but they have relatively poor hydrology and geochemical characteristics and are associated with many natural resources.

4. Anhydrock could probably host a repository, but because its occurrence is very limited, the probability of finding a potentially suitable site is very small.

5. Chalk might constitute a marginally acceptable repository host rock, depending on the strength of the rock.

\subsection{RECOMMENDATIONS}

The following recommendations are the result of this evaluation:

1. Continue investigations of shale as a potential host rock for a geologic repository. Investigations of the other four rock types (sandstone, carbonate rocks, anhydrock, and chalk) should be deferred at this time. This recommendation is supported by the evaluation that shale is the most preferred of the five rock types considered with respect to its potential to be an acceptahle repository host rock. Even under the best of circumstances, the other four rock types do not have the potential of shale, although it is possible that an acceptable site might be located and developed in any of them. This recommendation is also supported by the following points: (a) further investigation of shales will increase the hydrologic and rock-type diversity of the DOE geologic repository program; (b) shale would offer the possibility of siting a repository in a number of regions in the conterminous United States; and (c) investigation of shales would provide data relevant to the understanding of clays, such as those proposed as backfill and packing material in repositories. 
2. Develop a data base that would be adequate to proceed with the 1dentification of a potential site in shale. The objective of this work would be to develop a technical data base that would support the site-screening steps ultimately leading to identifying a potentially acceptable geologic repository site. Activities in support of this objective should include (a) obtaining laboratory measurements of rock properties (thermal, mechanical, chemical) for a range of potentially relevant shales; (b) establishing a more detalled understanding of the behavior of shales and their components under conditions of heat, stress, radiation, and moisture similar to those expected in a repository (this would also be relevant to understanding bentonite behavior under repository conditions); and (c) performing technical analyses to more precisely identify the desired shale characteristics (e.g., degree of induration, organic content).

3. Establish cooperation with shale (argillaceous rock) repository programs in other countries. Belgium, Japan, and Italy are considering shale and related rocks (clays) as repository host rocks. Information exchange and other cooperative programs and facilities would be mutually beneficial and would minimize duplication of effort. Such programs are supported by the Nuclear Waste Policy Act of 1982.

4. Examlue the polemllal role of shale in che DUE. The technical merits of shale and its widespread occurrence favor its consideration for the DOE geologic repository program. 
This page intentionally left blank 


\section{GLOSSARY}

Anhydrock

Carbonate rocks

Chalk

Containment

Discriminator

Depositional environment

DOE

Dolostone

$\underline{E P A}$

Far field

Indurated rock
A sedimentary rock that consists primarily of the mineral anhydrite, which is calcium sulfate $\left(\mathrm{CaSO}_{4}\right)$. Anhydrocks are normally found at depths greater than $100 \mathrm{~m}$ because the calcium sulfate hydrates to gypsum $\left(\mathrm{CaSO}_{4} \cdot 2 \mathrm{H}_{2} \mathrm{O}\right)$ at more shallow depths.

As defined here, a rock type that includes both limestone and dolostone. Limestone is a sedimentary rock that consists primarily of the mineral calcite $\left(\mathrm{CaCO}_{3}\right)$; dolostone is a rock consisting primarily of the mineral dolomite $\left[\mathrm{CaMg}\left(\mathrm{CO}_{3}\right)_{2}\right]$. Chalk is not included.

A variety of marine limestone (calcium carbonate, $\mathrm{CaCO}_{3}$ ) that is white to light gray, very fine grained, soft and friable, and composed largely of the calcitic remains of planktonic organisms.

The confinement of radioactive waste within a designated boundary.

A technical factor that constitutes a basis for applying a rock evaluation criterion to the evaluation of the rock types. The discriminators were derived from the favorable and potentially adverse conditions in the DOE siting guidelines, published as $10 \mathrm{CFR}$ Part 960 (CFR 1984). They are defined by boundaries of scientific disciplines and within a discipline by their broad technical concepts as applied to radioactive waste management.

The list of environmental conditions under which a particular rock unit was formed. These conditions relate well to the rock's characteristics.

The Department of Energy.

A term for a rock comprised primarily of the mineral dolomite.

Environmental protection Agency.

The far field primarily addresses the behavior of the surrounding rock.

Rock that has been consolidated and rendered hard by heat or pressure or cementation. 
Isolation

MTHM

Near field

NRC

Nuclear Waste Policy Act of 1982)

OCRWM

ORNL

Radionuclide

Rock evaluation criteria (REC)

Rock type

Sandstone

SERP

Shale
Inhibiting the transport of radioactive material so that the amounts and concentrations of this material entering the accessible environment will be kept within prescribed limits.

Metric tons of heavy metal, equivalent to $1000 \mathrm{~kg}$ of uranium metal in nonirradiated fuel.

The room and pillar system of the repository.

Nuclear Regulatory Commission.

An act that establishes a program of research, development, and demonstration and provides for the siting of two repositories for the disposal of highlevel radioactive waste and spent nuclear fuel.

The DOE's Office of Civilian Radioactive Waste Management.

Oak Ridge National Laboratory, Oak Ridge, Tennessee.

A radioactive isotope of an element. As used here, it may refer to (a) the isotope per se or (b) all (including stable) isotopes of an element, especially in the context of geochemistry.

Non-site-specific questions, derived from relevant siting guidelines, 10 CFR Part 960 (CFR 1984), that form the basis for evaluating and ranking the rock types with respect to their potential to serve as the host rock for a geologic repositoxy.

As used in this report, one of five categories of broadly related rocks (anhydrock, chalk, shale, carbonate rocks, and sandstone) defined elsewhere in this glossary. A rock type is roughly the same as a 1ithology.

A lithified aggregate of grains of minerals or rock fragments (detrital sediments) in which the average size of the grains ranges from 0.0625 to $2 \mathrm{~mm}$. Quartz is the predominant component of most sandstones, although many varieties of sandstones occur, depending on the binding materials and the mineralogic composition of grains.

The DOE Sedimentary Rock Program at ORNL.

An indurated, bedded, or laminated sedimentary rock containing a large proportion of clay minerals (more than $50 \%$ of the material smaller than $62 \mu \mathrm{m}$ ). 
Siting

guidelines

A statement by the DOE of policy or procedure for the recommendation of sites for repositories for the disposal of high-level radioactive waste and spent nuclear fuel in geologic formations as defined in $10 \mathrm{CFR}$ Part 960.

Very near field The very near field encompasses the waste package and the emplacement borehole as the primary area of investigation. 
This page intentionally left blank 


\section{REFERENCES}

ABEL 1975. J. F. Abel, Jr., and D. W. Gentry, Evaluation of Excavation Experience: Pierre Shale, ORNL/SUB-75/70345, 1975 .

CFR 1983. Code of Federal Regulations, 10 CFR Part 60, Fed. Regist. 48(120), 28194 (June 21, 1983).

CFR 1984. Code of Federal Regulations, 10 CFR Part 960, Fed. Regist. $49(236), 47714$ (Dec. 6, 1984).

CFR 1985. Code of Federal Regulations, 40 CFR Part 191, Fed. Regist. 50(182), 38066 (Sept. 19, 1985).

COBBS ENGINEERING 1975. Cobbs Engineering, study of Mined Storage Caverns, ORNL/SUB-75/64509, 1975.

DOE 1984a. U.S. Department of Fnergy, Mission Plan for the Civilian Radioactive Waste Management Program, Overview and Current Program Plans, Vols. I and II, DOE/RW-0005 (Draft), Apr. 1984.

DOE 1984b. U.S. Department of Energy, Draft Environmental Assessment for the Reference Repository Location, Hanford Site, Washington, DOE/RW-0017, Dec. 1984.

EPA 1982. U.S. Environmental Protection Agency, C. B. Smith, D. J. Egan, Jr., W. A. Williams, J. M. Gruhlke, C. Y. Hung, and B. L. Serini, Population Risks from Disposal of High-Level Radioactive Wastes in Geologic Repositories, EPA 520/3-80-006, 1982.

GOICOECHEA 1982. A. Goicoechea, D. Hansen, and L. Duckstein, MultiObjective Decision Analysis with Engineering and Business Applications. John Wiley and Sons, New York.

KRAUSE 1979. H. F. Krause, H. H. Damberger, W. J. Nelson, S. R. Hunt, C. T. Ledvina, C. G. Treworgy, and W. A. White, Roof Straca of the Herrin (No. 6) Coal Member in Mines of Illinois: Their Geology and Stability, I11. State Geol. Surv. I11. Miner. Notes 72, 1979.

KRUMHANSL 1979. J. L. Krumhansl and W. D. Sundberg, "The Conasauga Near-Surface Heater Experiment - Implications for a Repository Sited in a Water-Saturated Argillaceous Formation," Use of Argillaceous Materials for the Isolating of Radioactive Wastes, Proceedings of the NEA Workshop, Paris, France, September 10-12, 1979, pp. 129-38, 1979.

MCVEY 1979. D. F. McVey, A. R. Lappin, and R. K. Thomas, "Test Results and Supporting Analysis of a Near-Surface Heater Experiment in the Eleana Argillate," Use of Argillaceous Materials for the Isolating of Radioactive Wastes, Proceedings of the NEA Workshop, Paris, France, Seplember 10-12, 1979, pp. 93-113, 1979 . 
NIEMI 1976. R. G. Niemi and W. H. Riker, "The Choices of Voting Systems," Sci. Am. 236(6), 21-32 (June 1976).

ONWI 1983. Office of Nuclear Waste Isolation, Engineered Waste Package Conceptual Design: Defense High-Level Waste (Form 1), Commercial HighLevel Waste (Form 1), and Spent Fuel (Form 2) Disposal in Salt, ONWI-438, April 1983.

ONWI 1984. Office of Nuclear Waste Isolation, Performance Assessment Plans and Methods for the Salt Repository Project, BMI/ONWI-545, August 1984.

OWI 1978. Office of Waste Isolation, Technical Support for GEIS: Radioactive Waste Isolation in Geologic Formations, Vols. $1-23$, Y/OWI/TM-36/1-36/23, Union Carbide Corp. Nuclear Div., Oak Ridge, Tenn., 1978 .

PETTIJOHN 1957. F. J. Pettijohn, Sedimentary Rocks, Harper and Row, New York, 1957.

SLATE 1981. S. C. Slate, W. A. Ross, and W. L. Parton, Commercial High-Level Waste Glass and Canister Definitions, PNL-3838, Sept. 1981. 
APPENDIX A

ROCK EVALUATION CRITERIA AND DISCRIMINATORS GOVERNING THEIR APPLICATION TO ROCK EVALUATION

A. G. CROFF

R. S. LOWRIE

OAK RIDGE NATIONAL LABORATORY

P. O. BOX X

OAK RIDGE, TENNESSEE $3 / 831$ 
This page intentionally left blank 
CONTENTS

INTRODUCTION . . . . . . . . . . . 125

A.1 POSTCLOSURE REPOSTTORY PERFORMANCE RECS . . . . . . 126

A.1.1 SYSTEM GUIDELINES, 960.4-1........... 126

A.1.2 GEOHYDROLOGY, 960.4-2-1............. 126

A.1.3 GEOCHEMISTRY, 960.4-2-2.............. 126

A.1.4 ROCK CHARACTERISTICS, 960.4-2-3......... 126

A.1.5 ClimATIC CHANGES, 960.4-2-4......... 127

A.1.6 EROSION, 960.4-2-5.............. 127

A.1.7 DISSOLUTION, 960.4-2-6........... 127

A.1.8 TECTONICS, $960.4-2-7 . . . . . . . . . . .128$

A.1.9 NATURAL RESOURCES, 960.4-2-8-1......... 128

A.1.10 SITE OWNERSHIP AND CONTROL, 960.4-2-8-2. . . . 128

A.2 PRECLOSURE REPOSITORY PERFORMANCE RECS . . . . . . . 129

A.2.1 PRECLOSURE RADIOLOGICAL SAFETY RECS. . . . . . 129

A.2.1.1 System Guidelines, 960.5-1. . . . . . 129

A.2.1.2 Population Density and Distribution,

960.5-2-1................ 129

A.2.1.3 Site Ownership and Contro1, 960.5-2-2 . . 129

A.2.1.4 Meteorology, 960.5-2-3........ 130

A.2.1.5 Offsite Installations and Operations,

$960.5-2-4 . . . . . . .130$

A.2.2 ENVIRONMENTAL, SOCIOECONOMIC, AND TRANSPORTATION

RECS . . . . . . . . . . ... 130

A.2.2.1 Environmental Quality.960.5-2-5. . . 130

A.2.2.2 Socioeconomic Impacts, 960.5-2-6. . . 130

A.2.2.3 Transportation, 960.5-2-7........ 131

A.2.3 EASE AND COST OF CONSTRUCTION, OPERATION, AND

CLOSURE RECS .................. 131

A.2.3.1 Surface Conditions, 960.5-2-8..... 131

A.2.3.2 Rock Characteristics, 960.5-2-9.... 131

A.2.3.3 Hydrology, 960.5-2-10....... 132

A.2.3.4 Tectonics, 960.5-2-11........ 132

A.3 REFERENCES. . . . ............... 132 
This page intentionally left blank 
This appendix presents the rock evaluation criteria (RECs) used as a basis for evaluating and ranking the rock types that are the subject of this report. The RECs were derived from the siting guidelines given in CFR 10 Part 960 (CFR 1984). However, because the siting guidelines are for the purpose of screening sites, whereas the current objective of this program is to evaluate rocks on a generic (i.e., non-site-specific) basis, the RECs necessarily reflect the general intent of the siting guidelines rather than the site-specific details contained therein.

A single REC, in the form of a question, was developed for each of the system and technical guidelines contained in Sections 960.4 (Subpart C - Postclosure Guidelines) and 960.5 (Subpart D - Preclosure Guidelines) that could be addressed generically. Each REC is also accompanied by a list of one or more "discriminators," which are the aspects of the REC that will form the basis for its application and which led to identification of the specific information required for evaluation of the rock types.

The RECs/considerations are organized into two major groups corresponding to Sections 960.4 and 960.5 of the siting guidelines:

SECTION A.1 - POSTCLOSURE REPOSITORY PERFORMANCE, and

SECTION A.2 - PRECLOSURE REPOSITORY PERFORMANCE.

Section 960.3-1-5 of the siting guidelines states that the preclosure guidelines in Section 960.5 contain eleven technical guidelines separated into three subgroups relating to, in decreasing order of importance, (1) preclosure radiological safety; (2) environment, socioeconomics, and transportation; and (3) ease and cost of siting, construction, operation, and closure. In parallel with this, the preclosure RECs contained in Sect. A.2 of this document have been separated into the following three subgroups, in decreasing order of importance:

$$
\begin{aligned}
& \text { SECTION A.2.1 - PRECLOSURE RADIOLOGICAL SAFETY RECs; } \\
& \text { SECTION A.2.2 - ENVIRONMENTAL, SOCIOECONOMIC, AND TRANSPORTATION RECs; } \\
& \text { SECTION A.2.3 - EASE AND COST OF SITING, CONSTRUCTION, OPERATION, AND } \\
& \text { CLOSURE RECs. }
\end{aligned}
$$

In addition, Sect. 960.3-1-5 of the siting guidelines also states that ". - evaluations sha1l place primary significance on the postclosure guidelines and secondary significance on the preclosure guidelines. . ." To reflect their significantly greater importance, all the postclosure RECs in Sect. A.l will be weighted more heavily than those in Sect. A.2 during the rock evaluation.

It should be noted that in evaluating the rocks on a generic basis, several siting guidelines cannot be addressed because they require sitespecific information to do so. Consequently, only five of the guidelines in Sect. 960.4 and two of the guidelines in Sect. 960.5 are used in the rock evaluation. 


\section{A.1.1 SYSTEM GUIDELINE, 960.4-1}

Criterion: To what extent will the host rock favorably affect the ability of the repository to comply with the requirements set forth in 10 CFR Part 60 and 40 CFR Part 191?

\section{Discriminator:}

- Information about system performance, because it depends on the site-specific aspects of the repository, is not correlated with rock types. Therefore, this criterion is not useful in differentiating between rock types concerning their ability to accommodate a repository, and it will not be considered further.

\section{A.1.2 GEOHYDROLOGY, $960 \cdot 4-2-1$}

Criterion: To what extent do the expected geohydrologic characteristics of, and the processes operating within, the host rock favorably affect the expected postclosure performance of the repository?

\section{Discriminator:}

- The expected pre-waste-emplacement groundwater flow rates in the host rock.

\section{A.1.3 GEOCHEMISTRY, $960 \cdot 4-2-2$}

Criterion: To what extent do the expected geochemical characteristics of, and the processes operating within, the host rock favorably affect the expected postclosure performance of the repository?

\section{Discriminators:}

- The expected upper concentration limits for the nuclides of interest and adverse conditions that might increase these limits.

- The expected retardation factors for the nuclides of interest and adverse conditions that might decrease them.

- The extent to which the geochemical environment is reducing.

- The expected degradation rate of potential waste package metals in the geochemical environment of the repository.

\section{A.1.4 ROCK CHARACTERISTICS, 960.4-2-3}

Criterion: To what extent do the characteristics and properties of, and the physical processes operating within, the host rock favorably affect the performance of the repository? 


\section{Discriminators:}

- The expected number of host rock formations of sufficient thickness and lateral extent to permit flexibility in selecting the depth, location, and configuration of the underground facility.

- The expected ability of the host rock and the surrounding geologic units to transfer decay heat.

- The ductility of the host rock (related to the ability of the rock to seal fractures induced by expected thermal, mechanical, or chemical activities or processes).

- The stability of the host rock under projected postclosure conditions.

\section{A.1.5 CLIMATIC CHANGES, 960.4-2-4}

Criterion: To what extent will future climatic changes/cycles correlated with typical host rock geohydrology affect repository performance?

\section{Discriminator:}

- Information about future climatic changes/cycles, because it applies to specific regions, areas, or sites, is not correlated with rock type. Therefore, this criterion is not useful in differentiating between rock types as to their generic suitability to accommodate a repository, and this criterion will not be considered further.

A.1.6 EROSION, $960.4-2-5$

Criterion: To what extent can erosion of the geologic units surrounding the host rock horizon affect repository performance?

\section{Discriminator:}

- Information about future erosion changes/cycles, because it applies to specific regions, areas, or sites, is not correlated with rock type. Therefore, this criterion is not useful in differentiating between rock types as to their generic suitability to accommodate a repository, and this criterion will not be considered further.

A.1.7 DISSOLUTION, $960.4-2-6$

Criterion: To what extent will dissolution processes operating in the host rock horizon affect repository performance?

Discrimillalur:

- The extent to which the host rock can dissolve in groundwater. 
A.1.8 TECTONICS, $960.4-2-7$

Criterion: To what extent does the host rock tend not to be associated with areas of sufficient tectonic activity/magnitude so that postclosure repository performance could be affected?

\section{Discriminator:}

- Information about future tectonic activity, because it applies to specific regions, areas, or sites, is not correlated with rock type. Therefore, this criterion is not useful in differentiating between rock types concerning their suitability to accommodate a repository, and it will not be considered further.

A.1.9 NATURAL RESOURCES, 960.4-2-8-1

Criterion: To what extent does the host rock tend to be associated with natural resources?

Discriminator:

- The extent to which the host rock is typically associated with valuable resources.

A.1.10 SITE OWNERSHIP AND CONTROL, 960.4-2-8-2

Criterion: To what extent are occurrences of the host rock located in areas where DOE can obtain ownership and control?

\section{Discriminator:}

- Information about site ownership and control, because it applies to specific regions, areas, or sites, is not correlated with rock Lype. Therefore, this cricerion is not useful in difterentiating between rock types concerning their suitability to accommodate a repository, and it will not be considered further. 


\section{A.2 PRECLOSURE REPOSITORY PERFORMANCE RECs}

\section{A.2.1 PRECLOSURE RADIOLOGICAL SAFETY RECS}

A.2.1.1 System Guidelines, $960.5-1$

Criterion: To what extent will the host rock occurrences tend to be located in sites that will favorably affect the ability of the repository to comply with applicable regulations concerning preclosure radiological safety and the protection of environmental quality and socioeconomic welfare (including transportation impacts) and to what extent can a repository in the host rock be couscructed, operated, and closed using reasonably available technology and in a simpler, more cost-effective manner than in other host rocks?

\section{Discriminator:}

- Information about system performance, because it depends on the sice-specific aspects of the repostlory, is ul currelaled with rock types. Therefore, this criterion is not useful in differentiating between rock types concerning their ability to accommodate a repository, and it will not be considered further.

\section{A.2.1.2 Population Density and Distribution, 960.5-2-1}

Criterion: To what extent do occurrences of the host rock tend to be located in areas where limitations on population density will significantly affect the ability to identify a site?

\section{Discriminator:}

- Information about population density and distribution, because it applies cu specific legions, areas, or sites, is not correlated with rock types and is not useful in differentiating between rock types concerning their ability to accommodate a repository. This criterion will not be considered further.

\section{A.2.1.3 Site Ownership and Control, 960.5-2-2}

Crilerion: To what exceul do occurrences of the host rock tend to be located in areas where obtaining DOE ownership and control of the 1 and for a repository site may be difficult?

\section{Discriminator:}

- Information about site ownership and control, because it applies to specific regions, areas, or sites, is not correlated with rock types and is not useful in differentiating between rock types concerning their ability to accommodate a repository. This criterion will not be considered further. 
A.2.1.4 Meteorology, 960.5-2-3

Criterion: To what extent do occurrences of the host rock tend to be located in sites where meteorologic conditions will mitigate the impact of radionuclide releases to the environment?

\section{Discriminator:}

- Infornation about meteorology, because it applies to specific regions, areas, or sites, is not correlated with rock type. Therefore, this criterion is not useful in differentiating between rock types concerning their ability to accommodate a repository, and it will not be considered further.

\section{A.2.1.5 Offsite Installations and Operations, 960.5-2-4}

Criterion: To what extent do occurrences of the host rock tend to be located in areas where repository construction, operation, and closure will not seriously be impacted by nearby industrial. transportation, and military installations?

\section{Discriminator:}

- Information about offsite installations and operations, because it applies to specific regions, areas, or sites, is not correlated with rock type. Therefore, this criterion is not useful in differentiating between rock types concerning their ability to accommodate a repository, and it will not be considered further.

\section{A.2.2 ENVIRONMENTAL, SOCIOECONOMIC, AND TRANSPORTATION RECs}

\section{A.2.2.1 Environmental Quality, 960.5-2-5}

Criterion: To what degree do occurrences of the host rock tend to be located so as to mitigate adverse impacts to the health and welfare of the public and to environmental quality during the construction, operation, and clusure of the reposilory?

\section{Discriminator:}

- Information about environmental quality, because it applies to specific regions, areas, or sites, is not correlated with rock type. Therefore, this criterion is not useful in differentiating between rock types concerning their ability to accommodate a repository, and it will not be considered further.

\section{A.2.2.2 Socioeconomic Impacts, 960.5-2-6}

Criterion: To what degree do occurrences of the host rock tend to be located such that the adverse socioeconomic impacts resulting from the construction, operation, and closure of the repositury can be mitigated? 


\section{Discriminator:}

- Information about socioeconomic impacts, because it applies to specific regions, areas, or sites, is not correlated with rock type. Therefore, this criterion is not useful in differentiating between rock types concerning their ability to accommodate a repository, and it will not be considered further.

\section{A.2.2.3 Transportation, 960.5-2-7}

Criterion: To what extent do the locations of host rock occurrences mitigate the impacts of radioactive waste transportation on the environment or the risk to the public?

\section{Discriminator:}

- Information about transportation, because it applies to specific regions, areas, or sites, is not correlated with rock type. Therefore, this criterion is not useful in differentiating between rock types concerning their ability to accomodate a repository, and it will not be considered further.

\section{A.2.3 EASE AND COST OF CONSTRUCTION, OPERATION, AND CLOSURE RECS}

\section{A.2.3.1 Surface Conditions, $960.5-2-8$}

Criterion: To what extent do the locations of host rock occurrences provide favorable surface characteristics (e.g., surface water, terrain) for a repository?

\section{Discriminator:}

- Information about surface conditions, because it applies to sperifir regions, areas, or sites, is not correlated with rock typos. Therefore, this criterion is not useful in differentiating between rock types concerning their ability to accommodate a repository, and it will not be considered further.

\section{A.2.3.2 Rock Characteristics, 960.5-2-9}

Criterion: To what extent do the host rock characteristics and properties provide for the safe construction, operation, and closure of a repository at the depths of interest?

\section{Discriminators:}

- The expected number of host rock formations of sufficient thickness and lateral extent to permit flexibility in selecting the depth, location, and configuration of the underground facilities.

- The expected constructibility of a repository in the host rock.

- The expected operational stability of a repository in the host rock. 


\section{A.2.3.3 Hydrology, $960.5-2-10$}

Criterion: To what extent are the geohydrologic properties and characteristics of the host rock compatible with the activities required to construct, operate, and close a repository?

\section{Discriminator:}

- The rate at which water is expected to flow into mined openings during construction and operation.

\section{A.2.3.4 Tectonics, $960.5-2-11$}

Criterion: To what extent does the host rock tend not to be associated with areas of sufficient tectonic activity/magnitude so that preclosure repository performance could be affected?

\section{Discriminator:}

- Information about futurc tcctonic activity, bccauoc it applico to specific regions, areas, or sites, is not correlated with rock type. Therefore, this criterion is not useful in differentiating between rock types concerning their suitability to accommodate a repository, and it will not be considered further.

\section{A. 3 REFERENCES}

CFR 1984. Code of Federal Regulations, 10 CFR Part 960, Fed. Regist., 49, (236) 47714 (Dec. 6, 1984). 
APPENDIX B

BASELINE/REFERENCE INFORMATION FOR THE SEDIMENTARY ROCK PROGRAM

A. G. CROFF

R. S. LOWRIE

OAK RIDGE NATIONAL LABORATORY

P. O. BOX X

OAK RIDCE, TENNESSEE 37831 
This page intentionally left blank 
CONTENTS

Page

INTRODUCTION . . . . . . . . . . . . . . . . . . 137

B.1 WASTE FORM-WASTE PACKAGE INFORMATION. . . . . . . . . . . 137

B.1.1 CONSOLIDATED PWR AND BWR FUEL ELEMENTS . . . . . . 137

B.1.2 COMMERCIAL HIGH-LEVEL WASTE. ............. 137

B.2 REFERENCE REPOSITORY DESCRIPTION. . . . . . . . . . . . 141

B.2.1 LAYOUT OF REPOSITORY .................. . . 141

B.2.1.1 Surface Facilities. . . . . . . . 141

B.2.1.2 Shafts................. 141

B.2.1.3 Underground Configuration .......... 141

B.2.2 REPOSITORY OPERATIUNS. . . . . . . . . . . . 141

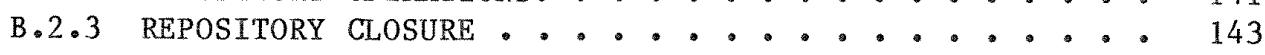

B.3 GEOLOGTC DATA . . . . . . . . . . . . . . . . . . . 144

B.4 REFERENCES. . . . . . . . . . . . . . . . . . . 144 
This page intentionally left blank 


\section{INTRODUCTION}

The primary objective of this report is to evaluate the potential of five sedimentary rock types - specifically, shale, carbonates (1imestone/ dolostone), sandstone, chalk, and anhydrock - to serve as the host rock for a geologic repository and to rank them in order of suitability. For the ranking to be valid, the same baseline/reference information must be used in the evaluation of each rock type. Information of this type falls into three categories: (1) nature and characteristics of the waste form-waste package to be placed in the repository; (2) nature and characteristics of the repository, such as its capacity and depth; and (3) since the evaluation of the rocks is to be non-site-specific, generic vertical rock sections needed for some of the studies that are typical of those associated with the specified rock types.

\section{B.1 WASTE FORM-WASTE PACKAGE INFORMATION}

A repository in any one of the rock types may handle waste in the form of (1) intact spent-fuel assemblies from pressurized-water reactors (PWRs) and boiling-water reactors (BWRs), (2) consolidated PWR and BWR spent fuel elements, (3) commercial high-level waste (CHLW), and (4) defense highlevel waste. This report considers only consolidated PWR fuel elements and CHLW since these two offer the desired diversity while resulting in a worst-case (highest temperatures, stresses, etc.) analysis.

\section{B.1.1 CONSOLIDATED PWR AND BWR FUEL ELEMENTS}

It will likely be desirable to remove the individual fuel elements from the spent fuel assembly and consolidate the elements from several assemblies in a single canister. Table B.l gives the characteristics of intact fuel assemblies, and Table B.2 lists the characteristics of typical spent fuel elements. We have assumed that intact fuel assemblies will be received at the repository and that the elements will be pulled and placed in a canister in the repository surface facilities. We have chusen to use the reference spent fuel package developed for the salt repository program (see Fig. B.1) as the reference consolidated spent fuel package for the Sedimentary Rock Program (ONWI 1983). This package will hold the rods from 6 PWR assemblies (1548 rods) or 18 BWR assemblies ( 1134 rods) and is quite similar to packages under development for use in tuff or basalt. The actual material of construction and final configuration will depend on the behavior of the rock types as we11 as the environment in the borehole. In any case, the design will necessarily meet the requirements of 10 CFR 60.113 (CFR 1983).

\section{B. 1.2 COMMERCIAL HIGH-LEVEL WASTE}

The waste form for CHLW is a borosilicate glass (SLATE 1981). Table B.3 lists the CHLW characteristics. Figure B.2 shows the reference cIllw canistex, which is made of $304 \mathrm{~L}$ stainless sleel. The veluaviul of the rock, as well as the borehole environment, will determine both the need for an overpack and its material of construction. 
Table B.1. Characteristics of spent fuel assemblies

\begin{tabular}{|c|c|c|}
\hline Characteristic & PWR & BWR \\
\hline \multicolumn{3}{|l|}{ Mechanical characteristics } \\
\hline $\begin{array}{l}\text { Overal1 length range, in. } \\
\text { Width (square), in. }\end{array}$ & $\begin{array}{l}149-186 \\
8.1-8.5\end{array}$ & $\begin{array}{r}84-179 \\
4.3-6.5\end{array}$ \\
\hline $\begin{array}{l}\text { Number of fuel elements per assembly } \\
\text { Fuel element diameter, in. } \\
\text { Fuel element length, in. } \\
\text { Element pitch, in. }\end{array}$ & $\begin{array}{c}100-264 \\
0.360-0.440 \\
91.5-171 \\
0.496-0.580\end{array}$ & $\begin{array}{c}48-81 \\
0.483-0.570 \\
80.5-165 \\
0.640-0.842\end{array}$ \\
\hline Heavy metal content per assembly, MTHMa & $0.11-0.52$ & $0.19-0.20$ \\
\hline Assembly weight, $1 \mathrm{~b}$ & $1280-1450$ & 600 \\
\hline \multicolumn{3}{|l|}{ I'ypical characteristics as received } \\
\hline Age out of reactor & 5 years & 5 years \\
\hline Burnup (average conditions), MWd $\mathrm{b} / \mathrm{MTHM}$ & 33,000 & 27,500 \\
\hline Actinides and daughters, Ci/MTHM & 104,000 & 93,000 \\
\hline Fission products, Ci/MTHM & 453,000 & 365,000 \\
\hline Decay heat, W/MTHM & 1,800 & 1,400 \\
\hline Photon release, photons/s.MTHM & $1.3 \times 10^{16}$ & $1.0 \times 10^{16}$ \\
\hline Photon energy release, MeV/s •MTHM & $4.8 \times 10^{15}$ & $3.6 \times 10^{15}$ \\
\hline Burnup (high condition), MWd/MTHM & 50,000 & \\
\hline Actinides and daughters, Ci/MTHM & 155,000 & \\
\hline Fission products, Ci/MTHM & 640,000 & \\
\hline vecay heat, w/MrHM & 2,800 & \\
\hline Photon release, photons/s •MTHM & $1.9 \times 10^{16}$ & \\
\hline Photon energy release, MeV/s •MTHM & $7.3 \times 10^{15}$ & \\
\hline Age out of reactor & 10 years & 10 years \\
\hline Burnup (average conditions), MWd/MTHM & 33,000 & 27,500 \\
\hline Actinides and daughters, Ci/MTHM & 83,000 & 75,000 \\
\hline Fission products, Ci/MTHM & 302,000 & 249,000 \\
\hline Decay heat, W/MTHM & 1,100 & 900 \\
\hline Photon release, photons/s.MTHM & $7.7 \times 10^{15}$ & $6.2 \times 10^{15}$ \\
\hline Photon energy release, MeV/s •MTHM & $2.6 \times 10^{15}$ & $2.0 \times 10^{15}$ \\
\hline Burnup (high condition), MWd/MTHM & 50,000 & \\
\hline Actinides and daughters, Ci/MTHM & 124,000 & \\
\hline Fission products, Ci/MTHM & 442,000 & \\
\hline Decay heat, W/MTHM & 1,800 & \\
\hline Photon release, photons/s.MTHM & $1.1 \times 10^{16}$ & \\
\hline Photon energy release, MeV/s.MTHM & $3.8 \times 10^{15}$ & \\
\hline
\end{tabular}

$a_{\text {MTHM }}=$ metric tons of heavy metal. $\quad b_{\text {MWd }}=$ megawatt-days. 
Table B.2. Characteristics of spent fuel elementsa

\begin{tabular}{|c|c|c|}
\hline Characteristic & PWR & BWR \\
\hline Diameter, mm & 9.5 & 12.52 \\
\hline Length, m & 3.85 & 4.1 \\
\hline Weight of uranium per element, $\mathrm{kg}$ & 1.75 & 3.0 \\
\hline Thermal conductivity, $\mathrm{W} / \mathrm{m} \cdot \mathrm{K}$ & 5.5 & 5.5 \\
\hline specific heat, $\mathrm{J} / \mathrm{kg} \cdot \mathrm{K}$ & 264 & 264 \\
\hline Heat generation per element, ${ }^{b} \mathrm{~W}$ & 2.08 & 3.02 \\
\hline Emplacement limiting tompcrature, ${ }^{\circ} \mathrm{C}$ & 375 & 375 \\
\hline Leach rate, $\mathrm{g} / \mathrm{cm}^{2} \cdot \mathrm{d}$ & $10^{-5}$ & $10^{-5}$ \\
\hline Average fuel burnup, MWd/MTHM & 33.000 & 27,000 \\
\hline Radioactivity content; ${ }^{\mathrm{b}} \mathrm{Ci}$ & 1,515 & 952 \\
\hline
\end{tabular}

ORNL OWO $84-1257$

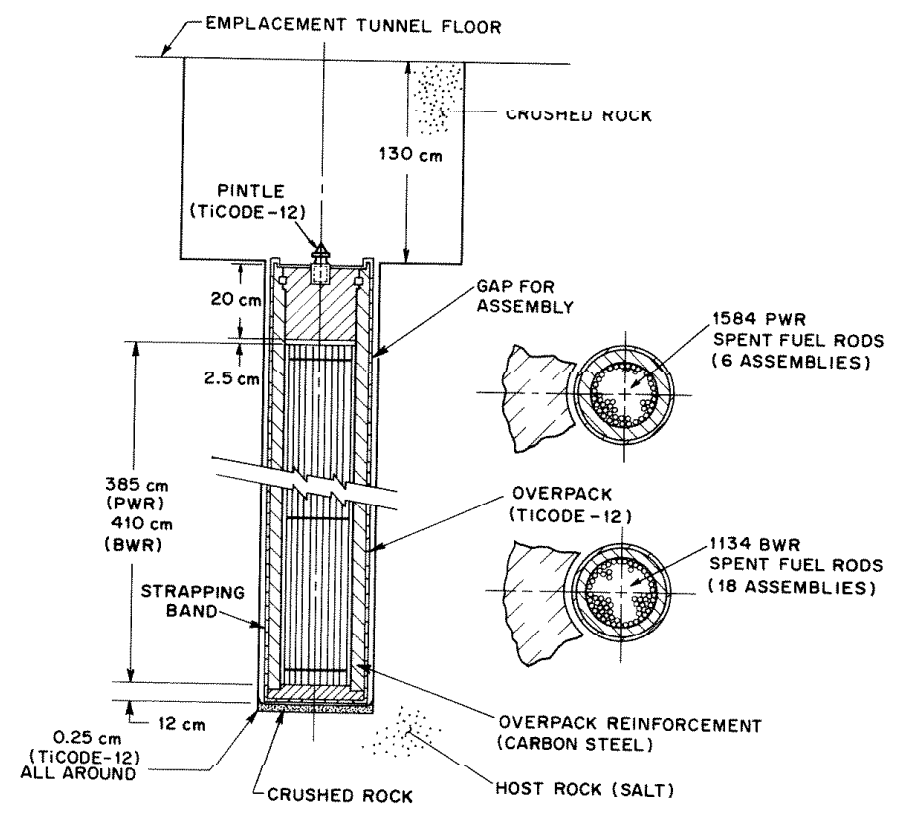

Fig. B.1. Reference spent fuel package for borehole emplacement. Source: ONWI 1983. 
Table B.3. CHLW characteristics

\begin{tabular}{|c|c|}
\hline $\begin{aligned} \text { Canister dimensions: } & \text { Diameter, m } \\
& \text { Length, } \mathrm{m}\end{aligned}$ & $\begin{array}{l}0.324 \\
3.0\end{array}$ \\
\hline Thermal conductivity of glass, ${ }^{\mathrm{a}} \mathrm{W} / \mathrm{m} \cdot \mathrm{K}$ & $0.8-1.3$ \\
\hline Specified heat of glass, J/kg.K & $700-800$ \\
\hline Density of glass, $\mathrm{g} / \mathrm{cm}^{3}$ & 3.1 \\
\hline Maximum heat output of canister at emplacement, $\mathrm{kW}$ & 2.2 \\
\hline Limiting glass temperature during package design life, ${ }^{\circ}{ }^{\circ} \mathrm{C}$ & 500 \\
\hline Limiting glass temperature afterpackage design 1 ife, ${ }^{\circ} \mathrm{C}$ & 100 \\
\hline Total weight of glass, $\mathrm{kg}$ & 595 \\
\hline Total weight of waste form, $\mathrm{kg}$ & 845 \\
\hline Radioactivity content of canister, $\mathrm{Ci}$ & $6.58 \times 10^{5}$ \\
\hline Active glass volume of canister, $\mathrm{m}^{3}$ & 0.19 \\
\hline
\end{tabular}

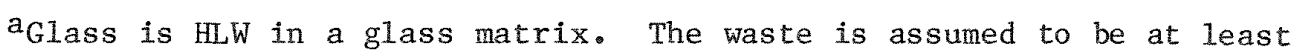
10 years out of reactor.

bThis limit represents the glass softening point beyond which glass devitrification is possible.

ORNL OWG 84-1259

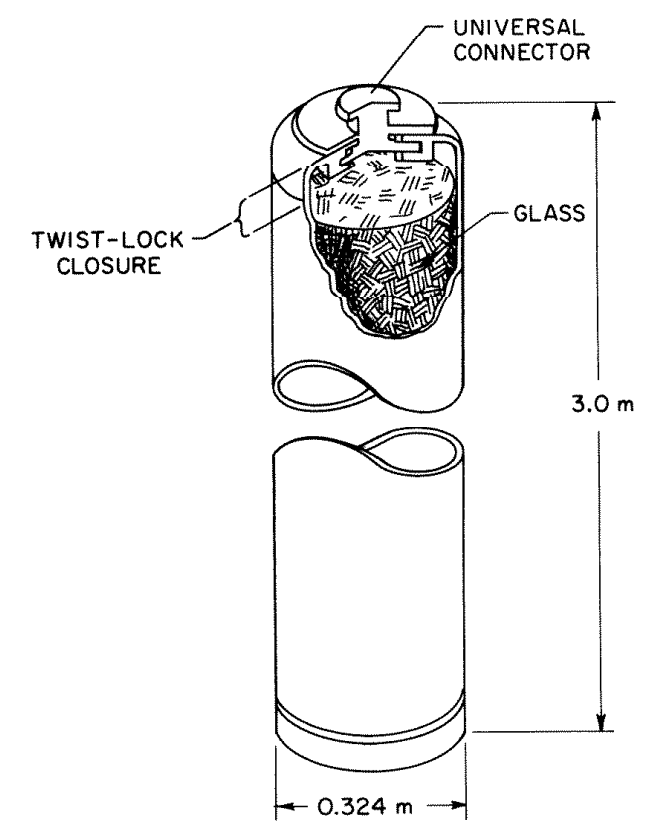

Fig. B.2. Reference commercial high-level waste canister. Source: ONWI 1983. 


\section{B.2 REFERENCE REPOSITORY DESCRIPTION}

The reference repository information presented here provides the generic background information to be used in calculating the engineering, design, construction, operation, closure, and costing aspects of deve1oping a geologic repository in each of the five rock types. Consequently, much of the information is descriptive. However, wherever possible, it uses ideas, concepts, and methods developed by other waste disposal projects, such as salt and tuff.

\section{B.2.1 LAYOUT OF REPOSITORY}

A geologic reposilory cau be described as consisting of three ele-ments: (1) surface facilities to receive, monitor, handle, and store the waste packages; (2) underground facilities in which the waste packages are emplaced: and (3) the shafts connecting them. Figure B.3 shows a schematic view of a conceptual repository. The repository will be sized to provide the space to permanently dispose of 70,000 metric tons of heavy metal (MTHM). It will be capable of receiving 3000 MTHM per year. The deptli of llie undesgruund facilities should range from a minimum of $300 \mathrm{~m}$ to a maximum of $\sim 1000 \mathrm{~m}$.

\section{B.2.1.1 Surface Facilities}

The surface facilities to receive, monitor, and store the waste, as well as those providing necessary support, are essentially the same regardless of the type of rock. Therefore, design and cost data deve1oped for a similarly sized repository by other geologic disposal projects can be utilized for rock evaluation purposes.

\section{B.2.1.2 Shafts}

The design of the shafts connecting the underground facilities with lie surface facilicies is dependent on the characteristics of both the host rock and the surrounding geologic media and will have to be worked out using a typical vertical rock section associated with the host rock. However, cost estimates can utilize information developed by other geologic disposal projects.

\section{B.2.1.3 Underground Configuration}

Waste packages will be emplaced in boreholes drilled in the floor of the underground waste disposal rooms as shown in Fig. B.4. The waste forms to be emplaced were described previously. The size and heat release data, together with the thermal and geomechanical characteristics of the host rock, will determine the actual design and extent of the underground facilities, as well as the minimum vertical thickness of the host rock formation. The geochemical environment expected in the boreholes will determine the design and material used for the overpack, if required.

\section{B.2.2 REPOSITORY OPERATIONS}

The repository will be assumed to operate $5 \mathrm{~d}$ per week, $24 \mathrm{~h}$ per day, 52 weeks per year. Waste will be received via rail or truck, 


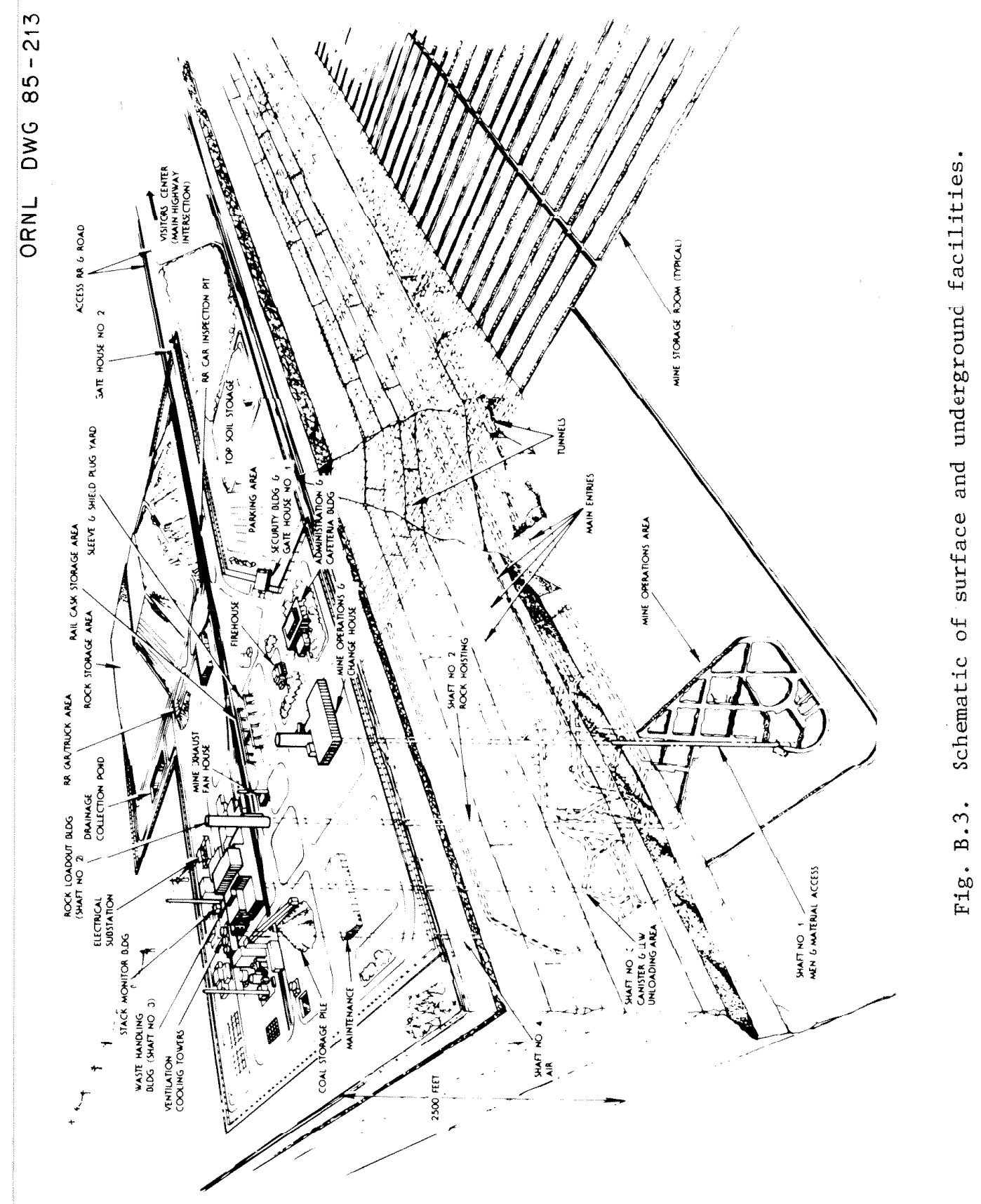


ORNL DWG $84-1256$

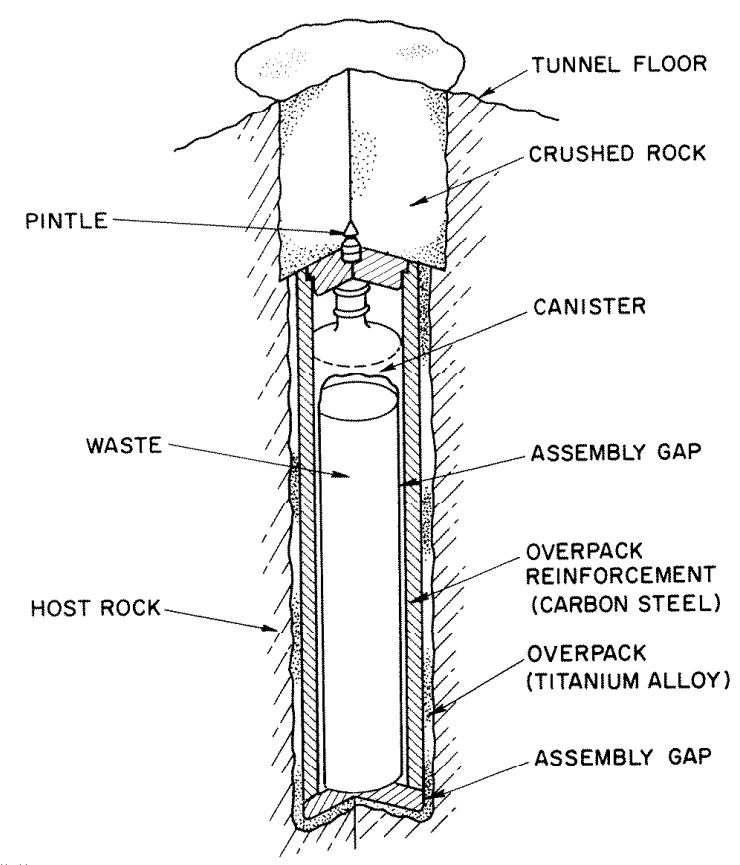

Fig. B.4. Generic waste package design

for emplacement in boreholes. Source: ONWI 1983.

inspected, stored (if necessary), packaged, lowered into the underground facilities, transported to the disposal room, and emplaced in the boreholes in the floor. Operations involving the development of new disposal rooms will be separated and isolated from the wasle lumdling uperations. Provisions will be made to hoist the excavated rock to the surface, store it, and later return it to the underground workings as backfill. In addition, the necessary health physics, security, administrative, and other supporting activities will be provided. It is assumed that dedicated facilities will be provided for all operations that involve the handling of radioactive waste.

\section{B.2.3 REPOSITORY CLOSURE}

Although procedures for closing a repository are very site-dependent, a generic outline for closure, useful for estimating effort and cost, will be employed. Basically, the underground openings will be backfilled with a host rock/bentonite mixture, any final engineered barriers installed, the shafts sealed and backfilled, and the surface facilities decontaminated and decommissioned. 


\section{B.3 GEOLOGIC DATA}

Typical generic stratigraphic sections for the five rock types considered herein are presented in Figs. B.5-B.9. They are intended to be representative of existing occurrences of the rock types that might be considered for siting a geologic repository so that data from similar actual rock formations can be utilized in the hydrologic, rock mechanito be at depth analyses. Note that the repository horizon is assumed mechanical mechanical, thermal, and hydrologic studies.

\section{B.4 REFERENCES}

CFR 1983. Title 10, Part 60 of the Code of Federal Rogulationo, Fed. Regist. 48(120), 28194 (June 21, 1983).

ONWI 1983. Office of Nuclear Waste Isolation, Englneered Waste Package Conceptual Dcaign: Derense H1gh-Level Waste (Form 1), Commercial HighLevel Waste (Form 1), and Spent Fuel (Form 2) Disposal in Salt,

SLATE 1981. S. C. Slate, W. A. Ross, and W. L. Parton, Commercial High-Level Waste Glass and Canister Definitions, PNL-3838, Pacific Northwest Laboratory, September 1981 .

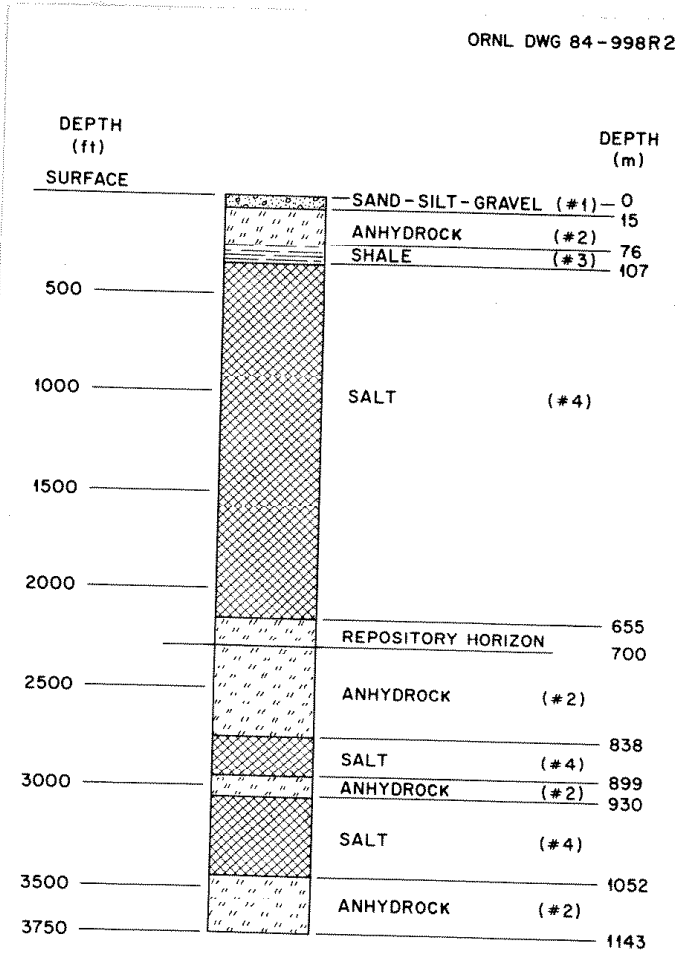

Fig. B.5. Typical stratigraphic section: anhydrock.

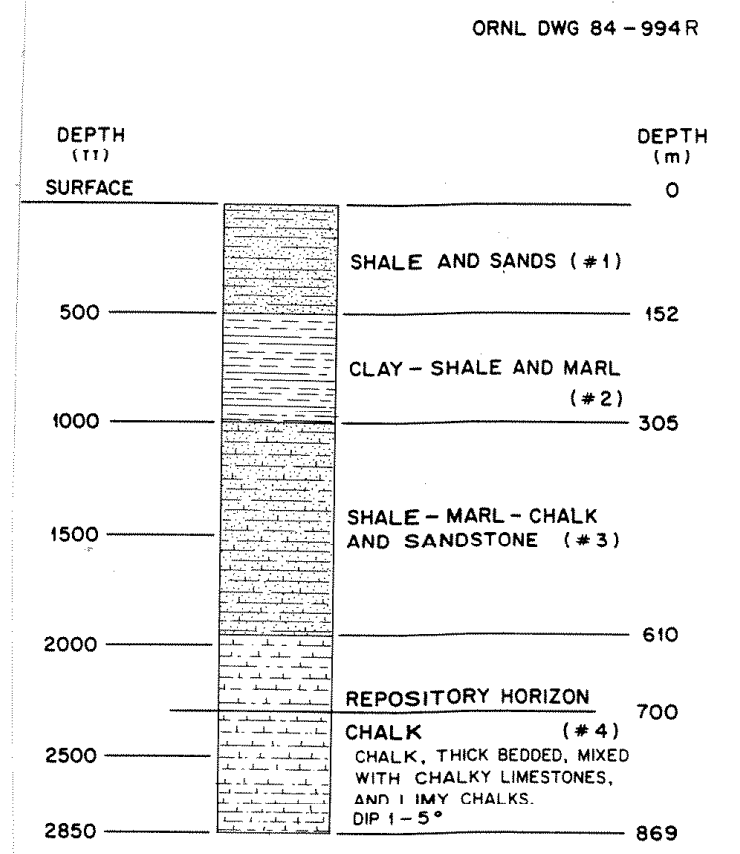

Fig. B.6. Typical otratigraphic section: chalk. 
ORNL DWG 84-996R2

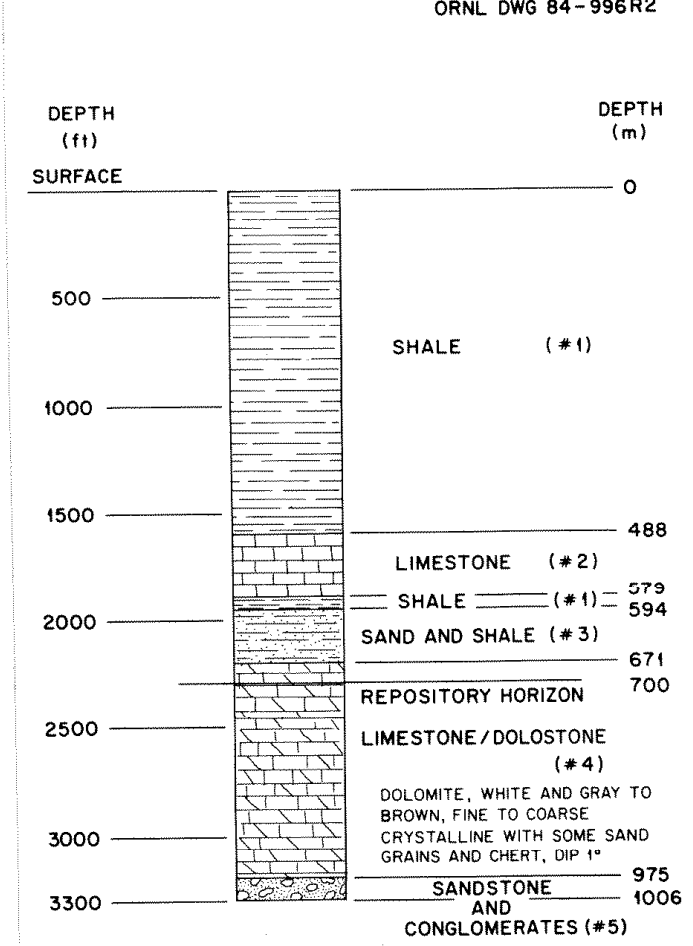

Fig. B.7. Typical stratigraphic section: limestone.
ORNL DWG 84-997R

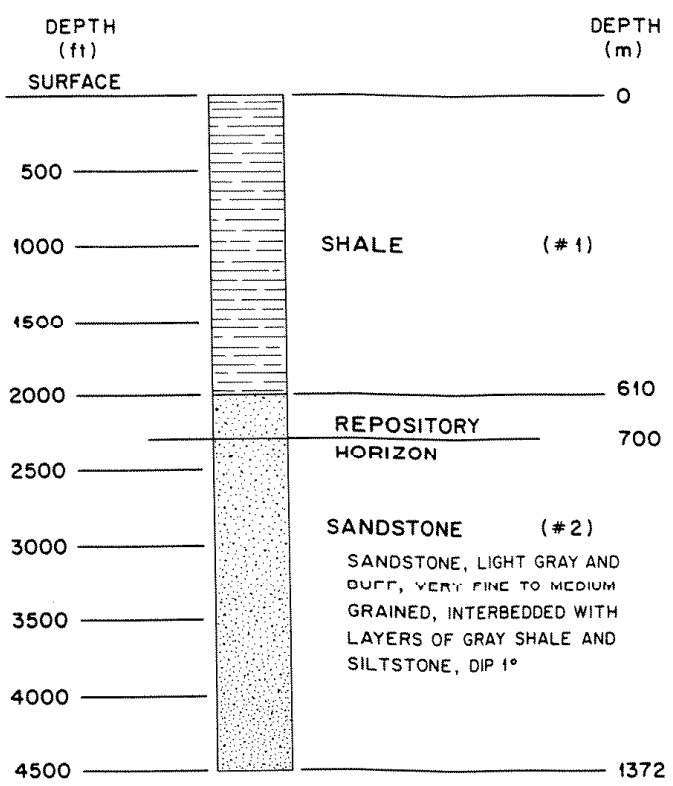

Fig. B.8. Typical stratigraphic section: sandstone.

ORNL OWG $84-995 R$

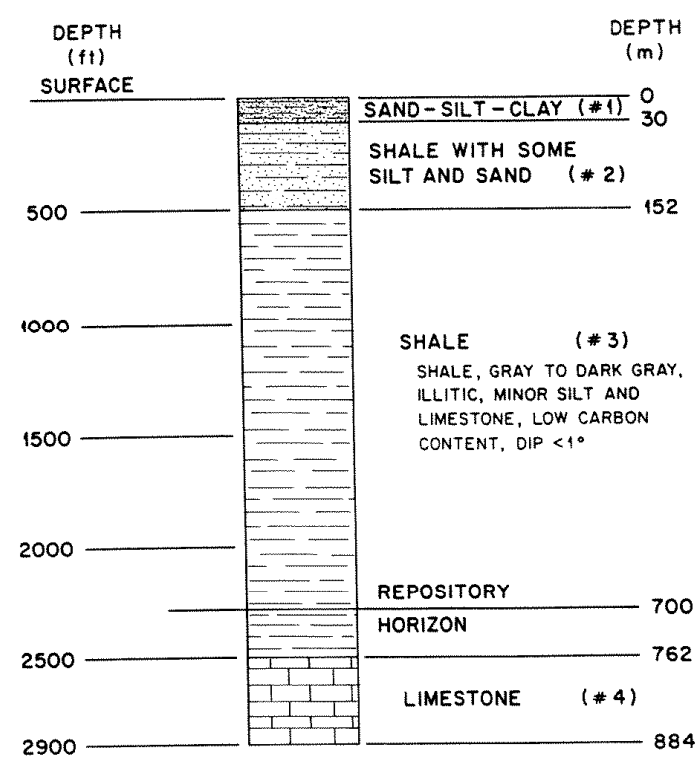

Fig. B.9. Typical stratigraphic section: shale. 


\title{
Evaluation of Five Sedimentary Rocks Other than Salt for Geologic Repository Siting Purposes
}

\author{
Volume 2: Appendixes C through $\mathrm{E}$
}

\section{November 2003}

Prepared by

A. G. Croff

T. F. Lomenick

R. S. Lowrie

S. H. Stow

OFFICIAL USE ONLY

May be exempt from public release under the Freedom of Information Act (5 U.S.C. 552), exemption number and category:

Exemption 5 - Privileged Information

Department of Energy review required before public release

Name/Org: Allen G. Croff, ORNL Date: October 10, 2003

Guidance (if applicable) 
EVALUATION OF FIVE SEDIMENTARY ROCKS

OTHER THAN SALT FOR GEOLOGIC REPOSITORY SITING PURPOSES

VOLUME 2: APPENDIXES C THROUGH E

\author{
A. G. Croff \\ T. F. Lomenick \\ R. S. Lowrie \\ S. H. Stow \\ Date Published: November 2003 \\ PREPARED FOR THE \\ UNITED STATES DEPARTMENT OF ENERGY \\ OFFICE OF CIVILIAN RADIOACTIVE WASTE MANAGEMENT

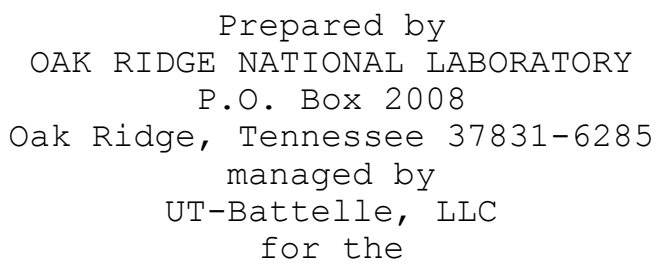


This page intentionally left blank 


\section{CONTENTS}

\section{VOLUME 2}

APPENDIX C HYDROLOGIC EVALUATION AND RANKING OF FIVE SEDTMENTARY ROCK TYPES AS POTENTIAL HOST ROCKS FOR DEEP GEOLOGIC REPOSITORIES. . . . . . . . . 1

APPENDIX D GEOCHEMISTRY OF SEDIMENTARY ROCKS RELEVANT TO REPOSITORY SITING ................. 117

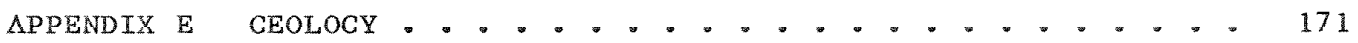

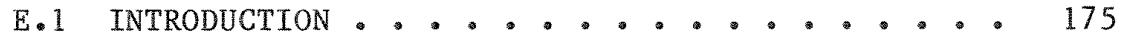

E.2 GEOLOGIC CHARACTERISTICS OF SHALE. . . . . . 179

E.3 GEOLOGIC CHARACTERISTTCS OF SANDSTONE DEPOSITS - 257

E.4 GEOLOGIC CHARACTERISTICS OF CHALR. . . . . . 377

E.5 GEOLOGIC CHARACTERIZATION OF CARBONATE ROCKS . 493

E.6 GEOLOGIC CHARACTERIZATION OF ANHYDROCK . . . . 541

E.7 SUMMARY........................ 575 
This page intentionally left blank 
APPENDIX C

HYDROLOGIC EVALUATION AND RANKING OF FIVE SEDIMENTARY ROCK TYPES AS POTENTIAL HOST ROCKS FOR DEEP GEOLOGIC REPOSITORIES

BERKELEY GEOSCIENCES ASSOCIATES

2150 SHATTUCK AVENUE

BERRELEY, CALIFORNTA 94704 
This page intentionally left blank 


\section{ABSTRACT}

A preliminary hydrologic evaluation and ranking of five sedimentary rock types as potential host rocks for deep geologic disposal of highlevel nuclear waste was performed. The rock types considered are anhydrock, chalk, carbonate rocks (limestone and dolostone), sandstone and shale. Ranking criteria were selected on the basis of technical requirements and responsiveness to existing regulatory guidelines. The criteria selected were pre-waste-emplacement groundwater travel time for postclosure conditions and groundwater inflow into the repository for preclosure conditions. In keeping with the guidelines, the postclosure criterion is given greater weight than the preclosure criterion.

Analyses for evaluation of travel times and inflows were performed using numerical modeling techniques for five reference sites. The reference sites were developed from reference geologic cross sections designed to reflect typical occurrences of the five rock types. A data base of hydrologic parameters necessary to the analyses was developed from the existing literature. On1y those subsets of each of the rock types that might reasonably be considered tor repository application were considered.

The ranking of the five rock types on the basis of the analysis for groundwater travel time is: (1) shale; (2) anhydrock; (3) sandstone; (4) chalk; and (5) carbonate rocks. The ranking on the basis of groundwater inflow is: (1) anhydrock; (2) shale; (3) sandstone; (4) chalk; and (5) carbonate rocks. In both cases there is a significant gap between the top three and last two rock types. The overall ranking, primarily based on the weighting attached to the postclosure criterion, is: (1) shale; (2) anhydrock; (3) sandstone; (4) chalk; and (5) carbonate rocks.

Finally, in recognition of the potential hydrologic impact of thermal loading, preliminary analyses of thermally induced buoyancy were performed for the three top ranked rock types. These analyses are not directly considered in the ranking because of the greater uncertainties associated with the necessary additional data base and because groundwater travel time is believed to be more responsive to the existing regulatory guide1ines. While very preliminary, the results of the thermal analyses would not change the ranking order. 
This page intentionally left blank 
ABSTRACT ............................... 3

C.1. INTRODUCTION ....................... 13

C.1.1 OBJECTIVE . . . .................... 13

C.1.2 SCOPE AND ORGANTZATION ............. 13

C.2. RANKING METHODOLOGY . . . . . . . . . . . . 15

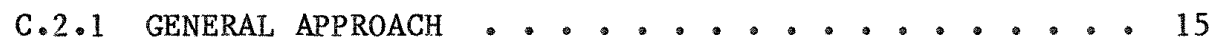

C.2.1.1 Existing Guidelines . . . . . . . 15

C.2.2 RANKING CRITERIA ................. 16

C.2.2.1 Postclosure ............. 16

C.2.2.2 Preclosure .............. 17

C.2.3 OTHER CONSIDERATTONS . . . . . . . . . . . . . 17

C.2.4 IMPLEMENTATION OF RANKING CRITERIA . . . . . . 19

C.2.4.1 Pre-Waste-Emplacement Travel Time . . . 19

C.2.4.2 Inflow............. 20

C.2.4.3 Data and Information Base ........ 20

C.3. HYDROGEOLOGIC SETTINGS .................... 21

C.3.1 ENVIRONMENTAL SETTINGS ............... 21

C.3.1.1 Anhydrock ............... 21

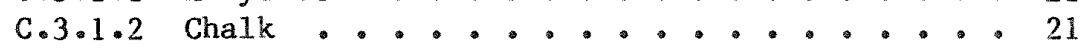

C.3.1.3 Carbonate Rocks (Limestone/Dolostone)... 22

C.3.1.4 Sandstone ............. 23

C.3.1.5 Shale ............. 24

C.3.2 PHYSICAL STRUCTURE ............... 24

C.3.2.1 Anhydrock ................ 25

C.3.2.2 Chalk ................. 25

C.3.2.3 Carbonate Rocks (Limestone/Dolostone). . . 25

C.3.2.4 Sandstone .............. 25

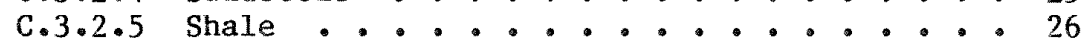

C.4. HYDROLOGIC SETTINGS . . . . . . . . . . . . . 27

C.4.1 GENERAI HYDROLOGIC BEHAVIOR . . . . . . . . . . . 27

C.4.1.1 Anhydrock .............. . 27

C.4.1.2 Chalk .............. 27

C.4.1.3 Carbonate Rocks (Limestone/Dolostone). . 28

C.4.1.4 Sandstone .............. 28

C.4.1.5 Shale ............... 28

C.4.2 GENERAL HYDROLOGIC CHARACTERISTICS . . . . . . . 29

C.4.2.1 Anhydrock ................ 29

C.4.2.2 Chalk . . . . . . . . . . . 29

C.4.2.3 Carbonate Rocks (Limestone/Dolostone). . . 29

C.4.2.4 Sandstone ............. 30

C.4.2.5 Shale ................ 30

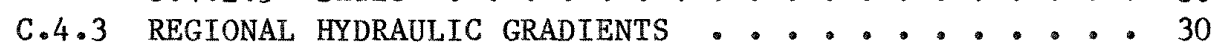


C.5. HYDROLOGIC PROPERTIES ................... 31

C.5.1 INTRODUCTION TO HYDROLOGIC PROPERTIES ....... 31

C.5.1.1 Properties Needed for Ranking ...... 31

C.5.1.2 Consideration of Scale Effects...... 31

C.5.1.3 Development of Ranges ......... 32

C.5.1.4 Development of Hydraulic Conductivity Data. 33

C.5.1.5 Development of Effective Porosity Data.. . 33

C.5.1.6 Development of Specific Storage Data. . 35

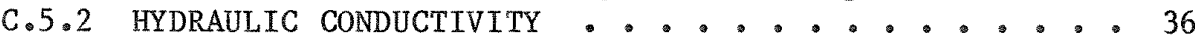

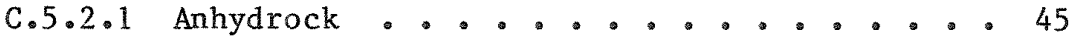

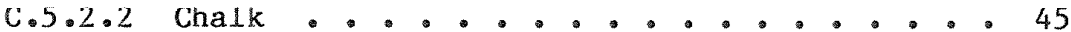

C.5.2.3 Carbonate Rocks (Limestone/Dolostone). . 46

C.5.2.4 Sandstone ............ 40

C. 5.2 .5 Sha1e ................ 47

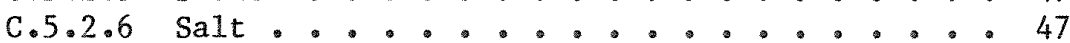

C.5.3 EFFECTIVE POROSITY .............. 47

C.5.3.1 Anhydrock ............... 47

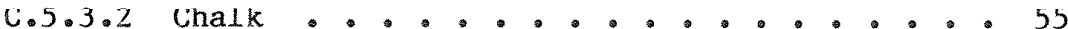

C.5.3.3 Carbonate Rocks (Limestone/Dolostone). . 55

C.5.3.4 Sandstone ............. 55

C.5.3.5 Shale ............. 55

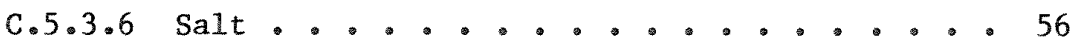

C.5.4 SPECIFIC STORAGE ........................ 56

C.5.5 ADOPTED SECTION PROPERTTES ............ 58

C.6. EFFECTS OF WASTE EMPLACEMENT ON HYDROLOGIC BEHAVIOR • . . 63

C.6.1 THERMAL EFFECTS ........................ 63

C.6.2 EXCAVATTON EFFECTS ................ 63

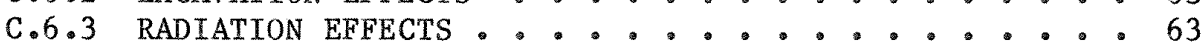

C.7. ANALYSIS . . . . . . . . . . . . . . . . 65

C.7.1 INTRODUCTION .................. 65

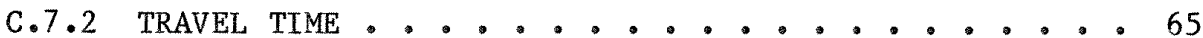

C.7.2.1 Method of Trave1 Time Analysis..... 65

C.7.2.2 Travel Time Results .......... 69

C.7.2.2.1 Anhydrock....... 70

C.7.2.2.2 Chalk........ 70

C.7.2.2.3 Carbonate rocks ...... 74

C.7.2.2.4 Sandscone........ 74

C.7.2.2.5 Shale....... 74

C.7.3 BOUNDARY CONDITIONS FOR TRAVEL TIME MODEL:

HIGH AND LOW CASES . . . . . . . . . . 75

C.7.4 DISCRETIZATIONS FOR TRAVEL TIME MODELS . . . . 80

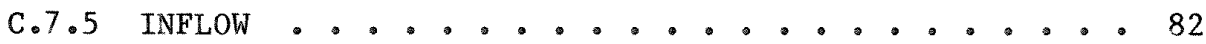

C.7.5.1 Method of Groundwater Inflow Analysis . 82

C.7.5.2 Groundwater Inflow Results ........ 87

C.7.5.2.1 Anhydrock......... 87

C.7.5.2.2 Chalk................... 88

C.7.5.2.3 Carbonate rocks...... 88

C.7.5.2.4 Sandstone . . . . 88

C.7.5.2.5 Shale........ 88 
C.7.6 DISCRETIZATIONS FOR INFLOW MODEL ........ 91

C.7.7 PRELIMINARY ANALYSIS OF COUPLED THERMAL-HYDROLOGICAL

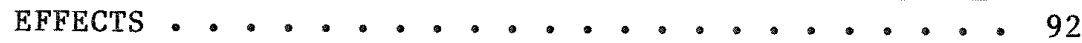

c.7.7.1 Introduction .............. 92

C.7.7.2 Analysis Approach ......... 93

C.7.7.2.1 Numerical Methods . . . . 993

C.7.7.2.2 Mode1 Development...... 94

C.7.7.3 Thermal Results ........ 96

C.7.7.4 Hydrologic Results .......... 96

C.7.7.4.1 Anhydrock ......... 96

C.7.7.4.2 Sandstone ........ 996

C.7.7.4.3 Shale .......... 96

C.7.7.5 Analysis of Results ......... 102

C.8. SUMMARY AND CONCLUSIONS ...................... 104

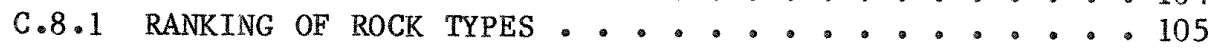

C.8.1.1 Trave1 Time Ranking ......... 105

C.8.1.2 Groundwater Inflow Ranking ....... 105

C.8.1.3 Other Considerations ........ 107

C.8.1.4 Overall Ranking .......... 108

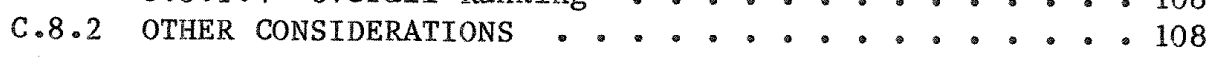

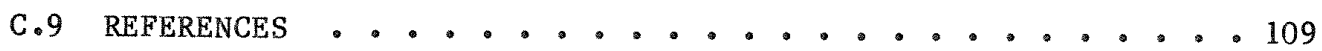


C.3.1. Reference stratigraphic section for anhydrock . . . . . 22

C.3.2. Reference stratigraphic section for chalk . . . . . . 22

C.3.3. Reference stratigraphic section for carbonate rocks (1imestone/dolostone) ............... 23

C.3.4. Reference stratigraphic section for sandstone . . . . 23

C.3.5. Reference stratigraphic section for shale . . . . . . 24

C.7.1. Geometry and boundary conditions used in calculation of pro-waotc-cmplaccment groundwater travel time for the typical case, anhydrock section . . . . . . . . 66

C.7.2. Geometry and boundary conditions used in calculation of pre-waste-emplacement groundwater travel time for the typical case, chalk section ............ . 66

C.7.3. Geometry and boundary conditions used in calculation of pre-waste-emplacement groundwater travel time for the typical case, carbonate rocks section ........ 67

C.7.4. Geometry and boundary conditions used in calculation of pre-waste-emplacement groundwater travel time for the typical case, sandstone section ........ 67

C.7.5. Geometry and boundary conditions used in calculation of pre-waste-emplacement groundwater travel time for the typical case, shale section .......... 68

C.7.6. Example of discretization used in the calculation of pre-waste-emplacement groundwater travel times . . . 69

C.7.7. Pre-waste-emplacement groundwater trave1 time paths in

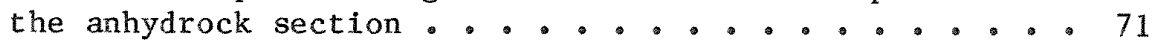

C.7.8. Pre-waste-emplacement groundwater travel time paths in the chalk section ................. 71

C.7.9. Pre-waste-emplacement groundwater travel time paths in the carbonate rocks section......... 72

C.7.10. Pre-waste-emplacement groundwater travel time paths in the sandstone section ........... 72

C.7.11. Pre-waste-emplacement groundwater travel time paths in the shale section....................... 73 
C.7.12. Boundary conditions for the travel time model "high" case, anhydrock section ............ . 75

C.7.13. Boundary conditions for the travel time model "1ow" case, anhydrock section . . . . . . . . . . . 75

C.7.14. Boundary conditions for the travel time model "high" case, chalk section............... 76

C.7.15. Boundary conditions for the travel time mode1 "1ow" case, chalk section............. 76

C.7.16. Boundary conditions for the travel time model "high" case, carbonate rocks (1imestone/dolostone) section. . 77

C.7.17. Boundary conditions for the travel time mode1 "Iow" case, carbonate rocks (1imestone/dolostone) section. . 77

C.1.18 Boundary conditions for the travel time model "high" case, sandstone section .............. 78

C.7.19. Boundary conditions for the travel time model "1ow" case, sandstone section .............. 78

C.7.20. Boundary conditions for the travel time model "high" case, shale section ................. 79

C.7.21. Boundary conditions for the travel time mode1 "1ow" case, shale section ................. 79

C.7.22. Discretization for travel time mode1, anhydrock section ......................... 80

C.7.23. Discretization for travel time model, chalk section . . 80

C.7.24. Discretization for travel time mode1, carbonate rocks (1imestone/dolostone) section ........... 81

C.7.25. Discretization for travel time model, sandstone section ... . ..................... 81

C.7.26. Discretization for travel time mode1, shale section . . 82

C.7.27. Geometry and boundary conditions used in calculation of groundwater inflow for the anhydrock section ..... 83

C.7.28. Geometry and boundary conditions used in calculation of groundwater inflow for the chalk section ...... . 84

C.7.29. Geometry and hnmdary conditions used in caloulation of groundwater inflow for the carbonate rocks section . . 84 
Figure

C.7.30. Geometry and boundary conditiono ueed in calculation of groundwater inflow for the sandstone section . . . 85

C.7.31. Geometry and boundary conditions used in calculation of groundwater inflow for the shale section . . . . . 85

C.7.32. Example of discretization used in calculating groundwator inflow . . ................ 86

C.7.33. Groundwater inflow versus time plot for the anhydrock section.................... 87

C.7.34. Groundwater inflow versus time plot for the chalk section..................... 89

C.7.35. Groundwater inflow versus time plot for the limestone section .......................... 89

C.T.36. Groundwater inflow versus time plot for the sandstone

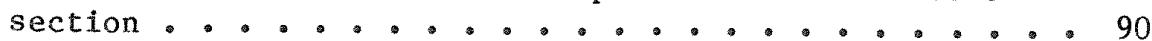

C.7.37. Croundwater inflow versus time plot for the shale

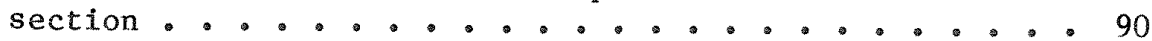

C.7.38. Discretization for inflow mode1, anhydrock section. . . 91

C.7.39. Discretization for inflow mode1, chalk section. .... 91

C.7.40. Discretization for inflow mode1, carbonate rocko (1imestone/dolostone) section ............... 91

C.7.41. Discretization for inflow mode1, sandstone section. . . 92

C.7.42. Discretization for inflow mode1, shale section. . . . 92

C.7.43. Discretization for coupled thermal-hydrologic model,

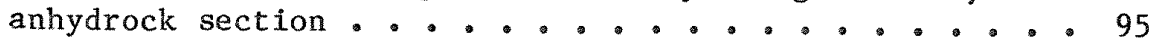

C.7.44. Discretization for coupled therma1-hydrologic mode1, sandstone section . . . . . . . . . . . 95

C.7.45. Discretization for coupled therma1-hydrologic mode1, shale section ..................... 95

C.7.46. Temperature field after 1,000 years for reference repository in anhydrock section ............. 100

C.7.47. Temperature field after 1,000 years for reference repository in sandstone section............. 100 
Figure

C,7.48. Temperature field after 1,000 years for reference repository in shale section . . . . . . . . . . . 100

C.7.49. Isothermal hydrologic results for anhydrock section . . 101

C.7.50. Nonisothermal hydrologic results for anhydrock section . 101

C.7.51. Isothermal hydrologic results for sandstone section. . 101

C.7.52. Nonisothermal hydrologic results for sandstone section . 102

C.1.53. Isothermal hydrologic results for shale section ..... 103

C.7.54. Nonisothermal hydrologic results for shale section ... 103

C.8.1. Typical groundwater inflow versus time plot for the five sedimentary rock types................. 106 


\section{LIST OF TABLES}

Table

Page

C.5.1. Hydraulic conductivity data base for anhydrock . . . . 36

C.5.2. Hydraulic conductivity data base for chalk . . . . . 37

C.5.3. Hydraulic conductivity data base for carbonate rocks . . 39

C.5.4. Hydraulic conductivity data base for sandstone .... . 41

C.5.5. Hydraulic conductivity data base for shale . . . . . 42

C.5.6. Hydraulic conductivity data base for salt . . . . . . 44

C.5.7. Poroaity data base for anhydrock . . . ...... 48

C.5.8. Porosity data base for chalk ............. 49

C.5.9. Porosity data base for carbonate rocks. . ...... 50

C.5.10. Porosity data base for sandstone ........... 51

C.5.11. Porosity data base for shale ............ . 52

C.5.12. Porosity data base for salt............ 54

C.5.13. Specific storage data base ......... . . . 57

C.5.14. Adopted section properties for anhydrock ....... 59

C.5.15. Adopted section properties for chalk . . . . . . . . 60

C.5.16. Adopted section properties for carbonate rocks. . . . 61

C.5.17. Adopted section properties for sandstone . . . . . . 62

C.5.18. Adopted section properties for shale . . . . . . . 62

C.7.1. Ten-kilometer travel time for chalk.......... 73

C.7.2. Ten-kilometer travel time for carbonate rocks . . . . 74

C.7.3. Properties and conditions for anhydrock emplacement . . 97

C.7.4. Properties and conditions for sandstone emplacement . . 98

C.7.5. Properties and conditions for shale emplacement . . . . 99

C.8.1 Pre-waste-emplacement travel time distances for 100,000 years........................... 106 


\section{C.1 INTRODUCTION}

Oak Ridge National Laboratory (ORNL) is conducting a preliminary evaluation and ranking of the suitability of five sedimentary rock types as potential host rocks for deep geologic disposal of high-level nuclear waste. The rock types being considered are anhydrock, chalk, carbonate rocks, sandstone and shale. This work is being conducted for the Sedimentary Rock Program (SERP) of the U.S. Department of Energy (DOE) by ORNL.

The full evaluation includes consideration of the geologic, hydrologic, geochemical, rock mechanical and thermal factors, affecting construction, operation and performance of a potential repository in each of the rock types. This report documents the study and findings related to the hydrologic evaluation and ranking of the five sedimentary rock types.

\section{C.1.1 OBJECTTVE}

The most serious threat to the isolation capability of a repository located in a deep geologic medium is migration of radionuclides with the groundwater. Accordingly, the majority of regulatory guidelines are directed at water-related transport of nuclides, and the major portion of available resources for characterization of sites presently being considered for repositories appears to be allocated to hydrologic-related studies. It is thus anticipated that the overall ranking of the five sedimentary rock types considered under the SERP will depend heavily on the hydrologic study discussed in this report.

The objective of this work is to perform a hydrologic evaluation and ranking of the five sedimentary rock types considered under the Sedimentary Rock Program. This evaluation and ranking considers the performance, construction and operation of a potential repository in each of the rock types, is responsive to appropriate existing guidelines promulgated by the DOE the U.S. Nuclear Regulatory Commission (NRC), and the U.S. Environmental Protection Agency (EPA), and is designed to be, to the extent possible, quantitative and unbiased.

\section{C.1.2 SCOPE AND ORGANIZATION}

This study is confined to a generic, hydrologic consideration of anhydrock, chalk, carbonate rocks, shale and sandstone. It is specifically restricted to existing information and data, thus field and laboratory tests for purposes of developing new data were specifically excluded from consideration from the onset of the study. Because specific sites are purposefully not considered, hypothetical reference sites were developed to allow for the analysis necessary to the evaluation and ranking of the rock types. The geology and general geometry of the five reference sites were developed by the Sedimentary Rock Program Staff of ORNL, and the hydrologic data and information for each of the reference sites were developed under this study. 
Ranking and evaluation are based on quantitative analyses of selected factors related to the construction, operation and long-term performance of a potential repository located in each of the five rock types. The ranking criteria and methodology were developed in consideration of technical requirements for construction, operation and long-term performance of a potential repository as dictated by technical judgment and applicable regulatory guidelines.

The ranking criteria selected and the method of implementation are presented in Sect. C.2. Hydrogeologic and hydrologic settings for each of the five rock types are discussed in Sects. C.3 and C.4, respectively, followed by a description of the information and data base in Sect. C.5. Effects of waste emplacement on hydrologic behavior is considered in Sect. C.6. The analyses performed for implementation of the ranking methodology are presented in Sect. C.7, and the actual ranking togethex with conclusions and recommendations are presented in sect. C.8. 


\section{C.2 RANKING METHODOLOGY}

The criteria and methodology used to hydrologically rank the five sedimentary rock types are discussed in this chapter. Two criteria are selected, one for postclosure conditions and one for preclosure conditions. As will be discussed, the terms "postclosure" and "preclosure" are adopted from DOE's siting guidelines for geologic repositories [contained in 10 CFR Part 960 (CFR 1984)], and refer to the period after the closing of the repository and to the period of construction and operation, respectively. The approach adopted in developing these criteria is presented in Sect. C.2.1, followed by descriptions of the criteria and related rechnical considerations. Finally, a description of how the five rock types will be evaluated and ranked on the basis of these criteria is presented in sect. C. 2.2 .

\section{C.2.1 GENERAL AYYROACH}

The objective of the hydrologic ranking methodology is to provide a formal means for ranking the hydrologic suitability of the five sedimentary rock types for application to high-level nuclear waste disposal through the consideration and evaluation of generic hydrologic characteristics of each of the five rock types. Qualities sought in ranking criteria include objectivity, definttiveness, practicality and simplicity of implementation.

The hydrologic ranking criteria used in this study were developed through consideration of desirable hydrologic characteristics and guidelines pertaining to hydrologic aspects of high-level waste repositories. Existing guidelines pertaining to hydrologic aspects of high-level radioactive waste repositories have been promulgated by the U. S. Congress (Nuclear Waste Policy Act of 1982), the U.S. Department of Energy (CFR 1984), the U.S. Nuclear Regulatory Commission (CFR 1983), and the U.S. Environmental Protection Agency (CFR 1985).

The existing guidelines are directed at the screening, nomination, selection and licensing processes and do not specifically address the generic evaluation and comparison of different rock types considered here. However, since one of the concerns that should be at least indirectly considered in the comparison process is the probability that sites in a given rock type will survive the screening, nominating and selection processes, it is apparent that the various guidelines do address concerns that are technically appropriate to evaluation and ranking of rock types. The selected criteria would thus be expected to stand both on technical merit and responsiveness to the existing guide1ines.

\section{C.2.1.1 Existing Guidelines}

The existing guidelines address hydrologic requirements, favorable and unfavorable conditions, and to a lesser extent the necessary types of lechulcal luformalion and dala. of the various existing guideline documents, DOE's 10 CFR 960 covering the screening, nomination and 
selection processes, appears to be most applicable to the present study. This document also contains direct reference to the major technical guidelines put forth in $\mathrm{NRC}^{\prime} \mathrm{s} 10 \mathrm{CFR} 60$ and $\mathrm{EPA}^{\prime} \mathrm{s} 40 \mathrm{CFR} 191$. The DOE guidelines are therefore most directly pertinent to the development of the criteria used in this study.

In the following, the two most applicable guidelines are considered. No attempt is made to discuss all of the guidelines that were examined in arriving at the ranking criteria selected for this study. It is believed that consideration and discussion of the other criteria will naturally evolve as the site selection process progresses for the Sedimentary Rock Program.

\section{C.2.2 RANKING CRITERIA}

The hydrologic guidelines presented in 10 CFR 960 are broadly grouped under the headinga of Postclosure Guidclinco (Subpart C), pertaining to factors to be considered in evaluating and comparing sites on the basis of expected repository performance after closure, and Preclosure Guidelines (Subpart D), pertaining to factors to be considered in evaluating and comparing sites on the basis of expected repository performance before closure. Similarly, postclosure and preclosure criteria have been selected for the present study and are discussed in this order to reflect the greater importance on the former, as stressed in 10 CFR 960.

\section{C.2.2.1 Postclosure}

The most direct postclosure hydrologic criterion for the present study is pre-waste-emplacement groundwater travel time. An expected pre-emplacement groundwater travel time to the accessible environment of less than 1,000 years along any pathway of likely and significant radionuclide travel pathway is the only geohydrologic disqualifying condition 1isted under the postclosure guidelines in $10 \mathrm{CFR} 960$. Further, a pre-emplacement groundwater trave1 time of more than 10,000 years is referred to as a favorable condition under geohydrologic qualifying conditions and as an informational need in Appendix III of that document.

From a technical standpoint, pre-emplacement groundwater travel time provides a straightforward means for considering a large number of hydrologic features and properties of the rock and arriving at a single, objective measure of probable long term repository performance. It directly ranks on the basis of a critical performance measure, and automatically integrates and weights the many hydrologic parameters of concern.

It must be noted, however, that pre-emplacement groundwater travel time does not consider all hydrologic factors related to the postclosure isolation potential of a high-level waste repository. In particular, pre-emplacement travel time does not consider thermal driving forces, dioperaion, or phenomena reaponoible for removal and introduction of 
radionuclides from the groundwater (collectively referred to here as sorption). While estimates of postclosure radionuclide travel times address these concerns, such travel times were not selected as the basis for ranking for several reasons. First, a number of key parameters necessary to the consideration of postclosure travel times are generally not known on the scales required for this study and would have to be estimated from very limited data. It is thus believed that groundwater travel time, while providing a more realistic measure of the performance of a potential repository, may because of greater uncertainties, prove to be a less suitable ranking criterion than pre-emplacement groundwater travel times for this study. Second, it is anticipated that sorption will be considered in a separate geochemical study where uncertainties associated with this phenomenon can be better considered. Finally, since a groundwater travel time of less then 1,000 years is a disqualifying condition for a site, it is believed that this performance measure should receive early consideration, that it is particularly appropriate as a ranking critcrion for a scoping study such as the present one, and that the refinements of thermal driving forces and sorption should come in a later study.

\section{C.2.2.2 Preclosure}

The only applicable hydrologic disqualifying condition under the preclosure guidelines in 10 CFR 960 is expected groundwater conditions likely to require engineering measures that are beyond reasonably available technology for exploratory shaft or repository construction, operation or closure. A similar statement is made for potentially adverse conditions in the hydrology section of that document. Because it is believed that excessive groundwater inflow is likely to be the most important hydrologic problem during the construction and operation of a proposed repository and is most likely to lead to the need for unreasonable engineering measures, groundwater inflow is selected as the preclosure criterion of choice for the hydrologic evaluation and ranking of the five rock types.

Estimation and evaluation of potential groundwater inflow for the five sedimentary rock types provides a straightforward, objective means of concidcring virtually all typical hydrologic features and properties of the rock that are likely to have significant hydrologic impact on the construction and operation of the repository. This approach has the advantage of ranking directly on the basis of a pertinent hydrologic performance measure, that of groundwater inflow rate, and avoids the need to separately consider and weight the large number of geologic and hydrologic parameters that influence groundwater inflow into the workings.

\section{C.2.3 DTHER CONSIDERATIONS}

Before examining how the above ranking criteria will be used, another evaluation factor, that of variability and uncertainty, should be discussed. It is considered here because it is not a formal ranking criterion in thic study, but does have beaxing on the implementation of the two primary criteria cited above. 
Because specific sites are not associated with the five rock types, generic information and data are used to estimate pre-emplacement groundwater travel times and groundwater inflow rates. The use of generic data leads to the obvious problem of deciding which values and characteristics are representative of each of the given rock types. This in turn leads to examination of the uncertainty and variability associated with each rock type. Variability in material properties and features is common1y observed among different occurrences of a given rock type as well as among different locations within the same occurrence. This latter variability, particularly if prevalent within a rock type, can have bearing on the potential suitability of the rock for the disposal of nuclear waste.

For the present generic study it is believed that detailed consideration of either type of variability would be premature. Variability and uncertainty are generally best considered through a probabilistic approach that allows for quantification of these factors within the context of a formalized methodology. The viability of such an approach, however, is contingent on adequacy of data implying the need for an extensive data hase. For the present study, a probahilistir apprnach wnuld require detailed information on the spatial variability within individual occurrences of the given rock types for a significant number of different sites. Such data do not exist at the present time. For the most part there are relatively limited data on rocks at low permeability sites and little of that data considers variability within a site.

The approach taken here is to adopt the reference geologic cross sections developed by the SERP staff at ORNL and within that context provide, using existing data and information, a preliminary semiquantitative picture of the type of variability that might be expected for rocks found at sites similar to the reference site. Thus, the intent is not to consider all possible occurrences of a given rock type. This latter approach would lead to enormous ranges and have little meaning for the present study.

As will be seen, sufficient data on the variability of tight rocks within given sites are not available and thus assumptions become necessary. Because of the uncertainties associated with these assumptions it was decided that variability should not be used as a primary ranking criterion. Rather it should remain a secondary consideration to be invoked in the final ranking in cases where two rock types appear similar on the basis of the primary criteria.

Before describing the implementation and analyses associated with the ranking criterla, it is important to clearly define the scope and intent of the methodology. The purpose of the analyses performed in this study is to produce a quantitative basis for comparative ranking of the five sedimentary rock types. The travel times and inflows presented are, under no circumstances, to be interpreted as having absolute relation to values that may be expected for any existing sites. Further, the ranges developed for each of the rock types should not be construed to have absoluce relacion to any sices ocher chan the reference sites developed for this study. 
It is clear, because of the judgment that is exercised in determining what subset of a given rock type may be suitable for waste disposal application and because of the constraints imposed by considering only a single reference cross section, that the ranges developed for this study are smaller than they might have been in a similar study with different assumptions. As previously stated, however, while perhaps less representative of the totality of existing sites, these smaller ranges provide a more useful basis for ranking the five rock types.

Finally, it is noted that the range of hydraulic properties and geologic settings found in nature is large for all of the rock types. Thus, it is conceivable that under favorable circumstances a hydrologically sultable site for high-level waste disposal con1d he found in any of the five rock types studied here. The purpose of this ranking study is not, therefore, to identify whether or not suitable sites may exist in a certain rock type, but rather to identify those rock types whose properties and geologic settings provide the most favorable conditions for waste isolation.

\section{2.4 TMPT.FMFNTATTON OF RANKTNS CRTTFRTA}

The way in which the ranking criteria will be implemented to evaluate the five sedimentary rock types is discussed in this section. Because the ranking criteria selected for this study are largely quantitative, implementation is, for the most part, obvious and straightforward. A brief discussion of the analyses for pre-waste-emplacement travel time and groundwater inflow is presented below, followed by consideration of the secondary criteria of variability and uncertainty.

\section{C.2.4.1 Pre-Waste-Emplacement Trave1 Time}

The groundwater travel time is the length of the flow path divided by the velocity where the velocity is the average groundwater flux passing through the rross-sertional area of the genlngis medium through which the flow occurs, perpendicular to the flow direction, divided by the effective porosity along the flow path. It is assumed that the flow system for each of the reference sites considered in this study is at equilibrium. The analysis is performed by solving the steady-state flow equation and then taking the resulting velocity field and estimating the average groundwater travel time by solving an advective equation for the geometry, material properties and boundary conditions expected at the reference site. The required material properties are the hydraulic conductivity tensors and effective porosities for each of the materials at the site. Because the reference sites exhibit bedding that is in most cases close to horizontal, it is assumed that the hydraulic conductivities can be adequately treated by consideration of the components parallel to and normal to the bedding planes.

High, typical and low travel times are calculated for each of the reference sites on the basis of selected ranges of material properties discussed below. The geometry and boundary conditions for each of the sites are derived from the reference sections and are discussed in Sects. C.4, C.5, and C.7. 


\section{C.2.4.2 Inflow}

Inflow as considered here is the volume per unit of time of water per meter of drift that would be expected to enter a repository and is presented as a function of time following excavation. Inflow is estimated by solving the transient flow equation for the expected conditions at a given site. The material properties needed for the analysis are the hydraulic conductivity tensors and specific storages of each of the materials in the area of the proposed repository. As in the case of travel time, only horizontal and vertical conductivities are considered.

High, typical and low values of groundwater inflow are calculated for each of the reference sites. The basis of estimating these ranges is discussed below and in Sects. C.4 and C.5.

\section{C.2.4.3 Data and Information Base}

As previously stated, the cross sections of the reference sites developed by the ORNL SERP staff were adopted for this study. The geometry and boundary conditions for each of the sites were fixed on the basis of these cross sections. For the purposes of this study, no attempt was made to vary either of these factors in calculating ranges of the ranking criteria of travel time and inflow. The intent is to examine, in a preliminary semiquantitative fashion, the relative ranges of hydrological parameters that might be expected and not to consider all possible combinations of geometry, boundary conditions and material properties.

In keeping with the intent of the study, only the material properties of the reference repository horizon at each of the reference sites were varied and these variations were kept within certain limits. These limits are loosely defined by assuming that only occurrences of the rock type that might be reasonably used for high-level waste disposal would be considered and that the values assigned for material properties should reflect measurements of the given rock types at real sites with geology and geometry similar to those shown in the reference cross sections. On the basis of these limits, high, low and typical values of material properties were developed as descrihed in Sert. C.5 and the analyses described in Sect. C.7 were performed to evaluated the ranges of the primary ranking criteria. 


\section{C.3 HYDROGEOLOGIC SETTTNGS}

This chapter treats the geological settings in which the hydrologic characteristics of the five rock types are to be evaluated. The general geologic settings are expressed in terms of reference stratigraphic sections developed for each of the rock types for use in ranking. As previously mentioned, the reference sections were developed by the ORNL SERP staff based upon the general depositional environment associated with each rock type. The individual strata were positioned such that a sufficiently thick horizon of the appropriate rock type would be present at an assumed repository depth of $700 \mathrm{~m}$.

The reference stratigraphic sections are introduced below in the context of the typical environmental setting for each rock type. Each horizon in the sections is numbered for later reference in assigning hydrologic properties for purposes of modeling. The physical structure of each rock as it relates to its hydrologic properties is then discussed, including evaluations of the common types of heterogeneities and their hydrological signiflcance.

\section{C.3.1 ENVIRONMENTAL SETTINGS}

\section{C.3.1.1 Anhydrock}

Anhydrock is an evaporite rock consisting almost entirely of the mineral anhydrite $\left(\mathrm{CaSO}_{4}\right)$. It is generally found in association with salt in horizons that range in thickness from tens of millimeters to tens of meters (DEAN 1983). Major impurities in anhydrock generally consist of salt, sandstone, siltstone or carbonate rocks.

The reference stratigraphic section for anhydrock is shown in Fig. C.3.1. The uppermost $15 \mathrm{~m}$ of the section is made up of sand, silt and gravel representative of recent surface deposits. Inderlying this is a thick sequence of evaporites, alternating anhydrock and salt, with one shale unit. The reference repository horizon is an anhydrock unit $183 \mathrm{~m}$ thick. The evaporite sequence is assumed to continue below the anhydrock horizon.

\section{C.3.1.2 Cha1k}

Chalk is a fine-grained and generally friable carbonate composed almost entirely of organic remains of fossil she11s of molluscs and foraminifera in an extremely fine-grained matrix (HOLMES 1965). Chalk may be deposited either in an open marine or a shallow water environment. Associated sedimentary rocks include fine-grained detrital material forming shales or mudstones, sandstones, and carbonate rocks. Chalk is often remarkably pure, consisting of over $95 \% \mathrm{CaCO}_{3}$. Impurities commonly include detrital quartz and clays (BELL 1977; CORBETT 1983).

The reference stratigraphic section for chalk is shown in Fig. C.3.2. The uppermost unte consists of shale and sandstone, underiain by a unt $\tau$ 
of clay, shale and marl. The next lower unit io compooed of shale, marl and chalk with some sandstone. The reference repository horizon is a 259-m-thick bedded chalk mixed with chalky carbonate rocks and limey chalks.

\section{C.3.1.3 Carbonate Rocks (Limestone/Dolostone)}

Carbonate rocks are sedimentary depnsits formed primarily from carbonate materials $\left(\mathrm{CaCO}_{3}\right)$ generally, but not always, in marine environments (HOLMES 1965). Many carbonate rocks are accumulations of organic remains and retain types of void space related to their genesis, such as oolitic and algal pulusily (McCOMAs 1963). Dulunile [CaMg $\left(\mathrm{CO}_{3}\right)_{2}$ ] is commonly formed from carbonate rocks by the replacement of some of the calcium by magnesium. The hydrologic characteristics of these two rock types are sufficiently similar to warrant combining them for purposes of this study. Carbonate rocks are commonly associated with shales and sandstones.

The reference stratigraphic section for carbonate rocks (1imestone/ Antestons) is shown in Fig. C.3.3. The uppermot hoxizon is a 488-m-thick

ORNL DWG 84-998R2

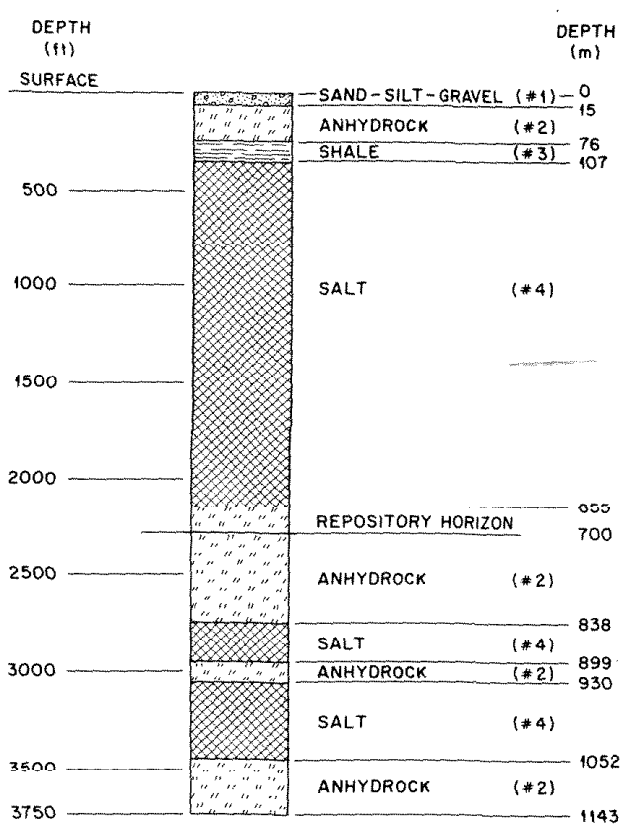

Fig. C.3.1. Reference stratigraphic section for anhydrock.

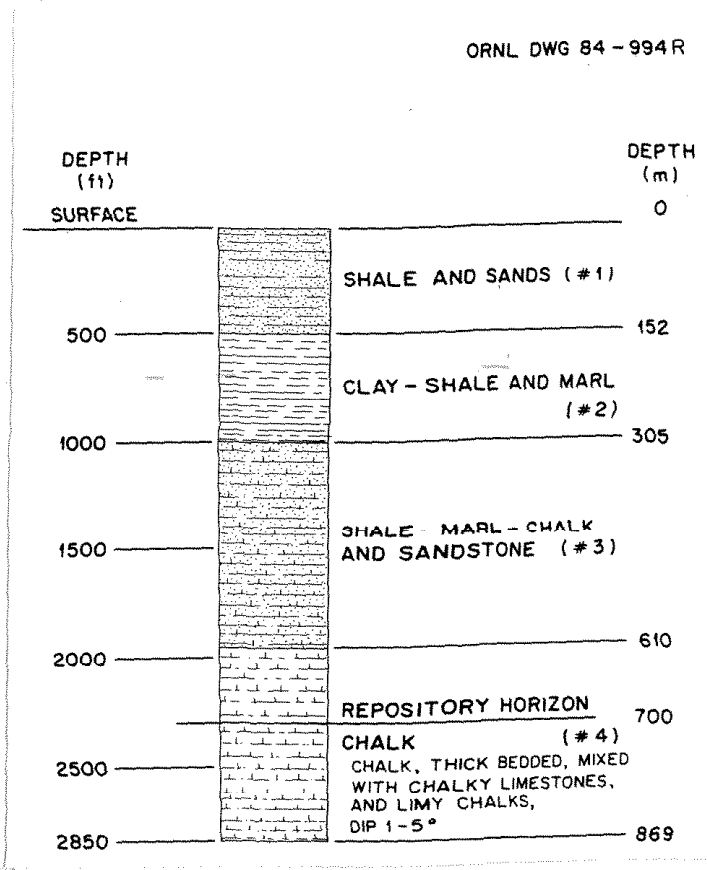

Fig. C.3.2. Reference stratigraphic section for chalk. 
shale unit, which is underlain by some $91 \mathrm{~m}$ of carbonate rocks. A thin, 15-m-thick shale unit underlies this upper carbonate, followed by $77 \mathrm{~m}$ of sand and shale. The reference repository horizon is $275 \mathrm{~m}$ of fine- to coarse-grained crystalline carbonate rocks (1imestone/dolostone) with some sand grains and chert. This is underlain by a horizon of sandstone and conglomerate.

\section{C.3.1.4 Sandstone}

Sandstone is a rock consisting primarily of small, rounded grains of quartz, buuld cogecher by a cementing macerlal. calclte, silica and hematite are common cementing materials (HOLMES 1965). Because of the abundance of its constitutive materials, very thick accumulations of sandstone are relatively common. As previously discussed, sandstones are commonly associated with the other common sedimentary rocks such as carbonate rocks and shales.

The reference stratigraphic section for sandstone is shown in Fig. C.3.4. This simple section consists of a 762-m-thick sandstone reference repository horizon overlain and underlain by some $600 \mathrm{~m}$ of shale.

ORNL OWG 84-996R2

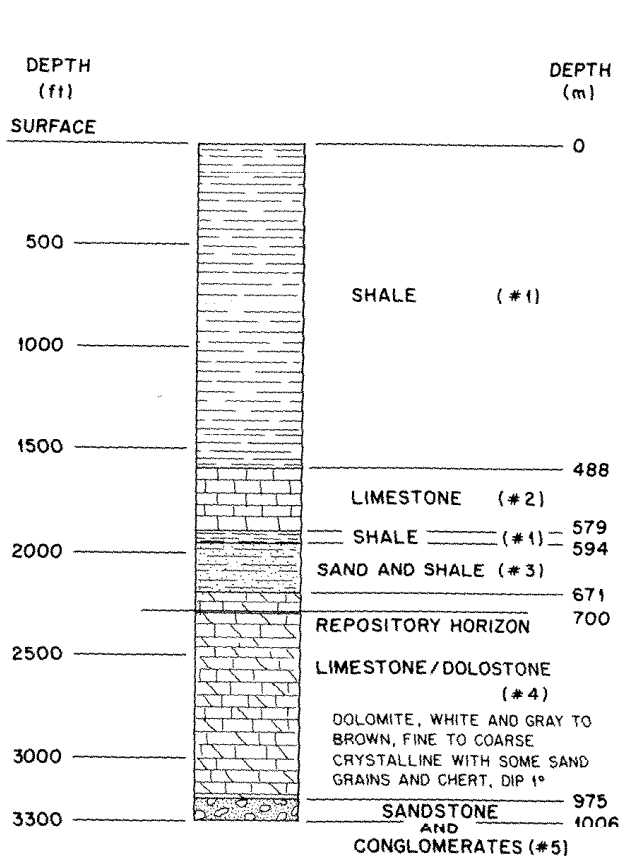

Fig. C.3.3. Reference stratigraphic section for carbonate rocks (1imestone/dolostone).
ORNL DWG $84-997 R$

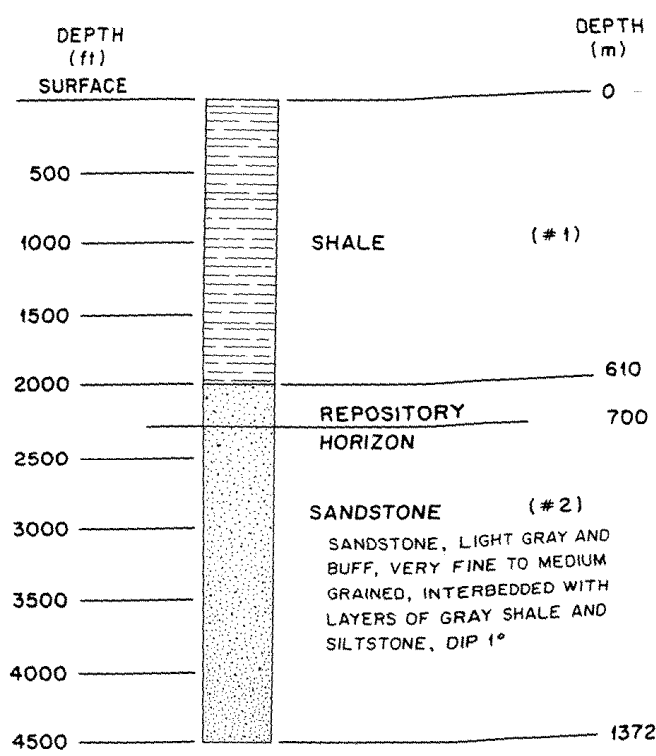

Fig. C.3.4. Reference stratigraphic section for sandstone. 


\section{C.3.1.5 Shale}

Shale is a we11-compacted and indurated mudstone or claystone consisting primarily of clay and silt-sized particles. The induration results in development of laminae consisting of a multitude of very thin layers of clays and other platy materials (HOLMS 1965). Shales, like sandstones, are often found in very thick horizons because of the local abundance of their constitutive materials. As previously noted, shales often occur in association with sandstones and carbonate rocks.

The reference stratigraphic section for shale is shown in Fig. C. 3.5 . This section consists of an upper 30-m-thick horizon of sand, silt and clay followed by $122 \mathrm{~m}$ of shale with some silt and sand. This is underlain by the reference repository horizon, a 610-m-thick unit of gray to dark gray, low carbon, illitic shale with minor silt and limestone. A 122-mthick carbonate horizon is assumed to underlie the shale.

\section{C.3.2 PHYSICAL STRUCTURE}

Those aspects of physical structure that influence the hydrologic behavior of each rock type are discussed in this section. The pertinent structural aspects include the rock fabric, nature of fracturing, and variability of occurrence.

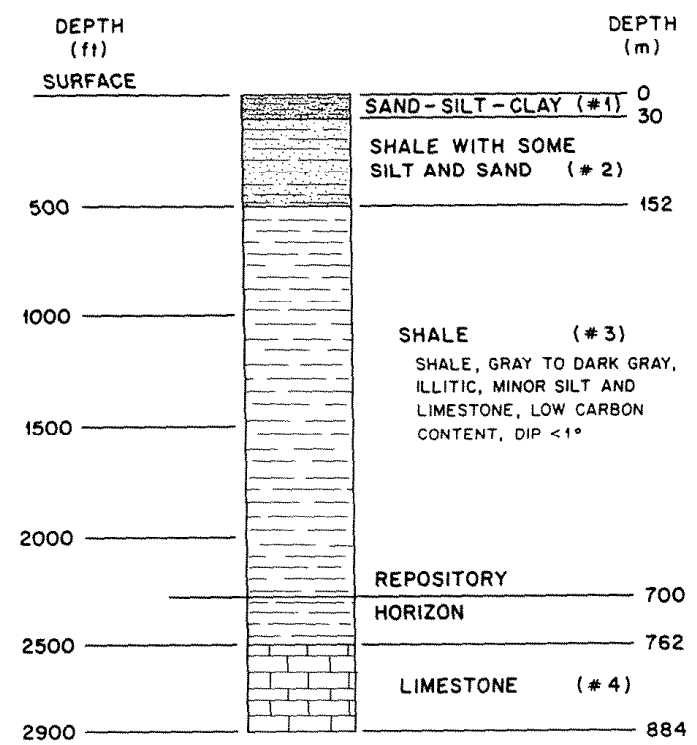

Fig. C.3.5. Reference stratigraphic section for shale. 


\section{C.3.2.1 Anhydrock}

Anhydrock has the highest average Young's modulus of the five rock types considered in this study. Because it is an evaporite, it generally occurs in crystalline form. Its strength and brittle nature cause it to fracture into many small fragments under stress, primarily along grain boundaries. When present, these fractures form the principal pathways for groundwater movement in an otherwise very low permeability rock. Variability occurs in the degree of fracturing and in the nature of impurities such as sill, clay or limestone. Hydration to gypsum $\left(\mathrm{CaSO}_{4} \cdot 2 \mathrm{H}_{2} \mathrm{O}\right)$ may occur locally, depending upon the in situ stress and the availability of water. Dissolution of anhydrock or associated gypsum by groundwater may form openings along bedding planes or fractures. In addition, the low hydraulic conductivity of some anhydrites permits the development of local but sometimes relatively large brine pockets that can be maintained over long time periods at near lithostatic pressures. An extensive discussion of the phystcal properties of anhydrice has been presented by DIEHL (1983).

\section{3.2 .2 Chalk}

Cha1k is commonly the weakest of the five rock types considered in this study. The very-fine-grained structure causes the unfractured rock to have a low hydraulic conductivity but a relatively high porosity (EDMUNDS 1973). However, because of its lack of strength, the high initial porosity is reduced as the chalk becomes more deeply buried (BELL 1977). Because of the very low permeability of the intact rock, fractures form the principal flow conduits for groundwater movement. Such fractures are infrequent and small in the tighter chalks, and more frequent and larger in the more conductive chalks. Because it is a carbonate, fractures in chalk can also be enlarged by dissolution. Variability occurs in the degree of fracturing, in the nature of impurities such as silts and clays, and because of interbedded shale or sand seams (HAKANSSON 1974).

\section{C.3.2.3 Carbonate Rocks (Limestone/Dolostone)}

Carbonate rocks generally occur as hard, fine-grained rocks containing we11-developed, interconnected fracture networks. The relatively low permeability generally observed in the intact, unfractured rock causes the fractures to be the primary conduits for groundwater movement. The rock mass permeability is therefore most closely related to the interconnection and openness of the fracture system. Carbonate rocks are known to support a wide range of fracture flow conditions, ranging from large, solution-widened cavities to fracture systems almost entirely sealed by secondary minerals. The various types of porosity found in carbonate rocks have been widely studied (e.g., HOHLT 1948; BEBOUT 1979; McCOMAS 1963; STEGE 1981; and CHOQUETTE 1970).

\section{C.3.2.4 Sandstone}

Sandstones occur as relatively porous, generally random assemblages of cemented silica grains. The permeability of an unfractured sandstone 
is therefore more closely correlatable to its porosity than for most rock types, and both permeability and porosity are strongly related to the degree of cementation and compaction. The cementation and diagenetic compaction of sandstones have been widely studied (HOHOLICK 1984; CHILINGARIAN 1981). The depositional environment also strongly influences permeability, particularly in nonmarine sandstones, through the geometry and degree of interconnection of the higher permeability sand lenses (KNUTSON 1976). Fracturing plays a less significant role in determining rock mass permeability than in most of the foregoing rock types.

\section{C.3.2.5 Shale}

Shale occurs as a generally low-porosity, low-permeability, highly indurated assemblage of fine-grained silts and clays. The fine grain size of the constitutive materials results in very low permeabilities in the intact rock. Compactional diagenesis strongly influences the porosity and permeability of shales, dind lis been widely studied (MAGARA 1980; CHILINGARIAN 1981). Fractures form abundantly in outcrop but tend to remain closed at depth because of the plasticity this rock commonly exhibits under high confining pressures. Variations in properties occur as a result of $10 \mathrm{cally}$ increasing amounts of coarser-grained materials in the shale, and as a result of variations in the intensity of fracturing, particularly in near-surface and more highly indurated deposits (LOMENICK 1983). 


\section{C.4 HYDROLOGIC SETTINGS}

In this chapter, the hydrologic role played by each of the five sedimentary rock types in a typical groundwater system is discussed. The general hydrologic behavior of the rock type is first described, followed by a discussion of its general hydrologic characteristics.

\section{C.4.1 GENERAL HYDROLOGIC BEHAVIOR}

\section{C.4.1.1 Anhydrock}

Anhydrock is a very low permeability rock in most deep occurxences and is classified as an aquitard or aquiclude in nearly all regional groundwater systems. Exceptions occur locally, primarily in near-surface deposits, because of increased porosity resulting from dissolution by groundwater (THORDARSON 1983). Anhydrock is not ot ten considered as a distinct hydrostratigraphic unit because it does not usually occur in sufficient thickness to warrant separate identification within a normal pvaporite sequenre.

Because of its low permeability, the role of anhydrock in regional flow is generally that of a bartier to vertical groundwater movement. Aquifers underlying thick anhydrite horizons may, depending upon the geologic situation, exhibit high artesian heads. An example is provided by the artesian Capitan Limestone aquifer that underlies the Castile evaporites in southern New Mexico (BROKAW 1972). Because of their low permeability, anhydrock beds also serve as traps for the upward migration of 011 and gas (POWERS 1978).

As previously mentioned, the depositional environment and low permeability of anhydrocks and their associated salt beds favor the development and long-term hydrologic isolation of sometimes relatively large ponkets of hrine and gas that can he at nearly lithostatio pressures (THORDARSON 1983). Brine pockets that flowed for 1 to 2 days have been encountered, for example, in deep boreholes within anhydrocks in the forementioned Castile formation (LAMBERT 1977).

Because of its relative rarity in thick sequences, its very low permeability, and its close association with more highly-soluble evaporites such as salt, very little hydrolngic experience has heen assembled in anhydrocks.

\section{C.4.1.2 Cha1k}

The hydrologic behavior of chalk can range from that of an aquifer to that of an aquitard or aquiclude, with the behavior in a given instance depending primarily upon the degree and nature of fracturing and the depth of burial. Chalk is a relatively weak rock and its permeability tends to decrease with depth. Because of its wide range of behavior, the hydrologic classification of chalk commonly varies by region, depending upon its local role as an aquiter or aquitard. The hydrologic role of a 
high-permeability chalk aquifer has been discussed by EDMUNDS (1973), and that of a low-permeability chalk aquitard has been discussed by GONZALES (1975). The relatively high porosity and low permeability of some chalks make them good potential reservoirs for oil and gas (SNYDER 1977). However, even in relatively tight beds such as the Austin chalk, small to moderate water supplies are locally obtainable from springs, highly-fractured zones, and sandstone beds (BRUNE 1983; NORDSTROM 1982). Because of its relative rarity and its often low permeability, little hydrologic experience has been assembled in chalk.

\section{C.4.1.3 Carbonate Rocks (Limestone/Dolostone)}

The hydrologic behavior of carbonate rocks, like chalk, ranges from that of an aquifer to that of an aquitard, with the behavior in a given instance depending primarily upon the fracture system. Because of their low but significant solubility in groundwater, large open conduits can develop for groundwater movement. Carbonate rocks can locally form important aquifers and can have greater hydraulic conductivities than nearly any other rock type (BRACE 1980). Because of their strength and low placticity, carbonato rocke can support open fxactures and therefore relatively high conductivities even at planned repository depths. The lower conductivity carbonate rocks are generally either less-extensively fractured or have fracture systems locally sealed by secondary minerals (STEGE 1981). Hydrologic experience with carbonate aquifers is extensive, but relatively little experience has been assembled in the lesspermeable horizons.

\section{C.4.1.4 Sandstone}

The hydrologic behavior of sandstone, like carbonate rocks, ranges from that of an aquifer to that of an aquitard, with the behavior in a given instance depending primarily upon the degree of cementation, the extent of fracturing, and the nature of interconnection of individual sandstone lenses. Although sandstone is never as permeahle as the mnst permeable limestones, several major regional groundwater aquifers are in sandstones. Examples are the St. Peter and Mount Simon sandstones in the Illinois Basin (HOHOLICK 1984), and the Eutaw and Tuscaloosa sandstones in Alabama and Mississippi (GONZALES 1975). The tighter sandstones can serve as reservoirs for oil and gas, and can have very low permeabilities (BRACE 1980). Production stimulation by induced fracturing is a common practice in the tighter sandstones (GIDLEY 1979). The general hydrolngir experience with the more permeable sandstone aquifers is extensive. Experience with the tighter gas and oil sands, while extensive, is less than that associated with the aquifers.

\section{C.4.1.5 Shale}

Shale is generally of such low permeability that its regional hydrologic behavior is almost exclusively that of an aquitard or aquiclude. Extensive, thick shale deposits can retard vertical groundwater movement and often act as confining beds for regional aquifers. Shales also locally serve as low permeability reservoirs for oil and gas (GUNZALES 1984). Hydrocarbon production at commercial levels from shales generally 
requires reservoir stimulation by induced fracturing (CUDERMAN 1984). Water supplies derived from shales are generally of low quantity and highly mineralized (LOMENICK 1983). Considering their low permeability, reasonably extensive hydrologic experience has been developed for shale horizons because of their abundance in nature and their important

regional roles in controlling groundwater movement, and because of their local importance as potential sources of oil and gas.

\section{C.4.2 GENERAL HYDROLOGIC CHARACTERISTICS}

\section{C.4.2.1 Anhydrock}

The intense degree of fracturing of most anhydrocks suggests that they may be successfully modeled as a porous continua for most practical applications. Flow is expected to occur within a complex network of short fractures along individual crystal boundaries, and to a lesser extent along joint planes related to regional tectonice. Because of its very low permeability, the validity of hydrologic continuum assumptions would be difficult to demonstrate on any reasonable scale. The occasional and sometimes large brine pockets would add an additional difficulty to detailed numerical modeling of anhydrock. Hydration to gypsum is accompanied by volume expansion that may locally increase porosity and permeability. Such hydration is thought to be responsible for floor heave observed in some tunnels in anhydrock (THORDARSON 1983). Interbedding of silts, clays and sands would be expected to result in an anisotropic medium with a larger horizontal than vertical hydraulic conductivity.

\section{C.4.2.2 Chalk}

Groundwater movement in the low permeability chalk beds of interest in nuclear waste disposal would be expected to occur primarily in a network of interconnected, smal1-aperture fractures. Continuum assumptions would be expected to be adequate provided the fractures are sufficiently well interconnected and do not exhibit a wide range of apertures (LONG 1982). Solution-enlarged fractures would be difficult to predict and mode1. The degree of anisotropy would be expected to depend largely upon the fracture pattern, with the greatest hydraulic conductivities being in the preferred direction of fracturing. For example, vertical fracturing is thought to locally control groundwater movement in the Austin chalk within those parts of the formation affected by folding (CORBETT 1982). In general, however, chalks are expected to exhibit higher horizontal than vertical conductivity, as is common for most sedimentary rocks.

\section{C.4.2.3 Carbonate Rocks (Limestone/Dolostone)}

Groundwater movement in the lower conductivity carbonate horizons of interest in nuclear waste disposal would, 1ike chalk, be expected to occur primarily in a network of interconnected, small aperture fractures. Because of their greater strength, fractures in carbonate rocks would be expected to be generally larger and more significant groundwater conductors than in chalk. The degree to which a continuum theory could be supported in a rarhnnate rock may he lese than in a rhalk hesause of the 
potential for a wider range of apertures. However, the higher hydraulic conductivities also expected in carbonate rocks would make the continuum assumptions easier to validate in the field. Fracturing in carbonate is often observed to be both horizontal and vertical. In general, the horizontal conductivity would be expected to be slightly greater than the vertical conductivity in a tight carbonate rock.

\section{C.4.2.4 Sandstone}

Groundwater movement in the low-conductivity sandstones of interest in nuclear waste disposal would be expected to occur within both the porous intact rock and in the fractures. Groundwater movement in tight sandstones is controlled primarily by compactional diagenesis, clay content, cementing materials, and degree of interconnection of the individual sand lenses (WALLS 1982; KNUTSON 1976). The influence of fractures on groundwater movement would depend upon the strength and degree of fracturing of the sandstone. In gencral, fracturee do not play the predominant hydrologic role in sandstones that they play in the harder rocks such as carbonate rocks, and a continuum theory would be expected to be more readily applicable to a sandstone. Many sandstones are relatively massive and unstratified, and the degree of anisotropy would not be expected to be large.

\section{C.4.2.5 Shale}

The plasticity that some shales may exhibit at depth suggests that fractures may not play the predominant role in groundwater movement that would be expected in some of the other rock types. Because of this, shales would be expected to be more readily modeled by anisotropic continuum methods and its hydrologic behavior would be expected to be predictable with less uncertainty than for rocks with fracture-dominated hydrologic properties. Because of the possible lack of significant fracturing, the ratio of horizontal to vertical conductivity would be expected to be higher in a shale than in most of the other rock types considered here.

\section{C.4.3 REGIONAL HYDRAULIC GRADIENTS}

Regional horizontal hydraulic gradients are generally low in flatlying sediments, being on the order of 0.0006 (several feet per mile). Vertical gradients are of ten somewhat larger because of the constrained vertical movement resulting from lower vertical conductivities in most sedimentary sequences. For purposes of the modeling studies in this report, horizontal gradients will be conservatively assumed to be 0.001 and vertical gradients will be assumed to be 0.01 . 


\section{C.5 HYDROLOGIC PROPERTIES}

Hydrologic properties of the five sedimentary rock types and other rocks associated with the selected reference sites are discussed in this chapter. The identification of and general considerations related to the hydrologic properties necessary to the ranking analyses are discussed in Sect. C.5.1. The actual values estimated for the various properties are presented together with appropriate documentation in Sects. C.5.2 through C.5.5.

\section{C.5.1 INTRODUCTION TO HYDROLOGIC PROPERTIES}

\section{C.5.1.1 Properties Needed for Ranking}

The analysis for estimating pre-waste-emplacement groundwater travel time involves solving the steady-state flow equation to get a potential field, developing a velocity field from the potential field and estimating travel time by solving a purely advective equation for the geometry, boundary conditions and material properties of the given site. The material properties required for the travel time analysis are thus hydraulic conductivity and effective porosity.

Groundwater inflow, for the purposes of this study, is defined as the volume of water per unit of time per meter of drift that would be expected to enter a repository and is calculated as a function of time following excavation. The analysis for inflow involves solving the transient flow equation for the geometry, including that of the drift, the boundary and initial conditions and the material properties of the given site. The material properties required for the inflow analysis are thus hydraulic conductivity and specific storage.

The three material properties that must be estimated for all of the geologic media at each of the reference sitos are therefore hydranlic. conductivity, effective porosity and specific storage. It should be noted that because the thermal loading resulting from radioactive decay is not considered in these analyses, isothermal assumptions are made and hydraulic conductivity as opposed to intrinsic permeability is used.

\section{C.5.1.2 Consideration of Scale Effects}

Estimated values for each of the three properties to be used in the analyses discussed in Sect. C.7 should be representative of the various geologic media on the scale of the analyses, which for the present study is tens to thousands of meters. The uncertainties inherent in developing these properties on the required scales are significant for most of the rock types being considered because of the ubiquitous problems associated with obtaining large-scale direct hydrologic field measurements in lower conductivity media.

In general, the most common hydrologic field tests, pumping and injection tests, are limited by the large times required to stress 
significant volumes of lower conductivity media. For the most part, tests even on the scale of meters are uncommon in these media, and most of the available data are from laboratory measurement of core samples on the order of centimeters.

Much of the data base developed in this chapter is taken from core data, particularly for determining effective porosity. These data do not reflect the large-scale effects of fractures on the hydrological parameters. Reliance on core data was required because of a lack of relevant field measurements. Estimation of hydrologic properties from core data is relatively common and is frequently done in the oil and gas industry where relatively low-conductivity host media are routinely evaluated.

The major problem associated with the use of core data is that the hydrologic properties of the core reflect relatively small intact pieces of rock. This can present a significant problem in cases of rocks such as granite where rlow is fracture dominated. The flow in some of the rock types considered in this study is probably fracture dominated. It is believed that continuum assumptions are valid on the scale of the models being used in this study. The problems of estimating large-scale continuum properties from core measurements are discussed for each of the properties to be estimated in later sections.

\section{C.5.1.3 Development of Ranges}

Ranges are associated with each of the data base parameters for the alternative host rock types because of the variability observed in nature. The base cases are defined by the typical values of the data base parameters. For each rock type, the "typical" value is a value that would be expected to be generally available at a number of field locations in a horizon of sufficient thickness and extent to be considered for nuclear waste disposal. However, due to the heavy reliance on the core data and the need to have the data base internally consistent in a relative sense, the typical values should be regarded as being representative of the more favorable properties of the rock types as related to repository performance in all cases. To obtain this consistency, considerable judgment had to be used in evaluating the database, and, in some instances (e.g., effective porosity), it was neceasary to diminish the importance of virtually all of the avallable data due to its characterizing locations not relevant to a repository (e.g., groundwater aquifers, heavily fractured rocks).

A lack of sufficient data for many of the hydrologic parameters did not permit a meaningful derivation of their typical value and range in strict probabilistic terms. The range in properties is therefore expressed as "high" and "low" values that bracket the typical value. These ranges are intended to account for the likely variations in properties but are not intended to be statistically rigorous or to include all extreme values. Because of the generic nature of this study and the wide variations commonly observed in hydrologic properties, all adopted data base values will be expressed as order-of-magnitude approximations. 


\section{C.5.1.4 Development of Hydraulic Conductivity Data}

Hydraulic conductivity is a measure of the ease with which groundwater can travel through a porous continuum under a given hydraulic gradient. Uncertainties in hydraulic conductivity values arise primarily from geologic variability within individual formations and from geologic variations observed from formation to formation of the same rock type. The results of these variations are evident in the wide ranges of hydraulic conductivities reported in the literature. These ranges of values are reflected in the data base in the form of order-of-magnitude ranges of likely hydraulic conductivities assigned to all rock types.

Much of the data base used in this study was taken from the literature of the oil and gas industry. Intrinsic permeability, measured in darcies ( 1 darcy $=10^{-12} \mathrm{~m}^{2}$ ), is universally used in this literature because of the highly variable temperatures and fluid types that must be considered. Hydraulic conductivity io moet widely used in the groundwater literature, because the thermal conditions and fluid types are less variable at the shallower depths normally considered. The data base used here is expressed in terms of hydraulic conductivities, and any conversions made from intrinsic permeability assumed water as the moving fluid and $20^{\circ} \mathrm{C}$ as the temperature. The degree of uncertainty in hydraulic conductivity resulting only from geologic variability is sufficiently high that any errors introduced by the assumption of a standard temperature and fluid type are small.

For each rock type, avallable hydraulic conductivity data from field tests are given preference over laboratory data from core analysis. Hydraulic conductivities derived from core measurements tend to be lower than those derived from field measurements in many rock types because of the inability of the core measurements to treat the effects of fractures. In addition, where some formations of a given rock type may be sufficiently permeable to be considered good groundwater aquifers, the adopted data base for modeling and ranking purposes has been drawn from the lower conductivity formations of that rock type that would be more suitable tor waste storage. As will be seen, this latter consideration applies particularly to carbonate rocks, sandstone and chalk.

\section{C.5.1.5 Development of Effective Porosity Data}

Effective porosity is traditionally considered to be that part of the total porosity that is actively involved in conducting fluid flow. Total porosity is the ratio of the volume of voids to the total volume of the rock, and effective porosity is therefore thought of as the ratio of the volume of conductive voids to the total volume of the rock. In practice, effective porosity is measured in tracer tests and is equal to the ratio of the specific discharge (flow rate per unit area) across a surface to the linear particle velocity of groundwater movement across that same surface. As is evident from its measurement, "effective porosity" is determined purely from hydraulic factors and is in fact a hydraulic rather than a volumetric property of the rock. 
Measurement of the linear particle velocity needed to determine effective porosity requires passing a nonreactive tracer through a volume of rock under a known hydraulic gradient. Appropriate effective porosities for purposes of the ranking analyses require that the volume tested be sufficiently large to result in values representative of the rock on a scale of tens to thousands of meters. Difficulties arise in performing these measurements because of the very low hydraulic conductivities of most of the rock types under consideration. Particle transport through porous media requires orders of magnitude greater time than the pressure pulse needed to measure hydraulic conductivity, and large-scale tracer tests may require years to complete, even in relatively permeable media. Because of these difficulties, field tracer tests in low conductivity sediments are almost nonexistent, and laboratory tracer tests on core samples are very rare.

Because of the lack of data on effective porosity in many rock types, $1 \tau$ was usually necessary to estimate the magnilude of this parameler from total porosity data. Such data are available from laboratory tests on cores and from geophysical density logs in the field. The laboratory tests have the problem of small sample volumes, while the field tests have calibration uncertainties. Despite these difficulties, the laboratory values of total porosity are normally considered to be reasonably representative of field conditions, and the primary source of uncertainty is in approximating the effective porosity from the total porosity data.

Effective porosity can be over an order of magnitude smaller than the total porosity. This difference tends to be greatest for those rocks whose hydraulic conductivity is derived primarily from fracture flow. Flow in tight, fractured media can occur in a very small fraction of the total rock volume and result in a very low effective porosity. While total porosities of less than 0.01 ( $1 \%$ ) are unusual in geologic media, effective porosities in deeply buried fractured rock can be less than $0.001(0.1 \%)$.

The difference between total and effective porosity varies among rock types, depending primarily upon the degree to which the fracture system has altered the hydraulic conductivity of the intact rock. In general, unless the fracture porosity is ilself siguificailly large, the greater the dependence of rock mass conductivity on fracture flow, the greater the difference will be between total and effective porosity. The dependence of rock mass conductivity on fracture flow is often manifested as a significant difference between rock mass and intact rock conductivity, which in turn are respectively related to field and core conductivity test results. Exceptions occur in rocks susceptible to dissolution, such as carbonate rocks, and in rocks that have been highly fractured.

Despite the uncertainties associated with effective porosity, the range of values observed in the field is not as large as the several orders of magnitude ranges associated with hydraulic conductivities. The incremental uncertainty introduced by effective porosity into the ranking analyses would therefore be expected to be less than that for lyydaulic cunduclivily. 


\section{C.5.1.6 Development of Specific Storage Data}

Specific storage is a measure of the volume of water that can be removed from or added to a volume of rock due to pressure changes within that volume. Specific storage in deep, confined strata results from the compressibility of the water and rock, and is orders of magnitude lower than specific storage in a water table aquifer where storage changes result primarily from emptying or filling unsaturated void space.

Accurate measurements of specific storage are obtained fxom multiple we11 interference tests in the field. These tests rely upon the observation of water level changes in monitoring wells at varying distances and directions from the pumping or injection we11. To obtain good accuracy, the monitoring wells must be hundreds to thousands of wel1 diameters from the pumping we11. As distances between wells increase, the scale of measurement increases as does the required test time. Field measurements of specific storage are rcasonably common in highcr conductivity aquifers but are very rare in the deep, low conductivity sediments of interest in waste disposal. This lack of information results primarily from the long testing times required, and from the high cost of drilling deep multiple wells.

No field data were found in the literature on specific storage for any of the low conductivity media considered in this study to be suitable for waste disposal. In addition, specific storage is not normally measured using core samples because of a lack of accuracy. Under such circumstances, the magnitude of specific storage is commonly approximated for deep, confined strata from compressibility data for the water and the sediments. The basic equation, as adapted from FREEZE (1979), is:

$$
S_{S}=\rho g\left(n_{t} C_{W}+C_{T}\right)
$$

where $S_{S}=$ specific storage,

$\rho=$ density of water,

$g=$ acceleration of gravity,

$\mathrm{n}_{\mathrm{t}}=$ total porosity,

$\mathrm{C}_{\mathrm{W}}=$ compressibility of water,

$\mathrm{C}_{\mathrm{r}}=$ compressibility of rock.

The compressibility of rock is defined for an isotropic, homogeneous elastic medium as the reciprocal of the bulk modulus, or:

$$
C_{r}=3(1-2 \mu) / E \text {, }
$$

where $\begin{aligned} \mu & =\text { Poisson's ratio } \\ E & =\text { modulus of elasticity. }\end{aligned}$

Because of a lack of data on specific storage, this property was estimated using Eqs. (5-1) and (5-2). Ranges were determined based upon the ranges associated with the input parameters. While this is not the most desirable procedure and while the results must be considered order of magnitude opproximatione, the values obtained do fall within the ranges that would be expected from field measurements and are considered to be adequate for these generic studies. 


\section{C.5.2 HYDRAULIC CONDUCTIVITY}

The hydraulic conductivity data bases developed for the ranking modeling studies are presented in Tables C.5.1 through $\mathrm{C.5.6}$ by rock type. The adopted data base values and the supporting information obtained from the literature are presented, respectively, for anhydrock, chalk, carbonate rocks, sandstone, and shale. An additional tabulation of data is provided for salt, a distinct rock type that appears on the reference stratigraphic section for anhydrock.

Tah1e C.5.1. Hydran1ic conductivity data base for anhydrock

\begin{tabular}{|c|c|c|c|c|c|}
\hline $\begin{array}{c}\text { No. } \\
\text { samples }\end{array}$ & $\begin{array}{l}\text { Horizontal } \\
\text { conductivity } \\
(\mathrm{m} / \mathrm{s})\end{array}$ & $\begin{array}{l}\text { Vertical } \\
\text { conductivity } \\
(\mathrm{m} / \mathrm{s})\end{array}$ & Reference & Origin and & comments \\
\hline
\end{tabular}

CORE DATA

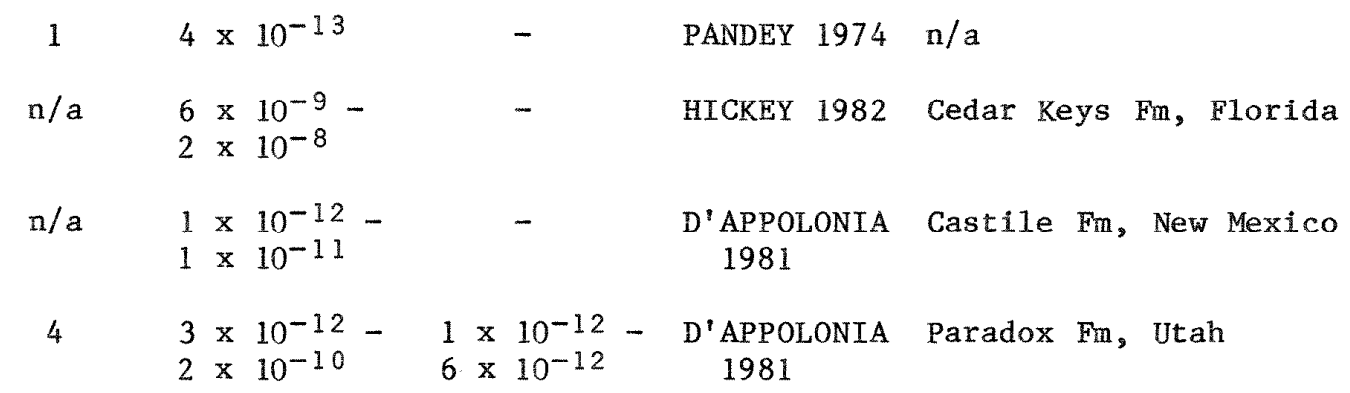

FTELD TEST DATA

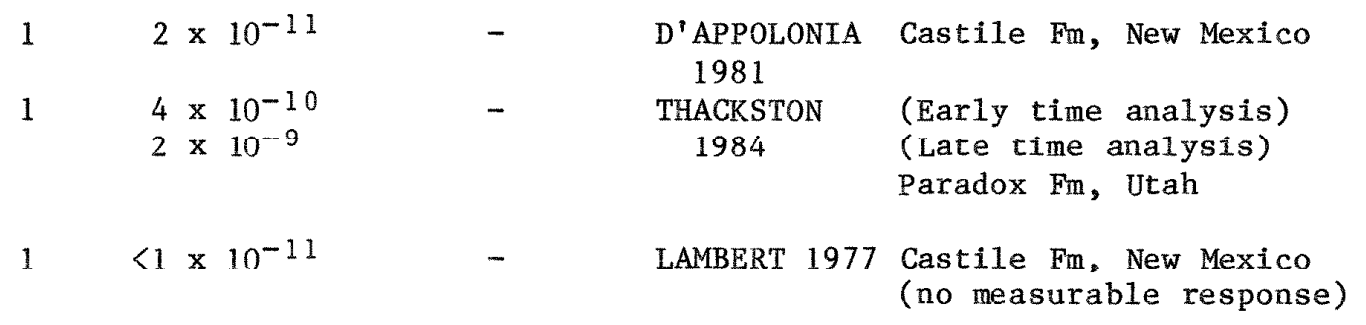

ADOPTED DATA BASE VALUES

\begin{tabular}{llll} 
& Typical & High & Low \\
\cline { 2 - 3 } $\begin{array}{c}\text { Horizontal hydraulic } \\
\text { conductivity, m/s }\end{array}$ & $1 \times 10^{-11}$ & $1 \times 10^{-10}$ & $1 \times 10^{-12}$ \\
$\begin{array}{c}\text { Vertical hydraulic } \\
\text { conductivity, } \mathrm{m} / \mathrm{s}\end{array}$ & $1 \times 10^{-12}$ & $1 \times 10^{-11}$ & $1 \times 10^{-13}$
\end{tabular}


Table C.5.2. Hydraulic conductivity data base for chalk

\begin{tabular}{|c|c|c|c|c|}
\hline $\begin{array}{l}\text { No. } \\
\text { samples }\end{array}$ & $\begin{array}{l}\text { Horizontal } \\
\text { conductivity } \\
(\mathrm{m} / \mathrm{s})\end{array}$ & $\begin{array}{l}\text { Vertical } \\
\text { conductivity } \\
(\mathrm{m} / \mathrm{s})\end{array}$ & Reference & Origin and comments \\
\hline \multicolumn{5}{|l|}{ CORE DATA } \\
\hline $\mathrm{n} / \mathrm{a}$ & $\begin{array}{l}9 \times 10^{-9}- \\
2 \times 10^{-8}\end{array}$ & $\begin{array}{l}8 \times 10^{-9}- \\
2 \times 10^{-8}\end{array}$ & EDMUNDS 1973 & $\begin{array}{l}\text { Upper \& Middle Chalk, } \\
\text { Berkshire, England } \\
\text { (shallow depths) }\end{array}$ \\
\hline $\mathrm{n} / \mathrm{a}$ & $\begin{array}{l}3 \times 10^{-10} \\
1 \times 10^{-9} \\
9 \times 10^{-10}\end{array}$ & - & BELL 1977 & $\begin{array}{l}\text { Lower Chalk, Yorkshire, } \\
\text { England } \\
\text { (mean value) }\end{array}$ \\
\hline $\mathrm{n} / \mathrm{a}$ & $\begin{array}{l}5 \times 10^{-10}- \\
2 \times 10^{-9} \\
1 \times 10^{-9}\end{array}$ & - & BELL 1977 & $\begin{array}{l}\text { Middle Chalk, Yorkshire, } \\
\text { England } \\
\text { (mean value) }\end{array}$ \\
\hline$n / a$ & $\begin{array}{l}1 \times 10^{-8}- \\
4 \times 10^{-8} \\
3 \times 10^{-8}\end{array}$ & - & BELL 1977 & $\begin{array}{l}\text { Upper Chalk, Yorkshire, } \\
\text { England } \\
\text { (mean value) }\end{array}$ \\
\hline $\mathrm{n} / \mathrm{a}$ & $3 \times 10^{-9}$ & - & CORBETT 1983 & Austin Chalk, Texas \\
\hline $\mathrm{n} / \mathrm{a}$ & $\begin{array}{l}0.0- \\
4 \times 10^{-9}\end{array}$ & - & DOYLE 1955 & $\begin{array}{l}\text { Austin Chalk, Texas } \\
\text { (minimum resolution not } \\
\text { indicated) }\end{array}$ \\
\hline 1 & $2 \times 10^{-5}$ & - & SNYDER 1977 & $\begin{array}{l}\text { Austin Chalk, Texas } \\
\text { (open fracture in core) }\end{array}$ \\
\hline $\mathrm{n} / \mathrm{a}$ & $1 \times 10^{-9}$ & - & SNYDER 1977 & Buda Chalk, Texas \\
\hline 27 & $\begin{array}{l}1 \times 10^{-10}- \\
1 \times 10^{-8} \\
2 \times 10^{-9}\end{array}$ & - & SNYDER 1977 & $\begin{array}{l}\text { Austin Chalk, Texas } \\
\text { (mean value) }\end{array}$ \\
\hline 5 & $\begin{array}{l}3 \times 10^{-10}- \\
4 \times 10^{-9} \\
1 \times 10^{-9}\end{array}$ & - & CORBETT 1983 & $\begin{array}{l}\text { Brushy Creek Section, } \\
\text { Austin Chalk, Texas } \\
\text { (mean value) }\end{array}$ \\
\hline 6 & $\begin{array}{l}7 \times 10^{-10}- \\
3 \times 10^{-9} \\
2 \times 10^{-9}\end{array}$ & - & CORBETT 1983 & $\begin{array}{l}\text { Longhorn Quarry, } \\
\text { Austin Chalk, Texas } \\
\text { (mean value) }\end{array}$ \\
\hline 6 & $\begin{array}{l}5 \times 10^{-10}- \\
2 \times 10^{-8} \\
7 \times 10^{-9}\end{array}$ & - & CORBETT 1983 & $\begin{array}{l}\text { Alamo Quarry Section, } \\
\text { Austin Chalk, Texas } \\
\text { (mean value) }\end{array}$ \\
\hline
\end{tabular}


Table C.5.2 (continued)

\begin{tabular}{|c|c|c|c|c|}
\hline $\begin{array}{l}\text { No. } \\
\text { samples }\end{array}$ & $\begin{array}{r}\text { Horizontal } \\
\text { conductivity } \\
(\mathrm{m} / \mathrm{s})\end{array}$ & $\begin{array}{l}\text { Vertical } \\
\text { conductivity } \\
(\mathrm{m} / \mathrm{s})\end{array}$ & Reference & Origin and comments \\
\hline 10 & $\begin{array}{l}1 \times 10^{-10}- \\
6 \times 10^{-10} \\
3 \times 10^{-10}\end{array}$ & - & CORBETT 1983 & $\begin{array}{l}\text { Langtry Section, } \\
\text { Austin Chalk, Texas } \\
\text { (mean value) }\end{array}$ \\
\hline 7 & $\begin{array}{l}1 \times 10^{-9}- \\
1 \times 10^{-8} \\
5 \times 10^{-9}\end{array}$ & - & CORBETT 1983 & $\begin{array}{l}\text { Mamulique Pass, } \\
\text { Austin Chalk, Texas } \\
\text { (mean value) }\end{array}$ \\
\hline 4 & $\begin{array}{l}1 \times 10^{-10}- \\
1 \times 10^{-8} \\
3 \times 10^{-9}\end{array}$ & - & CORBETT 1983 & $\begin{array}{l}\text { Parras Basin, } \\
\text { Austin Chalk, Texas } \\
\text { (mean value) }\end{array}$ \\
\hline 6 & $\begin{aligned} 1 & \times 10^{-10} \\
3 & \times 10^{-8} \\
1 & \times 10^{-8}\end{aligned}$ & - & CORBETT 1983 & $\begin{array}{l}\text { preuse Core, } \\
\text { Austin Chalk, Texas } \\
\text { (mean value) }\end{array}$ \\
\hline 225 & $\begin{array}{rrr}<1 & \times 10^{-10} \\
3 & \times & 10^{-9} \\
1 & \times & 10^{-10}\end{array}$ & - & CORBETT 1983 & $\begin{array}{l}\text { Beall Core, } \\
\text { Austin Chalk, Texas } \\
\text { (mean value) }\end{array}$ \\
\hline 88 & $\begin{array}{rll}<1 & \times 10^{-10}- \\
1 & \times & 10^{-7} \\
5 & \times & 10^{-9}\end{array}$ & - & CORBETT 1983 & $\begin{array}{l}\text { Varner-Wendler Core, } \\
\text { Austin Chalk, Texas } \\
\text { (mean value) }\end{array}$ \\
\hline 91 & $\begin{array}{rll}<1 & \times 10^{-10}- \\
1 & \times 10^{-9} \\
3 & \times 10^{-10}\end{array}$ & - & CORBETT 1983 & $\begin{array}{l}\text { Winterbotham Core, } \\
\text { Austin Chalk, Texas } \\
\text { (mean value) }\end{array}$ \\
\hline 152 & $\begin{aligned}<1 & \times 10^{-10}- \\
3 & \times 10^{-9} \\
5 & \times 10^{-10}\end{aligned}$ & - & CORBETT 1983 & $\begin{array}{l}\text { Weinert Core, } \\
\text { Austin Chalk, Texas } \\
\text { (mean value) }\end{array}$ \\
\hline 175 & $\begin{aligned}<1 & \times 10^{-10}- \\
2 & \times 10^{-6} \\
3 & \times 10^{-9}\end{aligned}$ & - & CORBETT 1983 & $\begin{array}{l}\text { Samuels Core, } \\
\text { Austin Chalk, Texas } \\
\text { (mean value) }\end{array}$ \\
\hline \multicolumn{5}{|c|}{ EIELD TEST DATA } \\
\hline $\mathrm{n} / \mathrm{a}$ & $4 \times 10^{-4}$ & - & EDMUNDS 1973 & $\begin{array}{l}\text { Upper \& Middle Chalk, } \\
\text { Berkshire, England }\end{array}$ \\
\hline $\mathrm{n} / \mathrm{a}$ & $1 \times 10^{-6}$ & - & SNYDER 1977 & $\begin{array}{l}\text { Austin Chalk, Texas } \\
\text { (estimated from fracture } \\
\text { data for fractured } \\
\text { areas) }\end{array}$ \\
\hline
\end{tabular}


Table C.5.2 (continued)

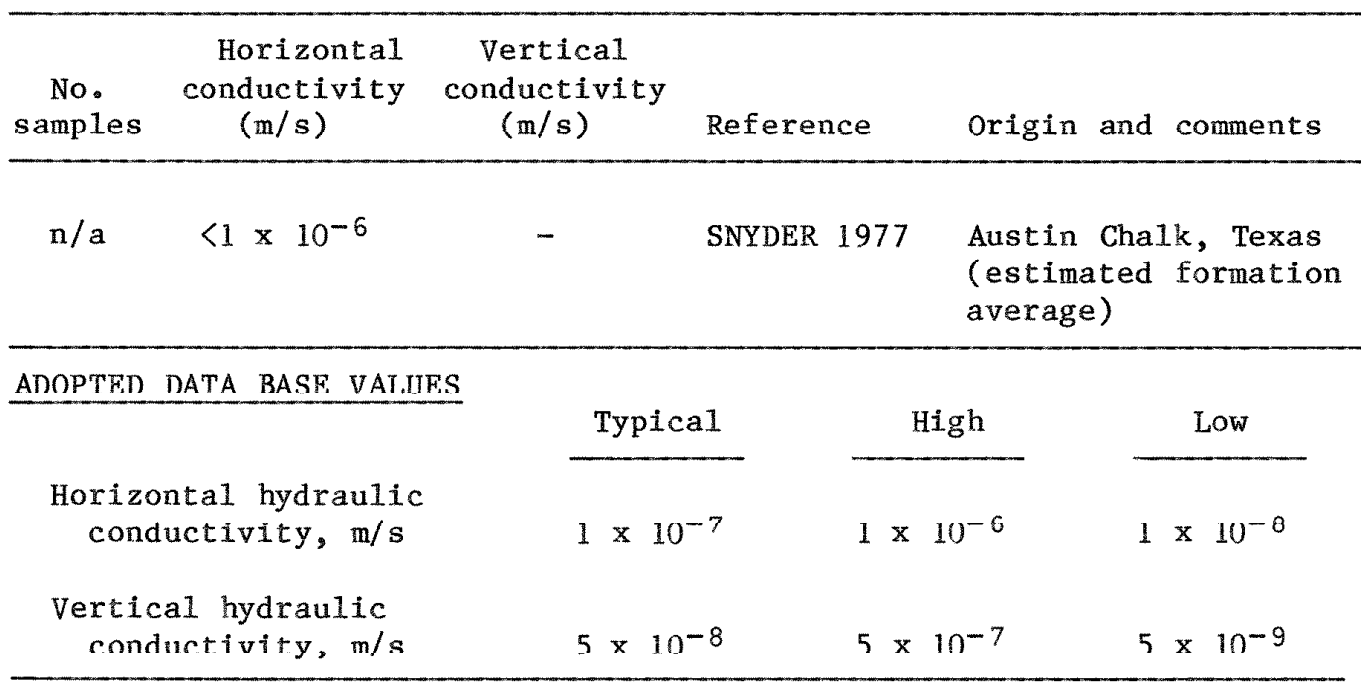

Table C.5.3. Hydraulic conductivity data base for carbonate rocks

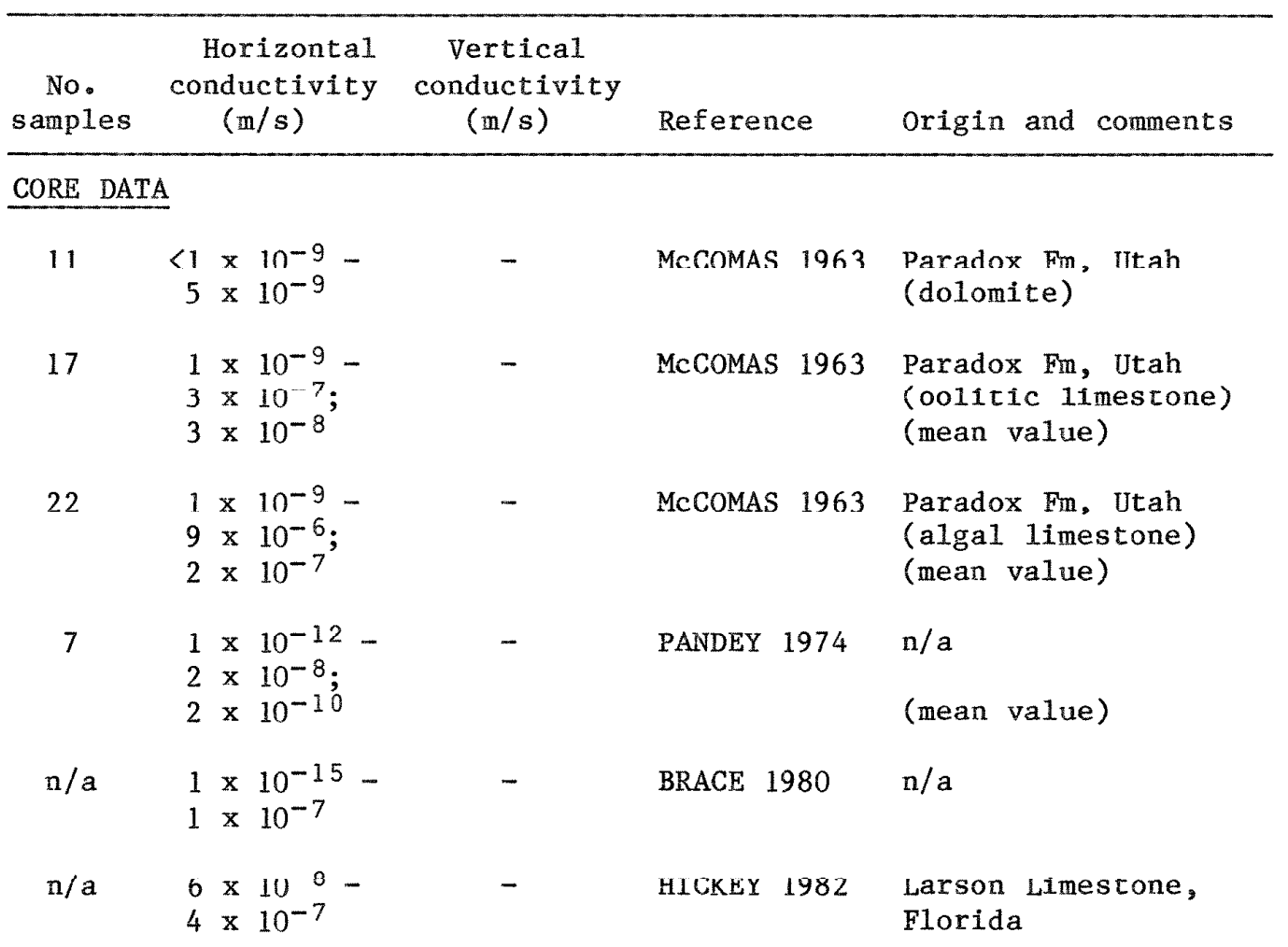


Table 0.5 .3 (continued)

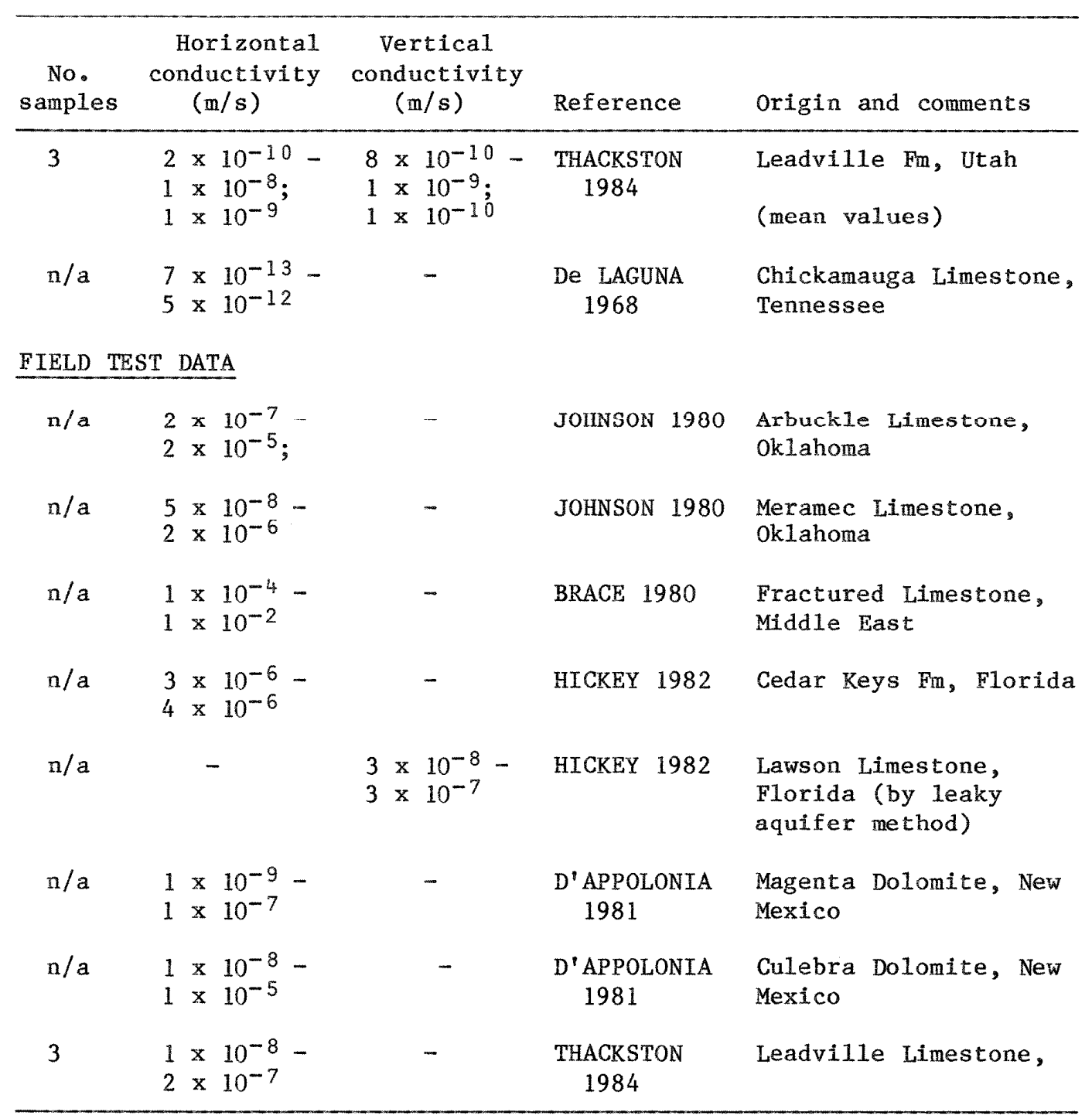

ADOPTED DATA BASE VALUES

\begin{tabular}{cccc} 
& Typical & High & Low \\
\cline { 2 - 3 } $\begin{array}{c}\text { Horizontal hydraulic } \\
\text { conductivity, m/s }\end{array}$ & $1 \times 10^{-6}$ & $1 \times 10^{-5}$ & $1 \times 10^{-7}$ \\
$\begin{array}{c}\text { Vertical hydraulic } \\
\text { conductivity, } \mathrm{m} / \mathrm{s}\end{array}$ & $5 \times 10^{-7}$ & $5 \times 10^{-6}$ & $5 \times 10^{-8}$ \\
\hline
\end{tabular}


Table C.5.4. Hydraulic conductivity data base for sandstone

\begin{tabular}{|c|c|c|c|c|}
\hline $\begin{array}{l}\text { No. } \\
\text { samples }\end{array}$ & $\begin{array}{l}\text { Horizontal } \\
\text { conductivity } \\
(\mathrm{m} / \mathrm{s})\end{array}$ & $\begin{array}{l}\text { Vertical } \\
\text { conductivity } \\
(\mathrm{m} / \mathrm{s})\end{array}$ & Reference & origin and comments \\
\hline \multicolumn{5}{|c|}{ CORE DATA } \\
\hline 1 & $4 \times 10^{-7}$ & - & PANDEY 1974 & $\mathrm{n} / \mathrm{a}$ \\
\hline 1 & $6 \times 10^{-10}$ & - & MANILLA 1980 & $\begin{array}{l}\text { Uinta Basin Gas Sand, } \\
\text { Utah (700 m depth) }\end{array}$ \\
\hline 4 & $\begin{array}{l}3 \times 10^{-10}- \\
2 \times 10^{-8}\end{array}$ & - & DOE 1981 & $\begin{array}{l}\text { Uinta Basin Gas Sand, } \\
\text { Colorado ( } 1950 \mathrm{~m} \text { depth) }\end{array}$ \\
\hline 12 & $\begin{array}{l}1 \times 10^{-12}- \\
2 \times 10^{-9}\end{array}$ & - & DOE 1981 & $\begin{array}{l}\text { Uinta Basin Gas Sand, } \\
\text { Utah ( } 2500 \mathrm{~m} \text { depth })\end{array}$ \\
\hline 2 & $\begin{array}{l}1 \times 10^{-11}- \\
3 \times 10^{-11}\end{array}$ & - & WALLS 1982 & $\begin{array}{l}\text { Cotton Valley Gas Sand, } \\
\text { Texas }\end{array}$ \\
\hline 9 & $\begin{array}{l}1 \times 10^{-11}- \\
1 \times 10^{-10}\end{array}$ & - & WALLS 1982 & $\begin{array}{l}\text { Spirit River Gas Sand, } \\
\text { Alberta }\end{array}$ \\
\hline $\mathrm{n} / \mathrm{a}$ & $\begin{array}{l}5 \times 10^{-5}- \\
1 \times 10^{-9}\end{array}$ & - & BRACE 1980 & $\mathrm{n} / \mathrm{a}$ \\
\hline 3 & $\begin{array}{l}1 \times 10^{-7}- \\
2 \times 10^{-7}\end{array}$ & $\begin{array}{l}1.7 \times 10^{-9}- \\
1.8 \times 10^{-9}\end{array}$ & $\begin{array}{l}\text { THACKSTON } \\
1984\end{array}$ & Cedar Mesa Fm, Utah \\
\hline 7 & $\begin{array}{l}3 \times 10^{-10}- \\
5 \times 10^{-7}\end{array}$ & $-\quad \begin{array}{r}<\times 10^{-12}- \\
2 \times 10^{-7}\end{array}$ & $\begin{array}{l}\text { THACKSTON } \\
1984\end{array}$ & $\begin{array}{l}\text { Elephant Canyon Fm, } \\
\text { Utah }\end{array}$ \\
\hline \multicolumn{5}{|c|}{ FIELD TEST DATA } \\
\hline $\mathrm{n} / \mathrm{a}$ & $\begin{array}{l}9 \times 10^{-6}- \\
2 \times 10^{-5}\end{array}$ & - & JOHNSON 1980 & $\begin{array}{l}\text { Bromide Sandstone, } \\
\text { Oklahoma }\end{array}$ \\
\hline $\mathrm{n} / \mathrm{a}$ & $\begin{array}{l}3 \times 10^{-11} \\
3 \times 10^{-10}\end{array}$ & - & GIDLEY 1979 & $\begin{array}{l}\text { Mesaverde Fm, Colorado } \\
\text { (gas sand) }\end{array}$ \\
\hline 1 & $2 \times 10^{-10}$ & - & GIDLEY 1979 & $\begin{array}{l}\text { Cotton Valley Gas Sand, } \\
\text { Texas }\end{array}$ \\
\hline $\mathrm{n} / \mathrm{a}$ & $1 \times 10^{-11}$ & - & WYMAN 1979 & $\begin{array}{l}\text { Fahler Gas Sand, } \\
\text { Alberta }\end{array}$ \\
\hline $\mathrm{n} / \mathrm{a}$ & $\begin{array}{l}1 \times 10^{-10}- \\
5 \times 10^{-10}\end{array}$ & - & BRACE 1980 & $\begin{array}{l}\text { General Values for } \\
\text { Gas Sands }\end{array}$ \\
\hline 2 & $\begin{array}{l}8 \times 10^{-12}- \\
2 \times 10^{-7}\end{array}$ & - & $\begin{array}{l}\text { THACKSTON } \\
1984\end{array}$ & $\begin{array}{l}\text { Elephant Canyon Fm, } \\
\text { Utah }\end{array}$ \\
\hline
\end{tabular}


Table C.5.4 (continued)

\begin{tabular}{lccc}
$\begin{array}{c}\text { No. } \\
\text { samples }\end{array} \begin{array}{c}\text { Honductivity } \\
(\mathrm{m} / \mathrm{s})\end{array}$ & $\begin{array}{c}\text { Vertical } \\
\text { conductivity } \\
(\mathrm{m} / \mathrm{s})\end{array}$ & Reference & Origin and comments \\
\hline ADOPTED DATA BASE VALUES & Typical & High & Low \\
$\begin{array}{c}\text { Horizontal hydraulic } \\
\text { conductivity, } \mathrm{m} / \mathrm{s}\end{array}$ & $1 \times 10^{-10}$ & $1 \times 10^{-8}$ & $5 \times 10^{-11}$ \\
$\begin{array}{c}\text { Vertical hydraulic } \\
\text { conductivity, } \mathrm{m} / \mathrm{s}\end{array}$ & $5 \times 10^{-11}$ & $5 \times 10^{-9}$ & $2.5 \times 10^{-11}$ \\
\hline
\end{tabular}

Table C.5.5. Hydraulic conductivity data base for shale

\begin{tabular}{|c|c|c|c|c|}
\hline $\begin{array}{l}\text { No. } \\
\text { samples }\end{array}$ & $\begin{array}{l}\text { Horizontal } \\
\text { conductivity } \\
(\mathrm{m} / \mathrm{s})\end{array}$ & $\begin{array}{l}\text { Vertical } \\
\text { conductivity } \\
(\mathrm{m} / \mathrm{s})\end{array}$ & Reference & Origin and comments \\
\hline \multicolumn{5}{|c|}{ CORE DATA } \\
\hline $\mathrm{n} / \mathrm{a}$ & $3 \times 10^{-11}$ & - & DOE 1981 & $\begin{array}{l}\text { Devonian Shale, } \\
\text { Pennsylvania }\end{array}$ \\
\hline $\mathrm{n} / \mathrm{a}$ & $\begin{array}{l}1 \times 10^{-11} \\
2 \times 10^{-8}\end{array}$ & $\mathrm{Kv}<<\mathrm{Kh}$ & $\begin{array}{l}\text { GONZALES } \\
1984\end{array}$ & $\begin{array}{l}\text { Devonian Michigan } \\
\text { Basin Shale, Michigan }\end{array}$ \\
\hline $\mathrm{n} / \mathrm{a}$ & $\begin{array}{lll}1 \times 10^{-13} \\
1 \times 10^{-10}\end{array}$ & - & $\begin{array}{c}\text { GONZALES } \\
1984\end{array}$ & $\begin{array}{l}\text { Triassic Dumbarton } \\
\text { Basin Shale, South } \\
\text { Caroliua }\end{array}$ \\
\hline $\mathrm{n} / \mathrm{a}$ & $\begin{array}{lll}1 & \times 10^{-11} \\
7 & \times 10^{-9}\end{array}$ & - & PANDEY 1974 & $\mathrm{n} / \mathrm{a}$ \\
\hline $\mathrm{n} / \mathrm{a}$ & $\begin{array}{lll}1 \times 10^{-16} \\
1 \times 10^{-11}\end{array}$ & - & BRACE 1980 & $\mathrm{n} / \mathrm{a}$ \\
\hline $\mathrm{n} / \mathrm{a}$ & $\begin{array}{l}3 \times 10^{-13} \\
2 \times 10^{-12}\end{array}$ & - & $\begin{array}{l}\text { De LAGUNA } \\
1968\end{array}$ & $\begin{array}{l}\text { Cambrian Conasauga } \\
\text { Shale, Tennessee }\end{array}$ \\
\hline
\end{tabular}

\section{FIELD TEST DATA}

\begin{tabular}{|c|c|c|c|}
\hline $\mathrm{n} / \mathrm{a} \quad 2 \times 10^{-11}$ & - & $\begin{array}{c}\text { GONZALES } \\
1984\end{array}$ & $\begin{array}{l}\text { Ordovician Maquoketa } \\
\text { Shale, Inlinois }\end{array}$ \\
\hline
\end{tabular}


Table C.5.5 (continued)

\begin{tabular}{|c|c|c|c|c|}
\hline $\begin{array}{c}\text { No. } \\
\text { samples }\end{array}$ & $\begin{array}{l}\text { Horizontal } \\
\text { conductivity } \\
(\mathrm{m} / \mathrm{s})\end{array}$ & $\begin{array}{l}\text { Vertical } \\
\text { conductivity } \\
(\mathrm{m} / \mathrm{s})\end{array}$ & Reference & Origin and comments \\
\hline $\mathrm{n} / \mathrm{a}$ & $1 \times 10^{-12}$ & - & $\begin{array}{l}\text { GONZALES } \\
1984\end{array}$ & $\begin{array}{l}\text { Triassic Dumbarton } \\
\text { Basin Shale, South } \\
\text { Carolina }\end{array}$ \\
\hline $\mathrm{n} / \mathrm{a}$ & $\begin{array}{l}0.0- \\
1 \times 10^{-9}\end{array}$ & - & $\begin{array}{l}\text { GONZAZES } \\
1984\end{array}$ & $\begin{array}{l}\text { Triassic Newark-Gertys- } \\
\text { urg Basin Shale, } \\
\text { Maryland (minimum } \\
\text { resolution not given) }\end{array}$ \\
\hline $\mathrm{n} / \mathrm{a}$ & $1 \times 10^{-11}$ & - & DOE 1981 & $\begin{array}{l}\text { Devonian Shale, } \\
\text { Pennsylvania }\end{array}$ \\
\hline $\mathrm{n} / \mathrm{a}$ & $\begin{array}{l}1 \times 10^{-11}- \\
1 \times 10^{-6}\end{array}$ & $\begin{array}{l}\mathrm{Kv}=1 / 2 \\
\text { to } 1 / 10 \mathrm{Kh}\end{array}$ & $\begin{array}{l}\text { D'APPOLONIA } \\
1980\end{array}$ & $\begin{array}{l}\text { Generic Shale } \\
\text { Properties }\end{array}$ \\
\hline $\mathrm{n} / \mathrm{a}$ & $\begin{array}{l}1 \times 10^{-12}- \\
1 \times 10^{-11}\end{array}$ & - & BRACE 1980 & $\begin{array}{l}\text { Pierre Shale, South } \\
\text { Dakota }\end{array}$ \\
\hline $\mathrm{n} / \mathrm{a}$ & $\begin{array}{l}1 \times 10^{-13}- \\
5 \times 10^{-10}\end{array}$ & - & BRACE 1980 & $\begin{array}{l}\text { Triassic Siltstone/ } \\
\text { Mudstone, South } \\
\text { Carolina }\end{array}$ \\
\hline
\end{tabular}

ADOPTED DATA BASE VALUES

\begin{tabular}{llll} 
Horizontal hydraulic \\
$\begin{array}{c}\text { conductivity, m/s } \\
\begin{array}{c}\text { vertical hydraulic } \\
\text { conductivity, m/s }\end{array}\end{array}$ & $1 \times 10^{-11}$ & $1 \times 10^{-10}$ & Low \\
\cline { 2 - 3 } & $1 \times 10^{-12}$ & $1 \times 10^{-11}$ & $1 \times 10^{-13}$ \\
\hline
\end{tabular}


Table $6.5 \cdot 6$. Hydraulic conductivity data base for salt

\begin{tabular}{|c|c|c|c|c|}
\hline $\begin{array}{l}\text { No. } \\
\text { samples }\end{array}$ & $\begin{array}{l}\text { Horizontal } \\
\text { conductivity } \\
\quad(\mathrm{m} / \mathrm{s})\end{array}$ & $\begin{array}{l}\text { Vertical } \\
\text { conductivity } \\
(\mathrm{m} / \mathrm{s})\end{array}$ & Reference & Origin and comments \\
\hline \multicolumn{5}{|l|}{ CORE DATA } \\
\hline 7 & $\begin{array}{r}<1 \times 10^{-12}- \\
2 \times 10^{-10}\end{array}$ & - & GLOYNA 1961 & $\begin{array}{l}\text { Hutchinson Salt, } \\
\text { Kansas (bedded) }\end{array}$ \\
\hline 11 & $\begin{array}{l}5 \times 10^{-10}- \\
6 \times 10^{-8}\end{array}$ & - & GLOYNA 1961 & $\begin{array}{l}\text { Grand Saline Salt, } \\
\text { Texas (dome) }\end{array}$ \\
\hline $\mathrm{n} / \mathrm{a}$ & $\begin{array}{l}3 \times 10^{-12}- \\
2 \times 10^{-9} \\
2 \times 10^{-10}\end{array}$ & - & $\begin{array}{l}\text { LAMBERT } \\
1977\end{array}$ & $\begin{array}{l}\text { Salado Fm, New Mexico } \\
\text { (bedded, } 640 \mathrm{~m} \text { depth) } \\
\text { (average value) }\end{array}$ \\
\hline $\mathrm{n} / \mathrm{a}$ & $\begin{array}{l}4 \times 10^{-11}- \\
2 \times 10^{-7} \\
2 \times 10^{-8}\end{array}$ & - & $\begin{array}{l}\text { LAMBERT } \\
1977\end{array}$ & $\begin{array}{l}\text { Salado Fm, New Mexico } \\
\text { (bedded, } 820 \mathrm{~m} \text { depth) } \\
\text { (average value) }\end{array}$ \\
\hline 5 & $\begin{array}{l}1 \times 10^{-10}- \\
4 \times 10^{-8} \\
5 \times 10^{-9}\end{array}$ & - & $\begin{array}{l}\text { GEVANTMAN } \\
\quad 1981\end{array}$ & $\begin{array}{l}\text { Grand Saline Salt, } \\
\text { Texas (dome) } \\
\text { (average value) }\end{array}$ \\
\hline 5 & $\begin{array}{lll}0.0 & - \\
7 \times & 10^{-10} \\
1 & \times & 10^{-10}\end{array}$ & - & $\begin{array}{l}\text { GEVANTMAN } \\
1981\end{array}$ & $\begin{array}{l}\text { Hutchinson Salt, } \\
\text { Kansas (bedded) } \\
\text { (average value) }\end{array}$ \\
\hline 4 & $<1 \times 10^{-12}$ & $<1 \times 10^{-12}$ & $\begin{array}{l}\text { THACKSTON } \\
1984\end{array}$ & $\begin{array}{l}\text { Paradox Fm, Utah } \\
\text { (bedded) }\end{array}$ \\
\hline \multicolumn{5}{|c|}{ EYLELD TEST DATA } \\
\hline 5 & $\begin{array}{l}4 \times 10^{-12}- \\
6 \times 10^{-11}\end{array}$ & - & $\begin{array}{l}\text { LAMBERT } \\
1977\end{array}$ & $\begin{array}{l}\text { Salado Fm, New Mexico } \\
\text { (bedded) }\end{array}$ \\
\hline $\mathrm{n} / \mathrm{a}$ & $\begin{array}{l}1 \times 10^{-12}- \\
1 \times 10^{-7}\end{array}$ & - & $\begin{array}{l}\text { D'APPOLONIA } \\
1980\end{array}$ & $\begin{array}{l}\text { Generic Bedded or Dome } \\
\text { Salt }\end{array}$ \\
\hline 6 & $\begin{array}{lll}7 \times 10^{-12}- \\
2 \times 10^{-10}\end{array}$ & - & $\begin{array}{l}\text { D'APPOLONIA } \\
1980\end{array}$ & $\begin{array}{l}\text { Salado Fm, New Mexico } \\
\text { (bedded) }\end{array}$ \\
\hline 1 & $\begin{array}{lll}1 \times 10^{-8} \\
3 \times 10^{-10}\end{array}$ & - & $\begin{array}{l}\text { THACKSTON } \\
1984\end{array}$ & $\begin{array}{l}\text { (Early time analysis) } \\
\text { (Late time analysis) } \\
\text { Paradox Fn, Utah }\end{array}$ \\
\hline \multicolumn{4}{|c|}{ ADOPTED DATA BASE VALUES } & Typical \\
\hline \multirow{2}{*}{\multicolumn{4}{|c|}{ Horizoncal hydraulic conductivicy, $\mathrm{m} / \mathrm{s}$}} & $\times 10^{-11}$ \\
\hline & & Vertical hydraulic conductivity, $\mathrm{m} / \mathrm{s}$ & & $\times 10^{-12}$ \\
\hline
\end{tabular}




\section{C.5.2.1 Anhydrock}

Hydraulic conductivity values for anhydrock from the available 1iterature are presented in Table C.5.1. Literature on the hydrologic properties of anhydrock was found to be the most difficult to find of all rock types studied. Data were scarce both from laboratory analyses of core samples and from field tests.

The limited laboratory and field results indicate that anhydrock has a very low hydraulic conductivity. Core results range from $4 \times 10^{-13}$ to $1.6 \times 10^{-8} \mathrm{~m} / \mathrm{s}$ and are typically on the order of $1 \times 10^{-11} \mathrm{~m} / \mathrm{s}$. Field test results indicate that horizontal conductivities range from $1.5 \times 10^{-11}$ to $2.3 \times 10^{-9} \mathrm{~m} / \mathrm{s}$ and are typical1y on the order of $10^{-11}$ to $10^{-10} \mathrm{~m} / \mathrm{s}$. However, an inability to measure some of the lower anhydrock conductivities encountered in the field have been reported (LAMBERT 1977), and the resulting field range may be biased toward the higher conductivity anhydrock atrata. Vcrtical hydraulic conductivitice were found only in core data, and varied over the relatively small range of $1.4 \times 10^{-12}$ to $5.5 \times 10^{-12}$ $\mathrm{m} / \mathrm{s}$.

Field observations of anhydrock outcroppings indicate an intense pattern of very closely spaced, short fractures. The similarity between the core and field results is supported by these observations which indicate that the fracturing may be on a sufficiently small scale such that the effects are seen in the core. In view of these similarities and of the reported inability to measure the lower conductivity horizons in some field tests, the typical data values will be taken to be $1 \times 10^{-11} \mathrm{~m} / \mathrm{s}$ for horizontal hydraulic conductivity and $1 \times 10^{-12} \mathrm{~m} / \mathrm{s}$ for vertical hydraulic conductivity. Probable maximum and minimum values will be assumed to be one order of magnitude higher and lower, respectively, than the typical values.

\section{5.2 .2 Chalk}

Hydraulic conductivity data for chalk developed from the 1iterature are presented in Table C.5.2. Although considerable information was found to be available from laboratory analyses of core samples, little information was found from in situ field tests. Both types of data were available from sites in England and Texas.

With one exception, the conductivities measured from core samples were several orders of magnitude lower than those measured in the tield. The sole exception was for a core containing a hydrologically significant fracture. The field hydraulic conductivity of chalk formations was found to vary greatly, depending upon the degree of fracturing. The English chalks for which data were available are used locally as major water supply aquifers, while the Texas chalks are much tighter and contain oil and gas. The field data for the Texas Austin chalk represents the more permeable, fractured portions of the formation, although some $50 \%$ of the formation has been estimated to be relatively unfractured (SNYDER 1977).

The hydraulic conductivity valuec adopted for the data baso reprasant the tighter end of the conductivity range, because only these chalks would 
be reasonably considered for nuclear waste disposal. The typical data base values adopted for this study are a horizontal conductivity of $1 \times 10^{-7} \mathrm{~m} / \mathrm{s}$ and a vertical conductivity of $5 \times 10^{-8} \mathrm{~m} / \mathrm{s}$. The high and low values of the conductivity range are one order of magnitude greater and lower than these values. These values are lower than the lowest available field data and reflect the lower conductivities expected in the relatively unfractured portions of a chalk formation.

\section{C.5.2.3 Carbonate Rocks (Limestone/Dolostone)}

Hydraulic conductivity values for carbonate rocks from the available literature are presented in Table C.5.3. Literature on carbonate rocks is relatively abundant for the more highly conductive members but is scarce for the tighter members of interest in waste disposal. Hydraulic conductivities for the more highly conductive carbonate rocks can be very high, exceeding $1 \times 10^{-2} \mathrm{~m} / \mathrm{s}$ (BRACE 1980). These are among the highest conductivities observed in any rock typc. Corc data are generally orders of magnitude lower than field values, reflecting the importance of fractures in controlling hydraulic conductivity.

A detailed review of the literature surveyed in this study indicated that the lower conductivity field data generally reflected either relatively thin beds of little interest to mined geologic disposal, or parts of thicker beds. Taking this into account, the typical data base values adopted for this study are a horizontal conductivity of $1 \times 10^{-6} \mathrm{~m} / \mathrm{s}$ and a vertical conductivity of $5 \times 10^{-7} \mathrm{~m} / \mathrm{s}$. The high and low values of the conductivity range are again one order of magnitude greater and lower than these values.

\section{C.5.2.4 Sandstone}

Hydraulic conductivity values for sandstone from the available literature are presented in Table C.5.4. Information on sandstone, like carbonate rocks, is relatively abundant in the hydrology literature for the more highly conductive members, with data on the lower conductivity members originating primarily in the oil and gas literature. Representative hydraulic conductivity values for sandstone range from $1 \times 10^{-5} \mathrm{~m} / \mathrm{s}$ on the high end to $1 \times 10^{-11} \mathrm{~m} / \mathrm{s}$ on the low end (De WIEST 1965; GIDLEY 1979). Core data was found to be similar in magnitude to field data, indicating a smaller influence of discrete fractures and a greater dependence of fluid movement on the bulk porosity.

Thick beds of very tight sandstones are found at many locations and can be reasonably considered for mined geologic disposal. The properties of these sandstones were therefore adopted for the data base. The typical data base values adopted for this study are a horizontal conductivity of $1 \times 10^{-10} \mathrm{~m} / \mathrm{s}$ and a vertical conductivity of $5 \times 10^{-11} \mathrm{~m} / \mathrm{s}$. The high values of the conductivity range are two orders of magnitude higher than the typical values, and the low values are one-half an order of magnitude lower than the typical values. This assymetric range was selected to reflect the large number of more permeable sandstones that might be conoidored for waste disposal. 


\section{C.5.2.5 Shale}

Hydraulic conductivity values for shale from the avallable literature are presented in Table C.5.5. The hydrologic properties of shale are not abundant in the literature because of its poor aquifer properties, and much of the available data originates from the oil and gas literature. Core data were found to be similar in magnitude to field data, indicating little influence of fractures on groundwater movement.

Thick beds of very tight shales are found at many locations and can be reasonably considered for mined geologic disposal. The typical data base values adopted for this study are a horizontal conductivity of $1 \times 10^{-11} \mathrm{~m} / \mathrm{s}$ and a vertical conductivity of $1 \times 10^{-12} \mathrm{~m} / \mathrm{s}$. The high and low values of the conductivity range are one order of magnitude higher and lower than the typical values.

C.5.2.6 $\underline{\text { Salt }}$

Although salt is not one of the potential host rocks being reviewed in this study, its presence in the reference stratigraphic section for anhydrite requires that its hydrologic properties be developed. Hydraulic conductivity values for salt from the available literature are presented in Table C.5.6. The hydrologic properties of salt are available primarily as a result of recent studies of this medium for nuclear waste disposal, and except for some core data, are not readily found in the 1iterature. Core and field test data were found to fall into the same general ranges, indicating a low influence of fractures on fluid movement.

The typical data base values are based on data for bedded salt, which has been found to be generally lower than for dome salt (GLOYNA 1961). The typical horizontal conductivity adopted for this study is $1 \times 10^{-11}$ $\mathrm{m} / \mathrm{s}$ and the typical vertical conductivity is $1 \times 10^{-12} \mathrm{~m} / \mathrm{s}$. High and low values were not determined because this medium is not being considered for waste disposal in this study.

\section{C.5.3 EFFECTIVE POROSITY}

The effective porosity data bases developed for the modeling studies are presented in Tables 0.5 .7 through $\mathrm{C} .5 .12$ by rock type. The adopted data base values and the supporting information obtained from the literature are presented below in the same order as for hydraulic conductivity.

\section{C.5.3.1 Anhydrock}

Porosity data for anhydrock from the avajlable literature are presented in Table C.5.7. As noted in the table, all values are for total porosity unless otherwise indicated. Effective porosity measurements are, however, available for several cores from the Paradox Formation in Utah. Because of the influence of fractures, the rock mass effective porosity of anhydrock would be expected to be lower than that observed in core meaourcmento. The adopted data baoc typical valuco are 0.01 for 
Table 6.5 .7 . Porosity data base for anhydrock ${ }^{a}$

\begin{tabular}{|c|c|c|c|c|}
\hline $\begin{array}{l}\text { No. } \\
\text { samples }\end{array}$ & Range & Mean & Reference & Origin and comments \\
\hline 1 & - & 0.000 & PANDEY 1974 & $\mathrm{n} / \mathrm{a}$ \\
\hline 3 & $0.006-0.025$ & 0.012 & $\begin{array}{l}\text { THACKSTON } \\
\quad 1984\end{array}$ & $\begin{array}{l}\text { Paradox Fm, Utah (effec- } \\
\text { tIve; } 925 \text { m depth) }\end{array}$ \\
\hline $\mathrm{n} / \mathrm{a}$ & $0.215-0.271$ & $\mathrm{n} / \mathrm{a}$ & $\begin{array}{l}\text { THACKSTON } \\
1984\end{array}$ & $\begin{array}{l}\text { Paradox Fn, Utah } \\
(925 \text { m depth })\end{array}$ \\
\hline $\mathrm{n} / \mathrm{a}$ & $0.116-0.215$ & $\mathrm{n} / \mathrm{a}$ & $\begin{array}{l}\text { THACKSTON } \\
1984\end{array}$ & $\begin{array}{l}\text { Paradox Fm, Utah (effec- } \\
\text { tive; } 1050 \text { m depth) }\end{array}$ \\
\hline $\mathrm{n} / \mathrm{a}$ & $0.077-0.359$ & $\mathrm{n} / \mathrm{a}$ & $\begin{array}{l}\text { THACKSTON } \\
1984\end{array}$ & $\begin{array}{l}\text { Paradox Fm, Utah } \\
(1075 \mathrm{~m} \text { depth) }\end{array}$ \\
\hline $\mathrm{n} / \mathrm{a}$ & $0.001-0.050$ & 0.01 & $\begin{array}{l}\text { THORDARSON } \\
1983\end{array}$ & $\begin{array}{l}\text { Estimated Total Inter- } \\
\text { crystalline Values, } \\
\text { Generic Rock Type. }\end{array}$ \\
\hline \multicolumn{5}{|c|}{ ADOPTED DATA BASE VALUES } \\
\hline & & \multicolumn{2}{|r|}{ Typical } & High \\
\hline \multicolumn{2}{|c|}{ Total porosity } & \multicolumn{2}{|r|}{0.01} & 0.005 \\
\hline \multicolumn{2}{|c|}{ Effective porosityb } & \multicolumn{2}{|r|}{0.001} & 0.0005 \\
\hline
\end{tabular}

a Total porosity values are given unless otherwise noted.

b Fracture effects considered; see Sect. C.5.3.1. 
Table C.5.8. Porosity data base for cha1k $\mathrm{k}^{\mathrm{a}}$

\begin{tabular}{|c|c|c|c|c|}
\hline $\begin{array}{c}\text { No. } \\
\text { samples }\end{array}$ & Range & Mean & Reference & Origin and comments \\
\hline 1 & - & 0.091 & MANGER 1963 & $\begin{array}{l}\text { Balmoral Chalk, Great } \\
\text { Britian }\end{array}$ \\
\hline 3 & $0.176-0.428$ & 0.288 & MANGER 1963 & The Chalk, Great Britian \\
\hline 3 & $0.023-0.070$ & 0.058 & MANGER 1963 & Chalk, Germany \\
\hline $\mathrm{n} / \mathrm{a}$ & - & 0.250 & MANGER 1963 & Reitbrook Field, Germany \\
\hline $\mathrm{n} / \mathrm{a}$ & $0.10-0.45$ & 0.30 & $\begin{array}{c}\text { EDMUNDS } \\
1973\end{array}$ & $\begin{array}{l}\text { Upper and Middle Chalk, } \\
\text { Bexkshire, England }\end{array}$ \\
\hline $\begin{array}{l}\mathrm{n} / \mathrm{a} \\
\mathrm{n} / \mathrm{a}\end{array}$ & $\begin{array}{l}0.225-0.329 \\
0.142-0.242\end{array}$ & $\begin{array}{l}0.288 \\
0.186\end{array}$ & BELL 1977 & $\begin{array}{l}\text { (total porosity) } \\
\text { (effective porosity) } \\
\text { Lower Chalk, Yorkshire, } \\
\text { England }\end{array}$ \\
\hline $\begin{array}{l}\mathrm{n} / \mathrm{a} \\
\mathrm{n} / \mathrm{a}\end{array}$ & $\begin{array}{l}0.198-0.367 \\
0.161-0.230\end{array}$ & $\begin{array}{l}0.326 \\
0.198\end{array}$ & $\begin{array}{ll}\text { BELL } & 1977 \\
\text { BELL } & 1977\end{array}$ & $\begin{array}{l}\text { (total porosity) } \\
\text { (effective porosity) } \\
\text { Middle Chalk, Norfolk, } \\
\text { England }\end{array}$ \\
\hline $\begin{array}{l}\mathrm{n} / \mathrm{a} \\
\mathrm{n} / \mathrm{a}\end{array}$ & $\begin{array}{l}0.387-0.524 \\
0.276-0.457\end{array}$ & $\begin{array}{l}0.470 \\
0.417\end{array}$ & $\begin{array}{ll}\text { BELL } & 1977 \\
\text { BELL } & 1977\end{array}$ & $\begin{array}{l}\text { (total porosity) } \\
\text { (effective porosity) } \\
\text { Upper Chalk, Kent, } \\
\text { England }\end{array}$ \\
\hline $\mathrm{n} / \mathrm{a}$ & $0.05-0.16$ & - & DAVIS 1979 & Austin Chalk. Texas \\
\hline $\mathrm{n} / \mathrm{a}$ & $0.09-0.30$ & - & CORBETT 1982 & Austin Chalk, Texas \\
\hline $\mathrm{n} / \mathrm{a}$ & - & 0.277 & CLOUD 1975 & Austin Chalk, Texas \\
\hline $\mathrm{n} / \mathrm{a}$ & - & 0.001 & SNYDER 1977 & $\begin{array}{l}\text { Austin Chalk, Texas } \\
\text { (effective porosity, } \\
\text { based on fracture data) }\end{array}$ \\
\hline $\mathrm{n} / \mathrm{a}$ & $0.06-0.08$ & - & DOYLE 1955 & Austin Cha1k, Texas \\
\hline ADOPTED & DATA BASE VALUES & & & \\
\hline & & \multicolumn{2}{|r|}{ Typical } & High \\
\hline \multicolumn{2}{|c|}{ Total porosity } & \multicolumn{2}{|r|}{0.10} & 0.20 \\
\hline \multicolumn{2}{|c|}{ Erfeclive pususilyb } & \multicolumn{2}{|r|}{0.001} & 0.0005 \\
\hline
\end{tabular}

a Total porosity values are given unless otherwise noted.

b Fracture effects considered; see Sect. C.5.3.2. 
Table C.5.9. Porosity data base for carbonate rocks ${ }^{a}$

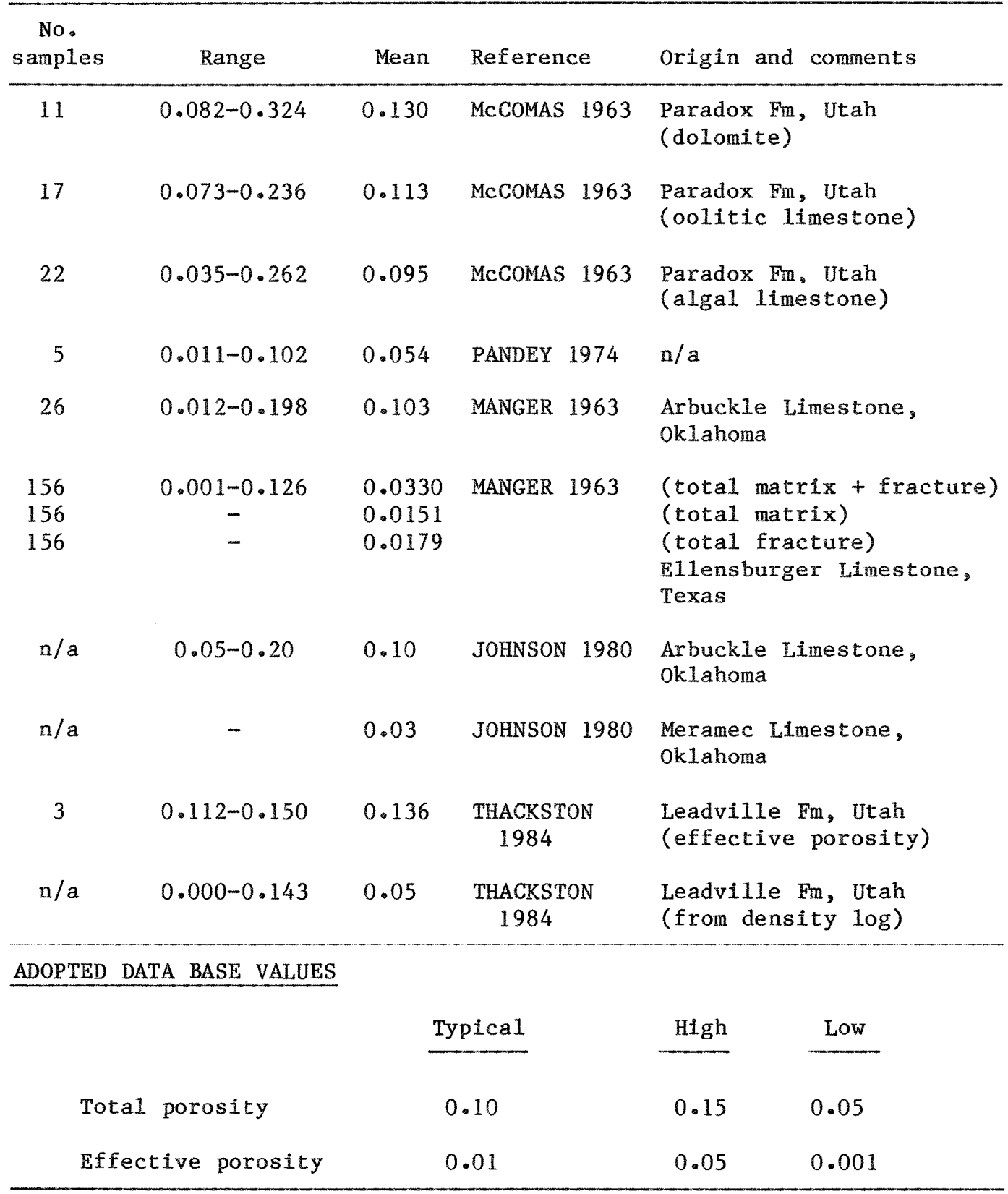

a Total porosity values are given unless otherwise noted. 
Table C.5.10. Porosity data base for sandstone ${ }^{a}$

\begin{tabular}{|c|c|c|c|c|}
\hline $\begin{array}{l}\text { No. } \\
\text { samples }\end{array}$ & Range & Mean & Reference & Origin and comments \\
\hline 1 & - & 0.187 & PANDEY 1974 & $\mathrm{n} / \mathrm{a}$ \\
\hline 25 & $0.089-0.241$ & 0.152 & FATT 1958 & $\begin{array}{l}\text { Miscellaneous Western } \\
\text { U.S. Locations }\end{array}$ \\
\hline 24 & $0.055-0.178$ & 0.112 & MANGER 1963 & Reagan Sandstone, Kansas \\
\hline 14 & $0.036-0.200$ & 0.103 & MANGER 1963 & $\begin{array}{l}\text { St. Peter Sandstone, } \\
\text { Wisconsin }\end{array}$ \\
\hline 12 & $0.169-0.233$ & 0.207 & MANGER 1963 & $\begin{array}{l}\text { Wilcox Sandstone, } \\
\text { Uklahoma }\end{array}$ \\
\hline 32 & $0.053-0.213$ & 0.141 & MANGER 1963 & $\begin{array}{l}\text { Johnson Sandstone, } \\
\text { Oklahoma }\end{array}$ \\
\hline 297 & $0.060-0.233$ & 0.150 & MANGER 1963 & $\begin{array}{l}\text { Bradford Sandstone, } \\
\text { Pennsylvania }\end{array}$ \\
\hline 8 & $0.047-0.171$ & 0.111 & MANGER 1963 & Berea Sandstone, Ohio \\
\hline 1 & - & 0.202 & MANGER 1963 & $\begin{array}{l}\text { Mesaverde Sandstone, } \\
\text { Wyoming }\end{array}$ \\
\hline $\mathrm{n} / \mathrm{a}$ & - & 0.102 & MANILLA 1980 & Uinta Basin Gas Sand, Utah \\
\hline 4 & $0.055-0.162$ & 0.099 & DOE 1981 & $\begin{array}{l}\text { Piceance Basin Gas Sand, } \\
\text { Colorado }\end{array}$ \\
\hline 12 & $0.018-0.108$ & 0.073 & DOE 1981 & Uinta Basin Gas Sand, Utah \\
\hline $\mathrm{n} / \mathrm{a}$ & - & 0.045 & WYMAN 1979 & Fahler Sandstone, Alberta \\
\hline $\mathrm{n} / \mathrm{a}$ & $0.073-0.182$ & - & $\begin{array}{l}\text { THACKSTON } \\
1984\end{array}$ & (Total; by density log) \\
\hline 1 & - & 0.094 & $\begin{array}{l}\text { THACKSTON } \\
1984\end{array}$ & $\begin{array}{l}\text { (Effective) } \\
\text { Cedar Mesa Sandstone, Utah }\end{array}$ \\
\hline $\mathrm{n} / \mathrm{a}$ & $0.019-0.316$ & - & $\begin{array}{l}\text { THACKSTON } \\
\quad 1984\end{array}$ & (Total; by density 10 g) \\
\hline 3 & $0.052-0.199$ & 0.125 & $\begin{array}{l}\text { THACKSTON } \\
1984\end{array}$ & $\begin{array}{l}\text { (Effective) } \\
\text { Elephant Canyon Sandstone, } \\
\text { Utah }\end{array}$ \\
\hline ADOPTED & DATA BASE VALUES & & & \\
\hline \multicolumn{4}{|c|}{ Typical } & High \\
\hline \multicolumn{2}{|c|}{ Total porosity } & \multicolumn{2}{|r|}{0.08} & 0.05 \\
\hline \multicolumn{2}{|c|}{ Effective porosity } & \multicolumn{2}{|r|}{0.01} & 0.005 \\
\hline
\end{tabular}

a Total porosity values are given unless otherwise noted. 
Table C.5.11. Porosity data base for shale ${ }^{a}$

\begin{tabular}{|c|c|c|c|c|}
\hline $\begin{array}{l}\text { No. } \\
\text { samples }\end{array}$ & Range & Mean & Reference & Origin and comments \\
\hline 2 & $0.003-0.056$ & 0.030 & PANDAY 1974 & $\mathrm{n} / \mathrm{a}$ \\
\hline 2 & $0.074-0.076$ & 0.075 & MANGER 1963 & $\begin{array}{l}\text { Devonian Chattanooga } \\
\text { Shale, Kentucky } \\
\text { (subsurface sample) }\end{array}$ \\
\hline 1 & - & 0.113 & MANGER 1963 & $\begin{array}{l}\text { Mississippian Hamilton } \\
\text { Shale, Missouri } \\
\text { (outcrop sample) }\end{array}$ \\
\hline 4 & $0.073-0.106$ & 0.091 & MANCFR 1963 & $\begin{array}{l}\text { Pennsylvanian Chanute } \\
\text { Shale, Kansas } \\
\text { ( } 230 \mathrm{~m} \text { sample depth) }\end{array}$ \\
\hline 1 & - & 0.016 & MANGEK 1963 & $\begin{array}{l}\text { Carboniferous shale, } \\
\text { Scotland (outcrop) }\end{array}$ \\
\hline 2 & $\mathrm{n} / \mathrm{a}$ & 0.009 & MANGER 1963 & $\begin{array}{l}\text { Cambrian Ophir Shale, } \\
\text { Utah (subsurface sample) }\end{array}$ \\
\hline $\mathrm{n} / \mathrm{a}$ & - & 0.010 & MANGER 1963 & $\begin{array}{l}\text { Ordovician Martinsburg } \\
\text { Shale, Pennsylvania } \\
\text { (quarry sample) }\end{array}$ \\
\hline 5 & $0.020-0.101$ & 0.052 & MANGER 1963 & $\begin{array}{l}\text { Silurian Shales, Great } \\
\text { Britian (outcrop samples) }\end{array}$ \\
\hline $\mathrm{n} / \mathrm{a}$ & $0.009-0.046$ & $<0.03$ & $\begin{array}{c}\text { GONZALES } \\
1984\end{array}$ & $\begin{array}{l}\text { Devonian New Albany Shale, } \\
\text { L111nois-Indiana-Kentucky }\end{array}$ \\
\hline $\mathrm{n} / \mathrm{a}$ & $0.03-0.10$ & - & $\begin{array}{c}\text { GONZALES } \\
1984\end{array}$ & $\begin{array}{l}\text { Devonian Michigan Basin } \\
\text { Shale, Michigan }\end{array}$ \\
\hline $\mathrm{n} / \mathrm{a}$ & - & 0.03 & $\begin{array}{c}\text { GONZALES } \\
1984\end{array}$ & $\begin{array}{l}\text { Devonian Applachian Basin } \\
\text { Shale, Ohio }\end{array}$ \\
\hline $\mathrm{n} / \mathrm{a}$ & - & 0.005 & $\begin{array}{c}\text { GONZALES } \\
1984\end{array}$ & $\begin{array}{l}\text { Triassic Dumbarton Basin } \\
\text { Shale, South Carolina } \\
\text { (effective porosity) }\end{array}$ \\
\hline $\mathrm{n} / \mathrm{a}$ & - & 0.0117 & DOE 1981 & $\begin{array}{l}\text { Devonian Gas Shale, } \\
\text { Pennsylvania }\end{array}$ \\
\hline $\mathrm{n} / \mathrm{a}$ & - & 0.03 & $\begin{array}{l}D^{\prime} \text { APPOLONIA } \\
1980\end{array}$ & $\mathrm{n} / \mathrm{a}$ \\
\hline 5 & $0.005-0.019$ & 0.012 & $\begin{array}{l}\text { De LAGUNA } \\
1968\end{array}$ & $\begin{array}{l}\text { Cambrian Conasauga Shale, } \\
\text { Tennessee }\end{array}$ \\
\hline
\end{tabular}


Table C.5.11 (continued)

\section{ADOPTED DATA BASE VALUES}

\begin{tabular}{lll} 
Typical & High & Low \\
\cline { 3 - 3 } 0.03 & 0.10 & 0.01 \\
0.01 & 0.05 & 0.005 \\
\hline
\end{tabular}

a Total porosity values are given unless otherwise noted.

b See Sect. C.5.3.5 for explanation. 
Table C.5.12. Porosity data base for salta

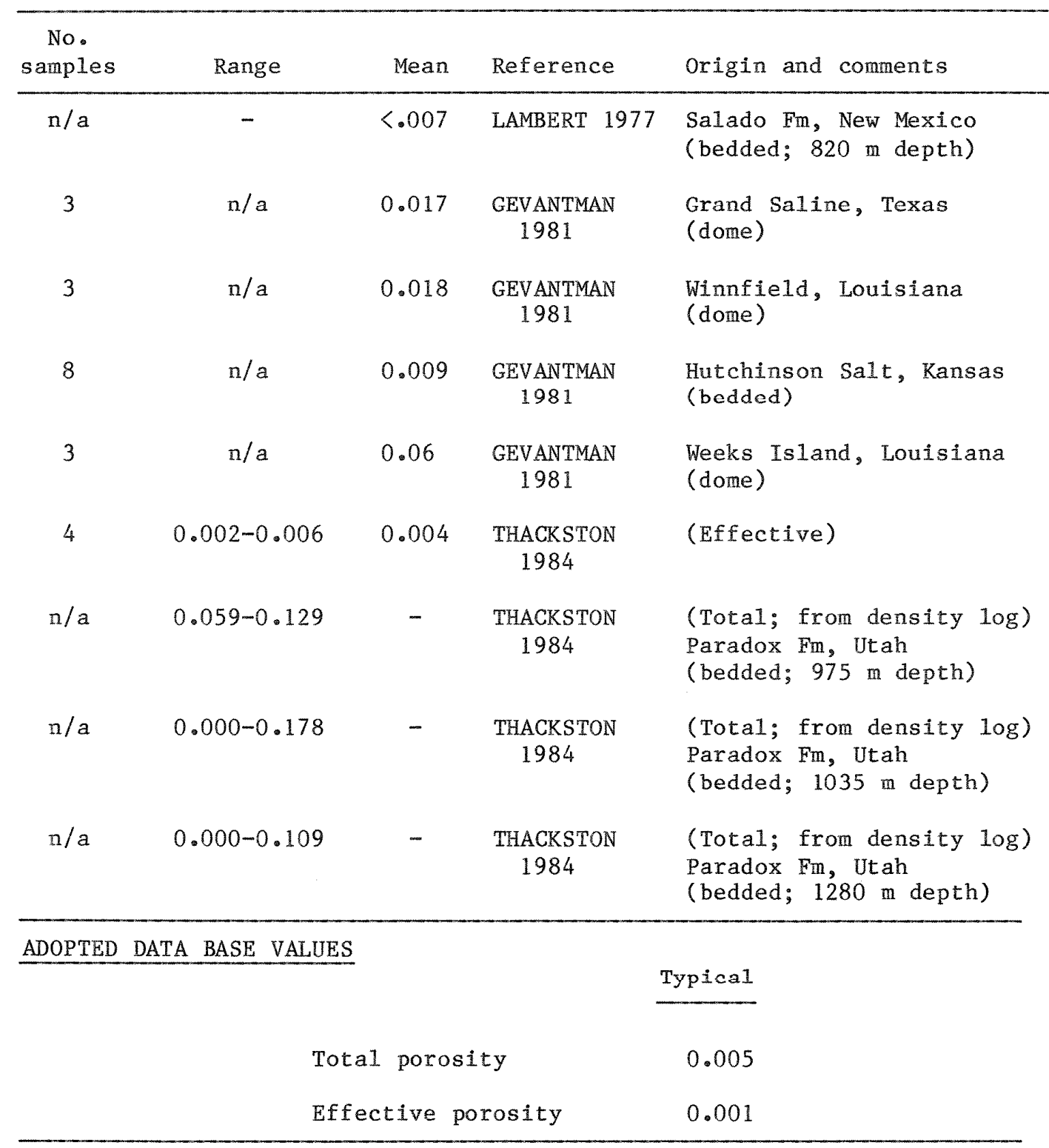

a Total porosity values are given unless otherwise noted. 
total porosity and 0.001 for effective porosity. The ranges are approximately one-half order of magnitude higher and lower than the typical values.

\section{C.5.3.2 Chalk}

Porosity data for chalk from the available literature are presented in Table C.5.8. Although the interstitial porosity of the chalk is high, it has been found to be pressure and, therefore, depth sensitive. Because the repository is expected to be relatively deep, the porosity data base was selected to represent the lower end of the range. In addition, the significant role of fractures in governing fluid movement suggests that effective porosity will be considerably lower than total porosity in chalk. The adopted data base typical values are 0.10 for total porosity and 0.001 for effective porosity. The ranges are approximately one-half order of magnitude higher and lower than the typical values.

\section{C.5.3.3 Carbonate Rocks (Limestone/Dolostone)}

Porosity data for carbonate rocks from the available literature are presented in Table C.5.9. In view of the of fsetting influences of the fracturing and of the relatively high matrix porosities locally observed in many carbonate rocks, the effective porosity was assumed to be one order of magnitude lower than the total porosity. The adopted data base typical values are 0.10 for total porosity and 0.01 for effective porosity. The ranges are variable, extending to one order of magnitude on the low side for effective porosity.

\section{C.5.3.4 Sandstone}

Porosity data for sandstone from the available literature are presented in Table C.5.10. Although sandstone porosities can be relatively high, the data base was selected to emphasize the tighter sandstones of the type that could reasonably be considered for waste disposal. The weak influence of fractures indicated by the hydraulic conductivity data suggests a smaller difference between total and effective porosity than was expected for the rock types previously discussed. The adopted data base typical values are 0.08 for total porosity and 0.01 for effective porosity. The high and low values are within an order of magnitude of the typical values, with the greatest range being assigned to the high value because of the potentially significant influence of flow in the unfractured matrix in the higher-conductivity sandstones.

\section{C.5.3.5 Shale}

Porosity data for shale from the available literature are presented in Table c.5.11. Because shale can be relatively compressible depending upon its stress history, the porosity of shale can be relatively high. The data base was selected to emphasize the compacted, older shales that would be expected to have been relatively deeply buried and therefore more representative of shales at the proposed repository depths. The difforcnco botween total and offective porocity is expected to bo small 
in shale because of the generally low influence of individual fractures on groundwater movement. The adopted data base typical values are 0.03 for total porosity and 0.01 for effective porosity. The high and low values are within an order of magnitude of the typical values, and largely reflect uncertainties in degree of compaction.

\section{C.5.3.6 Salt}

Porosity data for salt from the available literature are presented in Table C.5.12. Dome salt has a consistently greater porosity than bedded salt because of the deformation that accompanies the upward movement of the dome. Both total and effective porosity data for bedded salt are available from the Paradox Formation in Utah, and indicate about one-half an order of magnitude difference. The adopted data base typical values are therefore based primarily upon the bedded salt data, and are 0.005 for total porosity and 0.001 for effective porosity. Ranges of these values were not determined because salt is not being considcred here as a host rock.

\section{C.5.4 SPECIFIC STORAGE}

The specific storage data base is presented in Table 6.5 .13 for all rock types. Although measurements of specific storage would be expected to be available in the literature for those members of each rock type permeable enough to be used as water supply aquifers, such data were not considered here because only the tighter, less permeable members would be reasonably considered for nuclear waste storage.

In view of the lack of available information from direct measurement, specific storage was estimated for each rock type based upon the rock and water compressibility relationships described in Eqs. (5-1) and (5-2) (see Sect. C.5.1.6). Although the predictive capabilities of these equations are relatively weak for specific applications, the results have been found to generally fall within the range of values determined from field tests and are considered to be appropriate for the generic studies being considered here.

The geomechanical data used in computing specific storagc arc presented along with the computed storage values in Table C.5.13. Other elements of the specific storage data base include: the total porosity of the rock as reported in Tables $C .5 .7$ through $C .5 .12$; the density of water, assumed to be a constant $1000 \mathrm{~kg} / \mathrm{m}^{3}$; and the compressibility of water, assumed to be a constant $4.35 \times 10^{-10} \mathrm{~m}^{2} / \mathrm{N}$.

The results show relatively little sensitivity to the ranges in geomechanical properties. The adopted data base values were generally assigned higher ranges than the computed results indicated, to account for additional uncertainties present in the computational method. With the exception of anhydrock and chalk, rounding of the computed results gave the same storage values to all rocks. Anhydrock and chalk varied from the general pattern because of their unusually high and low elastic moduli, reopcctively. The rcoulting typical data baoc opccific otorage 
Table C.5.13. Specific storage data basea

\begin{tabular}{lccc}
\hline Rock type and property & Typica1 & High & Low \\
\hline ANHYDROCK & & & \\
\hline & & & \\
Elastic modulus, GPa & 04.1 & 82.1 & 46.1 \\
Poisson's ratio & 0.34 & 0.41 & 0.27 \\
Computed specific storage, L/m & $1.9 \times 10^{-7}$ & $5.1 \times 10^{-7}$ & $8.4 \times 10^{-8}$
\end{tabular}

\section{CHALK}

Elastic modulus, GPa

Poisson's ratio

0.25

10.7

2.9

Computed specific storage, $\mathrm{L} / \mathrm{m}$

$2.6 \times 10^{-6}$

$4.1 \times 10^{-6}$

0.16

CARBONATE ROCKS (LIMESTONE/DOLOSTONE)

Elastic modulus, GPa

42.9

Poisson's ratio

0.26

66.9

0.36

18.9

Computed specific storage, $\mathrm{L} / \mathrm{m}$

$7.5 \times 10^{-7}$

$1.7 \times 10^{-6}$

0.16

SANDSTONE

Elastic modulus, GPa

Poisson's ratio

$20 \cdot 4$

0.20

Computed specific storage, L/m

$1.2 \times 10^{-6}$

$32 \cdot 3$

0.32

8.5

$3.5 \times 10^{-6}$

0.08

$5.4 \times 10^{-7}$

\section{SHALE}

Elastic modulus, $\mathrm{GPa}$

Poisson's ratio

20.8

31.7

0.31

9.9

0.21

$2.8 \times 10^{-6}$

0.11

Computed specific storage, $L / m$

$9.5 \times 10^{-7}$

$2.8 \times 10^{-6}$

$4.3 \times 10^{-7}$

$\underline{\text { SALT }}$

Elastic modulus, GPa

Poisson's ratio

Computed specific storage, $\mathrm{L} / \mathrm{m}$

9.0

0.35

$1.0 \times 10^{-6}$

ADOPTED DATA BASE VALUES FOR SPECIFIC STORAGE

\begin{tabular}{|c|c|c|c|c|c|}
\hline \multirow[b]{2}{*}{ Anhydrock } & $\begin{array}{l}\text { Typical } \\
(\mathrm{L} / \mathrm{m})\end{array}$ & \multicolumn{2}{|r|}{$\begin{array}{l}\text { High } \\
(\mathrm{L} / \mathrm{m})\end{array}$} & \multicolumn{2}{|c|}{$(\stackrel{\mathrm{Low}}{\mathrm{L} / \mathrm{m})}$} \\
\hline & $1 \times 10^{-7}$ & 5 & $\times 10^{-7}$ & 5 & $\times 10^{-8}$ \\
\hline Cha1k & $5 \times 10^{-6}$ & 1 & $\times 10^{-5}$ & 1 & $\times 10^{-6}$ \\
\hline Carbonate rocks & $1 \times 10^{-6}$ & 5 & $\times 10^{-6}$ & 5 & $\times 10^{-7}$ \\
\hline Sandstone & $1 \times 10^{-6}$ & 5 & $\times 10^{-6}$ & 5 & $\times 10^{-7}$ \\
\hline Shale & $1 \times 10^{-6}$ & 5 & $\times 10^{-6}$ & 5 & $\times 10^{-7}$ \\
\hline Salt & $1 \times 10^{-6}$ & & - & & - \\
\hline
\end{tabular}

a Geomechanical properties of elastic modulus and Poisson's ratio obtained from M. Loken, RE/SPEC Inc., October 1984. The computation of specific storage is described in the text. 
values were $1 \times 10^{-7} \mathrm{~L} / \mathrm{m}$ for anhydrock, $1 \times 10^{-6} \mathrm{~L} / \mathrm{m}$ for carbonate rocks, sandstone, shale and salt, and $5 \times 10^{-6} \mathrm{~L} / \mathrm{m}$ for chalk. The high and low values were taken to be approximately one-half order of magnitude larger and smaller than the typical value for each rock type.

\section{C.5.5 ADOPTED SECTION PROPERTIES}

Typical hydrologic properties were required for each modeled stratum in the reference geologic sections for the five rock types being considered as potential repository host rocks. The hydrologic properties of the strata overlying and underlying the repository horizons in the reference sections were determined from the foregoing data bases for the repository horizons, and from general knowledge of hydrologic material properties of the various rock types and depositional environments as reported in standard works (De WIEST 1965).

The final hydrologic data base values for the reference sections, including those for the repository horizon, are given in Tables C.5.14 through C.5.18. The horizon numbers shown on the tables correspond to those shown on the reference sections in Sect. C.3. Ranges of values are only given for the hydraulic conductivities and specific storages of the repository horizons.

Effective porosity was not varied in the modeling studies because of its positive correlation with hydraulic conductivity in sedimentary rocks (CHILINGARIAN 1981). If this correlation had been taken into account, increasing or decreasing conductivities would have been accompanied by increasing or decreasing porosities, respectively, and the net effect of these simultaneous changes would have been to reduce the predicted range of travel times. The alternative of increasing conductivity while decreasing porosity, or vice-versa, would have significantly increased predicted travel distances but would have not been physically realistic. The decision to not vary effective porosity in the modeling studies is an attempt to achieve a middle ground between these extremes. 
Table C.5.14. Adopted section properties for anhydrock

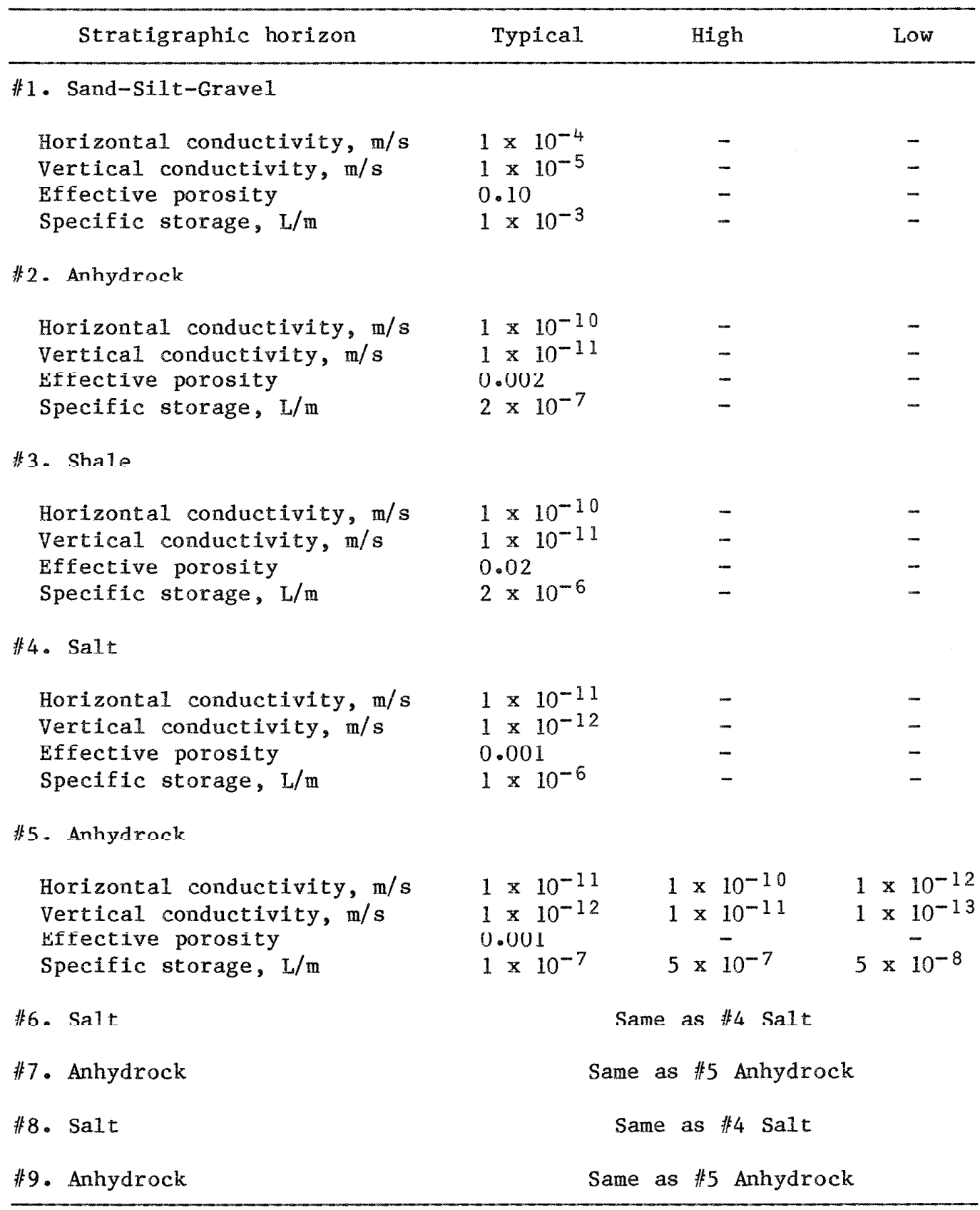


Table C.5.15. Adopted section properties for chalk

\begin{tabular}{|c|c|c|c|c|}
\hline Stratigraphic horizon & Typical & High & & Low \\
\hline \multicolumn{5}{|l|}{ \#1. Shale-Sand } \\
\hline $\begin{array}{l}\text { Horizontal conductivity, } \mathrm{m} / \mathrm{s} \\
\text { Vertical conductivity, } \mathrm{m} / \mathrm{s} \\
\text { Effective porosity } \\
\text { Specific storage, } \mathrm{L} / \mathrm{m}\end{array}$ & $\begin{array}{l}1 \times 10^{-5} \\
1 \times 10^{-6} \\
0.05 \\
1 \times 10^{-4}\end{array}$ & $\begin{array}{l}- \\
- \\
-\end{array}$ & & $\begin{array}{l}- \\
- \\
-\end{array}$ \\
\hline \multicolumn{5}{|l|}{ \#2. Clay-Shale-Marl } \\
\hline $\begin{array}{l}\text { Horizontal conductivity, } \mathrm{m} / \mathrm{s} \\
\text { Vertical conductivity, } \mathrm{m} / \mathrm{s} \\
\text { Effective porosity } \\
\text { Specific storage, } \mathrm{L} / \mathrm{m}\end{array}$ & $\begin{array}{l}1 \times 10^{-9} \\
1 \times 10^{-10} \\
0.02 \\
2 \times 10^{-6}\end{array}$ & $\begin{array}{l}- \\
- \\
-\end{array}$ & & $\begin{array}{l}- \\
- \\
-\end{array}$ \\
\hline \multicolumn{5}{|l|}{ \#3. Shale-Mar1-Chalk-Sandstone } \\
\hline $\begin{array}{l}\text { Horizontal conductivity, } \mathrm{m} / \mathrm{s} \\
\text { Vertical conductivity, } \mathrm{m} / \mathrm{s} \\
\text { Effective porosity } \\
\text { Specific storage, } \mathrm{L} / \mathrm{m}\end{array}$ & $\begin{array}{l}1 \times 10^{-8} \\
1 \times 10^{-9} \\
0.01 \\
2 \times 10^{-6}\end{array}$ & $\begin{array}{l}- \\
- \\
-\end{array}$ & & $\begin{array}{l}- \\
- \\
-\end{array}$ \\
\hline \multicolumn{5}{|l|}{ \#4. Chalk } \\
\hline $\begin{array}{l}\text { Horizontal conductivity, } \mathrm{m} / \mathrm{s} \\
\text { Vertical conductivity, } \mathrm{m} / \mathrm{s} \\
\text { Effective porosity } \\
\text { Specific storage, } \mathrm{L} / \mathrm{m}\end{array}$ & $\begin{array}{l}1 \times 10^{-7} \\
5 \times 10^{-8} \\
0.001 \\
5 \times 10^{-6}\end{array}$ & $\begin{array}{l}1 \times 10^{-6} \\
5 \times 10^{-7} \\
\\
1 \times 10^{-5}\end{array}$ & $\begin{array}{ll}1 & \mathrm{x} \\
5 & \mathrm{x} \\
1 \mathrm{x}\end{array}$ & $\begin{array}{l}10^{-8} \\
10^{-9} \\
-10^{-6}\end{array}$ \\
\hline
\end{tabular}


Table C.5.16. Adopted section properties for carbonate rocks

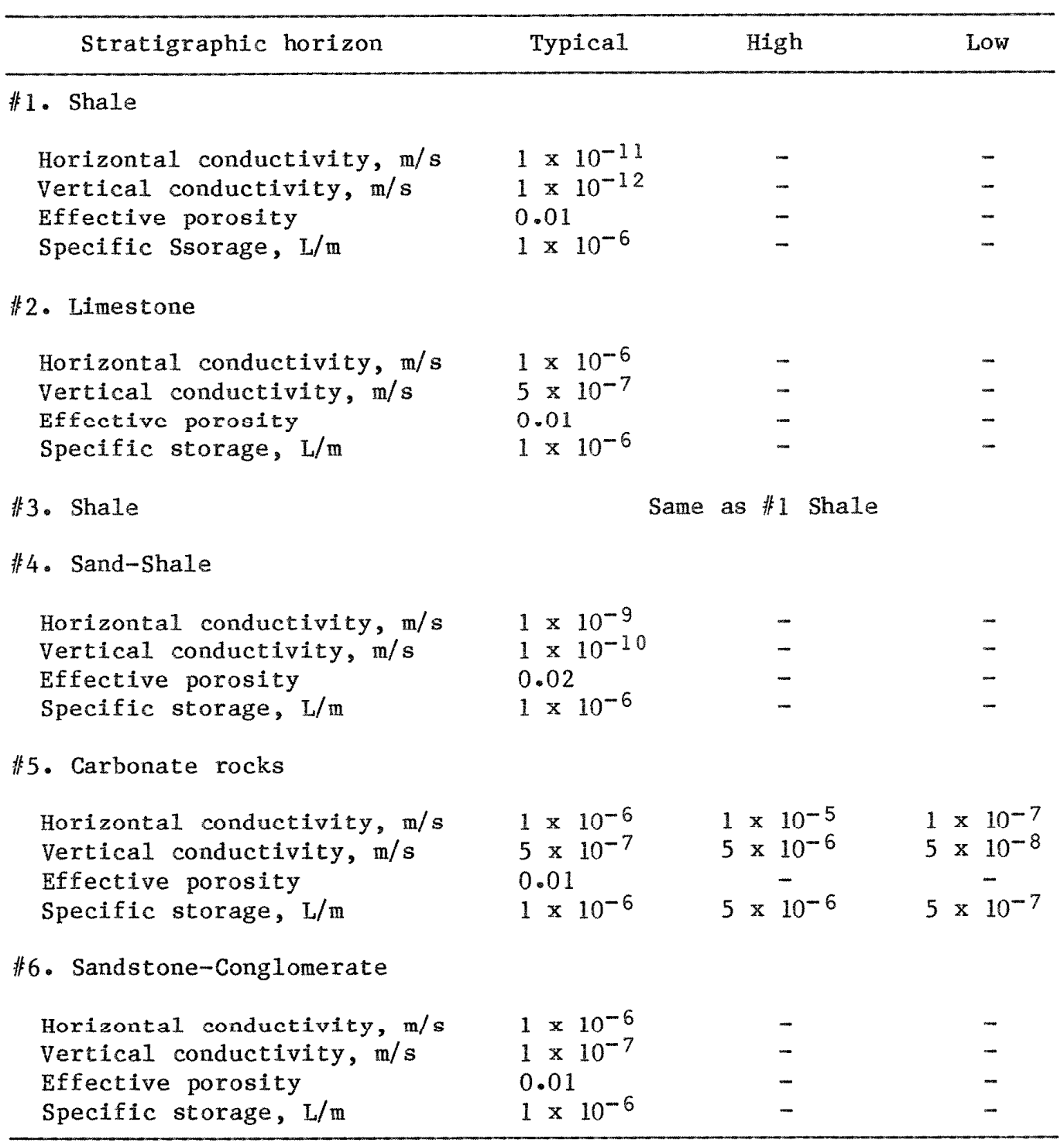


Table C.5.17. Adopted section properties for sandstone

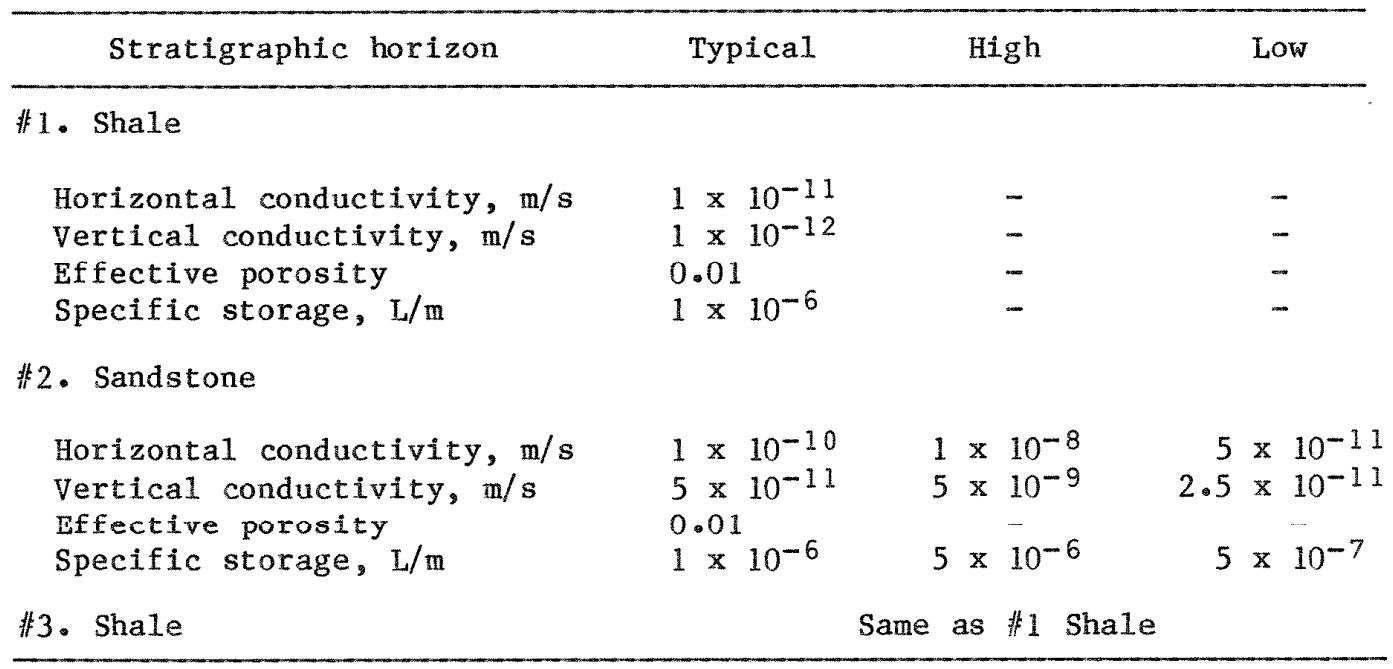

Table C.5.18. Adopted section properties for shale

\begin{tabular}{|c|c|c|c|c|}
\hline Stratigraphic horizon & Typical & High & & Low \\
\hline \multicolumn{5}{|l|}{ \#1. Sand-Silt-Clay } \\
\hline $\begin{array}{l}\text { Horizontal conductivity, } \mathrm{m} / \mathrm{s} \\
\text { Vertical conductivity, } \mathrm{m} / \mathrm{s} \\
\text { Effective porosity } \\
\text { Specific storage, } \mathrm{L} / \mathrm{m}\end{array}$ & $\begin{array}{l}1 \times 10^{-7} \\
1 \times 10^{-8} \\
0.10 \\
1 \times 10^{-3}\end{array}$ & $\begin{array}{l}- \\
- \\
-\end{array}$ & & $\begin{array}{l}- \\
- \\
-\end{array}$ \\
\hline \multicolumn{5}{|l|}{ \#2. Shale-Silt-Sand } \\
\hline $\begin{array}{l}\text { Horizontal conductivity, } \mathrm{m} / \mathrm{s} \\
\text { Vertical conductivity, } \mathrm{m} / \mathrm{s} \\
\text { Effective porosity } \\
\text { Specific storage, } \mathrm{L} / \mathrm{m}\end{array}$ & $\begin{array}{l}1 \times 10^{-9} \\
1 \times 10^{-10} \\
0.05 \\
1 \times 10^{-5}\end{array}$ & $\begin{array}{l}- \\
- \\
-\end{array}$ & & $\begin{array}{l}- \\
- \\
-\end{array}$ \\
\hline \multicolumn{5}{|l|}{ \#3. Shale } \\
\hline $\begin{array}{l}\text { Horizontal conductivity, } \mathrm{m} / \mathrm{s} \\
\text { Vertical conductivity, } \mathrm{m} / \mathrm{s} \\
\text { Effective porosity } \\
\text { Specific storage, } \mathrm{L} / \mathrm{m}\end{array}$ & $\begin{array}{l}1 \times 10^{-11} \\
1 \times 10^{-12} \\
0.01 \\
1 \times 10^{-6}\end{array}$ & $\begin{array}{l}1 \times 10^{-10} \\
1 \times 10^{-11} \\
5 \times 10^{-6}\end{array}$ & $\begin{array}{ll}1 & x \\
1 & x \\
5 & x\end{array}$ & $\begin{array}{l}10^{-12} \\
10^{-13} \\
- \\
10^{-7}\end{array}$ \\
\hline \multicolumn{5}{|l|}{ 非4. Carboantes } \\
\hline $\begin{array}{l}\text { Horizontal conductivity, } \mathrm{m} / \mathrm{s} \\
\text { Vertical conductivity, } \mathrm{m} / \mathrm{s} \\
\text { Effective porosity } \\
\text { Specific storage, } \mathrm{L} / \mathrm{m}\end{array}$ & $\begin{array}{l}1 \times 10^{-6} \\
5 \times 10^{-7} \\
0.01 \\
1 \times 10^{-6}\end{array}$ & $\begin{array}{l}- \\
- \\
-\end{array}$ & & $\begin{array}{l}- \\
- \\
-\end{array}$ \\
\hline
\end{tabular}


Excavation and waste emplacement are expected to affect the nearfield hydrologic system around the repository. These effects may result from thermal loading due to radioactive decay of the waste, from stress changes induced by excavation, tunnel support, and backfiliing, and possibly also from the effects of radiation. Because these effects, with the exception of thermal loading, are expected to be very-nearfield phenomena and because relatively little quantitative information is avallable about the magnitude of these effects on groundwater movement, they will be discussed here in a general way and will not be used as a basis for ranking.

\section{C.6.1 THERMAL EFFECTS}

Thermal effects are the best understood of the three types of effects considered here. Heat generation by the emplaced waste causes temperature rises in the vicinity of the repository, which may affect groundwater flow patterns, local groundwater and rock chemistry, material and chemical properties of the waste container, and properties of the packing and backfill materials.

Because a strictly hydrological perspective is taken in this study, only those heat effects related to groundwater movement are considered here. The most significant effect is expected to be the buoyancy driving force, which is reasonably well understood in porous media and can be modeled (KING 1981). Less well understood are the very-nearfield effects of thermal expansion on fracture closure about the waste container. Of primary concern to both effects are the absolute temperatures that develop with time.

The temperatures in a rock mass are governed by the thermal conductivity and specific heat capacity of the rock. The greater the thermal conductivity and the lower the specific heat capacity, the more rapidly is heat diffused into the rock and the lower the temperatures. of the five rock types considered here, anhydrock has the best properties for diffusing heat. The significance of this advantage is not expected to be large, however, and can be compensated for in the other rock types by varying the patterns of waste container emplacement.

A preliminary analysis of thermal effects on groundwater movement in the anhydrock, sandstone and shale sections has been performed and is presented in Sect. C.7.7. These preliminary results suggest that although the coupled thermal effects may cause significant increases in the groundwater travel distance, they do not appear to alter the results of the ranking methodologies adopted for this study.

\section{C.6.2 EXCAVATION EFFECTS}

The rock mass is expected to be disturbed by the effects of blasting and drift excavation, and by croop offects during and after the 50- to 80- 
year operational period. These effects are expected to result in minor displacement of the rock surrounding the openings, causing increases in porosity and permeability in some areas and decreases in others. The interrelationships are highly complex and depend upon the excavation methods, the rock support system and the time required for its installation, the shape of the opening, the rock type, the magnitude and orientation of the in situ stress field, the temperature, and the amount of time the support system is operational.

Two primary hydrologic effects are expected to result from repository excavation. These are (1) changes in the magnitudes of the hydrologic parameters in the host rock in the very near field of the repository, and (2) changes in the orientations of the hydraulic gradients in the host rock in the vicinity of the repository. The first of these effects is expected to be highly complex, but is generally expected to result in a reduced hydraulic conductivity in the radial direction about the drift and an increased hydraulic conductivity in the axial direction along the drift. The second of these effects results from groundwater inflow into the repository excavation during the 50- to 80-year operational period, which may generate a significant perturbation to the local groundwater flow system. Changes in rock properties would be expected to be confined to the very near field, but changes in hydraulic gradients may occur over a considerably larger area.

Important issues associated with these hydrological effects include the extent of rock damage zones, backfill and packing material resaturation, and the design and placement of seals. Although these considerations are expected to become important in performance assessment, their complexities and site-specific nature do not support their use in generic ranking considerations.

\section{C.6.3 RADIATION EFFECTS}

Radiation emitted from the waste containers and by any radionuclides that may be released will enter into and be absorbed by the packing materials and the host rock. Although little is known about radiation effects for the rock types and at the radiation levels considered here, any effects on hydrologic material properties that would occur would be expected to be small and confined to the very near field of the waste container. If the packing materials are installed relatively early, their high water content resulting from their high porosity would be expected to absorb much of the radiation released. 


\section{C.7 ANALYSIS}

\section{C.7.1 INTRODUCTION}

The analyses for travel time and groundwater inflow, performed to rank the five sedimentary rock types, are described in this chapter. Under each analysis a description of the methodology is presented, followed by the presentation of results.

\section{C.7.2 TRAVEL TIME}

\section{C.7.2.1 Method of Trave1 Time Analysis}

The pre-waste-emplacement groundwater travel time is estimated by first solving the steady state groundwater flow equation:

$$
\frac{\partial}{\partial x_{i}}\left(\frac{k_{i j} \rho g}{\mu}\right) \frac{\partial \phi}{\partial x_{j}}=0
$$

where $k_{i j}=$ perneability tensor,

$\rho=$ density of the fluid,

$\mu=$ viscosity of the fluid,

$\phi=$ hydraulic potential,

$\mathrm{x}_{i}=$ Cartesian coordinates,

$g=$ gravitation constant.

The relatively complex geometry, coupled with the anisotropic hydraulic conductivities considered in these analyses, necessitate the use of numerical solution techniques in the form of a computer code. The numerical code selected for this study is based on a weighted residual implementation of the finite element method. The code is documented in (BACA 1981) and will not be described here.

Because steady-state flow conditions are assumed for the purposes of this comparative evaluation, solution of the flow equation produces a single non-time dependent potential field. The groundwater travel time is derived from the water particle velocity which is defined at each point in the field as the Darcian velocity divided by the effective porosity of the local material. The velocity field is therefore determined from the potential field by invoking Darcy's law and knowing the effective porosity at each point in the modeling domain.

The material properties and regional gradients of the reference geologic sections for each of the five rock types are presented in Sects. C.3 and C.5. The geometry and boundary conditions used in the travel time analyses for the typical cases are shown in Figs. C.7.1 through 6.7 .5 . It was assumed that all of the rock types were initially saturated with groundwater for the purpose of calculating postclosure groundwater travel times. 
ORNL DWG $85-6$
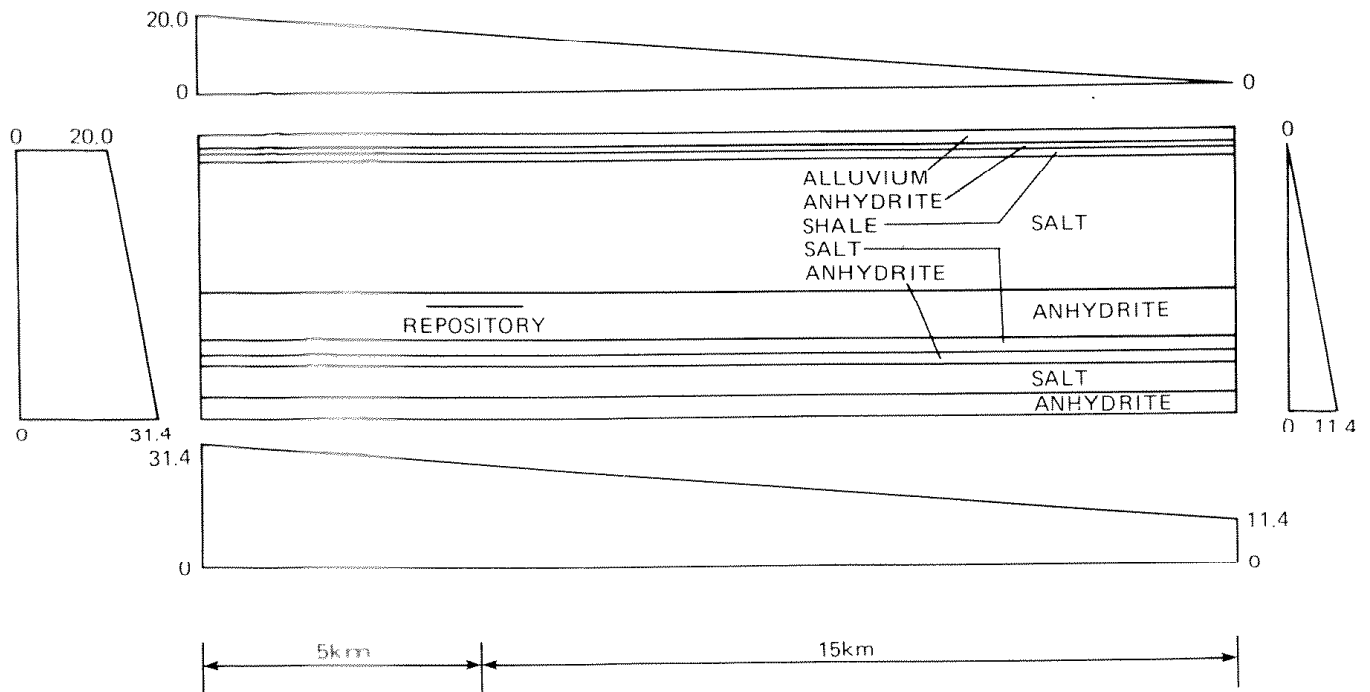

VERTICAL EXAGGERATION: $\times 5$

Fig. C.7.1. Geometry and boundary conditions used in calculation of pre-waste-emplacement groundwater travel time for the typical case, anhydrock section

ORNL DWG 85-7

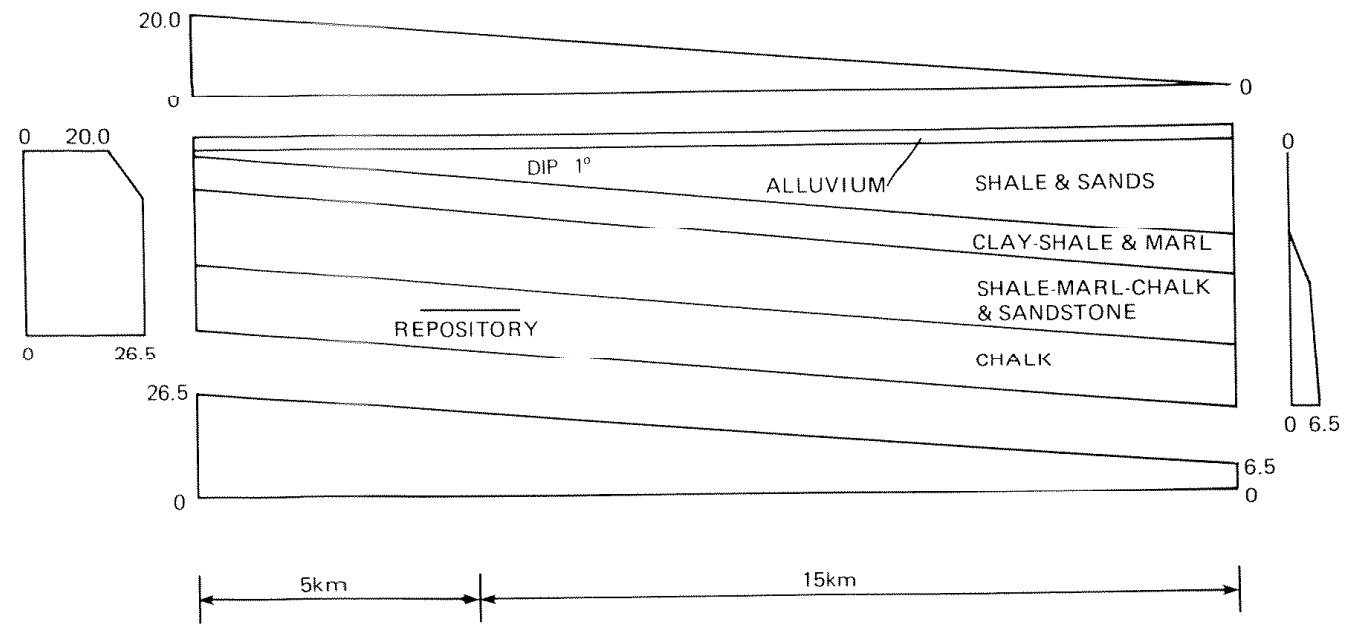

VERTICAL EXAGGERATION: $\times 5$

Tig. 0.7 .2 . Gometry and boundary conditions nes in calculation of pre-waste-emplacement groundwater travel time for the typical case, chalk section. 
ORNL DWG 85-8

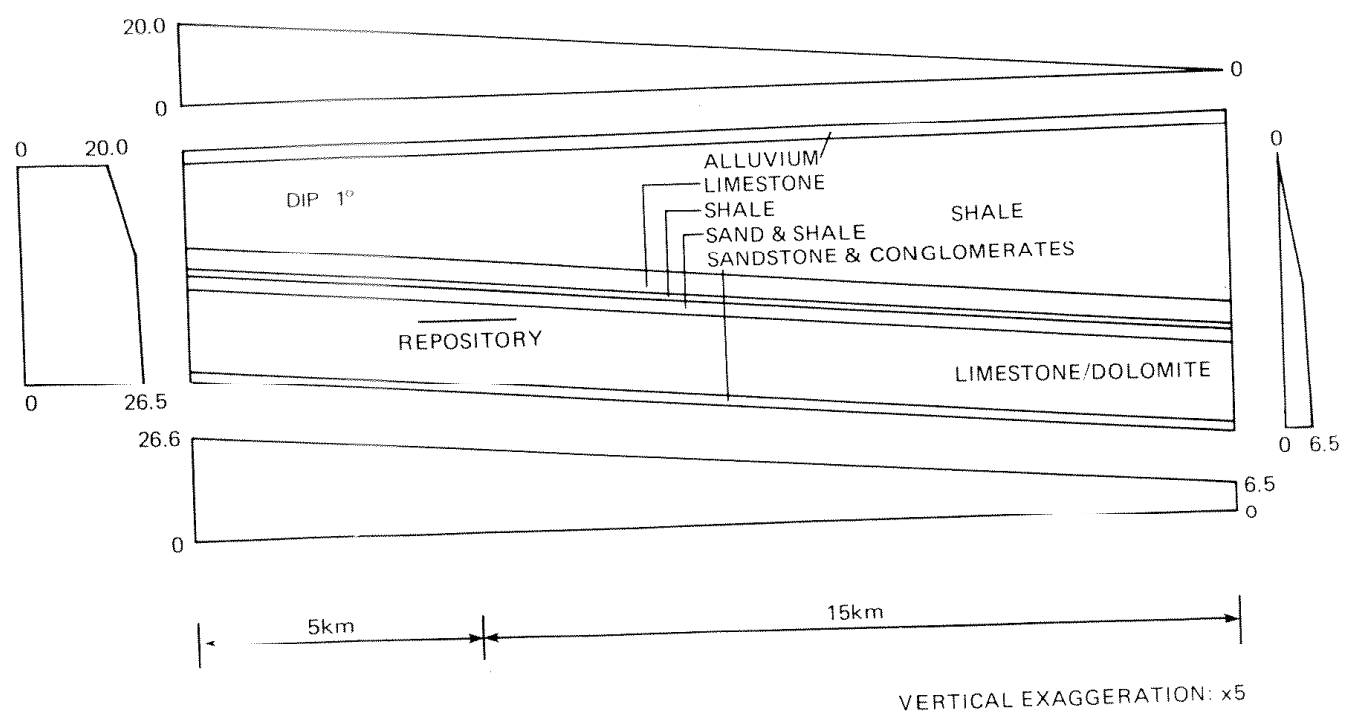

Fig. 0.7 .3 . Geometry and boundary conditions used in calculation of pre-waste-emplacement groundwater travel time for the typical case, carbonate rocks section.

ORNL DWG 85-9

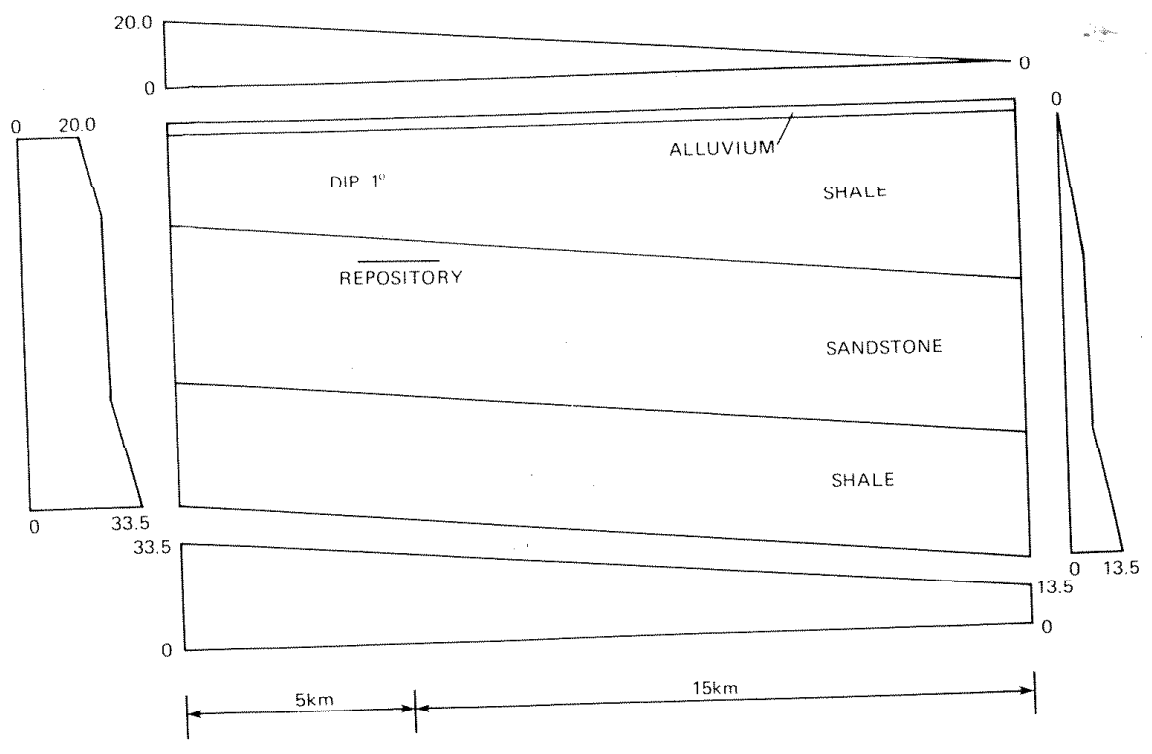

VERTICAL EXAGGERATION: $\times 5$

Fig. C.7.4. Geometry and boundary cunditions uocd in calm1ation of pre-waste-emplacement groundwater travel time for the typical case, sandstone section. 


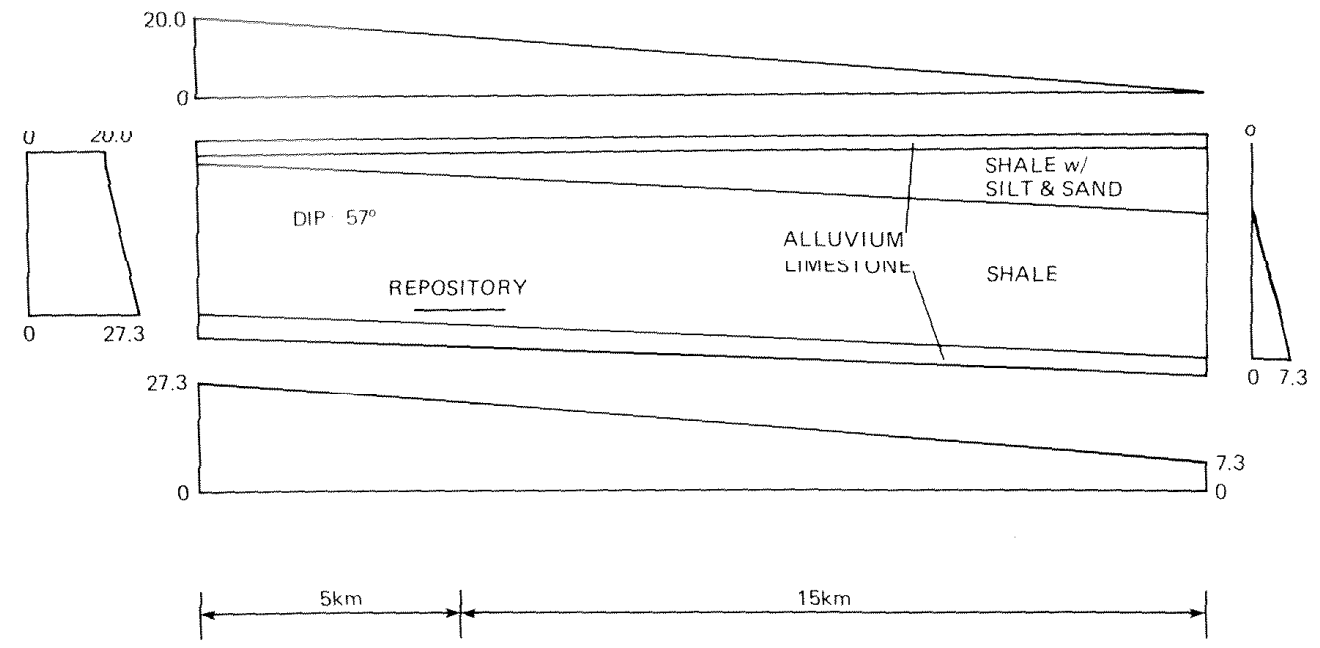

VERTICAL EXAGGERATION: $\times 5$

Fig. C.7.5. Geometry and boundary conditions used in calculation of pre-waste-emplacement groundwater travel time for the typical case, shale section.

The boundary conditions used in the travel time analyses are derived from the regional gradients and the geometry of the section in the following manner. An upper constant potential boundary condition is imposed at the base of a 50-m-thick assumed layer of unconsolidated alluvium at the top of each section. The head on this boundary is assumed to vary linearly from a potential of $20 \mathrm{~m}$ on the left to $0 \mathrm{~m}$ on the right over the $20-\mathrm{km}$ length of the top surface of the model. This results in the assumed 0.001 horizontal regional gradient described in sect. C.3.

The other boundary conditions are estimated by solving a separate problem involving a second model referred to here as the boundary condition model. The boundary condition model uses the same geometry as the travel time model, but the top boundary is set uniformly to a potential of $0 \mathrm{~m}$, the left and right boundaries are set to no flow conditions, and the lower boundary is set as a uniform constant potential boundary. The value of the lower boundary is determined by trial and error to result in a potential of $6.5 \mathrm{~m}$ at the repository. Given the constant $700-\mathrm{m}$ repository depth, this potential conforms to the assumed upward vertical regional gradient of 0.01 between the repository and the upper boundary at the bottom of the unconsolidated alluvium.

The vertical potential profile near the right side of the boundary condition model provides the right boundary condition for the travel time 
mode1. The vertical potential profile near the left side of the boundary condition model with the addition of $20 \mathrm{~m}$ to account for the horizontal regional gradicnt provides the left boundary condition for the travel time model. Finally, the lower boundary condition of the travel time model is simply the lower boundary of the boundary condition model adjusted for the horizontal regional gradient. While not completely accurate from a theoretical standpoint, it is believed that the method used to derive boundary conditions is more than sufficient for the present purpose of ranking.

The boundary conditions shown in Figs. C.7.1 through C.7.5 are for the typical case for each of the rock types, and were developed using values of material properties that would be expected to be generally available for nuclear waste disposal at a number of field locations. Different boundary conditions had to be calculated for the high and low cases because of the changing material properties in the reference horizon. These boundary conditions were also determined using the approach described above for the typical cases. The resulting head distributions are presented in Sect. C.7.3.

The reference geologic sections were discretized into elements for travel time modeling. An example of the finite element meshes used in the analyses is shown in Fig. C.7.6. This example is for the sandstone sertion and is shown at a uniform scale with no vextical exaggeration. The discretizations for all sections are presented in Sect. C.7.4 drawn with a five times vertical exaggeration for clarity.

\section{C.1.2.2 Iravel Time Results}

Before discussing the results of the groundwater travel time analyses, a word of caution shnuld he introduced. As stated in Sect. C.?, a large number of assumptions were of necessity made in conducting this study and the numbers generated by the analyses for the typical cases as well as the ranges associated with the high and low cases should be used only for relative comparison of rock types and not for absolute judgmencs. It is noted that the so-called typical, high and low cases only reflect ranges of material properties in the reference horizon and cannot be expected to

ORNL DWG 85-11

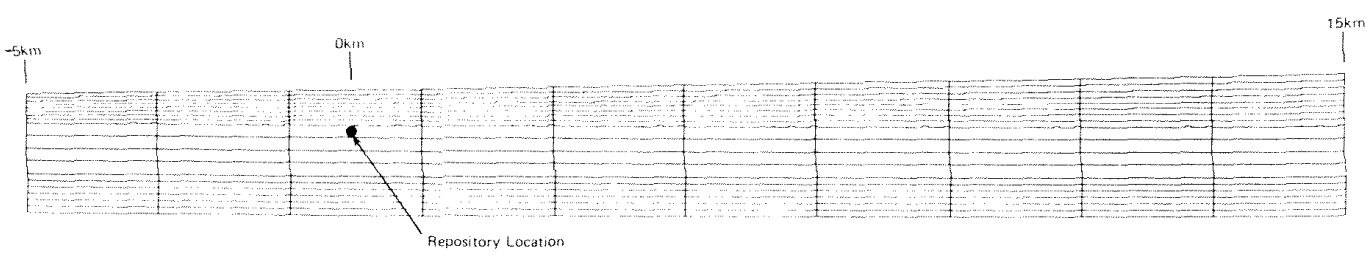

Fig. C.7.6. Example of discretization used in the calculation of pre-waste-emplacement groundwater travel times. 
address the overall range that may be expected for the reference section as a whole.

Because the reference sections considered in this study were selected on the basis of good potential for deep geologic disposal of high-level radioactive waste, relatively long pre-waste-emplacement groundwater travel times are expected to the accessible environment for the more suitable rock types. Analyses indicate that the five rock types fall into two very distinct groups. Three of the rock types, anhydrock, sandstone and shale, exhibit very long travel times; the other two, chalk and carbonate rocks, show very significantly shorter travel times.

Because of the low velocities associated with the former three rock types, it is impractical to carry the analyses out to the time required to reach the accessible environment. The travel time results for these rock types are therefore presented as distance traveled in 100,000 years rather than time to the accessible environment. For the other two rock types, it is practical to carry the analyses out to the time required to reach the accessible environment, but it is not practical to model an area large enough to contain the 100,000-year travel distance for direct comparison to the former three rock types. Since comparison of the better rock types is of greater interest, the results of the analyses are presented in Figs. C.7.7 through $\mathrm{C.7.11}$ as distance traveled in 100,000 years, and the distances exceeded are given for the chalk and carbonate rocks sections. The actual groundwater travel time to the accessible environment is present for these latter two rock types in Tables C.7.1 and $\mathrm{C} .7 .2$.

\section{C.7.2.2.1 Anhydrock}

The 100,000-year travel time paths for the anhydrock section are shown on Figure C.7.7. For the typical case the path is $32 \mathrm{~m}$ horizontally and $34 \mathrm{~m}$ up for a total path length of $47 \mathrm{~m}$. For the high case, the corresponding numbers are $315 \mathrm{~m}, 37 \mathrm{~m}$ and $317 \mathrm{~m}$; for the low case, the numbers are $3 \mathrm{~m}, 20 \mathrm{~m}$ and $20 \mathrm{~m}$.

\section{C.7.2.2.2 Chalk}

The trave1 time analysis, as seen in Fig. C.7.8, indicates that the water particle velocity in the chalk section is relatively large. Table C.7.1 further suggests a very significant difference between the high case and the typical and low cases. Comparison of travel paths on Fig. C.7.8 shows that travel time is significantly lower for the high case because the groundwater particle does not enter the lower conductivity overlying shaley layer before it reaches the accessible environment. This result indicates that the assumption of lower conductivity horizons overlying the chalk horizon may present chalk in a somewhat nonconservatively favorable light. As discussed in Sect. C.2 and C.5, however, the objective of this study is to compare rock types on the basis of a consistent set of standard conditions and not to predict the absolute range of results for a given rock type. 
ORNL DWG $85-12$
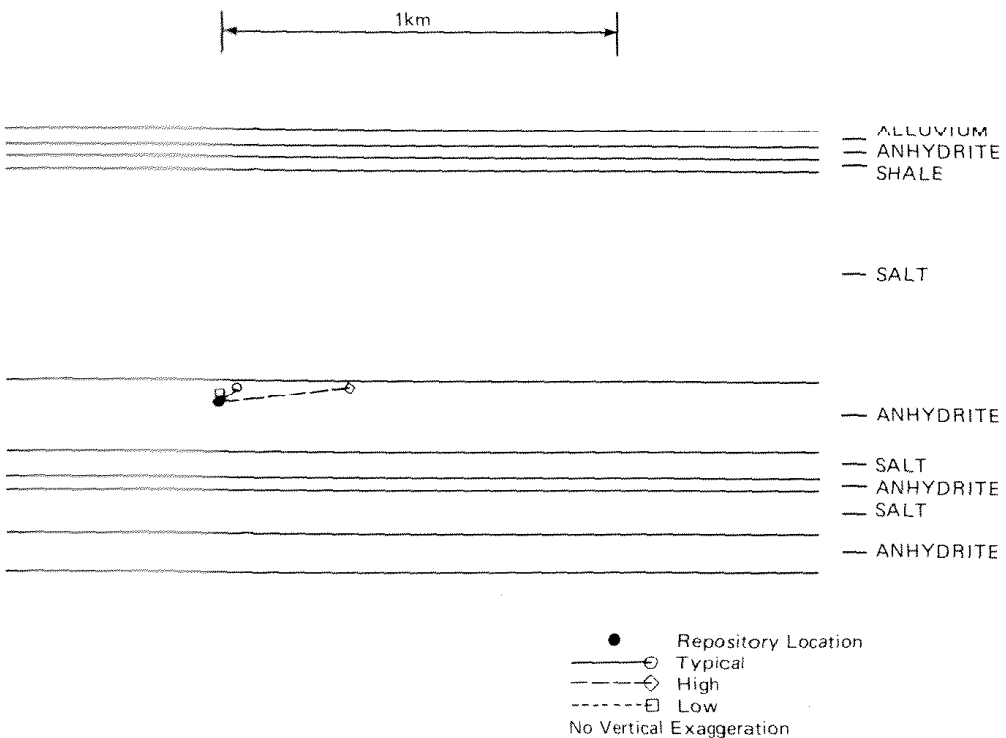

Fig. C.7.7. Pre-waste-emplacement groundwater travel time paths in the anhydrock section.

ORNL DWG $85-13$

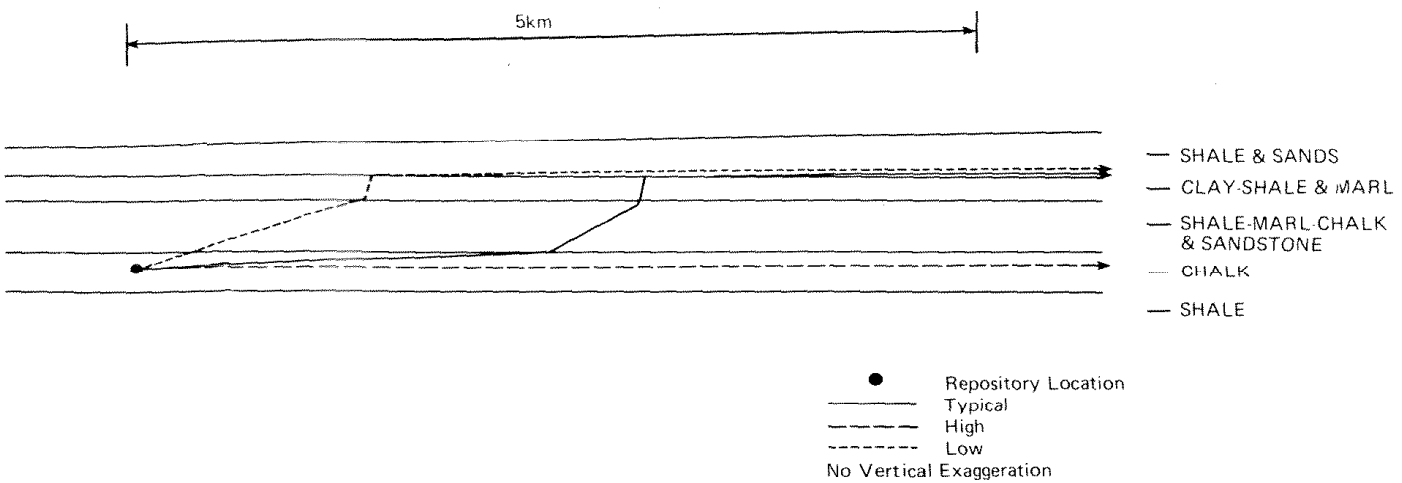

Fig. C.7.8. Pre-waste-emplacement groundwater travel time paths in the chalk section. 
ORNL DWG 85-14

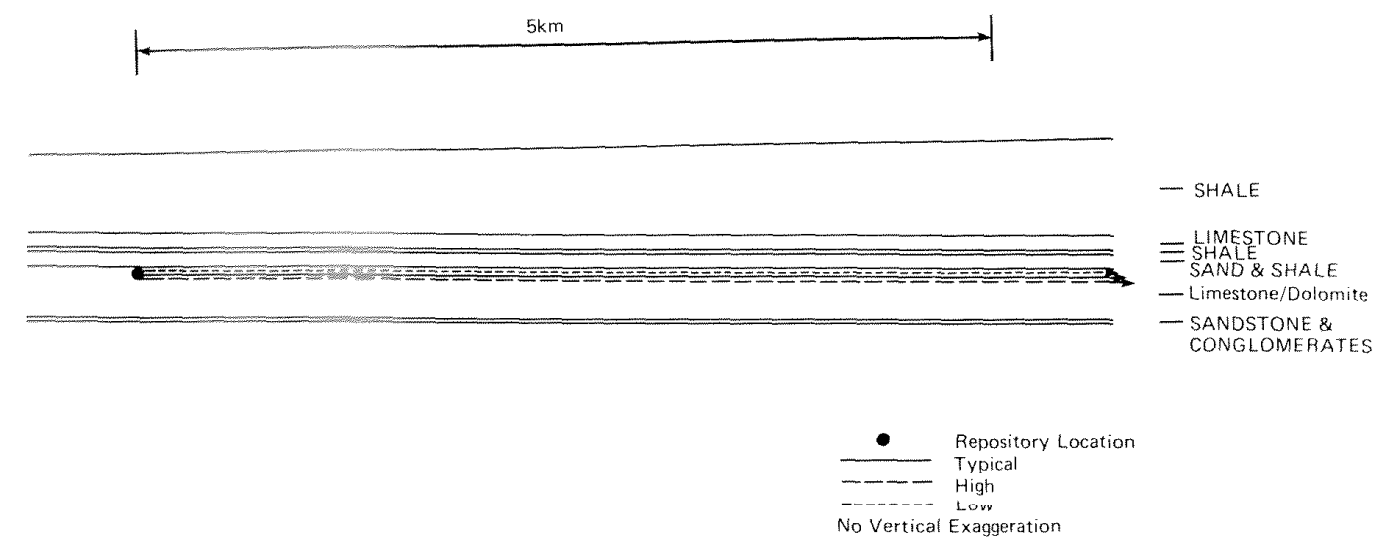

Fig. C.7.9. Pre-waste-emplacement groundwater travel time paths in :he carbonate rocks section.

ORNL DWG 85-15
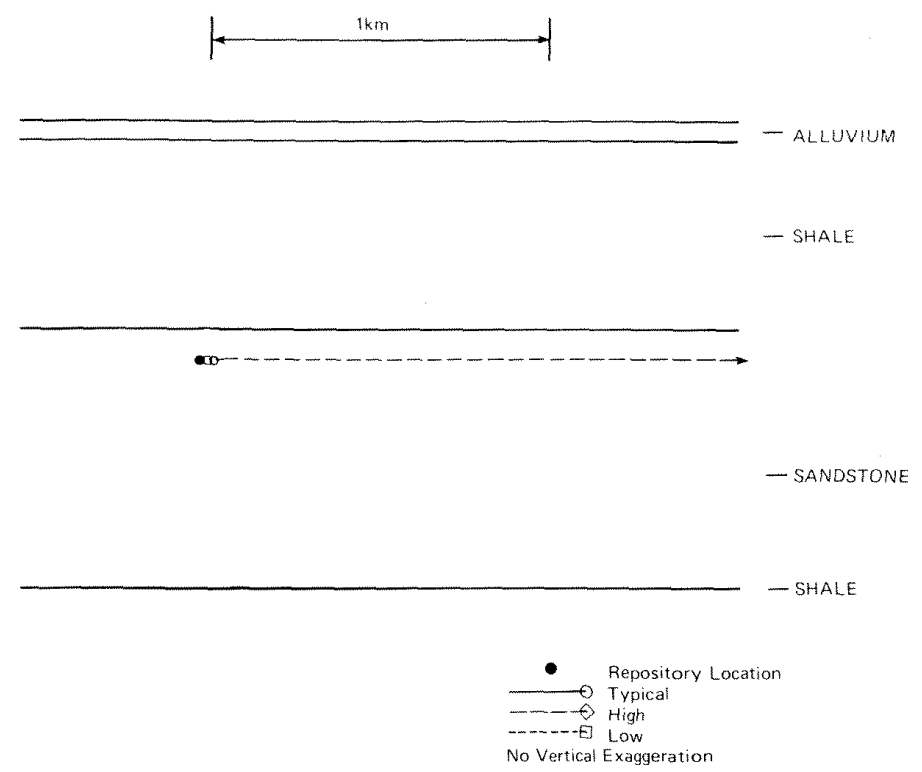

Fig. C.7.10. Pre-waste-emplacement groundwater travel time paths in the sandstone section. 
ORNL DWG $85-16$

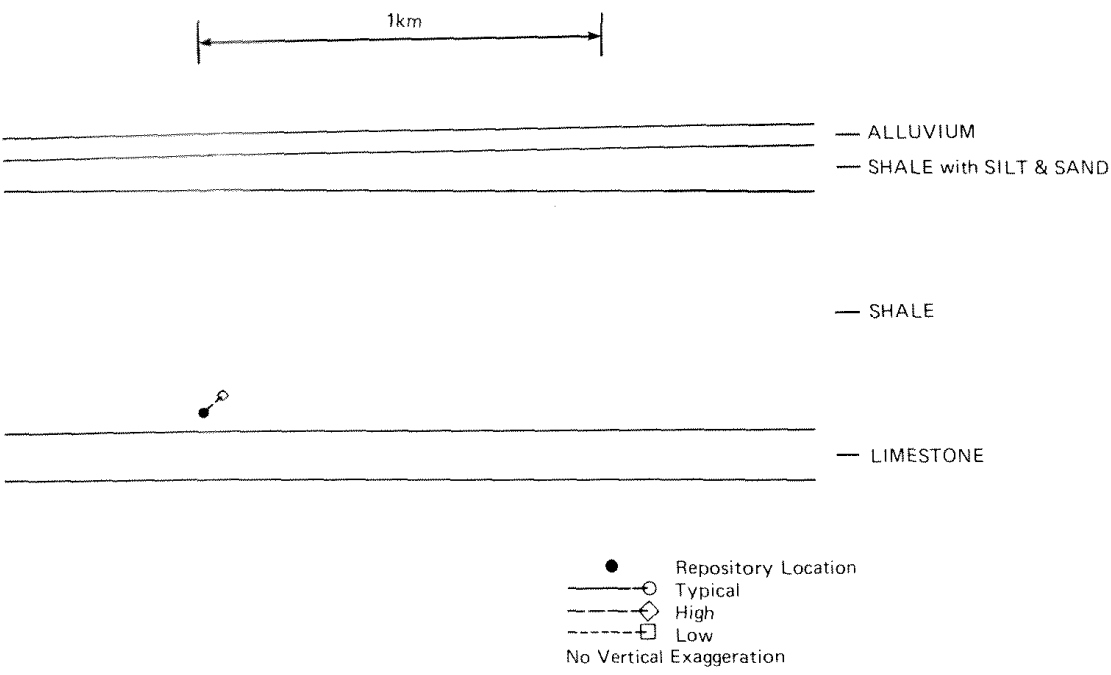

Fig. C.7.11. Pre-waste-emplacement groundwater travel time paths in the shale section.

Table C.7.1. Ten-kilometer travel time in chalk

\begin{tabular}{lcc}
\hline & Travel time (years) & \\
\hline Expected & High & Low \\
\hline 36,900 & 310 & 47,400
\end{tabular}


Table 0.7 .2 . Ten-kilometer travel time in carbonates

\begin{tabular}{lcr}
\hline & Travel & time (years) \\
\hline Expected & High & Low \\
\hline 3,200 & 320 & 31,700 \\
\hline
\end{tabular}

\section{C.7.2.2.3 Carbonate rocks}

Figure 0.7 .9 and Table C.7.2 show the groundwater velocity to also be large in the reference carbonate rocks section. All of the travel time paths in carbonate rocks, however, are seen to remain willilin the reference horizon because of the overlying less conductive sand-shale layers. Had the overlying layers been carbonate rocks or some other more conductive material, vertical movement would have been much more significant. Like chalk, the carbonate rocks section may thus present carbonate rocks in a somewhat nonconservatively favorable light.

\section{C.7.2.2.4 Sandstone}

Like the carbonate rocks, all travel paths for the sandstone remain in the reference horizon because of the less-permeable confining shale layer. For the typical case the path is $30-\mathrm{m}$ horizontally and $3-\mathrm{m}$ upward for a total path length of $30 \mathrm{~m}$. For the high case the path is $3,149-\mathrm{m}$ horizontally and 53-m downward for a total path length of 3,150 m. Note that the downward direction results from the dip of the confining shale bed. For the low case the travel distance is $15-\mathrm{m}$ horizontally and $3-\mathrm{m}$ upward, for a total of $15 \mathrm{~m}$. The relatively large range in travel time distances results from the relatively large range in conductivities selected in Sect. C.5. As with the two foregoing rock types, the lower conductivity shale layers above and below the reference horizon constrain vertical movement and cause the results to present sandstone as being somewhat more favorable than it might otherwise have been if a different reference section had been selected. As noted in Sect. C.3, however, the reference geologic section for the sandstone is representative of some existing sandstone occurrences.

\section{C.7.2.2.5 Shale}

In Fig. C.7.11 the groundwater velocity for the shale section can be seen to be relatively low. The total travel time path length for the typical case is $6 \mathrm{~m}$, the horizontal being $5 \mathrm{~m}$ and the vertical being $4-\mathrm{m}$ upward. The corresponding numbers for the high case are $56 \mathrm{~m}, 41 \mathrm{~m}$ and $37 \mathrm{~m}$ and for the low case $0.6 \mathrm{~m}, 0.5 \mathrm{~m}$ and $0.3 \mathrm{~m}$. For this particular section the upward vertical gradient has the potential for being nonconservative. If the vertical gradient had been downward and the path had gone into the underlying carbonate rocks, a shorter travel time may have resulted. 
C.7.3 BOUNDARY CONDITIONS FOR TRAVEL TIME MODEL: HIGH AND LOW CASES

ORNL DWG $85-29$

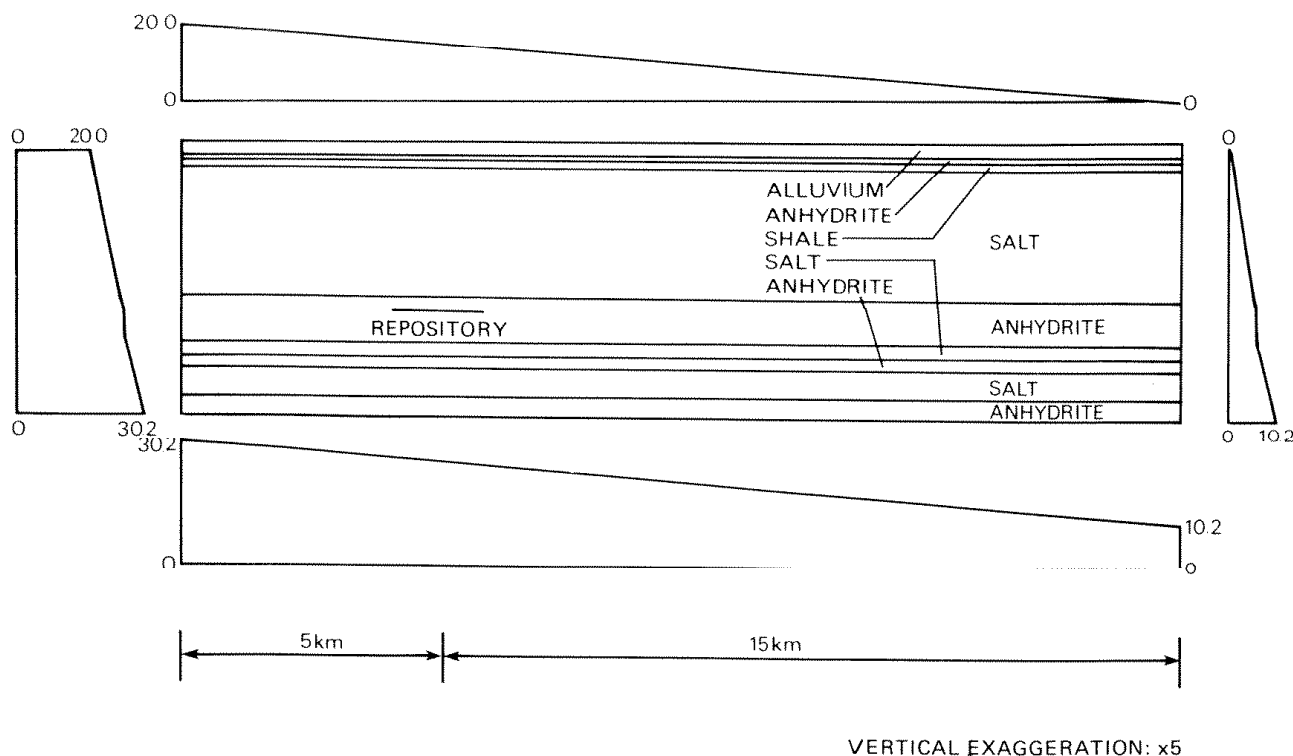

Fig. C.7.12. Boundary conditions for the travel time model "high" case, anhydrock section.

ORNL DWG $85-30$

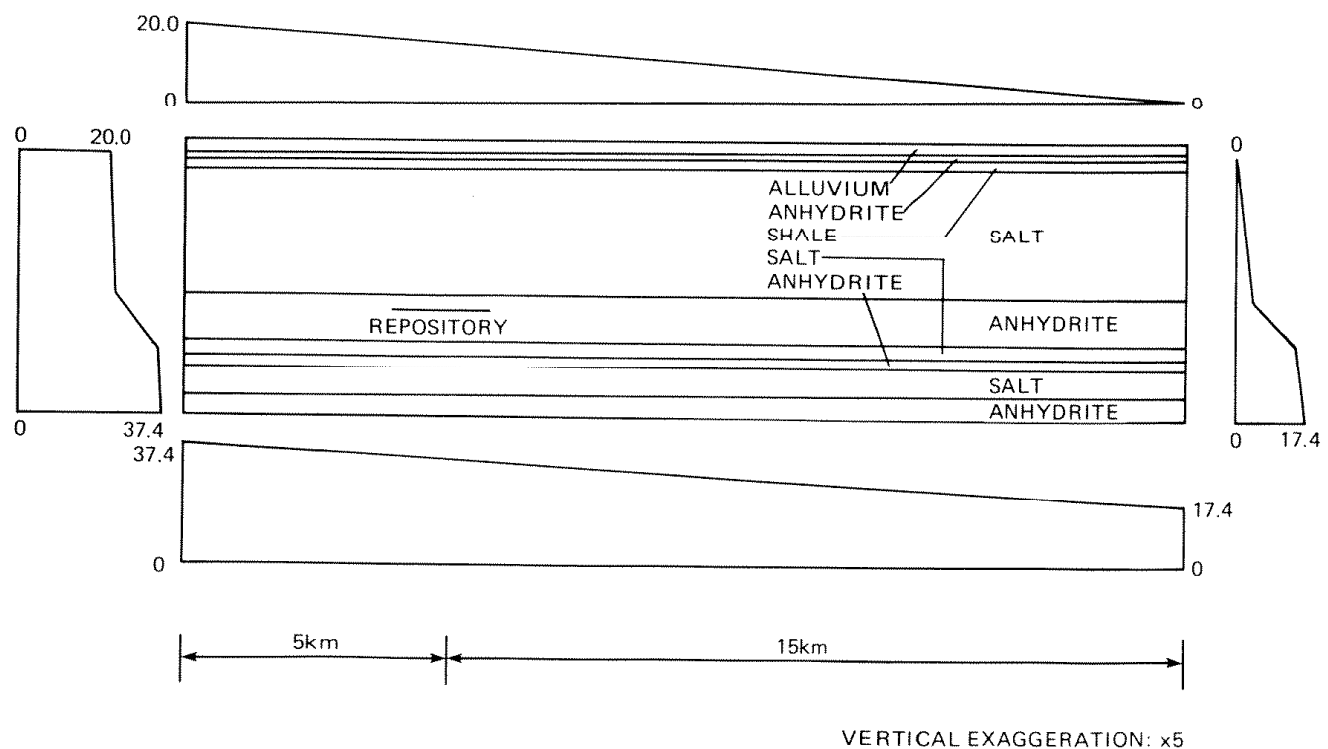

Fig. C.7.13. Boundary conditions for the travel time model "low" case, anhydrock section. 
ORNL DWG 85-31

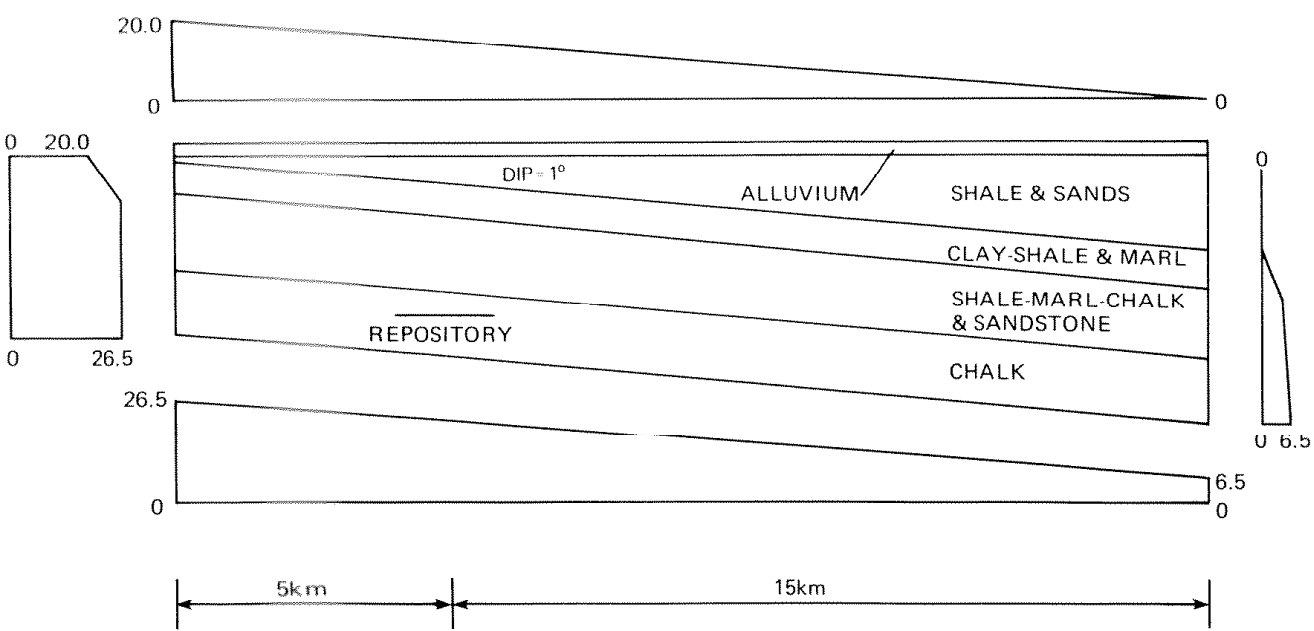

VERTICAL EXAGGERATION: X5

Fig. C.7.14. Boundary conditions for the travel time model "high" case, chalk section.

ORNL DWG $85-32$

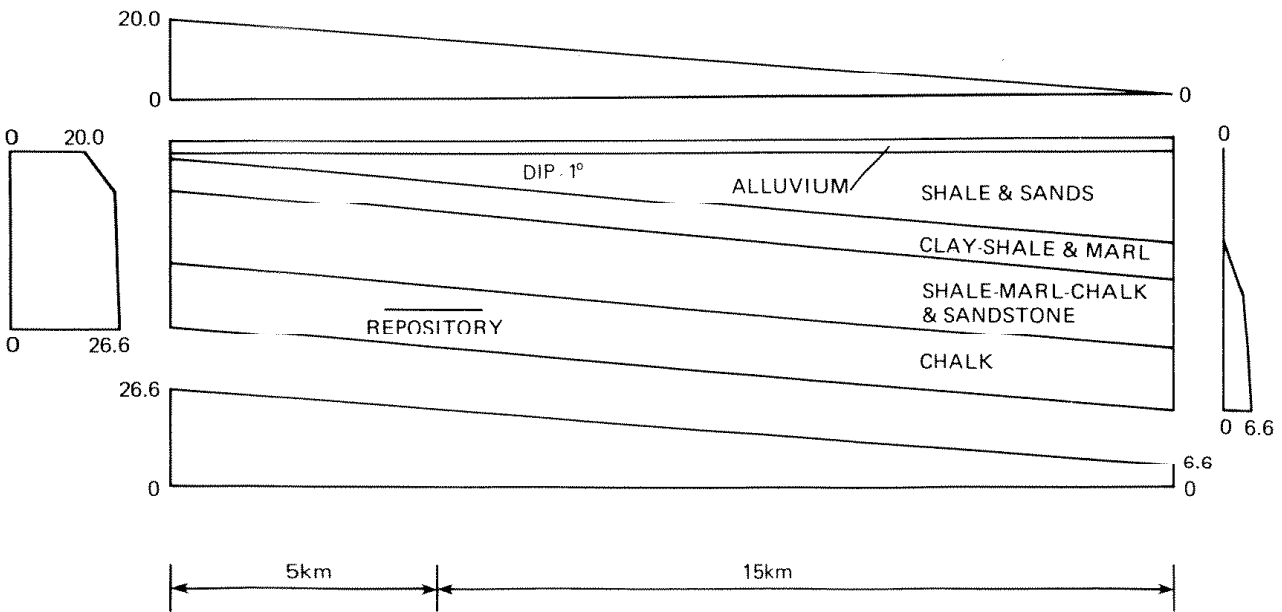

VERTICAL EXAGGERATION: $\times 5$

Fig. C.7.15. Boundary conditions for the travel time mode1 "Iow" case, chalk section. 
ORNL DWG 85-33

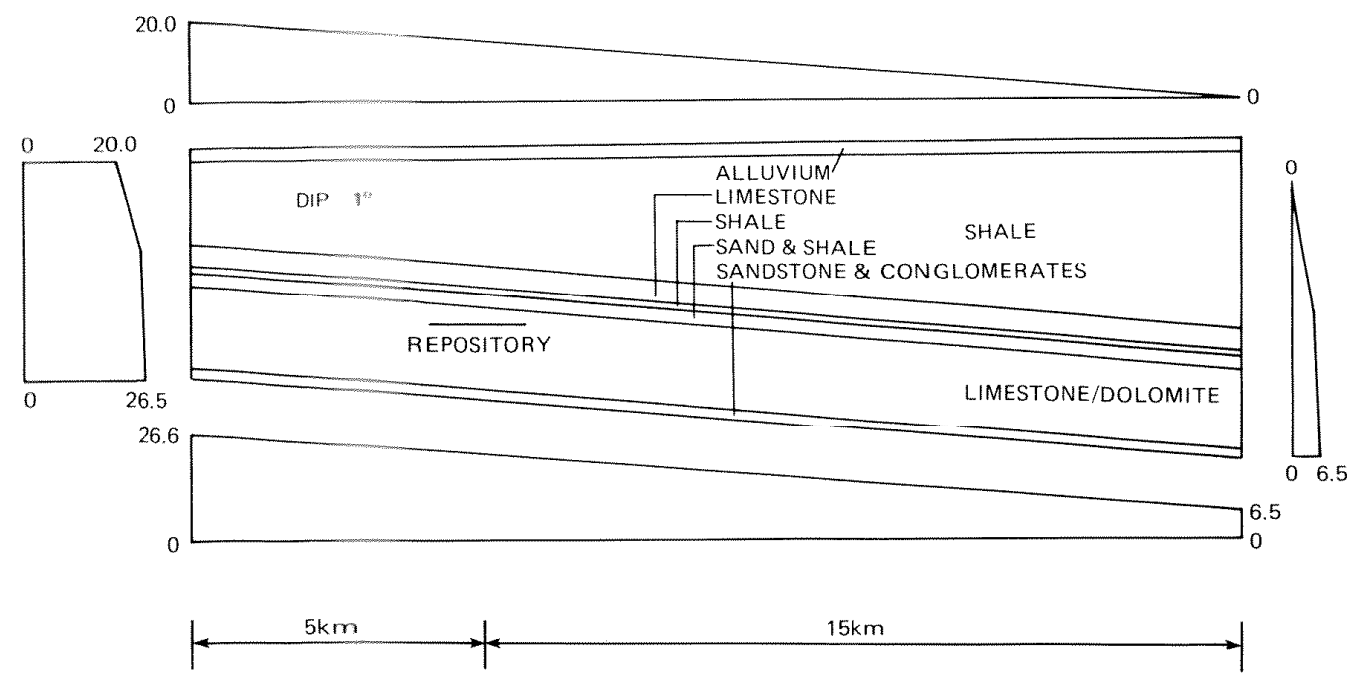

VERTICAL EXAGGERATION: $\times 5$

Fig. C.7.16. Boundary conditions for the travel time model "high" case, carbonate rocks (1imestone/dolostone) section.

ORNL DWG $85-34$
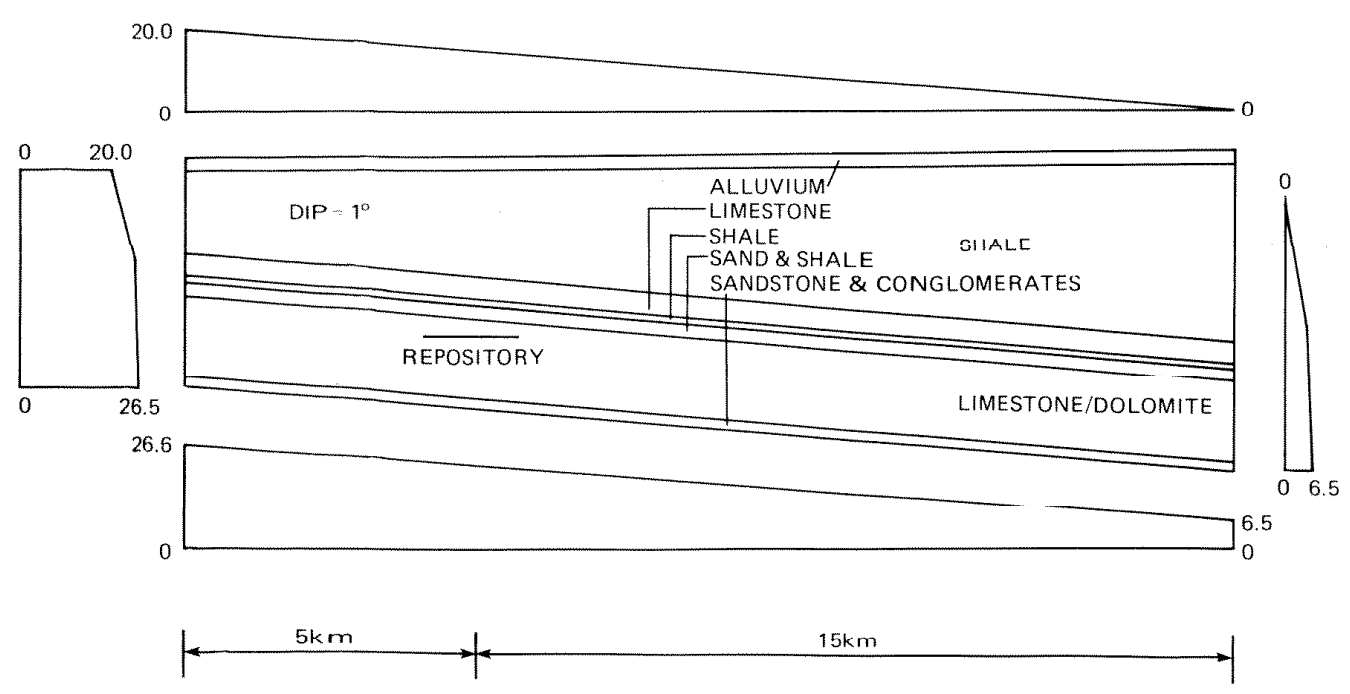

VERTICAL EXAGGERATION : $\times 5$

Fig. C.7.17. Boundary conditions for the travel time model "low" case, carbonate rocks (limestone/dolostone) section. 
ORNL DWG 85-35

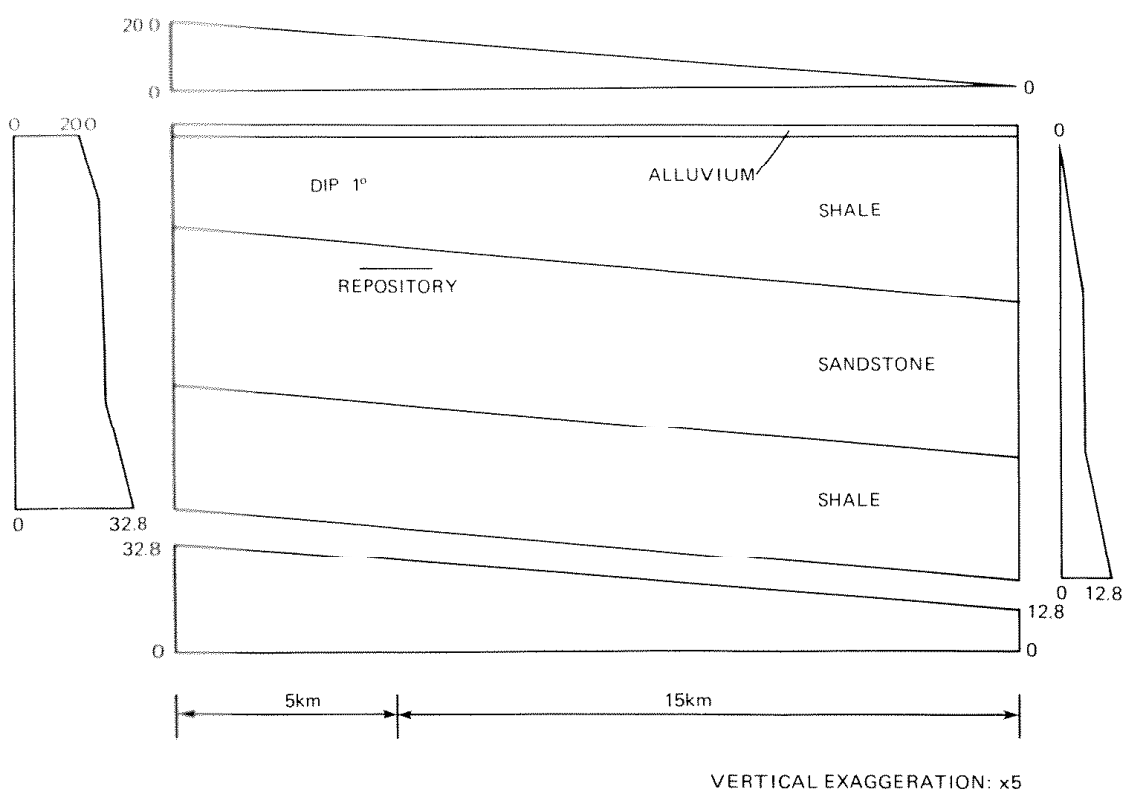

Fig. C.7.18 Boundary conditions for the travel time model "high" case, sandstone section.

ORNL DWG 85-36

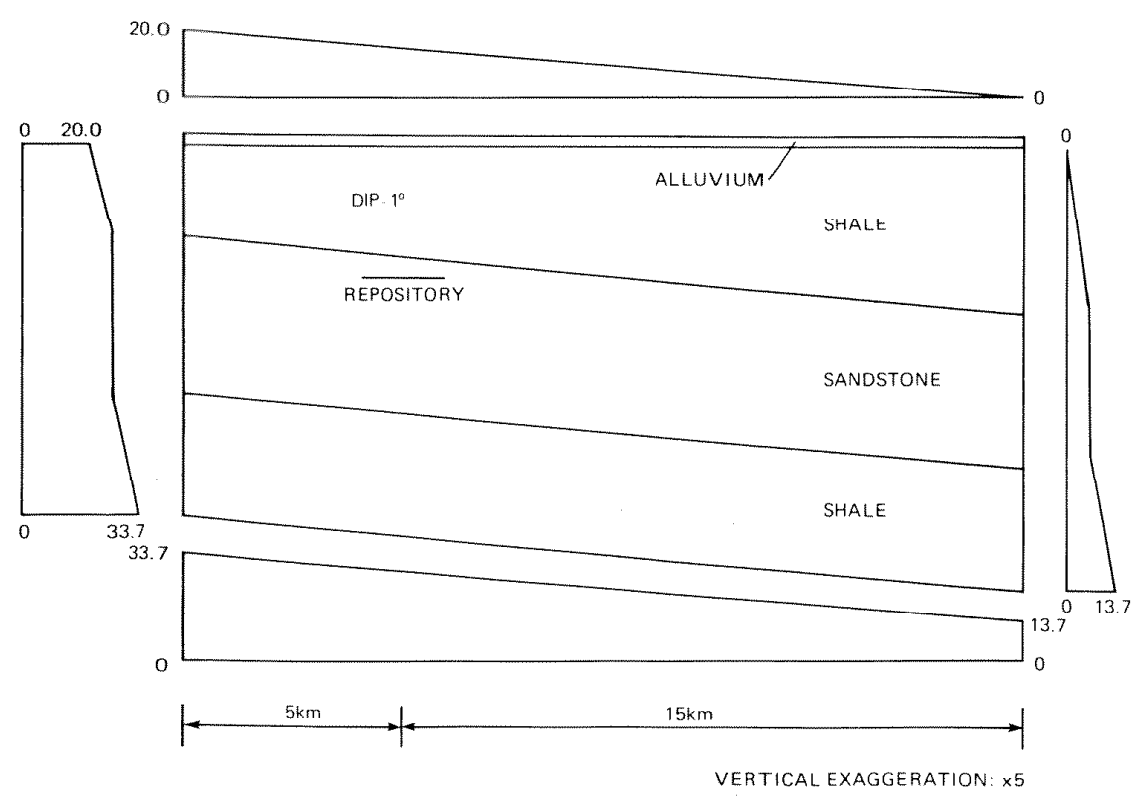

Fig. C.7.19. Boundary conditions for the trave1 time mode1 "low" case, sandstone section. 
ORNL DWG 85-37

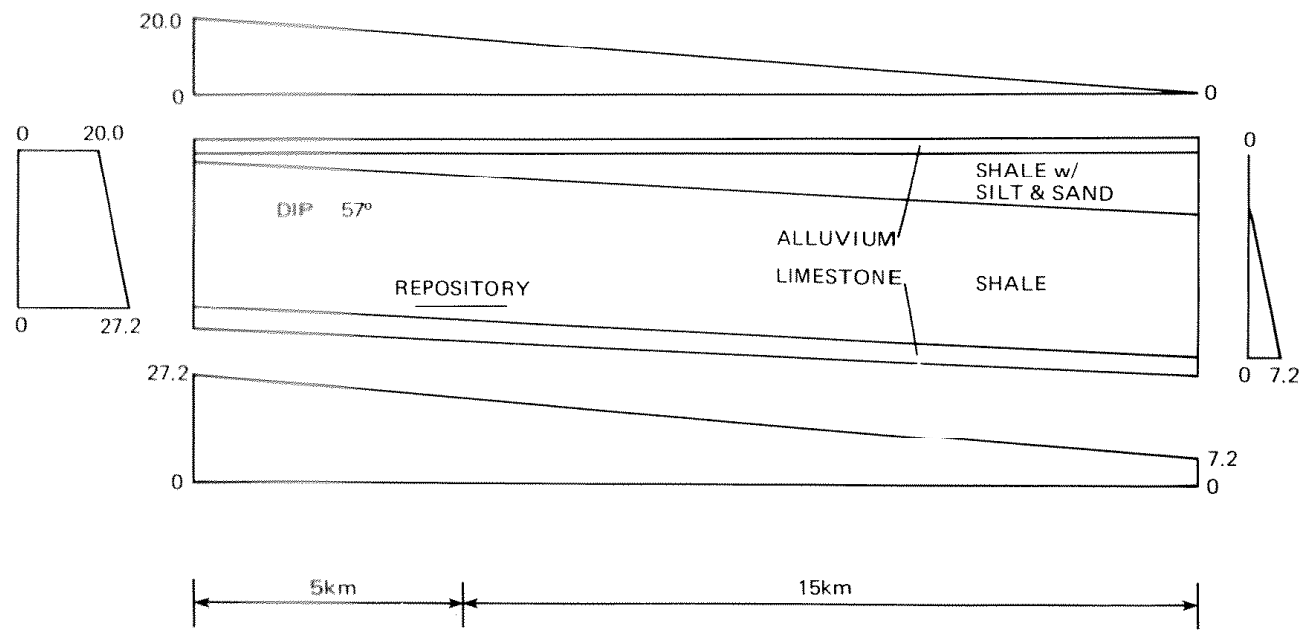

VERTICAL EXAGGERATION $\times 5$

Fig. C.7.20. Boundary conditions for the travel time model "high" case, shale section.

ORNL DWG 85-38

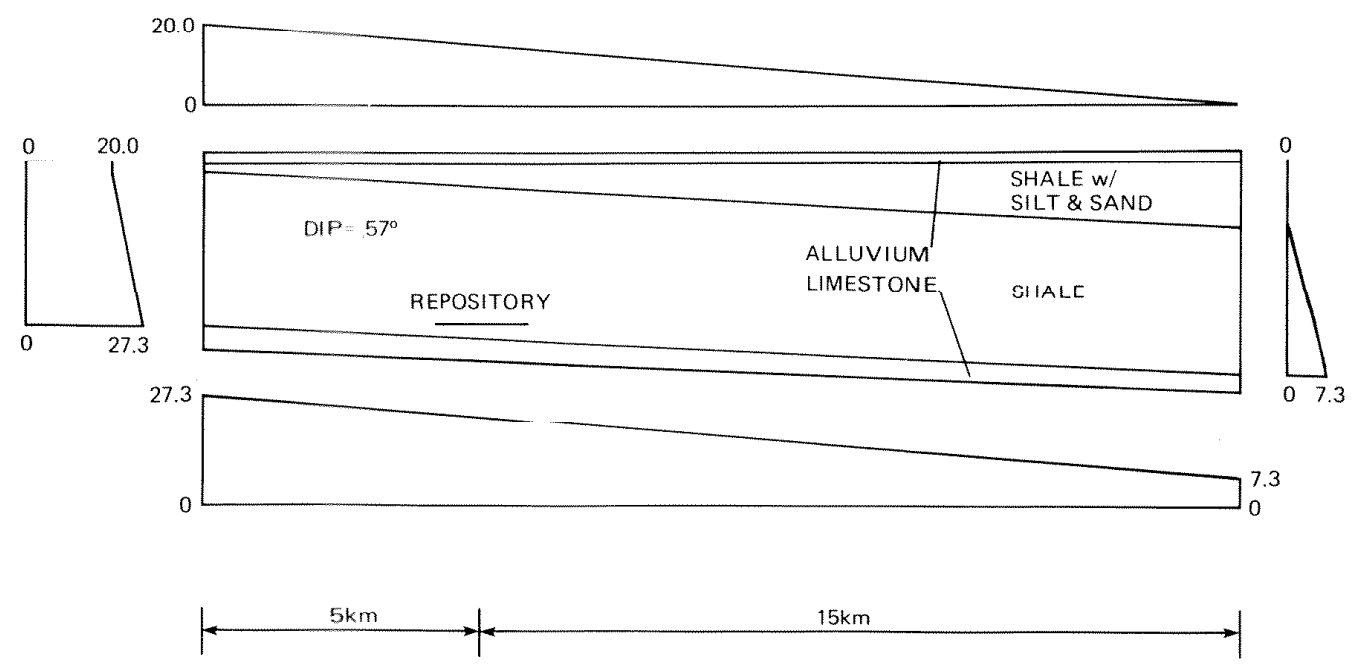

VERTICAL EXAGgERATION: $\times 5$

Fig. C.7.21. Boundary conditions for the trave1 time mode1 "10w" case, shale section. 
C.7.4 DISCRETTZATTONS FOR TRAVEL TIME MODELS

ORNL DWG 85-39
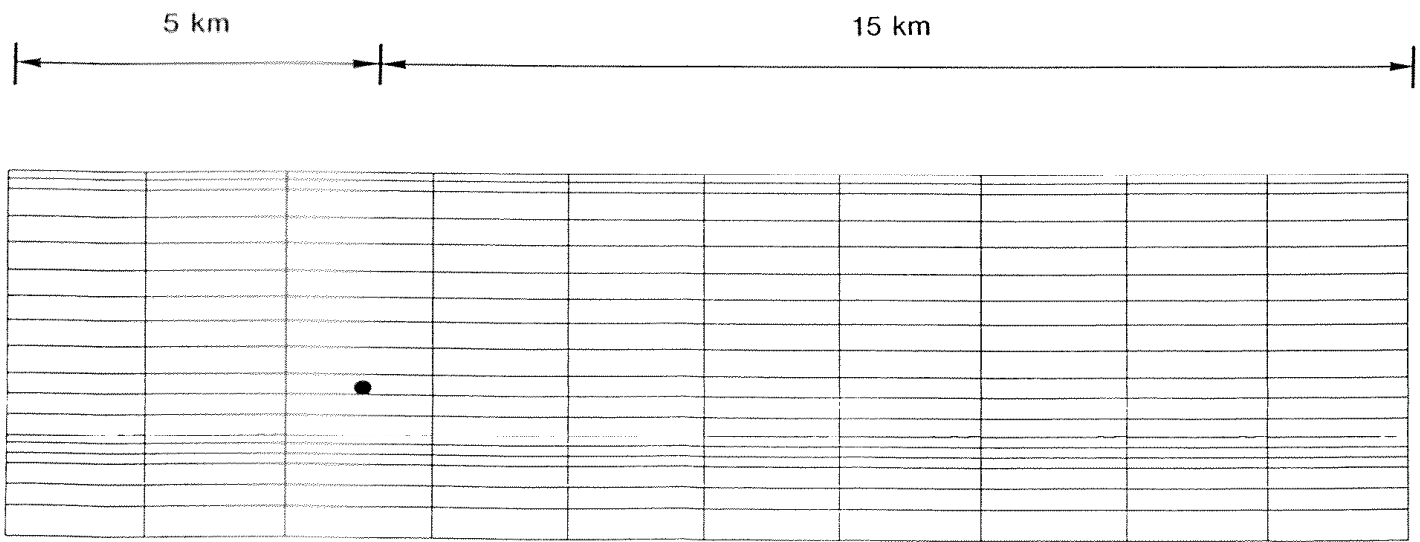

- REPOSITORY LOCATION

VERTICAL EXAGGERATION: $\times 5$

Fig. C.7.22. Discretization for travel time model, anhydrock section.

ORNL DWG 85-40
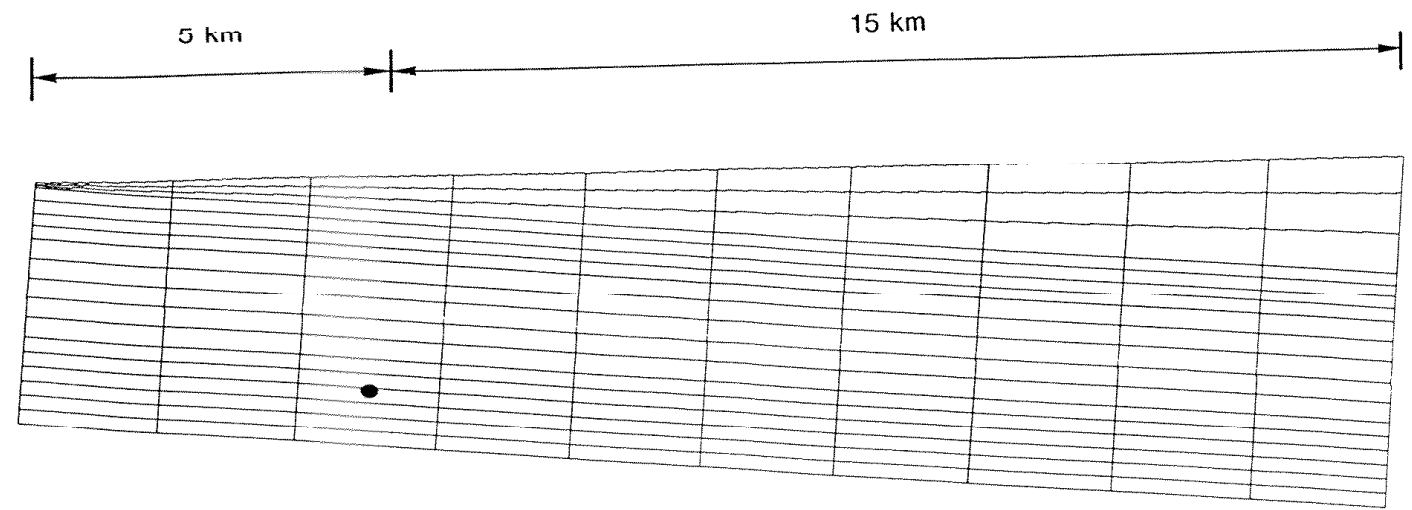

- REPOSITORY LOCATION

VERTICAL EXAGGERATION: $\times 5$

Fig. C.7.23. Discrecizacion for cravel time model, chalk section. 
ORNL DWG $85-41$
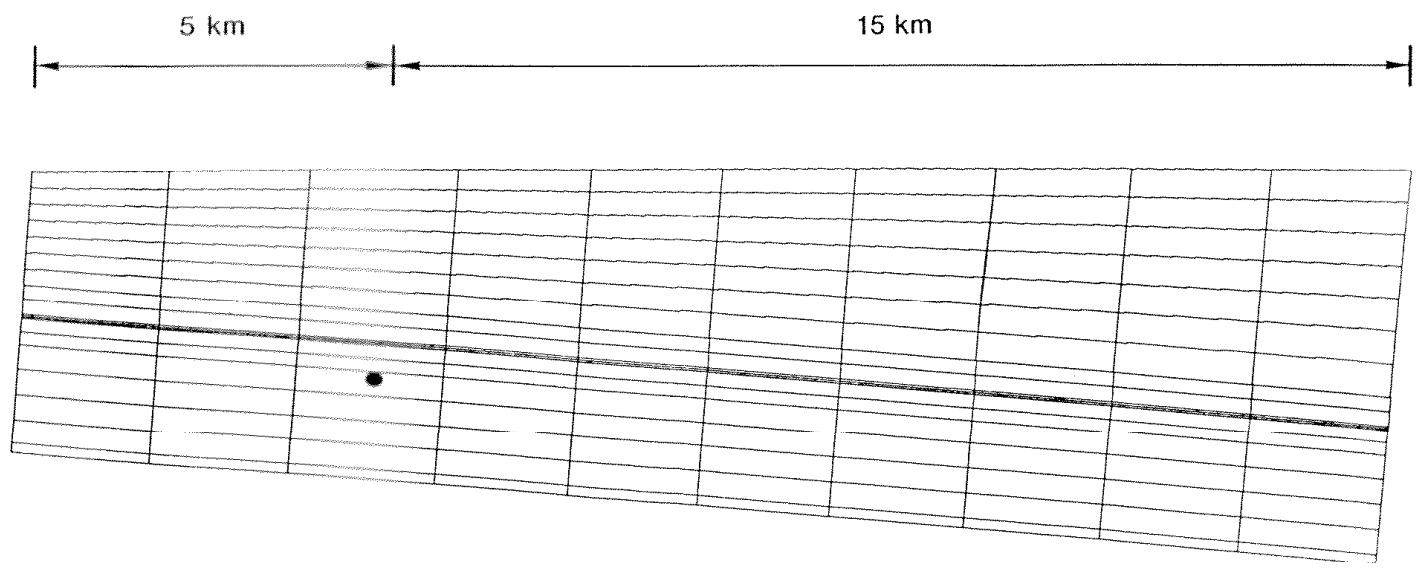

- REPOSITORY LOCATION

VERTICAL EXAGGERATION: $\times 5$

Fig. C.7.24. Discretization for travel time model, carbonate rocks (1imestone/dolostone) section.

ORNL DWG $85-42$
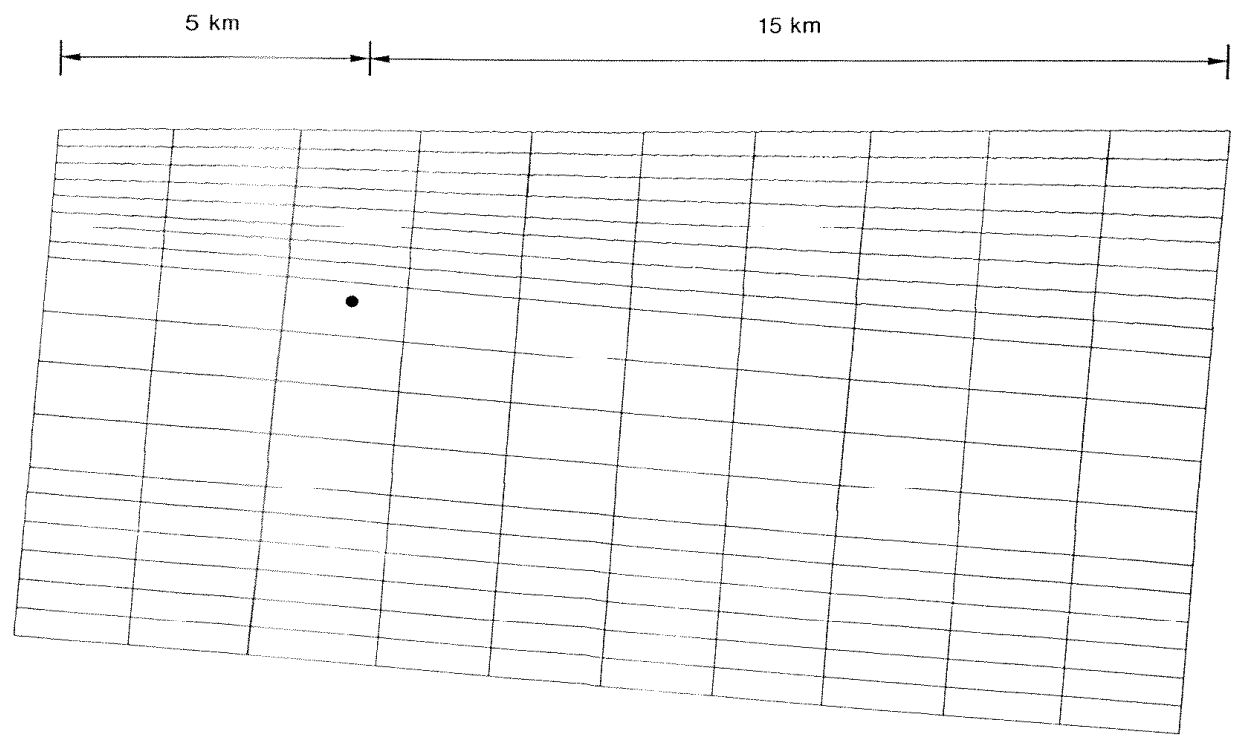

- REPOSITORY location VERTICAL EXAGgeration: x5

Fig. C.7.25. Discretization for travel time mode1, sandstone sertion. 

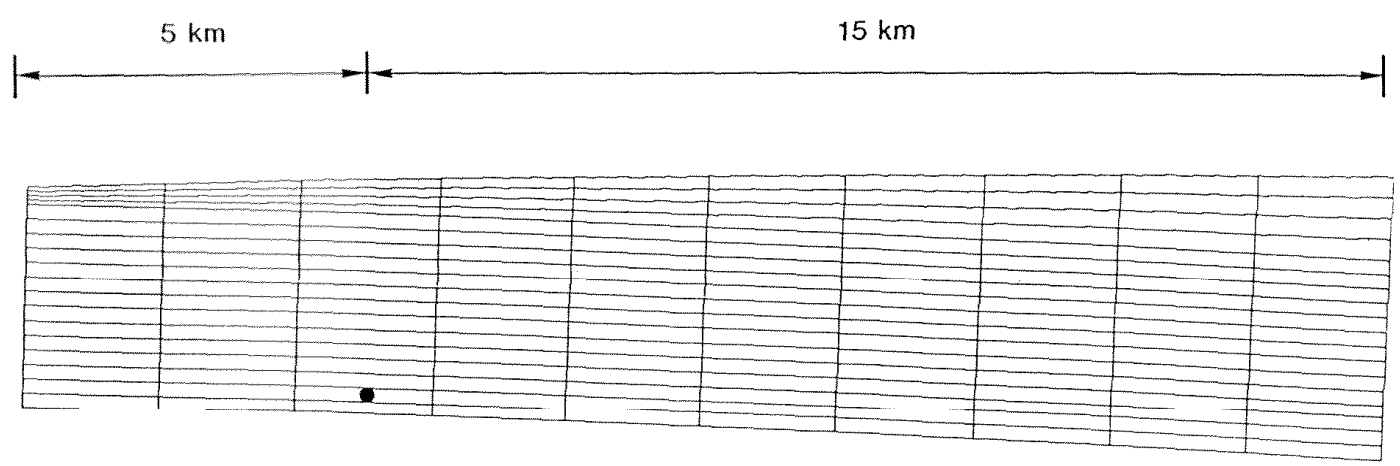

- REPOSITORY LOCATION

VERTICAL EXAGGERATION: $\times 5$

Fig. C.7.26. Discretization for travel time model, shale section.

\section{C.7.5 INELOW}

The groundwater inflow, for the purposes of ranking the five sedimentary rocks addressed in this study, is estimated as the volume of groundwater that nay be expected to enter a very long drift of 5.5 m diameter per meter of drift. Because the repository layouts have not been developed for the various rock types, the effects of flow field interference resulting from the multiple drifts of the final repository are not considered. Rather, it is belleved that the inflow, estimated on the basis of a single drift, provides a more than adequate basis for comparison ranking of the five sedimentary rock types.

Inflow into a drift will be relatively large soon after excavation and decrease with time to approach a steady-state value. Because the early time inflow can be significantly greater than the inflow at steady state, a transient finite element solution is used in this analysis.

\section{C.7.5.1 Method of Groundwater Inflow Analysis}

The inflow is estimated by solving the transient groundwater equation:

$$
\frac{\partial}{\partial x_{i}}\left(\frac{k_{i j} \rho g}{\mu}\right) \frac{\partial \phi}{\partial x_{j}}=s_{S} \frac{\partial \phi}{\partial t}
$$

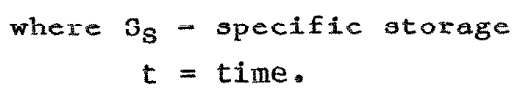


The layered geometry, aniootropy of the rock, and transient nature of this problem preclude the use of closed-form analytic solutions for calculating groundwater inflow. Such solutions would facilitate the analysis and provide good insight into the relative importance of the various parameters associated with the problem. Investigation into possible analytic solutions, however, produced only a steady-state solution for a system of three isotropic layers from the heat txansfer literature (SCHOFTFLn 1931). While te may be possible to extend this snintion to anisotropic layers, the important early time inflow effects would be 1ost. Thus a numerical code based on the finite element method was used to solve the transient flow equation for this study.

The geometry and boundary conditions for each of the five rock types are shown on Figs. $C .7 .27$ through $\mathrm{C.7.31}$, and an example of the finite element mesh is shown on Fig. C.7.32. The meshes used for each of the five rock types are presented in Sect. C.7.6.

In all cases the left boundary, with the exception of the drift, is creaced as a no flow condition on the basis of symmetry. The constant potential boundary at the drift is set to $-650 \mathrm{~m}$ to represent the $650 \mathrm{~m}$ of saturated rock above the repository. The outer three boundaries, as can be seen in the figures, have varying houndary conditions. This variation reflects the slightly different approaches taken to modeling the geologic sections depending on the variations in material properties.

In the case of the anydrock section, shown in rig. C.7.27, 1t was anticipated that the overall low permeability of the materials would

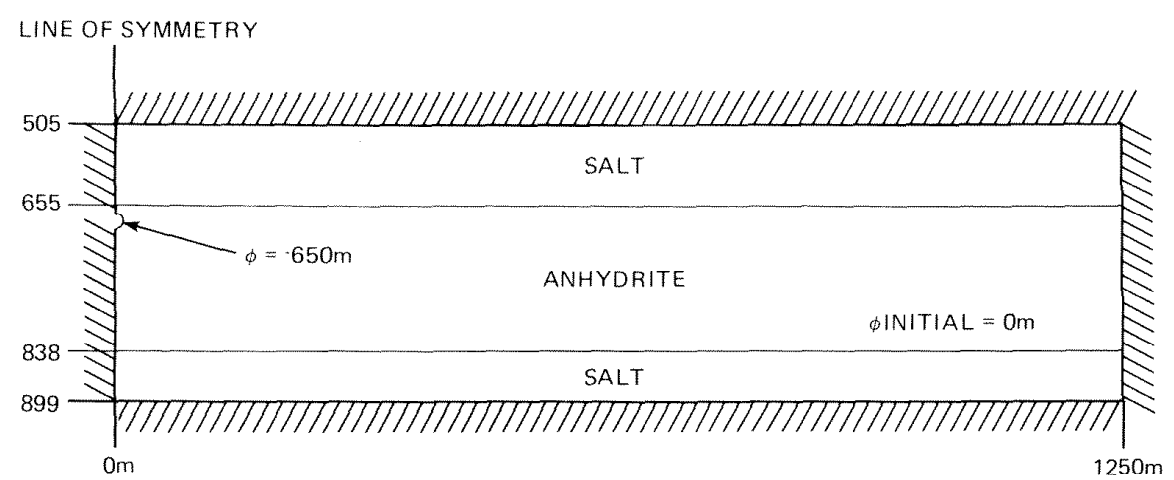

\section{////// NO FLOW BOUNDARY CONDITION}

Fig. C.7.27. Geometry and boundary conditions used in calculation of groundwater inflow for the anhydrock section. 


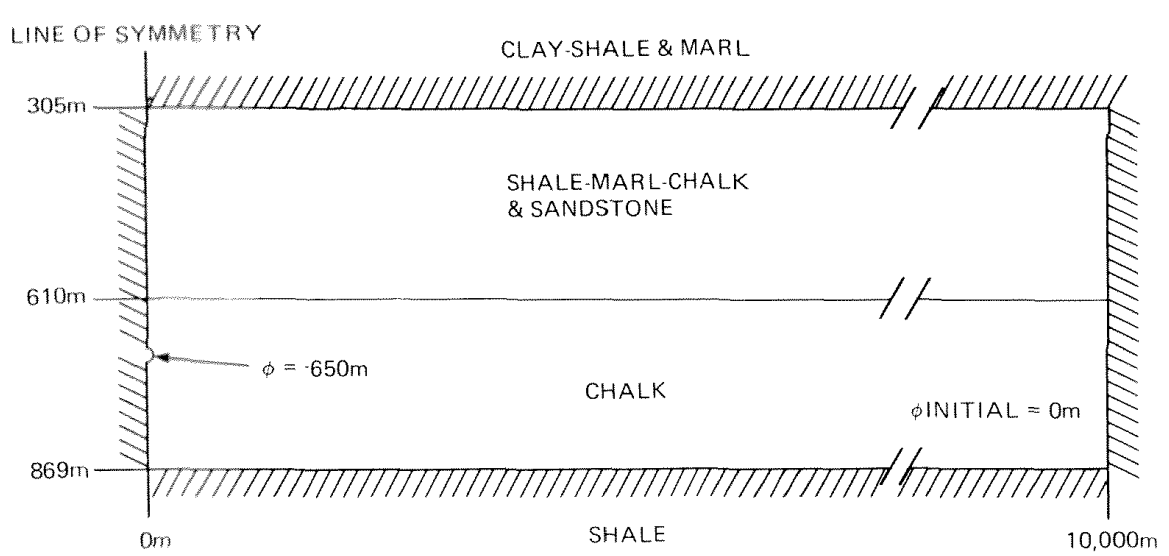

$/ / / / / /$ NO FLOW BOUNDARY CONDITION

Fig. C.7.28, Geometry and boundary conditions used in calculation of groundwater Inflow for the chalk section.

ORNL DWG 85-19

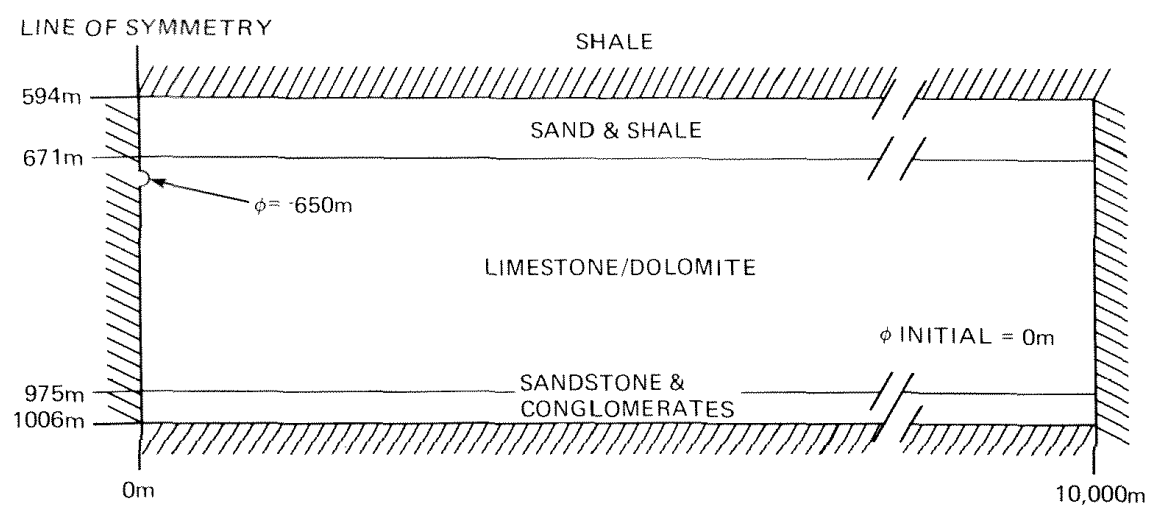

$/ / / / / /$ NO FLOW BOUNDARY CONDITION

Fig. C.7.29. Geometry and boundary conditions used in calculation of groundwater inflow for the carbonate rocks section. 
ORNL DWG 85-20

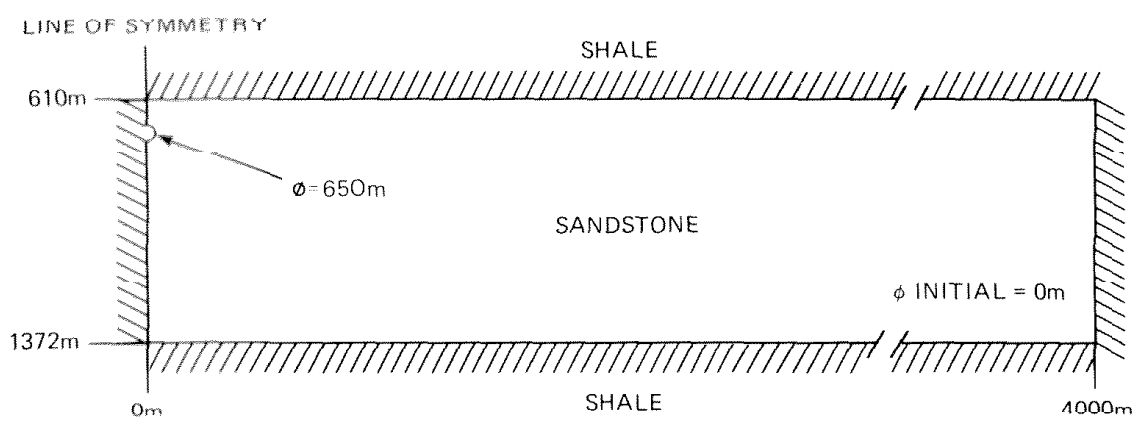

$/ / / / / /$ NO FLOW BOUNDARY CONDITION

Fig. C.7.30. Geometry and boundary conditions used in calculation of groundwater inflow for the sandstone section.

ORNL DWC OE-21

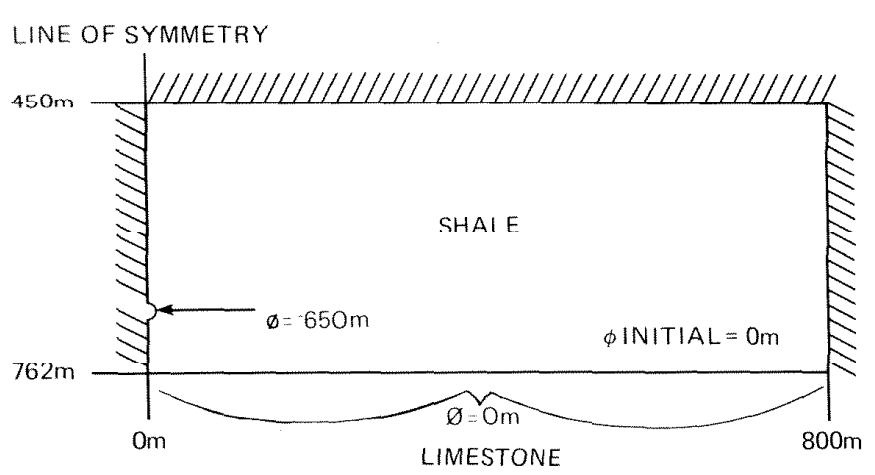

Fig. C.7.31. Geometry and boundary conditions used in calculation of groundwater inflow for the shale section. 
ORNL. DWG $85-22$

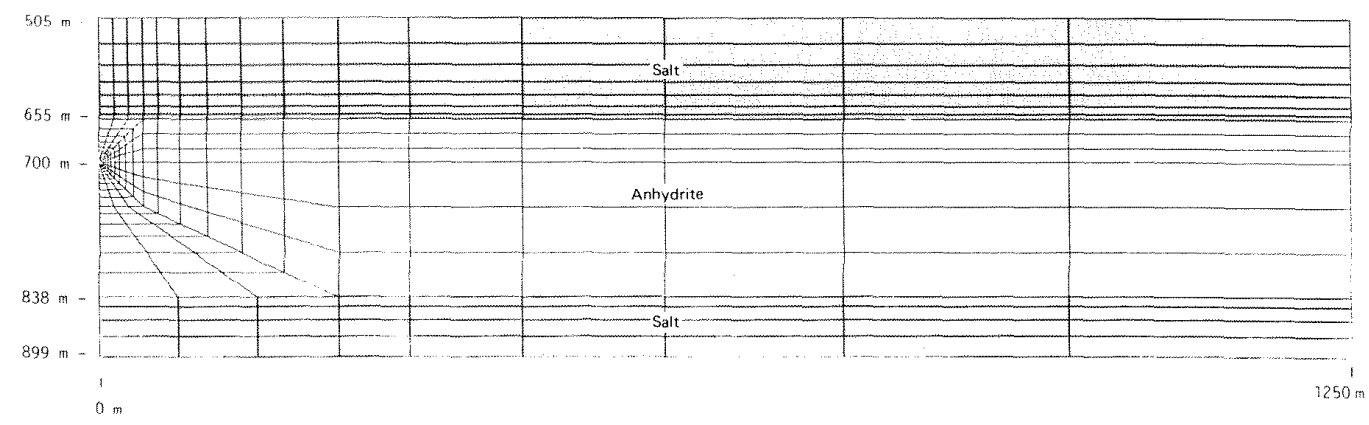

Fig. C.7.32. Example of discretization used in calculating groundwater inflow.

result in relatively slow propagation of the pressure front. The approach taken was thus to consider an area large enough that the front would not approach the boundaries during the time of interest and arbitrarily assign no flow conditions to the outer boundaries of the model. The size of the area considered is approximately $400 \mathrm{~m}$ vertically and $1,250 \mathrm{~m}$ horizontally. The maximum time considered for the anhydrock is 10 years, by which time inflow is reasonably constant.

In the case of the chalk section the relatively large permeability contrast between the chalk and the underlying shale is used to justify a no flow boundary condition at the base of the cha1k. The other two outer boundaries, shown in Fig. C.7.28, are located at distance in an attempt to avoid the pressure front. It is found, however, that the pressure front for the high conductivity case travels almost $10,000 \mathrm{~m}$ and approaches the right boundary in approximately two years. For practical reasons the mesh was not extended beyond $10,000 \mathrm{~m}$ and inflow for the high case for the chalk is only reported out to two years.

In the case of the carbonate rocks section, the relatively high contrasts in conductivities are used to justify the upper and lower no flow boundaries shown in Fig. C.7.29. The relatively high conductivity of the carbonate rocks resulted in the pressure front approaching the right boundary in a fraction of a year for typical, high and low cases. As in the case of the chalk, no attempt is made to extend the mesh.

The boundary conditions for the sandstone section are similar to those of the carbonate rocks. In this case, however, the pressure front does not approach the right boundary and inflows are calculated out to 10 years. 
In the shale section, the top and right boundaries are located at distance to avoid the pressure front. The lower boundary is located at the shale-carbonate rocks contact at the base of the shale and is fixed at $0 \mathrm{~m}$. It is assumed that the relatively high conductivity of the carbonate rocks allows for significant flow within that formation thcrcby maintaining the constant potential boundary condition.

\section{C.7.5.2 Groundwater Inflow Results}

The results of the inflow calculations are shown in Figs. 0.7 .33 through 0.7 .37 as plots of inflow versus time. It should be noted that the plots are $\log -\log$ and that the inflow approaches the steady-state value much more rapidly than appears in the plots.

\section{C.7.5.2.1 Anhydrock}

As shown in Fig. 6.7 .33 , the groundwater inflow for the anhydrock section is relatively low for all cases. Because the permeability of the upper and lower salt layers is similar to the that of the anhydrock reference horizon, it is believed that the location of the repository relative to the salt layers is not significant. Thus the reference section is neither conservative nor nonconservative. It is interesting

ORNL DWG $85-23$

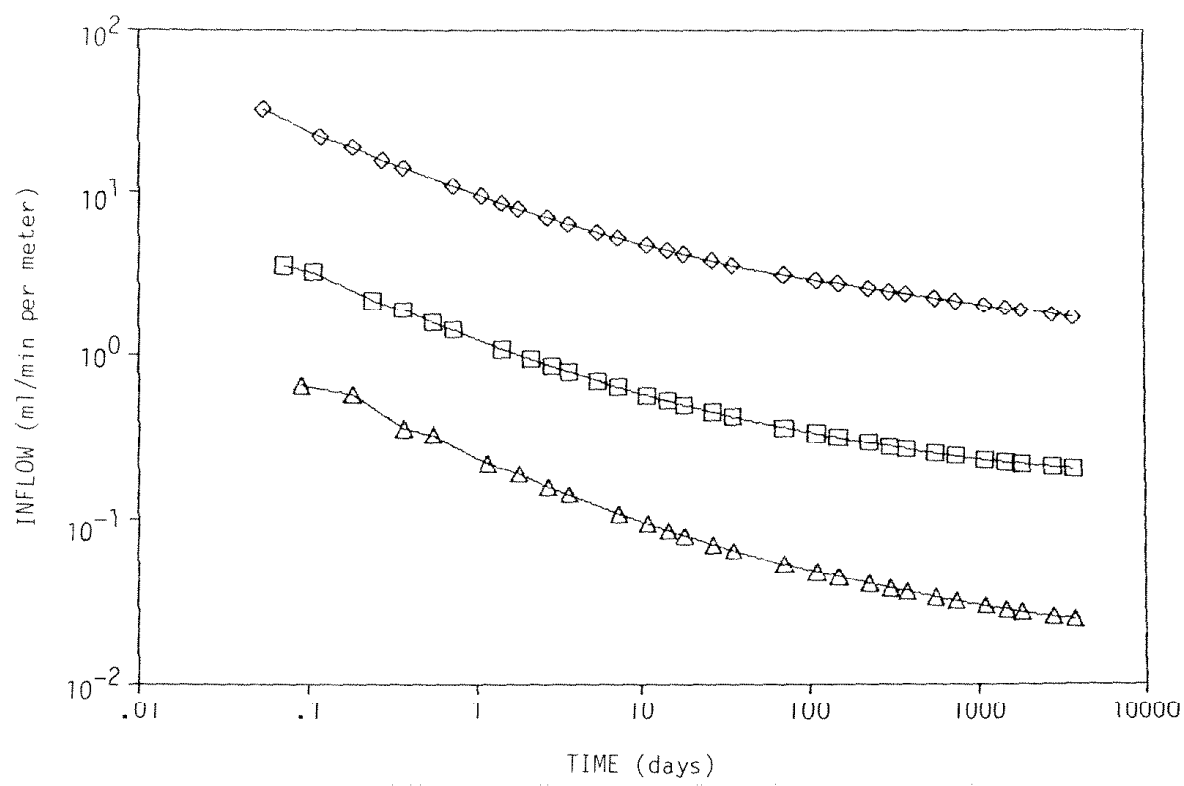

Fig. C.7.33. Groundwater inflow versus time plot for the anhydrock section. 
to note that because salt has a higher specific storage than anhydrock and because the pressure fronts take a finite time to reach the salt, the range of inflows actually increases with time.

\section{C.7.5.2.2 Chalk}

The groundwater inflow for the chalk, as seen in Fig. C.7.34, is relatively great for all cases. This inflow is also probably somewhat nonconservatively low because of the relatively lower permeability shaley layers above and below the reference horizon.

\section{C.7.5.2.3 Carbonate rocks}

As seen in Fig. C.7.35, the inflow for the carbonate rocks is the largest of the five rock types. Like the chalk, the predicted inflows may be somewhat nonconservatively low because of the overlying layer of relatively low permeability sand-shale.

\section{C.7.5.2.4 Sandstone}

The inflow for the sandstone, particularly for the high case, is significant1y higher than the anhydrock but far less than the carbonate rocks or chalk, as seen in Fig. C.7.36. This inflow is also probably nonconservatively low because the reference horizon is bounded on the top and bottom by lower-permeability shale layers.

\section{C.7.5.2.5 Shale}

The inflow for the shale is similar to the anhydrock. Fig. C.7.37, however, suggests that the results for the reference section are probably conservatively high because of the proximity of the repository to the high conductivity underlying carbonate rocks layer. It is also of interest to note that the inflow drops off more steeply with time than in the anhydrock section, probably vecause of lie giedies speciflc slorage of the shale. 
ORNL DWG $85-24$

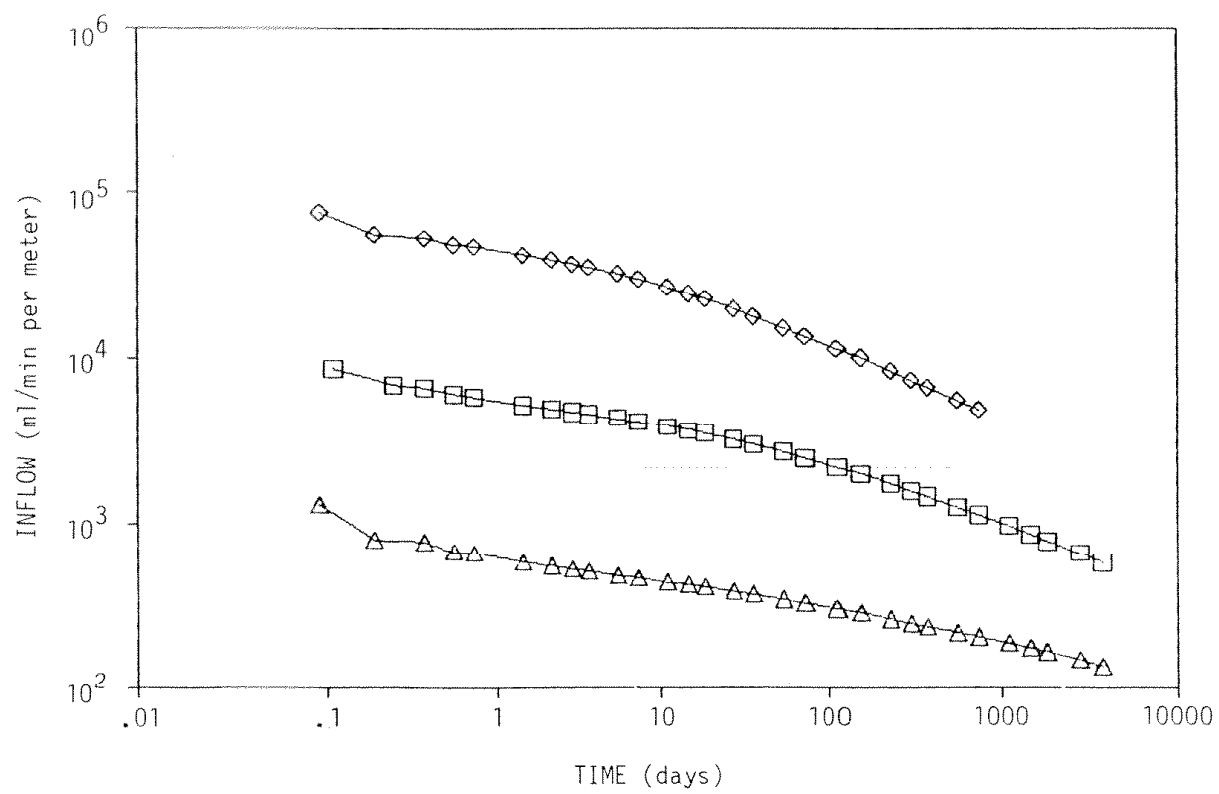

Fig. C.7.34. Groundwater inflow versus time plot for the chalk section.

ORNL DWG 85-25

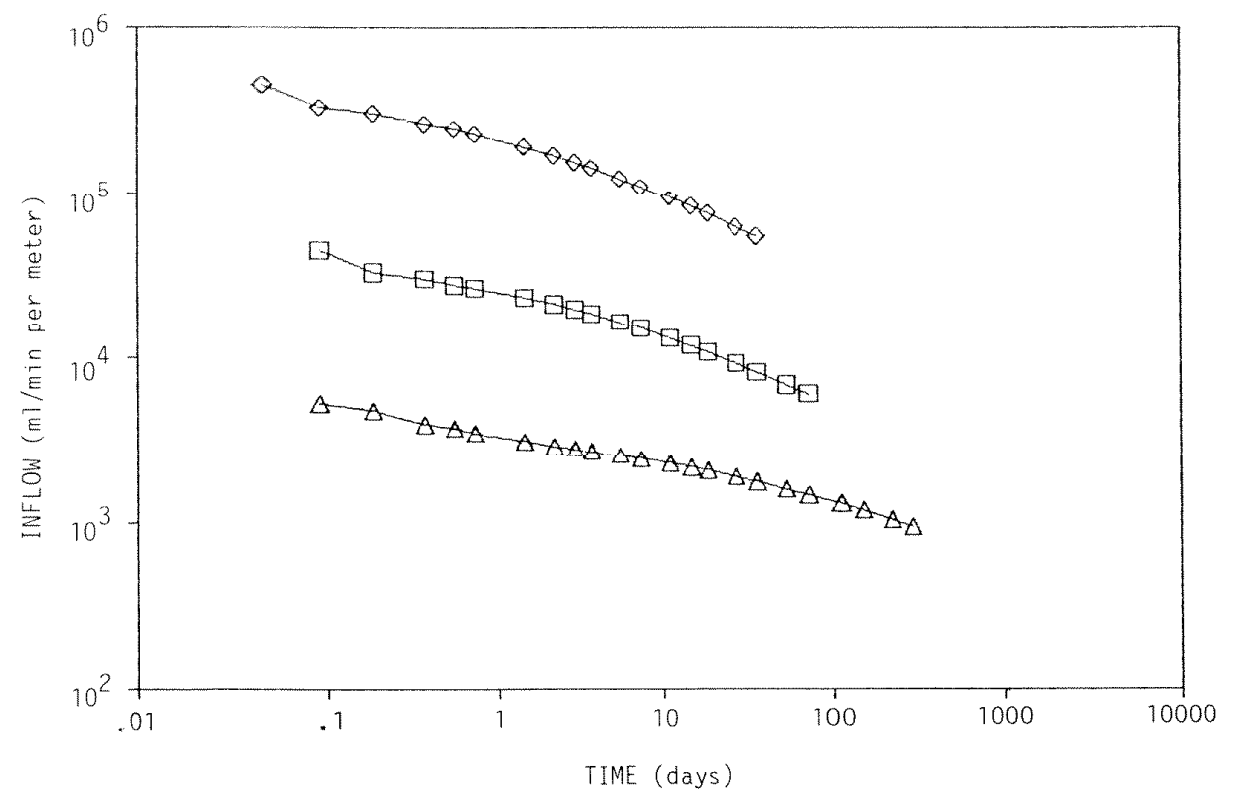

Fig. C.7.35- Groundwater inflow voreue time plot for the limestono section. 
ORNL DWG $85-26$

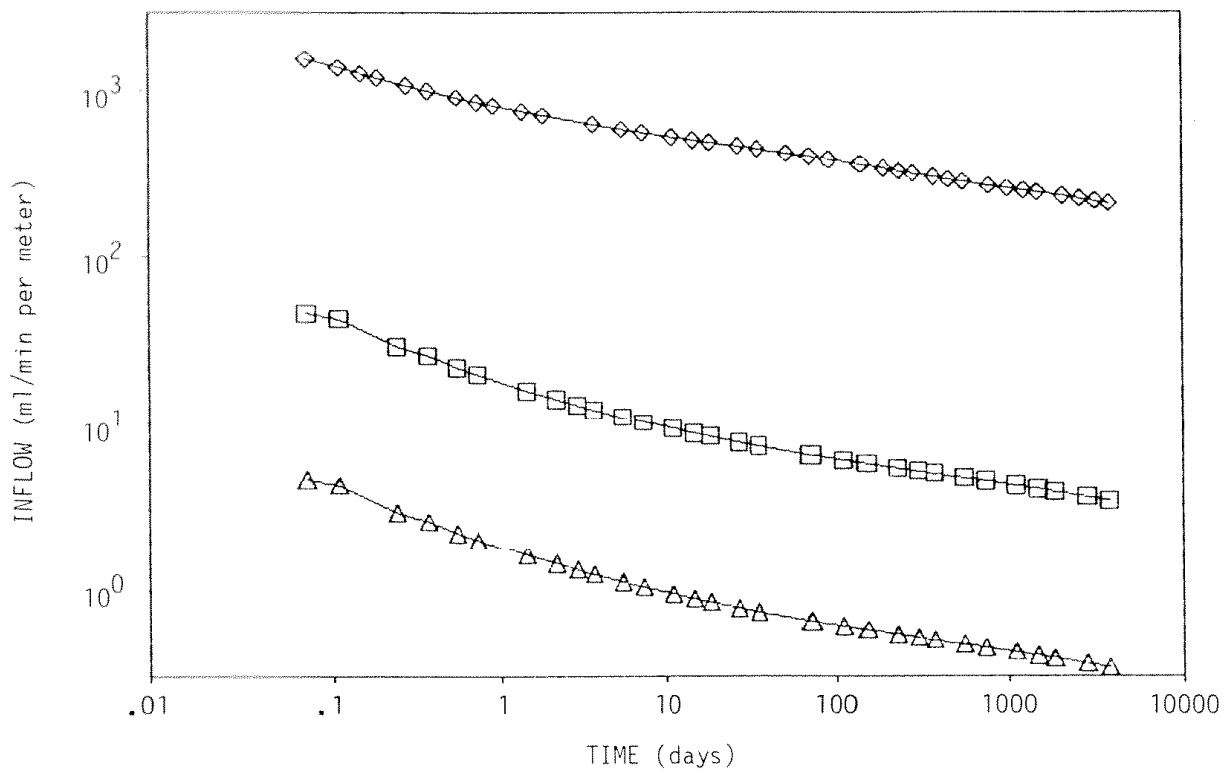

Fig. C.7.36. Groundwater inflow versus time plot for the sandstone section.

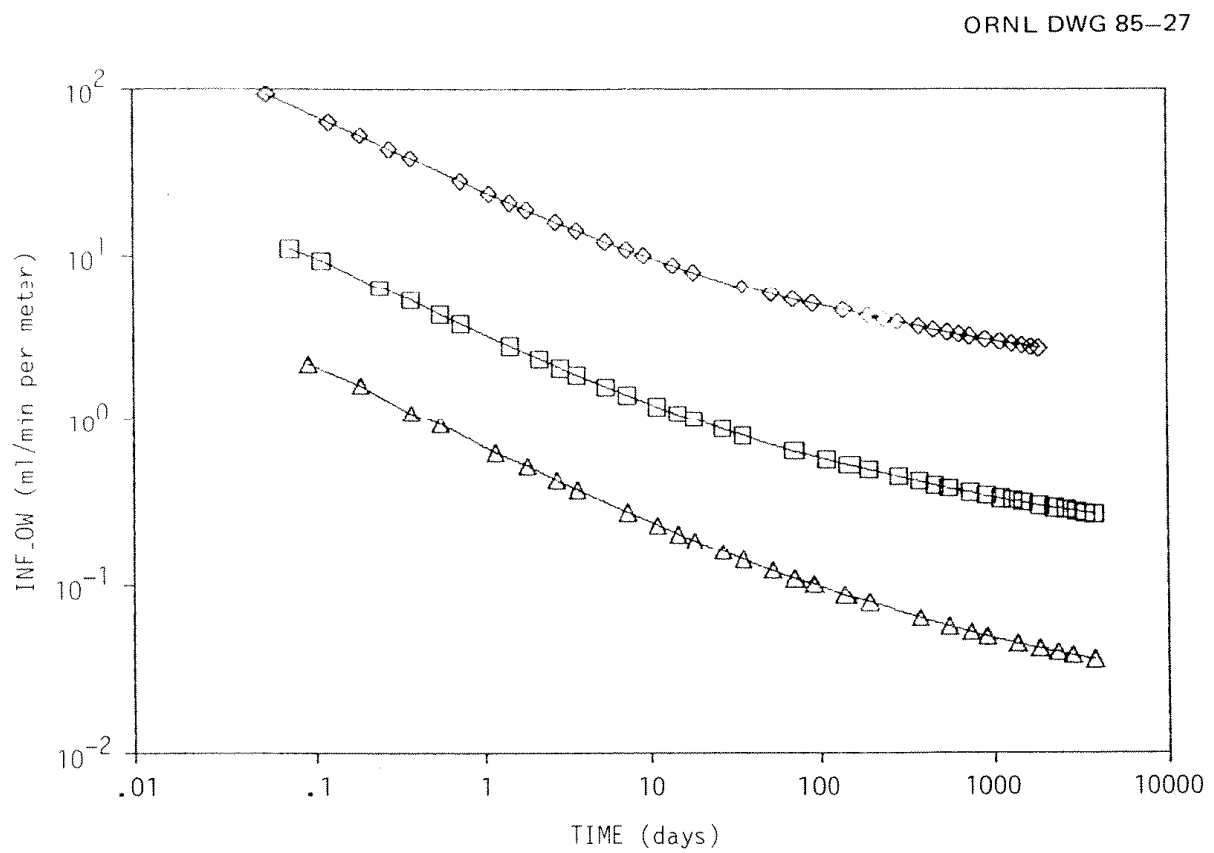

Fig. C.7.37. Groundwater inflow versus time plot for the shale section. 
ORNL DWG 85-44

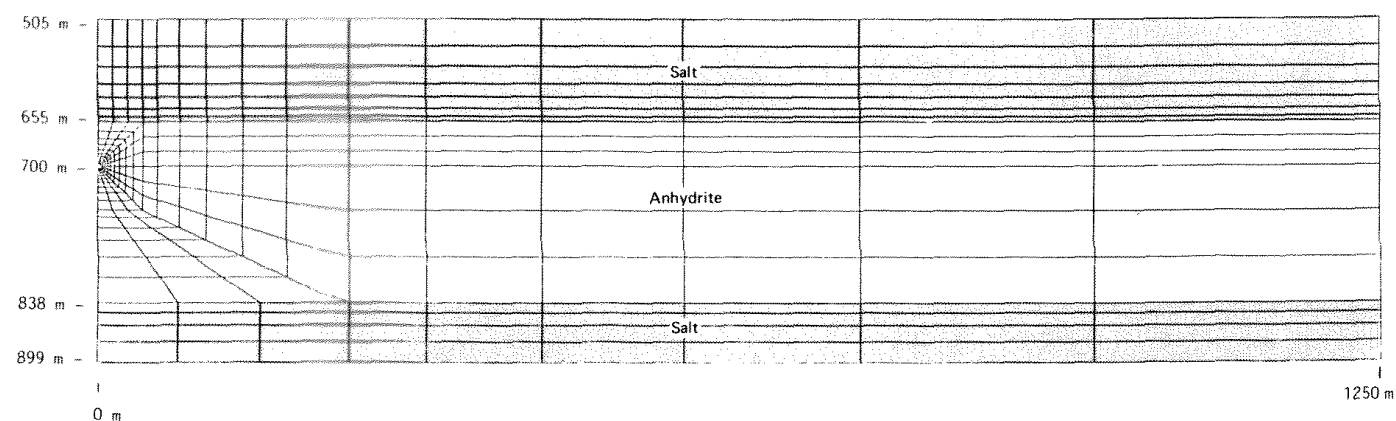

Fig. C.7.38. Discretization for inflow mode1, anhydrock section. No vertical exaggeration.

ORNL DWG 85-45

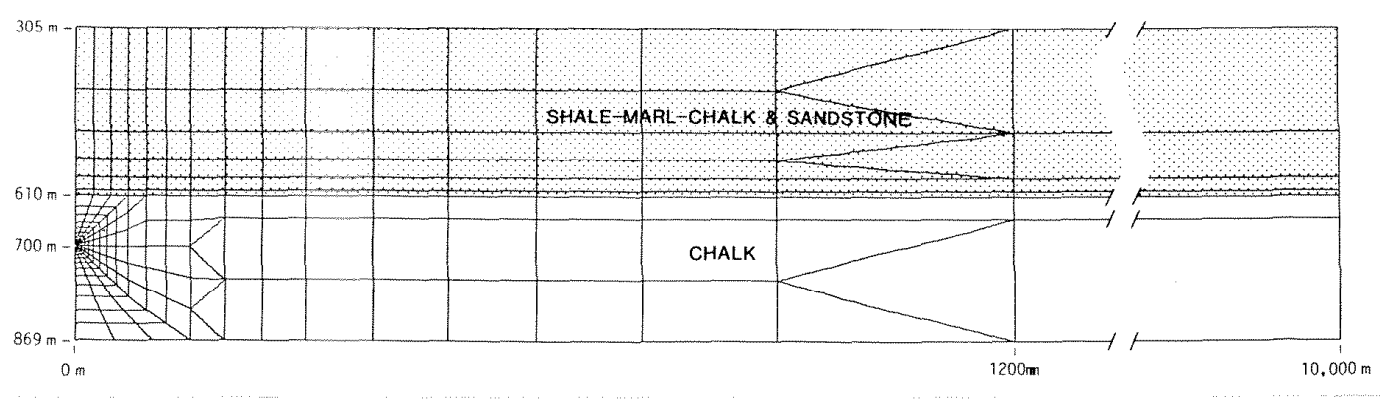

Fig. C.7.39. Discretization for inflow model, chalk section. No vertical exaggexation.

ORNL DWG 85-46

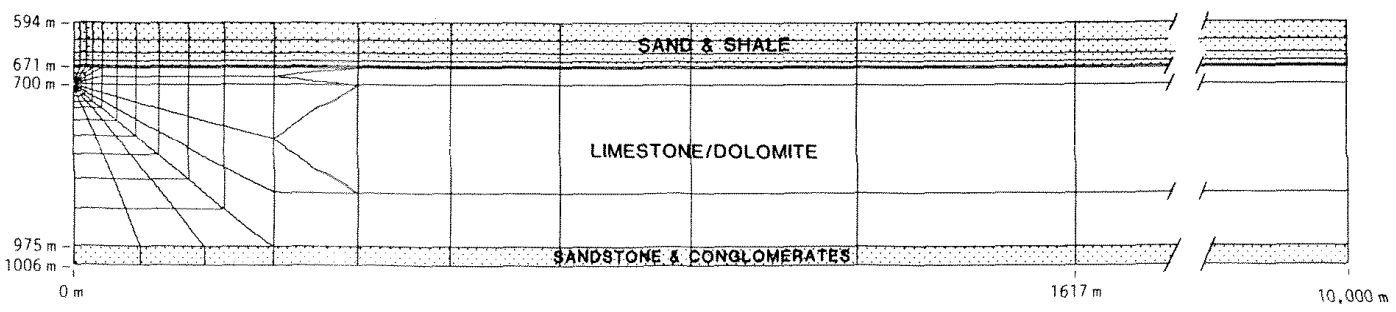

Fig. C.7.40. Discretization for inflow mode1, carbonate rocks (1imestone/dolostone) section. No vertical exaggeration. 
ORNL DWG 85-47

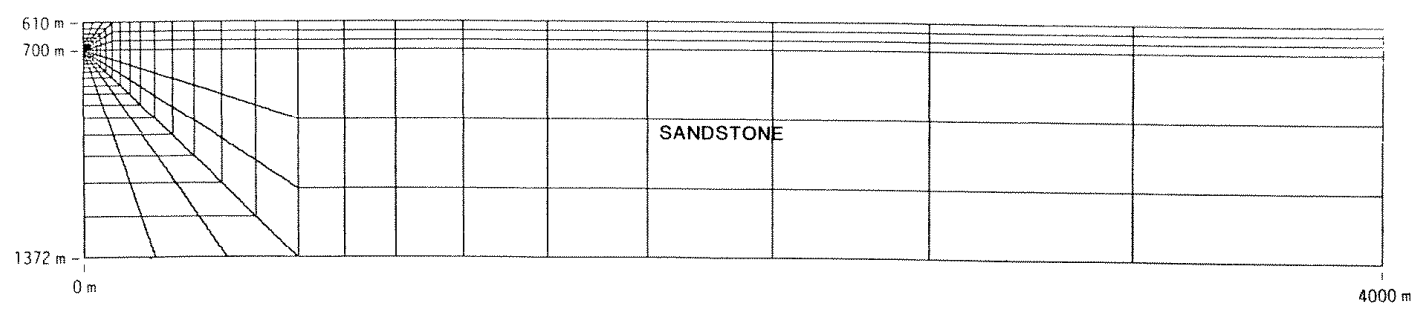

Fig. C.7.41. Discretization for inflow mode1, sandstone section. No verlical exaggeration.

ORNL DWG 85-48

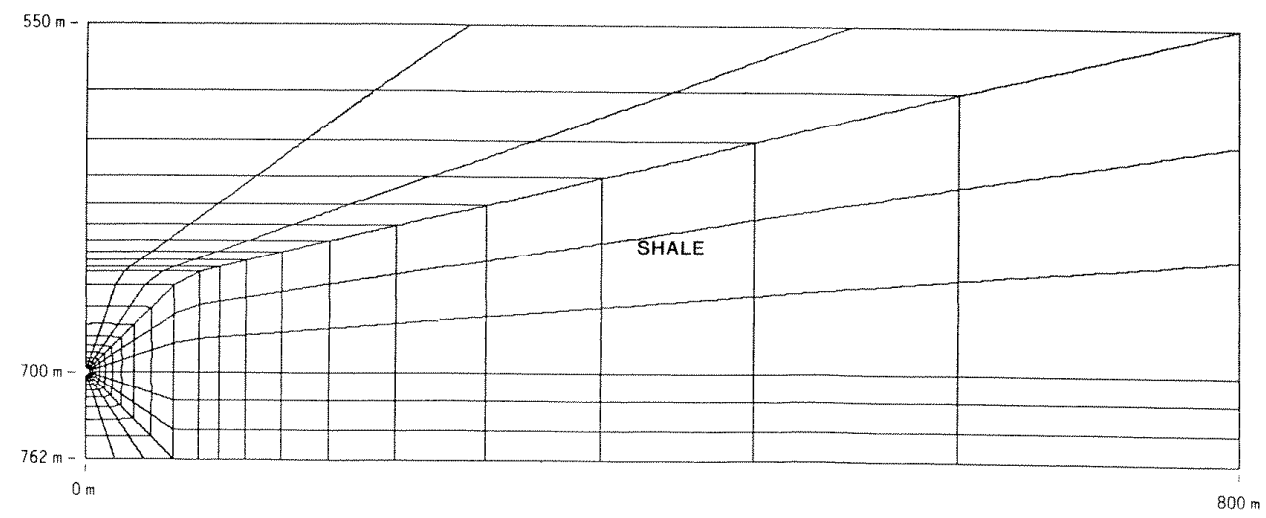

Fig. C.7.42. Discretization for inflow model, shale section. No vertical exaggeration.

\section{C.7.7 PRELIMINARY ANALYSIS OF COUPLED THERMAL-HYDROLOGICAL EFFECTS}

\section{C.7.7.1 Introduction}

The heat generated by radioactive wastes emplaced in a repository is expected to affect the near-field hydrologic system about the repository. These effects result primarily from changes in the density and viscosity of the groundwater, but significant heat loading may also cause other coupled mechanical and chemical effects not considered here. As discrissed in Sert. C..2, thermal driving forces were not conoidcred among the ranking criteria for this study because of the limited ava11ability of the required data base and because the DOE siting guidelines are directed toward pre-emplacement rather than post-emplacement 
groundwater travel times (CFR 1984). However, thermal-hydrological effects may produce hydrologic driving forces that are significantly more important than the in situ hydraulic gradients. A prelfminary analysis of coupled thermal-hydrological effects for the three highest ranked sedimentary rock types was performed to evaluate the importance of these effects, to provide guidance for further more detailed studies of post-emplacement conditions, and to assess if including these effects in the analysis would significantly alter the ranking of the rock types.

\section{C.7.7.2 Analys1s Approach}

\section{C.7.7.2.1 Numerical Methods}

The modeling associated with coupled thernal-hydrological analyses presented here were performed for Berkeley Geosciences Associates by staff members of Resource Management Associates (RMA) using a two dimenstonal fintte element model (KING 1981). Resource Management Associates staff members were selected on the basis of their proficiency in heat transfer modeling. The analyses were performed in three steps:

1. Develop time histories of temperature for a two dimensional field that includes the repository and the surrounding rock.

2. Using these temperatures and the pre-emplacement hydraulic gradients, compute the resulting driving forces controlling nonisothermal groundwater movement.

3. Determine the average direction and rate of movement for groundwater "particles" originating at specific locations in the modeled area.

For step (1), the transport of heat by advection in low-permeability rocks, such as those of the present study, is not significant and a purely conductive model can be used (KING 1981). For steps (2) and (3). it was assumed that the rock could be treated as a continuum for groundwater movement and boundary conditions were placed at distance in an attempt to avoid pressure and temperature fronts.

The thermal computations are based on the heat flux equation:

$$
q_{h}=p c \nabla \cdot(q T)-D_{t} \nabla T,
$$

where $\mathrm{q}_{\mathrm{h}}=$ heat $\mathrm{flux}$ rate,

$c=$ specific heat of water,

$q=$ Darcian velocity of water,

$\mathrm{T}$ = temperature above a reference temperature,

$\nabla=$ vector gradient operator,

$D_{t}=$ net thermal conductivity of the rock-water system,

$\rho=$ density of water.

The temperature at a given location is obtained by combining $\mathrm{Eq}$. (7 3) with the conservation of energy equation: 


$$
\frac{\partial}{\partial t}\left(S_{t} T\right)+\nabla \cdot q_{h}=Q
$$

where $S_{t}=$ bulk specific heat of the rock-water system,

$\mathrm{Q}=$ thermal loading rate.

The flow computations are based on a nonisothermal extension of Darcy's law:

$$
\mathrm{v}=-\frac{\mathrm{k} \phi}{\mu \mathrm{n}_{\mathrm{e}}} \cdot\left(\nabla \mathrm{h}+\delta_{\mathrm{b}} \nabla \mathrm{z}\right)
$$

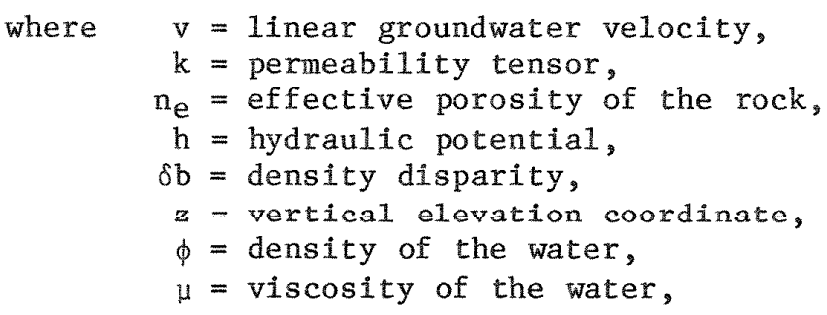

The scalar term $\delta b$ accounts for buoyancy effects resulting from temperature-induced variations in density. The $\nabla$ symbol denotes the vector gradient operator.

\section{C.7.7.2.2 Mode1 Development}

The coupled thernal-hydrologic analysis was applied to three of the five sedimentary rock types studied, that show most promise for nuclear waste disposal. These are anhydrock, sandstone and shale. A common finite element mesh was developed for use with all three rock types, and is shown with the modeled reference genlngies in Figs. C.7.43 through C.7.45. The geologic settings used in these analyses are simplified versions of the reference sections developed by the Sedimentary Rock Program Staff and presented in Sect. C.3. The detailed stratigraphic representations on the sections were simplitied to tacilitate these preliminary analyses, particularly for the anhydrock section. An additional simplification was made by assuming all sedimentary horizons to be horizontal.

Each finite element mesh represents a two dimensional vertical section extending from $50 \mathrm{~m}$ beneath the ground surface (the assumed common depth of unconsolidated alluvium in the ranking studies) to a total depth of $1,200 \mathrm{~m}$, passing through a reference repository at a depth of $700 \mathrm{~m}$. The sections are each $6,400-\mathrm{m}$ wide. The reference repository is assumed to be $2,240-\mathrm{m}$ wide, based upon an assumed $5 \mathrm{~km}^{2}$ total repository area. The repository excavation, including possible damaged rock zones, is assumed to be $8-\mathrm{m}$ high. The dimensions of the geologic strata are shown on Figs. C.7.43 through 0.7 .45 . 
ORNL DWG $85-49$

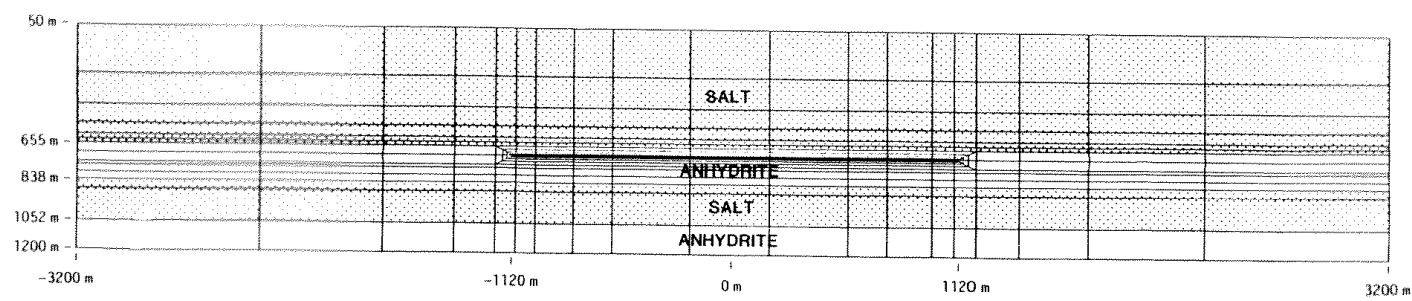

Fig. 6.7 .43 . Discretization for coupled thermal-hydrologic model, anhydrock section.

ORNL DWG $85-50$

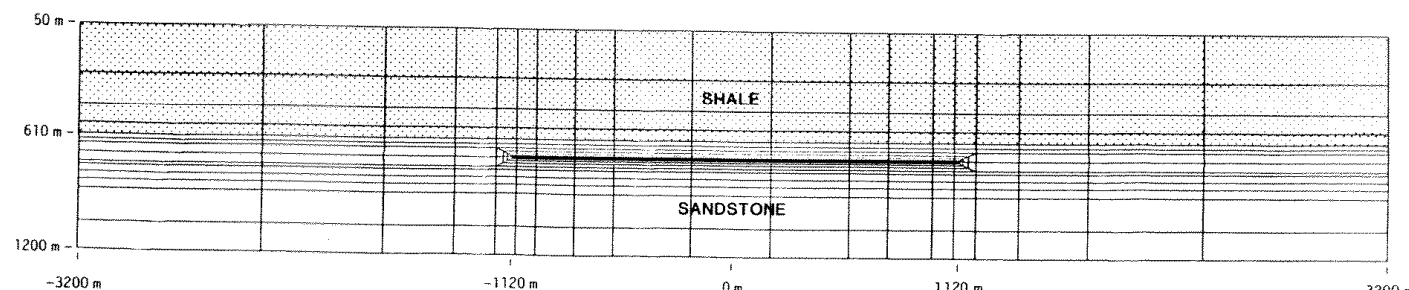

Fig. C.7.44. Discretization for coupled thermal-hydrologic mode1, sandstone section.

ORNL DWG 85-51

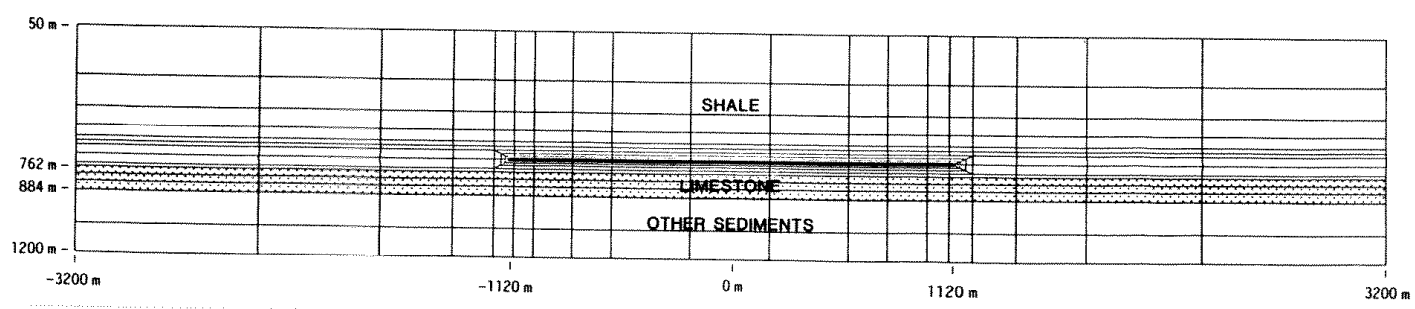

Fig. C.7.45. Discretization for coupled thernal-hydrologic model, shale section. 
The material properties and thermal conditions for the three rock types are presented in Tables 0.7 .3 through C.7.5. The thermomechanical properties and thermal boundary conditions were developed by RE/SPEC Inc., for use in studying the geomechanical and thermal aspects of the Rock Evaluation Report and represent typical values and conditions associated with the various rock types. The hydrologic properties and boundary conditions are the same as those used for the typical cases in the ranking studies presented in this report. Because these coupled analyses are preliminary and were not used in ranking, ranges of values were not studied. The heat source was assumed to be 10-year-old spent fuel, uniformly distributed within the repository excavation. A11 analyses were performed for a 10,000-year time period.

\section{C.7.7.3 Thermal Results}

Contour plots of the temperature fields at 1,000 years after waste emplaccment are shown in Figs. C.7.46 through C.7.48. The verlically axisymetric appearance of the plots reflect the varying thermal properties of the layered media. The contours show that heat is dissipated most readily by the anhydrock, followed in turn by the sandstone and shale. Anhydrock has the highest thermal conductivity and therefore has the best capability to dissipate heat of the three potential host rocks studied here. Shale has the lowest thermal conductivity of the three rocks, and therefore the heat generated will dissipate more slowly. The maximum temperature reached in the sandstone section, however, was greater than in the other rocks because of a greater reference geothermal gradient. The maximum temperatures reached after 1,000 years were computed to be $152^{\circ} \mathrm{C}$ for anhydrock, $199^{\circ} \mathrm{C}$ for shale, and $202^{\circ} \mathrm{C}$ for sandstone. Because of the higher geothermal gradient assumed for the reference sandstone section, the maximum temperatures computed for sandstone emplacement are conservatively high.

\section{C.7.7.4 Hydrologic Results}

Two hydrologic analyses were performed for each rock type, the first considering only isothermal flow, and the second considering nonisothermal flow. The results are discussed below by rock type.

\section{C.7.4.1.1 Anhydrock}

The hydrologic results for the isothermal and nonisothermal cases for anhydrock emplacement are shown in Figs. C.7.49 and C.7.50, respectively. These results show the travel paths of groundwater "particles" released at the moment of waste emplacement at the top of the repository excavation. As can be seen in the figures, the 10,000-year travel distance of a few meters in the isothermal case is increased to as much as $60 \mathrm{~m}$ when thermal loading is considered. This latter travel distance is sufficient to move the particle into the overlying salt horizon.

\section{C.7.7.4.2 Sandstone}

The hydrologic results for the isothermal and nonioothermal caoco for sandstone emplacement are shown in Figs. C.7.51 and C.7.52, respectively. 
Table 6.7 .3$. Properties and conditions for anhydrock emplacement ${ }^{a}$

\begin{tabular}{|c|c|c|c|}
\hline Property & Salt & Anhydrite & Backfill \\
\hline Specific heat, $\mathrm{J} / \mathrm{kg} \cdot{ }^{\circ} \mathrm{C}$ & $9.31 \times 10^{2}$ & $5.16 \times 10^{2}$ & $5.16 \times 10^{2}$ \\
\hline $\begin{array}{l}\text { Horizontal thermal } \\
\text { conductivity, } \mathrm{J} / \mathrm{s} \cdot \mathrm{m} \cdot{ }^{\circ} \mathrm{C}\end{array}$ & 6.02 & $4 \cdot 70$ & 4.70 \\
\hline $\begin{array}{l}\text { Thermal conductivity } \\
\text { ratio, vert/horiz }\end{array}$ & 0.69 & 1.00 & 1.00 \\
\hline Effective porosity & 0.001 & 0.001 & 0.30 \\
\hline Total porosity & 0.005 & 0.010 & 0.30 \\
\hline $\begin{array}{l}\text { Horizontal hydraulic } \\
\text { conductivity, } \mathrm{m} / \mathrm{s}\end{array}$ & $1 \times 10^{-11}$ & $1 \times 10^{-11}$ & $1 \times 10^{-10}$ \\
\hline $\begin{array}{l}\text { Vertical hydraulic } \\
\text { conductivity, m/s }\end{array}$ & $1 \times 10^{-12}$ & $1 \times 10^{-12}$ & $1 \times 10^{-10}$ \\
\hline Specific storage, $\mathrm{L} / \mathrm{m}$ & $1 \times 10^{-6}$ & $1 \times 10^{-7}$ & $1 \times 10^{-6}$ \\
\hline Density of rock, $\mathrm{kg} / \mathrm{m}^{3}$ & 2190 & 2960 & 2072 \\
\hline $\begin{array}{l}\text { Temperature at uppex } \\
\text { boundary }(-50 \mathrm{~m}),{ }^{\circ} \mathrm{C}\end{array}$ & 16.1 & & \\
\hline $\begin{array}{l}\text { Temperature at lower } \\
\text { boundary }(-1200 \mathrm{~m}),{ }^{\circ} \mathrm{C}\end{array}$ & 30.0 & & \\
\hline
\end{tabular}

aThe thermal and mechanical properties and conditions were obtained by personal communication from M. Loken, RE/SPEC Inc., September and October 1984. 
Table 0.7 .4 . Properties and conditions for sandstone emplacement ${ }^{a}$

\begin{tabular}{|c|c|c|c|}
\hline Property & Salt & Anhydrite & Backfill \\
\hline Specific heat, $\mathrm{J} / \mathrm{kg} \cdot{ }^{\circ} \mathrm{C}$ & $8.37 \times 10^{2}$ & $7.12 \times 10^{2}$ & $7.12 \times 10^{2}$ \\
\hline $\begin{array}{l}\text { Horizontal thermal } \\
\text { conductivity, } \mathrm{J} / \mathrm{s} \cdot \mathrm{m} \cdot{ }^{\circ} \mathrm{C}\end{array}$ & $2 \cdot 25$ & 3.40 & 3.40 \\
\hline $\begin{array}{l}\text { Thernal conductivity } \\
\text { ratio, vert/horiz }\end{array}$ & 0.76 & 1.00 & 1.00 \\
\hline Effective porosity & 0.01 & 0.01 & 0.30 \\
\hline Total porosity & 0.03 & 0.08 & 0.30 \\
\hline $\begin{array}{l}\text { Horizontal hydraulic } \\
\text { conductivity, } \mathrm{m} / \mathrm{s}\end{array}$ & $1 \times 10^{-11}$ & $1 \times 10^{-10}$ & $1 \times 10^{-10}$ \\
\hline $\begin{array}{l}\text { Vertical hydraulic } \\
\text { conductivity, } \mathrm{m} / \mathrm{s}\end{array}$ & $1 \times 10^{-12}$ & $5 \times 10^{-11}$ & $1 \times 10^{-10}$ \\
\hline Specific storage, $L / m$ & $1 \times 10^{-6}$ & $1 \times 10^{-6}$ & $1 \times 10^{-6}$ \\
\hline Density of rock, $\mathrm{kg} / \mathrm{m}^{3}$ & 1800 & 2294 & 2294 \\
\hline $\begin{array}{l}\text { Temperature at upper } \\
\text { boundary }(-50 \mathrm{~m}),{ }^{\circ} \mathrm{C}\end{array}$ & 7.5 & & \\
\hline $\begin{array}{l}\text { Temperature at lower } \\
\text { boundary }(-1200 \mathrm{~m}),{ }^{\circ} \mathrm{C}\end{array}$ & $51 \cdot 25$ & & \\
\hline
\end{tabular}

a The thermal and mechanical properties and conditions were obtained by personal communication from M. Loken, RE/SPEC Inc., September and October 1984. 
Table 6.7 .5$. Properties and conditions for shale emplacement ${ }^{a}$

\begin{tabular}{|c|c|c|c|c|}
\hline Property & Shale & Carbonates & $\begin{array}{l}\text { Other } \\
\text { Sediments }\end{array}$ & Backfil1 \\
\hline $\begin{array}{l}\text { Specific heat, } \\
\mathrm{J} / \mathrm{kg} \cdot{ }^{\circ} \mathrm{C}\end{array}$ & $7.96 \times 10^{2}$ & $8.37 \times 10^{2}$ & $8.37 \times 10^{2}$ & $7.96 \times 10^{2}$ \\
\hline $\begin{array}{l}\text { Horizontal thermal } \\
\text { conductivity, } \\
\mathrm{J} / \mathrm{s} \cdot \mathrm{m} \cdot{ }^{\circ} \mathrm{C}\end{array}$ & 1.89 & 4.20 & 1.73 & 1.89 \\
\hline $\begin{array}{l}\text { Thermal conductivity } \\
\text { ratio, vert/horiz }\end{array}$ & 0.76 & 1.00 & 1.00 & 0.76 \\
\hline Effective porosity & 0.01 & 0.01 & 0.01 & 0.30 \\
\hline Total porosity & 0.03 & 0.10 & 0.03 & 0.30 \\
\hline $\begin{array}{l}\text { Horizontal hydraulic } \\
\text { conductivity, } \mathrm{m} / \mathrm{s}\end{array}$ & $1 \times 10^{-11}$ & $1 \times 10^{-6}$ & $1 \times 10^{-11}$ & $1 \times 10^{-11}$ \\
\hline $\begin{array}{l}\text { Vertical hydraulic } \\
\text { conductivity, m/s }\end{array}$ & $1 \times 10^{-12}$ & $5 \times 10^{-7}$ & $1 \times 10^{-12}$ & $1 \times 10^{-12}$ \\
\hline $\begin{array}{l}\text { Specific storage, } \\
\text { L/m }\end{array}$ & $1 \times 10^{-6}$ & $1 \times 10^{-6}$ & $1 \times 10^{-6}$ & $1 \times 10^{-6}$ \\
\hline $\begin{array}{l}\text { Density of rock, } \\
\mathrm{kg} / \mathrm{m}^{3}\end{array}$ & 2563 & 2600 & 2600 & 2563 \\
\hline $\begin{array}{l}\text { Temperature at upper } \\
\text { boundary }(-50 \mathrm{~m}) \text {, } \\
{ }^{\circ} \mathrm{C}\end{array}$ & 13.9 & & & \\
\hline $\begin{array}{l}\text { Temperature at lower } \\
\text { boundary }(-1200 \mathrm{~m}) \text {, } \\
{ }^{\circ} \mathrm{C}\end{array}$ & 28.8 & & & \\
\hline
\end{tabular}

aThe thermal and mechanical properties and conditions were obtained by personal communication from M. Loken, RE/SPEC Inc., September and October 1984. 
ORNL. DWG 85-52

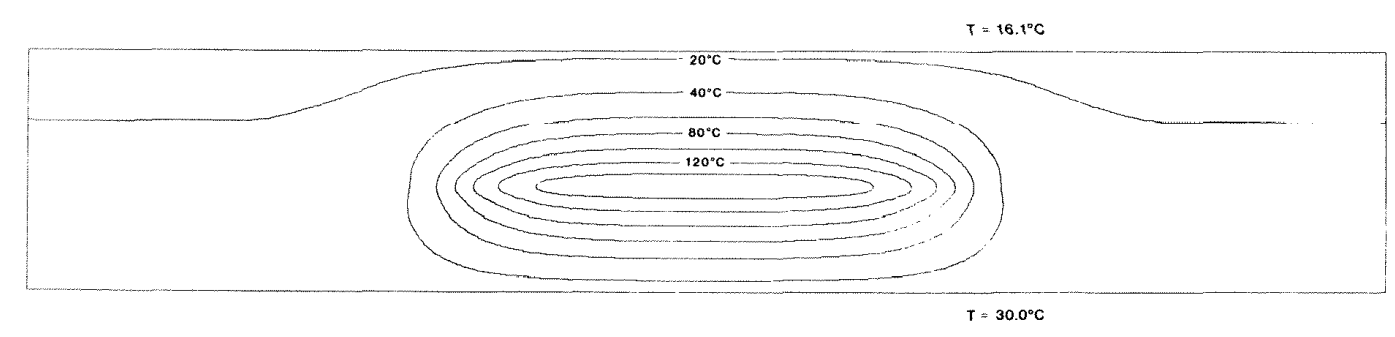

Fig. C.7.46. Temperature field after 1,000 years for reference repository in anhydrock section.

ORNL DWG $85-53$

$\mathrm{T}=7.5^{\circ} \mathrm{C}$

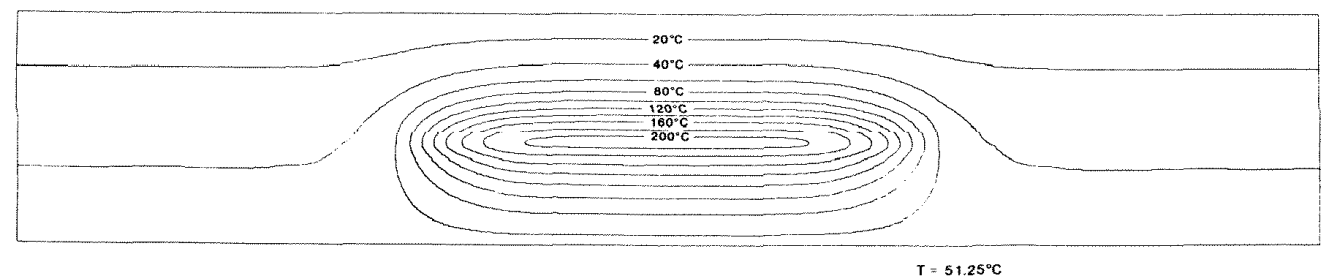

Fig. 0.7.47. Temperature field after 1,000 years for reference repository in sandstone section.

ORNLL DWG $85-54$

$T=13.9^{\circ} \mathrm{C}$

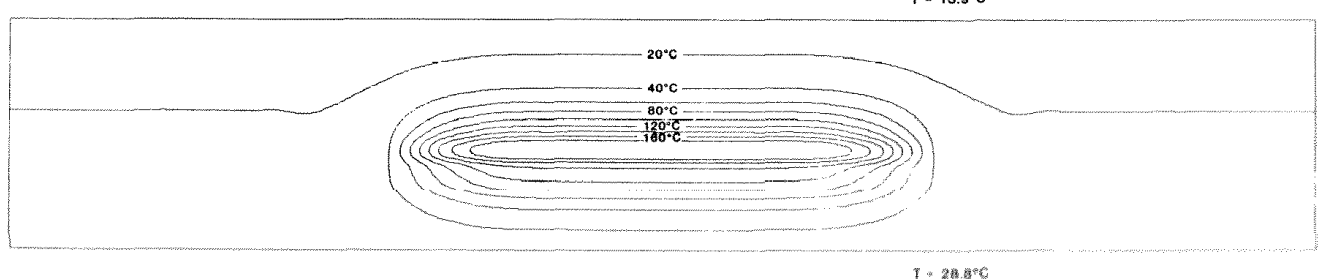

Fig. C.7.48. Temperature fleld after 1,000 years for rets repostrory ln shate section. 
ORNL DWG OS-SE

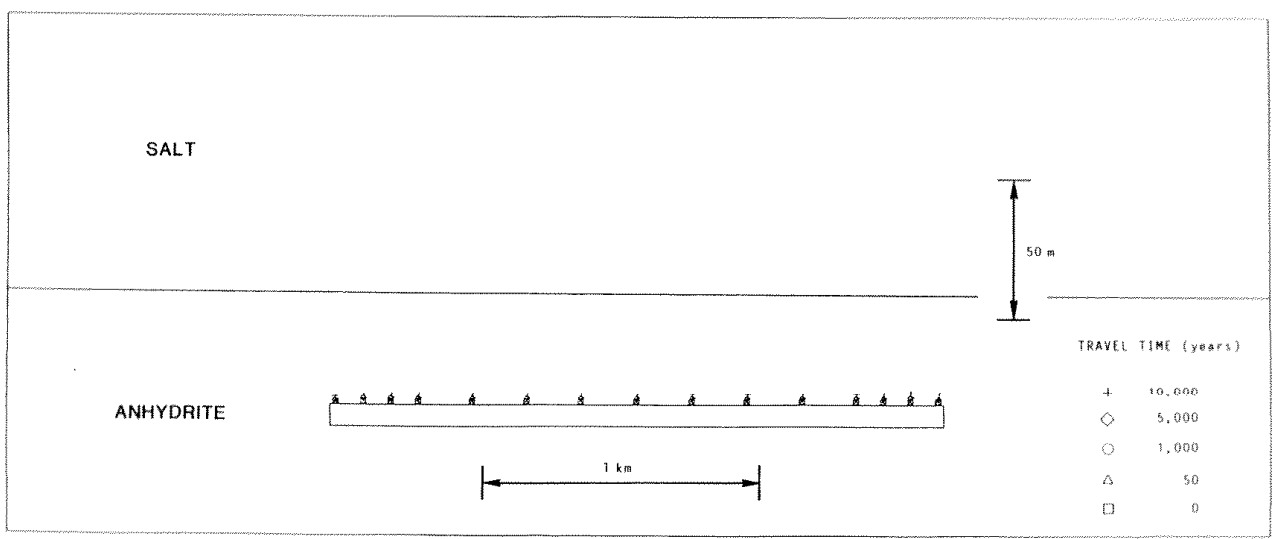

F1g. C.7.49. Isothermal hydrologic results for anhydrock section.

ORNL DWG 85-56

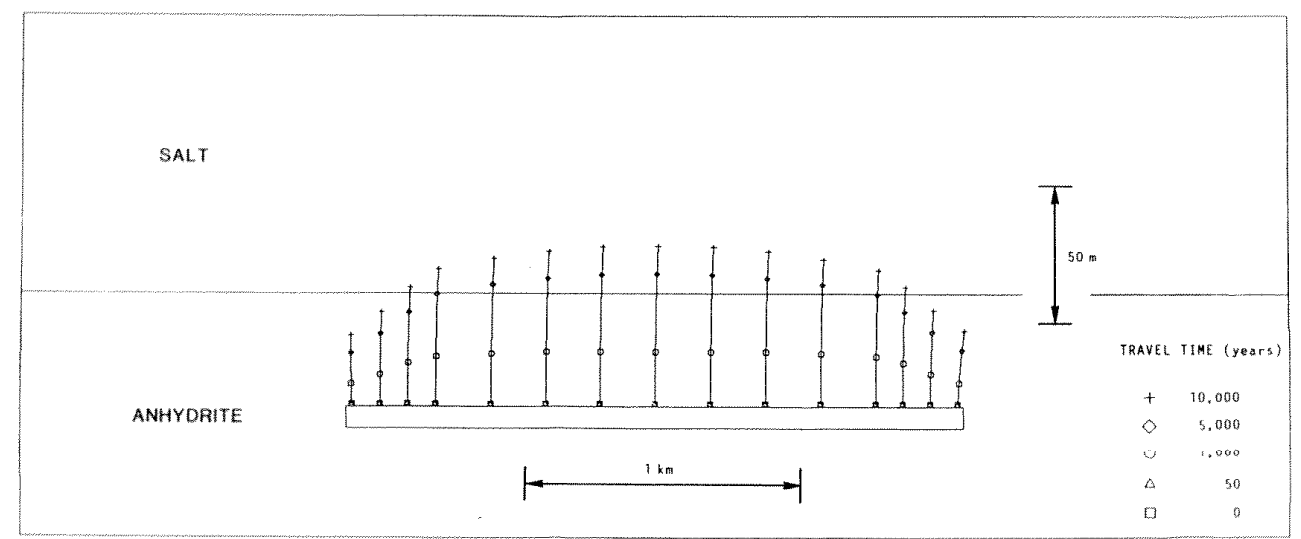

wg. 6.7 .50 . Nonisothermal hydrologic results for anhydrock section.

ORNL DWG $85-57$

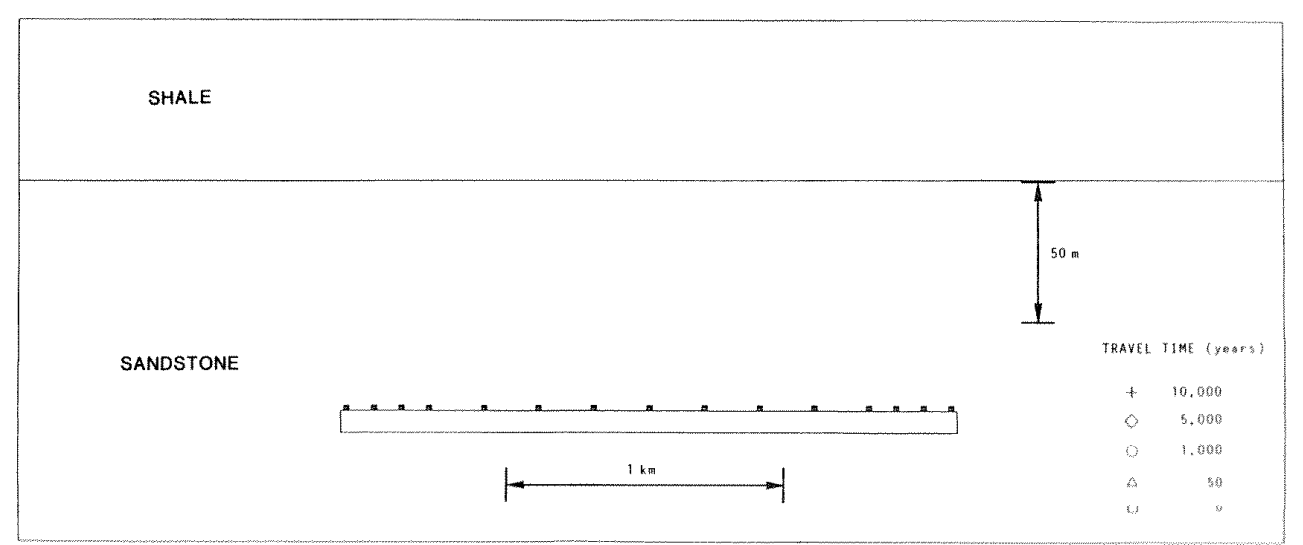

Fig. C.7.51. Tsothermal hydrologic results for sandstone secton. 
ORNL DWG $85-58$

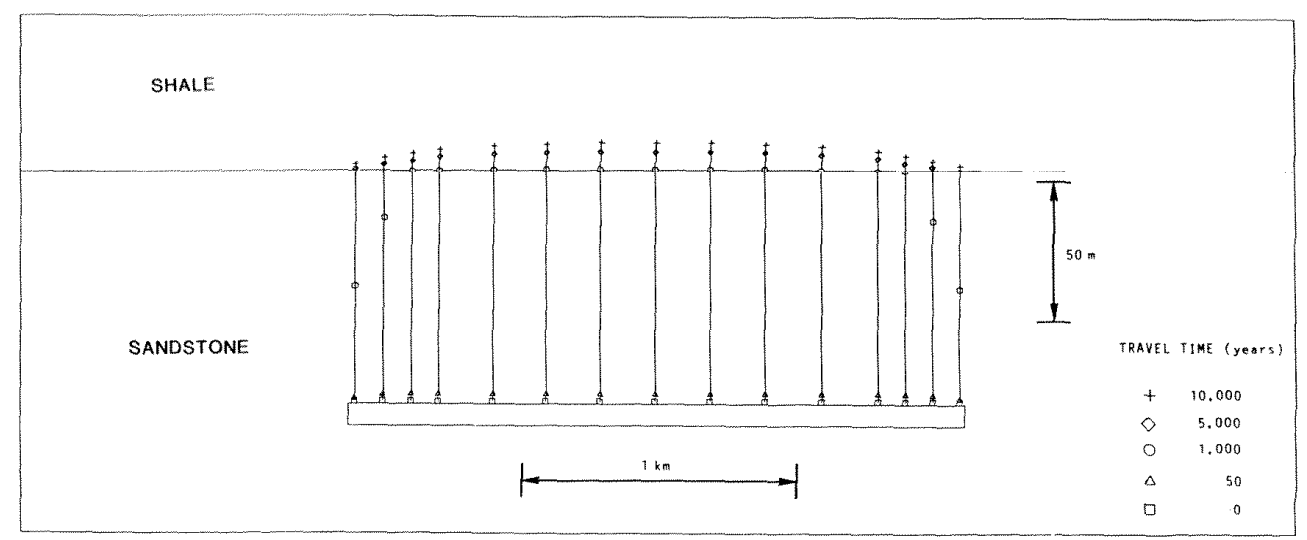

Fig. C.7.52. Nonisothermal hydrologic results tor sandstone section.

These results show that the 10,000-year trave1 distance of a few meters in the isothermal case is increased to about $95 \mathrm{~m}$ in the nonisothermal case. It is interesting to note that the long term, essentially horizontal movement of groundwater in sandstone in the isothermal case (see Fig. C.7.10) was modified to include significant vertical movement when thermal effects were considered, even though the applied regional horizontal and vertical hydraulic gradients are the same in all cases. In the nonisothermal case, the groundwater "particle" was seen to enter the overlying shale horizon within 1,000 years, whereas in the isothermal case this lower conductivity shale horizon tightly constrained vertical movement.

\section{$0.7 \cdot 7 \cdot 4 \cdot 3 \quad$ Sha1c}

The hydrologic results for the isothermal and nonisothermal cases for shale emplacement are shown in Figs. 0.7 .53 and 0.7 .54 , respectively. These results show an increase in the 10,000-year trave1 distance from a few meters to about $30 \mathrm{~m}$, most of which is in vertical movement. The travel distance is shorter than in the other two media despite the greater thermal gradients hecause of shale's low permeability and high effective porosity. Because of the thickness of the shale host rock in the reference section, the groundwater "particle" was seen to remain within the shale during the fu11 10,000 years of the analysis.

\section{C.7.7.5 Analysis of Results}

The coupled thermal-hydrologic analyses presented here are preliminary. They are based upon simplified section geometries and material characteristics, and do not consider the wide range of coupled thermal effects that may be significant to the long-term isolation capability of a repository host rock. These studies are $11 \mathrm{mited}$ to the direct effects of heat on groundwater movement in continuum analysis. Other thermal effects on the groundwater and rock chemistry, the material and chemical properties of the waste container. thermally induced diffusive processes, and potential stress-permeability relationships may be significant and should be studied to obtain a more complete understanding of thermal effects in the host rock. 
ORNL DWG $85-59$

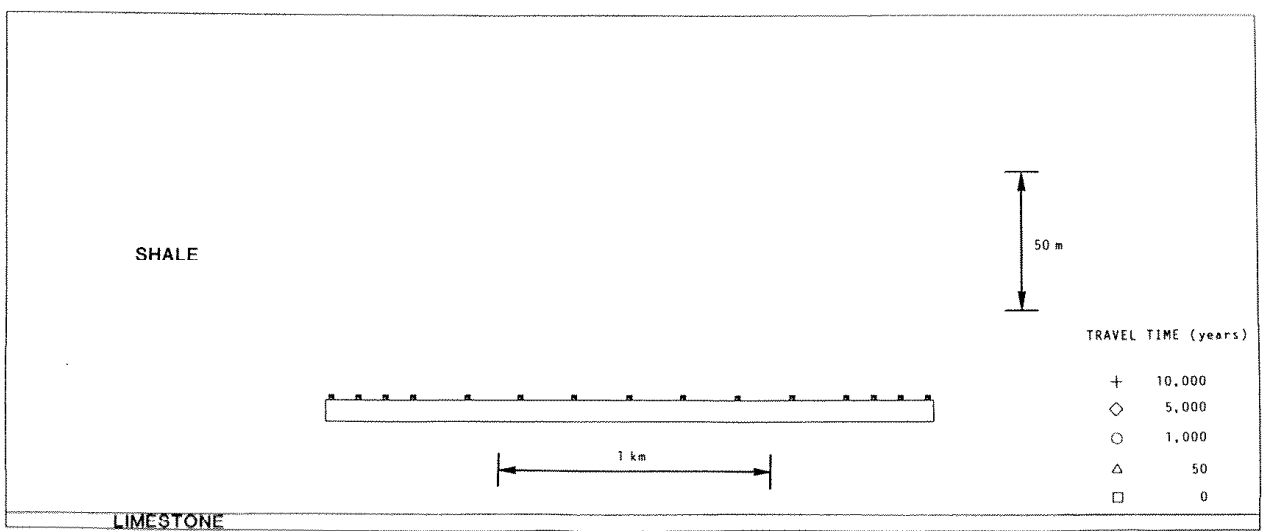

Fig. C.7.53. Isothermal hydrologic results for shale section.

ORNL DWG $85-60$

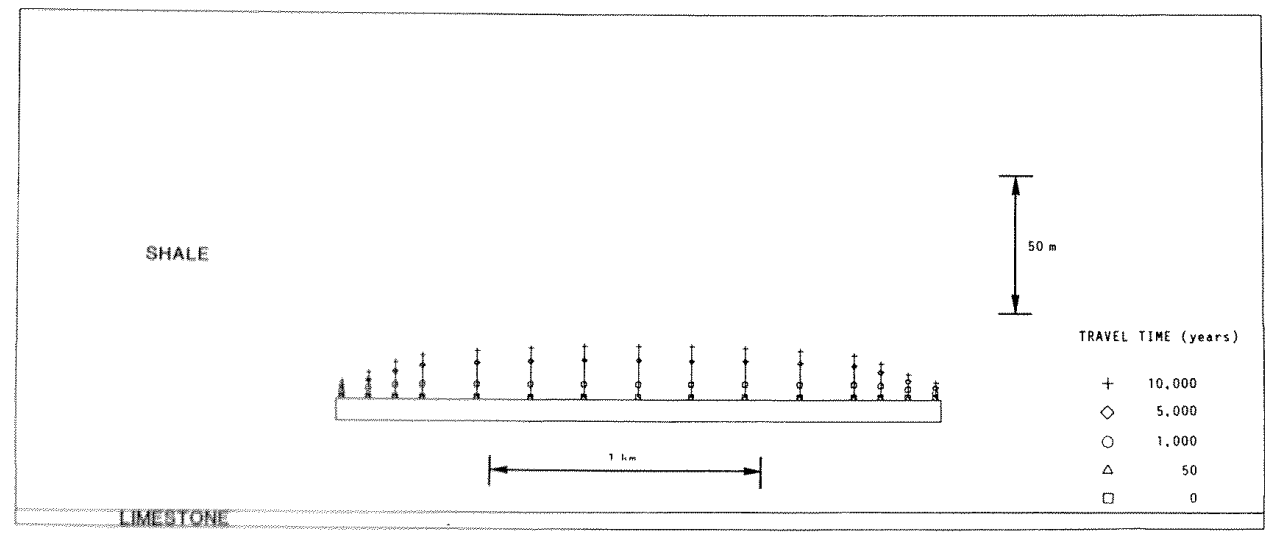

1.9. 0.7 .5 . Wontsothermal hydrologic results for shale section.

Athough the coupled thermal-hydrologic analyses are based upon a large number of sumplitylug assumptions and must be considered to be of

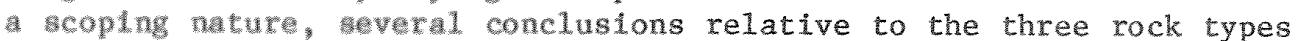
studied nuy be drawn. of these rock types, shale was found to have the shortcest themally coupled, 10,000-year travel distance, followed respecbively by anydrock and sandstone. for the cases studied, the higher thermal conductivltes of anhydrock and sandstone were found to be compersated by the low permeablilty and high, effective porosity of shale. However, the wesult for sandstone may be conservatively high hacanse of the Wgher in thu thermal gradent associated with that reference secthon:

The three rock typer selected for coupled thermal-hydrologic studies are those that were found to be of greatest promise in the formal hydro-

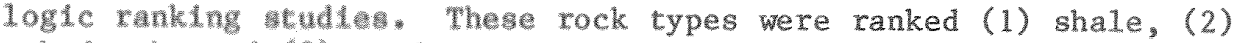
anhydrock, and (3) sandston in chose studies. This same of ranking was Ind cated by the werully coupled studies. It may therefore be concluded that desplut the mcertalnties in the coupled analyses, the

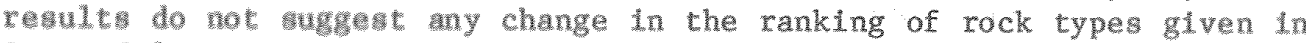
sact con 


\section{C.8 SUMMARY AND CONCLUSIONS}

A preliminary hydrologic evaluation and a ranking of the suitability of five sedimentary rock types as potential host rocks for deep geologic disposal of high-level nuclear waste were performed. The rock types considered were anhydrock, chalk, carbonate rocks, sandstone and shale. This evaluation and ranking considered the performance, construction and operation of a potential repository in each of the rock types. The performance criteria adopted for ranking were based upon and responsive to appropriate existing guidelines promulgated by the DOE, the NRC and the EPA, and were designed to be as quantitative and unbiased as possible.

Ranking was performed on the basis of both postclosure and preclosure criteria and were responsive, to the extent possible, to the DOE siting guidelines presented in 10 CFR 960 (CFR 1984). Pre-waste-emplacement groundwater travel time was selected as the most meaningful postclosure criterion, and is an estimate of the groundwater travel time to the accessible environment. Groundwater inflow into repository drifts was oclected ao the moot meaningful preclosure critarion, and provides an indication of the engineering measures that may be required for water removal during construction and operation. Each of these criteria provides a means of considering a large number of hydrologic features and rock properties and arriving at objective measures of the probable suitability of the five rock types for deep geologic disposal of high-level waste. They directly rank on the basis of critical performance measures, and automatically integrate and weight the many hydrologic and geologic parameters of concern.

The study was confined to the generic, hydrologic consideration of the five sedimentary rock types. It was specifically restricted to existing information and data, and the ranking was based upon studies of generalized, reference stratigraphic sections developed to reflect typical geologic environments for oach rock type considered.

Before discussing the results, it is important to review the limitations and qualifications associated with this study. The purpose of the study was to produce a quantitative basis for comparative ranking of the five sedimentary rock types. Thus, the estimated travel times and inflows are, under no circumstances, to be interpreted as having absolute relation to values that may be expected for any existing sites. Further, the ranges developed for each of the rock types should not be construed to have absolute relation to any existing sites or to, in any sense, be inclusive of the travel times or inflows that may be found at existing sites of a particular rock type. Rather, because of the judgment that has been exercised in determining what subset of a given rock type may be suitable for waste disposal application and because of the constraints imposed by considering only a single generic reference cross section, the ranges developed for this study are much smaller than might have been found in a similar study with different assumptions. While perhaps less representative of the totality of existing sites, these smaller ranges provide a more usetul basis tor ranking the tive rock types. 
It should also be noted that the range of hydraulic properties and geologic settings found in nature is large for all rock types, and that it is conceivable that under favorable circumstances a suitable site for high-level waste disposal could be found in any of the five rock types studied here. The purpose of this ranking study is not, therefore, to identify whether or not suitable sites may exist in a given rock type, but rather to identify those rock types whose typical properties and geologic settings provide the most favorable conditions for waste disposal.

Finally, it should be reiterated that the groundwater travel times estimated in this study consider only advective transport and do not reflect the radionuclide travel times that would be expected for an actual repository. For the tighter rock types, in particular, it is expected that consideration of dispersive and thermally related driving forces may lead to radionuclide travel times that are very significantly greater than the groundwater travel times estimated here.

\section{C.8.1 RANKING OF ROCK TYPES}

\section{C.8.1.1 Travel Time Ranking}

The results of the pre-waste-emplacement groundwater travel time analyses described in Sect. C.7 are sumarized in Table C.8.1. The results are presented as distance traveled over 100,000 years. Groundwater velocities for the chalk and carbonate rocks sections were found to be very significantly greater than the other rock types, with the velocities in carbonate rocks being greater than those in chalk. Sandstone showed a greater range in velocities than anhydrock, resulting from the perceived possibility of higher conductivity sandstones. Shale uniformly showed the lowest groundwater velocities of all rock types studied. The ranking of the five rock types on the basis of groundwater travel time is thus: (1) shale; (2) anhydrock; (3) sandstone; (4) chalk; and (5) 1imestone.

As can be seen, the first three rock types rank relatively closely on the basis of the typical cases. The shale, however, was shown to have the shortest travel distance because it is has a lower conductivity than the sandstone and a higher effective porosity than the anhydruck. Because the sandstone in the reference section is surrounded by low-permeability shale layers, it is suggested that the travel distances derived in the sandstone analyses may be nonconservatively low. The travel distances computed for the high and low cases for these three rock types show the same ranking as the typical cases. In view of the ranges and perceived degrees of relative conservatism associated with the various reference sections, it is believed that the ranking presented in the previous paragraph for the travel time analyses is valid for the purposes of the present study.

\section{C.8.1.2 Groundwater Inflow Ranking}

The ranking based on the groundwater inflow analyses that are discussed in sect. C.7 is summanized un Fig. C.8.1. WLLh the exception of anhydrock and shale it can be seen that the inflow ranking corresponds 
Table C.8.1. Pre-emplacement distance traveled by groundwater in 100,000 years

\begin{tabular}{|c|c|c|c|}
\hline \multirow[b]{2}{*}{ Rock type } & \multicolumn{3}{|c|}{ Travel distance (m) } \\
\hline & Expected & High & Low \\
\hline Anhydrock & 46 & 317 & 20 \\
\hline Chalk & $>15,000$ & $\gg 15,000$ & $>15,000$ \\
\hline Carbonate rocks & $\gg 15,000$ & $\gg 15,000$ & $>15,000$ \\
\hline Sandstone & 30 & 3,150 & 15 \\
\hline Shale & 6 & 55 & $<1$ \\
\hline
\end{tabular}

ORNL DWG 85-28

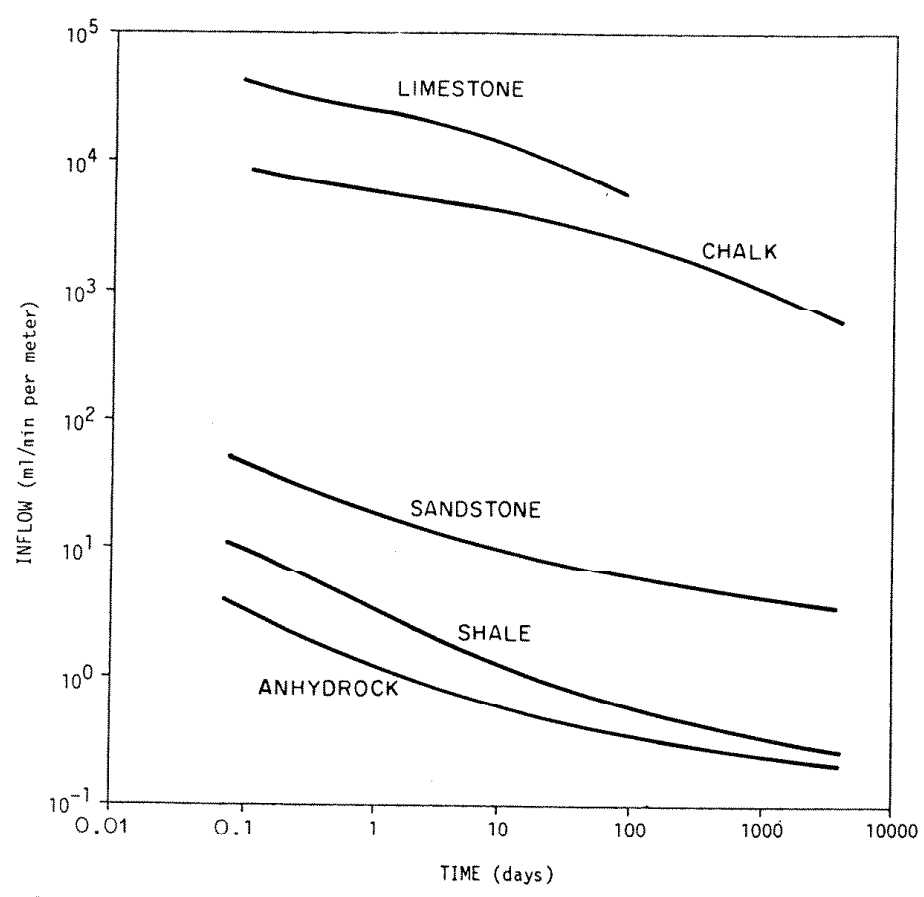

Fig. C.8.1. Typical groundwater inflow versus time plot for the five sedimentary luck Lypes. 
to the travel time ranking described above. Because of the close proximity of the relatively high-conductivity carbonate rocks to the repository in the reference shale section as opposed to the relatively uniform hydraulic properties in the anhydrock section, it is believed that the inflow for the shale is conservatively high. Because the ranking is to be done within the context of the reference sections, however, the order of the inflow ranking was not changed. Finally, while the ranges between the high and low cases for each of the rock types is relatively large, it is believed that differences are not great enough to affect the overall inflow ranking. The ranking for the five rock types on the basis of groundwater inflow is thus: (1) anhydrock; (2) shale; (3) sandstone; (4) chalk; and (5) carbonate rocks.

\section{C.8.1.3 Other Considerations}

other considerations in final ranking include a number of qualitative criteria such as the relative importance of the postclosure and preclosure guidelines, the degrees of conservatism associated with the reference geologic sections, and the uncertainties in hydrologic properties of the rock types that muld not he readily incorporated into the numerical analyses.

Postclosure guidelines are stated to be of greater importance than preclosure guidelines in DOE'S $10 \mathrm{CFR} 960$. This rationale is based upon the relative importance of long term waste isolation as compared with the short-term engineering problems encountered during construction and operation. On this basis the travel time should be given greater weight than the groundwater inflow in the overall ranking of the five rock types.

Relative degrees of conservatism were afforded to the performance of the different rock types by virtue of their geologic environment in the reference geologic sections. As discussed in Sect. C.7 and briefly summarized above, the performance of chalk, carbonate rocks and sandstone was enhanced by the overlying lower conductivity shatey horizons, the performance of anhydrock was relatively unaffected by the section, and the performance of shale was detracted by the underlying higher conductivity carbonate rocks horizon.

Uncertainties in hydrologic properties, discussed in Sect. C.5, are considered to result primarily from the intrinsic heterogeneity of the rock types and the influence of fracturing. The properties of chalk and carbonate rocks are most strongly influenced by fracturing and the greatest uncertainties must therefore be associated with these rocks. A relatively high degree of uncertainty is also associated with anhydrock because of the lack of hydrologic experience in this rock type the possible presence of large, isolated pockets of pressurized brine and gas. Although a lower degree of uncertainty is associated with sandstones than with the foregoing rock types, difficulties are expected to arise in defining the nature of interconnection of individual sandstone lenses important to detailed travel time assessments. The plasticity of shales at depth restricts the influence of fractures on groundwater movement, but some vartabilicy may silil be expected due to fracturting and due to lithologic changes. 


\title{
C.8.1.4 Overa11 Ranking
}

Based upon the foregoing quantitative and qualitative considerations, it is apparent that the overall ranking of the five rock types should be:

\author{
1. Shale \\ 2. Anhydrock \\ 3. Sandstone \\ 4. Chalk \\ 5. Carbonate rocks
}

An overall review of the results for the typical cases, the ranges developed from the high and low cases, and the qualitative considerations described above suggest that the first three rock types as a group are very significantly better than the remaining two rock types. Less obviously, the shale and anhydrock were found to be somewhat better than the sandstone.

\section{C.8.2 OTHER CONSIDERATIONS}

The final hydrologic ranking as reflected above is believed to represent a logical, objective ranking of the the five sedimentary rock types considered in this study. As stated in Sect. C.2, however, it does not consider all of the factors related to containment capability. While it is anticipated that these factors will be considered in other studies, it is appropriate to briefly discuss some of the potential impacts here.

The most important factor likely to affect the hydrologic containment capability of a potential deep geologic repository is chemical retardation. It is expected that other studies will show that chemical effects collectively referred to here as sorption will be greatest in the shale and possibly least in the anhydrock, with sandstone falling between depending on the nature of the impurities. It is thus expected that shale will remain the rock type of choice.

The other important factor to consider is thermally induced buoyancy. Because thermal buoyancy is dependent on the nature of the geologic secLivi lo a greater extent than sorption, and because buoyancy is a function of the layout of the repository, its evaluation for ranking purposes is relatively difficult. Although the results of a preliminary scoping study of this effect, described in Sect. C.7.7, indicate that its consideration would not change the order of ranking, it is recommended that a separate and more detailed study be performed to evaluate this phenomenon.

Finally, it is believed that other factors such as stress-related changes in permeability due to excavation or thermal effects will be small and not affect the final ranking presented in this study. 


\section{C.9 REFERENCES}

AGARWAL 1979. R. G. Agarwal, R. D. Carter, and C. B. Pollock, "Evaluation and Performance Prediction of Low-Permeability Gas Wells Stimulated by Massive Hydraulic Fracturing," J.Pt. Tech. 31(3), 362-71 (1979).

BACA 1981. R. G. Baca and R. C. Arnett, Analysis of Fracture Flow and Transport in the Near-Field of a Nuclear Waste Repository, Rockwe11 Hanford Operations Basalt Waste Isolation Project Report, RHO-BWI-SA-81 (March 1981).

BAIN 1973. G. L. Bain, Feasibility Study of East Coast Triassic Basins for Waste Storage: Data Availability, U.S. Geological Survey Open File Report (1973).

BARR 1980. G. E. Barr and D. D. Gonzalez, "Current Status of the Hydrogeology for the WIPP," Workshop on Thermomechanical-Hydrochemical Modeling for a Hardrock Waste Repnsitory, Lawrence Berkeley Laboratory, LBL 11204 (Ju1y 29-31, 1980).

BEAR 1979. J. Bear, Hydraulics of Groundwater. McGraw-Hill Inc, New York, 1979.

BEBOUT 1979. D. Bebout, G. Davies, C. H. Moore, P. S. Scholle, and N. C. Wardlaw, Geology of Carbonate Porosity, American Association of Petroleum Geologists, Continuing Education Course Note Series No. 11 (Apri1 1979).

BELL 1977. F. G. Bell, "A Note on the Physical Properties of the Chalk," Eng. Geol. 11, 217-225 (1977).

BENNETT 1975. E. N. Bennett and C. D. Forgerson, "Predicting Rosorves and Forecasting Flow Rates of Relatively Tight Gas Wells using Limited Performance Data," J. of Pet. Techno1. 27, 585-591 (May 1975).

BRACE 1980. W. F. Brace, "Permeability of Crystalline and Argillaceous Rocks," Int. J. Rock Mech. Min. Sci.\& Geomech. Abstr. 17, 241-251 (1980).

BREDEHOEFT 1979. J. D. Bredehoeft, "An Analysis of the nakota Aquifer System in South Dakota," Proceedings Symposium on Recent Trends in Hydrogeology, Lawrence Berkeley Laboratory (February 8-9, 1979).

BROKAW 1972. A. L. Brokaw, C. L. Jones, M. E. Cooley, and W. H. Hays, Geology and Hydrology of the Carlsbad Potash Area, Eddy and Lea Counties, New Mexico, U.S. Geological Survey Open File Report (1972).

BRUNE 1983. G. M. Brune and G. L. Duffin, Occurrence, Availability and Quality of Groundwater in Travis County, Texas, Texas Department of Water Resources Report 276, Austin (1983). 
BUXTON 1981. T. M. Buxton and D. F. Sibley, "Pressure Solution Features in a Shallow Buried Limestone," J. of Sed. Petrol. 51(1), 19-26

(March 1981).

CFR 1983. Code of Federal Regulations, 10 CFR Part 60, Fed. Regis. 48(120), 28194 (June 21, 1983).

CFR 1984. Code of Federal Regulations, 10 CFR Part 960, Fed. Regis. 49(236), 47714 (Dec. 6, 1984).

CFR 1985. Code of Federal Regulations, 40 CFR Part 191, Fed. Regis. 50 (182), 38066 (Sept. 19, 1985).

CHILINGARIAN 1981. G. V. Chilingarian, Compactional Diagenesis, in Sediment Diagenesis, A. Parker and B. Sellwood, Editors. NATO ASI Series C: Mathematical and Physical Sciences Vo1. 115, D. Reidel Pub1ishing Company, Boston, pp. 57-167 (1981).

CHOQUETTE 1970, P. W. Choquette and L. C. Pray, Geologic Nomenclature and Classification of porosity in Sedimentary Carbonates, Am. Assoc. of Pet. Geol. Bull. 54(2) 207-250 (February 1970).

CLOUD 1975. K. W. Cloud, The Diagenesis of the Austin Chalk, Master of Science Thesis, Univ. of Texas, Dallas (1975).

CORBETT 1982. K. P. Corbett, Structural Stratigraphy of the Austin Chalk, Master of Science Thesis, Texas A\&M University, College Station (1982).

CORBETT 1983. K. P. Corbett, "Structural Stratigraphy of Austin Chalk," Am. Assoc. of Pet. Geo1. Bu11. 67, 443 (1983).

CUDERMAN 1984. J. Cuderman, New Borehole Fracturing Technique Improves Gas Production, Sandia Technology Report 8(1), 18-23 (May 1984).

DANIEL 1954. E. J. Danie1, Fractured Reservoirs of Middle East, Am. Assoc. of Pet. Geol. Bul1. 38, 774-815 (1954).

D'APPOLONIA 1980. D'Appolonia Consulting Engineers, Repository Sealing Design Approach - 1979, prepared for Battelle office of Nuclear Waste Isolation Report, ONWI-55 (March 1980).

D'APPOLONIA 1981. D'Appolonia Consulting Engineers, Sealing Considerations for Repository Shafts in Bedded and Dome Salt, prepared for Battelle office of Nuclear Waste Isolation, ONWI-255 (December 1981).

DEAN 1983. W. E. Dean and K. S. Johnson, Editors, Anhydrite Deposits of the United States and Characteristics of Anhydrite Important for Storage of Radioactive Wastes, U.S. Geological Survey Professional Paper, Draft (1983).

De LAGUNA 1968. W. de Laguna, E. C. Struxness, T. Tamura, H. O. Weeren, W. C. McClain, and R. C. Sexton, Engineering Development of Hydraulic Fracturing as a Method for Permanent Disposal of Radioactive Wastes, Oak Ridge National Laboratory, ORNL-4259 (August 1968). 
De WIEST 1965. R. De Wiest, Geohydrology, John Wiley and Sons, Inc., New York (1965).

DIEHL 1983. S. F. Dieh1 and W. Z. Savage, Physica1 Properties of Anhydrite in Anhydrite Deposits of the United States and Characteristics of Anhydrite Important for Storage of Radioactive Wastes, U.S. Geological Survey Professional Paper, Draft (1983).

DOE 1981. U.S. Department of Energyt, Volume 2 - Main body of: Semiannual Report for the Unconventional Gas Recovery Program, U.S. Department of Energy, Morgantown Energy Technology Center, Morgantown, West Virginia, DOE/METC/SP-1108 (November 1981).

DOE 1983. U.S. Department of Energy, Unconventional Gas Resources: Available Publications Listing, prepared by Lewin and Associates, Inc. for U.S. Department of Energy, Morgantown Energy Technology Center, Morgantown, West Virginia, DUE/MC/19239-1295 (May 1983).

DOYLE 1955. W. M. Doyle, Production and Reservoir Characteristics of the Austin Chalk in South Texas. Trans. of the Gulf Coast Assoc. of Geol. Soc. (Biloxi, Miss.), Vol. V, 3-10, (Oct. 1955).

DRAVIS 1979. J. J. Dravis, Sedimentology and Siagenesis of the Upper Cretaceous Austin Chalk Formation, South Texas and Northern Mexico, Ph.D. Thesis, Rice University (1979).

EDMUNDS 1973. W. M. Edmunds, P. E. R. Lovelock, and D. A. Gray, "Interstitial Water Chemistry and Aquifer Properties in the Upper and Middle Chalk of Berkshire, England," J. of Hydrol. 19, 21-31 (1973).

ELMDAHL 1955. B. A. Elmdahl, "The Fundamental Principles of Core Analysis and their Application to Gulf Coast Formations," Trans. of the Gulf Coast Assoc. of Geol. Soc. (Biloxi, Miss.), Vol. V, 51-64 (October 1955).

FATT 1958. I. Fatt, "Compressibility of Sandstones at Low to Moderate Pressures," Am. Assoc. of Pet. Geol. Bull. 42(8), 1924-1957 (August 1958).

FREEZE 1979. R. A. Freeze and J. A. Cherry, Groundwacer, Prenc1ce-Ha11, Inc., Englewood Cliffs, New Jersey, 1979.

GEVANTMAN 1981. L. H. Gevantman, Editor, Physical Properties Data for Rock Salt, U.S. National Bureau of Standards Monograph 167 (January 1981).

GIDLEY 1979. J. L. Gidley, D. H. Mutti, D. E. Nierode, D. M. Kehn, and T. W. Muecke, "stimulation of Low-Perneability Gas Formations by Massive Hydraulic Fracturing - a Study of Well Performance," J. of Pet. Technol. 31(4) (Apri1 1979).

GLOYNA 1961. E. F. Gloyna and T.D. Reynolds, "Permeability Measurements of Rock Salts," J. of Geo. Res. 66(11) (November 1961).

GonZALeS 1975. S. Gonzales, Geohydrolog1c - Eng Lieerlug Geulugy Evaluation of the Selma Group in Western Alabama and Northeast Mississippi for Possible Radioactive Waste Disposal, prepared for office of Waste Isolation, Y/OWI/SUB-4310/1 (June 1975). 
GONZALES 1977. S. Gonzales, Supplemental Field and Literature Investigation of the Upper Cretaceous Austin Group (Chalk) of Texas with Regard to its Potential for Radioactive-waste Isolation, prepared for office of Waste Isolation, Y/OWI/SUB-4310/4 (June 1977).

GONZALES 1984. S. Gonzales and K. S. Johnson, Shales and Other Argillaceous Strata in the United States, prepared by Earth Resource Associates, Inc., for Oak Ridge National Laboratory, Draft (Apri1 1984).

HAKANSSON 1974. E. Hakansson, R. Bromley, and K. Perch-Nielsen, "Maastrichtian Chalk of Northwest Europe - a Pelagic Shelf Sediment," Spec. Pub1s. Int. Ass. Sediment 1, 211-233 (1974).

HANDIN 1957. J. Handin and R. V. Hager,Jr., "Experimental Deformation of Sedimentary Rocks under Confining Pressure: Tests at Room Temperature on Dry Samples," Am. Assoc. of Pet. Geol. Bu11. 41(1), 1-50 (January 1957).

HATHEWAY 1982. A. W. Hatheway and G. A. Kiersch, "Engineering Properties of Rock," in Handbook of Physical Properties of Rocks, CRC Press Inc., West Palm Beach, Florida (1982), pp. 289-331.

HICKEY 1982. J. J. Hickey and W. E. Wilson, Results of Deep-well Injection testing at Mulberry, Florida, U.S. Geol. Survey Water Res. Investigation 81-75 (February 1982).

HOHLT 1948. R. B. Hohlt, The Nature and Origin of Limestone Porosity, quarterly of the Colorado School of Mines, Vol. 43, No. 4 (October 1948).

HOHOLICK 1984. J. D. Hoholick, T. Metarko, and P. E. Potter, "Regional Variations of Porosity and Cement: St. Peter and Mount Simon Sandstones in Illinois Basin," All. Assoc. of Pet. Geol. Bu11. 68(6), 7533-764 (June 1984).

HOLMES 1965. A. Holmes, Principles of Physical Geology. Ronald Press Co., New York (1965).

JONHSON 1980. K. S. Johnson, K. V. Luza, and J. F. Roberts, Disposal of Industrial wastes in Oklahoma, Oklahoma Geological survey, Circular No. 80 (1980).

KALYONCU 1979. R. S. Kalyoncu, J. P. Boyer, and M. J. Snyder, Characterization and Analysis of Devonian Shales as Related to Release of Gaseous Hydrocarbons, We11 P-1, Sullivan Co. Indiana, Battelle Columbus Laboratories (May 18, 1979).

KING 1981. I. P. King, D. B. McLaughlin, W. R. Norton, R. G. Baca, and R. C. Arnett, Parametric and Sensitivity Analysis of Waste Isolation in a Basalt Medium, Rockwell Hanford Operations, RHO-BWI-C-94 (February 1981).

KNUTSON 1976. C. F. Knutson, "Modeling of Noncontinuous Fort Union and Mesaverde Salldslute Reservolis, Piceatice Basill, Nurlliweslera Culuradu," Soc. of Pet. Eng. J., 175-188 (August 1976). 
LAMBERT 1977. S. J. Lambert and J. W. Mercer, Hydrologic Investigations of the Los Medanos Area, Southeastern New Mexico, 1977, Sandia

Laboratories, SAND77-1401 (1977).

LIN 1978. W. Lin, Measuring the Permeability of Eleana Argillite from Area 17, Nevada Test Site, Using the Transient Method, Lawrence Livermore Laboratory, UCRL-52604 (December 11, 1978).

LOMENICK 1983. T. F. Lomenick, S. Gonzales, K. S. Johnson, and D. Byerly, Regional Geological Assessment of the Devonian-Mississippian Shale Sequence of the Appalachian, Illinois, and Michigan Basins Relative to Potential Storage/disposal of Radioactive Wastes, Oak Ridge National Laboratory, ORNL-5703 (January 1983).

LONG 1982. J. C. S. Long, J. S. Remer, C. R. Wilson and P. A. Witherspoon, "Porous Media Equivalents for Networks of Discontinuous Fractures," Watcr Reo. Res. 18(3), 645 (1982).

MAGARA 1980. K. Magara, "Comparison of Porosity-depth Relationships of Shale and Sandstone," J. of Pet. Geol. 3, 175-185 (1980).

MANGER 1963. G. E. Manger, Porosity and Bulk Density of Sedimentary Rocks, U.S. Geo1. Sur. Bul1. 1144-E, 55 p. (1963).

MANILLA 1980. R. D. Mani11a, Semi-annual Report for the Unconventional Gas Recovery Program, U.S. Department of Energy, Morgantown Energy Technology Center, Morgantown, West Virginia (November 1980).

MARINE 1974. I. W. Marine, "Geohydrology of Buried Triassic Basin at Savannah River Plant, South Carolina," Amer. Assoc. of Pet. Geol. Bul1. 58, 1825-1837 (1974).

MARINE 1974. I. W. Marine and G. E. Siple, "Buried Triassic Basin, South Carolina and Georgia, Geol. Soc. of Am. Bul1. 85, 311-320 (1974).

MAXWELL 1964. J. C. Maxwe11, "Influence of Depth, Temperature, and Geologic Age on Porosity of Quartzose Sandstone," Am. Assoc. of Pet. Geol. Bu11. 48(5), 697-709 (May 1961).

McCOMAS 1963. M. R. McComas, Productive Core Analysis Characteristics of Carbonate Rocks in the Four Corners Area, Four Corners Geological Society, Fourth Field Conference (1963).

MEADE 1963. R. H. Meade, "Factors Influencing the Pore Volume of Finegrained Sediments under Low-to-moderate Overburden Loads," Sedimentology 2, 235-242 (1963).

NORDSTROM 1982. P. L. Nordstrom, Occurrence, Availability and Chemical Quality of Groundwater in the Cretaceous Aquifers of North-Central Texas, Texas Department of Water Resources Report 269, Austin (1982).

NUTTER 1975. L. J. Nuttex, Hydrogeology of the Triaooic Rocko of Maryland, Maryland Geological Survey Rept. Invest. 26 (1975). 
OBERT 1967. L. Obert and W. I. Duvall, Rock Mechanics and the Design of Structures in Rock, John Wiley \& Sons, Inc., 1967.

ONWI 1979. Office of Nuclear Waste Isolation, Proceedings of the National Waste Terminal Storage Program, Information Meeting, ONWI-62 (October 30-November 1, 1979).

OHLE 1951. E. L. Ohle, "The Influence of Permeability on Ore Distribution in Limestone and Dolomite," Econ. Geol. 46, 667-706 (1951).

PANDEY 1974. G. N. Pandey, M. R. Tek, and D. L. Katz, "Diffusion of Fluids Through Porous Media with Implications in Petroleum Geology," Am. Assoc. of Pet. Gen1. Bul1. 58(2), 291-303 (February 1974).

POWERS 1978. D. W. Powers, S. J. Lambert, S. E. Shaffer, L. R. Hi11, and W. D. Weart, Geological Characterization Report, Waste Isolation rilot plant (WIPP) Site, Southeastern New Mexico, Sandia Laboratories, SAND 78-1596, Vol. 2 (August 1978).

ROBERTSON 1979. E. C. Robertson, Therma1 Conductivitico of Rocks, U.3. Geological Survey Open File Report 79-356 (1979).

SCHOFIELD 1931. F. H. Schofield, "The Heat Loss from a Cylinder Embedded in a Wa11," Phil. Mag. 12(76), Supp1. Aug. 329-349 (1931).

SCOTT 1977. R. J. Scott, "The Austin Chalk-Buda Trend of South Texas,"

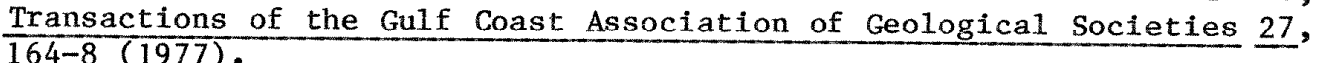

SELLEY 1978. R. C. Selley, "Porosity Gradients in North Sea 0il-bearing Sandstones," J. Geol. Soc. Lond. 135, 119-132 (1978).

SNYDER 1977. R. H. Snyder and M. Craft, "Evaluation of Austin and Buda Formations from Core and Fracture Analysis," Trans. Gulf Coast Ascocof Geol. Soc. 27, 376-385 (1977).

STEGE 1981. B. Stege, "Limestone Bedrock as a Barrier to Uranium MigraLion, Sterra Pena Blanca, Chihuahua, Mexico," Am. Assoc. Petrol. Geol. Studies in Geo1. 13 (1981).

TAYLOR 1950. I. M. Taylor, "Pore-space Reduction in Sandstonee," Am. Assoc. of Pet. Geo1. Bul1. 34(4), 701-716 (April 1950).

TAYLOR 1982. 0. J. Taylor, Three-dimensional Mathematical Model for Simulating the Hydrologic System in the Piceance Basin, Colorado, U.S. Geological Survey Open File Report 82-637 (1982).

THACKSTON 1984. J. W. Thackston, L. M. Preslo, D. E. Hoexter, and N. Donnelly, Results of Hydraulic Tests at Gibson Dome No. 1, E1k Ridge No. 1, and E. J. Kubat Boreholes, Paradox Basin, Utah, prepared by Woodward-Clyde Consultants for the office of Nuclear Waste Isolation, Balle11e Memorial institute, ONW1-491 (March, 1984). 
THOMAS 1971. R. D. Thomas and D. C. Ward, "Effect of Overburden Pressure and Water Saturation on Gas Permeability of Tight Sandstone Cores," J. Pet. Technol. Paper No. SPE 3634 (1971).

THORDARSON 1983. W. Thordarson, Hydrology of Anhydrite, in Anhydrite Deposits of the United States and Characteristics of Anhydrite Important for Storage of Radioactive Wastes, U.S. Geological Survey Professional Paper, Draft (1983).

USCONGRESS 1983. U.S. Congress, Nuclear Waste Policy Act of 1982. Public Law 97-425, 42 USC 10101 (January 1983).

VONDFR HAAR 1984. S. P. Vonder Haar, Porosity of Coastal Deltaic Sandstones, Cerro Prieto Geothermal Field, Baja California, Mexico. Lawrence Berkeley Laboratory, LBL-17650 (April 1984).

WALLS 1982. J. D. Walls, "Tight Gas Sands - Permeability, Pore Structure, and Clay," J. of Pet. Technology 34(11), 2708-2714 (1982).

WAT.TON 1960. W. C. Wa 1 ton, Leaky Artesian Aquifer Conditions in Illinois, Illinois Water Survey Rept. Invest. No. 39 (1960).

WOOD 1982. J. R. Wood and T. A. Hewett, "Fluid Convection and Mass Transfer in Porous Sandstones-ma Theoretical Mode1, "Geochimica et Cosmochimica Acta 46, 1707-1713 (May, 1982).

WYMAN 1979. R. E. Wyman, S. A. Holditch and P. L. Randolph, "Analyses of an Elmworth Hydraulic Fracture--Alberta, Canada," Society of Petroleum Engineers of AIME, 243-255, Dallas, Texas (1979).

YOUNG 1964. A. Young, P. F. Low, and A. S. McClatchie, "Permeability Studies of Argillaceous Rocks," J. Geophys. Res. 69(20), 4237 (1964).

YoInN 1978. n. C. Young, Chemieal and Physical Properties of Michigan Antrim Shale, preprints, Second Eastern Gas Shales Symposium, U.S. Department of Energy, Morgantown Energy Technology Center Pub. METC/SP-78/6, Vol. 1, pp. 129-137 (1978). 
This page intentionally left blank 
APPENDIX D

GEOCHEMISTRY OF SEDIMENTARY ROCKS RELEVANT TO HIGH-LEVEL NUCLEAR WASTE REPOSITORY SITING

\author{
D. M. RYE \\ M. C. MONAGHAN \\ P. R. DIXON \\ YALE UNIVERSITY \\ DEPARTMENT OF GEOLOGY AND GEOPHYSICS \\ p. ก. BNX 6666 \\ NEW HAVEN, CONNECTICUT 06511 \\ D. B. BROOKINS \\ UNIVERSITY OF NEW MEXICO \\ DFPARTMFNT OF GFOTOCY \\ ALBUQUERQUE, NEW MEXICO 87131 \\ S. H. STOW \\ OAK RIDGE NATIONAL LABORATORY \\ P. 0. BOX X \\ OAK RIDGE, TENNESSEE 37831
}


This page intentionally left blank 
D.1. INTRODUCTION *.............,

D.1.1 GENERAL . . ................... 121

D.1.2 REVIEW OF CRITERIA. . . . . . . . . . . ... 121

D.1.3 REPORT APPROACH AND OBJECTIVE .......... 122

D.2. RADIONUCLIDE SOLUBILITY AND MOBILITY . . . . . . . . 124

D.2.1 INTRODUCTION. . . . . . *.......... 124

D.2.2 CONDITIONS OF RADIONUCLIDE SOLUBILITY . . . . 124

D.2.3 CONDITIONS OF RADIONUCLIDE RETARDATION. . . . . 126

D.3. GEOCHEMISTRY OF FORMATIONAL WATERS . . . . . . . . . 135

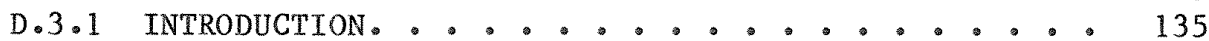

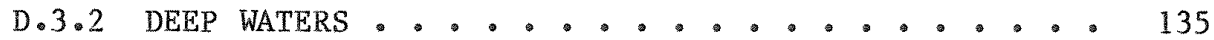

D.3.3 COMPARISON OF WATERS................. 138

D.4. PETROLOGY AND GEOCHEMISTRY OF THE MAJOR ROCK TYPES . . 140

n.4.1 TNTRONTITTTON. .................... 140

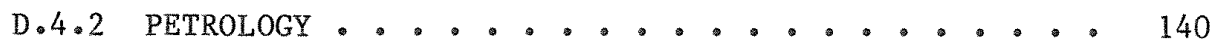

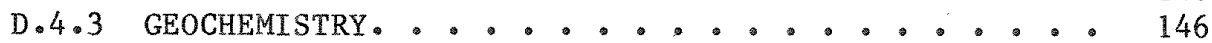

D.4.3.1 Bulk Composition.......... 146

D.4.3.2 Solubility of the Rocks......... 146

D.4.3.3 Cation Exchange Capacity....... 151

D.5. EVATIUATTON OF THE MAJOR ROCK TYPES BASED ON

DISCRIMINATORS . . . . . . . . . . . . . . . 153

D.5.1 DISCRIMINATORS FOR RANKING........... 153

D.5.2 REVIEW OF THE DATA BASE .............. 153

D.5.3 DISCUSSION OF THE DATA FOR EACH DISCRIMINATOR • • 153

D.5.3.1 Existing Conditions.......... 153

D.5.3.1.1 Radionuclide concentration

$1 \mathrm{imits.........} 153$

D.5.3.1.2 Retardation factors..... 153

D.5.3.1.3 Reducing conditions.... 155

D.5.3.1.4 Rock dissolution...... 156

U.5.3.2 Adverse Conditions .......... 157

D.5.3.2.1 Radionuclide concentration

limits. . . . . . . 157

D.5.3.2.2 Retardation factors..... 158

D.5.3.2.3 Reducing conditions.... 158

D.5.3.2.4 Rock dissolution. . . . . 158

D.5.3.3 Relative Evaluation for Each

Discriminator......... 159

D.5.3.3.1 Radionuclide concentration

limits........ 159

D.5.3.3.2 Retardation factors.... 160

D.5.3.3.3 Reducing conditions.... 160

D.5.3.3.4 Rock dissolution. . . . . 160

D.5. OVERALL EVALUAILUN AND KANKING UF THE ROCK TYYES . . . 161

D.7. REFERENCES ..................... 162 
This page intentionally left blank 


\section{D.1 INTRODUCTION}

\section{D.1.1 GENERAL}

The Oak Ridge National Laboratory (ORNL) is conducting a generic study of five types of sedimentary rocks [anhydrock, carbonate rocks (dolostone-1imestone), chalk, sandstone, shale] to evaluate their relative suitability for possible high-level nuclear waste repository siting. The evaluation will be derived from a variety of data bases, including those that contain technical information on geologic characteristics, resources, rock mechanics, hydrologic behavior, and geochemical parameters.

The geochemical environment is a prime factor controlling the degradation of waste packages and the subsequent behavior of released radionuclides in a repository and the surrounding rocks. Thus, geochemical considerations are critical in selecting the most desirable rock types for repositories. Assessment of the geochemical environment in the repository is a complicated task because it involves intercoupling data on radionuclide behavior, the composition of waters that will be present, and the mineralogy and chemical composition of rocks that the waters and radionuclides will contact. Superimposed on these considerations are the impacts that radiation and heat will have on the stability and the geochemical nature of the water and the rock.

This appendix represents an assessment of the geochemical characteristics for each of the five rock types under consideration and an application of these characteristics to an evaluation of radionuclide behavior. The report is generic in nature, and conclusions are drawn from literature representative of the geochemistry of rocks and waters from throughout the United States.

\section{D.1.2 REVIEW OF CRITERIA}

Rock evaluation criteria (RECs), which are defined and discussed in Appendix A, have been written so that the subject rock types can be evaluated and ranked. The RECs are derived from the DOE siting guidelines of the U.S. Code of Federal Regulations (10 CFR 960) and were written to reflect relevant site selection guidelines contained in Sects. 960.4 (Subpart C - Postclosure Guidelines) and 960.5 (Subpart D - Preclosure Guidelines). Each REC is followed by a series of "discriminators," which are the factors that allow for technical discussion and quantification of the REC, thus providing the basis for its evaluation. The following RECs and discriminators, taken from Appendix A, represent those that apply to geochemical facets.

\section{Postclosure REC A.1.3}

Criterion: To what extent do the expected geochemical characteristics of, and the processes operating within, the host rock favorably affect the expected postclosure performance of the repository? 


\section{Discriminators:}

- The expected upper concentration limits for the nuclides of interest and adverse conditions that might increase these limits.

- The expected retardation factors for the nuclides of interest and adverse conditions that might reduce these factors.

- The extent that the geochemical environment is reducing.

A11 of these discriminators are somewhat intercelated; for instance, the reducing environment is a controlling factor in an element's solubility or retardability. Each discriminator reflects specific points noted in the siting guidelines; therefore, each is discussed separately.

Postclosure REC A.1.7

Criterion: To what excent will dissolution processes operating in the host rock horizon affect repository performance?

\section{Discriminator:}

- The extent to which the host rock can dissolve in groundwater.

\section{D.1.3 REPORT APPROACH AND OBJECTIVE}

An evaluation was made of five types of sedimentary rocks from the standpoint of their geochemical suitabilities for high-level radioactive waste repository siting. In this study, the rock types were assumed to have similar hydrological and rock mechanical properties. It was also assumed that water will move through the repository and will interact with the waste package, eventually releasing radionuclides. The objective, therefore, was to determine the potential for mobility of radionuclides in the waters associated with the five sedimentary rock types (formational waters).

The solubility of a given radionuclide in the formational waters (groundwater) at any repository site will be controlled by the chemistry of these waters and by the solubilities of the phases containing the radionuclides (BROOKINS 1984; DAYAL 1982; WANG 1980). Movement of the radionuclides after package dissolution in the far field will be controlled by the chemistry of the radionuclides, the mineralogy and texture of the host rocks, and the rate of movement and chemistry of groundwaters (BROOKINS 1983, 1984; DAYAL 1982; WANG 1980; CARNAHAN 1984; EASTMAN 1978; ISHERWOOD 1981; KIRBY 1984; KOCHER 1983; KOMARNENI 1981; MOODY 1982; O'KELLEY 1984; WILSON 1977; KRISHASWAMI 1982; KELMERS 1984; LANGMUIR 1978, 1980; MEANS 1978, 1982a, 1983; ROBERTSON 1984; ZUTIC 1982; DONGARRO 1980). Hence, in the following discussion, emphasis is placed on the relationship between radionuclide solubility and mobility (or, conversely, retardation), on the one hand, and on the chemistry of the groundwaters and mineralogic and textural characteristics of the rock types, on the nther. 
The material is thus organized to address initially basic concepts concerning the solubility and mobility of radionuclides (Sect. D.2), geochemical characteristics of groundwaters (Sect. D.3), and the petrology and geochemistry of rock types (Sect. D.4). Section D.5 is directed toward a relative evaluation of the rock types based on each of the discriminators. The final section $(D .6)$ then presents an overall evaluation and ranking of the rocks in the form of a hierarchy from most suitable to least suitable, based on each of the four geochemical discriminators discussed in sect. D.5. 


\section{D.2.1 INTRODUCTION}

In the near field, the potential for radionuclide mobility is principally determined by the solubility of the radionuclide-bearing phases present in the waste package components and by the "getting" capacity of similar phases in the surrounding backfill and host rocks. Complex watersolid interactions, combined with the thermal and radiolytic effects expected in the near field, and the probability of formation of aqueous radionuclide complexes, make exact predictions of radionuclide mobility and solubility very difficult (BROOKINS 1984; $0^{\prime}$ RELLEY 1984). In the far field, the potential for radionuclide mobility is determined by the geochemistry of the formational water, the geochemistry of the aquifer, and the solubility of the radionuclides in the formational water (BROOKINS 1984). This potential for mobility can be estimated from studies of radionuclide solubility in geochemical environments similar to those of the far field (BROOKINS 1983). The actual mobility of the radionuclides in the far field is determined by the geochemistry of the formational water (gromiwater), the genchemistry of the aquifer, and the adsorption/ desorption behavior of the radionuclides in the coupled geochemical environment of the aquifer and formational water (KIRBY 1984). The actual mobility can best be estimated from studies of the adsorption/ desorption behavior of the radionuclides in geochemical environments similar to those of the coupled aquifer-formational water systems (KELMERS 1984).

The discussion is directed, first, toward defining the general types of aqueous geochemical environments in which the solubilities of most of the radionuclides may be enhanced or reduced, by examining the known solubilities and insolubilities of the radionuclides in a variety of aqueous geochemical environments. This is followed by a discussion of the general types of 1 ithological and aqueous geochemical environments in which the mobilities of most of the radionuclides may be enhanced or reduced, by examining the known adsorption/desorption behaviors of the radionuclides in a variety of 1ithological and aqueous geochemical environments.

\section{D.2.2 CONDITIONS OF RADTONUCLIDE SOLUBILITY}

The far-field environment is expected to be very different from the ncar field environment of a repository. Effects of heat aud radiolysis will significantly alter the pre-waste-emplacement chemistry of the rock and water in the near field. Changes in $\mathrm{pH}$, redox conditions, and the potential for retardation may occur. In the far field, conditions will be more similar to pre-emplacement conditions. Radionuclides that reach the far field are expected to be trace constituents only. Both the $\mathrm{pH}$ and the redox potential will, in effect, control the rock-water interactions, mineral stability, and related parameters.

The potential for solubility of a radionuclide in any formational water is largely a function of: 
1. the acidity or alkalinity of the formational water,

2. the oxidizing or reducing conditions of the formational water,

3. the total dissolved solids (TDS) concentration and speciation of formational water,

4. the presence or absence of inorganic and organic ligands or of complexing species in the formational water,

5. the temperature and dissolved gas content of the groundwater, and

6. the physical and chemical nature of the repository host rock and the waste (form) parkage.

These factors are not independent (BROOKINS 1984; MEANS 1978). They may act in concert or in opposition; that is, the presence of a particular organlc molecule does not guarantee solubility of a radionuclide unless other geochemical conditions are also present.

Tables D.2.1 and D.2.2 list the conditions of solubility and insolubility, respectively, of the radionuclides in a variety of geochemical environments, with special emphasis on the effects of redox, $\mathrm{pH}$, and complexing species on the solubility or insolubility of the redoxsensitive radionuclides. These data, which are based on references in the tables, indicate the following:

1. In general, the lower the oxidation state of a polyvalent radionuclide, the greater its insolubility.

2. The common complexing species that cause the radionuclides to become soluble are $\mathrm{HCO}_{3}^{-}, \mathrm{CO}_{3}{ }^{2-}, \mathrm{HPO}_{4}{ }^{2-}, \mathrm{SO}_{4}{ }^{2-}, \mathrm{F}, \mathrm{Cl}^{-}, \mathrm{OH}^{-}$, and organic species (actinides such as radium may precipitate).

3. Soluble $\mathrm{OH}^{-}$and $\mathrm{CO}_{3}{ }^{2-}$ complexes dominate at alkaline $\mathrm{pH}$ levels.

4. Some of the pentavalent and hexavalent actinides readily form soluble anionic complexes with $\mathrm{CO}_{3}^{2-}$ at $\mathrm{pH}$ levels greater than 7 .

5. Typically, radionuclide solubility is enhanced at pH levels less than 6 .

6. Soluble $\mathrm{F}$ and $\mathrm{SO}_{4} 2-$ complexes are favored at low $\mathrm{pH}$ levelo.

7. Soluble $\mathrm{HPO}_{4}{ }^{2-}$ complexes are favored at neutral pH.

8. In general, a lower concentration of dissolved solids results in lower radionuclide solubility.

These results indicate that reducing groundwaters with $\mathrm{pH}$ levels in the range of 6 to 7 and with low TDS concentrations should favor low solubility of redox-sensitive nuclides.

The solubility (or insolubility) of a radionuclide in the near-field environment may be significantly altered by the radiation and thermal 
fields produced by wastes. It is quantitatively impossible to assess these changes at this time because experimental data relevant to them are not available. Nevertheless, some qualitative judgments can be made as to the nature of certain reactions that may take place. Solubility generally increases with temperature. This, coupled with the possibility that effects of thermal and radiation loads may degrade organic matter to produce more soluble organic molecules, and thus a higher complexing potential, will lead to greater solubility of radionuclides. The $\mathrm{pH}$ and redox conditions in the aqueous environment will also have an effect. The irradiation of water may produce acidic and oxidizing conditions, which are tantamount to increasing solubility.

\section{D.2.3 CONDITIONS OF RADIONUCLIDE RETARDATION}

It is convenient and conventional to address the problem of radionuclide retardation in terms of laboratory studies of sorption and desorption. (Note: Tt is rengnized that the use of laboratory $\mathrm{k}_{\mathrm{d}}$ values is somewhat controversial, but $K_{d} s$ are an integral part of studies such as this and can yield information of a relative nature for assessment of retardation.) The parameter $\mathrm{K}_{\mathrm{d}}$ is usually referred to in such work and is given as units of volume of tluid per mass of element sorbed (i.e., in $\mathrm{mL} / \mathrm{g}$ or $\left.\mathrm{m}^{3} / \mathrm{kg}\right)$. The retardation factor, $\mathrm{R}$, is expressed as:

$$
R=1+\left(K_{d} \rho\right) / \Phi,
$$

where $\rho=$ density in $\mathrm{g} / \mathrm{cm}^{3}$, and $\Phi=$ total porosity.

The retardation factor is the ratio of the velocity of formational water to the velocity of the radionuclides, and any $R$ value that exceeds 1 indicates that the radionuclide will move more slowly than does the formational water. For equivalent values of $\mathrm{K}_{\mathrm{d}}$ and $p$, rocks with high porosity will have a low retardation factor.

Although $\mathrm{K}_{\mathrm{d}}$ values have been compiled for a large number of different conditions, both in the field and in the lahoratory, they are novertheless only of generic use in addressing the problem of the far-field behavior of radionuclides. They are primarily useful in assessing potential far-field sites for the retardation of radionuclides only. Both favorable and unfavorable sites for potential radionuclide retardation can thus be assessed.

Retardation factors have heen assessed by the National Academy of Science - National Research Council (NAS-NRC) (NRC 1983), and R values have been given for many rocks for different conditions. These tabulated data indicate that the $R$ value may vary from 1 to 20,000 , with a range of 1 to 1.5 orders of magnitude common. For clay, soil, and shale, $\mathrm{R}$ values are greater than 1 for all radionuclides of interest except iodine $(R=1)$. Further, except for technetium (range, 1 to 20 ; best value $=5$ ), the preferred values for the other radionuclides range from 50 to 5000 . No values are given for sandstone or carbonate rocks. Values ranging from 5 to 1000 (best values), except for iodine $(R=1)$, are given for radionuclides in the rocks surrounding a salt repository; however, most $R$ 


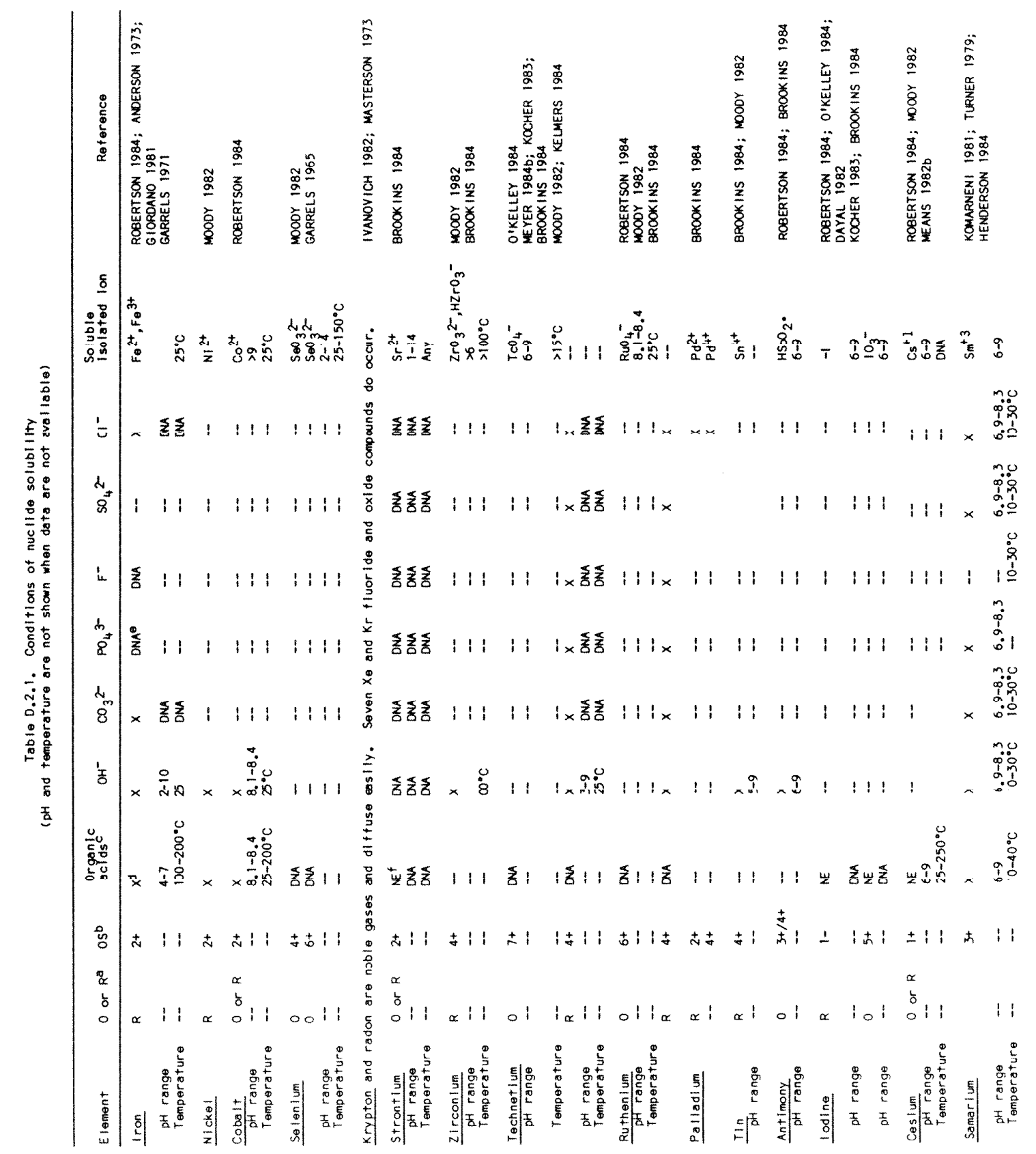




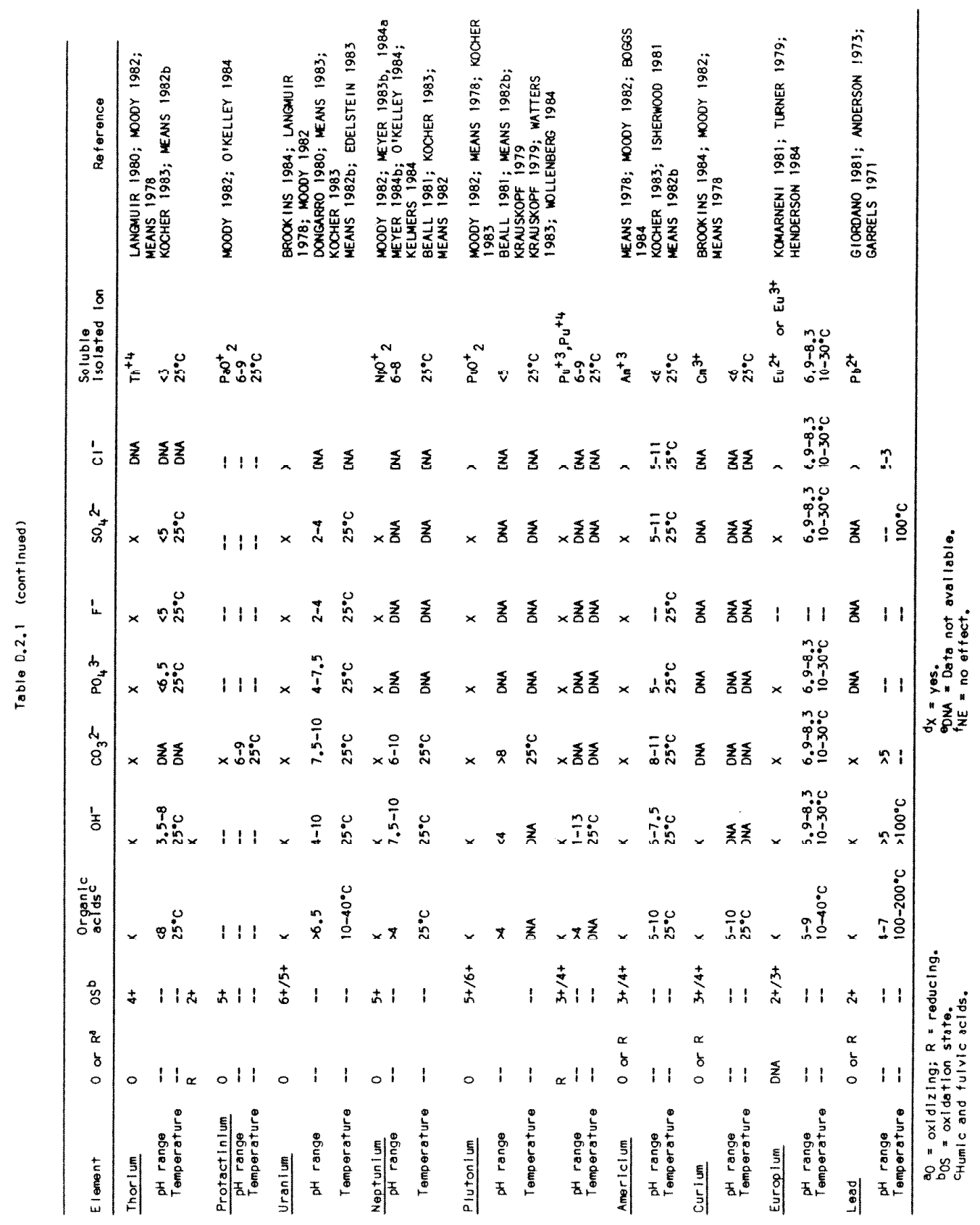




\section{$p \cdot 1^{27} \quad 0-64$}

Table D.2.1. Conditions of nucllde solubllity

(pH and temperature are not shown when data are not ava lable)

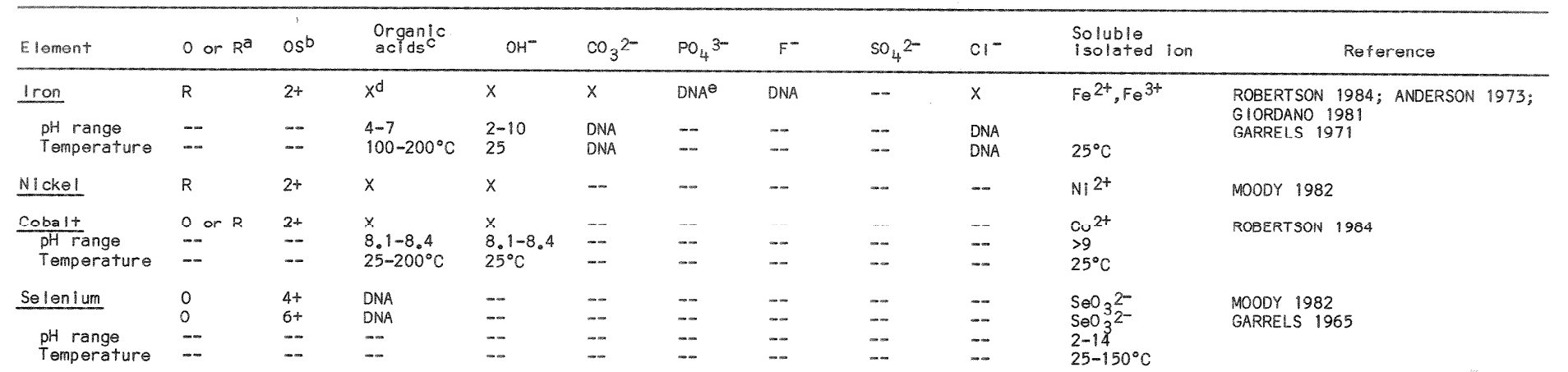

Krypton and radon are noble gases and diffuse easlly. Seven $\mathrm{Ke}$ and $\mathrm{Kr}$ fluorlde and oxide compounds do occur.

\begin{tabular}{|c|c|c|c|c|c|c|c|c|c|c|c|}
\hline$\frac{\text { Strontium }}{\text { pH range }}$ & $\begin{array}{l}0 \text { or } R \\
-\infty\end{array}$ & $\begin{array}{l}2+ \\
-\infty\end{array}$ & $\begin{array}{l}\text { NEf } \\
\text { DNA } \\
\text { DNA }\end{array}$ & $\begin{array}{l}\text { DNA } \\
\text { DNA } \\
\text { DNA }\end{array}$ & $\begin{array}{l}\text { DNA } \\
\text { DNA } \\
\text { DNA }\end{array}$ & $\begin{array}{l}\text { DNA } \\
\text { DNA } \\
\text { DNA }\end{array}$ & $\begin{array}{l}\text { DNA } \\
\text { DNA } \\
\text { DNA }\end{array}$ & $\begin{array}{l}\text { DNA } \\
\text { DNA } \\
\text { DNA }\end{array}$ & $\begin{array}{l}\text { DNA } \\
\text { DNA } \\
\text { DNA }\end{array}$ & $\begin{array}{l}S r^{2+} \\
1-14 \\
\text { Any }\end{array}$ & BROOKINS 1984 \\
\hline$\frac{\text { Zirconlum }}{\text { ph range }}$ & $\begin{array}{l}R \\
-\infty \\
-\infty\end{array}$ & $\frac{4+}{-\infty}$ & $-\infty$ & $00^{\circ} \mathrm{C}$ & -- & - & $+\infty$ & - & $-\infty$ & $\begin{array}{l}\mathrm{ZrO}_{3}{ }^{2-}, \mathrm{HZrO}_{3}- \\
>6 \\
>100^{\circ} \mathrm{C}\end{array}$ & $\begin{array}{l}\text { MOODY } 1982 \\
\text { BROOK INS } 1984\end{array}$ \\
\hline$\frac{\text { Technetium }}{\mathrm{pH} \text { range }}$ & 0 & $\begin{array}{l}7+ \\
-\infty\end{array}$ & DNA & -- & - & - & - & $-\infty$ & -- & $\mathrm{TCO}_{6-9}^{--}$ & $\begin{array}{l}\text { O'KELLEY } 1984 \\
\text { MEYER } 1984 b ; \text { KOCHER 1983; } \\
\text { BROOKINS } 1984\end{array}$ \\
\hline $\begin{array}{l}\text { Temperature } \\
\text { ph range } \\
\text { Temperature }\end{array}$ & $\begin{array}{l}-\infty \\
-\infty\end{array}$ & $\overrightarrow{4+\infty}+$ & $\begin{array}{l}- \\
\text { DNA } \\
--\end{array}$ & $\begin{array}{l}x \\
3-9 \\
25^{\circ} \mathrm{C}\end{array}$ & $\begin{array}{l}x \\
x \\
\text { DNA } \\
\text { DNA }\end{array}$ & $\begin{array}{l}-\infty \\
\bar{D} \\
\text { DNA } \\
\text { DNA }\end{array}$ & $\begin{array}{l}-\bar{x} \\
\text { DNA } \\
\text { DNA }\end{array}$ & $\begin{array}{l}-- \\
\overline{D N A} \\
\text { DNA }\end{array}$ & $\begin{array}{l}\bar{x} \\
\text { DNA } \\
\text { DNA }\end{array}$ & $\begin{array}{l}>15^{\circ} \mathrm{C} \\
- \\
-\end{array}$ & MOODY 1982; KELMERS 1984 \\
\hline$\frac{\text { Ruthenlum }}{\text { pH range }}$ & $\begin{array}{l}0 \\
R \\
R\end{array}$ & $\frac{6+}{4+}$ & $\underset{-\infty}{\text { DNA }}$ & $\frac{m}{x}-\infty$ & $-\infty$ & $\bar{x}$ & $\bar{x}$ & $-\infty$ & $\overline{-\infty}$ & $\begin{array}{l}\mathrm{RuO}_{4}- \\
8.1-8.4 \\
25^{\circ} \mathrm{C} \\
--\end{array}$ & $\begin{array}{l}\text { ROBERTSON } 1984 \\
\text { MOODY } 1982 \\
\text { BROOKINS } 1984\end{array}$ \\
\hline Palladium & $\begin{array}{l}R \\
--\end{array}$ & $\begin{array}{l}2+ \\
4+\end{array}$ & - & $-\infty$ & -- & $-\infty$ & - & & $\begin{array}{l}x \\
x\end{array}$ & $\mathrm{Pd}^{2+}$ & BROOKINS 1984 \\
\hline$\frac{\operatorname{Tin}}{\mathrm{pH}}$ range & $\stackrel{R}{-}$ & $4+$ & $-\cdots$ & $\begin{array}{l}x \\
5-9\end{array}$ & $-\infty$ & - & - & & - & $\mathrm{Sn}_{-\infty}^{4+}$ & BROOKINS 1984; MOODY 1982 \\
\hline$\frac{\text { Antimuny }}{\mathrm{pH} \text { range }}$ & $\stackrel{\circ}{--}$ & $3+4$ & -- & $\begin{array}{l}x \\
6-9\end{array}$ & -- & $-\infty$ & $-\infty$ & -- & - & $\underset{6-9}{\mathrm{HSDU}_{2}}$ & ROBERTSON 1984; BROOKINS 1984 \\
\hline lodine & R & $1-$ & NE & - & - & $\rightarrow$ & - & - & - & -1 & $\begin{array}{l}\text { ROBERTSON 1984; OKELLEY 1984; } \\
\text { DAYAL } 1982\end{array}$ \\
\hline $\begin{array}{l}\mathrm{pH} \text { range } \\
\mathrm{pH} \text { range }\end{array}$ & $0^{-\infty}$ & $5+$ & $\begin{array}{l}\text { DNA } \\
\text { NE } \\
\text { DNA }\end{array}$ & -- & $-\infty$ & $-\infty$ & $-\infty$ & $-\infty$ & $-\infty$ & $\begin{array}{l}6-9 \\
103= \\
6-9\end{array}$ & KOCHER 1983; BROOKINS 1984 \\
\hline $\begin{array}{l}\text { Cesium } \\
\text { phrange } \\
\text { Temperature }\end{array}$ & $\operatorname{O}_{-\infty}$ or $R$ & $\frac{1+}{-\infty}$ & $\begin{array}{l}\mathrm{NE} \\
6-9 \\
25-250^{\circ} \mathrm{C}\end{array}$ & $-\infty$ & $-\infty$ & $-\infty$ & $-\infty$ & $-\infty$ & $-\infty$ & $\begin{array}{l}\mathrm{Cs}^{+1} \\
6-9 \\
\text { DNA }\end{array}$ & $\begin{array}{l}\text { ROBERTSON } 1084 \text {; MOOOY } 1982 \\
\text { MEANS } 1982 \mathrm{~b}\end{array}$ \\
\hline Samarlum & & $3+$ & $x$ & $x$ & $x$ & $x$ & $-\infty$ & $x$ & $x$ & $\mathrm{Sm}^{+3}$ & $\begin{array}{l}\text { KOMARNEN 1981; TURNER 1979; } \\
\text { HENDERSON 1984: }\end{array}$ \\
\hline PH range & $-\infty$ & $-\infty$ & $\begin{array}{l}5-9 \\
10-40^{\circ} \mathrm{C}\end{array}$ & $\begin{array}{l}6.9-8.3 \\
10-30^{\circ} \mathrm{C}\end{array}$ & $\begin{array}{l}6.9-8.3 \\
10-30^{\circ} \mathrm{C}\end{array}$ & $6.9-8,3$ & $\overline{10}-30^{\circ} \mathrm{C}$ & $\begin{array}{l}6,9-8,3 \\
10-30^{\circ} \mathrm{C}\end{array}$ & $\begin{array}{l}6.9-8.3 \\
10-30^{\circ} \mathrm{C}\end{array}$ & $6-9$ & \\
\hline
\end{tabular}


Table 0.2.1 (continued)

\begin{tabular}{|c|c|c|c|c|c|c|c|c|c|c|c|}
\hline 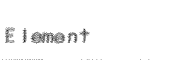 & $\mathrm{O}$ or $\mathrm{R}^{\mathrm{a}}$ & $o^{b}$ & $\begin{array}{l}\text { Organtc } \\
\text { aclis }\end{array}$ & $\mathrm{OH}^{-}$ & $\mathrm{CO}_{3}^{2-}$ & $\mathrm{PO}_{4}{ }^{3-}$ & $F^{-\infty}$ & $\mathrm{SO}_{4}{ }^{2-}$ & $\mathrm{Cl}^{-}$ & $\begin{array}{l}\text { Soluble } \\
\text { isolated lon }\end{array}$ & Reference \\
\hline Thor lun & 0 & $4+$ & $x$ & $x$ & $x$ & $x$ & $x$ & $x$ & DNA & $T h^{2+4}$ & $\begin{array}{l}\text { LANGMUIR 1980; MOOOY } 1982 \text {; } \\
\text { MEANS } 1978\end{array}$ \\
\hline $\begin{array}{l}\text { pht range } \\
\text { Tomperature }\end{array}$ & $-\infty$ & $-\infty$ & $\begin{array}{l}<8 \\
25^{\circ} \mathrm{C}\end{array}$ & $\begin{array}{l}3.5-8 \\
25^{\circ} \mathrm{C} \\
\times\end{array}$ & $\begin{array}{l}\text { DNA } \\
\text { DNA }\end{array}$ & $\begin{array}{l}<6.5 \\
25^{\circ} \mathrm{C}\end{array}$ & $\begin{array}{l}<5 \\
25^{\circ} \mathrm{C}\end{array}$ & $\begin{array}{l}<5 \\
25^{\circ} \mathrm{C}\end{array}$ & $\begin{array}{l}\text { DNA } \\
\text { DNA }\end{array}$ & $\begin{array}{l}<3 \\
25^{\circ} \mathrm{C}\end{array}$ & KOCHER 1983; MEANS 1982b \\
\hline$\frac{\text { Protactininium }}{\text { ph range }}$ & $\begin{array}{l}0 \\
-\infty\end{array}$ & $=$ & $-\infty$ & $=-$ & $\begin{array}{l}x \\
6-9 \\
25^{\circ} \mathrm{C}\end{array}$ & - & $-\infty$ & $-\infty$ & $-\infty$ & $\begin{array}{l}\mathrm{PaO}^{+} \\
6-9 \\
25^{\circ} \mathrm{C}\end{array}$ & MOODY 1982; O'KELLEY 1984 \\
\hline Uranlum & 0 & $6+/ 5+$ & $x$ & $x$ & $x$ & $x$ & $x$ & $x$ & $x$ & & $\begin{array}{l}\text { BROOK INS 1984; LANGMU IR } \\
\text { 1978; MOODY } 1982\end{array}$ \\
\hline $\mathrm{pH}$ range & -- & $-\infty$ & $>6.5$ & $4-10$ & $7.5-10$ & $4-7.5$ & $2-4$ & $2-4$ & DNA & & $\begin{array}{l}\text { DONGARRO 1980; MEANS 1983; } \\
\text { KOCHER } 1983\end{array}$ \\
\hline Temperature & $-\infty$ & $-\infty$ & $10-40^{\circ} \mathrm{C}$ & $25^{\circ} \mathrm{C}$ & $25^{\circ} \mathrm{C}$ & $25^{\circ} \mathrm{C}$ & $25^{\circ} \mathrm{C}$ & $25^{\circ} \mathrm{C}$ & DNA & & MEANS 1982b; EDELSTEIN 1983 \\
\hline$\frac{\text { Neptunium }}{\mathrm{pH} \text { range }}$ & 0 & $5+$ & $\begin{array}{l}x \\
>4\end{array}$ & $\begin{array}{l}x \\
7.5-10\end{array}$ & $\begin{array}{l}x \\
6-10\end{array}$ & $\begin{array}{l}x \\
\text { DNA }\end{array}$ & $\begin{array}{l}X \\
\text { DNA }\end{array}$ & $\begin{array}{l}X \\
\text { DNA }\end{array}$ & DNA & $\mathrm{NpO}_{6-8}^{+} 2$ & $\begin{array}{l}\text { MOODY 1982; MEYER 1983b, } 1984 a \\
\text { MEYER 1984b; O'KELLEY 1984; } \\
\text { KELMERS 1984 }\end{array}$ \\
\hline Temperature & $-\infty$ & $-\infty$ & $25^{\circ} \mathrm{C}$ & $25^{\circ} \mathrm{C}$ & $25^{\circ} \mathrm{C}$ & DNA & DNA & DNA & DNA & $25^{\circ} \mathrm{C}$ & $\begin{array}{l}\text { BEALL } 1981 ; \text { KOCHER } 1983 \\
\text { MEANS } 1982\end{array}$ \\
\hline Plutonlum & 0 & $5+16+$ & $x$ & $x$ & $x$ & $x$ & $x$ & $x$ & $x$ & $\mathrm{PuO}_{2}^{+}$ & $\begin{array}{l}\text { MOODY 1982; MEANS 1978; KOCHER } \\
1983\end{array}$ \\
\hline pH range & - & & $>A$ & $<4$ & $>8$ & ONA & DNA & DNA & DNA & $<5$ & $\begin{array}{l}\text { BEALL 1981; MEANS 1982b; } \\
\text { KRAUSKOPF } 1979\end{array}$ \\
\hline Temperature & -- & $-\infty$ & DNA & DNA & $25^{\circ} \mathrm{C}$ & DNA & DNA & DNA & DNA & $25^{\circ} \mathrm{C}$ & $\begin{array}{l}\text { KRAUSKOPF 1979; WATTERS } \\
\text { 1983; WOLLENBERG } 1984\end{array}$ \\
\hline $\begin{array}{l}\text { pH range } \\
\text { Temperature }\end{array}$ & $\stackrel{R}{-\infty}$ & $\begin{array}{l}3+/ 4+ \\
-\infty\end{array}$ & $\begin{array}{l}x \\
>4 \\
\text { DNA }\end{array}$ & $\begin{array}{l}x \\
1-13 \\
25^{\circ} \mathrm{C}\end{array}$ & $\begin{array}{l}X \\
\text { DNA } \\
\text { DNA }\end{array}$ & $\begin{array}{l}x \\
\text { DNA } \\
\text { DNA }\end{array}$ & $\begin{array}{l}x \\
\text { DNA } \\
\text { DNA }\end{array}$ & $\begin{array}{l}x \\
\text { DNA } \\
\text { DNA }\end{array}$ & $\begin{array}{l}X \\
\text { DNA } \\
\text { DNA }\end{array}$ & $\begin{array}{l}\mathrm{Pu}^{+3}, \mathrm{Pu}+4 \\
6-9 \\
25^{\circ} \mathrm{C}\end{array}$ & \\
\hline Americlum & 0 or $R$ & $3+/ 4+$ & $x$ & $x$ & $x$ & $x$ & $x$ & $x$ & $x$ & $\mathrm{Am}^{+3}$ & $\begin{array}{l}\text { MEANS 1978; MOODY 1982; BOGGS } \\
1984\end{array}$ \\
\hline $\begin{array}{l}\text { pH range } \\
\text { Temperature }\end{array}$ & - & $-\infty$ & $\begin{array}{l}6-10 \\
25^{\circ} \mathrm{C}\end{array}$ & $\begin{array}{l}6-7.5 \\
25^{\circ} \mathrm{C}\end{array}$ & $\begin{array}{l}8-11 \\
25^{\circ} \mathrm{C}\end{array}$ & $\begin{array}{l}5- \\
25^{\circ} \mathrm{C}\end{array}$ & $25^{\circ} \mathrm{C}$ & $\begin{array}{l}5-11 \\
25^{\circ} \mathrm{C}\end{array}$ & $\begin{array}{l}5-11 \\
25^{\circ} \mathrm{C}\end{array}$ & $\begin{array}{l}<6 \\
25^{\circ} \mathrm{C}\end{array}$ & $\begin{array}{l}\text { KOCHER 1983; ISHERWOOD } 1981 \\
\text { MEANS 1982b }\end{array}$ \\
\hline Cur lum & 0 or $R$ & $3+/ 4+$ & $x$ & $x$ & DNA & DNA & DNA & DNA & DNA & $\mathrm{Cm}^{3+}$ & $\begin{array}{l}\text { BROOKINS 1984; MOODY 1982; } \\
\text { MEANS } 1978\end{array}$ \\
\hline $\begin{array}{l}\text { pH range } \\
\text { Temperature }\end{array}$ & - & $-\infty$ & $\begin{array}{l}6-10 \\
25^{\circ} \mathrm{C}\end{array}$ & $\begin{array}{l}\text { DNA } \\
\text { DNA }\end{array}$ & $\begin{array}{l}\text { DNA } \\
\text { DNA }\end{array}$ & $\begin{array}{l}\text { DNA } \\
\text { DNA }\end{array}$ & $\begin{array}{l}\text { DNA } \\
\text { DNA }\end{array}$ & $\begin{array}{l}\text { DNA } \\
\text { DNA }\end{array}$ & $\begin{array}{l}\text { DNA } \\
\text { DNA }\end{array}$ & $\begin{array}{l}<6 \\
25^{\circ} \mathrm{C}\end{array}$ & \\
\hline Europlum & DNA & $2+/ 3+$ & $x$ & $x$ & $x$ & $x$ & -- & $x$ & $x$ & $\mathrm{Eu}^{2+}$ or $\mathrm{Eu}^{3+}$ & $\begin{array}{l}\text { KOMARNEN 1981; TURNER 1979; } \\
\text { HENDERSON 1984; }\end{array}$ \\
\hline $\begin{array}{l}\mathrm{pH} \text { range } \\
\text { Temperature }\end{array}$ & $-\infty$ & $-\infty$ & $\begin{array}{l}6-9 \\
10-40^{\circ} \mathrm{C}\end{array}$ & $\begin{array}{l}6.9-8.3 \\
10-30^{\circ} \mathrm{C}\end{array}$ & $\begin{array}{l}6.9-8.3 \\
10-30^{\circ} \mathrm{C}\end{array}$ & $\begin{array}{l}6.9-8.3 \\
10-30^{\circ} \mathrm{C}\end{array}$ & $-\infty$ & $\begin{array}{l}5.9-8.3 \\
10-30^{\circ} \mathrm{C}\end{array}$ & $\begin{array}{l}6,9-8,3 \\
10-30^{\circ} \mathrm{C}\end{array}$ & $\begin{array}{l}6.9-8.3 \\
10-30^{\circ} \mathrm{C}\end{array}$ & \\
\hline Lead & 0 or $R$ & $2+$ & $x$ & $x$ & $x$ & DNA & DNA & DNA & $x$ & $\mathrm{~Pb}^{2+}$ & $\begin{array}{l}\text { GIORDANO 1981; ANDERSON 1973; } \\
\text { GARRELS 1971 }\end{array}$ \\
\hline $\begin{array}{l}\text { pH range } \\
\text { Temperature }\end{array}$ & $-\infty$ & $-\infty$ & $\begin{array}{l}4-7 \\
100-200^{\circ} \mathrm{C}\end{array}$ & $\begin{array}{l}>5 \\
>100^{\circ} \mathrm{C}\end{array}$ & $>5$ & $-\infty$ & $-m$ & $100^{\circ} \mathrm{C}$ & $5-3$ & & \\
\hline
\end{tabular}

$a_{0}=$ oxidizlng: $R=$ reducing.

boS = oxidation state.

$d x=$ yes

DNA = Data not avallable.

chumic and fulvic acids.

$N E=$ no effect. 


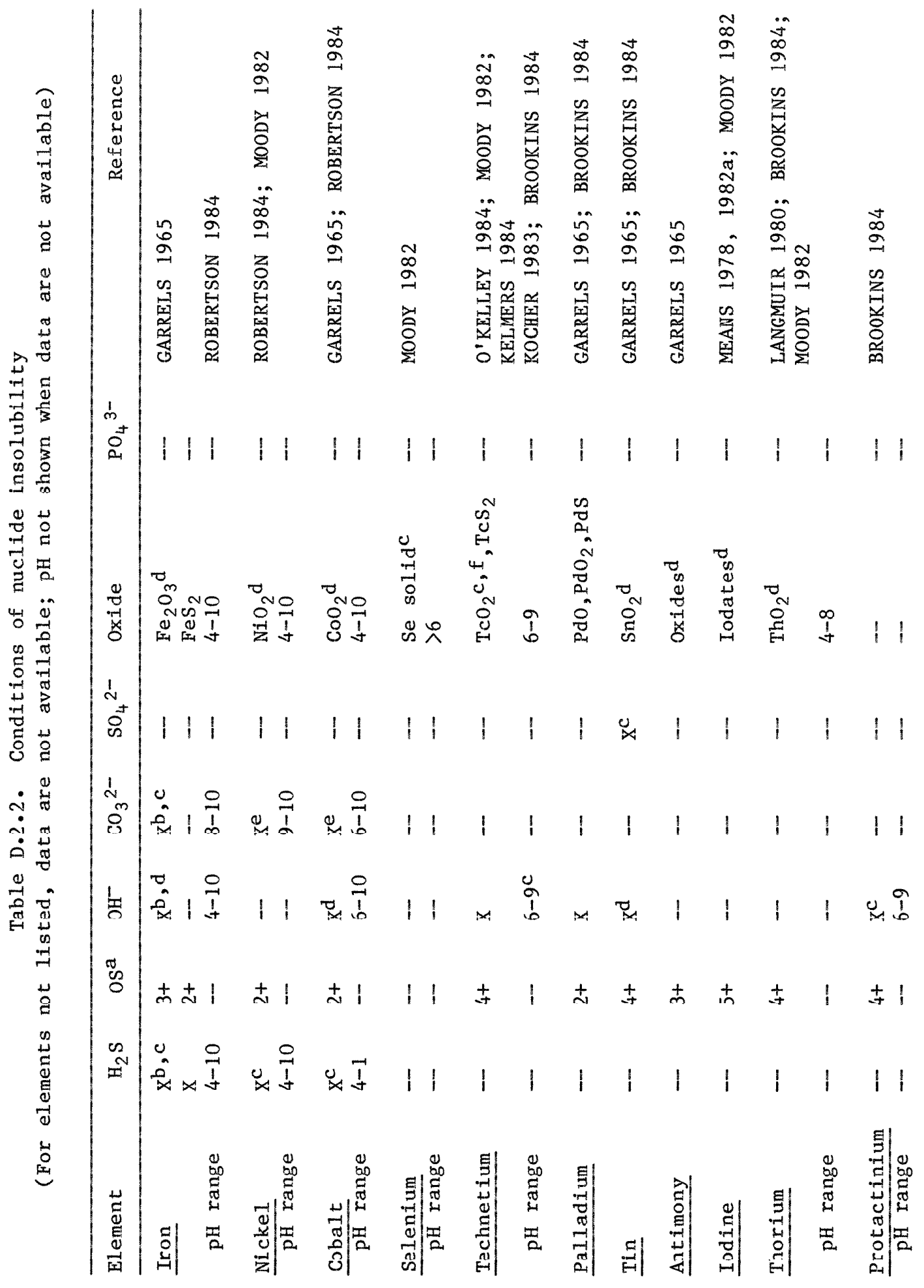




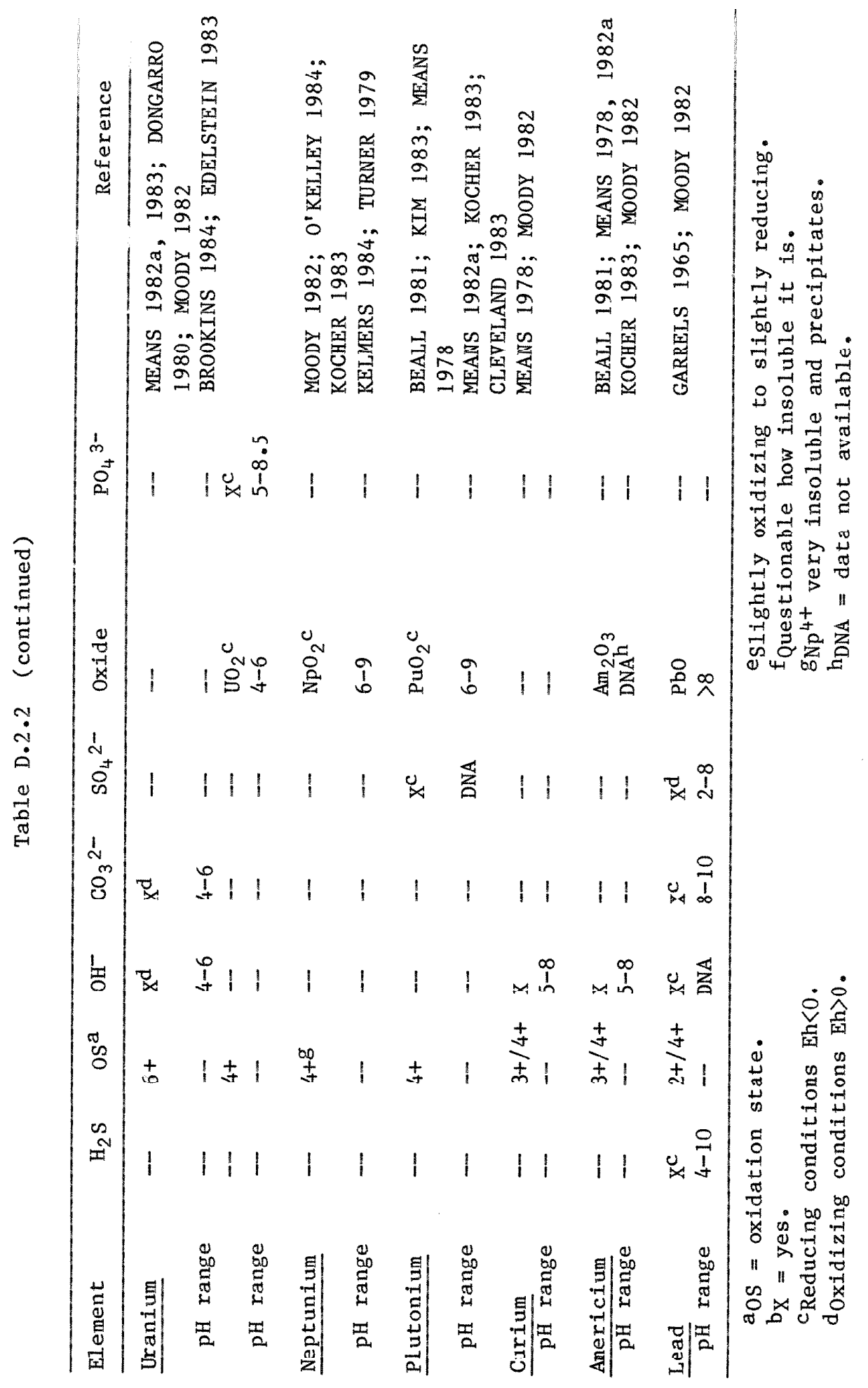


values are lower in the salt than the other rocks by a factor of 5 to 100. If the assumption is made that the values used for retardation in a salt system are applicable to anhydrock, and possibly to chloride-rich waters such as those encountered in some sandstones, then the NAS-NRC data (NRC 1983) suggest more internally consistent $R$ values for shale than for other sedimentary rock types. that:

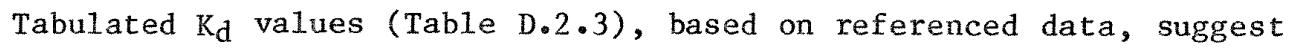

1. Radionuclides are usually strong1y sorbed onto clays and, to a lesser degree, onto oxides and hydroxides.

2. Smectites sorb radionuclides more effectively than does illite, which, in turn, sorbs radionuclides more effectively than does kaolinite.

3. Sorption onto clays is most favorable in the pH range 7 to 8.5 .

4. Minerals such as calcite, dolomite, and anhydrite have poor sorbing characteristics in comparison with clay minerals.

5. The presence of dissolved organic ligands decreases the ability of clays to sorb radionuclides.

6. Sorption of radionuclides onto clays is decreased in high-ionicstrength waters.

7. The higher the charge on the radionuclide, the greater the tendency for the radionuclide to sorb onto clays.

The ability of a rock to retard elements can be estimated in a relative fashion based on the $K d$ values of its constituent minerals because $\mathrm{K}_{\mathrm{d}}$ is the principal variable that controls retardation in the subject rocks. Clay minerals typically have $\mathrm{K}_{\mathrm{d}}$ values much greater than other minerals (Table D.2.3), while typical total porosity values among the subject rocks vary from only 1 to $10 \%$ (anhydrock $=1 \%$, shale $=3 \%$, sandstone $=8 \%$, carbonate rocks and chalk $=10 \%$; data from $\Delta$ ppendix $\mathrm{C}$ ). It is clear, therefore, that clay-rich rocks with relatively low porosity will have a great retardation ability and that rocks with low clay contents, even though they may have low porosity, will have little ability to retard elements.

The results also suggest that reducing groundwaters that are nearly neutral to slightly alkaline ( $\mathrm{pH} 7$ to 8 , low total-dissolved-solids concentrations, and low organic ligand concentrations) are best for retardation and that aquifers with high ion exchange capacities, particularly those with high clay contents, are best.

The effects of waste emplacement could be deleterious in the near and very-near fields with respect to radionuclide retardation. The radiation and thermal fields induced on the rocks may lead to dehydration, phase 


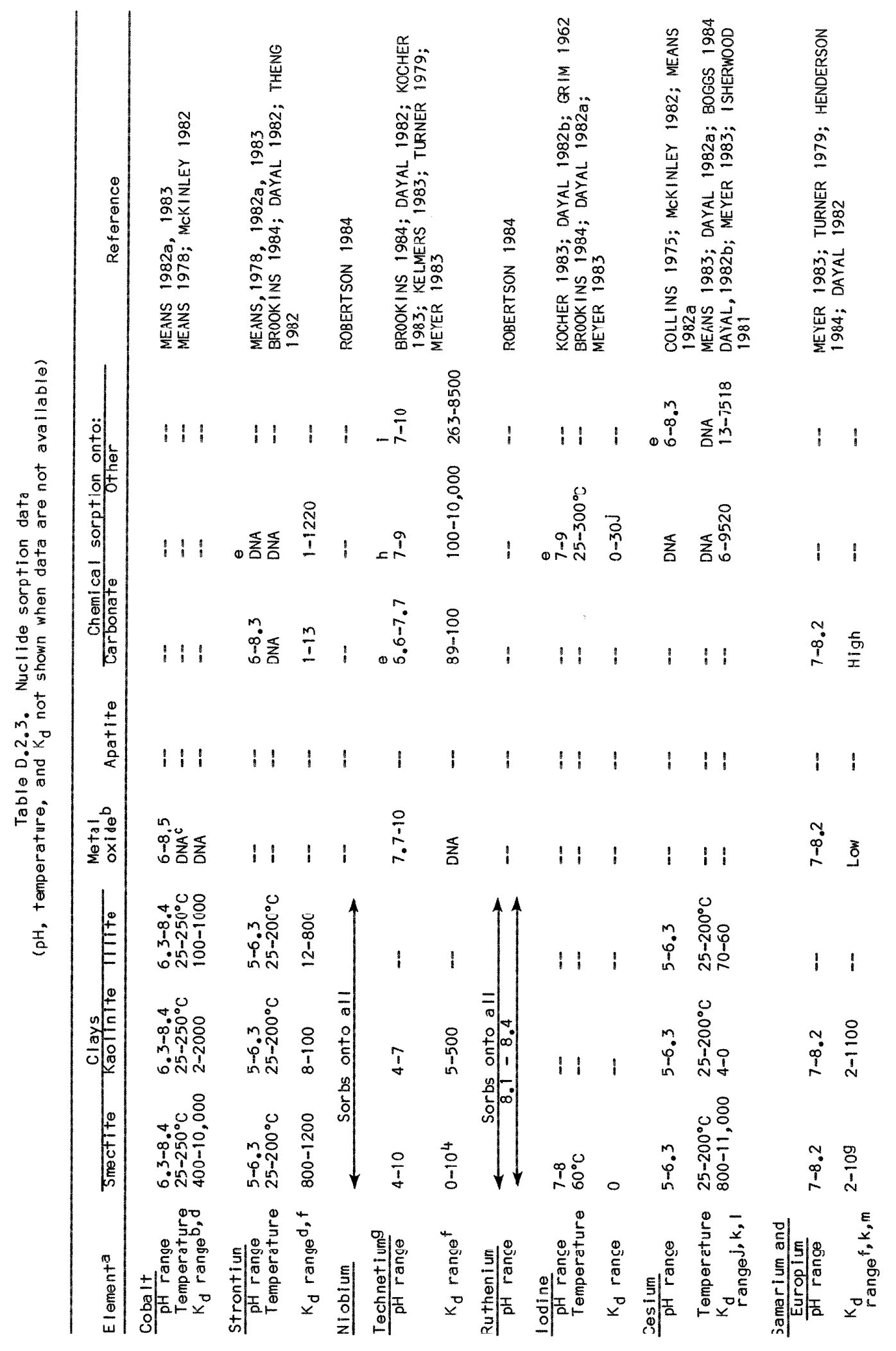




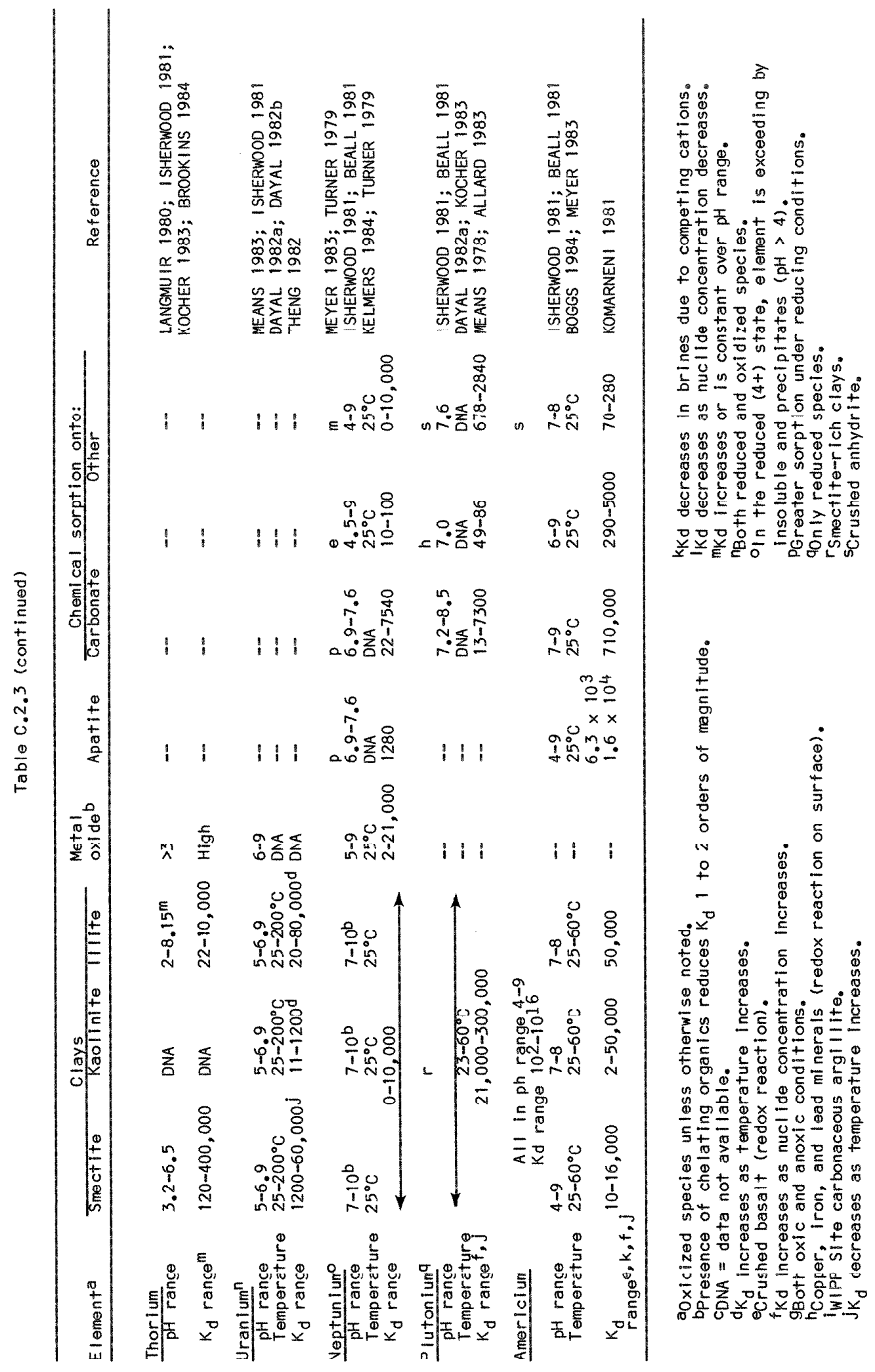


changes, and general degradation of clay minerals and organic phases, thereby reducing sorption. Maximum temperatures associated with wastes are not great enough, however, to degrade clays. Increased temperatures may also create conditions that lead to greater solubility and higher TDS contents in formational water. Such conditions, in turn, will result in lower sorption values on clays. Alternatively, the higher temperatures may cause additional small-scale fracturing, which would allow greater interaction between waters (and contained nuclides) and rock and, thus, increase the capacity of the rock to sorb. It must be emphasized that these effects of radiation and heat are largely unverified and will dominate only in the near field. 


\section{D.3 GEOCHEMISTRY OF FORMATIONAL WATERS}

\section{D.3.1 INTRODUCTION}

The chemical composition of a formational water is determined by the mineralogical, geochemical, and physical characteristics of the host rock, the chemistry of the water before it enters the host rock, and the characteristics of water flow within the host rock (CHERRY 1979; GRAF 1965).

Two easily discernible formational water types can be defined, based on the relative abundance of formational water in the host rock. The first of these comes from rocks (carbonate rocks, sandstones) in which significant amounts of water occur and from which enough water can realistically be obtained for analysis. The other type occurs in rocks (anhydrock, chalk, shale) with extremely low abundances of formational water. The compositions of formational waters from the high-water-content rocks (i.e., those from wich water can be extracted for chemical analysis) can be fairly well defined (MEANS 1982b, 1983; GIORDANO 1981; COLLINS 1975; CHERRY 1979; WHTTF 1963, 1965; CARPENTER 1969; FAITH 1983; CRAF 1966; KELLER 1983; MERINO 1975; SCHMTDT 1973). The compositions of formational waters in the low-water-content rocks are difficult to establish. In addition, formational waters can be divided into two types, deep and shallow, depending on their proximity to the surface of the earth and whether they are recharged by surface waters.

There are considerable compositional differences between the shallow and deep formational waters. While analytical data for the shallow groundwaters are abundant in the literature, those for deep groundwaters are not. Typically, the deep waters, which do not appreciably interact with fresher shallow waters, are very saline and may have TDS contents of we11 over 100,000 ppr. Tables 0.3 .1 and $D .3 .2$, respectively, contain representative analyses for shallow and deep groundwaters from different sedimentary rock types; references from which the data have beon taken are noted.

The shallow groundwaters typically represent a hydrologic system in which there is appreciable transport and lack of steady-state conditions between the water and rock. In contrast, the deep groundwaters, which may be connate, are older and often represent steady-state conditions. Because of these chemical distinctions, it is necessary to direct the following discussion toward only the data representative of deep formational waters, which are assumed to be representative of those that would occur at prospective repository depths. No analytical data are available for deep waters from chalk, but it can realistically be assumed that such waters would be similar to those from limestones and dolostones.

\section{D.3.2 DEEP WATERS}

In general, deep waters are anoxic (KOCHER 1983), have a neutral to moderately alkaline $\mathrm{pH}$ of 7 to 10 (KOCHER 1983), and have high chloride concencs (WHIl' 1903). Kecent work (LINDBERG 1984) indicates that redox measurements made on sha1low, young groundwaters are subject to question. 


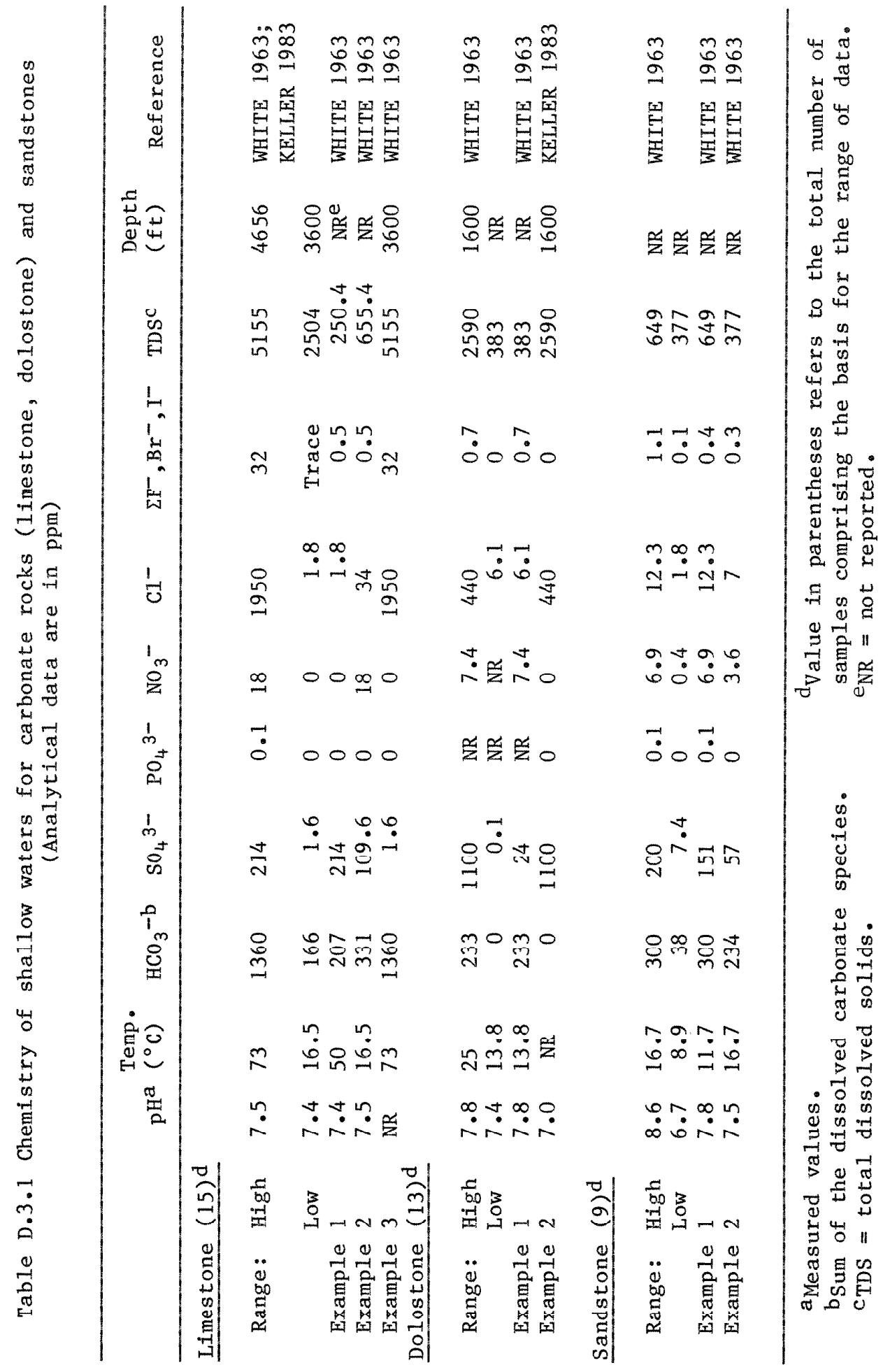




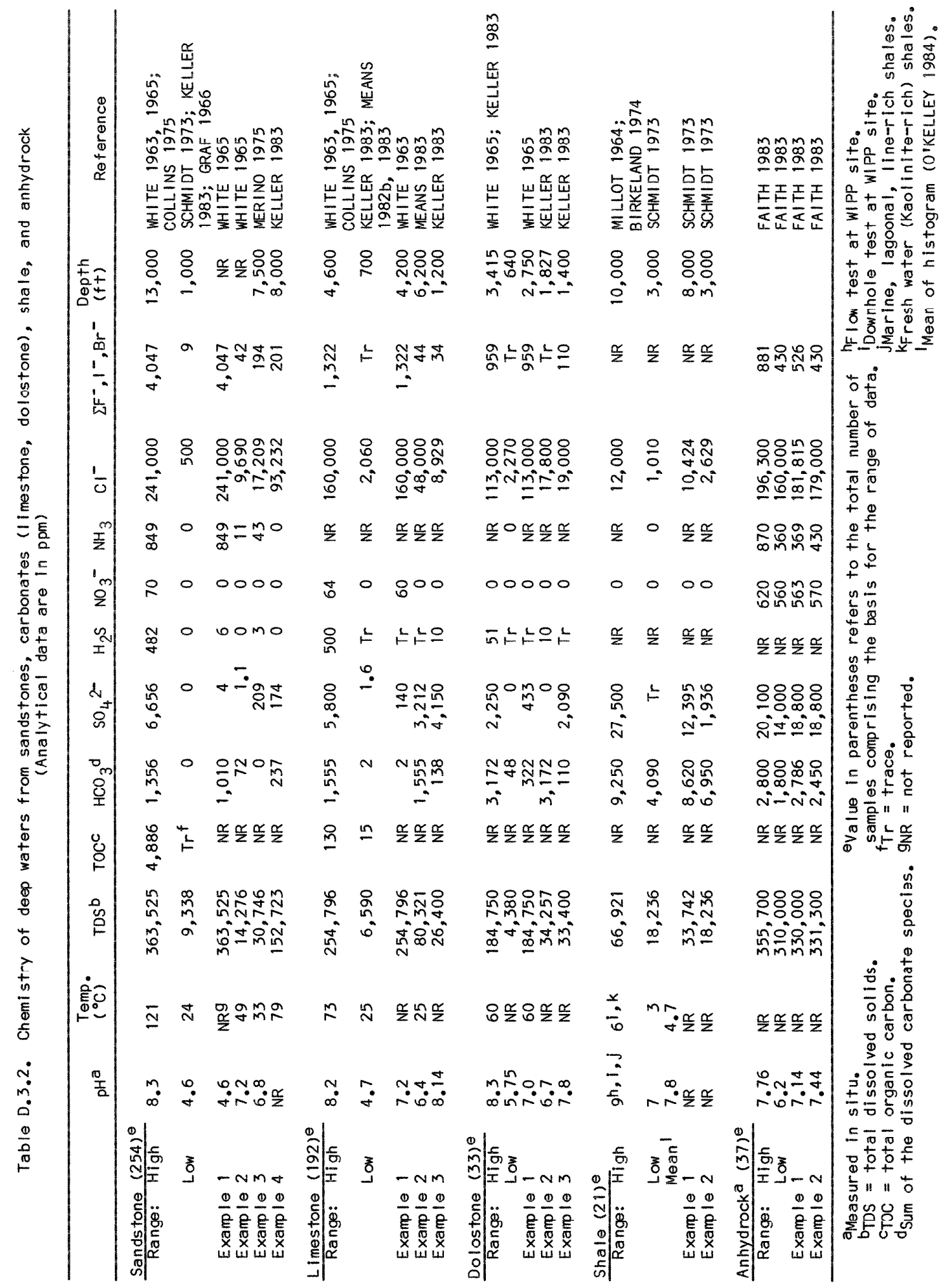


Similar observations may apply to deep waters. The data on deep waters, which are shown in Table $\mathrm{D} .3 .2$, indicate the following:

1. Deep waters from sandstones and carbonate rocks have highly variable chemistries. Shale and anhydrock waters are less variable but are, nevertheless, locally complex.

2. Anhydrock brines have very high TDS contents (dominated by chloride and sodium, with substantial amounts of sulfate and smaller, but significant amounts of magnesium and carbonate). The $\mathrm{pH}$ values range from 6.0 to 7.3 , averaging near 7 . The potential for complex formation is very high, especially with chloride.

3. Marine shales contain deep waters with $\mathrm{pH}$ levels of 7 to 9 and high concentrations of dissolved $\mathrm{HCO}_{3}{ }^{-}$. The TDS content is variable but averages abuul 30,000 ppra, which is lower than that for most other subject rocks. Dissolved carbonate is substantial, whereas chloride content is relatively low compared with the other rocks.

4. Freshwater shales commonly contain deep waters with $\mathrm{pH}$ levels of 3 to 8 and low TDS and sulfate contents.

5. There is a fairly consistent relationship between depth and water composition for each rock type. The deeper waters, which in some cases are from depths considerably greater than prospective repository horizons, are more saline than are shallow waters; this is especially well shown by chloride and TDS contents. The data are not abundant enough, however, to allow strict characterization of only those waters from the 300- to 1000-m-depth range.

6. Although radiolysis of dissolved gases may have a great effect on very-near-field geochemistry, there are very few data on the presence and nature of dissolved gases in deep waters.

\section{D.3.3 COMPARISON OF WATERS}

Anhydrock brines contain the highest average TDS contents of any of the waters from the five rock types considered. They have very high concentrations of total dissolved chloride, with appreciable amounts of sulfate and some $\mathrm{HCO}_{3}{ }^{-}$. In addition, some of the brines are slightly more acidic ( $\mathrm{pH} 6$ to 7 ) than are other waters.

The carbonate rocks, limestone and dolostone, also have high TDS contents, with very high average amounts of total dissolved chloride and low to moderate amounts of total dissolved $\mathrm{HCO}_{3}{ }^{-}$and sulfate. The $\mathrm{pH}$, which is commonly, but not always, buffered in such rocks to a value near 8 , varies from less than 5 to 8 . 
Waters from sandstones tend to be extremely varied in composition, presumably in large part because of the nature of their cementing agents. The TDS contents vary from less than 10,000 to $360,000 \mathrm{ppm}$, with the high TDS values proportionate to high total dissolved chloride.

Waters from shales possess moderate TDS contents, averaging about $30,000 \mathrm{ppm}$, and fairly low to low-moderate concentrations of total dissolved chloride (i.e., lower than in other rocks). Both sulfate and $\mathrm{HCO}_{3}{ }^{-}$tend to be slightly higher in these waters than in the others under consideration, but the $\mathrm{pH}$ typically ranges from 7 to 9 . 


\section{D.4 PETROLOGY AND GEOCHEMISTRY OF THE MAJOR ROCK TYPES}

\section{D.4.1 INTRODUCTION}

The previous discussion has concentrated on the formational waters that occur in the subject rock types. Of equal importance in controlling radionuclide mobility are the mineralogic and chemical compositions of the rocks. In deep hydrologic systems, the composition of the formational water is controlled by many factors, including the mineralogy of the associated rock, the composition of the water prior to its contact with the rock, and rate of flow. In addition, the mineralogic composition of the rock is a key factor in deternining the mobility of radionuclides through retardation processes such as sorption. This section is, therefore, devoted to a discussion of the composition of the rock types.

\section{D.4.2 PETROLOGY}

The five major rock types being considered for high-level radioactive waste disposal are compositionally highly variable both in their sedimentary petrolngy and in their genchemistry. To facilitate discussion of the sedimentary petrology of these rock types, three of the major 1ithological groups have been subdivided into a number of subgroups. Anhydrock and chalk have not been subdivided. It is recognized that gradations between subgroups and major lithological groups exist. For the purposes of this evaluation, however, discussion is directed only at the major 1ithological groups and subgroups as defined by a restricted range of mineralogical and geochemical criteria (PETTIJOHN 1975; BLATT 1980, 1982). The subgroups for the rock types are:

- Sandstone subgroups are defined by the proportions of quartz, feldspar, lithic grains, and clay (GARRELS 1971; PETTIJOHN 1963; ROGERS 1950; POTTER 1978; YERINO 1984; TUCKER 1982; TUREKIAN 1977; WEDEPOHL 1969; NELSON 1977). The subgroups are: quartz arenite, lithic arenite, arkose, and graywacke.

- Carbonate rock subgroups are defined by their mineralogy (GARRELS 1971; CARPENTER 1969; PETTIJOHN 1975; BLATT 1980; WEDEPOHL 1969; POTTER 1982). These subgroups are limestone and dolostone.

- Shale subgroups are defined by the presence or absence of organic and carbonate rock constituents (GARRET.S 1971; McKTNT.FY 1982; PETTIJOHN 1975; BLATT 1980, 1982; WEDEPOHL 1969; POTTER 1982; SHAW 1965; GIPSON 1966; MANHEIM 1969; HARRISON 1982; BONNE 1982; ARMANDS 1973; VINE 1970; CAMPBELL 1965). These subgroups are organtc shale, marl, and normal shale.

The features of sedimentary rocks that have primary control over the movement of water and radionuclides include:

- Mineralogic composition of detrital grains. This factor determines, in part, the chemistry of the formational water. Such is especially crue in deep groundwacers where there is an extended period of contact and interaction between the detrital grains and interstitial 
water, thus approaching steady-state conditions. In addition, the detrital grains help determine the cation exchange capacity (CEC) of the rock.

- Cement abundance and composition. The nature of the cement that holds the detrital grains together has an influence similar to that imposed by the detrital grains. In some cases, the cement may be more important than the grains. Many detrital grains represent material that has survived long periods of weathering and erosion and therefore is relatively unreactive. In contrast, cements may have been deposited from an aqueous solution and have not been exposed to weathering. The solubility of sandstones is, in large part, determined by the nature of cementing agents present in the rock. In general, the high-calcite-cemented sandstones may be more soluble than argillaceous sandstones. Quartz-cemented sandstones are the least soluble of the group. When the cement starts to dissolve, the sandstone is weakened and triable. Pressure solution effects tend to reduce rock porosity and, usually, permeability and hydraulic conductivity as well. These effects are most common when clay mineral films surround quartz grains; henre, they are most common in argillaceous sandstones. Pressure solution effects are not restricted to argillaceous sandstones, however, but may also occur in other types of sandstones. Pressure solution effects may occur in sandstones without clay mineral cement (NELSON 1977); however, they are rare and are usually restricted to impure sandstones with a high content of oxyhydroxide cement.

The abundance of cement in sandstones is difficult to quantify because of the wide variability of both detrital and authigenic constituents. Low-cement sandstones include quartz arenites and some lithic arenites, and these rocks typically exhibit rather high permeabilities. Clay-rich sandstones, such as arkose and graywacke, are less permeable. Carbonate rock cements, which are common in graywacke and some arkoses, are frequently present in moderate abundance in lithic arenites and even in some quartz arenites as well. In sandstone uranium deposits, for example, rock permeability decreases both with increasing argillaceous and carbonate rock cement content, although some of the carbonate rock cement is younger than the clay minerals.

- Porosity, permeability, and fracture density. These parameters are primary factors in controlling the movement of water through the rock. The porosity and permeability can be determined by the nature of the detrital grains and the cement; for instance, the shape of the grains and the composition of the cement are important. Fractures represent the means by which water moves through rocks that have little intergranular permeability and are very significant in controlling water movement in nondetrital rocks.

The bulk mineralogy of the five rock types and subgroups is summarized in Tables D.4.1 through D.4.4. The nature of the cements is also noted, where appropriace. The rollowing poincs are important to note: 


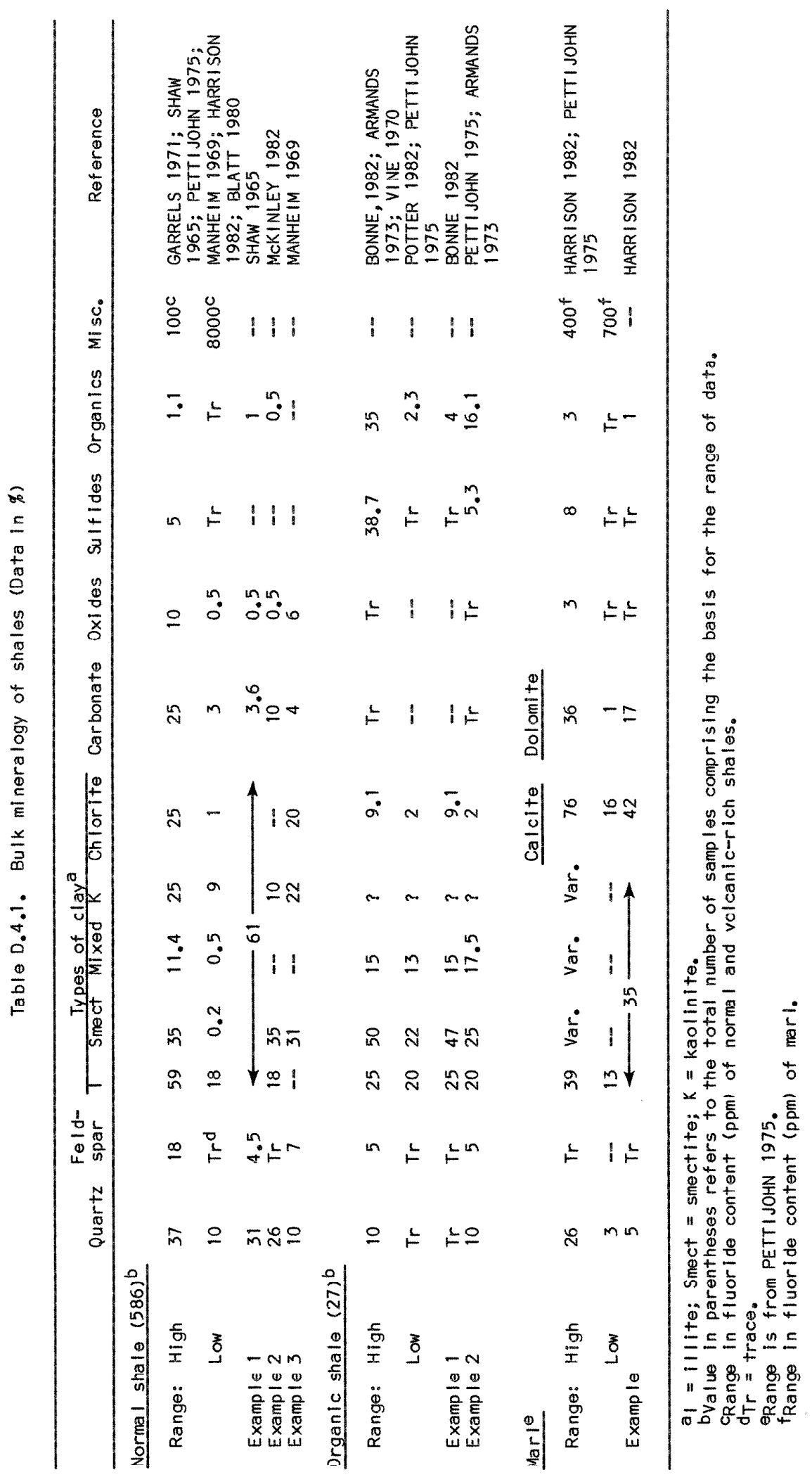




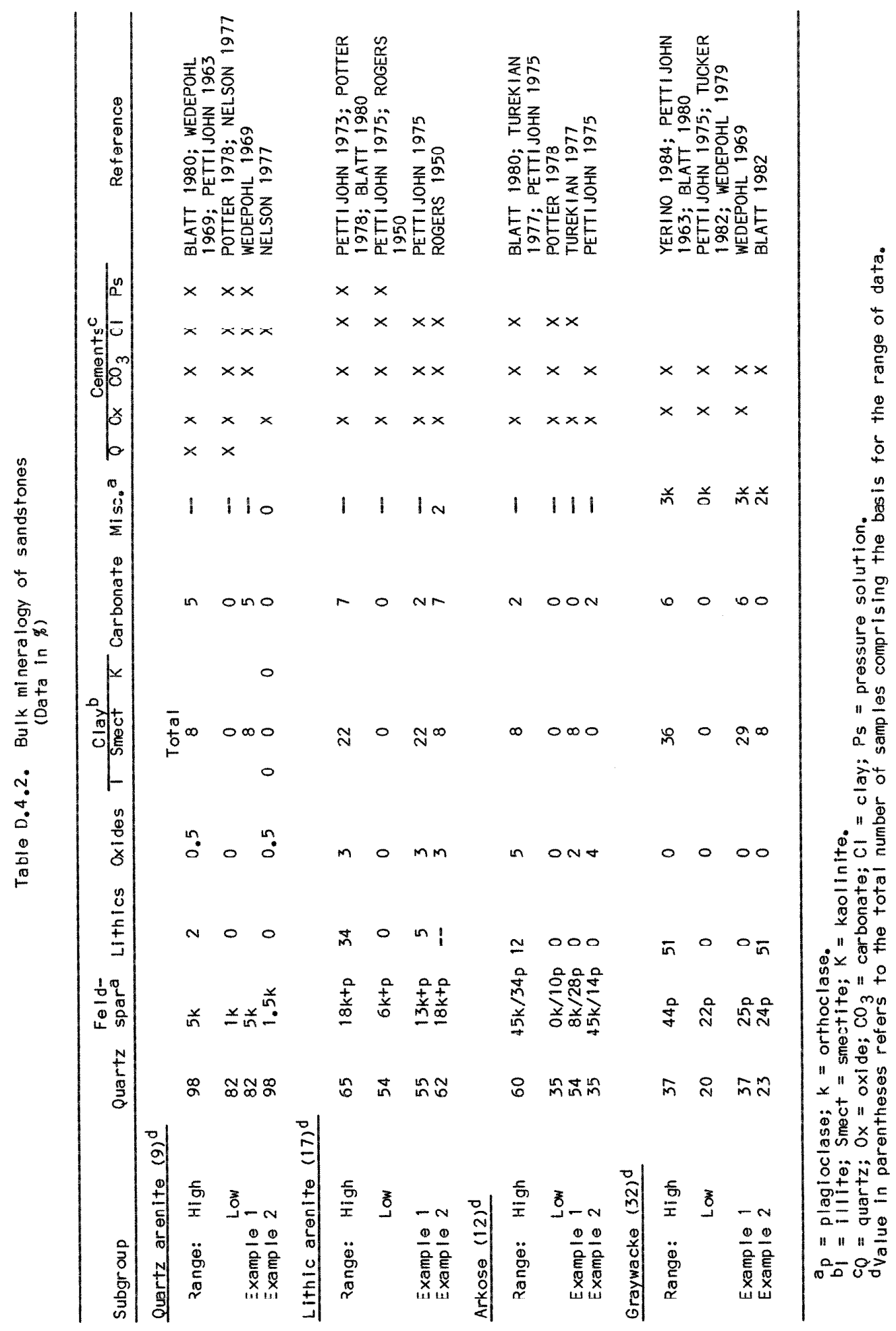




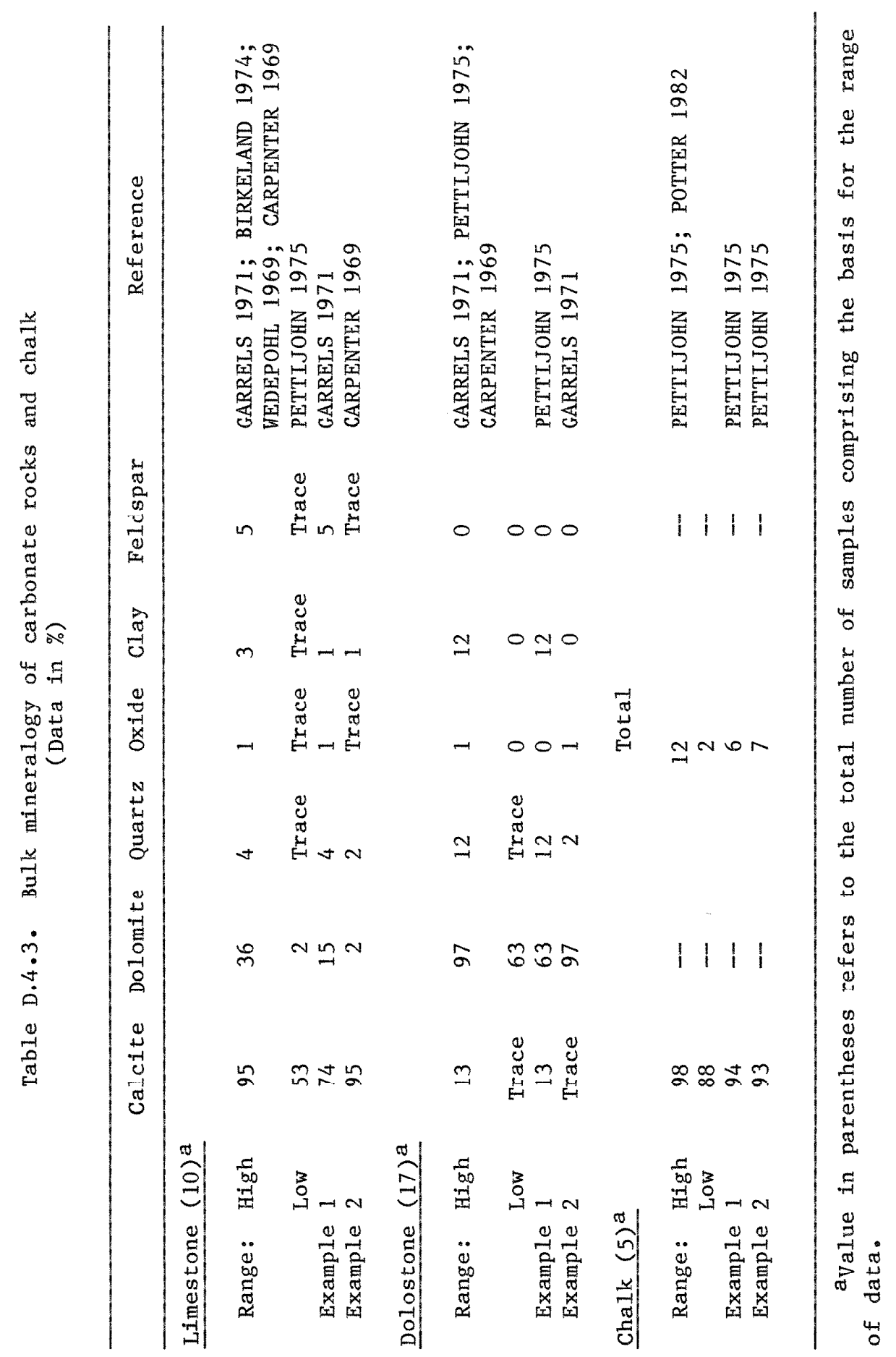


Table D.4.4. Bulk mineralogy of anhydrock (Data in \%)

\begin{tabular}{|c|c|c|c|c|c|c|}
\hline & Halite & Anhydrite & $\begin{array}{l}\text { Carbonate } \\
\text { rock }\end{array}$ & Gypsum & Clay & Reference \\
\hline \multicolumn{7}{|l|}{ Range: ${ }^{a}$} \\
\hline \multirow[t]{3}{*}{ High } & 5 & 98 & 15 & 94.26 & 20 & BLATT 1980 \\
\hline & & & & & & PETTIJOHN 1975 \\
\hline & & & & & & GARRELS 1971 \\
\hline Low & $\begin{array}{l}0 \\
0\end{array}$ & $\begin{array}{l}65 \\
95\end{array}$ & Trace & 60.5 & Trace & STEWARD 1963 \\
\hline Example $2^{c}$ & 0 & 88 & 11.7 & - & 0.3 & PETTIJOHN 1975 \\
\hline Example $3^{\mathrm{d}}$ & 0 & 2.3 & 15 & 77.67 & 5 & PETTIJOHN 1975 \\
\hline
\end{tabular}

a Based on a total of 32 samples.

bDeposits $>500 \mathrm{ft}$ deep; estimated values from stratigraphic columns. c Deposits $>500 \mathrm{ft}$ deep.

$A_{\text {Deposits }}<500 \mathrm{ft}$ deep.

1. Quartz is a significant component, although of great variability in abundance, in clastic rocks (sandstones and shales). Even in normal shales, it may comprise over one-third of the rock.

2. Feldspar may be the major mineral component in some sandstones.

3. Shales contain a variety of clay minerals, but smectite and illite are the dominant ones.

4. Clay may be a significant component of sandstones and is nearly always present.

5. Carbonate rock and oxide contents in shales and sandstones are highly variable and may be as high as 5 to $10 \%$ each.

6. Organic matter is common in shales and may be very abundant in organic shale; it is not found significantly in sandstones.

7. Sandstone cements are highly variable; oxides, carbonate rocks, and clays are the common cementing materials.

8. Carbonate rocks, including chalk, are composed chiefly of calcite and dolomite; other constituents, including clay, are of much lesser abundance but may occur in significant quantities.

9. Anhydrock is a fairly pure monomineralic rock with a generally low abundance of clay. 


\section{D.4.3 GEOCHEMISTRY}

\section{D.4.3.1 Bulk Composition}

Bulk chemical compositional data for the subject rocks are found in Tables D.4.5 through D.4.8. The key points are as follows:

1. $\mathrm{SiO}_{2}$ and $\mathrm{Al}_{2} \mathrm{O}_{3}$ are the major components of the clastic rocks, and $\mathrm{SiO}_{2}$ may comprise almost $100 \%$ of some sandstones.

2. Water is present in all shales in significant ( 4 to $5 \%$ ) amounts.

3. Sulfur is commonly present in shales and sandstones and may be found in significant (approximately 5\%) amounts in organic shale and marl.

4. Organic carbon is present in essentially all shales and may be a major component (over $5 \%$ ) in organic shales.

5. Water, sulfur, and organic carbon are of very low (1ess than $1 \%$ ) abundances in carbonate rocks and chalk.

6. Anhydrock may contain large amounts of water (20\%) and has a very low organic carbon content (less than $1 \%$ ).

\section{D.4.3.2 Solubility of the Rocks}

The occurrence of rock dissolution is dependent on the equilibrium state of the rock and associated fluid and the kinetics of dissolution. The wide variability in the chemical compositions of the formational waters associated with each of the major rock types and of the rocks themselves precludes definition of a precise potential for dissolution of each of the major rock types. In addition, the rate of dissolution of each of the rocks will be a function of the degree of undersaturation, the texture, and the fabric of the rock (EASTMAN 1978; GARRELS 1965; BLATT 1980, 1982; TUCKER 1982; BRAITSH 1971).

There are few applicable data on colubilitico of the rocks in saline environments. It is possible, however, to evaluate the relative solubilities of the rocks by using the solubilities of the constituent minerals, for which there are numerous data, as a basis if the extrapolation is done with caution. Table 0.4 .9 contains solubility data (CRPC 1962) for a number of the major rock-forming minerals of interest and represents the basis on which a relative evaluation may be made for the subject rocks (Sect. D.5.3.1.4). These data show that the solubilities of the minerals are highly variable, with those for gypsum and anhydrite being the highest followed by dolomite and calcite. The silicate minerals are essentially insoluble. For comparative purposes, the solubility of salt under similar conditions is $35.7 \mathrm{~g} / 100 \mathrm{~mL}$ water. 


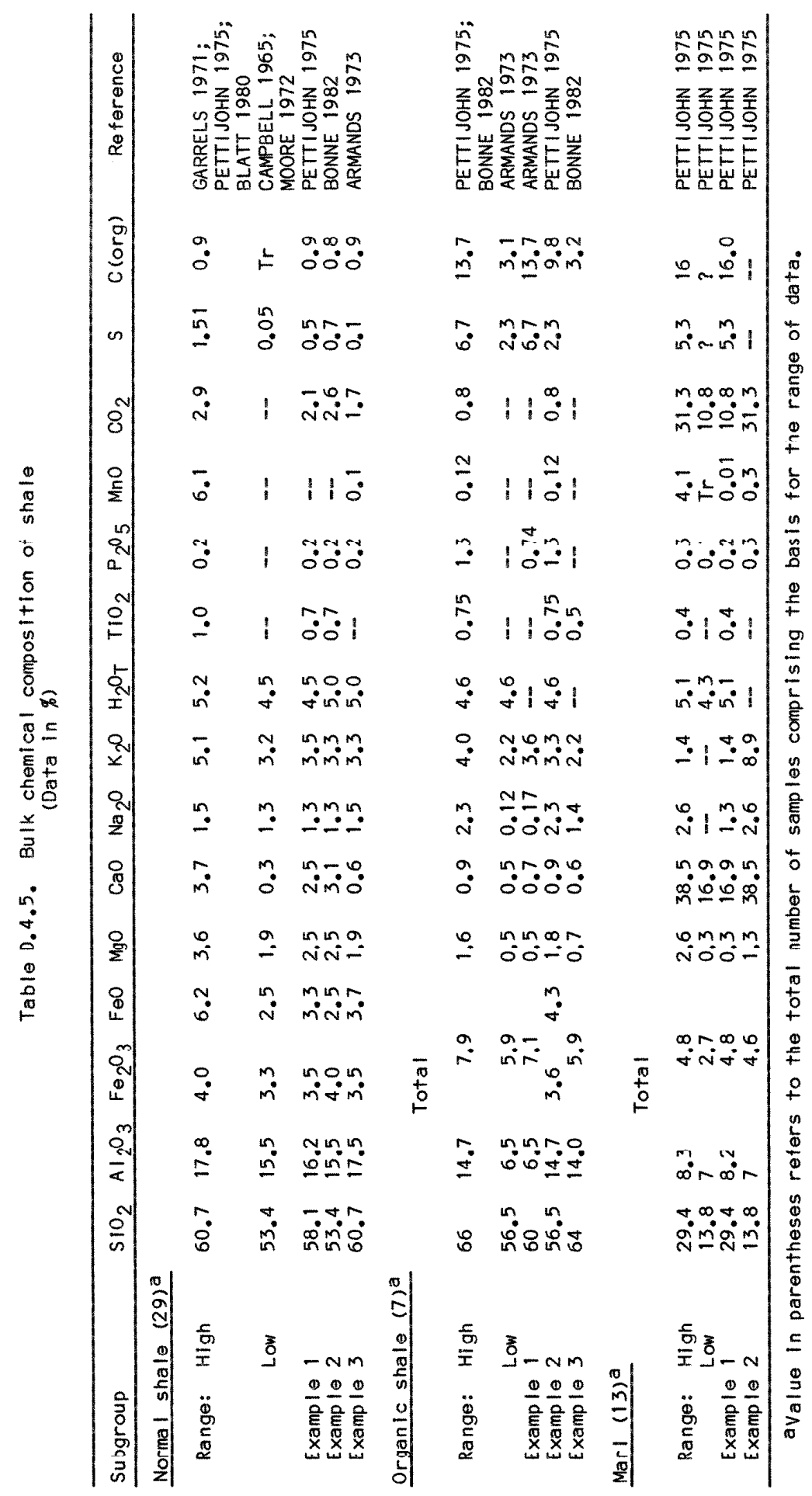




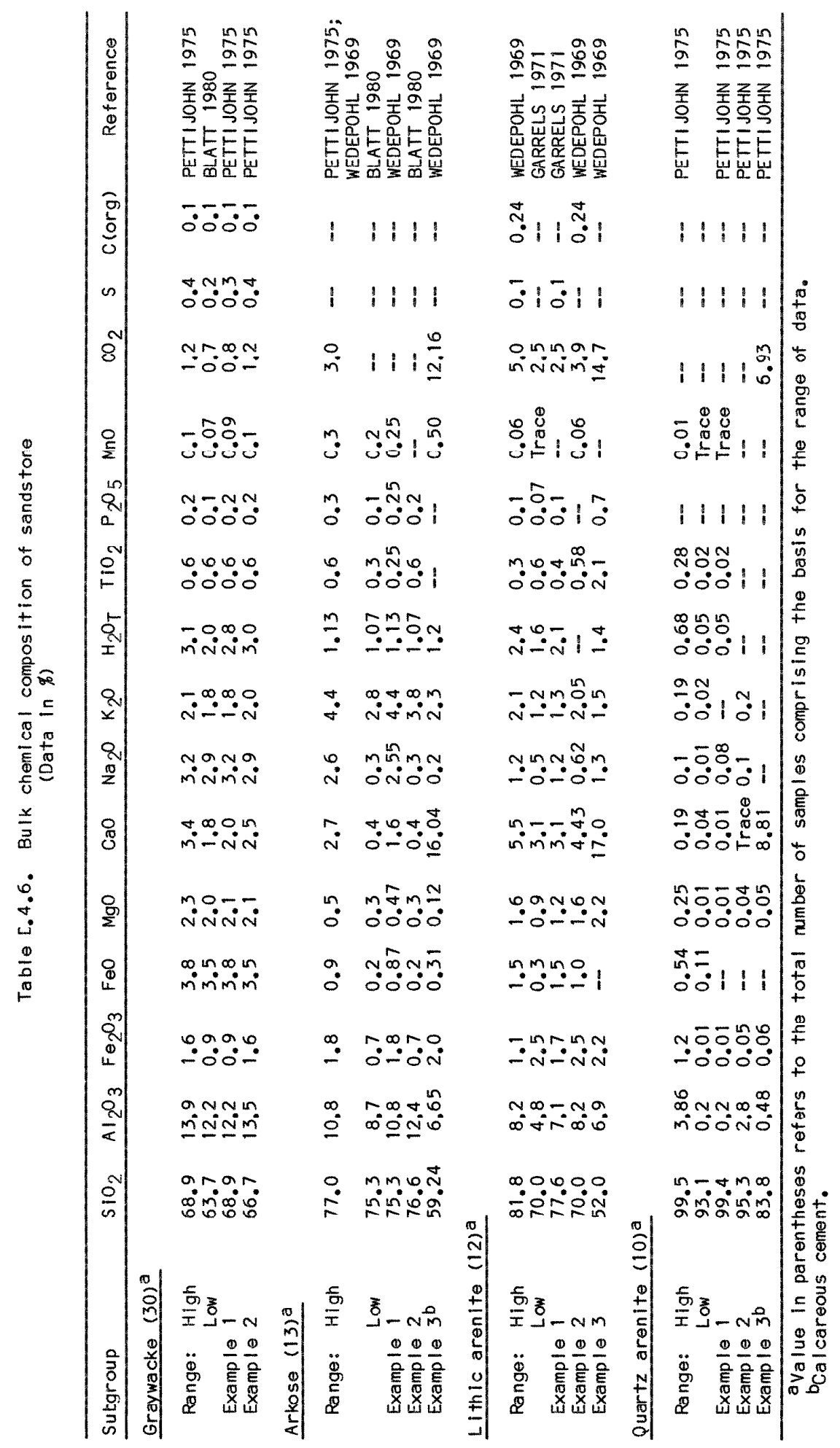




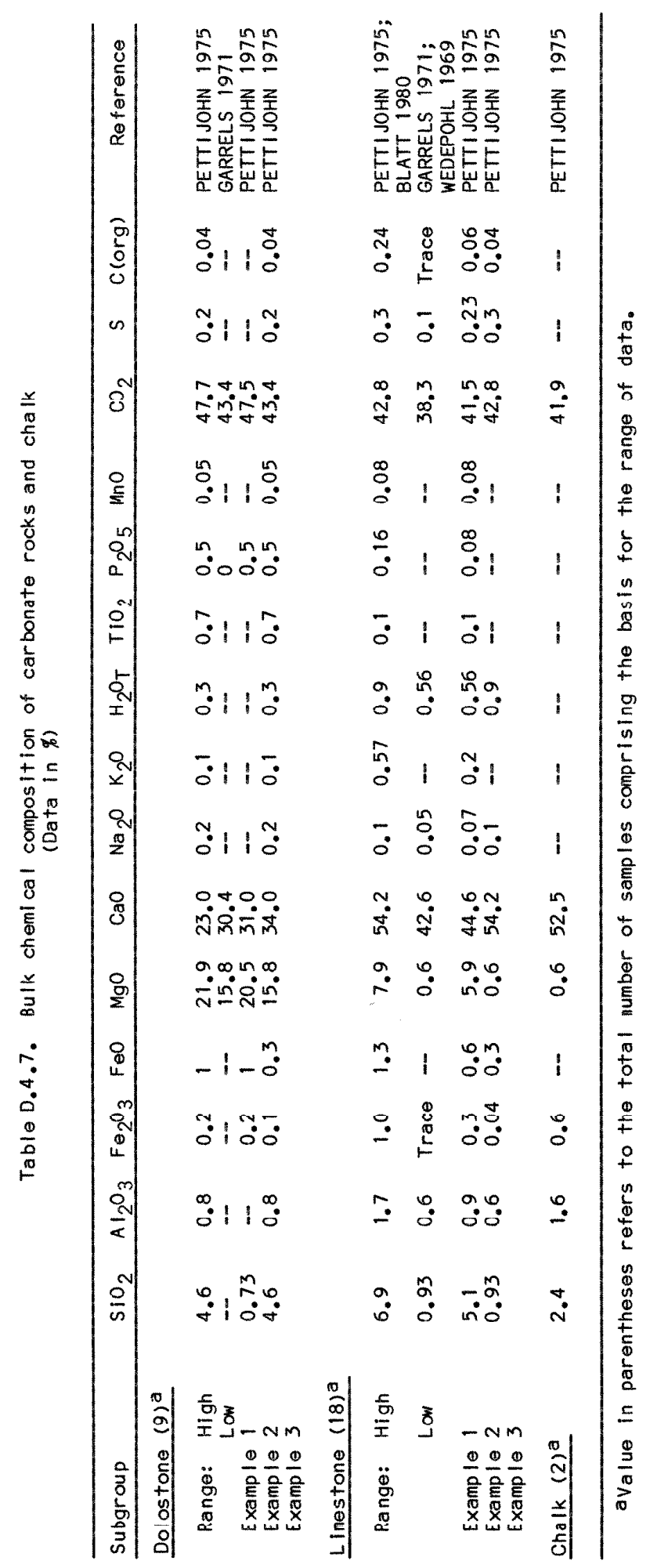




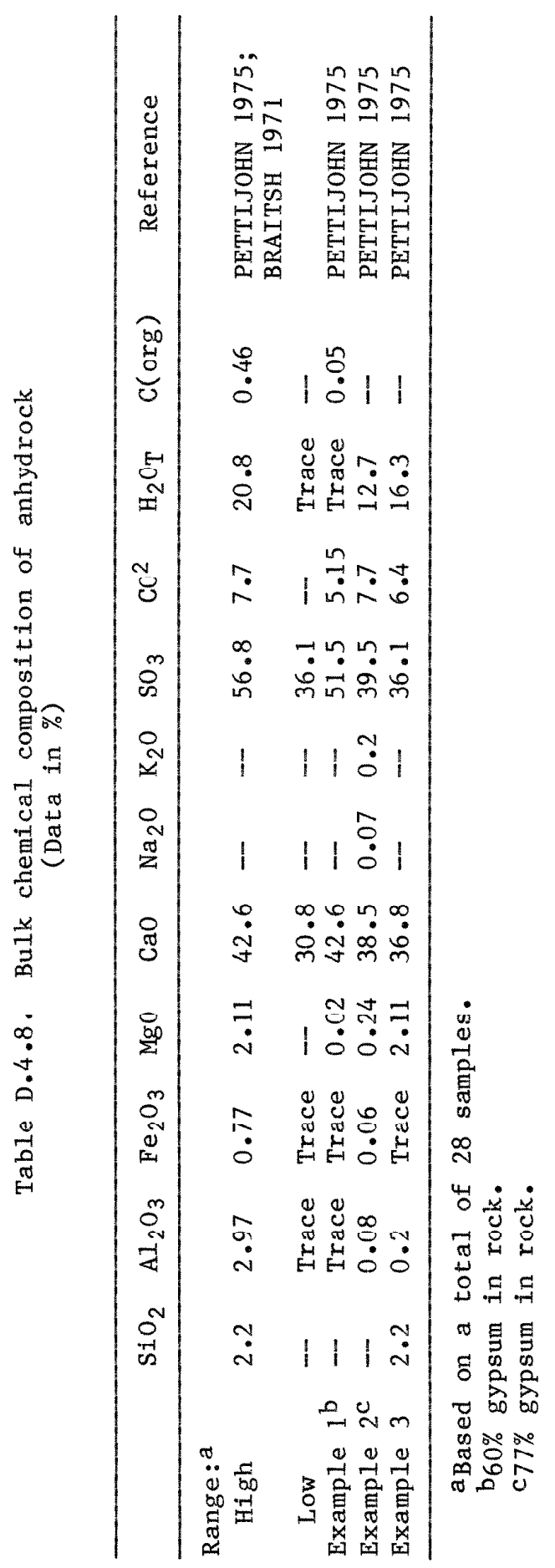


Table D.4.9. Solubilities for some common rock-forming minerals found in the subject rocks

\begin{tabular}{lcl}
\hline Mineral & $\begin{array}{c}\text { Solubility } \\
\text { Anhydrite }\end{array}$ & \multicolumn{1}{c}{$\begin{array}{c}\text { Rock type } \\
\text { represented }\end{array}$} \\
\hline Calcite & 0.209 & Anhydrock \\
Dolomite & 0.0014 & Limestone \\
Gypsum & 0.032 & Dolostone \\
Microcline feldspar & 0.241 & Anhydrock \\
Muscoviteb & ND (i) & Sandstone \\
Orthnc1ase feldspar & very highly insoluble & Shale \\
Quartz & ND (i)a & Sandotonc \\
\hline
\end{tabular}

a No data are given for microcline and orthoclase; however, they have solubilities similar to that of muscovite and, thus, are quite insoluble. buscovite is similar to illite.

Source: (CRPC 1962).

\section{D.4.3.3 Cation Exchange Capacity}

The cation exchange capacity (CEC) values are given for many minerals (Tahle $0.4 .1 n$ ), and $K_{d}$ and $R$ values are often available as well (Tablc D.2.3) (LASAGA 1984). The CEC values indicate that smectites and mixedlayer smectiteillites will be more efficient in sorbing radionuclides than either illite or kaolinite. Most shales are smectite- to illitebearing as opposed to being kaolinitic, whereas many sandstones are kaolinitic (with the lowest $\mathrm{CEC}$ ). In addition, although anion exchange capacity (AEC) data are less common than CEC data, some work (KHARAKA 1973) shows that hentonites and illitic shales effectively sorb (crchangc) chloride and sulfate, two of the more important complexing agents for radionuclides.

Organic compounds also have high $\mathrm{CEC}$ and $\mathrm{AEC}$ values. In rocks such as shales with minor to moderate TOC contents, the retardation of radionuclides may thus be further facilitated. 
Table D.4.10. Cation exchange capacities of selected clays and other minerals

\begin{tabular}{lc}
\hline Mineral & $\begin{array}{c}\text { Range } \\
(\mathrm{meq} / 100 \mathrm{~g})^{\mathrm{a}, \mathrm{b}}\end{array}$ \\
\hline Zeolites & $230-620$ \\
Kaolinite & $2-15$ \\
Illite & $16-50$ \\
Sodium smectitec & $100-150$ \\
Calcium smectite & $80-150$ \\
Vermiculite & $100-150+$ \\
Chlorite & $10-40$ \\
Halloysite & $5-10$ \\
Glauconite & $11-20$ \\
Palygorskite & $20-30$ \\
Allophane & 70 \\
Organic matter & $130-350+$ \\
Foldspar & $<1$ \\
Quartz & $<1$ \\
Carbonate & $<10$ \\
\hline
\end{tabular}

aMeasured at $\mathrm{pH} 7$. Variations in the range are caused by: (1) particle size to surface area, (2) imbalance lattice defects, and (3) $\mathrm{pH}$ and temperature.

bMore water-rich than calcium-bearing smectite.

CData are derived from: (ISHERWOOD 1981; MEANS 1982a, 1983; BEALL 1981; GRIM 1962; BIRKELAND 1974; AMPHLETT 1958; MCBRIDE 1980; AMES 1978). 


\section{D.5 EVALUATION OF THE MAJOR ROCK TYPES BASED ON DISCRIMINATORS}

\section{D.5.1 DISCRIMINATORS FOR RANKING}

The geochemical discriminators used for ranking the five major rock types were discussed in Sect. D.1.2. The following comments apply to these discriminators:

- The geochemistry of the groundwaters should minimize the potential for dissolution and mobilization of the radionuclides of interest.

- The geochemistry of the major lithological groupe chould maximize the potential for retardation of the radionuclides of interest.

- The solubility of the rock type should be minimized.

\section{D.5.2 REVIEW OF THE DATA BASE}

In Scct. D.2, it wao ohown that the potential for diocolution of the radionuclides of interest in the far field is minimized in reducing groundwaters that have $\mathrm{pH}$ levels of 7 to 8 and low TDS concentrations. In addition, it was indicated that the potential for mobilization of the radionuclides of interest in the far field is minimized in groundwaters with pH levels of 7 to 8 and low TDS and organic ligand concentrations; many radionuclides are strongly adsorbed onto media of high ion exchange capacity.

The data in Sect. D.3 showed that the least favorable groundwaters (because of their high TDS, halogen, and sulfate concentrations) are found in anhydrocks. Waters from shales generally have lower TDS contents and fewer complexing ions than do waters from other rock types.

In Scct. D.4, it wao shown that anhydrock has the greatest potential for dissolution if water is present and that the sandstones and shales have the least potential for dissolution. In addition, it was shown that rocks containing clay minerals and/or organic materials have high CECs.

\section{D.5.3 DISCUSSION OF THE DATA FOR EACH DISCRIMINATOR}

This ocction is divided into threc portions. The first (D.5.3.1) addresses the discriminators under existing, or ambient (no emplaced waste), conditions. The second (D.5.3.2) addresses the impacts (adverse) of waste emplacement on each discriminator. The third (D.5.3.3) combines the observations for existing and adverse conditions into a ranking of each rock type for each of the four discriminators.

\section{D.5.3.1 Existing Conditions}

\section{D.5.3.1.1 Radionuclide concentration limits}

The solubilities of the radionuclides are controlled by many factors, including the potential for complexation (reflected by the TDS, chloride, 
sulfate, etc., contents of the waters), the $\mathrm{pH}$, and redox conditions. Based on these data, the relative potential for solubility of nuclides for each rock type can be evaluated as follows:

1. Most soluble

Waters from anhydrocks contain very high concentrations of complexing ions and may be slightly acidic. For instance, TDS contents are often over $300,000 \mathrm{ppm}$, with chloride and sulfate as major constituents, and the $\mathrm{pH}$ is usually in the range of 6.2 to 7.8. There is also little tendency for highly reducing conditions to exist in anhydrock waters, as will be noted in Sect. D.5.3.1.3. These observations suggest that such waters will result in relatively great solubility of radionuclides, with the obvious exception of $\mathrm{Ra}$ which will precipitate as $\mathrm{RaSo}_{4}$.

2. Moderately suluble

Carbonate waters contain highly variable, but somewhat lower, concentrations of complexing ions than do anhydrock waters: nevertheless, the ion content is still significant. The $\mathrm{pH}$ is of ten slightly alkaline, and the waters appear to generally be reducing. Waters from sandstone are similar. For example, carbonate rock waters may contain well over 200,000 ppm TDS (over 300,000 for sandstone waters), but values well under $50,000 \mathrm{ppm}$ are common for both rock types. The dominant complexing ion is chloride. The pH values, while highly variable, may exceed 8 but may also be as low as 4.6. As noted later, the waters appear to have a reducing character. Therefore, these rock types are ranked second. No data are available for deep water from chalk. It is expected that such waters will be similar to those formed in carbonate rocks.

\section{Least soluble}

Shale waters have lower TDS contents than do other waters. The available data indicate TDS concentrations under 70,000 ppm; sulfate and chloride are the principal complexing ions. The $\mathrm{pH}$ values, especially those for waters frum marine shales, are neutral to silghtly alkaline. Because of the high organic contents of the rocks, the waters should be of a reducing nature, thereby limiting radionuclide solubility. For these reasons, radionuclide solubility in shale waters should be less than that in waters from other rocks.

\section{D.5.3.1.2 Retardation factors}

Primary factors that control the retardation of radionuclides include the flow, textural, and mineralogical characteristics of the rock and the composition of the formational waters. In general, rocks with high clay, organic matter, and oxide contents will sorb ions. Formational waters with high conplexing potential decrease the tendency for a rock to sorb, but certain clays may preferentially sorb complexing ions. Based on these concepts, the rocks can be evaluated wilh regard lo thelr pocenclal to retard radionuclides in the following fashion: 


\section{Greatest retardation}

Because they have high clay and organic matter contents and their formational waters contain fewer complexing agents than do other waters, shales have the greatest potential for retarding radionuclides. The lower abundance of complexing ions in shale waters was noted above. Shales typically contain more than $50 \%$ clay; the dominant clays are illite and smectite, which have CECs as high as $150 \mathrm{meq} / 100 \mathrm{~g}$. Organic shales may contain as much as $35 \%$ organic matter; organic matter has a very large CEC (130 to $350+$ meq/100 g). Therefore, shales are ranked first with regard to ability to retard radionuclides.

\section{Moderate retardation}

Sandstones generally contain significant amounts of clay and often have oxides as cementing agents. The formational waters possess somewhat more complexing ability than do shale waters, as noted above. Sandstones have highly variable clay contents, with graywacke containing as much as $36 \%$. Typically, however, clay comprises less than $10 \%$ of a sandstone. Oxide cements are common in most sandstone types, but quantitative data on abundances are not available. For these reasons, sandstone is ranked second, considerably behind shale, with regard to radionuclide retardation.

3. Least retardation

Carbonate rocks, chalk, and anhydrock, in this order, have the least ability to retard radionuclides. The complexing ability of the groundwaters in these rocks is very great, especially for anhydrock, as noted above. Clay contents for these rock types are highly variable but typically are under $5 \%$, and organic matter is rarely found, especially in anhydrock. Therefore, these rock types are ranked last with respect to retardation ability.

\section{D.5.3.1.3 Reducing conditions}

Only a few reliable data are available for the redox conditions that prevail at potential repository depths. The redox conditions will be determined by many factors, including the mineralogy of the host rock at these depths. While waters at great depths in all the subject rocks may be reducing, the data for water chemistry and rock mineralogy allow an evaluation of the redox conditions for the subject rock types on a relative basis:

\section{Most reducing}

As discussed above, virtually all shales contain some organic matter, and some are composed of over one-third organic materials. Sulfide minerale are ubiquitouc in chalc but are moot abundant, 
comprising several percent of the rock, in organic-rich shale. Although data are not reported on the $\mathrm{H}_{2} \mathrm{~S}$ contents of shale waters, it is reasonable to assume that $\mathrm{H}_{2} \mathrm{~S}$ is present. For these reasons, shale is ranked as the rock type with the greatest potential for generating a reducing environment.

\section{Moderately reducing}

Sandstones of ten contain small amounts of organic material, and waters from sandstones of ten contain $\mathrm{H}_{2} \mathrm{~S}$, thereby indicating a reducing environment. Sulfide minerals are either nonexistent or very rare in sandstone. The ability of sandstone to produce an environment with a low redox potential is far less than that of shale because of the paucity of these important constituents. Therefore, sandstone is rated considerably below shale in this regard. However, $\mathrm{H}_{2} \mathrm{~S}$ may also be present in many carbonate rocks.

3. Least reducing

Carbonate rocks, chalk, and anhydrock, in this order, represent the rocks in which the least reducing environments should be found. Organic material is rare in these rocks, although limestones (and chalk) may serve as reservoir rocks for petroleum. Also, coal is often found in carbonate rocks. Nevertheless, organic matter is not pervasively distributed in carbonate rocks and chalk; it is highly localized. Although sulfide minerals are found in carbonate rocks, they are generally localized. Anhydrock is virtually devoid of organic matter and sulfides. Formational waters for carbonate rocks may contain $\mathrm{H}_{2} \mathrm{~S}$. These rocks, therefore, are ranked last with regard to their natural reducing environments.

\section{D.5.3.1.4 Rock dissolution}

Based on the solubilities of the rock-forming minerals contained in each of the subject rock types and assuming that formational waters are undersaturated with respect to each of the rock-forming minerals in the major rock groups, the rocks can be ranked according to their potential for solubility as follows:

1. Least soluble. Sandstones and shales are less soluble than the other rocks considered. The relative solubilities of sandstone and shale under deep conditions are difficult to assess, but both should be fairly insoluble. Solubilities for the principal constituent minerals in these two rocks (quartz, feldspars, clays) are extremely low, and many are listed simply as "insoluble." Shales with high carbonate rock contents will exhibit greater solubilities than those with low carbonate rock contents. The solubility of the cementing agent in sandstone may also be the controlling factor in assessing the solubility of this rock. Sandstones with carbonate rock cement will be much more soluble than thosc with siliccous or oxide cements. It is important to 
also point out that the higher CECs of shales relative to sandstones make them somewhat less vulnerable to dissolution from deep-seated waters.

Therefore, sandstones and shales are ranked first with regard to their abilility to resist dissolution. Of the two rocks, shales should generally be more insoluble than sandstones, although the nature of the cementing agent and the exact mineral composition of shale will dictate this relationship. Nevertheless, both rocks are far more insoluble than the other rocks under consideration.

2. Moderately soluble. Limestones, dolostones, and chalks are much more soluble than is either sandstone or shale. The principal constituent minerals, calcite and dolomite, have solubilities of 0.0014 and $0.032 \mathrm{~g}$ per $100 \mathrm{~mL}$ of cold water, respectively, which would increase under acidic conditions. Because of these high snlubilities, deep dissolution in these rocks is more common than in sandstones or shales. Therefore, these rocks are rated second with regard to dissolution potential.

3. Most soluble. Anhydrocks are soluble in the presence of water. In addition to the hydration of anhydrite to form gypsum, the gypsum, too, is soluble. The solubilities of anhydrite and gypsum are, respectively, 0.209 and $0.241 \mathrm{~g}$ per $100 \mathrm{~mL}$ of cold water. These values are orders of magnitude greater than those for any of the other principal rock-forming minerals found in the subject rocks. Therefore, anhydrock is, by far, the least desirable with regard to potential for dissolution.

\section{D.5.3.2 Adverse Conditions}

Because few quantitative data exist that allow evaluation of the adverse effects of waste emplacement on the geochemical environment, no attempt has been made to consistently rank the rock types. It is possible to note, however, adverse reactions that might occur with respect to the four discriminators. All effects will be in the very near and near fields.

The effects of radiolysis on shales and shale waters, as well as on the other rocks, are basically unknown; at the 0klo natural reactor $(16,000$ MW-years energy), radiolysis was apparently not an important factor for radionuclide migration. Hence, radiolytic effects may not be too significant, except perhaps in the near tield at the waste package-water interface.

\section{D.5.3.2.1 Radionuclide concentration limits}

Radiation effects on water may create acidic and oxidizing conditions, thereby increasing nuclide solubility. Temperature increases can also enhance solubility. Such effects are not specific to any particular rock type. However, the effects of radiation and heat in degrading organic matter to produce complexing agents could be significant in organichearing sha1es. 


\section{D.5.3.2.2 Retardation factors}

The greatest effect of thermal and radiation loads might be to degrade or to decompose phases that sorb radionuclides. The effects on organic phases have not been quantified. It can be shown, however, that heat produced by emplaced wastes will have little effect on the crystal chemistry and structure of clay minerals typically found in shales. Dehydration of clays represents loss of surface-sorbed, interlayered, and lattice-bound water. Surface-sorbed water is readily lost from illite and smectite at temperatures below $100^{\circ} \mathrm{C}$; slight loss of sorbed and interlayered water occurs up to approximately $300^{\circ} \mathrm{C}$. Lattice-bound water is lost gradually above 300 to $350^{\circ} \mathrm{C}$ for illite and smectite; kaolinite does not undergo dehydration until a temperature of approximately $400^{\circ} \mathrm{C}$ is reached. Clay lattice structures persist until approximately $800^{\circ} \mathrm{C}$ in spite of dehydration (GRIM 1962).

The observations discussed above represent relatively short time periods for heating. Recent work by Eber1 and Hower (EBERL 1976) indicates that smectite will degrade to illite below $100^{\circ} \mathrm{C}$ over a time frame of 104 to $10^{5}$ years, with a resulting reduction in capability to rerard radinnuclides by sorption. Similar work on illite has not been conducted.

The effect of radiation on the clay minerals, kaolinite and palygorskite, has been studied by Haire and Beall (HAIRE 1979). Alpha radiation is noted to reduce long-term stability and to create morphological changes. Similar work on illite has not been conducted.

Therefore, it appears that adverse effects from waste emplacement, which will generate maximum rock temperatures of 250 to $300^{\circ} \mathrm{C}$, may be minimal and highly localized in the short term and near to very-near field, especially for rocks that have a high illite to smectite ratio. The long-term and far-field effects are largely unknown at present, but probably will be minimal in most shales.

It is possible that temperature increases may actually increase sorptive capacity in the subject rocks. Heat may create small secondary fractures in the near field, thereby increasing surface area and sorptive capacity.

\section{D.5.3.2.3 Reducing conditions}

The impacts of heat and radiation on the redox character of minerals and groundwaters are not well documented. It is $1 \mathrm{ikely,} \mathrm{however,} \mathrm{that}$ the greatest effects will be on clays and organic matter, but the adversity with regard to redox potential is unknown. Radiolysis of water, however, may produce an oxidizing condition for all rock types.

\section{D.5.3.2.4 Rock dissolution}

In the near field the increase in temperature associated with waste emplacement will most drastically affect anhydrock, followed by the carbonate rocks and chalk. Sandstones and shales will be least affected. 
The radiolysis of minerals and organic matter may create more acidic conditions, which would result in increased solubility, especially for rocks that contain carbonate minerals.

\section{D.5.3.3 Relative Evaluation for Each Discriminator}

Observations presented in the two previous subsections (D.5.3.1 and D.5.3.2) will be evaluated to arrive at a final ranking of each of the subject rock types for each of the four discriminators. In this evaluation, prime consideration will be given to the characteristics of the rock types under existing conditions. This is because there are very few quantitative (or even qualitative) data on the impacts (adverse or otherwise) of waste emplacement on the rocks and groundwaters, and the impacts will only be in the very-near and near fields; thus, rock and water characteristics under existing conditions should be those that are given greatest weight in an evaluation. The relative rankings for each of the rock types are given in Table D.5.1.

\section{D.5.3.3.1 Radionuclide concentration limits}

Many impacts of waste emplacement will be equivalent for all rock types with regard to control of radionuclide solubility limits. Knowledge of the impact on organic matter and the resulting changes in solubility is lacking. Therefore, the evaluation of the rock types for this discriminator reflects that presented for the existing conditions. Shale is ranked first because of the lower complexing potential and reducing nature of the formational waters. Carbonate rocks, chalk, and sandstone are ranked second because of their higher TDS contents and complexing potential and the lower reducing potential of their waters. Anhydrock is ranked third because of the unfavorable composition of its formational water.

Table D.5.1. Relative evaluations of the subject rock types for each of the four discriminators ${ }^{a}$

\begin{tabular}{lcccc}
\hline & $\begin{array}{c}\text { Radionuclide } \\
\text { concentration limit }\end{array}$ & $\begin{array}{c}\text { Retardation } \\
\text { factor }\end{array}$ & $\begin{array}{c}\text { Reducing } \\
\text { conditions }\end{array}$ & $\begin{array}{c}\text { Rock } \\
\text { dissolution }\end{array}$ \\
\hline Anhydrock & 3 & 4 & 3 & 3 \\
Carbonate rocks & 2 & 3 & 3 & 2 \\
Chalk & 2 & 3 & 3 & 2 \\
Sandstone & 2 & 2 & 2 & 1 \\
Shale & 1 & 1 & 1 & 1 \\
\hline
\end{tabular}

$a_{A}$ ranking of 1 indicates the most favorable rock type. 


\section{D.5.3.3.2 Retardation factors}

The overwhelming capability of shale to retard radionuclides results in its first-place ranking with regard to this discriminator. The possible loss of sorptive capacity due to waste emplacement - reactions that have not been verified - is not considered to be significant and will not adversely impact this favorable characteristic of shale. The other subject rock types have significantly less retarding capability than does shale; their capabilities, in a relative sense, would be similarly affected by waste emplacement. Thus, sandstones, which can have a moderate ability to retard radionuclides, are ranked second. The carbonate rocks and chalk, which may contain small amounts of sorbing phases, are ranked third, and anhydrock, which has rainimal sorbing capacity, is ranked fourth.

\section{D.5.3.3.3 Reducing conditions}

Radiolysis of water to produce a near-field oxidizing condition may occur for all rock types and, therefore, is not a factor to be considered in relative evaluation. The impacts of waste emplacement on the constituent minerals and organic phases for the subject rocks are not well docu mented and will not extend to the far field. The evaluation results in shale being assigned a rank of 1 in the same fashion as it was ranked first under existing conditions. The composition of shale was shown to be most favorable for creating a reducing environment. Sandstone is assigned a second rank, and carbonate rocks, chalk, and anhydrock are assigned the third rank since they have relatively little compositional ability to produce or to maintain a reducing environment.

\section{D.5.3.3.4 Rock dissolution}

The relative solubilities of the subject rocks vary over a wide range. It has been shown that the solubilities of the constituent minerals for the rocks differ by many orders of magnitude. Under existing conditions, shale and sandstone are the most insoluble, followed by carbonate rocks, cha1k, and anhydrock. The differences among the three groups are great. Waste emplacement will increase temperatures and may lower pH levels, thus increasing the solubilities of all rock types in the near field. The most significant increases should be for the carbonate rocks, chalk, and anhydrock. Thus, shale and sandstone are ranked first with regard to this discriminator. Carbonate rocks and chalk are ranked second, far behind the first; and anhydrock is assigned third place, far bchind the second. 
Based on the previously described data base and the geochemical discriminators, the relative ranking shown below can be derived for the five subject rock types. Adverse effects of the radiation and thermal loads from emplaced wastes on the rocks will probably be greatest in shale because of its high clay and organic matter content. At present, it is not possible to quantify these effects, which will prevail only in the near field; therefore, they are not weighed in the evaluation and ranking of the rock types.

1. Shalcs posscss high ion exchange capacitico and are not readily soluble. Waters from shales contain moderate amounts of complexforming anions and commonly have a mildly alkaline $\mathrm{pH}$, thus further decreasing both the solubility and the complex formation of many radionuclides of interest. The geochemical environment may be more reducing for shales than other rocks. Shales rank highest for all four discriminators; thus, they are the most favorable rock types.

2. Sandstones are less favorable than shales. The solubilities of sandstones are strongly controlled by the nature of the cementing agents present and may show wide variation. Waters from sandstones vary significantly in composition and $\mathrm{pH}$. Complex formation may be high in sandstone waters. Sandstones have a moderate ability to retard radionuclides and produce a moderate reducing environment. Sandstones generally rank second in all four discriminators and, therefore, are ranked second overall.

3. Limestones, dolostones (carbonate rocks), and chalk are more soluble than are sandstones, and their groundwaters possess a moderate to high potential for complex formation. Despite a high buffering potential, these rocks are especially vulnerable to acidic watere and are thue soluble. They have variable, but limited, abilities to geochemically retard radionuclides. These rocks rank either second or third for all discriminators and are generally we11 behind shale and sandstone. Therefore, they are ranked third.

4. Anhydrocks, in many occurrences, are isolated from meteoric waters and are commonly interbedded with carbonate rock and halite rocks. Under such anhydrous conditions, these rocks possess many favorable geochemical characteristics for repository consideration. However, brines from anhydrocks are very amenable to complex formation. In addition, anhydrock is potentially very soluble and has essentially no ability to geochemically retard radionuclides. Anhydrock ranks last for all discriminators; therefore, it is rated last in the overall evaluation. 


\section{D.7 REFERENCES}

ALLARD 1983. B. Allard and J. Rydberg, "Behavior of Plutonium in Natural Waters," Plutonium Chemistry, Am. Chem. Soc. Symp. Ser. 216, 275-95 (1983).

AMES 1978. L. L. Ames, Radionuclide Interactions With Soil and Rock Media, Vo1. 1, EPA 520/6-78-007, 360, Battelle Memorial Institute, Columbus, Ohio, 1978 .

AMPHLETT 1958. C. B. Amphlett, "Ion Exchange in Clay Minerals," Endeavour $17,150-55$ (1958).

ANDERSON 1973. G. M. Anderson, "The Hydrotherma1 Transport and Deposition of Galena and Sphalerite Near 100 C," Econ. Geol. 68, 480-92 (1973).

ARMANDS 1973. C. Armando, "Ccochemical Studico of Uranium, Molybdcnum and Vanadium in a Swedish Alum Shale," Stockholm Contributions In Geology, 45, ed. I. Hessland, University of Stockholm, Sweden, 1973.

BEALL 1981. G. Bea11, "A Review of the Sorption of Actinides on Natural Minera1s," Alternate Nuclear Waste Forms and Interactions in Geologic Media, CONF-8005107, 262-87 eds., L. Boatner and Go Battle, Jr., 1981.

BIRKELAND 1974. P. W. Birkeland, Pedology, Weathering, and Geomorphological Research, Oxford University Press, Oxford, England, 1974.

BLATT 1980. H. Blatt, G. Middleton, and R. Murray, Origin of Sedimentary Rocks, 2nd ed., 782, Prentice-Ha11, Inc., Princeton, N.J., 1980.

BLATT 1982. H. Blatt, Sedimentary Petrology, 564, W. H. Freemand and Company, San Francisco, 1982.

BOGGS 1984. S. Boggs, Jr. and M. Seitz, The Influence of Dissolved Organic Substances in Groundwater on Sorption Behavior of Americium and Neptunium, ANL-83-84, 30, Argonne Nat. Lab., Argonne, I11., 1984 .

BONNE 1982. A. A. Bonne and R. H. Heremano, "Inveotigation on the Boom Clay, A Candidate Host Rock for Final Disposal of High-Level Solid Waste," Developments in Sedimentology 35, International Clay Conference 1981, eds. H. Van 01phen and F. Veniale, Elsevier, Amsterdam, 1982.

BRAITSH 1971. 0. Braitsh, Salt Deposits: Their Origin and Composition, 272, tr. P. Burek and A. Nairn, Springer-Verlag, New York, 1971 .

BROOKINS 1983. D. G. Brookins, "Migration and Retention of Elements at the Oklo Natural Reactor," Environ. Geol. 4, 201-08 (1983).

BROOKINS 1984. D. G. Brookins, Geochemical Aspects of Radioactive Waste Disposa1, 345, Springer-Verlag, New York, 1984 .

CAMPBELL 1965. F. A. Campbell and G. D. Williams, "Chemical Composition of Shales of Mannville Group (Lower Cretaceous) of Central Alberta, Canada," Am. Assoc. Pet. Geol. Bul1. 49, 81-87 (1965). 
CARNAHAN 1984. C. L. Carnahan, C. W. Miller, and J. S. Remer, "Verification and Improvement of Predictive Algorithms for Radionuclide Migration," NRC Nuclear Waste Geochemistry 1983, Proceedings of the Nuclear Regulatory Commission, 416-40, eds. D. H. Alexander and G. F. Bichard, NUREG/CP-0052, 1984.

CARPENTER 1969. A. B. Carpenter and J. C. Miller, "Geochemistry of Saline Subsurface Water, Saline County (Missouri)," Chem. Geol. 4, 135-67 (1969).

CHERRY 1979. R. A. Cherry and J. A. Freeze, Groundwater, 605, Prentice-Ha11, Inc., Princeton, N.J., 1979.

CleVEland 1983a. J. M. Cleveland, T. F. Rees, and K. T. Nash, "Groundwater Composition and Its Relationship to Plutonium Transport Processes," plutonium Chemistry, Am. Chem. Soc. Symp. Ser. 216, 335-46 (1983).

CLEVELAND 1983b. J. M. Cleveland, T. F. Rees, and K. L. Nash, "Neptunium and Americium Speciation in Selected Basalt, Granite, Shale and Tuff Groundwaters," Science 220, 271-73 (1983).

COLLINS 1975. A. Collins, Geochemistry of Oilfield Waters, Developments in Petroleum Science, 1, 496, Elsevier, New York, 1975.

CRPC 1962. Chemical Rubber Publishing Co., Handbook of Chemistry and Physics, 43rd ed., Chemical Rubber Publishing Company, Cleveland, Ohio, 1962 .

DAYAL 1982a. R. Dayal, B. S. Lee, R. J. Wilke, K. J. Swyler, P. Soo, T. M. Ahn, W. S. McIntyre, and E. Veakis, Nuclear Waste Management Technical Support in the Development of Nuclear Waste Form Criteria for the NRC, Task 1: Waste Package Overview, NUREG/CR-2333 (BNL-NUREG-51458, Vo1. 1) Brookhaven Nat. Lab., Upton, N.Y., 1982.

DAYAL 1982b. R. Daya1 and R. T. Wi $1 \mathrm{ke}$, "Role of Clay Minera1s as Backfill in Radioactive Waste Disposal," Developments in Sedimentology 35, International Clay Conference 1981, eds. $\mathrm{H}$. Van Olphen and F. Veniale, Elsevier, Amsterdam, 1982 .

DONGARRO 1980. G. Dongarro and D. Langmuir, "The Stability of $\mathrm{UO}_{2} \mathrm{OH}^{+}$and $\mathrm{UO}_{2}\left[\mathrm{HPO}_{4}\right]_{2}{ }^{2-}$ Complexes at $25^{\circ} \mathrm{C}, "$ Geochim. Coschim. Acta $44,1747-51$ (1980).

EASTMAN 1978. R. Eastman, "Geologic Disposal of Radioactive Wastes," 59, Unpublished Senior Essay, Yale University, 1978.

EBERL 1972. D. Eberl and D. Hower, "Kinetics of Illite Formation," Geol. Soc. Am. Bull. $87,1326-30$ (1976).

EDELSTEIN 1983. N. J. Fdelstein, R. Silva Bucher, and H. Nitsche, Thermodynamic Properties of Chemical Species in Nuclear Waste, ONWI-399 (LBL-14325), Batte1le Memorial Institute, Columbus, Ohio, 1983. 
FAITH 1983. S. Faith, P. Spiegler, and K. R. Rehfeldt, "The Geochemistry of Two Pressurized Brines from the Castile Formation in the Vicinity of the Waste Isolation Pilot Plant (WIPP) Site," Environmental Evaluation Group-21, 69, Health and Environment Department of New Mexico, 1983.

GARRELS 1965. R. Mo Garrels and C. L. Christ, Solutions, Minerals and Equilibria, 431, Harper and Row, New York, New York, 1965.

GARRELS 1971. R. M. Garrels and F. T. Mackenzie, Evolution of Sedimentary Rocks, 400, W. W. Norton and Company, New York, New York, 1971.

GEHMAN 1962. H. M. Gehman, Jr., "Organic Matter in Limestones," Geochim. Coomochim. Acta 26, 885-97 (1962).

GIORDANO 1981. T. H. Giordano and H. L. Barnes, "Lead Transport in

Mississippi Valley - Type Ore Solutions," Econ. Geol. 68, 480-92 (1973).

GIPSON 1966. M. Gipson, Jr., "A Study of the Relations of Depth, Porosity, and Clay Mineral Orientation in Pennsylvanian Shales," J. Sediment. Petrol. 36, $888903(1966)$.

GRAF 1965. D. Graf, I. Friedman, and W. Meents, "The Origin of Saline Formation Waters, II: Isotopic Fractionation by Shale Micropore Systems," I11. State Geol. Surv. Cir. 393, 32 (1965).

GRAF 1966. D. L. Graf, W. F. Meents, I. Friedman, and N. F. Shimp, "The Origin of Saline Formation Waters, III: Calcium Chloride Waters," I11. State Geo1. Survey Circ. 397, 1-40 (1966).

GRIM 1962. R. E. Grim, Applied Clay Minerology, McGraw-Hi11, New York, New York, 1962 .

HAIRE 1979. R. G. Haire and G. W. Bea11, "Consequences of Radiation from Some Transplutonium Elements on Clays Selected for Waste Isolation," S. Fried (ed.), Radioactive Waste in Geologic Storage, 291-95, American Chemical Society, Washington, D.C., 1979.

HARRISON 1982. R. K. Harrison, M. E. Stuart, and G. E. Strong, "The Significance of Fluorine in Some Argillaceous Rocks of England," Developments in Sedimentology 35, International Clay Conference 1981, eds. H. Van Olphen and F. Veniale, Elsevier, Amsterdam, 1982.

HENDERSON 1984. P. Henderson, Developments in Geochemistry 2: Rare Earth Element Geochemistry, 317-69, Elsevier, New York, New York, 1984.

ISHERWOOD 1981. D. Isherwood, Geoscience Data Base Handbook for Modeling a Nuclear Waste Repository, Volumes 1 and 2, NUREG/CR--0912, Vo1. 1 (UCRL-52719 Vo1. 1), 1-101, Lawrence Livermore Lab., Livermore, Calif •, 1981 .

IVANOVICH 1982. M. Ivanovich and R. S. Harmon, Uranium Series Disequilibrium: Applications to Environmental Problems, Clarendon Press, Oxford, England, 1982. 
KELLER 1983. S. J. Keller, "Analysis of Subsurface Brines of Indiana," DNR Geological Survey Occasional Paper 42, Printed by Authority of the State of Indiana, 1983.

KELMERS 1984a. A. D. Kelmers, R. J. Clark, N. H. Cutshall, G. K. Jacobs, J. S. Johnson, J. H. Kessler, and R. E. Meyer, Evaluation of Radionuclide Geochemical Information Developed by DOE High-Level Nuclear Waste Repository Site Projects, ORNL/TM-9109, 50, Oak Ridge Nat. Lab., Oak Ridge, Tenn., 1984.

KELMERS 1984b. A. D. Kelmers, R. J. Clark, N. H. Cutsha11, J. S. Johnson, and J. H. Kessler, "Evaluation of DOE Radionuclide Solubility Data and Selected Retardation Parameters: Description of Calculation and Expcrimental Activities," NRC Nuclear Waste Geochemistry '83, Proceedings of the U.S. Nuclear Regulatory Commission, 151-69, eds. D. H. Alexander and G. F. Birchard, NUREG/CP-0052, 1984 .

KHARAKA 1973. Y. K. Kharaka and A. F. Berry, "Simultaneous Flow of Water and Solutes Through Geological Membranes - I: Experimental Investigation," Senchim. Cosmochim. Acta 37, 2577-2603 (1973).

KIM 1983. J. I. Kim, C. H. Lierse, and F. Baumgartner, "Complexation of the Plutonium(IV) Ion in Carbonate-Bicarbonate Solutions," plutonium Chemistry, Am. Chem. Soc. Ser. 216, 317-34 (1983).

KIRBY 1984. L. J. Kirby, ed., Radionuclide Distribution and Migration Mechanisms at Shallow Land Burial Sites, NUREG/CR-3607 (PNL-4823) Pacif ic Northwest Lab., Richland, Wash., 1984.

KOCHER 1983. D. C. Kocher, A. L. Sjoreen, and C. S. Bard, Uncertainties in Geologic Disposal of High-Level Wastes - Groundwater Transport of Radionuclides and Radiological Consequences, ORNL-5838 (NUREG/CR-2506) 215, Oak Ridge Nat, Lab., Oak Ridge, Tenn., 1983.

KOMARNENI 1981. S. Komarneni and R. Roy, "Hydrothermal Transformation in Candidate Overpack Materials and their Effects on Cesium and Strontium Sorption," Nuc1. Technol. 54, 118-22 (1981).

KRAUSKOPF 1979. K. B. Krauskopf, Introduction to Geochemistry, 2nd ed., McGraw-Hil1, New York, New York, 1979 .

KRISHASWAMI 1982. S. Krishaswami, W. C. Graustein, K. K. Turekian, and J. F. Dowd, "Radium, Thorium and Lead Isotopes in Groundwaters: Application to the in situ Determination of Absorption-Desorption Rate Constants and Retardation Factors," Water Resour. Res. 18, 1633-75 (1982).

LANGMUIR 1978. D. Langmuir, "Uranium Solution - Mineral Equilibria at Low Temperatures with Applications to Sedimentary Ore Deposits," Geochim. Cosmochim. Acta 42, 547-69 (1978).

LANGMUIR 1980. D. Langmuir and J. S. Herman, "The Mobility of Thorium in Natural waters at Low l'emperatures," Geochim. Cosmochim. Acta 44,, 1/53-66 (1980). 
LASAGA 1984. A. C. Lasaga, "Chemical Kinetics of Water-Rock Interactions," J. Geophys. Res. 89, 4009-25 (1984).

LINDBERG 1984. R. D. Lindberg and D. D. Runnel1s, "Groundwater Redox Reactions: An Analysis of Equilibrium State Applied to Eh Measurements and Geochemical Modeling," Science 225, 925-27 (1984).

MANHEIM 1969. T. T. Manheim and J. L. Biscoff, "Geochemistry of Pore Waters from Shell Oil Company Drill Holes in the Continental Slope of the Northern Gulf of Mexico," Chem. Geol. 4, 63-82 (1969).

MASTERSON 1973. W. L. Masterson and E. L. Slowinski, Chemical Principles, W. B. Saunders Co., Toronto, Canada, 1973.

MCBRIDE 1980. M. B. McBride, "Interpretation of the Variability of Selectivity Coefficients for Exchange Between Ions of Unequal Charge on Smectites," Clays Clay Miner. 28, 255-61 (1980).

McKINLEY 1982. I. G. McKinley and J. M. West, Sorption/Desorption Properties of Argillaceous Strata from Boreholes at Harwell, Oxfordshire, ENPU 82-6, 63, Institute of Geological Sciences, 1982 .

MEANS 1978. J. L. Means and D. Crerar, "Migration of Radioactive Wastes: Radionuclide Mobilization by Complexing Agents," Science 200, 1477-80 (1978).

MEANS 1982a. J. L. Means, The Importance of Organic Compounds in Groundwater as Radionuclide-Mobilizing Agents, ONWI-348, Battelle Memorial Institute, 1982.

MEANS 1982b. J. L. Means, The Organic Geochemistry of Deep Groundwaters, ONWI-268, 22, Battelle Memorial Institute, 1982.

MEANS 1983. J. L. Means, A. S. Maest, and D. A. Crerar, the Urganic Geochemistry of Deep Groundwaters and Radionuclide Partitioning Experiments Under Hydrothermal Conditions, ONWI-448, Battelle Memorial Institute, 1983.

MERINO 1975. E. Merino, "Diagenesis in Tertiary Sandstones from Kettleman North Dome, California - II. Interstitial Solutions: Distribution of Aqueous Species at $100^{\circ} \mathrm{C}$ and Chemical Relation to Diagenetic Mineralogy," Geochim. Cosmochim. Acta 39, 1624 (1975).

MEYER 1983a. D. Meyer and J. J. Howard, Evaluation of Clays and Clay Minerals for Application to Repository Sealing, ONWI-486, Battelle Memorial Institute, 1983.

MEYER 1983b. R. E. Meyer, W. D. Arnold, F. I. Case, S. Y. Shiao, and D. A. Palmer, Valence Effect on Absorption. A Preliminary Assessment of the Effects of Valence State Control on Sorption Measurements, ORNL-5905 (NUREG/CR-2863), 25, Oak Ridge Natienal Lahoratory, Oak Ridge, TN, 1983. 
MEYER 1984a. R. Meyer, W. Arnold, and F. Case, Valence Effects on the Sorption of Nuclides on Rocks and Minerals, ORNL-5978, 40, Dak Ridge Nat. Lab., Oak Ridge, Tenn., 1984.

MEYER 1984b. R. E. Meyer, W. D. Arnold, and F. I. Case, "Valence Effects on Sorption: Laboratory Control of Valence State," NRC Nuclear Waste Geochemistry '83, Proceedings of the U.S. Nuclear Regulatory Commission, eds. D. H. Alexander and G. F. Bichard, NUREG/CP-0052, 106-24, 1984.

MILLOT 1964. G. Mi1lot, Geologie Des Argiles, Masson Et Cie, Paris, 1964.

MOODY 1982. J. Moody, Radionuclide Migration/Retardation: Research and Development Technology Status Report, ONWI-321, 71, Battelle Memorial Instituce, Columbus, Uhio, 1982.

MOORE 1972. C. H. Moore, Jr., J. M. Smitherman, and S. H. Allen, "Pore System Evolution in a Cretacenis Carbonate Beach Sequence," Stratigraphy and Sedimentology, Sect. 6, Proc. Int. Geol. Congr. 24, 124-36 (1972).

NASH 1983. K. L. Nash and J. M. Cleveland, "Stability Constants, Entha1ples, and Entropies of PLutonium(III) and Plutonium(IV) Sulfate Complexes," plutonium Chemistry, Am. Chem. Soc. Symp. Ser. 216, 251-62 (1983).

NELSON 1977. R. Ne1son and J. Handin, "Experimental Study of Fracture Permeability in Porous Rock," Am. Assoc. Pet. Geol. Bu11. 61, 227-36 (1977).

NRC 1983. National Research Council, A Study of the Isolation System for Geologic Disposal of Radioactive Waste, DOE/NE/93031--T1. Prepared by the Waste Isolation Systems Panel Board on Radioactive Waste Management, Commission on Physical Sciences, Mathematics, and Resources of the National Research Council, National Academy Press, Washington, D.C., 1983.

$0^{\circ}$ KELLET 1984. G. U'Kelley and R. Meyer, The Role of Geochemical Factors in the Assessment and Regulation of Geologic Disposal of High-Level Radioactive Waste, ORNL-5988, 30, Dak Ridge Nat. Lab., Oak Ridge, Tenn., 1984.

PETTIJOHN 1963. F. J. Pettijohn, "Chemical Composition of Sandstones Excluding Carbonate and Volcanic Sands," U.S. Geol. Surv. Prof. Pap. 440-S, 1963.

PETTIJOHN 1975. F. J. Pettijohn, Sedimentary Rocks, 628, 3rd ed., Harper and Row, New York, New York, 1975.

POTTER 1978. P. E. Potter, "Petrology and Chemistry of Modern Big River Sands, J. Geol. 86 , 423-49 (1978).

POTTER 1982. P. E. Potter, J. B. Maynard, and W. A. Pryor, Sedimentology

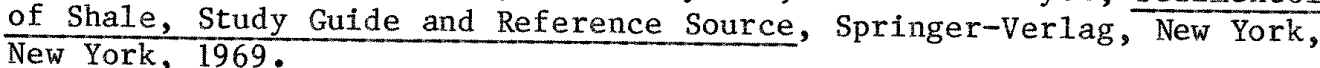


ROBERTSON 1984. D. Robertson, A. Toste, K. Abe1, and R. Brodzinski, Radionuclide Migration in Groundwater. Annual Progress Report for 1982, NUREG/CR-3554, 70, Pacific Northwest Lab., Richland, Wash., 1984.

ROGERS 1950. J. Rogers, "The Nomenclature and Classification of Sedimentary Rocks," Am. J. Sci. 248, 297-311 (1950).

SCHMIDT 1973. G. Schmidt, "Interstitial Water Composition and Geochemistry of Deep Gulf Coast Shales and Sandstones," Am. Assoc. Pet. Geol. Bull. 57, 321-37 (1973).

SHAW 1965. D. B. Shaw and C. E. Weaver, "The Mineralogical Composition of Shales," J. Sediment. Petrol. 35, 213-22 (1965).

STEWARD 1963. F. Steward, "Marine Evaporites," U.S. Geol. Surv. Prof. Pap. $440-Y, 53$ (1963).

THENG 1982. B. K. G. Theng, "Clay-Activated Organic Reactions," Developments in Sedimentology 35, International Clay Conference 1981, eds. H. Van 01phen and F. Veniale, Elsevier, Oxford, England, 1982.

TUCKER 1982. M. E. Tucker, Sedimentary Petrology - An Introduction, Wiley, New York, New York, 1982 .

TURNER 1979. D. R. Turner and M. Whitfield, "Control of Seawater Composition," Nature 281, 468-69 (1979).

TUREKIAN 1977. K. K. Turekian and P. A. Rona, "Eastern Atlantic Fracture Zones as Potential Disposal Sites for Radioactive Waste," Environ. Geol. 2, 59-62 (1977).

VINE 1970. J. D. Vine and E. B. Tourtelot, "Geochemistry of Black Shale Deposits - A Sumnary Report," Econ. Geol. 65, 253-72 (1970).

WANG 1980. K. Wang and Y. Katayama, "probable Leaching Mechanisms for Spent Fuel," Alternate Nuclear Waste Forms and Interactions in Geologic Media, CONF-800S107, 58-70, eds. L. Boatner and G. Battle, Jr., 1980 .

WATTERS 1983. R. L. Watters, "Aquatic Chemistry of Plutonium," Plutonium Chemistry, Am. Chem. Soc. Symp. Ser. 216, 297-315 (1983).

WEDEPOHL 1969. K. H. Wedepoh1, "Composition and Abundance of Common sedimentary Rocks," Handbook of Geochemistry, Vol. 1, ed. K. H. Wedepoh1, Springer-Verlag, New York, New York, 1969.

WHITE 1963. D. White, J. Hem, and G. Waring, "Chemical Composition of Subsurface Waters," U.S. Geo1. Surv. Prof. Pap. 440-F, 67 (1963).

WHITE 1965. D. White, "Saline Waters of Sedimentary Rocks," Fluids in Subsurface Environments, 342-66, eds. A. Young and J. Galley, published by American Association of Petroleum Geologists, Oklahoma, 1965. 
WILSON 1977. M. D. Wilson and E. D. Pittman, "Authigenic Clays in Sandstone - Recognition and Influence on Reservoir Properties and paleoenvironmental Analysis," J. Sediment. Petrol. 47, 3-31 (1977).

WOLLENBERG 1984. H. A. Wollenberg, D. G. Brookins, L. H. Cohen, S. Flexser, M. Abashian, M. Murphy, and A. E. Williams, "Uranium, Thorium and Trace Elements in Geologic Occurrences as Analogues of Nuclear Waste Repository Conditions," NRC Nuclear Waste Geochemistry 1983, Proceedings of the U.S. Nuclear Regulatory Commission, eds. D. H. Alexander and G. F. Birchard, NUREG/CP-0052, 1984 .

YERINO 1984. L. N. Yerino and J. B. Maynard, "Petrography of Modern Marine Sands from the Peru-Chile Irench and Adjacent Areas," Sedimentology 31 , 83-89 (1984).

ZUTIC 1982. V. Zutic and W. Stumm, "On the Role of Survace Complexation Weathering Reactions. Dissolution Kinetics of Hydrous Alumina in the Presence of Organic Ligands," Developments in Sedimentology 35, International Clay Conference 1981, eds. H. Van 0lphen and F. Veniale, Elsevier, New York, New York, 1982. 
This page intentionally left blank 
APPENDIX E

GEOLOGY 
This page intentionally left blank 
CONTENTS

E.1 INTRODUCTION. . . . . . . . .... 175

E.2 GeOlogic Characteristics of SHALE . . . . . . . 179

E.3 GEOLOGIC CHARACTERISTICS OF SANDSTONE DEPOSITS. • . . . 257

E.4 GEOLOGIC CHARACTERISTICS OF CHALK . . . . . . . 377

E.5 GEOLOGIC CHARACTERIZATION OF CARBONATE ROCKS. ...... 493

E.6 GEOLOGIC CHARACTERIZATION OF ANHYDROCK. . . . . . 541

E.7 SUMMARY ............... . . 575 
This page intentionally left blank 
SECTION E. 1

INTRODUCTION 
This page intentionally left blank 


\section{E.1 INTRODUCTION}

This part of Appendix $\mathrm{E}$ contains information on the geologic characteristics of each of the five rock types being evaluated: shale, sandstone, chalk, carbonate rocks (1imestone/dolostone), and anhydrock. The data are found in Sects. E.2 through E.6, each representing one of the rock types. Each section was prepared by an expert, or experts, recognized in their extensive knowledge of the rock type.

Each of the Sects. E.2 to E.6 follows a similar outline so that comparison of data for different rock types can be made. For each rock type, the first subsection presents a discussion of the rock's classification and definition. Because most sedimentary rocks can be formed in a variety of different depositional environments, and because this depositional environment of ten controls the geometry and dimensions of rock bodies, the second subsection is accordingly devoted to a discussion of the depositional environments of formation for each lithology. The third subsection then covers the geometric and dimensional characteristics of the rock types since this is the major geologic cunsidetalivu empluyed in evaluating the rocks. The fourth and fifth subsections provide a review of the hand specimen and field characteristics of the rocks and a description of the rocks typically found as bounding lithologies to the rock under consideration. The sixth subsection covers the expected reaction of the rock type to external events, such as dissolution and erosion. A brief review of associated resources is found in the seventh subsection, which is intentionally brief because more detailed assessment of the resource characteristics of the five rock types is given in Appendix $F$. Finally, the eighth subsection constitutes a summary chapter that contains compilations of the characteristics described in the previous chapters; data and observations are summarized in tabular form and generally by depositional environment, allowing comparison of various facies for each rock type. Section $\mathrm{E} .7$ is a brief overall summary of the information devcloped for the five rock types, with emphasis on comparisun of the rock types and their depositional environments with respect to their potential for repository siting.

At an early stage in the development of the approach to be used in presentation of the geologic data, it was determined that some initial winnowing needed to be performed so that efforts could be effectively directed toward deccription of rocks in depositional environments that have a high potential for siting. For instance, there are numerous types of sandstones formed in certain depositional environments that typically cannot meet the qualitative geometric considerations for repository siting; i.e., thickness and lateral continuity are typically inadequate. Accordingly, it was determined that efforts should not be directed toward characterization of such types of rocks and, therefore, that only depositional environments that typically produce rock bodies at least $50-\mathrm{m}$ thick with lateral continuity of at least $25 \mathrm{~km}^{2}$ would be described. An exception to this rule is for anhydrock, which of ten occurs in bodies greater than 30-m thick, but rarely in greater than 50-m thick; therefore, the $30-\mathrm{m}$ figure was used for anhydrock. 
This appendix is generic in nature. In order to present technical data and Information so that general characteristics of each rock type can be described, it is necessary, of course, to refer to the geologic formations that occur in various geographical areas. Reference to such areas is intended simply to provide technical examples for generic characterization and in no way should be interpreted as suggestive of the suitability or unsuitability of that area for repository siting. 
SECTION E.2

\section{GEOLOGIC CHARACTERISTICS OF SHALE}

SERGE GONZALES

KENNETH S. JOHNSON

EARTH RESOURCE ASSOCIATES, INC。 ATHENS, GEORGIA 30601

PAUL E. POTTER

DEPARTMENT OF GEOLOGY UNIVERSITY OF CINCINNATI CINCINNATI, OHIO 45221 
This page intentionally left blank 
E.2.1. DEFINITION OF SHALE. . ................ 183

E.2.1.1 NATURE OF SHALE . . . . . . . . . . . . . 183

E.2.1.2 DOMESTIC STUDIES INVOLVING SHALES $\cdot . \cdot \cdot^{\circ} \cdot{ }^{\circ} \cdot{ }^{\circ} 184$

E.2.1.3 FOREIGN STUDIES INVOLVING ARGILLACEOUS ROCKS • . 186

E.2.2. CLASSIFICATION OF SHALES AND THETR DEPOSITIONAL

ENVIRONMENTS . . . . . . . . . . . . . . . 187

E.2.2.1 WHAT IS SHALE? ............. 187

E.2.2.1.1 Definitions and Rock clasoifications. 187

E.2.2.1.2 Coping with Variability....... 195

E.2.2.2 DEPOSITIONAL ENVIRONMENTS OF SHALE. . . . . 197

E.2.2.2.1 Origin of Shales......... 197

E.2.2.2.2 Models of Shale Deposition..... 197

E.2.2.3 SHALY BASTNS.................. 204

E.2.3. GEOMETRY AND DIMENGIONS OF SHALE DEPOSITS. . . . . . 206

E.2.4. CHARACTERTSTICS OF SHALE DEPOSTTS. . . . . . . . . 210

E.2.4.1 LITHOLOGY .................... 210

E.2.4.1.1 Mineralogy and Geochemistry. . . . 210

E.2.4.1.2 Texture............... 214

E.2.4.1.3 Lateral and Vertical Homogeneity . . 215

E.2.4.2 STRATIFICATION AND OTHER PRIMARY SEDIMENTARY

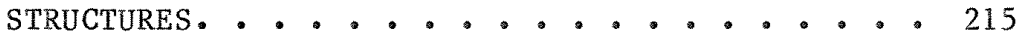

E.2.4.3 NON-SHALE INTERBEDS ............ 216

E.2.4.4 SECONDARY STRUCTURES ............. 217

E.2.4.5 PLASTTCITY. . . . . . . . . . . . . . . 218

E.2.4.6 POROSITY AND HYDRAULIC CONDUCTTVITY...... .218

E.2.5. LITHOLOCIES OF BOUNDINC ROCK TYPES . . . . . . . . . 221

E.2.6. REACTION OF SHALE TO EXTERNAL EVENTS . . . . . . . . 224

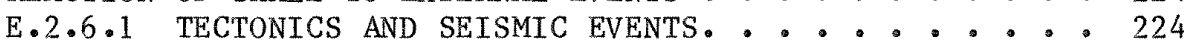

E.2.6.2 DISSOLUTION AND BRECCIATION . . . . . . . . 226

E.2.6.3 WEATHERING AND EROSION. . . . . . . . . . 226

E.2.6.4 MAN-MADE OPENINGS IN SHALES . . . . . . . 228

E.2.7. MINERAL RESOURCES IN OR ASSOCIATED WITH SHALES • . . . 230

E.2.7.1 GENERAL CONSIDERATIONS. . ......... 230

E.2.7.2 HYDROCARBONS AND SHALES ............ 230

E.2.7.3 NON-PETROLEUM RESOURCES AND SHALES. . . . . . . 231

E.2.7.4 HYDRODYNAMTC-RESOURCE ASPECTS . . . . . . . . 233

E.2.8. DEPOSITIONAL ENVIRONMENTS AND SHALE HOST ROCKS . . . . 236

E.2.9. REFERENCES . . . . . . . ........... 240 
This page intentionally left blank 


\section{E.2.1.1 NATURE OF SHALE}

Shale is a widely used, common English-language term for a lithified, fine-grained, clay-rich sedimentary rock. The term is loosely used interchangeably in the geologic community with the other technical words, such as mudstone, mudrock, and claystone. Both shales and mudrocks belong to the larger class of "fine-grained, argillaceous sediment," which includes both lithified rocks and their unlithified equivalents. The description "fine-grained" means that most of the particles are smaller than 62 um. Hence, clay (particles less than $4 \mu \mathrm{m}$ ) and lesser amounts of silt ( 4 to $62 \mathrm{\mu m})$ predominate; minor amounts of sand ( 62 to $2,000 \mathrm{\mu m})$ and tossil debris larger than 2,000 $\mu \mathrm{m}$ may also be present.

Thronghout this report the generic term "shale" is used instead of the term mudrock because of the wider usage and more general acceptance of the former term. The term "shale" is furthermore limited to indurated rocks and does not include equally fine-grained, but unconsolidated to semi-consolidated clays, silts, and marls, especially typical of the Tertiary System in the United States.

Shales are the most abundant sedimentary rocks and are estimated to form about 60 percent of the geologic column on a worldwide basis. The continental United States is no exception because shales or their metamorphic equivalents are present in all the lower 48 states.

Although much is known about the general stratigraphic and regional distribution of shales in the United States, only two summaries exist (DAMES 1978; GONZALES 1984). In addition, knowledge abont the origin and detailed physical and chemical properties of shales lags far behind that of sandstones, carbonate rocks, and evaporites, chiefly because the economic value of shales is less. Shales, nonetheless, represent economic resources; they function as important source rocks for petroleum; they are oil and gas reservoirs; they host certain metallic ore deposits and industrial minerals; and they serve as raw materials themselves for today's technological and industrialized society. Because of their low permeability, shales tend to inhibit fluid flow and thus serve as seals and barriers relative to the movement of groundwater and petroleum.

General reference sources about shales include individual chapters in textbooks by Pettijohn (PETTIJOHN 1975) and Blatt et al. (BLATT 1980), as well as the book by Potter et al. (POTTER 1980). Much useful information is also contained in special issues of two foreign periodicals: (1) volume 137 of the Journal of the Geological Society of London (1980) is devoted to black shales; (2) volume 14 of the Quarterly Journal of Engineering Geology, London (1981), treats the engineering properties of mudrocks. Shales are discussed at some length in the Encyclopedia Britannica (ENCYCLOBRIT 1974). 


\section{E.2.1.2 DOMESTIC STUDIES INVOLVING SHALES}

There has historically been interest in shales and clays within the United States relative to their potential as host rocks for nuclear waste disposal. The purpose of the following discussion is not to elaborate on those projects that have investigated shales and related rocks, but merely to summarize the relationship of these past studies as appropriate background.

During the mid-1970's, the now-defunct office of Waste Isolation (OWI) recommended, supported, and administered several semi-regional to state-level studies of particular shale and clay formations as potential host rocks for the storage of radioactive wastes. The investigated units and the authors responsible for the studies were: (1) Green River Formation of Colorado, Utah, and Wyoming (NETHERLAND 1975); (2) New Albany Shale, Borden Group, and Maquoketa Shale in Indiana (DROSTE 1976a; 1976b); (3) Porters Creek and Yazoo Clays of the Gulf Coast and the Floyd and Chattanooga Shales in Mississippi, Alabama, and Tennessee (MELLEN 1976); and (4) Triassic shales (various formation names) distributed within several localized basins along the eastern seaboard (WEAVER 1976a). These same Triassic deposits were additionally investigated in a general way by the U.S. Geological Survey (BAIN 1973), as well as under a contract administered by the Savannah River Laboratory (DAMES 1980). OWI also supported a regional-based investigation of several shale formations within the eastern part of the country (JOHNSON 1976).

During this same time frame, OWI directed several basic studies about the nature and properties of clay-rich rocks. Reports by Weaver (WEAVER 1976), Walsh and Bathke (WALSH 1976), and Weaver (WEAVER 1977), for example, considered the basic mineralogy and the thermal properties of shales and clays.

The U.S. Geological Survey was active during the early to mid-1970's in efforts to investigate shales and related rocks in the context of waste disposal. A number of specitic shale-rich tormations were inventoried and studied in a very generalized manner, while several were scrutinized in somewhat more detail on a regional basis in a report by Merewether et a1. (MFRFWFTHFR 1973). Converse1y, varions Survey personnel conducted a large number of regional to fairly detailed studies about the geology, geochemistry, hydrology, and mineralogy of one very persistent and widespread shale unit, the Upper Cretaceous Pierre Shale of the northern Great Plains. I'he resulting extensive body of basic geologic data and various interpretations derived from it have been summarized by Shurr (SHURR 1977) and Schultz et al. (SCHULTZ 1980).

One of the earliest concerns about rocks rich in water-bearing clay minerals was the effect of thermal loading from waste emplacement. In addition to the earlier OWI studies cited above, direct field studies involving in situ thermal experiments have been conducted on the Devonian-Mississippian Eleana Argil1ite at the Nevada Test Site (LAPPIN 1979; MCVEY 1979) and on the Upper Cambrian Conasauga Group at the Oak Ridge Nationa1 Tahoratory (ORNT,) (KRIMHANST, 1979a; 1979h; 1979c). From 
the near-surface heater test in the Eleana Argillite, it was observed that the effects of clay contraction cause the opening of preexisting joints in the rocks which could lead to increase of steam and water close to the heat sources. Thermal and mechanical data from the near-surface heater experiment in the Conasauga Formation at Oak Ridge suggest that the shale rocks did not fracture further as a consequence of being heated, but the rocks actually showed a decrease in permeability.

Interest in and utilization of the shales of the Conasauga Group for the slurry injection/disposal of low- and intermediate-level radioactive wastes at the ORNL site have also produced a body of literature on this particular shale-rich unit (De LAGUNA 1968; WEEREN 1976; HAASE 1984).

With regard to the Eleana Arg1111te, much of the ear1y and current geologic understanding about this unit has been derived from various U.S. Geological Survey studies (POOLE 1961; POOLE 1965; SKIPP 1979). other more site-specific studies about the Eleana Formation are summarized by Gonzales and Johnson (GONZALES 1984).

In recent years several other generalized inventories and/or datacompliation projects have also focused on shales. Several of these sludies provided valuable information for various DOE documents, such as the generic environmental impact statement, and include reports by Dames and Moore (DAMES 1978), Apps et al. (APPS 1978), Connolly and Woodward (CONNOLLY 1980), and Isherwood et al. (ISHERWOOD 1981).

The Battelle Memorial Institute office of Nuclear Waste Isolation (ONWI) began a major study in the early $1980^{\prime} \mathrm{s}$ that was designed to conpile, evaluate, and summarize large volumes of regional data on shales and clays in the United States. Objectives of the original study were to identify shales and clays that met certain thickness and depth criteria, and then to describe the geology, stratigraphy, hydrology, mineral resources, and other characteristics of the resulting large number of possible candidate formations. Because of certain programmatic changes, the report from that scudy was finalized and released through ORNL (GONZALES 1984).

In addition to the interest and investigative efforts on shale as summarized to this point, another major DOE program has for years been directed through a wide range of studies at the gas-bearing shales of Devonian and Mississippian age in the Appalachian, Michigan, and Illinuls Basins. These so-called Easleru Gas Sliales (also huw simply termed Devonian Shales) were studied mainly for their unconventional gas-resource potential under a multifaceted program coordinated and administered by the Morgantown, West Virginia Energy Technology Center. The body of literature from these basic and applied investigations is voluminous (DOE 1983). A briefer summary about these thick, shalebearing sequences is presented by Potter et al. (POTTER 1982). This extensive volume of geologic, stratigraphic, and resource data has also been interpreted with regard to the potential of these shales for possible waste disposal (LOMENICK 1983). 


\section{E.2.1.3 FOREIGN STUDIES INVOLVING ARGILLACEOUS ROCKS}

Although specific investigations on shales, clay minerals, and shalerich formations in the United States are perhaps more numerous than one might initially expect, interest in clay-rich rocks for possible waste disposal in some European countries is possibly even more pronounced. Potential host rocks principally under study in foreign programs are granites, salt, and clay-rich or argillaceous strata. An important point of distinction in comparison to the American program is that the argillaceous rocks under strong consideration by Belgium and Italy are waterrich, semi-unconsolidated clays of Tertiary age. Thus, these strata are very different from the rock-mechanically more competent, indurated shales that are the focus of this report. Japan has also selected some clay deposits for further study along with several other rocks, but their efforts are not as advanced as those of the two European nations (HARMON 1983). Three foreign countries, namely France, United Kingdom, and Canada, are also considering shales and clays, but generally in a second level of effort behind another rock type (in each case, granite).

Part of the strong Belgian effort is because the Boom Clay underlies that nation's principal nuclear research facility at Mol. An underground laboratory has been constructed within the target clay formation and will be the center for various hydrologic, rock-mechanical, and thermal tests conducted in situ. Research into these areas was initiated this year and is expected to extend for at least 4 to 5 years.

Italy has embarked on a program partly similar to the Belgian effort. A deep borehole and various in situ thermal studies have been undertaken in the clay deposit beneath the Trisaia Nuclear Research Center; meanwhile an underground research laboratory in clay for detailed in situ studies is being contemplated. Clay deposits at other sites in Italy, especially Sicily, are also being characterized, and some exploratory drilling has been completed.

More specific information about the intentions and actual investigative plans of most foreign nations is contained in the Proceedings of the International Conference on Radioactive Waste Management [INTERNATIONAL ATOMIC ENERGY AGENCY (IAEA) 1983]. A more detailed discussion abuul foreign developments involving clay-rich and other sedimentary rocks is also presented in Appendix $\mathrm{H}$ of this report. 


\section{E.2.2.1 WHAT IS SHALE?}

\section{E.2.2.1.1 Definitions and Rock Classifications}

Tourlelot (TOURLELOT 1960) reviewed the history of the term "shale" in the English literature starting as far back as the 17 th century, and he believes the first effort at a definition is to be found in a 1747 miner's handbook by William Hoosan, a Derbyshire miner with over 40 years of experience. Subsequent definitions are many (Table E.2.2.1), although all focus on the basic, fine-grained, argillaceous character of this rock type. Low permeability to the transmission of fluids is an important secondary characteristic of shale and is the direct consequence of its texture and composition.

Almost all who have studied and classified fine-grained, argillaceous rocks use grain size (clay and silt content) and stratification (bedding and lamination or their absence) as important classifying criteria (Table E.2.2.1). The diverse names and subtypes given in this table result from whether clay particles are defined as being less than 2,4 , or $5 \mathrm{um}$ in size and from how much clay needs be present, either 33, 50 , or 67 percent. Most workers have specified that a fine-grained, argillaceous rock must contain from 50 to 67 percent or more clay-sized particles.

Another complicating factor is that with burial and increasing temperatures, clay minerals, deposited originally at the water-sediment interface, are transformed into coarser, better crystallized platy minerals (Fig. E.2.2.1). The result is that what was textura11y a clay at the time of deposition becomes coarser-grained, or more like a siltstone, with burial (WEAVER 1980a). Because of this process, Weaver proposed a new term called "physilite," which, however, has never been widely used.

Siltstones or indurated silts differ from shales in that they contain a silt-sized framework that forms two-thirds or more of the rock. Thus, siltstones are very gritty and possibly even slightly sandy and, as a consequence, commonly have appreciably more permeability than shales. Geologists consider siltstone to be a distinctly different rock type than shale.

Potter et al. (POTTER 1980) recognizes six subtypes of shales. These subtypes are based upon the percent of clay-sized material and the type of stratification (Table E.2.2.2). Also recognized within the classification are nonindurated sediments and metamorphic equivalents. A guide for the description of stratification (Table E.2.2.3) and a 1ist of commonly used modifiers (Table E.2.2.4) are also provided. Additional laboratory study of samples is needed to provide precise estimates on the percent of clay and silt, as well as the minor components, such as the amount and kind of carbonate rock minerals, organic matter, type of clay minerals, presence of finely disseminated pyrite, etc. 
Table E.2.2.1. Definitions of fine-grained argillaceous rocks per (WEAVER 1980)

\begin{tabular}{|c|c|}
\hline Definition & $\begin{array}{l}\text { Reference } \\
\text { source }\end{array}$ \\
\hline \multicolumn{2}{|l|}{ Argillite } \\
\hline $\begin{array}{l}\text { Siltstone or shale with a high degree of } \\
\text { induration }\end{array}$ & TWENHOFFEL 1950 \\
\hline $\begin{array}{l}\text { Indurated axgillaceous rock without visible } \\
\text { parting, cleavage or foliation; less than } \\
\text { half the micaceous paste and clay minerals } \\
\text { have been reconstituted }\end{array}$ & FLAWN 1953 \\
\hline Massive shale & GRIM 1968 \\
\hline Claystone & MILLOT 1970 \\
\hline $\begin{array}{l}\text { Metamorphosed mudstone or shale with no cleavage } \\
\text { Clay-Shale }\end{array}$ & PETTIJOHN 1975 \\
\hline $\begin{array}{l}\text { Contains more than } 64 \% \text { clay and is fissile } \\
\text { An indurated and laminated rock containing } \\
\text { more than } 65 \% \text { clay }\end{array}$ & $\begin{array}{l}\text { BLATT } 1980 \\
\text { POTTER } 1980\end{array}$ \\
\hline \multicolumn{2}{|l|}{ Claystone } \\
\hline $\begin{array}{l}\text { Indurated clays; retain considerable coherence } \\
\text { on bcing wctted after drying }\end{array}$ & TWENHOFEL 1950 \\
\hline $\begin{array}{l}\text { Weakly indurated, composed predominantly of } \\
\text { "clay-sized" particles }(<10 \mu \mathrm{m})\end{array}$ & FLAWN 1953 \\
\hline Massive rock in which clay predominates & INGRAM 1953 \\
\hline Contains $>75 \%$ clay & PICARD 1971 \\
\hline Indurated clay & PETTIJOHN 1975 \\
\hline $\begin{array}{l}\text { More than } 65 \% \text { material }<5 \mu \mathrm{m} \\
\text { and between } 75 \text { to } 100 \% \text { silicates }\end{array}$ & LEWAN 1978 \\
\hline $\begin{array}{l}\text { Nonlaminated, argillaceous rock with } \\
<33 \% \text { silt }\end{array}$ & LUNDEGARD 1980 \\
\hline $\begin{array}{l}\text { Nonlaminated, indurated argillaceous rock with } \\
<33 \% \text { silt }\end{array}$ & POTTER 1980 \\
\hline A nonfissile mudrock with $>67 \%$ clay & BLATT 1980 \\
\hline
\end{tabular}


Table E.2.2.1 (Continued)

\begin{tabular}{cc} 
Term & $\begin{array}{c}\text { Reference } \\
\text { source }\end{array}$ \\
\hline
\end{tabular}

Mudrock

Massive claystone or siltstone; contains at least $50 \%$ silt and clay

INGRAM 1953

Terrigenous rocks that contain

FOLK 1974

$>50 \%$ silt and/or clay

A fine-grained, argillaceous rock lacking

SPEARS 1980 both fissility and lamination and having $<40 \%$ quartz

General term for a fine-grained argillaceous

BLATT 1980 rock

Mudshale

Contains 33 to $67 \%$ silt and is fissile

BLATT 1980

An indurated, laminated rock containing 33 to $65 \%$ clay-sized particles

POTTER 1980

Laminated, argillaceous rock with 33 to $67 \%$ silt

LUNDEGARD 1980

Mudstone

Clays and silts mingled with water form muds, and both claystones and siltstones have been termed mudstones

Forty sedimentologists recommended the term mud be dropped; why not drop mud-stone?

Rocks with subequal silt and clay

FOLK 1974

Blocky or massive claystones

PETTIJOHN 1975

Material $<5$ um from 45 to $65 \%$ of rock

LEWAN 1978

A non-fissile mudrock with 33 to $67 \%$ silt

BLATT 1980

Clay-sized constituents form 33-65\% of rock and stratification is thicker than $10 \mathrm{~cm}$

POTTER 1980 
Table E.2.2.1 (Continued)

\begin{tabular}{|c|c|}
\hline Definition & $\begin{array}{l}\text { Reference } \\
\text { source }\end{array}$ \\
\hline \multicolumn{2}{|l|}{ "Physilites" } \\
\hline $\begin{array}{l}\text { Rocks with a high content of phyllosilicates } \\
\text { (sheetlike) clay minerals }\end{array}$ & WEAVER 1980 \\
\hline \multicolumn{2}{|l|}{ Shale } \\
\hline $\begin{array}{l}\text { Claystone and siltstone with cleavage parallel } \\
\text { to bedding }\end{array}$ & TWENHOFEL 1950 \\
\hline $\begin{array}{l}\text { Fine-grained rock containing } 50 \text { to } 100 \% \text { clay-size } \\
\text { particles with clay minerals constituting } \\
\text { at least } 25 \% \text { of the total rock volume }\end{array}$ & PICARD 1953 \\
\hline More indurated than claystone & FLAWN 1953 \\
\hline Fissile claystone, siltstone, and mudstone & INGRAM 1953 \\
\hline Fissile mudrock & FOLK 1974 \\
\hline Fissile mudstone & PETTIJOHN 1975 \\
\hline More than $65 \%$ material $<5 \mu \mathrm{m}$ & LEWAN 1978 \\
\hline More than $50 \%$ material $<62 \mu \mathrm{m}$ & POTTER 1980 \\
\hline \multicolumn{2}{|l|}{ Silt-shale } \\
\hline $\begin{array}{l}\text { A fine-grained, fissile rock that contains } \\
>67 \% \text { silt }\end{array}$ & BLATT 1980 \\
\hline \multicolumn{2}{|l|}{ Siltstone } \\
\hline $\begin{array}{l}\text { A fine-grained, nonfissile indurated rock } \\
\text { that contains }>67 \% \text { silt }\end{array}$ & BLATT 1980 \\
\hline $\begin{array}{l}\text { A fine-grained, gritty, indurated rock } \\
\text { containing }>66 \% \text { silt-size particles }\end{array}$ & POTTER 1980 \\
\hline
\end{tabular}


ORNL DWG 84-1203

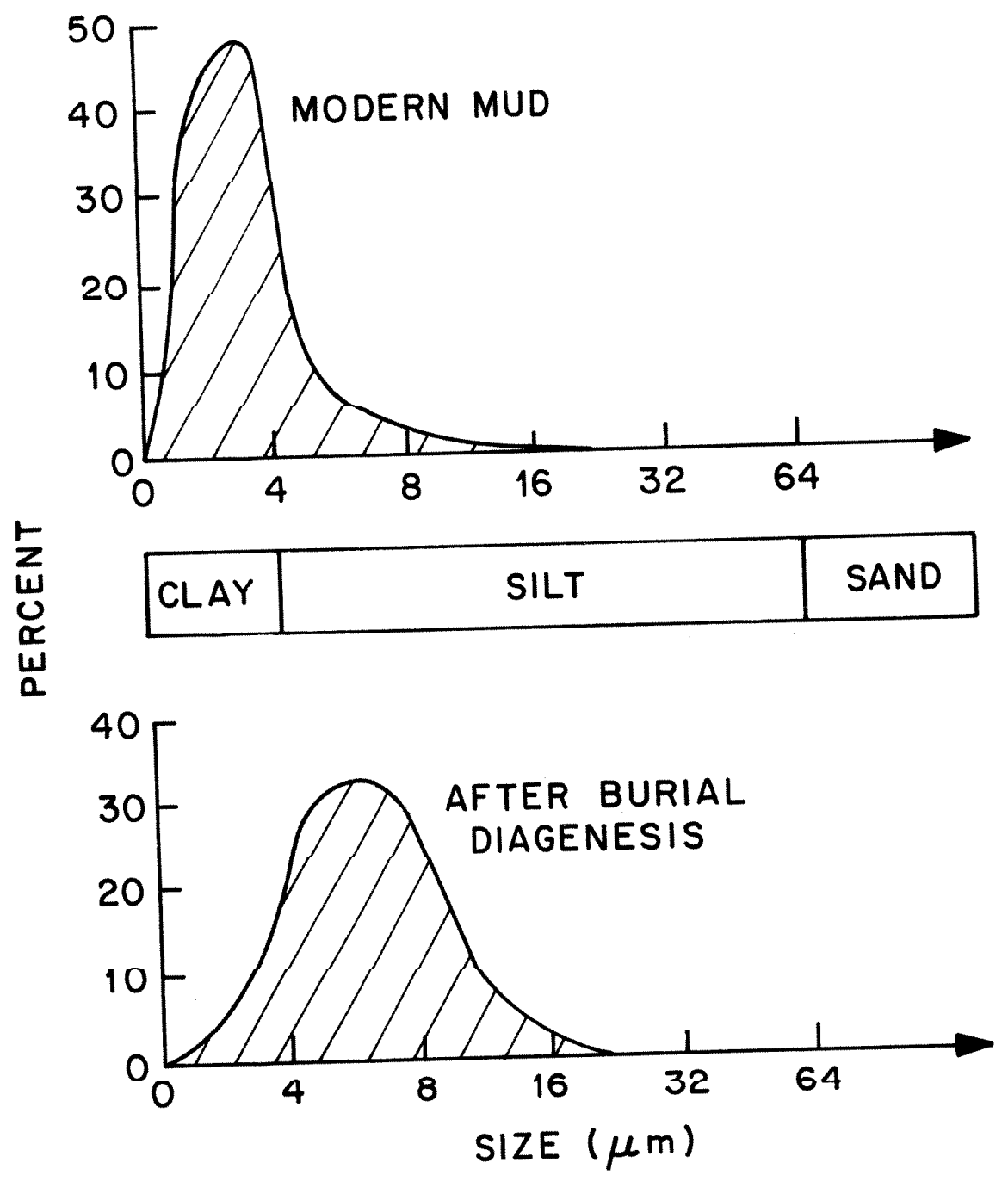

Fig. E.2.2.1. Diagrammatic representation of the difference in grain size between modern muds and their ancient 1ithified equivalents. With increased burial, the original clay minerals recrystallize into coarser, silt-sized platy minerals found in ancient shales. 
Table E.2.2.2. Classification of shale and related rock types (POTTER 1980)

ORNL DWG 84-1204

\begin{tabular}{|c|c|c|c|c|c|}
\hline \multicolumn{3}{|c|}{$\begin{array}{l}\text { PERCENTAGE } \\
\text { CLAY - SIZE } \\
\text { CONSTITUENTS }\end{array}$} & $0-32$ & $33-65$ & $66-100$ \\
\hline \multicolumn{3}{|c|}{ FIELD ADJECTIVE } & GRITTY & LOAMY & FAT OR SLICK \\
\hline \multirow{2}{*}{ 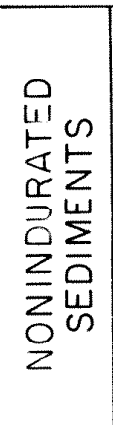 } & $\begin{array}{l}\text { on } \\
\text { 岗 }\end{array}$ & 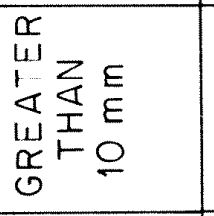 & $\begin{array}{l}\text { BEDDED } \\
\text { SILT }\end{array}$ & $\begin{array}{l}\text { BEDDED } \\
\text { MUD }\end{array}$ & $\begin{array}{l}\text { BEDDED } \\
\text { CLAYMUD }\end{array}$ \\
\hline & 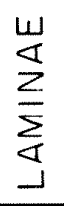 & $\begin{array}{l}\circlearrowleft Z E \\
N \leq E \\
\omega I O\end{array}$ & $\begin{array}{c}\text { LAMINATED } \\
\text { SILT }\end{array}$ & $\begin{array}{l}\text { LAMINATED } \\
\text { MUD }\end{array}$ & $\begin{array}{l}\text { LAMINATED } \\
\text { CLAYMUD }\end{array}$ \\
\hline \multirow{2}{*}{ 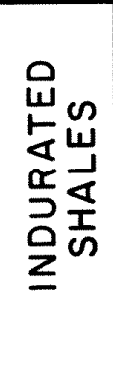 } & 号 & 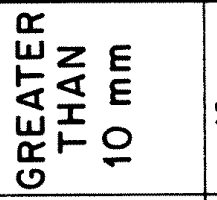 & $\begin{array}{l}\text { BEDDED } \\
\text { SILTSTONE }\end{array}$ & MUDSTONE & CLAYSTONE \\
\hline & 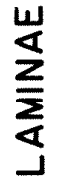 & 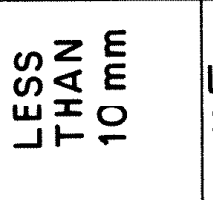 & $\begin{array}{l}\text { LAMINATED } \\
\text { SILTSTONE }\end{array}$ & MUDSHALE & CLAYSHAIE \\
\hline \multirow{3}{*}{ 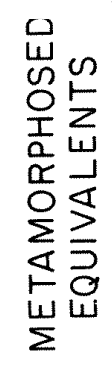 } & \multirow{3}{*}{\multicolumn{2}{|c|}{ 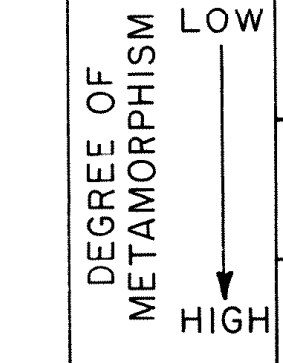 }} & $\begin{array}{l}\text { QUARTZ } \\
\text { ARGILLITE }\end{array}$ & \multicolumn{2}{|c|}{ ARGILLITE } \\
\hline & & & $\begin{array}{l}\text { QUARTZ } \\
\text { SLATE }\end{array}$ & \multicolumn{2}{|c|}{ SLATE } \\
\hline & & & \multicolumn{3}{|c|}{ PHYLLITE AND/OR MICA SCHIST } \\
\hline
\end{tabular}


Table E.2.2.3. Stratification used to describe shales (POTTER 1980)

ORNL DWG 85-261

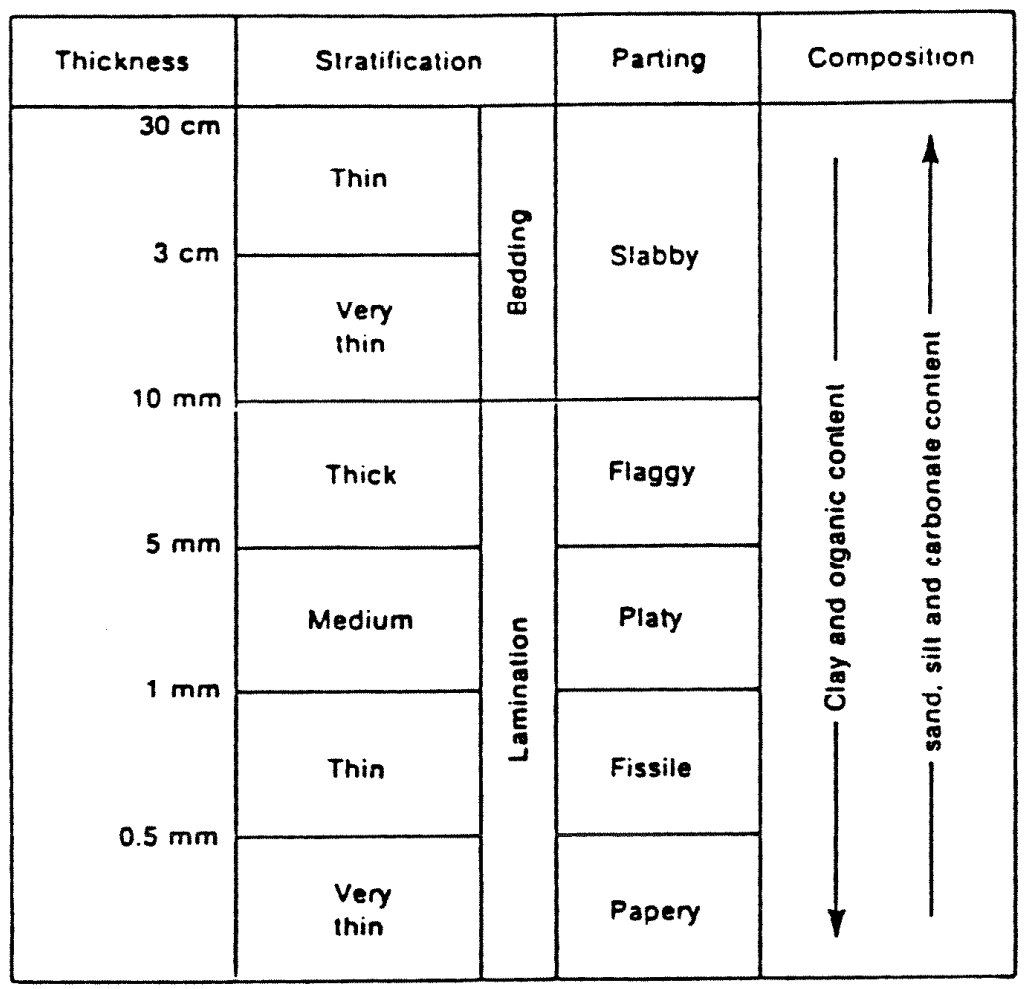


Table E.2.2.4. Common modifiers used to characterize shales (POTTER 1980)

\begin{tabular}{|c|c|c|}
\hline $\begin{array}{l}\text { Category } \\
\text { described }\end{array}$ & Source of information & Modifiers \\
\hline Mineralogy & $\begin{array}{l}\text { Petrographic or X-ray diffraction } \\
\text { analysis - percentage of specific } \\
\text { minerals such as quartz, feldspar, } \\
\text { kaolinite, illite, etc. }\end{array}$ & $\begin{array}{l}\text { Calcareous, carbona- } \\
\text { ceous, dolomitic, } \\
\text { ferruginous, felds- } \\
\text { pathic, glauconitic, } \\
\text { gypsiferous, micaceous, } \\
\text { nodular, phosphatic, } \\
\text { pyrititerous, quartzose, } \\
\text { siliceous, etc. }\end{array}$ \\
\hline $\begin{array}{l}\text { Carbonate } \\
\text { rock }\end{array}$ & $\begin{array}{l}\text { Dilute HCl and stain in field or } \\
\text { section; also X-ray }\end{array}$ & $\begin{array}{l}\text { Calcaroous, dotomitic, } \\
\text { sideritic }\end{array}$ \\
\hline Color & Munsel1 Color Chart & $\begin{array}{l}\text { Actual colors plus } \\
\text { numerical codes for them }\end{array}$ \\
\hline Induration & Visual and tactile observation & Hard, soft, plastic, etc. \\
\hline Fracture & Visual observation & $\begin{array}{l}\text { Conchoidal, hackly, } \\
\text { blocky, brittle, } \\
\text { splintery, earthy, etc. }\end{array}$ \\
\hline Grain size & $\begin{array}{l}\text { Hand lens or binocular micro- } \\
\text { scopic observation with grain-size } \\
\text { comparator }\end{array}$ & $\begin{array}{l}\text { List relative } \\
\text { percentages of silt } \\
\text { and clay fractions }\end{array}$ \\
\hline $\begin{array}{l}\text { Lamination } \\
\text { and } \\
\text { bedding }\end{array}$ & $\begin{array}{l}\text { Measured thickness and visual } \\
\text { observation }\end{array}$ & $\begin{array}{l}\text { Actual thickness values } \\
\text { and descriptive terms } \\
\text { such as parallel, wavy, } \\
\text { lenticular, flaser, } \\
\text { disturbed, etc. }\end{array}$ \\
\hline $\begin{array}{l}\text { Fossil } \\
\text { content }\end{array}$ & $\begin{array}{l}\text { Visual observation and } \\
\text { comparison to paleontologic } \\
\text { sets or data sources }\end{array}$ & $\begin{array}{l}\text { Kind, quality, and } \\
\text { condition of fossils; } \\
\text { genera and species if } \\
\text { Important }\end{array}$ \\
\hline $\begin{array}{l}\text { Bioturbation/ } \\
\text { trace } \\
\text { fossils }\end{array}$ & $\begin{array}{l}\text { Visual observation and } \\
\text { comparison to paleontologic } \\
\text { sets or data sources }\end{array}$ & $\begin{array}{l}\text { Kind, quality, and } \\
\text { condition of fossils; } \\
\text { genera and species if } \\
\text { important }\end{array}$ \\
\hline organic & $\begin{array}{l}\text { Visual observation and } \\
\text { segregation for testing } \\
\text { and reflectance studies }\end{array}$ & $\begin{array}{l}\text { Woody, spores, odors, } \\
\text { kerogen, color alteration } \\
\text { and vitrinite reflectance } \\
\text { values }\end{array}$ \\
\hline
\end{tabular}


In addition to the fine-grained argillaceous rocks of predominantly terrigenous or detrital origin, there is a related group of rocks that is rich in biological components contributed from small siliceouorganisms such as siliceous diatoms, sponges, and radiolarians; and from calcareous forms, such as algae and foraminifera. Some of the siliceous organisms yield a siliceous gel which can indurate a shale and, where abundant, can cause it to grade into a chert or chert-like rock such as the Monterey Shale of California.

Calcareous algae and foraminifera yield fine-grained carbonate rocks, which become cement and can produce an indurated shale. Where such rocks are rich in organic matter, they commonly are called oil shales. The terrigenous (clastic or detrital) shales are, however, the focus of this report because they are much more abundant and more characteristic of this rock type in general.

The above discuesion indicatco that ohalco are highly variablc with respect to mineralogy, stratification, thickness, and other geologic characteristics. This situation is both an asset and a disadvantage: an asset because the right or most desirable shale is certain to exist somewhere, and can meet the vast majority of requirements needed for a successful repository; a disadvantage because shales are clearly troublesome to classify and to analyze.

\section{E.2.2.1.2 Coping with Variability}

As with all rocks, modifiers are needed to describe variations of color and composition in hand samples; in addition, gradations into carbonate rocks, siltstone, sandstone, and evaporites must be recognized. Larese and Heald (LARESE 1977) showed how to classify the many mixtures of pure shale, sandstone, siltstone, and carbonate rocks. They named and quantitatively defined ten admixtures (Fig. E.2.2.2). Shales may grade laterally across a sedimentary basin into any of these lithologies in either an abrupt or a gradual manner. These relationships are well illustrated by Davis (DAVIS 1970) in his study of the Cretaceous Mowry Shale in Wyoming. Likewise, shales may vertically pass abruptly or gradually into other lithologies or be interbedded with them. Thus, while many stratigraphic units are called shales - the Ohio Black Shale, Mancos Shale, Utica Shale, and Rome Shale to only name a few - virtually all shales contain some interbeds of other lithologies and/or eventually grade into other lithologies when traced laterally.

Another important consideration is the thickness of other intercalated lithologies. In a hand specimen, shale may be finely interlaminated millimeter by millimeter with carbonate rocks, siltstone, sandstone, or evaporite rock types. On a larger scale, interbedded lithologies may be tenths of meters or more in thickness.

Shale classification and mutually understood nomenclature is of practical significance if shale is considered as a possible repository host rock. A comprehensive, descriptive classification of shales is essential to he1p non-genlngists effertively relate the genlogical features of this rock type to engineering and chemical properties regardless of the dimensions of the shale sample. This can be seen in the nomenclature applied 

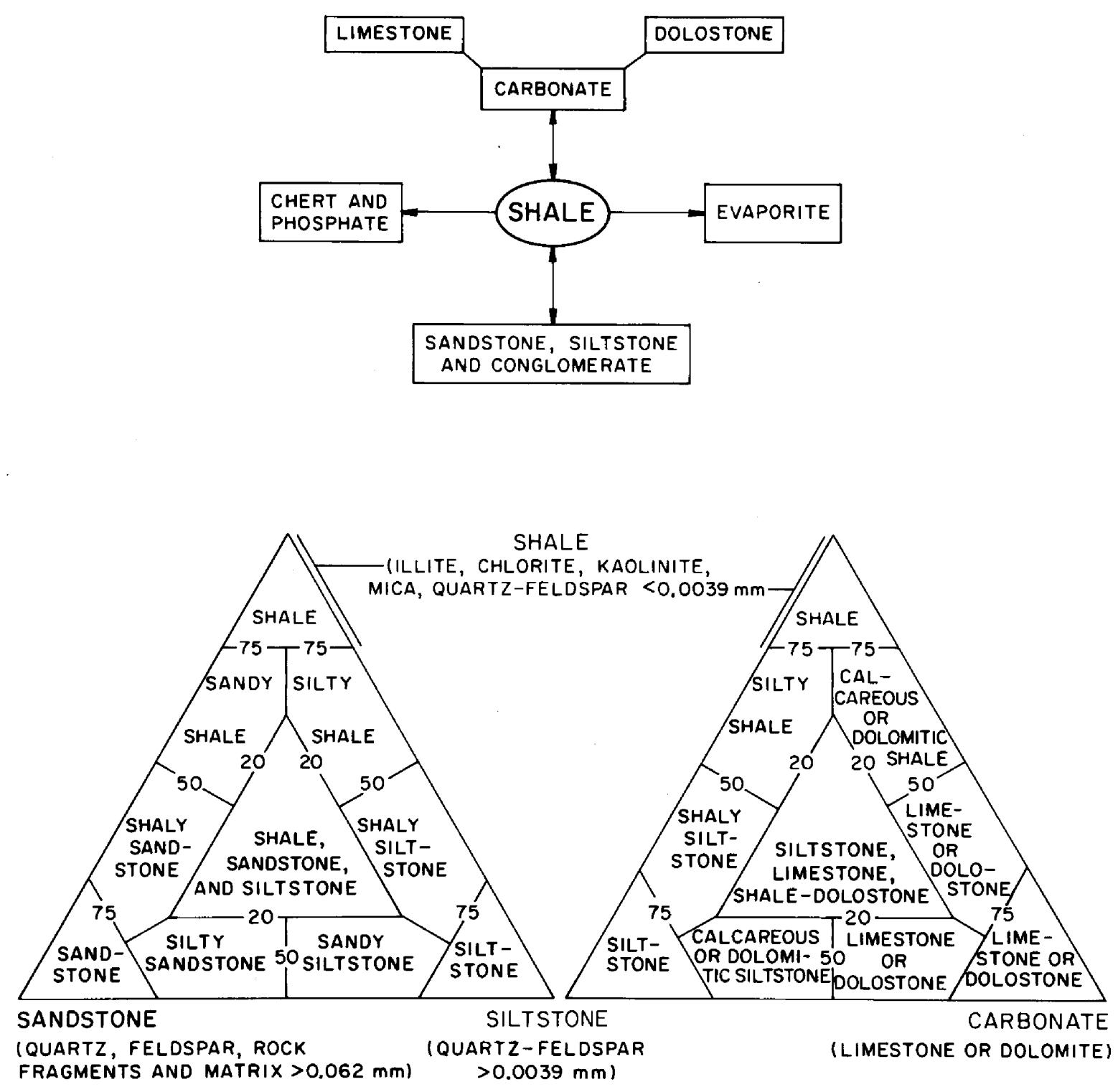

Fig. E.2.2.2 Variability of shale and methods of classifying its many complex mixtures. Shale may grade into or be interbedded with any of the other seven major sedimentary lithologies (upper part). Triangular diagrams (LARESE 1977) (lower part) provide one approach to a nomenclature for shaly rocks of mixed composition. 
as a shale varies laterally and vertically as the result of increased calcareous content and/or the presence of limestone interbeds. Bulk modulus, tensile and shear strengths, and geochenical properties will vary similarly, as will the rock's responses to wetting and drying, high temperatures, and solutioning agents.

\section{E.2.2.2. DEPOSITIONAL ENVIRONMENTS OF SHALES}

\section{E.2.2.2.1 Origin of Shales}

All shales were originally formed in water below wave base so that particles of but a few $\mu \mathrm{m}$ in size finally settled to the bottom to form mud, after perhaps days, weeks, or even months in suspension. Although this is an old concept, the recent discussion by Stanley and Wear (STANLEY 1978) indicates its current applicability. Shale-rich basins al1 require an abundant supply of finely dispersed clay, and, as a rule, a rapid rate of basin subsidence. These conditions generally imply "deep" water (i.e., below wave base), but thin shales can also be formed from shallow, muddy water where organic baffles trap mud along a coastline in mangrove swamps or lagoons. Farther offshore, mud accumulates below wave base on many marine shelves. Another way for a shale to form is when a deep subsea fan temporarily ceases to be supplied by silt and sand from its canyon so that a "mud blanket" develops upon it. Still another possibility is where turbid river water floods and creates a temporary lake over the wide floodplain of a large river. An abundant supply of mud also means that the watersheds of the supplying rivers were located in a wet climate and that they had moderate to high relief in their headwaters so that sediment yields were high. Hayes (HAYES 1967) noted that modern marine shelves bordering a land mass with a wet climate are muddier than those with a dry climate.

\section{E.2.2.2.2 Mode1s of Shale Deposition}

All sedimentary rocks form in three major sedimentary environments, namely, continental, transitional, and marine; within each, numerous subenvironments can be observed (Fig. E.2.2.3). Shale occurs in a11 of these, but with greatly different abundance. Bodies of shale in these environments tend to have different thickness, genmetry, lateral continuity, and interbedded 1ithologies. In addition, properties such as silt content, stratification, amount of calcium carbonate, and bioturbation also vary as do others, although systematic, detailed studies are quite 1imited. A complicating factor in studies of how some of the physical, mineralogical, and chemical characteristics of shales vary with sedimentary environment is the well known increase of shale density and decrease of porosity with depth of burial (ANSTEY 1980). These relationships are shown in Fig. E.2.2.4. In addition, there is a well established change of clay-mineral composition with time (Fig. E.2.2.5) as studied by WEAVER (1967). Therefore, prime emphasis is given to how abundance, geometry, thickness, lateral continuity, interbedded Iithologies and, to some degree, silt content vary with depositional environment. Table E.2.2.5 provides information on these parameters and some basic references. Examination of this table reveals that shale formed in marine environments such as marine shelves, slopes, and deep basins is most abundant and generally thickest and most widespread. 
ORNL DWG 84-1206
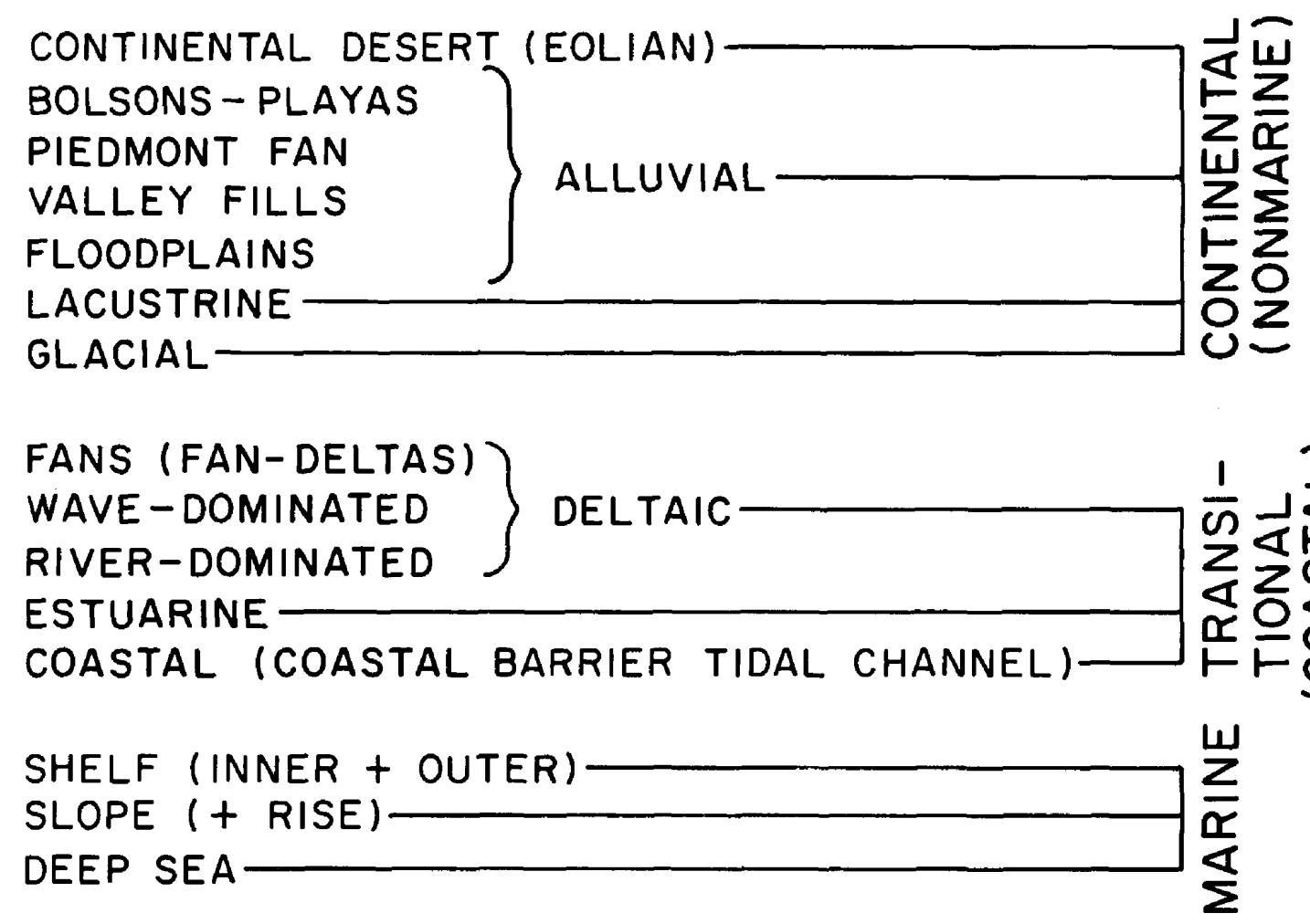

Fig. E.2.2.3. Principal subenvironments of deposition in which shales accumulate (POTTER 1980). 

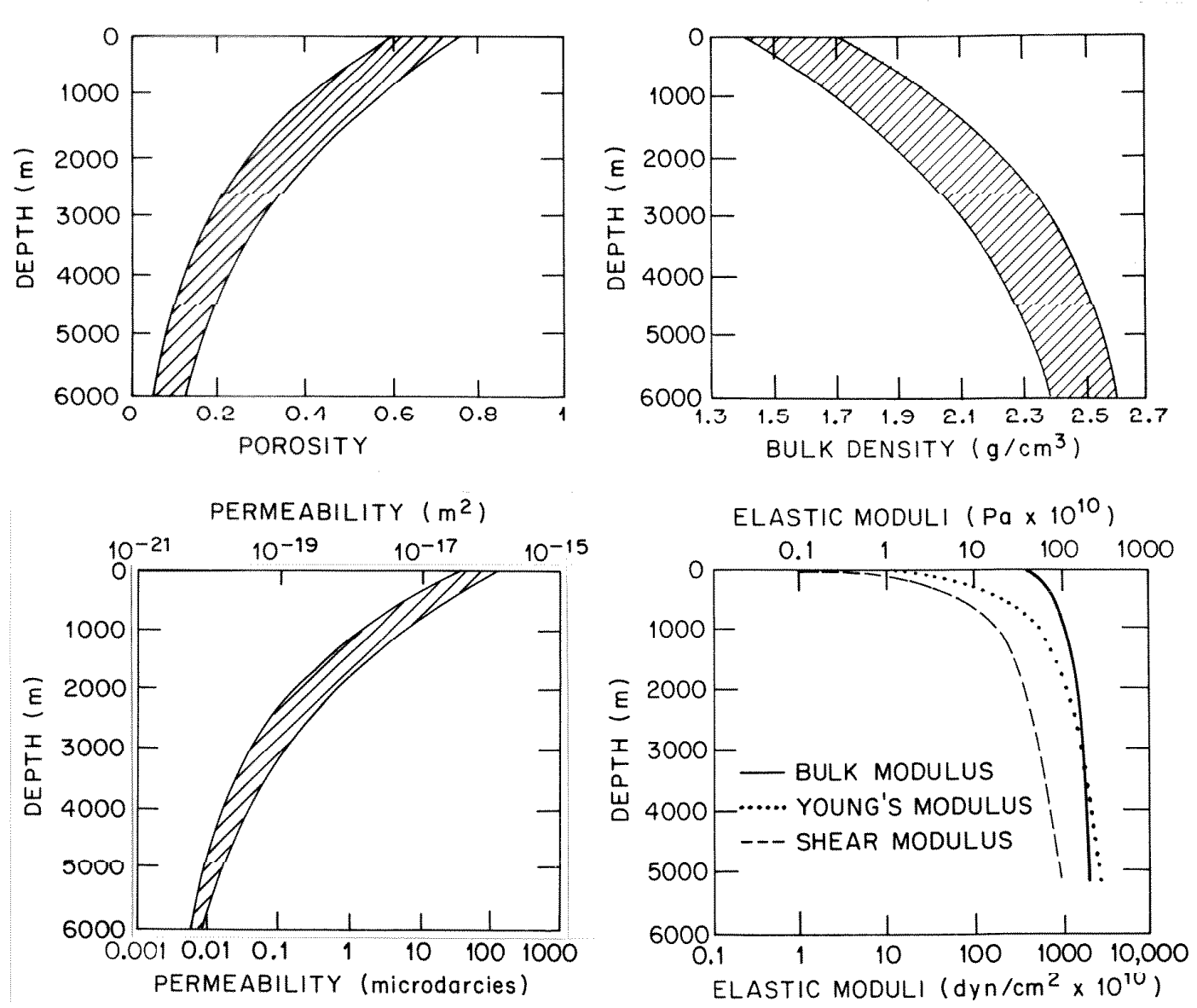

Fig. E.2.2.4. Changes in shale properties with increasing depth; shown are pornsity, hulk density, nermeahility, and elastic moduli. The hachured areas indicate the range of values for most shales. Based upon data from BRYANT (1975), GREGORY (1977), and SHARP (1983). Diagram courtesy of Mr. Joseph Davis, Atlantic Richfield Company, Dallas, Texas. 
ORNL DWG 84-1208

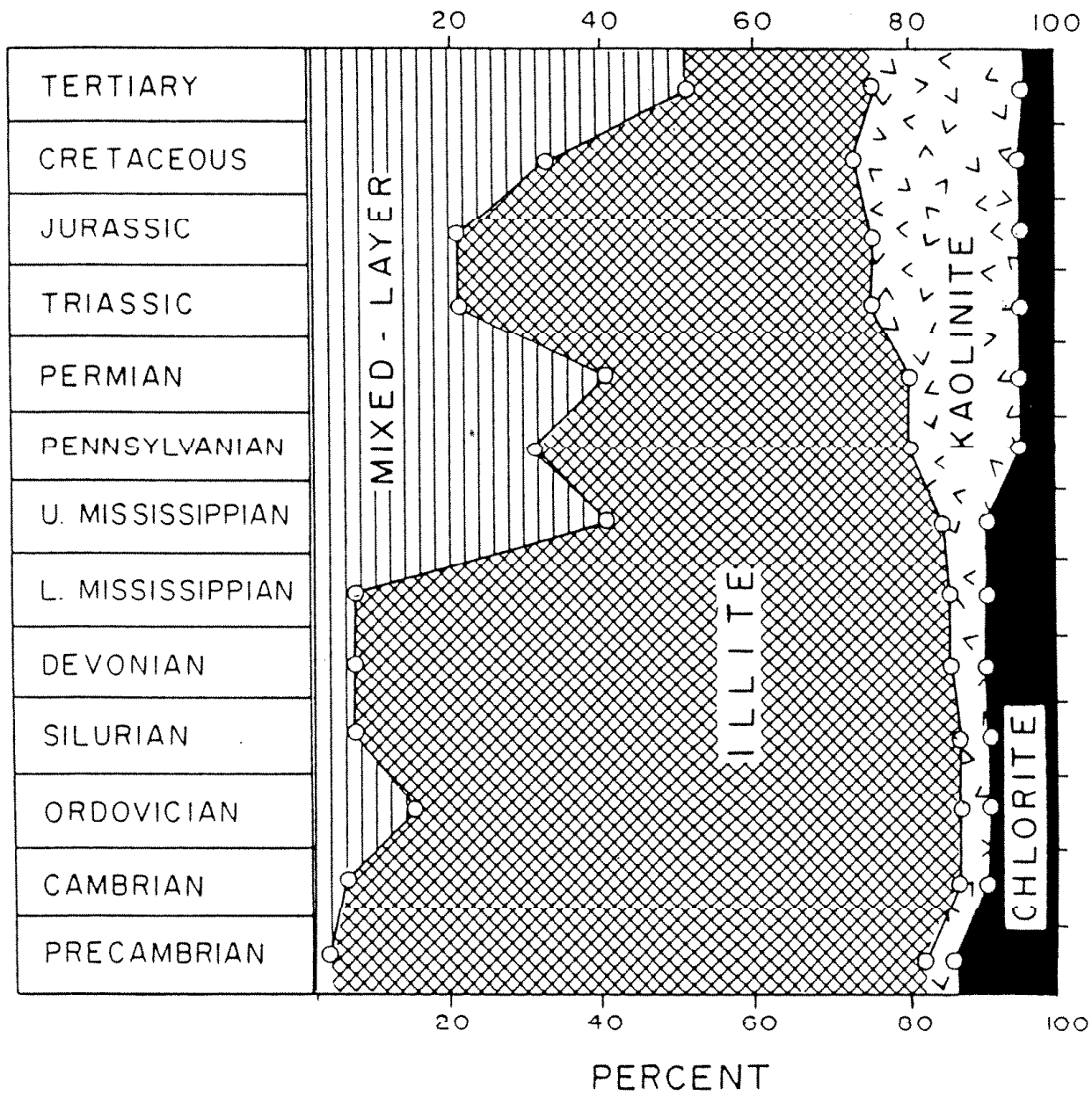

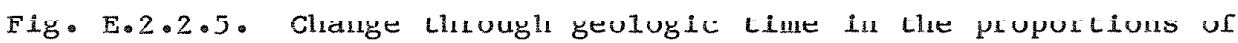
different clay-mineral groups as based upon analyses of some 40,000 shale and mud samples from North America (WEAVER 1967). 
Table E.2.2.5. Depositional environments and major physical characteristics of shales

\begin{tabular}{|c|c|}
\hline Characteristics & $\begin{array}{l}\text { Reference } \\
\text { source }\end{array}$ \\
\hline \multicolumn{2}{|l|}{ Nonmarine } \\
\hline $\begin{array}{l}\text { Continental desert - Shales rare, always thin, } \\
\text { scattered, and discontinuous. Formed in } \\
\text { ephemeral streams and lakes. }\end{array}$ & $\begin{array}{l}\text { MCGINNIES } 1968 \\
\text { GLENNIE } 1970\end{array}$ \\
\hline $\begin{array}{l}\text { Alluvial fan - Rare, thin shales become more } \\
\text { abundant on distal rather than medial or } \\
\text { proximal parts of fan. Continuity is always } \\
\text { poor and interbedded lithologies are } \\
\text { conglomerates, pebbly sandstones, and } \\
\text { sandstones. }\end{array}$ & BULL 1972 \\
\hline $\begin{array}{l}\text { Bolsons and playas - shales may be abundant and } \\
\text { thick with fair continuity which, however, } \\
\text { may be interrupted by sandstone channels. } \\
\text { Interbedded lithologies include sandstone, } \\
\text { salt, and gypsum. }\end{array}$ & \\
\hline $\begin{array}{l}\text { Valley fills and floodplains - Poor to good abun- } \\
\text { dance of shales, but continuity is poor because } \\
\text { of interruption by fluvial channels. Commonly } \\
1 \text { to } 10 \mathrm{~m} \text { thick. Interbedded lithologies are } \\
\text { siltstone and sandstone. Shales vary from } \\
\text { silty to exceptionally pure, and accessory } \\
\text { components include plant debris, coal, or, } \\
\text { where climate was arid, gypsum and caliche. } \\
\text { Penusylvanlan coal measures of eascern } \\
\text { Kentucky are good ancient example. }\end{array}$ & FISK 1947 \\
\hline $\begin{array}{l}\text { Lacustrine - Closely related to bolsons and playas, } \\
\text { with thickness of shales ranging from a few } \\
\text { meters to several hundred or more; ovate } \\
\text { bodies with good continuity of pure to } \\
\text { calcareuus, urganic-rich shale. Inlerbedded } \\
\text { lithologies include sandstone, carbonate } \\
\text { rocks, salt, and gypsum. Best example in } \\
\text { the United States is the Green River Formation } \\
\text { of Colorado, Utah, and Wyoming. }\end{array}$ & $\begin{array}{ll}\text { MATTER } & 1978 \\
\text { PICARD } & 1981\end{array}$ \\
\hline $\begin{array}{l}\text { Glacial - Include boulder clays (till and tillite), } \\
\text { lake deposits, glacial outwash, and other } \\
\text { melt-water deposits. Shale is uncommon and } \\
\text { where present has poor continuity. }\end{array}$ & \\
\hline
\end{tabular}


Tab1e E.2.2.5 (Continued)

\begin{tabular}{|c|c|c|}
\hline Environment & Characteristics & $\begin{array}{l}\text { Reference } \\
\text { source }\end{array}$ \\
\hline
\end{tabular}

Transitional

Deltas

River-dominated - Shales are abundant with wide range of thickness, up to several hundred meters for delta-front shales which grade into those of open shelf. Delta-front shales have good continuity and where water was deep have wel1-defined clinoform structure. Interhedded 1ithologies are mostly sandstone and siltstone, but some carbonate rocks and coals possible bordering distributary bays.

Wave-dominated - Shales not abundant in delta proper, where they interfinger up-dip into sandy coastal barriers; shales grade downdip into those of open shelf.

Fan-deltas - Shales not abundant on delta itself, except at distal fringe, where they thicken and grade into thick basinal shales. Shales grade up-dip into sandstones and conglomerates. Carbonate rocks possible down-dip. Continuity poor to fair.

Estuarine - Yoor to moderate abundance of shales with poor to fair continuity because of interruption by sand-filled channels.

Coastal - Poor to moderate abundance of shales in inshore mudbe1t; thickness up to 10 meters or more. Shales may be 1ncerrupced by sandy coastal barriers and tidal channels.

Marine

Shelf - Shales are abundant and include wide, thick and thin sheets of pure shale with exceptional lateral continuity. Interbedded lithologies are sandstones and carbonate rocks, possibly salt and gypsum. Uncommon shelf channels or canyons may interrupt continuity.
FISK 1954

KOLB 1967

SHIRLEY 1966

BROUSSARD 1975

WESCOTT 1980

HAYES 1982

OOMKEINS 1960

ROY 1980

AUGUSTINUS 1978

AUGUSTINUS 1980

WELLS 1981

SHIDELER 1977

STANLEY 1978

STANLEY 1983 
Table E.2.2.5 (Continued)

\begin{tabular}{lcc}
\hline Environment & Characteristics & $\begin{array}{c}\text { Reference } \\
\text { source }\end{array}$ \\
\hline
\end{tabular}

Marine (Continued)

Slope - Abundance of shales also good, but most shale units tend to have complex shapes and variable thickness up to several hundred meters. Slumps 1ikely and deposits are commonly involved in later deformation.

Deep basin - Shales have excellent abundance and are almost always the dominant lithology. nvate to elongate, thick bodies up to hundreds of meters or more thick interbed up-dip with silty and sandy turbidites and even carbonate rocks turbidites of we11-developed subsea fans. slumping common and deposits likely to be involved in later deformation.
STANLEY 1978

DOYLF, 1981

STANLEY 1983

PIPER 1978

STANLEY 1981

The shales formed on ancient marine shelves range in thickness from a few tens of meters to more than one hundred meters, and, as a rule, form wel1-defined, traceable units. These characteristics are well illustrated by the Devonian-Mississippian Chattanooga and the Ordovician Sylvan Shales. Continuity is by far the greatest in shelf deposits. The very uniform thickness of the Mississippian Fraileys Shale throughout a large region, namely the Illinois portion of the Illinois Basin, demonstrates this parameter well (ATHERTON 1975). Such shales are commonly free of slump reacures. Many ancienc shelf deposits were formed on cratons or passive continental margins and, as a consequence, have not experienced much subsequent structural deformation.

Shales are most abundant in the deeper marine basins where original water depth was greater and where subsidence was more rapid than along the adjacent shelf. Here, muddy sediments accumulated to the extent that shales with thicknesses up to hundreds or even thousands of meters formed. Such deposits developed along the slopes, at the base of slopes, near ancient subsea fans, or on a deep-basin plain where turbidity currents deposited much silt and sand far below wave base. Typical sites for these centers of shale deposition were along ancient active continental margins or in deep basins later associated with mountain building. Penecontemporaneous slump features are fairly common in some of these shales; some of these shales have also been Involved in later structural deformation. Thin shales are known to have formed at the base of marine shelves along ancient, passive continental margins. 
River-dominated deltas, such as the typical bird-foot delta of the Mississippi River, also produced abundant shales, especially where they prograded into deep water and created thick delta-front deposits. Such deposits have a prominent clinoform structure; sandstone and siltstone are the chief interbedded 1ithologies. Slump structures are common in some of these shales. Some thinner and less continuous shales formed in interdistributary bays where associated lithologies are sandstone, possibly coal, and (rarely) carbonate rocks.

None of the other environments are as rich in shale as is the marine environment and only the marine environment produces shale of great thickness and lateral continuity. A possible exception is certain thick and laterally continuous shales formed in large, persistent lakes. The calcareous shales of the Green Kiver formation in the western United States represent one such example.

\section{E.2.2.3 SHALY BASTNS}

Requirements for the formation of shale-rich basins appear to be threefold: (1) the source region must have had a wet climate, so that erosion was great and its rivers had ample kinetic energy to carry a high and sustained load of suspended sediment to the sea; (2) relief in the hinterland of the basin was moderate to high, in order to provide ample potential energy for both water and sediment movement; and (3) within the basin proper, clay particles could everywhere settle to the bottom. Thick shales also imply sustained mud supply and continuous basin subsidence.

High mountains, such as those characterized by high potential energy, might have developed along an active continental margin (where a continental plate collides with an oceanic plate) or like the conditions along the west coast of most of the western-hemisphere continents. This type of setting would yield vast quantities of mud where the climate is wet (high kinetic energy), but little where the climate is dry (low kliellc energy). This relacionship has been well shown by studies along the west coast of South America (ZIEGLER 1981; FONTAINE 1983). The shales of such marine basins tend to be deformed, because of the intense stress generated by the interaction of oceanic and continental plates; complex structure is therefore typical. Conversely, mud may also be transported long distances by large rivers whose headwaters are in the mountains of such active continental margins, but whose deltas are located on passive margins thousands of kilometers distant. The orinoco and Amazon kivers well illustrate such conditions; namely, that major rivers deposit mud and sand on passive margins far removed from the mountains that are related to active continental margins and that are the sources of sediment. On such passive margins, shaly basins are likely to have but little tectonic deformation, except possibly for diapirism (salt and/or shale) and growth faults.

Another major source of mud occurs where high relief is formed by the interaction of two continental plates and rainfall is also high, as is the case in the Himalayas of northeastern India and northern Burma. 
Thick shales also occur in major rifts when they become flooded, provided a large river empties into the rift, or the rift borders had moderate to high relief and abundant rainfall.

Deposition leading to the formation of shales is less likely to be abundant in marine basins marginal to, or on, large low-1ying cratons with dry climates. In such areas, low potential energy combines with low kinetic energy to yield only a few low-discharge rivers. Shaly basins do occur on cratons where the latter are bounded by mountain ranges whose rivers drain cratonward and form deltas and/or muddy seas during times of high worldwide sea level. Such marine shales represent well-defined, distinct units that cover thousands of square kilometers and commonly have thicknesses of tens to a few hundred meters, but which thin cratonward. 
An understanding of the geometry and dimensions of shales is clearly of importance to any assessment of the suitability of this rock type for possible repository siting. Because of the very sizable number of shales in the United States, Gonzales and Johnson (GONZALES 1984) inventoried and described the characteristics of only those that exceeded $75 \mathrm{~m}$ in thickness. It may, however, be possible to consider shales that are $50 \mathrm{~m}$ thick as potential host rocks, for purposes of ORNL's Sedimentary Rock Repository Program.

Shale deposits range in thickness from a few millimeters to more than a thousand meters. Likewise, their lateral distribution or extent ranges from a few hundred square meters to greater than one million square kilometers. Within this great variance, however, there are a significant number of major shale units that are $>75 \mathrm{~m}$ in thicknese and that cxtend with that thickness for more than $50 \mathrm{~km}$ in all directions (GONZALES 1984). The number of shale formations with comparable lateral extents, but only $50 \mathrm{~m}$ thick, is even greater.

Many shale deposits were formed in relatively stable tectonic environments. Long-lived marine or lacustrine basins allowed slow accumulation of fine-grained sediments over large areas for long periods of geologic time. Also, cratonic, shelf, or prodelta environments in many basins were sites of steady, continuous sinking of the crust, which permitted slow and uninterrupted accumulation of thick shales over these large regions. Shales formed in all of these environments tend to be flay-lying and tabular to sheet-like with considerable homogeneity over much of their extent. Shales that were formed on marine shelves, large river deltas, and deeper marine basins tend to be more persistent among the tabular deposits. Even in some very thick marine and deltaic shales, the overall spatial representation appears as a fairly thin sheet, given the very large lateral dimensions. The Upper Cretaceous Pierre Shale, for example, extend throughout much of North and South Dakota, or an area of several hundred thousand square kilometers, at thicknesses up to $700 \mathrm{~m}$ (SHURR 1977). Despite its significant thickness, this extensive shale still resembles a thin tabular body. The Pennsylvanian Fxcello Shale extends through four Midcontinent states, yet does not exceed $3 \mathrm{~m}$ in thickness (CASSIDY 1968).

Other shales are lens-like to ovate to elongate; these shapes are typical of some marine and deltaic deposits. Stratigraphic sequences formed by repeated cycles of transgression and regression are prone to have shales (and other clastic units) of this type. The Cretaceous Mesaverde Formation reveals clastic units with these characteristics in several western states (GILL 1966; MASTERS 1967). In spite of the geometries, the vertical and lateral dimensions can still be appreciable, being measured from tens to hundreds of meters in the former and kilometers in the latter. An unusually thick shale deposit is the Tertiary Peace Valley Beds, which are $>4,000 \mathrm{~m}$ thick within the Ridge Basin of California, yet do not extend more than $15 \mathrm{~km}$ laterally (LINK 1978). Still other shales are very elongate to linear to lenticular, hut only me of the two lateral dimensions is likely 
to be sizable. In these cases, one lateral dimension may be only a few meters whereas the other is expressed in hundreds or thousands of meters. Several types of nonmarine deposits are characterized by this type of geometry; nonmarine shales found in the Pennsylvanian "coal measures" of the Appalachian Basin would be typical examples (FERM 1970; DONALDSON 1974). Where shales tend to be tabular and laterally persistent, the associated lithologies, typically sandstones, siltstones, and various clastic gradations also tend to be tabular. The result is clastic stratigraphic successions composed of tabular units; these are typically found in certain marine and deltaic deposits.

Shales that display unusual (appreciable vertical thickness, but minimal lateral extent) geometries are those with large-scale slump features and Lliuse that have formed diapirs. Such characteristics are due, respectively, to contemporaneous sliding or slumping during deposition or to plastic flowage after deposition. These features and shales marked by them are undesirable from the standpoint of this report. Shale diapirs present in the Tertiary of the Texas Gulf Coast are a well-known example (BROONER 1967; BISHOP 1977).

In Lerms of vercical dimensions, shales range trom a tew millimeters through all thickness gradations up to hundreds and even more than one thousand meters. The latter is a rare circumstance; actually, such shales typically contain other clastic lithologies as interbeds but seem predoninantly composed of shale. Numerous shale units fall within the 50 to $150 \mathrm{~m}$ range; most shale bodies are more typically a few to $10 \mathrm{~m}$ thick.

Many nonmarine shales are less than $5 \mathrm{~m}$ thick and few ever exceed $10 \mathrm{~m}$ in thickness. Typical examples are shales formed under desert and alluvia1fan conditions (GLENNIE 1970; BULL 1972). Exceptions are channe1-filling shales and certain lacustrine units that can be several hundred meters thick. Channel fills, however, are discontinuous and generally have a complex shape. Several "gorge" or channel-filling shales have been recognized in the Tertiary sequences of the Sacramento Basin of California (IIAGKEL 1960; EDMONDSON 1972). Shale diapirs are commonly extensive in the vertical direction (several hundred to several thousand meters), but these bodies are typically difficult to define in terms of their lateral dimensions, unless geophysical techniques are utilized (MUSGRAVE 1968).

Tabular to sheet-1ike shale units range from a few hundred up to more than several thousand square kilometers in extent. Thus, the range is from extremely localized to exteuls that cover several staces. Certain marine, deltaic, and nonmarine shales, such as those deposited in channe1s, on floodplain surfaces, and on inner continental shelves, are prone to be elongate. One lateral dimension is orders of magnitude greater than the other.

Many thick shales that were formed in delta-front and marine-slope environments reveal a clinoforn structure or configuration within the main, thickest portion of the shale. By clinoform structure is meant an internal, large-scale inclined structure that was formed as a result of deposition on a gentle slope of a few degrees. Both lateral dimensions are extensixp, 
and are measured in tens to hundreds of kilometers. In both the down-dip and up-dip directions, the shale thins appreciably, yet commonly retains its full thickness in the other dimension. Although many deltaic and associated marine deposits are felt to display this internal geometry, the Gammon Member of the Pierre Shale in the Powder River Basin represents an excellent example (ASQUTTH 1974).

A number of Paleozoic marine shales that are both thick and laterally persistent extend over two or more entire structural-depositional basins as we11 as across the intervening structural highs. The Chattanooga Shale (and equivalents such as the Woodfork Shale) represents a typical example that is both thick and persistent in more than one geologic basin (GONZALES 1984). The Pierre Shale is clearly another such widespread unit found in several basins (SHURR 1977).

It is even common to find thin layers or zones that are traceable farther than the main shale unit. Lateral persistence may be followed on the basis of outcrops, well-log signature, unique geochemistry or minera1ogy, or distinctive internal structures. Some we11-illustrated examples are phosphate-rich black shales in certain Pennsylvanian cyclotherms in the Midcontinent as described by Hecke1 (HECKEL 1977) and the Three Lick Bed within the Devonian Ohio Shale as discussed by Provo (PROVO 1978). These unusual intervals within shales represent diagnostic time markers.

Shale deposits more than $75 \mathrm{~m}$ thick underlie vast tracts in most parts of the United States, and many individual shale units actually extend over regions at least several thousand square kilometers in areal extent (GONZALES 1984). A generalized distribution of these shales is shown in Fig. E.2.3.1. From a collective standpoint, several million square kilometers in this nation are underlain by one or more thick shale units. Some of the more extensive and thick shale deposits in the eastern United States are as follows: Upper Ordovician Maquoketa Group and Cincinnatian Series; Upper Devonian-Lower Mississippian New Albany Shale, Antrim Shale, E1lsworth Shale, Upper Olentangy Shale, and Huron Shale; and Lower Mississippian Coldwater Shale. Throughout the Great Plains and Midcontinent, a series of thick shales of Mississippian, Pennsylvanian, and Permian ages underlie much of that region, whereas thick Cretaceous shales, such as the Pierre, Skull Creek, Kiowa, Mowry, Bclle Fourchc, Carlilc, Graneros, and Marias River are also widespread in the northern Great Plains. A number of thick and widespread shales that are chiefly Cretaceous and Tertiary in age are found in the Rocky Mountains and Colorado Plateau, whereas the Great Basin contains several major Paleozoic sequences, such as the Eleana, Pilot, and Chainman Shales. Thick shales of Jurassic, Cretaceous, and Tertiary age are also known from the Great Valley of California.

The vast majority of these thick, areally extensive shales were formed under marine conditions or in large delta systems that merged into marine basins. Present-day subsurface conditions are such that large expanses are underlain by these thick, largely marine and/or deltaic shales within depths of 300 to $1,000 \mathrm{~m}$. 


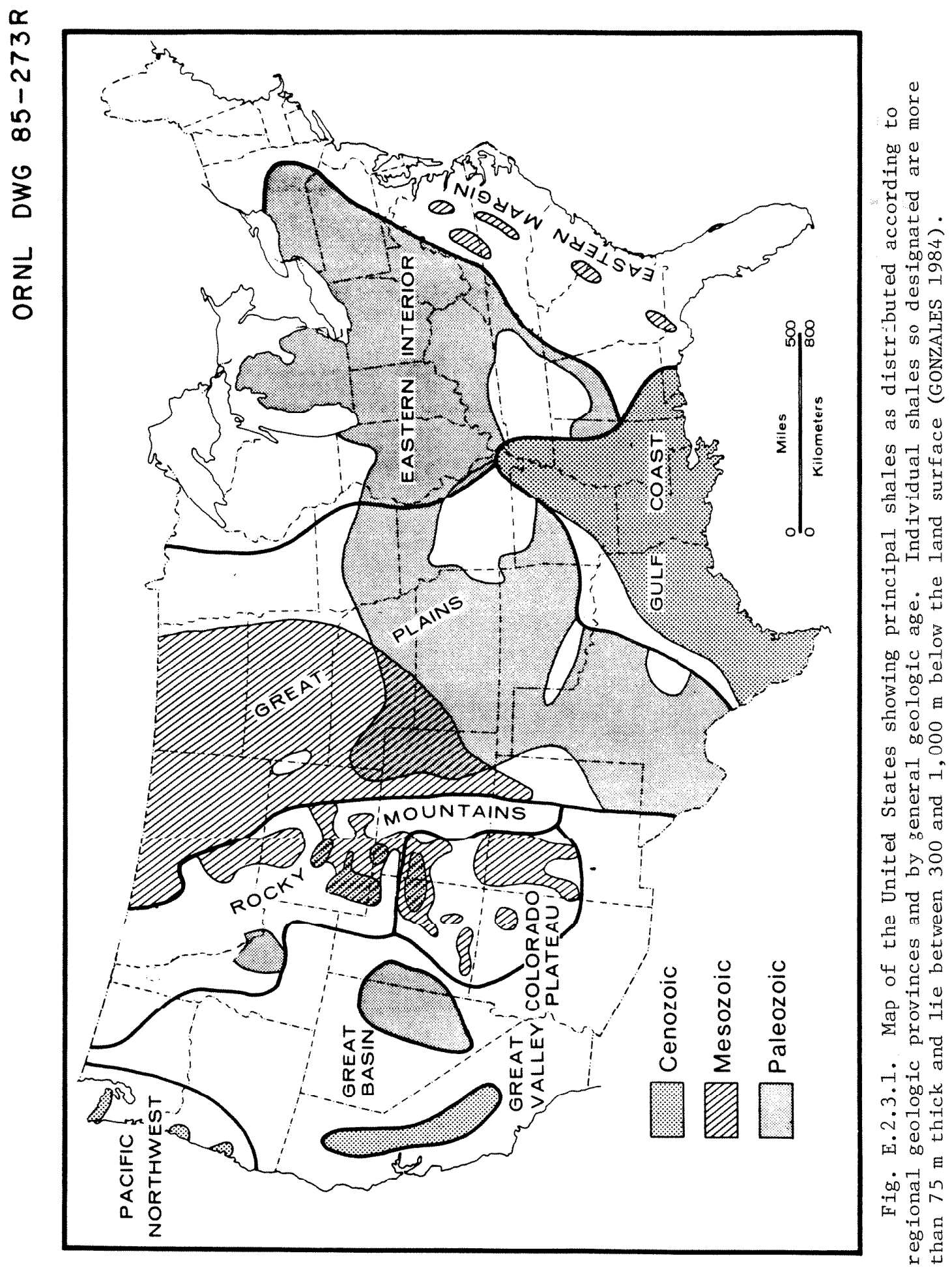




\section{E.2.4 CHARACTERISTICS OF SHALE DEPOSITS}

Much of the material discussed in this subsection is drawn from references that have been acknowledged in the preceding chapters. In particular, these data sources include Potter (POTTER 1980), Gonzales and Johnson (GONZALES 1984), and the various references cited on Table E.2.2.5. Additional literature sources are cited as appropriate.

This subsection addresses commentary on the lithologic character, including mineralogy, texture, and homogeneity of shales, the stratification (bedding-lamination) of shales, the nature of certain primary and secondary sedimentary structures present in shales, and certain other selected properties of shales. The discussion is essentially divided into two categories: (1) a general treatment of the spectrum or range of properties; (2) a more specific consideration of these same properties for those shales formed in the few depositional environments capable of yielding shale deposits of persistent lateral and vertical extents.

Some of the material presented and discussed here is summariped, alnng with other data similarly summarized from the other sections; the resulting condensed information is treated in sect. E.2.8 by means of a summary table and brief text.

\section{E.2.4.1 LITHOLOGY}

\section{E.2.4.1.1 Mineralogy and Geochemistry}

Although shales and related fine-grained argillaceous rocks can contain a wide range of minerals, the typical, or "average," mineralogy consists of clay minerals, quartz, feldspars, calcite and/or dolomite (in some, silica is present in addition to the detrital quartz), and various iron-oxide minerals. The clay minerals clearly can be the dominant phase, being close to $60 \%$ of the total mineralogy (PETTIJOHN 1975). Nearly $30 \%$ nf mnat shales is detrital quartz, whereas the remaining $10 \%$ is divided among the other mineral constituents. It should be noted finally that these relative abundances only relate to the non-organic portion of shales; in many shales, organic matter of various types can account for a few percent of the total rock volume.

Clay minerals, whether the particles are clay or silt in sime, are not only the dominant mineralogic phase in shales, but also the component on which the greatest amount of basic research has been conducted. The principal clay-mineral species are kaolinite, smectite as mainly montmorillonite, illite, finely divided muscovite (in argillites), and chlorite. Vermiculite and some other less common clay minerals have been identified in some deposits, but generally they do not make a significant mineralogic contribution. Another important category, however, is the mixed-layer clays, which generally are intermediate forms involving smectite (montmorillonite), illite, and muscovite. One unique mixed-layer clay is glauconite, a distinctively green mineral that appears to be exclusively formed in marine environments. 
Smectites are hydrated, expandable clay minerals. Shales and/or commercial clay deposits rich in the principal smectite mineral montmorillonite are commonly also called bentonites or bentonitic shales. These occurrences are typical of many Cretaceous and Tertiary strata found in the Great Plains, Rocky Mountains, and other western areas. The bentonitic content is the result of extensive volcanic tephra (mainly volcanic glasses) that were deposited under marine and certain lacustrine conditions after airfall and were altered to smectite.

As shown previously in Fig. E.2.2.5, (WEAVER 1967) has shown a definite distribution pattern of the clay minerals through geologic time. The dominance of illite in older deposits appears to be the result of its increased mineral stability as a result of longer and deeper burial. Thus, younger deposits that are rich in illite would appear to have been more deeply buried than those shales low or lacking in illite. Burial diagenesis in essence produces illite; where temperatures and/or the depth of burial are greal enough, different polymorphs of 1111 te and greater crystallinity, plus the presence of white mica or muscovite, can be used to describe/identify argillites, or mark the ill-defined sedimentary/ metamorphic temperature boundary (De SEGONZAC 1970; WINKLER 1974). Chlorite is a mineral typically associated with illite, whereas abundant muscovite, formed mainly by the conversion of illite, would indicate lowtemperature metamorphic units according to many authors.

The clay mineralogy of shales reflects two sources of influence, original provenance of the sediment and diagenetic alteration after deposition. The relative importance of these two controls has been a topic of extended debate in the sedimentology 1iterature. Two concluding observations may be made, however, to the distribution shown in Fig. E.2.2.5. The absence of smectite and near absence of mixed-layer clays containing smectite in older strata probably can be accounted for by destruction/conversion by diagenesis (MACKENZIE 1975). Weaver (WEAVER 1967) feels that the greater abundance of kaolinite in younger rocks reflects the influence of changes in weathering brought on by the emergence of land plants in the Late Paleozoic.

Some, and in certain cases most, of the clay minerals in a shale may be diagenetic in origin. IL is also fell that some clays and some of the feldspars grew in place within the depositional environments; i.e., they are so-called authigenic minerals (POTTER 1980). The contribution made by these processes is not known. In certain rocks that have a geologically young source of volcanic (tuffaceous) material, zeolites such as analcime can also form authigenically (SHEPPARD 1973).

The principal cementing agents in shales are carbonate rocks (calcite, dolomite, possibly ankerite in a few cases) and silica. These cements are present in shales as the result of biogenic processes, direct chemical precipitation, diagenetic changes, and/or post-depositional introduction from percolating fluids. Relatively little is known about which processes are more important, how cements in particular shales were formed, and related considerations. Compared to the amount of study conducted on cementation in sandstones and carbunale lucks (BATHURST 1971; DAPPLES 1972; FOLK 1974; BLATT 1979), virtually no effort has been directed at this topic in shales. 
In general inorganic-geochemical terms, shales are rocks that are composed principally of silica $\left(\mathrm{SiO}_{2}\right)$ and alumina $\left(\mathrm{Al}_{2} \mathrm{O}_{3}\right)$; nearly $75 \%$ of the bulk chemistry of average shales consists of these two oxides (PETTIJOHN 1975). Oxides of iron, magnesium, calcium, sodium, and potassium, with small amounts of carbon and water, account for the remaining $25 \%$ of the bulk chemistry.

Even though the final clay mineralogy may reflect the influence of both provenance and diagenesis, gross chemistry basically demonstrates only a relationship with the source of the sediments that constitute a particular shale. Interestingly, however, most of the geochemical research effort on shales has dealt with their trace-element, in particular heavy-metal, geochemistry (TOURTELOT 1970). A practical relationship of the high content of uranium found in certain black shales is the use of these "marker" units in geologic correlation because of their diagnostic responses on gamma-ray well logs (SWANSON 1961; MAJCHSZAK 1978). Stratigraphic correlations using trace-element geochemistry without the benefit of wel1 logs have, however, been made for the Devonian Esopus Shale in New York (FENNER 1967).

Various studies have also combined gross-chemical and trace-element analyses to fully describe the geochemical nature of certain shales (TOURTELOT 1970; SCHULTZ 1976; MOORE 1978), but no applied utility has really been derived from these analytical studies. An exception may be the article by Vine and Tourtelot (VINE 1970) where the detailed geochemistry of black shales is discussed; important implications for shales as the source of metals eventually concentrated in ore deposits were included in their commentary. There does appear to be a definite complexingretention of metals in many black, and some non-black, shales due to their content of organic matter.

Organic matter in shales can influence or determine the color of these fine-grained rocks. Where several ( 3 to $5 \%$ ) organic carbon is present. the shale units are black, or are certainly dark brown to dark gray. The presence of organic matter in much lower amounts, albeit in localized concentrations, can create zones, blotches, or irregular patterns of green coloration that reflect reduced iron compounds (McBRIDE 1974). MCBr1de (MCBRIDE 1974) also felt, as had some earlier investigators, that those sediments with high ratios of ferric $\left(\mathrm{Fe}^{+3}\right)$ to ferrous $\left(\mathrm{Fe}^{+2}\right)$ iron will be red or purple, whereas those with low ratios will be green or gray. Some green shales which do not have appreciably high contents of organic matter, however, derive their overall coloration because of the reduced nature of the iron compounds. Data on the relative importance of organic carbon to the ratio of the different valence states of iron, as presented by Potter (POTTER 1980), seem to indicate that very sma11 amounts (1ess than $0.5 \%$ organic carbon) can produce reduced $\left(\mathrm{Fe}^{+2}\right)$ iron, and thus lead to green and/or gray colors.

More significant than coloration or the capability to retain heavy metals, organic matter in shales is significant because shales are considered a (some would say the) principal source of petroleum (TISSOT 1978). From an organic-geochemistry viewpoint, the capacity of a shale, 
or any source rock, to generate hydrocarbons is a function of the amount of organic matter in the rock, the type of organic matter present, and the degree of thermal maturation that has been applied to that organic matter. There are several ways in which to classify the organic matter present in sedimentary rocks, and these are discussed in some detail by Hunt (HUNT 1979). One of the more revealing approaches, as developed by Tissot and his co-workers (TISSOT 1978) and modified by Bostick (BOSTICK 1979), identifies four varieties of kerogen, designated Types I, II, III, and IV. Each type occupies a unique position on a Van Krevelen diagram (hydrogen/carbon ratio plotted against oxygen/carbon ratio). The algalamorphous nature of the organic matter increases in Types I and II, whereas the herbaceous to woody, or to charcoal in the utmost case, incrcaocs in the other typee; woody material is dominant in Type III and charcoaled material is dominant in Type IV. of interest to petroleum geochemists is the fact that Types I and II are much more capable of generating oil and gas under conditions of increasing thermal maturation; Type III is nearly always gas-prone (BOSTICK 1979; HUNT 1979). Type IV, by contrast, is principally associated with coal, but may generate some gas.

A related question is, "How much organic matter is needed for the rock to qualify as a source bed?" The minimum amount seems to be around $0.5 \%$ organic carbon, although some oil and gas can apparently be generated from shales with slightly less than this percentage. According to Tissot and Welte (TISSOT 1978), all identified source beds average slightly more than $2.0 \%$ organic carbon.

Considerable effort has been expended in recent years by the petroleum industry to determine thermal maturity of shales by detailed microscopic examination of certain components of the organic kerogen. This work was first undertaken by Burgess (BURGESS 1974) and has been greatly refined. An excellent, current review of the techniques is presented by Van Gijzel (VAN GIJZEL 1982). Application of these thermal-maturity data to the study of sedimentary basins within a petroloum exploration program is given by Milner (MILNER 1982).

other methods for determining thermal maturity of shales from studies of organic components are reviewed by Bostick (BOSTICK 19/9). Another method is the use of the coloration in conodonts, a unique assemblage of jaw-1ike and teeth-1ike microfossils (EPSTETN 1977; HARRIS 1979). Weaver (WEAVER 1980) has suggested that detailed K/Ar-age dating, using the incremental release technique, can be coupled with oxygen isotope data to yield a geochemically based geothermometric method applicable to shales.

Hunt (HUNT 1979) has presented some data on the type of kerogen in various shales: (1) Green River kerogen-rich marlstones ("oil shales") clearly Type I with high H/C ratios; (2) Woodford Shale (black shale phase), and Monterey, Pierre, and Bakken Shales - Type II, or largely oil-prone; and, (3) Atoka Shale - Type III and largely gas prone. Hunt (HUNT 1979) also presents data indicating the range of percent organic carbon for selected shales: (1) Pennsylvanian Cherokee Group shales (gray and green) - 0.3 to $1.8 \%$; (2) Cretaceous pierre and Mowry shales 1.0 to $1.2 \%$; (3) Devonian Woodford and Tertiary Monterey Shales (black 
shale phases) - 2.0 to $4.8 \%$; and (4) Pennsylvanian Paradox Formation (calcareous black shale) $-8.5 \%$. By contrast, even though it lies outside of this country, the only oil shale currently yielding synthetic crude oil is the Irati Formation of Brazil; it contains nearly $10 \%$ organic carbon (HUNT 1979).

Shales with significant amounts of organic matter expressed as percent organic carbon can form in various depositional environments. Black shales, for example, may be mainly deposited in deep-water marine basins, but can also be produced in restricted, shallow-water basins or along marine shelves. Other black shales are clearly deltaic, while some are developed under cyclothemic (marine/deltaic/nonmarine) conditions. Black to dark-brown oil shales can also be created in lacustrine environments. As discussed by Bostick (BOSTICK 1979), there seems to be better agreement relating depositional environment and kerogen type than efforts to relate environments to the mere presence of organic matter in the resulting sediments. Type I kerogen therefore appears typically in lacustrine and certain vaporitic deposits; Type II is mainly characteristic of marine shales; while Type III is found in sediments deposited along continental margins, or where deltaie to marine transitions are common. Type IV is typical of deltaic to nonmarine settings.

\section{E.2.4.1.2 Texture}

Shale, as discussed in Sects. E.2.1 and E.2.2 of this report, is as much a textural term as anything. Shales, and many related fine-grained rocks, are dominated by minerals that largely fall within the clay- $(<4$ $\mu \mathrm{m})$ and silt- $(4-62 \mu \mathrm{m})$ size fractions.

As observed in these preceding chapters, and despite the dominance of clay minerals, many of the clay-mineral particles, as well as other detrital grains, technically fall within the silt-size range. This relationship can be seen in Fig. E.2.2.1 and the related discussion in that chapter. Most mineral grains in shales are, however, <62 um in sizo. Those particles that are commonly present in shales and are $>62 \mu \mathrm{m}$ include sand (quartz and other minerals, such as the so-called "heavy" minerals) grains, fossil fragments, microfossils and megafossils, and discrete fragments of organic material. Still larger masses, commonly reaching several meters in lateral dimension and from centimeters to a few meters in vertical dimension, are various mineral concretions. The latter are treated in the succeeding discussion on sedimentary structures.

Shales also illustrate certain relationships between textures, or variations thereto, and stratification. Thus, shales, namely those formed by turbidity-current deposition, may themselves reveal graded bedding or may be involved within interbedded clastic sequences called "Bouma" cycles (WALKER 1967). Shales, especially those of lacustrine origin (VAN HOUTEN 1969; PICARD 1972), may also be varved, evidence of seasonally controlled deposition that includes textural variation. In an ideal varve of annual nature, the 1ighter-colored layer was formed more rapidly in the summer and is low in organic matter and high in sl1L; the wincer couplec is darker, and richer in both organic matcer and clay-sized particles. 


\section{E.2.4.1.3 Lateral and Vertical Homogeneity}

Shales can range from very inhomogenous to very homogenous either laterally or vertically, depending upon what type of depositional conditions were responsible for the formation of the shales and any associated lithologies. In most shales, homogeneity is more pronounced in the lateral dimension where shales, or specific zones within larger shale intervals, can extend hundreds to thousands of kilometers without appreciable change in lithology, mineralogy, stratification, etc.

Vertical homogeneity of the same magnitude is less likely largely because slight fluctuations in depositional conditions through time are more likely to result in changes to other lithologies or variations in the texture, mineralogy, or primary sedimentary structures of a shale. Various clastic sequences that consist of thin (a few centimeters to a few meters) units of interbedded siltstone, sandstone, and shales commonly will display hundreds of individual strata over a vertical dimension measured in a few hundred meters. Turbidite and marine-slope to fan deposits typically show such repetitive sequences.

Conversely, while many, commonly thin shales can extend great lateral distances, other shales may be relatively to very inhomogenous in that direction. Sudden changes or fluctuations in subenvironments of deposition result in pronounced facies changes to other lithologies or various gradations. This is especially true of many types of nonmarine shales and some deltaic deposits where channels (distributary, alluvial) are involved.

Shales formed along marine shelves and slopes probably display a more consistent homogeneity in both dimensions than other shales. Shales formed in large prograding delta systems in stable cratonic basins in many instances will display similar characteristics.

\section{E.2.4.2 STRATIEICATION AND OTHER PRTMARY SENTMENTARY STRUCTURES}

Some discussion has already been afforded this topic in Sect. E.2.2, but only as was necessary in regard to classification. Here, both stratification and other primary (made at the time of deposition) sedimentary structures are considered.

Shales can either he laminated, where the stratification layers are $<10 \mathrm{~mm}$ thick, or bedded, where the layers exceed $10 \mathrm{~mm}$ in thickness. Table E.2.2.3 1ists the actual bedding terms used to describe various subdivisions of this stratification. In a general way, shales that are richer in clay minerals and/or organic matter tend to be laminated; those richer in silt, with possibly a lower clay content and more mineral content, tend to be bedded. In either circumstance, the stratification is described as parallel horizontal, which reflects the periodic or episodic deposition of suspended sediment from still water.

Certain shales, particularly those formed under alluvial-deltaic conditions, can also be cross-bedded or cross-laminated. As observed in the 
preceding section, some shales are also varved. This is an example of laminations that occur within a larger bedded unit (VAN HOUTEN 1969). Still other shales appear simply as massive, or massively bedded, units. Deeper-water marine-slope shales, shales involved in slump features, or inside diapirs are typically bedded in this mannex. Massive bedding is the result of long-term, moderately rapid, suspension-based sedimentation in these deeper-water environments. Another cause is extensive bioturbation or the active reworking of the soft sediments prior to induration by various burrowing organisms. This mechanism is the cause of similar massive bedding in chalks.

Primary stratification not only varies between shales formed in different depositional environments, but also within the same shale formation that largely resulted from deposition in the same environment or very similar ones. Picard and High (PICARD 1972), for example, demonstrated that the Green River Shale in Wyoming exhibited more than 12 different types of stratification.

In addition to stratification, shales exhibit a wide range of primary structures such as ripple marks, mud cracks, crnss hoditing, flasor marks, sole marks, and clay intraclasts. A good review of these features is given by Potter et al. (POTTER 1980). The basic utility of these structures is in determining the direction of current flow and analyzing conditions in depositional environments.

\section{E.2.4.3 NON-SHALE INTERBEDS}

Interbeds found within shale units vary considerably in their lateral and vertical dimensions. They can be very thin, i.e., a few millimeters to a few centimeters, or moderately thick, i.e., a few meters, or thick, i.e., several tens of meters. These non-shale 1ithologies can be as laterally persistent as the associated shale, or, at the other end of the spectrum, they can be lenticular, elongate, or discontinuous, although this condition appears not to be as common.

The lithologies represented typically are coarser-grained clastics, namely siltstones, sandstones, and, less commonly, conglomerates. These clastic interbeds are typical of most non-marine environments (see Table E.2.2.5) as well as some deltaic and marine conditions.

Other 1ithologies are a1so found as interbeds; typica11y these include various carbonate rocks, dolostone, anhydrock, and even salt. Almost all of these associations are formed in marine environments; however, some lacustrine shales will exhibit similar chemically precipitated interbeds. A related feature is that the shales whose interbeds include various carbonate rocks also tend to have calcareous cement themselves. In similar manner, silica-cemented shales are likely to have interbeds of chert or novaculite associated with them.

Shales that vertically merge into closely associated interbed 1ithologies may actually derive some benefit from this association. For example, a calcite-cemented shale with several discrete interbeds of argillaceous 
limestone over a few tens of meters of vertical dimension might prove superior as a roof interval than just the carbonate-cemented shale over that same interval.

\section{E.2.4.4 SECONDARY STRUCTURES}

Secondary structures formed in shales are the result of: (1) compaction and dewatering and related self-deformation; (2) diagenetic (chemical) processes; and (3) tectonic or orogenic stresses. Features formed in response to the first two processes are still described as sedimentary structures; those caused by externally applied physical stresses are typical geologic structures such as faults, folds, joints, and fractures.

Sedimentary structures are typically of academic interest; for a thorough review of such features and their characteristics, the reader is referred to Potter et al. (POTTER 1980). Some exceptions include shale diapirs, which are themselves compaction/self-deformation features, and large concretions. Because such diapirs represent masses of sediment that have been intruded or squeezed into overlying units, and are commonly aoociated with faulting and ovorpreceured shalee, they are not considered further.

Concretions are features that can be found in shales that might be given consideration as a potential host. They are localized concentrations of cement or other mineral matter that has typically developed around a nucleus, commonly organic material, and that displaces the regular stratification. Compositions include those rich in carbonate, ironoxide, silica, or sulfide minerals. Black shales rich in organic matter are commonly more likely to contain concretions than most other shales. Many shales totally lack concretions, either large or small.

Tectonically caused structures are discussed in some detail within Sect. E.2.6, Reaction to External Events, but joints, probably the most widcly otudicd otructural fcature found in ohalco, are bricfly troatod here too. Regional joint systems appear to retain more consistent orientations in these finer-grained strata than do other lithologies (NICKELSEN 1967), although other investigators have shown that, loca11y, coal (LONG 1979) and sandstone (TILLMAN 1983) display more consistent patterns. Despite widespread study, especially in the Appalachian Basin (see references in TILLMAN 1983, for numerous investigations) and around the Colorado Plateau (KELLEY 1960), the exact cause(s) of regionally persistent joints in shales is not fully known and/or understood. Various reasons have been cited (SHUMAKER 1976) and include: (1) association with localized to regional folding; (2) response to broad regional uplift; (3) offloading of overburden strata due to erosion; and (4) reactivation of more deeply buried structures.

In spite of the frequency of joints and regional joint systems, there does not also seem to be any clear understanding as to the exact depths that joints seen at the land surface extend into the subsurface. Also, there appears to be no systematic study that has attempted to determine the relative density of joints in shales. Both these structural geology considerations (i.e., depth of open joints or fractures and density of joints) would appear to assume a site-specific nature. 


\section{$\mathrm{E} \cdot 2.4 .5$ PLASTICITY}

Some shales are very plastic, almost approaching semi-consolidated clays. This type of shale clearly has a higher content of clay minerals, less cement, or a lesser degree of overall compaction-induration. Other shales that are considerably less plastic reflect higher contents of nonclay minerals, higher content of silt-and/or sand-size grains, higher carbonate rock or silica cements, or a higher degree of induration.

To our knowledge, there has been no study directly relating plasticity of shale to its ability to seal secondary openings. Brace (BRACE 1980), however, has made some qualitative statements on the matter, and these are discussed in more detail relative to porosity in Sect. E.2.4.6. Suffice it to say that, given appropriate depth/overburden (pressure and temperature) conditions, many shales are adequately plastic to seal joints, fractures, small faults, and even aid in sealing larger, through-going faults. Other shales, whether they are presentiy at or near the land surface or at similar depths, probably are not sufficiently plastic to seal such openings.

Some Paleozoic shales, whose rock-mechanical properties are undoubtedly superior to softer, more plastic examples from a rock-strength standpoint, have nonetheless demonstrated much plasticity when subjected to appreciable, ancient stress fields. Shale units in the Southern Appalachians, for example, have themselves been extremely deformed and contorted even though they serve as the plastic, glide surfaces on which intervals of more competent rocks were overthrust in a series of successive ramp-like movements (HARRIS 1977).

\section{E.2.4.6 POROSITY AND HYDRAULIC CONDUCTIVITY}

Shales rarely are tested for their porosity or hydraulic conductivity, and thus there are few data available on these properties as compared to the abundance of such data for sandstones, carbonate rocks, and other petroleum-reservoir rocks. Data generally available, however, show that shales commonly do have moderate porosities of 3 to $15 \%$ and have very low hydraulic conductivities of $10^{-8}$ to $10^{-11} \mathrm{~cm} / \mathrm{s}$.

Bulk density, which reflects the percentage of pore space in a shale, decreases with increasing depth of burial, with most of the marked decrease occurring in the first few hundred meters of burial (ATHY 1930; GIPSON 1966; CONYBEARE 1967; BURST 1969; RIEKE 1974). When originally deposited, muds in the Gulf Coast area had water contents ranging from 70 to $90 \%$ by volume (BURST 1969). Upon burial to a depth of $1,000 \mathrm{~m}$, the water content is reduced to about $30 \%$, with some 20 to $25 \%$ as clayinterlayer water, and 5 to $10 \%$ as residual pore water.

Similar findings of markedly reduced porosity were shown by Conybeare (CONYBEARE 1967). He concluded that at burial depths less than $500 \mathrm{~m}$, water is readily expelled from muddy sediments but at a progressively decreasing rate. At a burial depth of $500 \mathrm{~m}$, the porosity of shale should be dboul 30\%. Al a depth range of 500 to $1,700 \mathrm{~m}$, water is expelied 
at a uniform rate until a porosity of about 10 to $15 \%$ is reached. At burial depths greater than $1,700 \mathrm{~m}$, it is extremely difficult to expel additional pore water, and the porosity remains between 5 and $10 \%$ to depths of $2,500 \mathrm{~m}$.

Rieke and Chilingarian (RIEKE 1974) discussed the variation that has been reported for the relationship between porosity and depth of burial involving shales and argillaceous sediments. They summarized data from ten reports that indicated that porosity varied from 15 to $45 \%$ upon burial at $600 \mathrm{~m}$, from 5 to $30 \%$ at $1,500 \mathrm{~m}$, and 3 to $20 \%$ at $3,000 \mathrm{~m}$. They pointed out that although porosity of shale is mainly a function of maximum overburden stress (depth of burial) and time, it also is affected by 1ithology, depositional environment, overpressured-fluid zones, diagenesis, and tectonic stress. The interrelation between these several factors is complex, and thus there are great variations in the porosity-depth curves for shales from various basins.

Data on shale porosity at various locations have been reported by several investigators. Gipson (GIPSON 1966) reports values of 3.3 to $10.1 \%$ in Pennsylvanian shales cored to depths of about $450 \mathrm{~m}$ in Kentucky. Manger (MANGER 1963) showed a large range in values, from about 1 to $19 \%$, for some 40 shales from outcrops, mines, and boreholes in the United States and Europe. Gonzales and Johnson (GONZALES 1984) reported that Devonian gas shales have porosities of 0.9 to $4.6 \%$ in the Illinois Basin, 3 to $10 \%$ in the Michigan Basin, and about $3 \%$ in the Appalachian Basin. De Laguna (De LAGUNA 1968) reported that cores of the Conasauga Shale in Tennessee have porosities that range from 0.5 to $1.9 \%$ and average about $1.2 \%$ 。

In contrast to bulk porosity, the effective porosity of a shale is the percent of the total volume of the rock that consists of interconnecting pore spaces, and this value is always significantly smaller than the bulk-porosity for a given shale. Data on effective porosity are sparsc. Devonian gas shalcs from rennoylvania frerc dcocribcd ao having an effective porosity of $1.17 \%$ (DOE 1981), and Triassic shales from South Carolina were cited as having an effective porosity as low as $0.5 \%$ (GONZALES 1984).

Hydraulic conductivity is a measure of the capacity of a rock to allow fluids to pass through it. Although the term, hydraulic conductivity ( $\mathrm{K}$, cxpressed in $\mathrm{cm} / \mathrm{s}$ ), is commonly uocd intcrchangeably in the literature with permeability $[\mathrm{k}$, expressed in millidarcies ( 1 darcy $\left.\left.9.87 \times 10^{-13} \mathrm{~m}^{2}\right)\right]$, the units are different: the terms are related by the expression $\mathrm{K}=9.6 \times 10^{-7} \mathrm{k}$ (RIEKE 1974).

In a general assessment of permeability of argillaceous rocks, Brace (BRACE 1980) reported that shales commonly have in situ hydraulic conductivities of about $10^{-9}$ to $10^{-11} \mathrm{~cm} / \mathrm{s}$. When comparing data from laboratory tests with data from in situ tests, he concluded that the resultant values for shales generally agreed within a factor of 10 . Thus, the results of laboratory testing for hydraulic conductivity may provide a good estimate for in situ results. Inasmuch as the samples and in situ 
tests reported upon by Brace (BRACE 1980) ranged from depths as great as $1,400 \mathrm{~m}$, he also concluded that fractures and in situ fracture permeability may play only a minor hydrologic role for deeply buried shales, and that fractures in such shales probably seal at modest depths owing to the plasticity of these rocks.

Gonzales and Johnson (GONZALES 1984) reported hydraulic conductivities of $10^{-6}$ to $10^{-9} \mathrm{~cm} / \mathrm{s}$ for Devonian shales in the Michigan and Appalachian Basins, of $10^{-9} \mathrm{~cm} / \mathrm{s}$ for the Ordovician Maquoketa Shale in the Illinois Basin, and of $10^{-7}$ to $10^{-11} \mathrm{~cm} / \mathrm{s}$ for shales in the Triassic Basins along the East Coast. Abel and Gentry (ABEL 1975) reported hydraulic conductivities of $10^{-6}$ to $10^{-10} \mathrm{~cm} / \mathrm{s}$ for the Cretaceous pierre, Bcarpaw, and Claggett shalcs in the Northcrn Grcat plaino. For the Cambrian Conasauga Shale in Tennessee, De Laguna (De LAGUNA 1968) reported hydraulic conductivities of $6 \times 10^{-10^{\prime}}$ to $3 \times 10^{-11} \mathrm{~cm} / \mathrm{s}$ for samples obtained at depths ranging from 50 to $850 \mathrm{~m}$ on the Oak Ridge Reservation. 


\section{E.2.5 LITHOLOGIES OF BOUNDING ROCK TYPES}

The principal lithologies associated with major shale deposits are sandstone and siltstones. To a slightly lesser degree, shales are associated in the latter case, and salt is the principal associated lithology; however, various deposits of anhydrock, potash, trona, and gypsum are either interbedded with, overlain and/or underlain by, or grade laterally into shales. In some deltaic and floodplain deposits, shales are bounded by coal seams or by sequences of interbedded sandstone, siltstone, and coal. Although this is a wide range of lithologies for bounding rock types, it results from the nearly ubiquitous nature of shales, which in turn reflects the numerous depositional environments in which shales have repeated1y formed throughout geologic time. Descriptions of the 1ithologies that bound most of the regionally extensive and thick shales in the United States are provided by Gonzales and Johnson (GONZALES 1984).

The contacts between shales and their associated lithologies in the vertical dimension can be either abrupt and sharp, gradational, or repetitious as the result of several short-term transgressions and. regressions. Shale units can also merge laterally into these other lithologies either in an abrupt or gradational manner. Vertical changes from shale to any of its bounding 1ithologies can take place across dimensions measured in terms of centimeters to a few meters; lateral changes may occur across distances of a few meters, tens of meters, or tens of kilometers. In the latter case, facies changes involving shale and other lithologies are the result of gradual variations in sedimentation through time across an entire depositional basin, or widespread deltaic progradations and marine transgressions.

Shales deposited in most nonmarine environments, with the exception of certain lacustrine deposits, tend to experience more numerous and more abrupt changes into other lithologies, especially in the lateral direction. Marine and deltaic shales, by contrast, are more persistent laterally, and changes into the bounding lithologies in the lateral direction tend to be more gradual. These same laterally persistent shales can, nevertheless, display the full range of contact relationships as described above. Thus, the real dimension becomes one of relative thickness. Here, too, those shales formed in several marine environments, together with certain deltaic and lacustrine examples, are typically thicker than their associated bounding lithologies.

In clastic envixonments, sandstones and siltstones generally represent deposition in environments that are high-energy and/or are closer to the source areas or distribution centers for the clastic sediments. On the other hand, shales may result from accumulation of the finergrained clastic materials in low-energy environments that are farther from the source areas of the clastic detritus. Inasmuch as these two principal environments are laterally gradational, major shales commonly grade laterally into sandstones and/or siltstones over great distances, but they also commonly grade vertically into these same rock types owing 
to the transgressive and regressive nature of marine and deltaic/nonmarine clastic environments. Shales bounded by sandstones and/or siltstones can be found in rock sequences of all geologic ages and in all parts of the United States.

The classic study by Fisk (FISK 1947) of the fine-grained alluvial deposits of the modern Mississippi River system illustrates we11, especially by means of his many maps and cross sections, the relationships between muds and their associated coarser-grained clastics. Likewise, the cross sections made by Ferm and Horne (FERM 1979) of the Carboniferous coal-bearing alluvial deposits from eastern Kentucky, and those illustrated by Donaldson et al. (DONALSON 1979) for coal-bearing sequences in West Virginia, reveal similar lateral and vertical relationships between shales and their associated sandstones and siltstones. However, where marine shales predominate elsewhere in such coal measures, their continuity has been shown to be much greater, as demonstrated for the pennsyLvania Lawson and Purington Shales in the ILlinois Basin (WANLESS 1964).

Tn nther marine environments, shales are bounded above, below, and/or laterally by carbonate rock units. Carbonate rock strata generally represent shallow-water, shelf, or even slope to deeper-water accumulations that occurred in tectonic settings similar to those that locally favored deposition of shales; thus, the two rock types are commonly interbedded in a number of regions in the United States. For example, major shales are partly or totally bounded by carbonate rocks in several parts of the eastern United States, in the Midcontinent region, and in the Great Basin of the West. Much of the Paleozoic stratigraphic column across the central or Midcontinent part of the country consists mainly of very extensive marine limestones and dolostones interbedded with shales. Good, wel1-studied examples of thin limestones interbedded with shales occur in parts of the famous Upper ordovician Cincinnatian Series in Southwestern Ohio and adjacent states (SCOTFORD 1965; MEXER 1981). In the latter part of the Paleozoic Era, more clastic-dominated sedimentation in deltaic, floodplain, and alluvial systems yielded shales whose bounding lithologies were mainly sandstone, siltstones, and coals.

Evaporices and some shales were deposited in similar environments in the United States, and it is not uncommon to find them interbedded locally, particularly in the Permian of the Midcontinent region. Both these rock types are characteristics of areas with stable tectonic settings. Consequently, the nature of the sediment being deposited depended upon the abundance of fine-grained clastic material entering the region and the salinity of evaporating sea water encroaching across the same region. Salts of Silurlan age, for example, are mainly associated with carbonate rocks in the Michigan Basin; equivalent salt strata in the northern Appalachian Basin are, however, more commonly interbedded with shales. Evaporite deposits of nahcolite, dawsonite, and trona are also associated with the "oil shales" or marly beds rich in organic matter that typify the lacustrine Green River Formation in Colorado, Utah, and Wyoming (HITE 1967; CULBERTSON 1971). 
Shales themselves can clearly be considered the bounding lithologies for other sedimentary lithologies. Reference here is made to the various lens-like, lenticular, elongate, or ovoid bodies of sandstone and siltstone, and less commonly limestone or dolostone (reef deposits, in particular), that are entirely enclosed within a thick shale deposit. offshore marine bars, fluvial channels, tidal channels, and alluvial fans are some of the typical depositional environments in which coarser clastic sediments such as sand and silt can accumulate and give rise to isolated bodies of sandstone and siltstone that are encased in shales. Carbonate rock reefs and slope-bank deposits are commonly partially enclosed by shales where evaporites and/or other carbonate rocks were not deposited. These occurrences are commonly of interest to the petroleum industry because such shale-enclosed deposits constitute highly prospective oil-bearing stratigraphic traps (MACKENZIE 1972; MAZZULLO 1980). The converse, namely where deltaic and alluvial channels are filled with shale and the bounding lithologies are either sandstones or siltstones, is known, but is less common. As noted previously in this report, several Tertiary shales in California, however, appear to occupy such channels or gorges (HACKEL 1966; EDMONDSON 1972). 


\section{E.2.6.1 TECTONICS AND SEISMTC EVENTS}

The following discussion concentrates solely upon geologic circumstances and makes no attempt to delve into various rock-mechanical data and allied considerations. Those subjects for all five rock types are treated in Appendix G.

Major shale deposits are located in almost all parts of the United States, and a large proportion of these shales are in regions whose past tectonic hiotorico have been milk and whose current seismic activity is low. Many of the major shales were deposited during various episodes of epeirogenic downwarping of the craton in the central part of the country, and almost all parts of the craton, except for the upper Mississippi Valley area centered around New Madrid, Missouri, exhibit very low levels of seismic activity. Other regions of thick shales, including much of the Rocky Mountains and the Colorado plateau, are also characterized by low seismic activity as evidenced by inclusion in seismic-risk zones 0 or 1. There are, of course, thick shales in many areas of the western and far western United States where modern fault movement and seismicity are much more pronounced. As a result, the rocks, including shales, in many such areas are strongly deformed.

Many shales that are present in areas of low seismicity tend to be low in their overall structural deformation. Except for regional and local joint patterns, and restricted zones and isolated cases of faulting, shales in such areas typically are nearly horizontal and largely undisturbed. In mountain trends that resulted from active plate-tectonics movements, or in very deeply buried basins adjacent to active tectonic trends, shales tend to be much more deformed. Carboniferous shale deposits in the Ouachita Mountains of Arkansas illustrate well both pronounced tectonic control on codimentation and subsequent intense deformation within a major orogenic belt (MORRIS 1974). Shales in such tectonic and/or plate-tectonic settings are prone to be faulted, jointed, fractured, or contorted. Shales can also act as the glide planes for decollement zones; this is typical in the south-central to southern Appalachians where low-angle thrust faults are common (HARRIS 1977). Highly plastic shales in the Gulf Coast have also been shown to be genetically involved in the development and generation of growth faults (BRUCE 1973).

If a buried shale unit is subjected to the slow application of stress through tectonic or seismic activity, the basic rock properties of shale under conditions of subsurface pressures and temperatures tend to allow the rock to deform plastically. Furthermore, the flowage and high plasticity of certain clays and claystones even after a relatively shorttime application of stress is well understood from laboratory studies. Dames and Moore (DAMES 1978) summarized various data from several rockmechanical tests that clearly revealed that shales were susceptible to creep. However, well-indurated shales also exhibit some measure ot ductile behavior by means of plastic flow in response to stresses applied 
over longer periods of time. Lisenbee (LISENBEE 1976) has indicated that several Cretaceous shales, all highly contorted and displaying clear evidence of squeezing and flowage, have intruded an overlying sequence of Tertiary strata in the Galisteo Syncline of New Mexico. Regional structure in the form of faults, local stress, and natural-gas pressure as a buoyancy force on the shales are postulated as the cause for these shale diapirs.

In the case of rapid application of stress, or where the shale is brittle due to its composition and/or degree of compaction, the shale may rupture and become either fractured or faulted. Some studies (such as HARRIS 1960 and TILLMAN 1983), have shown that more competent rocks, namely sandotoncs, dolostoncs, and limcstoncs, are more apt to be jointed or fractured than the interbedded shales. Whether such joints never developed in the less-competent shale or healed themselves over time owing to the plastic nature of the rock is uncertain. With deeply buried shales, stress-induced secondary openings may be rendered nearly as impermeable as the surrounding undisturbed shale, as has been postulated by Brace (BRACE 1980). In other cases, faults or fractures may remain open for longer periods of time, allowing fluide to enter them thio situation can lend to the partial or total filling of these openings with secondary minerals.

The study by Tillman and Barnes (TILLMAN 1983) has in fact utilized such secondary joint-filling mineralization as a geochemical/ geothermometric means of deciphering both deformation and fluid-migration histories in part of the northern Appalachian Basin. Although sandstone was the rock type sampled in their study, the techniques may be applicable to shales.

There are, however, shales whose joints, fractures, and faults apparently do not become sealed. Evidence for this includes: (1) open fractures and joints are clearly visible in shales at surface outcrops; (2) staining and/or water flowage along thee openinge is vieiblo in underground openings such as mines and tunnels; and (3) deeply buried basement structures (faults), when reactivated, are strongly believed to create fracturing in and preferential gas production from Devonian shales in several trends in the Appalachian Basin (NUCKOLS 1978). Dames and Moore (DAMES 1978) have reported measurable water inflow from several intervals of jointed Upper Cretaceous Mancos Shale in the Azotea tunnel of New Mexico and Colorado. Minor seepage of water from jointo in ohalc in two other tunnels was also reported. The maximum depths of the three tunnels ranged from 230 to $570 \mathrm{~m}$. In contrast, Simpson (SIMPSON 1965) has shown that the Mississippian Floyd Shale, in the Birmingham iron-ore district where faulting and jointing are developed, has retained its impermeability to depths of a few hundred meters and acts as the aquiclude responsible for developing artesian-water problems in the mines there.

Some shales even exhibit fractures and joints that are confined to the subsurface and lack any obvious expression at the land surface. Although the cause of such unique fractures is not known for certain, the tact that they seem confined to certain stratigraphic intervals has 
suggested to some workers that overpressuring by natural gas is the responsible mechanism (SHUMAKER 1976). This particular phenomenon has been detected in several areas involving the Devonian gas shales, but is far more common in the shales of the Gulf Coast as described and explained in a classic paper by Bruce (BRUCE 1973).

\section{E.2.6.2 DISSOLUTION AND BRECCIATION}

By normal standards of rock solubility, shale is not a soluble rock, and thus it is not likely to be dissolved by groundwater or other fluids commonly associated with shales. The low hydraulic conductivity (see previous discussion, Sect. E.2.4.6) of shales inhibits access of groundwater and other fluide into the rock maso so that diosolution of cvaporites or other soluble minerals that might be interbedded with, or encased within, a shale is also generally unlikely. The most likely paths whereby fluids would enter a shale is through more permeable interbeds, such as sandstone, limestone, or dolostone that might be present, or through unsealed faults and/or fractures that might have developed.

Brecciation of a chale depooit may occur in thooc regiono where the shale is underlain by, or interbedded with, soluble rocks such as salt, anhydrock, or carbonate rocks that have been partly or totally dissolved, causing collapse and brecciation of overlying rock layers. Examples of such natural dissolution-induced brecciation are known from the Paradox Basin of Utah (HUNTOON 1979), the Permian Basin of New Mexico (ANDERSON 1978), and the Williston Basin of North Dakota (PARKER 1967). These brecciated zones may form channels for groundwater movement, provided the voids in the breccia are not plugged subsequently with fine-grained particles or precipitated mineral deposits. Where the dissolution zone in a soluble rock unit is laterally extensive, the result on the overlying shale layers may be collapse and development of a breccia bed that is as extensive as the dissolution zone. Where the underlying soluble rock is dissolved to form a cavity that is relatively high and not too cxtcnoive, the reoult may be collapoc and brccciation in a ncarcylindrical pipe that extends up into or through the overlying shale.

In the case of the Green River Formation, development of the lower aquifer system in the Piceance Basin of Colorado is actually attributable to the dissolution of associated evaporite minerals enclosed within the oil shale/marlstone units. This lower aquifer is also designated the "leached zone" because appreciable secondary porosity and permeability has been created as the result of the dissolution of soluble minerals by percolating groundwater. The principal mineral that has been dissolved is nahcolite, a sodium bicarbonate mineral. It is estimated that as much as 20 vol \% of the lower member of the Green River Formation originally consisted of soluble minerals (WEEKS 1974). Thus, where hydrologic conditions and rigid rock-property characteristics allowed water access to soluble components within a major shale, dissolution occurred without resultant collapse and/or brecciation.

\section{E.2.6.3 WEATHERING AND EROSION}

Shale weathers more readily than most other sedimentary rocks in all climatic conditions of the United States (humid, arid, hot, or cold), but 
this weathering is generally restricted to outcrops or to depths down to several tens of meters below the land surface. The severity of climatic conditions, the relief of the topography, and the presence or absence of structural features such as faults and joints, when combined with the inherent rock-mass properties of the shale, will influence the rate of weathering and erosion. Some manifestations of stratification in shales are only evident at or near the land surface and thus appear related to weathering. The same shales, when viewed deeper in the subsurface by means of mine access or recovered cores, lack similar bedding expression.

The relatively weak bonding between clay particles in most poorly cemented shales causes the rock to weather and disaggregate more rapidly than other rocks. Also, the greater surface area of particles per unit volume of shale permits more rapid alteration of the component grains than in most other clastic rocks. Shales tend to be more resistant to erosion only where they are well cemented with silica or carbonate rock minerals; even then, they tend to be less resistant than other rocks in the region.

Tnasmuch as shalos woather rapid1y in all rlimatos, they typirally are easily eroded and form low valleys in their outcrop areas. These valleys may be broad or narrow, depending upon the width of the outcrop belt and the thickness and character of rocks underlying contiguous areas. Where a shale unit contains thin or thick interbeds of a generally more resistant rock, such as sandstone, carbonate rocks, or dolostone, the entire shale sequence may be somewhat more resistant and combine with the other strata to form a topographic high. For a complete discussion on the drainage patterns, relief, and weathering characteristics of shales, the article on terrain analys is by means of aerial photography (WAY 1973) is particularly instructive.

Ferguson (FERGUSON 1967) has documented an interesting relationship involving shales and deep erosional valleys in the Allegheny Plateau. In that region, the orientation of these valleys parallels the more prominent joint systems, which the author feels were formed as the result of stress release, which in turn was induced by rapid valley erosion in those areas. These stress-release joints may actually extend several hundred meters into the subsurface, suggesting such zones will continue to represent future trends of reduced resistance and deeper erosion.

Other than field observation of the effects of weathering and erosion on shales, one method useful in comparing the relative resistance of one shale or similar fine-grained rock to another such rock is the slake-durability test designed by and described by Franklin and Chandra (FRANKLIN 1972). The response to this engineering-geology testing index varies widely and depends upon the lithology being tested. Those shales that are more durable (i.e., with higher index values) are those which are more impermeable (more indurated), have little or no reaction to wetting, and have good intergranular strength. Unfortunately, there does not seem to be any systematic variation in index values relative to the geologic age of the samples tested. Data generated from one-cycle durability tests by Gamble (GAMBLE 19/1) are reported in vames and Moore (DAMES 1978); other comparable test results are given by Franklin and Chandra (FRANKLIN 1972). 


\section{E.2.6.4 MAN-MADE OPENINGS IN SHALES}

There are numerous examples in the geologic, engineering geology, and civil-engineering literature that document slope-stability problems involving shales. The most widely reported problems are along highways where outcrops of shales have been excavated in roadcuts. Dams and other large civil engineered structures have also been affected. Landslide problems in such shales can result from the strike and dip of the shale formation, degree of jointing or faulting, slope angle, and the degree of interference caused by the construction itself. Failure to properly divert surficial runoff or other drainage waters from the shale-1ined slope has added to the potential for stability problems in some cases.

A more practical nature to this study is the response of shales to or in underground excavations. Abel and Gentry (ABEL 1975) have discussed the excavation record of the Upper Cretaceous Mancos and Pierre Shales and found that conventional dri11-blast-removal techniques and largediameter boring machines were both amenable to producing the desired diameter tunnels. The Azotea water-diversion tunnel in southern Colorado and northorn Now Moxico was drivon successfully more than $20 \mathrm{~km}$ through the Mancos Shale at depths up to nearly $600 \mathrm{~m}$. Instability problems in the pierre shale are related principally to its high moisture content, reflected by a smectite-dominated mineralogy able to absorb water and be geomechanically affected in the process.

Shales are commonly the roof strata in coal mines in the pennsylvanian coal-bearing sequences mined in the eastern, interior, and Midcontinent parts of the country. Failures and/or roof falls are common in some of these coal mines where thin shales in the roof are bounded by we11defined parting planes. A classic study of the relationship between roof lithologies and roof failures in coal mines is by Krause (KRAUSE 1979). Failure of certain shale roofs is to be expected, because of depositionally-induced structures that are current planes of weakness, raaction to wotting and drying cycles due to the mining activity itself, and the fairly low rock-mechanical strength of thin shales where they are exposed in essence as lateral beams. Measures to prevent these circumstances must be taken into account in the mine design. The use of closely spaced supports (timbers, steel bracing, etc.) is generally used in main drifts of coal mines because rock bolting is typically ineffective to "hold up" thin shales, even if the anchoring point of the bolts is in a non-shale lithology above the shale.

Mines fully developed within a shale or closely related rock are relatively few because shales are generally not the target of underground excavation. An exception includes several mines excavated in the oil shales (kerogen-rich marlstones) of Colorado by the U.S. Bureau of Mines and two commercial ventures (PRIEN 1974). The mines are of basically room-and-pillar design; in the case of the earliest mine constructed several decades ago at Anvil Points for federal government research, the rooms and pillars are each $18 \mathrm{~m}$ square, and the height of the rooms is $22 \mathrm{~m}$ done in two stages. Access to the mine is via an adit from a steep escarpment, while the depth below the land surtace is less than $4 \mathrm{b0} \mathrm{m}$. 
With minimal rock bolting, the roof in this mine has remained very stable for the several decades of research use. The large percentage of carbonate rocks (up to $60 \%$ of the non-kerogen portion) is a significant contributor to this favorable response.

The utilization of shales and other rock types for mined storage caverns is discussed at some length by Cobbs Engineering (COBBS ENGINEERING 1975). As noted in the next chapter, more underground caverns for storage of petroleum products have been developed in shale than in any other rock type. Although some problems are realized during construction of certain caverns due to slaking caused by the absorption of water, adequate humidity control can generally arrest this condition. In like manner, the relatively low mechanical strength of shale can be compensated for by good engineering design of the cavern(s) and, thus, adequate roof support can be obtained. Similar to the carbonate rock-rich units of the Green River Formation, shales that were calcareous or dolomitic displayed greater strength and in turn made superior cavern host media (COBBS ENGINEERING 1975).

Shales have ohviously heen penetrated hy thousands of horeholes drilled in the exploration for and production of various mineral resources. Boreholes drilled with water-based drilling fluids (muds) may encounter two problems when drilling through certain shales: (1) the water causes the shales to swell, resulting in heaving and sloughing of material into the borehole, and (2) particles of clay from the shales are dispersed in the drilling mud so that eventually the "solids" content of the mud is affected (DICKEY 1979). In addition, even certain hard, compact shales tend to cave badly into boreholes. O'Brien and Chenevert (O'BRIEN 1973) have classified problem drilling shales into five different categories. At one end of the spectrum are those shales high in their content of smectite clays; these tend to be the most adversely affected by swelling - they are soft, and prone to high dispersion as we11. At the other end are those high in illite and chlorite; these shales do not disperse or swe11. but they may or may not be prone to caving problems. 


\section{E.2.7 MINERAL RESOURCES IN OR ASSOCIATED WITH SHALES}

\section{E.2.7.1 GENERAL CONSIDERATIONS}

The mineral value of shales as rock materials general1y is limited to certain formations where they can be mined easily at, or near, their outcrops or at very shallow depths. Some shales, however, do local1y contain within them other types of mineral resources, such as hydrocarbons and metals, which make them susceptible to exploration and extraction through boreholes or underground mines, even at considerable depths. Also, other shales are interbedded with, and/or are underlain by, important mineral resources that can be mined or produced from simi1 ar and greater depths. A discussion of the mineral resources contained within or associated with major shale deposits of the United States is presented by Gonzales and Johnson (GONZALES 1984).

Shales are mined and used as bulk rock materials mainly in the manufacture of brick, tile, lightweight aggregate, and portland cement. Mining of shale for such common construction products is restricted to open-pit mines. Certain other specialty shales and clays, such as bentonite, kaolinite, and ball and fire clays, are also worthy of recovery, especially for ceramics and refractories; but the economics of producing even these materials generally prohibits anything but open-pit mining. Thus, the most common mode of extracting shales as mineral resources is surface mining. Even the surface extraction of a shale for its own physical properties would not be expected to have an adverse impact on the geologic disposal of radioactive wastes intended for that same rock unit where it occurs several hundreds of meters deeper in an adjacent area.

\section{E.2.7.2 HYDROCARBONS AND SHALES}

Hydrocarbons, mainly in the form of natural gas and less commonly as crude oil, occur in fractured shales in the eastern, western, and southwestern United States. Other hydrocarbon material is present as the vast volumes of solid kerogen in the well known Green River oil shales of Tcrtiary agc in Colorado, Utah, and Wyoming. Because of a high content of the carbonate rock minerals dolomite and calcite, these so-called oil shales should actually be termed "kerogenous marls or marlstones" (VAN WEST 1972). Other shales rich in solid kerogen are various Devonian, Mississippian, and Pennsylvanian black shales that occur throughout the Midcontinent and eastern parts of the country. These oil shales, black shales, and kerogen-rich units principally represent resources for the future, namely as a possible source of synthetic oil (syncrude). Lamar (LAMAR 1956) showed the wide range in both geologic age and potential yields for such shales within a single state - Illinois.

Natural gas continues to be produced commercially in very sizable volumes from several Devonian-Mississippian shale sequences of the Appalachian Basin (LOMENICK 1983); gas production there has been cotabliohed for dccadco ( $\mathrm{RAY} 1977$ ) and wao the comorcial rationalo for the establishment of the DOE-sponsored research program involving these 
so-called Eastern Gas Shales. Petroleum is produced from similar black shales in the Illinois Basin (BASSETT 1977) and in the Michigan Basin (ELLS 1978). Much of the production from the Michigan Basin shale sequence, however, comes from an interbed unit called the Berea Sandstone. Most of the production from these basins is from fractured shale units, but some comes from sandstone-siltstone interbeds within the shale-rich sequences.

The production of crude oil from fractured shales is less common than that of natural gas, but can be locally significant. Warn and Sidwell (WARN 1953) indicate that some production from the long-discovered Spraberry trend in West Texas comes from shales; Murray (MURRAY 1968) reports that the Mississippian Bakken Shale in a Williston Basin field serves as one of the productive reservoirs and as the most likely source bed for the other oil found in the main sandstone reservoir. Volk (VOLK 1972) recounts the historically significant fact that the second oldest o11-producing area in the United staces is the Denver Basin, and that the earliest (1876) production there was from the Florence Field, south of Denver. This still-productive field has yielded several million barrels of oil from fractures in the Cretaceous Pierre Shale. Volk also noted that the first flowing oil field (Boulder Field) in the basin was discovered 26 years later and it was also produced from fractured Pierre Shale. Mallory (MALLORY 1977) has summarized the significance of oil-productive shales in both the Denver and San Juan Basins. There is also modest oil production from several small fields in the Mississippian E1lsworth Shale in western Michigan (ELLS 1978).

Possibly the most significant oil-producing shale unit may eventually prove to be the Tertiary Monterey Formation in south-central coastal California and adjacent of fshore tracts (Santa Maria Basin). This complex rock sequence contains several lithologies and its shales are very siliceous due to a large biogenic (diatom) contribution within the original depositional environment (ISAACS 1984). Several significant offshore oil fields involving the fractured Monterey Formation have been discovered recently. By contrast, the same fractured siliceous-shale and chert formation has been productive from the onshore Santa Maria district for several decades (REGAN 1949).

\section{E.2.7.3 NON-PETROLEUM RESOURCES AND SHALES}

Metals of commercial significance that are found within shales in concentrations adequate to be considered for economic recovery include aluminum, cobalt, copper, lead, silver, uranium, and zinc. Aluminum will only be extracted from domestic aluminum-rich shales in the future, when and if the cost of recovery becomes competitive with that of aluminum from bauxite. No cobalt has been produced in this country since 1971, and none of the previously productive deposits in Idaho (Blackbird district), Missouri (Southeast lead belt), and Pennsylvania (Cornwall iron ores) involved shales (SIBLEY 1979). Lead, silver, and zinc have been domestically recovered from both surface and underground mines; the Pioche mining district in eastern Nevada is an example where these metals

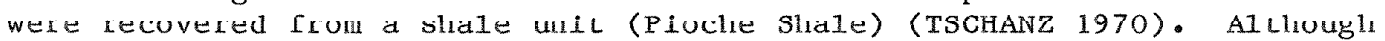


uranium is known to be concentrated (average of 0.007 percent $\mathrm{U}_{3} \mathrm{O}_{8}$ ) in the upper part of the Devonian-Mississippian Chattanooga Shale throughout central Tennessee and adjacent states (SWANSON 1961), this low-grade resource has never been placed into commercial production. Another potential uranium resource is the low-grade ore contained in red shale units of the Permian Wichita Group of northern Texas and southern Oklahoma (St CLAIR 1976). The Kolm Shale in Sweden has, however, supported some production of uranium (FINCH 1973). Most significant uranium deposits in the United States that are associated with sedimentary host rocks occur in sandstones (NASH 1981).

Stratiform sulfide-ore deposits of copper, lead, and zinc are commonly hosted in sedimentary (many rocks have hy now been metamorphosed) rocks (GUSTAFSON 1981). Several important ore deposits or districts occur in or are associated with shales, but the better-known examples, such as the Kupferschiefer Shale, the Mount Isa lead-zinc deposit, the Zambia-Zaire copper belt, and the Rammelsberg barite-lead-zinc ores, all occur in foreign countries. of the 28 principal deposits cited as most characteristic by these authors, only 3 are present in the United States, and of those, only one directly involuses shale as the host rock. That example is the Creta deposit in southwestern oklahoma where so-called "red-bed" copper (also yields up to $0.1 \mathrm{~g} / \mathrm{kg}$ of silver) has been recovered from the Permian Flowerpot Shale that was formed in an evaporite basin (JOHNSON 1976). A potentially important future copper resource that is associated with fine-grained clastic rocks (argillites) has been identified within the Precambrian Belt Series (Revett Formation) of western Montana (HARRISON 1972).

other deposits, such as the so-called Mississippi Valley-type leadzinc ores, are almost exclusively hosted in carbonate rocks, even though shales may be present within the stratigraphic sequence. Many economic geologists are of the view, however, that shales spatially associated with major meta11ic ore deposits may have served another important role, namely, that these shales were the snurre of the metals (TACKSON 1967; CARPENTER 1974; HANOR 1979). Circulating thermal brines containing various complexing agents apparently removed sizable volumes of metallic ions and transported them to sites of localized reducing conditions where tormation of the sultide ore bodies took place.

Although most of the so-called "micron-size" gold occurrences in the western stares, as exemplified by the Car1in, Nevada, deposit, are associated with impure carbonate rocks, the recently discovered Alligator Ridge (Nevada) deposit is contained in the Devonian-Mississippian Pilot Shale (STANFORD 1984). This formation, as described by Gonzales and Johnson (GONZALES 1984), locally contains dolomitic siltstones, silty shales, and impure nodular limestones. Thus, this example of low-grade gold mineralization nevertheless retains a strong relationship to a carbonate rock-host sequence.

A wide variety of rock and mineral resources are interbedded with, or underlie, major shale deposits in the United States. Coal beds, suitable tor underground mining, are interbedded with some rennsylvanian 
shales in the Midcontinent region (FAY 1979) and with some Cretaceous and Tertiary shales in several western states (AVERITT 1972; GLASS 1975). In evaporite-bearing sequences in the United States, thick shales contain and/or overlie significant deposits of salt, potash, nahcolite, dawsonite, or trona (JOHNSON 1978). Some of these evaporite resources are already being developed, whereas others may be extracted in the future when it becomes commercially feasible. Metal-bearing carbonates; bedded barite and phosphate; and high-purity deposits of sandstone for glass sand, of limestone for flu-gas and metallurgical applications, and of dolostone for chemical uses are also interbedded with, and/or underlie, some major shale units (GONZALES 1984). Although the association of phosphate ore and shales is not as significant from a commercial-production standpoint as the Florida pebble-phosphate deposits, some ore has been produced from the Chattanooga Shale in Tennessee and the major western (Idaho, Montana) ore zones are present within the Meade Peak Shale Member of the Phosphoria Formation (GURR 1979). Production from these phosphatic shales, while much less than that of Florida, is still significant in dollar value. occurrences of presently non-commercial phosphate are also reported from the Monterey Formation (siliceous shale) of California and the Maquoketa Shalc of Iova (EMIGH 1975). Mott and Drcver (MOTT 1983) aloo roport an interesting, although uneconomic, occurrence of uranium-enriched, phosphatic shale within the Wilkins Peak Member of the Green River Formation in southwestern Wyoming.

\section{E.2.7.4 HYDRODYNAMTC-RESOURCE ASPECTS}

With respect to potable groundwater, shales rarely constitute important aquifers, and in fact are typically aquicules. However, shales, where fractured, do contain some water. Because the extent of a fractured shale unit is generally not great, such shale aquifers tend to be localized. Also, yields from wells are typically small and commonly the water is of marginal to poor quality. Groundwater recovered from some shales, such as Devonian-Mississippian units in Oklahoma (Woodford Shale) and West Virginia (Millboro Shalo) and uecd locally for domeotic purposes, would technically be considered as mineralized (MARCHER 1971; SINNOTT 1978).

A more common occurrence is groundwater that is present in porouspermeable interbeds or lenses of sandstone, siltstone, limestone, or dolostone within thicker bodies of shale. Another typical setting is to find groundwater in thick, regionally extensive sandstone and limestone aquifers that comprise interstratified clastic-carbonate rocks sequences that include persistent shales. This relationship is we11 illustrated by the Lower Paleozoic bedrock aquifers in the Upper Mississippi region (BLOYD 1975). In many instances, the groundwater is abundant and potable and thus very suitable for domestic utilization; in other cases, the groundwater is moderately mineralized and may or may not be usable. In certain other areas, the groundwater is highly mineralized, enough that it is classified as natural brine. Concentrations of total dissolved solids for this latter case generally range from $100 \mathrm{~g} / \mathrm{L}$ to in excess of $250 \mathrm{~g} / \mathrm{L}$. Brines that are commercially recovered as chemical feedstock in eastern Ohio and West Virginia come from Devonian and 
Mississippian sandstone aquifers that are interbedded with shales and siltstones (COX 1968). The depth of production in the Kanawha Valley of West Virginia approximates $600 \mathrm{~m}$ while the brines recovered in eastern Ohio are produced from depths ranging between 175 and $300 \mathrm{~m}$. Devonian brine-bearing units (Detroit River Group) in the Michigan Basin also represent a commercial source where shales are part of the adjacent stratigraphic succession (SORENSEN 1974). Depending upon location within the Basin and which brine-bearing horizon(s) is involved, the depth of production can be as shallow as a few hundred meters or as deep as 1,500 $\mathrm{m}$.

Selected aquifers that are closely associated with shales and yield appreciable quantities of good quality water include the Mississippian Mansha11 Sandstone (Coldwater Shale); Upper Cretaceous Eagle and Judith River Formations (Pierre Shale); and Permian Garber Sandstone-Wellington Formation aquifer (Hennessey Shale) (GONZALES 1984). Freshwater in the Marsha11 aquifer extends to a fairly shallow depth of $120 \mathrm{~m}$; production from the other aquifers is from depths of a few to several hundred meters. Although less-indurated Tertiary clay-rich formations such as the Porters Creek and Yazoo Clays are not being considered in this report, they too are commonly associated with generally shallow, highly prolific freshwater aquifers throughout the Gulf Coast region. In many areas, however, the water quality in these sand aquifers becomes too saline for domestic utilization. The depth of this transition occurs within a few tens to a few hundreds of meters below the land surface.

Shales, because of their very low permeability when well indurated and unfractured, make excellent seals by which fluids such as petroleum (oil and gas) and groundwater are prevented from migrating upward or laterally out of permeable reservoirs and aquifers, respectively. Thus, shales are commonly the impermeable layer or cap above confined or artesian groundwater systems. A classic example of a shale-bounded, artesian groundwater source is the regionally significant Lower Cretaceous Dakota Sandstone (Formation) of the northern and north-central Great Plains (SClloov 1971). Depending upon geographical location, either the Mancos or Graneros Shale directly overlies this well-known groundwater aquifer. Shales are more common than any other sedimentary lithology as the impermeable seal or aquitard for confined aquifers.

Shales and evaporites (salt and anhydrock) represent the most common seals above petroleum-bearing traps. Lower Cretaceous and Jurassic shales form the seal at Prudhoe Bay, the largest oil ficld in North Amcrican (MORGRIDE 1972). The famous East Texas field is the largest accumulation of oil in the conterminous United States; and, although it is mainly sealed by a chalk unit, the Cretaceous Eagle Ford Shale is also involved in the overall seal-trap geometry. Of the more than 100 supergiant oil fields (each contains $>10^{9}$ billion barrels of recoverable crude oil) in the world, nine are present in the United States, including the two fields cited above (HALBOUTY 1970). In seven of these huge fields, shales serve the sealing mechanism. There are another 30 giant fields (each contains $>0.5 \times 10^{9}$ million barrels of recoverable crude oil) in the nation; shales are the principal seal for 25 of these. These fields generally produce from depths of a few to several thousand meters. A 
significant exception is the Lima Field in Ohio and Indiana where the Trenton Limestone reservoir (sealed by the Utica Shale) produced principally from depths between 300 and $400 \mathrm{~m}$ (COOGAN 1984). Hundreds of smaller oil and gas fields are also sealed by shale formations or by rock sequences that contain shale.

Shales also demonstrate their high degree of competency and very low permeabilities by being excellent rocks in which to excavate/construct caverns for the underground storage of hydrocarbons (LPG). In a survey of these mined caverns, Cobbs Engineering (COBBS ENGINEERING 1975) found that 44 successful (structurally sound and not abandoned due to water influx) mined-cavern facilities had been constructed in the United States. Of these, 27 had heen developed in shales. Two other shalebased caverns had properly functioned for one and two decades respectively before being abandoned due to water problems. At the time of abandonment, the caverns still retained their structural integrity. Three other caverns built in shales were initially unsuccessful: in one case improper construction methods caused a structural failure; in the second, a design flaw prevented use of the structurally sound cavern; and in the third, the ravern wnild not pass the requiled pressure test. Present-day improvements in hydrological and rock-mechanical modeling, construction technology, and geologic exploration would avoid the problems encountered in these unsuccessful caverns.

Despite the few unsuccessful efforts cited above, $60 \%$ of the mined LPG caverns in non-salt host rocks still active in this country are found in shales. The largest number of cavern facilities that have been deve1oped in one stratigraphic unit are those formed in the shales of the Ordovician Maquoketa Group in the Midcontinent and Eastern Interior parts of the country (GONZALES 1984). 


\section{E.2.8 DEPOSITIONAL ENVIRONMENTS AND SHALE HOST ROCKS}

The purpose of this brief section is not to identify any specific shale-bearing formations or particular stratigraphic units. Rather, the data assembled in this appendix make it possible to identify several depositional environments whose shales generally display physical characteristics that might make them more suited as potential host rocks for a future radioactive-waste repository.

Because no individual shale units are being evaluated or kept in mind, the range of physical properties that are summarized in Table E.2.8.1 below for each of the selected environments provides the generic sense desired by the ORNL Sedimentary Rock Program. To a large degree, the properties that are listed in the table are controlled or influenced by the specific depositional environment in which shales are known to form. However, $1 t$ must be borne in mind that certain properties either do not display any measurable difference or do not contrast from one environment to another, or that no (or inadequate) data are available to make such a contrast.

Among the four environments represented, several very important properties for shales demonstrate little variance. Properties such as thickness, lateral extent, and homogeneity in both the lateral and vertical dimension thus reveal that the gross geometries and extents of shales formed in all these environments are clearly within desirable limits. Expressed another way, shales that are generically associated with these depositional environments are sufficiently thick, homogeneous, and extensive to consider further.

Therefore, shales formed along marine shelves and slopes, especially if the environments were positioned along stable continental margins and/or in stable cratonic settings, probably represent the generic model with the greatest potential. Deeper-water marine basins exhibit good. although somewhat less, potential; the difference is largely due to structural-deformation considerations. Shales formed in large, riverdominated deltaic systems, especially those that display a pronounced progradation (delta front deposits) into adjacent matine, cralonic basins, represent an attractive model as we11. A few widespread lacustrine shales demonstrate good lateral and vertical continuity and thus technically constitute the only non-marine model that exhibits promise.

Referral back to Table E.2.2.5 therefore reveals that, with the exception of the limited lacustrine category, all other non-marine environments produce shales that lack positive physical characteristics. The same statement applies to the remaining types of deltaic systems and the other transitional environments. Only in the marine category are the three specific subenvironments represented in this final summary. 
Table E.2.8.1. Host-rock properties of shales relative to preferred depositional environments

\begin{tabular}{|c|c|c|c|c|}
\hline Property & $\begin{array}{l}\text { Deep } \\
\text { marine } \\
\text { basin }\end{array}$ & $\begin{array}{l}\text { Marine } \\
\text { shelf/ } \\
\text { slope }\end{array}$ & $\begin{array}{c}\text { River- } \\
\text { dominated } \\
\text { delta front }\end{array}$ & Lacustrine \\
\hline Geometry & Tabular & Tabular & $\begin{array}{l}\text { Tabular- } \\
\text { clinoforn }\end{array}$ & Tabular \\
\hline \multicolumn{5}{|l|}{ Dimension } \\
\hline Thickncoo (range), m & $5-10^{2}$ & $5-100^{\prime} \mathrm{s}$ & $5-100^{\prime} 3$ & $5-100^{\prime} \mathrm{a}$ \\
\hline Thickness (common), m & $50-100^{\prime} \mathrm{s}$ & $10-150$ & $10-100^{\mathrm{s}} \mathrm{s}$ & $50-100^{\prime} \mathrm{s}$ \\
\hline Extent (range), $\mathrm{km}^{2}$ & $10^{3}-10^{6}$ & $10^{3}-10^{6}$ & $10^{3}-10^{6}$ & $10^{3}-10^{6}$ \\
\hline Extent (common), $\mathrm{km}^{2}$ & $10^{4}-10^{6}$ & $10^{4}-10^{6}$ & $10^{4}-10^{5}$ & $10^{4}-10^{6}$ \\
\hline \multicolumn{5}{|l|}{ Lithology } \\
\hline $\begin{array}{l}\text { Mineral and } \\
\text { Geochemistry }\end{array}$ & Typical & Typical & Typical & $\begin{array}{l}\text { High carbon- } \\
\text { ate and } \\
\text { evaporite } \\
\text { content }\end{array}$ \\
\hline Texture & Typical & Typical & Typical & Typical \\
\hline $\begin{array}{l}\text { Lateral homo- } \\
\text { geneity, } \mathrm{km}\end{array}$ & $10^{2}-10^{3}$ & $10^{2}-10^{3}$ & $10^{2}-10^{3}$ & $10^{2}-10^{3}$ \\
\hline $\begin{array}{l}\text { Vertical homo- } \\
\text { geneity, m }\end{array}$ & $10^{\prime} \mathrm{s}-100^{\prime} \mathrm{s}$ & $10^{\circ} \mathrm{s}$ & $10^{\circ} \mathrm{s}$ & $10^{\prime} \mathrm{s}-100^{\prime} \mathrm{s}$ \\
\hline \multicolumn{5}{|l|}{ Stratification } \\
\hline Thickness (range), m & $\begin{array}{l}\mathrm{cm}^{\prime} \mathrm{s} \text { to } \\
100^{\prime} \mathrm{s}\end{array}$ & $\begin{array}{l}\mathrm{cm}^{\prime} \mathrm{s} \text { to } \\
\text { meters }\end{array}$ & $\begin{array}{l}\mathrm{cm} ' \mathrm{~s} \text { to } \\
\text { meters }\end{array}$ & $\begin{array}{l}\mathrm{cm}^{\prime} \mathrm{s} \text { to } \\
\text { meters }\end{array}$ \\
\hline \multirow[t]{2}{*}{ Type } & - & paralle1/ & orizontal & \\
\hline & -0 & other ty & s possible & varved \\
\hline $\begin{array}{l}\text { Other primary } \\
\text { structures }\end{array}$ & Present & Present & Present & Present \\
\hline
\end{tabular}


Table E.2.8.1 (Continued)

\begin{tabular}{|c|c|c|c|c|}
\hline Property & $\begin{array}{l}\text { Deep } \\
\text { marine } \\
\text { basin }\end{array}$ & $\begin{array}{l}\text { Marine } \\
\text { shelf/ } \\
\text { slope }\end{array}$ & $\begin{array}{l}\text { River- } \\
\text { dominated } \\
\text { delta front }\end{array}$ & Lacustrine \\
\hline \multicolumn{5}{|c|}{ Nature of Interbeds } \\
\hline Lithology & $\begin{array}{l}\text { Clastic } \\
\text { and } \\
\text { carbonate } \\
\text { rock } \\
\text { (some evap }\end{array}$ & $\begin{array}{l}\text { Clastic } \\
\text { and } \\
\text { carbonate } \\
\text { rock } \\
\text { orite posei }\end{array}$ & $\begin{array}{l}\text { Clastic } \\
\text { (some } \\
\text { coal) } \\
\text { ble) }\end{array}$ & $\begin{array}{l}\text { Carbonate } \\
\text { rock } \\
\text { and } \\
\text { evaporite }\end{array}$ \\
\hline Thickness, m & $1-10^{\prime} \mathrm{s}$ & $1-10^{\prime} \mathrm{s}$ & $1-5 / 10$ & $1-10^{\prime} \mathrm{s}$ \\
\hline Uniformity & $\begin{array}{l}\text { Similar to } \\
<\text { shales }\end{array}$ & $>$ and & $\begin{array}{l}\text { Similar to, } \\
<\text { shales }\end{array}$ & $\begin{array}{l}\text { Similar to, } \\
>\text { and < } \\
\text { shales }\end{array}$ \\
\hline
\end{tabular}

\section{Secondary Structures Joints - describe

May be less so due to carbonate rock cement

Potentially present in all four; no environmentrelated data

Same as for porosity

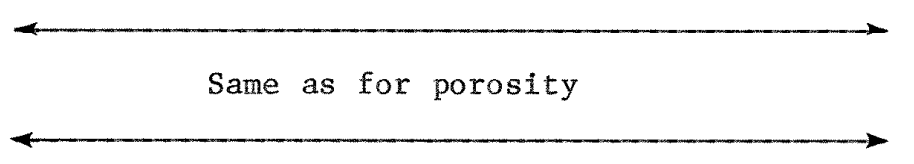

\begin{tabular}{|c|c|c|c|c|}
\hline ertical 1ithology & $\begin{array}{l}\text { coarser, } \\
\text { clastic } \\
\text { (some } \\
\text { carbonate } \\
\text { rock } \\
\text { possible) }\end{array}$ & $\begin{array}{l}\text { coarser, } \\
\text { clastic } \\
\text { carbonate } \\
\text { rock and } \\
\text { evaporite }\end{array}$ & $\begin{array}{l}\text { coarser, } \\
\text { clastic } \\
\text { (and coal) }\end{array}$ & $\begin{array}{l}\text { coarser, } \\
\text { clastic, } \\
\text { carbonate } \\
\text { rock and } \\
\text { evaporite }\end{array}$ \\
\hline ertical thickness, & $10-100^{\prime} \mathrm{s}$ & $10-100^{\prime} \mathrm{s}$ & $10^{\prime} \mathrm{s}$ & $10^{\prime} \mathrm{s}$ \\
\hline
\end{tabular}

Shale flowage, Concretions possible in slumps, and a11 four

Typical for shales but no deposition-related data

Potentially present in all four; no environmentNo definitive data 
Table E.2.8.1 (Continued)

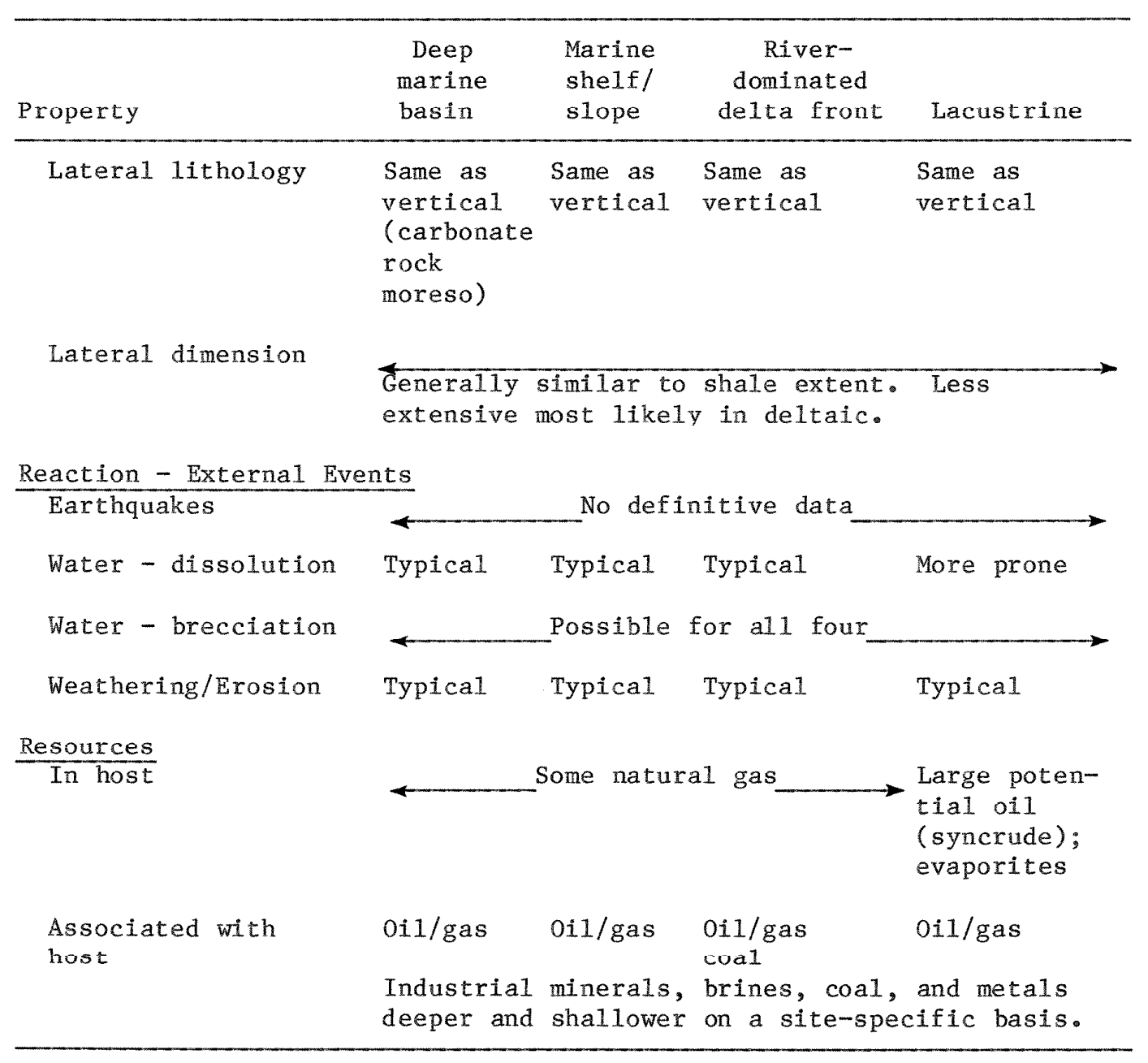




\section{E.2.9 REFERENCES}

ABEL 1975. J. F. Abe1, Jr. and D. W. Gentry, Evaluation of Excavation Experience: Pierce Shale, ORNL/SUB-75/70345, 1975.

ANDERSON 1978. R. Y. Anderson, K. K. Kietzke, and D.J. Rhodes, "Development of Dissolution Breccias, Northern Delaware Basin, New Mexico and Texas," Geology and Mineral Deposits or Ochoan Rocks in Delaware Basin and Adjacent Areas, G. S. Austin, Comp., New Mexico Bur. Mines \& Mineral Resources Circ. 159, p. 47-52, 1978.

ANSTEY 1980. N. A. Anstey, Seismic Exploration for Sandstone Reservoirs, Boston, IHRDC, 1980 .

Ayps 1978. J.A. Apps, N. G. Cook, and ‥ A. Witherspoon, An Appratsa1 of Underground Radioactive Waste Disposal in Argillaceous and Crystalline Rocks: Some Geochemical, Geomechanical, and Hydrological questions, T.BT,-7047, 1978.

ASQUTTH 1974. D. W. Asquith, "Sedimentary Models, Cycles, and De1tas, Upper Cretaceous, Wyoming," Am.Assoc. Pet. Geol. Bu11., 58, 2274-2283 (1974).

ATHERTON 1975. E. Atherton, C. Collinson, and J. A. Lineback, "Mississippian System," Handbook of Illinois Stratigraphy, H. B. Willman et al., Illinois Geol. Survey Bull. 95, 1975, p. 123-163.

ATHY 1930. L. F. Athy, "Density, Porosity, and Compaction of Sedimentary Rocks," Am. Assoc. Pet. Geol. Bul1., 14, 1-24 (1930).

AUGUSTINUS 1978. P. G. E. F. Augustinus, "The Changing Shoreline of Surinam (South America)," Found. Sci. Research - Surinam/Netherlands Antilles, Univ. Utrecht Pub. No. 95, 1978.

AUGUSTINUS 1980. P. G. E. F. Augustinus, "Actual Development of the Chenter Coast of Suriname (South America)," Sediment. Geol., 26, 91-113, $(1980)$.

AVERTTT 1972. P. Averitt, "Coal," Geologic Atlas of the Rocky Mountain Region, W. W. Mallory et al., eds, Rocky Mountain Assoc. of Geologists, pp. 297-299, 1972 .

BAIN 1973. G. L. Bain, Feasibility Study of East Coast Triassic Basins for Waste Storage, Data Availability, U.S. Geol. Survey Open-File Rept., 1973.

BASSETT 1977. J. L. Bassett and N. R. Hasenmueller, "The Albany Shale and Correlative Strata in Indiana," Proceedings, First Eastern Gas Shales Symposium, MERC/SP-77/5, 183-194, 1977 .

BATHURST 1971. R. G. C. Bathurst, Carbonate Sediments and Their Diagenesis, Elsevier Sci. Pub. Co., New York, 1971 . 
BISHOP 1977. R. S. Bishop, "Shale Diapir Emplacement in South Texas LaWard and Sherriff Examples," Gulf Coast Assoc. Geo1. Soc. Trans, 27, 20-8 (1977).

BLATT 1979. H. Blatt, "Diagenetic Processes in Sandstone," Aspects of Diagenesis, P. A. Scholle and P. R. Schluger, eds., Soc. Econ. Paleont. Minera1. Spec. Pub. No. 20, 1979, p. 141-158.

BLATT 1980. H. Blatt, G. Middleton, and R. Murray, Origin of Sedimentary Rocks, 2nd ed., Englewood Cliffs, N.J., Prentice-Ha11, 1980.

BLOYD 1975. R. M. B1 nyd, Summary Appraisals of the Nation's Groundwater Resources - Upper Mississippi Region, U.S. Geol. Survey Prof. Paper 813-B, 1975.

BOSTICK 1979. N. H. Bostick, "Microscopic Measurement of the Level of Catagenesis of Solid Organic Matter in Sedimentary Rocks to aid Exploration for Petroleum and to Determine Former Burial Temperature - A Review," Asperts of Diagenesis, P. . Schol1e and P. R. Schluger, eds.. Soc. Econ. Paleont. Minera1. Spec. Pub. No. 26, 1979, p. 17-43.

BRACE 1980. W. F. Brace, "Permeability of Crystalline and Argillaceous Rocks," Int. J. Rock Mech.\& Min. Sci., 17, 241-251 (1980).

BROONER 1967. F. I. Brooner, Jr., "Shale Diapirs of the Lower Texas Gulf Coast Typified by the North LaWard Diapir," Gulf Coast Assoc. Geol. Socs. Trans., 17, 126-134 (1967).

BROUSSARD 1975. M. L. Broussard, ed., Deltas - Models for Exploration, Houston Geol. Soc. Pub., 555p, 1975.

BRUCE 1973. C. H. Bruce, "Pressured Shale and Related Sediment neformation Mechanism for Development of Regional Contemporaneous Fau1ts," Am. Assoc. Pet. Geol. Bul1., 57, 878-886 (19173).

BRYANT 1975. W. R. Bryant, W. Hottman, and P. Trabant, "Permeability of Unconsolidated and Consolidated Marine sediments, Gulf of Mexico," Marine Geotech., 1, 1-23 (1975).

BUTI. 1972. W. B. Bull, "Recognition of Alluvial-fan Deposits in the Stratigraphic Record," Recognition of Ancient Sedimentary Environments, J. K. Rigby and W. K. Hamblin, eds., Soc. Econ. Paleont. Mineral. Spec. Pub. 16, 1972, p. 63-83.

BURGESS 1974. J. D. Burgess, "Microscopic Examination of Kerogen (Dispersed Organic Matter) in Petroleum Migration," Am. Assoc. Pet. Geo1. Bul1., 53, 73-93, 1969 .

BURST 1969. J. F. Burst, "Diagenesis of Gulf Coast Clayey Sediments and Its Possible Relation to Petroleum Migration," Am. Assoc. Pet. Geol. Bu11., 53, 73-93, 1969. 
CARPENTER 1974. A. B. Carpenter, Mo L. Trout, and E. E. Pickett, "Preliminary Report on the Origin and Chemical Evolution of Lead- and Zinc-rich 0il Field Brines in Central Mississippi," Econ. Geol., 69, 1191-1206 (1974).

CASSIDY 1968. M. M. Cassidy, "Excello Shale, Northeastern Oklahoma: Clue to Locating Buried Reefs," Am. Assoc. Pet. Geol. Bul1., 52, 295-312 (1968).

COBBS ENGINEERING 1975. Cobbs Engineering, Study of Mined Storage Caverns, ORNL/SUB-75/64509, 1975.

COLE 1985. R. D. Cole and M. D. Picard, "Primary and Secondary Sedimentary Structures in oil Shale and other Finc-grained Rocko, Creen River Formation (Eocene), Utah and Colorado," Utah Geology, 2, 49-67 (1985).

CONYBEARE 1967. C. E. B. Conybeare, "Influence of Compaction on Stratigraphic Analysis," Bull. Canadian Petro. Geol., 15, 331-345 (1967).

CONNOLLY 1980. J. R. Connolly and L. A. Woodward, preliminary Inventory of Pre-Ccnozoic Clay Shalco and Argillitco of the Conterminouc United States, SAND \#79-2015, 1980 .

COOGAN 1984. A. H. Coogan and M. M. Parker, "Six Potential Trapping Plays in Ordovicin Trenton Limestone, Northwestern Ohio," 0i1 \& Gas Jour., $82,121-126$ (1984).

Cox 1968. D. P. Cox and C. D. Edgerton, Jr., "Salines," Mineral Resources of the Appalachian Region, U.S. Geological Survey and U.S. Bureau of Mines staffs, U.S. Geo1. Survey prof. Paper 580, 327-337, 1968 .

CULBERTSON 1971. W. C. Culbertson, "Stratigraphy of the Trona Deposits in the Green River Formation, Southwest Wyoming," Univ. Wyo. Contri. Geol., 10, 15-23 (1971).

DAMES 1978. Dames and Moore, Technical Support for GEIS: Radioactive Waste Isolation in Geologic Formations: Volume 6, Baseline Rock Properties - Shale, Y/OWI/TM-36/6, 1978.

DAMES 1980. Dame and Moore, Review of Potential Host Rocks for Radioactive Waste Disposal in the Southeast United States - Triassic Basin Subregion, DP-1569, 1980 .

DAPPLES 1972. E. C. Dapples, "Some Concepts of Cementation and Lithification of Sandstones," Am. Assoc. Pet. Geol. Bull., 56, 3-25 (1972).

DAVIS 1970. J. C. Davis, "Petrology of Cretaceous Mowry Shale of Wyoming," Am. Assoc. Pet. Geol. Bull., 54, 487-502 (1970).

De LAGUNA 1968. W. de Laguna, T. Tamura, H. O. Weeren, E. G. Struxness, W. C. McClain, and R. C. Sexton, Engineering Development of Hydraulic Fracturing as a Method for Permanent Disposal of Radioactive Wastes, ORNL-4259, 1968 . 
De SEGONZAC 1970. G. D. de Segonzac, "The Transformation of Clay Minerals During Diagenesis and Low-grade Metanorphism: A Review," Sedimentology, 15, 281-346 (1970).

DICKEY 1979. P. A. Dickey, Petroleum Development Geology, PennWe11 Pub. co., Tulsa, Okla., 1979.

DOE 1981. U.S. Department of Energy, Volume II - Main Body of Semi-Annual Report for Unconventional Gas-Recovery Program, DOE/METC/SP1108,1981 .

DOE 1983. U.S. Department of Energy, The Unconventional Gas Resources: Avallable Publicalions, DOE/MC/19239-1295, 1983.

DONALDSON 1974. A. C. Donaldson, "Pennsylvanian Sedimentation of Central Appalachians," Carboniferous of the Southeastern United States, Garrett Briggs, ed., Geol. Soc. Amer. Spec. Paper 148, 1974, p. 47-78.

DONALDSON 1979. A. C. Donaldson, M. W. Presley, and J. J. Renton, eds, Carboulferuus Coal Guidebook, West Va. Gcol. \& Econ. Survey Bu11. B37, 3 vols., 1979.

DOYLE 1981. L. J. Doyle and O. H. Pilkey, eds., Geology of Continental Slopes, Soc. Econ. Paleont. Mineral Spec. Pub. 27, 1981.

DROSTE 1976a. J. B. Droste, Supplementary Report on the Geology of Two Areas in Southwestern Indiana as Potential Solid Waste Repository Sites, Y/OWI/SUB-7062/1, 1976 .

DROSTE 1976b. J. B. Droste and C. J. Vitaliano, Geologic Report of the Maquoketa Shale, New Albany Shale, and Borden Group Rocks in the Illinois Basin as Potential Solid Waste Repository Sites, Y/OWI/SUB-7062/1, 1976.

EDMONDSON 1972. W. F. Eluondson, "Geologic Effects Produccd by Compaction of the Meganos Gorge Fill," Am. Assoc. Pet. Geol., Pacific Section, Misc. Papers, 14, 13-20 (1972).

ELLS 1978. G. D. E11s, "An Appraisal of Known Antrim Shale and Berea Oil and Gas Pools in Michigan," Preprints, Second Eastern Gas Shales Symposium, METC/SP-78/6, 1, 280- 290 (1978).

EMIGH 1975. G. D. Emigh, "Phosphate Rock," Industrial Minerals and Rocks, S. J. Lefond et al., eds, Amer. Institute Mining, Metall. \& Petro. Engineers, 1975, p. 935-962.

ENCYCLOBRIT 1974. Encyclopedia Britannica, "Shales, Macropedia," Chicago, Encyclopedia Britannica, Inc., 15th ed., 1974, p. 634-638.

EPSTEIN 1977. A. G. Epstein, J. B. Epstein, and L. D. Harris, Conodont Color Alteration - An Index to Organic Metamorphism, U.S. Geol. Survey Prof. Paper 995. 1977. 
FAY 1979. R. O. Fay, S. A. Friedman, K. S. Johnson, J. F. Roberts, W. D. Rose, and $P . K$. Sutherland, The Mississippian and Pennsylvanian (Carboniferous) Systems in the United States - Oklahoma, U.S. Geol. Survey Prof. Paper 1110-R, 1979 .

FENNER 1967. P. Fenner and A. F. Hagner, "Correlation of Variations in Trace Elements and Mineralogy of the Esopus Formation, Kingston, New York," Geochim. et Cosmochim Acta, 31, 237-261 (1967).

FERGUSON 1967. H. F. Ferguson, "Valley Stress Release in the Allegheny Plateau," Eng. Geol., 4, 63-71 (1967).

TERM 1970. J. Co Ferm, "Allegheny Deltaic Deposits," Deltaic Sedimentation - Modern and Ancient, J. P. Morgan, ed., Soc. Econ. Paleont. Mineral. Spec. Pub. 15, 1970, p. 246-255.

FERM 1979. J. C. Ferm and J. C. Horne, Carboniferous Depositional Environments in the Appalachian Region: Columbia, S.C., Univ. South Carolina, Dept. Geol. Coal Group Rept., 1979.

FINCH 1973. W. I. Finch, A. P. Butler, Jr., F. C. Armstrong, and A. E. Weissenborn, "Uranium," United States Mineral Resources, D. A. Brobst and W. P. Pratt, eds., U.S. Geol. Survey Prof. Paper 820, 1973, p. $456-468$.

FISK 1947. H. N. Fisk, Fine-grained Alluvial Deposits and Their Effects on Mississippi River Activity, U.S. Army Corps Engineers, Mississippi River Comm. Rept., 1947.

FISK 1954. H. N. Fisk, E. McFarlan, Jr., and C. R. Kolb, "Sedimentary Framework of the Modern Mississippi Delata," J. Sed. Petro1., 24, 76-99 (1954).

FLAWN 1953. T. T. Flawn, "rctrographic Claooification of Argillacoous Sedimentary and Low Grade Metamorphic Rocks in Subsurface," Am. Assoc. Pet. Geo1. Bu11., 37, 560-565 (1953).

FOLK 1974a. R. L. Folk, Petrology of Sedimentary Rocks, Austin Texas, Hemphi11, 1974 .

FOLK 1974b. R. L. Folk, "The Natural History of Crystalline Calcium Carbonate; Effect of Magnesium Content and Salinity," J. Sed. Petro1., 44, 40-53 (1974).

FONTAINE 1983. D. A. Fontaine, Source and Reservoir Rock Factors Tertiary Hydrocarbon Accumulations and Basins, Pacific Coastal South America (Parts 1 and 2), Houston Geol. Soc. Bul1., no. 11, p. 8-13 and no. 12, p. 8-14, 1983.

FRANKLIN 1972. J. A. Franklin and R. Chandra, "The Slake-Durability Test," Int. J. Rock Mech. Min. Sciences, 9, 325-341 (1972). 
GAMBLE 1971. J. C. Gamble, Durability - Plasticity Classification of Shales and Other Argillaceous Rocks, Univ. Illinois, unpublished PhD dissertation, 1971 .

GILL 1966. J. R. Gill and W. A. Cobban, Regional Unconformity in Late Cretaceous Wyoming, U.S. Geol. Survey Prof. Paper 550-B, p. 20-27, 1966.

GIPSON 1966. M. Gipson, Jr., "A Study of the Relations of Depth, Porosity, and Clay Mineral Orientation in Pennsylvanian Shales," J. Sed. Petrol., 36, 888-903 (1966).

GLASS 1975. G. B. Glass, W. G. Wende11, F. K. Root, and R. M. Brekenridge, "Energy Resources Map of Wyoming," Wyoming Geol. Survey map, 1975.

GLENNIE 1970. K. W. Glennie, "Desert Sedimentary Environments," Developments in Sedimentology, Elsevier Pub. Co., Amsterdam, 1970.

GONZALES 1984. S. Gonzales and K. S. Johnson, Shales and other Argillaccoue Strata in the United States, ORNL/SUB/8/1-6/79/1, 1984.

GREGORY 1977. A. R. Gregory, "Aspects or Rock Physics from Laboratory and Log Data that are Important to Seismic Interpretation," Seismic Stratigraphy - Applications to Hydrocarbon Exploration, C. E. Payton, ed., Am. Assoc. Pet. Geo1. Mem. 26, 1977, p. 15-46.

GRIM 1968. R. E. Grim, Clay Mineralogy, 2nd ed., McGraw-Hi11, New York, 1968 .

GURR 1979. T. M. Gurr, "Geology of U.S. Phosphate Deposits," Min. Eng., $\underline{31}, 682-691$ (1979).

GUSTAFSON 1981. L. B. Gustafson and N. Williams, "Sediment-hosted Stratiform Deposits of Copper, Lead, and Zine," Seventy-fifth

Anniversary Volume, Economic Geology, B. J. Skinner, ed., Economic Geol. Pub. Co., 1981, p. 139-178.

HAASE 1984. C. S. Haase, E. C. Walls, and C. D. Farmer, Stratigraphic and Structural Data for the Conasauga Group and the Rome Formation on the Copper Creek Fault Block Near Oak Ridge, Tennessee: Preliminary Data from Test Borehole ORNL-JOY \#⿰冫欠 ORNL/TM-9159, 1984.

HACKEL 1966. O. Hackel, "A Summary of the Geology of the Great Valley," Geology of Northern California, E. H. Bailey, ed., Calif. Div. Mines \& Geol. Bull. 190, 1966, p. 215-238.

HALBOUTY 1970. M. T. Halbouty, A. A. Meyerhoff, R. E. King, R. H. Dott, Sr., H. D. Klemme, and T. Shabad, "World's Giant Oil and Gas Fields, Geologic Factors Affecting Their Formation, and Basin Classification," Geology of Giant petroleum Fields, M. T. Halbouty, ed., Am. Assoc. Pet. Geo1. Mem. 14, 1970, p. 502-555. 
HANOR 1979. J. S. Hanor, "The Sedimentary Genesis of Hydrothermal Fluids," Geochemistry of Hydrothermal Ore Deposits, H. L. Barnes, ed., John Wiley, 2nd ed., New York, 1979, p. 137-172.

HARMON 1983. K. M. Harmon, "Survey of Foreign Terminal Radioactive Waste Storage Programs," Proceedings, Inter. Conf. Rad. Waste Management (Seattle, Wash.), 1983, p. 199-205.

HARRIS 1979. A. G. Harris, "Conodont Color Alteration, an Organomineral Metamorphic Index and its Application to Appalachian Basin Geology," Aspects of Diagenesis, P. A. Scholle and P. R. Schluger, eds., Soc. Econ. Paleont. Minera1, spec. Pub. No. 26, 1979, p. 3-16.

HARRIS 1977. L. D. Harris and R. C. Milici, Characteristics of Thinskinned Style of Deformation in the Southern Appalachians, U.S. Geol. Survey Prof. Paper 1018, 1977.

HARRIS 1960. J. F. Harris, G. L. Taylor, and J. C. Walper, "Relation of Deformational Fractures in Sedimentary Rocks to Regional and Local Structures," Am-Ascor. Pet. Cen1. Bu11., 44, 1853-73 (1960).

HARRISON 1972. J. E. Harrison, "Precambrian Belt Basin of Northwestern United States: Its Geometry, Sedimentation, and Copper Occurrences," Geo1. Soc. Amer. Bull, 83, 1215-1240 (1972).

HAYES 1967. M. O. Hayes, "Relationship Between Coastal Climate and Bottom Sediment Type on the Inner Continental Shelf," Marine Geol., 5, $111-132$ (1967).

HAYES 1982. M. O. Hayes and J. Michel, "Shoreline Sedimentation Within a Forearc Embayment, Lower Cook Inlet, Alaska," J. Sed. Pet., 52, $251-263(1982)$.

HFCKFT. 1977. P. H. Hecke1, "Origin of Phosphatic Black Sha1e Faries in Pennsylvanian Cyclothems of Mid-Continent North America," Am. Assoc. Pet. Geol. Bul1., 61, 1045-1068 (1977).

HITE 1967. R. J. Hite and J. R. Dyni, "Potential Resources of Dawsonite and Nahcolite in the Piceance Creek Basin, Northwest Colorado," Colo. Sch. Mines Quart., 62, 25-38 (1967).

HUNT 1979. J. M. Hunt, Petroleum Geochemistry and Geology, San Francisco, W. H. Freeman Company, 1979 .

HUNTOON 1979. P. W. Huntoon and H. R. Richter, "Breccia Pipes in the Vicinity of Lockhart Basin, Canyonlands Area, Utah," Four Corners Geol. Soc. 9th Field Conf. Guidebook, 1979, p. 47-53.

INGRAM 1953. R. L. Ingram, "Fissility of Mudrocks," Geo1. Soc. Amer. Bu11., 64, 869-878 (1953).

IAEA 1983. Internationa1 Atomic tnergy Agency, rroceedings, International Conference on Radioactive Waste Management (Seattle, Washington), IAEA Pub1. IAEA-CN-43, Paris, France, 1983. 
ISAACS 1984. C. M. Isaacs, "The Monterey - Key to Offshore California Boom," 0i1 \& Gas Jour., 82, 75-81 (1984).

ISHERWOOD 1981. D. Isherwood, et al., "Shale," Geoscience Data Base Handbook for Modeling a Nuclear Waste Repository, NUREG/CR-0912, Chap. 1, v. 2, p. 1-103, 1981 .

JACKSON 1967. S. A. Jackson and F. W. Beales, "An Aspect of Sedimentary Basin Evolution: The Concentration of Mississippi Valley-type ore During Late Stages of Diagenesis," Can. Pet. Geo1. Bu11., 15, 383-433 (1967).

JoHNSON 1976. K. S. Johnson, "Permian Copper shales of Southwestern Oklahoma," Stratiform Copper Deposits of the Mid-Continent Region, A Symposium, K. S. Johnson and R. L. Croy, eds., Okla. Geol. Survey Circ. 77,1976, p. 3-14.

JOHNSON 1978. K. S. Johnson and S. Gonzales, Salt Deposits in the United States and Regional Geologic Characteristics Important for Storage of Radioactive Waste, Y/OWI/SUB 7414/1, 1978 .

KELLEY 1960. V. C. Kelley and N. J. Clinton, Fracture Systems and Tectonic Elements of the Colorado Plateau, Univ. New Mexico Pub. in Geology No. 6, 1960 .

KOLB 1967. C. R. Kolb and R. I. Kaufman, "Prodelta Clays of Southeast Louisiana," Marine Geotechnique, A. F. Richards, ed., Univ. I11. Press, Urbana, I11., 1967, p. 3-21.

KRAUSE 1979. H. F. Krause, H. H. Damberger, W. J. Nelson, S. R. Hunt, C. T. Ledvina, C. G. Treworgy, and W. A. White, Roof Strata of the Herrin (No. 6) Coal Member in Mines of Illinois: Their Geology and Stability, Ill. Geol. Survey I11. Minerals Note $72,1979$.

KRUMHANSL 1979a. J. L. Krumhansl, Preliminary Results Report Conasauga Near-surface Heater Experiment, SAND $\$ 179-0745,1979$.

KRUMHANSL 1979b. J. L. Krumhans1, Final Report: Conasauga Near-surface Heater Experiment, SAND \#79-1855, 1979 .

IKRUMIIANSL 1979c. J. L. Krumhans 1 and W. D. Sundberg, "The Conasauga Near-Surface Heater Experiment - Implications for a Repository Sited in a Water-Saturated Argillaceous Formation," Use of Argillaceous Materials for the Isolating of Radioactive Wastes, Proceedings of the NEA Workshop, Paris, France, September 10-12, 1979, pp. 129-38, 1979 .

LAMAR 1956. J. E. Lamar, W. J. Armon, and J. A. Simon, Illinois 0i1 Shales, Illinois Geol. Survey Circ. 208, 1956.

LAPPIN 1979. A. R. Lappin and W. A. O1sson, "Material Properties of Eleana Argillite - Extrapolations to other Argillaceous Rocks, and Implications for Waste Management," NEA Workshop (Paris, France) Proceedings, 1979, p. 75-89. 
LARESE 1977. R. E. Larese and M. T. Heald, Petrogrpahy of Selected

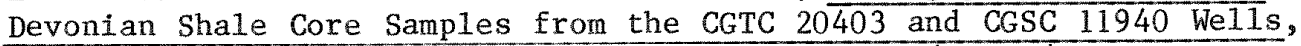
Lincoln and Jackson Counties, West Virginia, MERC/CR-77/6, 1977 .

LEWAN 1978. M. D. Lewan, "Laboratory Classification of Very finegrained Sedimentary Rocks," Geol., 으, 745-8 (1978).

LINK 1978. M. H. Link and R. H. Osborne, "Lacustrine Facies, Pliocene Ridge Basin, California," Modern and Ancient Lake Sediments, A. Matter and M. E. Tucker, eds., Inter. Assoc. Sedimentology Spec. Pub. 2, 1978, p. 167-186.

LISENBEE 1976. A. L. Lisenbee, "Shale Diapiriam and the Structura1 Development of Galisteo Syncline, Santa Fe County, New Mexico," Tectonics and Mineral Resources of Southwestern North America, L. A. Woodward and S. A. Northrop, eds., New Mexico Geol. Soc. Spec. Pub. No. 6,1976, p. $88-94$.

LOMENICK 1983. T. F. Lomenick, S. Gonzales, K. S. Johnson, and D. W. Byerly, Regional Gcological Aoocooment of the Devonian-Mississippian Shale Sequence of the Appalachian, Illinois, and Michigan Basins Relative to Potential Storage/Disposal of Radioactive Wastes, ORNL-5703, 1983.

LONG 1979. B. R. Long, "Regional Survey of Surface Joints in Eastern Kentucky," Proceedings, Third Eastern Gas Shales Symposium, METC/SP-7916, 1979, p. 445-450.

LUNDEGARD 1980. P. D. Lundegard and N. D. Samuels, "Field Classification of Fine-grained Rocks," J. Sed. Pet. 50, 781-6 (1980).

MACKENZIE 1972. D. B. MacKenzie, "Primary Stratigraphic Traps in Sandstones," Stratigraphic Oil and Gas Fields - Classification, Exploration Methods and Caoc Hiotorico, R. E. King, ed., Am. Assoc. pot. Geol. Mem. 16, 1972, p. 47-63.

MACKENZIE 1975. F. T. MacKenzie, "Sedimentary Cycling and the Evolution of Sea Water," Chemical Oceanography, J. P. Riley and G. Skirrow, eds•, Academic Press, New York, 1975, p. 309-364.

MAJCHSZAK 1978. F. L. Majchszak, "Progress Report on Characterization of the Devonian Black Shales in Ohio," Proceedings, First Eastern Gas Shales Symposium, MERC/SP-77/5, 1978, p. 668-677.

MALLORY 1977. W. W. Mallory, "Fractured Shale Hydrocarbon Reservoirs in Southern Rocky Mountain Basins," Exploration Frontiers of the Central and Southern Rockies, H. K. Veal, ed., Rocky Mountain Assoc. Geologists Symposium Guidebook, 1977 , p. 89-94.

MANGER 1963. G. E. Manger, Porosity and Bulk Density of Sedimentary Rocks, U.S. Geol. Survey Bull. 1144-E, 1963. 
MARCHER 1971. M. V. Marcher and R. H. Bingham, Reconnaissance of the Water Resources of the Tulsa Quadrangle, Northeastern Oklahoma, Okla. Geo1. Survey Hydro. Atlas 2, 1971.

MASTERS 1967. C. D. Masters, "Use of Sedimentary Structures in Determination of Depositional Environments, Mesaverde Formation, Williams Fork Mountains, Colorado," Am. Assoc. Pet. Geo1. Bu11. 51, 2033-43 (1967).

MATTER 1978. A. Matter and M. E. Tucker, eds., Modern and Ancient Lake Sediments, Inter. Assoc. Sedimentology Spec. Pub. 2, 1978.

MAZZULLO 1980. S. J. Mazzul1o, ed., Stratigraphic Traps in Carbonate Rocks, Amer. Assoc. Petroleum Geologists Reprint Series No. 23, 1980.

MCBRIDE 1974. E. F. MCBride, "significance of Color in Red, Green, Purple, Olive, Brown, and Gray Beds of Difunta Group, Northeastern Mexico," J. Sed. Pet., 44, 760-73 (1974).

McVEY 1979. D. F. McVey, A. R. Lappin, and R. K. Thomas, "Test Results and Supporting Analysis of a Near-Surface Heater Experiment in the Eleana Argillate," Use of Argillaceous Materials for the Isolating of Radioactive Wastes, Proceedings of the NEA Workshop, Paris, France, September 10-12, 1979, pp. 93-113, 1979 .

McGINNIES 1968. W. G. McGinnies, B. J. Goldman, and P. Payne, eds., Deserts of the World, Tuscon, Arizona, Univ. Arizona Press, 1968.

MELLEN 1976. F. F. Mellen, Basal Ottawa Limestone, Chattanooga Shale, Floyd Shale, Porter's Creek Clay, and Yazoo Clay in parts of Alabama, Mississippi, and Tennessee as Potential Host Rocks for Underground Emplacement of Waste, Y/OWI/SUB-76/87950, 1976.

MEREWETHER 1973. E. A. Merewether, J. A. Sharps, J. R. Gi11, and M. E. Cooley, Shale Mudstone, and Claystone as Potential Host Rocks for Underground Emplacement of Waste, USGS-4339-5, 1973.

MEYER 1981. D. L. Meyer, R. C. Tobin, W. A. Pryor, W. B. Harrison, and R. G. Osgood, "Stratigraphy, Sedimentology, and Paleoecology of the Cincinnatian Series in the Vicinity of Cincinnati, Ohio," GSA Cincinnati '81 Field Trip Guidebooks, v. 1, Stratigraphy - Sedimentology, T. G. Roberts, ed., Amer. Geol. Inst. Field Trip No. 12, 1981, p. 31-72.

MILLOT 1970. G. Millot, Geology of Clays, Springer-Verlag, New York, 1970.

MILNER 1982. C. W. D. Milner, "Geochemical Analyses of Sedimentary Organic Matter and Interpretation of Maturation and Source Potential," How to Assess Maturation and Paleotemperatures, Soc. Econ. Paleont. Mineral. Short Course No. 7, 1982, p. 217-52.

MOORE 1978. D. M. Moore, "A Sample of the purington Shale Prepared as a Geochemical Standard," J. Sed. Pet., 48, 995-8 (1978). 
MORGRIDGE 1972. D. L. Morgridge and W. B. Smith, Jr., "Geology and Discovery of Prudhoe Bay Field, Eastern Arctic Slope, Alaska," Stratigraphic Oil and Gas Fields - Classification, Exploration Methods, and Case Histories, R. E. King, ed., Am. Assoc. Pet. Geol. Mem. 16, 1972 , p. 489-501.

MORRIS 1974. R. C. Morris, "Sedimentary and Tectonic History of the Dauchita Mountains," Tectonics and Sedimentation, W. R. Dickinson, ed., Soc. Econ. Paleont. Mineral Spec. Pub. No. 22, 1974, p. 120-142.

MOTT 1983. L. V. Mott and J. I. Drever, "Origin of Uraniferous Phosphate Beds in Wilkins Peak Member of Green River Formation, Wyoming," Am. Assoc. Pet. Geol. Bul1., 57, 70-82 (1983).

MURRAY 1968. G. H. Murray, Jr., "Quantitative Fracture Study - Sanish pool, Mckenzie Comnty, North Dakota," Am. Assoc. Pet. Geol. Bul1. 52. 57-65 (1968).

MUSGRAVE 1968. A. W. Musgrave and W. G. Hicks, "Outlining Shale Masses by Geophysical Methods," Diapirism and Diap1rs, Jules Braunstein and $G$. D. O'Brien, eds., Am. Assoc. Pet. Geol. Mem. 8, 1968, p. 122-136.

NASH 1981. J. T. Nash, H. C. Granger, and S. S. Adams, "Geology and Concepts of Genesis of Important Types of Uranium Deposits," Seventyfifty Anniversary Volume, Economic Geology, B. J. Skinner, ed., Economic Geo1. Pub. Co., 1981, p. 63-116.

NETHERLAND 1975. Netherland, Sewe11, and Associates, Preliminary Regional Study of the 0il Shales of the Green River Formation in the Tri-State Area of Colorado, Utah, and Wyoming to Investigate Their Utility for Disposal of Radioactive Waste, ORNL/SUB-75/70345, 1975.

NICKELSEN 1967. R. P. Nicke1sen and V. D. Hough, "Jointing in the Appalachian Plateau of Pennsylvania," Geol. Soc. Amer. Bu11., 78 , $609-630$ (1967).

NUCKOLS 1978. F. R. Nuckols, TII, "Exploration Parameters Derived from Historical Devonian Shale production in Western West Virginia," Preprints, Second Eastern Gas Shales Symposium, METC/SP-78/6, v. 1, p. $169-173,1978$.

O'BRIEN 1973. D. R. O'Brien and M. E. Chenevert, "Stabilizing Sensitive Shales Inhibited Potassium-based Drilling Fluids," J. Petro. Tech., no. 9, 1089-1100 (1973).

OOMKENS 1960. E. Oomkens and J. H. J. Terwindt, "Inshore Estuarine Sediments in the Haringvliet (Netherlands)," Geol. en Mijnbouw, 39, $701-10,1960$.

PARKER 1967. J. M. Parker, "Salt Solution and Subsidence Structures, Wyoming, North nakota, and Montana," Am. Assoc. Pet.Geo1. Bu11.. 51. $1929-47,1967$. 
PETTIJOHN 1975. F. J. Pettijohn, Sedimentary Rocks, 3rd ed., Harper and Row Pub., New York, 1975.

PICARD 1953. M. D. Picard, "Marlstone - A Misnomer as Used in the Uinta Basin, Utah," Am. Assoc. Pet. Geol. Bul1., 37, 1075-7, 1953.

PICARD 1971. M. D. Picard, "Classification of Fine-grained Sedimentary Rocks," J. Sed. Pet., 41, 179-95 (1971).

PICARD 1972. M. D. Picard and L. R. High, Jr., "Criteria for Recognizing Lacustrine Rocks," Recognition of Ancient Sedimentary Environments, J. K. Rigby and W. K. Hamblin, eds., Soc. Econ. Paleont. Minera1. Spec. Pub. No. 16, 1972, p. 108-145.

PICARD 1981. M. D. Picard and L. R. High, Jr., "Physical Stratigraphy of Ancient Lacustrine Deposits," Recent and Ancient Nonmarine Depooitional Environmento: Modelo for Exploration, F. C. Ethridge and R. M. Flores, eds., Soc. Econ. Paleont. Mineral Spec. Pub. No. 31, 1981, p. 233-260.

PIPER 1978. D. J. W. Piper, "Turbidite Muds and Silts on Deep Sea Fans and Abyssal plains," Sedimentation in Submarine Canyons, Fans, and Trenches, D. J. Stanley and G. Kelling, eds., Dowden, Hutchinson and Ross, Inc., Stroudsburg, $\mathrm{Pa} ., 1978, \mathrm{p} .163-189$.

POOLE 1961. F. G. Poole, F. N. Houser, and P. P. Orkild, Eleana Formation of Nevada Test Site and Vicinity, Nye County, Nevada, U.S. Geo1. Survey Prof. Paper 424-D, 1961, p. D104-111.

POOLE 1965. F. G. Poole, P. P. Orkild, M. Gordon, Jr, , and H. Duncan, Age of the Eleana Formation (Devonian and Mississippian) in the Nevada Test Site, U.S. Geol. Survey Bu11. 1224-A, 1965, p. A51-53.

POTTER 1980. P. E. Potter, J. B. Maynard, and W. A. Pryor, Sedimentology of Shale, Springer-Verlag, New York, 1980.

POTTER 1982. P. E. potter, J. B. Maynard, and W. A. Pryor, "Appalachian Gas Bearing Devonian Shales: Statements and Discussions," $0 i 1$ \& Gas J., $80,(4), 290,292-3,295-6,298,302,304,309,312,315-6$, and 318 (1982).

PRIEN 1974. C. H. Prien, "Current Oil Shale Technology: A Summary," Energy Resources of the Piceance Creek Basin, Colorado, D. K. Murray, ed., Rocky Mountain Assoc. Geologists 25th Field Conf. Guidebook, 1974, p. 141-150.

PROVO 1978. L. J. Provo, R. C. Kepferle, and P. E. Potter, "Division of Black Ohio Shale in Eastern Kentucky," Am.Assoc. Pet. Geo1. Bul1., 62, 1703-13 (1978).

RAY 1977. E. O. Ray, "Devonian Shale Production - Eastern Kentucky Field," The Future Supply of Nature-Made petroleum and Gas, proceedings, first UNITAR Conference on Energy and the Future, R. F. Meyer, ed., Pergamon Press, 1977, p. 679-696. 
REGAN 1949. L. J. Regan, Jro and A. W. Hughes, "Fractured Reservoirs of Santa Maria District, California," Am. Assoc. Pet. Geol. Bull., 33, $32-51,1949$.

RIEKE 1974. H. H. Rieke and G. V. Chilingarian, Compaction of Argillaceous Sediments: Developments in Sedimentology No. 16, Elsevier Sci. Pub. Co., New York, 1974.

ROY 1980. P. S. Roy, B. G. Thom, and L. D. Wright, "Holocene Sequences on an Einbayed High-Energy Coast: An Evolutionary Mode1," Sed. Geo1. 26, $1-19$ (1980).

SCHOON 1971. R. A. Schoon, Geology and Hydrology of the Dakota Formation in South Dakota, South Dakota Geo1. Survey Rept. Invest. 104, 1971 .

SCHULtZ 1976. L. G. Schultz, H. A. Tuurtelol, and F. J. Flanagau, "Cudy Shale SCO-1, from Natrona County, Wyoming," Descriptions and Analyses of Eight New USGS Rock Standards, F. J. Flanagan, ed., U.S. Geol. Survey Prof. Paper 840,1976, p. 21-23.

SCHULTZ 1980. L. G. Schultz, H. A. Tourtelot, J. R. Gill, and J. G. Boerngen, Composition and Properties of the Pierre Shale and Equivalent Rocks, Northern Great Plains Region, U.S. Geol. Survey Prof. Paper 1064-B, 1980, p. B1-114.

SCOTFORD 1965. D. M. Scotford, "Petrology of the Cincinnatian Series Shales and Environmental Implications," Geol. Soc. Amer. Bull., 76, 193-222 (1965).

SHARP 1983. J. M. Sharp, Jr., "Permeability Controls on Aquathermal Pressuring," Am. Assoc. Pet. Geol. Bull., 67, 2057-61 (1983).

SHEPARD 1954. F. P. Shepard, "Nomenclature Based on Sand-Silt-Clay Ratios," J. Sed. Pet. 24, 151-158 (1954).

SHEPPARD 1973. R. A. Sheppard and A. J. Gude, III, "Zeolites and Associated Authigenic Silicate Minerals in Tuffaceous Rocks of the Big Sandy Formation, Mohave County, Arizona," U.S. Geol. Survey Prof. Paper $830,1973$.

SHIDELER 1977. G. L. Shideler, "Late Holocene Sedimentary Provinces, South Texas Outer Continental Shelf," Am. Assoc. Pet. Geo1. Bul1., 61, 708-722 (1977).

SHIRLEY 1966. M. L. Shirley and J. A. Ragsdale, eds., "Deltas in Their Geologic Framework," Houston Geol. Soc. Pub., 1966.

SHUMARER 1976. R. C. Shumaker, "A Digest of Appalachian Structural Geology," Devonian Shale production and Potential, R. C. Shumaker and W. K. Overbey, Jr., eds., MERC/SP-76/2, 1976, p. 75-93. 
SHURR 1977. G. W. Shurr, The Pierre Shale, Northern Great Plains; A Potential Isolation Medium for Radioactive Wastes, U.S. Geol. Survey Open-File Rept. 77-776, 1977 .

SIBLEY 1979. S. F. Sibley, Cobalt, U.S. Bureau Mines Mineral Commodity Profile, 1979 .

SIMPSON 1965. T. A. Simpson, Geologic and Hydrologic Studies in the Birmingham Red-Iron-Ore District, Alabama, U.S. Geol. Survey Prof. Paper 473-C, 1965, p. C1-C47.

SINNOT 1978. A. Sinnot and E. M. Cushing, Summary Appraisals of the Nation's Ground-water Resources - Mid-Atlantic Region, U.S. Geol. Survey Prof. Paper 813-I, 1978.

SKIPP 1979. B. Skipp, "Great Basin Region, Chapter P," Paleotectonic Investigations of the Mississippian System in the United States: Part 1 , Introduction and Regional Analyses of the Mississippian System, L. C. Craig, et a1., eds., U.S. Geol. Survey Prof. Paper 1010-P, 1979, p. $273-328$.

SORENSEN 1974. H. O. Sorensen and R. T. Segall, "Natural Brines of the Detroit River Group, Michigan Basin," Fourth Symposium on Salt, A. H. Coogan, ed., Northern Ohio Geo1. Soc., 1974, p• 91-99.

SPEARS 1980. D. A. Spears, "Towards a Classification of Shales," J. Geo1 Soc. London, 137, 125-129 (1980).

St CLAIR 1976. A. E. St. Clair, T. J. Evans, and L. E. Garner, compilers, Energy Resources of Texas, Texas Bur. Econ. Geol. Energy and Mineral Resources of Texas Atlas, 1976.

STANFORD 1984. W. D. Stanford, "Alligator Ridge: From a Lone Prospector's Discovery to an Operating Gold Mine," Min. Eng., 36, (6), 593-598 (1984).

STANLEY 1978. D. J. Stanley and G. Kelling, eds., Sedimentation in Submarine Canyons, Fans, and Trenches, Dowden, Hutchinson and Ross, Inc., Stroudsburg, Pa., 1978 .

STANLEY 1978. D. J. Stanley and C. M. Wear, "The 'Mud-Line': An Erosion-Deposition Boundary on the Upper Continental Slope," Marine Geo1., 28, M19-M29 (1978).

STANLEY 1981. D. J. Stanley and A. Maldonado, "Depositional Models for Fine-Grained Sediment in the Western Hellenic Trench, Eastern Mediterranean," Sedimentology, 28, 273-290 (1981).

STANLEY 1983. D. J. Stanley, Parallel Laminated Deep-Sea Muds and Coupled Gravity Flow-Hemipelagic Settling in the Mediterranean, Smithsonian Inst. Contri. Marine Sciences, No. 19, 1983. 
SWANSON 1961. V. E. Swanson, Geology and Geochemistry of Uranium in Marine Black Shales, A Review, U.S. Geol. Survey Prof. Paper 356-C, 1961, p. 67-110.

TILLMAN 1983. J. E. Tillman and H. L. Barnes, "Deciphering Fracturing and Fluid Migration Histories in Northern Appalachian Basin," Am. Assoc. Pet. Geo1. Bu11., 67, 692-705 (1983).

TISSOT 1978. B. Tissot and D. H. Welte, Petroleum Formation and Occurrence, Springer-Verlag, New York, $19 \overline{78 .}$

TOURTELOT 1960. H. A. Tourtelot, "Origin and Use of the Word "Shale'," Am. J. Sci., Bradley Vol., 258-A, 335-343 (1960).

TOURTELOT 1970. E. B. Tourtelot, Selected Annotated Bibliography of Minor-Element Content of Marine Black Shales and Related Sedimentary Rocks, U.S. Geol. Survey Bul1. 1293, 1970.

TSCHANZ 1970. C. M. Tschanz and E. H. Pampeyan, Geology and Mineral Deposits of Lincoln County, Nevada, Nevada Bur. Mines and Geology Bu11. $73,1970$.

TWENHOFEL 1950. W. H. Twenhofe1, Principles of Sedimentation, McGraw-Hi11, New York, 1950.

VAN GIJZEL 1982. P. Van Gijze1, "Characterization and Identification of Kerogen and Bitumen and Determination of Thermal Maturation by Means of Qualitative and Quantitative Microscopical Techniques," How to Assess Maturation and Paleotemperatures, Soc. Econ. Paleont. Mineral. Short Course No. 7, 1982, p. 159-216.

VAN HOUTEN 1969. F. B. Van Houten, "Late Triassic Newark Group, North Central New Jersey and Adjacent Pennsylvanian and New York," Geology of Selected Areas in New Jersey and Eastern Pennsylvania and Guidebook to Excursions, S. Subitzky, ed., Rutgers Univ. Press, New Brunswick, N.J., 1969, p. $314-47$.

VAN WEST 1972. F. P. Van West, "Green Rivex Oil Shale," Geologic Atlas of the Rocky Mountain Region, W. W. Mallory et al., eds., Rocky Mountain Assoc. Geologists, 1972, p. 287-292.

VINE 1970. J. D. Vine nd E. B. Tourtelot, "Geochemistry of Black Shale Deposits: A Summary Report," Econ.Geo1., 65, 253-272 (1970).

VOLK 1972. R. W. Volk, "Petroleum and Natural Gas, Denver Basin and the Las Animas Arch," Geologic Atlas of the Rocky Mountain Region, W. W. Mallory et al., eds., Rocky Mountain Assoc. Geologists, 1972, p. 281-282.

WALKER 1967. R. G. Walker, "Turbidite Sedimentary Structures and Their Relationship to Proximal and Distal Depositional Environments," J. Sed. Pet. 37, 25-43 (1967). 
WALSH 1976. E. L. Walsh and E. A. Bathke, Thermal Calculations in Shale, Y/OWI/SUB-76/16502, 1976.

WANLESS 1964. H. R. Wanless, "Local and Regional Factors in Pennsylvanian Cyclic Sedimentation," Symposium on Cyclic Sedimentation, D. F. Merriam, ed॰, Kansas Geol. Soc. Bu11. 169, Pt. 2, 1964, p. 593-606.

WARN 1953. G. F. Warn and R. Sidwe11, "Petrology of the Spraberry Sands of West Texas," J. Sed. Pet., 23, 67-74 (1953).

WAY 1973. D. S. Way, Terrain Analysis: A Guide to Site Selection Using Aerial Photographic Interpretation, Dowden, Hutchinson and Ross, Inc., Stroudsburg, Pa., 1973.

WEAVER 1967. C. E. Weaver, "Potassium, Illite, and the Ocean," Geochim. Cosmochim. Acta, 31, 2181-96 (1967).

WEAVER 1976a. C. E. Weaver, Waste Storage Potential of Triassic Basins in Southeast United States, Y/OWI/SUB-7009/2, 1976.

WEAVER 1976b. C. E. Weaver, l'hermal Properties of Clays and Shales, $\mathrm{Y} / \mathrm{OWI} / \mathrm{SUB}-7009 / 1,1976$.

WEAVER 1977. C. E. Weaver, Fine-Grained Sheet Silicate Rocks, Y/OWI/SUB-7009/4, 1977 .

WEAVER 1980a. C. E. Weaver, "Fine-Grained Rocks: Shales or Physilites," Sed. Geo1. 27, 301-313 (1980).

WEAVER 1980b. C. E. Weaver, Use of K-Ar Dating and Oxygen Isotopes for Determining the Thermal History of Shales, OWI-107, 1980.

WEEKS 1974. J. B. Weeks, "Water Resources of Piceance Creek Basin, Colorado," Energy Resources of the Piceance Creek Basin, Colorado, D. K. Mur ray, ed., Rucky Mouncain Assoc. Geologists zbth Field cont. Guidebook, 1974, p. 175-180.

WEEREN 1976. H. O. Weeren. An Evaluation of Waste Disposal by Shale Fracturing, ORNL/TM-5209, 1976.

WEISE 1980. B. R. Weise, Wave-Dominated Delta Systems of the Upper Cretaceuus Sall Miguel Formation, Maverick Basin, South l'exas, lexas Bur. Econ. Geol. Rept. Inv. 107, 1980.

WELLS 1981. J. T. Wells and J. M. Coleman, "Physical processes and Fine-Grained Sediment Dynamics, Coast of Surinam, South America," J. Sed. Pet. 51, 1053-68 (1981).

WESCOTT 1980. W. A. Wescott and F. G. Ethridge, "Fan-Delta Sedimentology and Tectonic Setting - Yallahs Fan Delta, Southeast Jamaica," Am. Assoc. Pet. Geo1. Bu11. 64, 374-399 (1980). 
WINKLER 1974. H. G. F. Winkler, Petrogenesis of Metamorphic Rocks, 4th ed., Springer-Verlag, New York, $\overline{1976 .}$

ZIEGLER 1981. A. M. Ziegler, S. F. Barrett, and C. R. Scotese, "Paleoclimate Sedimentation and Continental Accretion," Trans. Roy. Phil. Soc. London, Ser. A. 301, 253-264 (1981). 
SECTION E•3

GLOLOGIC CIARACTERIBTICS OF GANDBTONE DEPOSITS

BY

STEVEN G. DRIESE

DEPARTMENT OF GEOLOGICAL SCIENCES

UNIVERSITY OF TENNESSEE

KNOXVILLE, TN 37996-1410

AND

ROBERT H. DOTT, JR.

DEPARTMENT OF GEOLOGY AND GEOPHYSICS

UNIVERSITY OF GEOLOGY AND GEOPHYSICS

UNIVERSITY OF WISCONSIN

MADISON, WI 53706 
This page intentionally left blank 
E.3.1 DEFINITION OF ROCK TYPE ................... 263

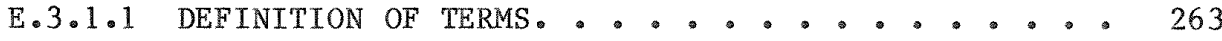

E.3.1.2 SANDSTONE COMPOSITION AND CLASSIFICAIION . . . 263

E.3.2 GEOLOGIC ENVIRONMENT AND SANDSTONES . . . . . . . . . 265

E.3.2.1 TECTONIC SETTING .................. 265

E.3.2.2 DEPOSITIONAL FRAMEWORK FOR SANDSTONES. . . . 266

E.3.2.2.1 Terrestrial Environments...... 270

E.3.2.2.1.1 Alluvial Fan Deposits. . 270

E.3.2.2.1.2 Eolian Dune Deposits.. 270

E.3.2.2.1.3 Braded Stream Deposits. . 270

E.3.2.2.2 Transitional Environments...... 271

E.3.2.2.2.1 De1taic Deposits.... 271

E.3.2.2.2.2 Progradational Shoreline/

Barrier Island Deposits. 271

E.3.2.2.3 Open-Marine Environments....... 271

E.3.2.2.3.1 Shallow-Marine shelf

Deposits....... 271

E.3.2.2.3.2 Submarine Fan and

Turbidite Deposits... 271

E.3.3 GEOMETRY AND DIMENSIONS OF SANDSTONE DEPOSITS $\cdot \bullet^{\circ} \cdot \bullet^{\circ} 272$

E.3.3.1 GENERAL DISCUSSION ............... 272

E.3.3.2 GEOMETRY AND DIMENSIONS FOR SPECIFIC ENVIRONMENTS. 276

E.3.3.2.1 Terrestrial Environments.......2 276

E.3.3.2.1.1 Subenvironments Excluded

from Further Consideration 276

E.3.3.2.1.2 Alluvial Fan Deposits. .276

E.3.3.2.1.3 Eolian Dune Deposits... 276

E.3.3.2.1.4 Braided River Deposits.. 276

E.3.3.2.2 Iransicional Environmencs 277

E.3.3.2.2.1 Subenvironments Excluded

from Further Consideration 277

E.3.3.2.2.2 Deltaic Deposits... 277

E.3.3.2.2.3 Progradational Shoreline

Deposits...., 277

E.3.3.2.3 Open-Marine Environments....... 278

E.3.3.2.3.1 Subenvironment Excluded

from Further Consideration 278

E.3.3.2.3.2 Sha11ow-Marine She1f

Deposits ...... 278

E.3.3.2.3.3 Submarine Fan/Turbidite

Deposits ...... 279

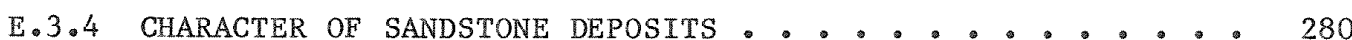

E.3.4.1 GENERAL DISCUSSION ............... 280

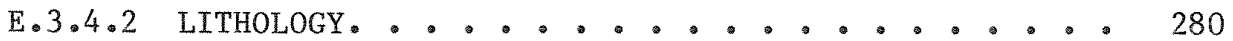

E.3.4.2.1 Terrestrial Environments. . . . 280

E.3.4.2.1.1 Alluvial Fan Deposits. 280 
Page

E.3.4.2.1.2 Eolian Dune Deposits ... 283

E.3.4.2.1.3 Braided River Deposits.. 283

E.3.4.2.2 Transitional Environments...... 284

E.3.4.2.2.1 Deltaic Deposits . . . 284

E.3.4.2.2.2 Progradational Shoreline

Deposits . . . . 285

E.3.4.2.3 Open-Marine Environments. ..... 285

E.3.4.2.3.1 Shallow-Marine Shelf

Deposits . . . . 285

E.3.4.2.3.2 Submarine Fan/Turbidite

Deposits . . . . 286

E.3.4.3 BEDDING CHARACTERISTICS. . ....... 286

E.3.4.3.1 Terrestrial Deposits........ 286

E.3.4.3.1.1 Alluvial Fan Deposits. . 286

E.3.4.3.1.2 Eolian Dune Deposits . . 287

E.3.4.3.1.3 Braided River Deposits. 287

E.3.4.3.2 Transitional Environments ..... 287

E.3.4.3.2.1 De1taic Deposits .... 287

E.3.4.3.2.2 Progradational Shoreline

Deposits ...... 287

E.3.4.3.3 Open-Marine Environments. .... 288

E.3.4.3.3.1 Shallow-Marine Shelf

Deposits ..... 288

E.3.4.3.3.2 Submarine Fan/Turbidite

E.3.4.4 NATURE OF INTERBEDS. . . . . . 288

E.3.4.4.1 Terrestrial Environments. . . . . 288

E.3.4.4.1.1 Alluvial Fan Deposits. . 288

E.3.4.4.1.2 Eolian Dune Deposits . . 288

E.3.4.4.1.3 Braided River Deposits.. 289

E.3.4.4.2 Transitional Environments . . . . 289

E.3.4.4.2.1 De1taic Deposits .... 289

E.3.4.4.2.2 Progradational Shoreline

Deposits . . . . 289

E.3.4.4.3 Open-Marine Environments. . . . 290

E.3.4.4.3.1 Shallow Marine Shelf

Deposits ...... 290

E.3.4.4.3.2 Submarine Fan/Turbidite

Deposits ...... 290

E.3.4.5 POROSITY AND PERMEABILITY.......... 290

E.3.4.5.1 General Discussion of Porosity. . . . 290

E.3.4.5.2 General Discussion of Permeability. . 297

E.3.4.5.3 Terrestrial Environments. ..... 298

E.3.4.5.3.1 Alluvial Fan Deposits. . 298

E.3.4.5.3.2 Eolian Dune Deposits . 298

E.3.4.5.3.3 Braided River Deposits . 302

E.3.4.5.4 Transitional Environments ..... 302

E.3.4.5.4.1 Deltaic Deposits .... 302

E.3.4.5.4.2 Progradational Shoreline

Dcpooito 
Page

E.3.4.5.5 Open-Marine Environments..... 302

E.3.4.5.5.1 Shallow-Marine Shelf

Deposits ..... 302

E.3.4.5.5.2 Submarine Fan/Turbidite

Deposits ...... 303

E.3.5 BOUNDING LITHOLOGIES. . .......... 304

E.3.5.1 TERRESTRIAL ENVIRONMENTS ......... 304

E.3.5.1.1 Alluvial Fan Deposits ....... 304

E.3.5.1.2 Eolian Dune Deposits....... 304

E.3.5.1.3 Braided River Deposits....... 304

E.3.5.2 TRANSITIONAL ENVIRONMENTS.......... 304

E.3.5.2.1 Deltaic Deposits........ 304

E.3.5.2.2 Progradational Shoreline Deposits . . 304

E.3.5.3 OPEN-MARINE ENVIRONMENTS ......... 305

E.3.5.3.1 Shallow-Marine Deposits ..... 305

E.3.5.3.2 Submarine Fan/Turbidite Deposits. . . 305

E.3.6 EXTERNAL EVENTS AND THEIR INFLUENCE ON SANDSTONE DETOSITS • 306

E.3.6.1 TERRESTRIAL ENVIRONMENTS .......... 306

E.3.6.1.1 Alluvial Fan Deposits ....... 306

E.3.6.1.2 Eolian Dune Deposits. ...... 306

E.3.6.1.3 Braided River Deposits...... 306

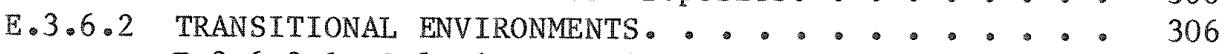

E.3.6.2.1 Deltaic Deposits........ 306

E.3.6.2.2 Progradational Shoreline Deposits... 306

E.3.6.3 OPEN-MARINE ENVIRONMENTS .................. 306

E.3.6.3.1 Sha1low-Marine Deposits ..... 306

E.3.6.3.2 Submarine Fan/Turbidite Deposits. . 307

E.3.7 RESOURCES CONTAINED IN OR ASSOCIATED WITH SANDSTONE . . 308

E.3.7.1 TERRESTRIAL ENVIRONMENTS .......... 308

E.3.7.1.1 Alluvial Fan Depooito..... 308

E.3.7.1.2 Eolian Dune Deposits....... 308

E.3.7.1.3 Braided River Deposits....... 308

E.3.7.2 TRANSITIONAL ENVIRONMENTS. . . ..... 308

E.3.7.2.1 De1taic Deposits........ 308

E.3.7.2.2 Progradational Shoreline Deposits . . 308

E.3.7.3 OPEN-MARINE ENVIRONMENTS ......... 309

E.3.7.3.1 Shallow-Marine Deposits :... 309

E.3.7.3.2 Submarine Fan/Turbidite Deposits. . . 309

E.3.8 SUMMARY AND RECOMMENDATIONS ............ 310

E.3.8.1 GENERAL DISCUSSION ............ 310

E.3.8.2 TERRESTRIAL ENVIRONMENTS ....... 310

E.3.8.2.1 Alluvial Fan Deposits ....... 310

E.3.8.2.2 Eolian Dune Deposits....... 310

E.3.8.2.3 Braided River Deposits...... 310

E.3.8.3 TRANSITIONAL ENVIRONMENTS. . . . . 310

E.3.8.3.1 Deltaic Deposits......... 310

E.3.8.3.2 Progradational Shoreline Deposits . . 313 
Page

E.3.8.4 OPEN-MARINE ENVIRONMENTS ............. 313

E.3.8.4.1 Shallow-Marine Shelf Deposits..... 313

E.3.8.4.2 Submarine Fan/Turbidite Deposits. . . 313

E.3.8.5 PRELIMINARY RANKING OF SPECIFIC DEPOSITIONAL

ENVIRONMENTS ................... 313

E.3.9 SUPPLEMENTAL DATA ..................... 315

E.3.10 REFERENCES. . . ..................... 355 


\section{E.3.1 DEFINITION OF ROCK TYPE}

\section{E.3.1.1 DEFINITION OF TERMS}

The term "sandstone" is commonly used to denote a lithified aggregate of mineral or rock grains in which the average size of the gralus ranges from 0.0625 to $2 \mathrm{~mm}$ in diameter (PETTIJOHN 1972; PETTIJOHN 1975). Sandstones are broadly divided into three major groups, based on the mode of origin of their constituent grains:

(1) Terrigenous sand grains are produced by the weathering and breakdown of preexisting rock material. These sandstones are said to be extrabasinal, in the sense that the grains are gentrally derived from somewhere outside the basin of deposition.

(2) Carbonate sand grains are locally produced within the basin of deposition, by either organic or inorganic precipitation of carbonate, and are not debris formed by the breakdown of preexisting rocks.

(3) Pyroclastic sand grains are produced as ejecta from volcanic eruptions.

Terrigenous sandstones are the focus of this report. pyroclastic sandstones constitute a group of rocks of more igneous affinity and are therefore not considered here.

\section{E.3.1.2 SANDSTONE COMPOSITION AND CLASSIFICATION}

Terrigenous sandstones are not monomineralic, but instead consist of varying proportions of three principal types of sediment grains, quartz, feldspar, and rock fragments, plus a wide variety of accessory mineral grains (PETTIJOHN 1972; PETTIJOHN 1975). Intergranular constituents may be: pote-filling cements, such as calcile, dulumile, yuarla, us inun oxides; fine-grained $(<0.03-\mathrm{mm})$ interstitial material of polygenetic origin (termed matrix); and/or pores (open spaces) between grains. A wide spectrum of classification schemes and nomenclature exists for terrigenous sandstones ( $c f$, summaries by KLEIN 1963; PETTIJOHN 1972; SCHOLLE 1979), most of which utilize the relative proportions of quartz, feldspar, rock fragments, and interstitial matrix. A representative classification of terrigenous sandstones is shown in Fig. E.3.1.1. 


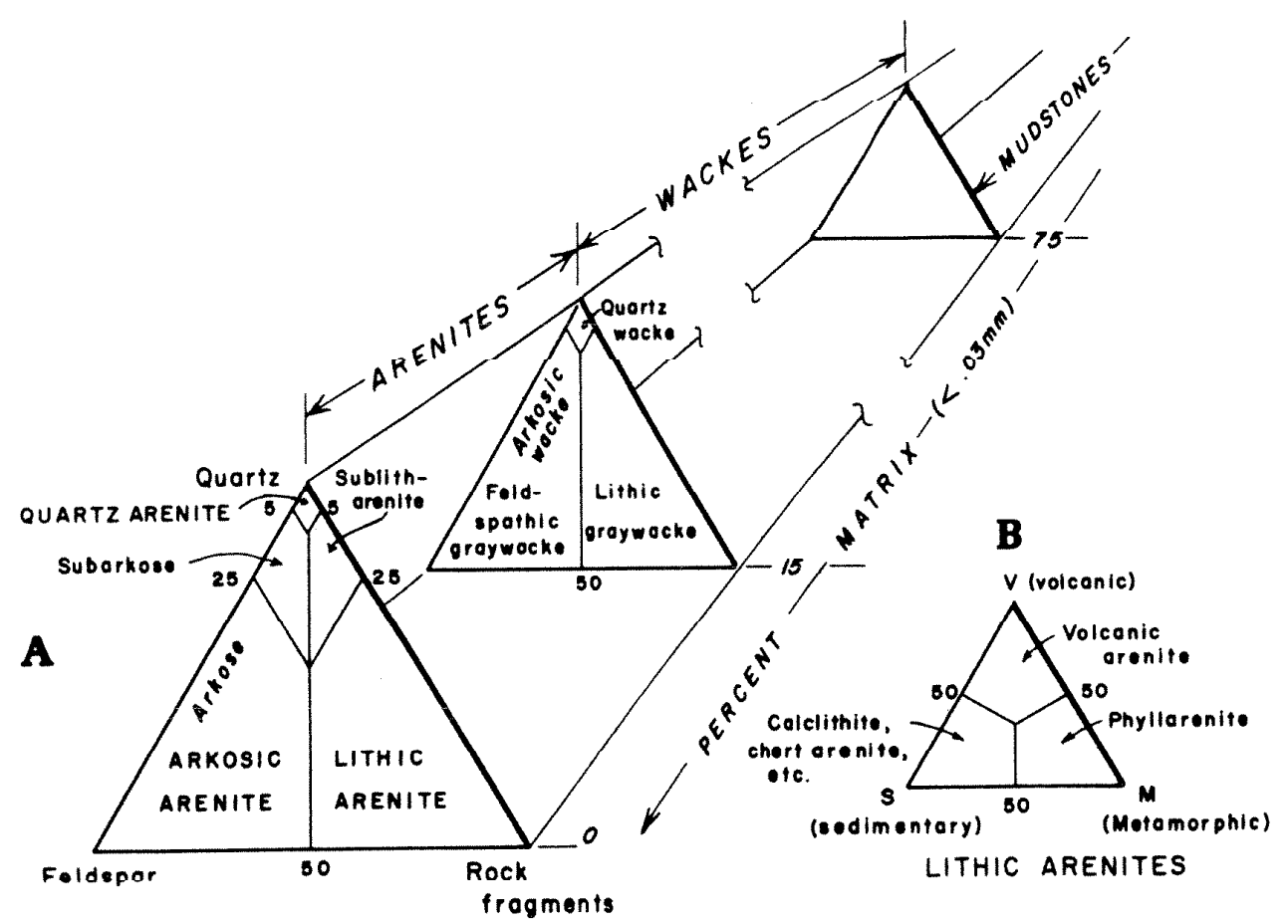

Fig. E.3.1.1. Classification of terrigenous sandstones proposed by Pctijohn (PETTIJOHN 1975), with modifications (A) from Dott (DOTT 1964), and (B) Folk (FOLK 1968). 


\section{E.3.2 GEOLOGIC ENVIRONMENT OF SANDSTONES}

\section{E.3.2.1 TECTONIC SETTING}

Five broad categories of sedimentary basin types for sandstones were proposed by Dickinson (DICKINSON 1974):

(1) Oceanic basins include the physiographic regions of the deep oceans known as the continental rise and abyssal plain. Although the bulk of the sedimentary rocks deposited in this setting are largely pelagic and fine grained (i.e., not sandstone), thin sandstone beds deposited by turbidity currents are also common.

(2) Rifted continental margins occur following rifting and separation within a continental crustal plate. In the early stages of rift development, crustal extension causes high-angle block faulting and related volcanism. The associated high relief promotes rapid erosion and subsequent deposition of thick sequences of arkosic sandstone. As continued plate separation occurs, subsidence permits marine flooding of narrow fault-block basins, followed by deposition of evaporites. Finally, with increasing plate separation ${ }_{7}$ an open ocean develops, bounded on each side by a passive or tralling-edge shelf margin. The nearshore and shelf portions of this margin (miogeosyncline) may consist of quartzose sandstone, whereas the deep-water prism of slope sediments (eugeosyncline) consists largely of graywacke.

(3) Arc-trench systems occur as a result of the convergence of two crustal plates (either oceanic crust subducted under continental crust or oceanic subducted under oceanic). The most important site of sandstone deposition is the forearc basin, which occurs between the magmatic arc and the deep-sea trench. Forearc basins receive sediments from the volcanic, plutonic, and metamorphic complexes which comprise the arc, resulting in deposition of lithic and/or feldspathic arenites and/or wackes. Trench sediments are typically turbidites and trench/ocean floor scrapings derived from the subducting plate. Backarc and intraarc basins may also be present in conjunction with the arctrench system.

(4) Peripheral (foreland) basins occur in conjunction with mountain building, which in turn may result from subduction, collision, and crustal suture between two continental plates. They are typified by Iithic and/or quartzose sandstone.

(5) Intracontinental (interior) basins are generally surrounded by what appears to be a quiescent tectonic environment, that is, their origin cannot easily be ascribed to plate tectonics. Quartzose sandstone typifies this setting. The strong influence of tectonics on sandstone composition was more recently sumarized by Dickinson and Suczek (DICKINSON 1979). 


\section{E.3.2.2 DEPOSTTIONAL FRAMEWORK FOR SANDSTONES}

Sandstone characteristics are not only affected by provenance (source area), tectonic setting, and transport history but also by the environment of deposition. Pettijohn (PETTIJOHN 1975) defined a sedimentary environment as "being defined by a particular set of physical and chemical variables that corresponds to a geomorphic unit of stated size and shape." This geomorphic definition of depositional environment is adhered to in this report. The principal environments in which sandstones are deposited are listed here.

This listing is based on work by Seeley (SEELEY 1970), Reading (RFADTNG 1978), Walker (WALKER 1979), Blatt and others (BLATT 1980), Reineck and Singh (REINECK 1980), Davis (DAVIS 1983), and others.

1. Terrestrial environments:
(a) alluvial fans
(b) Eolian sand seas (ergs)
(s) hraided rivers
(d) meandering rivers
(e) glacial and glaciofluvial systems*
(f) lakes/swamps*

2. Transitional (marginal-marine) environments:
(a) deltas
(b) tidal flats
(c) estuaries/lagoons/salt marshes*
(d) barrier islands/regressive shoreline systems
(e) glacio-marine systems*

3. Open-marine environments:

(a) shallow-marine shelves

(b) continental slope and rise systems (as submarine fans, turbidites)

(c) deep ocean (abyssal pla1n)*

As is demonstrated in subsequent sections of this report, all of the properties of sandstones important in relation to their assessment for suitability as high-level nuclear waste repository sites (e.g., geometry, lithology, bedding characteristics, porosity, and permeability patterns) can be related in some way to depositional environment. Figures E.3.2.1E.3.2.7 show the distributions for the conterminous United States of sandstone deposits of each of the major depositional environments listed in Sect. E.3.2.2. These distributions, in part, reflect the relationship between tectonic setting and depositional environments.

*Denotes environments in which sandstone deposits are typica11y a intilor component of the sedimencary record or deposics of that environment are only rarely preserved. 
ORNL DWG $85-215$

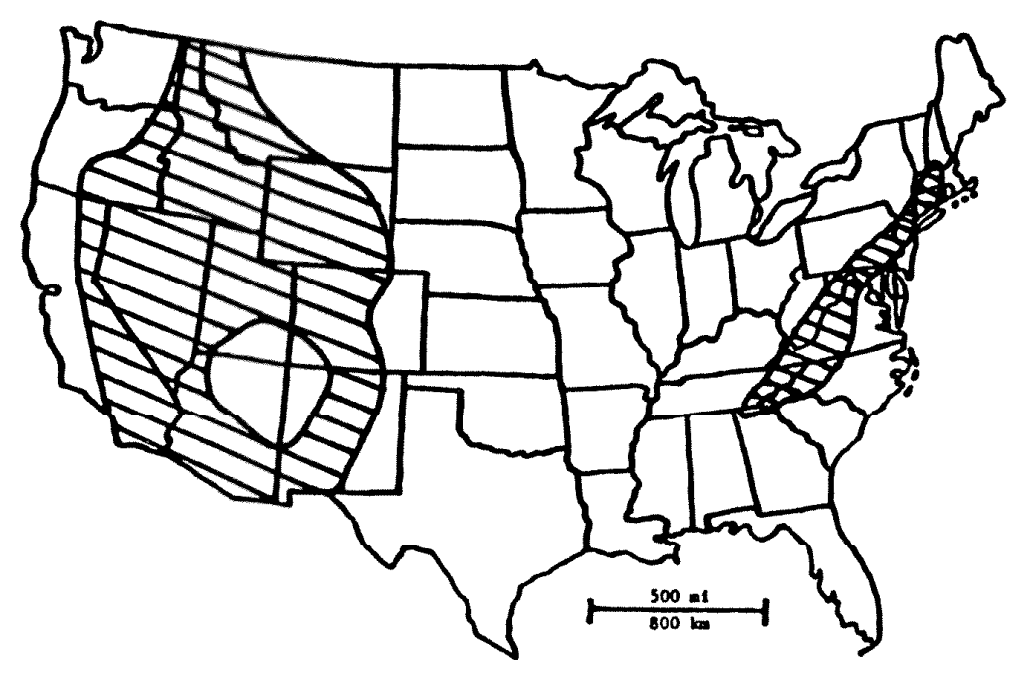

Fig. E.3.2.1. Map of the United States showing distribution of alluvial fan sandstone and conglomerate, both in outcrop and in the range of 300 to $1500 \mathrm{~m}$ below the land surface. Quaternary fans of the basin and range are also included.

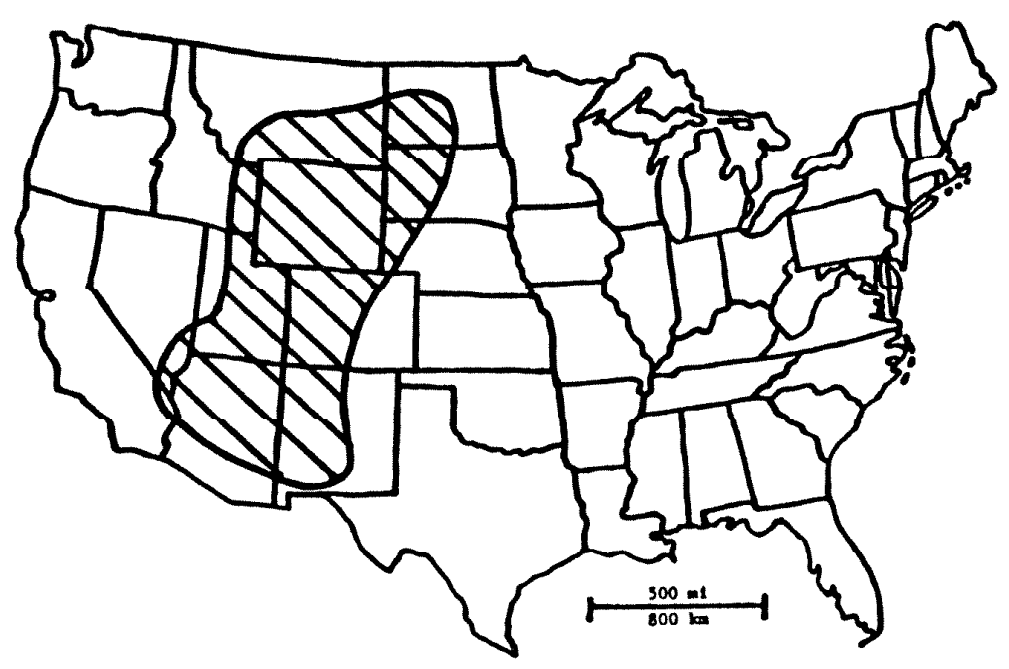

Fig. E.3.2.2. Map of the United States showing distribution of eolian dune sandstone deposits both in outcrop and in the range of 300 to $1500 \mathrm{~m}$ below the land surface. 


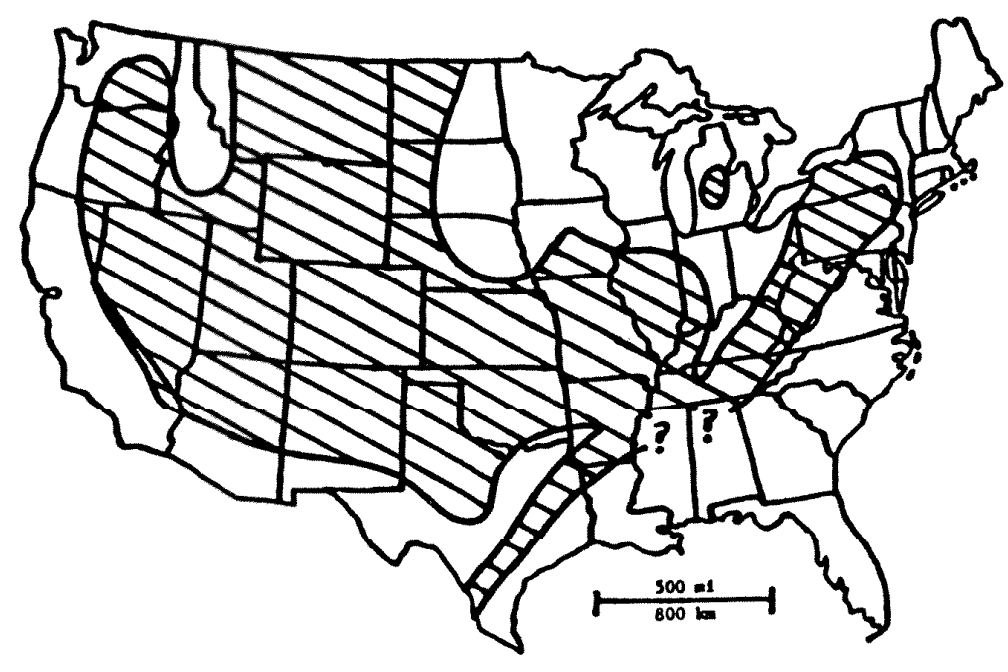

Fig. E.3.2.3. Map of the United States showing distribution of fluvial (both braided and meandering) sandstones both in outcrop and in the range of 300 to $1500 \mathrm{~m}$ below the land surface.

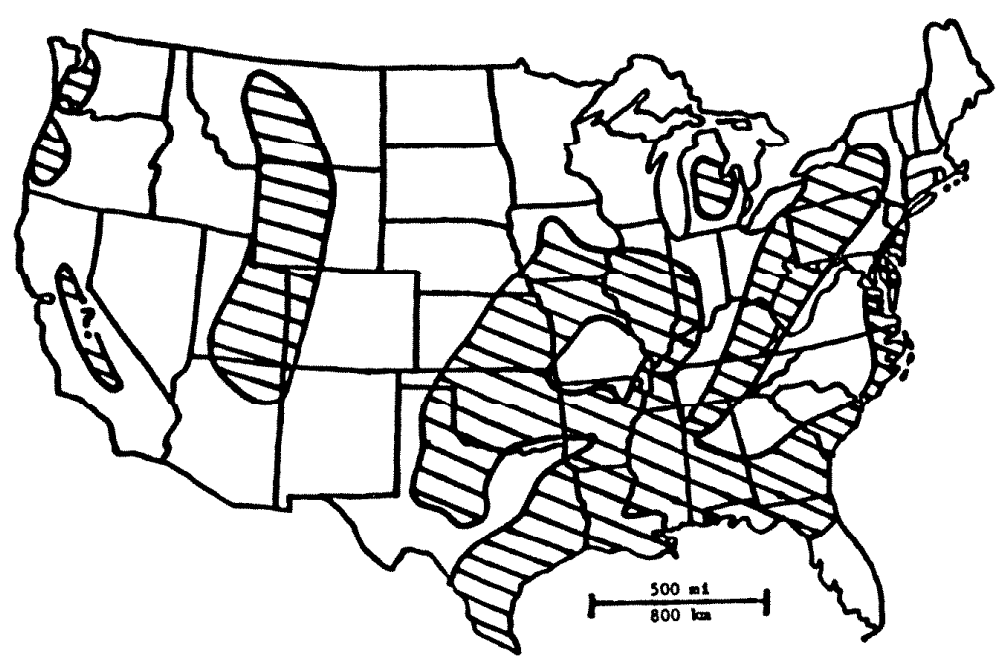

Fig. E.3.2.4. Map of the United States showing distribution of deltaic/marginal-marine sandstones, both in outcrop and in the range of 300 to $1500 \mathrm{~m}$ below the land surtace. 
ORNL DWG 85-219

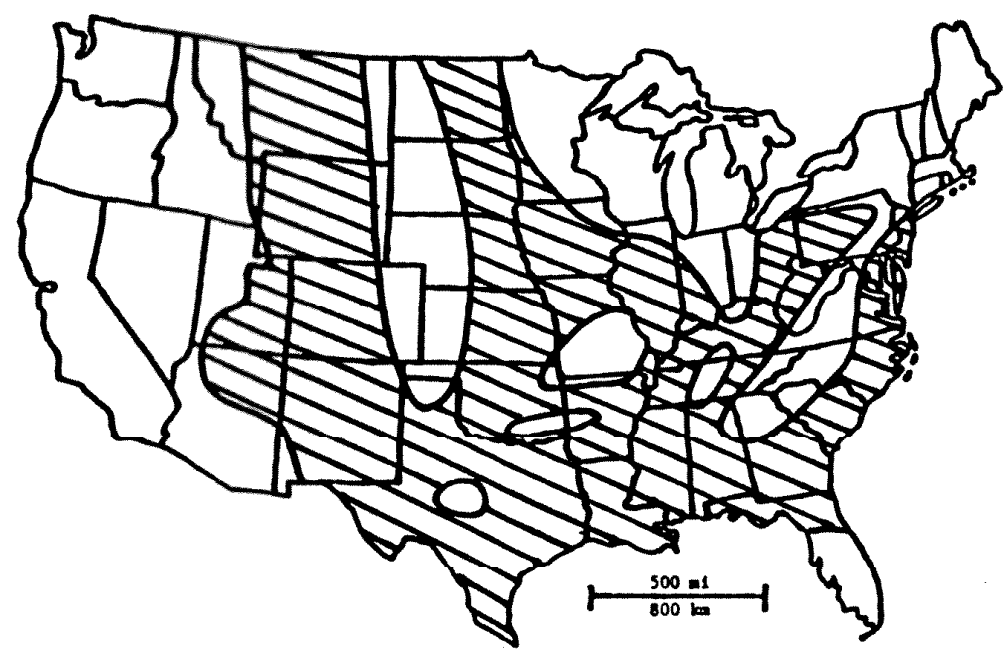

Fig. E.3.2.5. Map of the United States showing distribution of barrier island/prograding shoreline sandstone deposits, both in outcrop and in the range of 300 to $1500 \mathrm{~m}$ below the land surface.

ORNL OWG $85-220$

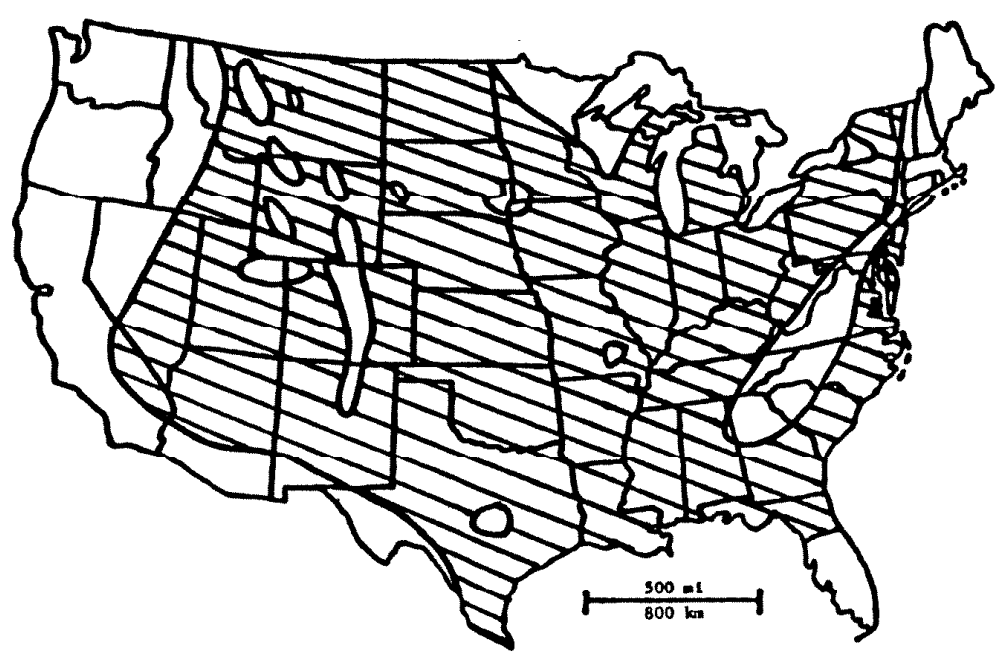

Fig. E.3.2.6. Map of the United States showing distribution of marine shelf and tidal flat sandstones, both in outcrop and in the range of 300 to $1500 \mathrm{~m}$ below the land surface. 


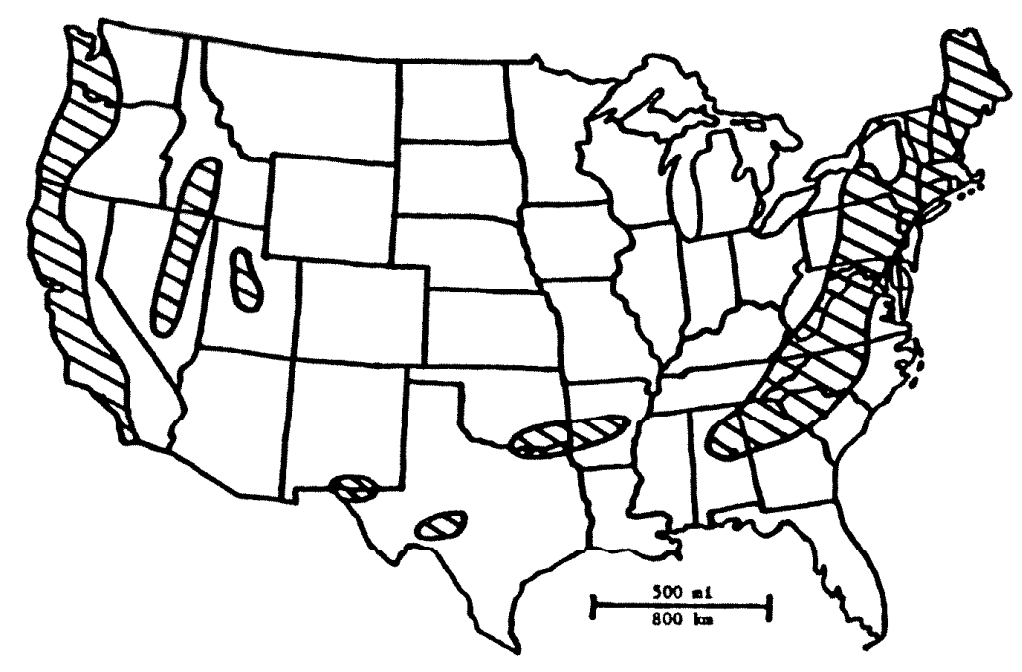

Fig. E.3.2.7. Map of the United states showing distribution of deep-water (submarine fan/turbidite) sandstone deposits both in outcrop and in the range of 300 to $1500 \mathrm{~m}$ below the land surface.

\section{E.3.2.2.1 Terrestrial Environments}

\section{E.3.2.2.1.1 Alluvial Fan Deposits}

Alluvial fans generally form in tectonically active settings characterized by extension and development of horst-and-graben structures. A large amount of topographic relief (on the order of several thousand meters) is necessary in order to form fans (Fig. E.3.2.1).

\section{E.3.2.2.1.2 Eolian Dune Deposits}

Eolian dune systems (ergs) may form in any tectonic setting in which there is a very low mean annual precipitacion. Stable craton inceriors situated in low latitudes and dominated by dry, high-pressure systems are especially favorable sites for eolian sandstone deposition (Fig. E.3.2.2).

\section{E.3.2.2.1.3 Braided Stream Deposits}

No particular tectonic setting is characteristic of the braided stream setting, with possible occurrences in stable craton interiors, passive (trailing-edge) continental margins, and active (collisional) margins. An abundance of sand-sized and coarser material, highly variable discharge, and a lack of bank-stabilizing terrestrial vegetation al1 favor the braided stream depositional system (Fig. E.3.2.3). 


\section{E.3.2.2.2 Transitional Environments}

\section{E.3.2.2.2.1 Deltaic Deposits}

Deltas may form along marine coasts or along lacustrine shorelines in almost any tectonic setting but are most abundant along tectonically passive trailing-edge coasts or within stable craton interiors

(Fig. E.3.2.4).

\section{E.3.2.2.2.2 Progradational Shoreline/Barrier Island Deposits}

Development of prograding sandy shore line systems is favored by stable, gently sloping coastal areas with at least a modest supply of sediment. Irailing-edge (passive) margins and stable craton interiors are common sites of deposition (Fig. E.3.2.5).

\section{F. 3.2.2.3 Open-Marine Fnvi ronments}

\section{E.3.2.2.3.1 Shallow-Marine Shelf Deposits}

Shallow-marine shelt sandstones occur primarily within stable craton interiors and along passive, trailing-edge margins. They tend to be absent or quite limited in extent along collision zones where plates converge (Fig. E.3.2.6).

\section{E.3.2.2.3.2 Submarine Fan and Turbidite Deposits}

Deep-water sandstones commonly accumulate In very active tectonic environments. One setting is that of forearc and/or backarc basins deve1oped in association with subduction in a deep-ocean trench. Another common occurcence is along a passive shelf margin in the continental slope-and-rise setting, which is commonly dissected by submarine canyons. Sediments derived from land areas and deposited on the continental shelf are subsequently resedimented into deeper water via submarine canyons and may accumulace to form chick clastic wedges (F1g. E.3.2.7). 


\section{E.3.3 GEOMETRY AND DIMENSIONS OF SANDSTONE DEPOSITS}

\section{E.3.3.1 GENERAL DISCUSSION}

The geometry and dimensions of sandstone deposits reflect variations both in tectonic setting and depositional environment. A wide spectrum of geometric and genetic classification schemes have been employed for sandstones. One of the earliest geometric classification schemes was proposed by Krynine (KRYNTNE 1948) and included four principal types: (a) blanket or sheet, (b) tabular, (c) prism or wedge, and (d) shoestring (Fig. E.3.3.1). These geometric descriptions were defined on the basis of specific width-to-thickness ratios and were independent of genesis. potter (PUIIER 1962; 1963) Later moditied Krynine's classitication and defined only two basic categories of sandstone deposit - sandstone sheets or blankets and elongate sandstone bodies (Fig. E.3.3.2). Sandstone sheets or blankets have length-to-width ratios of about $1: 1$ and cover areas ranging from a few to several thousand square kilometers. Elongate sandstone bodies, in contrast, characteristically have a length dimension that exceeds the width dimension and include pods, ribbons, and dendroids ( $H$ ig. $\left.E_{3} \cdot 3 \cdot 3 \cdot 2\right)$. Pods have a length-to-width ratio less than $3: 1$, whereas ribbons (also known as shoestring sandstones) are more elongate, with length-to-width ratios greater than $3: 1$ and commonly as high as $20: 1$. Dendroids are highly elongate sandstone bodies which exhibit highly conspicuous branching or sinuous patterns. Lateral migration and coalescence of ribbons and dendroids may result in development of sandstone belts.

Many of the concepts concerning the relationship between tectonic activity and sandstone geometry were first developed by Krynine (KRYNINE 1948; 1951) and later summarized by Folk (FOLK 1974) (Fig. E.3.3.3). Stabilized crustal blocks (cratons) with interior basins or trailing-edge (passive) margins are characterized by low relief and widespread blanket or sheet-1ike sandstone deposits. Lenticular sandstone deposits are produced by tectonic processes of intermediate intensity such as tolding and thrusting. Violent plate collisions associated with subduction, intense folding and thrusting, metamorphism, and volcanism result in the deposition of thick, wedge-shaped accumulations of sandstone. The high-angle block faulting associated with rifting and plate separation may also result in thick wedge-shaped sandstone deposits.

In the sections that follow, the typical geometric characteristics of the sandstone deposits for each major depositional environment are summarized. However, not all depositional environments yield sandstone bodies of sufficient dimensions (thickness and areal extent) to be seriously considered as repository sites. Only those environments that typically accumulate sandstone bodies in excess of $150 \mathrm{ft}$ (approximately $50 \mathrm{~m}$ ) thick and are lateral1y extensive over at least 10 square miles (approximately $25 \mathrm{~km}^{2}$ ) are discussed in detail in this report. 
ORNL DWG $85-222$

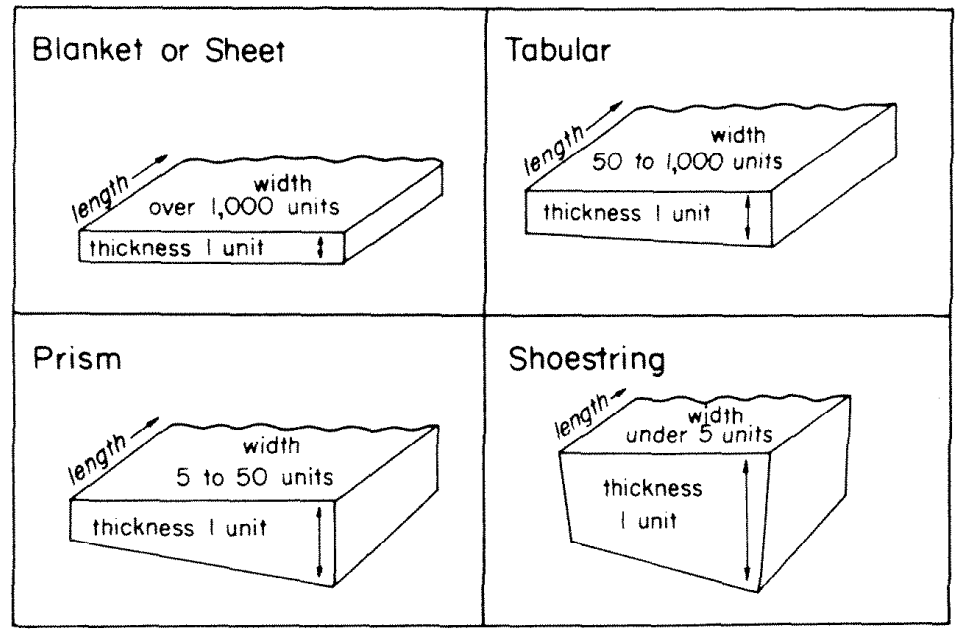

Fig. E.3.3.1. Geometric classification of sandstone bodies based on thickness-to-width ratio (after KRYNINE 1948). 
ORNL DWG 85-223

\section{SHEET Or BLANKET}
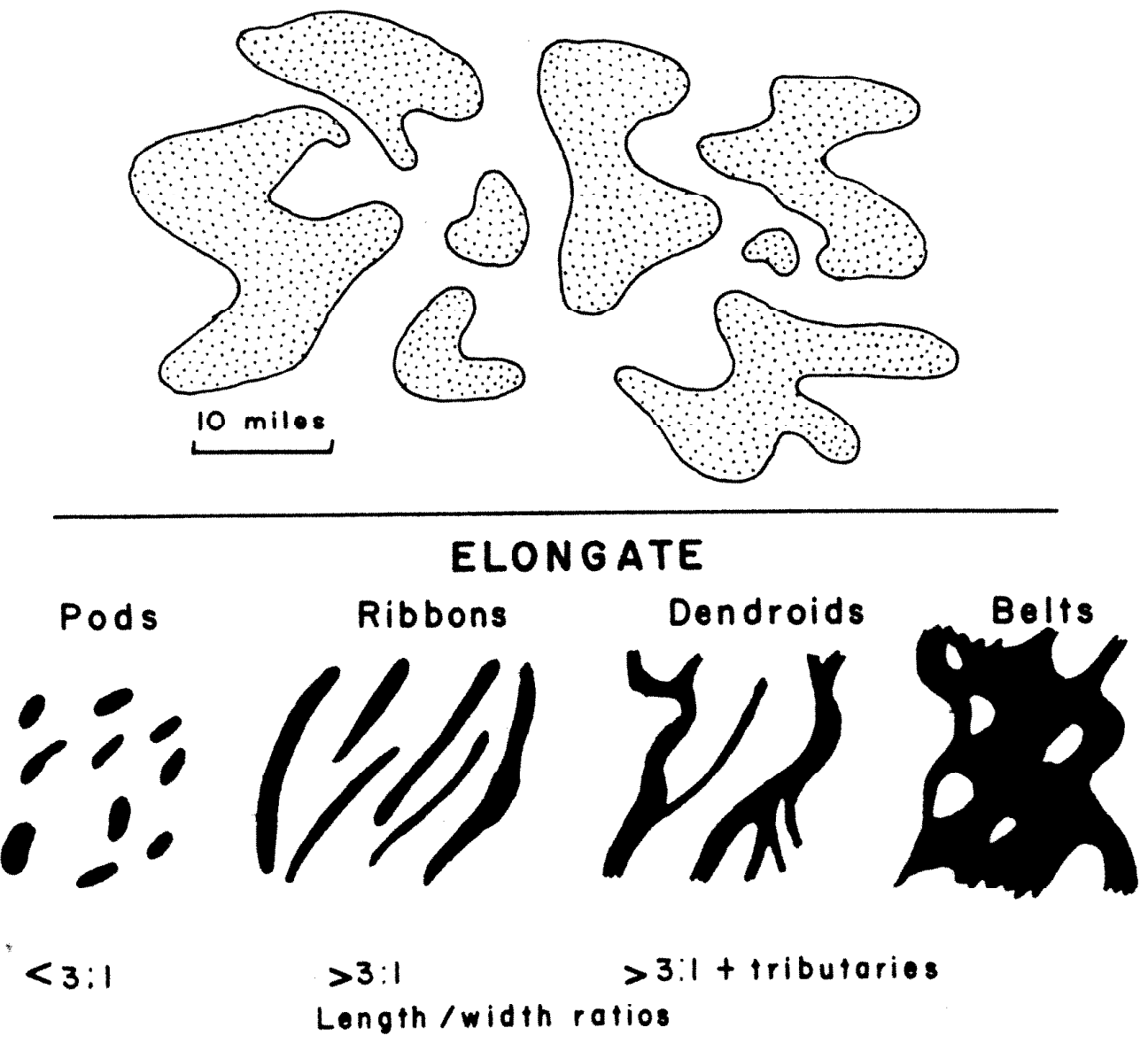

Fig. E.3.3.2. Geometric classification of sandstone bodies based on length-to-width ratio and overall shape in plan view (after POTTER 1962; 1963). 


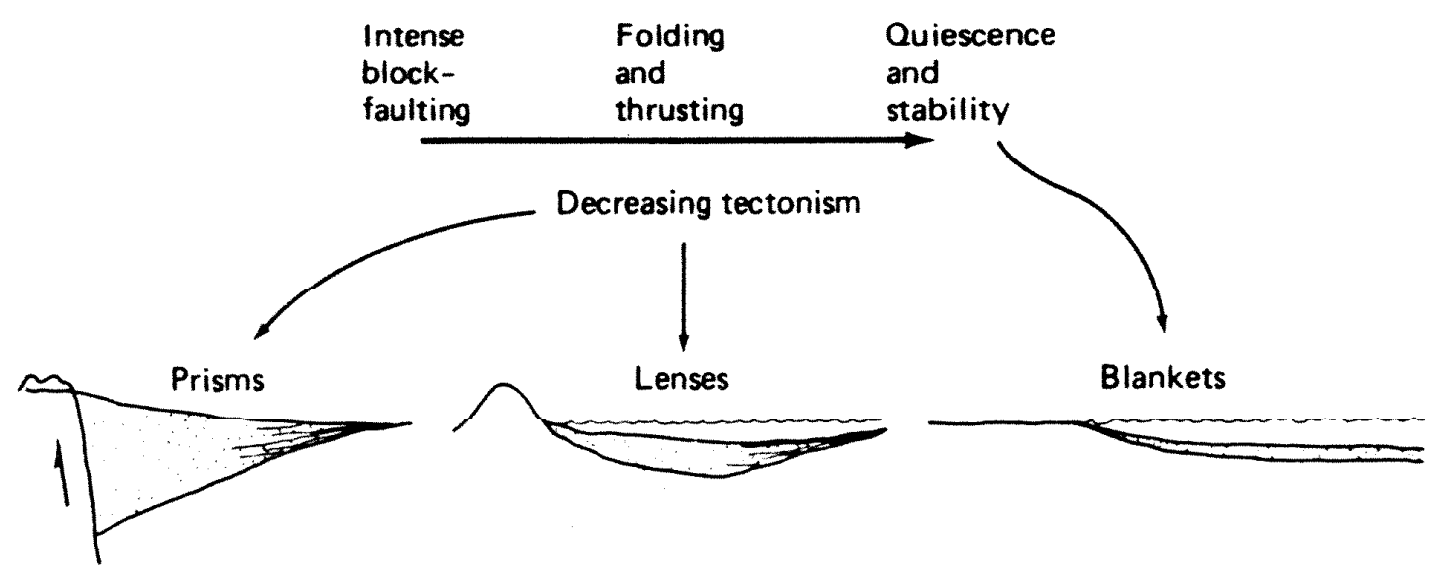

Alluvial fans grading into fluvial deposits (rarely marine)
Fluvial, deltaic, and shallow marine
Aeolian, beach, and shallow marine

Maturity usually low,

increases away from source as size

decreases away from source.

Maturity usually high,

uniform maturity and size over wide areas.

Preferred associations of the tectonic stages

(There are numerous exceptions)

Fig. E.3.3.3. General relationships between tectonic activity and sandstone geometry (summarized by FOLK 1974 and KRYNINE 1948; 1951). 


\section{E.3.3.2 GEOMETRY AND DIMENSIONS FOR SPECIFIC ENVIRONMENTS}

\section{E.3.3.2.1 Terrestrial Environments}

\section{E.3.3.2.1.1 Subenvironments Excluded from Further Consideration}

The geometry and dimensions of texrestrial sandstone deposits range considerably and are a function of depositional environment. Several of the tercestrial subenvironments 1isted in Sect. E.3.2.2 can be dismissed from further consideration in this report: (1) glacial (and glaciofluvial) and lacustrine systems are discounted because sandstones do not typically comprise a substantial proportion of their deposits (Tables E.3.9.1 and E.3.9.2); and (2) although substantial portions of meandering river deposits consist of sandstone, they do not typically meet the necessary geometric criteria (thickness and lateral extent) to be seriously considered as repository media (Tables E.3.9.2-E.3.9.5).

\section{E.3.3.2.1.2 Alluvial Fan Deposits}

A fan shape in areal view and a wedge or lens shape in cross section is characteristic of alluvial fans. Shape is largely a function of the amount of tectonic movement along boundary faults and the nature of the sedimentary processes operating on the surface of the fan.

The thickness of alluvial fan sequences ranges from several hundred to a few tens of thousands of meters thick. A common thickness is in the range of several hundred meters. (Table E.3.9.6).

The lateral extent of alluvial fan deposits is variable, ranging from tens to a few thousand square kilometers. The most common areal extent is a few hundred square kilometers (Table E.3.9.6).

\section{E.3.3.2.1.3 Eolian Dune Deposits}

Eolian dune sequences generally exhibit a tabular shape (areal dimension many orders of magnitude greater than thickness).

The thickness of eolian dune sequences ranges from tens to hundreds of meters; the most common thickness is in the range of a few hundred meters (Table E.3.9.7).

The lateral extent of eolian dune deposits is considerable, ranging from thousands to hundreds of thousands of square kilometers. The most common areal extent is in the range of several tens of thousands of square kilometers (Table E.3.9.7).

\section{E.3.3.2.1.4 Braided River Deposits}

Braided stream deposits may have a sheet-1ike to broadly lenticular shape in cross section and are distinctly multistory (internally made up of numerous smaller-scale channel fills stacked one on top of another). Area1 (plan) shape is that of straight to slightly sinumus, elongate body of varying dimensions. 
The thickness of braided stream deposits ranges from tens to hundreds of meters. The most common thickness is in the range of a few hundred meters (Table E.3.9.8).

The lateral extent of braided stream deposits is highly variable but is usually in the range of a few thousand square kilometers. As a general rule, prevegetation (pre-Silurian) braided stream deposits show the greatest lateral extents (Table E.3.9.8).

\section{E.3.3.2.2 Transitional Environments}

\section{E.3.3.2.2.1 Subenvironments Excluded from Further Consideration}

The geometry and dimensions of terrestrial sandstone deposits range considerably and are a function of depositional environment. Several of the transitional environments 1 isted in Sect. E.3.2.2 can be dismissed from further consideration in this report. Although substantial proportions of tidal flat and barrier island deposits consist of sandstone, they do not typically meet the necessary geometric criteria (thickness and lateral extent) to be seriously considered as repository media (Tables E.3.9.9 and E.3.9.10). Estuarine, Lagoon, salt marsh, and glaciomarine systems are discounted because sandstones do not typical1y make up a substantial proportion of their deposits.

\section{E.3.3.2.2.2 Deltaic Deposits}

A triangular areal shape is characteristic for deltas, but there is much variation depending on whether the system is dominated by fluvial, wave, or tidal processes. The deposits are thick and wedge- or lensshaped in cross section.

The thickness of deltaic sequences ranges from a few tens of meters (e.g., some cratonic deltas) to several thousand meters (e.g., deltas deposited along rapidly subsiding coasts). The most common thickness is

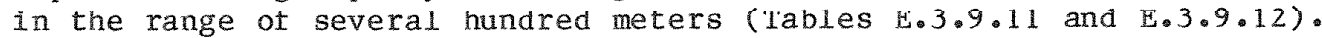

The lateral extent of deltaic deposits ranges from a few tens of square kilnmeters (e.g., small lacustrine deltas) to tens of thousands of square kilometers (major marine deltas). The most common areal extent is in the range of a few thousand square kilometers (Tables E.3.9.11 and $\mathrm{E} \cdot 3.9 .12)$.

\section{E.3.3.2.2.3 Progradationa1 Shoreline Deposits}

Progradational shoreline sequences may be sheet-like or form elongate belts in areal view and are generally tabular to prism-like in cross section.

Thicknesses of progradational shoreline sandstones range from lens to hundreds of meters; a common thickness is in the range of about 30 to $50 \mathrm{~m}$ (Table E.3.9.10). 
The lateral extent of progradational shoreline sandstones ranges from hundreds to tens of thousands of square kilometers. A common areal extent is in the range of a few thousand square kilometers (Table E.3.9.10).

\section{E.3.3.2.3 Open-Marine Environments}

\section{E.3.3.2.3.1 Subenvironment Excluded from Further Consideration}

The geometry and dimensions of open-marine sandstone deposits range considerably and are a function of depositional environment. The deepocean (abyssal plain) environment (Sect. E.3.2.2) can be dismissed from further consideration in this report because sandstones do not typically comprise a substantial portion of the deposits; instead, pelagic sediment (red clay and biogenic oozes) are most common.

Two major types of occurrences of marine shelf sandstones exist in North Anerica. Type I consists of shallow-marine shelf sandstones not laterally traceable into shoreline sandstones but which were deposited on, and now lie completely enclosed within, marine shelf shales and mudstones. These deposits exhibit a characteristic coarsening-upward textural pattern and a distinct ribbon geometry. Type II consists of shallow-marine shelf sandstones laterally traceable into shoreline sandstone facies or which exhibit a sheet-like geometry.

Type I deposits are excluded from any further detailed discussion in this report because they do not satisfy the minimum thickness and lateral extent criteria necessary for them to be considered as potential repository sites. Type II sandstones, especially those deposited on tidedominated shelves, do meet the prescribed geometric criteria and are therefore discussed in detail in subsequent sections of this report.

Marine shelf sandstones are among the most prevalent in the stratigraphic record. Type I deposits are especially abundant in the Cretaceous of western North America, whereas Type II deposits occur most abundantly in the Precambrian and Paleozoic. It should be noted that Type II sandstones are commonly difficult to distinguish paleoenvironmentally from nearshore marine deposits of the shoreline, tidal flat, and barrier island environments.

\section{E.3.3.2.3.2 Shallow-Marine Shelf Deposits}

Shallow-marine shelf sandstone deposits are characteristically tabular in cross section, with length and width dimensions many orders of magnitude greater than the thickness. A sheet or blanket morphology typifies the plan view.

The thickness of shallow-marine shelf sandstone deposits ranges from tens to several thousand meters; a common thickness is in the range of several hundred meters. The thickest deposits occur in Precambrian and Lower Paleozoic strata (Tables E.3.9.9 and E.3.9.13).

The lateral extent of shallow-marine shelf sandstune deposits is considerable, ranging from hundreds to hundreds of thousands of square 
kilometers. A common areal extent is in the range of tens of thousands of square kilometers (Tables $E_{0} 3.9 .9$ and E.3.9.13).

\section{E.3.3.2.3.3 Submarine Fan/Turbidite Deposits}

Deep-water sandstone sequences typically display a thick wedge or lens shape in cross section. The areal (plan) shape for deposits accumulated downslope from the submarine canyon is fan-like. The sequence as preserved in the stratigraphic record may display an elongate configuration parallei to the paleobathymetry.

The thickness of deep-water sandstone sequences ranges from hundreds to thousands of meters. A common thickness is in the range of 500 to $1000 \mathrm{~m}$. However, it should be noted that only half of the thickness may actually be composed of sandstone and that interbedded lithologies will make up a major part of the stratigraphic section (Tables E.3.9.14 and $\mathrm{E} \cdot 3 \cdot 9 \cdot 15)$.

The lateral extent of deep-water sandstone deposits can be considerable: these sequences may extend thousands of kilometers along a depositional strike and have a width of tens to hundreds of kilometers. However, because deep-water sandstone sequences are generally associated with very active tectonic regimes, tectonic disturbance (folding or faulting) of the stratigraphic package may greatly reduce lateral continuity as preserved in the geologic record (Tables E.3.9.14 and E.3.9.15). 


\section{E.3.4 CHARACTER OF SANDSTONE DEPOSITS}

\section{E.3.4.1 GENERAL DISCUSSION}

Terrigenous sandstones exhibit great chemical inhomogeneity, which is a consequence of their mineralogic variability. Table E.3.4.1 1ists the mean composition of each of the four major sandstone classes defined in Fig. E.3.1.1.

(1) Orthoquartzite (also commonly known as quartz arenite) is the class of relatively quartz-rich and matrix-poor sandstone.

(2) A 1ithic arenite is a sandstone rich in rock (1ithic) tragments and lacking interstitial matrix.

(3) A graywacke (an older field term now genera11y equated with matrix-rich sandstones) is a dominantly feldspar- and/or rockfragment-rich sandstone that contains abundant matrix. Quartzrich graywacke is also common.

(4) Arkose is collectively the feldspar-rich sandstone class.

Table E.3.4.2 shows the relative abundances of these four major sandstone classes as estimated by several different authors. Although it is difficult to determine what the composition and/or mineralogy of the "average" sandstone would be, Pettijohn et al. (PETTIJOHN 1972) suggested a modal composition of $65 \%$ quartz, $15 \%$ feldspar, and $18 \%$ rock fragments as possibly representative.

Lithologic characteristics of sandstones range considerably for different depositional environments. This aspect was we11-documented by Selley (SELLEY 1978) in a study of North Sea Jurassic sandstones (Fig. E.3.4.1). Overall energy regime and constancy of physical sedimentary prucesses affech buli lexture and compusllion of sandslone. Because most depositional environments are indigenous to specific tectonic settings, the tectonic regime and composition of the source area are also important factors.

\section{E.3.4.2 LITHOLOGY}

\section{E.3.4.2.1 Terresleial Enviromments}

\section{E.3.4.2.1.1 Alluvial Fan Deposits}

The mineralogy of alluvial fan deposits is extremely heterogeneous and is dependent upon the characteristics of the source area. The combination of high relief, rapid erosion and deposition, and little chemical weathering (aridity or cold climate) allows for preservation of feldspars and unstable ferromagnesian silicate minerals. Most alluvial fan sandstones are classified as arkoses or 1ithic arenites/wackes and therefore exhibit high compositional immaturity (Table E.3.9.16). 
Table E.3.4.1. Mean chemical compositions of four principal sandstone classes (from PETTIJOHN 1975).

\begin{tabular}{|c|c|c|c|c|}
\hline $\begin{array}{c}\text { Constituent } \\
(\%)\end{array}$ & Orthoquartzite ${ }^{a}$ & $\begin{array}{l}\text { Lithic } \\
\text { areniteb }\end{array}$ & Graywackec & Arkosed \\
\hline $\mathrm{SiO}_{2}$ & 95.4 & 66.1 & 66.7 & 77.1 \\
\hline $\mathrm{TiO}_{2}$ & 0.2 & 0.3 & 0.6 & 0.3 \\
\hline $\mathrm{Al}_{2} \mathrm{O}_{3}$ & 1.1 & 8.1 & 13.5 & 8.7 \\
\hline $\mathrm{Fe}_{2} \mathrm{O}_{3}$ & 0.4 & 3.8 & 1.6 & 1.5 \\
\hline Feo & 0.2 & 1.4 & 3.5 & 0.7 \\
\hline Mno & -- & 0.1 & 0.1 & 0.2 \\
\hline MgO & 0.1 & 2.4 & 2.1 & 0.5 \\
\hline $\mathrm{CaO}$ & 1.6 & 6.2 & 2.5 & 2.7 \\
\hline $\mathrm{Na}_{2} \mathrm{O}$ & 0.1 & 0.9 & 2.9 & 1.5 \\
\hline $\mathrm{K}_{2} \mathrm{O}$ & 0.2 & 1.3 & 2.0 & 2.8 \\
\hline $\mathrm{H}_{2} \mathrm{O}^{+}$ & 0.3 & 3.6 & 2.4 & 0.9 \\
\hline $\mathrm{H}_{2} \mathrm{O}^{-}$ & - & 0.7 & 0.6 & -- \\
\hline $\mathrm{P}_{2} \mathrm{O}_{5}$ & -- & 0.1 & 0.2 & 0.1 \\
\hline $\mathrm{CO}_{2}$ & $1.1^{e}$ & 5.0 & 1.2 & 3.0 \\
\hline $\mathrm{SO}_{3}$ & -- & - & 0.3 & -- \\
\hline s & - & - & 0.1 & - \\
\hline $\mathrm{c}$ & - & - & 0.1 & -- \\
\hline Total & 100.7 & 100.0 & 100.4 & 100.0 \\
\hline
\end{tabular}

acomputed from 26 published analyses.

bomputed from 20 analyses.

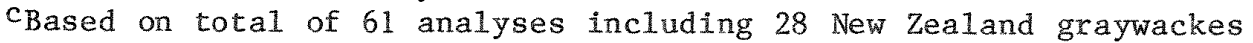
(Paleozoic and Mesozoic) (from REED 1957).

dComputed from 32 published analyses.

eEstimated from $\mathrm{CaO}$. 
Table E.3.4.2. Estimated relative abundance of four major sandstone classes (from PETTIJOHN 1972)

\begin{tabular}{lcccc}
\hline \multicolumn{1}{c}{ Class } & $\begin{array}{c}\text { Krynine }^{\mathrm{a}} \\
(1948)\end{array}$ & $\begin{array}{c}\text { Tallman }^{\mathrm{b}} \\
(1949)\end{array}$ & $\begin{array}{c}\text { Middletonc } \\
(1960)\end{array}$ & $\begin{array}{c}\text { Pettijohnd } \\
(1963)\end{array}$ \\
\hline Quartz arenite (orthoquartzite) & 22.5 & 45 & 34 & 34 \\
Arkose & 32.5 & 17 & 16 & 15 \\
$\begin{array}{l}\text { Lithic arenite ("low rank" } \\
\text { graywacke or subgraywacke) }\end{array}$ & 35.0 & 17 & 24 & 26 \\
$\begin{array}{l}\text { Graywacke ("high rank" } \\
\text { graywacke) }\end{array}$ & 10.0 & 21 & 26 & 20 \\
\begin{tabular}{l} 
Miscellaneous \\
\hline
\end{tabular} & & & 5 \\
\hline
\end{tabular}

a Basis of estimate not stated.

based on sample of 275 sandstones. Cambrian to Tertiary in age, from all parts of the United States.

${ }^{c}$ Based on 167 sandstones for which chemical analyses appear in the published literature.

dBased on 121 sandstones in the Johns Hopkins University collection for which thin sections were available. (Age and distribution of samples given in PETTIJOHN 1963.)

ORNL. DWG $85-253$

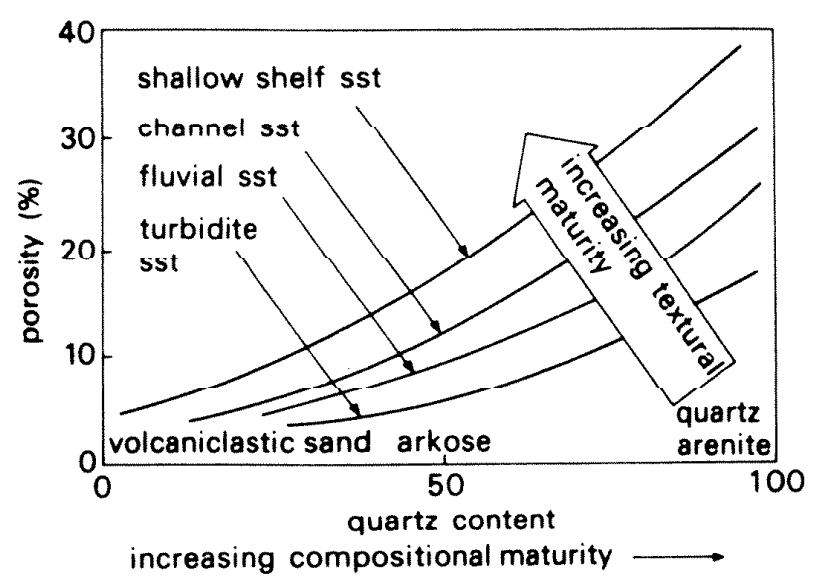

Fig. E.3.4.1. Relationship between compositional and textural maturity, depositional environment, and porosity for Jurassic sandstones from the North Sea. Porosity increases with increasing compositional and textural maturity; textural maturity is, in turn, related to depositional eHVilumenl (Frun SELLET 1978; modirled by TUCKER 1981.) 
Texture follows a predictable vertical and lateral pattern. prograding alluvial fans exhibit an overall coarsening-upward trend as coarser proximal fan facies are deposited over finer distal fan facies. There is also a progressive decline in grain size with increasing distance from the fan apex. Alluvial fan deposits are extremely poorly sorted and grains are highly angular due to the lack of reworking of deposits. Alluvial fan sandstones are thus classified as very texturally immature.

Lateral homogeneity and lateral continutty of sandstones deposited in the alluvial fan setting are typically very poor because most beds are highly lenticular. A variety of depositional processes operate in the fan system (e.g.. debris flow, sieve, braided stream, and sheet flood deposition), all of which contribute to lateral inhomogeneity of lithologic parameters.

Vertical homogeneily of 1ilhologic properties of alluvial fan deposits is typically very poor due to the distinct lenticularity of beds. Debris flow deposits commonly exhibit inverse or inverse-to-normal grading. Sieve lobe deposits display a concentration of coarser material at the front of the lobe and lack interstitial fine material. Sheet flood and stream channel deposits may show fining-upward patterns within beds.

\section{E.3.4.2.1.2 Eolian Dune Deposits}

The mineralogy of eolian dune sandstones is relatively simple and is dominated by quartz; most eolian dune sandstones are classified as quartz arenites (Table E.3.9.17).

Texture follows no predictable pattern (either vertically or laterally) within the entire deposit. Component quartz sand grains are extreme1y well-rounded and sorted; the texture of most eolian dune sandstones can thus be characterized as supermature. Grain size is typically fine to medium sand and is positively skewed. Clay-sized material is generally rare to absent.

Lateral homogeneity of lithologic properties of eolian dune sandstones is typically very high, although on the scale of individual bedding units there may be subtle variation.

Vertical homogeneity of lithologic properties is generally high when the deposit is considered on a macroscopic scale. Small-scale textural changes occur vertically and can be related to depositional processes. Wind ripple deposits occur as millimeter-thick, inversely graded laminations. Avalanche (grain flow) deposits occur as centimeter-thick, coarser-grained lenses that pinch out at the toes of cross-bed sets. Suspension (grain fall) deposits occur as millimeter- to centimeter-thick, normally graded layers that drape preexisting depositional topography.

\section{E.3.4.2.1.3 Braided River Deposits}

The mineralogy of braided stream sandstones is highly variable and is dependent upon the composition of the source terrain. Examples of 
ancient deposits range from compositionally mature quartz arenites to immature feldspathic and lithic arenites. Mineralogy is also dependent upon the topographic relief and degree of weathering within the source area; high relief and slow chemical decomposition (due to arid or cold conditions or to rapid burial) favor compositional immaturity. Braided stream sandstones are probably best typified by immature to submature compositions (Table E.3.18).

Texture of braided stream deposits follows some predictable patterns. At the broadest scale, a decrease in grain size away from the source (i.e., downstream) is to be expected. Because of the flashy discharge characteristics of braided streams, an overall vertical grain-size trend is not apparent, although individual channel-fill subunits commonly display at least crude fining-upward sequences. Sorting and roundness a1so increase in a downstream direction. At the scale of a hand specimen or thin section, braided stream sandstones exhibit poor to moderate sorting and rounding; they are thus characterized as texturally submature.

Lateral homogeneity of lithologic properties of braided stream sandstones is typically poor because of the highly lenticular nature of most bedding units.

Vertical homogeneity of lithologic properties is very poor because the braided stream deposit is a multistory composite of individual channel-fill sequences stacked one on top of another. Individual channel-fill units are up to ten meters thick and several hundred meters wide.

\section{E.3.4.2.2 Transitiona1 Environments}

\section{E.3.4.2.2.1 Deltaic Deposits}

Mineralogy of deltaic sandstones varies widely and is dependent upon the characteristics of the bedrock source in the drainage area for the rivers feeding the de1ta. Submature composition (e.g., subarkose, sublitharenite/wacke) is most common (Table E.3.9.19). plant detritus is colmion.

Texture follows a predictable pattern. A typical prograding delta produces a coarsening-upward sequence. In addition, there will be a systematic seaward-fining. In genera1, the delta-plain deposits are a mixture of sandstone and mudstone, de1ta-front deposits are predominanty sandstone, and prodelta deposits are mostly mudstone. Textural maturity (sorting and rounding) will be highest in delta-front sheet sandstones and distributary channel/mouth bar sandstones. Textural maturity is lowest in the thin sandstones of prodeltaic and interdistributary marsh/bay origin.

Lateral homogeneity and continuity of sandstones deposited in a deltaic setting are typically poor due to rapid lateral facies changes and slifling of distributary chantels acruss the della plafino 
Vertical homogeneity of sandstones deposited in a deltaic setting is generally poor due to fluctuations in sediment size and composition carried by distributaries. Fining-upward patterns are especially common.

\section{E.3.4.2.2.2 Progradational Shoreline Deposits}

The mineralogy of progradational shoreline sandstones ranges from mature to submature. Quartz is distinctly dominant, with feldspar, rock fragments, and detrital micas as secondary constituents. Biogenic carbonate grains (fossil fragments) and glauconite may be locally abundant. Nearshore facies are generally lacking in interstitial clay matrix, but substantial amounts may be present in offshore facies. Sublitharenite and subarkose are predominant lithologies, although quartz arenites occur in nearshore racies.

Texture follows a predictable coarsening-upward pattern within the entire progradational shoreline deposit. Shoreface deposits are commonly fine to very fine sand, with an increase to medium or coarse sand taking place in nearshore and beach deposits which cap the progradational sequence. Component quartz sand gxains are moderately to well sorted and rounded; Lexcure can hius be classified ds subledule lo maluse. Claysized material is abundant only in the more offshore (shoreface) facies.

Lateral homogeneity of lithologic properties of progradational shoreline sandstones is typically very high, although on the scale of individual bedding units there may be subtle variation.

Vertical homogeneity of lithologic properties ranges from low to moderate. Individual bedding units may fine upward with coincident mineralogic variation. Upper (nearshore) facies will exhibit greater mineralogical and textural maturity than lower (offshore) facies.

\section{E.3.4.2.3 Open-Marine Environments}

E.3.4.2.3.1 Shallow-Marine Slieif Depuslls

The mineralogy of shallow-marine shelf sandstones is dominated by quartz, with lesser amounts of feldspar, rock fragments, detrital micas, and fossil debris (calcite). Glauconite occurs commonly and is especially diagnostic. Most shallow-marine shelf sandstones are characterized as quartz arenites to sublitharenites or subarkoses, thus indicaling a malure lo submature composition.

Texture follows predictable patterns. Fining-upward grain-size trends characterize transgressive sequences, whereas coarsening-upward trends typify progradational sequences. At the scale of a hand sample or thin section, shallow-marine shelf sandstones are moderately to well. rounded and sorted and lack abundant interstitial fines (clay matrix). These sandstones are thus characterized as texturally mature to submature.

Lateral homogeneity of lithologic properties of shallow-marine shelf sandstones is typically very high because of the laterally continuous nature of the bedding. 
Vertical homogeneity of lithologic properties of shallow-marine shelf sandstones ranges from moderate to high depending on the amount of interbedding and textural differences within individual beds (most are normally graded).

\section{E.3.4.2.3.2 Submarine Fan/Turbidite Deposits}

The mineralogy of deep-water sandstones is extremely diverse because of the great range in grain size, the broad potential source area, and the rapid rates of accumulation. Rock fragments (particularly volcanic), feldspars, micas, and clay minerals are all derived from an adjacent magmatic arc/orogenic belt and are enriched relative to quartz; deepwater sandstones are therefore characteristically lithic arenites/wackes or feldspathic arenites/wackes, highly compositionally immature (Table E.3.9.20).

Texture follows some specific trends, especially for submarine fan sequences. An overall coarsening-upward textural pattern typifies the prograding submarine fan. At an intermediate scale, individual channel, levee, and turbidite sequences show a fining-upward trend. At the scale of a hand sample or thin section, deep-water sandstones are extremely poorly sorted and rounded and contain abundant interstitial fine material (clay matrix); they are thus characterized as very texturally immature.

Lateral homogeneity of lithologic properties of deep-water sandstones is typically very poor due to the broadly lenticular nature of individual bedding units. Thin-bedded turbidites are an exception and show lateral continuity of beds on a scale of hundreds to perhaps thousands of meters.

Vertical homogeneity of lithologic properties is typically very poor because of significant textural changes within individual beds, which can be ascribed to various depositional processes. Mineralogical changes commonly accompany these textural changes (e.g., coarser channel sandstones contain abundant rock fragments, whereas finer turbidite and levee sandstones are enriched in quartz, feldspar, and detrital micas).

\section{E.3.4.3 BEDDING CHARACTERISTICS}

\section{E.3.4.3.1 Terrestrial Deposits}

\section{E.3.4.3.1.1 Alluvial Fan Deposits}

Thicknesses of beds in alluvial fan deposits range from tens of centimeters to several tens of meters. A range of a few meters is typical (Table E.3.9.21).

Bedding type is dependent upon depositional processes and is dominated by massive (nongraded) bedding and medium- to very-large-scale cross bedding.

other primary structures include horizontal stratification, inverse and normally graded bedding, and chaotic slumpe and folde. 


\section{E.3.4.3.1.2 Eolian Dune Deposits}

The thickness of eolian dune sandstone beds ranges from tens of centimeters to a few tens of meters. A common thickness of a bedding unit would be in the range of a few meters (Table E.3.9.22).

The type of bedding is characteristically medium- to very-large-scale cross bedding. Dip angles of 20 to $30^{\circ}$ are typical for cross beds.

other primary structures include horizontal stratification, convolute bedding, and rare aqueous current structures formed in interdune depressions or wadis.

\section{E.3.4.3.1.3 Braided River Deposits}

The thickness of braided stream sandstone beds ranges from centimeters to several meters. A common thickness of a bedding unit is in the range of tens of centimeters to a meter.

The type of bedding is characteristically medium- to 1arge-scale cross bedding. Dip angles of 20 to $32^{\circ}$ are typical for cross beds.

Other primary structures include horizontal stratification, channel surfaces, and ripple cross lamination.

\section{E.3.4.3.2 Transitional Environments}

\section{E.3.4.3.2.1 Deltaic Deposits}

The thickness of sandstone beds ranges from centimeters to several meters. A common thickness of a bedding unit is in the range of tens of centimeters.

The type of bedding is dependent upon the subenvironment considered. Medium- to large-scale cross bedding is prevalent in distributary channe 1 sandstones and commonly passes upward into ripple cross stratification.

other primary structures include soft-sediment deformacion of prodelta mud (convolute bedding, diapiric features, slump beds, load structures, etc.) and bioturbation by plant roots and burrowing organisms.

\section{E.3.4.3.2.2 Progradational Shoreline Deposits}

Thicknesses of sandstone beds range from centimeters to a few meters. A common thickness of a bedding unit is in the range of a few tens of centimeters.

The type of bedding is characteristically medium-to large-scale cross bedding. Dip angles of 5 to $30^{\circ}$ are typical for cross bed sets.

Other primary structures include horizontal stratification, bioturbation structures, ripple cross laminacion, normally graded bedding, and hummocky stratification. 


\section{E.3.4.3.3 Open-Marine Environments}

\section{E.3.4.3.3.1 Shallow-Marine Shelf Deposits}

Thicknesses of shallow-marine shelf sandstone beds range from centimeters to a few meters. The most common bed thickness is in the range of a few tens of centimeters (Table E.3.9.23).

The type of bedding is characteristically medium-scale cross bedding. Dip angles of 20 to $32^{\circ}$ are typical for cross beds.

other primary structures include hummocky stratification, wave and current ripple lamination, bioturbation structures, horizontal lamination, and sma11-scale scour or channel-like features.

\section{E.3.4.3.3.2 Submarine Fan/Turbidite Deposits}

The thickness of deep-water sandstone beds ranges from centimeters to tens of meters. In general, the thickest beds are deposits in the inner fan channel subenvironment of the submarine fan. Turbidites deposited in the outer fan subenvironment are typified by thicknesses in the range of tens of centimeters to a few meters (Table E.3.9.24).

Bedding is characteristically normally graded, with ripple cross laminations also abundant. Bedding is highly variable and is dependent upon depositional processes.

other primary structures include bottom markings (flute and groove casts), load structures, inversely graded bedding, fluid-escape structures (dish-and-pillar, convolute lamination), massive (structureless) bedding, and large channel surfaces.

\section{E.3.4.4 NATURE OF INTERBEDS}

\section{E.3.4.4.1 Terrestrial Environments}

\section{E.3.4.4.1.1 Alluvial Fan Deposits}

Lithologies commonly interbedded with alluvial fan sandstones include abundant conglomerate and breccia (both clast- and matrix-supported), siltstone beds, and clay drape laminae.

The thickness of lithologies interbedded with alluvial fan sandstones ranges from centimeters to hundreds of meters. Conglomerate and breccia comprise the bulk of many alluvial fan sequences.

Uniformity of 1ithologies interbedded with alluvial fan sandstone is typically poor because of the highly lenticular nature of bedding. Most interbeds cannot be traced laterally more than a few hundred meters.

\section{E.3.4.4.1.2 Eolian Dune Deposits}

Lithologies commonly interbedded with eolian dune sandstone include siltstone, silty mudstone, thin carbonate stringers and lenses, thin 
gravel lag layers, and evaporite sequences (halite, gypsum, or anhydrite). These are primarily interdune deposits.

The thickness of lithologies interbedded with eolian dune sandstone ranges from millimeters to tens of meters, although a range of tens of centimeters is most common.

Uniformity of lithologies interbedded with eolian dune sandstone ranges from low to high depending on the type of lithology. Most pinch out laterally within the enclosing sandstone over distances of less than one kilometer. Vertical uniformity within individual interbeds is typically high.

\section{E.3.4.4.1.3 Braided River Deposits}

Lithologies commonly interbedded with braided stream sandstones include conglomeratc, oiltotone, and oholc. Braided strcam deposits can range from sandstone- to conglomerate-dominated.

Thicknesses of lithologies interbedded with braided stream sandstones range from millimeter-thick shale layers to meter-thick conglomerate beds. A common interbed thickness is in the range of tens of centimeters.

Uniformity of lithologies interbedded with braided stream sandstones is typically low due to the highly lenticular nature of most bedding units. Most interbeds are not uniform over distances of greater than a few tens of meters.

\section{E.3.4.4.2 Transitiona1 Environments \\ E.3.4.4.2.1 Deltaic Deposits}

Lithologies commonly interbedded with deltaic sandstones include siltstone, shale, and coal. Detrital micas and plant fragments may be locally abundant in siltstone.

The thickness of lithologies interbedded with sandstone varies from millimeter-thick laminatione to tene to hundrede of meters.

Uniformity of lithologies interbedded with sandstone is typically poor, both laterally and vertically. Notable exceptions are the mudstone and shale which comprise the prodelta and are uniform over greater lateral and vertical distances (perhaps tens of kilometers).

\section{E.3.4.4.2.2 Progradational Shoreline Deposits}

Lithologies commonly interbedded with progradational shoreline sandstone include siltstone and shale or mudstone, with rare concentrations of glauconite or fragmented fossil grains.

Thicknesses of 1ithologies interbedded with progradational shoreline sandstone range from millimetore to tono of motoro, although a range of tens of centimeters is most common. 
Uniformity of 1ithologies interbedded with progradational shoreline sandstone ranges from low to high depending on the type of 1ithology. offshore (lower shoreface and equivalent shelf environments) shale and mudstone exhibit the greatest uniformity over distances of hundreds to thousands of meters. Nearshore facies may contain very discontinuous siltstone, shale, and mudstone layers.

\section{E.3.4.4.3 Open-Marine Environments}

\section{E.3.4.4.3.1 Sha1low-Marine Shelf Deposits}

Lithologies commonly interbedded with shallow-marine shelf sandstones include siltstone, mudstone and shale, and shallow-marine limestone and dolostone.

Thicknesses of lithologies interbedded with shallow-marine shelf sandstones range from millimeter-thick shale layers to meter-thick limestones and dolostones. A thickness in the range of a few tens of centimeters is probably most common.

Uniformity of Iithologies interbedded with shallow-marine shelf sandstones ranges from low to high depending on the type of lithology. Shale and mudstone layers are generally laterally discontinuous, whereas 1. imestone and dolostone beds may persist laterally for tens of kilometers or more.

\section{E.3.4.4.3.2 Submarine Fan/Turbidite Deposits}

Lithologies commonly interbedded with deep-water sandstones include shale, siltstone, conglomerate, and pebbly mudstone. Pelagic radiolarian cherts and 1imestones also occur, though rarely.

Thicknesses of lithologies interbedded with deep-water sandstones range from millimeter-thick shale layers to massive conglomerates a few hundred meters thick. Interbeds in the range of centimeters to several meters thick are most common.

Uniformity of lithologies interbedded with deep-water sandstones is typically very poor due to the broadly lenticular nature of most bedding units. An exception is that of thin-bedded turbidites, which may extend laterally for hundreds to perhaps thousands of meters.

\section{E.3.4.5 POROSITY AND PERMEABILITY}

\section{E.3.4.5.1 Genera1 Discussion of Porosity}

Sandstone porosity is almost entirely a function of the amount of cementing material present between sand grains and the extent to which the larger grains interdigitate (DAVIS 1969). It is important at the outset to distinguish between "total" and "effective" porosity of sandstone. Total porosity is the total fractional void space of a porous medium expressed as a percentage of the bulk volume, which, in a 
sandstone, will include the volume of all pores regardless of whether or not they are open to the flow of fluids (MUSKAT 1946). Effective porosity, in contrast, refers only to that part of the total pore space which is available to fluid flow. Nonindurated sands from freshly deposited sand bodies were tested (PRYOR 1973) and exhibited total porosities ranging from 17 to 55\%, which could be related to depositional environment and associated textural parameters such as grain size and sorting. Beard and Weyl (BEARD 1973) also demonstrated a close relationship between porosity and gxain size and sorting for artificially mixed and packed sands. Sandstones typically display porosities lower than nonindurated sands because of the porosity-destructional nature of diaprocesses (PETTIJOHN 1972; HAYES 1979; BLATT 1980).

(1) Cementing agents such as calcite, dolomite, quartz, iron oxides, clays, and other minerals are precipitated between open pore spaces by circulating fluids (either fresh, brackish, saline, or hypersaline).

(2) Burial compaction causes rearrangement of the original depositional grain-packing configuration and associated pore-fluid expulsion. In addicion, plastic deformation and riowage of ductile grains (e.g., detrital micas and pelitic rock fragments) can be substantial.

(3) Deep burial conditions may allow for extensive pressure solution at grain-to-grain boundaries, resulting in grain interpenetration and subsequent reprecipitation of soluble material at points of least principal stress. Data for total porosity measurements on about 2200 sand and sandstone samples show a majority of measured values between 6 and 32\%, with a mean value estimated to be around $20 \%$ (Fig. E. 3.4.2).

It has been well documented that sandstone porosity generally decreases with burial depth along some porosity gradient. Atwater and Milles (ATWATER 1965) denunslraled a porosity gradient of $1.265 \%$ per $305 \mathrm{~m}$ (1000 ft) of burial for late Tertiary sandstones in southern Louisiana. Burial depth alone is not the only important factor. Selley (SELLEY 1978) summarized the most important factors affecting porosity gradients as (a) geostatic (overburden) pressure, (b) hydrostatic (pore-fluid) pressure, (c) mineralogic composition, (d) geothermal gradient, and (e) pore-fluid chemistry. Selley's literature review indicated that porosity gradients increase with increasiug yeullexild gradient and decreasing quartz content and that porosity may be preserved at greater than anticipated depths due to abnormally high pore pressure (overpressure) and to the presence of hydrocarbons.

Recent studies have also demonstrated that sandstone porosity does not decrease uniformly with depth as at first supposed, but that it is common for a zone of secondary porosity to develop due to dissolution of unstable mineralogic components in the subsurface (HAYES 1979; SCHMTDT 1979) (Fig. E.3.4.3). The depths at which the processes of secondary porosity enhancement can occur vary from shallow to greater than $4000 \mathrm{~m}$. Figures E.3.4.4, E.3.4.5, and E.3.4.6 are from Schmidt and McDonald (SCHMIDT 1979) and summarize the following key points. 


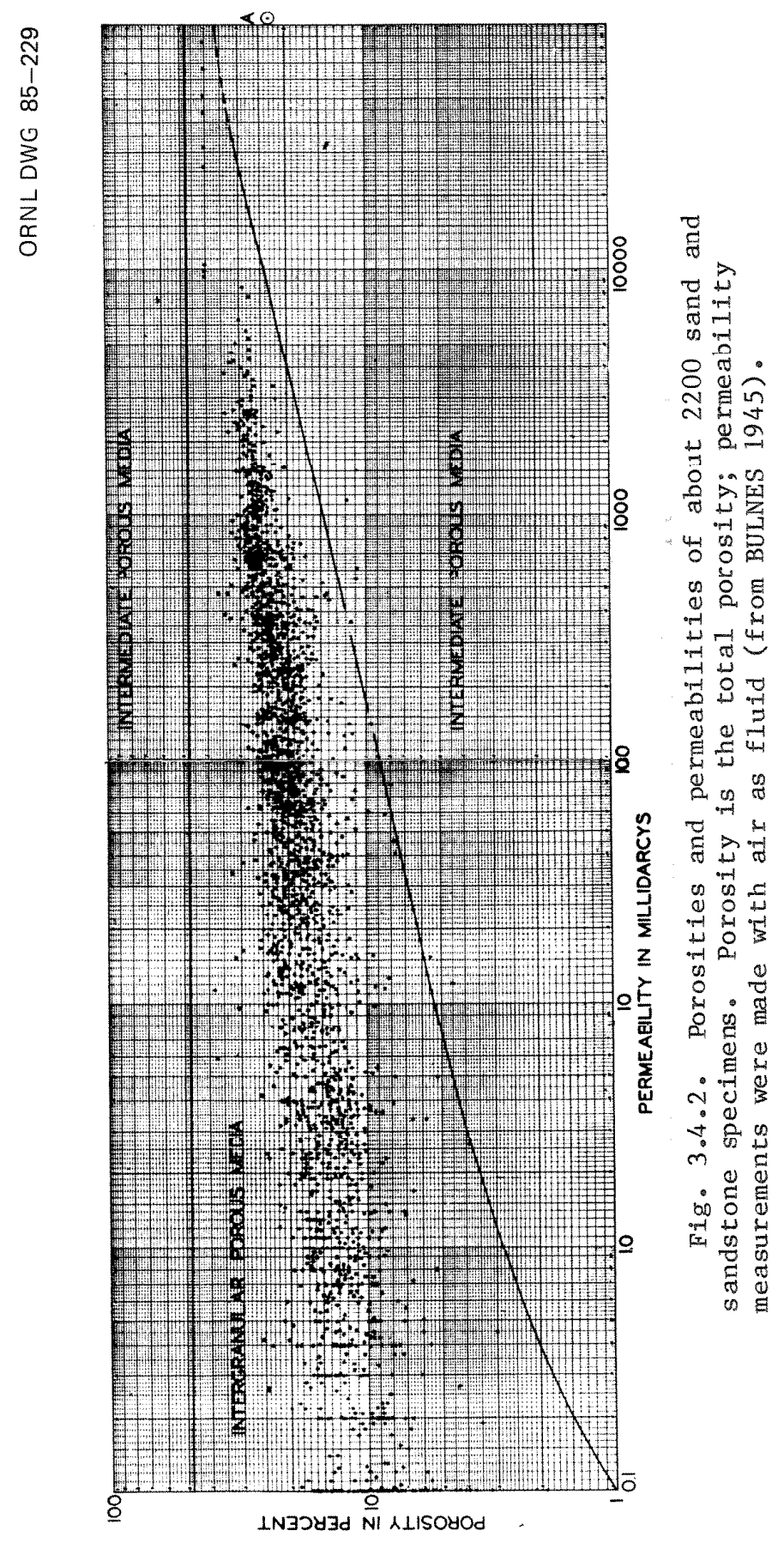


ORNL DWG 85-225

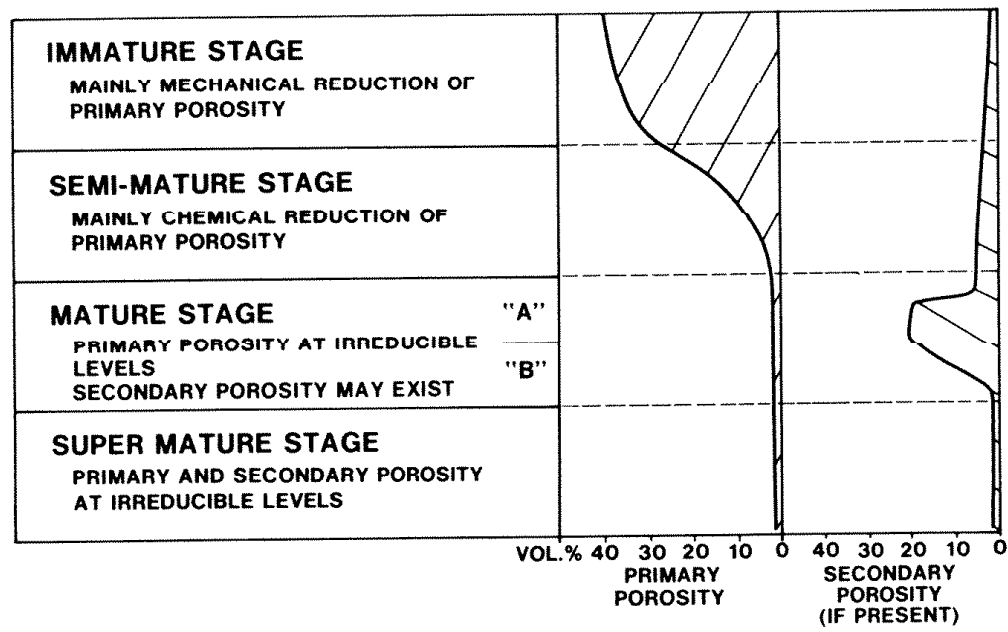

Fig. E. 3.4.3. Stages of porosity reduction and secondary porosity development during burial diagenesis of sandstone (from SCHMIDT 1979). 


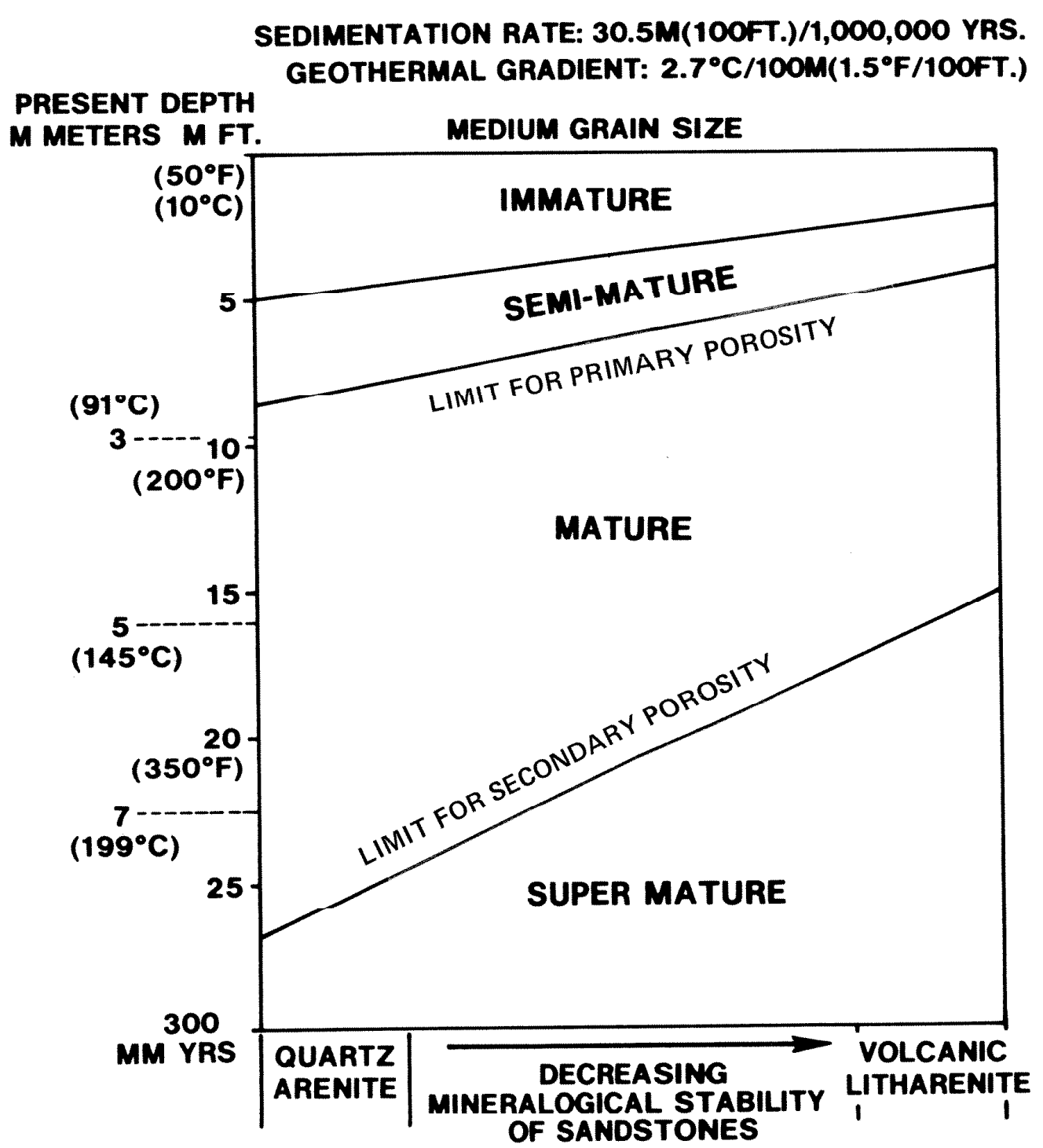

Fig. E.3.4.4. Influence of sandstone mineralogy or porosity history during burial diagenesis. Note that porosity reduction occurs at shallower burial depths for mineralogically unstable lithic sandstones whereas porosity can be preserved to greater depths for mineralogically stable quartz sandstones (from SCHMTDT 1979). 
LITHOLOGY: MEDIUM GRAINED QUARTZ ARENITE SEDIMENTATION RATE: 30.5M(100FT.)/1,000,000 YRS. GEOTHERMAL GRADIENT: $2.7^{\circ} \mathrm{C} / 100 \mathrm{M}\left(1.5^{\circ} \mathrm{F} / 100 \mathrm{FT}.\right)$

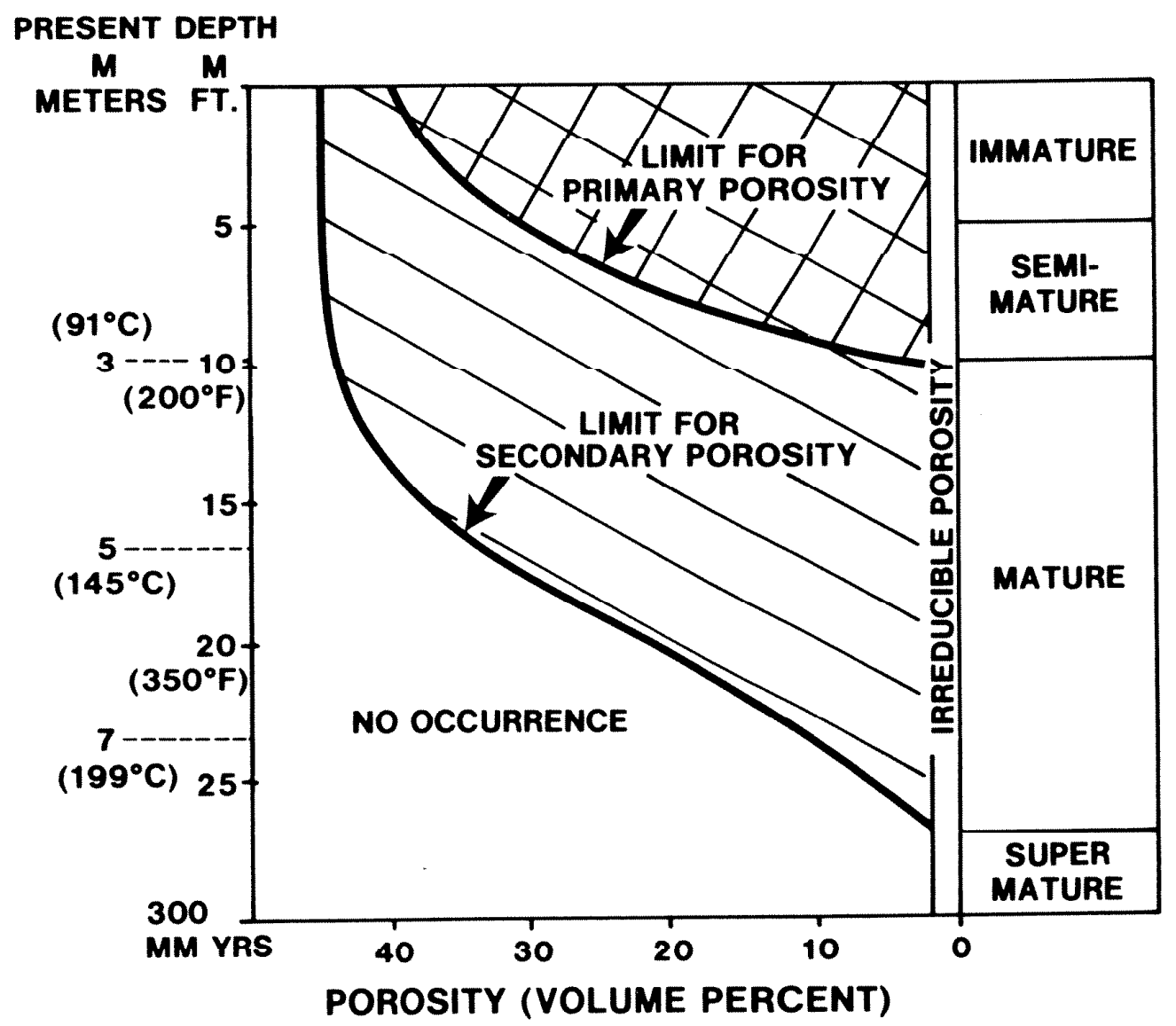

Fig. E.3.4.5. Maximum porosity of quartz arenites as a function of depth of burial. Note that a secondary porosity can be higher than original primary porosity at some depths and porosity stages. In addition, the depth limit for secondary porosity can be almost twice as deep as that of primary porosity (from SCHMIDT 1979). 


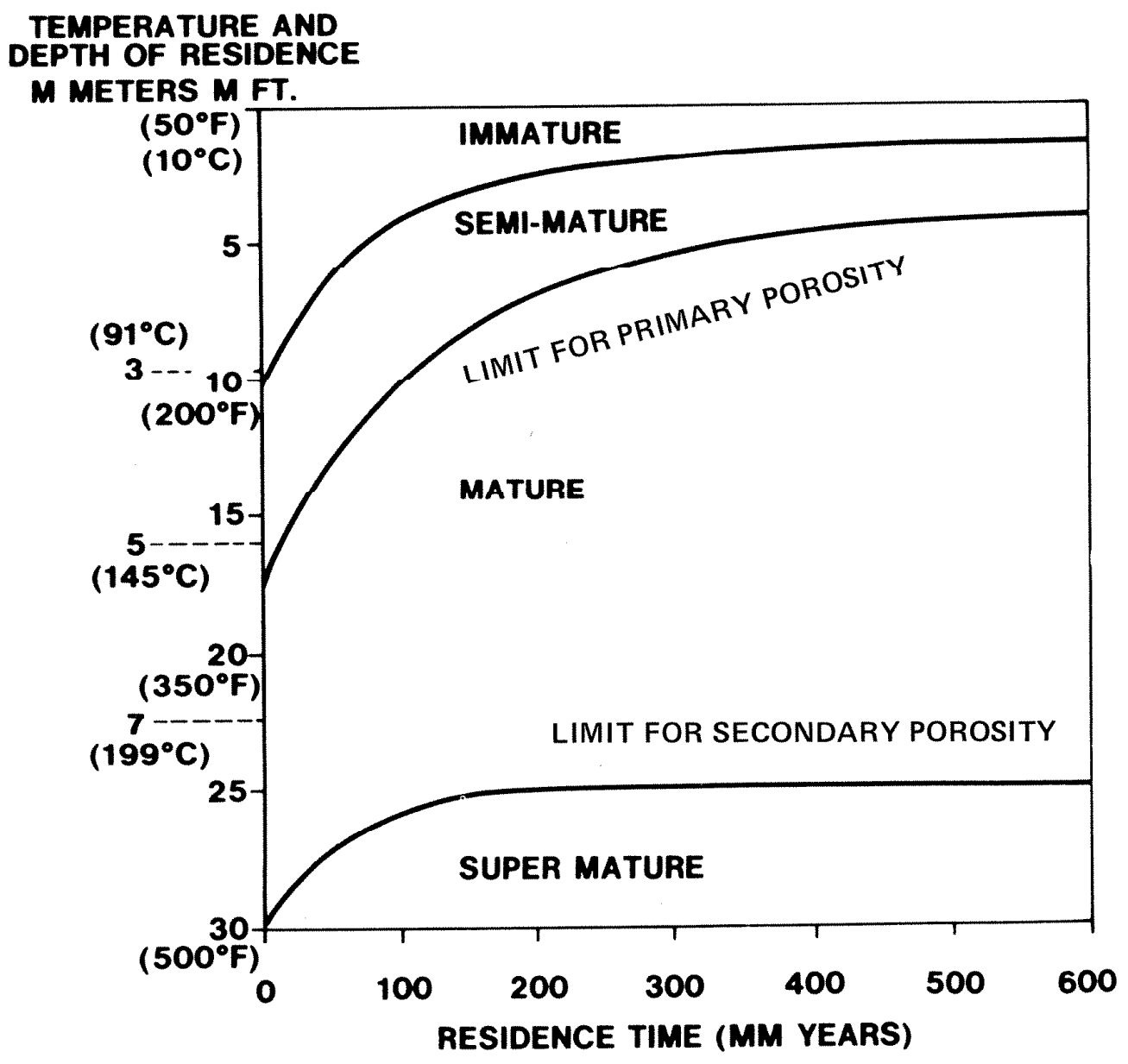

LITHOLOGY: MED. GRAINED QUARTZ ARENITE GEOTHERMAL GRADIENT: $2.7^{\circ} \mathrm{C} / 100 \mathrm{M}\left(1.5^{\circ} \mathrm{F} / 100 \mathrm{FT}\right.$.)

Fig. E.3.4.6. Influence of temperature and residence time on porosity history during burial diagenesis (from SCHMIDT 1979)。 
(1) Up to $40 \%$ of initial depositional (primary) porosity typical of most sands decreases to 1 to $2 \%$ irreducible porosity at depths of about $2000 \mathrm{~m}$ (volcanic lithic arenite) to $3000 \mathrm{~m}$ (quartz arenite) due to mechanical compaction and chemical precipitation of cements.

(2) Secondary porosity develops due to dissolution of unstable framework grains and cements. In a quartz arenite, maximum secondary porosities exceed $40 \%$ at about $4000 \mathrm{~m}$ depth and from there decline with increasing depth to $8000 \mathrm{~m}$. Only a small amount of irreducible secondary porosity then remains.

(3) Porosity reduction is also enhanced by increasing both residence time (Fig. E.3.4.2) and residence temperature; however, lengthening the residence time of the sandstone beyond 400 million years produces very little porosity reduction.

Although this aspect is discussed in greater detail in subsequent sections, it is important to mention here that depositional environments can control the porosity distributions of sandstones. This aspect was wel1 documented (SELLEY 1978) in a study of porosity gradients for Jurassic sandstones from the North Sea (Fig. E.3.4.1). Higher-energy depositional environments (and those characterized by a greater constancy of physical sedimentary processes) are typified by well-winnowed, texturally mature (high degree of rounding and sorting, lack of interstitial matrix) sandstones, which exhibit higher porosities. Conversely, lowerenergy environments (and/or those characterized by very episodic sedimentation) are typified by less texturally mature sandstones and therefore reduced porosities.

\section{E.3.4.5.2 General Discussion of Permeability}

Earlier it was shown that porosity is a fundamental property determined by the sediment or rock characteristics and burial diagenetic history. Permeability is dictated by some of the same features as porosity, but in addition, effective porosity, the shape and size of the pores and pore interconnections (pore throats), and physical characteristics of the fluid phaoc traveling through the pores must be considered (MUSKAT 1946; LEVORSEN 1967; DAVIS 1969). From Darcy's law, permeability $(\mathrm{K})$ depends on the rate $(\mathrm{Q})$ at which fluid flows through a cross-sectional unit of rock: $Q=(\mathrm{K} / \mu)(\mathrm{dp} / \mathrm{d} 1)$, where $\mu$ is the fluid viscosity and $\mathrm{dp} / \mathrm{d} 1$ is the pressure gradient in the direction of flow. This report adheres to this definition of permeability. Although many attempts have been made to formulate a simple linear relationship between porosity and permeability, the number of variables affecting permeability is so large that no simple relationship exists (DAVIS 1969). Nonindurated sand samples from freshly deposited sand bodies were tested (PRYOR 1973) and ranged from 4 md to $500 \mathrm{~d}$, which could be related to depositional environment and associated textural parameters such as grain size and sorting. Beard and Wey1 (BEARD 1973) also demonstrated a close relationship between permeability and grain size and sorting for artificially mixed and packed cande. Data for about 2200 aand and sandstone samples indicate a range of permeability measurements between 0.1 millidarcy and 10 darcy, with 
the greatest density of values between 10 millidarcy and 1 darcy (Fig. 3.4.2). The lower permeabilities typical of indurated sandstones (as compared with nonindurated sands) can be attributed to the same diagenetic processes responsible for porosity destruction, as discussed earlier.

Pettijohn and others (PETTIJOHN 1972) summarized the specific properties of sandstones that are most important in predicting the porosity and permeability characteristics of sandstones (Table E.3.4.3). Primary controls on permeability are small-scale (e.g., grain size and sorting), intermediate-scale (sedimentary structures) and large-scale (mass lithologic and bedding characteristics) (Table E.3.4.4). A consequence of these many stratigraphic and sedimentologic factors is that the permeability of sandstone is typically anisotropic, that is, the vertical permeability of sandstone can be very low even though the horizontal permeability may be quite high (DAVIS 1969; PETTIJOHN 1972). Actual samples taken from a large sandstone body in a direction perpendicular to bedding showed large variations in permeability, probably due to the occurrence of interstratified shales (MUSKAT 1946). Piersol and others (PIERSOL 1940) measured horizontal and vertical permeabilities for a large number of sandstone samples and found that the median ratio of horizontal to vertical permeabilicy was 1 to 5 . About $12 \%$ of the samples had a rallo greater than 3 to 0 , and slightly less than $6 \%$ had vertical permeabi1ities greater than horizontal. One study (GREENKORN 1964) found that 81 out of a total of 142 sandstones samples had significant permeability anisotropy. On1y 63 of the samples had recognizable stratification, but of these, 43 had their direction of maximum permeability parallel with stratification. Of the 23 samples in which vertical permeability was the greater, 17 either had no visible stratification or the bedding made an angle of more than $45^{\circ}$ with the horizontal plane,

\section{E.3.4.5.3 Terrestrial Environments}

\section{E.3.4.5.3.1 Alluvial Fan Deposits}

Porosicy and permeabilicy daca for ancient alluvial fan sandstones are lacking. Because of their overall coarse grain size (conglomerate and breccia), high initial depositional porosities and permeabilities are common in Holocene and Recent alluvial fan deposits.

\section{E.3.4.5.3.2 Eolian Dune Deposits}

The nature of porosity in eollan sandstone is interparticle and of both primary and secondary origin. Because of their high textural maturity and loose packing arrangement when first deposited, eolian dune sands have high initial depositional porosities and permeabilities. Porosity ranges from 0 to $35 \%$ but is more typically in the range of 10 to $20 \%$ (Tables $\mathrm{E} \cdot 3 \cdot 9 \cdot 25$ and $\mathrm{E} \cdot 3 \cdot 9 \cdot 26$ ).

Lateral and vertical permeabilities of eolian dune sandstones range from tenths of a millidarcy to several darcys, Ubiquitous high-angle crossbedding allows for significant anisotropy of permeability, as do the subtle variations in texture that are ascribable to different eolian depositional processes. A common permeability is in the range of a few hundred millidarcys (Tables E.3.9.25 and E.3.9.26). 
Table E.3.4.3. Sumnary of important properties of sandstone and their effects on porosity and permeability

(from PETTIJOHN 1972)

\begin{tabular}{ll}
\hline $\begin{array}{c}\text { Rock } \\
\text { property }\end{array}$ & Effects on permeability and porosity \\
\hline Texture & \\
\hline Grain size & $\begin{array}{l}\text { Permeability decreases with grain size; } \\
\text { porosity unchanged. }\end{array}$ \\
Sorting & $\begin{array}{l}\text { Permeability and porosity decrease as } \\
\text { sorting becomes poorer, }\end{array}$ \\
Packing & $\begin{array}{l}\text { Little data available, but tighter packing } \\
\text { porosity }\end{array}$ \\
Fabric & $\begin{array}{l}\text { In absence of lamination, controls } \\
\text { anisotropy of permeability; permeability is } \\
\text { a maximum parallel to mean shape fabric. }\end{array}$ \\
Cement & The more cement, the less permeability and \\
porosity
\end{tabular}

Sedimentary structures

Parting lineation

Maximum permeability and nost probably parallels fabric in plane of bedding.

Crossbedding

Scant available data suggest that horizontal permeability parallels direction of inclination and that the steeper the dip of the foreset, the weaker the horizontal vector of permeability.

Ripple mark

Little data, but fine grain and more laminations combine to cause low permeability and hence ripple zones are commonly barriers to flow.

Grooves and flutes

As judged by fabric, permeability should parallel long dimension.

Slump structures

No data, but probably always greatly reduce horizontal permeability.

Biogenic structures

Destroy depositional fabric and bedding and thus drastically reduce permeability and cause minimal, if any, horizontal anisotropy of permeability. Effect on porosity is unknown, but may be negligible. 
Table E.3.4.3 (continued)

\begin{tabular}{ll}
$\begin{array}{c}\text { Rock } \\
\text { property }\end{array}$ & Effects on permeability and porosity \\
\hline Lithology & \\
Sandstone & Thicker beds tend to be coarser grained and \\
& thus nore permeable, if cement is not a \\
& factor. If weakly or uncemented, ratio of \\
& maximum to minimum permeability is perhaps \\
& less than 5 to 1 if cement controlled, \\
& racio may reach loo to 1 or more. \\
& The prime barrier to flow that outshadows \\
all others by far. Thus it is the arrange & ment of sand and shale much more than per- \\
meability variation within the sand that & controls flow in most reservoirs. \\
\hline
\end{tabular}


Table E.3.4.4. Hierarchical sequence of primary controls on permeability in sandstones (from PETTIJOHN 1972)

\begin{tabular}{ll}
\hline Control & Remarks \\
\hline Texture and fabric & \\
Defined by grain size, sorting, & $\begin{array}{l}\text { Fundamental "building blocks" that } \\
\text { define the primary pore system. }\end{array}$ \\
packing, and shape orientation & $\begin{array}{l}\text { Depositional fabric may be } \\
1 \text { to a few cn }{ }^{3}\end{array}$ \\
& $\begin{array}{l}\text { completely destroyed by burrowing } \\
\text { organisms. }\end{array}$
\end{tabular}

Sedimentary structures

Crossbedding, ripple mark, and parting lineation are most common and nearly always have preferred orientation and anisotropic fabrics. Scale: 1 to $10^{2} \mathrm{~m}^{3}$.

\section{Bedding facies}

Defined by bed thickness, types and abundances of sedimentary structures, and frequency of shale beds. Scale: $10^{2}$ to $10^{5} \mathrm{~m}^{3}$.

Directional structures consist of anisotropic fabrics so that individual structures should behave as "flow packets."

Probably the most important primary control on permeability distribution in a sandstone body. Shale beds act as impermeable barriers to flow and are one of the more continuous 1ithologies.

\section{Composite sand bodies}

Superposition of one "cycle" of sand upon another, cycles commonly separated by unconformities. Scale: $10^{6}$

Characteristic of many alluvial and deltaic sands. Multilateral as well to $10^{10} \mathrm{~m}^{3}$. 


\section{E.3.4.5.3.3 Braided River Deposits}

The nature of porosity in braided stream sandstones is primarily interparticle and of both primary and secondary origin. Because of their generally coarse grain sizes, braided stream sands have high initial depositional porosities and permeabilities. Porosity ranges from 0 to $30 \%$ but is more typically 10 to $20 \%$.

Lateral and vertical permeabilities of braided stream sandstones range from tenths of a millidarcy to a darcy. Ubiquitous crossbedding allows for significant anisotropy of permeability, as do the distinct variations in texture ascribable to the multistory nature of the deposit. A common permeability is in the range of a few hundred millidarcys.

\section{E.3.4.5.4 Transitiona1 Environments}

\section{E.3.4.5.4.1 Deltaic Deposits}

Porosity in deltaic sandstones is interparticle and of both primary and secondary origin. Deltaic sandstones may have high initial deposiLlonal porosities and permeabilicies due co rapid races or accumulacion. Porosity ranges from 0 to $30 \%$. A common porosity value is in the range of 15 to $20 \%$ (Tables E.3.9.27 and E.3.9.28).

Lateral and vertical permeabilities for deltaic sandstones range from tenths of a millidarcy to several darcys. A common permeability value is in the range of a few hundred millidarcys (Tables E.3.9.27 and E.3.9.28).

\section{E.3.4.5.4.2 Progradational Shoreline Deposits}

Porosity in progradational shoreline sandstones is primarily interparticle and of both primary and secondary origin. Nearshore facies dominated by well-sorted sandstone may have relatively high initial depositional porosities and permeabilities. Porosity ranges from 0 to $25 \%$ bul is wore lyplcally in lie ratlye of $10 \mathrm{LO} 15 \%$ (Table E.3.29).

Lateral and vertical permeabilities of progradational shoreline sandstones range from tenths of hundreds of millidarcy. Abundant crossbedding and shale/mudstone interbeds allow for significant anisotropy of permeability. A common permeability is in the range of tens of millidarcys (Table E.3.9.29).

\section{E.3.4.5.5 Open-Marine Environments}

\section{E.3.4.5.5.1 Shallow-Marine Shelf Deposits}

Porosity and permeability data are scarce for Type II shelf deposits but are abundant for Type I sequences, perhaps because of their proven hydrocarbon potential. Data for Type I shelf deposits suggest porosities in the range of 3 to $30 \%$ and permeabilities in the range of a few tenths of a millidarcy to several darcys. 
E.3.4.5.5.2 Submarine Fan/Turbidite Deposits

Porosity in deep-water sandstones is both interparticle and intraparticle and is chiefly secondary, due to the unstable mineral composition and abundance of interstitial fine material (clay matrix).

Porosity ranges from almost zero to $35 \%$ but is more typically in the range of 5 to $15 \%$ (Tables E.3.9.30, E.3.9.31, and E.3.9.32).

Lateral and vertical permeabilities of deep-water sandstones range from almost zero millidarcy to several darcys. Significant variations in texture and sedimentary structures within individual beds allow for considerable anisotropy of permeability. A common permeability is in the range of tenths to a few hundred millidarcys (Tables E.3.9.30-E.3.9.32). 


\section{E.3.5 BOUNDING LITHOLOGIES}

\section{E.3.5.1 TERRESTRIAL ENVIRONMENTS}

\section{E.3.5.1.1 Alluvial Fan Deposits}

The alluvial fan system is typically bounded on one side by a highland source terrain and fault scarp and on the down-fan side by braided stream, eolian dune, and lacustrine/playa lake environments. In rare cases, alluvial fans debouch directly into a marine environment as a fandelta. A possible coarsening-upward sequence might include playa facies (siltstone, mudstone, evaporites) at the base, eolian dune sandstone in the middle, and alluvial tan tacies (conglomerate, breccia, sandstone) at the top. The reverse sequence (fining-upward) is also possible.

\section{F. 3.5.1.2. Folian Dine Deposits}

Eolian dune systems typically grade latera11y into alluvial fan, wadi, playa lake, and sabkha environments. Fluvial or lacustrine facies could be tound above or below desert strata in contormable relationship. A possible coarsening-upward sequence might include playa facies (siltstone, mudstone, evaporites) at the base, eolian dune sandstone in the middle, and alluvial fan facies (conglomerate, sandstone) at the top. The reverse sequence is also likely to occur.

\section{E.3.5.1.3 Braided River Deposits}

Braided stream systems grade laterally into a large number of other depositional systems, including alluvial fans, meandering streams, glaciers, and deltas. One possible progradational sequence might include the following, from base to top: meandering stream deposits $\rightarrow$ braided strean deposits $\rightarrow$ alluvial fan deposits. In the precambrian and early Paleozoic, a common transgressive sequence observed from base to top is: crystalline basement rocks $\rightarrow$ noncontormity $\rightarrow$ braided stream deposits (arkoses) $\rightarrow$ shallow-marine shelf deposits (quartz arenites).

\section{E.3.5.2 TRANSTTTONAT. FNVTRONMFNTS}

\section{E.3.5.2.1 Deltaic Deposits}

The delta system is transitional between continental (fluvial) and open-marine shelf environments. In a prograding succession, deltaic deposits are typically succeeded upward by fluvial (meandering or braided stream) sandstone, conglomerate siltstone, and shale. Bounding fluvial deposits range from several to a few hundred meters in thickness. Deltaic deposits typically overlie open-marine shelf siltstone, mudstone, and thin-bedded sandstone. Shelf sequences range in thickness from tens to several hundred meters.

\section{E.3.5.2.2 Progradational Shoreline Deposits}

Prograding shoreline systems typically grade seaward into marine shelf environments and landward into terrestrial (principally fluvial) 
environments. A possible progradational stratigraphic package might include marine shelf siltstone and shale at the base, shoreline sandstone in the middle, and fluvial sandstone and conglomerate at the top.

\section{E.3.5.3 OPEN-MARINE ENVIRONMENTS}

\section{E.3.5.3.1 Sha1low-Marine Deposits}

Shallow-marine shelf environments grade laterally in a shoreward direction into progradational shoreline, tidal flat, and barrier island systems. The deposits of these nearshore marine and marginal-marine systems may be stratigraphically above or below marine shelf deposits. Shallow-marine shelf environments grade laterally in a seaward direction into deeper-water slope, canyon, or submarine fan systems and may overlie these deeper-water facies. Shallow-marine shelf environments may also be laterally adjacent to carbonate shelf buildups such as a reef.

\section{E.3.5.3.2 Submarine Fan/Turbidite Deposits}

Deep-water sandstones deposited in a continental slope-and-rise setting are typically succeeded laterally by the even deeper fine-grained deposits of the abyssal plain. Progradation of submarine fan/turbidite deposits over abyssal plain facies is therefore a common association. Landward lateral equivalents of the submarine fan/turbidite system would include marine shelf and/or deltaic deposits; with progradation, it is, therefore, common to have these shallow-water facies overlie deep-water sandstones. 


\section{E.3.6 EXTERNAL EVENTS AND THETR INFLUENCE ON} SANDSTONE DEPOSITS

\section{E.3.6.1 TERRESTRIAL ENVIRONMENTS}

\section{E.3.6.1.1 Alluvial Fan Deposits}

Tectonic events influence the distribution, geometry, and composition of alluvial fan deposits. Fan development is favored by large-scale displacements along normal faults, exposing high-relief source terrains. Rapid subsidence of down-dropped fault blocks favors thick accumulation of alluvial fan deposits. Seismic events and heavy precipitation may help to mobll1ze large-scale debris flows on the fan surface.

\section{E.3.6.1.2 Eolian Dune Deposits}

Fluctuations in water table level in conjunction with seismic events may result in 1iquefaction of eolian dune deposits. Small-scale gravity faults and slump/breccia zones are produced in large dunes by gravity funces delling on danp sands.

\section{E.3.6.1.3 Braided River Deposits}

External processes producing ephemeral or seasonal discharge are essential for braided stream deposition. Tectonic events may result in the development of added topographic relief in the source area, which in turn provides the overabundance of coarse bed-load material, resulting in a braided channel pattern.

\section{E.3.6.2 TRANSITIONAL ENVIRONMENTS}

\section{E.3.6.2.1 Deltaic Deposits}

DeIla systems are characterlzed by high rates of sedinent accumulation and thus may have high initial depositional porosities. Loading or seismic events may induce diapirism, liquefaction, slumping, and other types of synsedimentary deformation.

\section{E.3.6.2.2 Progradationa1 Shoreline Deposits}

Eustatic changes in sea-level or episodic subsidence produced by tectonic events greatly influence the distributions and thicknesses of sandstone in a prograding shoreline system. Tectonic uplifts provide a source of terrigenous clastic sediments from which progradational clastic sequences are constructed.

\section{E.3.6.3 OPEN-MARINE ENVIRONMENTS}

\section{E.3.6.3.1 Shallow-Marine Deposits}

Perhaps the only major external event to affect the deposition and/or characteristics of shallow-marine shelf sandstones is that of eustatic 
sea level changes. Such worldwide changes in relative sea level in shallow epicontinental (epeiric) seas could have intermittently flooded and then subaerially exposed vast regions of stable craton interiors.

\section{E.3.6.3.2 Submarine Fan/Turbidite Deposits}

The submarine fan/turbidite system is one of extremely rapid sedimentation in a very active tectonic setting. Unstable accumulations of sediment are periodically released by seismic events and move downslope into deeper water as slumps, subaqueous debris flows and grain flows, and turbidity currents. 


\section{E.3.7 RESOURCES CONTAINED IN OR ASSOCIATED WITH SANDSTONE}

\section{E.3.7.1 TERRESTRIAL ENVIRONMENTS}

\section{E.3.7.1.1 Alluvial Fan Deposits}

Tertiary, Pleistocene, Holocene, and Recent alluvial fan deposits, if not lithified, are excellent groundwater aquifers. Gold, uranium, and other economically important minerals occur in alluvial fan deposits within sandstone, conglomerate, and breccia. Hydrocarbon occurrences are rare.

\section{E.3.7.1.2 Eolian Dune Deposits}

Eolian dune sandstones are known as important hosts (reservoirs) for oil and natural gas, especially in the Rocky Mountain region of the United States. Laterally equivalent fluvial and alluvial fan deposits may contain uranium and possibly some economically important metals.

\section{E.3.7.1.3 Braided River Deposits}

Braided stream sandstones are rarely hosts for oil and natural gas (a. notable exception is the occurrence of petroleum in Prudhoe Bay, Alaska). More important are the abundances of uranium and some economically important metal deposits hosted in braided stream deposits of the western United States.

\section{E.3.7.2 TRANSITIONAL ENVIRONMENTS}

\section{E.3.7.2.1 Deltaic Deposits}

Deltaic sandstones are known as hosts for oil and natural gas. The common occurrence of fine-grained, organically rich source beds stratigraphically beneath deltaic sandstones makes deltas favorable sites for hydrocarbon generation and accumulation. Notable reservoirs are the Tertiary of the Gulf Coast and the Pennsylvanian of the Appalachian Basin, Illinois Basin, and mid-continent region.

Resources associated with deltaic sandstones include extensive coal and peat beds deposited in upper delta plain marsh and swamp environments.

\section{E.3.7.2.2 Progradational Shoreline Deposits}

Progradational shoreline sandstones and barrier-island sandstones are known as important hosts for oil and natural gas. The common occurrence of fine-grained, organically rich source beds stratigraphically beneath shoreline and barrier-island sandstones makes these systems especially favorable sites for hydrocarbon accumulation. They are especially important in the Tertiary of the Gulf Coast and the Pennsylvanian of the Appalachian Basin, Illinois Basin, and mid-continent region. 
E.3.7.3 OPEN-MARINE ENVIRONMENTS

\section{E.3.7.3.1 Shallow-Marine Deposits}

Type II shelf sandstone sequences, in contrast to Type I deposits, are not known as important hosts for oil or natural gas. Similarly, they are not known for other economically important minerals.

\section{E.3.7.3.2 Submarine Fan/Turbidite Deposits}

Deep-water sandstones are known as important hosts for oil and natural gas. They are particularly important along the western margin of the United States. 


\section{E.3.8 SUMMARY AND RECOMMENDATIONS}

\section{E.3.8.1 GENERAL DISCUSSION}

As has been shown, the properties of sandstone deposits are clearly dependent upon depositional environments. Some properties are favorable in the sense of choosing a desirable repository site, whereas others are unfavorable. These salient properties are discussed in the sections which follow. General characteristics for sandstone deposits of all depositional environments considered are listed in Table E.3.8.1.

\section{E.3.8.2 TERRESTRIAL ENVIRONMENTS}

\section{E.3.8.2.1 Alluvial Fan Deposits}

Favorable charactexistics of alluvial fan deposils include the great thickness of the entire stratigraphic package and of individual bedding units. Unfavorable characteristics include limited lateral extent, heterogeneity of mineralogical and textural properties, lenticularity of beds, interbeding with porous and permeable congloneratic facies, limited geographic distribution (confined to extensional tectonic terrains), and resource potential.

\section{E.3.8.2.2 Eolian Dune Deposits}

Favorable characteristics of eolian dune deposits include the great thickness and lateral extent of the entire stratigraphic package, thick bedding units, high homogeneity of mineralogical and textural properties, and great continuity of beds. Unfavorable characteristics include typically high porosity and permeability and associated resource potential for hydrocarbons.

\section{E.3.8.2.3 Braided River Deposits}

Few favorable characteristics seem apparent for braided river deposits. Unfavorable characteristics include thinness and lack of lateral extent for the entire stratigraphic package, thinnesa of individual bedding units or fining-upward cycles, lenticularity of beds, common interbedding with porous and permeable conglomerate, relatively high porosity and permeability, and resource potential.

\section{E.3.8.3 TRANSTTIONAL ENVTRONMENTS}

\section{E.3.8.3.1 Deltaic Deposits}

Favorable characteristics of deltaic deposits include the great thickness of the entire stratigraphic package and of many bedding units, interbedding with impervious shale, great lateral extent (marine deltas), and widespread geographic distribution of the deposit. Heterogeneity of mineralogical and textural properties, lenticularity of bedding units, rclatively high porosity and permeability, high rcoource potcntial for hydrocarbons, and interbedded coal deposits are unfavorable characteristics. 


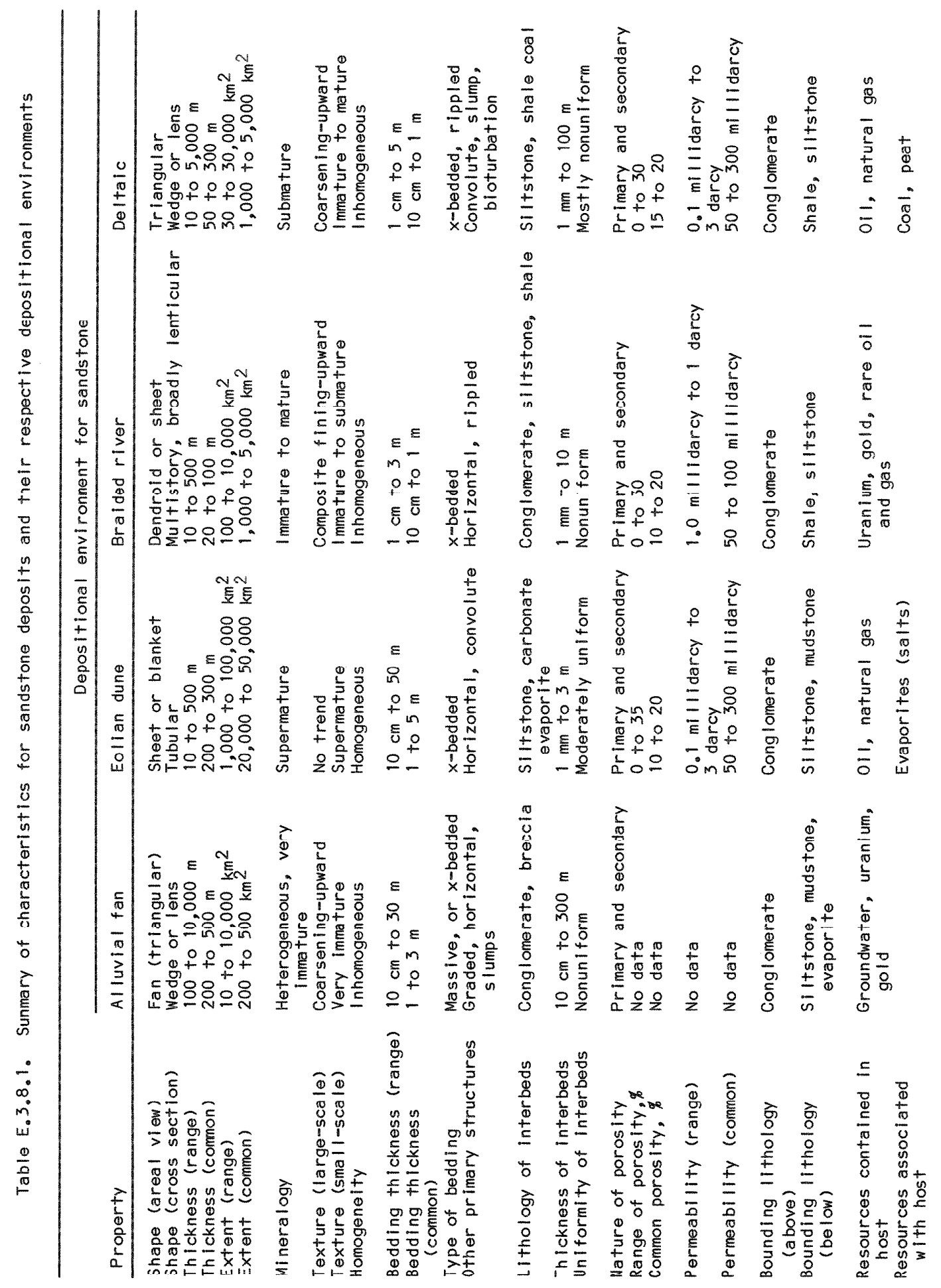




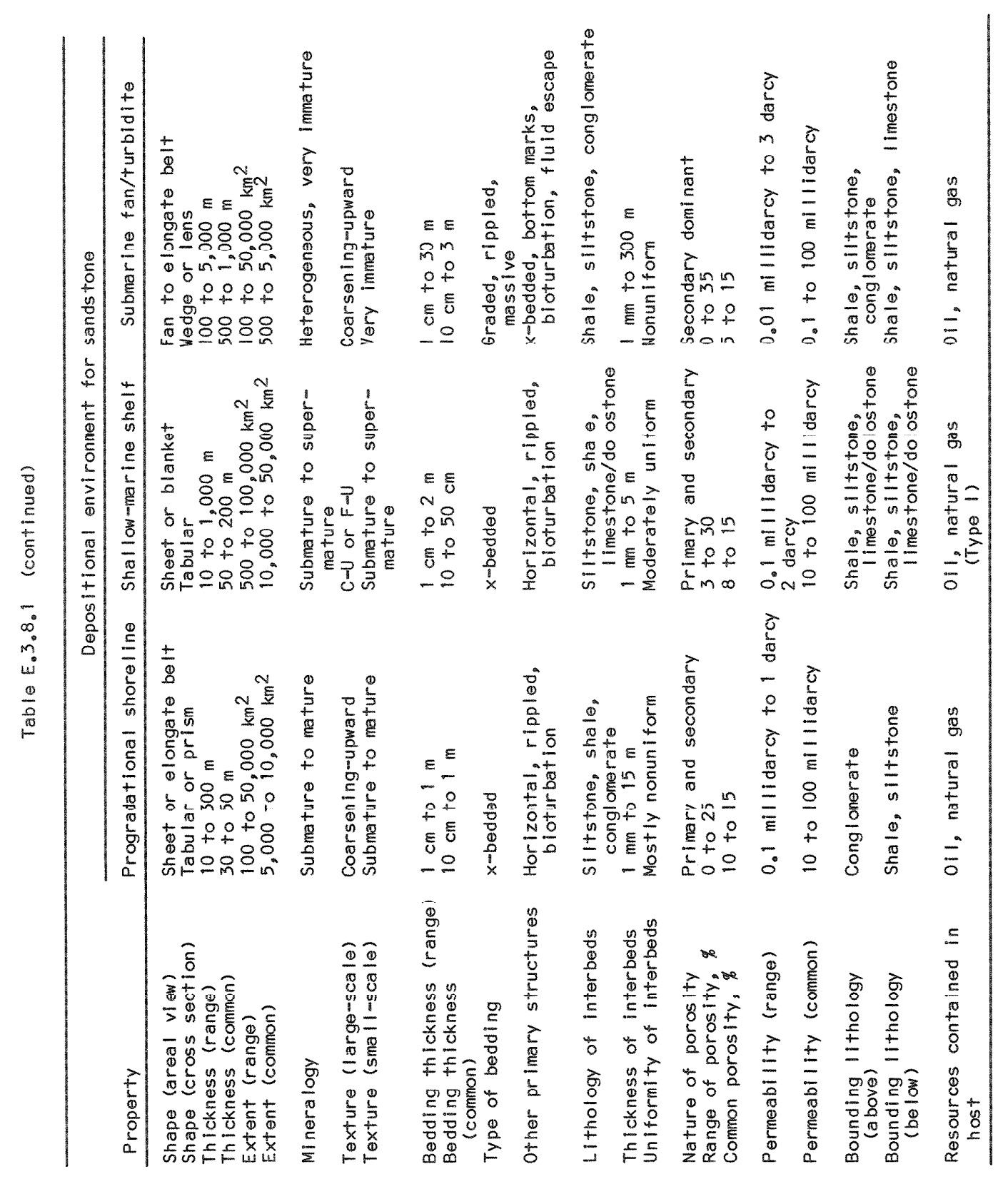




\section{E.3.8.3.2 Progradational Shoreline Deposits}

Few favorable characteristic of progradational shoreline deposits seem apparent. Unfavorable characteristics include thinness of the entire stratigraphic package and of individual bedding units, possible interbedding with porous and permeable conglomerate, high porosity and permeability, and resource potential for oil and natural gas.

\section{E.3.8.4 OPEN-MARINE ENVIRONMENTS}

\section{E.3.8.4.1 Shallow-Marine Shelf Deposits}

Favorable characteristics of shallow-marine shelf deposits include moderate thickness of the entire stratigraphic package coupled with great lateral extent, wide geographic distribution across the United States, moderate mineralogic and textural homogeneity, continuity of beds, and common interbedding with impervious shale. Unfavorable characteristics include relatively high porosity and permeability and associated resource potential for hydrocarbons.

\section{E.3.8.4.2 Submarine Fan/Turbidite Deposits}

Favorable characteristics of deep-water sandstone deposits include the great thickness and lateral extent of the entire stratigraphic package, thickness of individual bedding units, interbedding with abundant quantities of impervious shale, and relatively lower overall porosity and permeability. Unfavorable characteristics include high mineralogical and textural inhomogeneity, lenticularity of bedding (except for thin-bedded turbidite packages), limited geographic distribution (1imited to orogenically active and tectonized terrains), and resource potential for ofl and natural gas.

\section{E.3.8.5 PRELIMINARY RANKING OF SPECIFIC DEPOSITIONAL ENVIRONMENTS}

based on the previous discussions, we arrive at the tollowing ranking (in descending order) of the seven depositional environments known to contain substantial quantities of sandstone:

(1) An Eolian dune sandstone sequence containing a pervasive interparticle cementing agent that would serve to reduce porosity and permeability to a minimum.

(2) A thick shallow-marine shelf sandstone sequence, again containing a pervasive interparticle cementing agent that would serve to reduce porosity and permeability to a minimum.

(3) The middle and outer turbidite-dominated facies of a prograding submarine fan sequence. This is typically a flysch, that is, a unfformly repetitive sequence of interbedded sandstone, siltstone, and shale.

(4) The prodelta and outer delta-front facies of a prograding deltaic sequence. These facies consist of interbedded sandstone, siltstone, and shale. 
(5) Poorer choices for potential repository sites would probably be in alluvial fan, braided river, and progradational shoreline deposits.

The poorest choices for potential repository sites would be in the deposits eliminated from consideration at the outset: meandering river, glacial, lacustrine, tidal flat, and barrier island deposits. 
E.3.9 SUPPLEMENTAL DATA

Following is a series of tables that contain detailed data and references upon which the previous discussion on sandstone deposits is based. 


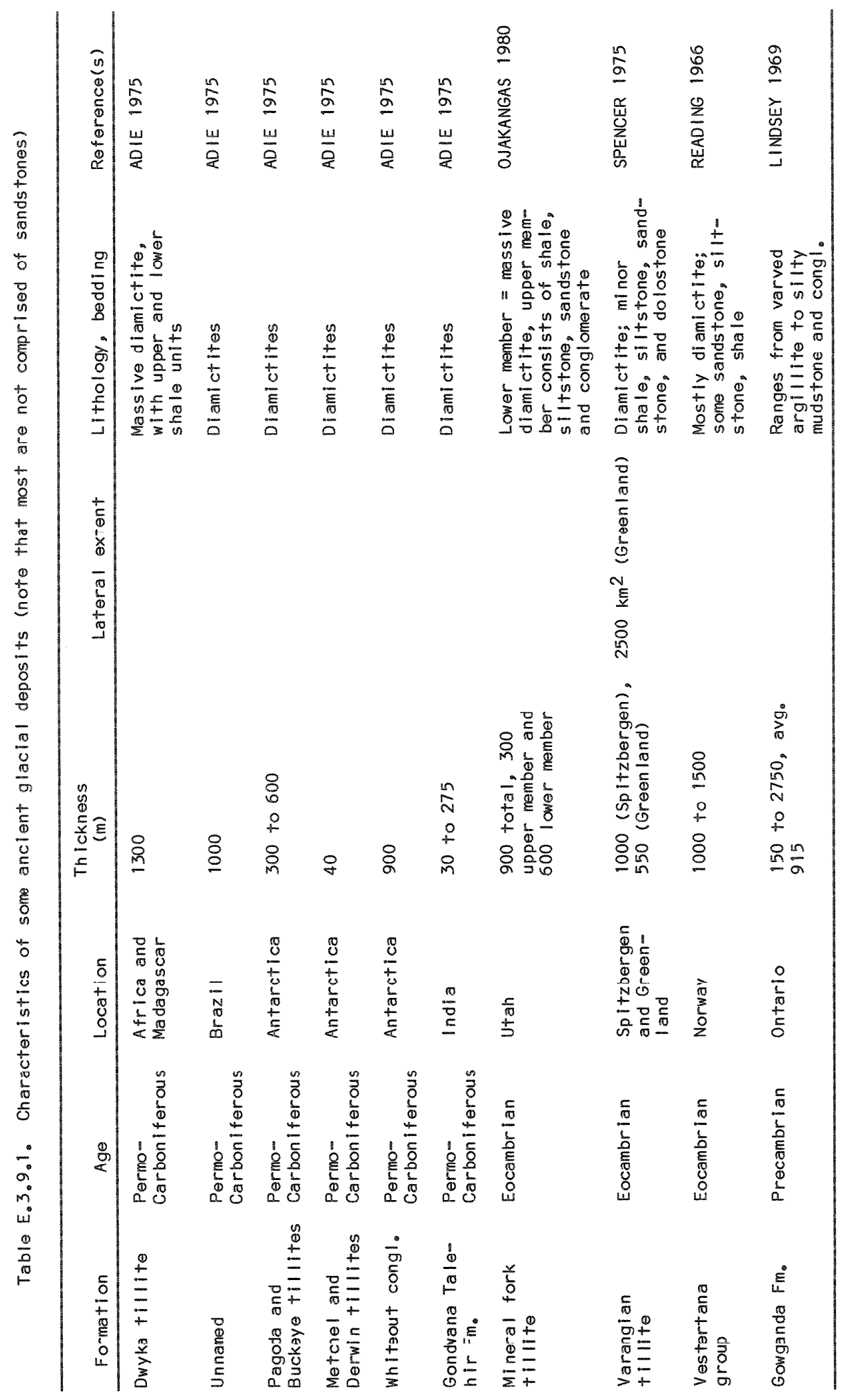




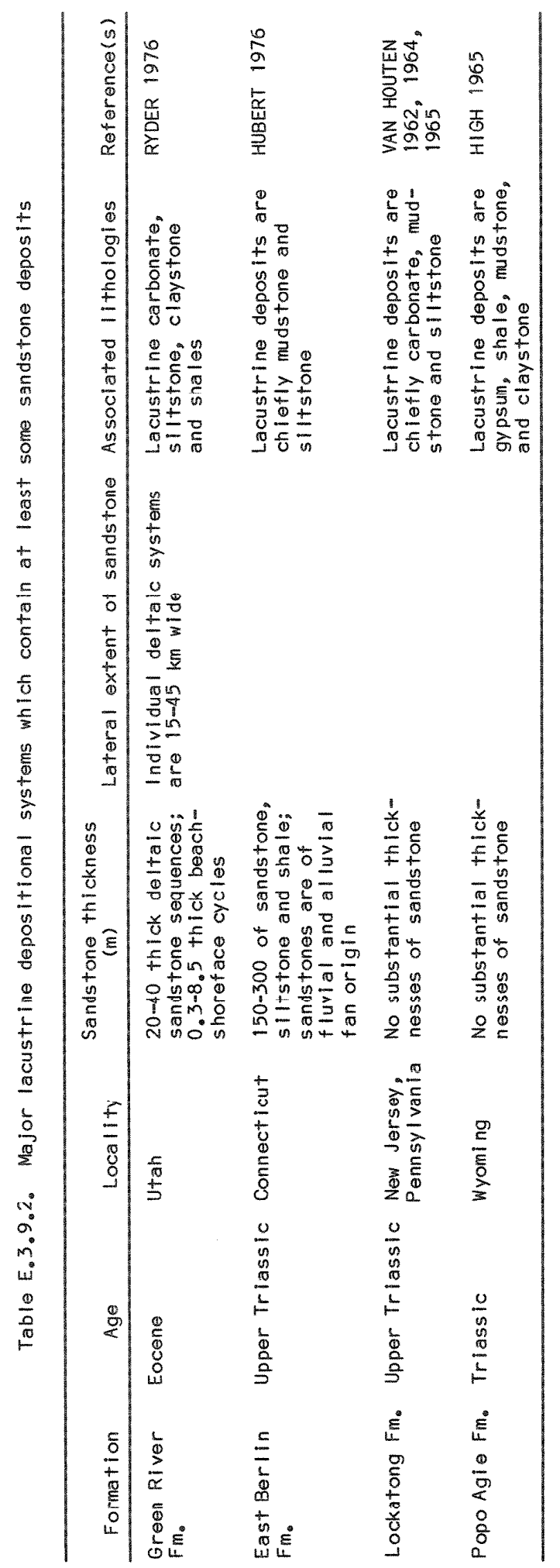




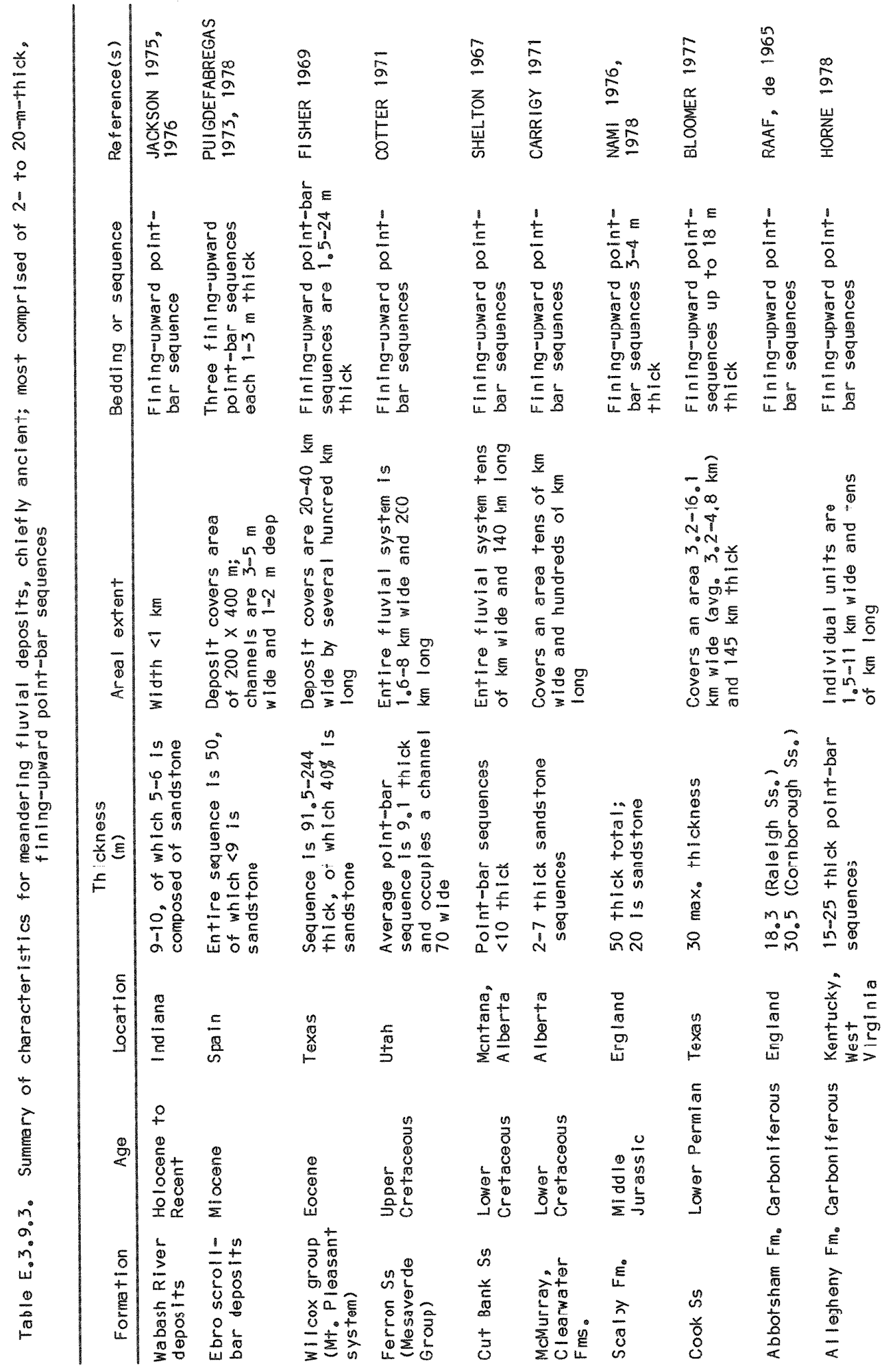




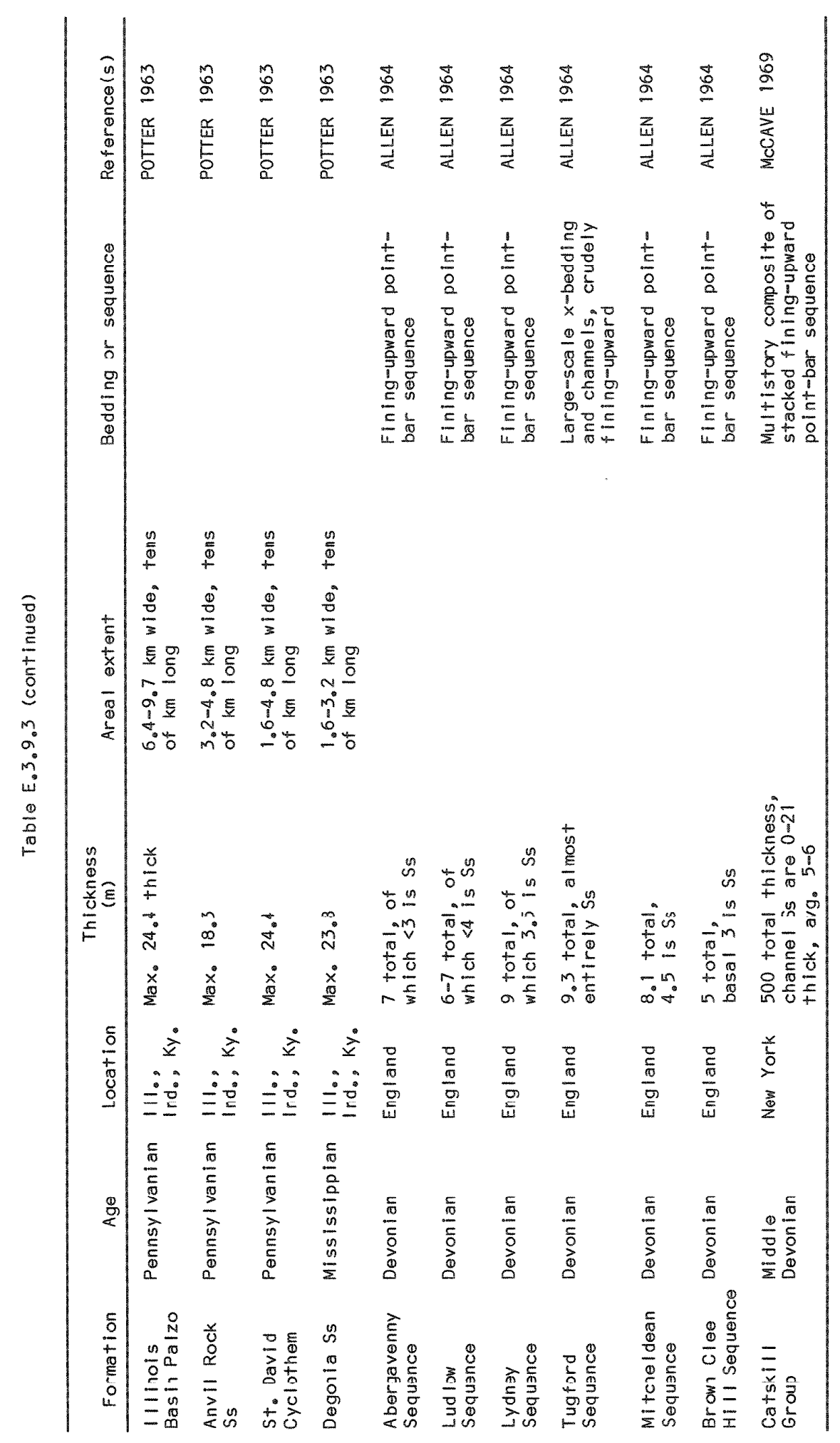


Table E.3.9.4. Dimensions of some fluvial paleochannels (after SCHUMM 1972)

\begin{tabular}{|c|c|c|c|}
\hline Channe1 & Width & $\begin{array}{l}\text { Depth } \\
\text { (m) }\end{array}$ & Reference(s) \\
\hline J Channe1 & $457 \mathrm{~m}$ & 15.2 & HARMS 1966 \\
\hline Rocktown Channel & $0.81 \mathrm{~km}$ & $\begin{array}{l}7.6 \text { (range } \\
4.6-30.5 \text { ) }\end{array}$ & RUBEY 1925 \\
\hline $\begin{array}{l}\text { Indiana Channels } \\
\text { New Goshen } \\
\text { Terre Haute } \\
\text { Winslow }\end{array}$ & $\begin{array}{l}0.81 \mathrm{~km} \\
0.40 \mathrm{~km} \\
792.5 \mathrm{~m}\end{array}$ & $\begin{array}{l}12.2 \\
12.2 \\
15.2\end{array}$ & FRIEDMAN 1960 \\
\hline Englevale Channel & $0.81 \mathrm{~km}$ & $18 \cdot 3$ & HOWARD 1965 \\
\hline $\begin{array}{l}\text { Pre-Pennsylvanian } \\
\text { Channe1 }\end{array}$ & $6.04 \mathrm{~km}$ & 61 & SIEVER 1951 \\
\hline Bush City Channel & $\begin{array}{l}0.6 \mathrm{~km} \text { wide } \times \\
21 \mathrm{~km} \text { long }\end{array}$ & 16.8 & CHARLES 1941 \\
\hline Tonganoxie Channel & $22.5 \mathrm{~km}$ & 305 & LINS 1950 \\
\hline $\begin{array}{l}\text { Chinle Fm. } \\
\text { (Shinarump Mbr.) }\end{array}$ & $\begin{array}{l}3-305 \mathrm{~m} \\
\text { avg } \\
9.1-15.2 \mathrm{~m}\end{array}$ & $4 \cdot 6-38$ & STOKES 1961 \\
\hline $\begin{array}{l}\text { Morrison Fm. } \\
\text { (Salt Wash Mbr.) }\end{array}$ & $\begin{array}{l}2-610 \mathrm{~m} \\
\text { avg. } 61 \mathrm{~m}\end{array}$ & $\begin{array}{l}0.6-30.5 \\
\text { avg. } 4.6\end{array}$ & STOKES 1961 \\
\hline
\end{tabular}

Table E.3.9.5. Thickness of point-bar sequences for some modern meandering rivers

Thickness of point-bar

$$
\text { sequence }
$$

\begin{tabular}{lcc} 
River & (m) & Reference(s) \\
\hline Mississippi & $20-25$ & FISK 1944, 1947 \\
Niger & $10-15$ & ALLEN 1965 \\
Brazos & $15-20$ & BERNARD 1963 \\
$\begin{array}{l}\text { "Sma11" meandexing } \\
\text { rivers }\end{array}$ & $1-3$ & DAVIS 1983; WALKER 1979 \\
\hline
\end{tabular}




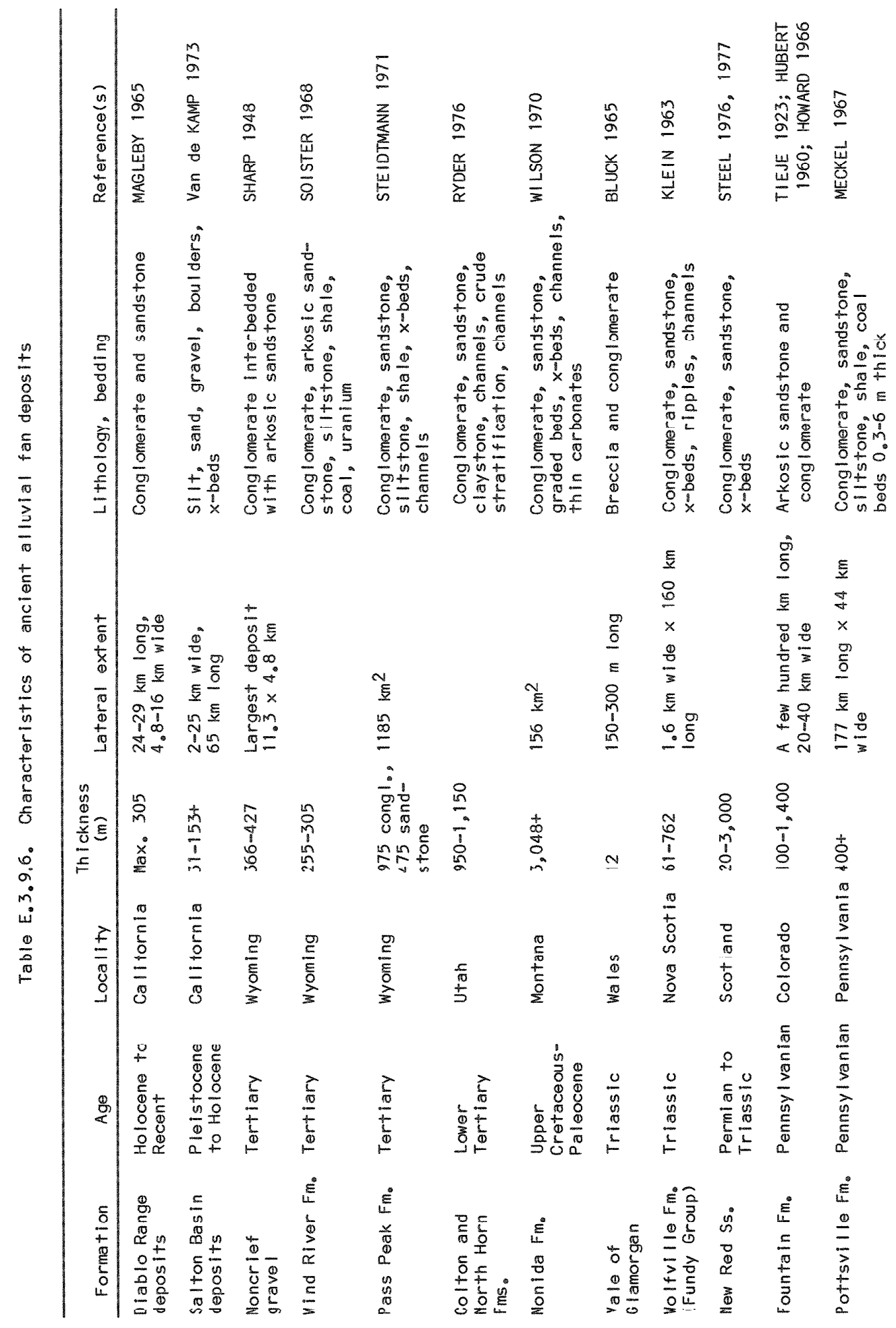




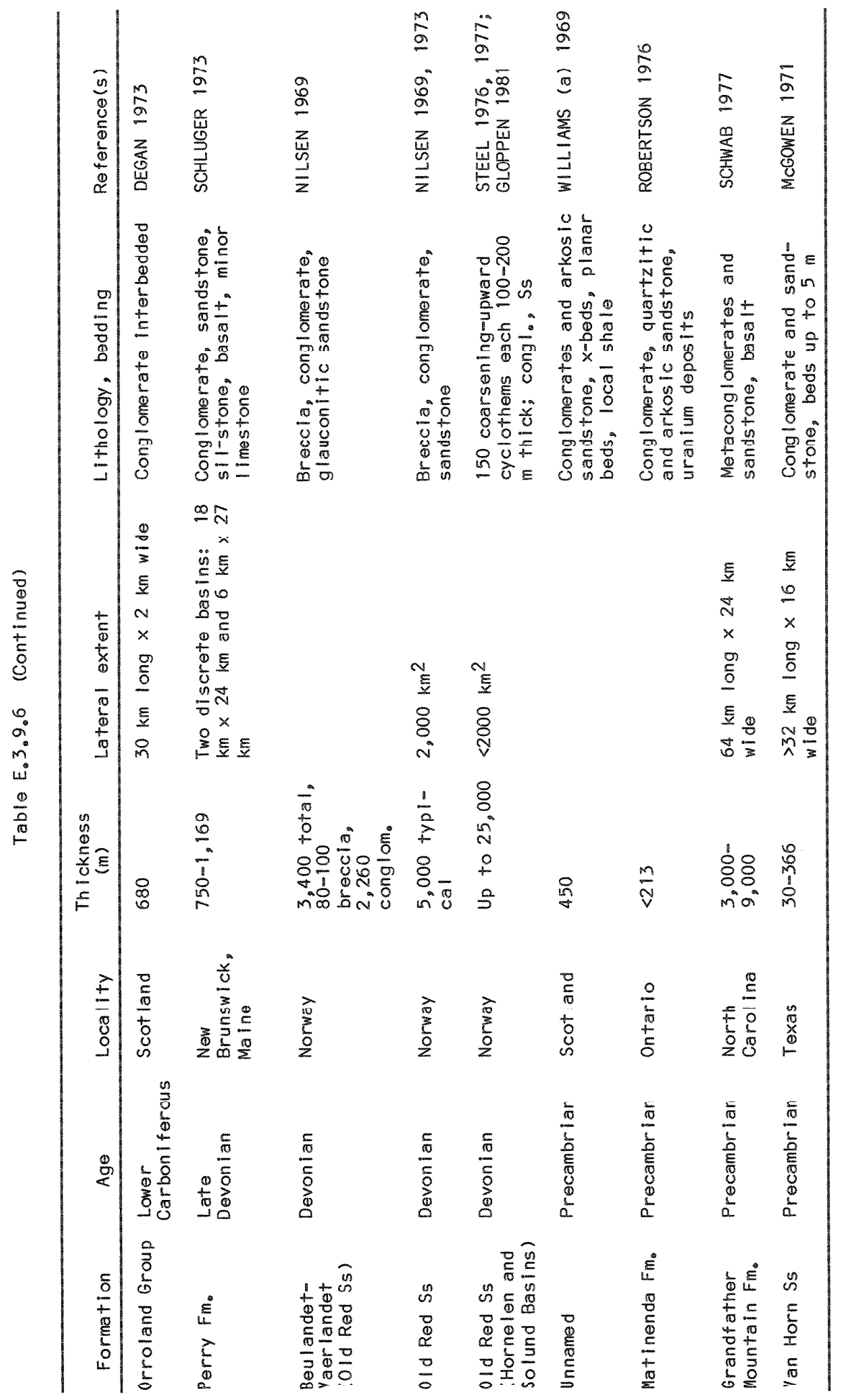




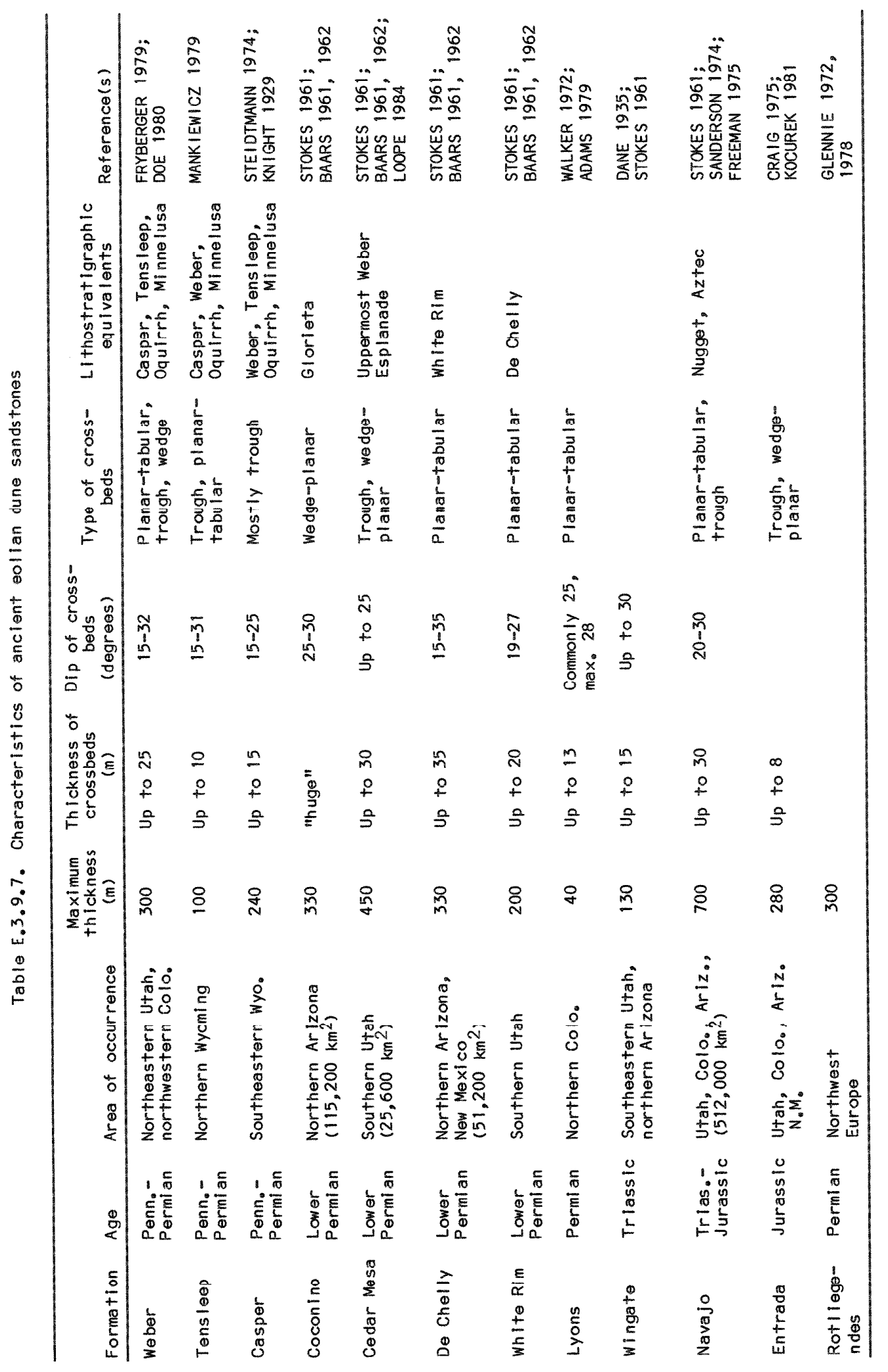




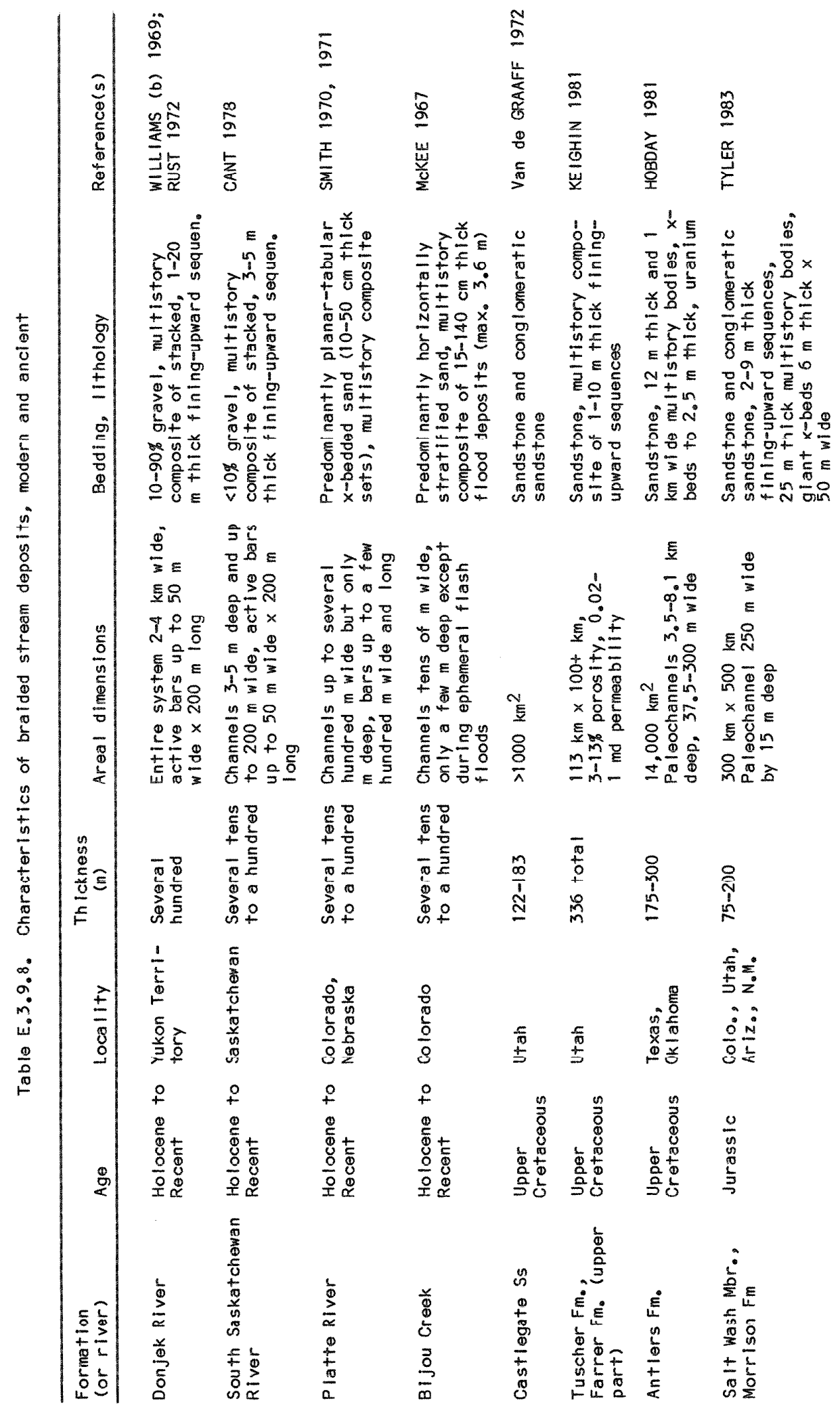




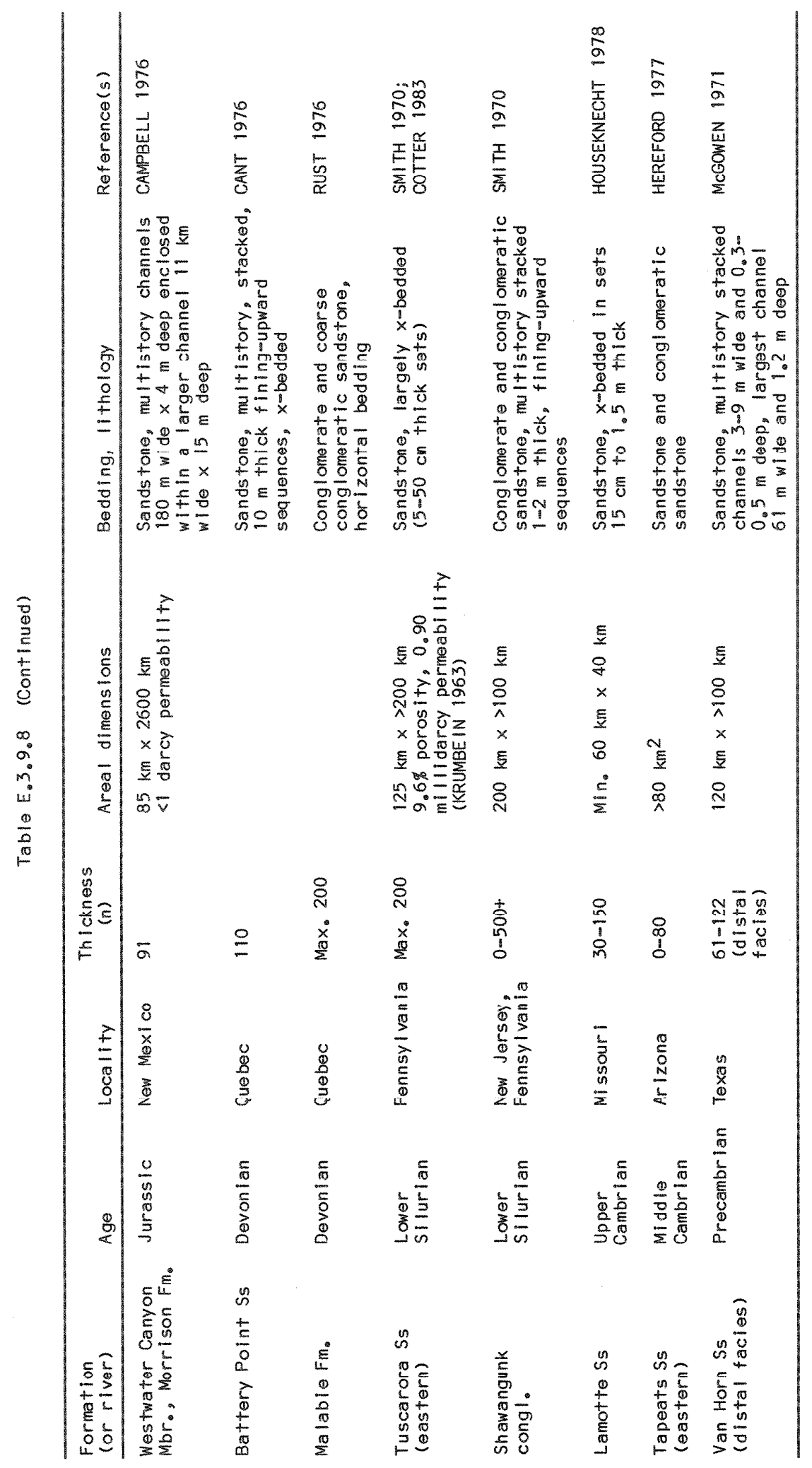




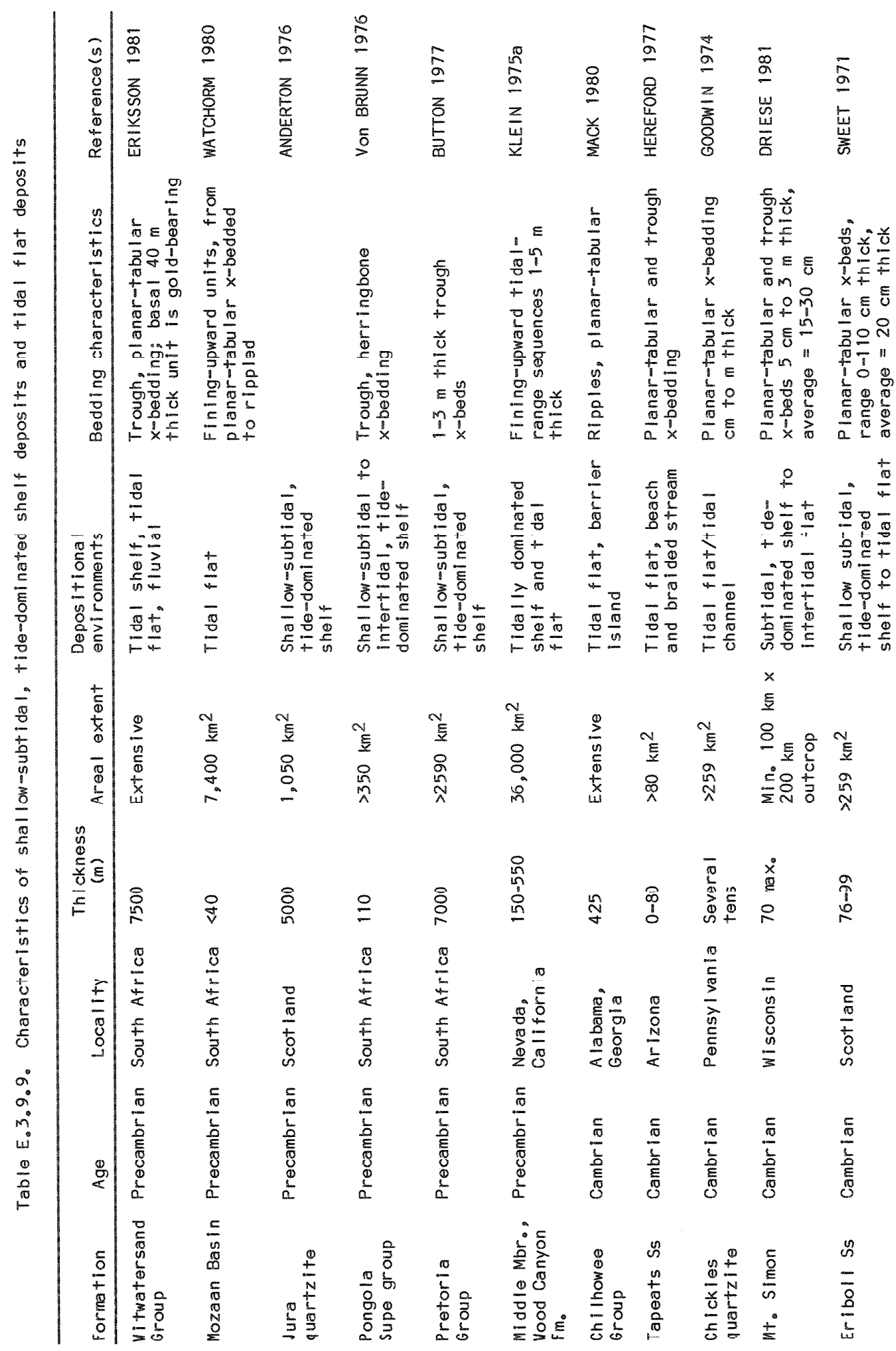




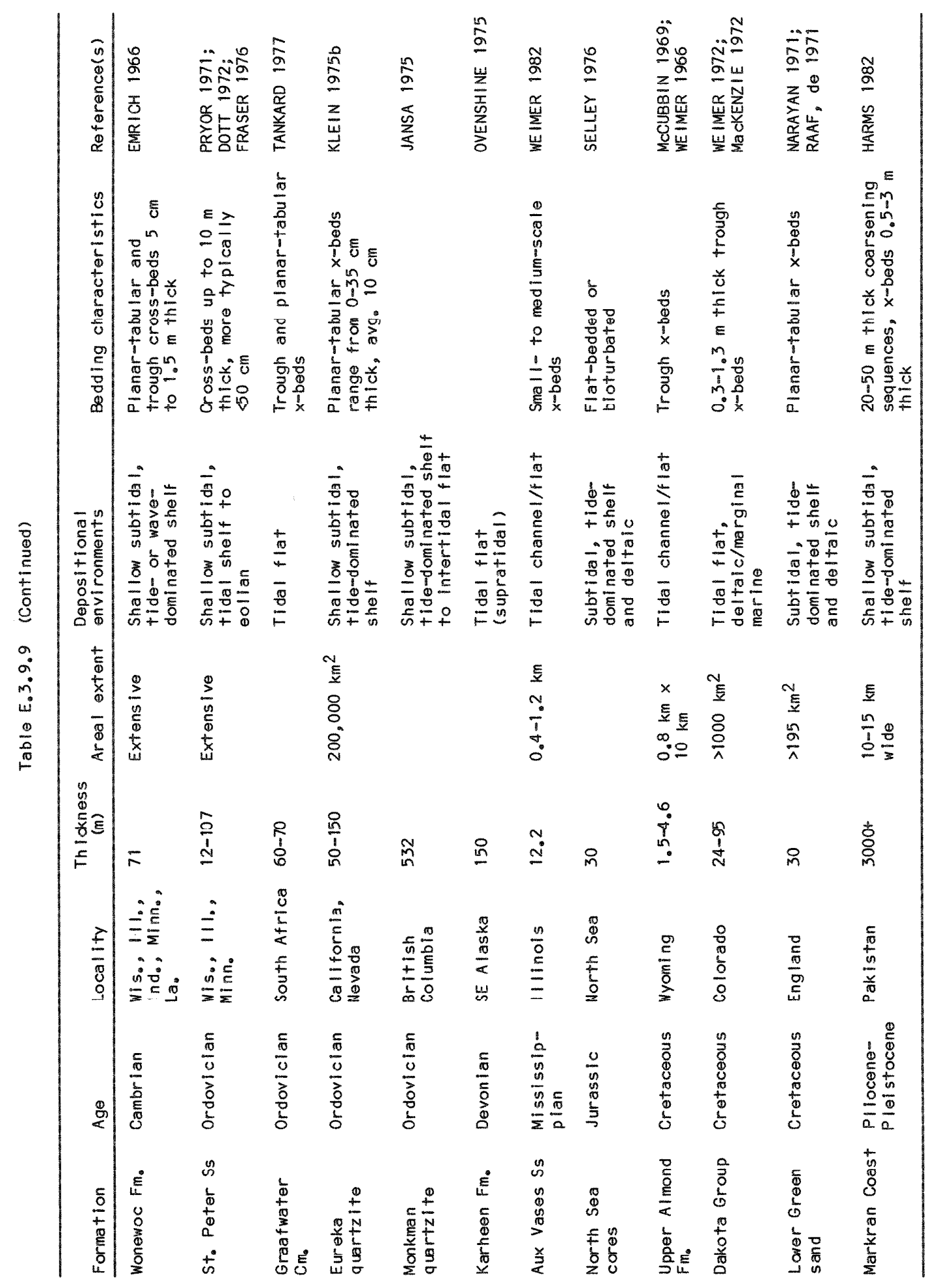




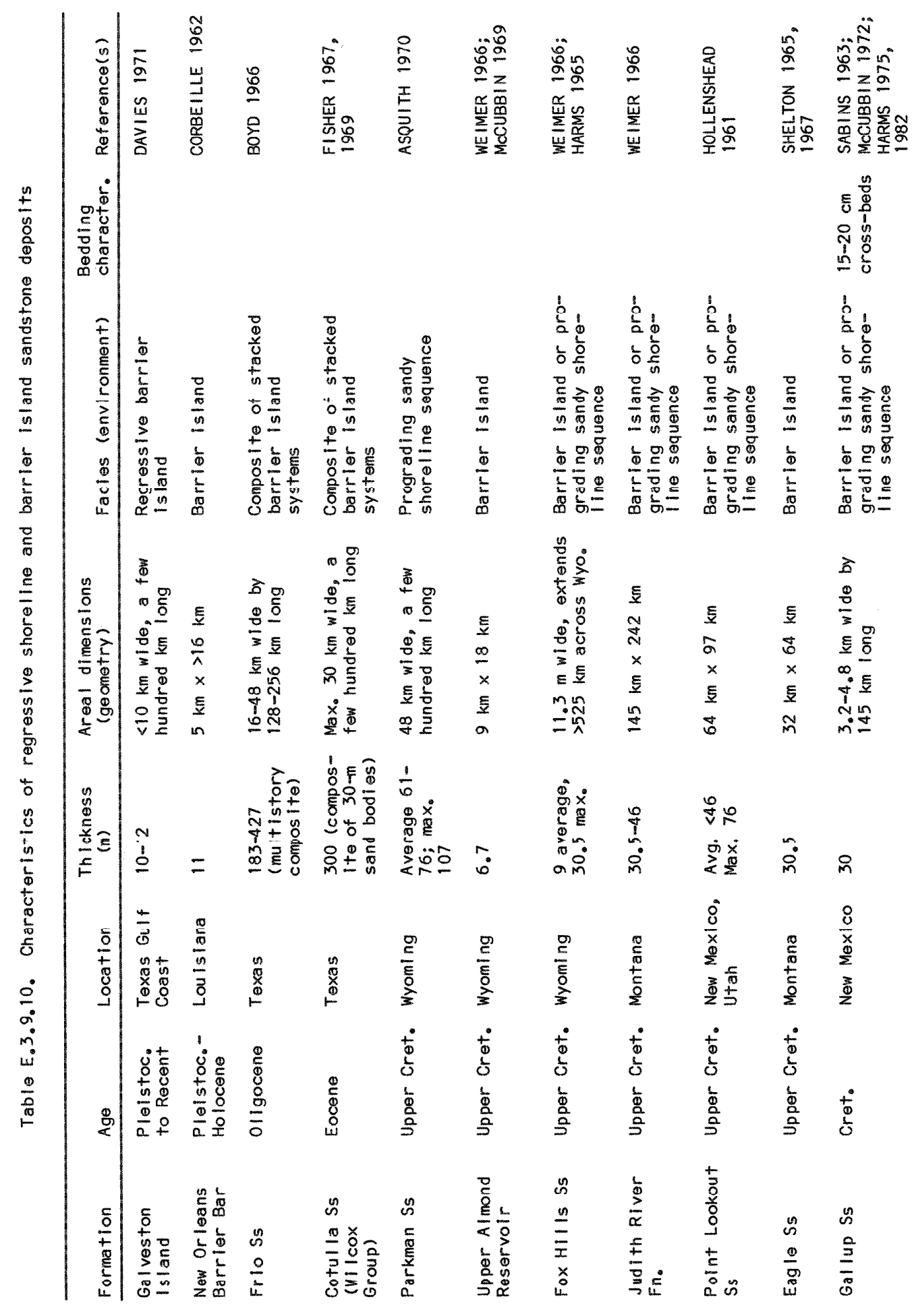




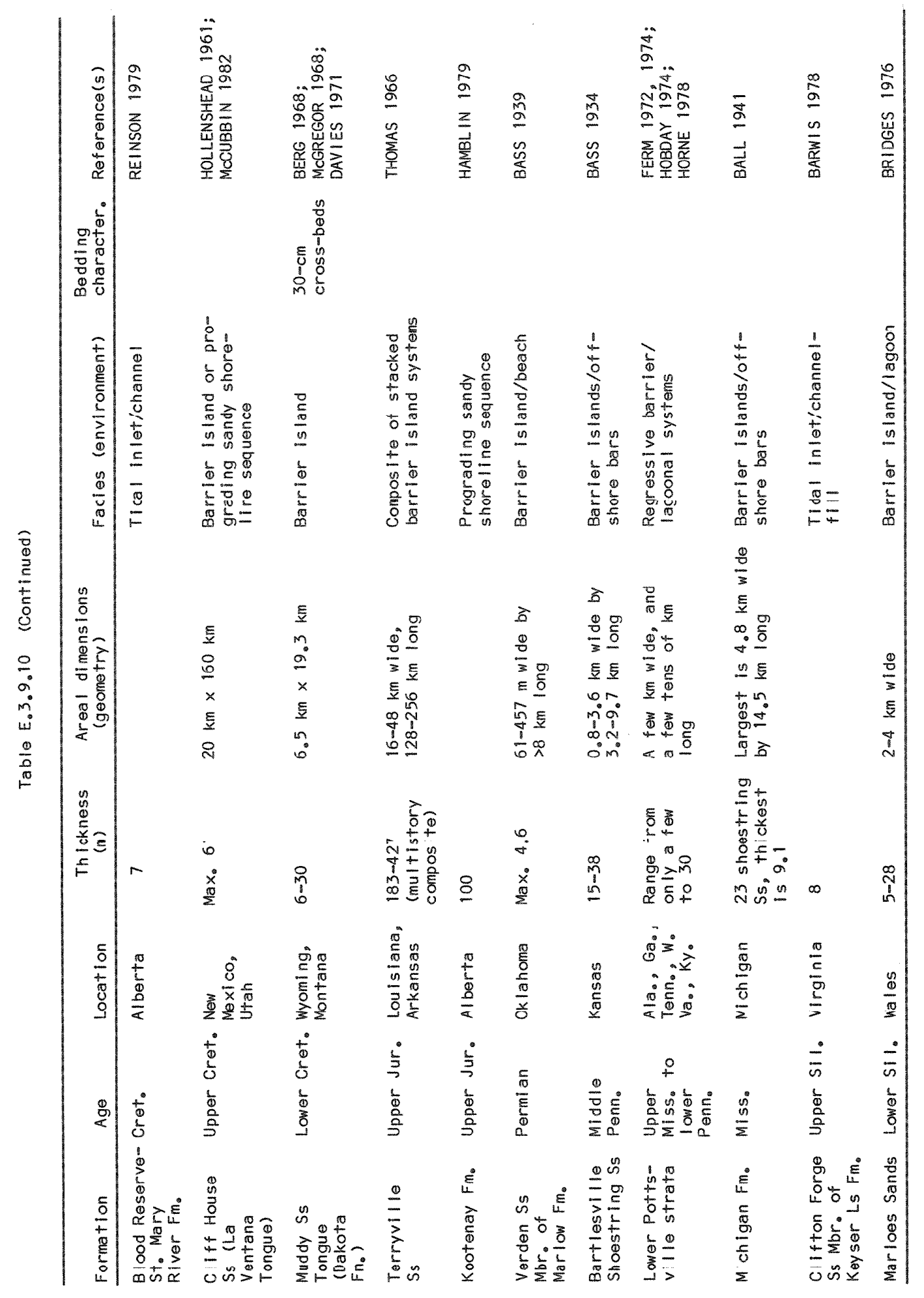




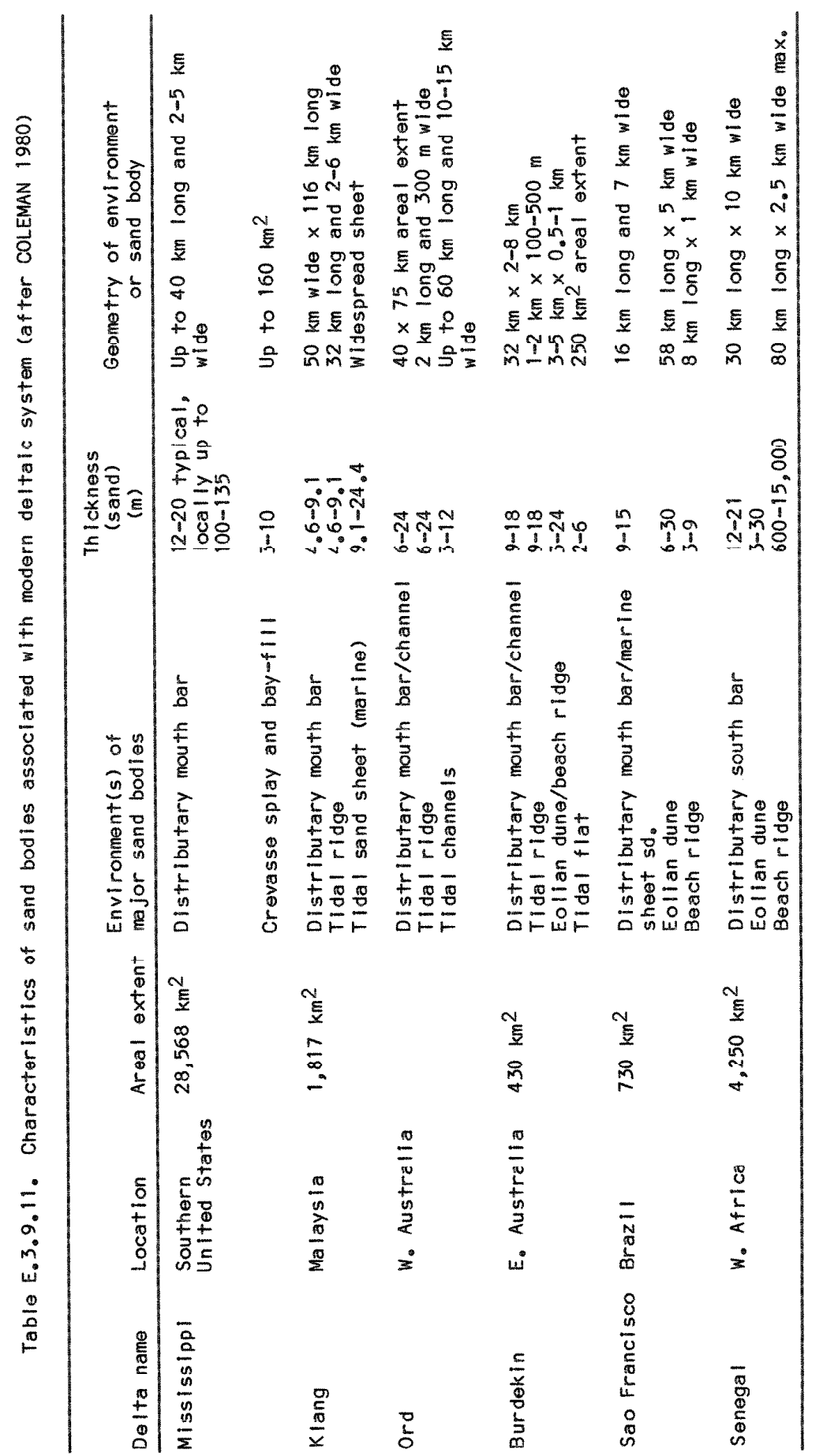




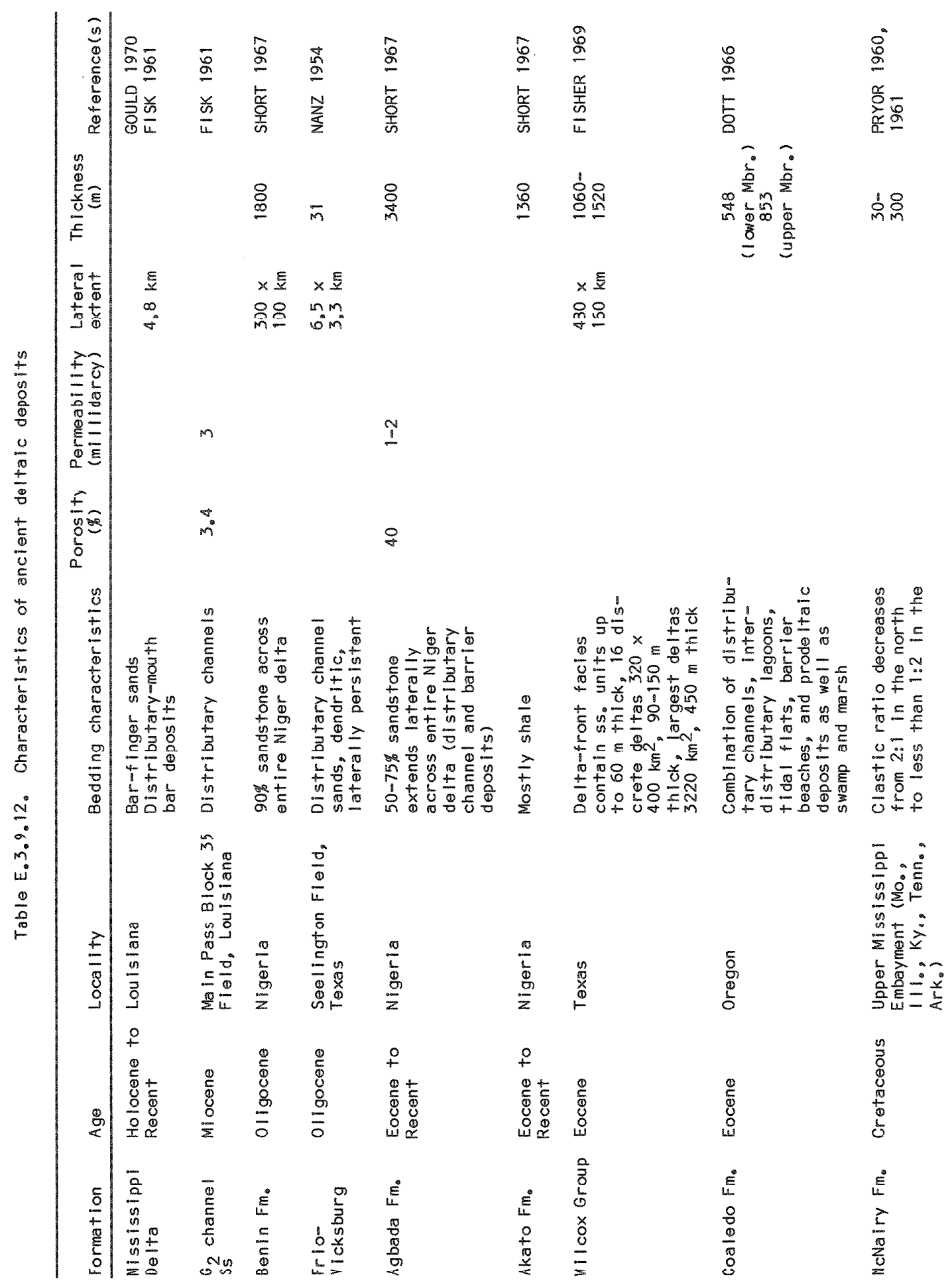




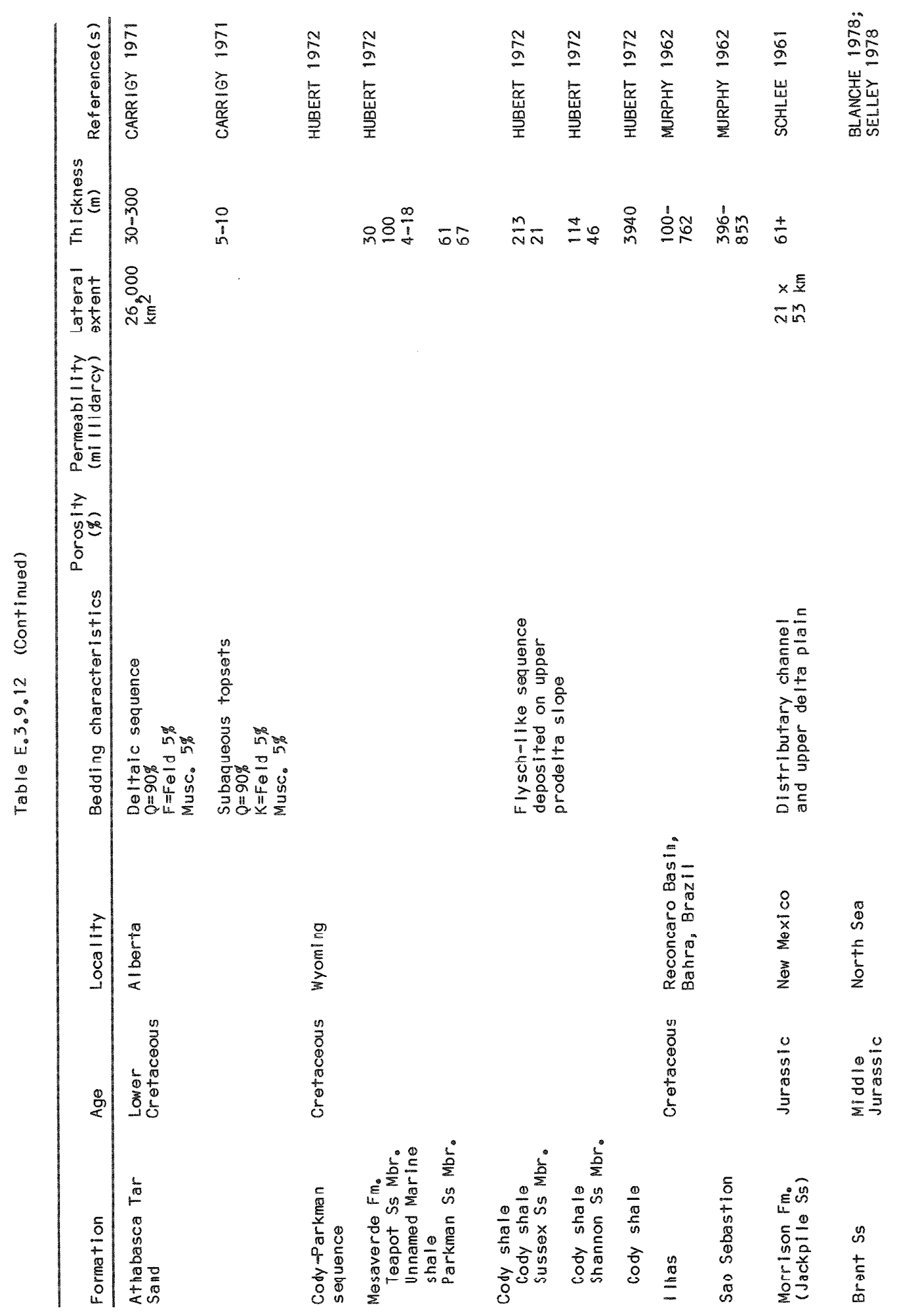




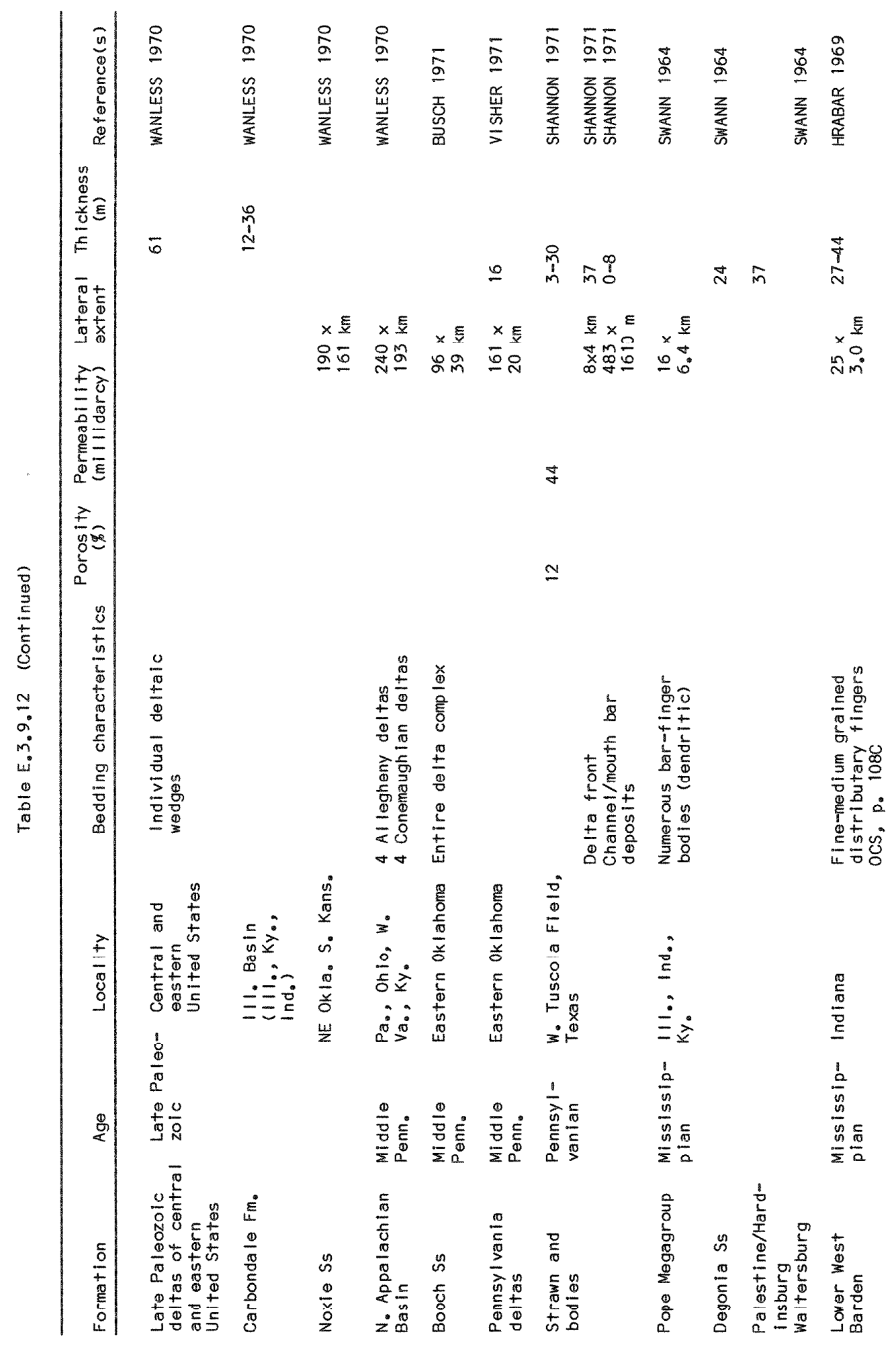




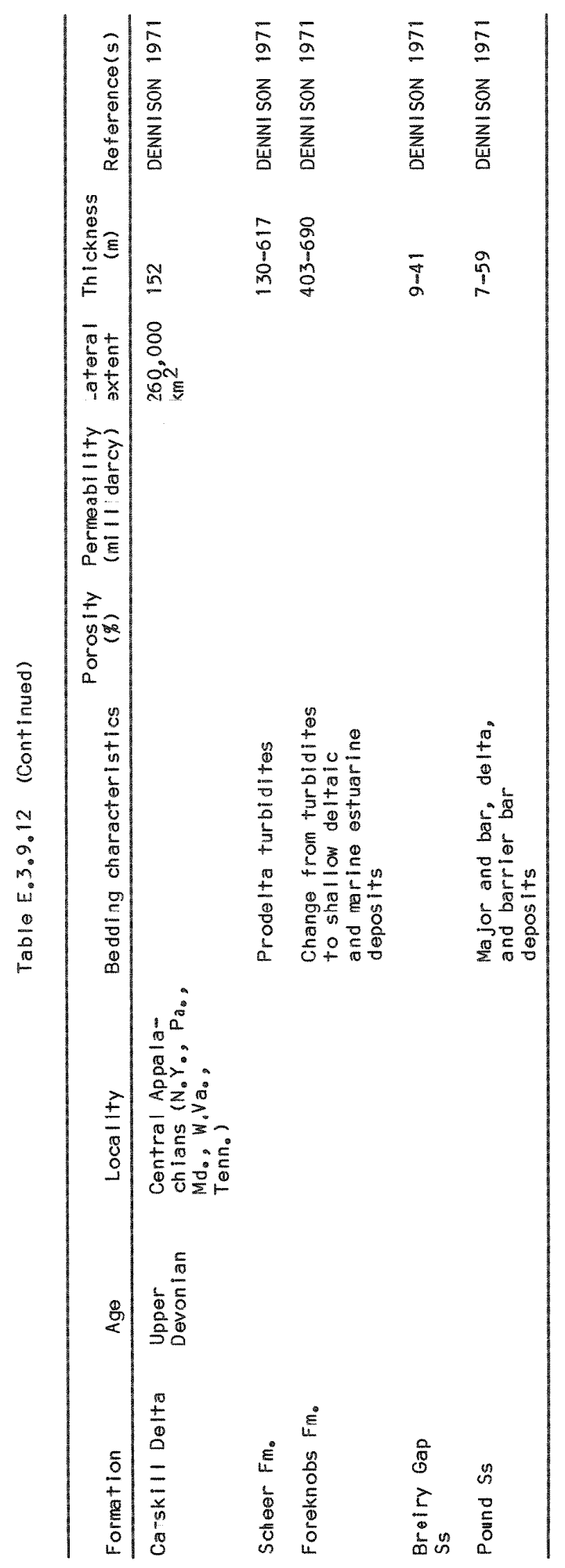




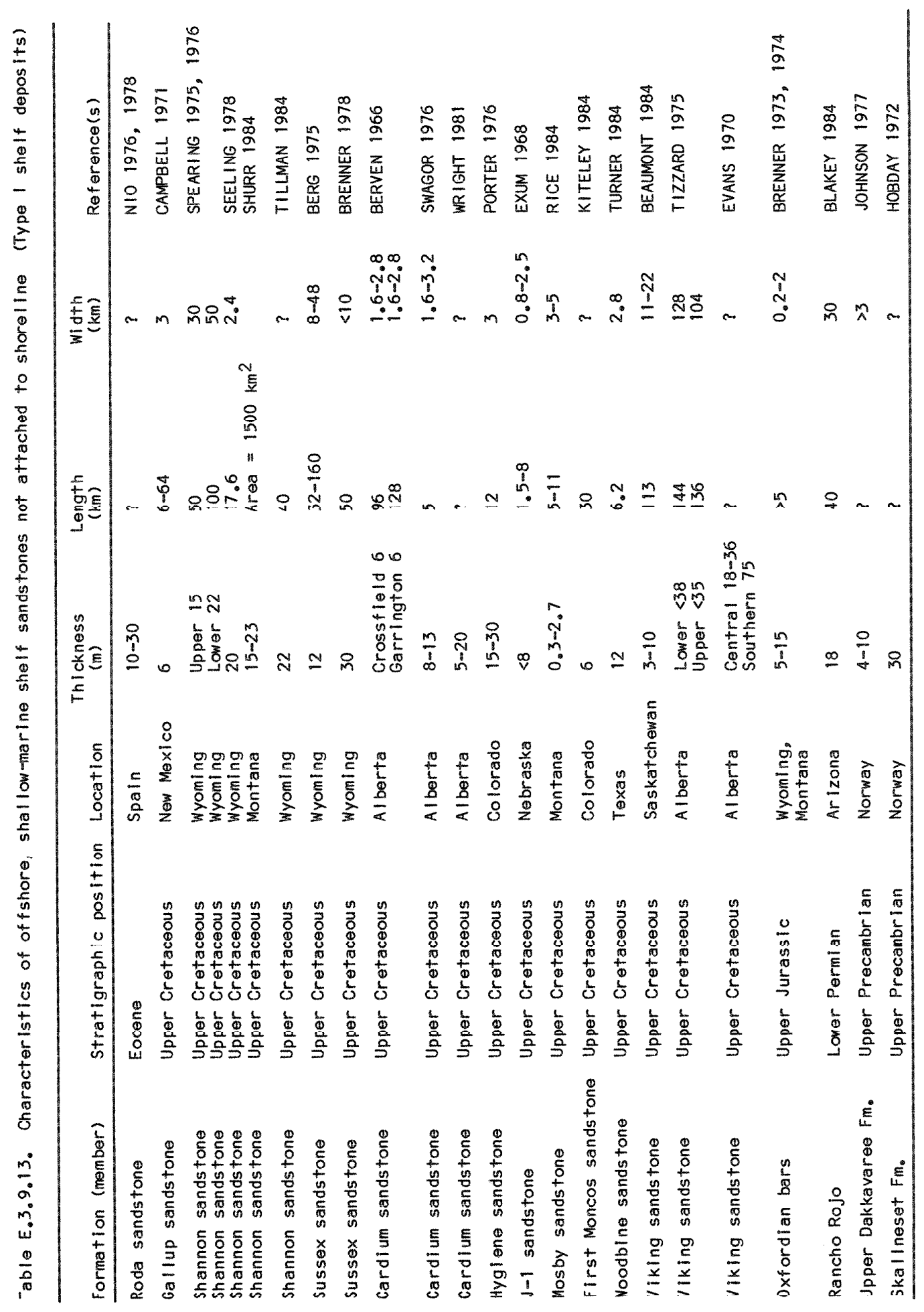




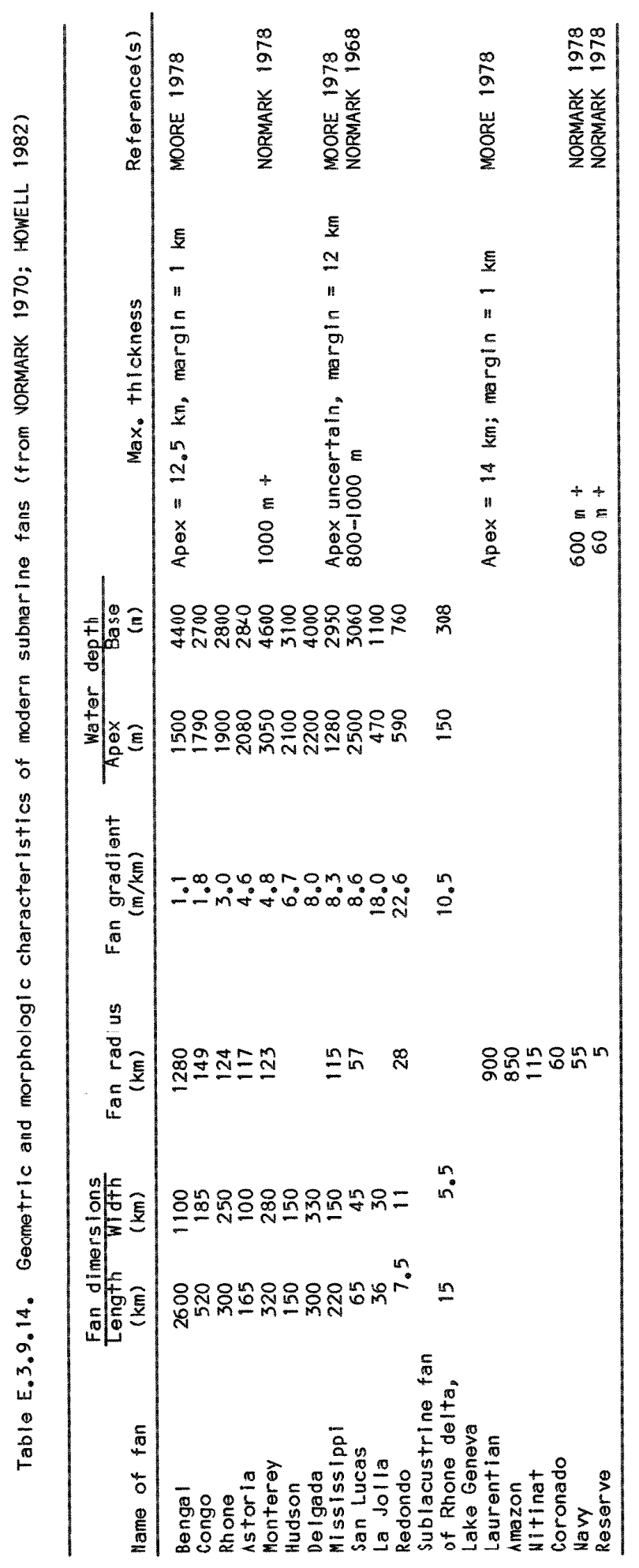




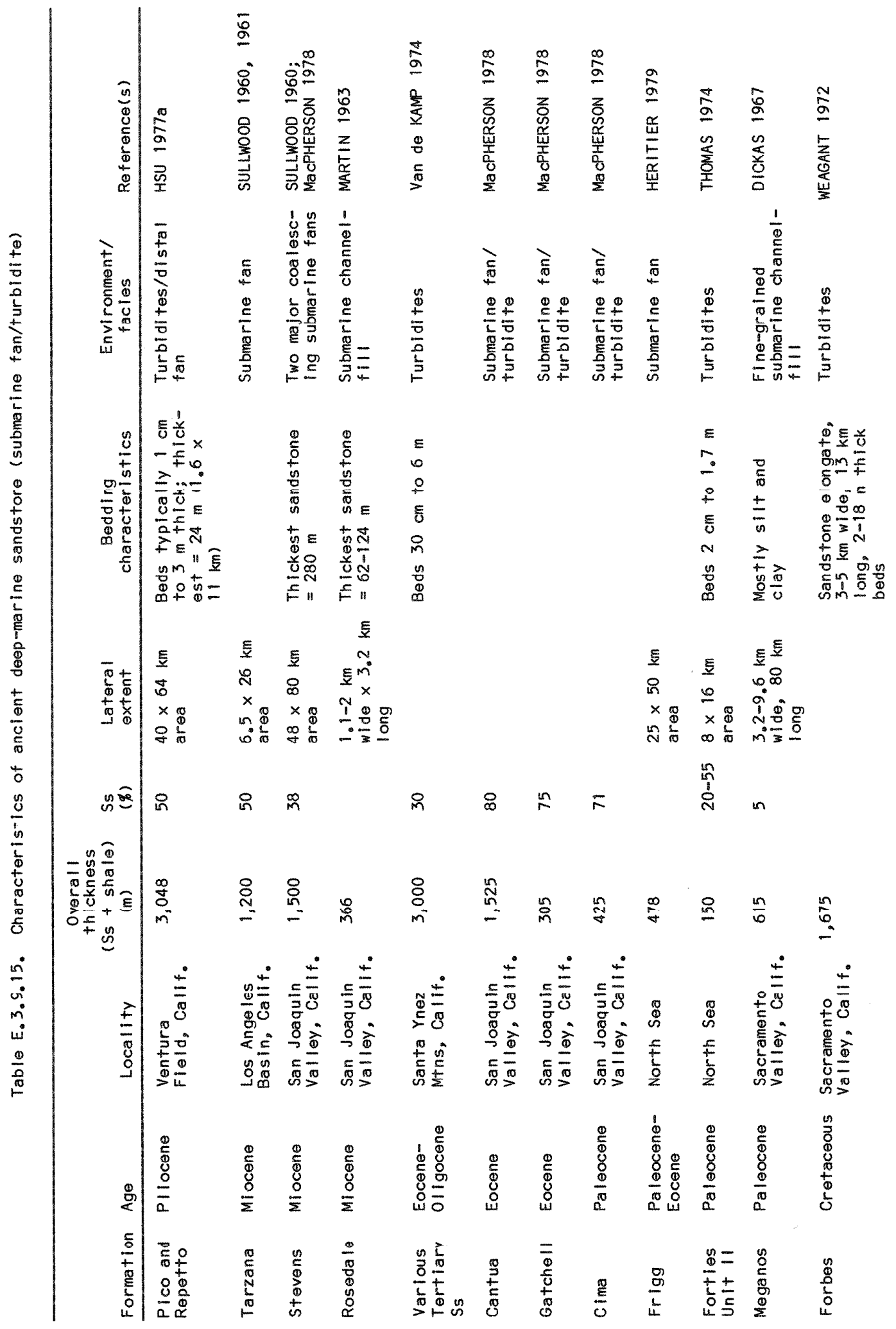




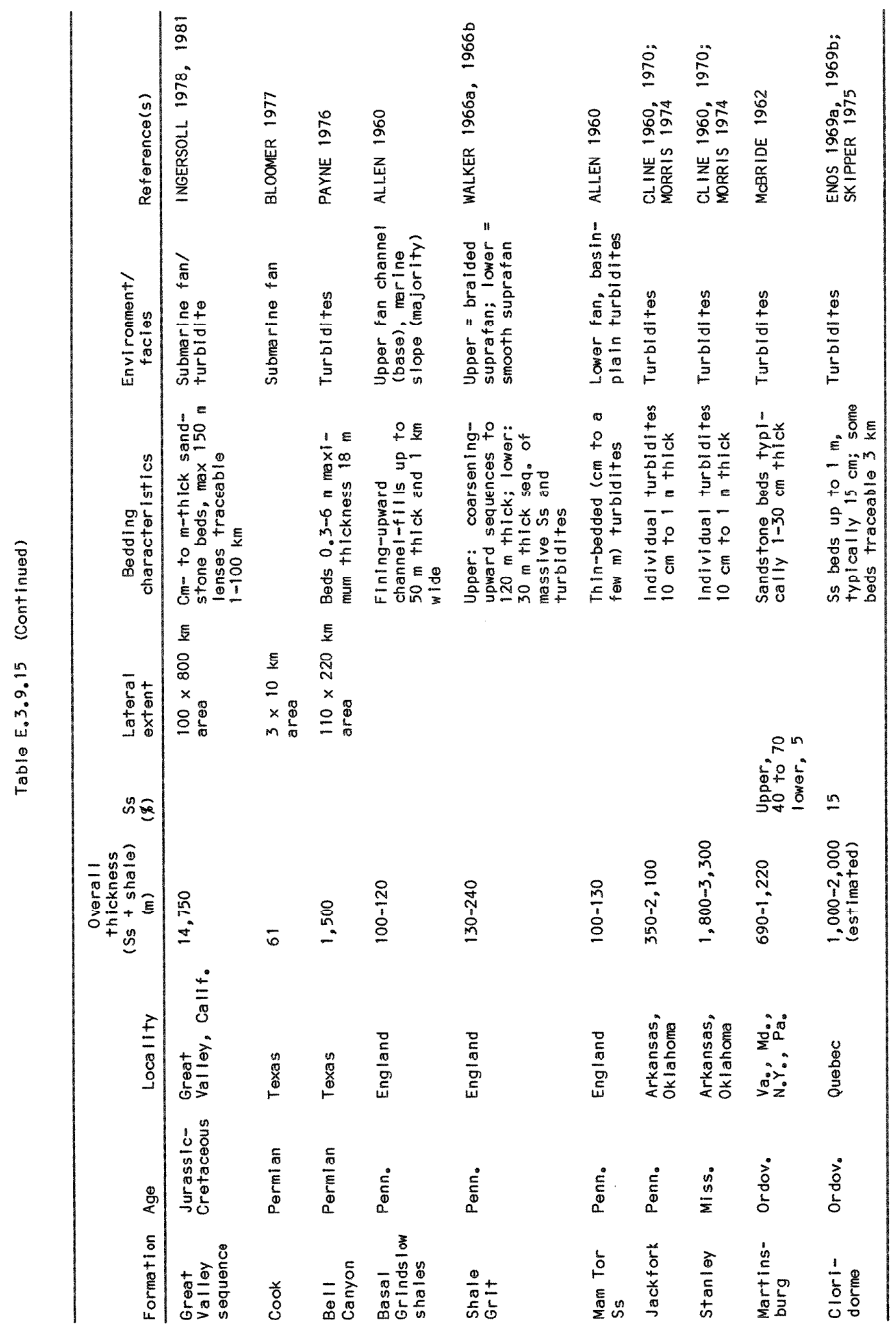


Table E.3.9.16. Petrographic data for several alluvial fan sequences

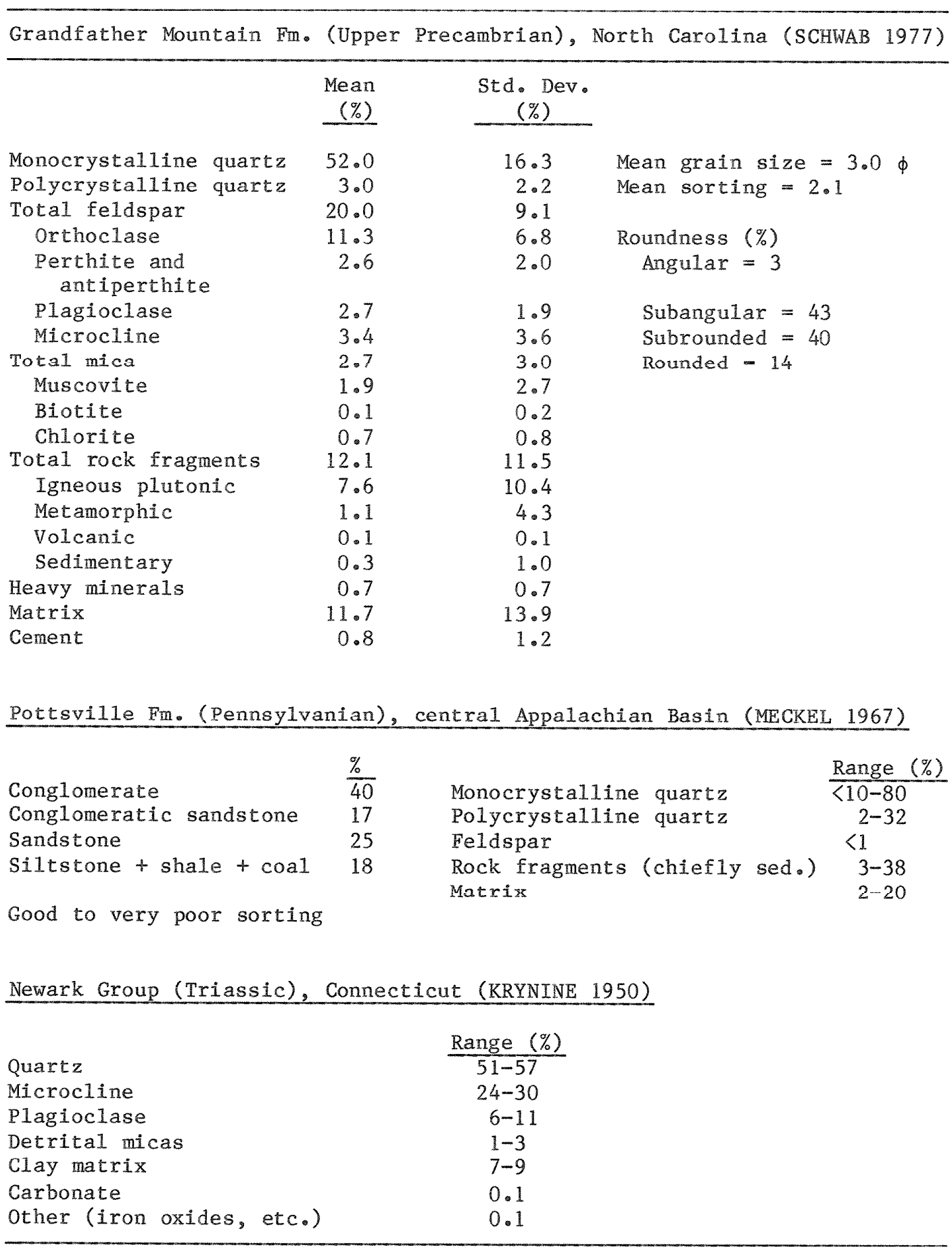


Table E.3.9.17. Ranges and means of principal constituents for Navajo Sandstone (UYGUR 1980) and Lyons Sandstone (ADAMS 1979), which are representative of eolian dune sandstones

\begin{tabular}{|c|c|c|c|c|c|}
\hline \multirow[b]{2}{*}{ Constituent } & \multicolumn{2}{|c|}{ Navajo (Jurassic) } & \multicolumn{3}{|c|}{ Lyons (Permian) } \\
\hline & Range & $\%$ Mean $(\%)$ & & Range $(\%)$ & Mean (\%) \\
\hline \multicolumn{6}{|l|}{ Framework grains: } \\
\hline Quartz plus chert & $72-97$ & 88 & \multirow{3}{*}{\multicolumn{3}{|c|}{$\begin{array}{cc}90.6-99.5 & 96.6 \\
0-8.2 & 2.5 \\
\text { (feldspars not } \\
\text { differentiated) }\end{array}$}} \\
\hline K-feldspar & $2-16$ & 8 & & & \\
\hline Plagioclase & $0-8$ & 3 & & & \\
\hline Rock fragments & $0-3$ & 1 & & $0-2.3$ & 0.9 \\
\hline \multicolumn{6}{|l|}{ Cements } \\
\hline Silica & (not dif) & ierentiated) & & $23-63$ & 44.5 \\
\hline Calcite & (not dif) & erentiated) & & $0-63$ & 37.8 \\
\hline Iron oxide & (not dif: & erentiated) & & $0-57$ & 18.4 \\
\hline \multicolumn{6}{|l|}{ Total rock volume } \\
\hline Grains & $59-72$ & 66 & & $66.0-97.8$ & 83.8 \\
\hline Cements & $2-25$ & 9 & & $1.0-21.5$ & 11.9 \\
\hline Matrix & $0-3$ & 0.8 & (not & differen & tiated) \\
\hline \multirow[t]{2}{*}{ Total porosity } & $7-35$ & 24 & & $0-12.5$ & 4.4 \\
\hline & $N=60$ & samples & & $\mathrm{N}=11 \mathrm{~s}$ & amples \\
\hline Mean grain size & \multicolumn{2}{|c|}{$\begin{array}{l}1.98-3.53 \phi \\
0.31-0.65\end{array}$} & \multicolumn{3}{|c|}{$1.0-2.5 \phi$} \\
\hline $\begin{array}{l}\text { Mean sorting } \\
\text { coefficient }\end{array}$ & & \multicolumn{3}{|c|}{$0.10-0.5 \phi$} \\
\hline
\end{tabular}


Table E.3.9.18. Petrographic data for several braided stream deposits

Lamotte Sandstone (Upper Cambrian), Missouri (HOUSEKNECHT 1978), based on 110 samples

Range (\%) Mean (\%)

$\begin{array}{lcc}\text { Monocrystalline quartz } & 31.7-90.9 & 74.7 \\ \text { Polycrystalline quartz } & 2.0-8.5 & 3.8 \\ \text { K-feldspar } & 0.6-3.5 & 1.7 \\ \text { Plaginclase } & 0.4-3.1 & 1.1 \\ \text { Plutonic rock fragments } & 0.2-3.5 & 1.0 \\ \text { Volcanic rock fragments } & 0.7-52.5 & 10.7 \\ \text { Accessory minerals } & 0.4-1.7 & 0.8 \\ \text { Matrix (detrital + authigenic) } & 4.2-10.5 & 6.3 \\ \text { Mean size mono. quartz }(\phi) & 1.91-2.18 & 1.97 \\ \text { Std. dev. mono. quartz } & 0.63-0.93 & 0.77\end{array}$

Tuscarora ${ }^{a}$ Sandstone (Lower Silurian), Pennsylvania, Virginia, and West Virginia (SIBLEY 1976)

Detrital quartz, \%

Authigenic quartz (cement), \%

Clay (detrital + authigenic), \%

porosity, \%

other (chiefly heavy minerals), \%

Size, $\mathrm{mm}$

Sorting

Quartz grains showing pressure

solution, \%

$\begin{array}{cc}74-75 & 74 \\ 20-23 & 21 \\ 1-4 & 2 \\ 1-3 & 2 \\ 0-1 & <1 \\ 0.3-0.4 & 0.3 \\ \text { very we11 to we11 } & \text { we11 } \\ 6-8 & 7\end{array}$

Tuscher and Farrer Fns. (Upper Cretaceous), Utah (KEIGHIN 1981)

\begin{tabular}{|c|c|c|}
\hline & Iuscher th. & Farrer Fm. \\
\hline Depth below surface, m & $1641-1655$ & $1793-1801$ \\
\hline Number of samples & 14 & 9 \\
\hline Quartz, \% & 35.7 & 29.3 \\
\hline Feldspar, \% & 4.5 & 3.9 \\
\hline Chert, \% & 3.4 & 4.7 \\
\hline Rock fragments, \% & 11.9 & 12.8 \\
\hline Calcite cement, \% & 5.5 & 2.4 \\
\hline
\end{tabular}

a Samples analyzed (185) included both braided-stream and marine shelf facies. 


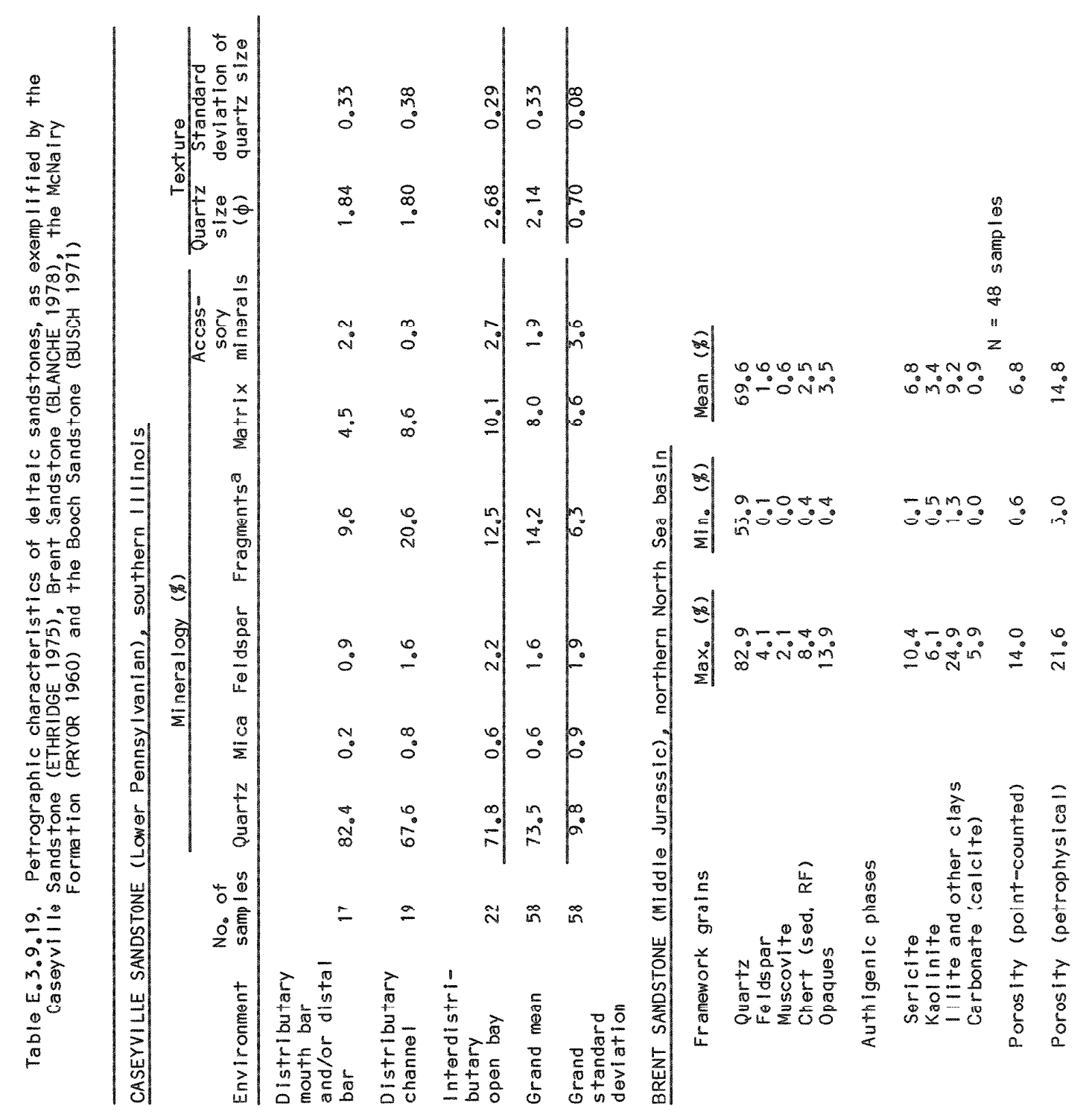




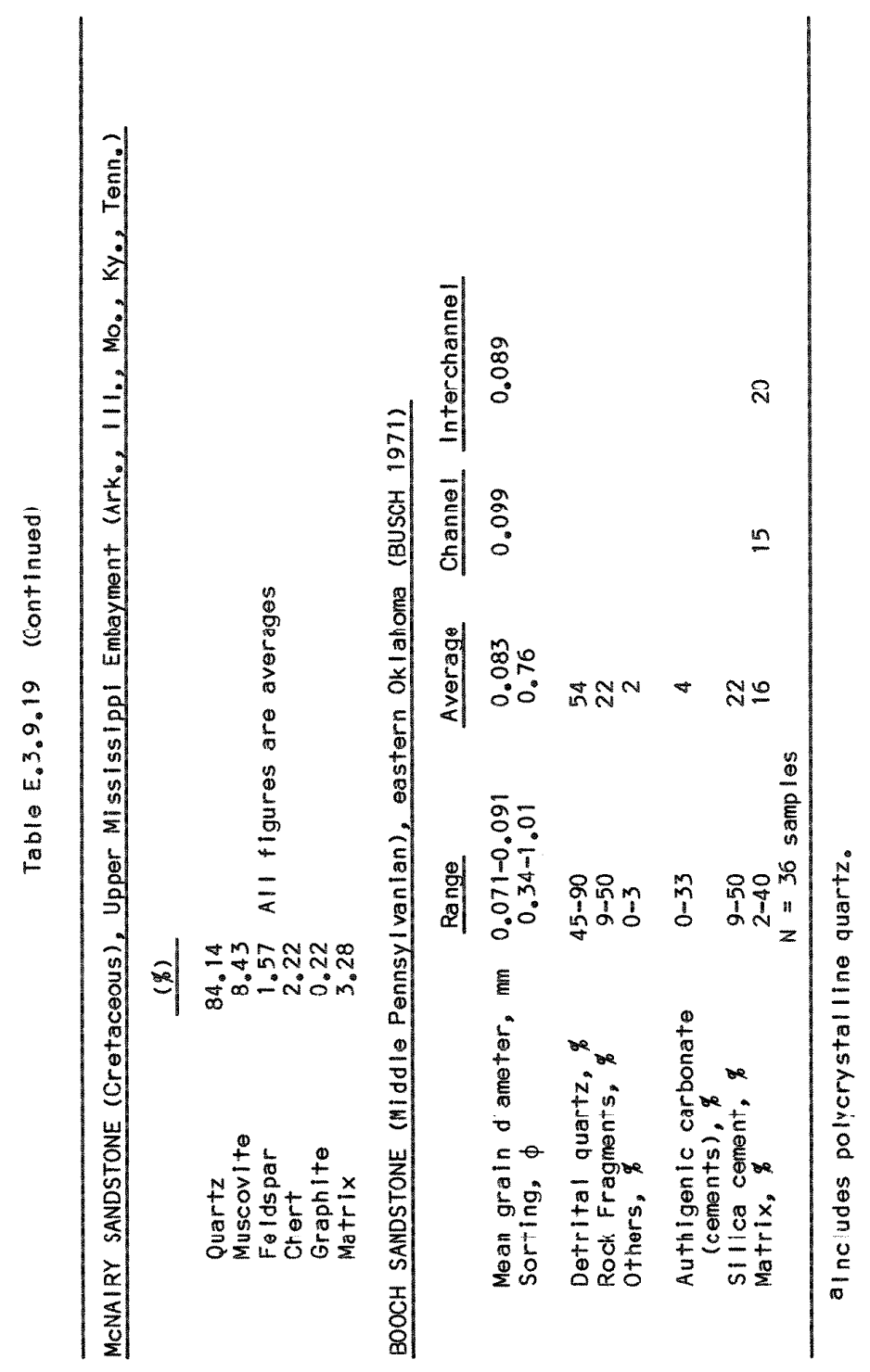


Table E.3.9.20. Ranges and means of principal constituents for:

(I) Martinsburg Formation (Ordovician), Pennsylvania (MCBRIDE 1962); (II) Stanley Group (Mississippian) and Jackfork Group (Pennsylvanian), Oklahoma and Arkansas (MORRIS 1979); (III)

Great Valley Sequence (Jurassic, Cretaceous), California

(DICKINSON 1972; INGERSOLL 1981) and (IV) Umpqua

Formation (Eocene), Oregon (BURNS 1979). These

sequences represent the spectrum of deep-water sandstone deposits in terms of texture and composition.

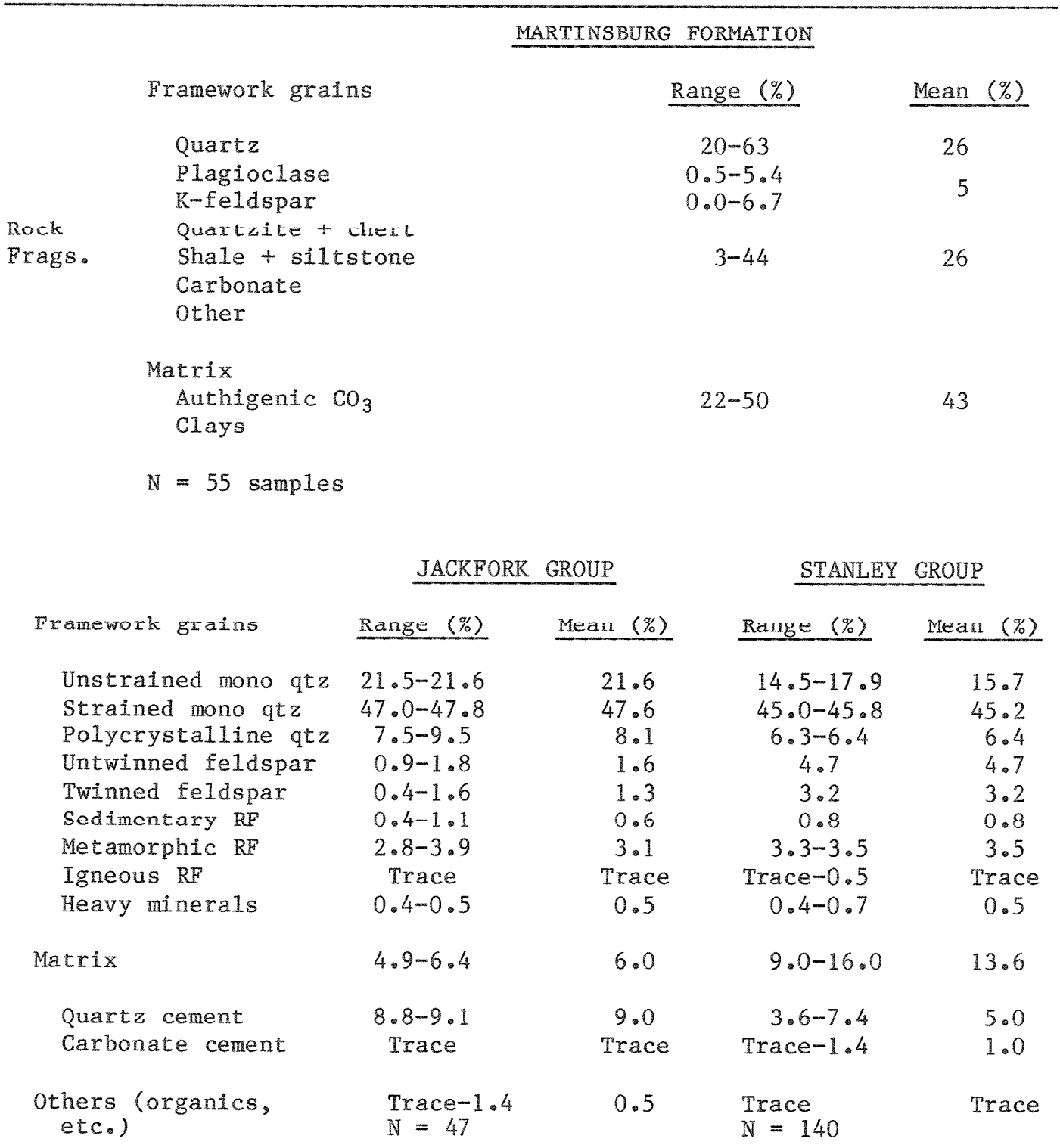


Table E.3.9.20 (Continued)

GREAT VALLEY SEQUENCE (GROUP)

$\begin{array}{lcc} & \text { Range }(\%) & \text { Mean }(\%) \\ \text { QFL quartz } & 25-40 & 34.5 \\ \text { QFL feldspar } & 21-40 & 30.1 \\ \text { QFL lithic fragments } & 23-53 & 35.6 \\ \text { QFL detrital micas } & 2-10 & 5.6 \\ & & \\ \text { Plagioclase/total feldspar ratio } & 0.55-0.92 & 0.73 \\ \text { Volcanic lithic/total lithic ratio } & 0.29-0.70 & 0.51 \\ \text { Polycrystalline quartz/total quartz ratio } & 0.03-0.3 / & 0.13\end{array}$

UMPQUA FORMATION

Framework grains

Monocrystalline quartz

Polycrystalline quartz

Total quartz

$\mathrm{K}$-feldspars

Plagioclase

Feldspar-bearing plutonic PF

Total feldspar

Sedimentary RF

Volcanic RF

Metamorphic RF

Total rock fragments

Accessory minerals

Matrix

Detrital constituents

Cement

QFL quartz

QFL feldspar \%

QFL 1ithics

Lithics sedimentary

Lithics volcanic

Lithics metamorphic
Range (\%)

$17.4-20.1$

$8.6-12.7$

$26.0-31.6$

$0.4-2.0$

$12 \cdot 3-14 \cdot 6$

$2.0-5.7$

$14 \cdot 9-21.6$

$4.6-12.6$

$11.7-30.2$

$6.7-9.5$

$28.4-43.3$

$2.8-10.1$

$5 \cdot 2-14 \cdot 3$

$76 \cdot 1-84.8$

$15 \cdot 2-23.9$

$33.6-39.6$

$19.6-25.9$

$34 \cdot 5-46 \cdot 3$

$9.9-34.8$

$38.1-69.0$

$18.5-30.8$
Mean (\%)

18.4

9.9

28.3

1.0

12.9

3.4

17.3

9.3

20.1

7.8

37.2

6.7

10.5

80.6

19.4

35.3

21.0

43.8

27.2

51.1

21.7

$$
\mathrm{N}=29 \text { samples }
$$


Table E.3.9.21. Summary of maximum particle size and bed thickness for four Devonian alluvial fan sequences in the Hornelen Basin of Norway (from GLOPPEN 1981)

\begin{tabular}{|c|c|c|c|c|c|c|c|c|}
\hline & \multicolumn{2}{|c|}{ Hjortestegvatnet } & \multicolumn{2}{|c|}{ Nibbevatent } & \multicolumn{2}{|c|}{ Svartevatnet } & \multicolumn{2}{|c|}{ Lassenipa } \\
\hline & Interm.a & Dist.b & Prox.c & Dist. & Prox. & Interm. & Prox. & Dist. \\
\hline MPS, $d \mathrm{~cm}$ & 17.2 & 9.1 & 21.8 & 10.6 & 20.6 & 12.9 & 16.3 & 9.1 \\
\hline $\mathrm{BTh}, \mathrm{e} \mathrm{cm}$ & 34.9 & 24.4 & 40.4 & 26.9 & 55.7 & 39.4 & 38.4 & 21.4 \\
\hline BTh:MPS & 2.0 & 2.7 & 1.8 & 2.5 & 2.7 & 3.1 & 2.3 & 2.3 \\
\hline $\begin{array}{l}\text { Downfan } \\
\text { MPS } \\
\text { decrease }\end{array}$ & 11.6 & $\mathrm{~cm} / \mathrm{km}$ & 14 & $\mathrm{~cm} / \mathrm{km}$ & 5. & $\mathrm{~cm} / \mathrm{km}$ & & \\
\hline $\begin{array}{l}\text { Downfan } \\
\text { BTh } \\
\text { decrease }\end{array}$ & 15.10 & $\mathrm{~cm} / \mathrm{km}$ & 16.8 & $\mathrm{~cm} / \mathrm{km}$ & 10 & $8 \mathrm{~cm} / \mathrm{km}$ & & \\
\hline
\end{tabular}

a Internediate fan facies. bistal fan facies. CProximal fan facies. dMaximum particle size. eBed thickness. 
Table E.3.9.22. Distribution of genetic subunits and units (and covered slope) in four outcrop exposures of the Weber Sandstone (Pennsylvanian-Permian), Dinosaur National Monument and vicinity, Utah and Colorado (from FRYBERGER 1979)

\begin{tabular}{|c|c|c|c|c|}
\hline \multirow[b]{2}{*}{$\begin{array}{l}\text { Generic unita } \\
\text { or subunit }\end{array}$} & \multirow[b]{2}{*}{$\begin{array}{l}\text { Hog Canyon } \\
(264 \mathrm{~m})\end{array}$} & \multicolumn{3}{|c|}{ Section (\%) } \\
\hline & & $\begin{array}{l}\text { Sand Canyon } \\
(280 \mathrm{~m})\end{array}$ & $\begin{array}{l}\text { Deerlodge Park } \\
\quad(232 \mathrm{~m})\end{array}$ & $\begin{array}{l}\text { Irish Canyon } \\
(281 \mathrm{~m})\end{array}$ \\
\hline $\begin{array}{l}\text { Smal1 ( }<0.31 \mathrm{~m} \\
\text { thick)- and medium } \\
(0.31-6.1 \mathrm{~m} \text { thick })- \\
\text { scale, wedgeplanar } \\
\text { and planar-tabular } \\
\text { cross-bedding }\end{array}$ & 23 & 26 & 18 & 21 \\
\hline $\begin{array}{l}\text { Trough cross- } \\
\text { bedding }\end{array}$ & 7 & 21 & 58 & 33 \\
\hline $\begin{array}{l}\text { Large-scale } \\
(>6.1 \mathrm{~m} \text { thick) } \\
\text { planar-tabular } \\
\text { cross-bedding } \\
\text { (commonly } \\
\text { contorted) }\end{array}$ & 53 & 27 & 16 & 33 \\
\hline $\begin{array}{l}\text { Horizontally } \\
\text { laminated } \\
\text { or bedded }\end{array}$ & 5 & 4 & 4 & 10 \\
\hline $\begin{array}{l}\text { Massive } \\
\text { (structureless) }\end{array}$ & 11 & 5 & 3 & 2 \\
\hline $\begin{array}{l}\text { Nonmarine } \\
\text { carbonate lens }\end{array}$ & 1 & 1 & 1 & 1 \\
\hline Covered slope & 0 & 16 & 0 & 0 \\
\hline $\begin{array}{l}\text { Mean thickness } \\
\text { of genetic } \\
\text { units, m }\end{array}$ & 12 & 12.2 & 9.1 & 13.4 \\
\hline $\begin{array}{l}\text { Mean thickness } \\
\text { of genetic } \\
\text { subunits, m }\end{array}$ & 5.8 & 5.8 & 5.8 & 5.8 \\
\hline
\end{tabular}

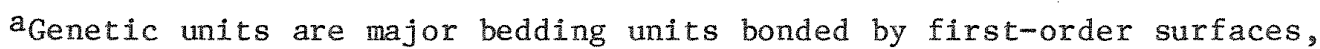
whereas genetic subunits are bounded by second-order surfaces. 
Table E.3.9.23. Cross-bed thickness and dip angles for several tidal shelf and tidal flat sandstone deposits (after SWETT 1971; KLEIN 1977)

\begin{tabular}{|c|c|c|c|c|c|c|}
\hline \multirow[b]{2}{*}{ Formation } & \multirow{2}{*}{ 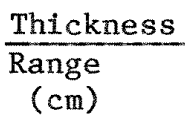 } & \multicolumn{2}{|c|}{ of cross-bed sets } & \multicolumn{3}{|c|}{ Dip angle of cross-bed sets } \\
\hline & & $\begin{array}{l}\text { Mean } \\
(\mathrm{cm})\end{array}$ & $\begin{array}{l}\text { No. of } \\
\text { samples }\end{array}$ & $\begin{array}{l}\text { Range } \\
\text { (degrees) }\end{array}$ & $\begin{array}{c}\text { Mean } \\
\text { (degrees) }\end{array}$ & Samples \\
\hline $\begin{array}{l}\text { Eribol1 Ss } \\
\text { (Cambrian) }\end{array}$ & $0-110$ & 20 & 254 & $10-45$ & 25 & 98 \\
\hline $\begin{array}{l}\text { Sterling Qtz } \\
\text { (Precambrian) }\end{array}$ & $0-80$ & 25 & & $10-40$ & 22 & \\
\hline $\begin{array}{l}\text { Zabriskie Qtz } \\
\text { (Cambrian) }\end{array}$ & $0-60$ & 15 & & & & \\
\hline $\begin{array}{l}\text { Eureka Qtzite } \\
\text { (Ordovician) }\end{array}$ & $0-30$ & 10 & & & & \\
\hline
\end{tabular}

Table E.3.9.24. Variability of bedding characteristics and internal structures for 156 Martinsburg Formation (Ordovician) turbidites (McBRIDE 1962) and Great Valley Sequence (Jurassic-Cretaceous) submarine fans (DICKINSON 1972)

\begin{tabular}{lc}
\hline & \multicolumn{1}{c}{ Martinsburg } \\
Types of bedding and internal structures & Frequency (\%) \\
\hline Graded beds & 51 \\
Horizontally laminated & 29 \\
Cross-laminated & 19 \\
Convolute beds & 0.05 \\
Massive beds & 0.02
\end{tabular}

\section{Great Valley Sequence}

Thin-bedded ( $1-5 \mathrm{~cm})$ mudstone-siltstone layers intercalated with thin beds $(1-20 \mathrm{~cm})$ of graded or laminated, fine-grained sandstone

Medium- to coarse-grained, massive or graded $25-40$ sandstones in beds $25 \mathrm{~cm}$ to $1 \mathrm{~m}$ thick, with thin intercalated mudstone-siltstone layers

Pebble and cobble conglomerate, locally bouldery, $0-10$ in massive or imbricated thick beds (1-15 m), with intercalcated layers and lenses of sandstone 


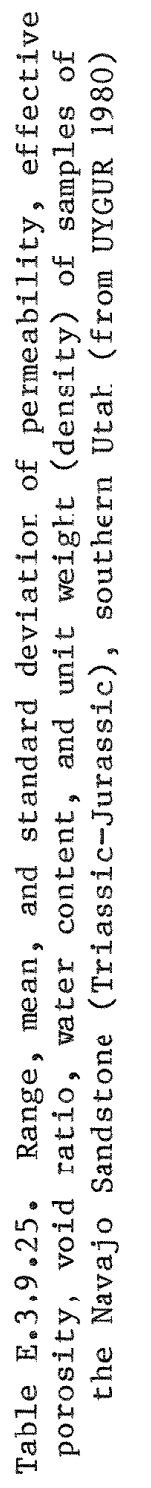

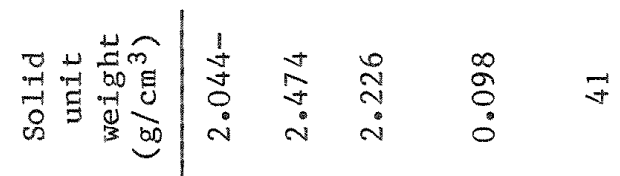

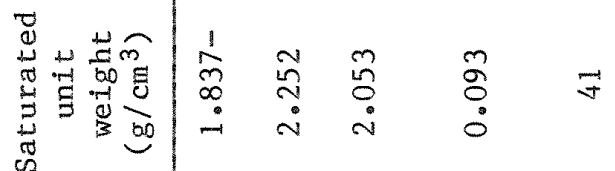

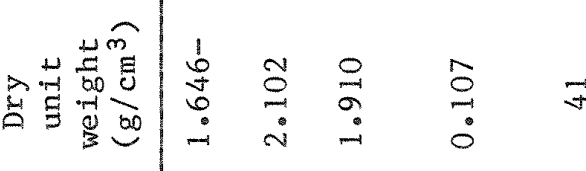

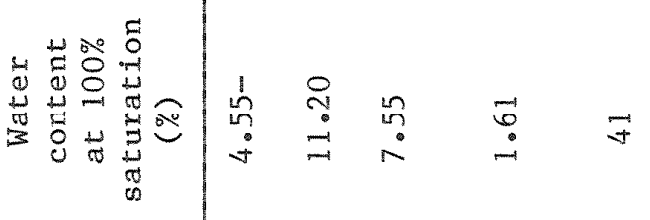

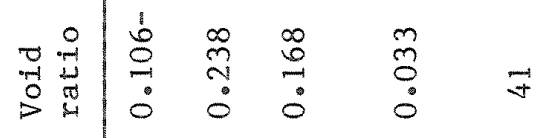

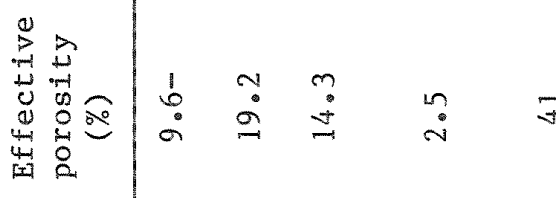

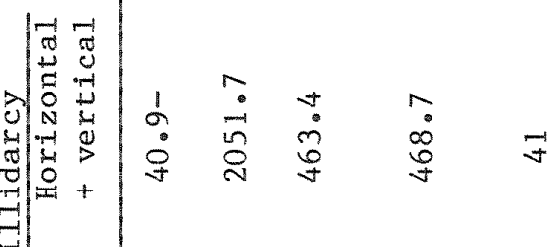

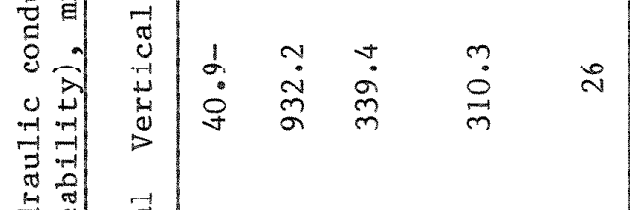

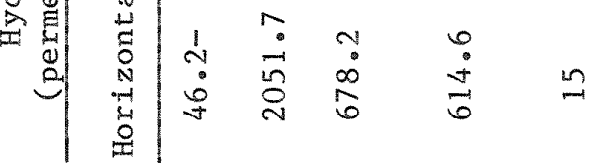

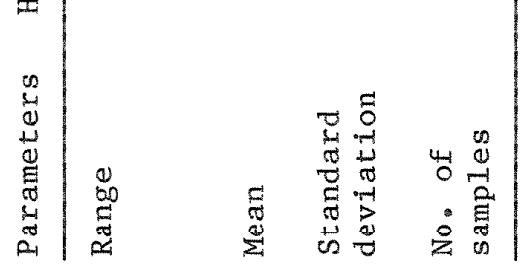




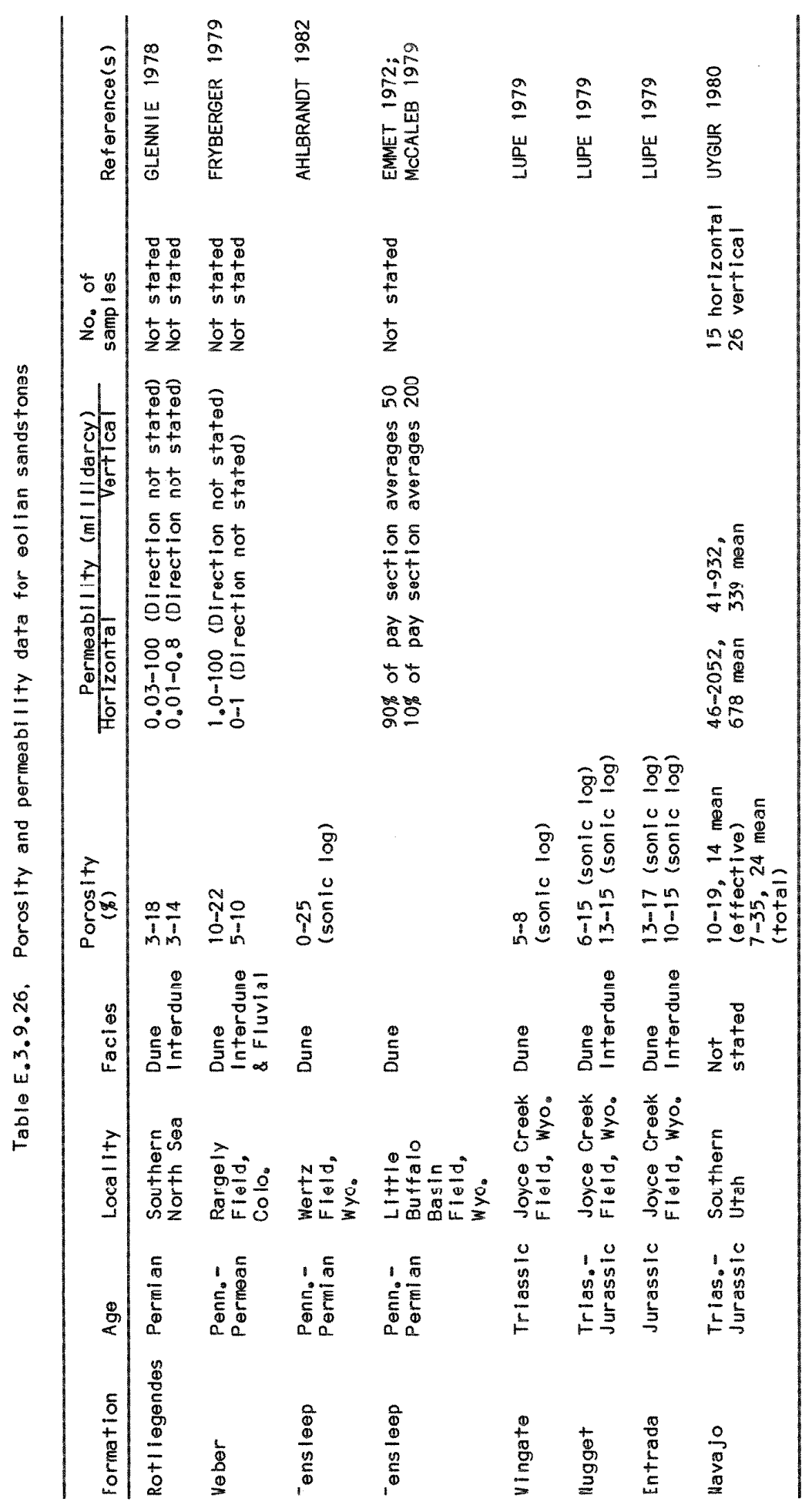


Table E.3.9.27. Porosity and permeability as a function of depositional environment, Brent Sandstone (Jurassic) deltaic deposits, North Sea (BLANCHE 1978;

SELLEY 1978)

\begin{tabular}{|c|c|c|c|}
\hline \multirow[b]{2}{*}{ Environment } & \multicolumn{2}{|c|}{ Porosity (\%) } & \multirow{2}{*}{$\begin{array}{l}\text { Permeability } \\
\text { range } \\
\text { (millidarcy) }\end{array}$} \\
\hline & Range & $\overline{\text { Mean }}$ & \\
\hline Delta plain & $3-29$ & 22.8 & $0.079-1732$ \\
\hline Distributary channel & $4-29$ & 25.4 & $0.073-79$ \\
\hline Delta slope & $9-26$ & 22.8 & $0.28-140$ \\
\hline Prodelta & $4-23$ & 17.0 & $0.69-20$ \\
\hline
\end{tabular}

Table E.3.9.28. Porosity and permeability as a function of depositional environment, Lower West Baden Sandstone (Mississippian), Indiana (HRABAR 1969)

\begin{tabular}{llcc}
\hline Facies & Environment & $\begin{array}{c}\text { Porosity } \\
(\%)\end{array}$ & $\begin{array}{c}\text { Permeability } \\
\text { (millidarcy) }\end{array}$ \\
\hline Cross bedded & Distributary channe1 & $22-27$ & $\begin{array}{c}137-3330 \\
\text { avg }\end{array}$ \\
Ripple bedded & $\begin{array}{l}\text { Levee/overbank/inter- } \\
\text { dislibulary ? }\end{array}$ & $7-22$ & avg 10 \\
\hline
\end{tabular}


Table E. 3.9.29. Porosity and permeability data for Cretaceous barrier island/shoreline sandstone sequences, San Juan Basin, New Mexico (PETERSON 1968)

\begin{tabular}{lccc}
\hline Formation & $\begin{array}{c}\text { Thickness } \\
(\mathrm{m})\end{array}$ & $\begin{array}{c}\text { Average porosity } \\
(\%)\end{array}$ & $\begin{array}{c}\text { Average permeability } \\
\text { (millidarcy) }\end{array}$ \\
\hline Dakota & $\begin{array}{c}26-76 \\
\text { avg }=61\end{array}$ & 11 & 14 \\
Gallup & 30 & 13.6 & 37 \\
Point Lookout & $43-76$ & 10 & $\begin{array}{c}21 \text { avg } \cdot \text {, but } \\
\text { as high as } 150\end{array}$ \\
C1iff House & 30 & 10.3 & 0.54 \\
Pictured Cliffs & $3-21.3$ & 18.1 & 2.96 \\
\hline
\end{tabular}




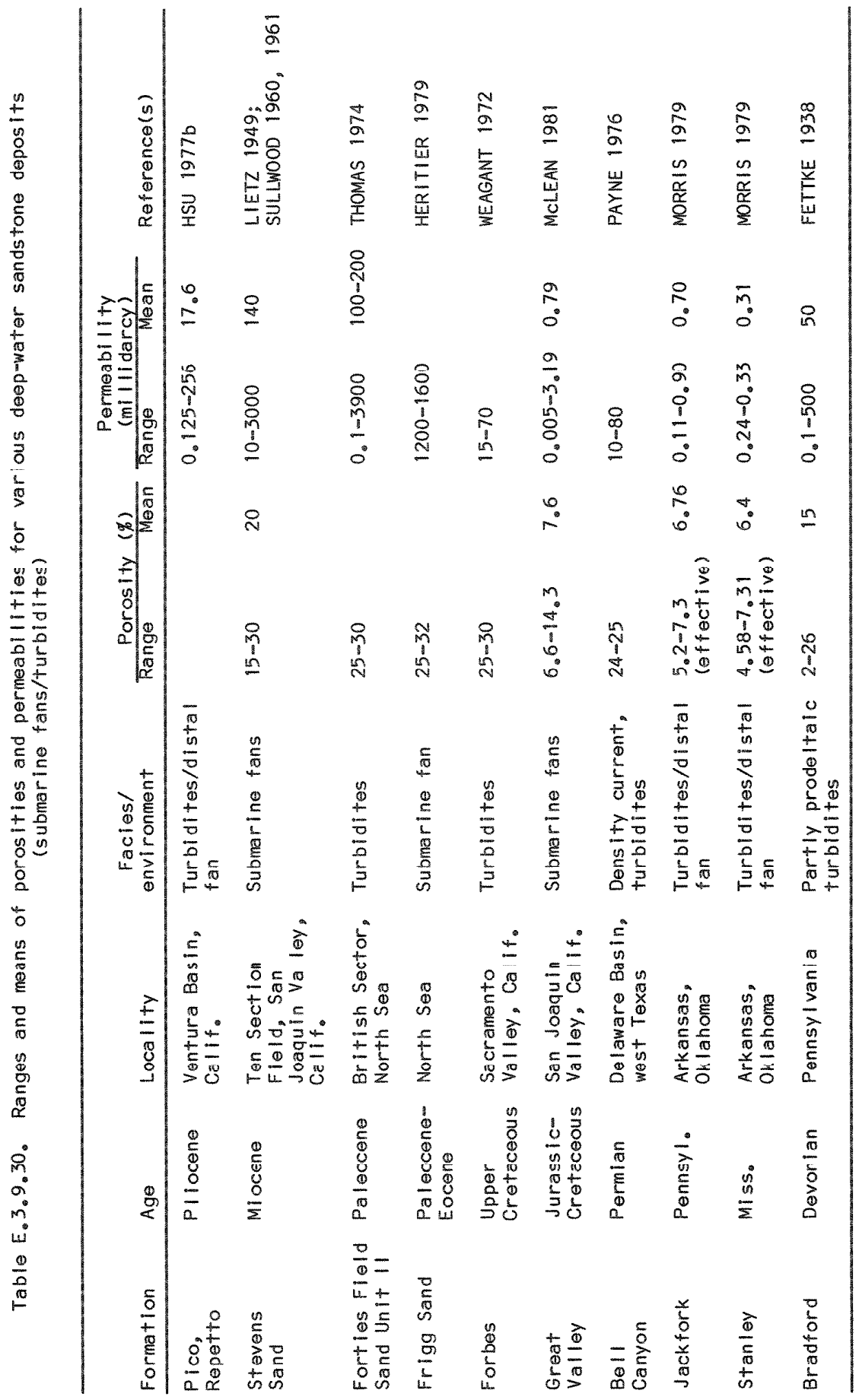


Table E.3.9.31. Porosity and permeability as a function of depositional environment, formation (petrofacies), and burial depth for Great Valley Sequence (Jurassic-Cretaceous), California (MCLEAN 1981)

\begin{tabular}{lccc}
\hline Depositional facies & $\begin{array}{c}\text { Mean porosity } \\
(\%)\end{array}$ & $\begin{array}{c}\text { Mean permeability } \\
\text { (millidarcy) }\end{array}$ & No. samples \\
\hline Basin plain & 8 & 1.48 & 9 \\
Overbank & 4 & 0.04 & 7 \\
Depositional lobes & 10 & 0.20 & 16 \\
Interchanne1 & 14 & 1.51 & 5 \\
Fan fringe & 12 & 0.90 & 8 \\
Inner and midfan channels & 10.5 & 0.05 & 19 \\
& & & \\
Formation/petrotacies & & & \\
Rumsey & 8 & 3.19 & 4 \\
Sites/Cnrtina & 14.3 & 0.90 & 14 \\
Venado/Cortina & 13 & 0.04 & 19 \\
Fiske Creek/Boxer & 6.6 & 0.03 & 7 \\
Brophy Canyon/Boxer & 9 & 0.03 & 6 \\
Lodoga & 8 & 0.09 & 2 \\
Stony Creek & 7.5 & 0.005 & \\
\hline
\end{tabular}

Table E.3.9.32. Permeability as a function of burial depth for the Pico and Repetto Formations (P1iocene), Ventura Basin, California (HSU 1977b)

\begin{tabular}{ccc}
\hline $\begin{array}{c}\text { Depth interval } \\
(\mathrm{m})\end{array}$ & $\begin{array}{c}\text { Geometric mean permeability } \\
\text { (millidarcy) }\end{array}$ & $\begin{array}{c}\text { Range of permeability } \\
\text { (millidarcy) }\end{array}$ \\
\hline $900-1300$ & 60 & $4-256$ \\
$1600-1750$ & 15 & $0.25-128$ \\
$2000-2200$ & 7 & $0.125-128$ \\
$2500-2750$ & 5 & $0.125-128$ \\
$2750-3100$ & 0.8 & $0.125-4$ \\
\hline
\end{tabular}


ADAMS 1979. J. Adans and J. Patton, "Sebkha-Dune Deposition in the Lyons Formation (Permian), Northern Front Range, Colorado," M. Geol. $16,47-57$ (1979).

ADIE 1975. R. J. Adie, "Permo-Carboniferous Glaciation of the Southern Hemisphere," in A. E. Wright and F. Mosely (ed.), Ice Ages: Ancient and Modern, Seel House Press, Liverpool, England, 1975, pp. 287-300.

AHLBRANT 1982. T. S. Ahlbrant and S. G. Fryberger, "Introduction to Eolian Deposits," in P. A. Schn11e and D. Spearing (eds), Sandstone Depositional Environments, A.A.P.G. Mem No. 31, 1982, pp. $11-47$.

ALLEN 1960. J. R. L. Allen, "The Mam Tor Sandstones: A "Turbidite" Facies of the Namurian Deltas of Derbyshire, England," J. Sediment Petro1. 30, 193-208 (1960).

ALLEN 1964. J. R. L. Allen, "Studies in Fluviatile Sedimentation: Six Cyclothems from the Lower 01d Red Sandstone, Anglo-Welsh Basin," Sedimentology 3, 163-198 (1964).

ALLEN 1965. J. R. L. Allen, "A review of the Origin and Characteristics of Recent Alluvial Sediments," Sedimentology 5, 89-191 (1965).

ANDERTON 1976. "Tidal Shelf Sedimentation: An example from the Scottish Dalradian," Sedimentology 23, 429-458 (1976).

ASQUTTH 1970. D. O. Asquith, "Depositional Topography and Major Marine Environments, Late Cretaceous, Wyoning," Am.Assoc. Pet. Geo1. Bul1. 54, $1184-1224$ (1970).

ATWATER 1965. G. I. Atwater and F. F. Miller, "The Effect of Decrease in Porosity with Depth on Future Development of $0 i 1$ and Gas Reserves in South Louisiana" (abstract), Am. Assoc. Pet. Geol. Bul1. 49, 334 (1965).

BAARS 1961. D. L. Baars, "Permian Blanket Sandstones of Colorado plateau," in J. A. Peterson and J. C. Osmond (eds.), Geometry of Sandstone Bodies, A.A.P.G. Spec. Pub1., 1961, pp. 179-207.

BAARS 1962. D. L. Baars, "Permian System of Colorado Plateau,: Am. Assoc. Pet. Geol. Bul1. 46, 149-218 (1962).

BALL 1941. M. W. Ball, T. J. Weaver, H. H. Crider, and D. S. Ball, "Shoestring Gas Fields of michigan," in A. I. Levorsen (ed.), Stratigraphic Type 0il Fields, Am. Assoc. Pet. Geol. Bul1., 1941, $237-266$.

BARWIS 1978. J. H. Barwis and J. H. Makurath, "Recognition of Ancient Tidal Inlet Sequences: An Example from the Upper Silurian Keyser Limestone in Virginia," sedimentology 25, 61-82 (1978). 
BASS 1934. N. W. Bass, "Origin of Bartlesville Shoestring Sands, Greenwood and Butler Counties, Kansas," Am.Assoc. Pet. Geol. Bull.18, 1313-1345 (1934).

BASS 1939. N. W. Bass, "Verden Sandstone of Oklahoma, An Exposed Shoestring Sand of Permian Age," Am.Assoc. Pet. Geol. Bull. 23, 559-581 (1939).

BEARD 1973. D. C. Beard and P. K. Weyl, "Influence of Texture on Porosity and Permeability of Unconsolidated Sand," Am. Assoc. Pet. Geol. Bull. 57, 349-369 (1973).

BEAJMONT 1984. E. A. Beaumont, "Retro-gradational Shelf Sedimentation: Lower Cretaceous Viking Formation, Central Alberta," in R. W. Tillman and C. T. Siemers (eds.), Siliciclastic Shelf Sediments, S.E.P.M. Spec. Pub. No. $34,1974,163-177$.

BERG 1968. R. R. Berg and D. K. Davies, "Origin of Lower Cretaceous Muddy Sandstone at Bel1 Creek Field, Montana," Am. Assoc. Pet. Geol. Bull. 52, 1888-1898 (1968).

BERG 1975. R. R. Berg, "Depositional Environment of Upper Cretaceous Sussex Sandstone, House Creek Field, Wyoming," Am. Assoc. Pet. Geol. Bu11. 59, 2099-2110 (1975).

BERNARD 1963. H. A. Bernard and C. F. Major, Jr., "Recent Meander Belt Deposits of the Brazos River: An alluvial "sand" model" (abstract), Am. Assoc. Pet. Geol. Bull. 47, 350-351 (1963).

BERVEN 1966. R. J. Berven, "Cardiun Sandstone Bodies, Crossfie1dGarrington Area, Alberta," Can. Pet. Geol. Bull. 14, 208-240 (1966).

BLAKEY 1984. R. C. Blakey, "Marine Sand-Wave Complex in the Permian of Central Arizona," J. Sediment Petrol. 54, 29-51 (1984).

BLANCHE 1978. J. B. Blanche and J. H. MCD. Whitaker, "Diagenesis of Part of the Brent Sand Formation (Middle Jurassic) of the Northern North Sea Basin," J. Geol. Soc., London 135, 78-82 (1978).

BLATT 1980. H. Blatt, G. V. Middleton, and R. C. Murray, Origin of Sedimentary Rocks (2d ed॰), Prentice-Hall, Englewood Cliffs, N.J., 1980, p. 782 .

BLOOMER 1977. R. R. Bloomer, "Depositional Environments of a Reservoir Sandstone in West-Central Texas," Am. Assoc. Pet. Geol. Bull. 61, $334-359$ (1977).

BLUCK 1965. B. J. Bluck, "The Sedimentary History of Some Triassic Conglomerates in the Vale of Glamorgan, South Wales," Sedimentary 4, 225-245 (1965).

Boyn 1966. D. R. Bnyd and D. F. Dyer, "Frio Barrier Bar System of South Texas," Am. Assoc. Pet. Geo1. Bu11. 50, 170-178 (1966). 
BRENNER 1973. R. L. Brenner and D. K. Davies, "Storm-Generated Coquinoid Sandstone: Genesis of High-Energy Marine Sediments from the Upper Jurassic of Wyoming and Montana," Geol. Soc. Am. Bu11. 84, 1685-1698 (1973).

BRENNER 1974. R. L. Brenner and D. K. Davies, "Oxfordian Sedimentation in Western Interior United States," Am. Assoc. Pet. Geol. Bull. 58, 407-428 (1974).

BRENNER 1978. R. L. Brenner, "Sussex Sandstone of Wyoming: Example of Cretaceous offshore Sedimentation," Am. Assoc. Pet. Geo1. Bu11.62, 181-200 (1978).

BRIDGES 1976. P. H. Bridges, "Lower Silurian Transgressive Barrier Islands, Southwest Wales," Sedimentology 23, 347-362 (1976).

BULNES 1945. A. C. Bulnes and R. U. Fitting, Jr., "An Introductory Discussion of the Reservoir Performance of Limestone Formations," Pet. Technol. 8(1), 1945 .

BURNS 1979. L. K. Burns and F. G. Ethridge, "Petrology and Diagenetic Effects of Lithic Sandstones: Paleocene and Eocene Umpqua Formation, Southwest Oregon," in P. A. Scholle and P. R. Schluger (eds.), Aspects of Diagenesis, S.E.P.M. Spec. Pub1. No.26, 1979, pp.307-317.

BUSCH 1971. D. A. Busch, "Genetic Units in Delta Prospecting," Am. Assoc. pet. Geol. Bull. 55, 1137-1154 (1971).

BUTTON 1977. A. Button and r. G. Vos, "Subtidal and Intertidal Clastic and Carbonate Sedimentation in a Macrotidal Environment: An Example from the Lower Proterozoic of South Africa," Sediment. Geol. 18, 175-200 (1977).

CAMPBELL 1971. C. V. Campbe11. "Depositional Mode1: Upper Cretaceous Gallup Beach Shoreline, Ship Rock Area, Northwestern New Mexico," J. Sediment. Petrol. 41, 395-409 (1971).

CAMPBELL 1976. C. V. Campbe11, "Reservoir Geometry of a Fluvial sheet Sandstone," Am.Assoc. Pet. Geo1. Bu1l. 60, 1009-1020 (1976).

CANT 1976. D. J. Cant and R. G. Walker, "Development of a BraidedFluvial Facies Model for the Devonian Battery Point Sandstone, Quebec," Can. J. Earth Sci. 13, 102-119 (1976).

CANT 1978. D. J. Cant and R. G. Walker, "Fluvial Processes and Facies Sequences in the Sandy, Braided South Saskatchewan River," Sedimentology $25,625-648$ (1978).

CARRIGY 1971. M. A. Carrigy, "Deltaic Sedimentation in Athabasca Tar Sands," Am. Assoc. Pet. Geo1. Bull. 55, 1155-1169 (1971).

CHARLES 1941. H. H. Gharles, "Busll elly oll Fleld, Anderson Counly, Kansas," in J. I. Levorsen (ed.), Stratigraphic Type Oil Fields, Am. Assoc. Petrol. Geol. Bull., 1941, pp. 43-56. 
CLINE 1960. L. M. Cline, "Stratigraphy of the Late Paleozoic Rocks of the Quachita Mountains, Okahoma," Ok1a. Geol. Surv. Bul1. No. 85, 1960, $113 \mathrm{pp}$.

CLINE 1970. L. M. Cline, "Sedimentary Features of Late Paleozoic Flysch, Quachita Mountains, Oklahoma," in J. Lajoie (ed.), Flysch Sedimentology of North America, Geol. Assoc. Can. Spec. Pap. 7, 1970, pp. 85-101.

COLEMAN 1980. J. M. Coleman and D. B. Prior, Deltaic Sand Bodies, A.A.P.G. Short Course, Education Course Note Series No. 15, 1980, $171 \mathrm{pp}$.

COLLINSON 1968. J. D. Collinson, "Deltaic Sedinentation Units in the Upper Carboniferous of Northern England," Sedimentology 10, 223-254 (1968).

CORBEILLE 1962. R. L. Corbei11e, "New Orleans Barrier Island," Gulf Coast Assoc. Geol. Soc. Trans. 12, 223-229 (1962).

COTTER 1971. E. Cotter, "Paleoflow Characteristics of a Late Cretaceous River in Utah from Analysis of Sedimentary Structures in the Ferron Sandstone," J. Sediment Petrol. 41, 129-138 (1971).

COTTER 1983. E. Cotter, "Shelf, Paralic, and Fluvial Environments and Eustatic Sea-Level Fluctuations in the Origin of the Tuscarora Formation (Lower Silurian) of Central Pennsylvania," J. Sediment Petrol. 53, 25-49 (1983).

CRAIG 1975. L. c. Craig and D. r. Shawe, "Jurassic Rocks of EastCentral Utah," in J. E. Fasset (ed.), Canyonlands County, Four Corners Geol. Soc., 8th Annu. Field Conf., pp. 157-165, 1975.

DANE 1935. C. H. Dane, Geology of the Salt Valley Anticline and Adjacent Areas, Grand County Utah, U.S., Geol. Surv. Bu11. 863, 1935, $184 \mathrm{pp}$.

DAVIES 1971. D. K. Davies, F. G. Ethridge, and R. R. Berg, "Recognition of Barrier Environments," Am. Assoc. Pet. Geol. Bul1. 55, 550-565 (1971).

DAVIS 1969. S. N. Davis, "Porosity and Permeability of Natura1 Materials," in R. J. M. De Wiest (ed.), Flow Through Porous Media, Academic Press, New York, 1969, pp. 54-89.

DAVIS 1983. R. A. Davis, Jr., Depositional Systems - A Genetic Approach to Sedimentary Geology, Prentice-Hall, Englewood Cliffs, New Jersey, 1983, 669 pp.

DEGAN 1973. C. E. Degan, "Tectonic Control of Sedimentation at the Margin of a Carboniferous Depositional Basin in Kirkudbrightshire," Scott. J. Geol. 9, 1-28 (1973). 
DENNISON 1971. J. M. Dennison, "Petroleum Related to Middle and Upper Devonian Deltaic Facies in Central Appalachians," Am. Assoc. Pet. Geol. Bu11. 55, 1179-1193 (1971).

DICKAS 1967. A. B. Dickas and J. L. Payne, "Upper Paleocene Buried Channel in Sacramento Valley, California," Am. Assoc. Pet. Geol. Bul1. 51, 873-882 (1967).

DICKINSON 1972. W. R. Dickinson and E. I. Rich, "Petrologic Interva1s and Petrofacies in the Great Valley Sequence, Sacramento Valley, California," Geol. Soc. Am. Bull. 63, 3007-3024 (1972).

DICKINSON 1974. W. R. Dickinson, "Plate Tectonics and Sedimentation," in W. R. Dickinson (ed.), Tectonics and Sedimentation, S.E.P.M. Spec. Pub1. No. 22, 1974, pp. 1- $\overline{27}$.

DICKINSON 1979. W. R. Dickinoon and C. A. Suczek, "Plate Tectonics and Sandstone Composition," Am. Assoc. Pet. Geol. Bull. 65, 2164-2182

(1979).

DOE 1980. T. W. Doe and R. H. Dott, "GEnetic Significant of Deformed Cross-Bedding - With Examples from the Navajo and Weber Sandstones of Utah," J. Sediment Petrol. 50, 793-812 (1980).

DOTT 1964. R. H. Dott, Jr., "Wacke Graywacke and Matrix-What Approach to Immature Sandstone Classification?" J. Sediment Petro1. 34, 625-632 (1964).

DotT 1966. R. H. Dott, Jr., "Eocene Deltaic Sedimentation at Coos Bay, Oregon," J. Geo1. 74, 373-420 (1966).

DOTT 1972. R. H. Dott, Jr., and M. A. Roshardt, "Analysis of CrossStratification in the St. Peter Sandstone in Southwestern Wisconsin," Geol. Soc. Am. Bu11. 83, 2589-2596 (1972).

DRIESE 1981. S. G. Driese, C. W. Byers, and R. H. Dott, Jr., "Trial Deposition in the Basal Upper Cambrian Mt. Simon Formation in Wisconsin," J. Sediment Petro1. 51, 367-381 (1981).

EMMETT 1972. W. R. Emmett, K. W. Beaver, and J. A. McCaleb, "Pennsylvanian Tensleep Reservoir, Little Buffalo Basin 0il Field, Big Horn Basin, Wyoming," M. Geol.9, 21-31 (1972).

EMRICH 1966. G. O. Emrich, Ironton and Galesville (Cambrian) Sandstones in Illinois and Adjacent Areas, I1l. State Geol. Surv., Circ. 403, $196655 \mathrm{pp}$.

ENOS 1969a. P. Enos, "Anatomy of a Flysch," J. Sediment Petro1. 39, $680-723(1969 a)$.

ENOS 1969b. P. Enos, Cloridome Formation, Middle Ordovician Flysch, Northern Gaspe Peninsula, Quebec, Geol. Soc. Am., Spec. Pap. No. 117, $1969 \mathrm{~b}, 66 \mathrm{pp}$. 
ERIKSSON 1981. K. A. Eriksson, B. R. Turner, and R. G. Vos, "Evidence of Tidal Processes from the Lower Part of the Witwatersrand Supergroup," Sediment. Geo1. 29, 309-325 (1981).

ETHRIDGE 1975. F. G. Ethridge, T. R. Gopinath, and D. K. Davies, Recognition of Deltaic Environments from Small Samples, "in M. L. Broussard (ed.), Deltas, Models for Exploration, Houston Geol. Soc. Houston, 1975, pp. 151-164.

EVANS 1970. W. E. Evans, "Imbricate Linear Sandstone Bodies of the Viking Formation in Dodsland-Hoosier Area of Southeastern Saskatchewan, Canada," Am.Assoc. Pet. Geol. Bull. 54, 469-486 (1970).

EXUM 1968. F. a. Exum and J. C. Harms, "Comparison of Marine-Bar with Valley-Fill Stratigraphic Traps, Western Nebraska," Am. Assoc. Pet. Geol. Bul1. 52, 1851-1868 (1968).

FERM 1972. J. C. Ferm, R. C. Milici, and J. E. Eason, Carboniferous Depositional Environments in the Cumberland Plateau of Southern Tennessee and Northern Alabama, Tenn., Div. Geol. Rep. Invest No. 33, $1972,32 \mathrm{pp}$.

FERM 1974. J. C. Ferm, "Carboniferous Environmental Models in Eastern United States and Their Significance," in G. Briggs (ed॰), Carboniferous of the Southeastern United States, Geol. Soc. Am., Spec. Pap. No. 148, 1974, pp.79-95.

FETTKE 1938. C. R. Fettke, The Bradford Oil Field P. Geol. Surv., 4th Series, $1938 \mathrm{pp} \cdot 214-228$.

FISHER 1967. W. L. Fisher and J. H. McGowen, "Depositional Systems in the Wilcox Group of Texas and Their Relationship to Occurrence of 0il and Gas," Gulf Coast Assoc. Geol. Soc., Trans. 17, 105-215 (1967).

FISHER 1969. W. L. Fisher and J. H. McGowen, "Depositional Systems in Wilcox Group (Eocene) of Texas and Their Relation to Occurrence of 0il and Gas," Am. Assoc. Petro1. Geo1. Bu11. 53, 30-54 (1969).

FISK 1944. H. N. Fisk, Geological Investigations of the Alluvial Valley of the Lower Mississippi River, Mississippi River Commission, Vicksburg, Mississippi, $194478 \mathrm{pp}$.

FISK 1947. H. N. Fisk, Fine-Grained Alluvial Deposits and Their Effects on Mississippi River Activity, Mississippi River Commission, Vicksburg, Mississippi, 1947, $82 \mathrm{pp}$.

FISK 1961. H. N. Fisk, "Bar-Finger Sands of Mississippi Delta," in

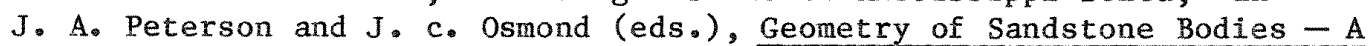
Symposium, A.A.P.G. Spec. Publ., 1961, pp.29-52.

FOLK 1968. R. L. Folk, Petrology of Sedimentary Rocks, Hemphills Book

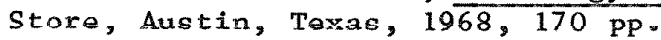


FOLK 1974. R. L. Folk, Petrology of Sedimentary Rocks, Hemphills Book

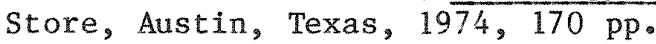

FRASER 1976. G. S. Fraser, "Sedimentology of a Middle ordovician Quartz Arenite-Carbonate Transition in the Upper Mississippi Valley," Geol. Soc. Am. Bull. 86, 833-845 (1976).

FREEMAN 1975. W. E. Freeman and G. S, Visher, "Stratigraphic Analysis of the Navajo Sandtone," J. Sediment Petrol.45, 651-668 (1975).

FRIEDMAN 1960. S。A. Friedman, Channel-Fi11 Sandstones in the Midd1e Pennsylvanian Rocks of Indiana, Indiana, Geol. Surv., Rep. Prog. 23, 1960,59 pp.

FRYBERGER 1979. S. G. Fryberger, "Eolian-Fluvatile (Continental) Origin of Ancient Stratigraphic Trap for Petroleum in Weber Sandstone, Rangely oil Field, Colorado," M. Geol. 16, 1-36 (1979).

GLENNIE 1972. K. W. Glennie, "Permian Rotliegendes of Northwest Europe Interpreted in Light of Modern Desert Sedimentation Studies," Am. Assoc. Pet. Geol. Bul1. 56, 1048-1071 (1972).

GLENNIE 1978. K. W. Glennie, G. C. Mudd, and P. J. C. Nagtegaal, "Depositional Environment and Diagenesis of Permian Rotliegendes Sandstones in Leman Bank and Sole Pit Areas of the U.K. Southern North Sea," J. Geo1. Soc., London 135, 25-34 (1978).

GOODWIN 1974. P. W. Goodwin and E. J. Anderson, "Associated Physical and Biogenic Structures in Environmental Subdivision of a Cambrian Tidal Sand Body," J. Geol. 82, 779-794 (1974).

GLOPPEN 1981. T. G. Gloppen and R. Jo Stee1, "The Deposits, Internal Structure and Geometry in Six Alluvial Fan-Fan Delta Bodies (DevonianNorway) - A Study in the Significance of Bedding Sequence in Conglomerates," in f. G. Ethridge and R. M. Flores (eds.), Recent and Ancient Nonmarine Depositional Environments: Models for Exploration, S.E.P.M. Spec. Pub1. No. 32, 1981, pp. 49-69.

GOULD 1970. H. R. Gould, "The Mississippi Delta Complex," in J.P. Morgan and $\mathrm{R}_{\bullet} \mathrm{H}_{0}$. Shaver (eds.), Deltaic Sedimentation, Modern and Ancient, S.E.P.M. Spec. Pub1. No. 15, 1970, pp. 3-30.

GREENKORN 1964. R. A. Greenkorn, C. R. Johnson, and L. K. Shallenberger, "Directoral Permeability of Heterogeneous Anisotropic Porous Media," Trans. Soc. Pet. Eng. AIME 231, 124-132 (1964).

HAMBLIN 1979. A. P. Hamblin and R. G. Walker, "Storm-Dominated Shallow Marine Deposits: The Fernie-Kootenay (Jurassic) Transition, Southern Rocky Mountains," Can. J. Earth Sci.16, 1673-1690 (1979).

HARMS 1965. J. C. Harms, D. B. MacKenzie, and D. G. McCubbin, "Depositional Environment of the Fox Hills Sandetonco Near Rock Springe, Wyoming," Wyo. Geol. Assoc., 19th Annu. Field Conf., 1965, 113-130. 
HARMS 1966. J. C. Harms, "Stratigraphic Traps in a Valley Fill, Western Nebraska," Am. Assoc. Pet. Geol. Bu11. 50, 2119-2149 (1966).

HARMS 1975. J. C. Harms, J. B. Southard, D. R. Spearing, and R. G. Walker, Depositional Environments as Interpreted from Primary

Sedimentary Structures and Stratification Sequences, S.E.P.M. Short Course Notes No. 2, 1975, $161 \mathrm{pp}$.

HARMS 1982. J. C. Harms, J. B. Southard, and R. G. Walker, Structures and Sequences in Clastic Rocks, S.E.P.M. Short Course Notes No. 9, $1982,249 \mathrm{pp}$.

HAYES 1979. J. B. Hayes, "Sandstone diagenesis - The Hole Truth," in P. A. Scholle and P. R. Schluger (eds.), Aspects of Diagenesis, S.E.P.M. Spec. Publ. No. 26, 1979, pp. 127-139.

HEREFORD 1977. R. Ilereford, "Deposition of the Tapeats Sandstone (Cambrian) in Central Arizona," Geol. Soc. Am. Bul1. 88, 199-211 (1977).

HERITIER 1979. F. E. Heritier, P. Losse1, and E. Wathne, "Frigg Field Large Submarine-Fan Trap in Lower Eocene Rocks of North Sea Viking Graben," Am. Assoc. Pet. Geo1. Bull. 63, 1999-2020 (1979).

HIGH 1965. L. R. High, Jr., and M. D. Picard, "Sedimentary Petrology and Origin of Analcime-rich Popo Agie Member, Chugwater (Triassic) Formation, West-Central Wyoming," J. Sediment Petro1. 35, 49-70 (1965).

HOBDAY 1972. D. K. Hobday and H. G. Reading, "Fair Weather Versus Storm Processes in Shallow Marine Bar Sequences in the Late Precambrian of Finnmark, North Norway," J. Sediment Petrol. 42, 318-324 (1972).

HOBDAY 1974. D. K. Hobday, "Beach-and Barrier-Island Facies in the Upper Carboniferous of Northern Alabama," in G. Briggs (ed.), Carboniferous of the Southeastern U.S., Geol. Soc. Am., Spec. Pap. No. 148, 1974, pp. 209-223.

HOBDAY 1981. D. K. Hobday, C. M. Woodruff, Jr., and M. W. McBridge, "Paleotopographic and structural Controlo on Non-Marinc Scdimentation of the Lower Cretaceous Antlers Formation and Correlating North Texas and Southeastern Oklahoma," in F. G. Ethridge and R. M. Flores (eds.), Recent and Ancient Nonmarine Depositional Environments: Models For Exploration, S.E.P.M. Spec. Publ. No. 31, 1981, pp. 71-87.

HOLLENSHEAD 1961. C. T. Hollenshead and R. L. Pritchard, "Geometry of Producing Mesaverde Sandstones, San Juan Basin," in J. A. Peterson and J. C. Osmond (eds.), Geometry of Sandstone Bodies, A.A.P.G. Spec. Pub1. 1961, pp. 98-118.

HORNE 1978. J. C. Horne, J. C. Ferm, F. T. Caruccio, and D. P. Baganz, "Depositional Models in Coal Exploration and Mine Planning in Appalachian Region," Am. Assoc. Pet, Geol. Bull. 62, 2379-2411 (1978). 
HOUSEKNECHT 1978. D. W. Houseknecht and F. G. Ethridge, "Depositional History of the Lamotte Sandstone of Southeastern Missouri," J. Sediment Petrol. 48, 575-586 (1978).

HOWARD 1966. J. D. Howard, "Patterns of Sediment Dispersal in the Fountain Formation of Colorado," M. Geol. 3, 147-153 (1966).

HOWARD 1965. L. W. Howard and W. H. Schoewe, "The Englevale Channel Sandstone," Kans. Acad. Sci. Trans. 68, 1965, pp. 88-106.

HOWELL 1982. D. G. Howell and W. R. Normark, "Sedimentology of Submarine Fans," in p. a. Scholle and D. Spearing (eds.), Sandstone Depositional Environments, A.A.P.G. Men. No. 31, 1982, pp. $\frac{365-404 .}{\text {. }}$

HRABAR 1969. S. V. Hrabar and P. E. Potter, "Lower West Baden

(Mississippi) Sandstone Body of Owen and Green Counties, Indiana," Am. Assoc. Pet. Geol. Bull. 53, 2150-2160 (1969).

HSU 1977a. K. J. Hsu, "Studies of Ventura Field, California, I: Facies Geometry and Genesis of Lower P1iocene Turbidites," Am. Assoc. Pet. Geo1. Bull. 61, 137-168 (1977a).

HSU 1977b. K. J. Hsu, "Studies of Ventura Field, California, II: Lithology, Compaction and Permeability of Sands," Am. Assoc. Pet. Geol. Bu11. 61, 169-191 (1977b).

HUBERT 1960. J. F. Hubert, "Petrology of the Fountain and Lyons Formations, Front Range, Colorado," Col. Sch. Mines Quart. 55(1), 1-242 (1960).

HUBERT 1972. J. F. Hubert, "Sedimentology of Upper Cretaceous CodyParkman Delta, Southwestern Powder River Basin, Wyoming," Geol. Soc. Am. Bul1. 83, 1649-1670 (1972).

HUBERT 1976. J. F. Hubert, A. A. Reed, and P. J. Carey, "Paleogeography of the East Berlin Formation, Newark Group, Connecticut Valley," Am. J. Sci. 276, 1183-1207 (1976).

INGERSOLL 1978. R. V. Ingerso11, "Submarine Fan Facies of the Upper Cretaceous Great Valley Sequence, Northern and Central California," Sediment Geol. 21, 205-230 (1978).

INGERSOLL 1981. R. V. Ingersoll and W. R. Dickinson, "Great Valley Group (Sequence), Sacramento Valley, California," in V. Frizzell (ed॰), Upper Mesozoic Franciscan Rocks and Great Valley Sequence, Central Coast Ranges, California, Pacific Section, S.E.P.M. Guidebook, Vo1. 1, 1981, pp. 1-33.

JACKSON 1975. R. G. Jackson, "Velocity-Bed-Form-Texture Patterns of Meander Bends in the Lower Wabash River of Illinois and Indiana," Geol. Soc. Am. Bull. 86, 1511-1522 (1975). 
JACKSON 1976. R. G. Jackson, "Depositional Model of Point Bars in the Lower Wabash River," J. Sediment Petro1. 46, 579-594 (1976).

JANSA 1975. L. F. Jansa, "Tidal Deposits in the Monkman Quartzite (Lower Ordovician), Northeastern British Columbia, Canada," in R. N. Ginsburg (ed॰), Tidal Deposits, Springer-Verlag, New York, 1975, 153-161.

JOHNSON 1977. H. D. Johnson, "Shallow Marine Sandbar Sequences: An Example from the Late Precambrian of North Norway," Sedimentology 24, 245-270 (1977).

KEIGHIN 1981. C. W. Keighin and T. D. Fouch, "Depositional Environments and Diagenesis of Some Nonmarine Upper Cretaceous Reservoir Rocks, Uinta Basin, Utah," in F. G. Ethridge and R. M. Flores (eds॰), Recent and Ancient Nonmarine Depositional Environments: Models For Exploration, S.E.P.M. Spec. Publ. No. 31, 1981, pp. 109-125.

KITELEY 1984. L. W. Kiteley and M. E. Field, "Shallow Marine Depositional Environments in the Upper Cretaceous of Northern Colorado," in R. W. Tillman and C. T. Siemers (eds.), Siliciclastic Shelf Sediments, S.E.P.M. Spec. Pub1. No. 34, 1984, pp. 179-204.

KLEIN 1963. G. deV. Klein, "Analysis and Review of Sandstone Classifications in the North American Literature, 1940-1960," Geo1. Soc. Am. Bul1. 74, 555-576 (1963).

KLEIN 1975a. G. deV. Klein, "Paleotidal Range Sequences, Middle Member, Wood Canyon Formation (Late Precambrian), Eastern California and Western Nevada," in R. N. Ginsburg (ed.), Tidal Deposits, Springer-Verlag, New York, 1975a, pp. 171-177.

KLEIN 1975b. G. deV. Klein, "Tidalites in the Eureka Quartzite (Ordovician), Eastern California and Western Nevada," in R. N. Ginsburg (ed•), Tidal Deposits, Springer-Verlag, New York, 1975b, pp. 145-151.

KLEIN 1977. G. deV. Klein, Clastic Tidal Facies, Continuing Education Publication Co., Champaign, Illinois, 1977, 149 pp.

KNIGHT 1929. S. H. Knight, "The Fountain and the Casper Formations of the Laramie Basin," Univ. Wyom. Pub1. Sci. 1(1), 1-82 (1929).

KOCUREK 1981. G. Kocurek and R. H. Dott, Jr., "Distinctions and Uses of Stratification Types in the Interpretation of Eolian Sand," J. Sediment Petro1. 51, 579-595 (1981).

KRYNINE 1948. P. D. Krynine, "The Megascopic Study and Field Classification of Sedimentary Rocks," J. Geol. 56, 130-165 (1948).

KRYNINE 1950. P. D. Krynine, "Petrology, Stratigraphy, and Origin of Triassic Sedimentary Rocks of connecticut," Conn. State Geol. Nat. Hist. Surv., Bull. No. 73, 1950, 247 pp. 
KRYNINE 1951. P. D. Krynine, "A Critique of Geotectonic Elements," Trans. Am. Geophys. Union 32, 743-748 (1951).

LEVORSEN 1967. A. I. Levorsen, Geology of Petroleum, 2d ed, W. H. Freeman, San Francisco, 1967, 72 pp.

LIETZ 1949. W. T. Lietz, "The Performance of the Ten Section 0i1 Field," Tech. Pap. 2643, Trans. Am. Inst. Min. Metall. Pet. Eng. 186, 251-258 (1949).

LINDSEY 1969. D. A. Lindsey, "Glacial Sedimentology of the Precambrian Gowganda Formation, Ontario, Canada," Geol. Soc. Am. Bul1. 80, 1685-1702 (1969).

LINS 1950. T. W. Lins, "Origin and Environment of the Tonganoxie Sandstone in Northeastern Kansas," Kans. State Geol. Surv., Bul1. 86, 105140 (1950).

LOOPE 1984. D. B. Loope, "Eolian Origin of Upper Paleozoic Sandstones, Southeastern Utah," J. Sediment Petro1. 54, 563-580 (1984).

LUPE 1979. R. Lupe and T. S. Ahlbrandt, "Sediments of the Ancient Eolian Environment - Reservoir Inhomogeneity," in E. D. Mckee (ed.), A Study of Global Sand Seas U.S., Geol. Surv., Prof. Pap. 1052, 1979, pp. 241-252.

MACK 1980. G. H. Mack, "Stratigraphy and Depositional Environments of the Chilhowee Group (Cambrian) in Georgia and Alabama," Am. J. Sci. 280, 247-517 (1980).

MacKENZIE 1972. D. B. MacKenzie, "Tidal Sand Flat Deposits in Lower Cretaceous Dakota Group Near Denver, Colorado," M. Geol.9, 269-277 (1972).

MacPHERSON 1978. B. A. MacPherson, "Sedimentation and Trapping Mechanism in Upper Miocene Stevens and Older Turbidite Fans of Southeastern San Joaquin Valley, California," Am. Assoc. Pet. Geol. Bu11. 62, 2243-2274 (1978).

MAGLEBY 1965. D. C. Magleby and I. E. Klein, Ground-Water Conditions and Potential Pumping Resources Above the Corcoran Clay - An Addendum to the Groun-Water Geology and Resources Definite Plan Appendix, 1963, U.S., Bur. Reclamation, Open-File Report, 1965, 21 plates.

MANKIEWICZ 1979. D. Mankiewicz and J. R. Steidtmann, "Depositional Environments and Diagenesis of the Tensleep Sandstone, Eastern Big Horn Basin, Wyoming," in P. A. Scholle and P. R. Schluger (eds.), Aspects of Diagenesis, S.E.P.M. Spec. Pub1. No. 26, 1979, pp. 319-336.

MARTIN, 1963. B. Martin, "Rosedale Channe1-Evidence for Late Miocene Submarine Erosion in Great Valley of California," Am. Assoc. Pet. Geol. Bu11. 伊, 价1-156 (1963)。 
MCBRIDE 1962. E. F. McBride, "Flysch and Associated Beds of the Martinsburg Formation (Ordovician), Central Appalachians," J. Sediment. Petro1. 32, 39-91 (1962).

McCALEB 1979. J. A. McCaleb, "The Role of the Geologist in Exploitation," Course notes, Am. Assoc. Pet. Geol. Reservoir Fundamentals School, Vail, Colorado, Ju1y 9-13, 1979, 42 p.

McCAVE 1969. I. N. McCave, "Correlation of Marine and Non-Marine Strata with example from Devonian of New York State," Am. Assoc. Pet. Geol. Bul1. 53, 155-162 (1969)。

MCCUBBIN 1969. D. G. McCubbin and M. J. Brady, "Depositional Environment of the Almond Reservoirs, Patrick Draw Field, Wyoming," M. Geol. 6, 3-26 (1969).

McCUBBIN 1972. Do Go McCubuin, "Facies and Paleocurxents of Gallup Sandstone, Model for Alternating Deltaic and Strand-Plain Progradation" (abstract), Am. Assoc. Pet.Geol. Bu11.56, 638 (1972).

MCCUBBIN 1982. D. G. McCubbin, "Barrier-Island and Strand-Plain Facies," in P. A. Scholle and D. Spearing (eds.), Sandstone Depositional Environments, A.A.P.G. Mern。 No. 31, 1982, pp. 247-279.

McGOWEN 1971. J. H. McGowen and C. G. Groat, Van Horn Sandstone, West Texas - An Alluvial Fan Model for Mineral Exploration, Tex. Bur. Econ. Geol. Rep. Invest No. 72, 1971, 57 pp.

McGREGOR 1968. A. A. McGregor and C. A. Biggs, "Bell Creek Field, Montana: A Rich Stratigraphic Trap," Am.Assoc. Pet. Geol. Bull. 52, $1869-1887$ (1968)。

MCKEE 1967. E. D. McKee and H. L. Berryhi11, "Flood Deposits, Bijou Creek, Colorado," J. Sediment Petrol. 37, 829-851 (1967).

MCLEAN 1981. H. McLean, "Reservoir Properties of Submarine-Fan Facies: Great Valley Sequence, California," J. Sediment Petrol. 51, 865-872 (1981).

MECKEI 1967. L. D. Mecke1, "Origin of Pottsville Conglomerates (Pennsylvanian) in the Central Appalachians," Geol. Soc. Am. Bu11.78, 223-258 (1967).

MOORE 1978. G. T. Moore, G. W. Starke, L. C. Bonham, and H. O. Woodbury, "Mississippi Fan, Gulf of Mexico - Physiography, Stratigraphy, and Sedimentational Patterns," in A. H. Bouma, G. T. Moore, and J. M. Coleman (eds.), Framework, Facies and 0il Trapping Characteristics of the Upper Continental Margin, A.A.P.G., Stud. Geol. No. 7, 1978, pp. 155-191.

MORRIS 1974. R. C. Morris, "Carboniferous Rocks of the Ouachita Mountaino, Arkansas $\Lambda$ otudy of Facica Pattcrno Mlong the Unotable Slope and Axis of a Flysch Trough," in G. Briggs, (ed.), Symposium on the Carboniferous Rocks of the Southeastern United States, Geol. Soc. Am. Spec. Pap. No. 148, 1974, pp. 241-279. 
MORRIS 1979. R. C. Morris, K. E. Proctor, and M. R. Koch, "Petrology and Diagenesis of Deep-Water Sandstones, Ouachita Mountains, Arkansas and Oklahoma," in P. A. Scholle, and P. R. Schluger (eds.), Aspects of Diagenesis, S.E.P.M. Spec. Pub1. No. 26, 1979, pp. 263-279.

MURPHY 1962. M. A. Murphy and S. O. Schlanger, "Sedimentary Structures in Ilhas and Sao Sebastion Formations (Cretaceous) Reconcavo Basin, Brazil," Am. Assoc. Pet. Geol. Bull. 46, 457-477 (1962).

MUSKAT 1946. M. Muskat, The Flow of Homogeneous Fluids Through Porous Media, J. W. Edwards, Ann Arbor, Michigan, 1946, 763 pp.

NAMI 1976. M. Nami, "An Exhumed Jurassic Meander Belt from Yorkshire, England," Geol. Mag. 113, 47-52 (1976).

NAMI 1978. M. Nami and Mo R. Leeder, "Changing Channel Morphology and Magnitude in the Scalby Formation (M. Jurassic) of Yorkshire, England," in A. D. Miall (ed.), Fluvial Sedimentology, Can. Soc. Pet. Geol. Mem. No. 5,1978 , pp. 431-440.

NANZ 1954. R. H. Nanz, Jr., "Genesis of 0ligocene Sandstone Reservoir, Seeligson Field, Jim Wells and Kleberg Counties, Texas," Am. Assoc. Pet. Geol. Bull. 38, 96-117 (1954).

NARAYAN 1971. J. Narayan, "Sedimentary Structures in the Lower Greensand of the Weald, England, and Bas-Boulonnais, France," Sediment Geo1. 6, 73-109 (1971).

NILSEN 1969. T. H. Nilsen, "Old Red Sedimentation in the BuelandetVaerlandet Devonian District, Western Norway," Sediment Geol. 3, 35-57 (1969).

NILSEN 1973, T. H. Nilsen, "Devonian (O1d Red Sandstone) Sedimentation and Tectonics of Norway," in M. D. Pitcher (ed.), Arctic Geology, A.A.P.G. Mem. No. 19, 1973, pp. 471-481.

NIO 1976. S. D. Nio, "Marine Transgression as a Factor in the Formation of Sand Wave Complexee," Ceol. Mijnbouw 55, 18-40 (1976).

NIO 1978. S. D. Nio and J. C. Siegenthaler, A Lower Eocene EstuarineShelf Complex in the Isabena Valley, State Univ. Utrecht, Sedimentology Group, Rep. No. 18, 1978, pp. 1-44.

NORMARK 1968. W. R. Normark and J. R. Curray, "Geology and Structure of the Tip of Baja California, Mexico," Geol. Soc. Am. Bull. 79, 1589-1600 (1968).

NORMARK 1970. W. R. Normark, "Growth Patterns of Deep-Sea Fans," Am. Assoc. Pet. Geo1. Bu11. 54, 2170-2195 (1970). 
NORMARK 1978. W. R. Normark, "Fan Valleys, Channels, and Depositional Lobes on Modern Submarine Fans: Characters for Recognition of Sandy Turbidite Environments," Am. Assoc. Pet. Geol. Bu11.62, 912-931 (1978).

OJAKANGAS 1980. R. W. Ojakangas and C. L. Matsch, "Upper Precambrian (Eocambrian) Mineral Fork Tillite of Utah: A Continental Glacial and Glaciomarine Sequence," Geol. Soc. Am. Bul1. 91, 495-501 (1980).

OVENSHINE 1975. A. T. Ovenshine, "Tidal Origin of Parts of the Karheen Formation (Lower Devonian), Southeastern Alaska," in R. N. Ginsburg (ed.), Tidal Deposits, Springer-Verlag, New York, 1975, pp. 127-133.

PAYNE 1976. M. W. Payne, "Basinal Sandstone Facies, Delaware Basin, West Texas and Southeast New Mexico," Am. Assoc. Pet. Geol. Bu11.60, 517-527 (1976).

PETERSON 1968. J. A. Petersun, A. J. Loleil, C. W. Spencer, and R. A. U11rich, "Sedimentary History and Economic Geology of San Juan Basin, New Mexico and Colorado," in J. E. Galley, (ed.), Subsurface Disposal in Geologic Basins - A Study of Reservoir Strate, A.A.P.G. Mern. No. 10. 1968 , pp. 186-231.

PETTIJOHN 1972. F. J. Pettijohn, P. E. Potter, and R. Siever, Sand and Sandstone, Springer-Verlag, New York, 1972, 618 pp.

PETTIJOHN 1975. F. J. Pettijohn, Sedimentary Rocks, 3d ed., Harper and Row, New York, 1975, 628 pp。

PIERSOL 1940. R. J. Piersol, L. E. Workman, and M. C. Watson, "Porosity, Total Liquid Saturation, and Permeability of I11inois $0 i 1$ Sands, "I11. State Geo1. Surv. Rep. Invest. No. 67, 1940.

PORTER 1976. K. W. Porter, "Marine Shelf Model, Hygiene Member of Pierre Shale, Upper Cretaceous, Denver Basin, Colorado," in R. C. Epis and R. J. Weimer (eds.), Studies in Colorado Field Geology, Prof. Contrib. Colo. Sch. Mines No. 8, 1976, pp. 251-271.

POTTER 1962. P. E. Potter, Late Mississippian Sandstones of Illinois Basin, I11. State Geol. Surv., Circ. No. 340, 1962, 36 pp.

POTTER 1963. P. E. Potter, Late Paleozoic Sandstones of the Illinois Basin, II1. State Geol. Surv., Rep. Invest. No. 217, 1963, 92 pp.

PRYOR 1960. W. A. Pryor, "Cretaceous Sedimentation in Upper Mississippi Embayment," Am. Assoc. Pet. Geol. Bu11.44, 1473-1504 (1960).

PRYOR 1961. W. A. Pryor, "Sand Trends and Paleoslope in Illinois Basin and Mississippi Embayment," in J. A. Peterson and J. Co Osmond (eds.), Geometry of Sandstone Bodies, A.A.P.G. Spec. Publ. 1961, pp. 119-133.

PRYOR 1971. W. A. Pryor and E. J. Amaral, "Large-Scale CrossStratification in the St. Peter Sandstone," Geo1. Soc. Am. Dul1. 02, 239-244 (1971). 
PRYOR 1973. W. A. Pryor, "Permeability-Porosity Patterns and Variations in Some Holocene Sand Bodies," Am. Assoc. Pet. Geol. Bul1. 57, 162-189 (1973).

PUIGDEFABREGAS 1973. C. Puigdefabregas, "Miocene Point-Bar in the Ebro Basin, Northern Spain," Sedimentory 20, 133-144 (1973)。

PUIGDEFABREGAS 1978. C. Puigdefabregas and A. Van V1iet, "Meandering Stream Deposits from the Tertiary of the Southern Pyrenees," in A. D. Miall (ed.), Fluvial Sedimentology, Can. Soc. Petrol. Geol. Mem. No. 5, 1978 , pp. $469-486$.

RAAF, de 1965. J. F. M. Raaf, de, H. G. Reading, and R. G. Walker, "Cycilc Sedimentation in Lower Westphalian of North Devon, England," Sedimentology $4,1-52$ (1965).

RAAF, de 1971. J. F. M. Raaf, de and J. R. Boersma, "Tidal Deposits and Their Sedimentary Structures (Seven Examples fron Western Europe)," Geol. Mijnbouw 50, 479-504 (1971).

READING 1Y/8. H. G. Reading, Sedimentary Environments and Facies, E1sevier, New York, 1978, 557 pp.

READING 1966. H. G. Reading and R. G. Walker, "Sedimentation of Eocambrian Tillites and Associated Sediments in Finnmark, Northern Norway," Paleogeogr., Paleoclimatol., Paleoecol. 2, 177-212 (1966).

REINECK 1980. H.-E. Reineck and I. B. Singh, Depositional Sedimentary Envi ronments, 2d ed., Springer-Verlag, New York, 1980, 549 pp.

REINSON 1979. G. E. Reinson, "Facies Models 14: Barrier Island Systems," in R. G. Walker (ed.), Facies Models, Geoscience Canada, Reprint Ser. 1, 1979, pp. 57-74.

KICE 1984. D. W. K1ce, "W1despread, Shallow-Marine, Storm-Generated Sandstone Units in the Upper Cretaceous Mosby Sandstone, Central Montana," in R. W. Tillman and C. T. Siemers (eds.), Siliciclastic Shelf Sediments, S.E.P.M., Spec. Pub1. No. 34, 1984, pp. 143-161.

ROBERTSON 1976. J. A. Robertson, "The Blind River Uranium Deposits the Ores and their Setting," Ont. Div. Mines, Misc. Pap. No. 65, 1976, $45 \mathrm{pp}$.

RUBEY 1925. W. W. Rubey and N. W. Bass, "Geology of Russell county, Kansas," Kans., State Geol. Surv., Bul1. No. 10, 1925, pp. 1-86.

RUST 1972. B. R. Rust, "Structure and Process in a Braided River," Sedimentology $18,221-246$ (1972).

RUST 1976. B. R. Rust, "Stratigraphic Relationships of the Malbaie Formation (Devonian) Gaspe, Quebec," Can. J. Earth Sci. 13, 1556-1559 (1976). 
RYDER 1976. R. T. Ryder, T. D. Fouch, and J. H. Elison, "Early Tertiary Sedimentation in the Western Uinta Basin, Utah," Geol. Soc. Am. Bull. 87, 496-512 (1976).

SABINS 1963. F. F. Sabins, Jr., "Anatomy of Stratigraphic Traps, Bisti Oil Fields, New Mexico," Am. Assoc. Pet. Geol. Bul1. 47, 193-228 (1963).

SANDERSON 1974. I. D. Sanderson, "Sedimentary Structures and Their Environmental Significance in the Navajo Sandstone, San Rafael Swe11, Utah," Brigham Young Univ. Res. Stud., Geo1. Ser. 21, 215-246 (1974).

SCHLEE 1961. J. S. Schlee and R. H. Moench, "Properties and Genesis of "Jackpile" Sandstone, Laguna, New Mexico," in J. A. Peterson and J. C. osmond (eds.), Geometry of Sandstone Bodies, A.A.P.G., Spec. Pub1.1961, p. 134-150.

SCHLUGER 1973. R. Ro Schluger, "Stratigraphy and Sedimentary

Environments of the Devonian Perry Formation, New Brunswick, Canada, and Maine, U.S.A.," Geol. Soc. Am. Bu11. 84, 2533-2548 (1973).

SCHMIDT 1979. V. Schmidt and D. A. McDonald, "The Role of Secondary Porosity in the Course of Sandstone Diagenesis," in P. A. Scholle and P. R. Schluger (eds.), Aspects of Diagenesis, S.E.P.M., Spec. Publ. No. 26,1979 , pp. $175-2 \overline{07}$.

SCHOLLE 1979. P. a. Scholle, A Color Illustrated Guide to Constituents, Textures, Cements and Porosities of Sandstones and Associated Rocks,

A.A.P.G., Mem. No. 28, 1979, 201 pp.

SCHUMM 1972. S. A. Schumm, "Fluvial Paleochannels," in J. K. Rigby and W. K. Hamblin (eds.), Recognition of Ancient Sedimentary Environments, S.E.P.M॰, Spec. Pub1. No. 16, 1972, pp. 98-107.

SCHWAB 1977. F. L. Schwab, "Grandfather Mountain Formation: Depositional Environment, Provenance, and Tectonic Setting of Late Precambrian Alluvium in the Blue Ridge of North Carolina," J. Sediment Petrol. 47, 800-810 (1977).

SEELING 1978. A. Seeling, "The Shannon Sandstones, A further Look at the Environment of Deposition at Heldt Draw Field, Wyoming," M. Geol. 15, 133-144 (1978).

SELLEY 1970. R. C. Selley, Ancient Sedimentary Environments, Chapman and Ha11, London, 1970,237 pp.

SELLEY 1976. R. C. Selley, "Subsurface Environmental Analysis of North Sea Sediments," Am. Assoc. Pet. Geol. Bul1.60, 184-195 (1976).

SELLEY 1978. R. C. Selley, "Porosity Gradients in North Sea Dil-Bearing Sandstones," J. Geol. Soc., London 135, 119-132 (19778).

SHANNON 1971. J. P. Shannon, Jr, and A. R. Dah1, "Deltaic Stratigraphic Traps in West Tuscola Field, Taylor County, Texas," Am. Assoc. Pet. Geol. Bu11. 55, 1194-1205 (1971). 
SHARP 1948. R. P. Sharp, "Early Tertiary Fanglomerate, Big Horn Mountains, Wyoming," J. Geol. 56, 1-15 (1948).

SHELTON 1965. J. W. She1ton, "Trend and Genesis of Lowermost Sandstone Unit of Eagle Sandstone at Billings, Montana," Am. Assoc. Pet. Geol. Bu11. 49, 1385-1397 (1965).

SHELTON 1967. J. W. Shelton, "Stratigraphic Models and General Criteria for Recognition of Alluvial, Barrier-Bar, and Turbidity-Current Sand Deposits," Am. Assoc. Pet. Geol. Bul1. 51, 2441-2461 (1967).

SHORT 1967. K. C. Short and A. J. Stauble, "Outline of Geology of Niger Delta," Am. Assoc. Pet. Geol. Bu11. 51, 761-779 (1967).

SHURR 1984. G. W. Shurr, "Geometry of Shelf Sandstone Bodies in the Shannon Sandstone of Southeastern Montana," in R. W. Tillman and C. T. Siemers (eds॰), siliciclastic Shelf Sediments, S.E.P.M., Spec. Publ. No. $34,1984, \mathrm{pp} .63-83$.

SIBLEY 1976. D. F. Sibley and H. Blatt, "Intergranular Pressure Solution and Cementation of the Tuscarora Orthoquartzite," J. Sediment Petrol. 46, 881-896 (1976).

SIEVER 1951. R. Siever, "The Mississippi-Pennsylvanian Unconformity in Southern Illinois," Am. Assoc. Pet.Geol. Bull. 35, 542-581 (1951).

SKIPPER 1975. K. Skipper and G. V. Middleton, "The Sedimentary Structures and Depositional Mechanics of Certain Ordovician Turbidites, Cloridorme Formation, Gaspe Peninsula, Quebec," Can. J. Earth Sci. 12, $1934-1952$ (1975).

SMITH 1970. N. D. Smith, "The Braided Stream Depositional Environment: Comparison of the Platte river with Some Silurian Clastic Rocks," Geol. Soc. Am. Bul1. 81, 2993-3014 (1970).

SMITH 1971. N. D. Smith, "Transverse Bars and Braiding in the Lower P1atte river, Nebraska," Geol. Soc. Am. Bul1. 82, 3407-3420 (1971).

SOISTER 1968. P. E. Soister, Stratigraphy of the Wind River Formation in South-Central Wind River Basin, Wyoming, U.S. Geol. Surv. Prof. Pap. No. 594-A, 1968, pp. A1-A50.

SPEARING 1975. D. R. Spearing, "Shallow Marine Sands," in J. C. Harms, J. B. Southard, D. R. Spearing, and R。 Go Walker (eds。), Depositional Environments as Interpreted from Primary Sedimentary Structures and Stratification Sequences, S.E.P.M. Short Course Notes No. 2, 1975, pp. 103-132.

SPEARING 1976. D. R. Spearing, "Upper Cretaceous Shannon Sandstone: An Offshore, Shallow Marine Sand Body," Wyo. Geol. Assoc. Guide. 28th Annu. Field Conf. , 65-72. 
SPENCER 1975. A. M. Spencer, "Late Precambrian Glaciation in the North Atlantic Region," in a. E. Wright and F. Moseley (eds.), Ice Ages; Ancient and Modern, Seel House Press, Liverpoo1, 1975, pp。 $7-42$

STEEL 1976. R. J. Steel, "Devonian Basins of Western Norway-Sedimentary Response to Tectonism and to Varying Tectonic Context, "Techtonophsics $36,207-224$ (1976).

STEEL 1977. R. J. Steel, "Triassic Rift Basins of Northwest Scotland-Their Configuration, Infililg, and Development, " in $K$. G. Finstad and R. C. Selley (coordinators), Proceedings of the Mesozoic Northern North Sea Symposium, Norwegian Pet. Soc., MNNSS-77, 1977, pp. 1-18.

STEIDTMANN 1971. J. R. Steidtmann, "Origin of the Pass Peak Formation and Equivalent Early Eocene Strata, Central Western Wyoming," Geol. Soc. An. Bu11. 82, 156-176 (1971).

STETDTMANN 1974. J. R. Steidtmann, "Evidence for Eolian Origin of Cross-Stratification in Sandstone of the Casper Formation, Southermost Laramie Basin, Wyoming," Geol. Soc. Am. Bul1. 85, 1835-1842 (1974).

STOKES 1961. W. L. Stokes, "Fluvial and Eolian Sandstone Bodies in Colorado Plateau," in J. A. Peterson and J. c. Osmond (eds.), Geometry of Sandstone Bodies, A.A.P.G., Spec. Publ., 1961, pp. 151-178.

SULLWOOD 1960. H. H. Sullwood, Jr., "Tarzana Fan, Deep Subnarine Fan of Late Miocene Age, Los Angeles County, California," Am. Assoc. Pet. Geol. Bul1. 44, 433-457 (1960)。

SULLWOOD 1961. H. H. Sullwood, Jr., "Turbidites in Oil Exploration," in J. A. Peterson and J. C. Osmond (eds.), Geometry of Sandstone Bodies, A.A.P.G., Spec. Publ., 1961, pp. 63-81.

SWAGOR 1976. N. S. Swagor, T. A. Oliver, and B. A. Johnson, "Carrot Creek Field, Central Alberta," in M. M. Lerand (eds.), The Sedimentology of Selected Clastic $0 i 1$ and Gas Reservoirs in Alberta, Can. Soc. Pet. Geol., 1961, pp. 78-95.

SWANN 1964. D. H. Swann, "Late Mississippian Rhythmic Sediments of Mississippi Valley," Am. Assoc. Pet. Geol. Bu11.48, 637-658 (1964).

SWEET 1971. K. Sweet, G. deV. Klein, and D. E. Smith, "A Cambrian Tidal Sand Body - The Eribol1 Sandstone of Northwest Scotland: An AncientAnalog," J. Geo1. 79, 400-415 (1971).

TANKARD 1977. A. J. Tankard and D. K. Hobday, "Tide-Dominated Back Barrier Sedimentation, Early Ordovician Cape Basin, Cape Peninsula, South Africa," Sediment. Geol. 18, 135-160 (1977).

THOMAS 1974. A. N. Thomas, P. J. Walmsley, and D. A. L. Jenkins, "Furlies Fiela, Nulllı Sed," All. Assuc. Pet. Geol. Bull. 58, 396406 (1974). 
THOMAS 1966. W. A. Thomas and C. J. Mann, "Late Jurassic Depositional Environment, Louisiana and Arkansas," Am. Assoc. Pet. Geo1. Bu11. 50, $170-182(1966)$.

TIEJE 1923. A. J. Tieje, "The Red Beds of the Front Range of Colorado: A Study in Sedimentation," J. Geol. 31, 192-207 (1923).

TILLMAN 1984. R. W. Tillman and R. S. Martinsen, "The Shannon ShelfRidge Sandstone Complex, Salt Creek Anticline Area, Powder River Basin, Wyoming," in R. W. Tillman and C. T. Siemers (eds.), Siliciclastic Shelf Sediments, S.E.P.M., Spec. Publ. No. 34, 1984, pp.85-142.

TIZZARD 1975. P. G. Tízzard and J. F. Lerbekmo, "Depositional History of the Viking Formation, Suffield Area, Alberta, Canada, Bull, Can. Pet. Geol. 23, 715-752 (1975).

TUCKER 1981. M. E. Tucker, Sedimentary Petrology - An Introduction, John Wiley and Sons, New York, 1981, 252 pp.

TURNER 1984. J. R. Turner and S. J. Conger, "Environment of Deposition and Reservoir Properties of the Woodbine Sandstone at Kurten Field, Brazos Co., Texas," in R. W. Til1man and C. T. Siemers (eds.), Siliciclastic Shelf Sediments, S.E.P.M. Spec. Pub1. No. 34, 1984, pp. 215-249.

TYLER 1983. N. Tyler and F. G. Ethridge, "Depositional Setting of the Salt Wash Member of the Morrison Formation, Southwest Colorado," J. Sediment Petrol. 53, 67-82 (1983).

UYGUR 1980. K. Uygur and M. D. Picard, "Reservoir Characteristics of Jurassic Navajo Sandstone, Southern Utah," Utah Geol. Assoc., Henry Mountains Symp. 1980, pp. 277-286.

Van de GRAAFF 1972. F. R. Van de Graaff, "Fluvial-Deltaic Facies of the Castlegate Sandstone (Cretaceous), East-Centra1 Utah," J. Sediment Petrol. 42, 558-571 (1972).

Van de KAMP 1973. P. C. Van de Kamp, "llolocene Continental Sedimentation in the Salton Basin, California, A Reconnaissance," Geol. Soc. Am. Bul1. 84, 827-848 (1973).

Van de KAMP 1974. P. C. Van de Kamp, J. D. Harper, J. J. Conniff, and D. A. Morris, "Facies Relations in the Eocene-01igocene in the Santa Ynez Mountains, California," J. Geol. Soc., London, 130, 545-565 (1974).

Van HOUTEN 1962. F. B. Van Houten, "Cyclic Sedimentation and the Origin of Analcime-Rich Upper Triassic Lockatong Formation, West-Central New Jersey and Adjacent Pennsylvania," Am. J. Sci. 260, 561-576 (1962).

Van HOUTEN 1964. F. B. Van Houten, "Cyclic Lacustrine Sedimentation, Upper Triassic Lockatong Formation, Central New Jersey and Adjacent rennsylvania," Kans. State Geol. Surv. Bull. 169, 1969, pp. 497-531. 
Van HOUTEN 1965. F. B. Van Houten, "Crystal Casts in Upper Triassic Lockatong and Brunswick Formations," Sedimentology 4, 301-313 (1965).

VISHER 1971. G. S. Visher, B. S. Saitta, and R. S. Phares, "Pennsylvanian Delta Patterns and Petroleum Occurrences in Eastern Oklahoma," Am. Assoc. Pet. Geol. Bul1. 55, 1206-1230 (1971).

Von BRUNN 1976. V. Von Brunn and D. K. Hobday, "Early Precambrian Tidal Sedimentation in the Pongola Supergroup of South Africa," J. Sediment Petrol. 46, 670-679 (1976).

WALKER 1966a. R. G. Walker, "Deep Channels in Turbidite-Bearing Formations," Am. Assoc. Pet. Geol. Bull. 50, 1899-1917 (1966a).

WALKER 1966b. R. G. Walker, "Shale Grit and Grindslow Shales; Transition from Turbidite to Shallow Water Sediments in the Upper Carboniferous of Northern England, J. Sediment Petrol. 36, 90-114 (1966b).

WALKER 1978. R. C. Walkor, "Doep Water Sandstone Facies and Ancient Submarine Fans: Models for Exploration for Stratigraphic Traps," Am. Assoc. Pet. Geol. Bu11. 62, 932-966 (1978).

WALKER 1972. T. R. Walker and J. C. Harms, "Eolian Origin of Flagstone Beds, Lyons Sandstone (Permian), Type Area, Boulder Country, Colorado," M. Geol. 9, 279-288 (1972).

WALKER 1979. R. G. Walker (ed.), Facies Models, Geoscience Canada, Reprint Ser. 1, Geol. Assoc. Can. 1979, 211 pp.

WANLESS 1970. H. R. Wanless, J. R. Baroffio, J. R. Gamble, J. C. Horne, D. R. Orlopp, A. Rocha-Campos, J. E. Souter, P. C. Trescott, R. S. Vail, and C. R. Wright, "Late Paleozoic Deltas in the Central and Eastern Inited States," in J. P. Morgan and R. H. Shaver (ods.), Deltaie Sedimentation, Modern and Ancient, S.E.P.M. Spec. Pub1. No. 15, 1970, pp. 215-245.

WATCHORM 1980. M. B. Watchorm, "Fluvial and Tidal Sedimentation in the 300 Ma Mozaan Basin, South African," Precambrian Res.13, 27-42 (1980).

WFACANT 1972. F. E. Weagant, "Grimes Gas Field, Sacramento Valley, California," in R. E. King (ed.), Stratigraphic Oil and Gas Fields, A.A.P.G. Mem. No. 16, 1972, pp. 428-439.

WEIMER 1966. R. J. Weimer, "Time-Stratigraphic Analysis and Petroleum Accumulations, Patrick Draw Field, Sweetwater County, Wyoming," Am. Assoc. Pet. Geo1. Bul1. 50, 2150-2175 (1966).

WEIMER 1972. R. J. and C. B. Land, "Field Guide to Dakota Group (Cretaceous) Stratigraphy, Golden-Morrison Area, Colorado," M. Geol.9, 241-267 (1972). 
WEIMER 1982. R. J. Weimer, J. D. Howard, and D. R. Lindsay, "Trial Flats and Associated Tidal Channels," in P. a. Scholle and D. Spearing (eds.), Sandstone Depositional Environments, A.A.P.G. Mem. No. 31, 1982, pp. 191-245.

WILLIAMS (a) 1969. G. E. Williams, "Characteristics and Origin of a precambrian Pediment," J. Geology 77, 183-207 (1969)。

WILLIAMS (b) 1969. P. F. Williams and B. R. Rust, "The Sedimentology of a Braided River," J. Sediment Petrol. 39, 649-679 (1969).

WILSON 1970. M. D. Wilson, "Upper Cretaceous-Paleocene Synrogenic Conglomerates of south-Western Montana," Am. Assoc. Pet. Geo1. Bu11. 54, 1843-1867 (1970).

WRIGHT 1981. M. E. Wright and R. G. Walker, "Cardium Formation (U. Cretaceous) at Seebe, Alberta-Storm Transported Sandstones and Conglomerates in Shallow Marine Depositional Environments Below Fairweather Wave Base," Can. J. Earth Sci. 18, 795-809 (1981). 
This page intentionally left blank 
APPEND IX E.4

GEOLOGIC CHARACTERISTICS OF CHALK

D. E. HATTIN

DEPARTMENT OF GEOLOGY

INDTANA UNIVERSITY

BLOOMINGTON, INDIANA 47405 
This page intentionally left blank 


\section{CONTENTS}

Page

E.4.1 DEFINITION OF ROCK TYPE ................ 381

E.4.1.1 GENERAL NATURE OF CHALK. . . . . . . . . . 381

E.4.1.2 VARIETIES. . . . . . . . . . . . . . 381

E.4.1.3 OTHER FEATURES ............... 382

E.4.1.4 CHALKS COVERED IN THIS REPORT.......... 382

F.4.? GFOIOGTC ENVTRONMFNT OF CHALK . . . . . . . . . . . . 383

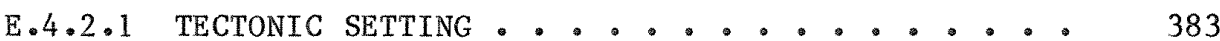

E.4.2.1.1 Oceanic Chalk.......... 383

E.4.2.1.2 Cratonic Chalk........... 383

E.4.2.1.2.1 Europe ...... 383

E.4.2.1.2.2 North America.... 384

E.4.2.2 DEPOSITIONAL FRAMEWORK ............ 390

F.4.2.2.1 Gulf Coastal Plain........... 390

E.4.2.2.2 Western Interior Region...... 393

E.4.3 GEOMETRY AND DIMENSIONS OF AMERICAN CHALK BODIES . . . . 397

E.4.3.1 GEOMETRY ................... 397

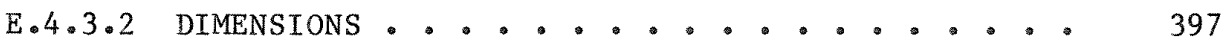

E.4.3.2.1 General Statement ....... 397

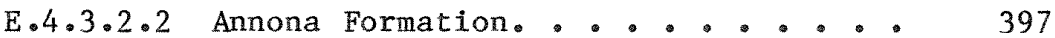

E.4.3.2.3 Austin Chalk......... 400

E.4.3.2.4 Demopolis Chalk........ 401

E.4.3.2.5 Greenhorn Limestone - Fairport Chalk

E.4.3.2.6 Mooreville Formation...... 404

E.4.3.2.7 Niobrara Chalk.......... 404

E.4.3.2.8 Pecan Gap Formation........ 405

E.4.3.2.9 Prairie Bluff Chalk...... 406

E.4.3.2.10 Saratoga Formation......... 406

E.4.3.2.11 Summary ............. 407

E.4.4 CHARACTERISTICS OF CHALK. . . . . . . . . . . . 408

E.4.4.1 LITHOLOGY. .................. 408

E.4.4.1.1 Composition of Chalk. . . . . . 408

E.4.4.1.1.1 Mineralogy . . . . 408

E.4.4.1.1.2 Insoluble Residues. . 412

E.4.4.1.1.3 Chemical Analyses. . . 412

E.4.4.1.2 Texture ........... 420

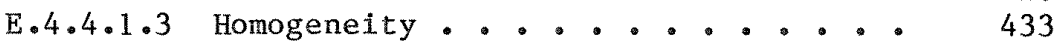

E.4.4.1.3.1 General Considerations. 433

E.4.4.1.3.2 Examples...... 434

E.4.4.1.3.3 Concluding Remarks.. 436

E.4.4.2 BEDDING. . . .................... 436

E.4.4.3 NATURE OF INTERBEDS. . ............ 438

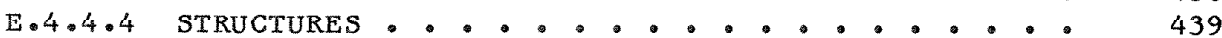


$\underline{\text { Page }}$

E.4.4.4.1 Primary Structures......... 439

E.4.4.4.2 Secondary Structures........ 439

E.4.4.4.2.1 Faults...... 439

E.4.4.4.2.2 Fractures and Joints... 447

E.4.4.5 POROSITY - PERMEABILITY ............. . 454

E.4.5 BOUNDING UNITS. ...................... 465

E.4.5.1 THEORETICAL CONSIDERATIONS ............ 465

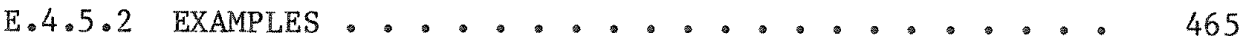

E.4.6 REACTION TO EXTERNAL EVENTS ................. 467

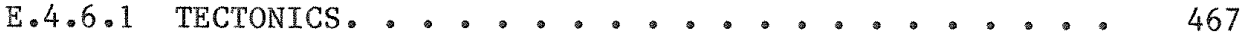

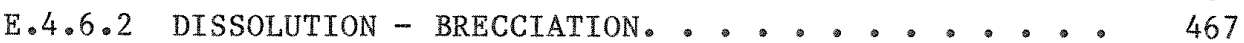

E.4.6.3 WEATHERING AND EROSION ............. 469

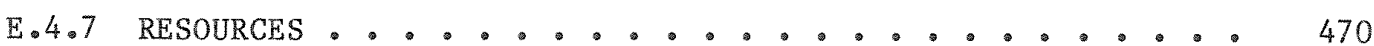

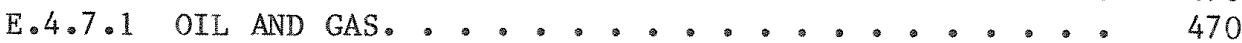

E.4.7.2 WATER....................... 470

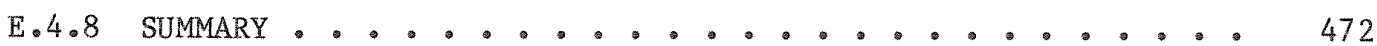

E.4.9 REFERENCES. ....................... 479 


\section{E.4.1 DEFINITION OF ROCK TYPE}

\section{E.4.1.1 GENERAL NATURE OF CHALK}

Chalk is produced by diagenetic alteration of nannoplankton-rich carbonate ooze in both deep-sea and shelf-sea settings. All deposits having sufficient thicknesses and lateral extents to be of interest to readers of this report are of the latter type, so remarks made in this section pertain to shelf-sea chalks.

The term "chalk" has been used as the name for a wide variety of fine-grained pelagic carbonate rocks, and no simple definition suffices to embrace all chalky 1ithotypes. Most authorities agree that the term "chalk" refers usually to a variety of marine limestone that is white to light gray, very fine grained, soft and friable, porous, and composed largely of the calcitic remains of planktonic organisms, especially those derived from the single-celled nannoplanktonic algae known as cocco1ithophores. Scholle (SCHOLLE 1977a) notes that all such deposits undergo progressive lithification as a function of burial depth or other factors so that distinctions between hard and soft nannofossil deposits are arbitrary and lack special significance. Nevertheless, Bromley and Gale (BROMLEY 1982) restricted the term to those chalky rocks that can be deformed readily by the fingernail or knife blade, and coined the name "chalkstone" for the massively lithified equivalent thereof. The purest chalk deposits may contain as much as $99 \% \mathrm{CaCO}_{3}$, practically all of which is low-magnesium calcite. Such chalks are common in Europe and England, but chalks having more than $95 \% \mathrm{CaCO}_{3}$ are uncommon in the United States. Because of their high purity, the classical chalks of England and continental Europe are prevallingly white or light gray, even in the subsurface. Chalks that contain significant amounts of clay and/or organic matter are typically of much darker colors where unweathered, but are usually white, pale shades of gray, yellow, or orange where weathered. Although not restricted thereto, most of the world's chalk is of cretaceous age. Typically, stratigraphic units composed of chalk have exceedingly broad distribution.

\section{E.4.1.2 VARIETIES}

Chalk occurs in many varieties, depending upon degrees of departure from rock having the most typical texture and composition (SCHOLLE 1977a). Relatively pure chalk may grade successively into argillaceous chalk, marl, calcareous shale, and noncalcareous shale - the whole progression of facies reflecting relative distances from sources of very fine-grained terrigenous detritus, or temporal changes in proportions of terrigenous and pelagic carbonate deposition in a given area. Durham (DURHAM 1957) proposed a classification of chalk and related lithotypes based on percentages of terrigenous detritus, with the term "chalk" being reserved for rocks having $95 \%$ or more $\mathrm{CaCO}_{3}$, marly chalk for those having 85 to $95 \% \mathrm{CaCO}_{3}$, chalk marl for those having 75 to $85 \% \mathrm{CaCO}_{3}$, etc. Few writers have used such rigid definitions for the several gradational formal claooification wore to be adoptcd. Gradation to oandy challe, inotcad 
of marly chalk, occurs where chalk deposits were laid down close to shorelines (BOTTJER 1978; WITZKE 1983).

Typical chalk may also grade into calcarenite through intermediate shelly chalk facies that represent progressive increases in quantities of foraminifers, inoceramid prisms, bryozoans, calcispheres, etc. (HATTIN 1975; HANCOCK 1975; BOTTJER 1978).

Addition of intergranular and intragranular cement to a typical soft chalk produces chalky limestone (chalkstone) or even hard, brittle limestone (HATTIN 1971; KENNEDY 1975; MIMRAN 1978). This sort of transition has been documented also for deep-sea deposits (SCHLANGER 1974).

A relatively uncommon variety of chalk is that which has been diluted by pyroclastics. Diagenetic alteration of such material produces bentonitic chalk, which may grade into bentonitic marl when it is located near major bentonite seams (BOTTJER 1978). Interbedding and lateral gradation of chalk and pyroclastic material near a Late Cretaceous eruptive center in Texas have also been reported (YOUNG 1975; MILLER 1978).

Chalk may pass locally into dolomitic chalk, where the carbonate section has been affected by diagenetic addition of magnesium (SCHOLLE 1974; JORGENSEN 1983). Such rock is uncommon among Cretaceous chalk deposits. Glauconitic and phosphatic chalks are common but, like dolomitic chalk, are volumetrically of small importance.

\section{E.4.1.3 OTHER FEATURES}

In addition to coccoliths, chalk may contain carbonate skeletal remains derived from many other organisms, especially including calcispheres, planktonic forams, benthic forams, sponges, corals, bryozoans, articulate brachiopods, diverse molluscan groups (especially inoceramid and ostreid bivalves and belemnites), serpulid worms, and echinoderms (especially echinoids and crinoids) (SURLYK 1974: HANCOCK 1975; SCHOLLE 1983).

Ekdale and Bromley (EKDALE 1984) noted that most shelf-sea chalks are thoroughly biocurbated, and thus have massive structure. This characteristic is true of U.S. Gulf Coast chalks; however, most chalk (marly chalk or chalky marl) of the U.S. Western Interior is laminated and not bioturbated (HATTIN 1975).

\section{E.4.1.4 CHALKS COVERED IN THIS REPORT}

In America a number of rock units have for a long time been called "chalk." Most such units are, indeed, micritic, rich in nannoplankton, high in porosity, and loosely consolidated. Few have the high degree of carbonate purity ( $95 \%$ or more $\mathrm{CaCO}_{3}$ ) that characterizes so much of the European chalk. Because this report is generic in design, its findings are based on data derived from all major American Upper Cretaceous rock units that have been called chalk and that, except for a strict standard of lifgli purtly, pussess olher allribules of Lrue chalk. Slrallgraphilc units that have sufficient thicknesses and lateral extents for a repository are tabulated elsewhere in this report. 


\section{E.4.2 GEOLOGIC ENVIRONMENT OF CHALK}

\section{E.4.2.1 TECTONIC SETTING}

\section{E.4.2.1.1 Oceanic Chalk}

Holocene and ancient chalk deposits are products of two markedly contrasting tectonosedimentary regimes, including the deep sea and the much shallower water cratonic shelves. The Deep Sea Drilling Project has amply documented the widespread occurrence of chalk-forming nannoplankton oozes in the deep sea, and Schlanger and Douglas (SCHLANGER 1974) have described in considerable detail the pelagic ooze-chalk-limestone diagenetic transition. Indeed, the occurrence of deep-sea chalk has been widely documented (ROTH 1975; WISE 1971; MATTER 1975; and many others). Because American chalk formations likely to be considered for the purposes of this project are not of deep-sea origin, such deposits are not considered further in this report.

\section{E.4.2.1.2 Cratonic Chalk}

Among the world's chalk deposits, the most widespread, best exposed, or most readily accessible by drilling are those of northwestern Europe (including the British Isles), where the main chalk formations are of Late Cretaceous (Early Cenomanian through Maastrichtian) and Paleocene age, and the U.S. Gulf Coastal Plain/Western Interior regions, where the principal chalk deposits are of Late Cretaceous (Late Cenomanian through Maastrichtian) age. In both of these large areas, chalk deposits are the product of pelagic carbonate deposition and diagenesis on relatively stable portions of the earth's crust.

\section{E.4.2.1.2.1 Europe}

Prior to Late Cretaceous time, northwestern Europe was a relatively stable cratonic shelf comprising vast areas of little-deformed Mesozoic rocks that surrounded smaller hilly-to-mountainous massifs comprising basement rocks that were deformed during the Late Carboniferous Variscan and older orogenies. The Late Cretaceous sea slowly transgressed the region, and chalk-forming muds were deposited across much of the area extending from Northern Ireland to Poland, Romania, and the southern part of the Russian platform. In places, the Cretaceous strata overstep older, flat-1ying strata and come to rest on Paleozoic or Precambrian basement rocks. In such areas, chalk facies grade into bioclastic or terrigenous sandy facies (KENNEDY 1974). Across much of the continent, Cretaceous rocks are little deformed, and the Late Cretaceous apparently was a time of relative tectonic quiet (ZIEGLER 1975). Throughout the region, however, subsidence and accumulation of sediment were not uniform. Relatively thick sections of chalk were formed in more basinal areas (HANCOCK 1975; KENNEDY 1975), and, locally, the European chalk reaches thicknesses in excess of $1000 \mathrm{~m}$. In local troughs within such basins, Upper Cretaceous deposits reach thicknesses as great as $2000 \mathrm{~m}$. Adjacent to somc such troughs are oval areas of earlier (Jurassic) subsidence that 
became instead areas of uplift known as inversion axes (HANCOCK 1975; HANCOCK 1984). Other depositional highs (or swe11s) were controlled by basement structures, and are the sites of condensed or incomplete successions (KENNEDY 1974). In the North Sea area, fault-controlled grabens (part1y established in Jurassic time and partly during the Cretaceous) exerted strong influence on Cretaceous deposition (HANCOCK 1984), resulting in the accumulation of thicker-than-usual chalk deposits. Elsewhere, regional folding produced locally steep dips in European chalks (e.g., the Isle of Wight, England). Many aspects of the European-chalk tectonic setting are common also to chalk deposits of the U.S. Gulf Coast region.

\section{E.4.2.1.2.2 North America}

Gulf Coast Region. For the most part, chalk formations of the Gulf Coastal Plain dip gently $\left(<1^{\circ}\right)$ towards the Gulf of Mexico and descend gradually to subsurface depths as great as 1500 to $2450 \mathrm{~m}$ (MELLEN 1958; DRAVIS 1979; GRABOWSKI 1981a). Depositton of these chalks occurred on the relatively stable (but gradually subsiding) marine shelf that formed the southern margin of Cretaceous North America. The origin and tectonic setting of this shelf are related to the opening of the Gulf of Mexico the nature and timing of which has caused much debate (HELWIG 1975). Current thought (e.g., JACKSON 1981; ANDERSON 1983; JACKSON 1983) centers on the hypothesis of Late Triassic Early Jurassic rifting, which not only initiated the Gulf but also affected an area underlying what is now the Gulf Coastal Plain (Fig. E.4.2.1). Graben and half-graben structures were filled with continental Eagle Mills redbeds. As rifting and subsidence proceeded, the first marine waters entered newly created restricted basins and evaporated to form the Louann Salt, which was laid down on a planar angular unconformity (SENI 1983). As the developing Gulf of Mexico reached the size and configuration of a Mediterranean sea, a broad belt of rifted crust along its northern margin was blanketed by Upper Jurassic coastal and shallow-marine carbonate and evaporite sediments that created a typical shelf configuration. From this time onward, the newly created shelf was marked alternately by (1) regressive episodes accompanied by deposition of formations rich in allochthonous detritus, and (2) transgressive episodes that favored accumulation of autochthonous carbonate sediments (including chalk-forming muds) in relatively shallow water shelf environments. The Saratoga and Annona chalks of Arkansas, the Demopolis and Prairie Bluff chalks of Alabama and Mississippi, and the Austin and Pecan Gap chalks of Texas are examples of chalk formations that were deposited during transgressive maxima (RUSSELL 1982; BOTTJER 1978; DRAVIS 1979). Although present-day dips are small (generally $<1^{\circ}$ except near faults), the shelf was marked by several structural highs and lows that had influence locally on both thickness and facies development of chalk-bearing formations (e.g., STEHLI 1972; BOTTJER 1978; DRAVIS 1979; CORBETT 1982; ROBERTS 1982). Cretaceous highs include features controlled by Paleozoic positive areas such as the San Marcos arch of central Texas (MURRAY 1961; CORBETT 1982), areas of Cretaceous igneous activity, such as Jackson Dome in Mississippi (MELLEN 1958) and Pilot Knob in central Texas (YOUNG 1975), domal and diapiric movement of salt, as in the East Texas basin (WOOD 1981), relict rudist reefs (STEHLI 1964), and slsumgly pusilive dumal uplifls, such ds lie Munsue uplifl of 

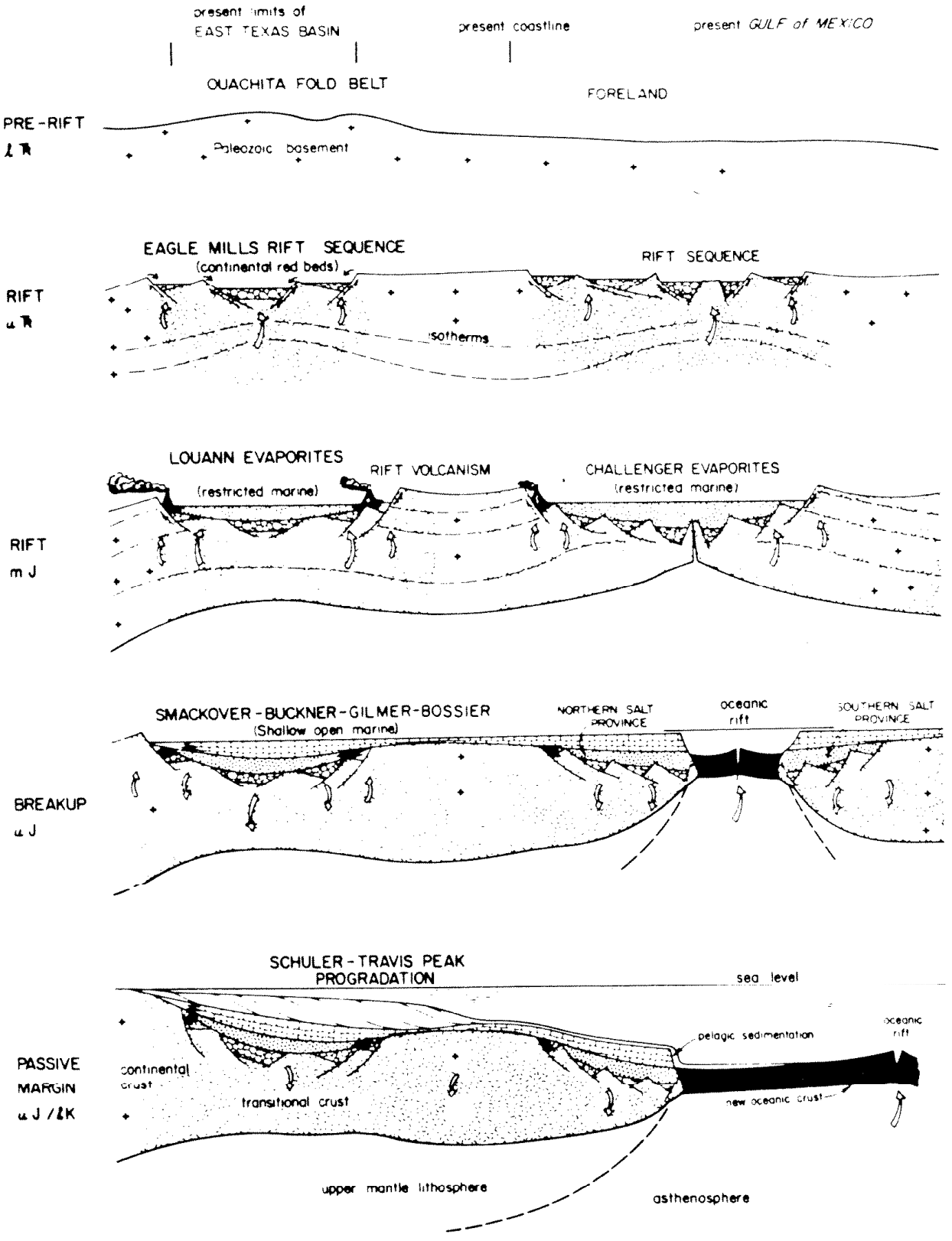

Fig. E.4.2.1. Schematic cross sections showing Triassic to Early Cretaceous tectonosedimentary evolution of East Texas basin and adjoining Gulf of Mexico. Source: M. P. A. Jackson, Tectonic Environment During Early Filling of the East Texas Basin, Circular 81-7, University of Iexas Bureau of Economlc Geviogy, 1981 . 
Louisiana and Sabine uplift on the Texas-Louisiana border (STEHLI 1964; ROBERTS 1982). Variously sized and shaped basins lay between or adjacent to the many positive features, including the Rio Grande embayment of southwestern Texas, East Texas embayment, and northern Louisiana syncline (Fig. E.4.2.2).

The manner in which such structures affect thickness and facies changes is manifested in the Austin Chalk, which thins from $100 \mathrm{~m}$ or more in adjacent areas to only about $30 \mathrm{~m}$ across the San Marcos arch (MURRAY 1961) and contains a greater volume of coarse skeletal debris there. The Austin Chalk and Pecan Gap Formation are known to thicken greatly in peripheral synclines developed around salt diapirs in the East Texas basin (SENI 1983). Late Cretarenns ignenus artivity at Pilot Knob, Texas, caused local interbedding of pyroclastics and chalk in the Austin Chalk (YOUNG 1975). According to Mellen (MELLEN 1958), erosion of the Late Cretaceous Jackson dome of Mississippi furnished some of the sand that is intertongued with surrounding chalk units.

Normal faulting occurred in many areas of the Gulf Coast from Late . Turassim-Farly Cretarenus time until the Cenozoic. (MIIRRAY 1961). One of the major fault zones, Luling-Mexia, extends across much of the Austin Chalk outcrop of central and southern Texas, but faulting apparently had no noticeable effect on Austin deposition.

Western Interior Region. At the close of Jurassic time, the U.S. Western Interior region was the scene of a vast alluvial and lacustrine plain extending from southern Canada to south-central Arizona and New Mexico and from Kansas to central Utah and southeastern Idaho. Nonmarine beds of the Morrison Formation, consisting of sandstone and mudstone with minor limestone and coaly beds, were deposited as a region-wide blanket on a sea-floor plain that had emerged during regression, marking the end of the last marine Jurassic cycle of sedimentation (PETERSON 1972)。 Although earliest Cretaceous time was rharacterized mainly hy a long episnde of nondepnsition and ernsion, a large part of the region was inundated in Albian time during the first of several great Cretaceous marine transgressions. The blanket of sandstones and shales that accumulated during this episode did little to alter the essentially level surface that would later serve as the foundation for younger cretaceous sediments.

During Late Cretaceous time, the U.S. Western Interior was the scene of a vast seaway that, at peaks of transgression, extended from Missouri, Iowa, and Minnesota on the east to Arizona, Utah, western Wyoming, and western Montana on the west (Fig. E.4.2.3). This seaway opened southwardly via the Texas-Louisiana shelf to the Gulf of Mexico and northwardly to the Arctic Ocean. The seaway developed within a foreland basin (DICKINSON 1976) related tectonically to the Sevier orogenic belt of Nevada, Utah, and Idaho - the uplands of which furnished much of the terrigenous detritus in the Cretaceous section (Fig. E.4.2.4). Structura11y, the foreland basin developed asymmetrically, with greatest subsidence along the western part where large volumes of detritus accumulated in pledmont, fluvial, deltaic, marginal marine, and nearshore shelf environments (REESIDE 1944, 1957; 


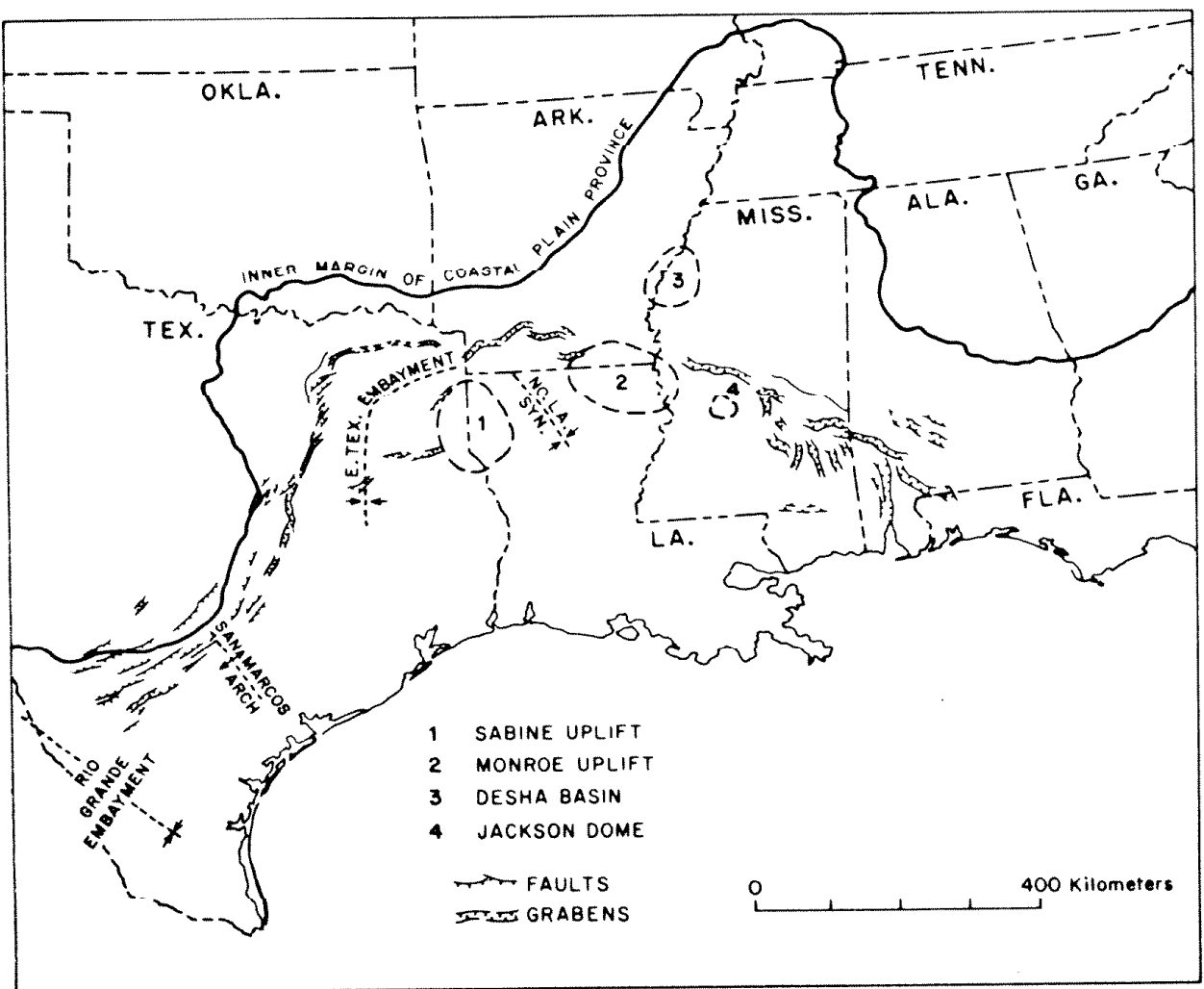

Fig. E.4.2.2. Map of Gulf Coastal Plain province showing features mentioned in text. Modified from G. E. Murray, Geology of the Atlantic and Gulf Coastal Province of North America, Harper and Brothers, New York, 1961. 
ORNL DWG 84-1165

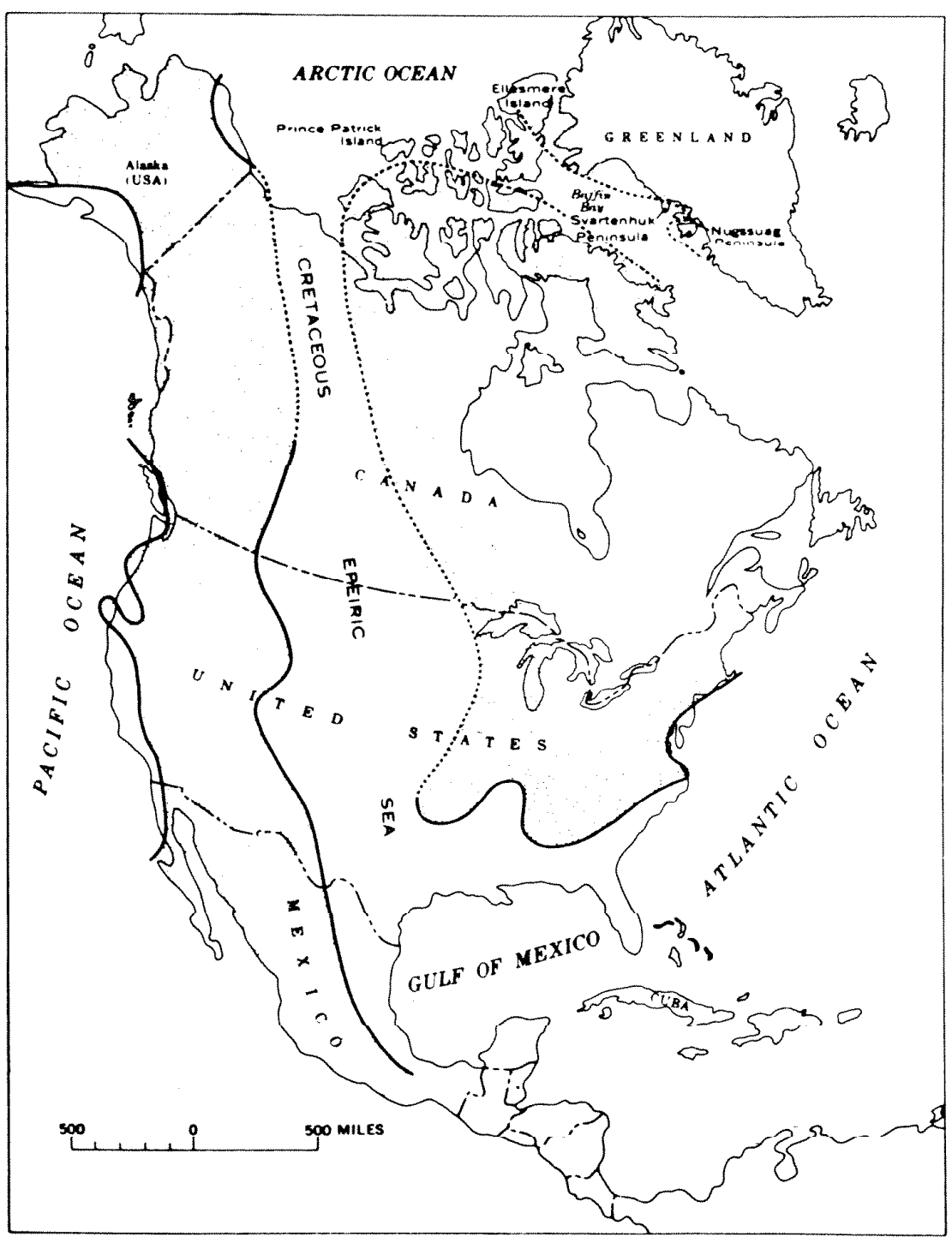

Fig. E.4.2.3. Paleogeography of North America during Late Campanian time, showing configuration of the Western Interior Sea and its connections with the Arctic Dcean and Gulf of Mexico. Source: J. R. Gi11 and W. A. Cobban, Stratigraphy and Geologic History of the Montana Group and Equivalent Rocks, Montana, Wyoming, and North and South Dakota, Prof. Paper 776, U.S. Geolog. Surv., 1973. 
ORNL D WG 84-1166

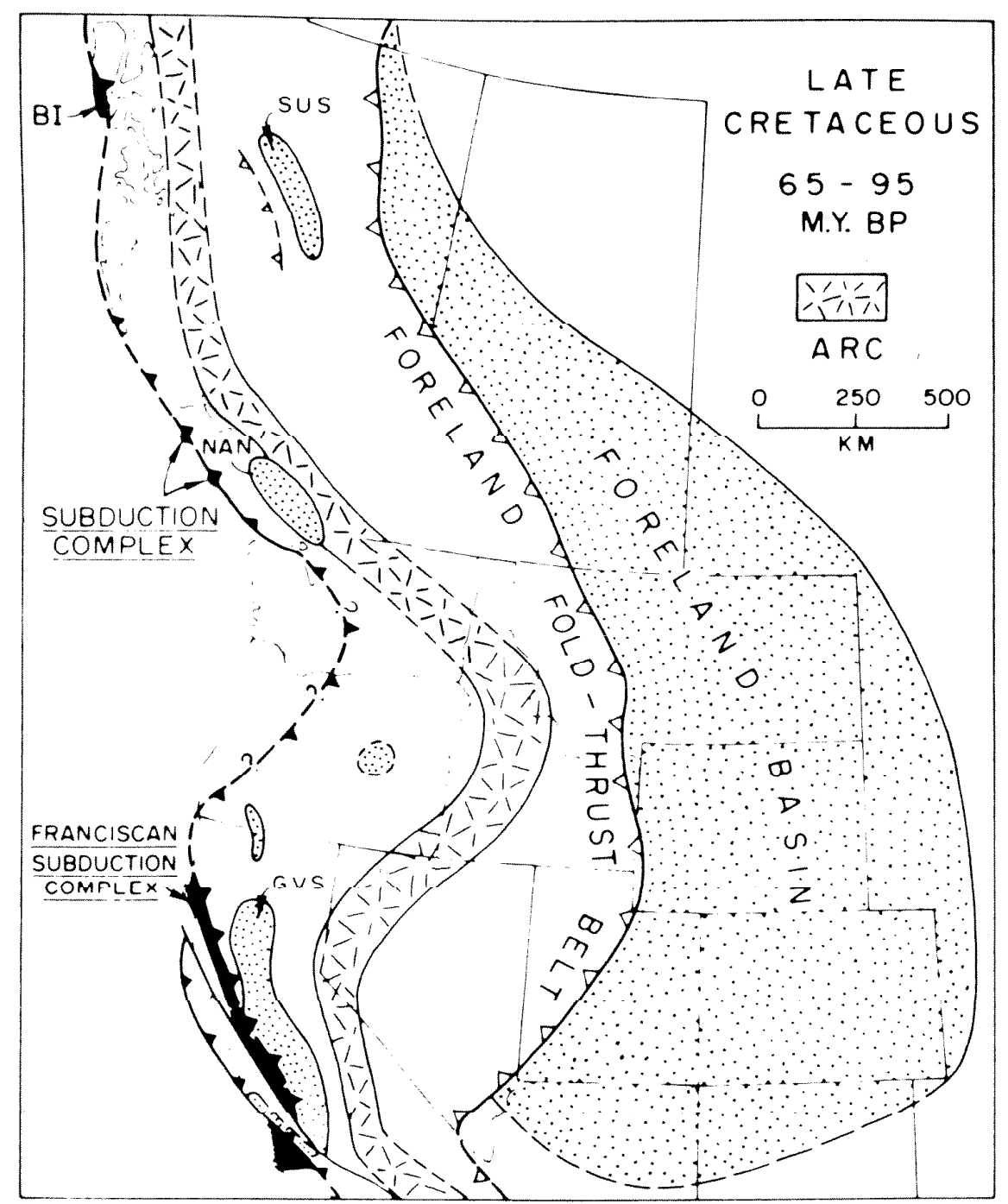

Fig. E.4.2.4. Map showing tectonic configuration of part of western North America during Late Cretaceous time and foreland basin that was flooded by the Western Interior Sea. Source: W. R. Dickinson, "Sedimentary Basins Developed During Evolution of Mesozoic-Cenozoic Arc-Trench System in Western North America," Con. J. Earth Sci. 13, 1268-87 (1976). 
ARMSTRONG 1968; MCGOOKEY 1972; KAUFFMAN 1977; WEIMER 1978; and many others). The eastern half of this basin comprised a more stable, westwardly sloping shelf that received relatively little detritus from eastern source areas (TOURTELOT 1968; WEIMER 1970; McGOOKEY 1972). During two Late Cretaceous transgressional peaks, chalk-forming nannoplankton-rich mud was deposited on parts of the eastern shelf that were most remote from the influence of both western and eastern source areas (Fig. E.4.2.5). These chalk deposits are truncated by erosion on the east and grade westwardly and northwestwardly into marls, calcareous shales, and hard, brittle limestones. Throughout the time of chalk deposition, the eastern shelf [= "ramp" noted by Rice and Shurr (RICE 1983)] was an area of relative tectonic quiescence. Small positive movements along or adjacent to the Transcontinental Arch produced broad areas of thinning in the upper carbonate rock unit (WEIMER 1978; WITZKE 1983), and highs along this trend have produced locally condensed sections within the lower carbonate rock unit (HATTIN 1975, 1979). Regional uplift along the Iranscontinencal Arch produced a major nonconformity within the Upper Cretaceous of the eastern shelf area (MEREWETHER 1981; WITZKE 1983). This nonconformity separates deposits of the first and second cycles of Late Cretaceous marine deposition in the area. Recurrent movements along the Transcontinental Arch have also produced local intraformational nonconformities within and atop the upper chalk formation (Niobrara) of the Great Plains (WITZKE 1983) and influenced facies patterns within that unit (RICE 1983)。

Along the trend of the Transcontinental Arch, only one area stood above sea level at times when chalk-forming mud was deposited. This feature, the Sioux Ridge, had a marked effect on local facies development and can be likened to the European massifs described above.

\section{E.4.2.2 DEPOSITIONAL FRAMEWORK}

\section{E.4.2.2.1 Gulf Coastal Plain}

Chalk-bearing formations of the Gulf Coastal Plain are part of an Upper Cretaceous section that was deposited on a broad, relatively stable shelf which had been constructed by seaward progradation and vertical aggradation of both cerrigenous decrical and carbonace/evaporice sediments during Late Jurassic and Early Cretaceous times. As noted earlier in the discussion on tectonic setting, the shelf comprised a number of basins and highs, most of which had at least some influence on regional or local trends in chalk thickness or facies development. All across the shelf from Georgia to southwestern Texas, Upper Cretaceous deposits manifest marked depositional cyclicity, although the symmetry of such cyclic sequences, details of lithic succession, and prominence of intercycle nonconformities differ from one region to another. In general, chalk deposits mark the transgressional peaks (Fig. E.4.2.6), whereas terrigenous detrital units (including some nonmarine beds) and/or nonconformities mark regressional maxima. The cyclic nature of Upper Cretaceous successions in the Gulf Coastal plain has been documented by many authors (STEPHENSON 1940; DURHAM 1957; RUSSELL 1975; SCHOLLE 1977b; BOTTJER 1978; REINHARDT 1980; SOHL 1980). All example ur LhIs cycilelly ls sllown lil Fig. E.4.2.7. 


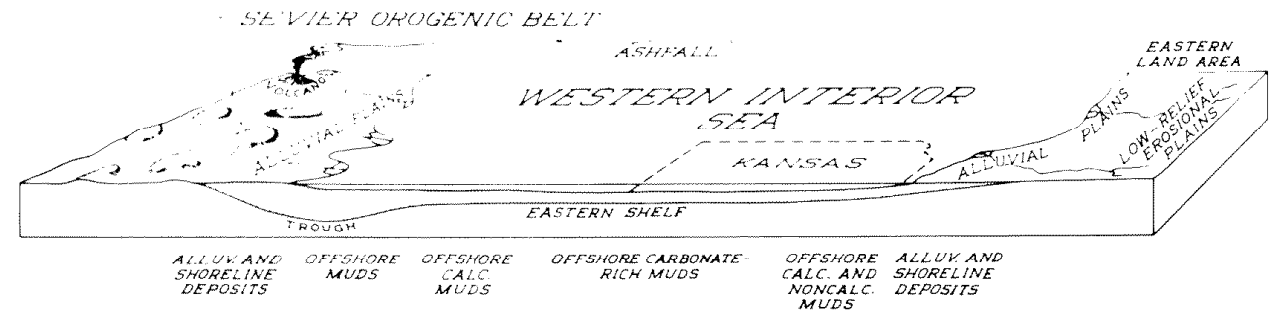

Fig. E.4.2.5. Block diagram depicting a portion of the Western Interior Sea during deposition of the Late Cretaceous Niobrara Chalk. Source: D. E. Hattin, Stratigraphy and Depositional Environment of Smoky Hill Chalk Member, Niobrara Chalk (Upper Cretaceous) of the Type Axea, Western Kansas, Bul1. 225; Kans. Gcolog. Sur=, 1982.

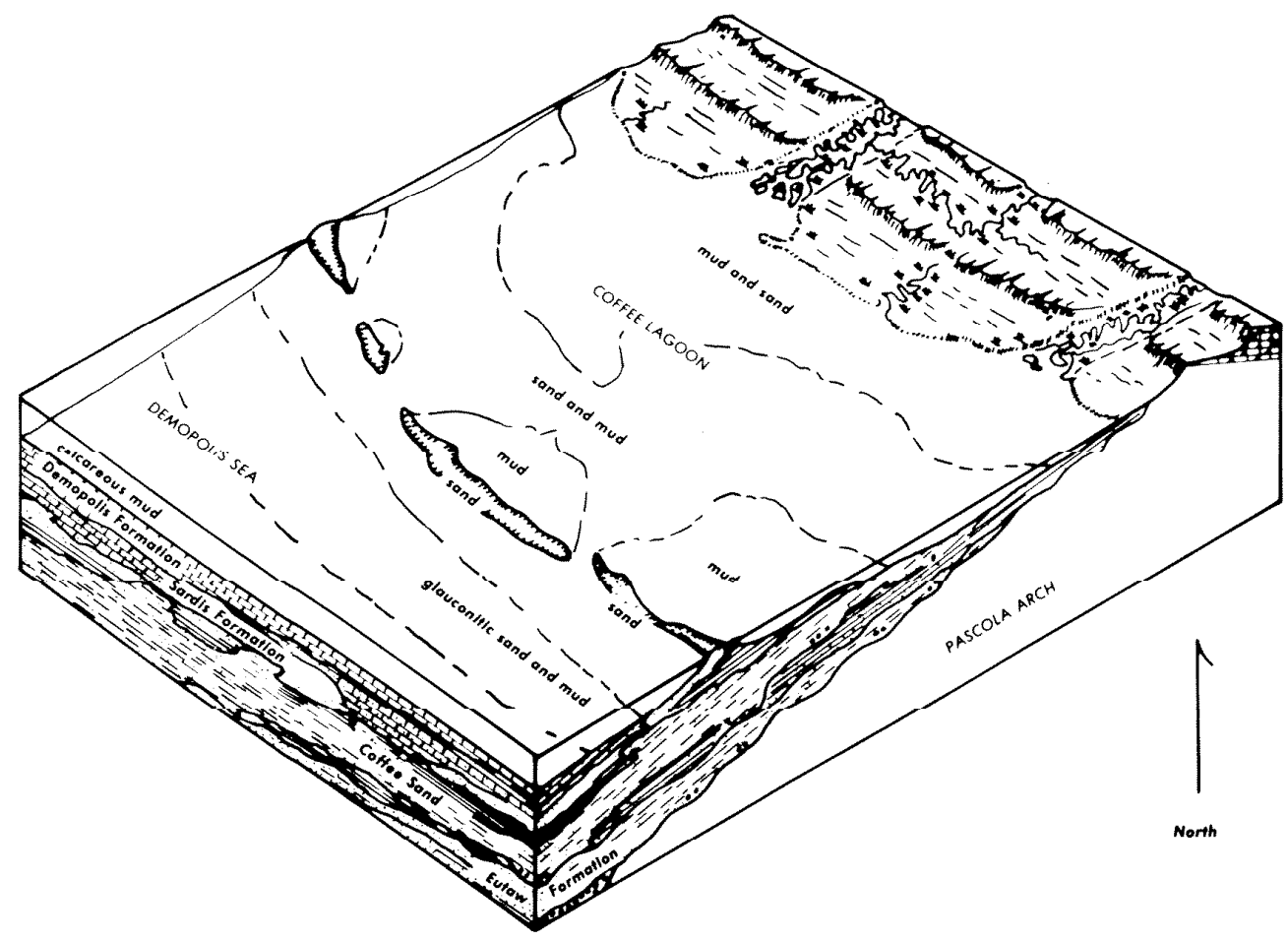

Fig. E.4.2.6. Block diagram of coastal area of Tennessee near peak of transgression that produced the late Cretaceous Demopolis chalks and marls. Source: E. E. Russe11, Stratigraphy of the Outcropping Upper Grelaceous In Weslerm Teniessee, Bu11. 75, Tenn. Dive of Geo1., 1975, p. Al-A65. 


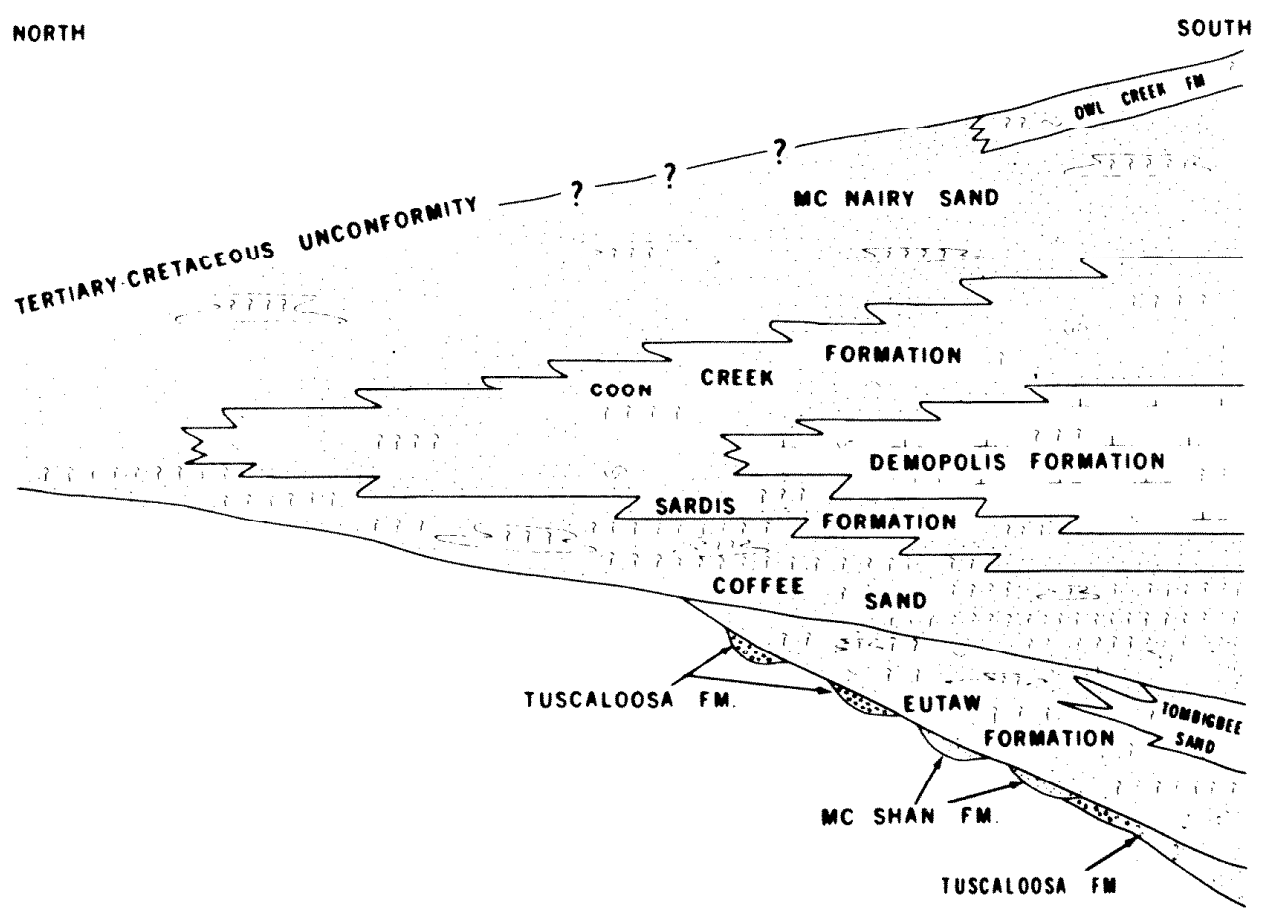

Fig. E.4.2.7. Schematic correlation diagram showing Late Cretaceous formations in western Tennessee outcrop. Datur is center of Demopolis Formation, which grades southward into nearly pure chalk. Note classic, wedge-shaped geometry of Coffee Sand-McNairy Sand interval, with wedge of chalky Demopolis sediments marking transgressional maximum. Source: E. E. Russell, Stratigraphy of the Outcropping Upper Cretaceous in Western Tennessee, Bu11. 75, Tenn. Div. of Geo1. 1975, p. Al-A65. 
During episodes of chalk deposition, the continental shelf sloped gently seaward, becoming progressively deeper farther offshore (BOTTJER 1978; DRAVIS 1979) and having the general attributes of a ramp (DRAVIS 1979; GRABOWSKI 1981a,b). Except for local episodes of volcanism, the effects of salt dome/diapir tectonics, and apparently contemporary smal1scale normal faulting, the shelf was relatively stable. In general, chalk-forming muds were deposited far from shore in quiet water, which accounts in part for their widespread uniformity of facies. However, shallow-water, high-energy conditions prevailed on the San Marcos platform during deposition of the Austin Chalk (DURHAM 1957; DRAVIS 1979) and nearshore conditions, marked by abundance of sandy chalk or abrupt lateral gradations of chalk to sandstone, have been noted (BOTTJER 1978; COPELAND 1968). According to both Bottjer (BOTTJER 1978) and Dravis (DRAVIS 1979), rhythmically bedded chalks (e.g•, Annona of Arkansas, Austin of Texas off San Marcos arch) represent deeper water than the more massive chalk deposits. In general, coastal plain chalk deposits thicken duwndip (i.e., Lowards the Gulf of Mexico) and into basins (such as the Rio Grande embayment).

Upper Cretaceous formations of the Gulf Coastal Plain are comnonly separated by nonconformities (STEPHENSON 1929; COPELAND 1972), and breaks of smaller magnitude occur within chalk formations or at contacts between chalk and marl formations. For such smaller breaks within the Austin Chalk, Durhan (DURHAM 1957) used the terin "discontinuity surface." More recently (BROMLEY 1975) that term has been redefined to include several kinds of minor breaks, including omission surfaces and hardgrounds. The former have been recognized beneath the Annona and Saratoga chalks of Arkansas (BOTTJER 1978) and between the Austin Chalk and Taylor Marl of Texas (FURSICH 1981). Apparently, the only well-developed hardground involving the Gulf Coast Upper Cretaceous is the Arcola Limestone, which lies atop the Mooreville Formation of Alabama (BOTTJER 1981).

\section{E.4.2.2.2 Western Interior Region}

Across most of the Western Interior basin, Late Cretaceous strata manifest marked cyclicity (PIKE 1947; WEIMER 1960; HATTIN 1964; KAUFFMAN 1967; and many others) that reflects major transgressive/regressive movements of interior seas. Maximum basinal subsidence occurred near the western margin of the seaway depicted in Fig. E.4.2.5, but maximum depth of deposition probably occurred closer to the depositional axis, which lay somewhere in eastern Colorado and Wyoming (EICHER 1969; ASQUITH 1970).

Along the eastern half of the basin, the lowest two of the cyclic sequences contain significant bodies of chalk, chalky limestone, and laminated marly chalk. These deposits, including the Greenhorn Limestone plus Fairport Chalk Member of the Carlile Shale and the Niobrara Chalk, reflect mostly quiet and deeper water deposition on a gently sloping middle-to-outer shelf or ramp shortly before, during, and just after peak transgressional episodes. In the best-developed cyclic sequence (Greenhorn), the purest ( = central) chalk body is embraced by a lithologically symmetrical arrangement of inner shelf and marginal marine deposits (Fig. E.4.2.8). Eastward transgression across the castern shelf produccd, 


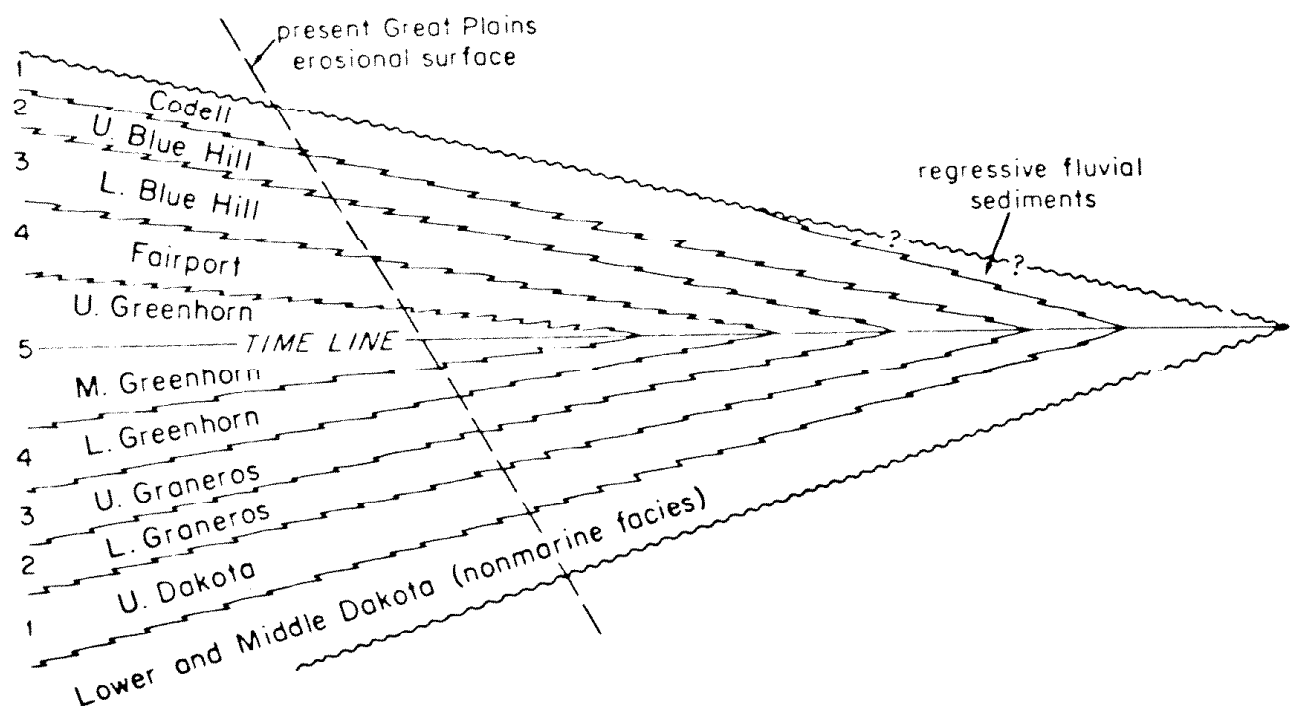

Fig. E.4.2.8. Schematic stratigraphic cross section showing theoretical wedge-1ike geometry of facies within limits of the Greenhorn transgressive-regressive cycle of deposition. 1, marginal-marine sands; 2, sandy ohalo; 3, silty shale; 4, impure chalk with calcarenite; 5, chalk and chalky lime stone. Source: D. E. Hattin, "Western Interior of North America," pp. 13-18 in Reyment, R. A., and Bengtson, compilers, Mid-Cretaceous Events: Report on Results Obtained 1974-1983 by IGCP Project No. 58, Publ. Yalaeont. Inst. Univ. Uppsala, Spec. Vol. 5, 1985. 
in far offshore areas, a vertical sequence including nearshore sands, sandy shale, silty shale, calcarenitic chalk, and chalk plus chalky limestone. During regression, this lithic sequence was reversed. Theoretically, in a symmetrical cyclic sequence of this sort, the central facies (i.e., chalk) should grade laterally, towards old shorelines, through each of the other facies. In much of the Western Interior this cannot be demonstrated in an eastward direction from areas of purest chalk development because the entire section has been largely truncated by erosion. Exceptions to this generalization have been recorded in the Sioux Ridge area (southeastern South Dakota, southwestern Minnesota) and west-central Minnesota, where detritus-dorinated facies of both Greenhorn and Niobrara age have been reported (WITZKE 1983). Westwardly from areas of purest chalk development, the chalky facles grade progressively, in distances of hundreds of kilometers, to rocks that have little carbonate content (Fig. E.4.2.9). Thus, chalk grades into marl or chalky shale, then into calcareous clayey shale. noncalcareous clayey shale, and finally into nearshore and marginal marine sandy beds. The generally north-south alignment of facies belts that was recognized by Reeside (REESIDE 1957) applies equally to chalky parts of the section.

Within the chalky facies, wide persistence of time-para11el, chalky limestone marker beds and mostly very gradual changes of thickness and facies suggest a sea floor of extreme flatness over a broad region of the basin. Exceptions are few. Within the Greenhorn and Niobrara intervals, relatively abrupt facies changes occur only near the Transcontinental Arch and in west-central Minnesota, where topographic highs on the Precambrian basement formed the only recorded islands in the area of Late Cretaceous chalk deposition (SHURR 1981; WITZKE 1983). The relatively abrupt thinning of the Niobrara interval occurs only in areas close to the Transcontinental Arch of Colorado (WEIMER 1978) and the Dakotas (RICE 1983). Condensed sections of the Greenhorn developed over modest highs in Kansas (HATTIN 1975) and south-central Colorado (HATTIN 1979). 
ORNL DWG 84-1171

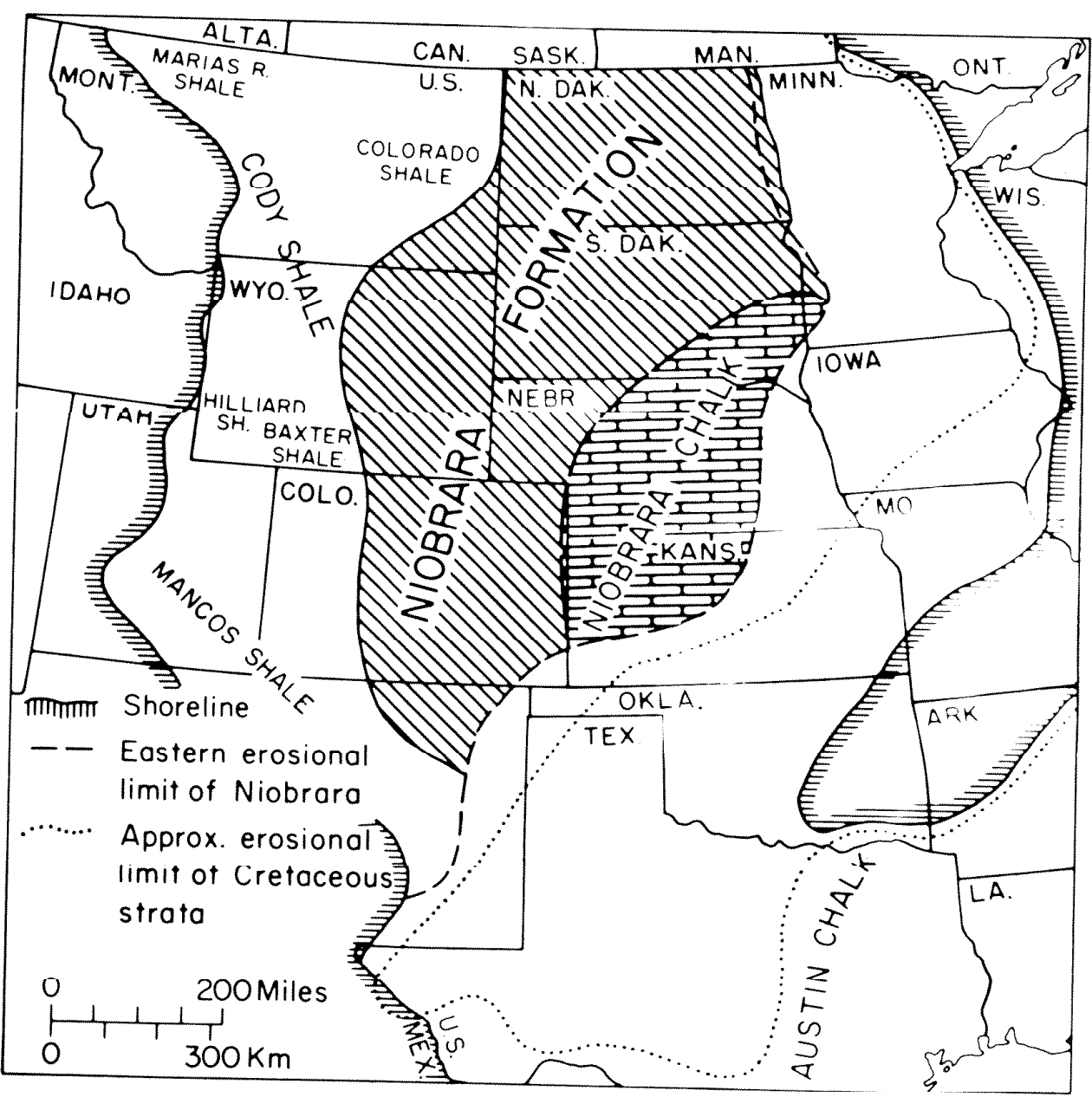

Fig. E.4.2.9. Map showing paleogeography of Western Interior region at peak of second Late Cretaceous transgression and regional distribution of the Niobrara Chalk, the less calcareous Niobrara Formation, and equivalent shale units to the west. Source: D. E. Hattin, Stratigraphy and Depositional Environment of Smoky Hill Chalk Member, Niobrara Chalk Geol. Surv., 1982 . 


\section{E.4.3 GEOMETRY AND DIMENSIONS OF AMERICAN CHALK BODIES}

\section{E.4.3.1 GEOMETRY}

American chalk deposits have prevailingly tabular geometry, with horizontal dimensions that are as much as three orders of magnitude greater than thickness. For example, in the Great Plains, the Niobrara Chalk is approximately $200 \mathrm{~m}$ in maximum thickness and has a lateral extent that approaches or exceeds $300 \mathrm{~km}$. All known chalk bodies of the American Cretaceous grade laterally into rocks of contrasting facies (COPELAND 1968; STACH 1976; STAPP 1978; HATTIN 1982), but most of the rock that can by fairly narrow definition be called chalk occurs in widespread blankets having relatively small thickness. Such deposits may thicken into basins and thin over arches; however, such thickening or thinning is usually gradual, and abrupt depositional termination is rare. Exceptions Involve relatively abrupt thinning of the Austin cha1k of Texas over the San Marcos arch (CORBETT 1982), and abrupt termination of the Greenhorn Limestone against the Sioux Ridge of South Dakota and adjacent states (SHURR 1981).

Wherever chalk contains distinct bedding, the individual beds tend to change thickness gradually rather than abruptly and tend to be time paralle1 (DURHAM 1957; HATTIN 1971, 1982; SMITH 1978; LAFERRIERE 1984). Although oyster biostromes are common locally in some chalk deposits, carbonate buildups are rare. Kennedy and Juignet (KENNEDY 1974) have described what appear to be banks in Upper Cretaceous chalks of northern France, and bryozoan bioherms have been recorded in the Maastrichtian and Paleocene chalks of Denmark and Sweden (SURLYK 1980), but such local changes in geometry are very rare in American Cretaceous chalk deposits. Here and there, penecontemporaneous seafloor scour cut shallow (usually $\leqslant 1 \mathrm{~m}$ ) channels in American chalky muds (e.g., DURHAM 1957, in Austin Chalk; FREY 1972, in Fort Hays Member, Niobrara Chalk; HATTIN 1975, in Greenhorn Limestone), and the overlying beds thicken downward to fill such channe1s, but upward thickening related to bank or bioherm buildup is exceedingly rare.

\section{E.4.3.2 DIMENSIONS}

\section{E.4.3.2.1 General Statement}

Because U.S. chalk deposits are essentially limited to the Upper Cretaceous and are relatively few in number, this section goes beyond a general statement on chalk-body dimensions. Instead, brief characterization, outcrop and subsurface extent, and thickness ranges are given for each of the major American units that are (or have commonly been called) chalk. Stratigraphic position and nomenclature of these units are shown in Figs. E.4.3.1 and E.4.3.2. The units are treated in alphabetical order.

\section{E.4.3.2.2 Annona Formation}

The Annona Formation (Annona Chalk of authors) of southwestern Arkansas has been described as a hard, blue-gray to white, thick-bedded, 
ORNL DWG $84-1172$

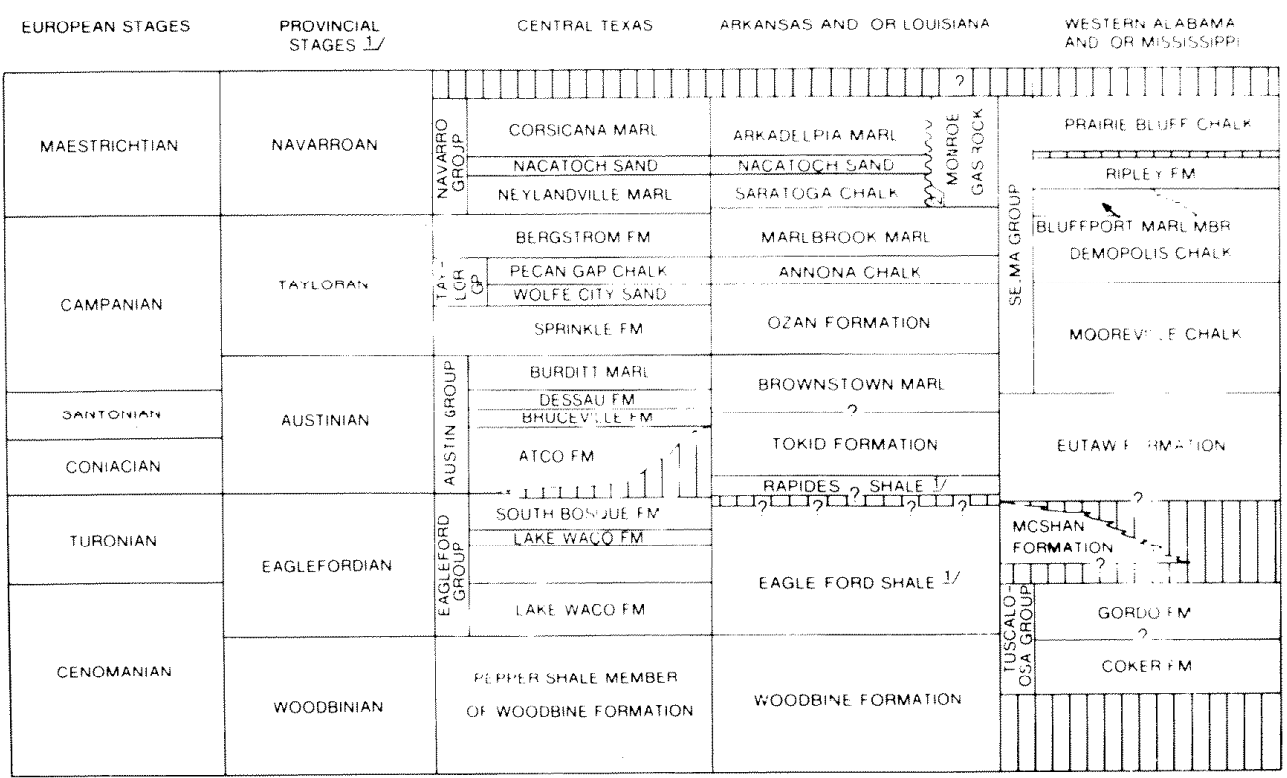

Fig. E.4.3.1. Stratigraphic nomenclature and correlation of chalk-bearing Upper Cretaceous sections of the Gulf Coastal Plain. Chalk units include Austin Group and Pecan Gap of Texas; Annona and Saratoga of Arkansas; Mooreville, Demopolis and prairie Bluff of Alabama; and Mississippi. 1, Following usage of Shreveport Geol. Soc. (1968); 2, informa1 name. Source: P. A. Scholle, Current 0il and Gas Production from North American ITper Cretaceous Chalks, Circular 767 . Geological Survey, 1977. 
ORNL DWG 84-1173

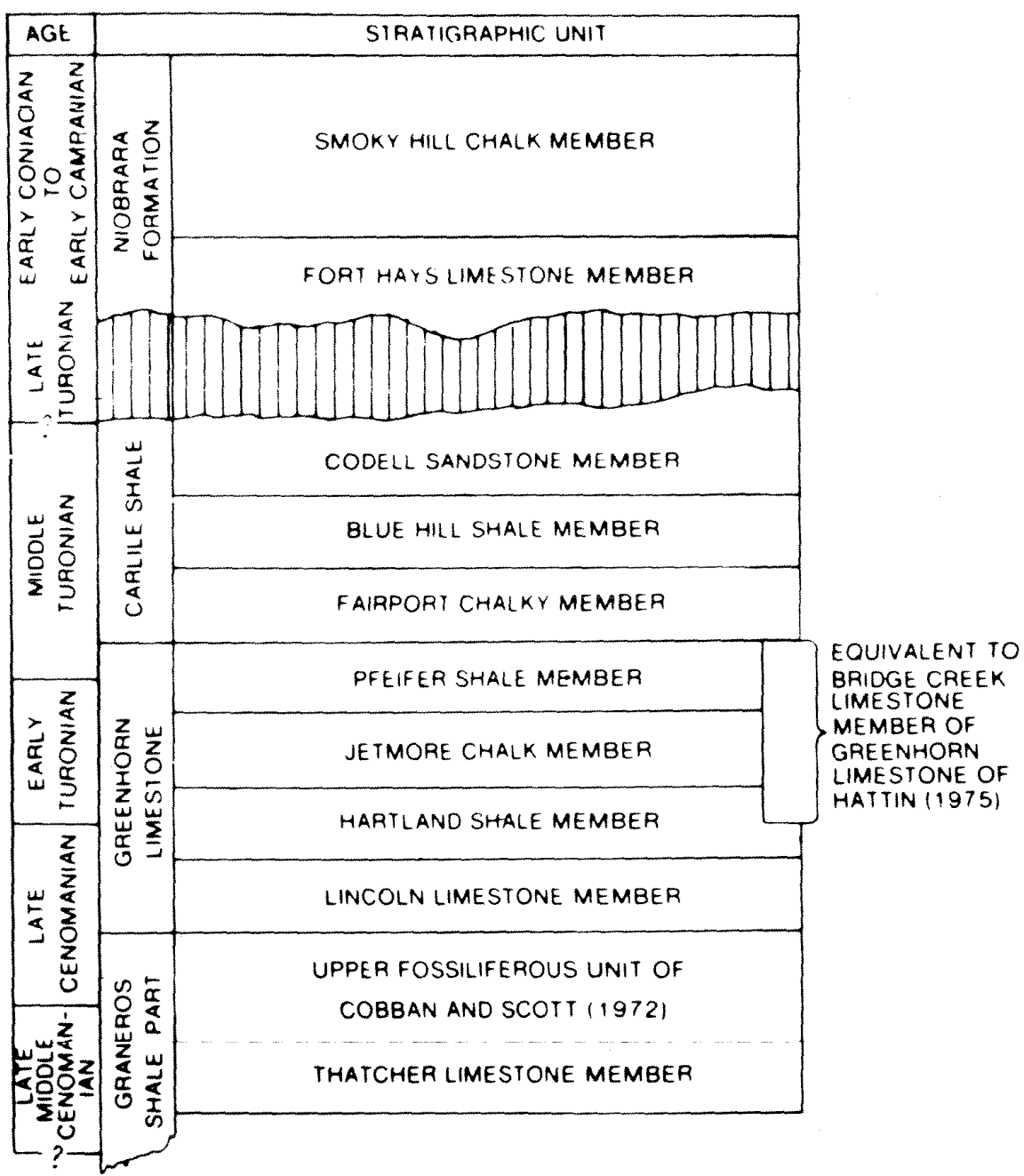

Fig. E.4.3.2. Stratigraphic nomenclature of chalk-bearing Upper Cretaceous section of U.S. Western Interior region. Chalk units include Greenhorn, Fairport Chalk Member of Carlile Shale, and Niobrara. Source: P. A. Scholle, Current $0 i 1$ and Gas Production from North American Upper Cretaceous Chalks, Circular 767, Geological Survey, 1977. 
and massive, slightly fossiliferous chalk (DANE 1929). However, Bottjer (BOTTJER 1978) has shown that the formation actually consists of local condensed beds less than one meter thick, massive calcarenitic chalk as much as $6 \mathrm{~m}$ thick, massive chalk as much as $6.3 \mathrm{~m}$ thick, and rhythmically bedded chalk and marly chalk as much as 21 m thick. Along the discontinuous Arkansas outcrop, the formation thickens southwestwardly from nothing to $30 \mathrm{~m}$ near the Texas border. Downdip in the Arkansas subsurface the Annona thickens to a maximum of $44 \mathrm{~m}$ at the southwesternmost corner of the State (DOLLOFF 1967). Along the southern edge of southwestern Arkansas, depth to the Annona is in the 600- to 850-m range. In the subsurface of Webster Parish, northwestern Louisiana, the Annona consists of hard, white-to-bluish gray, massive chalk with a few shaly or gritty streaks and is about 30.5 to $36.5 \mathrm{~m}$ thick (MARTIN 1954). Mellen (MELLEN 1958) has recognized the Annona-equivalent in the subsurface of western Mississippi, where thickness is in the 30-m range. Westward from Arkansas, the Annona expands to a thickness of approximately 91.5 to $122 \mathrm{~m}$ in Red River County, Texas (STEPHENSON 1937), and then thins abruptly to apparent pinchout a few kilometers farther to the west (McNULTY 1981). Minimum lateral dimensions of the Annona Formation are $300 \mathrm{~km}(\mathrm{E}-\mathrm{W})$ by $230 \mathrm{~km}(\mathrm{~N}-\mathrm{S})$, but the formation exceeds a thickness of $46 \mathrm{~m}$ only in northeastern Texas.

\section{E.4.3.2.3 Austin Chalk}

Among American upper Cretaceous chalk formations, the Austin has the greatest range of stratigraphic, structural, petrologic, thickness, and nomenclatural variations. The formation crops out in a sigmoidal belt that extends from the Mexican border on the southwest to northeastern Texas and can be traced downdip (generally gulfward) for many tens of kilometers in the subsurface. Relatively complex vertical and lateral facies changes have led to the introduction of at least 12 names for various members, facies, and tongues, but some of these have never been formalized and application of names differs among workers. Most authors agree that different nomenclature is required for northeastern, central, and southwestern Texas (DURHAM 1957). In central Texas, the genera1 sequence includes (ascending): Atco (mainly chalk, with marl and clay seams), Bruceville (mainly mar1, with chalk beds scattered throughout; unit grades southwestwardly into chalk), Hutchins (mainly chalk, with marl interbeds that thicken southwestwardly), Dessau (mainly chalk, with fossiliferous glauconitic limestone in lower part), Burditt (interbedded chalk and marl), and Pflugerville (mainly chalk, with some interbedded mar1). The Atco division, which is bedded on a meter scale, is the best chalk unit and comprises approximately one-third of the Austin (SCHOLLE 1977b). Across most of Texas, the Austin is separated from adjacent formations by unconformities. In northeastern Texas, the Austin grades into sands, although the upper and lower parts persist for some distance as chalk tongues.

According to Cloud (CLOUD 1975), the Austin "consists mainly of gray-to-white chalks and chalky limestones interbedded with yellowish white-to-gray mar1s and marlstones." Dravis reported that Austin color ranges from buff to nearly black, that outcropping rocks are usually of 
lighter color, and that darker colors correlate generally with higher total organic content (DRAVIS 1979). According to Grabowski, organicrich chalks occur principally in deeper cores, whereas organic-poor chalk occurs in shallow cores from the San Marcos platform (GRABOWSKI 1981a). Although rhythmic bedding is common in the Austin outcrop of most areas (DURHAM 1957; DRAVIS 1979), distinct beds of shale are thin and widely scattered in subsurface sections, and bedding is not rhythmic. Most cores have low percentages of total shale-bed thickness. More typical of the subsurface are intervals of lighter colored shale-free chalk that alternate with darker colored shale-rich zones. Corbett reported that three divisions are commonly recognizable in the Austin subsurface: lower massive chalk, middle chalk marl, and upper massive chalk (CORBETT 1982). Downdip, the Austin becomes a dense, hard, micritic limestone (SCOTT 1977). The formation generally thickens downdip and grades entirely into shale approximately $100 \mathrm{~km}$ from the outcrop (STAPP 1978).

In the type section (Travis County, central Texas), the Austin is $107 \mathrm{~m}$ (CLOUD 1975) to $110 \mathrm{~m}$ (CORBETT 1982) thick. The formation is thickest $(>300 \mathrm{~m})$ northeast of there (in eastern Grayson County) and thinnest farther south (over the San Marcos arch), where it is locally only $34 \mathrm{~m}$ thick in Bexar County (SEEWALD 1960). Southwestwardly from the San Marcos arch, the Austin thickens again, reaching approximately $290 \mathrm{~m}$ in Val Verde County near the Mexican border.

Subsurface thickness trends are similar to those of the outcrop. Minimum thickness is $31 \mathrm{~m}$ in Brazos County (HOLDITCH 1982). Farther southwest, the Austin reaches $213 \mathrm{~m}$ in thickness in Dimmit County (SCOTT 1977); and, in eastern Milam County, thickness is as much as $244 \mathrm{~m}$ (HOLDITCH 1982). An isopach map (prepared by MILLER 1978) shows fairly abrupt thickness changes, with maximum differential in adjacent Milam and Falls counties, where the range is 41 to $234 \mathrm{~m}$. The average thickness in both surface and subsurface sections apparently is $100 \mathrm{~m}$ or more. Lateral dimensions of the Austin Chalk are several hundred kilometers (along the outcrop) by approximately $100 \mathrm{~km}$ (downdip from the outcrop).

\section{E.4.3.2.4 Demopolis Chalk}

The Demopolis Chalk (Formation of authors) crops out in an arcuate belt that extends from east-central Alabama into northeastern Mississippi and thence northward into southern Tennessee, a distance that exceeds $500 \mathrm{~km}$. For most of this distance, the formation is dominated by cha1k that is overlain, and locally underlain, by marl. The Demopolis apparently has its best development as a chalk facies in the Marengo and Sumter counties area of western Alabama, where it reaches maximum thickness of approximately 150 to $158 \mathrm{~m}$. In that area the formation is usually described as brittle, light to medium gray, very light gray- to white-weathering, marly to almost pure chalk (that is, thinly to weakly bedded or massive)(CARLSTON 1944; EARGLE 1948; NEWTON 1961; COPELAND 1968; SELF 1976). Even where the chalk is bedded, the bed contacts are gradational and difficult to distinguish. The massive chalk facies grades upward into 18 to $20 \mathrm{~m}$ of clayey chalk and sandy calcareous clay 
(SELF 1976) or dark olive-gray, massive chalky marl, very clayey chalk, and calcareous clay (COPELAND 1972) that has much more clay, silt, and sand than the massive chalk, and is called Bluffport Marl Member. Locally, thinly bedded marly chalk lies at the base of the formation (CARLSTON 1944; COPELAND 1968). East of Marengo County, the Demopolis becomes increasingly sandy and within Montgomery County, east-central Alabama, is at first divided into two tongues by a sand wedge (Cusseta Member) of the Ripley Formation and then grades into sandstone (EARGLE 1948; JONES 1967).

West of Sumter County, in Kemper County, Mississippi, the Demopolis is much thinner, consisting of $64 \mathrm{~m}$ of white-weathering, hard, bluishgray, massive chalk that is overlain by $15 \mathrm{~m}$ of dull gray, clayey chalk, or chalky clay and calcareous silty clay assigned to the Bluffport Marl Member (HUGHES 1958). Farther north, in Oktibbeha County, Mississippi, the Demopolis is a tough, bedded, medium-gray (fresh) to glaring white (weathered) chalk that spalls into rounded platelets. In the upper $40 \mathrm{~m}$, Newman recorded a sequence that includes mottled chalk, rhythmically bedded chalk, silty chalk, and massive chalk that is capped by $14 \mathrm{~m}$ of gray, argillaceous, silty, slightly arenaceous chalk and chalky clay of the Bluffport Member (NEWMAN 1975). In adjacent Lowndes County, Mississippi, the Demopolis Chalk includes (ascending) $61 \mathrm{~m}$ or marl, $60 \mathrm{~m}$ of relatively thick-bedded chalk that has marl interbeds, and, at the top, 14 to $15 \mathrm{~m}$ of marl that is assigned to the Bluffport Member (RUSSELL 1982). Farther north, the central chalk unit thins and wedges out near the Mississippi-Tennessee border, and the lower and upper marl units merge. In Tennessee, the entire formation consists of gray massive-bedded fossiliferous argillaceous marls (RUSSELL 1975).

In southwestern Alabama, the Demopolis ranges in thickness from 128 to $158 \mathrm{~m}$ in outcrop (COPELAND 1968; HATTIN 1976) and from 134 to $147 \mathrm{~m}$ in the subsurface (NEWTON 1961). The Bluffport Mar1 Member accounts for about 15 to $20 \mathrm{~m}$ of this thickness (NEWTON 1961; SELF 1976). In Marengo County, western Alabama, the depth to the top of the Demopolis ranges from zero in outcrop to a maximum of $423 \mathrm{~m}$. Farther southward (downdip), structural complications cause wide variations in the depth to the top of the Demopolis at equivalent latitudes. In the Mobile graben of southwesternmost Alabama, depth to the top of the Demopolis is approximately 2300 to $2500 \mathrm{~m}$, whereas in central-southern Alabama the structure is a relatively simple homocline and depth to top of the Demopolis is on the order of $1000 \mathrm{~m}$ (MOORE 1971). Hughes showed that in the western part of Kemper County, Mississippi, the Demopolis Chalk reaches a subsurface thickness of $160 \mathrm{~m}$, of which approximately $19 \mathrm{~m}$ is classified as B1uffport Mar1 Member (HUGHES 1958). Along the western edge of that county, depth to the top of the Demopolis is $430 \mathrm{~m}$.

In east-central Mississippi, the Demopolis Chalk can be differentiated from the rest of the Selma Group for a distance extending at least $55 \mathrm{~km}$ downdip (southwestward1y). In central-southern Alabama, the top of the Demopolis can be recognized at least $80 \mathrm{~km}$ downdip (southwardly), although the unit is not usually differentiated from the Mooreville Formation in that area. 


\section{E.4.3.2.5 Greenhorn Limestone - Fairport Chalk Member}

Although classified as a member of the Carlile shale, the Fairport Chalk Member is related genetically to the Greenhorn Limestone Formation (of many areas). Within this interval, best development of the chalky facies is in Kansas, where the section is dominated by soft, laminated, very fine-grained coccolith-rich marly chalk (shaly chalk and chalky shale of authors). These rocks are mostly olive-gray where fresh, and pale shades of gray, yellow, or orange where much weathered. The section is punctuated by thin to medium bioturbated beds of impure chalk, chalk, and chalky limestone that are time parallel and can be traced for great distances. Calcarenite, as very thin lenses and mostly thin lensing beds, occurs in the lower one-fourth and upper one-third of lie Greenhora and middle part of the Fairport. The purest chalks lie in the upper half of the Greenhorn. The Fairport is progressively less calcareous upward.

Westward from Kansas, the section becomes progressively more argillaceous, and the chalky character is largely lost along the Rocky Mountain front. Northeastwardly from Kansas, the section thins and becomes generally less chalky. In hulliedslenu Nebraska, the section is characterized by an interbedded sequence of chalky shale, shaly chalk, slightly calcareous shale, and hard skeletal limestone that is less than half the minimum thickness recorded in Kansas.

In west-central and western Kansas, the Greenhorn-Fair port interval ranges from a minimum of $51 \mathrm{~m}$ thick in the Osborne County outcrop to $85 \mathrm{~m}$ in Hamilton County, where only about one-fourth of the Fairport is chalky. The entire unit thus thickens southwestwardly from north-central Kansas, but thickness of the purer chalk and marly chalk interval probably nowhere exceeds 50 to $60 \mathrm{~m}$.

In the northwestern Iowa, western Minnesota, eastern South Dakota and southeastern North Dakota area, the Greenhorn ranges from 5.5 to $12 \mathrm{~m}$ (WITzKE 1983). Whese tecugulied, the Fairpuit of this area is not chalky.

In the subsurface of northwestern Kansas, the Greenhorn ranges from 27 to $30.5 \mathrm{~m}$ and the Fairport from 24 to $46 \mathrm{~m}$ (MERRIAM 1957). Depth to top of the Greenhorn increases northwestward from $168 \mathrm{~m}$ in Graham County and $213 \mathrm{~m}$ in Gove County to approximately $580 \mathrm{~m}$ in Rawlins County and $610 \mathrm{~m}$ in Cheyenne County. Approximate lateral dimensions of the Greenhorn-Fairport interval, in the area of best development as a chalk facies (northwestern Kansas), are $320 \mathrm{~km}$ (NE-SW) by $300 \mathrm{~km}$ (NW-SE).

Westward from Kansas, the Greenhorn-Fairport interval thins towards the Rocky Mountain front. In Otero County, Colorado, the thickness is approximately $61 \mathrm{~m}$. On the Model anticline, thickness is approximately $50 \mathrm{~m}$. In northwestern Pueblo County, Colorado, thickness is approximately $75 \mathrm{~m}$ but much of the section is nonchalky. Along an essentially north-south line in eastern Colorado, close to the Kansas border, subsurface thickness of the Greenhorn-Fairport interval ranges from $61 \mathrm{~m}$ to $82 \mathrm{~m}$ (RMAG no date). On a roughly east-west line from northeastern kit Carson County, easternmost Colorado, to Jefferson County (near Denver), depth to top of the Greenhorn-Fairport interval increases progressively westward from approximately $700 \mathrm{~m}$ to $2680 \mathrm{~m}$ (RMAG no date). 


\section{E.4.3.2.6 Mooreville Formation}

Although common1y called Mooreville Chalk, this formation actually consists primarily of gray marl, calcareous clay, and clayey chalk that are commonly silty or fine-sandy and locally glauconitic (VESTAL 1946; EARGLE 1948; JONES 1967; COPELAND 1968; RUSSELL 1967). The basal Mooreville is locally sandy and glauconitic or phosphatic. In Alabama, the upper 1.8 to $3.0 \mathrm{~m}$ comprise two to four beds of hard, impure limestone which are separated by beds of gray marl or calcareous clay, the whole being called Arcola Limestone Member (JONES 1967; COPELAND 1968). In Mississippi, this member is recognizable but less well developed (RUSSELL 1967).

At its type locality in Lee County, northeastern Mississippi, the Mooreville is $36 \mathrm{~m}$ thick. The formation pinches out shortly to the north, in Prentiss County, but thickens southward1y to $76 \mathrm{~m}$ in Kemper County, near where the outcrop crosses into Alabama. Thickness is $81 \mathrm{~m}$ in Sumter County, western Alabama (JONES 1967), and increases to its apparent maximum of $183 \mathrm{~m}$ in Montgomery County in east-central Alabama (KNOWLES 1963). East of Montgomery County, the formation thins but continues with little lithologic change to Macon County, where the basal part merges laterally into chalky sand. The Mooreville is on $1 \mathrm{y} 30.5 \mathrm{~m}$ thick in southern Macon County, where clayey chalks, typical of the formation, grade into sands of the Blufftown Formation. Above the basal Blufftown sands, a long tongue of chalky Mooreville extends farther eastward to within $24 \mathrm{~km}$ of the Georgia border (COPELAND 1972).

The Mooreville Formation crops out in a southwestwardly convex belt that extends from Prentiss County in northeastern Mississippi to Russell County in eastern Alabama, a distance of several hundred kilometers. In east-central Mississippi, the Mooreville can be differentiated from the rest of the Selma Group for a distance of at least $70 \mathrm{~km}$ downdip (southwestwardly). In south-central Alabama, the formation can be traced at least $20 \mathrm{~km}$ downdip (southwardly), but in most of the southern Alabama subsurface the Mooreville and Demopolis are not usually differentiated.

In Marengo County, western Alabama, depth to top of the Mooreville ranges from nil in outcrop to a maximum that exceeds $432 \mathrm{~m}$ in the southwestern part of that county. According to data presented by Newton and others (NEWTON 1961), thickness of the Mooreville Formation averages $90 \mathrm{~m}$ in the subsurface of Marengo County, Alabama. In the subsurface of Kemper County, Mississippi, the Mooreville Formation ranges in thickness from 72 to $82 \mathrm{~m}$ and depth to top of the formation increases westward to as much as $588 \mathrm{~m}$ in the western part of that county (HUGHES 1958). In Calhoun County, north-central Mississippi, depth to top of the Mooreville is approximately $366 \mathrm{~m}$ at a distance of $50 \mathrm{~km}$ downdip (west) from the outcrop, and approximately $550 \mathrm{~m}$ (just $27 \mathrm{~km}$ ) farther west in Yalobusha County, Mississippi (MELLEN 1958).

\section{E.4.3.2.7 Niobrara Cha1k (Formation of many areas)}

The Niobrara Chalk comprises a lower thick-bedded, relatively brittle, extensively bioturbated chalky limestone member (Fort Hays) and 
a much thicker, softer, mostly well-laminated marly chalk or chalk-marl member (Smoky Hi11). Little-weathered rocks are predominant1y olive gray to dark olive gray, whereas the much-weathered rocks are generally pale shades of gray, yellow, or orange. In little-weathered exposures, the bioturbated rock is generally lighter colored than the laminated rock. The formation reaches greatest carbonate purity in western Kansas and parts of Nebraska and southeastern South Dakota, where it can properly be called chalk. Elsewhere the formation contains so much marl, calcareous shale and hard brittle limestone that the term "formation" is preferable.

In Kansas, where the chalk facies reaches its best development, the maximum outcrop thickness (Logan County) is $210 \mathrm{~m}$ (JOHNSON 1958). Dip in this area is extremely shallow, approximately $3.5 \mathrm{~m} / \mathrm{km}$ towards the northeast in Logan County and $2.3 \mathrm{~m} / \mathrm{km}$ slightly east of north in adjacent Gove County. In a northwestwardly directed line of cross section therefrom, Hann shows an overall thinning trend in the subsurface of western Kansas and northeastern Colorado, with a minimum of approximately $86 \mathrm{~m}$ in a well situated approximately $60 \mathrm{~km}$ northeast of Denver (HANN 1981). From Logan County, Kansas, northeastwardly towards southeastern South Dakota, the Niobrara also shows a progressive thinning trend, diminishing in Kansas to $198 \mathrm{~m}$ near the Nebraska border, and thinning further to $137 \mathrm{~m}$ in Furnas County, southern Nebraska. The formation is only 61 to $62 \mathrm{~m}$ thick in the area of northeastern Nebraska and southeastern South Dakota that centers around Yankton, South Dakota. Farther north the formation thins further and changes facies to marlstone and shale as reported by Merewether and Cobban (MEREWETHER 1981).

Southwestwardly from Logan County, Kansas, the Niobrara thickens to $217 \mathrm{~m}$ in Otero County, Colorado (DANE 1936), and to $225 \mathrm{~m}$ in northwestern Pueblo County, Colorado (SCOTT 1964), where the Fort Hays beds have lost their chalky character and the Smoky Hill is more shaly than in Kansas. In the gas-producing area of northeastern Colorado, northwestern Kansas, and southwestern Nebraska, the Niobrara ranges from a minimum of approximately $142 \mathrm{~m}$ in northwestern Cheyenne County, Kansas (HANN 1981), to approximately $177 \mathrm{~m}$ in Yuma County, Colorado (LOCKRIDGE 1978). In the latter area, depth to the top of the Niobrara is in the 460- to $850-\mathrm{m}$ range. Approximate lateral dimensions of the Niobrara Chalk, in the area of best development as a chalk facies, are $800 \mathrm{~km}$ (NE-SW) by $350 \mathrm{~km}$ (NW-SE).

\section{E.4.3.2.8 Pecan Gap Formation}

Chalk belonging to the Pecan Gap Formation is typically light gray, weathers white to cream-colored, is variably indurated and extensively bioturbated, and is thinly and indistinctly bedded (BREZINA 1974). The formation crops out over a distance of approximately $150 \mathrm{~km}$ in the Collin County to Lamar County area of northeastern Texas. The formation can be traced at least $110 \mathrm{~km}$ downdip (southeastwardly) from the Collin county outcrop. At the type locality and farther eastward, the rock is essentially a well-indurated calcilutite, whereas farther to the south and west the formation is less we11 indurated and contains both calcilutite and calcarenite, which includes considerable quartzose sand. Much of the 
formation is a true foramini-feral-nannoplankton chalk. Statements on outcrop thickness are inconsistent owing to variable assignment of adjacent beds. Brezina claims that the formation apparently reaches maximum thickness of about $15 \mathrm{~m}$ near Farmersville, Collin County (BREZINA 1974). The formation thins southwardly to $8.5 \mathrm{~m}$ in southern Collin County and thins northeastwardly to $7.6 \mathrm{~m}$ in eastern Lamar County (BREZINA 1974), beyond which it thins abruptly to less than $1 \mathrm{~m}$ in western Red River County (ROUSE 1944). From Collin County southward, the Pecan Gap comprises two members: Rockwall, consisting of silty marl, and Lavon, consisting of silty chalk and calcarenite.

In his study of the subsurface Pecan Gap in Leon County, Texas, Stenze1 (STENZEL 1938) reported an average thickness of $32 \mathrm{~m}$, with a range of 3.0 to $72 \mathrm{~m}$ in 17 wells. Although salt domes are known in Leon County, Stenzel expressed uncertainty concerning the lower boundary of the Pecan Gap as the reason for wide thickness range in the county. In Leon County, depth to top of the Pecan Gap ranges from 1028 to $1222 \mathrm{~m}$. In the East Texas embayment, the subsurface Pecan Gap thickens greatly into secondary peripheral synclines adjacent to salt domes and diapirs. Seni and Jackson (SENI 1983) reported abrupt thickness increase to nearly $300 \mathrm{~m}$ adjacent to the Hainesville Dome of Wood County, northeastern Texas.

\section{E.4.3.2.9 Prairie Bluff Chalk}

The Prairie Bluff Chalk crops out in an arcuate belt extending from central Alabama to northeastern Mississippi - a distance of several hundred kilometers. The unit is commonly described as hard or compact, massive, bluish-gray to white sandy chalk. Phosphatized internal molds of macroin vertebrates and glauconite occur in some parts of the section locally. The formation grades into sandstones toward the east in central Alabama and towards the north in northern Mississippi. In Mississippi, outcrop thickness ranges from nil in the north to a maximum of approximately $27 \mathrm{~m}$ (RUSSELL 1982). In Alabama the range is approximately $21 \mathrm{~m}$ in the west (Sumter County) and $46 \mathrm{~m}$ in the central part (W. Lowndes County), with local thinning to only $3 \mathrm{~m}$. In descriptions of subsurface sections, the Prairie Bluff is not usually differentiated from other chalk formations of the Selma Group. However, Hughes showed a maximum thickness of about $9 \mathrm{~m}$ for the subsurface Prairie Bluff of Kemper County, Mississippi (HUGHES 1958), and Newton and others (NEWTON 1961) showed a thickness of about $30 \mathrm{~m}$ in the subsurface of Marengo County, Alabama. The formation is too thin to be considered as a repository.

\section{E.4.3.2.10 Saratoga Formation}

The Saratoga Formation crops out discontinuously along a narrow 90-km be1t that extends from northeastern Clarke County to westernmost Hempstead County, Arkansas. Downdip (southward), the formation is recognized in the subsurface of the southern tier of southwestern Arkansas counties (DOLLOFF 1967) and in northwestern Louisiana (MARTIN 1954). In outcrop, the lower part of the Saratoga Formation consists largely of fossi1iferous 1ight- to medium-gray, thick-bedded, massive chalk that is 
commly glauconitic in the lower part. The upper part comprises an argillaceous calcareous sand member. In the Arkansas subsurface, the Saratoga is composed primarily of massive glauconitic chalk with two or three thin shale breaks (DOLLOFF 1967). In the northwestern Louisiana subsurface, the formation consists of gray-to-white, hard-to-soft fossiliferous glauconitic chalk that is interbedded with small amounts of chalky shale or marly chalk.

In outcrop the formation ranges from 6 to $45 \mathrm{~m}$ (BOTTJER 1978), but at maximum only about $16 \mathrm{~m}$ of this thickness is made up of chalk. In the southwestern Arkansas subsurface, the chalky section reaches maximum thickness of 34 in in Union County, just north of the state line (DOLLOFF 1967). From there the Saratoga thins southward to $23 \mathrm{~m}$ in Webster parish, Louisiana (MARTIN 1954), and to $15 \mathrm{~m}$ in DeSoto and Red River Parishes, Louisiana (MURRAY 1948). Minimum lateral dimensions of the Saratoga Formation are $200 \mathrm{~km}(\mathrm{E}-\mathrm{W})$ by $95 \mathrm{~km}(\mathrm{~N}-\mathrm{S})$; however, the formation is ton thin to be used as a repoeitory unlcas in combination with the underlying Marlbrook Marl.

\section{E.4.3.2.11 Summary}

Dimensional data are sumarized in Table E.4.3.1, which includes information on general characteristics with respect to areal distribution and thickness. A minimum acceptable thickness is taken as $46 \mathrm{~m}$ (150 feet).

Table E.4.3.1. Summary of dimensional data on Upper Cretaceous chalk deposits of the United States

\begin{tabular}{lccc}
\hline Unit & $\begin{array}{c}\text { Maximum } \\
\text { thickness } \\
(\mathrm{m})\end{array}$ & $\begin{array}{c}\text { Great } \\
\text { lateral } \\
\text { extent }\end{array}$ & $\begin{array}{c}\text { Greater than } \\
\text { minimum } 46 \mathrm{~m} \\
\text { thickness }\end{array}$ \\
\hline Annona & 172 & yes & yco $^{\mathrm{a}}$ \\
Austin & 300 & yes & yes $^{\mathrm{b}}$ \\
Demopolis & 158 & yes & yes \\
Greenhornc & 86 & yes & yes \\
Mooreville & 183 & yes & yes \\
Niobrara & $210^{\mathrm{d}}$ & yes & yes \\
Pecan Gap & $300^{\mathrm{e}}$ & yes & yes \\
Prairie Bluff & 46 & yes & no \\
Saratoga & 34 & yes & nog \\
\hline
\end{tabular}

a In northeastern Texas.

bexcept in area of San Marcos arch.

CIncluding overlying Fairport Chalk Member of Carlile Shale.

dEven thicker where less chalky.

eIn peripheral sinks around salt domes and diapirs. Otherwise, maximum is apparently about $72 \mathrm{~m}$ in the subsurface. diapirs.

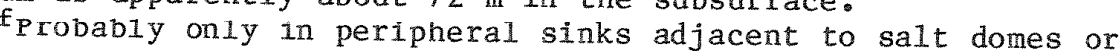

gThickness acceptable in combination with underlying Marlbrook Marl. 


\section{E.4.4 CHARACTERISTICS OF CHALK}

\section{E.4.4.1 LITHOLOGY}

\section{E.4.4.1.1 Composition of Chalk}

\section{E.4.4.1.1.1 Mineralogy}

Pure chalk consists almost entirely of low-magnesium calcite (HANCOCK 1975; SCHOLLE 1983), most being derived from the coccolithic remains of which chalk is primarily composed. Additional sources of this lowmagnesium calcite include (but are not limited to) tests of planktonic foraminifera, skeletal remains of benthic organisms (for American chalks, especially including ostreid and inoceramid bivalves), and secondary void-filling and neomorphic cements.

Dolomite has been detected in some chalks, especially European chalks, but this mineral is usually present only in trace quantities (SCHOLLE 1983). Examples of dolomite occurrence in American Cretaceous chalks include sparse rhombs inside foraminiferal chambers from deep Austin cores of Texas (GRABOWSKI 1981b) and as a rare replacement of cha1k matrix in the same unit (DRAVIS 1978).

Aragonite is rare in chalk deposits. Those organisms that had wholly aragonitic shells (e.g., gastropods, cephalopods, and some bivalves) are preserved (almost without exception) as molds, the shells having been destroyed by early diagenetic dissolution.

Accessory minerals are present in all chalk deposits, with quartz and clay minerals being foremost among them. Quartz occurs principally as clay- and silt-sized detritus, although sand-sized quartz occurs commonly in nearshore chalk (e.g., COPELAND 1968; BOTTJER 1978; WITZKE 1983). Stach (STACH 1976) reported a mean quartz content of $3.6 \pm 2.0 \%$ in samples of Niobrara Chalk from near Yankton, South Dakota, and $4.6 \pm 1.5 \%$ for samples from Marindahl Dam, South Dakota. Subsurface samples of the Smoky Hill Member, Niobrara Chalk, of northwesternmost Kansas contain from 2 to 28\% quarta, averaging $5.7 \%$ (n - 17). Samplca taken close to the contact with the overlying Pierre shale contain the highest percentages (KGS 1978). According to Carson (CARSON 1961), samples from the Denopolis Chalk of Mississippi contain an average of $1.5 \%(\mathrm{~s} . \mathrm{d} .=1.0 \%)$ quartz. Bottjer reported that the upper sandy chalk member, as well as marly chalks, in the Saratoga Chalk of Arkansas usually contains between 5 and $10 \%$ silt- and sand-sized quartz grains (BOTTJER 1978). These are just a few examples. Of course, where chalk grades into sandstone (COPELAND 1972), the percentage of quartz and other detritus gradually increases to nearly $100 \%$ 。

Except for the lowest bed of the Fort Hays Member (Niobrara Chalk) of Kansas, which contains abundant quartzose sand reworked from the underlying Carlile Shale, samples of chalk from this unit contain from less than 0.5 to $1.7 \%$ of quarts and foldopar (RUNNELLS 1949). Feldspar 
(usually in trace quantities) has also been reported from other American chalk units [e.g., the Smoky Hill Member of Kansas (HATTIN 1982), Pecan Gap of northeastern Texas (BREZINA 1974), and Demopolis Formation of Mississippi (CARSON 1961)].

Volcaniclastic material (other than bentonite) has been reported in Austin Chalk samples of central Texas (DRAVIS 1979), the Niobrara Chalk (rare) of southeastern South Dakota (STACH 1976), and the basal part of the Selma Group (Mooreville Formation) of the Monroe uplift and Jackson dome subsurface areas of Louisiana and Mississippi (KIDWELL 1951).

Clay minerals and other sheet silicates are represented in chalk deposits by many different mineral species, including montmorillonite (sometimes reported as smectite), illite, kaolinite, mixed-layer clays, chlorite, vermiculite and biotite. In the English Lower Chalk, Jeans (JEANS 1968) detected two antipathetic clay-mineral assemblages that can be correlated with facies and stratigraphy: (1) montmorillonite, illite and quartz; and (2) illite, kaolinite, chlorite, and vermiculite. Clays in the first assemblage were interpreted as authigenic; those clays of the second assemblage were believed to be detrital. Somewhat similar assemblages have been recorded in chalks of the Demopolis Chalk of Mississippi (CARSON 1961). In the detrital fraction of a sample of dark gray (unweathered?) chalk, Carson detected montmorillonite (>40\%), illite ( 10 to $40 \%)$ and kaolinite, chlorite, and quartz $(<10 \%)$; however, in a sample of yellowish tan (weathered?) chalk, he found illite $(>40 \%)$, montmorillonite and quartz (10 to $40 \%)$, and kaolinite and chlorite $(<10 \%)$. Chalk in a suite of Smoky Hill subsurface samples from northwesternmost Kansas (KGS 1978) contains only kaolinite (trace to $3 \%$ ) and illite (trace to $14 \%)$. Pollastro reported that much of the kaolinite in eastern Colorado Niobrara samples is of authigenic origin (POLLASTRO 1981). Stach analyzed the clay mineral content of numerous samples from several South Dakota sites (STACH 1976). Selected data from his thesis are included in Table E.4.4.1.

Few systematic heavy-mineral analyses have been carried out on samples of American chalk. Because of the small volume of such minerals in most samples, the analyses are usually based on study of insoluble residues. Runnells and Dubins conducted one of the earlier studies on samples of the Fort Hays Member (Niobrara Chalk) of Kansas (RUNNELS 1949) and detected a restricted heavy mineral suite consisting predominantly of ilmenite, leucoxene, magnetite, tourmaline, and zircon. No proportions were stated. A more systematic study was carried out on Mississippi chalk units by Carmichael (CARMICHAEL 1960), whose data are assembled here as Table E.4.4.2.

In southeastern South Dakota, the Niobrara Chalk locally contains a diverse suite of heavy minerals derived from the nearby Sioux Ridge (STEECE 1957). In addition to light minerals (quartz, feldspar, and illite), Steece detected magnetite, limonite, olivine, tourmaline, horn blende, and granitic rock fragments. Difference of provenance explains the difference between this assemblage and that reported by Carmichael (CARMICHAEL 1960). 
Table E.4.4.1. Clay-mineral content of unweathered samples from Niobrara Chalk of South Dakota

(Letters proceed upsection from A through O)

\begin{tabular}{|c|c|c|c|c|c|c|}
\hline \multicolumn{2}{|c|}{$\begin{array}{c}\text { Locality } \\
\text { and } \\
\text { sample }\end{array}$} & \multirow{2}{*}{$\frac{\text { Snectite }}{\text { Trace }}$} & \multirow{2}{*}{$\frac{\text { Illite }}{\text { Smectitea }}$} & \multirow{2}{*}{$\frac{\text { Kaolinite }}{\text { > Smectite }}$} & \multirow{2}{*}{$\frac{\text { Chlorite }}{\text { Trace }}$} & \multirow{2}{*}{$\frac{\begin{array}{r}\text { Mixed- } \\
\text { layered }\end{array}}{0}$} \\
\hline Yankton: & $\mathrm{A}$ & & & & & \\
\hline & $\mathrm{B}$ & Trace & <Smectite & <Smectite & Trace & Trace \\
\hline & $\mathrm{C}$ & Trace & 0 & 0 & 0 & Trace \\
\hline & $\mathrm{D}$ & Trace & 0 & 0 & 0 & Trace \\
\hline & $\mathrm{E}$ & Trace & 0 & 0 & 0 & Trace \\
\hline & $\mathrm{F}$ & Trace & <Smectite & <Smectite & 0 & Trace \\
\hline & G & Trace & 0 & SSmectite & 0 & Trace \\
\hline & $\mathrm{L}$ & Trace & 0 & SSmectite & 0 & Trace \\
\hline & 0 & Trace & 0 & 0 & $n$ & Trace \\
\hline
\end{tabular}

aproportion symbols to be read "is more abundant than," etc.

Source: R. L. Stach, Mineralogy and Stratigraphy of the Niobrara Formation, South Dakota, Master's thesis, University of South Dakota, Springfield, 1976 . 
Table E.4.4.2. Heavy minerals of samples from Demopolis Chalk and Prairie Bluff Chalk of Chickasaw County, Mississippi

\begin{tabular}{|c|c|c|c|c|c|c|c|c|c|c|c|c|c|c|}
\hline \multirow[b]{2}{*}{$\begin{array}{l}\text { Unit } \\
\text { and } \\
\text { samp. } \\
\text { no. }\end{array}$} & \multicolumn{14}{|c|}{ Heavy minerala } \\
\hline & 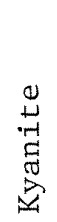 & $\begin{array}{l}\text { E } \\
0 \\
\text { H } \\
\stackrel{-1}{N}\end{array}$ & 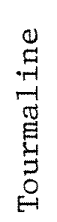 & 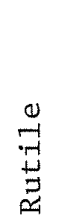 & 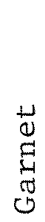 & 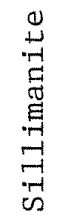 & 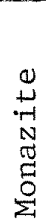 & 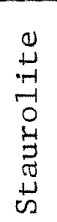 & 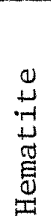 & 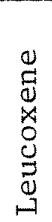 & 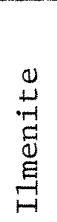 & 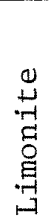 & 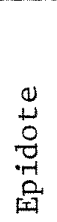 & 总 \\
\hline
\end{tabular}

\begin{tabular}{lrrrrrrrrrrrr}
\hline $\begin{array}{l}\text { Demo- } \\
\text { polis }\end{array}$ & & & & & & & & & & & & \\
$1-1$ & 38 & 9 & 3 & 5 & 5 & 13 & 15 & 5 & 5 & \\
$2-1$ & 2 & 4 & & & & 9 & 74 & 1 & 10 & \\
$2-2$ & 4 & 3 & & 10 & 2 & 2 & 47 & & 9 & 23 \\
$2-3$ & & 1 & 4 & & 1 & 1 & 35 & & 2 & 56 \\
$2-4$ & & 6 & 3 & 1 & 3 & 2 & 81 & & & 4
\end{tabular}

Prairie

Bluff

\begin{tabular}{rrrrrrrrrrrr}
$4-2$ & 10 & 12 & 17 & 10 & 3 & 5 & 15 & & 20 & 2 & \\
$4-3$ & 9 & 21 & 13 & 12 & 2 & 4 & 4 & & 26 & & 8 \\
$4-4$ & 15 & 26 & 10 & 8 & 3 & 4 & 9 & 5 & 9 & 2 & 9 \\
\hline
\end{tabular}

a Numerals refer to number of grains in 100-grain counts.

Source: V. 0. Carnichae1, The Ripley Formation and the Bluffport Member of the Demopolis Chalk in the Buena Vista, Mississipp1 Quadrangle, Master's thesis, Mississlppi Slale University, Mississippi State, 1960.

Glauconite, phosphatic minerals, pyrite, marcasite, and sparry calcite are the most common authigenic minerals in chalk, and have been decected in many European and Amerlcan chalk depusils. Less-commu authigenic minerals include kaolinite and siderite. Sand-sized irregular or pellet-like grains of glauconite are a common minor component of Gulf Coast chalks (e.g., BREZINA 1974; CLOUD 1975; BOTTJER 1978; DRAVIS 1979; GRABOWSKI 1981b; RUSSELL 1982), but this mineral is very sparse in Western Interior chalks and lacking in most sections. Examples of phosphatic-mineral occurrence include fillings of foraminiferal tests (DRAVIS 1979); granule- or pebble-sized nodules in the basal Austin Chalk (CLOUD 1975), condensed zones of the Saratoga and Annona chalks (BOTTJER 1978), and locally at the base of the Kansas Niobrara (personal observation. FREY 1972): phosphatic internal molds of macroinvertebrates in the Mooreville Formation and Prairie Bluff Cha1k of Alabama (KNOWLES 1963); and as replacements of foraminiferal test wa11s in the Austin 
Chalk (DRAVIS 1979) or coarser skeletal grains in the Annona Formation (BOTTJER 1978). Examples of marcasite occurrence include nodules in the Prairie Bluff Chalk of Mississippi (HUGHES 1958), in the Demopolis Chalk of Mississippi (CARSON 1961) and Alabama, and along bentonite seams or partially enclosing large inoceramid bivalves in the Smoky Hill Member (Niobrara Chalk) of Kansas (personal observations). Pyrite occurs as polycuboidal nodules in the Smoky Hill chalks of Kansas (HATTIN 1982); as nodules and pyritized burrows in the Austin Chalk of Texas (CLOUD 1975); as minute framboids inside foraminiferal tests of the Greenhorn Limestone (HATTIN 1975), Austin Chalk (DRAVIS 1979), and Smoky Hill Member (HATTIN 1982); as a skeletal replacement mineral (DRAVIS 1979; HATTIN 1982); as a matrix replacement mineral (DRAVIS 1979); or as a chamber-filling mineral. Sparry calcite is essentially ubiquitous as void-filling cement in chalk deposits and is the most important secondary mineral in American chalk deposits. This mineral, either as low-magnesium calcite or ferroan calcite, is most obvious as the filling of foraminiferal tests, calcispheres and macrohorings (e.g., HATTTN 196); CT.OIM 1975; BOTT.TFR 1978; DRAVTS 1979) and as the filling of joints and fractures in chalk (e.g., CLOUD 1975; CARSON 1961; personal observations). Neomorphic microsparry calcitic cements have been remarked in an earlier section of this report.

\section{E.4.4.1.1.2 Insoluble Residues}

Durham suggested a classification of chalk and related lithotypes based on the percentage of $\mathrm{CaCO}_{3}$ (DURHAM 1957). A relatively simple way to apply such a scheme is to determine the percentage of insoluble residue, and many authors have done so. Usually, the rock is digested in dilute HCl, which dissolves not only the carbonate but also any phosphatic materials (bones, teeth, scales, nodules, etc.). This problem is not significant, however, because the percentage of the remains is usually less than $1 \%$. Results of insoluble residue analysis for a number of American Cretaceous chalk units are incorporated in Tables E.4.4.3E.4.4.11, which are not all of the same design because of differing quality of data.

Insoluble residue data (as reported by BOTTJER 1978) for chalk and marly chalk samples from Saratoga formations are a composite based on all of Bottjer's localities:

$$
\begin{aligned}
& \mathrm{n}=31, \\
& \underline{\mathrm{r}}=7.8-39.8 \%, \\
& \mathrm{x}=28.4 \%,
\end{aligned}
$$

where

$\mathrm{n}=$ number samples,

$\underline{\underline{r}}=$ range of values in percent,

$\bar{x}=$ residue percentage.

\section{E.4.4.1.1.3 Chemical Analyses}

Relatively few American chalk samples have been subiected to detailed chemical analyses, and the published data differ widely in character 
Table E.4.4.3. Insoluble residue data for chalky limestone and shaly chalk samples of the Hartland and Jetmore members, Greenhorn Limestone, Kansasa,b

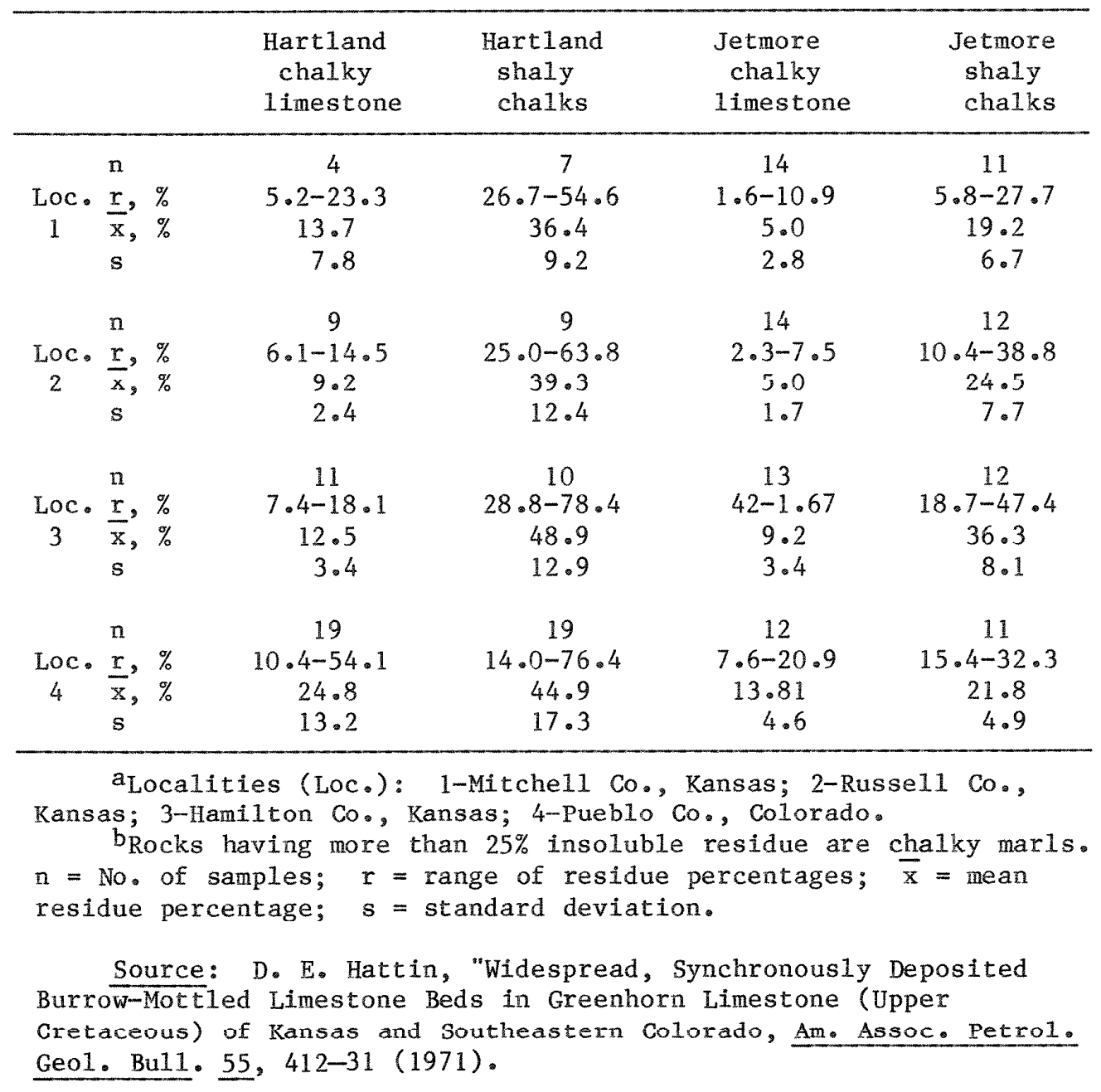


Table E.4.4.4. Representative insoluble residue data for Fort Hays Limestone Member, Niobrara Chalk, west central Kansas

\begin{tabular}{lccc}
\hline Locality & $\begin{array}{c}\text { Range } \\
(\%)\end{array}$ & $\begin{array}{c}\text { Mean } \\
(\%)\end{array}$ & No. of samples \\
\hline Ellis Co. Loc. 1 & $3.6-17.40^{\mathrm{a}}$ & 7.7 & 6 \\
E11is Co. Loc. 2 & $7.40,15.3^{\mathrm{a}}$ & $\mathrm{NA}^{\mathrm{b}}$ & 2 \\
El1is Co. Loc. 3 & $8.02,32.1^{\mathrm{a}}$ & $\mathrm{NA}$ & 2 \\
Smith Co. Loc. 1 & $2.36-62.16^{\mathrm{a}}$ & $4.2^{\mathrm{C}}$ & 6 \\
Rooks Co. Loc. 3 & $3.63-25.57^{\mathrm{a}}$ & 7.3 & 13 \\
Jewell Co. Loc. 1 & $2.92-8.65$ & 5.7 & 4 \\
\hline
\end{tabular}

a The highest values are for samples from the basal

Fort Hays, wich contains very fine quartzose sand that has been reworked from the underlying Code11 Sandstone Member of the Carlile Shale.

$\mathrm{b}_{\mathrm{NA}}=$ not available.

CDoes not include the high figure $(62.16 \%)$ because that sample is not a carbonate rock.

Source: R. T. Runnells and I. M. Dubins, "Chemical and Petrographic Studies of the Fort Hays Chalk," Kans. Geol. Surv. Bul1. 82(1), 36 (1949). 
Table E.4.4.5. Insoluble residue data for samples of Smoky Hill Chalk Member, Niobrara Chalk, of Kansas

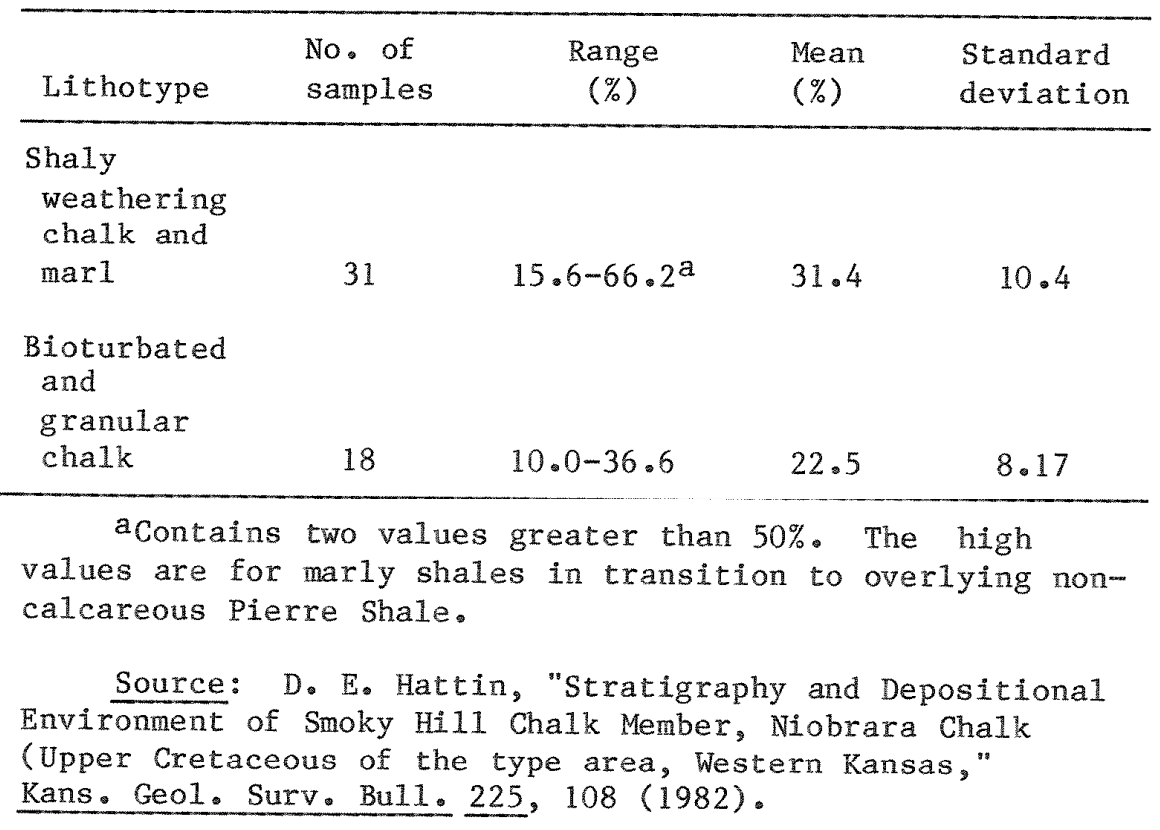

Table E.4.4.6. Insoluble residue data for samples of Niobrara Formation in southeastern South Dakota (Yankton, Marindahl Dam, Ethan, Fort Thompson) and the Black Hills

\begin{tabular}{lcccc}
\hline \multicolumn{1}{c}{ Locality } & $\begin{array}{c}\text { No. of } \\
\text { samples }\end{array}$ & $\begin{array}{c}\text { Range } \\
(\%)\end{array}$ & $\begin{array}{c}\text { Mean } \\
(\%)\end{array}$ & $\begin{array}{c}\text { Standard } \\
\text { deviation }\end{array}$ \\
\hline Yankton & 9 & $19.1-36.2$ & 26.8 & 4.7 \\
Ethan & 3 & $11.2-24.3$ & 16.7 & NA \\
Fort Thompson & 9 & $11.6-38.2$ & 26.3 & 7.3 \\
Marindah1 Dam & 3 & $13.2-23.4$ & 19.9 & NA \\
So. B1ack Hills & 7 & $11.4-25.7$ & 17.2 & 4.5 \\
\hline
\end{tabular}

$a_{N A}=$ not available.

Source: R. L. Stach, Mineralogy and Stratigraphy of the Niobrara Foundation, South Dakota, Master's thesis, University of South Dakota, Springfield, 1976. 
Table E.4.4.7. Insoluble residue data for chalk and marly chalk samples from Annona formations, southwestern Arkansas

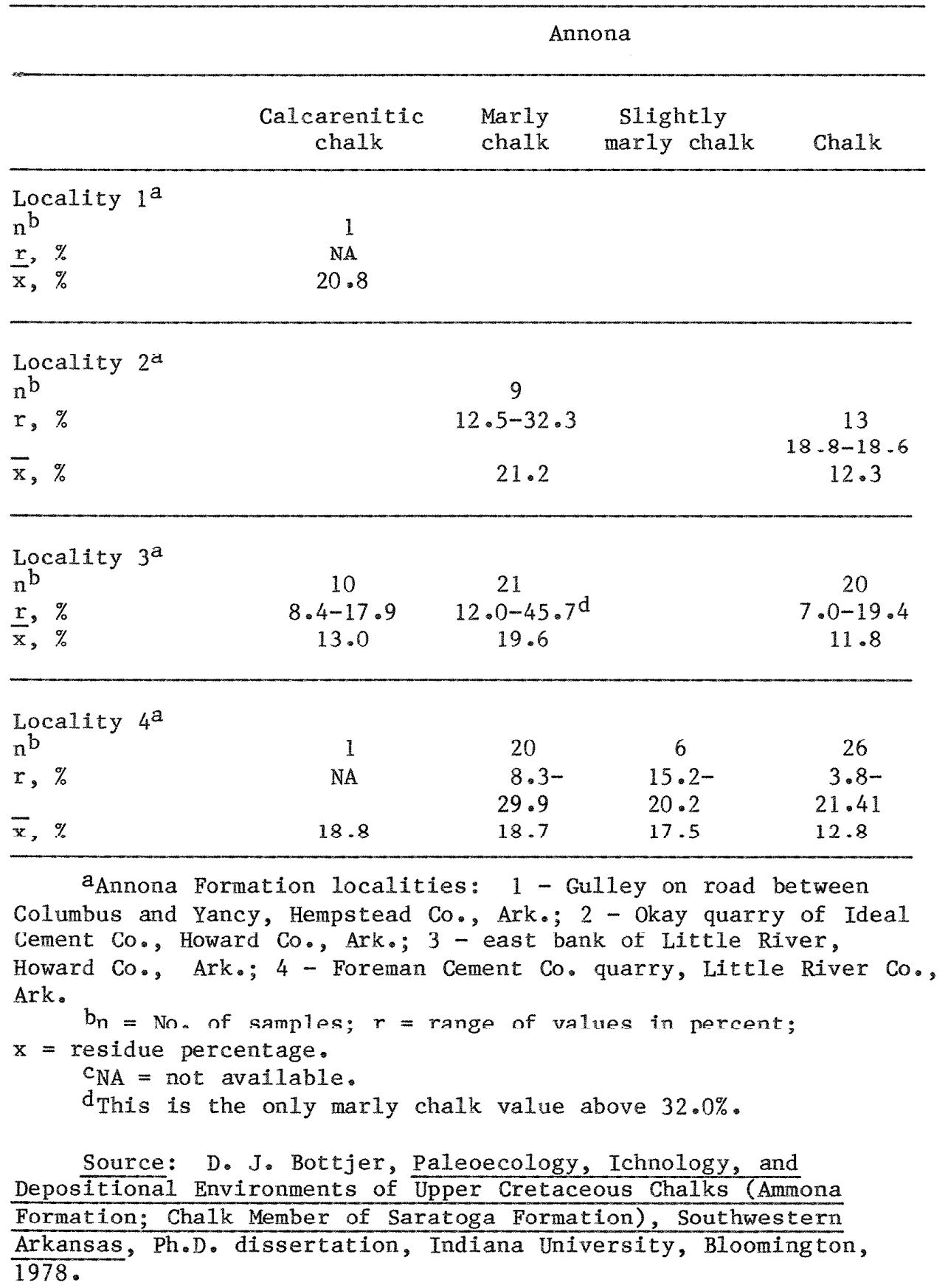


Table E.4.4.8. Insoluble residue data for subsurface Annona

Formation of western Mississippi, outcrop of Demopolis Chalk of Mississippi, and Pecan Gap Formation of Texas

\begin{tabular}{lccc}
\hline Unit & $\begin{array}{c}\text { Range } \\
(\%)\end{array}$ & $\begin{array}{c}\text { Mean } \\
(\%)\end{array}$ & No. of samples \\
\hline Annona $^{a}$ & $6.2-25.7$ & 17.4 & 75 \\
Demopolis & $10.0-28.0$ & 18.4 & $-\mathrm{b}$ \\
Pecan Gap & $9.6-17.2$ & 12.7 & 8 \\
\hline
\end{tabular}

aFrom $26.5-\mathrm{m}$ chalk sequence lying above the equivalent of Coffee Sand.

$b_{\text {Not }}$ stated.

Sources: Annona-F. F. Mellen, "Cretaceous Shelf Sediments of Mississippi." Miss. Geol. Surv. Bu11. 85.112 (1958). DemopolisT. G. Carson, A Sedimentary Study of Demopolis Chalk in the Artesia, Mississippi Quadrangle, Master's thesis, Mississippi State University, Mississippi State, 1961. Pecan Gap-J. L. Brezina, Stratigraphy and Petrology of the Pecan Gap Formation (Taylor Group, Upper Cretaceous) in Its Type Area, Master's thesis, University of Texas, Arlington, 1974 .

Table E.4.4.9. Insoluble residue data for samples of Austin Chalk of Texas

\begin{tabular}{llccr}
\hline County & Unit & No. of samples & $\begin{array}{c}\text { Range } \\
(\%)\end{array}$ & $\begin{array}{r}\text { Mean } \\
(\%)\end{array}$ \\
\hline Grayson & Atco & 7 & $12.5-26.2$ & 19.0 \\
Collin & Atco & 1 & 9.6 & NA $^{\text {a }}$ \\
Dallas & Atco & 4 & $7.1-20.3$ & 14.2 \\
Travis & Atco & 7 & $9.7-12.6$ & 11.7 \\
Bexar & Atco & 9 & $1.3-21.1$ & 8.0 \\
Medina & Atco & 6 & $3.7-6.3$ & 5.3 \\
Kinney & Atco & 9 & $3.0-21.7$ & 8.3 \\
Valverde & Atco & 5 & $1.8-6.8$ & 4.0 \\
Terrell & Atco & 6 & $3.6-6.8$ & 4.6 \\
Dallas & Hutchins & 3 & $13.7-23.1$ & 17.6 \\
Bexar & Dessau & 1 & 5.6 & NA \\
Uvalde & Big House & 3 & $15.2-29.5$ & 21.4 \\
Uvalde & Dessau & 4 & $2.2-15.9$ & 10.8 \\
Maverick & Big House & 2 & $10.9,11.6$ & NA \\
\hline
\end{tabular}

$a_{N A}=$ not available.

Source: K. W. Cloud, The Diagenesis of the Austin Chalk, Master's thesis, University of Texas, Dallas, 1975. 
Table $\mathbf{E . 4 . 4 . 1 0 . ~ I n s o l u b l e ~ r e s i d u e ~ d a t a ~ f o r ~ c h a l k ~ s a m p l e s ~}$ from Austin Chalk of Texas ${ }^{a}$

\begin{tabular}{|c|c|c|c|}
\hline Section & $\begin{array}{l}\text { No. of } \\
\text { samples }\end{array}$ & $\begin{array}{l}\text { Range } \\
(\%)\end{array}$ & $\begin{array}{l}\text { Mean } \\
(\%)\end{array}$ \\
\hline \multicolumn{4}{|l|}{ Brushy Creek } \\
\hline $\begin{array}{l}\text { Williamson Co. } \\
\text { Longhorn Cement Co. }\end{array}$ & 17 & $9.6-21.0$ & 15.0 \\
\hline & 13 & $3.7-21.9$ & 9.8 \\
\hline $\begin{array}{l}\text { Bexar Co. } \\
\text { Langtry }\end{array}$ & 9 & $6.4-21.6$ & 11.5 \\
\hline $\begin{array}{l}\text { Val Verde Co. } \\
\text { Nueces River }\end{array}$ & 13 & $3.0-10.0$ & 6.4 \\
\hline $\begin{array}{l}\text { Uvalde Co. } \\
\text { APCO C. Preuse B-1 Core }\end{array}$ & 1 & 18.6 & - \\
\hline Williamson $\mathrm{Co}$. & 15 & $12 \cdot 1-34 \cdot 0$ & 19.7 \\
\hline $\begin{array}{l}\text { APCO J.E. Standifer No. } 1 \text { Core } \\
\text { Bastrop Co. } \\
\text { Prairie J. Blumberg No. 1A Core }\end{array}$ & 4 & $8.3-24.8$ & 13.0 \\
\hline $\begin{array}{l}\text { Guadlupe Co. } \\
\text { Prairie H.T. Hurts No. } 1 \text { Core }\end{array}$ & 9 & $5.5-27.0$ & $15 \cdot 2$ \\
\hline $\begin{array}{l}\text { Gonzales Co. } \\
\text { Getty W.E. Beall No. } 1 \text { Core }\end{array}$ & 17 & $6 \cdot 8-41 \cdot 3$ & 15.1 \\
\hline $\begin{array}{l}\text { Frio Co. } \\
\text { Anoco No. } 1 \text { Varner-Wendler Core }\end{array}$ & 18 & $4 \cdot 5-31.2$ & 13.5 \\
\hline $\begin{array}{l}\text { Burleson Co. } \\
\text { Prairie/Convest Energy }\end{array}$ & 17 & $5 \cdot 5-23 \cdot 2$ & 12.0 \\
\hline $\begin{array}{l}\text { J.M. Winterbotham No. } 1 \text { Core } \\
\text { Zavala Co. } \\
\text { Prairie/Convest Energy }\end{array}$ & 17 & $2.5-37.6$ & 18.5 \\
\hline $\begin{array}{l}\text { Prairie/Convest Energy } \\
\text { H.B. Weinert No. } 1 \text { Core } \\
\text { Wilson Co. } \\
\text { Getty L.P. Samuels No. } 1 \text { Core }\end{array}$ & 14 & $8.04-53.6$ & 17.2 \\
\hline $\begin{array}{l}\text { Frio Co. } \\
\text { Getry G.E. Talbutt No. } 1 \text { Core }\end{array}$ & 24 & $5 \cdot 6-47 \cdot 8$ & 15.7 \\
\hline $\begin{array}{l}\text { Lasalle Co. } \\
\text { Transocean H.P. Orts No. } 2 \text { Core }\end{array}$ & 14 & $5.2-17.7$ & 10.5 \\
\hline Gonzales Co. & 33 & $8 \cdot 5-65 \cdot 2$ & 21.6 \\
\hline
\end{tabular}

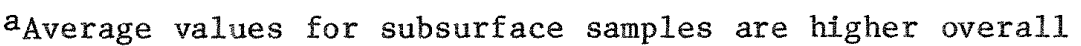
than those for surface samples.

Source: J. O. Dravis, Sedimentology and Diagenesis of the Upper Cretaceous Austin Chalk Formation, South Texas and Northern Mexico, Ph.D. dissertation, Rice University, Houston, Tex., 1979. 
Table E.4.4.11. Insoluble residue data for shaly or marly interbeds, Austin Chalk of Texas

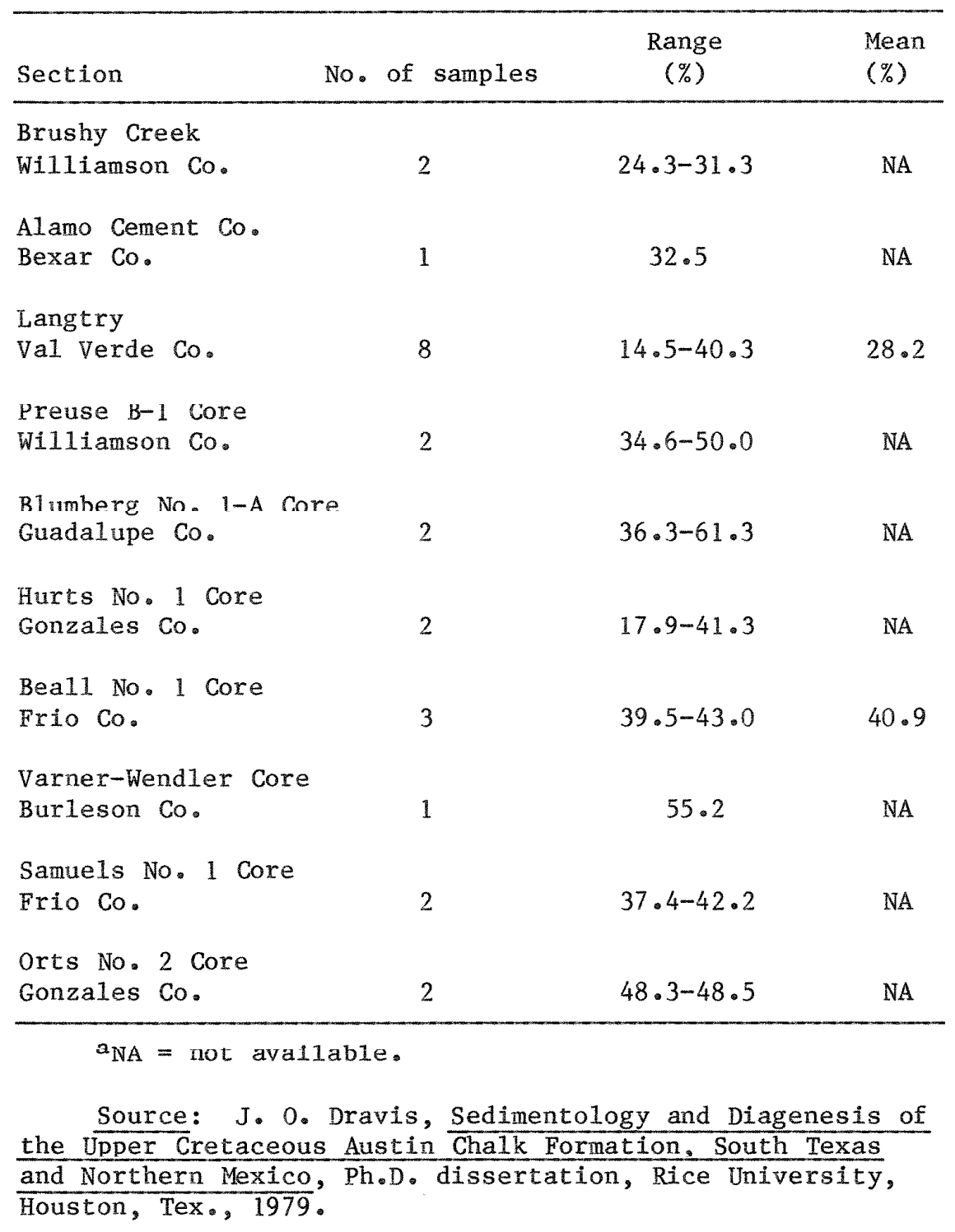


depending upon specific requirements of the particular study. Some authors do not state exact stratigraphic positions of samples or the degree to which the sampled section has been weathered. These data are thus presented for general information purposes only. Representative data are presented as a series of tables (Tables E.4.4.12-E4.4.21), starting with one that includes data from the very well-known English section of the Chalk (Table E.4.4.12).

Partial chemical analyses of Upper Cretaceous chalk and marl samples from U.S. Western Interior and Gulf Coastal Plan are shown in Table E.4.4.13.

A very large suite of samples from the Fort Hays Member, Niobrara Chalk, was analyzed by Runnells and Dubins (RUNNELLS 1949). Selected sections from their listing are included in Table E.4.4.14.

Organic carbon is an unimportant constituent in most parts of the English Chalk, but some American chalk units contaln relatively high percentages of organic carbon because of poor circulation on the seafloor and consequent development of anoxic or near-anoxic conditions. In an exhaustive study of organic matter in the subsurface Austin Chalk of southeastern Texas, Grabowski found that basinal chalks contain between " 0.5 and $5.0 \%$ amorphous sapropelic kerogen derived from marine organic matter with only trace amounts of terrestrial kerogen" (GRABOWSKI 1981b). In approximately 144 samples, the listed total organic content ranges from zero to a high of $14.1 \%$, with a mean value of $2.61 \%$ for the 139 samples for which a value is given. Unfortunately, the table does not indicate lithology. In his study of the Smoky Hill Chalk Member, Hattin reported that nonbioturbated chalk samples contain 0.5 to $5.8 \%$ organic carbon, with an average of $2.86 \%$ for 24 samples (HATTIN 1982). The most organic-rich beds of Smoky Hill chalk appear much darker on eroding slopes than the other chalks. The closeness of the Smoky Hill and Austin averages should be noted. In a study of the Greenhorn Limestone of Kansas and southeastern Colorado, Hattin noted that dark-colored laminated shaly chalks of Kansas contain higher percentages of organic carbon than do lighter-colored bioturbated chalk and chalky limestone beds (HATTIN 1971). The unweathered laminated chalks contain from 0.7 to $4.8 \%$ organic carbon, averaging $2.89 \%$ for 13 measurements, whereas the unweathered bioturbated chalks conlatn from 0.10 Lo $0.3 \%$ organte carbon, averaging $0.24 \%$ for 8 samples. The organic-rich laminated shaly chalks make up the larger part of the Greenhorn section in the study area. Both Hattin (HATTIN 1971) and Stach (STACH 1975) have demonstrated that weathered samples of chalk contain much less organic carbon than fresh samples. Data on both unweathered and moderately weathered chalk samples from South Dakota samples of the Niobrara Chalk are listed in Table E.4.4.22.

\section{E.4.4.1.2 Texture}

The component carbonate grains of chalks appear to fall into several general size classes that are defined and interpreted in somewhat different fashions, depending upon the worker and specific rock body under consideration. In general, however, chalk consists of a very fine silt/ clay fracliun (cunsisling peduminanly of cucculillis, theis isulated 


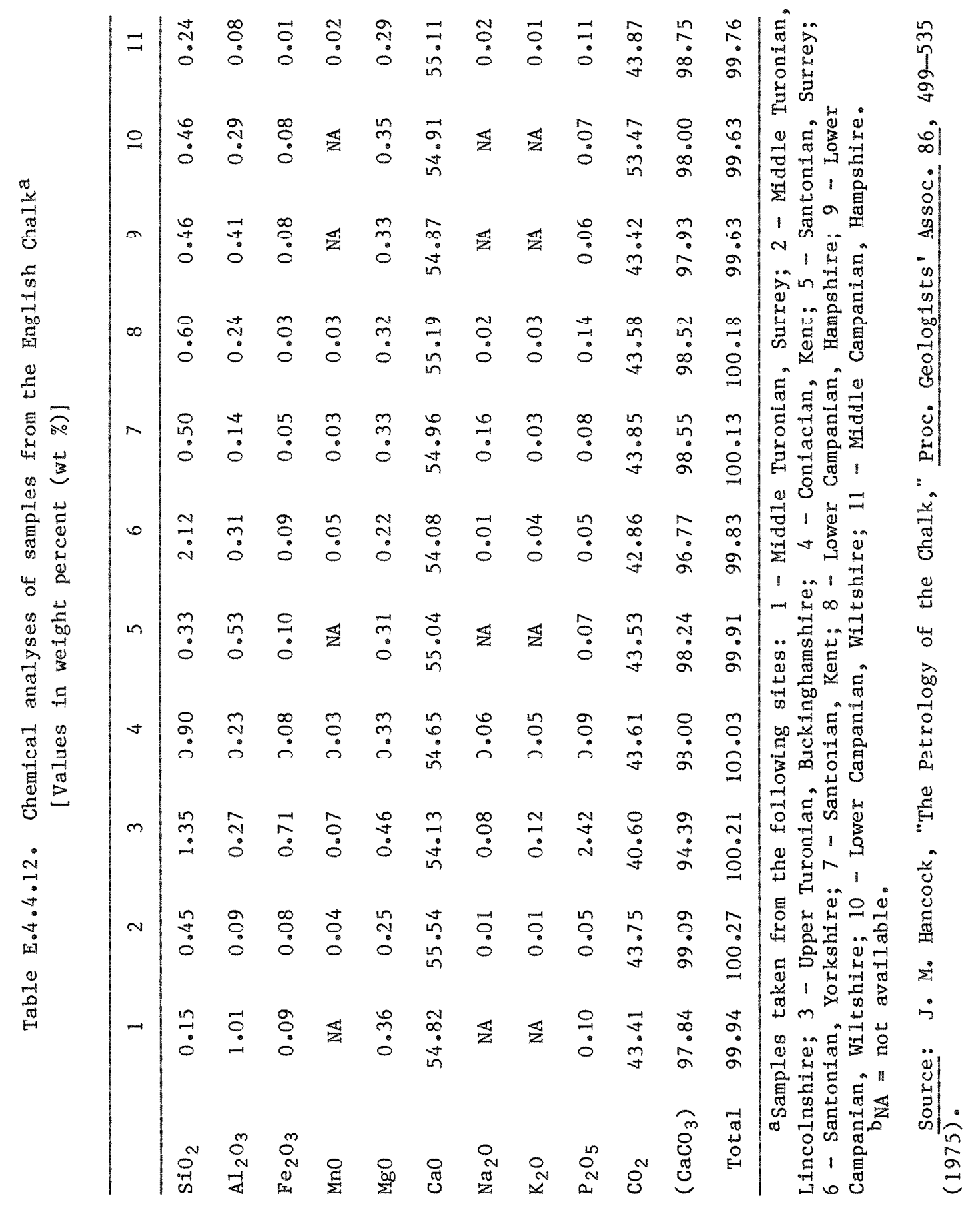


Table E.4.4.13. Partial chemical analyses of Upper Cretaceous chalk and marl samples from U.S. Western Interior and Gulf Coastal Plain [Values in weight percent (wt \%)]

\begin{tabular}{llcccccc}
\hline Unit & Locality & $\mathrm{CaCO}_{3}$ & $\mathrm{MgO}$ & $\mathrm{Al}_{2} \mathrm{O}_{3}$ & $\mathrm{SiO}_{2}$ & $\mathrm{Fe}_{2} \mathrm{O}_{3}$ & $\mathrm{Na}_{2} \mathrm{O}$ \\
\hline Demopolis & Demopolis, AL & 70.8 & 0.8 & 5.3 & 14.2 & 2.0 & 0.14 \\
Niobrara & Superior, $\mathrm{NP}^{\mathrm{a}}$ & 89.9 & 0.2 & 1.9 & 4.8 & 1.0 & 0.07 \\
Niobrara & Cedar, $\mathrm{KS}^{\mathrm{a}}$ & 93.4 & 0.2 & 0.5 & 3.0 & 0.7 & 0.06 \\
Niobrara & Hays, KS & 92.7 & 0.3 & 1.2 & 1.9 & 0.4 & 0.05 \\
Austin & Woodway, TX & 86.1 & 0.2 & 1.4 & 7.6 & 0.9 & 0.06 \\
Austin & Midlothian, TX & 85.6 & 0.3 & 1.7 & 6.6 & 1.3 & 0.09 \\
Annona & Okay. AR & 87.5 & 0.2 & 1.4 & 5.5 & 0.6 & 0.07 \\
\hline
\end{tabular}

a These samples are probably from the Fort Hays Member.

Source: R. D. Harvey, R. R. Frost, and T. J. Thomas, "Lake Marls, Chalks, and Other Carbonate Rocks with High Dissolution Rates in $\mathrm{SO}_{2}-$ Scrubbing Liquors," IIlinois State Geo1. Surv. Env. Geo1. Notes 68 (1974). 


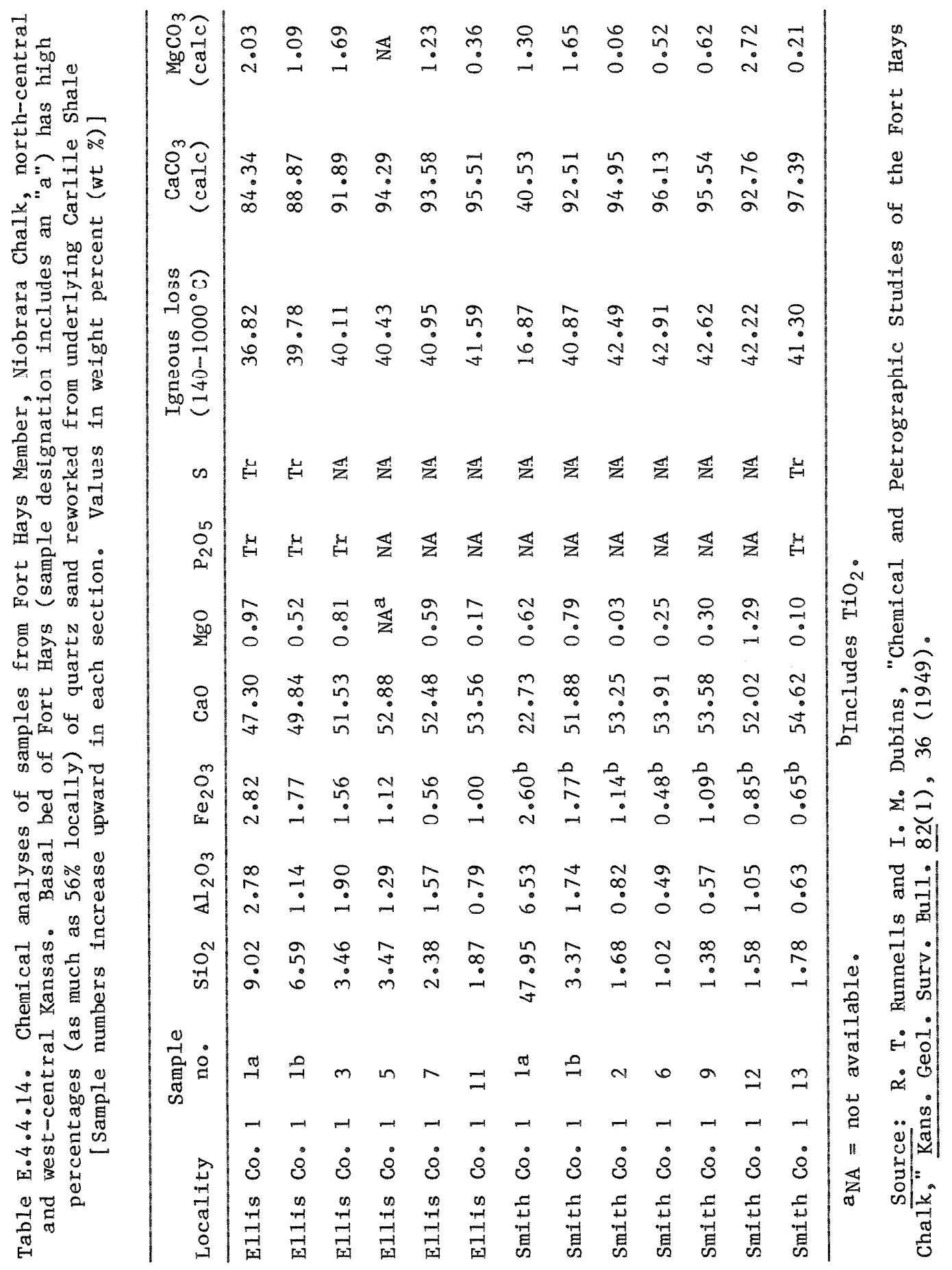




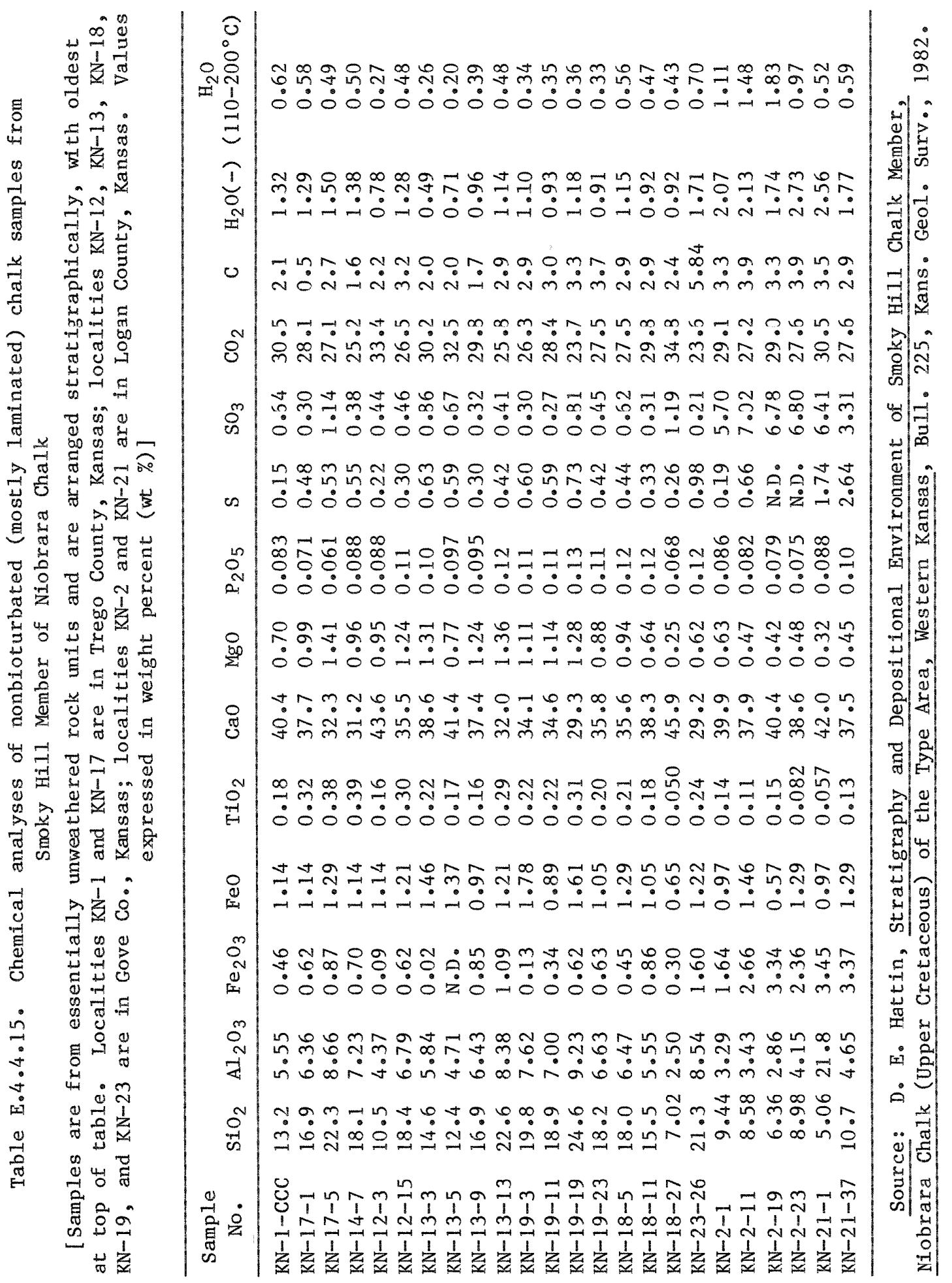




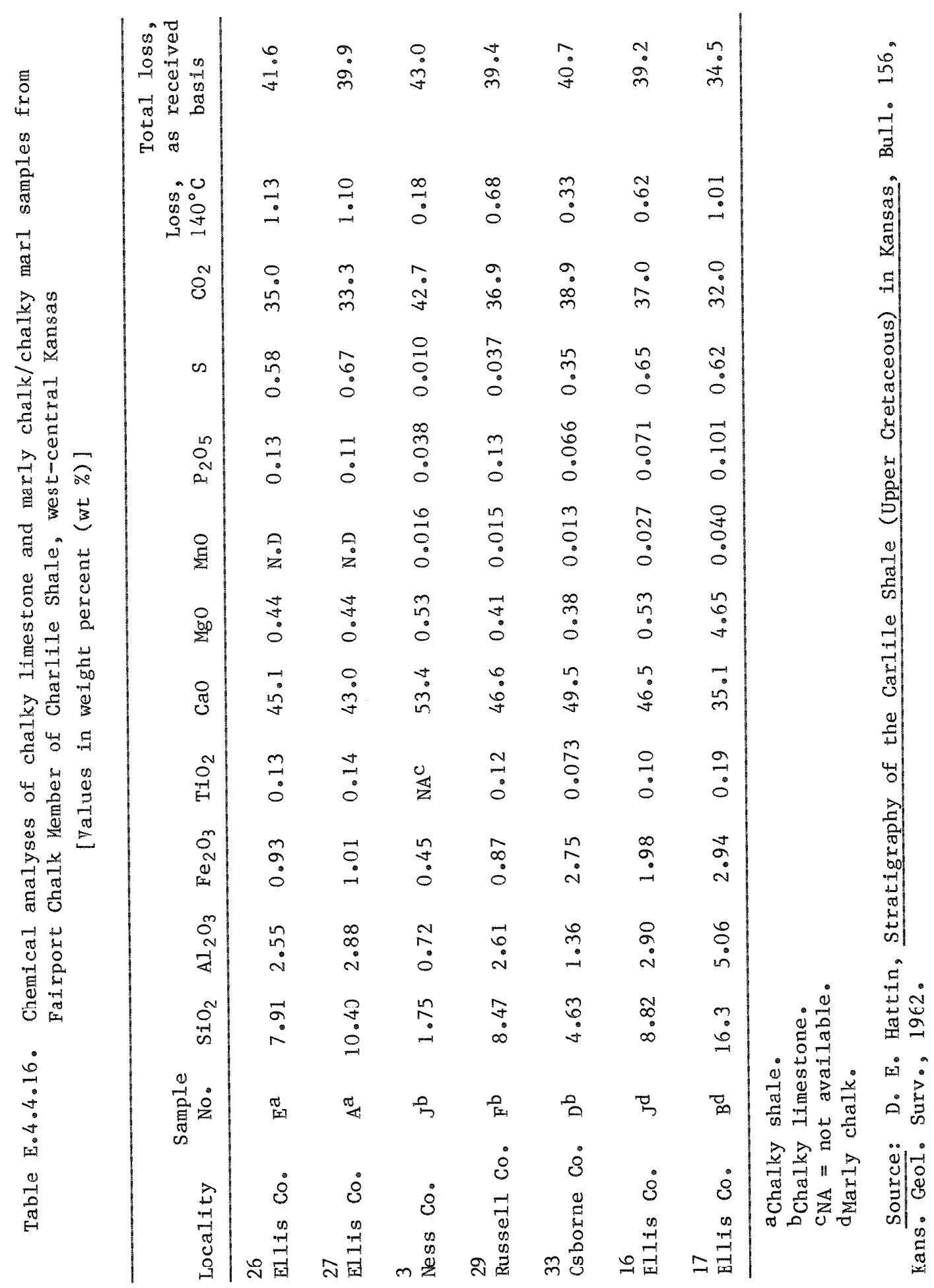


Table E.4.4.17. Partial chemical analyses of Niobrara Chalk samples from southeastern South Dakota

[Values in weight percent]

\begin{tabular}{lccccc}
\hline Locality & $\mathrm{CaCO}_{3}$ & $\mathrm{Al}_{2} \mathrm{O}_{3}$ & $\mathrm{FeO}$ & Volatiles & $\begin{array}{c}\text { Insoluble } \\
\text { matter }\end{array}$ \\
\hline Yankton Co. & 90.98 & 0.89 & 1.40 & 2.0 & 5.21 \\
Yankton Co. & 84.33 & 0.81 & 1.55 & 5.10 & 6.66 \\
Bon Homme Co. & 83.04 & 2.31 & 5.50 & 3.15 & 3.58 \\
Davison Co. & 92.36 & 1.60 & 1.98 & 1.72 & 4.72 \\
Bon Homme Co. 80.65 & 0.57 & 0.76 & 2.54 & 12.55 \\
Brule Co. & 74.13 & 1.44 & 1.37 & 5.06 & 15.46 \\
\hline
\end{tabular}

Source: E. P. Rothrock, A Geology of South Dakota,

Bu11. No. 15, South Dakota State Geol. Surv., 1944.

Table E.4.4.18. Chemical analyses of Niobrara Chalk samples from northeastern Nebraska

[Locality not stated. Values in weight percent (wt \%)]

\begin{tabular}{lcccccccc}
\hline Sample & Moisture & $\mathrm{SiO}_{2}$ & $\begin{array}{c}\mathrm{Fe}_{2} \mathrm{O}_{3}{ }^{+} \\
\mathrm{O}_{3}\end{array}$ & $\mathrm{CaO}$ & $\mathrm{CO}_{2}$ & $\mathrm{SO}_{3}$ & $\mathrm{Mg}$ & $\begin{array}{c}\text { Organic } \\
\text { matter }\end{array}$ \\
\hline Unweath. & 0.70 & 4.52 & 1.87 & 49.66 & 37.80 & 2.14 & $\mathrm{Tr}$ & 3.14 \\
$\begin{array}{c}\text { Weath } \\
\text { ered }\end{array}$ & 1.11 & 6.02 & 5.92 & 47.98 & 37.11 & 0.85 & $\mathrm{Tr}$ & 1.03 \\
\hline
\end{tabular}

Source: G. E. Condra, Geology and Water Resources of a Portion of the Missouri River Valley in Northeastern Nebraska, Pop. No. 215, U.S. Geol. Surv. Water Supply, 1908. 


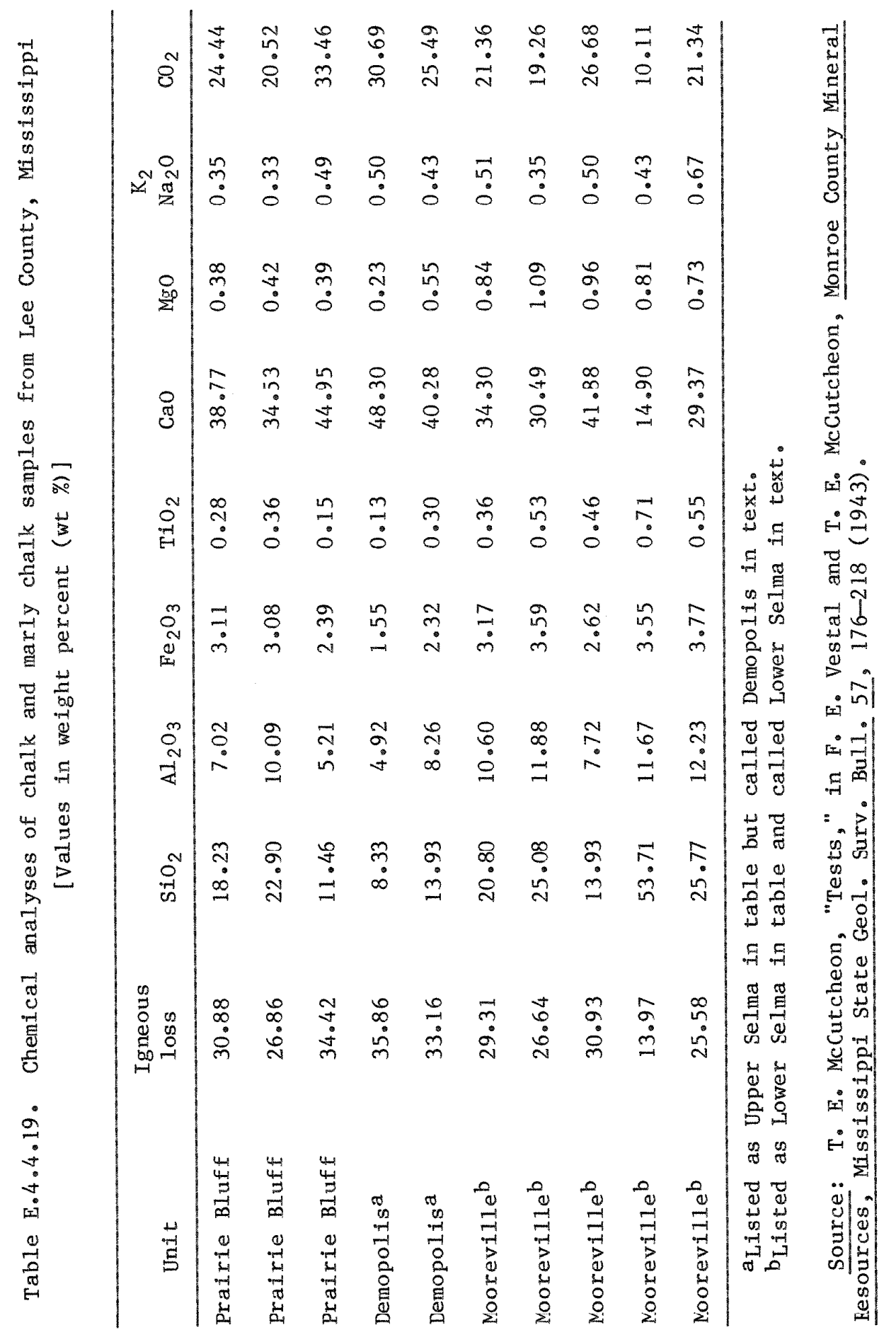




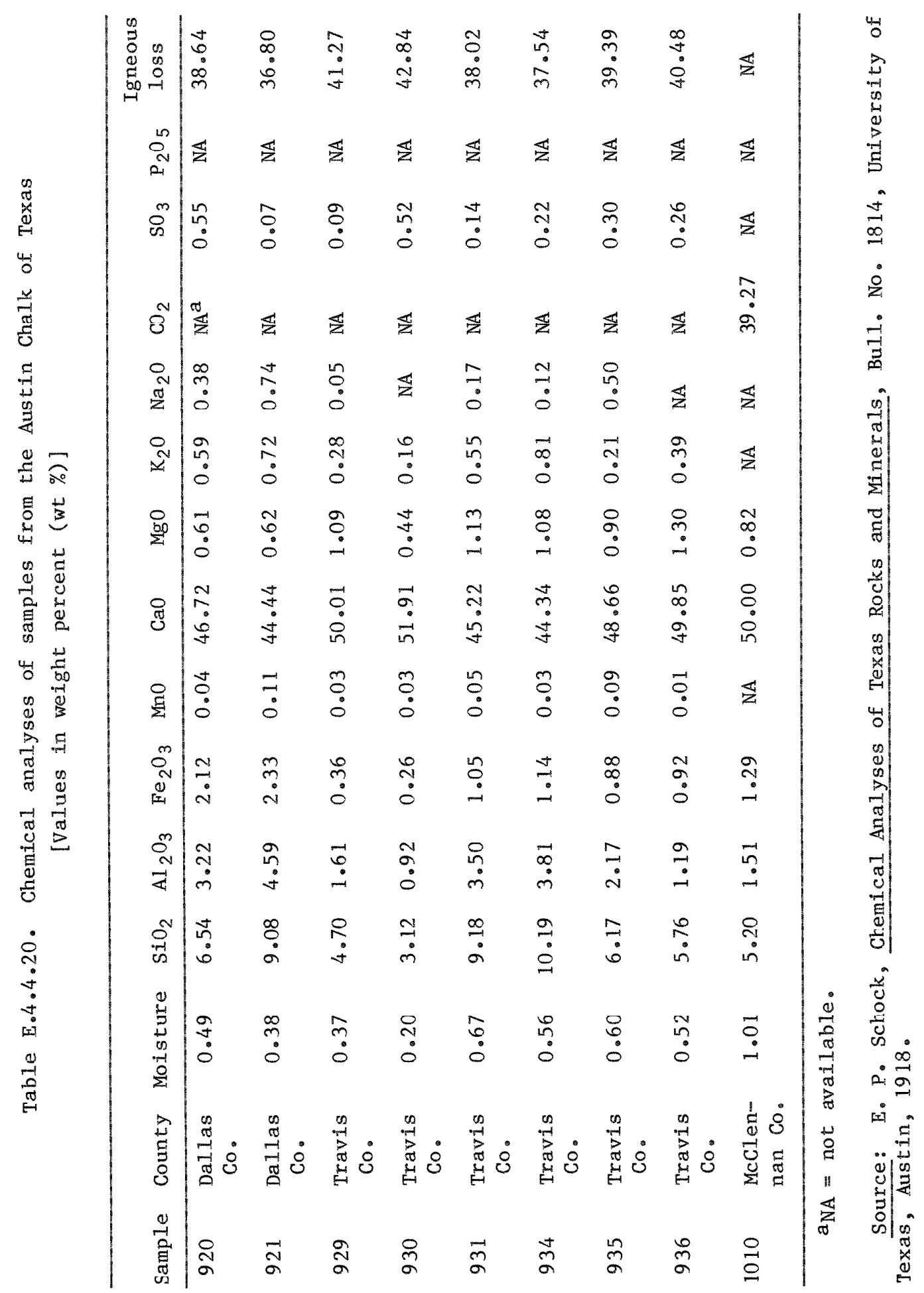




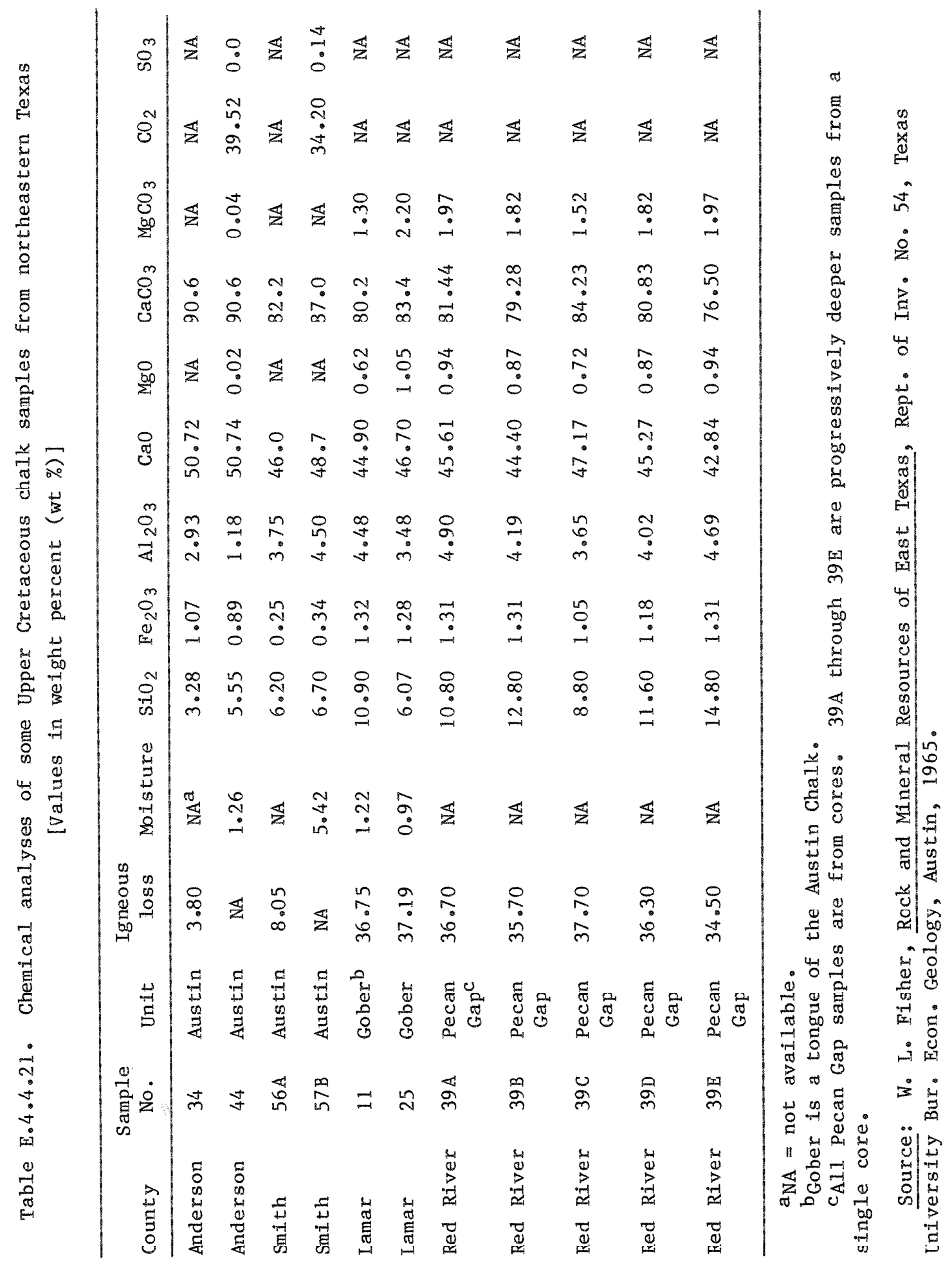


Table E.4.4.22. Organic carbon in samples of Niobrara Chalk from southeastern South Dakota

\begin{tabular}{|c|c|c|c|}
\hline Locality & Sample ${ }^{a}$ & Conditionb & $\begin{array}{c}\text { Organic carbon } \\
\text { determined on bulk } \\
\text { samples } \\
(\%)\end{array}$ \\
\hline \multirow[t]{7}{*}{ Yankton: } & A & UW & 5.14 \\
\hline & C & UW & 4.00 \\
\hline & F & UW & 7.06 \\
\hline & J & $w$ & $<0.5$ \\
\hline & $\mathrm{K}$ & W & $<0.5$ \\
\hline & L & W & $<0.5$ \\
\hline & $\mathrm{N}$ & W & $\mathrm{NA}$ \\
\hline \multirow[t]{8}{*}{ Ft. Thompson: } & A & MW & $N A^{C}$ \\
\hline & B & MW & 5.62 \\
\hline & D & $M W$ & 2.68 \\
\hline & F & MW & 3.50 \\
\hline & G & MW & 4.41 \\
\hline & $\mathrm{H}$ & MW & 5.23 \\
\hline & $\mathrm{J}$ & MW & ND \\
\hline & L & MW & $\mathrm{ND}$ \\
\hline \multirow[t]{2}{*}{ Chamberlain: } & $1 \mathrm{~A}$ & MW & 6.90 \\
\hline & $2 \mathrm{~A}$ & MW & 8.26 \\
\hline Ethan: & A & MW & 6.01 \\
\hline \multirow[t]{2}{*}{ Marindah1 Dam: } & c & MW & 6.31 \\
\hline & C & W & 0.05 \\
\hline \multicolumn{4}{|l|}{ Southern Black } \\
\hline Hills: & $\mathrm{D}$ & NS & $<0.05$ \\
\hline
\end{tabular}

${ }^{a}$ At each locality, samples are listed in upward order, with $A$ at the bottom.

bCondition: $\mathrm{UW}=$ unweathered; $\mathrm{W}=$ unweathered;

MW - moderatcly weathered; NS - not stated.

$c_{\mathrm{NA}}=$ not available. 
crystal elements, and microsparry calcite crystals), a coarser-silt to medium-sand fraction (consisting predominantly of calcispheres, foraminiferal tests, prisms from inoceramid bivalve shells, and fecal pellets), and a coarse sand/gravel fraction (consisting of larger skeletal grains and intraclasts). In most chalks the first of these size classes is by far the most important volumetrically.

Individual coccoliths range in size from 1 to $20 \mathrm{~m}$ (BUKRY 1969), and individual crystals from disintegrated coccoliths range from 0.2 to as much as $3 \mu \mathrm{m}$ (NEUGEBAUER 1974). In their study of northwestern European Maastrichtian chalks, Haakansson and others (HAAKANSSON 1974) found that most grains smaller than $5 \mu \mathrm{m}$ are remains of disintegrated coccoliths. They alsn found that silt- and clay-sized material make up as much as $93 \%$ of chalk samples analyzed and that the less-than-5- $\mu$ m component accounted for 87 to $92 \%$ of the silt- and clay-sized material. In the most extreme of their samples, the micritic material (= grains $<5 \mu \mathrm{m}$ ) made up $66 \%$ of the chalk. In other words, micrite is by far the most important ingredient of their Maastrichtian chalk samples. Furthermore, the silt-sized fraction of their samples was composed almost entirely of grains in the 5- to 20-um range.

Hancock (1975) gives a slightly different interpretation for the English Chalk, which contains two major grain-size classes, including 0.5 to $4 \mu \mathrm{m}$ (micrite) and 10 to $100 \mu \mathrm{m}$ (silt and very fine sand). Together, these classes make up perhaps $90 \%$ of the white chalk. The coarser fraction, especially that from 20 to $100 \mu \mathrm{m}$, is composed mainly of foraminifera, calcispheres, and skeletal fragments from various benthic invertebrate groups. Most of the finer material is derived from coccoliths.

The Austin chalk of Texas has trimodal grain-size distribution, with (1) a matrix, composed of coccolithic and other skeletal debris less than $20 \mu \mathrm{m}$ in maximum dimension; (2) coarser silt- to fine sand-sized foraminifera, calcispheres, and comminuted skeletal debris; and (3) much coarser material, including skeletal debris derived mainly from benthic invertebrates, intraclasts, and lithoclasts (DRAVIS 1979). Because of shallowwater deposition in parts of the Austin outcrop, the proportions of these three size classes range widely, with the coarser-silt and fine-sand fraction predominating locally over the muddy malrix, and wilh cuarser skeletal material locally making up as much as 30 to $40 \%$ of the rock. Cloud presents an excellent series of Austin Chalk photomicrographs and scanning electron micrographs (CLOUD 1975). Although he did not specify size ranges of chalk components in detail, he noted that the most common lithotypes are fossiliferous micrites, sparse biomicrites, and packed biomicrites. In the last of these, microscopically visible fossil remains make up more than $50 \%$ of the rock, but micrite (= grains $<5 \mu \mathrm{m}$ ) is the predominant component in a majority of thin sections studied by Cloud. Several of his photomicrographs show that micrite has been neomorphosed to microsparite (CLOUD 1975).

Bottjer tabulated extensive petrographic data on the Annona and Saratoga chalks of Arkansas (BOTTJER 1978). Stratigraphic position is slated for each bample, and percenlages of malsix and each glaill lype are 
given for 39 Saratoga and 53 Annona thin sections. For the Saratoga samples, matrix values range from 52.7 to $80.3 \%$; for the Annona samples, values range from 46.0 to $93.0 \%$. He reported that most of the matrix is microsparry (neomorphosed) calcite but that some micrite $(<5 \mu \mathrm{m})$ is present. For specific details on percentages of a wide range of detrital, skeletal, and authigenic-mineral-grain statistics, the tables in his work should be consulted (BOTTJER 1978).

The Fairport, Greenhorn, and Niobrara chalks described by Hattin (HATTIN 1962, 1975, 1982) are composed of three main size classes involving matrix, a coarser silt- to medium-sand-sized component, and a coarsegrained carbonate fraction. The matrix is of two kinds - micrite and microsparite - with the former $(<5 \mathrm{um})$ consisting largely of coccoliths and their component crystals and the latter (5 to $20 \mu \mathrm{m}$ ) consisting mostly of microsparite crystals. The coarser-silt and medium-sand component consists mainly of calcispheres (especially in the Greenhorn), tests of planktontc foramintfera, Inoceramıd prisms, and fecal pellets - the last of these being especially characteristic of Western Interior chalks. The coarse-grained fraction consists mainly of inoceramid and ostreid valve fragments, and predominates over matrix in some chalky calcarenites (see Table E.4.4.23).

Table E.4.4.23. Summary of grain-size distribution of main components in chalk

\begin{tabular}{|c|c|c|c|c|c|}
\hline \multirow[b]{2}{*}{$\begin{array}{l}\text { Common } \\
\text { components }\end{array}$} & \multicolumn{2}{|c|}{ Matrix } & \multicolumn{3}{|c|}{ Grains } \\
\hline & $\begin{array}{l}0-4 \\
(\mu \mathrm{m})\end{array}$ & $\begin{array}{l}5-20+ \\
(\mu \mathrm{m})\end{array}$ & $\begin{array}{l}\text { Coarser } \\
\text { silt }\end{array}$ & Sand & Grave1 \\
\hline $\begin{array}{l}\text { Coccolith } \\
\text { crystals }\end{array}$ & $\mathrm{x}$ & & & & \\
\hline Sina11 & & & & & \\
\hline $\begin{array}{l}\text { coccoliths } \\
\text { Large }\end{array}$ & $\mathrm{x}$ & & & & \\
\hline $\begin{array}{l}\text { coccoliths } \\
\text { Microsparry }\end{array}$ & & $\mathrm{x}$ & & & \\
\hline $\begin{array}{l}\text { calcite } \\
\text { Calcispheres }\end{array}$ & & $\mathrm{x}$ & $\mathrm{x}$ & $\mathrm{x}$ & \\
\hline Foram tests & & & $\mathrm{x}$ & $\mathrm{x}$ & \\
\hline Inoceramid & & & & & \\
\hline prisms & & & $x$ & $\mathrm{x}$ & \\
\hline Fecal pellets & & & & $\mathrm{x}$ & \\
\hline Skeletal debrisa & & & $\mathrm{x}$ & $\mathrm{x}$ & $\mathrm{x}$ \\
\hline Intraclasts & & & & $\mathrm{x}$ & $\mathrm{x}$ \\
\hline
\end{tabular}
prisms.

axcluding coccoliths, foram tests, and inoceramid 


\section{E.4.4.1.3 Homogeneity}

\section{E.4.4.1.3.1 Genera1 Considerations}

Enormous organic productivity in Late Cretaceous subtropical and warm-temperate seas created the potential for chalk-forming ooze accumulation on shelves that were situated (1) far from shorelines or (2) adjacent to low-relief land areas that contributed relatively little terrigenous detritus to the shelf environment.

Sediments that formed typical Upper Cretaceous shelf-sea chalks were deposited mostly far from shore and usually in the deeper and quieter parte of shelves, where the accumulation of pelagic carbonate particles could progress with only minimum dilution by terrigenous detritus. Such conditions prevailed across vast expanses of Cretaceous North America, especially along a shelf that bordered the northern Gulf of Mexico and on that which lay off the eastern shore of the Western Interior Sea. In these offshore, deeper-water settings, pelagic sediments were little affected by waves or currents, and areal variations in terrigenousdetrital influx wore gradual except in close proximity to swe11s, volcanoes, massifs, etc. Furthermore, these shelves were mostly stable or relatively so, with small-scale normal faulting, salt-dome movements, and very local volcanic activity being the only significant disruptive factors. Accordingly, most shelf-sea chalk deposits, in the United States and elsewhere, have exceptionally great lateral homogeneity, both within a given bed or within groups of depositionally related beds. Lateral changes in 1ithology are usually on the order of several kilometers to several tens of kilometers, with the extreme being several hundred kilometers.

Stratigraphically upward, chalk sections are, on average, less homogeneous than in the lateral or geographic sense. Few chalk units lack overall upward change in general 1ithology or interbeds of marly chalk, marl, calcarenus shale, nr hentonite. food circulation of marine bottom waters and continuous bioturbation of chalk-forming muds produced very thick sections of massive chalk in which there may remain no traces of interbeds. Where the same conditions prevailed, but with deposition being atfected by periodic influxes of significant amounts of fine-grained terrigenous detritus, a rhythmically bedded bioturbated chalk/marl sequence resulted. Nannoplankton-rich muds that were too soft to support a hurrowing infauna (or that were deposited under anoxic conditions) are preserved today as laminated chalk, which is usually interbedded with bioturbated chalk or chalky limestone beds.

Massive chalk units reach thicknesses measured in tens of meters, whereas in bedded sequences the vertical alternations are mostly on a decimeter-to-meter scale. We11-bedded chalk sequences usually involve alternation of two 1ithotypes, such as chalk and marl; in American chalk sequences, the contacts between the two are typically gradational. Thus, the vertical lithologic inhomogeneities of bedded chalk sequences generally do not involve great discontinuities in the mineralogical or textural properties of the stratigraphic section. 


\section{E.4.4.1.3.2 Examples}

The Demopolis Chalk of western Alabama and adjacent parts of Mississippi is commonly described as massive (e.g., CARLSTON 1944; EARGLE 1948; COPELAND 1968), although some authors have mentioned that the unit is weakly bedded (JONES 1967) or shows some bedding (COPELAND 1972) locally. The relatively pure chalk facies extends for scores of kilometers along the outcrop in western Alabama and northeastern Mississippi. In east-central Alabama, the formation becomes sandy and grades into the Cusseta Sand Member of the Ripley Formation, the change occurring within a distance of approximately 20 to $30 \mathrm{~km}$. Northward along the Mississippi outcrop, Russe11 and Keady noted that the formation becomes, in part, we11 bedded and becomes progressively more marly near the southern border of Tennessee (RUSSELL 1982).

Within we11-bedded sequences of bioturbated chalk, such as the Annona Chalk of Arkansas and Austin Chalk of nulliedstern dind southwescern Texas, lateral homogeneity is exceptionally well developed. The Annona chalk-marl rhythms extend along the Annona outcrop for nearly $50 \mathrm{~km}$ (BOTTJER 1978) but are not mentioned in a detailed study of the downdip (subsurface) area (DOLLOFF 1967). According to Durham, exact regional correlation of the Austin Chalk is possible because of wide lateral persistence of individual beds within rhythmically stratified sequences (DURHAM 1957). The Atco Chalk, which generally embraces approximately one-third of the total Austin thickness, comprises some $73 \mathrm{~m}$ of rhythmically bedded chalk and marl in the type area southwest of Waco, Texas. The unit maintains this character northward to Dallas, where thickness has been reduced to $62 \mathrm{~m}$ in a distance of $145 \mathrm{~km}$ (DURHAM 1957). Southwestwardly from the type area, marl beds in the Atco pinch out, the unit becomes more massive, and the thickness diminishes gradually to only $12 \mathrm{~m}$ on the San Marcos arch, some $200 \mathrm{~km}$ from Waco. Southwest of the San Marcos arch, the Atco thickens gradually to more than $120 \mathrm{~m}$ and regains its rhythmic character (DURHAM 1957). Above the Atco lie the Bruceville Marl and Vinson Chalk, which are laterally equivalent and are intertongued. The main area of intertonguing is Williamson County; but, within the marly facies, beds of chalk extend northward as far as Dallas, and within the chalky facies, beds of marl extend southward as far as Bexar County. The two genetically related facies thus maifest reglonal gradation by intertonguing along an outcrop distance of approximately $400 \mathrm{~km}$. Although not discussed here, other units of the Austin Chalk have similarly widespread lateral and vertical homogeneity; sharp lateral changes of facies are not characteristic of the Austin Cha1k (DRAVIS 1979). The only major interruption of the otherwise very widespread homogeneity of Austin Chalk facies patterns occurs across the San Marcos arch, where the

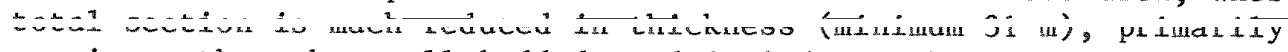
massive rather than well bedded, and includes much coarsely shelly chalk and numerous oyster bioherms. Even here, sharp lateral facies changes are lacking. On a much more local basis, chalky facies of the Austin Chalk are intertongued with beachrock and pyroclastic facies around eruptive centers such as Pilot Knob, Travis County, Texas. For both of these unusual facies the transition to more typical Austin facies occurs in distances 1000 than $1 \mathrm{~km}$ (YOUNG 1975). Alone among American chalk 
formations, the Austin contains numerous discontinuities or disconformities that are marked by local thinning or truncation of underlying beds and by abrupt vertical changes of lithology between some untts (DURHAM 1957). Downdip, the Austin changes facies gradually with increasing depth and distance from the outcrop. Data from Caldwell and Gonzales Counties are listed in Table E.4.4.24.

Table E.4.4.24. Data pertaining to facies changes in the subsurface Austin Chalk

\begin{tabular}{lccl}
\hline Locality & $\begin{array}{c}\text { Depth } \\
(\mathrm{m})\end{array}$ & $\begin{array}{c}\text { Chalk } \\
\text { thickness } \\
(\mathrm{m})\end{array}$ & \multicolumn{1}{c}{ Remarks } \\
\hline Caldwell Co. & 701 & 76.2 & $\begin{array}{c}15 \% \text { shaly or marly } \\
\text { streaks }\end{array}$ \\
Gonzales Co. & 2195 & 117.2 & $30 \%$ shale \\
Gonzales Co. & $>2896$ & 198.2 & $35 \%$ shale \\
Gonzales Co. & 3658 & $\mathrm{NA}^{\mathrm{a}}$ & $100 \%$ shale \\
\hline
\end{tabular}

$a_{\mathrm{NA}}=$ not available.

Source: W. L. Stapp, "What to Look For When Exploring the Austin Chalk," World 0il 186(2), 55-60 (1978).

Extremes of lateral persistence of lithic homogeneity are evident in the Greenhorn Limestone and Niobrara Chalk of western Kansas and adjacent states. Across vast areas of the Great Plains outcrop and subsurface, the Greenhorn is dominated by laminated marly chalk or chalk-marl that is calcarenitic in the lower one-fourth and characterized by a widely traceable sequence of chalky limestone beds in the upper 50 to $55 \%$ of the formation. This area is overlain by a nearly equal thickness of chalky strata assigned to the Fairport Member of the Carlile Shale, which consists mostly of impure chalk in the lower part and grades upward into progressively less pure chalks and marls (HATTIN 1962). This sequence retains its essential lithologic character across the entire Kansas outcrop - a distance of several hundred kilometers. From the Kansas border westwardly for another $225 \mathrm{~km}$, the laminated marly chalk and chalk-marl interbeds grade to chalky shale and the chalky limestone beds either disappear (Fairport) or grade into mostly hard, brittle limestone beds. All of these changes occur gradually over distances measuring scores of kilometers. Lateral uniformity of this section is evident in the wide traceability of individual beds, some of which extend for hundrcdo of kilometcrs (IIATTIN 1971, 1979). 
The Niobrara Chalk comprises two nembers - each of which has remarkable lateral homogeneity. In Kansas the lower member (Fort Hays) comprises a rhythmic sequence of thick bioturbated chalk and chalky limestone beds separated by thin to very thin bioturbated marly chalk interbeds. This essential character persists all across the Kansas outcrop (several hundred kilometers) and westward at least to the Rocky Mountain front. Westward from Kansas, the chalky limestones grade into harder micritic limestones and the interbeds (some of which thicken noticeably) grade into chalky or calcareous shale. In outcrop, these changes occur gradually over a distance of nearly $200 \mathrm{~km}$. The upper member (Smoky Hi11) contains a few intervals characterized by bioturbated chalk but consists mostly of laminated-to-massive nonbioturbated marly chalk and cha1k-mar1. Near the ton, the sertion grades to chalky shale. Marker bed study (HATTIN 1982) suggests that individual bedding units have wide traceability, as in the Fort Hays Member. Westward from Kansas, the Smoky Hill manifests only gradual change of character to less calcareous facies along the Rocky Mountain front, but even there much of the section still has a decidedly chalky character in outcrop. The Fort Hays and Smoky Hill are recognizable as chalky limestone and impure chalk facies, respectively, hut the sestion is much reduced in thickness there ( 61 to $62 \mathrm{~m})$.

\section{E.4.4.1.3.3 Concluding Remarks}

In the foregoing section, mention is made only of selected American chalk units. These units were chosen to illustrate the fact that whether chalk sections are massive or well bedded, whether individual beds are bioturbated or laminated, and whether chalk formations are thick or thin, chalk sections tend to have the following general characteristics:

1. wide lateral persistence of facies (tens to hundreds of kilometers);

2. wide traceability of beds within bedded sequences (tens to hundreds of kilometers):

3. mostly gradual changes of thickness and facies (usually over tens of kilometers);

4. vertical sequences that (a) lack interbeds, (b) comprise alternating successions of generically related lithotypes such as chalk and marly chalk or chalk and marl, or (c) show gradual upward change in dominant lithotype; and

5. abrupt changes of lithology occur mainly at discontinuities and disconformities within chalk sections, but these are uncommon in most American chalk formations.

\section{E.4.4.2 BEDDING}

The thickness of beds in chalk deposits ranges from laminations on a millimeter to centimeter scale (e.g., HATTIN 1982) to very thick, poorly bedded-to-nonbedded sequences of massive chalk, many meters in thickness. At the one extreme, laminations are characteristic of nonbioturbated chalk. At the other extreme, thick sections of massive chalk are the result of extensive bioturbation. 
Ekdale and Bromley have stated that with few exceptions shelf-sea chalks have been extensively bioturbated (EKDALE 1984). Even so, such pervasively bioturbated units as the English Middle Chalk and Upper Chalk have a faintly to distinctly bedded character, owing principally to shorter or longer pauses in deposition. The shorter pauses, resulting in omission surfaces (BROMLEY 1975), occur at 0.5- to 2.0-m intervals in these chalk units (HANCOCK 1975). Longer pauses, commonly accompanied by seafloor erosion, often involved synsedimentary lithification of surficial chalk-forming mud and development of hardgrounds, which also impart a bedded appearance. Certain chalk units of the Gulf Coastal Plain, including the Pecan Gap Formation of Texas and the Demopolis and Prairie Bluff Chalks of Alabama are, like the English Middle and Upper chalks, composed primarily of massive Lo weakly bedded chalk (JONES 1967; BREZINA 1974), but these units apparently lack hardgrounds.

In sharp contrast, the English Chalk Marl exhibits a rhythmic succession of chalk and marly chalk beds that are of subequal thickness and usually measurable on a decimeter scale. Kennedy and Garrison noted that both chalk and marly chalk beds are bioturbated throughout, and omission surfaces mark the Lops of some chalk beds (KENNEDr 1975). An almost identical sequence, also extensively bioturbated and with beds of decimeter scale, occurs in the Annona Chalk of Arkansas (BOTTJER 1978); but, in that formation, omission surfaces are rare. Except in central Texas (San Marcos arch), the Austin Chalk also manifests rhythmic bedding (CLOUD 1975; DRAVIS 1979), with massive, bioturbated chalk beds several decimeters to a meter or more in thickness, alternating with thinner marl or calcareous shale interbeds. An extreme form of rhythmic bedding occurs in the Atco Member of the Austin Chalk wherein beds of massive bioturbated chalk 0.6 to $1.2 \mathrm{~m}$ in thickness are separated by very thin partings of calcareous shale or marl (CLOUD 1975). An almost identical kind of bedding occurs in the Fort Hays Member of the Niobrara Chalk in Kansas. Another type of rhythmic sequence involving alternation of organic-rich laminated marly chalk and organic-poor bioturbated chalky limestone occurs in the Geenluin-Fairpuil clialh sequence of Kansas (HATTIN 1962, 1971, 1975) and in its less chalky equivalent in Colorado (HATTIN 1971; COBBAN 1972; PRATT 1984). The bioturbated limestone beds are usually from 1 to $4 \mathrm{dm}$ in thickness, whereas intervening laminated marly chalk units range usually from $2 \mathrm{dm}$ to $\geqslant 1 \mathrm{~m}$ in thickness. All of these rhythmic chalk sequences resulted from episodes of dilution by terrigenous detritus during which the background of pelagic carbonate sedimentation was affected by influx of clay and quartzose silt. Thickness of the shaly interbeds depends upon such factors as proximity to terrigenous source areas, intensity of pluvial cycles, tectonism in source areas, or some combination thereof.

An unusual kind of bedding is developed in the Smoky Hill Member of the Niobrara Chalk of Kansas and eastern Colorado. Thick intervals of laminated, organic-rich, impure chalk lack obvious rhythmic bedding and contain only a few, widely spaced bioturbated chalk intervals (HATTIN 1982). This chalk sequence is probably unique.

Within a single chalk unit, character of bedding can change laterally. For example, the upper $60 \mathrm{~m}$ of the Demopolis Formation of northern 
Mississippi is a well-bedded sequence consisting of relatively thick beds of chalk interbedded with marls (RUSSELL 1982), but in western Alabama the entire Demopolis $(152 \mathrm{~m})$ consists of marly to almost pure chalk that is weakly bedded to massive (JONES 1967). Similarly, the Austin Chalk of Texas is rhythmically bedded both northeast and southwest of the San Marcos arch; however, the shaly or marly interbeds diminish onto the arch, and the rhythmic bedding is not evident there (DURHAM 1957; DRAVIS 1979). In the Fort Hays Member of the Niobrara, very thin marly chalk partings in the upper one-third to one-half of the nember pass westwardly into thicker beds of calcareous shale in conjunction with thinning of limestone beds, such that the shaly lithotype predominates.

Within well-bedded American chalk sequences, individual beds can commonly be traced for long distances, in extreme cases for several hundred kilometers (DURHAM 1957; MELLEN 1958; HATTIN 1971, 1979; BOTTJER 1978; SMITH 1978; LAFERIERE 1984). Most such beds are probably time parallel as suggested not only by persistence of sequence but also from evidence of fossils and associated bentonite seams.

\section{E.4.4.3 NATURE OF INTERBEDS}

As construed herein, the term "interbeds" refers to layers of marly chalk, marl, calcareous shale, bentonite, etc., that are interposed between layers of more pure chalky carbonate rock. Interbeds may be of equal, greater, or lesser thickness than the chalk beds with which they alternate. Some chalk sequences are massive or indistinctly bedded (i.e., they lack interbeds). In other chalky sequences, chalk occurs in thin, widely separated beds and the marly or shaly interbeds comprise most of the section. In chalk sequences, the most common interbeds are composed of marly chalk or chalky marl (less commonly calcareous shale or clay) and are the product of dilution cycles induced by variations in rates of terrigenous detrital influx. Where pelagic muds accumulated on oxic bottoms, both chalky and marly interbeds are bioturbated (e.g., English Chalk Marl, Annona Formation of Arkansas, Austin Chalk of northeastern Texas, Fort Hays Member of Niobrara Chalk in western Kansas). Where detritus-rich carbonate muds were deposited under hypoxic or anoxic bottom conditions, the resulting marly interbeds are laminated (c.g., Greenhorn Limestone of Kansas; Smoky Hill Member of Niobrara Chalk in Kansas). Very thin bentonite seams make up a few interbeds in the Fort Hays Member of the Kansas Niobrara, but more usually bentonite seams are incorporated within thicker shale or marl interbeds of American chalk sequences (e.g., Austin Chalk, Annona Formation). Coquinoidal interbeds occur locally in the Austin Chalk of Texas. Finally, beds of pyroclastic material are interbedded 1ocally with chalk adjacent to Late Cretaceous eruptive centers (e.g., Austin of Texas; see YOUNC 1975; MILLER 1978).

In Texas, interbeds of the Austin Chalk are mostly on a centimeterto-decimeter scale, whereas the more chalky beds are thicker (DURHAM 1957; CLOUD 1975; DRAVIS 1979). According to Grabowski (1981b), the few primary shale beds recognized in the subsurface are calcareous, whereas most of the shaly chalk interbeds are actually swarms of microstylolites. The Pecan Cap of northeaotern Tersac io thinly and indiotinctly bedded 
(BREZINA 1974). The Saratoga chalk of Arkansas is massive and lacks interbeds (BOTTJER 1978). The Annona Formation of Arkansas has marly chalk or marl interbeds on a decimeter scale (BOTTJER 1978). The Mooreville Formation of Mississippi and Alabama is actually a marl with local chalky facies and is poorly bedded except in the lower part, where thin limestone and bentonite seams occur (RUSSELL 1982), and at the top, in the thin Arcola Mernber. In northern Mississippi, thick beds of chalk in the upper $60 \mathrm{~m}$ of the Demopolis Chalk are separated by thinner beds of marl (RUSSELL 1982). Although the Demopolis Chalk of western Alabama is at least, in part, of bedded character, lithologically distinct interbeds apparentiy are lacking. The massive Prairie Bluff Chalk of eastern Mississippi and western Alabama apparently lacks interbeds (HUGHES 1958; KEADY 1972; JONES 1967). The Greenhorn and Fairport rhalk section of Kansas is dominated by decimeter-to-meter-scale laminated marly chalk and chalky marl (= shaly chalk) "interbeds" that separate the purer and thinner beds of chalk or chalky limestone. In the Niobrara Chalk, marly chalk interbeds of the Fort Hays Member are on a centimeter-to-decimeter scale and grade westward into shaly marl or calcareous shale. Except for a few widely scattered chalk beds, the Smoky Hill Merber consists of laminated to massive marly chalk or rhalk-marl and thus larks the systematic lithic alternation usually referred to as interbedding.

\section{E.4.4.4 STRUCTURES}

\section{E.4.4.4.1 Primary Structures}

Most shelf-sea chalks have been thoroughly bioturbated (EKDALE 1984) so that beds are massive and lack such primary internal features as laminations, crossbeds, graded textures, etc. However, chalk of the Greenhorn, Fairport, and Niobrara units of Kansas are largely laminated on a millimeter-to-centimeter scale (HATTIN 1962, 1975, 1982). Laminations are preserved locally in shaly or marly interbeds of the Austin Chalk (MILLER 1978; DRAVIS 1979)。 Laminations are also preserved locally in the Fort Hays Member of the Ninhrara (FRFY 1972). Otherwise, beds of American chalk (whether thin or very thick) are generally massive and have been thoroughly bioturbated. Channel structures occur sparingly in American chalk, examples occurring in the Austin Chalk (CLOUD 1975; MILLER 19/8; GRABOWSKI 1981b), Greenhorn Limestone (HATTIN 1975) and Fort Hays Member of the Niobrara (personal observations). Biohermal structures consisting mainly of oysters occur locally in the Austin Chalk (DRAVIS 1979; MTT.T.F. 1978), and oyster biostromes occur locally in the Arkansas, Mississippi, and Alabama chalks (CARMICHAEL 1960). Except for burrows, primary structures are sparse in Cretaceous shelf-sea chalks of the United States.

\section{E.4.4.4.2 Secondary Structures}

\section{F.4.4.4.2.1 Faults}

U.S. Gulf Coastal Plain. Principal among secondary structures are faults, joints, and fractures, which are exceedingly common in Texas. Ihe Austin chalk is affected by several major zones of faulcing 
(Balcones, Luling, Charlotte, Mexia-Talco, and Mt. Enterprise), each of which apparently trends coughly parallel to structural strike of the Paleozolc basement (Fig. E.4.2.2). Nearly all of the faults are normal, with fault planes that dip 35 to $70^{\circ}$. In the Balcones system, the faults are discontinuous and partly en-echelon normal faults that are mostly downthrown on the gulfward side. Range of displacement is from almost nothing along hairline fractures to $520 \mathrm{~m}$ on the San Marcos arch (MURRAY 1961)。

The Luling fault system is similar to the Balcones syster, but downthrown blocks are on the landward sides of faults. Average fault plane dip is $45^{\circ}$, and total vertical displacement is approximately 460 to $610 \mathrm{~m}$ (MURRAY 1961). Movements began in Late Jurassic or Early Cretaceous time, but the faults are not known to have affected Cretaceous deposition (DRAVIS 1979).

The Charlolle fault system, which affects Eocene strata at the surface, lies gulfward and nearly parallel to the Balcones and Luling systems and may be a southwestward extension of the Mexia-Talco system (MURRAY 1961). The faults are normal. Some dip landward, and some dip gulfward. Several of the main faults are en-echelon normal faults that form a graben and have approximately $180 \mathrm{~m}$ of displacement. The Charlotte fault system may be the western end of a regionally developed belt of faults that extends across central and northeastern Texas, southern Arkansas, Mississippi, southwestern Alabama, and the panhandle of Florida (MURRAY 1961; MOORE 1971).

The Mexia-Talco fault system is a system of en-echelon grabens that crosses northeastern Texas from the San Marcos arch to the Arkansas border. The zone is discontinuous in outcrop and subsurface and comprises normal faults that are downdropped on landward or gulfward sides. Total displacement along the Luling and Mexia-Talco fault systems is 455 m (WEEKS 1945).

The Mount Enterprise fault system, unrelated to any of the foregoing systems, 1ies at the southern edge of the East Texas embayment. The faults are normal, have displacement that is both up and down to the basin, have fault planes inclined at 35 to $60^{\circ}$, and displace strata of the Eocene outcrop. Displacements are as much as 180 to 215 in in the Upper Cretaceous part of the section (MURRAY 1961).

Within the East Texas embayment, salt tectonics have caused extensive faulting, both normal and high-angle reverse, that disrupts both Austin and Pecan Gap chalks (Fig. E.4.4.1; also see Fig. 2 in WOOD 1982). Some such faults are aligned with the long axes of salt domes (WOOD 1981), and others are arranged radially with respect to domes (MUEHLBERGER 1962).

In addition to causing offsets in Texas chalk deposits, faulting has also formed fractures, cracks, and breccia within the Austin Chalk (STAPP 1978). Brecciation and fracturing caused by faulting has produced conditions for prolific oil production locally (STAPP 1978). Calcote and others have stated that reservoirs in the Austin Chalk are primarily 
ORNL DWG 84-1174

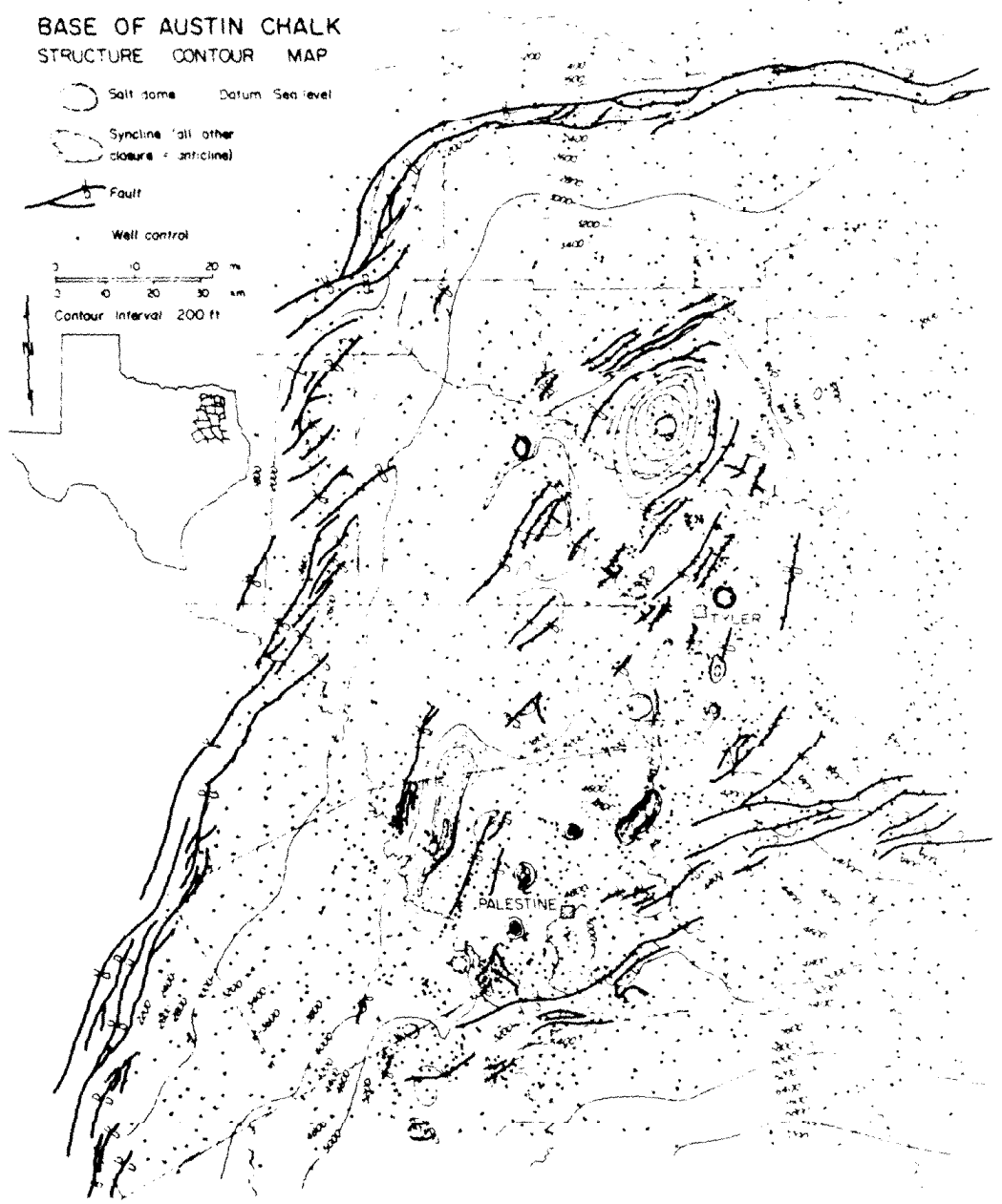

Fig. E.4.4.1. Structure contour map, base of Austin Chalk in the East Texas basin, showing deformation of strata caused by salt movement. Mexia-Talco fault system is at left and top of figure. Source:

D. H. Wood, Structural Effects of Salt Movement in the East Texas Basin, Circ. $81-7$, University of Texas Bureau Econ. Geol. 1981, pp. 21-27. 
fracture zones associated with normal faults (CALCOTE 1983). In some instances, faults serve to feed water into the chalk from other formations. In all of the above-mentioned Texas fault zones, the original movement may be as old as Late Cretaceous, but all subsurface faults that cut the Cretaceous have comparable displacement in overlying Eocene strata (CORBETT 1982). Major movement along all of these fault zones occurred in 0ligocene or Miocene time according to Corbett, who stated that there is no evidence that the fault zones are not contemporaneous (CORBETT 1982).

Along the Austin Chalk outcrop from Dallas to Langtry, Texas, Corbett recognized two styles of faulting, including (1) graben-in-graben, which prevails in the Dallas to San Antonio part of the outcrop; and (2) horstand-graben, which prevails between San Antonio and Langtry (CORBETT 1982). The first of these faulting styles comprises a conjugate set of normal faults that strike parallel to the Balcones fault system, plus a set or sets of cross-trending normal faults that are contained within the graben produced by downward movement along the first set. For both sets of faults, the average dip is $60^{\circ}$, with a range from 35 to $80^{\circ}$. The largest observed offset in such a graben-in-graben system was $5.5 \mathrm{~m}$. The faults are characterized by gouge zones, 1.0 to $10.0 \mathrm{~cm}$ thick, with crystalline calcite comprising as much as $75 \%$ of the total gouge volume (CORBETT 1982). The horst-and-graben style of faulting is made up of conjugate normal faults, the planes of which have an average dip of $70^{\circ}$ and a range of 50 to $80^{\circ}$. Seventy percent of these planes dip towards the southeast. Traces of faults having this structural style dip erratically within various beds making up the local section, with resulting large asperities along the faults that create zones having large voids and high porosity. The gouge comprises fault breccia consisting of large clasts set in a fine-grained matrix.

Corbett observed shear fracture in cores from two of six wells that he studied in connection with his analysis of Austin Chalk fractures (CORBETT 1982). In a Leon County core, he recorded prominent shear fractures with numerous slickensided fracture surfaces, especially in the interval 2126 to $2150 \mathrm{~m}$ deep, and many zones of rubble that probably are fault gouge. Dip on these fractures averages $70^{\circ}$. In a core from Zavalla County, Texas, Corbett (1982) recorded a single shear fracture (CORBETT 1982). Apparenlly, raulling of the Austia in the Texas subsurface is a widely recognized phenomenon, and much Austin oil production is associated with brecciated and fractured strata adjacent to faults (STAPP 1978).

Faults in the Austin Chalk of Texas are better documented than those in Upper Cretaceous rocks elsewhere in the Gulf Coastal Plain, but numerous faults have been recorded in the Louisiana-Alabama outcrop and subsurface. According to Woods, typical chalk reservoirs of Sabine Parish, Louisiana, are structural noses or anticlines cut by $\mathrm{NE}-\mathrm{SW}$ trending faults that are downthrown to the northwest (WoODS 1963). Each producing field is a complex of many individual reservoirs lying along a faulted "zone of flexures." Anderson noted that, in Sabine Parish, the surface is characterized by many lineations, a large number of which sepresenl faulls. He slated llat a sulplisitigly small number of lliese faults extend down into the Cretaceous (ANDERSON 1960). 
Upper Cretaceous strata of westem Tennessee are known to be offset locally by sma11-scale normal faults having displacements on the order of a few meters (RUSSELL 1975). At least one such fault is known to cut the Demopolis Formation, which in Tennessee consists of marl and chalky marl rather than chalk.

Sma11-scale normal faults are common in the Cretaceous-Tertiary outcrop of Mississippi, and several county geological reports mention faults or possible faults that cut Upper Cretaceous chalk deposits. Stephenson and Monroe note that, in several Mississippi counties, smalldisplacement faults are common in the Prairie Bluff Chalk and that, in Kemper County, much of the chalk is shattered, apparently by faulting (STEPHENSON 1940). Downdip in south-central Mississippi, graben structures of the Langsdale and Pickens fault zones are probably the subsurface extension of the Mexia-Talco fault system (MOORE 1971). Irregularly oriented grabens of several downdip areas in Mississippi are not related to the Mexia-Talco aystcm (MURRAY 1961).

The outcropping Selma Group of Alabama, including chalky formations, has been affected in Sumter and Marengo Counties by intense faulting in the northwest-trending Livingston fault zone (SCHNEEFLOCK 1972). This zone is unique in the Gulf Coastal Plain inasmuch as it consists of many horsts and grabens that are bounded by reverse faults (MONROE 1941; NEWTON 1961). The reverse faults formed as the Cretaceous strata subsided into a normally faulted graben-1ike structure that developed in Paleozoic rocks. Faults in the Paleozoic rocks are parallel to those that cut the outcropping Cretaceous rocks and may be part of a very Late- or Post-Cretaceous flexure (Jones flexure) or hingeline. Within the Livingston fault zone, faults are very numerous. Some can (or could be) traced for distances as great as $3 \mathrm{~km}$, and a few are normal. Along many of the reverse faults, displacements are on the order of 15 to $60 \mathrm{~cm}$. The largest recorded displacement is $27 \mathrm{~m}$, but the average is about $12 \mathrm{~m}$ (SELF 1976). Movement involved in forming a horst or graben did not occur solely along a single fault but along a series of closely spaced imbricate faults, each of small displacement.

According to Self, the Demopolis Chalk, Ripley Formation, and Prairie Bluff Chalk are offset by the faults of the Livingston zone (SELF 1976). Reverse faults within the Prairie Bluff Chalk along the Tombigbee River rarely exceed a width of $15 \mathrm{~cm}$. Drag in the Ripley and plastic flow along fault planes in the prairie Bluff suggest that reverse faulting occurred before 1ithification. The Livingston zone includes faults that displace both reverse faults and Selma strata. These faults formed after lithification and have a fault gouge consisting of slickensided calcite. These faults rarely have more than $30 \mathrm{~cm}$ of displacement. Fault breccia also has been recorded along the fault planes. Multiple displacements occurred along the normal faults, just as in the reverse faults. Some of the normal faults seem to be related to reverse faults; others are oriented random1y.

Self also mentions multistage faulting in Upper Cretaceous strata of southeastera Sumtex County, Alabama (SELF 1976). These faults have heon 
considered to be either of Post-Cretaceous age or the southeastern continuation of the Livingston zone. The oldest faults displace only the Prairie Bluff Chalk and are truncated by the Cretaceous-Paleocene unconformity. The youngest faults also displace Paleocene beds. All of these faults are normal - some are marked by plastic flow and others are marked by thin sheets of slickensided calcite. The faults commonly bound narrow horsts or grabens. The largest displacement is $6.4 \mathrm{~m}$. Self goes on to mention normal faults that displace the Cretaceous/Tertiary boundary of Wilcox County, Alabama, and normal faults with steeply dipping fault planes that displace Denopolis strata in the area lying northeast of the Livingston fault zone (SELF 1976). The latter have no preferred orientation, are marked by slickensided calcite or clay gouge, commonly intersect one another, and have evidence of multiple displacement along single faults. Most of the faults have less than $1 \mathrm{~m}$ of displacement, with a maximum of $7.6 \mathrm{~m}$ (SELF 1976).

In his report on the suuthweslew Alabamd subsurface, Moore mentions numerous faulted structures (MOORE 1971), including Jackson fault-Klepac dome, Mobile graben, and the Bethel, Gilbertown, Coffeeville-West Bend, Walker Springs, and Pollard fault zones (Fig. E.4.4.2). The Upper Cretaceous chalk-bearing Selma Group is $221 \mathrm{~m}$ thick on the upthrown side of the Jackson fault and $640 \mathrm{~m}$ thick on the downthrown side, thus indicating that deposition was contemporaneous with faulting. The fault bounds the west side of Klepac dome, which has a salt core. The Mobile graben is a north-south oriented structure that has been highly mobile "at least since Mesozoic time" (MOORE 1971). The Gilbertown, CoffeevilleWest Bend, Walker Springs, and Pollard fault systems form a connected series of relatively narrow grabens aligned with those of the Pickens and Langsdale fault zones of Mississippi. Together with the Mexia-Talco system of Texas, these grabens coincide approximately with the updip limit of the Louann Salt and may mark the periphery of the Jurassic salt basin (MURRAY 1961; MOORE 1971). Although the Livingston and Bethel fault zones lie well to the northeast of the more continuous belt of grabens, all of these systems have a similar trend and probably have a genetic relationship.

Wilson and others have documented numerous faults of the Gilbertown and Coffeeville West Bend zones that cut chalks of the Selua Gruup in Llie subsurface of Choctaw and Clarke counties, Alabama (WILSON 1976). Throw on some of these faults is reported as hundreds of meters, with displacement increasing at depth. These authors present one cross section which suggests that as many as six of these chalk-cutting faults can be encountered in a distance of $13 \mathrm{~km}$. The fault planes tend to flatten somewhat with depth. One fault plane (Cho-5) dips $80^{\circ}$ at the surface, $45^{\circ}$ in Lower Tertiary rocks, and 50 to $55^{\circ}$ in more competent Cretaceous strata: In the subsurface, major faults tend to be parallel or subparallel to faults mapped at the surface. All subsurface faults do not reach the surface. Some faults die out at shallow depths; others terminate against other faults. Some faults mapped in areas of the Alabama Tertiary outcrop are known to extend down into the Jurassic.

In oummary, chalks of the Gulf Coastal Plain are extensively broken by normal faults in several usually parallel systems. Both up-to-thebasin and down-to-the-basin faults are known, and most faults are normal. 
ORNL DWG $84-1175$

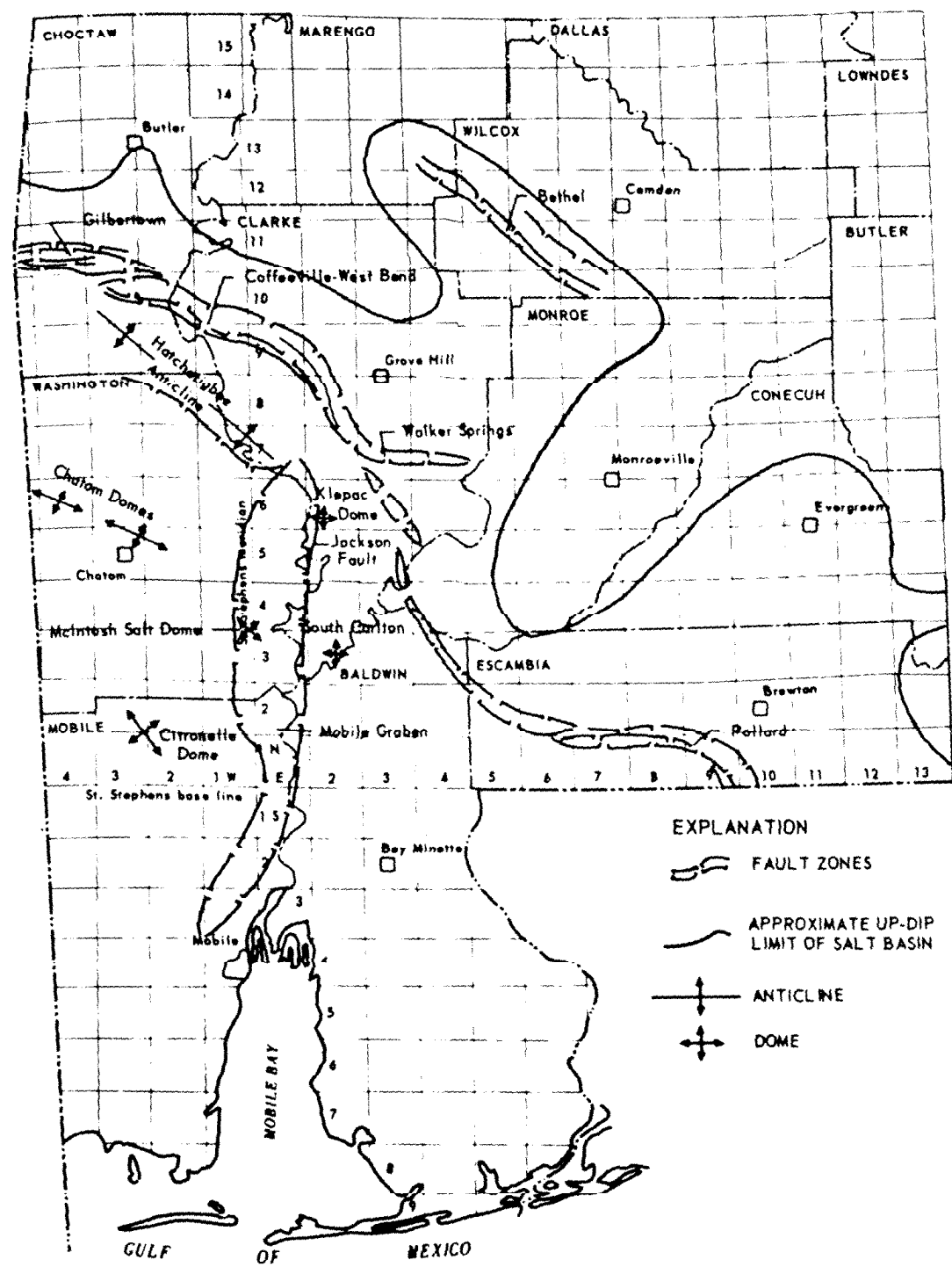

Fig. E.4.4.2. Map southwesten Alabama, showing location of prominent structural features. Note numerous fault zones. Source: D. B. Moore, Subsurface Geology of Southwest Alabama, BuI1. 99, Alabama Geol. Survey, 1971. 
In the most extensive system, narrow graben structures prevail. Some faults cut across the trend of major systems, and some faults are oriented randomly. Faulting apparently was more or less active in one place or another all through the time that Upper Cretaceous chalk-forming muds were deposited.

U.S. Western Interior. Small-scale normal faulting has been reported from nearly all areas of chalk exposure in the Great Plains and Rocky Mountain foothills. In Kansas numerous small (mostly normal faults) have been detected in the Greenhorn Limestone, Falrport Chalk Member of the Carlile Shale, and Niobrara Chalk (e.g., RUBEY 1925; BASS 1926; RUSSELL 1929a; JOHNSON 1958; FREY 1972; HATTIN 1982; LAFERIERE 1984)。 Most of these are normal faults (RUSSELL 1929a), with displacement ranging from a few centimeters to possibly $60 \mathrm{~m}$ or more (Johnson 1958). At least one such fault has a trace that extends approximately $5.6 \mathrm{~km}$ (JOHNSON 1958). Dip of fault planes ranges from 30 to $50^{\circ}$, with $45^{\circ}$ apparent1y being most common (JOHNSON 1958; RUBEY 1925). In an $11-m i 1 \mathrm{e}^{2}$ area of Ellis County, Kansas, Bass mapped 76 such faults (almost all located in the Niobrara Chalk), but was unable to detect any general trends in orientation of fault traces or regarding which side (i.e.. E.. $W_{0}, N_{0}$, or $S_{0}$ ) tended to be downdropped (BASS 1926). Nearly all of these faults are marked by sheets of slickensided calcitic gouge that reach thicknesses as great as 15 to $20 \mathrm{~cm}$. Within the Niobrara Chalk outcrop of Logan County, Kansas, Johnson recorded scores of similar faults that also lack an obvious trend (JOHNSON 1958). Faults have been recorded within the Niobrara outcrop by several other workers. Most of the Kansas faults that cut Upper Cretaceous chalk beds are in the Smoky Hill Member of the Niobrara, and all of those which cross formational contacts from chalky into nonchalky units die out within a short distance of the contact. Russel1 (RUSSELL 1929a) noted that tilted fault blocks in the Smoky Hill chalk are among the most striking features of that unit, with dips as great as $20^{\circ}$ locally. Small steep-sided folds also occur widely in the Smoky Hill Member (RUSSELL 1929a) and are associated with normal faults that trend parallel to fold axes. The Smoky Hill faults are not distributed even1y (RUSSELL 1929a); some areas of exposure have none, and others are littered by slabs of slickensided calcite derived from numerous faults (personal observation). Russell claimed that faults tend to be more numerous in structural lows near the top of the Smoky Hill Member and near the main north-south folds in the region (RUSSELL 1929a). Normal faults are less common in the Fort Hays Member (BASS 1926) but have been observed by the writer in several Kansas counties (e.g., Jewe11, Rooks, Ellis, Hamilton). Bass stated that of 81 faults mapped in Ellis County, Kansas, 74 are in the Smoky Hill Member and three are in the Fort Hays Member of the Niobrara (BASS 1926). The other four are in the Fairport Chalk Member of the Carlile Shale.

Although the Greenhorn and Niobrara are covered by glacial drift across most of Nebraska, good exposures occur along some of the major stream courses and Condra has reported small faults and flexures within Upper Cretaceous chalk units in the Missouri River valley (CONDRA 1908). In westernmost Oklahoma, the Greenhorn Formation is of fset by several small-throw normal faulto that arc marked by thin sheets of slickensided 
calcitic gouge (personal observation). Similar small-throw normal faults have been recorded in the Niobrara, mostly within the Smoky Hill Member, near Fort Collins, Colorado (HANN 1981), and the writer has observed sma11, normal-fault offsets in the Fort Hays Member near La Junta, Colorado, and in the Smoky Hill Chalk Member at the west edge of Pueblo, Colorado. In summary, normal faults are a common feature of Western Interior chalk outcrops and are largely of compactional rather than tectonic origin. The data are admittedly sketchy but suggest that normal faulting is less common in the thinner Greenhorn-Fairport chalk interval than in the Niobrara, and that the Niobrara faults are much more numerous in the Smoky Hil1 Mernber than in the Fort Hays.

\section{E.4.4.4.2.2 Fractures and Joints}

Gulf Coastal Plain. Chalk deposits of the Gulf Coastal Plain are described commonly as being fractured, but only the Austin Chalk of Texas has been studied extensively. Amongst some 822 fractures studied by Kurie (KURIE 1956) within the city of Austin, a preponderance are vertical to subvertical.

Corbett recorded nonvertical fractures in the Austin near Uvalde and Langtry, Texas (CORBETT 1982). Rogers measured more than 1000 fracture orientations in the Austin Chalk of Williamson County, Texas, and reported that their arrangement is an orthogonal pattern with modes at $N 20^{\circ}-30^{\circ} \mathrm{E}$ and $N 60^{\circ}-70^{\circ} \mathrm{W}$ (ROGERS 1963). Radial fracture patterns were recorded by White (WHITE 1960) in Austin exposures around Pilot Knob (Travis County), which is a volcanic feature that was emplaced during Austin deposition.

In his embracive analysis of the Austin Chalk, Dravis was unable to detect fractures in all cores that he studied and noted that even where fractures are present they do not extend throughout a given core (DRAVIS 1979). Fractures occur "as multiple sets, with lengths ranging from several centimeters up to a meter" (DRAVIS 1979). The fractures occur almost exclusively in the lighter-colored purer (and probably more brittle) chalk beds and usually terminate near the contact with adjacent argillaceous chalk zones or shale beds. The fractures are usually filled with ferroan calcite cement.

Schafer noted that in some parts of the Austin Chalk productive trend of South Texas, the unit can be divided into three parts: (1) an upper unit, $76 \mathrm{~m}$ thick, that is characterized by dense gray limestone with a few thin limy shale laminations and containing major fractures; (2) a middle unit, 67 to $70 \mathrm{~m}$ thick, consisting of gray-to-dark-gray shaly limestone that is carbonaceous at the base and contains mostly minor fractures; and (3) a basal unit, $30.5 \mathrm{~m}$ thick, consisting of generally nonfractured, dark gray, very limy, carbonaceous shale with some limestone streaks (SCHAFER 1980). Large fractures extend only through all or part of the upper unit and attenuate into shalier and more carbonaceous strata above and below. He thought that structural flexuring, faulting, or undetected movement of basement rock may all be factors causing areas of apparently greater fracture intensity, but concentration of fracture orientations in one or possibly two directions ovor a broad aroa suggests a rogional stross system. 
The most extensive study of Austin fractures is apparently that of Corbett, who gathered data on 2636 fractures at 17 surface localities between Dallas and Langtry, Texas (CORBETT 1982). In this area, he also examined 56 faults, the majority lying between Dallas and Austin. In his study, he recognized four divisions within the Austin Chalk, including (ascending) Atco Chalk Member, Dessau Chalk Member, Burditt Marl Memher, and Big House Chalk Member. Corbett used the term "massive chalk" for members (i.e., Atco and Big House) that behaved as a single unit structurally. Independent structural behavior occurred only in chalk beds that lie between marl beds having a thickness that is greater than onetenth that of the adjacent chalk bed. A summary of data on fracture intensity vs bed thickness and structural setting is presented in Table E.4.4.25, and a sumary of data on fractures within the three chalk members is included in Table $\mathrm{E} .4 .4 .26$.

Overall greatest fracture intensity in the Austin outcrop is in the San Antonio area, where the high is an average of 8.43 fractures per meter. The greatest density of faulting in the Balcones fault system also occurs in the San Antonio area.

The grabens mentioned in the section on Gulf Coastal Plain faults have a higher fracture intensity than do intervening horsts, and within the grabens the better-developed fractures are those that cut across the main fault trends. Approximately 60 to $80 \%$ of fractures developed within the Austin outcrop have strikes that are parallel to the Balcones fault system. According to Corbett, cross-trending fractures are developed to a greater degree from Dallas southwestwardly to San Antonio than from San Antonio westward to Langtry (CORBETT 1982). At Langtry, near the Mexican border, fractures cannot be related to the Balcones fault system because faults related to that system have not been mapped there. Fractures recorded at Lozier Canyon, west of Langtry, have no obvious relationship to those in the remainder of the Austin outcrop.

Corbett also studied fractures in cores from six wolls and on twontytwo fracture-identification logs (CORBETT 1982). Cores from four of these wells contained sufficient natural fractures to furnish useful data, which are included in Table E.4.4.27. Three of the four cores examined contained a cross-trending fracture geometry. Most fractures recorded in these cores are vertical, or nearly so. Fracture widths range from 0.01 to $1.0 \mathrm{~mm}$ - all are filled with sparry calcite, and most occux in swarms. Fractures are most abundant in the 1 ower third and upper third of the formation. The fracture identification logs indicated that two fracture orientations are developed, the most common being para1lel to bedding strike (NE) and the other being parallel to the dip azimuth (Table E.4.4.28). Corbett concluded that interpretation of subsurface fracture geometry requires a high concentration of wells.

Snyder and Craft have described the Austin Chalk oil-productive trend as a microfractured reservoir (SNYDER 1977), with the possibility of fractures occurring throughout the vertical interval. Snyder and craft made the additional observations: (1) fracture density averages between one to three tractures per $30 \mathrm{~cm}$ throughout the trend (maximum 25 tractures per $30 \mathrm{~cm}$ ); (2) about one-half of the fractures are closed or at 
Table E.4.4.25. Fracture intensity data, Austin Chalk outcropa

\begin{tabular}{|c|c|c|c|c|c|}
\hline Locality & $\begin{array}{l}\text { Bed } \\
\text { Thickness } \\
\quad(\mathrm{cm})\end{array}$ & $\begin{array}{c}\text { Fracture } \\
\text { intensity/m }\end{array}$ & $\begin{array}{c}\text { Mean } \\
\text { fracture } \\
\text { intensity/m }\end{array}$ & $\begin{array}{l}\text { Number of } \\
\text { fractures/ } \\
\text { traverse } \\
\text { length (m) }\end{array}$ & $\begin{array}{l}\text { Structural } \\
\text { position }\end{array}$ \\
\hline Dallas & $\begin{array}{r}50.8 \\
121.9 \\
45.7 \\
137.2\end{array}$ & $\begin{array}{l}7.28 \\
5.02 \\
2.66 \\
3.94\end{array}$ & 4.72 & $\begin{array}{l}72 / 9.91 \\
84 / 16.76 \\
17 / 6.40 \\
30 / 7.62\end{array}$ & $\begin{array}{l}\text { Graben } \\
\text { Graben } \\
\text { Graben } \\
\text { Graben }\end{array}$ \\
\hline Waco & $\begin{array}{l}33.0 \\
66.0 \\
40.6\end{array}$ & $\begin{array}{l}6.56 \\
5.14 \\
3.77\end{array}$ & 5.35 & $\begin{array}{l}94 / 14.02 \\
55 / 9.60 \\
50 / 13.26\end{array}$ & $\begin{array}{l}\text { Graben } \\
\text { Graben } \\
\text { Horst }\end{array}$ \\
\hline $\begin{array}{l}\text { San } \\
\text { Antonio }\end{array}$ & $\begin{array}{c}71.12 \\
96.5 \\
106.7 \\
129.5\end{array}$ & $\begin{array}{l}8.83 \\
9.35 \\
9.38 \\
6.14\end{array}$ & 8.43 & $\begin{array}{l}98 / 11.89 \\
101 / 10.82 \\
50 / 5.33 \\
158 / 25.91\end{array}$ & $\begin{array}{l}\text { Graben } \\
\text { Graben } \\
\text { Graben } \\
\text { Graben }\end{array}$ \\
\hline Uvalde & $\begin{array}{r}30.5 \\
109.2 \\
40.6 \\
106.7\end{array}$ & $\begin{array}{l}8.56 \\
8.96 \\
6.17 \\
2.10\end{array}$ & 6.46 & $\begin{array}{l}133 / 15.54 \\
105 / 11.73 \\
73 / 12.19 \\
28 / 15.24\end{array}$ & $\begin{array}{l}\text { Graben } \\
\text { Graben } \\
\text { Horst } \\
\text { Horst }\end{array}$ \\
\hline Langtry & $\begin{array}{l}30.5 \\
68.6 \\
86.4\end{array}$ & $\begin{array}{l}6.50 \\
3.18 \\
2.07\end{array}$ & 3.90 & $\begin{array}{l}104 / 16.00 \\
72 / 22.55 \\
63 / 30.33\end{array}$ & $\begin{array}{l}\text { Graben } \\
\text { Graben } \\
\text { Graben }\end{array}$ \\
\hline $\begin{array}{l}\text { Lozier } \\
\text { Canyon }\end{array}$ & $\begin{array}{l}10.2 \\
10.2 \\
81.3 \\
96.5\end{array}$ & $\begin{array}{l}4.46 \\
9.74 \\
3.35 \\
1.31\end{array}$ & 4.72 & $\begin{array}{l}68 / 15.24 \\
31 / 8.84 \\
31 / 9.30 \\
28 / 15.24\end{array}$ & $\begin{array}{l}\text { Anticline } \\
\text { Anticline } \\
\text { Anticline } \\
\text { Anticline }\end{array}$ \\
\hline
\end{tabular}

a Source: K. P. Corbett, Structural Stratigraphy of the Austin Cha1k, Master's thesis, Texas AdM Un1versicy, College Station, 1982. 
Table E.4.4.26. Summary of Austin Chalk fracture data, Dallas to Langtry, Texas

\begin{tabular}{|c|c|c|c|c|}
\hline Unit & $\begin{array}{c}\text { Fracture } \\
\text { intensity/m } \\
\text { (range) }\end{array}$ & $\begin{array}{c}\text { Fracture } \\
\text { intensity/m } \\
\text { (mean) }\end{array}$ & $\begin{array}{l}\text { Standard } \\
\text { deviation }\end{array}$ & $\begin{array}{l}\text { Number of } \\
\text { measure- } \\
\text { ments }\end{array}$ \\
\hline $\begin{array}{l}\text { Big House } \\
\text { Member }\end{array}$ & $\begin{array}{l}2.10-8.96 \\
\text { (al1 near } \\
\text { Uvalde) }\end{array}$ & 6.50 & 3.16 & 329 \\
\hline $\begin{array}{l}\text { Dessau } \\
\text { Member }\end{array}$ & $\begin{array}{l}<0.33-2.90 \\
\text { (lowest value } \\
\text { near Austin; } \\
\text { highest value } \\
\text { near De1 RIo) }\end{array}$ & 1.62 & 1.29 & 230 \\
\hline $\begin{array}{l}\text { Atco } \\
\text { Member }\end{array}$ & $\begin{array}{l}13.2-9.80 \\
\text { (highest and } \\
\text { lowest values } \\
\text { from Terrell c } \\
\text { Texas) }\end{array}$ & 5.54 & 2.67 & 2077 \\
\hline
\end{tabular}

Source: K. P. Corbett, Structural Stratigraphy of the Austin Chalk, Master's Thesis, Texas A\&M University, College Station, 1982.

Table E.4.4.27. Fracture data from oriented Austin Chalk cores, Brazos and Frio counties, Texas

\begin{tabular}{|c|c|c|}
\hline We11 & $\begin{array}{l}\text { Number of } \\
\text { fractures }\end{array}$ & $\begin{array}{c}\text { Fracture } \\
\text { intensity/m }\end{array}$ \\
\hline $\begin{array}{l}\text { No. } 1 \text { W. E. Beall } \\
\text { Frio Co., Texas } \\
\text { (S.W. of San Antonio) }\end{array}$ & not stated & 2.2 \\
\hline $\begin{array}{l}\text { Brown Dunlap A-1 } \\
\text { Brazos Co., Texas } \\
\text { (S.E. of Waco) }\end{array}$ & 48 & 10.50 \\
\hline $\begin{array}{l}\text { Margrave No. } 1 \\
\text { Brazos Co., Texas } \\
\text { (S.E. of Waco) }\end{array}$ & 71 & 4.57 \\
\hline $\begin{array}{l}\text { Nash No. } 1 \\
\text { Brazos Co., Texas } \\
\text { (S.E. of Waco) }\end{array}$ & 140 & 4.64 \\
\hline
\end{tabular}

Source: R. P. Curbell, Sliuclural Slialigrapliy of llie Austin Chalk, Master's Thesis, Texas A\&M University, College Station, 1982 . 
Table E.4.4.28. Fracture orientation data from fracture-identification logs

\begin{tabular}{|c|c|c|c|c|}
\hline $\begin{array}{l}\text { Group } \\
\text { No. }\end{array}$ & We11 & $\begin{array}{l}\text { Range } \\
\text { depth } \\
\text { (m) }\end{array}$ & $\begin{array}{l}\text { No. of } \\
\text { measure- } \\
\text { ments }\end{array}$ & $\begin{array}{c}\text { Fracture } \\
\text { orientation } \\
\text { azimuth/standard } \\
\text { deviation }\end{array}$ \\
\hline \multirow{3}{*}{1} & No. 1 Miertschin & $2370-2525$ & 4 & $\mathrm{~N} 25^{\circ} \mathrm{W} / 8.17^{\circ}$ \\
\hline & Noack-Mitschke & $2450-2595$ & 3 & $\mathrm{~N} 25^{\circ} \mathrm{W} / 10.0^{\circ}$ \\
\hline & Elford Bigon & $2170-2 / 20$ & $\begin{array}{l}1 \\
1 \\
1\end{array}$ & $\begin{array}{l}\mathrm{N} 25^{\circ} \mathrm{W} / 0.0^{\circ} \\
\mathrm{N} 85^{\circ} \mathrm{W} / 0.0^{\circ} \\
\mathrm{N} 35^{\circ} \mathrm{E} / 0.0^{\circ}\end{array}$ \\
\hline \multirow{9}{*}{2} & E.J. Parrish No. 3 & $2475-2665$ & 4 & $\mathrm{~N} 57^{\circ} \mathrm{E} / 22.17^{\circ}$ \\
\hline & $\begin{array}{l}\text { Lou E11a Cheeks } \\
\text { No. } 1\end{array}$ & $2650-2815$ & $\begin{array}{l}2 \\
2\end{array}$ & $\begin{array}{l}\mathrm{N} 45^{\circ} \mathrm{W} / 14 \cdot 14^{\circ} \\
\mathrm{N} 55^{\circ} \mathrm{E} / 14.14^{\circ}\end{array}$ \\
\hline & $\begin{array}{l}\text { Schmidt-Massey } \\
\text { No. } 1\end{array}$ & $2605-2770$ & $\begin{array}{l}1 \\
2\end{array}$ & $\begin{array}{l}\mathrm{N} 65^{\circ} \mathrm{W} / 0.0^{\circ} \\
\mathrm{N} 60^{\circ} \mathrm{E} / 7.07^{\circ}\end{array}$ \\
\hline & Jas Hunt A-166 & $2705-2750$ & 2 & $\mathrm{~N} 50^{\circ} \mathrm{W} / 21.21^{\circ}$ \\
\hline & $\begin{array}{l}\text { E.J. Parrish } \\
\text { No. 1-A }\end{array}$ & $2485-2670$ & 2 & $\mathrm{~N} 40^{\circ} / 7.07^{\circ}$ \\
\hline & Don Bissett No. 1 & $2680-2775$ & 1 & $\mathrm{~N} 45^{\circ} \mathrm{E} / 0.0^{\circ}$ \\
\hline & M. Whitewell No. 1 & $2560-2740$ & 7 & $\mathbb{N} 45^{\circ} \mathrm{W} / 15.28^{\circ}$ \\
\hline & $\begin{array}{l}\text { Mamie Schmidt } \\
\text { No. } 3\end{array}$ & $2515-2725$ & 5 & $\mathrm{~N} 79^{\circ} \mathrm{E} / 11.40^{\circ}$ \\
\hline & Schmidt No. 2 & $2615-2785$ & $\begin{array}{l}3 \\
1 \\
1\end{array}$ & $\begin{array}{l}\mathrm{N} 25^{\circ} \mathrm{W} / 0.0^{\circ} \\
\mathrm{N} 25^{\circ} \mathrm{E} / 0.0^{\circ} \\
\mathrm{N} 65^{\circ} \mathrm{E} / 0.0^{\circ}\end{array}$ \\
\hline \multirow{3}{*}{3} & $\begin{array}{l}\text { Humphrey-Benson } \\
\text { No. } 1\end{array}$ & $2290-2385$ & $\begin{array}{l}2 \\
1\end{array}$ & $\begin{array}{l}\mathrm{N} 70^{\circ} \mathrm{W} / 7.07^{\circ} \\
\mathrm{N} 15^{\circ} \mathrm{E} / 0.00^{\circ}\end{array}$ \\
\hline & Benn No. 1 & $2395-2515$ & 4 & $\mathrm{~N} 57.5^{\circ} / 9.57^{\circ}$ \\
\hline & $\begin{array}{l}\text { Leo Havermann } \\
\text { No. } 1\end{array}$ & $2515-2545$ & 1 & $\mathrm{~N} 65^{\circ} \mathrm{W} / 0.0^{\circ}$ \\
\hline \multirow[b]{2}{*}{4} & Gaas No. 1 & $2595-2600$ & 1 & $\mathrm{~N} 85^{\circ} \mathrm{W} / 0.0^{\circ}$ \\
\hline & Rust No. 1 & $2850-2885$ & $\begin{array}{l}2 \\
2\end{array}$ & $\begin{array}{l}\mathrm{E}-\mathrm{W} / 21.21^{\circ} \\
\mathrm{N} 50^{\circ} \mathrm{E} / 7.07^{\circ}\end{array}$ \\
\hline
\end{tabular}

Source: K. P. Corbett, Structural Stratigraphy of the Austin Chalk, Master's Thesis, Texas A\&M University, College Station, 1982 . 
least partially mineralized; (3) fracture width ranges from 0.1 to $0.4 \mathrm{~mm}$, but is rarely $>0.1 \mathrm{~mm}$; (4) $98 \%$ of the fractures are vertical; and (5) at least $50 \%$ of the Austin is devoid of fracturing (SNYDER 1977). Origin of the microfractures has been attributed mainly to compaction and subsidence (SNYDER 1977; STAPP 1978), although Scott (SCOTT 1977) believes the fracturing is attributable solely to downwarping.

Fracturing of Cretaceous chalks has received less attention outside Texas. Fisk prepared a small-scale structure map of the central Gulf Coastal plain that shows a fairly dense criss-crossed fracture pattern that involves Cretaceous and Tertiary deposits of Tennessee, Arkansas, Louisiana, and Mississippi (FISK 1944). In the subsurface of Louisiana, off the southeastern flank of the Sabine dome, a 152-m-thick fractured chalk section produces oil from depths that reach 610 to $762 \mathrm{~m}$ in the Zwolle field (WOODS 1963). Within the reservoir, fractured zones have erratic trends so that $58 \%$ of the wells ( 623 drilled to end of 1963) in the field were dry. Production is from a section that includes Saratoga, Marlbrook, Annona, Ozan chalks, plus the associated marl. Fractures occur throughout the chalk series. Fractured zones lying parallel to and in close proximity to normal faults form the typical reservoirs. Wonds stated that the chalk was compacted, uplifted, fractured, and jointed prior to deposition of overlying Paleocene beds (wooDs 1963). The upper part of the section was most affected by tensional fracturing. In the Pendleton-Many field of Sabine Parish, northwestern Louisiana, production is from an extensive fault-fracture system that trends southwestnortheast. The jointing, fracturing, and faulting are believed to form an interconnected lattice-type network of permeability channels (BROWN 1978). Oil production is from the Annona Formation-Marlbrook MarlSaratoga Formation sequence.

In the southwestern Arkansas outcrop, the Annona Chalk is vertically jointed on a meter scale, or much less locally. The rock is highly fractured even in fairly fresh exposures. In the same area, chalks of the largely massive Saratoga Formation are alon jninted on a meter scale and are highly fractured in most exposures (personal observations).

Examples of jointing in Mississippi chalk units have been recorded in the Selma Group, which is jointed almost everywhere in Lee County (VESTAL 1946). There, chalky clay (=marl?) of the Mooreville Formation is cut by two main sets of joints. In Monroe County, also, the Selma chalks are conspicunusly jointed in many exposures, most noticeably where the rock is more firmly consolidated (VESTAL 1943). Hughes noted that the Prairie Bluff Chalk of Kemper County, Mississippi, contains numerous joints or fracture patterns (HUGHES 1958). Carson reported extensive fractures and joints in the Demopolis Chalk that he suggested could have been caused by faulting (CARSON 1961). These joints are vertical and occur in two sets that are more or less at right angles.

Although Alabama chalks have been described as brittle, and faulting has been studied in some detail, joints and fractures are mentioned in few reports (e.g., MOORE 1971). Chalks of the Selma Group are jointed, and tensional tractures are associated with later-stage faulcing (SELF 1976), but systematic study of these features appears to be wanting. 
U.S. Western Interior. No systematic study has been made of joint or fracture systems in the Greenhorn, Fairport, or Niobrara chalks, although many authors (e.g., CONDRA 1908; BASS 1926; HODSON 1965; SHURR 1981) have mentioned such structures, which are apparently developed widely in the more brittle beds (personal observation). One generalization can be made, however. Within both major chalky intervals, joints tend to be more common and more closely spaced in the more bxittle chalky limestone beds than in the laminated marly chalks (shaly chalks of the 1iterature).

The most conspicuously jointed unit is the Fort Hays Member of the Niobrara, which in its chalk facies is best exposed in Kansas. In this well-bedded chalky limestone, unit joints are nearly vertical and spaced at intervals measured usually on a meter scale. Most commonly, distances between joints are several meters. In cliffs, one can readily observe individual joints that pass through several beds or even through essentially the entire thickness of the member. In highly weathered exposures, visible joints tend to be more closely spaced, and subhorizontal fracturing may be well developed. In northwestern Hamilton County, Kansas, the Fort Hays Member contains at least two, unequally developed joint sets, the trends of which are not consistent from one township to another (BASS 1926). In northeastern Nebraska, very ch1ck, massive beds of the Fort Hays have nearly vertical joints that intersect each other at angles approaching $90^{\circ}$ (CONDRA 1908). Northeast of St. James, such joints tend to be spaced at intervals $>1 \mathrm{~m}$.

The Smoky Hill Member is jointed very sparingly because the laminated marly chalks and chalky marls that dominate this unit are less brittle than the Fort Hays chalky limestones. Where they do occur, joints may extend vertically for several meters. In major exposures, joints tend to die out downward in the section, with best development in we11-weathered yellow chalk and weakest development in the underlying little-weathered gray chalk. Weathering apparently enhances joints, which may extend far below the base of a given exposure. Major joints apparently control the size of exosional pillars, which commonly have one or more relatively smooth vertical faces. Johnson has noted the occurrence of two sets of nearly vertical joints, almost at right angles to one another, in Logan County, Kansas (JOHNSON 1958). The joints are traceable for many miles and are probably associated with a major anticline. Massive (bioturbated) Smoky Hill chalk has only widely spaced joints, even where highly weathered, although the weathered rock may be highly fractured.

Even in 11tcle-weathered cut banks, the Smoky H111 chalk spalls readily (CONDRA 1908; HATTIN 1982), suggesting that hairline fractures may pervade the rock. A few vertical, calcite-filled microfractures have been observed in thin sections. Moderately weathered chalk is commonly laced with calcite-filled fractures that dip at angles of $45^{\circ}$ or less. Such fractures result from weathering and do not persist into areas of unweathered rock. The upper $50 \mathrm{~m}$ or so of the Smoky Hill of Kansas contains zones of crinkly chalk that are caused by minute subhorizontal gypsum-filled fractures. Shurr and Gognat mention fracture systems associated with post-Niobrara structures of the northern Great Plains, but systematic mapping apparently has not been undertaken (SHURR 1981). 
Within the Greenhorn-Fairport interval of Kansas, brittle bioturbated chalky limestone beds rarely exceed a thickness of 30 to $35 \mathrm{~cm}$ and are usually much thinner. Such beds tend to be jolnted in a decimeter-tometer scale, with wider spacing in the thicker beds. A few of the most brittle chalky limestone beds tend to fracture irregularly subparallel to bedding. Laminated marly chalks and chalky marls that dominate the interval contain large-scale vertical joints spaced at several-meter distances. Joints with smaller vertical extent occur at closer spacing locally. The marly chalk beds, like those of the Smoky Hill, spall readily even where freshly exposed and upon weathering break into sma11 chips along innumerable fractures. The Greenhorn-Fairport chalks share many secondary (i.e., joint and fracture) characteristics with the Niobrara across large areas of the Great Plains outcrop.

\section{\$.4.4.5 POROSITY - PERMEABILITY}

Cook and cook have reporced porosity values as high as $94 \%$ in some carbonate oozes of the Pacific Ocean (COOK 1972), but pelagic oozes that were the progenitors of Cretaceous and Tertiary shelf-sea chalks are believed to have had initial porosity of approximately 70 to $80 \%$ (SCHOLLE 1977a). Most of this primary porosity is interparticle porosity and consists mainly of void spaces between the loosely packed coccolithophore skeletal debris that dominates the pure chalk lithotype. Primary intraparticle porosity is mainly that associated with foraminiferal tests (FEAZEL 1979), although any skeletal remains containing internal chambers may contribute to this kind of porosity.

Almost from the moment of deposition, various diagenetic processes act to reduce initial porosity and permeability. Schlanger and Douglas reported that mechanical compaction (dewatering) of accumulated chalkforming oozes can reduce initial porosity to perhaps 50 to $60 \%$ within the first few tens to hundreds of meters of burial (SCHLANGER 1974) or even less than 50\% (SCHOLLE 1983). Because the ooze consists mainly of the stable low-magnesium calcite of coccoliths. 1ittle else may happen to the chalk until deep burial has occurred. Even the introduction of freshwater has little diagenetic effect on chalk-forming sediment because of chemical stability of the low-magnesium calcite composition and the low permeability. At greates deptls of burial, mechanical compaction becones less important, and chemical compaction (solution transfer) becomes dominant. This process, which is believed to be negligible at burial depths less than $300 \mathrm{~m}$ (NEUGEBAUER 1973, 1974), involves dissolution of calcium carbonate sediment along points of greatest stress and reprecipitation of secondary calcite in places of least stress (SCHOLLE 1983). Results of solution-transfer include microstylolites and flaser chalk, as well as secondary calcite, which occurs as overgrowths on the individual crystals that comprise coccoliths and as interstitial cement (NEUGEBAUER 1973, 1974; HANCOCK 1975; GARRISON 1977; SCHOLLE 1977a; SCHOLLE 1983). Burial diagenesis serves to occlude porosity and reduce permeability. According to Neugebauer, burial depths up to $1000 \mathrm{~m}$ produce no more than $5 \%$ of cement, but chalk becomes almost completely lithified at depths between 2000 and $4000 \mathrm{~m}$ (NEUGEBAJER 1974). Scholle and others have compared pususily vs. depth of chalk depusils frull several areas alld sliuw low, 
almost without exception, porosity decreases with increasing depth of burial (SCHOLLE 1983). Chalk deposits from different areas have different depth/porosity relationships (Fig. E.4.4.3), and this relationship is shown best in a graph that compares depth and porosity in European vs U.S. Western Interior chalks. Several factors can alter the usual reduction of porosity with increasing depth of deposition, including abnormal fluid pressures (geopressuring), early entry of oil or gas into the chalk, and fracturing (SCHOLLE 1979). The first two factors serve to retard or halt porosity reduction while the third can cause porosity increase. Scholle states that at depths of $275 \mathrm{~m}$, the Niobrara chalk of northeastern Colorado has a porosity of 45\% (SCHOLLE 1977a). At $850 \mathrm{~m}$, this has been reduced to 30 to $35 \%$, and at depths greater than $1830 \mathrm{~m}$, the porosity has been reduced to less than $10 \%$. Comparative figures for North Sea chalks (SCHOLLE 1975) are: 1500 to $2000 \mathrm{~m}, 15$ to $30 \%$ porosity; 2700 to $3300 \mathrm{~m}$, 2 to $25 \%$ porosity. However, geopressuring of North Sea chalks has allowed preservation of $40 \%$ porosity at depths as great as $3000 \mathrm{~m}$ (SCHOLLE 1979). W1th tncreasing depli of burial, permeabilily also decreases (Fig. E.4.4.4).

Diagenesis of chalk and consequent porosity reduction can be rather complex depending upon initial composition of the sediment. For example, Dravis claims that porosity trends in the Austin Chalk suggest an unusual primary composition and that five najor diagenetic processes were involved in porosity evolution, including early mechanical compaction, freshwater dissolution, burial stabilization of primary aragonitic material, pervasive pressure solution, and superimposed tectonic effects (DRAVIS 1979).

Not all chalk cementation is a phenomenon of burial diagenesis. Ample evidence has been advanced for early lithification of chalk-forming carbonate muds. The development of hard grounds in chalk deposits is a phenomenon related to sedimentary stillstand, burrowing of upper portions of the sediment column, and sea-floor erosion. The process has been described elegantly by Kennedy and Garrison (KENNEDY 1975) and defined succinctly by Bromley (BROMLEY 1978). Incipient hard grounds include hard, nodular chalk and softer burrow-filling chalk. Contact with overlying beds is sharp. In a fully developed hard ground, all of the chalk beneath the discontinuity surface consists of brittle, wel1-1ithified chalk. In the U.S. Western Interior, chalk-forming muds that were burrowed extensively during times of little terrigenous-detrital influx were diagenetically altered to chalky limestone, which contrasts with adjacent impure laminated marly chalk (HATTIN 1971, 1982). Rhythmic chalk-marl sequences of the Austin Chalk differ from those of the Greenhorn Limestone inasmuch as both chalk and marl beds are bioturbated, the marl beds preserving laminae only locally where bioturbation was incomplete (DRAVIS 1978). The chalky limestones differ from hard grounds inasmuch as omission surfaces are usually lacking at tops of chalky limestone beds and nodular chalk was not formed. Discontinuity surfaces do mark the tops of some chalk beds in the Austin Chalk, however (DURHAM 1957). Both European hard grounds and American chalky limestones have been extensively neomorphosed such that coccoliths of the original chalkforming muds have been largely obscured by crystal overgrowths and enlargement of interstitial cenent crystals. An important fact regarding 


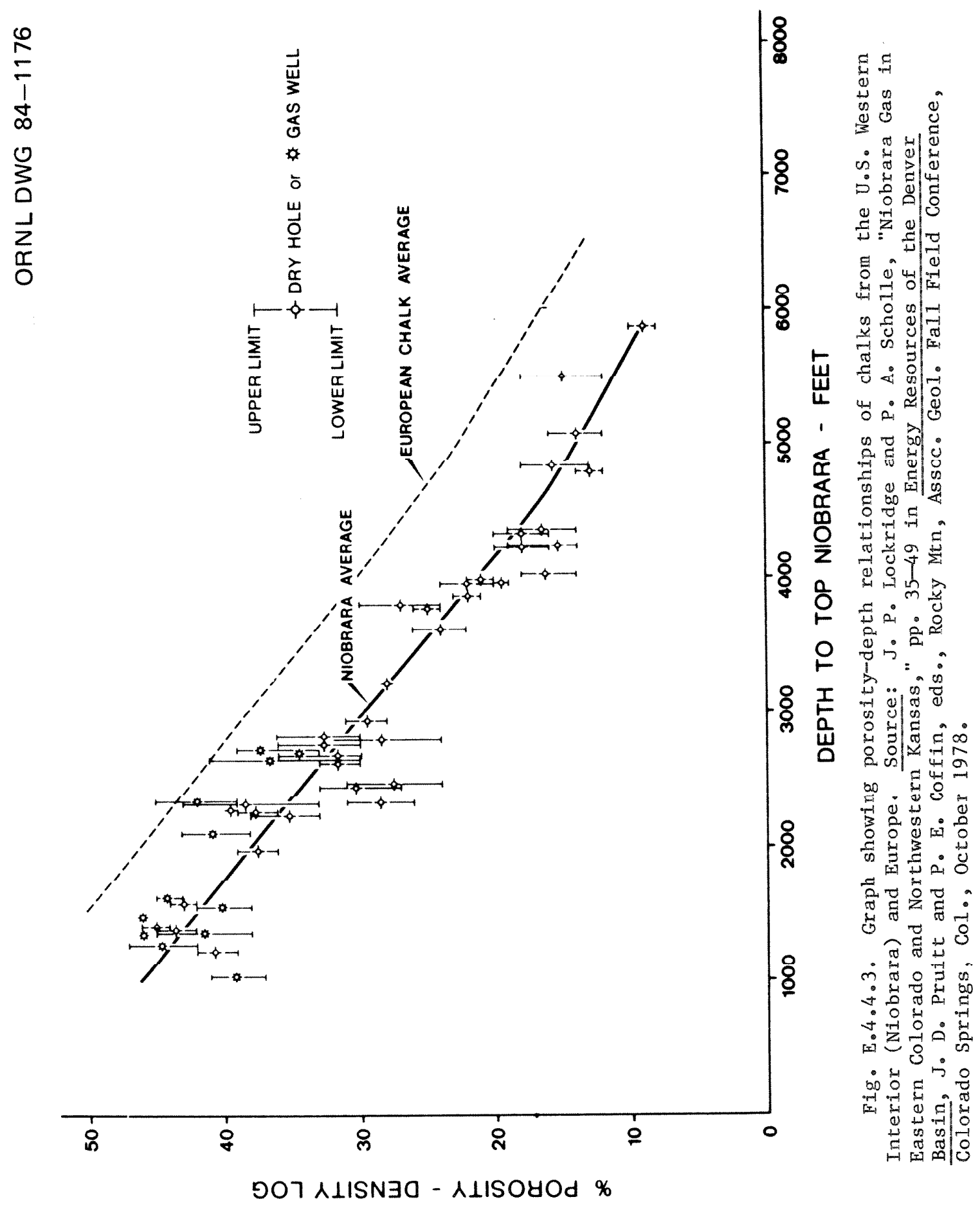




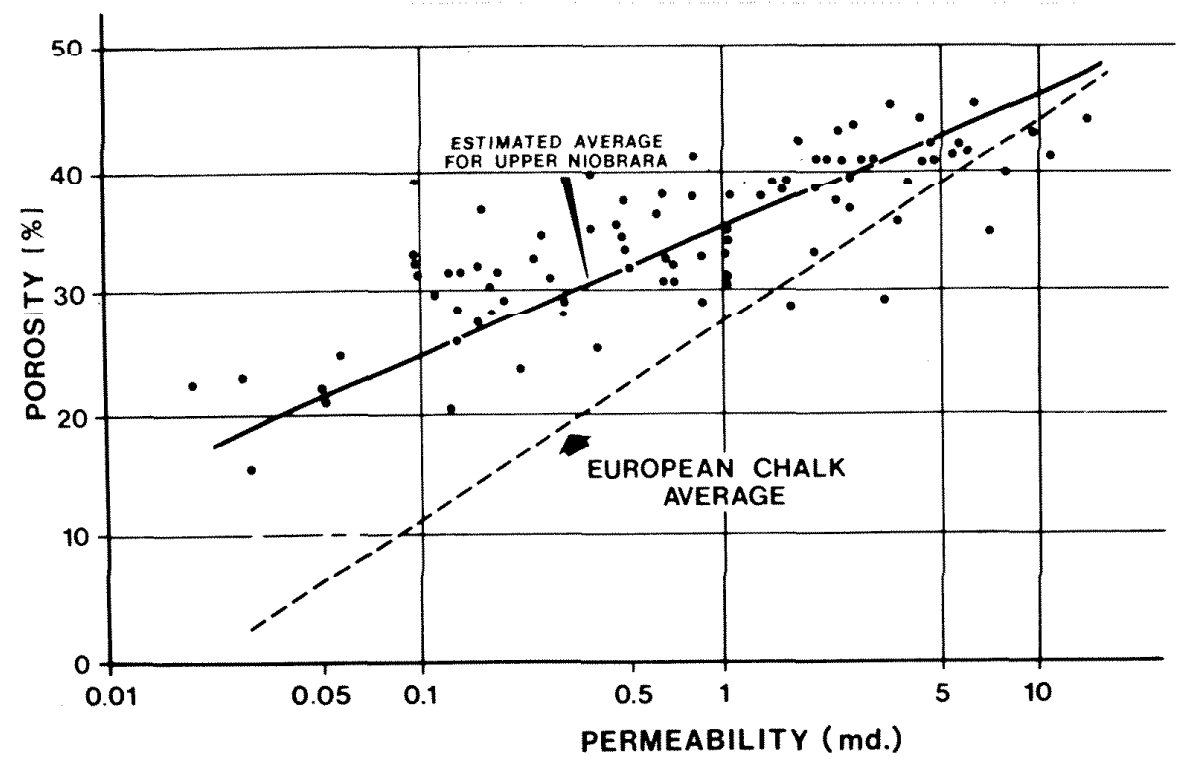

Fig. E.4.4.4. Graph showing relationship between porosity and permeability. Source: J. P. Lockridge and P.A. Scholla, "Niobrara Gas in Eastern Colorado and Northwestern Kansas," pp. 25-49 in Energy Resources of the Denver Basin, J. D. Pruitt and P. E. Coffin, eds., Rocky Mtn. Assoc. Geol. Fall Field Conference, Colorado Springs, Col., October 1978.

hard ground and bioturbated chalky limestone development is that, in both, the diagenetic texture bears considerable resemblance to that arrived at through deep-burial diagenesis, and the bioturbated rocks presumably have correspondingly lower porosity and permeability.

Data on matrix porosity and permeability of Upper Cretaceous chalk and other chalky lithotypes are of two classes: (1) general (for chalk of a given age, region, or burial depth), and (2) specific (for specified

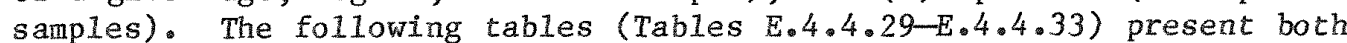
kinds of data. The last table (Table E.4.4.34) contains representative data on mean pore size for some Western Interior and Gulf Coastal Plain chalks.

In the Austin Chalk of Texas, Dravis found that pornstity is highest in the central Texas outcrop and decreases southwestward1y along the outcrop and downdip into the subsurface (DRAVIS 1979). The same trend was reported by Scholle (SCHOLLE 1977b). Similarly, Scholle (SCHOLLE 1977a) and Lockridge and Scholle (LOCKRIDGE 1978) reported decrease of Niobrara formational porosity from northeastern Colorado westward into the Denver basin in consequence of progressive increase in burial depth. 
Table E.4.4.29. General data on Upper Cretaceous chalk porosity and permeability.

\begin{tabular}{|c|c|c|c|c|c|}
\hline Author & Date & Locality & $\begin{array}{l}\text { Litho- } \\
\text { type }\end{array}$ & $\begin{array}{c}\text { Porosity } \\
(\%)\end{array}$ & $\begin{array}{l}\text { Permeability } \\
\text { (mil11darcy) }\end{array}$ \\
\hline Scholle & 1975 & North Sea & Chalk & $2-25^{a}$ & $0-0.5$ \\
\hline Scholle & 1975 & North Sea & Chalk & $15-20^{b}$ & $0.1-1.0$ \\
\hline Scholle & 1975 & England & Chalk & $38-48^{c}$ & $4 \cdot 0-13$ \\
\hline Scholle & 1974 & So. England & $\begin{array}{r}\text { Impure } \\
\text { chalk }\end{array}$ & $27-42^{d}$ & avg. 2.0 \\
\hline Scholle & 1974 & So. England & $\begin{array}{l}\text { Pure } \\
\text { chalk }\end{array}$ & $\begin{array}{c}40-48 \\
(\operatorname{avg} \cdot 43) d\end{array}$ & $\begin{array}{l}6-12 \\
(\operatorname{avg} \cdot 8)\end{array}$ \\
\hline Scholle & 1974 & Yorkshire & $\begin{array}{l}\text { Pure } \\
\text { hard } \\
\text { chalk }\end{array}$ & $17-20^{d}$ & $\begin{array}{l}0.4 \\
(\operatorname{avg} .)\end{array}$ \\
\hline Scholle & 1974 & No Ireland & $\begin{array}{l}\text { Very } \\
\text { hard } \\
\text { chalk }\end{array}$ & $4-13$ & $\begin{array}{l}0.1 \\
(\operatorname{avg} .)\end{array}$ \\
\hline Scholle & 1974 & Denmarke & $\begin{array}{l}\text { Pure } \\
\text { soft } \\
\text { chalk }\end{array}$ & 45 & $6.0+$ \\
\hline Mimran & 1978 & Yorkshire & $\begin{array}{l}\text { Hard } \\
\text { chalk }\end{array}$ & $8-17$ & - \\
\hline Mimran & 1978 & No. Ireland & $\begin{array}{l}\text { Very } \\
\text { hard } \\
\text { cha1k }\end{array}$ & $4-12$ & -- \\
\hline $\begin{array}{l}\text { Lockridge } \\
\& \text { Scholle }\end{array}$ & 1978 & $N \cdot$ E. Colorado & Chalk & $45^{f}$ & $0.1-16$ \\
\hline $\begin{array}{l}\text { Lockridge } \\
\& \text { Scholle }\end{array}$ & 1978 & N.E. Colorado & Chalk & $30-35 g$ & $\begin{array}{l}(\text { avg. }= \\
1.0)\end{array}$ \\
\hline $\begin{array}{l}\text { Lockridge } \\
\& \text { Scholle }\end{array}$ & 1978 & N.E. Colorado & Chalk & $<108^{h}$ & \\
\hline $\begin{array}{l}\text { Snydex } \\
\& \text { Craft }\end{array}$ & 1977 & So. Texas & $\begin{array}{l}\text { Hard } \\
\text { chalk }\end{array}$ & $3-9^{i}$ & $\begin{array}{l}0.1 \\
(\text { avg. })^{j}\end{array}$ \\
\hline Stapp & 1978 & C. Texas & Chalk & $12-18 \cdot 5^{k}$ & 1.0 \\
\hline $\begin{array}{l}\text { Scholle } \\
\& \text { Cloud }\end{array}$ & 1977 & C. Texas 1 & $\begin{array}{l}\text { Shaly } \\
\text { chalk }\end{array}$ & $15-30$ & $0.5-5^{\mathrm{m}}$ \\
\hline $\begin{array}{l}\text { Scholle } \\
\& \text { Cloud }\end{array}$ & 1977 & No. Mexico & $\begin{array}{l}\text { Hard } \\
\text { chalk \& }\end{array}$ & $\& 1 s$. & 0.01 \\
\hline Scholle & $1977 a$ & Cen. W. Kansas & Niobrara & $39 \cdot 9^{n}$ & \\
\hline Scholle & $1977 \mathrm{a}$ & W. Texas & Austin & $13 \cdot 3^{n}$ & \\
\hline Scholle & $1977 a$ & So. Texas & Austin & $18 \cdot 8^{n}$ & \\
\hline Scholle & $1977 a$ & C. Texas & Austin & $12 \cdot 6^{n}$ & \\
\hline Schafer & 1980 & $\begin{array}{l}\text { Guadalupe Co., } \\
\text { Texas }\end{array}$ & Austin & $16-20^{\circ}$ & \\
\hline Schafer & 1980 & Texas & Austin & $5-7 P$ & \\
\hline Schafe: & 1900 & Texas & Auslin & & $0.1-50.59$ \\
\hline
\end{tabular}


Table E.4.4.29 (Continued)

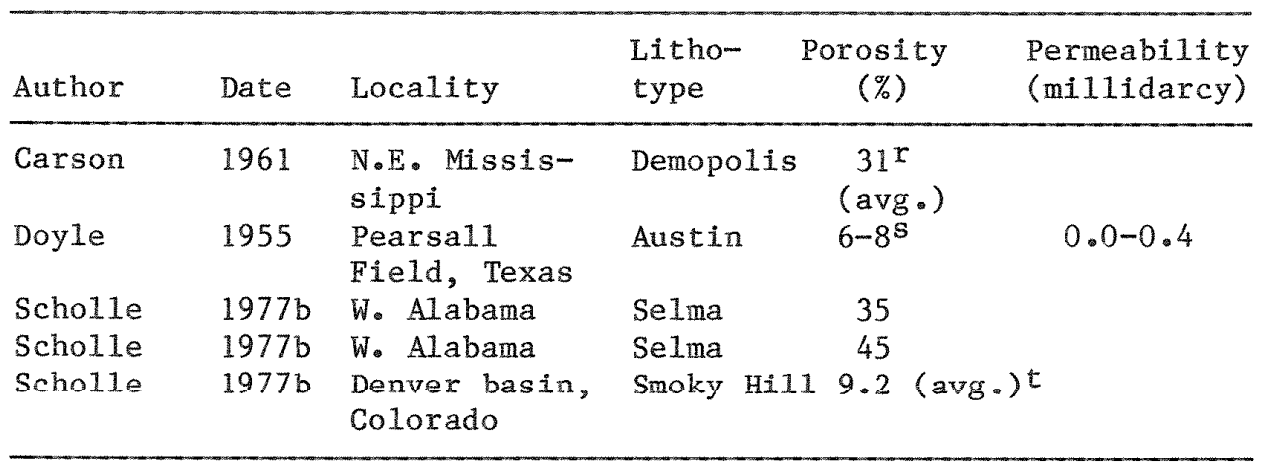

a Burial depth 2700 to $3300 \mathrm{~m}$.

burial depth 1500 to $2000 \mathrm{~m}$.

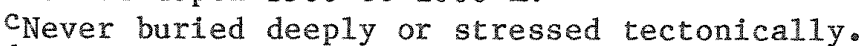

doutcrop.

eTnc1udes Paleocene cha1k.

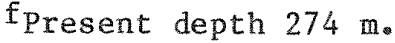

gPresent depth $854 \mathrm{~m}$.

hpresent depth $1830 \mathrm{~m}$.

i."Downdip" chalk.

jLocally 1.0 millidarey.

$\mathrm{k}_{\text {In }}$ streaks, loca11y.

$1_{\text {San Marcos arch. }}$

$\mathrm{m}_{\mathrm{To}}$ north, decreasing slightly.

nOutcrop.

'Shallow field.

PNormal porosity at depths $>1525 \mathrm{~m}$.

qNormal matrix permeability.

routcrop, avg. of 22 samples.

Snepth $1800 \mathrm{~m}$.

tDepth 1655 to $1667 \mathrm{~m}$. 
Table E.4.4.30. Porosity and permeability: Austin Chalk of South Texas and Louisiana

[A1] thicknesses in meters]

\begin{tabular}{|c|c|c|c|c|c|}
\hline \multirow[b]{2}{*}{ Locality } & \multirow[b]{2}{*}{ Depth (m) } & \multicolumn{2}{|c|}{ Porosity (\%) } & \multicolumn{2}{|c|}{ Permeability (millidarcy) } \\
\hline & & Range & Mean & Range & Mean \\
\hline Bushy Cr. Sec. & Outcrop & $\begin{array}{l}16.60- \\
21.40\end{array}$ & 19.19 & $\begin{array}{l}0.03- \\
0.43\end{array}$ & 0.12 \\
\hline $\begin{array}{l}\text { Longhorn } \\
\text { Cement Quarry }\end{array}$ & Outcrop & $\begin{array}{l}13.70- \\
28.40\end{array}$ & $19 \cdot 30$ & $\begin{array}{l}0.07- \\
0.34\end{array}$ & 0.18 \\
\hline $\begin{array}{l}\text { Alamo Cement } \\
\text { Quarry }\end{array}$ & Outerop & $\begin{array}{l}7.78- \\
31.10\end{array}$ & 21.98 & $\begin{array}{l}0.05- \\
2.15\end{array}$ & 0.69 \\
\hline $\begin{array}{l}\text { Nueces River } \\
\text { Sec. }\end{array}$ & Outcrop & - & 13.40 & & \\
\hline Langtry Sec. & Outcrop & $\begin{array}{l}6.81- \\
12.50\end{array}$ & 9.02 & $\begin{array}{l}0.01- \\
0.06\end{array}$ & 0.03 \\
\hline Preuse We11 & $336-362$ & $\begin{array}{l}11.90- \\
22.40\end{array}$ & 16.39 & $\begin{array}{l}0.00- \\
3.03\end{array}$ & 1.36 \\
\hline Standifer Well & $701-710$ & $\begin{array}{l}9.50- \\
11.30\end{array}$ & 10.40 & & \\
\hline Blumberg Well & $964-1002$ & $\begin{array}{l}3.30- \\
12.10\end{array}$ & 5.75 & & \\
\hline Hurts We11 & $1356-1392$ & $\begin{array}{l}6.80- \\
15.10\end{array}$ & 10.00 & & \\
\hline Bea11 We11 & $1710-1823$ & $\begin{array}{l}1.50- \\
9.60\end{array}$ & 4.48 & $\begin{array}{c}<0.01- \\
0.32\end{array}$ & 0.01 \\
\hline $\begin{array}{l}\text { Varner-Wendler } \\
\text { WeIl }\end{array}$ & $1784-1843$ & $\begin{array}{l}1.00- \\
15.10\end{array}$ & 8.10 & $\begin{array}{l}<0.01- \\
9.99\end{array}$ & 0.51 \\
\hline $\begin{array}{l}\text { Winterbotham } \\
\text { We11 }\end{array}$ & $1880-1945$ & $\begin{array}{l}1.60- \\
11.40\end{array}$ & 6.10 & $\begin{array}{c}<0.01- \\
0.14\end{array}$ & 0.03 \\
\hline Weinert Well & $2043-2104$ & $\begin{array}{l}1.80- \\
11.70\end{array}$ & 5.55 & $\begin{array}{c}<0.01- \\
0.36\end{array}$ & 0.05 \\
\hline Samuels We1l & $2125-2183$ & $\begin{array}{l}2.50- \\
12.70\end{array}$ & 6.68 & $\begin{array}{l}<0.01- \\
176.0\end{array}$ & 0.30 \\
\hline Talbott Well & $2201-2216$ & $\begin{array}{l}2.50- \\
6.20\end{array}$ & $4 \cdot 34$ & $\begin{array}{r}<0.01 \\
0.06\end{array}$ & 0.02 \\
\hline Orts We11 & $2195-2284$ & $\begin{array}{l}2.10- \\
6.10\end{array}$ & 4.10 & $\begin{array}{c}<0.01- \\
0.10\end{array}$ & 0.01 \\
\hline Southland We11 & $4207-4210$ & $\begin{array}{l}11.50- \\
13.0\end{array}$ & 12.25 & & \\
\hline Jackson We11 & $4443-4451$ & -- & 16.00 & & \\
\hline Burton We11, La. & $4268-4271$ & -- & 20.00 & & \\
\hline Turner We11, La. & $4939-5128$ & - & 22.00 & & \\
\hline Walker We11, La. & $5549-5555$ & -- & 16.00 & & \\
\hline
\end{tabular}

Source: J. J. Dravis, Sedimentology and Diagenesis of the Upper Cretaceous Austin Chalk Formation, South Texas and Northern Mexico, Ph.D. dissertation, Rice University, Houston, Tex., 1979. 
Table E.4.4.31. Porosity and permeability data for Austin Chalk of Texas

\begin{tabular}{|c|c|c|c|c|}
\hline Sample & County & $\begin{array}{l}\text { Stratigraphic } \\
\text { unit }\end{array}$ & $\begin{array}{l}\text { Porosity } \\
(\%)\end{array}$ & $\begin{array}{l}\text { Permeability } \\
\text { (mi111darcy) }\end{array}$ \\
\hline $\mathrm{ZGG}$ & Grayson Co. & Atco & 23.5 & 0.04 \\
\hline ZGJ & Grayson $\mathrm{Co}$. & Atco & 27.3 & 0.38 \\
\hline DRD & Dallas Co. & Atco & 29.1 & 0.34 \\
\hline DRF & Dallas Co. & Atco & 27.4 & 0.21 \\
\hline $\mathrm{DBM}$ & Dallas Co. & Bruceville & 21.0 & 0.29 \\
\hline DBX & Dallas Co. & $\begin{array}{l}\text { "Hutchins } \\
\text { Chalk" }\end{array}$ & 28.7 & 0.22 \\
\hline $\mathrm{DRX}$ & McLennan Co. & Atco & 30.2 & 0.66 \\
\hline DSB & McLennan Co. & Acco & 26.3 & 0.67 \\
\hline DRK & Travis Co. & Atco & 18.8 & 0.12 \\
\hline $\mathrm{EQG}$ & Travis Co. & Atco & 21.7 & 0.15 \\
\hline ZEN & Bexar Co. & Atco & 11.6 & 0.12 \\
\hline $\mathrm{ZFG}$ & Bexar Co. & Atco & 19.1 & 0.46 \\
\hline $\mathrm{ZFL}$ & Medina Co. & Atco & 23.0 & 0.15 \\
\hline ZFO & Medina Co. & Atco & $21 \cdot 4$ & 1.07 \\
\hline EOA & Uvalde Co. & Big House & 16.6 & 0.19 \\
\hline ZFR & Uvalde Co. & Dessau & 17.2 & 0.24 \\
\hline ZFX & Uvalde Co. & Dessau & 13.8 & 0.07 \\
\hline EPH & Maverick Co. & Big House & 9.6 & 0.01 \\
\hline EOW & Kinney Co. & Atco & 13.7 & 0.09 \\
\hline EOX & Kinney Co. & Atco & 13.1 & 0.06 \\
\hline EPA & Kinney Co. & Atco & 13.9 & 0.04 \\
\hline EON & Val Verde Co. & Atco & 11.1 & 0.04 \\
\hline EOD & Terrell Co. & Atco & 5.9 & 0.00 \\
\hline EOF & Terrell Co. & Atco & 7.1 & 0.01 \\
\hline EOK & Terrell Co. & Atco & 8.1 & 0.02 \\
\hline
\end{tabular}

Source: K. W. Cloud, The Diagenesis of the Austin Chalk, Master's thesis, University of Texas, Dallas, 1975. 
Table E.4.4.32. Porosity/permeability data for upper part of Niobrara Chalk, northwesternmost Kansas, based on cores from three boreholes in Cheyenne county

\begin{tabular}{|c|c|c|c|}
\hline WeI1 & $\begin{array}{l}\text { Depth } \\
\text { (m) }\end{array}$ & $\begin{array}{l}\text { Porosity } \\
(\%)\end{array}$ & $\begin{array}{l}\text { Horizontal } \\
\text { permeability } \\
\text { (millidarcy) }\end{array}$ \\
\hline $\begin{array}{c}\text { Murphin } 1-28 \\
\text { Neitzel } \\
" \\
" \\
" \\
" \\
" \\
" \\
" \\
" \\
"\end{array}$ & $\begin{array}{l}389.3 \\
389.9 \\
391.7 \\
392.3 \\
393.6 \\
394.2 \\
398.2 \\
401.8 \\
404.0 \\
405.5\end{array}$ & $\begin{array}{l}44.7 \\
41.3 \\
41.8 \\
38.4 \\
41.3 \\
41.5 \\
37.1 \\
32.7 \\
29.0 \\
34.1\end{array}$ & $\begin{array}{c}16.1 \\
11.0 \\
5.90 \\
2.18 \\
2.03 \\
5.98 \\
2.64 \\
1.96 \\
3.41 \\
1.33\end{array}$ \\
\hline $\begin{array}{c}\text { Murphin } \mathrm{B} 1-33 \mathrm{WaIz} \\
" \\
\text { " } \\
\text { " }\end{array}$ & $\begin{array}{l}391.1 \\
394.2 \\
396.4 \\
393.5 \\
399.1\end{array}$ & $\begin{array}{l}26.1 \\
41.0 \\
42.0 \\
39.6 \\
40.6\end{array}$ & $\begin{array}{l}\text { Not measured } \\
\qquad \begin{array}{l}2.60 \\
1.81 \\
1.33 \\
3.12\end{array}\end{array}$ \\
\hline $\begin{array}{l}\text { Murphin 1-22 } \\
\text { L. Carter } \\
\text { " } \\
" \\
" \\
\text { " }\end{array}$ & $\begin{array}{l}392.0 \\
393.9 \\
395.1 \\
396.0 \\
397.3\end{array}$ & $\begin{array}{l}24.4 \\
32.3 \\
41.1 \\
43.2 \\
40.5 \\
40.8\end{array}$ & $\begin{array}{l}0.46 \\
4.65 \\
2.66 \\
2.48 \\
2.20\end{array}$ \\
\hline
\end{tabular}

Source: Kansas Geological Survey, Open File Report, Amoco-197, 1978 . 
Table E.4.4.33. Porosity/permeability data for Niobrara Formation, Boettcher Quarry, near Ft. Collins, Colorado [Unit $A$ is at base; $G$ at top]

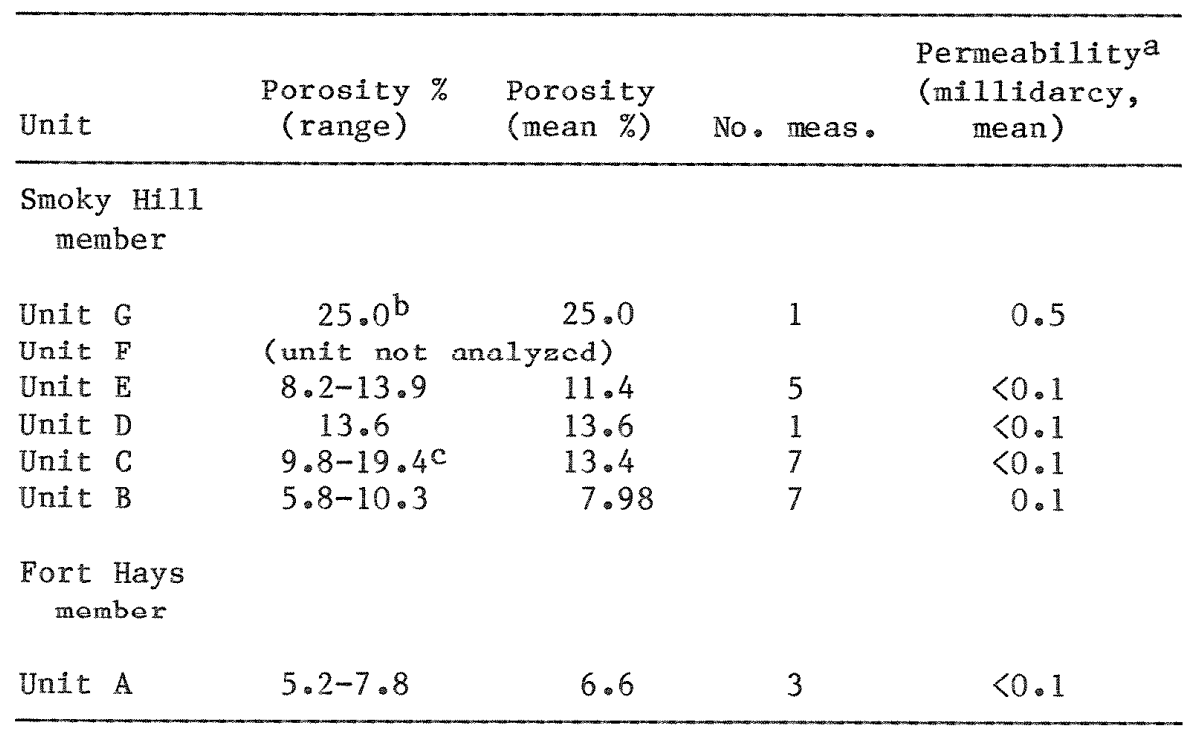

aEstimates taken from graph from J. P. Lockridge and P. A. Scholle, "Niobrara Gas in Eastern Colorado and Northwestern Kansas," pp. 35-49 in Energy Resources of the Denver Basin, J. D. Pruitt and R. E. Coffin, eds., Rocky Mtn. Assoc. Geol. Fall Field Conference, Colorado Springs, Col., October 1978.

bHigh permeability caused by tendency of rock to part along bedding,

cHighest value is in well-laminated rock filled with pellets.

Source: M. L. Haun, Petroleum Potential of the Niobrara Formation in the Denver Basin: Colorado and Kansas, Master's thesis, Colorado State University, Fort Collins, Col., 1981. 
Table E.4.4.34. Examples of pore-throat diameters for selected Upper Cretaceous chalk samples of the U.S. Western Interior and Gulf Coastal Plain

\begin{tabular}{llc}
\hline \multicolumn{1}{c}{ Locality } & \multicolumn{1}{c}{ Unit } & $\begin{array}{c}\text { Mean pore size } \\
(\mu \mathrm{m})\end{array}$ \\
\hline Demopolis, AL & Demopolis Chalk & 0.15 \\
Superior, NB & Niobrara Chalk & 0.35 \\
Cedar, KS & Niobrara Chalk & 0.39 \\
Hays, KS & Niobrara Chalk & 0.47 \\
Woodway, TX & Austin Chalk & 0.20 \\
Midlothian, TX & Austin Chalk & 0.18 \\
Okay, AR & Annona Formation & 0.20 \\
\hline
\end{tabular}

Source: R. D. Harvey, R. R. Frost, J. Thomas, Jr., "Lake Marls, Chalks, and Other Carbonate Rocks with High Dissolution Rates in $\mathrm{SO}_{2}$-Scrubbing Liquors, "Illinois State Gco1. Surv. Env. Geo1. Notes 68 (1974).

Part of the porosity in chalk is primary (matrix porosity), and part is secondary (fractures, solution, etc.). The effective porosity of chalk results from combinations of these kinds of porosity. Because chalk, once compacted and lithified, is a relatively brittle rock, fracturing is common, and fracturing is a major factor in the occurrence of oil reservoirs in such units as the Austin Chalk (HOLDITCH 1982; STAPP 1978; CALCOTE 1983). However, Dravis pointed out that fractures in the Austin Chalk subsurface appear in thin section to be completely healed by secondary calcite cement and concluded that the Austin is capable of producing oil from matrix porosity alone (DRAVIS 1979). Permeability of chalk (naturally low in all chalk) is groatly chhanced by fracturing, which may yield effective permeabilities as much as 50 to 500 times greater than those in similar unfractured chalk. Fracturing is apparently greatest in zones of tectonic activity and faulting whether or not faulting is caused by tectonism, adjustments of chalk to compaction in underlying sediments, or draping over buried topography. In addition to fracturing, permeability can be enhanced by the presence of permeable bedding planes (BECK 1977). 


\section{E.4.5 BOUNDING UNITS}

\section{E.4.5.1 THEORETICAL CONSIDERATIONS}

In an ideal, unbroken cycle of Upper Cretaceous marine shelf deposition, the purest chalk facies should occupy a central position that marks maximum transgression. If shelf deposition was influenced by a terrigenous detrital dispersal system, one could expect the chalk facies to be bounded below, above, and on the landward side by an orderly progression of lithotypes that manifest transition from the pelagic-dominated to terrigenous-dominated sedimentary regimes. Accordingly, the chalk facies should grade downward, upward, and towards terrigenous detrital source areas into marly rocks, which in turn should grade into calcareous shale, then noncalcareous shale, and eventually into the silty and sandy nearshore facies. Such a succession is, in fact, realized in only one (Greenhorn) of the many American Upper Cretaceous shelf-sea chalks (Fig. E.4.2.8). Other chalk units are bounded by either sandstone, shale, or chalk, and several are separated from adjacent strata by major or minor unconformities. Variations from the expected pattern were caused by such factors as (1) intercycle erosion, (2) omission of facies because of rapid transgression, (3) incomplete regression, and (4) deposition of chalk in relatively shallow water close to a shoreline.

Intercycle erosion could remove regressive portions of an earlier depositional cycle so that nearshore transgressive sands of a later cycle could lie directly (and unconformably) on an offshore facies such as chalk. Rapid transgression could result in omission of nearshore facies from a cyclic sequence so that the offshore chalks could lie unconformably on nearshore sands of an earlier depositional cycle. An extreme combination of situations (1) and (2) could result in chalk of a younger depositional cycle lying directly on chalk of a preceding depositional cycle. Incomplete regression could result in the chalk facies of two successive depositional cycles being separated only by marl rather than by a complete regressive-transgressive suite of gradational facies. Deposition of chalk close to shore and in relatively shallow water could produce a lateral or vertical chalk-sandstone transition that onits the intermediatc marl/calcarcous ohalc/noncalcarcous shalc gradation.

\section{E.4.5.2 EXAMPLES}

For any particular American chalk unit, the two bounding units may be of the same lithology or may be of contrasting lithology. Furthermore, a given bounding unit may include two or more contrasting facies. In Table E.4.5.1, the rock type(s) listed as bounding units for a particular formation is (are) the most typical for that chalk unit. Listings of two or more lithotypes reflects facies changes in the bounding unit or erosion of the underlying section. 
Table E.4.5.1. Typical bounding lithotypes of American Upper Cretaceous chalk units

$[D=$ disconformable or discontinuous; $C=$ unconformable $]$

\begin{tabular}{|c|c|c|c|c|}
\hline \multirow[b]{2}{*}{ Unit } & \multicolumn{2}{|c|}{ Nature of contact } & \multicolumn{2}{|c|}{ Bounding 1ithotype } \\
\hline & Lower & Upper & Lower & Upper \\
\hline Annona & $D$ & C & $\operatorname{Mar1}$ & $\operatorname{Mar1}$ \\
\hline Austin & $\mathrm{D}$ & $\mathrm{D}$ & Shale/marl & Mar1 \\
\hline Demopolis & $\mathrm{D}$ & $\mathrm{C}$ & $\begin{array}{l}\text { Limestone/ } \\
\text { mar1 }\end{array}$ & $\begin{array}{l}\text { Sand/clay/ } \\
\operatorname{mar} 1\end{array}$ \\
\hline $\begin{array}{r}\text { Greenhorn/ } \\
\text { Fairport }\end{array}$ & $\mathrm{D}$ & c & Shale & Shale \\
\hline Mooreville & $\mathrm{C}^{\mathrm{a}}$ & D & $\begin{array}{l}\text { Silty, clayey } \\
\text { sands/glauc. } \\
\text { sandst./marl } \\
\text { calc. clay }\end{array}$ & Chalk \\
\hline Niobrara & $\mathrm{D}$ & $\mathrm{c}^{\mathrm{b}}$ & Sandst./shale & Shale \\
\hline Peran Gap & $\mathrm{D}^{\mathrm{C}}$ & $n$ & Sandstonec & Mar1 \\
\hline Prairie Bluff & D & D & $\begin{array}{l}\text { Mar1/sandy } \\
\mathrm{Clay} / \mathrm{sand}\end{array}$ & $\begin{array}{l}\text { Cg1./ } \\
\text { Sandst./ } \\
\text { clay/mar1 }\end{array}$ \\
\hline Saratoga & $\mathrm{D}$ & $\mathrm{C}$ & Marl & $\begin{array}{l}\text { Sand/clay/ } \\
\text { mar1 }\end{array}$ \\
\hline
\end{tabular}

a Reported as disconformable by some authors.

bisconformable locally in northern Great Plains.

Where Pecan Gap is developed as a chalk facies. 


\section{E.4.6 REACTION TO EXTERNAL EVENTS}

\section{E.4.6.1 TECTONICS}

Across the Gulf Coastal Plain from South Texas to southern Alabama, high-angle normal and locally reverse faulting has affected much of the Upper Cretaceous chalk-bearing section. Much of the faulting is believed to be related to movements of Jurassic salt, and faulting is known to have continued into Cenozoic time. The extent to which salt might move in the future, or to what extent such movement might involve further faulting, is unknown, but principal evolution of salt domes and diapirs in the East Texas basin occurred during massive progradation of early Cretaceous terrigenous detritus (JACKSON 1981). Furthermore, the natural rate of Jurassic salt movement in Tertiary time was small compared to that of the Cretaceous, and the present tectonosedimentary regime indicates that the East Texas salt domes are more stable today than in the geologic past (SENI 1981).

The Wostern Tnterior area of Inper Cretarenus chalk dennsits includes several basement-controlled structural features (e.g., Transcontinental Arch, Chadron Arch, Central Kansas uplift) that have experienced cepeated vertical movement during Phanerozoic time (BUNKER 1981; WETMER 1978;

SHURR 1981; WATNEY 1984). These movements had sore influence on Cretaceous depositional patterns and on post-Cretaceous erosion, but the overall effect on chalk deposits has been minimal.

With respect to seismic risk, most of the Texas area that is underlain by Upper Cretaceous chalk deposits is in zone 0 , as is a substantial part of southern Alabama that contains subsurface chalk deposits (ESSA/CGS 1969). Otherwise, nearly all remaining areas of chalk deposits are in Zone 1, where only minor earthquake damage can be expected. Stated another way - in nearly all areas of the conterminous United States that are mierlain hy Upper Cretarenus chalk depnsits, there is a $90 \%$ prohahi1ity that within the next 50 years there will be no earthquake having horizontal acceleration greater than $4 \%$ of the acceleration of gravity (ALGERMISSEN 1976).

\section{E.4.6.2 DISSOLUTION - BRECCIATION}

The most stahle form of $\mathrm{CaCO}_{3}$ is calcite, which has a soluhility product of $4.5 \times 10^{-9}$, as compared with $6.0 \times 10^{-9}$ for the common lessstable polymorph, aragonite. Because chalk is composed predominantly of low-magnesium calcite, the rock is very stable compared with ordinary 1imestone, and the effects of epigenetic dissolution on chalk have therefore been minimal in most areas. In numerous areas, the English Chalk is characterized by conical depressions (called swallow holes) that are as much as several meters in diameter and a few meters in depth. Those depressions occurring along valley bottoms have been attributed to dissolution by water movement in the valleys (WOOLDRIDGE 1937), whereas those occurring elsewhere (slopes, level fields) are believed to have been produced by local-dissolutional activity of percolating rainwater (WESL 
1972). Apparent1y, phenomena of this sort are either very rare or lacking in American chalk deposits because they are not mentioned in any of the surveyed literature. Caves are rare in chalk and are lacking in American chalk deposits, although solution-widened joints have been reported in the Austin Chalk of Sabine Parish, Louisiana (Woods 1963). Movement of water through solutional openings has been reported for such units as the Demopolis Chalk of Alabama (CARLSTON 1944) and Niobrara Chalk of Kansas (WAITE 1947) and South Dakota (MCMEEN 1964), but details on size, character, and spacing of such features are not stated.

Solution of evaporites at depth is known to have caused collapse of chalk-bearing rock sections (SCOTT 1977). A recent notable example of man-induced collapse occurred in Ellis County, Kansas, where water from a disposal well apparently dissolved Permian evaporites and caused collapse that affected the entire overlying section up to and including an Upper Cretaceous chalk unit (Greenhorn/Fairport) that lay at the aurface (TINGMAN 1976).

\section{E.4.6.3 WEATHERING AND EROSION}

The extent of weathering and erosion to which chalk is subjected depends upon three main factors: climate, relief, and rock composition. The main ingredients of climate are temperature and rainfall. Wherever temperatures are sufficiently warm and rainfall is sufficiently high, thick residual soils will develop on chalk deposits, as in the Black Belt prairie of Alabama and Mississippi. In cooler and drier areas, such as the Great Plains of western Kansas and eastern Colorado, the soils deve1oped on chalk are very thin. Where rainfall is high and agricultural activity has been intensive, weathered chalk may be subjected to sheet erosion and gullying so as to produce the bald spots seen commonly in the Black Prairie of Mississippi and Alabama (CARLSTON 1944). Even in semiarid regions, such as western Kansas, chalk erodes rapidly in areas of high local relief adjacent to stream courses, and extensive badlands have developed locally in that area. Marly chalks, shaly chalks, and chalky marls are the recessively eroded units in rhythmically bedded chalky sequences (e.g., DURHAM 1957; MILLER 1978; BOTTJER 1978), and these rocks are more likely to become gullied or carved into badlands (personal obocrvation; NEWMAN 1975).

Literature searched for purposes of this report yielded few references to studies on rates of chalk erosion. Smith compared photographs of an erosional pillar in the Niobrara Chalk of western Kansas that were taken 50 years apart (SMITH 1944). He concluded that the pillar had been reduced $2.5 \%$ as viewed from the north and $6 \%$ as viewed from the south, and predicted total removal of the 55-ft pillar in 500 to 2000 years. In the 1970s a several-ton mass of rock fell from the top of this pillar, thus vastly accelerating the otherwise modest erosional rate. The most quantitative study encountered is that of West and Dumbleton, who made estimates regarding the rates at which swallow holes are formed by surficial dissolution of the English Chalk (WEST 1972). Assuming that (1) the chalk is removed only by solution, (2) rainfall is $700 \mathrm{~mm} / \mathrm{year}$, (3) one half of the fallen rain percolatco into the chalk, (4) solubility of 
the chalk is $0.24 \times 10^{-3} \mathrm{~g} / \mathrm{ml}$, and (5) density of the chalk is $1.6 \mathrm{~g} / \mathrm{cm}^{3}$, they calculated that the chalk surface would be lowered $0.5 \mathrm{~m}$ in 10,000 years. Under conditions involving no general lowering of the surface, and with runoff concentrated into areas covering only $1 \%$ of the whole, swallow holes $0.5 \mathrm{~m}$ deep would be produced in only 100 years. If runoff (as from a road) were to be concentrated into an area on $1 \mathrm{y} 0.1 \%$ of the whole, and assuming no losses owing to evaporation or transpiration, then solutional pipes $1 \mathrm{~m}$ deep could be produced in just 10 years.

From all of the foregoing discussion, one can deduce that the least amount of chalk erosion, whether chemical or mechanical, will occur in areas that combine (1) very low local relief, (2) low rainfall, and (3) relatively pure chalk. Of course, chalk deposits having suitable characteristics for purposes of this report might be buried beneath rocks of other facies, such as clay, shale, sand, sandstone, mar1, etc. In such situations, erosional rates of these other lithotypes would have to enter the equation. 


\section{E.4.7 RESOURCES}

\section{E.4.7.1 OIL AND GAS}

Upper Cretaceous chalk deposits are sources of oil and gas in many states of the Gulf Coastal Plain and U.S. Western Interior regions. A comprehensive summary of production figures, depths to tops of productive units, and factors involved in the entrapment of oil in chalk are included in an important work by Scholle (1977b), which should be consulted by users of this report (SCHOLLE 1977b). A recent flurry of successful drilling activity in the South Texas Austin Chalk oil trend and in the eastern Colorado/northwestern Kansas/southwestern Nebraska Niobrara Chalk gas area suggests that chalk deposits will continue to be attractive targets in future.

In Texas, several fields that produce from the Austin Chalk are in the million-barrel-plus category, and producing fields are scattered across much of central, southern, and eastern Texas. In Louisiana, each of several fields has produced in excess of 5 million barrels of oil from the Saratoga and Annona chalks, and two of these fields are also prolific gas producers. In Mississippi and Alabama, major oil production has come from the Selma Group (undifferentiated in Scholle's tables), and two fields have produced large quantities of gas from the same group. Production of hydrocarbons from Gulf Coast chalk units began more than 70 years ago, and new discoveries are still being made. Many thousands of boreholes penetrate the chalk formations that were principal drilling targets. In addition, many thousands of boreholes drilled to underlying Cretaceous and Jurassic targets also penetrate the chalk formations.

Production of hydrocarbons from Western Interior chalky strata dates back nearly 70 years. Production of oil from the relatively pure chalk facies has been small, and most of the oil has been produced from areas where the Greenhorn and Niobrara consist mainly of chalky marl, calcareous shale, and limestone rather than true chalk. Since 1972, extensive drilling on the east flank of the Denver-Julesburg basin and northern plunge of the Las Animas arch has yielded natural gas from Niobrara chalk intervals that lie 305 to $975 \mathrm{~m}$ below the surface (SMAGALA 1980). Shallow depths and consequent low drilling costs will make this area an attractive target for the foreseeable future.

\section{E.4.7.2 WATER}

Many reports concerned with groundwater resources contain statements to the effect that chalk formations are impermeable (or relatively so) and yield little water to wells. To a certain extent, this is true, as evident in the description by Carlston of large-capacity cisterns or "jug wells" which were once dug in the Demopolis Chalk for the storage of water (CARLSTON 1944). However, other reports contain statements suggesting that in some areas water flows readily through chalk: Waite reported that several wells in southeastern Scott County, Kansas, tap the 
Smoky Hill Chalk Member of the Niobrara (WAITE 1947). Shafer reported that the water supply for the town of Marion, Texas, comes from two sha1low dug wells at a rate of about $60 \mathrm{gpm}$ from the Austin Chalk (SHAFER 1966). McMeen noted that water for the city of Marion, South Dakota, comes from three 90-m wells that tap the Niobrara Chalk (MCMEEN 1964). Water for domestic and livestock needs is also derived from chalky carbonate strata, such as the Greenhorn Limestone of Baca County, Colorado (McLAUGHLIN 1954); Niobrara of Davison and Turner Counties, South Dakota (HANSEN 1984; MCMEEN 1964); Austin Chalk of Guadalupe County, Texas (SHAFER 1966); and Mooreville Formation of Alabama (CARLSTON 1944). Most American chalk deposits yield such small quantities of water from springs that 1ittle mention is made of them, and Russe11 (RUSSELL 1929b) noted apccifically that he was unable to find opringo isouing from the Smoky Hi11 chalks of western Kansas. Nevertheless, seeps and springs have been reported in the chalk of some areas - an example being the Austin Chalk of Bell County, Texas (ADKINS 1930).

Water movement through chalk deposits has been attributed mainly to fractures (MCLAUGHLIN 1954; JOHNSON 1958; SCHOLLE 1977a; BROWN 1978; STAPP 1978; SHURR 1981). In addition, faulte are believed to foed wator into chalk from other formations (STAPP 1978). This factor may be the reason for relatively high volumes of water that are locally delivered to wells that have been dug in chalk formations. 


\section{E.4.8 SUMMARY}

Chalk is a variety of marine limestone that is typically light colored, very fine grained, soft, friable, porous, and composed largely of calcareous nannoplankton. The purest chalks consist almost entirely of low-magnesium calcite, much of which is in the form of coccoliths, planktonic foraminifers, benthic bivalves, and diagenetic cement. Few American chalk deposits have $\mathrm{CaCO}_{3}$ content as high as $95 \%$. Chalk commonly grades into adjacent marls by the addition of clay, which tends to darken the rock color. Other varieties include sandy chalk, calcarenitic chalk, dolomitic chalk, glauconitic chalk, and phosphatic chalk, most of which are of small volumetric importance. Quartz and clay minerals are the chief detrital impurities in most chalk deposits, with percentages ranging from $<1 \%$ in pure chalks to dominance in areas of major facies change. Organic matter occurs in small quantities in most chalks, and is most abundant in nonbioturbated rocks.

By definition, chalk is very fine grained, with "matrix" predominating over "grains." Most matrix particles have diameters that are $20 \mu \mathrm{m}$ or less, and many chalks are predominantly micritic (grains $<5 \mu \mathrm{m}$ ). Coarser components consist mostly of forams, calcispheres, benthic skeletal debris, and fecal pellets.

Although chalk is presently forming in oceanic settings, most of the world's accessible chalk formations formed in relatively shallow-water cratonic-shelf environments, and most of those are of late Cretaceous age. Cretaceous shelf-sea chalks were deposited primarily during or near peaks of marine transgression when pelagic sources of carbonate sediment suffered little dilution by terrigenous detrital influx. Basement structure, contemporaneous tectonism, and volcanism influenced facies patterns, thickness variations, and vertical continuity of American chalk deposits, but these effects are mostly gradual or local in nature.

Chalk deposits have prevailingly tabular geometry, with horizontal dimensions that are as much as three orders of magnitude greater than thickness. Abrupt thinning or thickening of formations or individual beds is uncommon, and wide lateral persistence of facies and individual beds is characteristic of chalks in general. Several American chalk deposits meet the required criteria of thickness, lithologic homogeneity, and lateral dimensions.

Bedding of chalks includes laminations on a millimeter-to-decimeter scale, rhythmic alternations of genetically related lithotypes (e.g., chalk and marl) on a decimeter-to-meter scale, and poorly to nonbedded sequences of massive chalk. Whether chalk sections are massive or well bedded, whether individual beds are bioturbated or laminated, and whether chalk formations are thick or thin, chalk sections tend to have the following characteristics:

1. wide lateral persistence of facies;

2. wide traceability of beds within bedded sequences; 
3. mostly gradual changes of thickness and facies;

4. vertical sequences that (a) lack interbeds, (b) consist of rhythmic alternation of genetically related lithotypes (e.g., chalk and mar1), or (c) manifest gradual upward change in overall lithic character;

5. abrupt vertical changes only at unconformities or discontinuity surfaces.

Gulf Coastal Plain chalk deposits are extensively faulted in welldefined systems, some of which span nearly the entire province and seem to be related to subsurface withdrawal of Jurassic salt. Chalk adjacent to faults is commonly much fractured. Western Interior chalks are also fanlted, hut most of the fan1ts are in the thicker sections of marly chalk, are oriented at random, and seem to be related more to compaction than to deep-seated factors. Overal1, the Western Interior chalks are less fractured than those of the Gulf Coastal Plain. Apparently, fractures and joints are more common in purer, more brittle chalks, but impure chalk tends to spall readily along fractures during weathering. Anong American Upper Cretaceous chalks, the highest recorded fracture intensity is in the Anstin Chalk, which is extensively fanlted, hut data on other chalk units are not available.

Porosity of shelf-sea chalk decreases with the depth of burial. Initial porosities of 70 to $80 \%$ were reduced at first by mechanical compaction but at depths greater than $1000 \mathrm{~m}$ continued compaction and porosity loss was mainly by chemical compaction (solution transfer). Porosity reduction has also been effected by bioturbation-induced neomorphism occurring directly beneath the sea floor. Like porosity, permeability of chalk was reduced progressively with greater depth of burial, but these trends were commonly reversed by fracturing, overpressuring, or early entry of hydrocarbons into the chalk. The nature of lithic units that bound chalk units depends upon completeness of marine sedimentation cycles. In deposits of complete cycles, chalk units are bounded typically hy marls. There deposits of one cycle were transgressed rapidly, chalk deposits of the younger cycle may lie on regressive sands of the older cycle. Where intercycle erosion cut deeply into deposits of a preceding cycle, chalk of a younger cycle may rest directly on chalk of an older cycle. partial regression may be marked by a marl formation that separates two chalk formations. American chalk units are bounded by a variety of lithotypes, suggesting that depositional history was not the same for each of the cycles that contains a chalk formation.

American Cretaceous chalk units have suffered little as a result of post-Cretaceous tectonism. Salt movement in the Gulf Coastal Plain has had the most noticeable effect. Because of dominance of low-magnesium calcite mineralogy, the effects of surface and groundwater dissolution on chalk during the Quaternary Period has been slow and minimal. Solution-brecciation of chalk is a rare phenomenon. Erosional rates for chalk deposits are poorly known, but minimal mechanical and chemical erosion will occur in areas that combine (1) low rainfall, (2) very low local relief, and (3) relatively pure chalk or chalky limestone. 011 and gas have been produced from large areas underla1n by Gulf coast 
chalks, both from the chalk itself and from underlying reservoirs. In the U.S. Western Interior, hydrocarbon production from the more pure chalky strata mainly involves natural gas, most of which is being produced from northeastern Colorado and northwestern kansas. In both provinces, chalks have been perforated extensively during drilling that has been aimed at reservoirs beneath the chalk formations (Table E.4.8.1). 


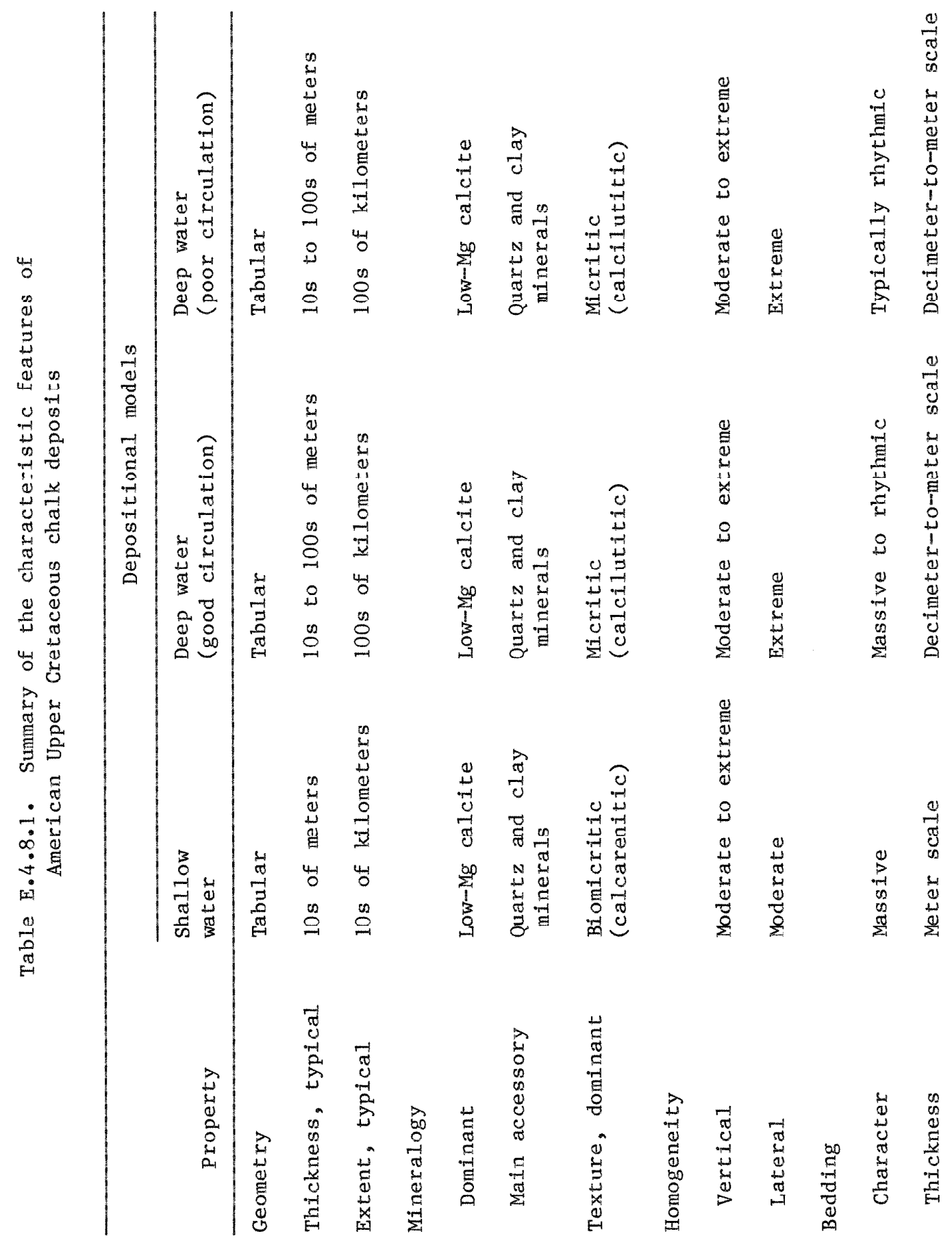




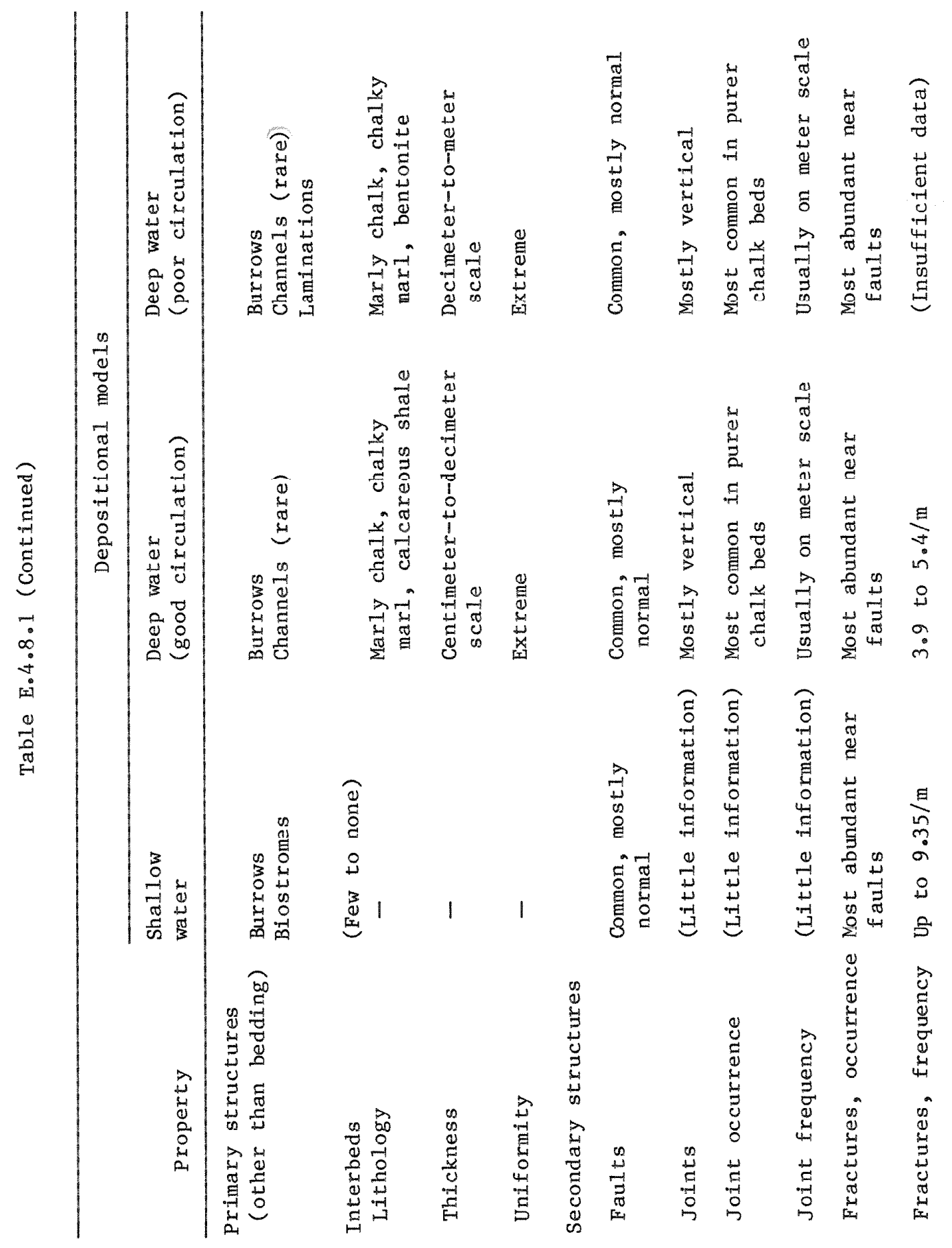




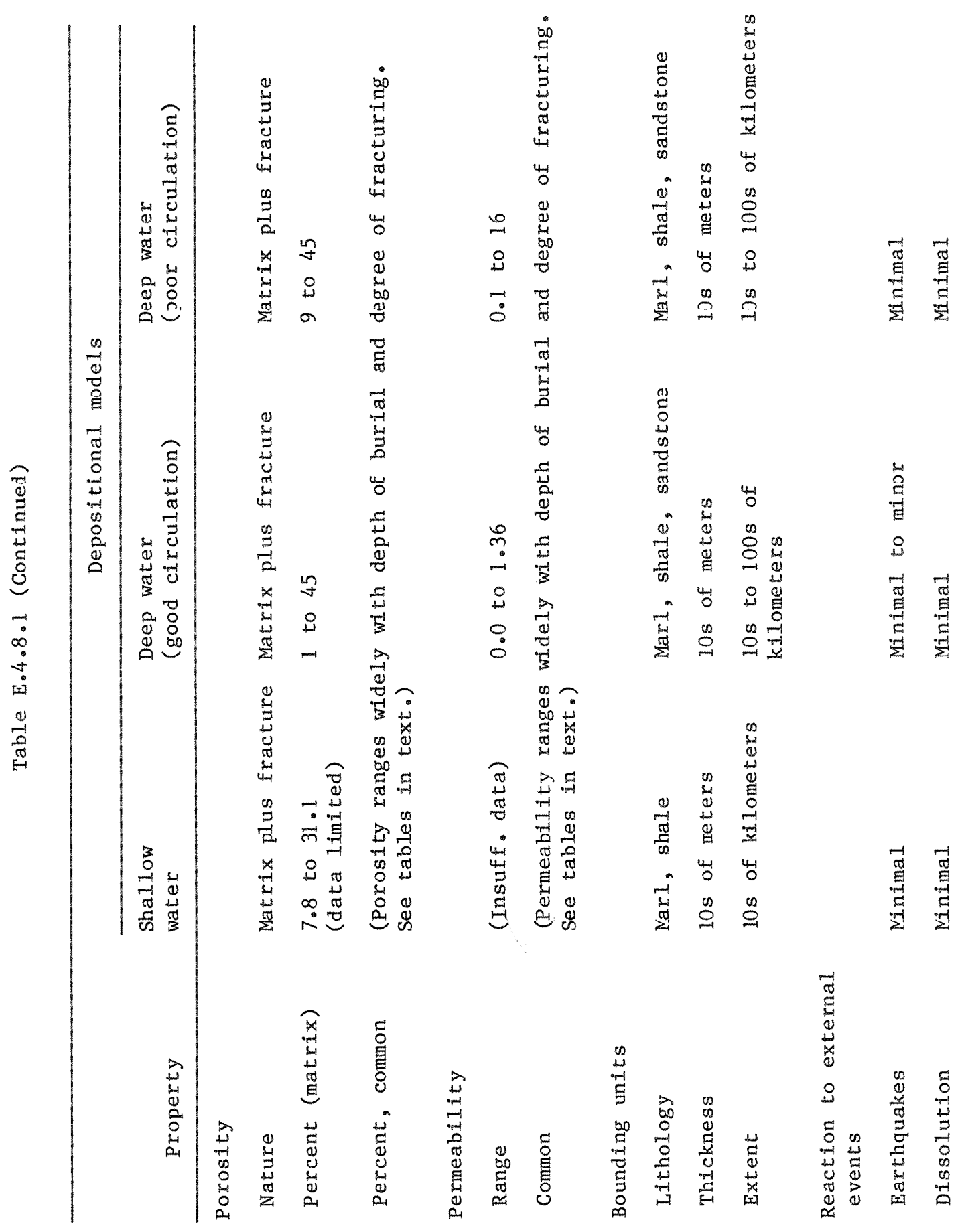




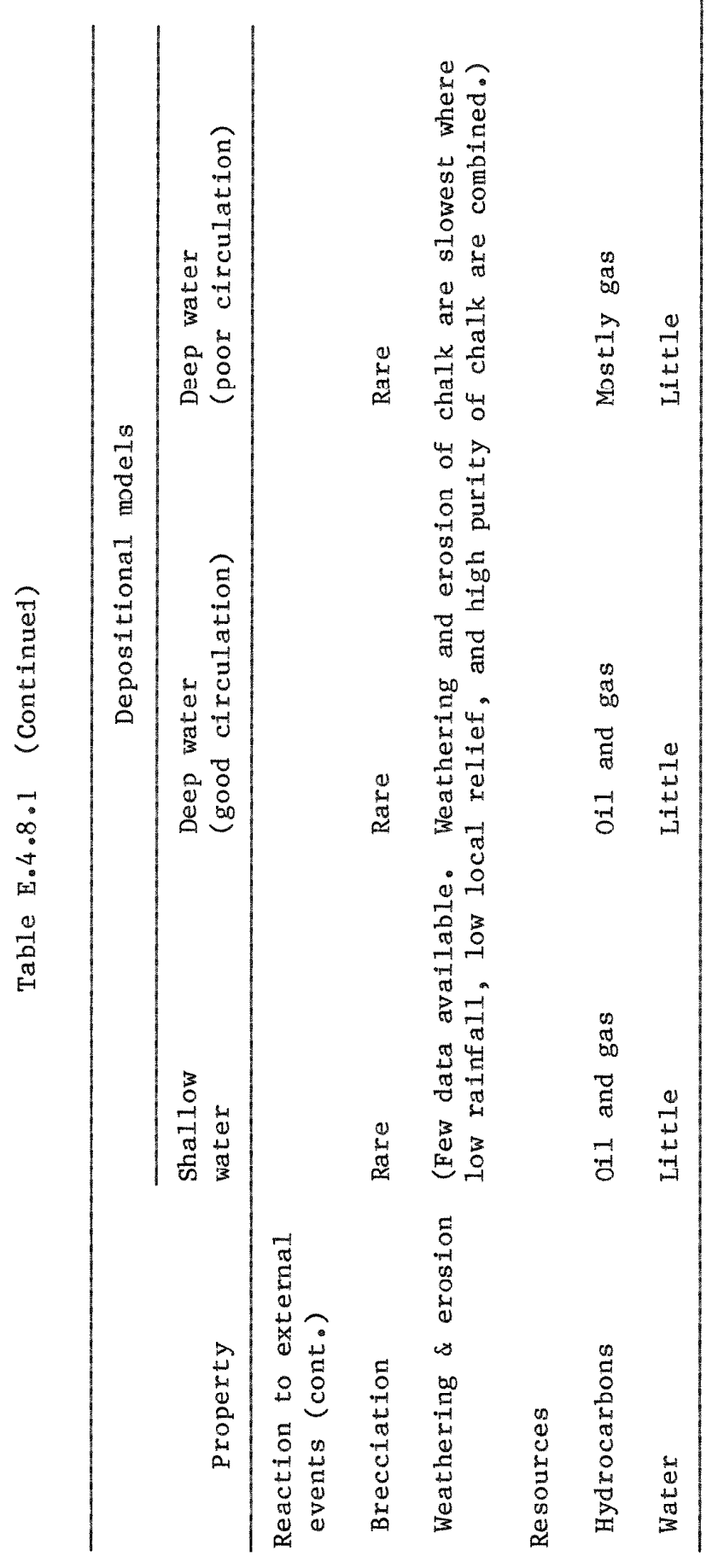




\section{E.4.9 REFERENCES}

ADKINS 1930. W. S. Adkins and M. B. Arick, Geology of Bel1 County, Texas, Bu11. 3016, University of Texas, Austin, 1930.

ALGERMISSEN 1976. S. T. Algermissen and D. M. Perkins, A Probabilistic Estimate of Maximum Acceleration in Rock in the Contiguous United States, Rept. 76-416, U.S. Geol. Surv. Open File, 1976.

ANDERSON 1960. H. V. Anderson, Geology of Sabine Parish, Bul1. 34, Louisiana Geol. Surv., 1960.

ANDERSON 1983. T. H. Anderson and V. A. Schmidt, "The Evolution of Middle America and the Gulf of Mexico-Caribbean Sea Region During Mesozolc Time", Geol. Soc. America Bull., 94, 941-66 (1983).

ARMSTRONG 1968. R. L. Armstrong, "Sevier Orogenic Belt in Nevada and Utah, Geol. Soc. America Bul1. 79, 429-58 (1968).

ASQUITH 1970. D. O. Asquith, "Depositional Topography and Major Marine Environments, Late Cretaceous, Wyoming," Am. Assoc. Petro1. Geol. Bu11., 54 1184-224 (1970).

BASS 1926. N. W. Bass, "Geologic Investigations in Western Kansas", Kan. Geol. Surv. Bul1. 11, $(1,2) 1-83$ (1926).

BECK 1977. J. Beck, A. Schultz, and D. Fitzgerald, "Reservoir Evaluation of Fractured Cretaceous Carbonates in South Texas," Trans. SPWLA Ann. Logging Symp, 18, 1977.

BERGQUIST 1943. H. R. Bergquist and T. E. McCutcheon, 1943, "Clay County (Geology and Tests)," Miss. State Geol. Surv. Bu11. 53, 11-91 (1943).

BOTTJER 1978. D. J. Bottjer, Paleoecology, Ichnology, and Depositional Environments of Upper Cretaceous Chalks (Annona Formation; Chalk Member of Saratoga Formation), South-western Arkansas, Ph.D. dissertation, Indiana University, Bloomington, 1978.

BOTTJER 1981. D. J. Bottjer, "The Arcola Limestone and the Absence of Extensive Hardgrounds in North American Upper Cretaceous Chalks (abstr)," Geol. Soc. America, Prog. with Abstracts, vol. 12, p. 390.

BREZINA 1974. J. L. Brezina, Stratigraphy and Petrology of the Pecan Gap Formation (Taylor Group, Upper Cretaceous) in its Type Area, Master's thesis, University of Texas, Arlington, 1974.

BROMLEY 1975. R. G. Bromley, "Trace Fossils at Omission Surfaces," pp. 399-428 in The Study of Trace Fossils, ed. R. W. Frey, Springer-Verlag, Berlin, 1975.

BRomLEY 1978. R. G. Bromley, "llaxdground Diagenesis," ed. R. W. Fairbridge and J. Bourgeois, Encyclopedia of Earth Sciences, VI. The Encyclopedia of Sedimentology, Hutchinson \& Ross, Stroudsburg, Dowden, p. 397-400. 
BROMLEY 1982. R. G. Bromley and A. S. Gale, "The Lithostratigraphy of the English Chalk Rock," Cretaceous Res. 3, 273-306 (1982).

BROWN 1978. R. O. Brown, "Application of Fracture Identification Logs in Cretaceous of North Louisiana and Mississippi," Trans. Gulf Coast Assoc. Geo1. Soc., 28, 75-91 (1978).

BUKRY 1969. David Bukry, Upper Cretaceous coccoliths from Texas and Europe, Art. 51 (Protista 2), Univ. Kansas Paleont, Contr•, 1969 .

BUNKER 1981. B. J. Bunker, "The Tectonic History of the Transcontinental Arch and Nemaha Uplift and their Relationship to the Cretaceous Rocks of the Central Midcontinent Region," in R. L. Rrenner et a1., Cretaceous Stratigraphy and Sedimentation in Northwest Iowa, Northeast Nebraska, and Southeast South Dakota, Iowa Geol. Surv. Guidebook Ser. No. 4, 1981, p. 1-23.

CALCOTE 1983. W. R. Calcote, R. J. Carroll, G. W. Crosby, et al., "Three-Dimensional Seismic Exploration in the Austin Chalk (Abstr.)," Geophysics 18, 800 (1983).

CARLSTON 1944. C. W. Cariston, Groundwater Resources of the Cretaceous Area of Alabama, Rept. 18, Ala. Geol. Surv. Spec., 1944.

CARMICHAEL 1960. V. O. Carmichael, The Ripley Formation and the Bluffport Member of the Demopolis Chalk in the Buena Vista, Mississippi quadrangle, Master's thesis, Mississippi State University, Mississippi State, 1960 .

CARSON 1961. T. G. Carson, A Sedimentary Study of the Demopolis Chalk in the Artesia, Mississippi Quadrangle, Master's thesis, Mississippi State University, Mississippi State, 1961.

crom 1975. K. W. Clnud, The Diagenesis of the Austin Chalk, Master's thesis, University of Texas, Dallas, 1975.

COBBAN 1972. W. A. Cobban and G. R. Scott, Stratigraphy and ammonite fauna of the Graneros Shale and Greenhorn Limestone near Pueblo, Colorado, Prof. Paper 645, U. S. Geol. Surv•, 1972.

CONDRA 1908. G. F. Condra, Geology and Water Resources of a Portion of the Missouri River Balley in Northeastern Nebraska, Pap. No. 215, U.S. Geol. Survey Water Supply, 1908.

COOK 1972. F.M. Cook and H. E. Cook, "Physical Properties in Synthesis," Initial Reports of Deep-Sea Drilling 9, 945-46 (1972).

COPELAND 1968. Copeland, C. W., Facies changes in the Selma Group in Central and Eastern Alabana, Alabama Geol. Soc., Guidbook, Sixth Ann. Field Trip, 1968 p. 2-26.

CURELAND 1972. C. Wo Copeland, "Upper Grecaceous series lil Cenlral Alabama," in Guidebook for Field Trips, ed. J. S. Tolson, 21 st Ann. Mtg., Southeast. Sect., Geol. Soc., 1972. 
CORBETT 1982. K. P. Corbett, Structural Stratigraphy of the Austin Chalk, Master's thesis, Texas A\&M University, College State, 1982.

DANE 1929. C. H. Dane, Upper Cretaceous Formations of Southwestern Arkansas, Arkansas Geo1. Surv. Bul1. No. 1, 1929.

DANE 1936. C. H. Dane, Pierce, W. G., and J. B. Reeside, Jr., 1936, The Stratigraphy of the Upper Cretaceous Rocks North of the Arkansas River in Eastern Colorado, Prof. Paper 186-K, U.S. Geol. Surv., 1936, pp. 207-32.

DICKINSON 1976. W. R. Dickinson, "Sedimentary Basins Developed During Evolution of Mesozoic-Cenozoic Arc-Trench System in Western North America," Can. Jour. Earth Sci. 13, 1268-87 (1976).

DOLLOFF 1967. J. H. Dolloff, R. A. Rozendal, E. N. Siratovich, F. M。 Swain, and $\mathrm{J}$. Woncti, "Subsurface Upper Crecaceous stratigraph of Southwestern Arkansas," Trans. Gulf Coast Assoc. Geol. Soc. 5, 3-10 (1955).

DOYLE 1955. W. M. Doyle, Jr., "Production and Reservoir Characteristics of the Austin Chalk in South Texas," Trans. Gulf Coast Assoc. Geol. Soc. 5, 3-10 (1955).

DRAVIS 1979. J. J. Dravis, Sedimentology and Diagenesis of the Upper Cretaceous Austin Chalk Formation, South Texas and Northern Mexico, Ph.D. dissertation, Rice University, Houston, Tex., 1979 .

DuRHAM 1957. C. O. Durham, The Austin Group in Central Texas, Ph.D. dissertation, Columbia University, New York, 1957.

EARGLE 1948. D. H. Eargle, The Cretaceous of East-Central Alabama, Southeast Geol. Soc., Guidbook, Sixth Field Trip, 1948, p. 41-75.

EICHER 1969. D. L. Eicher, "Cenomanian and Turonian Planktonic Foraminifera from the Western Interior of the United States," pp. 163-74 in Proc. First Int. Conf. on Planktonic Microfossils, Geneva, 1967, vol. 2, 1969 .

EKDALE 1984. A. A. Ekdale and R. G. Bromley, "Comparative Ichnology of She1f-Sea and Deep-Sea Chalk, Jour. Paleontol. 58, 322-32 (1984).

ESSA/CGS 1969. ESSA/Coast and Geodetic Survey, Seismic-Risk Map of the United States, U.S. Dept. Commerce, 1969.

FEAZEL 1979. C. T. Feaze1, J. Keany, and R. Mo Peterson, "Generation and Occlusion of Porosity in Chalk Reservoirs (Abstr.), Am. Assoc. Petrol. Geologists Bull. 63 , 448-9 (1979).

FISHER 1965. W. L. Fisher, Rock and Mineral Resources of East Texas Rept. of Inv. No. 54, Univ. Texas Bur. Econ. Geology, Austin, 1965.

FISK 1944. II. N. Fisk, Geological Investigations of the Alluvial Valley of the Lower Mississippi River, Miss. River Comm., Vicksburg, 1944. 
FREY 1972. R. W. Frey, Paleoecology and Depositional Environment of Fort Hays Limestone Member, Niobrara Chalk (Upper Cretaceous), West-central Kansas, Art. 58 (Cretaceous 3), Univ. Kansas Paleont. Contr., 1972.

FURSICH 1981. F. T. Fursich, W. J. Kennedy, T. J. Palmer, 1981, "Trace Fossils at a Regional Discontinuity Surface: The Austin-Taylor (Upper Cretaceous) contact in Central Texas," Jour. Paleontol. 55, 537-51 (1981).

GARRISON 1977. R. E. Garrison and Wo Jo Kennedy, "Origin of Solution Seams and Flaser Structure in Upper Cretaceous Chalks of Southern England," Sed. Geol. 19, 107-137 (1977).

GILL 1973. J. R. Gill and W. A. Cobban, Stratigraphy and Geologir History of the Montana Group and Equivalent Rocks, Montana, Wyoming, and North and South Dakota, Prof. Paper 776, U.S. Geol. Survey, 1973.

GRABOWSKI 1981a. G. J. Grabowski, Jr., "Source-Rock Potential of the Austin Chalk, Upper Cretaceous, Southeastern Texas," Trans. Gulf Coast Assoc. Geol. Soc. 31, 105-113.

GRABOWSKI 1981b. G. J. Grabowski, Jr•, Origin, Distribution and Alteration of Organic Matter and Generation and Migration of Hydrocarbons in Austin Chalk, Upper Cretaceous, Southeastern Texas, Ph.D. dissertation, Rice University, Houston, Tex•, 1981.

HAAKANSSON 1974. E. Haakansson, R. Bromley and K. Perch-Nielen, Maastrichtian Chalk of North-West Europe - A Pelagic Shelf Sediment, Spec. Publs. No. 1, Int. Assoc. Sedimentol., 1974, pp. 211-233.

HANCOCK 1975. J. M. Hancock, "The Petrology of the Chalk," Proc. Geolog. Assoc., 86, 499-535 (1975).

HANCOCK 1984. J. M. Hancock, "Cretaceous," in K. W. Glennie, Introduction to the Petroleum Geology of the North Sea, ed. Blackwe11 Sci. Pub1s., Oxford, 1984, pp. 133-50.

HANN 1981. M. L. Hann, Petroleum potential of the Niobrara Formation in Lhe Denver Basin: Colorado and Kansas, Mascer's chesis, Colorado State University, Fort Collins, 1981.

HANSEN 1984. D. S. Hansen, "Aquifers in South-Central South Dakota," Geol. Survey Research, Fiscal Year 1981, Prof. Paper 1275, U.S. Geol. Survey, 1984.

HARVEY 1974. R. D. Harvey, R。 R。 Frost, and J. Thomas, Jr., "Lake Mar1s, Chalks, and Other Carbonate Rocks with High Dissolution Rates in $\mathrm{SO}_{2}$-Scrubbing Liquors," Illinois State Geol. Surv. Env. Geol. Notes, 68 (1974).

HATTIN 1962. D. E. Hattin, Stratigraphy of the Carlile Shale (Upper Cretaceous) in Kansas, Bu11. 156, Kans. Geol. Surv., 1962. 
HATTIN 1964. D. E. Hattin, 1964, "Cyclic Sedimentation in the Colorado Group of West-Central Kansas," Kans, Geol. Surv. Bu11. 169, 205-217.

HATTIN 1971. D. E. Hattin, "Widespread, Synchronous1y Deposited, Burrow-Mottled Limestone Beds in Greenhorn Limestone (Upper

Cretaceous) of Kansas and Southeastern Colorado," Am. Assoc. Petrol. Geologists Bul1. 55, 214-31 (1971).

HATTIN 1975. D. E. Hattin, Stratigraphy and Depositional Environment of Greenhorn Limestone (Upper Cretaceous) of Kansas, Bul1. 209, Kansas Geol. Surv., 1975.

HATTIN 1979. D. E. Hattin, "Regional Stratigraphy of Limestone Marker Beds in Bridge Creek Member, Greenhorn Limestone (Upper Cretaceous), Western Interior United States," (abstr.) Am. Assoc. Petrol. Geol. Bul1. 63, 464 (1979).

HATTIN 1982. D. E. Hattin, Stratigraphy and Depositional Environment of Smoky Hil1 Chalk Member, Noibrara Chalk (Upper Cretaceous) of the Type Area, Western Kansas, Bul1. 225, Kans. Geol. Surv. 1982.

HATTIN 1985. D. E. Hattin, "Western Interior of North America," pp. 13-18 R. A. Reyment and Bengston, compilers, in Mid-Cretaceous Events: Report on Results Obtained 1974-1983 by IGCP Project No. 58, Palaeont. Inst. Univ. Uppsala, Spec. Vol. 5, 1985.

HELWIG 1975. J. Hlewig, "Tectonic Evolution of the Southern Continental Margin of North America from a Paleozoic Perspective, "In The Ocean Basins and Margins, vol. 3, The Gulf of Mexico and the Caribbean, eds. A. E. M. Nairu and F. G. Stehli, Plenum Press, New York, p. 243-55.

HOLDITCH 1982. S. A. Holditch and D. E. Lancaster, 1982, Economics of Austin Chalk production: 0il \& Gas J. 80 (32) 183-89 (1982).

HODSON 1965. W. G. Hodson, Geology and Groundwater Resources of Trego County, Kansas, Bul1. 174, Kans. Geol. Surv. 1965.

HUSHES 1958. R. J. Hughes, Jr., Kemper County Geology, Bul1. 84, Mississippi State Geol. Surv. 274 p.

JACKSON 1981. M. P. A. Jackson, Tectonic Environment During Early Filling of the East Texas Basin, Circular 81-7, University of Texas Bureau of Economic Geology, Austin, 1981 .

JACKSON 1983. M. P. A. Jackson and S. J. Seni, "Geometry and Evolution of Salt Structures in a Marginal Rift Basin of the Gulf of Mexico, East Texas," Geology 11, 131-35 (1983).

JEANS 1968. C. V. Jeans, "The Origin of the Montmorillonite of the European Chalk with Special Reference to the Lower Chalk of England," Clay Min., 311-29.

JOHNSON 1958. C. R. Johnson, Geology and Groundwater Resources of Logan County, Kansas, Bu11. 129, Kans. Geol. Surv•, 1958. 
JONES 1967. D. L. Jones, "The Selma Group in West Alabama," in Geology of the Coastal Plain of Alabama, ed. D. L. Jones, Geo1. Soc. America, Guidbook, 80th Ann. Mtg., 1967, pp. 26-32.

JORGENSEN 1983. No. 0. Jorgensen, "Dolomitization in Chalk from the North Sea Central Graben," Jour. Sed. Petrol., 53, 557-64 (1983).

KGS 1978. Kansas Geological Survey, Open File Report, Amoco-197, 1978.

KAUFFMAN 1967. E. G. Kauffman, "Coloradoan Macroinvertebrate Assemblages, Central Western Interior, United States," pp. 67-143 in

Paleoenvironments of the Cretaceous Seaway - A Symposium, Colorado Schont of Mines, Golden, May 1967.

KAUFFMAN 1977. E. G. Kauffman, "Geology and Biological Overview: Western Interior Cretaceous basin," ed. E. G. Kauffman, in Cretaceous Facies, Faunas, and Yaleoenvironments Across the Western Interior Basin, Mountain Geol., 14, 75-99 (1977).

KFADY 1972. D. M. Keady, Geologic Study along Highway 45 from Tennessee Line to Meridian, Mississippi, Bul1. 94, Mississippi Geol. Surv., 1972.

KENNEDY 1974. W. J. Kennedy and P. Juignet, "Carbonate Banks and Slump Beds in the Upper Cretaceous (Upper Turonian-Santonian) of Haute Normandie, France," Sedimento1. 21, 1-42 (1974).

KENNEDY 1975. W. J. Kennedy and R. E. Garrison, "Morphology and Genesis of Nodular Chalks and Hardgrounds in the Upper Cretaceous of Southern England," Sedimento1. 22, 311-86 (1975).

KIDWELL 1951. A. L. Kidwe11, "Mesozoic Igneous Activity in the Northern Gulf Coastal Plan," Trans. Gulf Coast Assoc. Geol. Soc. 1, 182-199 (1951).

KNOWLES 1963. D. B. Knowles, H. L. Reade, Jr., and J. C. Scott, 1963, Geology and Groundwater Resources of Montgomery County, Alabama, with Special Reference to the Montgomery Area, Water-Supply Paper 1606, U.S. Geol. Survey., 1963.

KURIE 1956. A. E. Kurie, Fractures in the Austin Group, Southern Travis County. Texas, Master's thesis, University of Texas, Austin, 1956.

LAFERIERE 1978. A. P. Laferiere, personal communication, 1978.

LAFERIERE 1984. A. P. Laferiere, personal communication, 1984.

LOCKRIDGE 1978. J. P. Lockridge and P. A. Scholle, "Niobrara Gas in Eastern Colorado and Northwestern Kansas," pp. 35-49 in Energy Resources of the Denver Basin, eds. J. D. Pruitt and P. E. Coffin, Rocky Mtn. Assoc. Geol. Fall Field Conference, Colorado Springs, Col., October 1978.

MARTIN 1954. J. L. Martin, L. W. Hough, D. L. Raggio, and A. E. Sandberg, Geology of Webster Parish, Bu11. No. 29, Louisiana Geo1. Surv., 1954. 
MATTER 1975. A. Matter, R. G. Douglas and K. Perch-Nielson, "Fossil Preservation, Geochemistry, and Diagenesis of Pelagic Carbonates from Shatsky Rise, Northwest Pacific," Init. Repts. Deep Sea Drilling Proj. 32, 891-907 (1975).

McCUTCHEON 1943. T. E. McCutcheon, "Tests," in F. E. Vestal, and T. E. McCutcheon, Monroe County Mineral Resources, Mississippi State Geol. Surv. Bu11. 57, 176-218 (1943)。

McGOOKEY 1972. D. P. McGookey et al. "Cretaceous System," in Geologic Atlas of the Rocky Mountain Region, Rocky Mtn. Assoc. Geologists, Denver, Co1., 1972, pp. 190-228.

McLAUGHLIN 1954. T. G. McLaughlin, Geology and Ground-water Resources of Baca County, Colorado, Supply Paper 1256, U.S. Geol. Survey Water, 1954.

MCMEEN 1964. J. A. McMeen, Groundwater Supply for the City of Marion, Spec. Rept. 27, South Dakota Geol. Surv•, 1964.

McNULTY 1981. C. L. McNulty, J. L. Brezina, W. C. Dawson, and F. W. Maluf, "Emendation of the Pecan Gap Chalk (Campanian) in Northeast

Texas," Trans. Gulf Coast Assoc. Geol. Soc. 31, 353-367.

MELLEN 1958. F. F. Mellen, "Cretaceous shelf sediments of Mississippi," Miss. State Geol. Surv. Bul1 85, 112 (1958)。

MEREWETHER 1981. E. A. Merewether and W. A. Cobban, "Mid-Cretaceous Formations in Eastern South Dakota and Adjoining Areas--Stratigraphic, Paleontologic, and Structural Interpretations," in Cretaceous Stratigraphy and Sedimentation in Northwest Iowa, Northeast Nebraska, and Southeast South Dakota, Iowa Geol. Survey Guidebook Series No. 4, 1981, pp. 43-56.

MERRIAM 1957. D. F. Merriam, Subsurface Correlation and Stratigraphic Relation of Rocks of Mesozoic Age in Kansas, Oil and Gas Invest. No. 14, Kans. Geol. Surv., 1957.

MILLER 1978. M. A. Miller, Stratigraphic Relations of the Austin Chalk (Upper Cretaceous) in Central Texas, Master's Thesis, Baylor University, Whan, Tex, 1978.

MIMRAN 1978. Y. Mimran, "The Induration of Upper Cretaceous Yorkshire and Irish Chalks," Sed.Geol. 20, 141-64 (1978).

MONROE 1941. W. H. Monroe, Notes on Deposits of Selma and Ripley Age in Alabama, Bul1. 48, Alabama Geol. Surv., 1971.

MOORE 1971. D. B. Moore, Subsurface Geology of Southwest Alabama, Bu11. 99, Alabama Geo1. Survey, 1971. 
MUEHLBERGER 1962. W. R. Muehlberger, P. S. Calabaugh, and M. L. Hightower, "Palestine and Grand Saline Salt Domes, Eastern Texas," in Geology of the GulfCoast and Central Texas and Guidebook of Excursions, eds. E. H. Rainwater and R. P. Zingula, Houston Geol. Soc. Guidebook, 1962 Ann. Mtg, Geol. Soc. American, pp. 226-77.

MURRAY 1948. G. E. Murray, Geology of DeSoto and Red River Parishers, Bu11. 25, Louisiana Geo1. Survey, 1948.

MURRAY 1961. G. E. Murray, Geology of the Atlantic and Gulf Coastal Province of North America, Harper \& Brothers, New York, 1961.

NEUGEBAUER 1973. J. Neugebauer, "The Diagenetic Problem of Chalk, " $\mathrm{N}_{\text {. }}$ Jb. Geol. u. Palaontologie Abh. 150, 182-206 (1973).

NEUGEBAUER 1974. J. Neugebauer, "Some Aspects of Cementation of Chalk," Spec. Pub1s. Int. Assoc. Sedimentol. 1, 14976 (1974).

NEWMAN 1975. S. M. Newman, A Paleoenvironmental Analysis of the Upper Demopolis and Lower Ripley Formations in the Rock Hill Area, Oktibbeha County, Mississippi, Master's thesis, Mississippi State University, Mississippi State, 1975.

NEWTON 1961. J. G. Newton, H. Sutcliffe, Jr., and P. E. LaMoreaux, Geology and Ground-water Resources of Marengo County, Alabama, County Rept. 5, Alabama Geol. Surv., 1961.

PETERSON 1972. J. A. Peterson, "Jurassic System," in Geologic Atlas of the Rocky Mountain Region, Rocky Mtn. Assoc. Geol., Denver, Colo., 1972, pp. 177-89.

PIKE 1947. W. S. Pike, Jr., "Intertonguing Marine and Nonmarine Upper Cretaceous Deposits of New Mexico, Arizona, and Southwestern Colorado," Mem. 24, Geol. Soc. America, 1947.

POLLASTRO 1981. R. M. Pollastro, "Authigenic Kaolinite and Associated Pyrite in Chalk of the Cretaceous Niobrara Formation, Eastern Colorado," Jour. Scd. Pctrol. 51(2), 553-62 (1981).

PRATT 1984. L. M. Pratt, "Influence of Paleoenvironmental Factors on Preservation of Organic Matter in Middle Cretaceous Greenhorn Formation, Pueb1o, Colorado," Am. Assoc. Petrol. Geolog. Bul1. 68, 1146-59 (1984).

REESIDE 1944. J. B. Reeside, Jr., Maps Showing Thickness and Genera1 Character of the Cretaceous Deposits in the Western Interior of the United States, Prelim. Map No. 10, U.S. Geol. Survey 0il and Gas Inv., 1944.

REESIDE 1957. J. B. Reeside, Jr., "Paleoecology of the Cretaceous Seas of the Western Interior of the United States," Geol. Soc. Amer. Mem. $67(2) 505-41$ (1957). 
REINHARDT 1980a. J. Reinhardt, Sedimentary Cycles in Upper Cretaceous Martinal Marine Deposits, Eastern Gulf Coastal P1ain (Abstr.): Geol. Soc. America Abstr. with Programs, vol. 12, 1980, p. 79.

REINHARDT 1980b. J. Reinhardt, "Upper Cretaceous Stratigraphy and Depositional Environments," in Upper Cretaceous and Lower Tertiary Geology of the Chattachoochee River Valley, Western Georgia and Eastern Alabama, eds. J. Reinhardt and T. G. Gibson, Geol. Soc. America, Ann. Mtg. Guidebook, Field Trip No. 20, 1980, pp. 386 92,

RICE 1983. D. D. Rice, G. W. Shurr, "Patterns of Sedimentation and Paleogeography Across the Western Interior Seaway During Time of Deposition of UPper Cretaceous EAgle Sandstone and Equivalent Rocks, Northern Great Plains, Mesozoic Paleogeography of the West-Central United States, eds. M. W. Reynolds and E. D. Dolly, Rocky Mtn. Sec., Soc. Econ. Paleont. Mineral., 1983, pp. 337-58.

RMAG no date. Rocky Mountay Assoc. Geologists, Subsurface Cross Sections of Colorado, Spec. Pub1. No. 2, Rocky Mtn. Assoc. Geologists, 1978.

ROBERIS 1982. B. H. Robercs, "Geology and I1norlagellate Palynology of the Upper Mooreville Chalk and Basal Demopolis Chalk (Upper Cretaceous) of Eastern Mississippi and West-Central Alabama (abstr.)," Palynology 6. $290(1982)$.

ROGERS 1963. C. W. Rogers, Structural Geology of the Round Rock Quadrangle, Williamson County, Texas, Master's thesis, University of Texas, Austin, 1963.

ROTH 1975. P. H. Roth, S. W. Wise, Jr, and H. Thierstein, Early Chalk Diagenesis and Lithification: Sedimentological Applications of Paleontological Approaches, Ninth Int. Sedimentological Congress, Extracts of Pub1., 1975, pp. 187-92.

ROTHROCK 1944. E. P. Rochrock, A Geology of Souch Dakoca, Bul1. No. 15, South Dakota State Geol. Surv., 1944.

ROUSE 1944. J. T. Rouse, "Correlation of the Pecan Gap. Wolfe City and Annona Formations in East Texas," Am. Assoc. Petro1. Geo1. Bu11. 28, $522-30(1944)$

RUBEY 1925. W. W. Rubey and N. Wo Brass, The Geology of Russell Counly, Kansas, Bul1. 10(1), Kans. Geol. Surv., $19 \overline{25 .}$

RUNNELLS 1949. R. T. Runne11s and I. M. Dubins, Chemica1 and Petrographic Studies of the Fort Hays Chalk, Bull. 82, pt. 1, Kans. Geo1. Surv., 1949.

RUSSELL 1967. E. E. Russe11, "The Selma Equivalents in Mississippi, Tennessee and Kentucky," in Geology of the Coastal Plain of Alabama, ed. D. E. Jones, Geo1. Soc. America, Guidebook, 80th Ann. Mtg., 1967, pp. 12-17. 
RUSSELL 1975. E. E. Russe11, Stratigraphy of the Outcropping Upper Cretaceous in Western Tennessee, Bull. 75, Tenn. Div. of Geo1., 1975, Pp. A1-A65.

RUSSELL 1982. E. E. Russe11 and D. M. Keady, "Notes on Upper Cretaceous Lithostratigraphy of the Eastern Mississippi Embayment," in Upper Cretaceous in the Lower Mississippi Embayment of Tennessee and Mississippi: Lithostratigraphy and Diostratigraphy, eds. E. E. Russell, D. M. Keady, E. A. Mancini, and C. E. Smith, Geol. Soc. America Guidebook, 1982 Ann. Met。, 1982, pp. 1-14.

RUSSELL 1929a. W. L. Russe11, "Stratigraphy and Structure of the Smoky Hi11 Chalk in Western Kansas," Am.Assoc. Petrol. Geol. Bul1. 13 595-604 (1929).

RUSSELL 1929b. W. L. Russe11, "Local Subsidence in Western Kansas," Am. Assoc. Petrol. Geol. Bull. 13, 605-609 (1929).

SCHAFER 1980. J. N. Schafer, "A Practical Method of Well Evaluation and Acreage Development for the Naturally Fractured Austin Chalk Formation, pp. 10-24 in Trans. SPWLA Twentieth Ann. Logging Symp., 1980 .

SCHLANGER 1974. S. O. Schlanger and R. Go Douglas, The Pelagic Ooze-Chalk-Limestone Trausition and Its Implications for Marine Stratigraphy, Spec. Publs. No. 1, Int. Assoc. Sedimentol., 1974, pp. $117-48$.

SCHNEEFLOCK 1972. R. D. Schneeflock, Jr., Possible Origins of the Livingston Fault Zone, Master's thesis, University of Alabama, Tuscaloosa, 1972.

SCHOCH 1918. E. P. Schoch, Chemical Analyses of Texas Rocks and Minera1s, Bu11. No. 1814, University of Texas, Austin, 1918.

SCHOLLE 1974. P. A. Scholle, Diagenesis of Upper Cretaceous Chalks from England, Northern Ireland, and the North Sea, Spec. Publs. No. 1, Int. Assoc. Sedimento1., 1974, pp. 177-210.

SCHOLLE 1975. P. A. Scholle, "Chalk Diagenesis," in J. M. Hancock and P. A. Scholle, "Chalk of the North Sea," in Petroleum and the Continental Shelf of North-West Europe, vol. 1. Geology, ed. A. W. Woodland, Wiley, New York, 1975, pp. 413-25.

SCHOLLE 1977a. P. A. Scholle, "Chalk Diagenesis and Its Relation to Petroleum Exploration: Oil from Chalks, a Modern Miracle?," Am. Assoc. Petrol. Geol. Bul1. 61, 982-1009 (1977).

SCHOLLE 1977b. P. A. Scholle, Current 011 and Gas Production from North American Upper Cretaceous Chalks, Circular 767, Geol. Surv., 1977.

SCHOLLE 1977c. P. A. Scholle and K. Cloud, "Diagenetic Patterns of the Austin Group and Theit Control of Petroleun Potential," in Grelaceous Carbonates of Texas and Mexico: Aplications to Surface Exploration, Rept. Inv. No. 89, eds. D. G. Bebout and R. G. Loucks, Univ. Texas Bureau Econ. Geol., 1977 pp.257-59. 
SCHOLLE 1979. P. A. Scholle, "Porosity Relations in Chalk Reservoirs," (abstr.), Am. Assoc. Petrol. Geol. Bul1. 63, 522 (1979).

SCHOLle 1983. P. A. Scholle, M. A. Arthur, and A. A. Ekdale, "Pelagic Environment," in Mem. 33, eds. P. A. Scholk, D. G. Bebout, and C. H. Moore, Am. Assoc. Petro1. Geologists pp. 620-91, 1983.

SCOTT 1964. G. R. Scott and W. A. Cobban, Stratigraphy of the Niobrara Formation at Pueblo, Colorado, Prof. Paper 454-L, U.S. Geol. Survey, 1964.

SCOTT 1977. R. J. Scott, "The Austin Chalk-Buda Trend of South Texas," Trans. Gulf Coast ASsoc. Geo1. Soc., 27 164-68 (1977).

SCOTT 1977. R. W. Scott, personal communication, 1977.

SEEWAid 1960. Ko O. Seewald, "Stratigraphy of the Austin Chalk, McLeman County, Texas," Cretaceous Stratigraphy of the Grand and Black Prairies, East-Central Texas, Baylor Geol. Soc., Field Conf. Guidebook, April 1960, pp. 110-17.

SELF 1976. "D. M. Self, "Faults in the Selma Group (Late Cretaceous) of West-Central Alabama," in Tertiary Faults in Southwestern Alabama, eds. C. W. Copeland, J. G. Newton, and D. Mo Self, Alabama Geol. Soc. Guidebook, 14th Ann. Field Trip, 1976, pp. 1-15.

SENI 1983. S. J. Sent and M. P. A. Jackson, "Evolution of Salt Structures, East Texas Diapir Province; Part 1: Sedimentary Record of Halokinesis," Am.Assoc. Petrol.Geol. Bul1. 67, 1219-44 (1983).

SENI 1981. S. J. Seni and C. W. Kreitler, Evolution of the East Texas Basin, Circ. 81-7, Univ. Texas Bureau Econ. Geolog, 1981, pp. 7-11.

SHAFER 1966. G. H. Schafer, Groundwater Resources of Guadalupe County, Texas, Rept. 19, Texas Water Div. Board, 1966.

SGS 1965. Shreveport Geological Society, Cretaceous of Southwest Arkansaa, Shreveport Geol. Soc. Guidebook, 1965 Tield Trip, 1965.

SHURR 1981a. G. W. Shurr, "Cretaceous Sea Cliffs and Structural Blocks on the Flanks of the Sioux Ridge, South Dakota and Minnesota," in R. L. Brenner et al., Cretaceous Stratigraphy and Sedimentation in Northwest Iowa, Northeast Nebraska, and Southeast South Dakota, Iowa Geol. Survey Guidebook Ser. No. 4, 1981, pp. 25-41.

SHURR 1981b. G. W. Shurr and T. A. Gognat, "Paleotectonism Reflected in the Niobrara of the Northern Great Plains (abstr.)," Geol. Soc. America Prog. with Abstracts, 13, 226 (1981).

SMAGALA 1980. T. Smagala and M. B. Cooper, "Cretaceous Niobrara Gas Play (abstr.)," Am. Assoc. Petrol. Geol. Bul1. 64, 786 (1980).

SMITH 1978. C. I. Smith, personal communication, 1978. 
SMITH 1944. H. T. U. Smith, Erosional Modification of Landmarks in Western Kansas During Historic Time, vol. 30(1), Univ. Kansas Sci. Bull., 1944, pp. 3-13.

SNYDER 1977. R. H. Snyder and M. Craft, "Evaluation of Austin and Buda Formations from Core and Fracture Analysis," Trans. Gulf Coast Assoc. Geol. Soc. 27, 376-85 (1977).

SOHL 1980. N. F. Sohl and C. C. Smith, "Notes on Cretaceous Biostratigraphy," in Upper Cretaceous and Lower Tertiary Geology of the Chattahoochee River Valley, Western Georgia and Eastern Alabama, eds. J. Reinhardt and T. G. Gibson, Geol. Soc. America, Ann. Mtg. Guidebook, Field Trip No. 20, 1980, pp. 392-402.

STACH 1976. R. L. Stach, Mineralogy and Stratigraphy of the Niobrara Formation, South Dakota, Master's thesis, University of South Dakota, Vermilition, 1976.

STAPP 1978. W. L. Stapp, "What to Look for When Exploring the Austin Chalk," World Oi1 186(2), 55-60 (1978).

STEECE 1957. F. V. Steece, Geology of the Canton Quadrangle, South Dakota-Iowa, Master's thesis, University of South Dakota, Vermilion, 1957.

STEHLI 1964. F. G. Stehli and W. B. Creath, "Foraminiferal Ratios and Regional Environments," Am. Assoc. Petrol. Geol. Bull. 48, 1810-27 (1964).

STEHLI 1972. F. G. Stehli, W. G. Creath, C. F. Upshaw, and J. M. Forgotson, "Depositional History of Gulfian Cretaceous of East Texas Embayment," Am. Assoc. Petrol. Geol. Bul1. 56, 38-67 (1972).

STENZEL 1938. H. B. Stenzel, The Geology of Leon County, Texas, Pub1. No. 3818, University of Texas, Austin, 1938.

STEPHENSON 1929. L. W. Stephenson, "Unconformities in Upper Cretaceous Series of Texas," Am. Assoc. Petrol. Geol. Bul1. 13, 1323-34 (1929).

STEPHENSON 1937. L. W. Stephenson, Stratigraphic Relations of the Austin, Taylor, and Equivalent Formations in Texas, Prof. Paper 186-G, U.S. Geol. Surv. 1932, 133-46.

STEPHENSON 1940. L. W. Stephenson and W. H. Monroe, The Upper Cretaceous Deposits, Bull. 40, Mississippi State Geol. Surv•, $19 \overline{40 .}$

SURLYK 1980. F. Surlyk, Upper Cretaceous and Danian Outcrops in Scania and East Denmark, 26th Int. Geol. Congress Guidebook, Excursion 069A, Paris, France, 1980.

SURLYK 1974. F. Surlyk and T. Birkelund, "An Integrated Stratigraphic Study of Fossil Assemblages from the Mastrichtian White Chalk of Northwestern Europe," in Concepts and Methods of Biostratigraphy. eds. E. G. Kauffman and J. E. Hazel, Dowden, Hutchinson \& Ross, Strausburg, $\mathrm{Pa} \bullet, 1974$, pp. 257-82. 
TINSMAN 1976. C. Tinsman, personal communication, 1976.

TOURTELOT 1968. H. A. Tourtelot and W. A. Cobban, Stratigraphic Significance and Petrology of Phosphate Nodules at Base of Niobrara Formation, East Flank of Black Hills, South Dakota, Prof Paper 594-L, U.S. Geol. Surv., 1968.

VESTAL 1943. F. E. Vestal, "Geology," in F. E. Vestal and T. E. McCutcheon, Monroe County Mineral Resources, Bu11. 57, Mississippi State Geol. Surv., $1943 \mathrm{pp} \cdot 11-175$.

VESTAL 1946. F. E. Vestal, Lee County Mineral Resources, Bu11. 63, Mississippi State Geo1. Surv., 1946.

WAITE 1947. H. A. Waite, "Geology and Groundwater Resources of Scott County, Kansas," Kansas Geol. Sur. Bu11. 66, 1947.

WATNEY 1984. W. L. Watney, personal communication, 1984.

WEEKS, 1945. A. W. Weeks, "Balcones, Luling, and Mexia Fault Zones in Texas," Am. Assoc. Petrol. Geol. Bul1. 29, 1733-37 (1945).

WEIMER 1960. R. J. Weimer, "Upper Cretaceous Stratigraphy, Rocky Mountain Area," An. Assoc. Petrol. Geol. Bul1. 44, 1-20 (1960)。

WEIMER 1970. R. J. Weimer, "Rates of Deltaic Sedimentation and Intrabasin Deformation, Upper Cretaceous of Rocky Mountain Region," in De1taic Sedimentation, Modern and Ancient, ed. J. P. Mortan, Spec. Publ. No. 15, Soc. Econ. Paleont. Minera1. 1970, pp. 270-92.

WETMER 1978. R. J. Weimer, "Influence of Transcontinental Arch on Cretaceous Marine Sedimentation: A Preliminary Report," pp. 211-222 in Proceedings of the 1978 Symposium of Rocky Mtn. Assoc. Geolog., Colorado Springs, Col. 1978.

WEST 1972. G. West and M. J. Dumbleton, "Some Observations on Swallow Holes and Mines in the Chalk," Quart. J. Eng. Geol. 5, 171-77 (1972).

WHTTE 1960. R. H. White, Jr., Petrology and Depositional Pattern in the Upper Cretaceous Austin Group, Pilot Knob Area, Travis County, Texas, Master's thesis, University of Texas, Austin, 1960.

WILSON 1976. G. V. Wilson, J. T. Kidd, and S. W. Shannon, "Relationships of Surface and subsurface Faults in Choctaw and Clarke Counties, Alabama," in Cretaceous and Tertiary Faults in Southwestern Alabama, eds. C. W. Copeland, J. G. Newton, and D. M. Self, Alabama Geol. Soc. Guidebook, 14th Ann. Field. Conf., 1976, pp. 58-79.

WISE 1971. S. W. Wise, Jr., and K. J. Hsu, "Genesis and Lithification of a Deep Sea Chalk," Eclog. Geol. Helvetiae, 64 273-78 (1971). 
WITZRE 1983. B. J. Witzke, G. A. Ludvigson, J. R. Poppe, and R. L. Ravn, "Cretaceous Paleogeography Along the eastern Margin of the Western Interior Seaway, Iowa, Southern Minnesota, and Eastern Nebraska and South Dakota," in Mesozoic Paleogeography of the West-Central United States, eds. M. W. Reynolds and E. D. Dolly, Rocky Mtn. Sec., Soc. Econ. Paleont. Mineral, 1983, pp. 225-52.

WOOD 1981. D. H. Wood, Structural Effects of Salt Movement in the East Texas Basin, Circ. 81-87, University of Texas Bureau Econ. Geol., 1981, pp. 12-27.

WOOD 1982. D. H. Wood and A. B. Giles, Hydrocarbon Accumulation Patterns in the East Texas Sale Dome Province, Circ. 82-86. University of Texas Bureau Econ. Geol., 1982.

WOODS 1963. D. J. Woods, "Fractured Chalk Oil Reservoirs, Sabine Parish, Louisiana," Trans. GuIf CuasL Assuc. Geul. Suc. 13, 127-38 (1963).

WOOLDRIDGE 1937. S. W. Wooldridge and J. F. Kirkaldy, "The Geology of the Mimms Valley," Proc. Geol. Assoc. 48, 307-14 (1937).

YOUNG 1975. K. Young, "Pilot Knob, a Marine Cretaceous Volcano," in Stratigraphy of the Austin Chalk in the Vicinity of Pilot Knob, eds. K. Young, D. S. Barker, and E. C. Jonas, Geol. Soc. America, South-Central Section, 9th Ann. Mtg., Field Trip Guidebook, 1975, pp. $8-20$.

ZIEGLER 1975. W. H. Ziegler, "Outline of the Geological History of the North Sea," in Petroleum and the Continental Shelf of North-West Europe, vol. 1, Geology, ed. A. W. Woodland, Wiley \& Sons, New York-Toronto, 1975 , pp. 131-48. 
APPENDIX E.5

GEOLOGIC CHARACTERIZATION OF CARBONATE ROCKS

KENNETH R. WALKER

306 KINGSTON COURT

KNOXVILLE, TENNESSEE 37919 
This page intentionally left blank 
E.5.1 DEFINTTION OF ROCK TYPE. . .............. 497

E.5.1.1 CARBONATE ROCK TYPES............ 497

E.5.1.2 CLASSIFICATIONS .............. 497

E.5.1.3 LITERATURE USED IN THIS STUDY ........ 498

E.5.2 GEOLOGIC ENVIRONMENT OF DEPOSITION . . . . . . . . 502

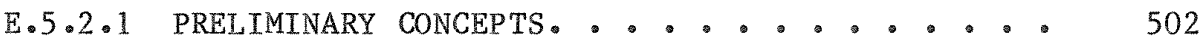

E.5.2.2 MODELS OF TECTONIC FRAMEWORK......... 506

E.5.2.3 DEPOSITIONAL-ENVIRONMENTAL MODELS . . . . . 507

E.5.3 GEOMETRY AND DIMENSIONS OF CARBONATE DEPOSTTS. . . . 515

E.5.3.1 DIMENSIONS AND GEOGRAPHIC DISTRIBUTION OF SEQITFNCFS. ................. 515

E.5.3.2 DIMENSIONS OF UNITS WITHIN SEQUENCES. . . $\quad 515$

E.5.3.3 DIMENSIONS OF INDIVIDUAL BEDS WITHIN UNITS. • 518

世. .4 CHAKACILKLSILS UK CARBUNATL DEPUSLIS. ........

E.5.4.1 LITHOLOGY OF CARBONATE ROCKS. . . . . . 520

E.5.4.1.1 Composition and Texture...... 520

E.5.4.1.2 Expected Lateral and Vertical

Homogeneity of Lithologies . . . 523

E.5.4.2 BEDDING AND PRIMARY STRUCTURES. . . . . 524

E.5.4.3 NATURE OF NONCARBONATE INTERBEDS. . . . . . 524

E.5.4.4 SECONDARY STRUCTURES. . . . . . . . . . 525

E.5.4.5 POROSITY AND PERMEABILITY PATTERNS. . . . . 526

E.5.5 BOUNDING ROCK TYPES................... 532

E.5.6 REACTION TO EXTERNAL EVENTS. . . . . . ....... 533

E.5.6.1 TECTONIC EVENTS ............... 533

E.5.5.2 UISSULUTTUN .................. 533

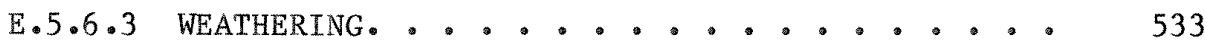

E.5.7 RESOURCES. . .................... . 534

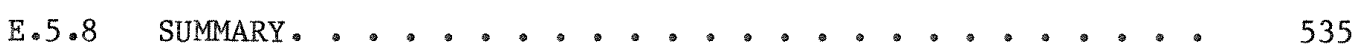

E.5.9 REFERENCES ....................... 536

E.5.10 GLOSSARY ...................... 539 
This page intentionally left blank 


\section{E.5.1 DEFINITION OF ROCK TYPE}

\section{E.5.1.1 CARBONATE ROCK TYPES}

The purpose of this report is to examine carbonate rock geologic properties in order to provide a conceptual and data basis for evaluation of this rock type as a potential host for a high-level waste repository. This report includes discussion of limestone and dolostone lithologies. A limestone is a sedimentary rock that consists predominantly of the mineral calcite $\left(\mathrm{CaCO}_{3}\right)$, and a dolostone consists predominantly of the mineral dolomite $\left[\mathrm{CaMg}\left(\mathrm{CO}_{3}\right)_{2}\right]$. These two sedimentary rock types taken together compose the category called carbonate rocks. Although the two rock types are usually deposited in adjacent environments, of ten are interlayered on all scales, and are chemically related, there are fundamental differences between them in terms of their properties. These ditterences are highlighted where appropriate throughout this report.

Theoretically, admixtures should occur between limestone or dolostone and the nther types of land-derived (terrigennus) sedimentary rock materials (e.g., quartz sand, clay minerals, or other products of rock weathering), but in fact carbonate rocks often tend to occur as rather pure end members with low percentages ( $<20$ vol \%) of admixed "impurities." The reason for this usual purity is simple: dolostone is a product of the alteration of limestones, and limestones are predominantly composed of skeletal material from marine organisms. Organisms are sparse in marine environments with turbid water, and when very much terrigenous material is being deposited, the water is usually turbid. So, although terrigenous rocks (sandstones and shales) and carbonate rocks are deposited at comparable rates, they are usually deposited in different environmental arrays and tend to occur more often in separate stratigraphic units (WALKER 1983). As is the case with most broad generic properties of rock types, there are, of course, many specific exceptions to this rule. However, for the sake of this report, carhonate rnoks are defined as those sedimentary rocks which consist of $50 \%$ or more by volume of the minerals calcite and/or dolomite.

One important characteristic of carbonate rocks, and the chiet ditference between these and other types of sedimentary rocks, is that carbonates contain mostly particles formed right in the environment of original sediment deposition. Sandstones and shales, on the other hand, consist mostly of particles derived from outside the environment of deposition. The properties of limestones and dolostones are more dependent on sedimentary environmental parameters than are those of most other rock types. Thus, more emphasis must be placed on original depositional environmental patterns when discussing the nature of carbonate rocks than is the case with other rock types (WILSON 1975).

\section{E.5.1.2 CLASSIFICATIONS}

Most sedimentary rock types are classified, at least in part, based on the size of their component grains, along with the mineralogy of the 
grains. Such a classification method is inappropriate for limestones and dolostones. Pure carbonate rocks are monomineralic (or dimineralic at most), so mineralogic observations are largely trivial. In the environment of deposition and not transported very far, their sizes tell more about the animals and plants involved than about other environmental conditions, such as current regime.

Thus, widely used classifications of carbonate rocks, especially limestones, are distinct from those used for other sedimentary rock types. The two most widely used limestone classifications are those of Folk (FOLK 1962) shown in Fig. E.5.1.1 and Dunham (DUNHAM 1962) shown in Fig. E.5.1.2. No universal1y accepted classification exists for dolostones. However, because theoe rocks are alteration producto and the particles of the original limestone are no longer easily visible, most classifications proposed emphasize the crystalline fabric of the rock. An example of such a classification, proposed by Friedman (FRIEDMAN 1965), is shown in Fig. E.5.1.3. Most workers use either Folk's or Dunham's classification when possible.

The clacoification by Folk omphacizoo the typec of particloo (callod allochems) which make up the framework of the rock (e.g., fossils, fecal pellets, intraclasts, or ooids). Dunham's scheme is based on the overall fabric of the rock (whether that fabric is grain-supported or mudsupported). Most workers use one of these two classifications or some combination of them. Throughout this report, the classification of Dunham is used because, as pointed out later, the fabric of a carbonate rock is clearly controlled by processes in the depositional environment and during later diagenesis; in turn, fabric controls many of the other rock properties of importance.

The most important point to be made here is that carbonate rocks in many ways are fundamentally different from other kinds of sedimentary rocks. The differences are nicely summarized by Laporte (LAPORTE 1968).

Brief definitions of a few additional terms used throughout this subtask report are given in the glossary.

\section{E.3.1.3 LITERATURE USED IN THIS STUDY}

In addition to the works referred to directly in the text of this subtask report, many other snurces were instrumental in the formulation of ideas. A more complete bibliography (1isted in alphabetical order by author) is on file in the Environmental Sciences Division of the Oak Ridge National Laboratory. 


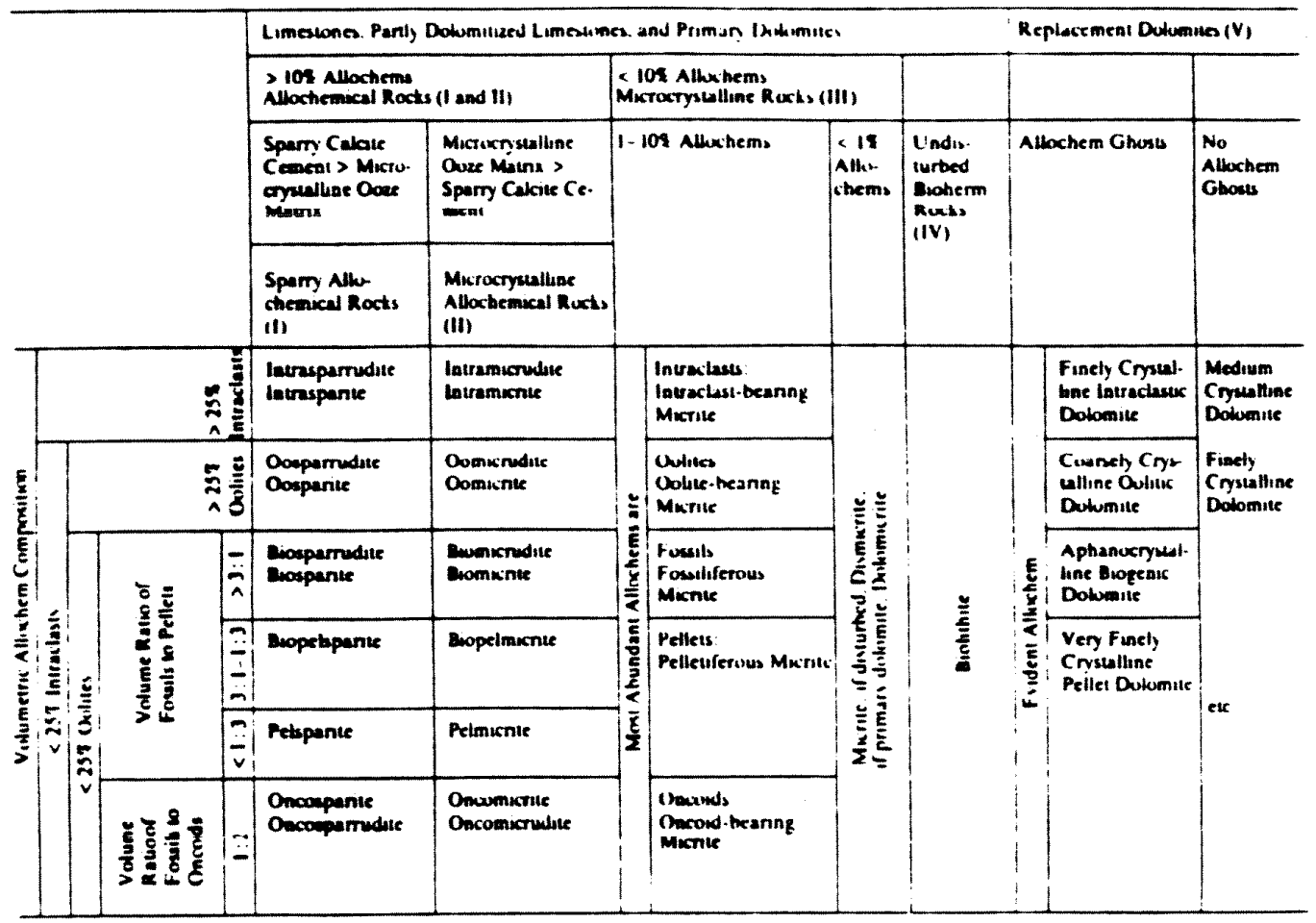

Fig. E.5.1.1. Carbunate rock classification of Folk (FOLK 1962) emphasizing the component grain types of a matrix material. 


\begin{tabular}{|c|c|c|c|c|c|c|c|c|}
\hline \multicolumn{6}{|c|}{$\begin{array}{l}\text { Allochthonous limestones } \\
\text { original components not organically } \\
\text { bound during deposition }\end{array}$} & \multicolumn{3}{|c|}{$\begin{array}{l}\text { Autochthonous limestones } \\
\text { original components organi- } \\
\text { cally bound during deposition }\end{array}$} \\
\hline \multicolumn{4}{|c|}{ Less than $10 \%>2 \mathrm{~mm}$ components } & \multicolumn{2}{|c|}{$\begin{array}{l}\text { Grcater than } \\
10 \%>2 \mathrm{~mm} \\
\text { components }\end{array}$} & \multirow{4}{*}{$\begin{array}{c}\text { By } \\
\text { organ- } \\
\text { isms } \\
\text { which } \\
\text { act } \\
\text { as } \\
\text { bafmes }\end{array}$} & \multirow{4}{*}{$\begin{array}{l}\text { By } \\
\text { organ- } \\
\text { isms } \\
\text { which } \\
\text { encrust } \\
\text { and } \\
\text { bind }\end{array}$} & \multirow{4}{*}{$\begin{array}{l}\text { By } \\
\text { organ- } \\
\text { isms } \\
\text { which } \\
\text { build } \\
\text { a rigid } \\
\text { frame- } \\
\text { work }\end{array}$} \\
\hline Cont & $\begin{array}{l}\text { ains lime } \mathrm{r} \\
<.03 \mathrm{~mm} \text { ) }\end{array}$ & & $\begin{array}{l}\text { No } \\
\text { lime } \\
\text { mud }\end{array}$ & \multirow{3}{*}{$\begin{array}{l}\text { Matrix } \\
\text { sup- } \\
\text { ported }\end{array}$} & \multirow{3}{*}{$\begin{array}{c}>2 \mathrm{~mm} \\
\text { com- } \\
\text { ponent } \\
\text { sup- } \\
\text { ported }\end{array}$} & & & \\
\hline \multicolumn{2}{|c|}{ Mud supported } & \multirow{2}{*}{\multicolumn{2}{|c|}{$\begin{array}{c}\text { Grain } \\
\text { supported }\end{array}$}} & & & & & \\
\hline $\begin{array}{c}\text { Less than } \\
10 \% \\
\text { grains } \\
1>0.3 \mathrm{~mm} \\
2 ? \mathrm{~mm})\end{array}$ & $\begin{array}{c}\text { Greater } \\
\text { than } \\
10 \% \\
\text { grains }\end{array}$ & & & & & & & \\
\hline $\begin{array}{l}\text { Mud- } \\
\text { stone }\end{array}$ & $\begin{array}{l}\text { Wacke- } \\
\text { stone }\end{array}$ & $\begin{array}{l}\text { Pack- } \\
\text { stone }\end{array}$ & $\begin{array}{l}\text { Grain- } \\
\text { stone }\end{array}$ & $\begin{array}{l}\text { Float- } \\
\text { stone }\end{array}$ & $\begin{array}{l}\text { Rud- } \\
\text { stone }\end{array}$ & $\begin{array}{l}\text { Baflle- } \\
\text { stone }\end{array}$ & $\begin{array}{l}\text { Bind. } \\
\text { stone }\end{array}$ & $\begin{array}{l}\text { Frame- } \\
\text { stone }\end{array}$ \\
\hline
\end{tabular}

Fig. E.5.1.2. Carbonate rock classification of Dunham (DUNHAM 1962) emphasizing the fabric of the rock and particularly the mud content. 
ORNL DWG 85-252

Crystallization Textures (shape of mineral crystals)

Anhedral

Subhedral

Euhedral

Crystallization Fabrics (size and mutual relations of crystals)

Equigranular

Xenotopic

Hypidiotopic

Idiotopic

Inequigranular

Xenotopic $\overbrace{\text { Poikilotopic }}^{\text {Porphyrotopic }}$

Porphyrotopic

Hypidiotopic

Poikilotopic

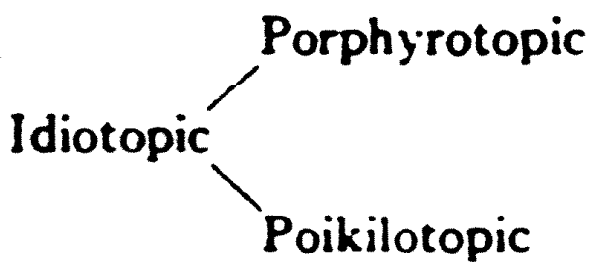

Fig. E.5.1.3. A classification of dolostones after Friedman (FRIEDMAN 1965) emphasizing the crystalline fabric of these rocks. 


\section{E.5.2 GEOLOGIC ENVIRONMENT OF DEPOSITION}

\section{E.5.2.1 PRELIMINARY CONCEPTS}

As is the case with most sedimentary rock types, the properties of a carbonate rock sequence are largely responses to conditions in the original environment of deposition "overprinted" to one degree or another by later diagenetic alterations. Thus, most of the remainder of this report is organized around first delineating the limited categories of environmental patterns which have been discerned in carbonate sequences, and then discussing the properties generated in rocks deposited in each of these patterns. There are, however, some characteristics held in common by all carbonate depositional patterns, and these will be enumerated first.

Contrary to the conventional wisdom that carbonate sediments are very slowly deposited compared with terrigenous clastics (such as sandstone, or siltstone and shale), the two broad categories of sediment have comparable depositional rates (WALKER 1983), as shown in Fig. E.5.2.1. Although there are a few exceptions to this rule (for example deltaic deposits among terrigenous types, or reef sediments among carbonates), in most other generalized environments which have representatives in both types of regime, the rates of deposition are approximately equal. However, in the two regimes, the distribution of the sediment mass relative to the "source" region for the material deposited is very different.

Other major differences exist between the two types of depositional regimes. These differences, which control many properties of the two kinds of sequences, are shown in Fig. E.5.2.2 and E.5.2.3 and discussed below.

Terrigenous sediment is, of course, derived from the landward side of a depnaitinnal environmental pattern and enters the environment as particulate material at point sources (such as streams) or line sources (such as on beaches) along the shore (Fig. E.5.2.2). Except for the finest fraction which is swept offshore and may be deposited there by suspension tallout, many of the particles are carried by bottom traction and deposited laterally (.. $\mathrm{g} \cdot$, as cross beds, or ripple beds of various kinds) relatively near the sources.

The consequences of this depositional mode are (1) a sequence that thins in an off-shore direction, (2) an on- to off-shore sea floor profile that tends to steepen with time, and (3) environmental belts (and consequent three-dimensional facies masses) that often roughly parallel the trend of the shoreline.

Carbonate sediments, on the other hand, do not consist predominantly of particles from outside the depositional regime but instead of materials derived from organisms within the regime mostly in the form of skeletons or skeletal pieces (LAPORTE 1968). The real source for the skeletons are chemicals ( $\mathrm{Ca}^{2}$ and $\mathrm{CO}_{3}{ }^{2-}$ 1ons) in sea water and nutrients 
ORNL-DWG 84-1291

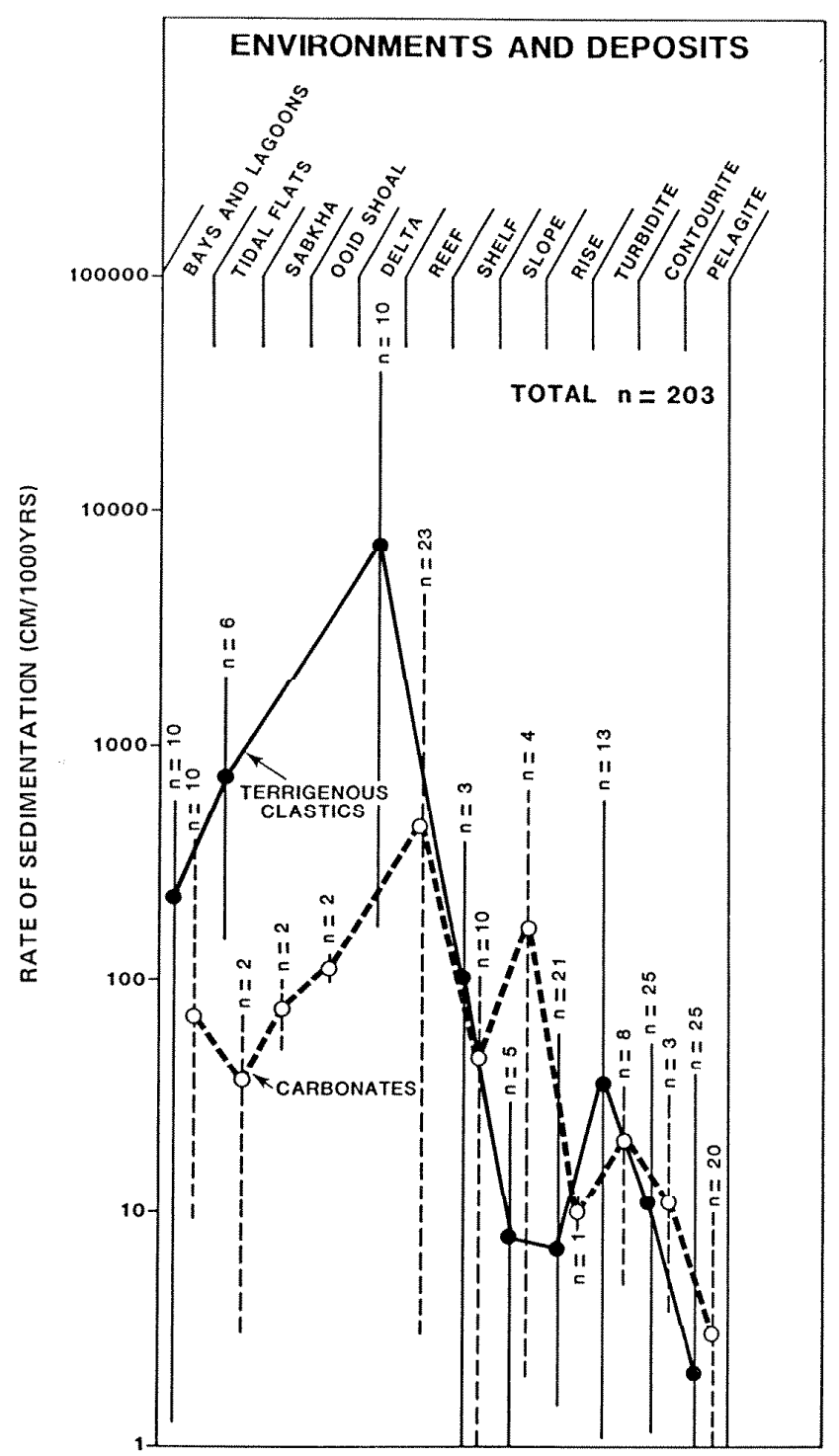

Fig. E.5.2.1. Graph showing analogous sedimentation rates in conparable carbonate and terrigenous clastic environments. The solid and dashed lines are trend lines added for ease of viewing (WALKER 1983). 
ORNL DWG 84-1260

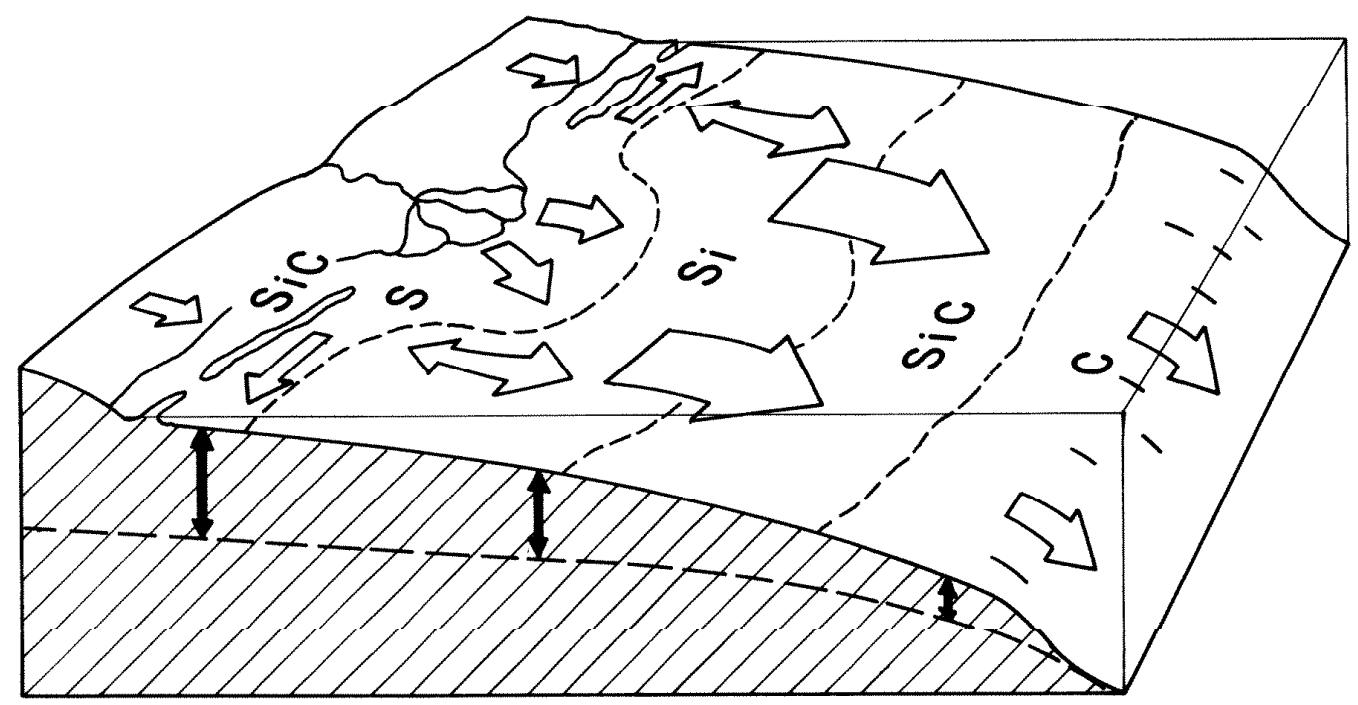

Fig. E.5.2.2. B1nck diagram showing typical terrigenons c1astic shelf development. Note point and line sources and shore-parallel sediment areas. Dashed line on front of block shows earlier shelf profile; note steepening with time. 


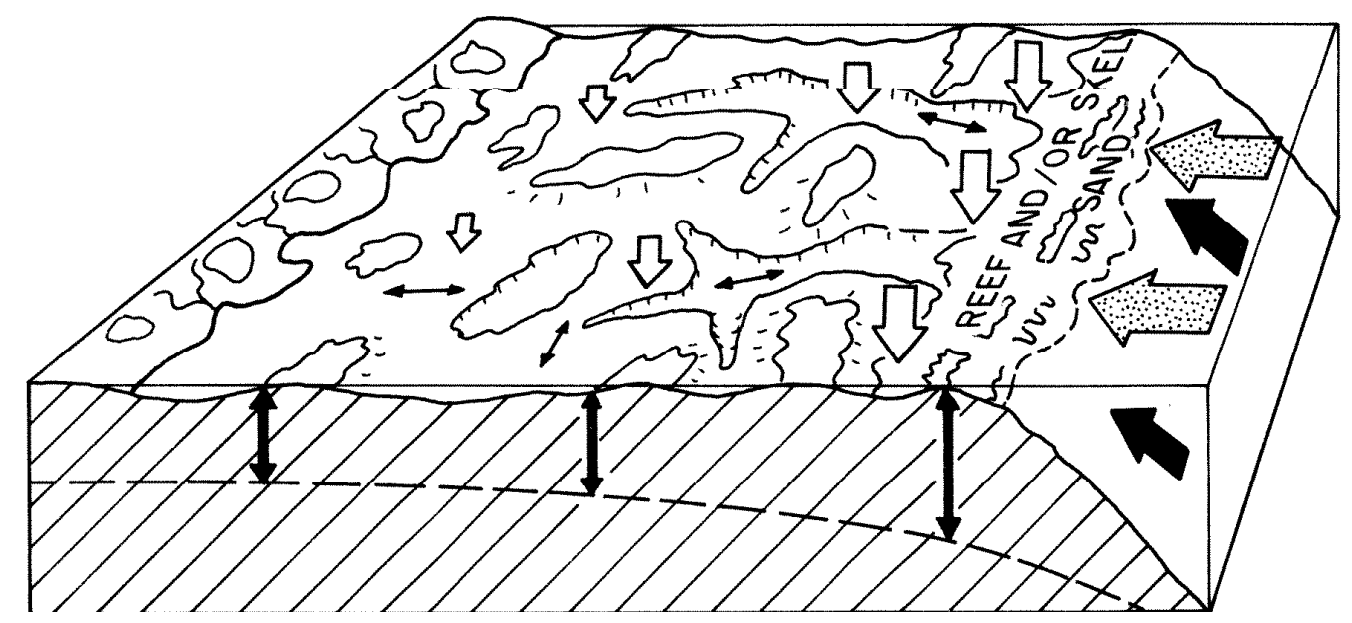

Fig. E.5.2.3. Block diagram showing typical carbonate shelf development. Note "source" of building material is off shelf toward right (organic and inorganic nutrients). Note patchy, mosaic-like environmental pattern. Dashed line on front of block is previous shelf profile; note flattening with time. 
swept into the regime largely from the seaward side. Thus, skeletal production tends to be greatest on the seaward side of the regine and the rate of deposition is consequently greatest there. Transportation of often quite large skeletons tends to be minimal in many carbonate environments (LAPORTF 1968), and the depositional vector is more or less vertical. Much material accumulates very near where it was formed during the life processes of the organisms. Because algal activity is the primary source of food for carbonate skeletal organisms, accumulation does not occur if the sea floor is beneath the lighted zone (from the water surface down to roughly $80 \mathrm{~m})$; additionally, most marine organisms cannot tolerate exposure to air for long. The result is that carbonate sediment production can be shut off by either slight deepening or slight shallowing of the environment.

The consequences of this depositional mode are (1) a sequence which cends to thicken in an off-shore direction (at least as far as the shelf margin), (2) an on- to off-shore sea floor profile which tends to become more gentle (flatter) with time, (3) subenvironments which have a patchy distribution, producing three-dimensinnal facies masses which are mnsaiclike and tend to grade laterally in all directions to other rock types within comparatively short distances, and (4) stratigraphic sequences which contain many cyclic units separated by breaks in deposition. Shelf-marginal environments such as reefs or skeletal-sandbanks produce rock masses that are exceptions to number (3), and instead tend to be linear in three dimensions.

The three-dimensional consequences of these differences between carbonate and terrigenous clastic regimes are of great importance in understanding and predicting the pattern of change of properties laterally and vertically within any sequence (WALKER 1983; WILSON 1974). They also bear upon the probability of finding a homogeneous 1ithic unit of sufficient size for construction of a repository.

\section{E.5.2.2 MODELS OF TECTONIC FRAMEWORK}

Because of the suppression of carbonate deposition when terrigenous clastic matertal is introduced in the environment in any but small quantities, carbonates tend to be deposited only in tectonically quiet zones or in subareas within tectonically active regions which are protected from the introduction of land-derived debris, e.g., the Triassic of northern Italy (BOSELLINI 1984). This association of carbonates (both limestones and dolostones) with tectonically stable conditions was pointed out as much as 25 years ago (KRUMBEIN 1963), and the association is still a recognized fact. But, whenever an area becomes 1solated by whatever means from terrigenous influx, carbonate production is usually established quickly and accumulation begins. The isolation may occur geographically (i.e., a physical separation of land source regions from depositional areas), for example, by an intervening, deeper water "catchment" basin (WALKER 1980), or may occur as a temporal separation of periods of terrigenous influx from periods of no terrigenous influx in the same deposiciullal area. The lacter mode produces stracigraphic sequences in which sandstone/shale beds are interbedded with limestone/dolostone beds (MOUNT 1984). 
Nevertheless, the association between carbonate deposition and tectonic stability is accepted by most workers. In terms of plate tectonic theory, this means that most carbonates in the geological record were deposited either along the "trailing" (or passive) margins of continental plates (READ 1982) or on the tops of continental plates in epeiric seas far from the active margins. The carbonate sequences deposited along trailing margins (the modern Bahama banks and the Florida Platform are examples of this type of plate-margin setting) eventually become involved in collisional events when the margin becomes a "leading" (or active) margin. Subsequently, these sequences are generally in seismically active zones for a considerable time span, though with sufficient time the areas involved may become quiescent again. An example of such a quiet-active-quiet succession can be found in the Appalachian Ridge and Valley Province of the east-central United States (WALKER 1980). Those carbonate rock sequences originally deposited in the stable interiors of continental plates have generally maintained their tectonically quiet setting subsequently, even though the time span between deposition and the present may have been hundreds of millions of years. Examples of such relatively long-lasting stability right up to the present are the thick Ordnvician dnlomites of the central United States (THACK.ER 1977) and the Permian limestones of West Texas (WILSON 1974; HILLS 1984). The tectonic stability of a given region containing carbonate rocks is of obvious importance in the present context, but the stability of the area during original deposition also has a hidden importance because it may have controlled some of the fundamental properties of the sediments (WILSON 1974)。

\section{E.5.2.3 DEPOSITIONAL-ENVIRONMENTAL MODELS}

As discussed above, the depositional environment controls many of the properties of limestones and dolostones. In addition, diagenesis (postdepositional alteration) begins, and in some cases is substantially completed, in a diagenetic environment closely related spatially and by process to the original environment of deposition. Thus, models of the common depositional patterns in which carbonate rocks develop are a logical framework for discussion of the properties characteristic of the consequent rock types.

Many workers have attempted to develop general models of carbonate depositional regimes. These attempts fall into four categories, depending on the basis or conceptual framework for the model. The first type of model has been based largely on an almost purely theoretical consideration of expected conditions during carbonate deposition. The second type has been based on a consideration of specific modern analogs of carbonate depositional environments. The third has been founded on a combination of specific modern and ancient analogs. Finally, the fourth type of model has combined theoretical considerations and knowledge of one or more ancient sequences as a basis for model development. Examples of these types will be briefly reviewed before choosing the model to be used here to organize discussion of properties.

Models developed in the 1950 s and early 1960 s were largely of the purely theoretical variety. Two examples are the models developed by 
Shaw (SHAW 1965) and Irwin (IRWIN 1965) for carbonate deposition in the broad epeiric seas of the Paleozoic era. The first of these is shown here in Fig. E.5.2.4 and the second in Fig. E.5.2.5.

Although both the Shaw and Irwin models are still occasionally cited by workers, especially when dealing with sequences largely composed of dolostone for which there are no really good modern analogs, they are no longer widely used. Another, even older example of this type of model (not illustrated here) is the discussion by Rich (RICH 1951) of shelves, slopes, and basins.

An example of the second type of model, based mostly on modern analog, is embodied in the books edited by Ginsburg (GINSBURG 1975) and Hardie (HARDIE 1977), in which several models are developed or implied for use in interpretation of carbonate tidal flat deposits. One such modern ana1 log model related to tidal flat interpretation is shown in Fig. E.5.2.6, derived from Hardie's book. Use of this and similar models depends on direct application of the "principle of uniformity of processes through time" (sometimes referred to as "uniformitarianism"). As Hardie has pointed out, this principle or a model developed through its application must be used with great caution because of changes in the rate of process application with changing circumstances (e.g•, under tidal ranges). Nonetheless, this type of model is of considerable help in predicting the properties of rocks deposited in known environments and thus is very useful for interpreting individual rock types but of little use as a framework for discussion of the properties of complex carbonate sequences.

The third type of depositional model is based on a complex combination of modern and ancient analogs, from which a plexus of properties are drawn from which the model is constructed. Two examples of such models are illustrated and briefly characterized here. The first of these is derived from the work of Wilson (WILSON $1974 ; 1975$ ) and is illustrated below in Figs. E.5.2.7 and E.5.2.8. This model spans the carbonate environments which stretch from a continental shoreline, across a broad shelf, shelf break, slope, and adjacent basin. Clearly, this is a very complex and comprehensive model. It is widely applicable and is an excellent framework for the study of limestone sequences. It is not, however, very well suited as a framework for the succinct summary of rock properties. On the other hand, the second example of "ancient analog" depositional models, though simpler and less comprehensive, is well suited for the purpose at hand. This is a model suggested by Reeckmann and Friedman (REECKMANN 1982), which is shown here in Fig. E.5.2.9.

The Reeckmann and Friedman model provides a reasonably comprehensive framework for the summarization of the generic properties of carbonate lithologies deposited in various environments. Where other types of environments not shown in this model possess properties of special interest, the exception is noted here in the text. In subsequent parts of this report, this model is used as a framework for discussion.

Before the discussion continues, however, the fourth type of model montioned abovo - relying mostly on theory and ancient analog - is 
ORNL DWG $85-232$

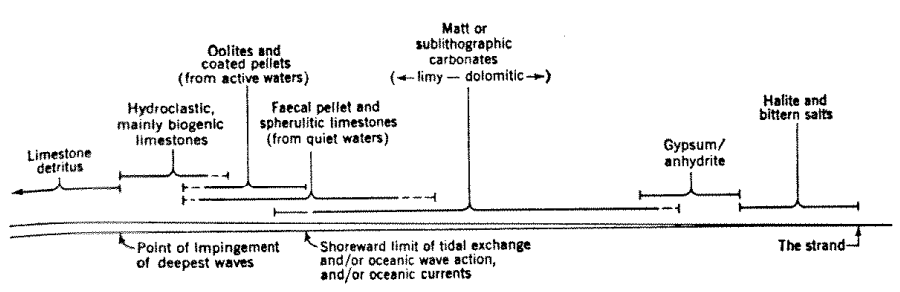

Vertical scole greatly exaggerated

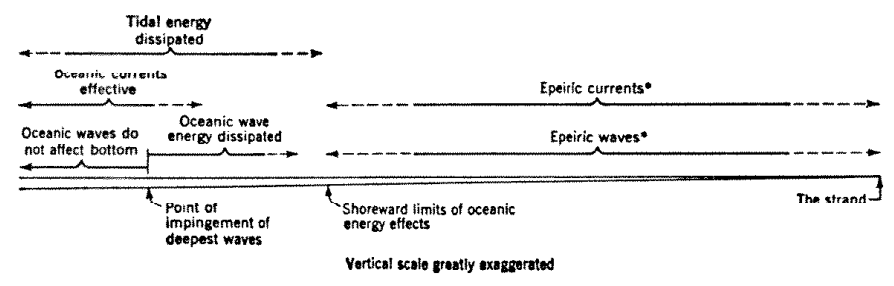

- There might easily have been multiple wave
ond tevrent tystems in the widest opericic seas

Fig. E.5.2.4. Carbonate depositional model (SHAW 1965).

ORNL DWG $85-233$

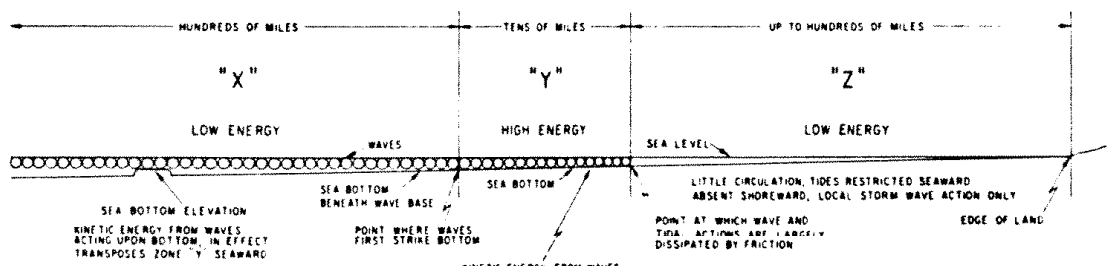

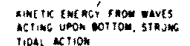

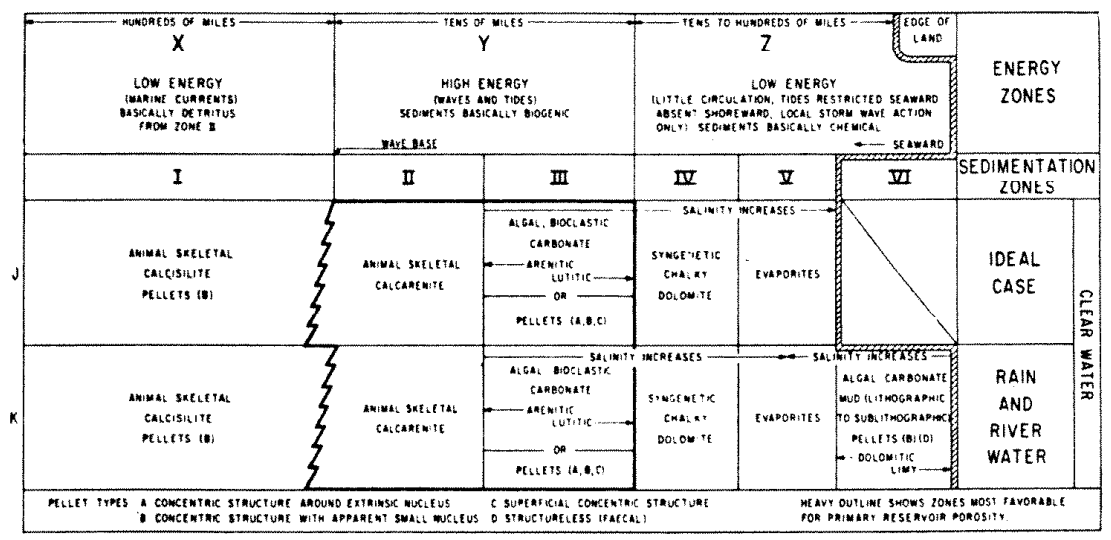

Fig. E.5.2.5. Carbonate depositional mode1 (IRWLN 1965). 


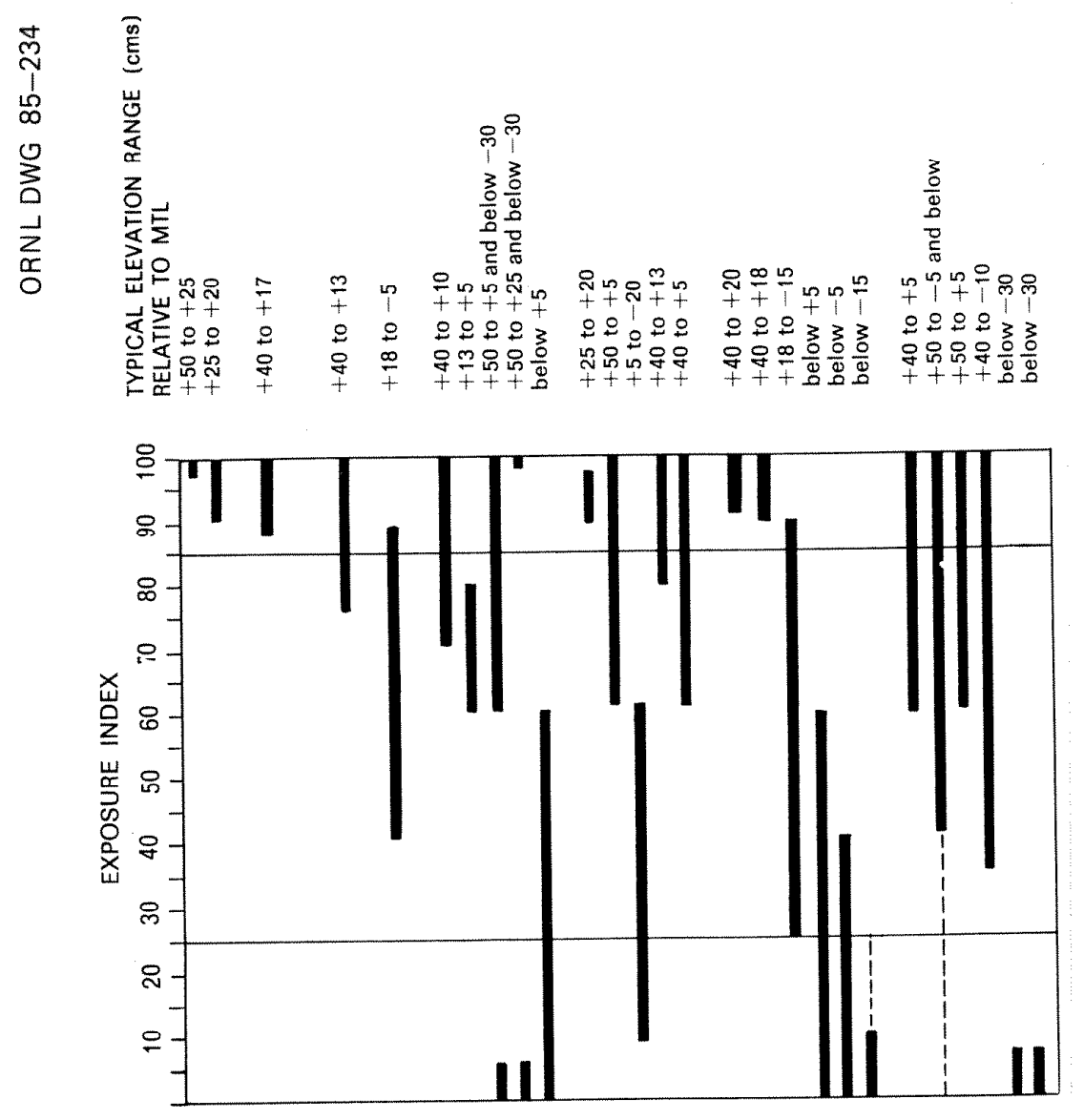

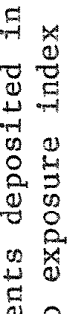

웅

可

y

E)

出

50

崖

EF

응

되 $\frac{0}{5}$

空号吉

起莣动

엄

욤

$\dot{x}$

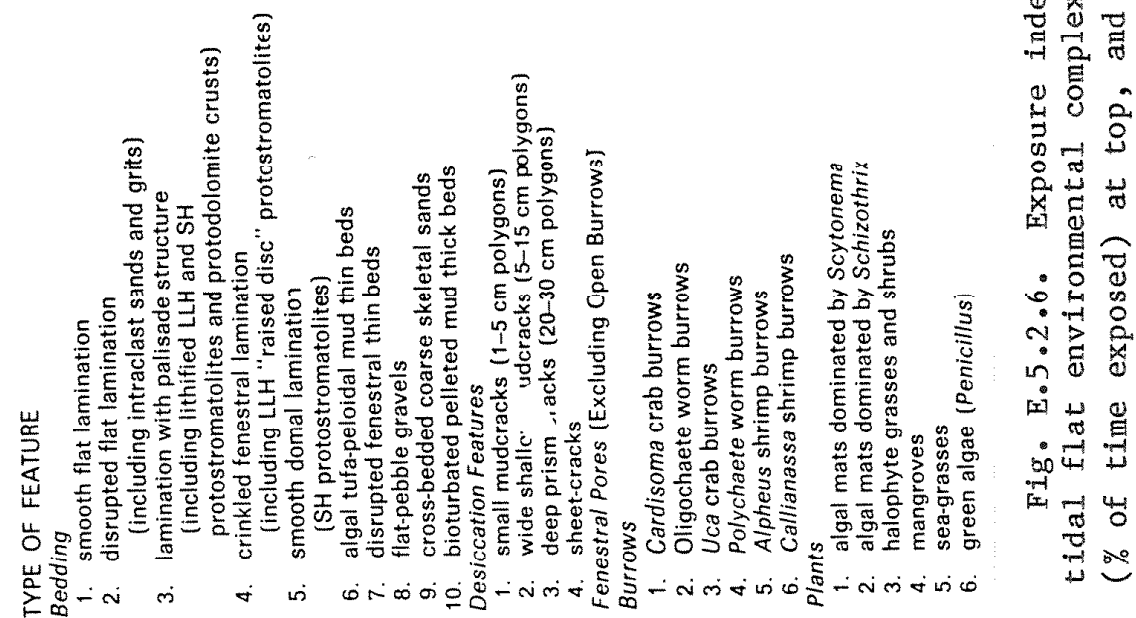


ORNL DWG $85-235$

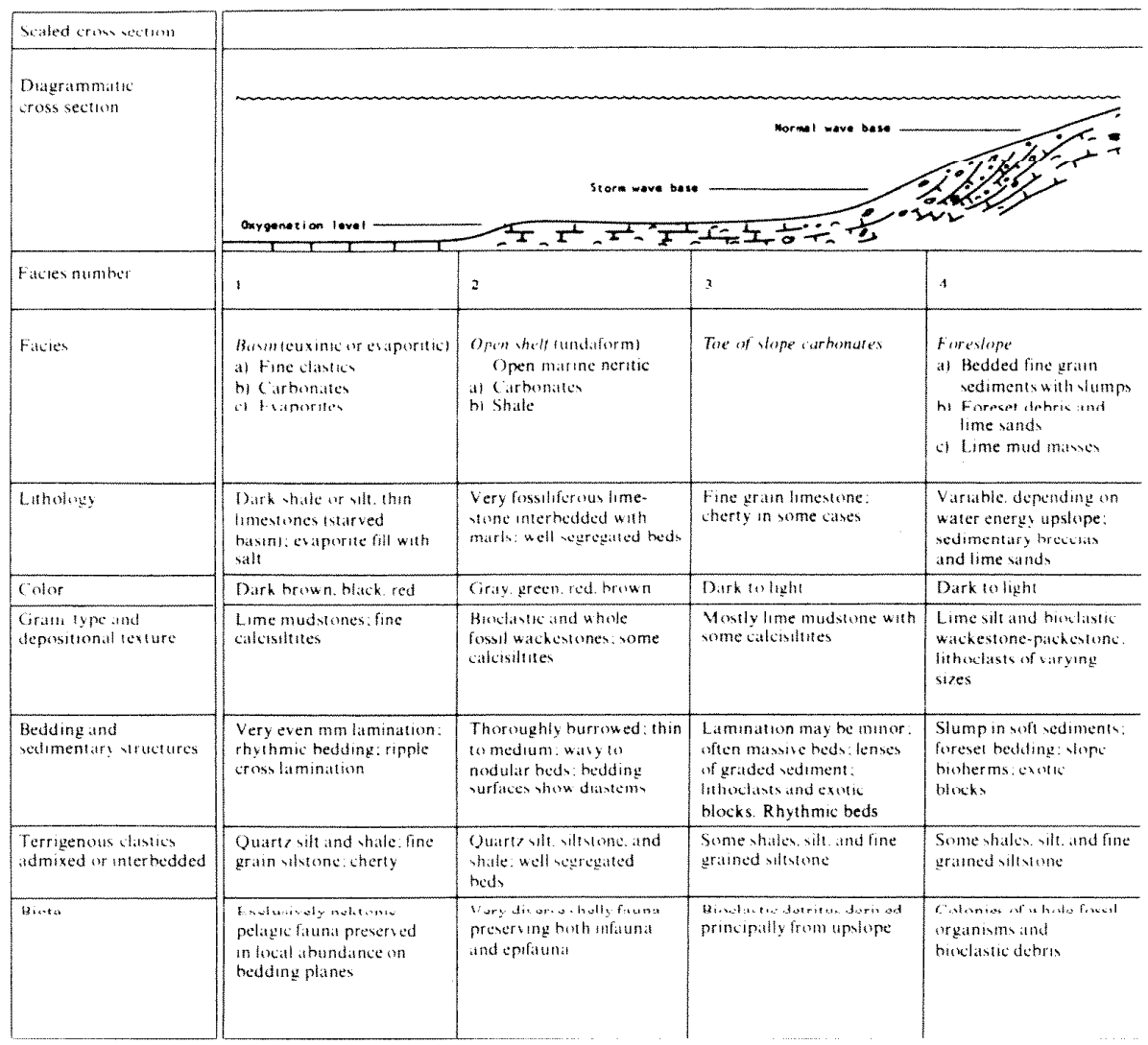

Fig. E.5.2.7. Basinal and slope carbonate environmental model after Wilson (WILSON 1975) showing characteristics of sediments of different environments along the profile. (Connects to left side of Fig. E.5.11.) 


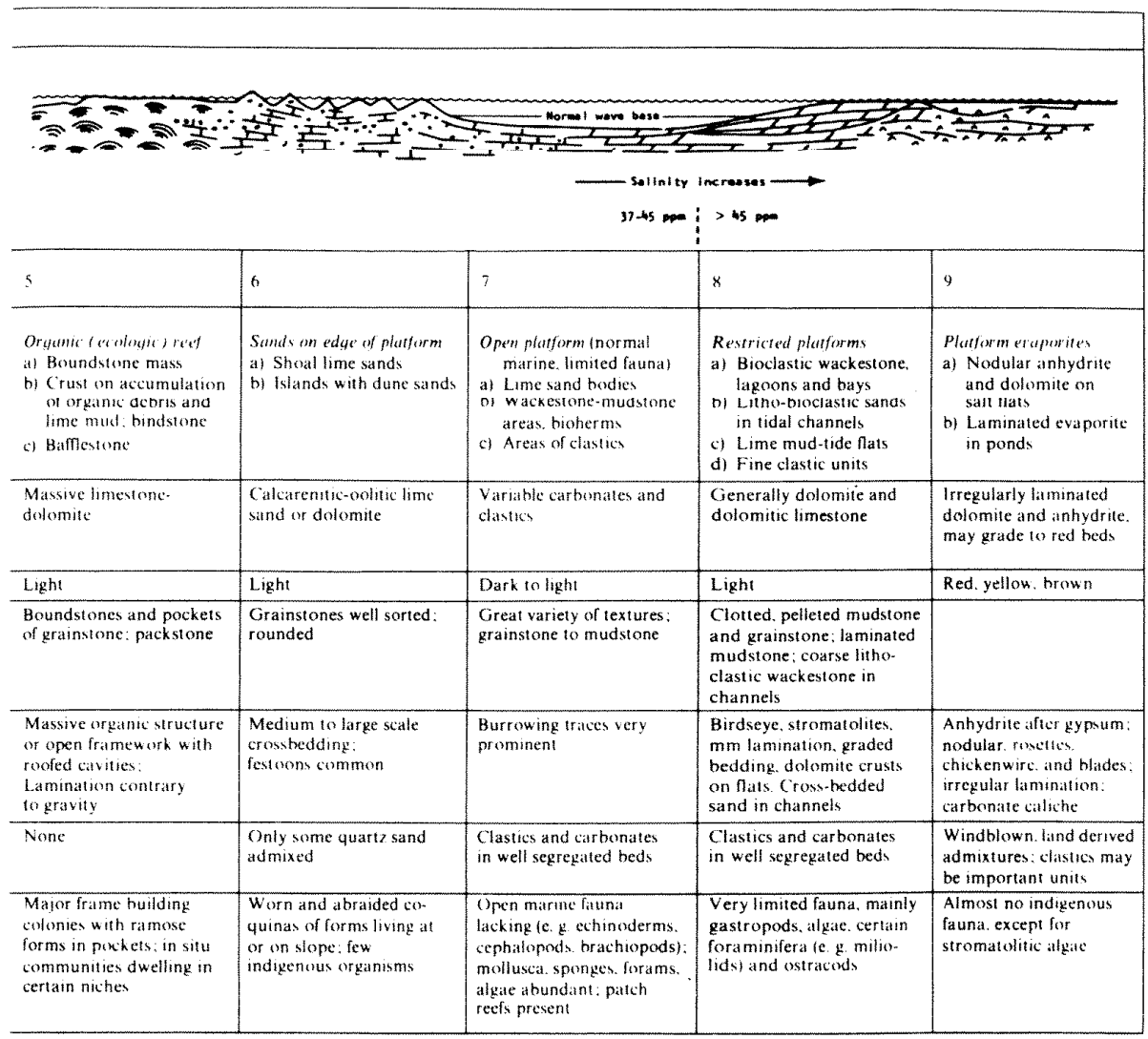

Fig. E.5.2.8. Shelf edge and platform carbonate environmental model after Wilson (WILSON 1975) showing characteristics of sediments deposited in various environments along protile, (Connects to right side of Fig. E.5.2.7.) 
ORNL DWG 85-237

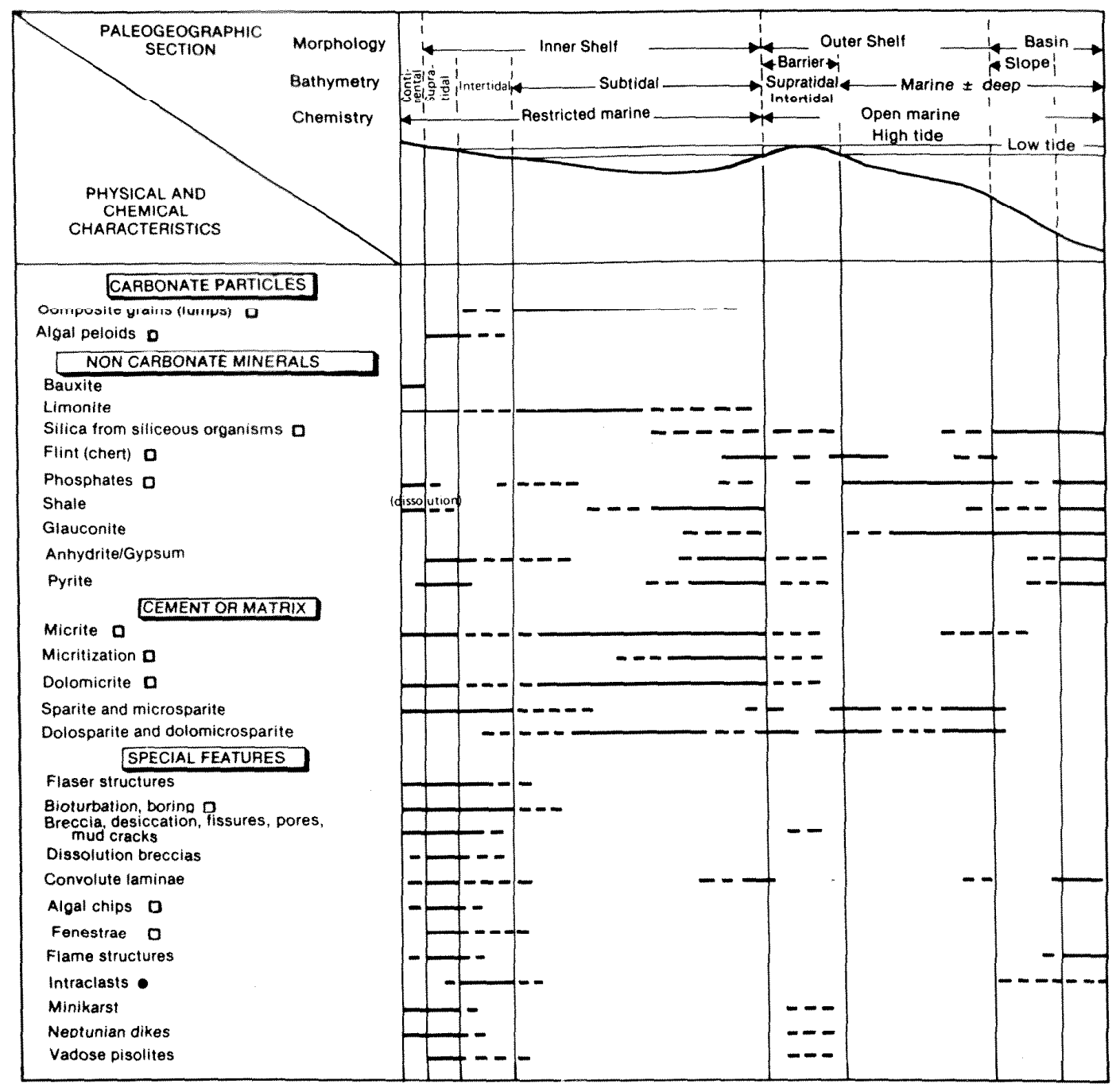

Fig. E.5.2.9. Carbonate depositional model of Reeckmann and Friedman (REECKMANN 1982) along top of figure and some of the physical characteristics of sediment for each environment (columns beneath environmental profile). 
illustrated. One problem with all of the previously discussed models is their failure to deal with basin evolution, or with the relationship between carbonate environmental patterns and (often contemporaneous) terrigenous clastic depositional patterns. It is important to add that such a comprehensive model is also not available in the literature devoted to terrigenous clastic sequences. One model which deals with these aspects is that of Walker, Shanmugam, and Ruppel (WALKER 1983). One feature of that study was a computer-simulated developmental model of the evolution through time of a sequence containing a large mass of carbonate rock which grades laterally to a large mass of terrigenous clastic rock (a sequence type common in the geological record). The result of that simulation is shown in Fig. E.5.2.10 and constitutes a hypothetical model of hasin evolution under those circumstances. Although this model has conceptual utility, it is not a good vehicle for discussion of detailed rock properties. Thus, the Reeckmann and Friedman (REECKMANN 1982) model is used here. An understanding of the geometry and dimensions of carbonate rocks is critical in allowing evaluation of this rock type for repository siting.

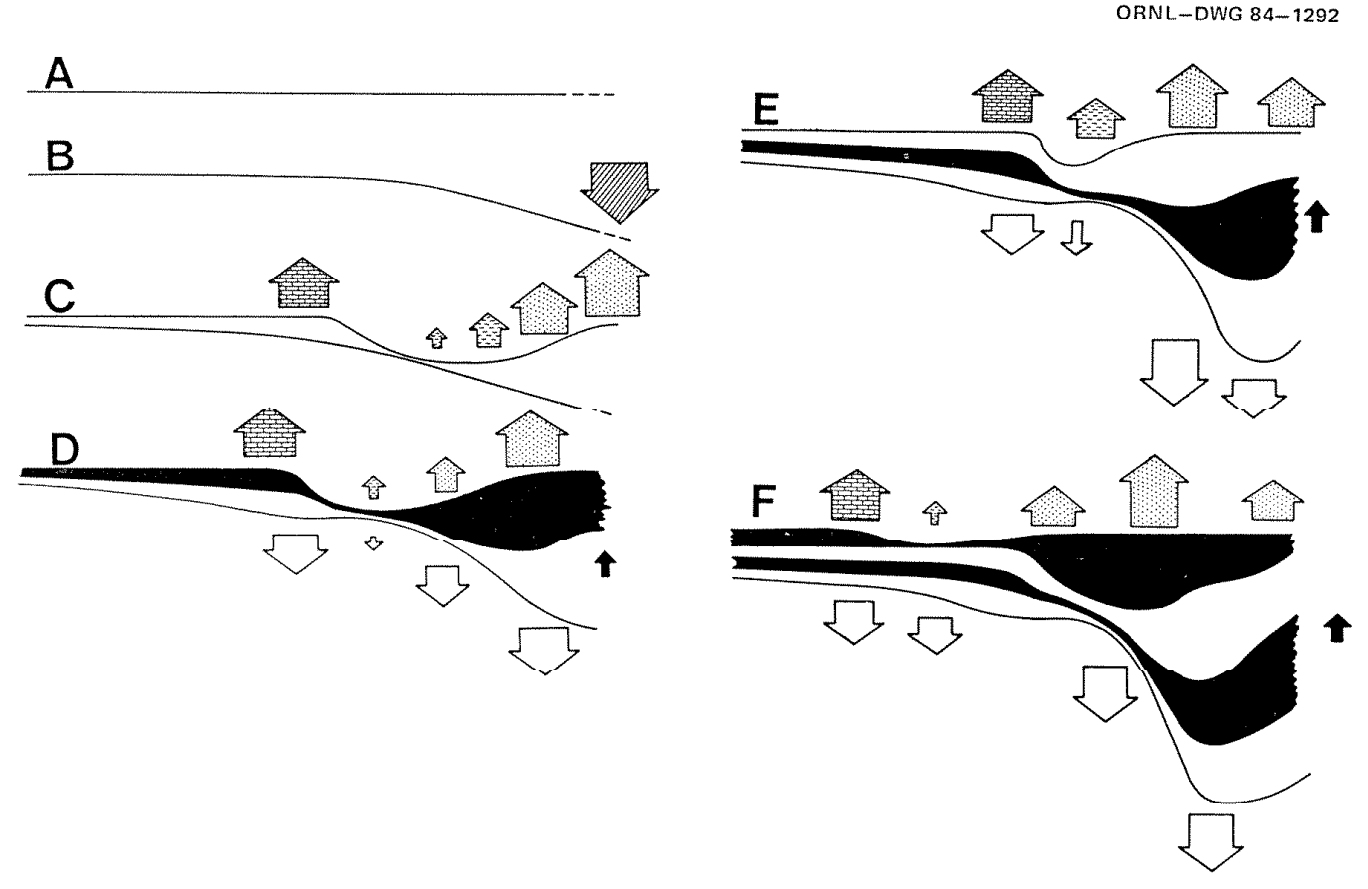

Fig. E.5.2.10. Basin developmental simulation mode1 (WALKER 1983) showing sequence development through time ( $A, B$, etc.) stages. Arrows above each profile show how much (by area of arrow) sediment of each type $($ sand $=$ dots, shale $=$ dashes, limestone $=$ bricks). Arrows below show amount of luading substdence caused by the welght of sediment deposited during previous stage. 


\section{E.5.3 GEOMETRY AND DIMENSIONS OF CARBONATE DEPOSITS}

Carbonate sequences can be extremely widespread, underlying the area of several states; but the dimensions of whole sequences (containing many rock units) may be very much different from the dimensions of individual, homogeneous rock units within the sequences (WILSON 1975).

\section{E.5.3.1 DIMENSIONS AND GEOGRAPHIC DISTRIBUTION OF SEQUENCES}

A carbonate sequence is defined here as a more or less coherent set of carbonate rock units, usually called a formation, which were originally deposited during a limited time span with a single complex environmental pattern. Some sequences are very widespread. Two examples can be mentioned to illustrate this point. Throughout much of the conterminous United States, rocks of late Cambrian and early Ordovician age consist of carbonate lithologies. This major sequence is called the Beekmantown Group in the central Appalachians, the Knox Group in the Midwest and the southern Appalachians, and the Ellenburger Group in Texas; a thick unit of the same age occurs beneath the Great Plains and elsewhere (MAZZULO 1978; CHURNET 1981; HARRIS 1963). The sequence is from a few hundred to several thousand meters thick and almost everywhere consists largely of dolostone. The second example consists of rocks of middle and late ordovician age which underlie (or are at the surface) almost as large an area of the United States as the dolostone sequence mentioned above (WALKER 1980; GROVER 1983). This second sequence example ranges again from a few hundred to $2000 \mathrm{~m}$ thick and consists largely of limestone.

other sequences are much more restricted in dimensions. Several carbonate sequences of Mesozoic age underlie parts of the Great Plains and the Gulf Coastal plain; others of the same age are restricted to the latter area. Table E.5.3.1 is certainly not exhaustive, but it lists some of the major carbonate rock sequences in the United States and their areal extent (these are mostly the wider spread sequences).

Within most of the regions of the United States mentioned in Table E.5.3.1, there are areas containing units of relatively pure limestone or dolomite which are nore than $100 \mathrm{~m}$ thick and within $1000 \mathrm{~m}$ of the surface of the earth. Figure E.5.3.1 shows the areas within the conterminous United States in which substantial deposits of carbonate rocks lie close (approximately $1000 \mathrm{~m}$ or less) to the earth's surface.

It is notable that there are virtually no limestone sequences either at the surface or buried at shallow depths $(<1000 \mathrm{~m})$ in the area east of the folded Appalachians (the central and eastern parts of the states along the Atlantic seaboard). Additionally, there are few such sequences west of the Rocky Mountain states.

\section{E.5.3.2 DIMENSIONS OF UNITS WITHIN SEQUENCES}

Most carbonate sequences are made up of a complex three-dimensional array of more or less homogoneous stratigraphic packages reforred to as 
Table E.5.3.1. Some major carbonace rock sequences in che unired staces

\begin{tabular}{|c|c|c|c|}
\hline Unit name & Age & $\begin{array}{l}\text { Dominant } \\
\text { rock type }\end{array}$ & Geographic extent \\
\hline $\begin{array}{l}\text { Beekmantown, } \\
\text { Knox, } \\
\text { Ellenburger }\end{array}$ & $\begin{array}{l}\text { Cambrian- } \\
\text { Ordovician }\end{array}$ & Dolostone & E, SE, SW, central U.S. \\
\hline $\begin{array}{l}\text { St. Paul, } \\
\text { Chickamauga }\end{array}$ & Ordovician & Limestone & $E, S E$, central U.S. \\
\hline "Niagaran" & Silurian & Limes tone & Northex MidwesL \\
\hline $\begin{array}{l}\text { St. Louis, } \\
\text { St. Genevieve }\end{array}$ & Mississippian & Limestone & Midwest \\
\hline $\begin{array}{l}\text { Capitan, } \\
\text { San Andreas }\end{array}$ & Permian & Limestone & Southwest, Midwest \\
\hline Smackover & Jurassic & Limestone & Gulf Coast \\
\hline Niobriara & Cretaceous & Limestone (chalk) & Central plains \\
\hline Austin & Cretaceous & Limestone (chalk) & Gulf Coast \\
\hline
\end{tabular}

Sources: (WALKER 1980; MAZZULO 1978; CHURNET 1981; HARRIS 1963; GROVER 1983; SHAVER 1977; FLORES 1977; HILLS 1984; BARIA 1982; MOORE 1981). 


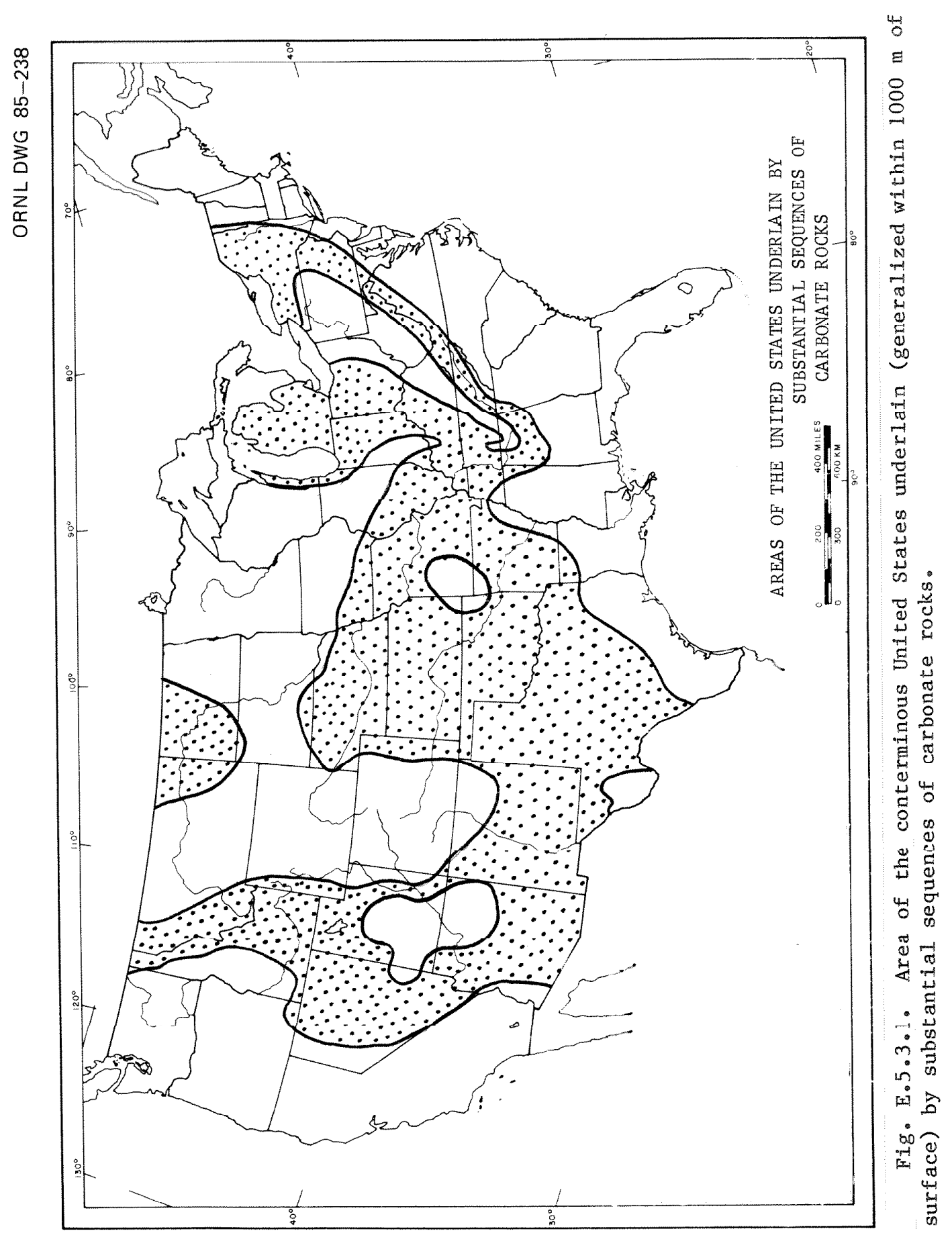


formations. These, in turn, may also be made up of three-dimensional mosaics of rock units which may be their lithologic homogeneity or by inhomogeneity. Thus, the question of the dimensions of individual units within sequences is a complicated one. Because, for the purpose of repository siting, the unit penetrated needs to have a reasonable degree of homogeneity, the discussion in this section is restricted to the expected dimensions of lithologically homogeneous units within the packages called formations. These within-formation packages are of ten referred to as facies.

Near-shore carbonate environments such as tidal flats, and even openshelf environments such as lagoons, tend to be mosaic-like in areal distribution, with rapid changes in sediment type laterally (for an explanation of this tendency, see Sect. E.5.2 of this report). The result of this is that for most carbonate environmental arrays, the deposits formed tend to show rapid changes in character and properties both vertically and horizontally (WILSON 1975). Dimensions of homogeneous rock units (facies) vary from decimeters to meters to a few kilometers laterally and from centimeters to tens of meters vertically. Thus, though rare, homogeneous lithic units with dimensions such as $100 \mathrm{~m}$ thick by $4 \mathrm{~km}$ wide do occur. Figure E.5.3.2 (1eft side), drawn from the work of Lumsden (LUMSDEN 1971), shows the frequency of facies of various thicknesses (shown in the figure in feet) in some typical limestones.

In fact, under one set of circumstances, very large and very honogeneous units are produced. This occurs when pervasive diagenesis converts many different rock types to dolostone over a broad area. Perhaps the best example of the results of this process is the Upper CambrianLower Ordovician Beekmantown-Knox-Ellenburger groups (see Table E.5.3.1) (HARRIS 1963). In this unit, which lies within $1000 \mathrm{~m}$ of the surface over an extremely broad area, the diagenetic process of dolomitization has converted many original limestone rock types into relative1y homogeneous dolostone formations. Some of these are many tens of meters thick and are homogeneous over lateral distances of tens of kilometers. These rock units sometimes also have the advantage that any tractures that formed during burial are often subsequently "healed" by remobilization of calcite and dolomite and reprecipitation within the fractures.

\section{E.5.3.3 DIMENSIONS OF INDIVIDUAL BEDS WITHIN UNITS}

Carbonate rock units invariably contain beds within them. The boundaries between these are marked by partings called bedding planes. Because most carbonate rocks were deposited in environmental patterns with shallow, irregular bathymetry, in which sedimentary subenvironments constantly shifted laterally as time passed, the beds tend to be thin and of very restricted lateral extent. Lumsden (LUMSDEN 1971) tabulated the distribution of bed thicknesses in 1imestones; his data, shown as a cumulative curve, are in the lower right part of Fig. E.5.3.2. He pointed out that beds less than $1 \mathrm{~m}$ overwhelmingly dominate in his sample, and in fact, most are less than $0.5 \mathrm{~m}$ thick. In most undolomitized (i.e., not secondarily homogenized) near-shore sequences, beds of 5 to $20 \mathrm{~cm}$ thick 11sial1y dominate. Thirker heds are generally found in suhtidal (more off-shore) parts of a sequence or in those parts which have been secondarily homogenized by diagenetic alteration. 

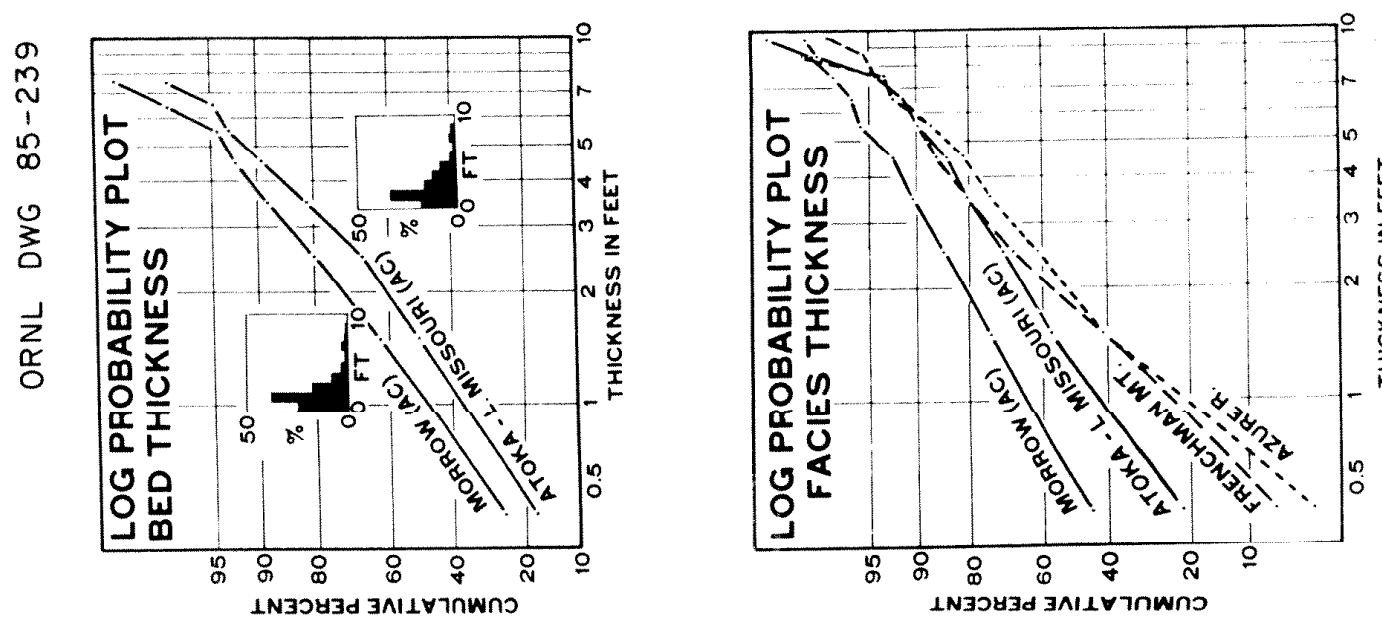

0
0
0
0
0
0
0
4

造造要
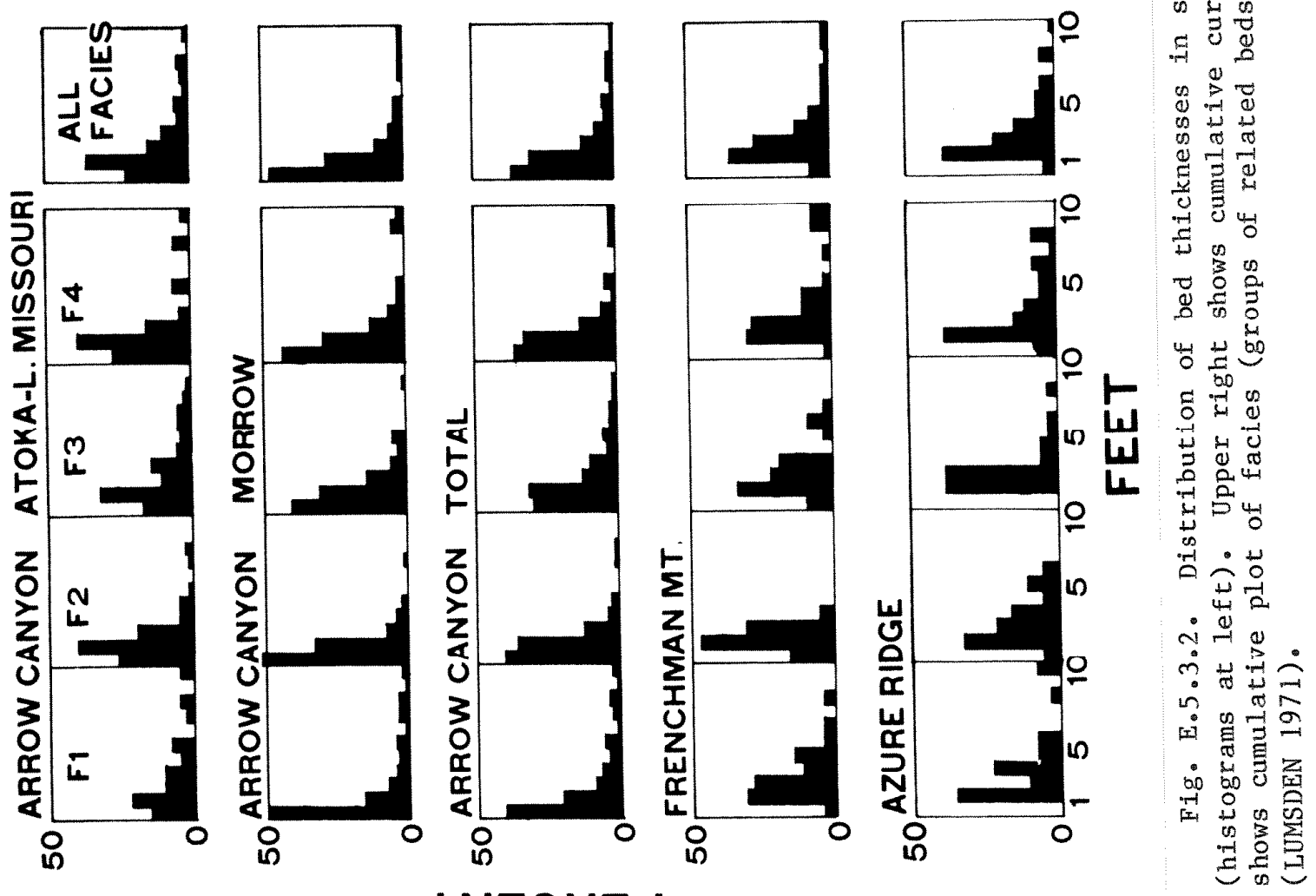

INJכY 


\section{E.5.4 CHARACTERISTICS OF CARBONATE DEPOSITS}

Many of the most fundamental characteristics of carbonate deposits have been summarized in other sections of this report. Thus, this section addresses only those properties which have not previously been covered.

\section{E.5.4.1 LITHOLOGY OF CARBONATE ROCKS}

\section{$\mathbb{E} .5 .4 .1 .1$ Composition and Texture}

As previously noted, carbonate rocks are fundamentally different from terrigenons clastic rocks. One of the chief differences is the origin of most carbonate particles within the environment of deposition or very nearby in adjacent environments (LAPORTE 1968). Most of these particles are skeletal in origin, although several categories of particles are the result of physiochemical precipitation or of reworking of previously deposited materials. Virtually all of these particles are multicrystalline aggregates composed of calcite (though in modern environments the the other psendomorph, aragonite, may be more common). In some ancient carbonates some or all of these particles have been altered to dolomite $\left[\mathrm{CaMg}\left(\mathrm{CO}_{3}\right)_{2}\right]$. As previously noted, then, carbonate rocks have a very limited "mineralogy," so that most characterization is done on the basis of component particle types (WILSON 1975; FOLK 1962; DUNHAM 1962). Figure E.5.4.1 exemplifies this by showing the distribution of fossil particle types versus environment. Note that there is a distinct variation with environment of deposition. Although not all of the 1 isted fossil particle types will be found in any single carbonate sequence, the distribution of these various grain types can be used to distinguish the deposits formed in different areas. At the same time, texture (or grain size), in many carbonate environments, is more a function of intraenvironmental particle production than it is of hydrodynamic particle delivery to the environment (DUNHAM 1962). For these reasons, more significance is placed on the nature of component particles than on grain size in the study of these rocks. This is different from terrigenous clastics, in which virtually all of the component grains have been hydrodynamically delivered to the environment of deposition by currents, so that careful gratn-slze analysts yields tmportant tnformation (FRIEDMAN 1978). Figure E.5.4.1 emphasizes biologically produced particle types, and the distribution of nonbiologically produced particle types is shown in the upper part of Fig. E.5.4.2 (intraclasts, 1ithoclasts, ooids, and pellets of nonfecal origin). Although some of these particle types are not as clearly environmentally restricted as many fossils, they are sti11 useful in recognizing the deposits of different parts of the regime (BATHURST 1975).

The one kind of material which requires some further explanation is the matrix material of carbonate rocks - the material that fills the interstices between the other grains in the rock. This consists of two types, cement and micrite (see Fig. E.5.2.9 for the distribution of these two categories across the environmental profile). Cement is crystalline malerial (usually calcile, bul vicasividily duluilile) which has gruwh 
ORNL DWG 85-240

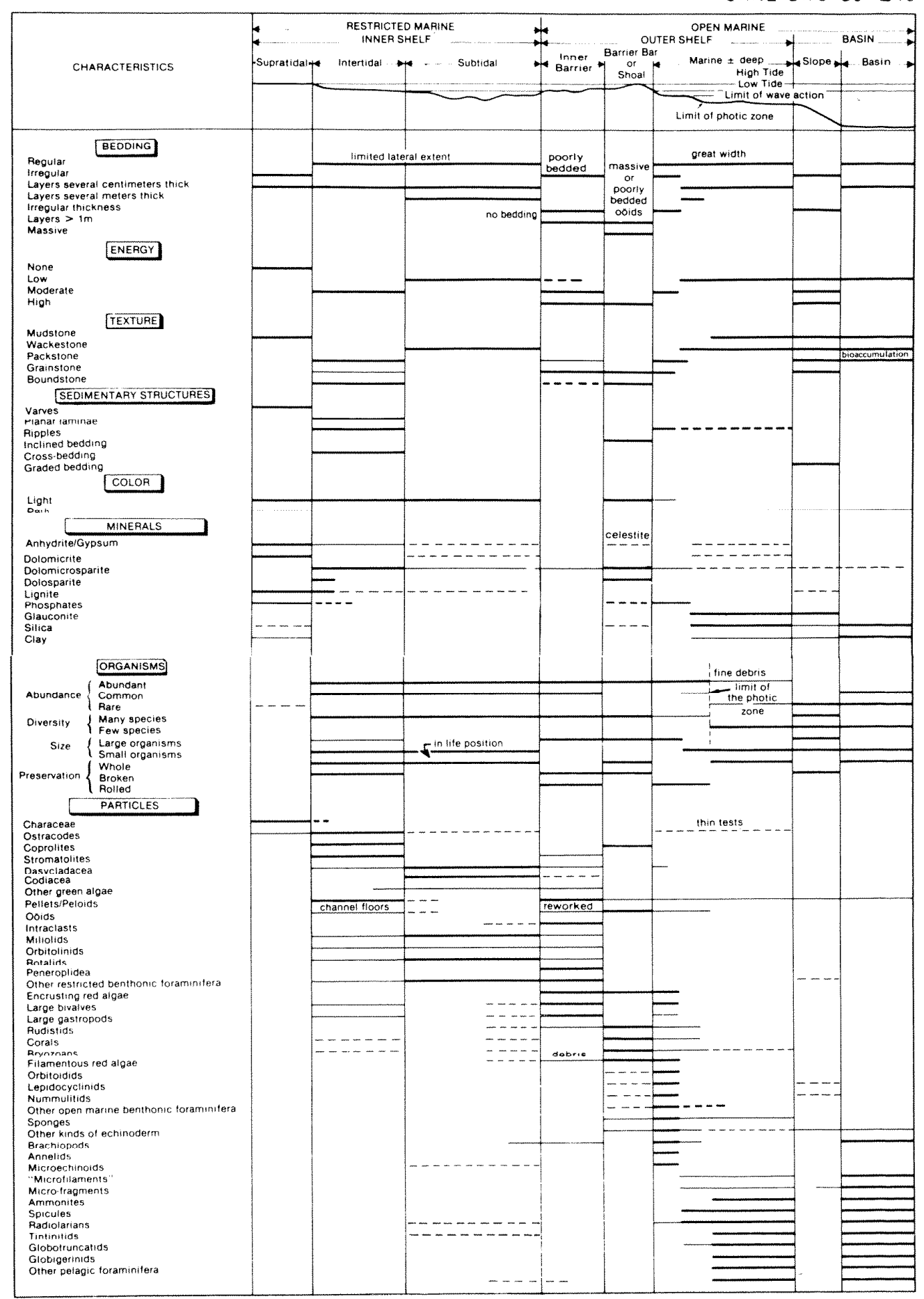

Fig. E.5.4.1. Characteristics of sediments deposited in various environments of Reeckmann and Friedman model (REECKMANN 1982), emphasizing importance of various skeletal types. 
ORNL DWG 85-241

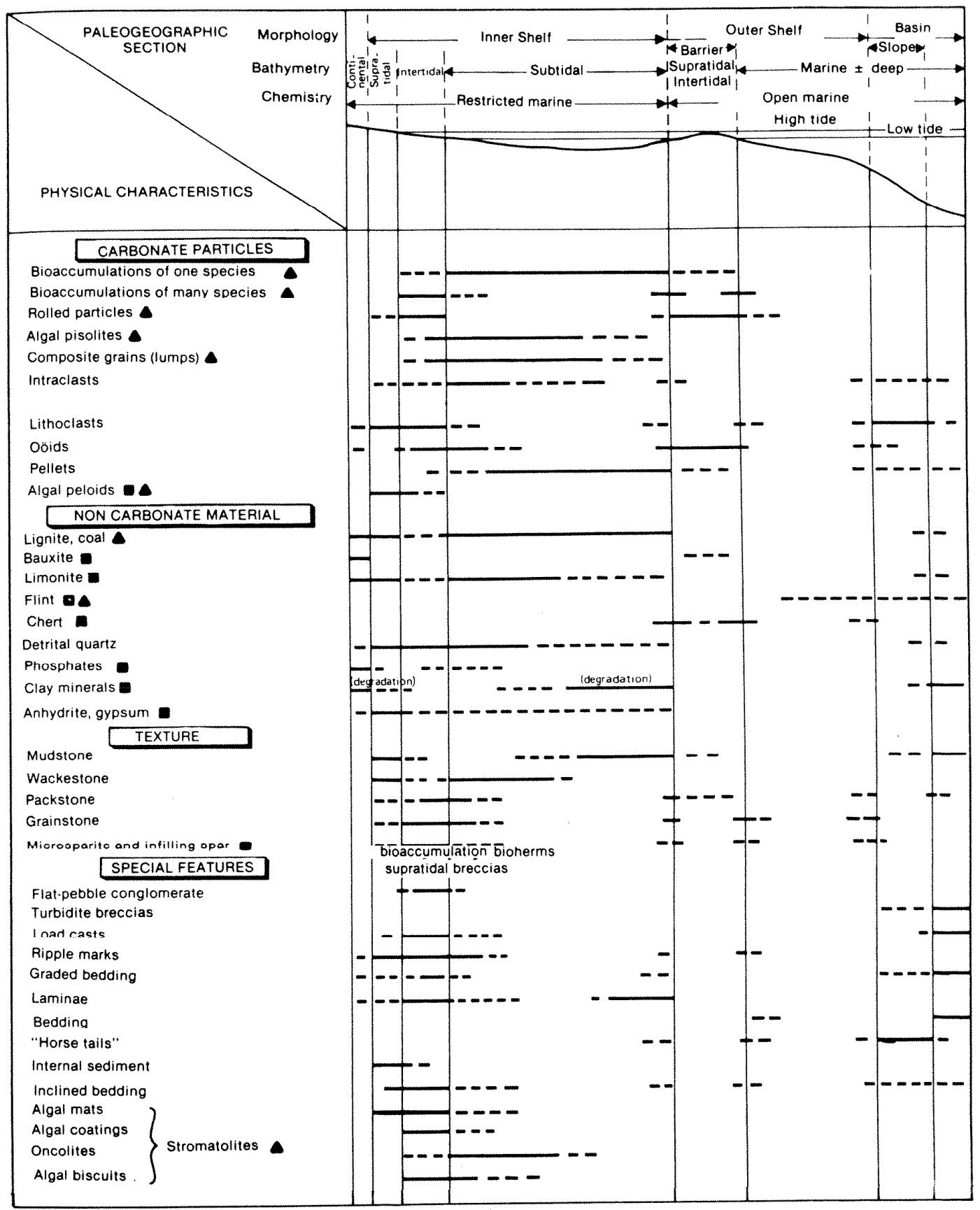

Fig. E.5.4.2. Characteristics of sediments deposited in various environments of Reeckmann and Friedman mode1 (REECKMANN 1982), emphasizing nonfoscil particlco and texturc. 
outward from the walls toward the center of pores. It consists of translucent, rather large crystals (20 to several hundred micrometers in dianeter) of variable morphology (BATHURST 1975). It is, of course, a product of diagenesis, and the size and morphology (LONGMAN 1980), as well as the trace and major element geochemistry of the crystals (MILLIKEN 1981), allows recognition of cement precipitated during various stages of the diagenetic history of the rock. In many carbonate grainstones which were originally deposited with high porosity and permeability, the cementation process began in the environment of deposition and essentially occluded all pore space before appreciable burial. Retention of primary pore space is the exception rather than the rule in carbonates. When porosity is found in ancient carbonate rocks, it is usually of secondary origin (that is, it formed after a nonporous stage by later processes).

The second variety of matrix material is called micrite and is the "mud" of carbonate environments. Dunham (DUNHAM 1962) pointed out the importance of currents of removal in interpreting carbonatco, that io, how much of the mud (in the form of micrite) has not been removed by winnowing from the sediment. (This is different from the usual concern with currents of delivery - that is, how strong a current was required to deliver the largest grains found in the sediment.) Thus, concentrating on the finest fraction in carbonate rocks allows some interpretation of the current regime of the environment of deposition, whereas the size of the larger grains present is not a result of delivery of those grains by currents, but instead is a measure of the size of indigenous grain producers. The presence or absence of mud and its relative abundance are important lithologic discriminators in carbonates. Most micrite-rich sediment (as is the case with terrigenous muds) probably had very high porosity, though only moderate permeability, when first deposited. Carbonate muds, however, because of their chemical ability, are quickly altered to an intergrown crystalline fabric (ZANKL 1969), porosity and permeability are reduced virtually to zero, and only secondary processes will reintroduce higher permeability.

In summary, only when expressed in general terms (i.e., fine, medium, coarse) is texture a major lithologic discriminator in carbonate rocks. Mineralogy is a more or less trivial observation in carbonates, except for the easily determined difference between limestone and dolostone. The chief lithologic discriminator in these rocks is the relative abundance of the various component grain types.

\section{E.5.4.1.2 Expected Lateral and Vertical Homogeneity of Lithologies}

As previously discussed in detail in Sect. E.5.2.3, most carbonate environmental arrays are patchy in the extreme, producing a mosaic-like geographic pattern of environments (WILSON 1975). Most distinct environmental areas are relatively small. Because of the near horizontality of mature carbonate shelves and their near-sea-level position, environmental migration directions and speeds tend to have a strong random distribution. The result is a complex, mosaic-like pattern in three dimensions to the lateral distribution of distinct sediment bodies. Many of these tend to have relatively small lateral and vertical dimensinns (that is, one lithologic unit gives way to another rapidly in all directions). 
There are two main circumstances, however, that may yield stratigraphic units of greater than average homogeneity and extent. First, occasionally in a sequence, a more linear subenvironment, such as a shelf-marginal reef or skeletal sandbank, will migrate with time in one direction at a right angle to the environmental trend, yielding a substantially thick and fairly widespread stratigraphic unit. When this happens, the unit produced may have vertical dimensions of many tens of meters and a lateral extent of several to tens of kilometers (BOSELLINI 1984; WALKER 1980; WALKER 1973; HECKEL 1974).

The second circumstance that yields units more homogeneous than average is probably more important here because it may produce even larger and even more homogeneous units. This situation arises when large-scale, post-depositional homogenization occurs over a broad area during diagenetic alteration of limestones to dolostones. At least occasionally in the geological record, this process has led to pervasive dolomitization of one or more formations, producing a more homogeneous unit both vertically and horizontally. Perhaps the best example of the result of this process is the upper Knox Group of Tennessee, Kentucky, and Alabama (CHURNET 1981: HARRIS 1963). Dolomitization, which occurred very soon after deposition and continued later (CHURNET 1981), has ultimately converted large parts of this group to rather homogeneous fine to medium crystalline dolostone. Some groups of beds make up units with a vertical thickness of more than 25 in which can be confidently traced laterally for $10 \mathrm{~km}$ or more.

\section{E.5.4.2 BEDDING AND PRIMARY STRUCTURES}

The bedding characteristics of carbonate rocks were discussed in Sect. E.5.3.2 (see especially Fig. E.5.3.2).

Because of the ubiquity and thoroughness of the cementation process within beds of carbonate rocks, the only primary structures of significance are the surfaces between beds of differing lithology (i.e.. bedding planes). These commonly remain as more or less open cracks long after deposition and may act as pathways for fluid migration at considerable depth of burial.

\section{E.5.4.3 NATURE OF NONCARBONATE INTERBEDS}

In the author's experience during the careful field measurement of thousands of meters of carbonate stratigraphic sections, shale was found to be the overwhelmingly dominant type of rock found interbedded with carbonate rocks. Usually there is a striking separation of the two 1ithologies, with each occurring as rather pure end members in separate beds. The carbonates often contain little noncarbonate material, and the shales are made up largely of such material. Interbedding may occur at all scales from thin shales in a dominantly limestone sequence to the reverse relationship between the two rock types. The most common occurrence, however, is thin (2- to $10-\mathrm{cm})$ shale beds intercalated with thin $(5-$ to $20-\mathrm{cm})$ limestone beds. Such a sequence contains many fluidflow pathways (the bedling planes), and tends, therefore, to have high fluid transmissivity. 
Nonetheless, sequences do occur in which coarser grained terrigenous clastic beds alternate with layers of carbonate rock (DRIESE 1984). Such sequences often show some cyclicity and usually are produced by the interplay between two adjacent, though entirely different, environments such as eolian dunes which encroach upon adjacent, marginal marine, carbonate tidal flats. Under these or other similar mixed environmental circunstances, carbonates may be interlayered with many other kinds of sedimentary rocks. As indicated earlier, such mixed environmental patterns are less common than relatively purer carbonate depositional regimes (WALKER 1983).

Finally, parts of the geologic record - especially in sequences of Permian and more rarely of Jurassic age - are characterized by carbonateevaporite stratigraphic successions. In these, limestone or dolostone beds are interspersed with beds of anhydrite, gypsum, or even rock salt (see the Subtask Report on the Geology of Anhydrock, Appendix E.6). This kind of mixed carbonate and evaporite sequence is, however, quite rare compared to purer sequences.

\section{E.5.4.4 SECONDARY STRUCTURES}

Carbonate rocks tend to behave in a brittle fashion during deformation, so they are usually characterized by fracture patterns. These of ten show no evidence of differential movement of fracture walls, so they may be classified as joints. Little research has been done on joint patterns in carbonate rock sequences, so most of the observations made here are based on the author's own field experience.

In carbonate sequences which are thinly bedded (beds from 1 to $\sim 20 \mathrm{~cm}$ thick), jointing is usually relatively closely spaced, with individual fractures on the order of 10 to $50 \mathrm{~cm}$ apart. These sequences also tend to (but do not always) have interbeds of fine-grained terrigenous clastic sedimentary rock (shale), so fluid transmissivity is isotropic. As interbeds decrease in abundance, and/or as bed thickness in more massive carbonates increases, joint spacing increases. Thicker bedded (more than $1-\mathrm{m}$ ) and purer carbonate sequences of ten have joint spacing in excess of $1 \mathrm{~m}$.

Perhaps more important than the abundance or spacing of jointing is the tendency for joint fractures in carbonate rocks to "self-heal." This is because of the relatively high solubility of carbonate minerals in even slightly acidic formation waters and the tendency for dissolved carbonate to reprecipitate with any fracture system. So, although in surface outcrops carbonate rocks often show abundant open fractures, at a slightly greater depth fractures belonging to the same system may have been healed by precipitation of calcite. This makes fracture pattern information obtained from outcrop less than totally reliable as a predictor of subsurface patterns.

Finally, the apparent behavior of carbonate rocks under greater confining pressures and at low strain rates is less well understood. Suffice it to say that many ancient carbonate sequenres show clear 
evidence of plastic behavior (through flowage-folding) at some previous stage in their history. Presumably an increase in temperature would encourage such behavior.

\section{E.5.4.5 POROSITY AND PERMEABILITY PATTERNS}

In general, porosity decreases with time in carbonate sediments. This diminution in porosity begins in the depositional environment, where initial porosities may be as high as $75 \%$ by volume (30\% in grain stones) and continues through various stages of burial, as shown in Fig. E.5.4.3. Rarely, substantial initial porosity is preserved, but porous carbonate rocks generally owe their porosity and permeability to secondary regeneration of porosity after burial. Initial porosity sites and types vary widely trom environment to environment across an onshore-ottshore profile, as shown in Fig. E.5.4.4. In some environments, initial porosity is intraparticle, such as internal cavities within fossils; in others, it is interparticle (interstitial, as hetween grains in skeletal sands); in still other environments, initial porosity may cut across grains as in bioerosional cavities in reef masses. There is a strong tendency for highest initial porosities to occur in shelf-marginal, current-agitated environments, such as skeletal sandbanks and reets, while much lower initial porosities are found in on-shelf, poorly winnowed sediments with a high carbonate mud content. Another peak in initial porosity is found in intertidal sediments where desiccation and high current activity may disrupt the sediment and leave a dilatant fabric.

As soon as the sediment passes (by burial) out of the zone of active sedimentation, processes begin which close initial porosity or, more rarely, enlarge it; other processes may begin to produce secondary porosity. Ultimately it is usually the latter set of processes that is more important in determining the final porosity and permeability found in the rock. These processes of the burial environment and their effects on the sediments of various depositional environments of an on- to off-shore profile are shown in Fig. E.5.4.5. Because this figure was initially

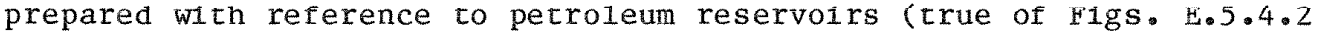
and $E \cdot 5 \cdot 4.3$ as we11), the labels "favorable" and "unfavorable" refer to those processes which produce highly porous reservoirs ("favorable") versus those which do not. Thus, for the present purpose, where minimal porosity and permeability are the features sought, those situations favorable to hydrocarbon reservoir production might be considered to be unfavorable for our purposes.

The highest porosities in most carbonate sequences are found in parts of the sequence which were deposited in shelf-marginal environments such as reefs. These sediments often have high initial porosities and, because they are lithified early, are more subject to the development of fracture porosity.

Finally, a comparison can be made between the porosity and permeability of dolomitic limestones and those of terrigenous sandstones. Under most circumstances, dolomitic limestones will have the highest porosities and permeabilities of any carbonate rocks, because the 


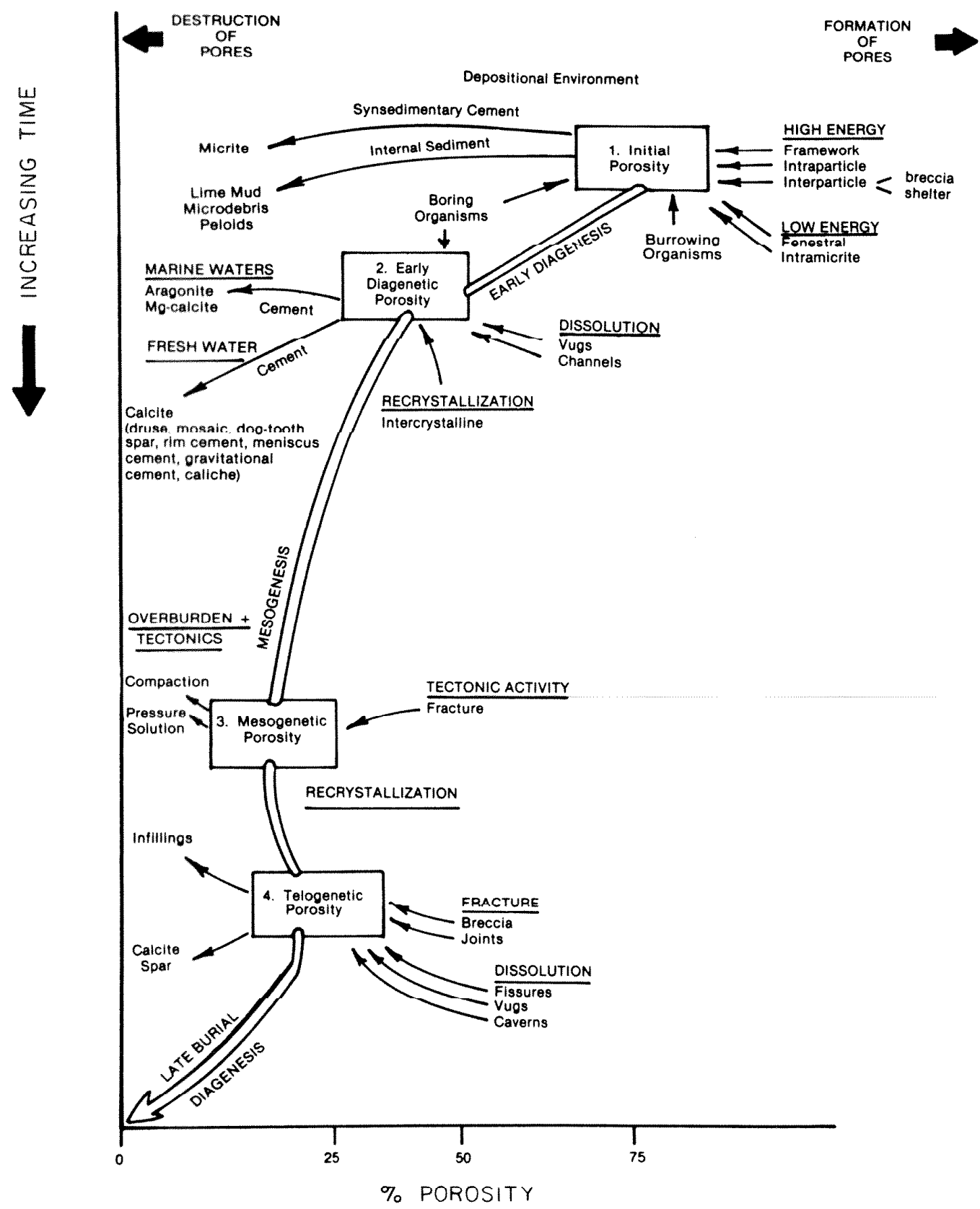

Fig. E.5.4.3. Processes that influence porosity and permeability after burial of carbonate rocks. From Reeckmann and Friedman (REECKMANN 1982). 


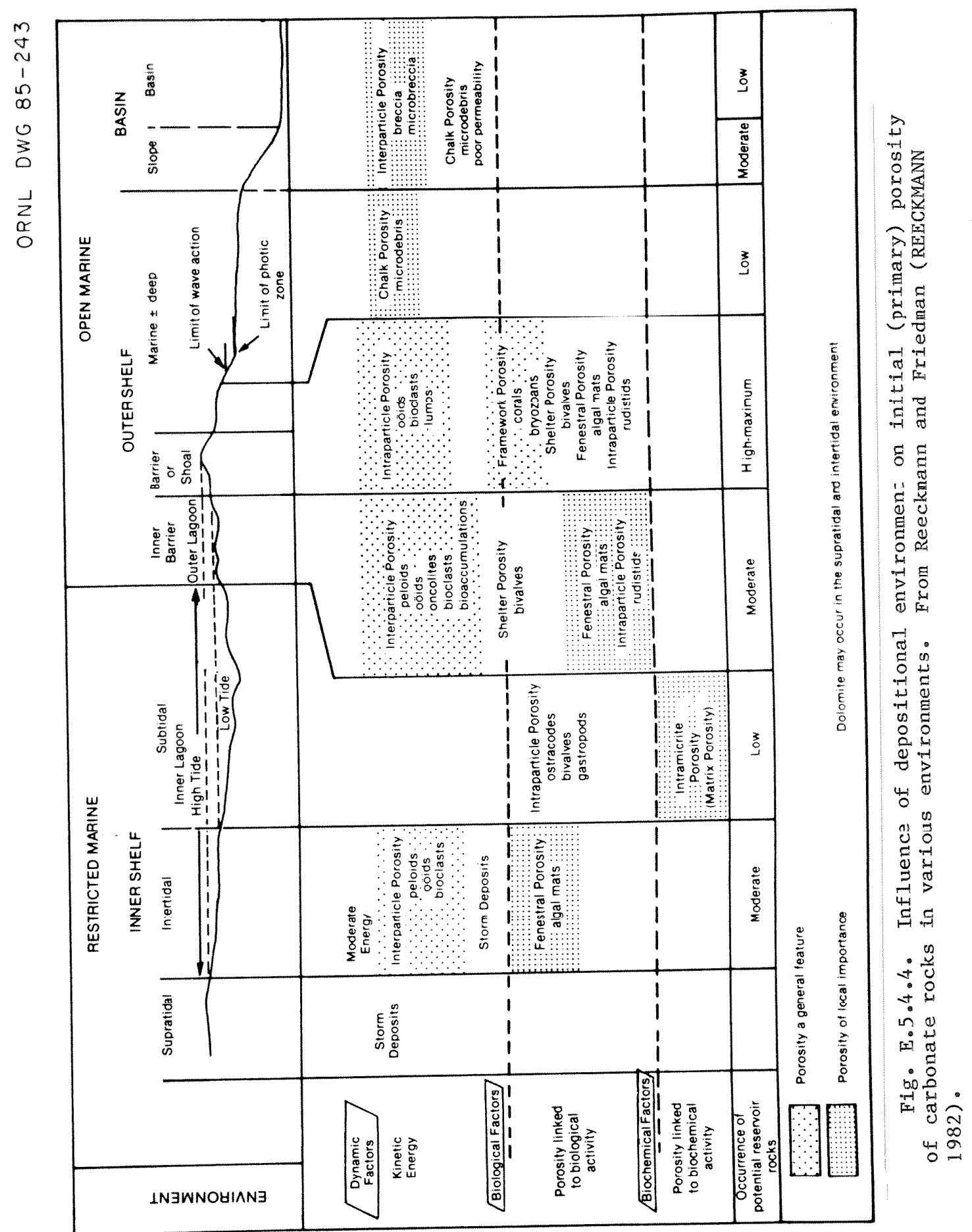




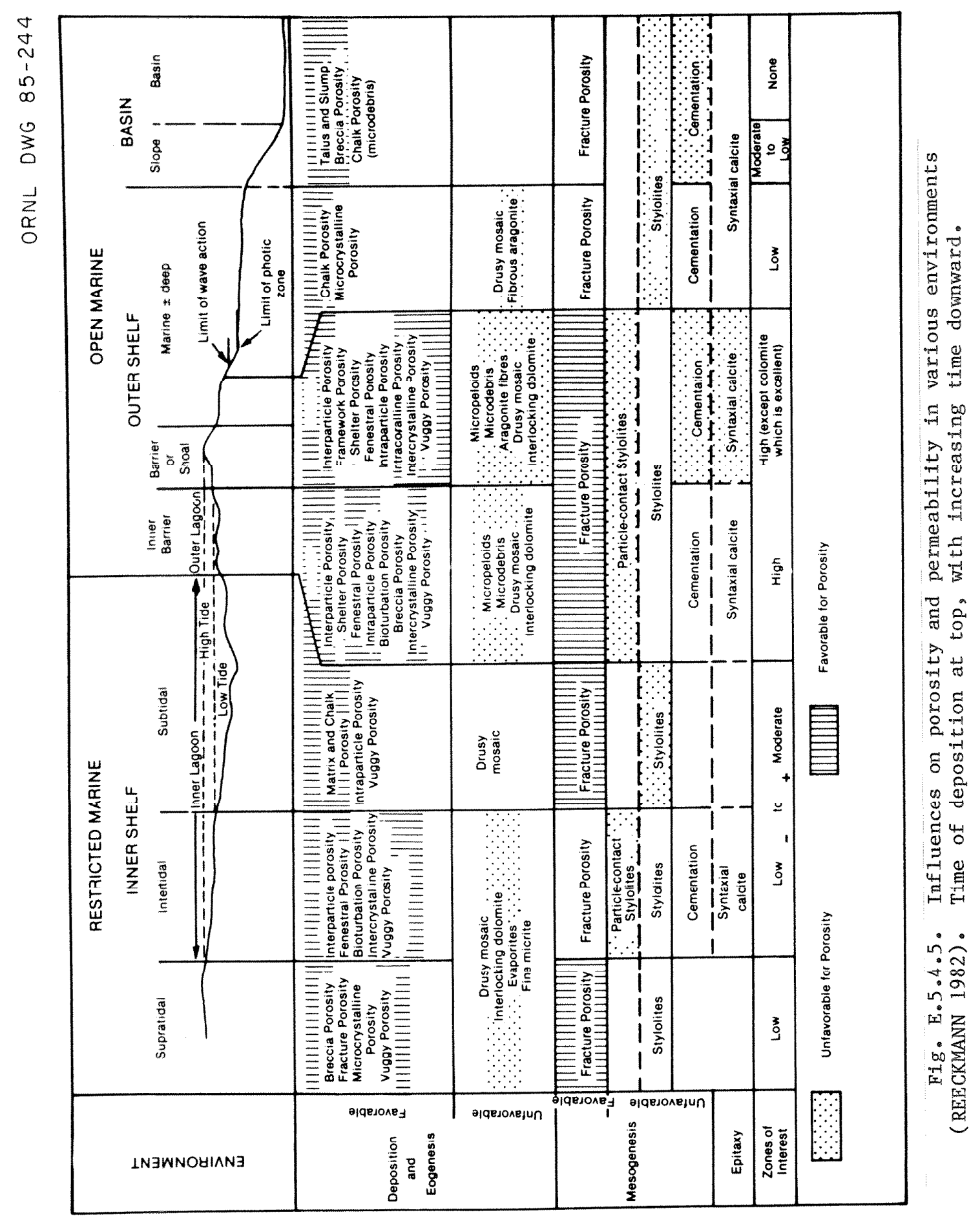


dolomitization process is a major producer of secondary porosity. Fig. E.5.4.6, drawn from Bulnes and Fitting (BULNES 1945), shows porosity and perneability measurements from 2200 sand and sandstone samples (upper part of figure) and 1200 dolomitic limestone specimens (1ower part of figure). The major conclusion that can be drawn from these data is that dolomitic limestone samples have a much higher permeability than sandstone samples when both rock types have the same porosity value (the difference in permeability is often as much as an order of magnitude). This relationship probably exists because the pores in carbonate rocks tend to be larger than those in terrigenous sandstones, for those of the former of ten cut across component grains and those of the latter are mostly intergranular. Thus, pore interconnection is greater and pore-throat diameters are larger in dolomitic limestones than in sandstones. Therefore, it is important to note that although dolomitic limestones and dolostones are the most favorable carbonate rock types for repository siting in terms of lateral extent and homogeneity, they are the least favorable in terms of porosity and permeability relationslips. 

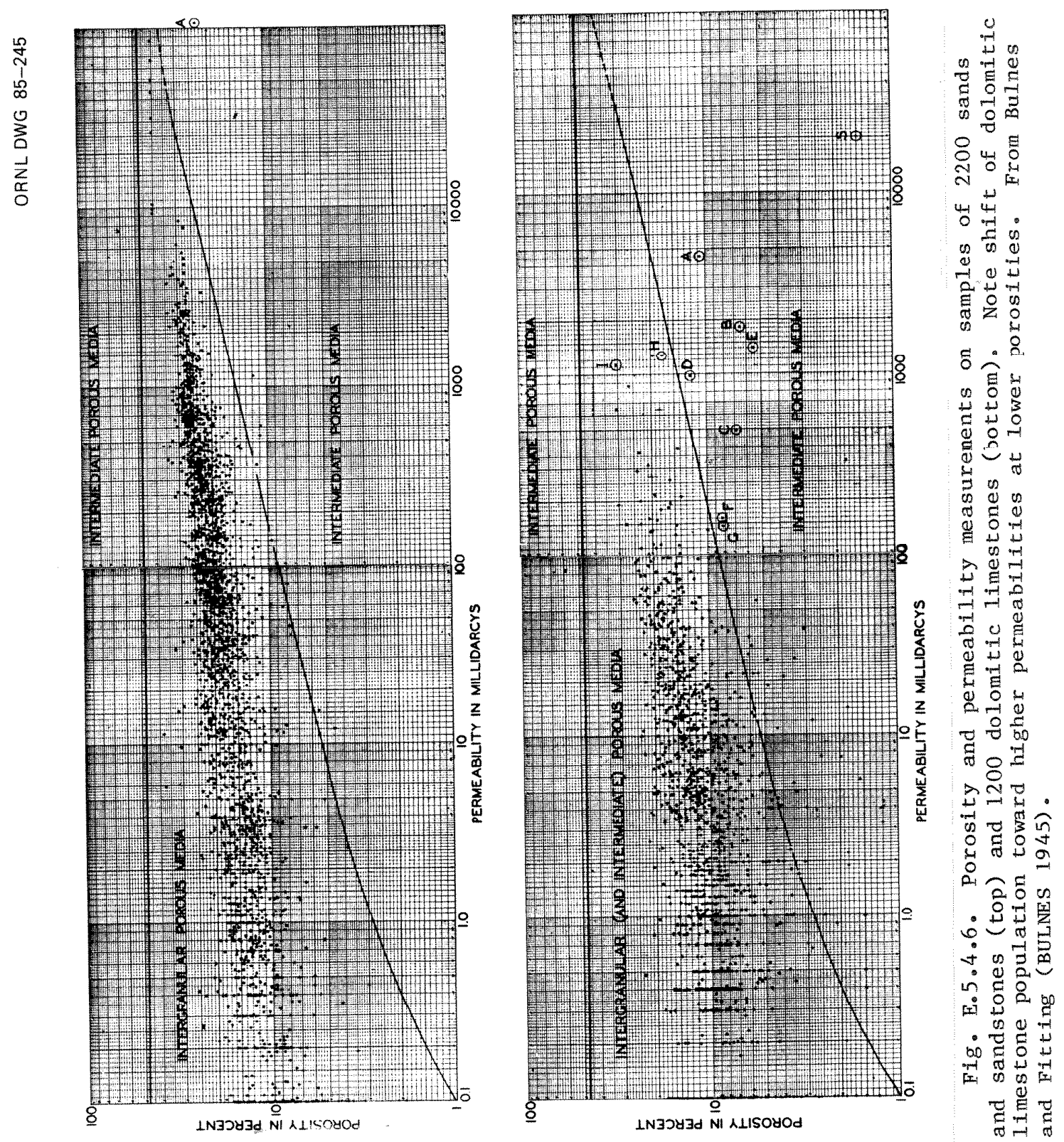


\section{E.5.5 BOUNDING ROCK TYPES}

Because of the generally antithetical relationship between carbonate sediment production and terrigenous material (WALKER 1983; also see Sects. E.5.1.1 and E.5.2.1 of this report), carbonate rock sequences tend to be associated with the distal edges of terrigenous depositional regimes that are farthest away from the land source. As a result, carbonate rocks usually grade laterally into shales. When deposition has been continuous through time, carbonate sequences also tend to be underlain and overlain by shales. This is one of the reasons that porous carbonates make excellent hydrocarbon reservoirs, for overlying shales act as a seal against fluid loss (REECKMANN 1982).

It is also true that shales tend to be the dominant rock type intercalated within carbonate rock sequences. Even thick carbonate units intcrnal to such ocquencca tend to be bounded by shales when they are not bounded by different carbonate 1ithologies.

on the other hand, temporal breaks in deposition are common in the geologic record and, because carbonate sequences are deposited very near to sea level (Sect. E.5.2.1), disconformable boundaries which mark breaks in deposition are perhaps more common above and below carbonate sequences than around other types of rocks (WILSON 1975). Where these deposition. breaks occur (for example, above the Upper Cambrian through Lower Ordovician Beekmantown-Knox-E1lenburger groups), the bounding lithologies are much less predictable. In these cases, the overlying lithologies may have been deposited in an environmental pattern totally unrelated paleogeographically and temporally to that in which the carbonate sequence was formed. Thus, such a sequence might be bounded by any sedimentary lithology. 


\section{E.5.6 REACTION TO EXTERNAL EVENTS}

Some of the external events to which a carbonate sequence, once deposited, might subsequently react have been treated in previous sections. However, for the sake of clarity, the expected reaction to these events will be briefly sumarized here.

\section{E.5.6.1 TECTONIC EVENTS}

Most carbonate rocks react to tectonic stresses by brittle failure, except under high confining pressures and elevated temperatures. Under the latter conditions, carbonate rocks may deform plastically. Fractures tend to be selt-healing in carbonate rocks because of the solubility of carbonate minerals and subsequent precipitation of this material in open fractures. This precipitational healing is much slower than the flowage healing seen in rock salt.

\section{E.5.6.2 DISSOLUTION}

Carbonate rocks consist largely of minerals (calcite and dolomite) that are highly soluble in most natural, slightly acidic, fresh waters. However, as is discussed in the Report on the Geochemistry of Sedimentary Rocks, Appendix D, the carbonate chemical system is one that is buffered. The result is that dissolution will continue unabated in an open system with a high throughput of groundwater, but will be quickly limited by the buffering action of the system in a closed or even a semiclosed system.

Nonetheless, terrains underlain by carbonate rock sequences are often characterized by karst topography as a result of subterranean dissolution of carbonate rock, production of a thick surficial residuum by weathering dissolution, and subsequent collapse and movement of the residuum. Many such terrains are also famous for their complex systems of caves produced by subsurface dissolution.

\section{E.5.6.3 WEATHERING}

As mentioned, the relatively high solubility of carbonate rocks makes the weathering process largely one involving dissolution and accumulation of residue. However, the mineral reactions which occur during the process are not well understood, and, although the residuum usually consists largely of clay minerals and iron oxides and hydroxides, how much of this material is truly residual and how much is formed de novo in place is still an enigma. 


\section{E.5.7 RESOURCES}

About $60 \%$ of the world's hydrocarbon reserves occur in carbonate sequences. In addition, major base metal reserves occur in stratiform mineral deposits associated with carbonate rock sequences (for example, in Ordovician carbonates of the middle and upper Mississippi River Valley and in central and eastern Tennessee). 


\section{E.5.8 SUMMARY}

Table E.5.8.1 summarizes the general properties of carbonate rocks in the various depositional environments that were used as the organizational basis for discussion in this report. Such a summary is, of necessity, very generalized. For any given unit deposited in any one of the environments, the properties may be found to be significantly different from those presented in the table as characteristic.

Table E.5.8.1 Summary of characteristic features of carbonate rock ${ }^{a}$

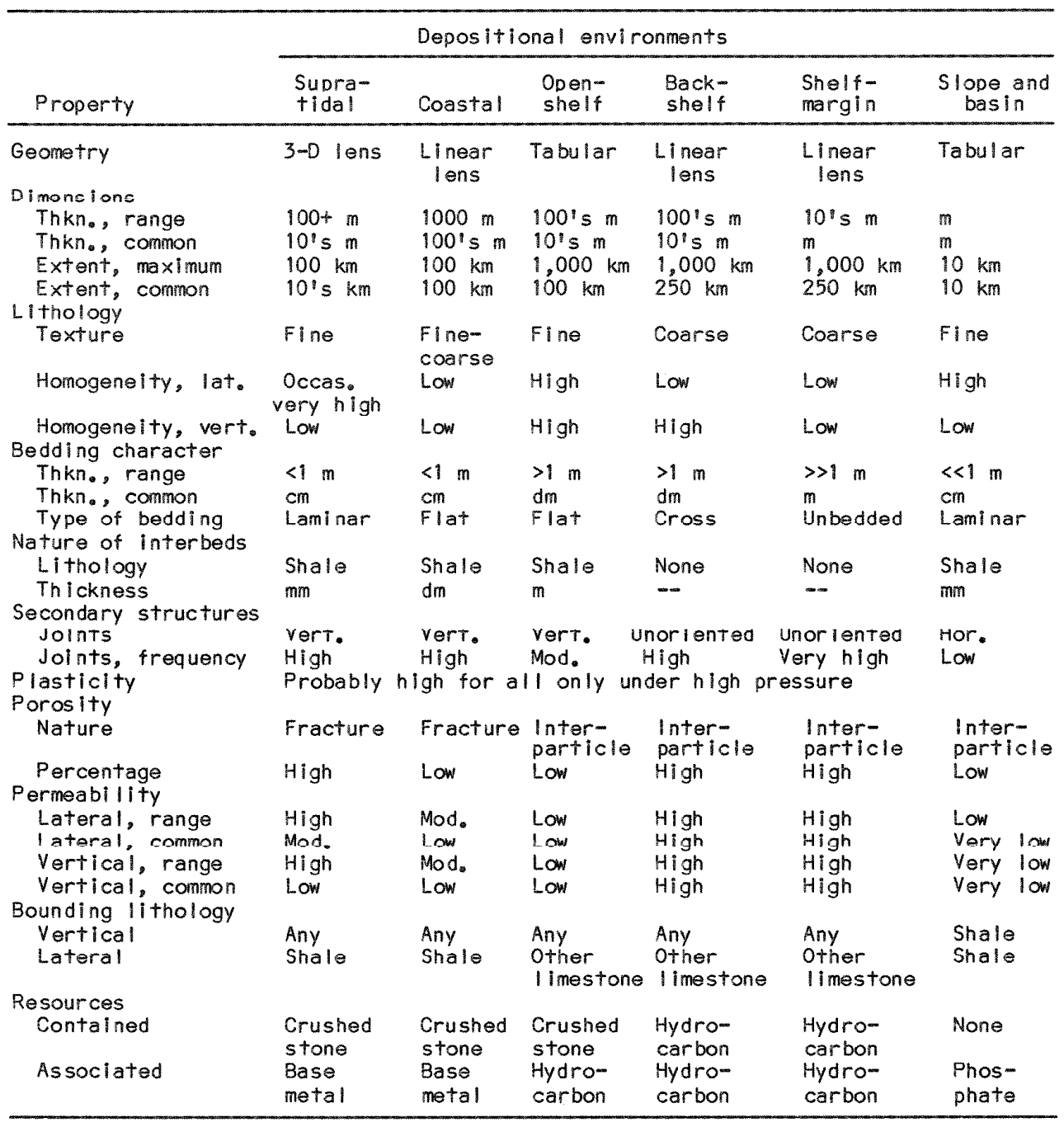

The most characteristic reaction of carbonate rocks to external factors is

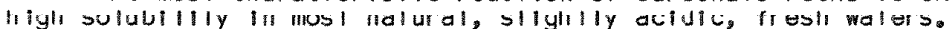




\section{E.5.9 REFERENCES}

BARIA 1982. L. R. Baria, et a1., "Upper Jurassic Reefs of the Smackover Formation, United States Gulf Coast," Am. Assoc. Pet. Geo1. Bul1. 66, 1449 (1982).

BATHURST 1975. R. G. C. Bathurst, Carbonate Sediments and Their Diagenesis, E1sevier, Amsterdam, 1975, p. 658.

BOSELLINI 1984. A. Bosellini, "Progradation Geometries of Carbonate Platforms: Examples from the Triassic of the Dolomites, Northern Italy," Sedimentology $31,1(1984)$.

BULNES 1945. A. C. Bulnes and R. U. Fitting, Jr., "An Introductory Discussion of the Reservoir Performance of Limestone Formations," Pet. Technol., (1945).

CHURNET 1981. H. G. Churnet, K. C. Misra, and K. R. Walker, "Genetic Implications of Trace Eloment Distribution patterns in the Upper Knox Carbonate Rocks, Copper Ridge District, East Tennessee," Sediment Geol., $30,173(1981)$.

DRIESE 1984. S. G. Driese and R. H. Dott, "Mode1 for Sandstone "Cyclothems" Based on Upper Member of Morgan Formation (Middle Pennsylvanian) of Northern Utah and Colorado," Am. Assoc. Pet. Geol. Bull. 68, 574 (1984).

DUNHAM 1962. R. Dunham, "Classification of Carbonate Rocks According to Depositiona1 Texture," in W. Ham, Classification of Carbonate Rocks, Am. Assoc. Pet. Geo1. Mem. 1, 108 (1962).

FLORES 1977. R. M. Flores, T. L. McMillan, and G. E. Walters, "Lithofacies and Sedimentation of Lower Permian Carbonates of the Leonard Mountain Area Glass Mountains, Western Texas," J. Sediment-Pet- 17, 1610 (1977).

FOLK 1962. R. Folk, "Spectral Subdivision of Limestone Types," in W. Ham, Classification of Carbonate Rocks, Am. Assoc. Pet. Geol. Mem. 1, 62 (1962).

FRIEDMAN 1965. G. Friedman, "Terninology of Crystallization Textures and Fabrics in Sedimentary Rocks," J. Sediment. Pet. 35, 643 (1965).

FRIEDMAN 1978. G. M. Friedman and J. Sanders, Sedimentology, John Wiley and Sons, New York, 1978, p. 792.

GINSBURG 1975. R. Ginsburg (ed.), Tidal Deposits: A Casebook of Recent Examples and Fossil Counterparts, Springer-Verlag, New York, 1975, p. 428.

GROVER 1983. G. Grover and J. F. Read, "Paleoaquifer and Deep-Burial Related Cements Defined by Regional Cathodoluminescence Patterns, Middle Ordovician Carbonates, Virginia," Am.Assoc. Pet. Geol. Bu11. 67, 1275 (1983). 
HARDIE 1977. A. Hardie, Sedimentation on the Modern Carbonate Tidal Flats of Northwest Andros Island, Bahamas, The Johns Hopkins University Press, Baltimore, The Johns Hopkins Untversity Studies in Geology, No. 22, 1977, p. 202 .

HARRIS 1963. L. D. Harris, "Dolomitization Model for Upper Cambrian and Lower Ordovician Carbonate Rocks in the Eastern United States," J. Res. U.S. Geol. Surv. 1, 63 (1963).

HECKEL 1974. P. H. Hecke1, "Carbonate Build-ups in the Geologic Record: A Review," in L. F. Laporte, Reefs in Time and Space, Soc. Econ. Paleontol. Mineral. Spec. Publ. 18, 90 (1974).

HLLLS 1984. J. M. Hills, "Sedimentation, Tectonism and Hydrocarbon Generation in Delaware Basin, West Texas, and Southeastern New Mexico," Am. Assoc. Pet. Geol. Bull. 68, 250 (1984).

IRWIN 1965. M. Irwin, "General Theory of Epeiric Clear Water Sedimentation," Am. Assoc. Pet. Geol. Bul1. 49, 445 (1965).

KRUMBEIN 1963. W. Krumbein and L. Sloss, Stratigraphy and Sedimentaion, W. H. Freemen, San Francisco, 1963, p. 660.

LAPORTE 1968. L. Laporte, "Recent Carbonate Environments and Their Significance to Carbonate Studies," in E. Drake, Evolution and Environment, Yale University Press, New Haven, Conn., 1968, p. 229.

LONGMAN 1980. M. Longman, "Carbonate Diagenetic Textures from Nearshore Diagenetic Environments," Am. Assoc. Pet.Geo1. Bu11. 64, 461 (1980).

LUMSDEN 1971. D. Lumsden, "Facies and Bed Thickness Distribution of Limestones," J. Sediment. Pet. 41, 593 (1971).

MAZZULO 1978. S. J. Mazzulo, "Early Ordovician Tidal Flat Sedimentation, Western Margin of the Proto-Atlantic Ocean," J. Sediment. Pet. 48, 49 (1978).

MILLIKEN 1981. K. L. Milliken, L. S. Land, and R. G. Loucks, "History of Burial Diagenesis Determined from Isotopic Geochemistry, Frio Formation, Brazoria County, Texas," Am. Assoc. Pet. Geo1. Bu11. 65, 1397 (1981).

MOORE 1981. C. H. Moore and Y. Druckman, "Buria1 Diagenesis and Porosity Evolution, Upper Jurassic Smackover, Arkansas and Louisiana," Am. Assoc. Pet. Geol. Bull. 65, 597 (1981).

MOUNT 1984. J. Mount, "Mixing of Siliciclastic and Carbonate Sediments in Shallow Shelf Environments," Geology 12, 432 (1984).

READ 1982. J. Read, "Carbonate Platforms of Passive (Extensiona1) Continental Margins: Types, Characteristics, and Evolution," Tectonophysics. 81, 195 (1982).

REECKMANN 1982. A. Reockmann and G. Friedman, Exploration for Carbonate Petroleum Reservoirs, John Wiley and Sons, New York, 1982, p. 213. 
RICH 1951. J. Rich, "Three Critical Environments of Deposition and Criteria for Recognition of Slope Deposits in Each of Them," Geol. Soc. Am. Bu11. $62,1(1951)$.

SHAVER 1977. R. Shaver, "Silurian Reef Geometry-New Dimensions to Explore," J. Sediment. Pet. 47,1409 (1977).

SHAW 1965. A. Shaw, Time in Stratigraphy, McGraw-Hill, New York, 1965, p. 353 .

THACKER 1977. J. Thacker and K. Anderson, "The Geologic Setting of the Southeast Missouri Lead District - Regional Geologic History, Structure, and Stratigraphy," Econ. Geo1.72, 339 (1977).

WALKER 1973. K. R. Walker and K. F. Ferrigno, "Major Middle ordovician Reef Tract in East Tennessee," Am. J. Sci. 273-A, 294 (1973).

WALKER 1980. K. Walker, T. Broadhead, and $F$. Keller, Middle Ordovician Carbonate Shelf to Deep Water Basin Deposition in the Southern Appalachians, University of Tennessee, Knoxvi11e, Tenn., 1980, p. 120.

WALKER 1983. K. Walker, G. Shanmugam, and S. Ruppe1, "A Model for Carbonate to Terrigenous Clastic Sequences," Geol. Soc. Am. Bu11. 94 , 700 (1983).

WILSON 1974. J. Wilson, Characteristics of Carbonate Platform Margins, Am. Assoc. Pet. Geo1. Bul1. 58, 810 (1974).

WILSON 1975. J. Wilson, Carbonate Facies in Geologic History, SpringerVerlag, New York, 1975, p. 471.

ZANKL 1969. H. Zank1, "Structural and Textural Evidence of Early Lithification in Fine-Grained Carbonate Rocks," Sedimentology 12, (1969). 


\section{E.5.10 GLOSSARY}

Allochem - discrete "organized" particle within a carbonate rock such as a fossil grain, an intraclast, or an ooid; term used in Folk's classification.

Basin - a topographically low area in which sediment tends to accumulate, as distinct from a depocenter.

Cement - precipitated crystalline material filling the interstices within a particulate sediment or filling other kinds of pore space within the rock. In carbonate rocks, this material is usually calcite, more rarely dolomite, and, even more rarely, other minerals.

Depocenter - an area of the earth's crust which subsides over a long period and, during subsidence, is the site of deposition of chick sequences of sedimentary rocks, as distinct from a basin.

Fabric - the spatial relationships between particles within a rock.

Intraclast - a "ripped-up" particle of previously deposited sediment (such as a mud flake) that subsequently is included within another sediment aggregate.

Micrite - microcrystalline calcite matrix material (the "mud" of carbonate rocks). Term from Folk's classification.

Ooid - concentrically laminated, physicochemically precipitated carbonate around a nucleus. Usually about 1 to $2 \mathrm{~mm}$ in diameter, and spherical. Modern ooids are composed of the mineral aragonite $\left(\mathrm{CaCO}_{3}\right)$; ancient ones are calcite $\left(\mathrm{CaCO}_{3}\right)$.

Pellet or Pelloid - usually ellipsoidal grain composed of micrite (carbonate mud); most range in size up to about $1 \mathrm{~mm}$. Smaller ones probably fecal in origin.

Spar or Sparite - "water-clear," translucent calcite as a crystalline mosaic, usually filling former voids in carbonate rocks (rarely dolomite instead of calcite). Term from Folk's classification.

Terrigenous - literally, land-derived; used to refer to sediment whose origin is as material eroded from older rocks on land, which is then transported to the environment of sediment deposition.

Texture - the size and shape of particles within the rock. 
This page intentionally left blank 
APPENDIX E.6

GEOLOGIC CHARACTERIZATION OF ANHYDROCK

KENNETH S. JOHNSON

SERGE GONZALES

EARTH RESOURCE ASSOCIATES, INC. 
This page intentionally left blank 
CONTENTS

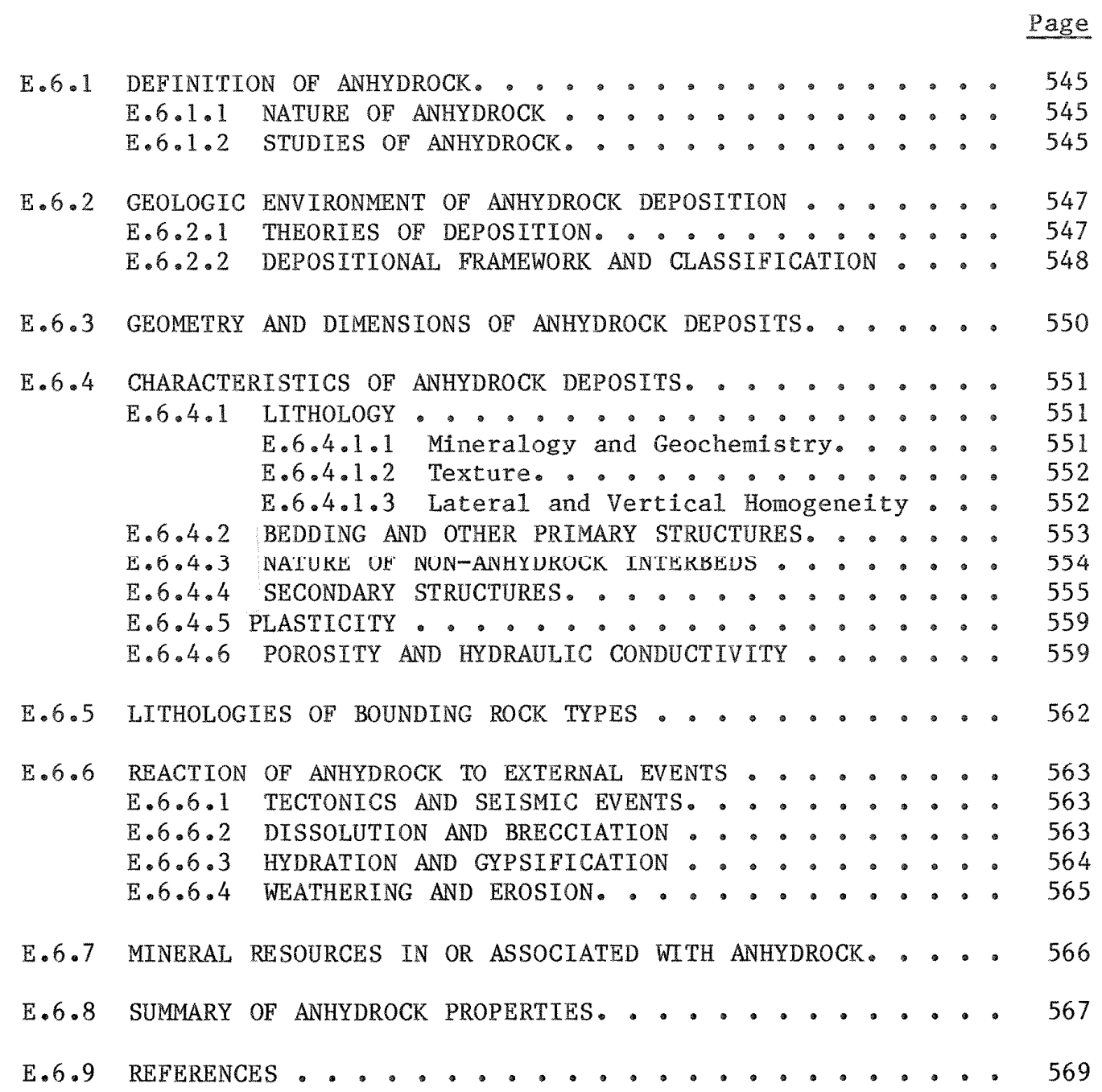


This page intentionally left blank 


\section{E.6.1 DEFINITTON OF ANHYDROCK}

\section{E.6.1.1 NATURE OF ANHYDROCK}

Anhydrite is the name given to the mineral compound composed of anhydrous calcium sulfate $\left(\mathrm{CaSO}_{4}\right)$ : Anhydrock is the name given to the sedimentary rock that consists primarily of anhydrous calcium sulfate. Anhydrock beds as much as 30 to $100 \mathrm{~m}$ thick have been deposited in a number of major evaporite basins in the United States, and many of these deposits are uniformly thick and homogeneous over areas of $1000 \mathrm{~km}^{2}$ or more. Gypsum, a mineral and sedimentary rock consisting of hydrous calcium sulfate $\left(\mathrm{CaSO}_{4} \cdot 2 \mathrm{H}_{2} \mathrm{O}\right)$, is commonly associated with anhydrock. The two calcium sulfate minerals may interchange through recrystallization accompanied by the gain or loss of two molecules of chenically combined water. These transformations occur because anhydrite is the more stable form of calcium sultate at the elevated temperatures and pressures of deep burial, whereas gypsum is more stable at the lower temperatures and pressures found in the shallow zone of circulating groundwaters.

\section{E.6.1.2 STUDIES OF ANHYDROCK}

Anhydrock has been studied on a limited scale as a potential disposal medium in Switzerland, Spain, Great Britain, and the United States (GONZALES 1980; GONZALES 1982). The United States effort, initiated by the U.S. Geological Survey in 1979, is a comprehensive literature survey (JOHNSON, in preparation) inventorying the age, stratigraphy, structure, thickness, depth, distribution, associated lithologies, and purity of al1 anhydrock deposits in the nation (Fig. E.6.1.1). Additional generic and site-specific data on the hydrologic, physical, and geochemical characteristics of anhydrock important for its evaluation as a potential host rock for radioactive waste disposal have been gathered by Diehl (in preparation), Thordarson (in preparation), and Potter (in preparation); their data on anhydrock properties are summarized mainly from studies conducted in Germany, Switzerland, and France, where anhydrock has been excavated in mines and tunnels. 


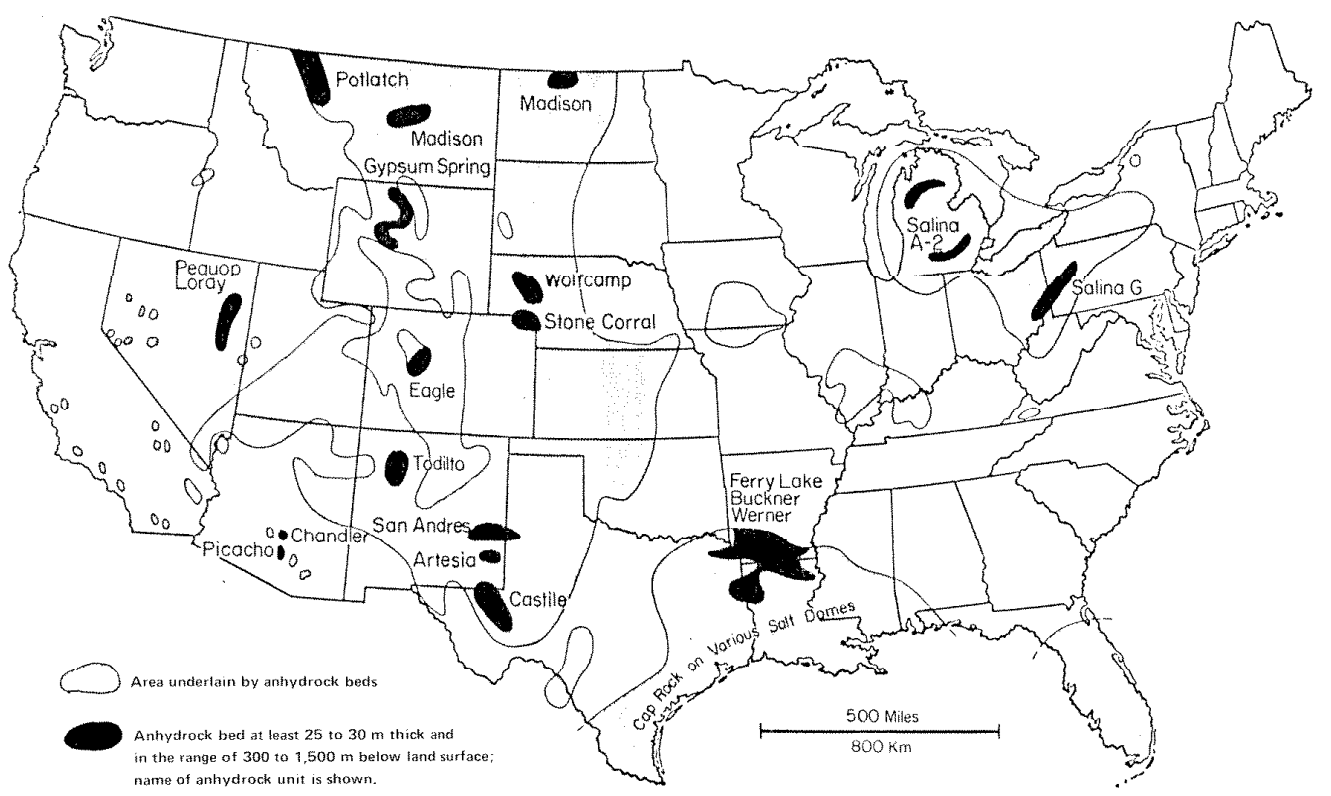

Fig. E.6.1.1. Map of the United States showing distribution of anhydrock deposits and those areas where individual anhydrock beds are thick and at moderate depths (from JOHNSON, in preparation). 


\section{E.6.2 GEOLOGIC ENVIRONMENT OF ANHYDROCK DEPOSITION}

\section{E.6.2.1 THEORIES OF DEPOSITION}

Massive deposits of gypsum and anhydrite form by evaporation of saline sea waters containing calcium sulfate. As water is evaporated, the remaining saline solutions become increasingly saturated with respect to calcium sulfate until, finally, gypsum and/or anhydrite are precipitated. These minerals are therefore referred to as "evaporites," along with similarly formed halite and potash deposits.

The depositional environment responsible for layers of sulfate rock is a much-discussed topic. The classic theory, first developed by ochsenius in his "bar theory," is that deposition occurs in a basin that is intermittently supplied with saline water, when water in the basin is evaporaled. This was accepled, will modiricalions, by Adans (1944), King (1947), Scruton (1953), Anderson (1972), and Dean (1978). Such a basin might be a lagoon, an estuary, or a large inland body of water having partially restricted contact with a larger body of saline water, such as the ocean.

Evaporation of water in a shallow-water or deep-water basin that is separated from the open ocean by a sill or shelf would produce brines of increasing concentration. When the salinity of such a brine reached about five times that of normal seawater, calcium sulfate would begin to precipitate. Continued influx of saline water to the basin would allow the precipitation of a considerable thickness of an essentially monomineralic deposit. Anhydrite should theoretically be the most stable calcium-sulfate mineral to form under most salinity and temperature conditions that are expected in an evaporite basin; however, gypsum is the mineral that generally forms in modern evaporite deposits and in laboratory experiments. The contradiction between theoretical and observed data on precipitation of gypsum or anhydrite remains unresolved.

Examples of modern restricted environments that embody many of the features of the classic, barred evaporite basin include the Gulf of Kara Bogaz on the Caspian Sea (DZENS LITOVSKIY 1962), the Bocana de Virrila on the Peruvian coast (MORRIS 1957), and the northern part of Great Salt Lake, Utah, when it was largely cut off from the main part of the lake by a railroad causeway in 1959 (MADISON 1970; WHELAN 1972). Although these modern settings are believed to simulate the general conditions under which ancient anhydrocks as much as 30-m thick were formed, the modern deposits typically contain beds of gypsum only a few meters thick, or they contain moderately thick evaporite sequences with little or no anhydrock or gypsum. Hence, there is a lack of modern-day analogues for the major thick and extensive anhydrock deposits formed in the geo$\operatorname{logic}$ past.

A recently developed concept for deposition of evaporites is that some of them form by precipitation from evaporating pore water present in unlithified supratidal mud flats or salt flats (called "sabkhes," for the 
Arabic word meaning salt flat) in arid regions. This concept is well covered by Kinsman (1966), Butler (1970), Shearman (1978), and Butler (1982). Studies of modern sediments in the supratidal environment along the Trucial Coast in the persian Gulf, along the shores of Baja, California, and near lagoons along the Gulf Coast show that crystals and nodules of gypsum and/or anhydrite are now forming by displacement of soft sediments in the sabkhas.

Pore-water brines in the sabkha environment are replenished at some localities by saline groundwater drawn upward by capillary action and at other localities by sea water washed over the sabkha during storms and abnormally high tides. Enlargement of the nodules eventually produces a rock unit of nodular gypsum and/or anhydrite. Some geologists have assumed that nodular gypsum in ancient rocks is indicative of a sabkhatype environment of deposition, but others caution that nodular gypsum can also develop in soft sediments beneath a body of water such as a lagoon or othex basin (DEAN 1975).

\section{E.6.2.2 DEPOSITIONAL FRAMEWORK AND CLASSIFICATION}

Attempts at classifying evaporite rocks (KRUMBEIN 1963; SCHREIBER 1978a; FRIEDMAN 1978; SCHREIBER 1982) have primarily produced classifications of depositional environments for evaporites. Whereas these are most successful in classifying salt deposits, they are less successful in classifying anhydrock deposits. The principal attempt at classification of anhydrock (MATKLEM 1969) is based upon structures and textures, and its main value is in standardizing the terminology used to describe anhydrock.

This report, by contrast, establishes a classification of the depositional environments for anhydrock deposits of the conterminous United States; it therefore has its roots in all the similar classifications listed above. Five environments are herein recognized for the principal anhydrock deposits: basin-center, basin-margin, shelf, sabkha, and playa environments.

Basin-center anhydrocks formed within large, deep basins with restricted connection to the open ocean. Evaporation of marine water flowing into the basin produced high-salinity brines from which anhydrite and other evaporite minerals were precipitated. Basin deepening preceded, and probably continued during, anhydrock deposition. Laterally extensive anhydrock deposits more than $30-\mathrm{m}$ thick accumulated in this environment. An example is the Permian Castile Formation of the Delaware Basin.

Basin-margin anhydrocks form at the peripheries of normal marine basins and are separated from the basin by reefs, sills, or other shallowwater zones that restrict free exchange of the waters between the basin and the basin-margin area. The basin-margin environment comprises an extensive area of shallow water in which marine water is evaporated as it traverses the region. Transgressive and regressive cycles of deposition of anhydrock and intcrbodded rocko are typical of this environmont. 
Anhydrock beds are laterally extensive, and they tend to range in thickness from 10 to $30 \mathrm{~m}$. Examples are the Permian San Andres Formation and other anhydrocks of the Permian Basin back-reef area.

Shelf anhydrocks occur within or adjacent to environments where extensive accumulations exist that show no relation to persistent basinal subsidence during deposition. The deposits formed at or near the margins of shallow seas that covered broad areas undergoing relatively slow and uniform subsidence. Irregularly distributed shoals (carbonate banks or clastic accumulations) established deeper water intershoal areas where anhydrite precipitated from evaporating marine water. These anhydrocks have irregular and limited areal extents and commonly range from 10 to $30 \mathrm{~m}$ thick. An example is the Jurassic Buckner Formation on the north side of the Gulf Coast Basin.

Sabkha anhydrocks are formed in a flat, salt-encrusted, desert plain that may be marginal to a body of marine water or that may be inland and far from the sea. Saline groundwaters perneating the land beneath a sabkha are drawn up to the surface by capillary action and evaporated, leaving behind precipitates of anhydrite and other salts as nodules and irregular layers within the preexisting carbonate and/or clastic muds (KINSMAN 1966; BUTLER 1970; SHEARMAN 1978). Sabkha anhydrocks are quite irregular in distribution, and they tend to be only a few meters thick and of restricted areal extent. No examples of thick and persistent sabkha anhydrocks are known in the United States.

Playa anhydrocks are formed in broad, shallow depressions in desert regions that occasional1y are covered with a thin sheet of water. They lack external drainage, and thus the water is evaporated and its dissolved solids are precipitated as anhydrite and other salts (depending upon the chemical composition of the water) on the floor of the playa. playa anhydrocks generally are of limited extent (depending upon the size of the playa) and are but a few meters thick. Exceptions to this, in terms of thickness, are the Miocene anhydrocks in the picacho and the Chandler basins of Arizona. 


\section{E.6.3 GEOMETRY AND DIMENSIONS OF ANHYDROCK DEPOSITS}

The thickness and lateral extent of anhydrock deposits are important criteria in the evaluation of the rock for purposes of this report. Most anhydrocks are latera11y extensive, sheet-1ike deposits that are 3 to $30 \mathrm{~m}$ thick, although some of them are as much as $100 \mathrm{~m}$ thick. Their great lateral extent reflects the predominantly stable conditions in areas where thick anhydrocks accumulated in the geologic past. Basincenter, basin-margin, and shelf environments typically were developed at sites of epeirogenic settling of the Earth's crust. This was conducive to the slow and uninterrupted accumulation of moderately thick to thick anhydrock deposits, provided that the climatic conditions and partial restriction of marine-water influx were appropriate.

Anhydrock deposits as much as $30 \mathrm{~m}$ thick underlie a number of large areas in various parts of the United states (Fig. E.6.1.1). Many major deposits of the basin-center, basin-margin, and shelf environments extend over areas of at least several thousand square kilometers, and their 1 ateral extent generally is $50 \mathrm{~km}$ or more in all directions (JOHNSON, in preparation). Some of the more extensive, thick anhydrock deposits are in the following formations: Castile Formation in the Delaware Basin, about $20,000 \mathrm{~km}^{2}$; Buckner Formation in the Gulf Coast Basin, about 6000 $\mathrm{km}^{2}$; San Andres Formation in the Permian Basin, about $30,000 \mathrm{~km}^{2}$; and Todilto Formation in the San Juan Basin, about $13,000 \mathrm{~km}^{2}$.

Whereas the vast majority of anhydrock beds are less than $10 \mathrm{~m}$ thick, there are 20 anhydrock deposits in the United States that are at least $30 \mathrm{~m}$ thick (Fig. E.6.1.1), and some are more than $100 \mathrm{~m}$ thick (JOHNSON, in preparation). The greatest thickness is found in the Castile Formation of the Delaware Basin, where four separate anhydrock beds are each 30 to $105 \mathrm{~m}$ thick and are separated by salt units of nearly equal thickness.

Basin-center and basin-margin anhydrocks typically combine both large areal extent and great thickness. Shelf and sabkha anhydrocks, on the other hand, tend to be areally extensive but are not generally as much as $30 \mathrm{~m}$ thick. Playa anhydrocks are of $11 \mathrm{~m} 1$ ced areal excent; they rarely extend more than 30 to $50 \mathrm{~km}^{2}$ kilometers. Although individual beds in the Miocene anhydrocks of the Picacho and Chandler basins in southern Arizona are as much as $37 \mathrm{~m}$ thick (JOHNSON, in preparation), playa anhydrocks generally are thin, usually only a few meters thick. 


\section{E.6.4 CHARACTERISTICS OF ANHYDROCK DEPOSITS}

\section{E.6.4.1 LITHOLOGY}

Most anhydrock deposits consist of massive sedimentary rock layers composed of intergrown crystals of the mineral anhydrite. Anhydrock beds typically consist of $>90 \%$ anhydrite, and some deposits are $>95 \%$ pure. Major impurities disseminated in anhydrock beds are carbonates, clay minerals, and (in some deposits) gypsum; but if the impurities are uniformly distributed throughout the anhydrock layer, the rock will behave as a homogeneous unit, and its overall characteristics will tend to be more uniform. Typically the carhonate and clay minerals occur in discrete laminae or in irregular, thin films that surround anhydrite nodules, whereas gypsum occurs along fractures, bedding planes, and at the contacts with other bounding rock units.

\section{E.6.4.1.1 Mineralogy and Geochemistry}

Anhydrite is hy far the dominant mineral in all major anhydrock rock units. Pure anhydrite contains $41.2 \%$ lime (CaO) and $58.8 \%$ sulfur trioxide $\left(\mathrm{SO}_{3}\right)$. Whereas the mineral usually is white or bluish gray, many deposits are discolored by impurities. The density of pure anhydrite is about $2.98 \mathrm{~g} / \mathrm{cm}^{3}$, and that of most massive rock units $1 \mathrm{~s}$ at least $2.95 \mathrm{~g} / \mathrm{cm}^{3}$, making anhydrock the most dense of all common sedimentary rocks.

Common impurities in bedded anhydrock are carbonate, silicate, and evaporite minerals. Carbonates include calcite $\left(\mathrm{CaCO}_{3}\right)$ and dolomite $\left[\mathrm{CaMg}\left(\mathrm{CO}_{3}\right)_{2}\right]$; silicates include clay minerals (mainly chlorite and illite), quartz, and local feldspars; evaporites include gypsum and halite $(\mathrm{NaCl})$. The carbonate and evaporite minerals generally are coprecipitates with anhydrite, and they exist as disseminated crystals interlocked with anhydrite crystals or as discrete, yet smal1, masses in laminae or matrix within the anhydrock beds. Silicate minerals typical1y are clastic particles that were transported into the basins by either air or water currents, and thus they are enveloped by anhydrite crystals. In some deposits, the silicate minerals occur as clastic laminae or matrix surrounding anhydrite nodules.

Anhydrite is the stable form for calcium sulfate at pressures and temperatures encountered 300 to $1000 \mathrm{~m}$ below the earth's surface. In the presence of water, and at lower pressures and temperatures, gypsum is the stable form for calcium sulfate. Intermediate metastable phases include basanite $\left(\mathrm{CaSO}_{4} \cdot 1 / 2 \mathrm{H}_{2} \mathrm{O}\right)$ and "soluble anhydrite" $\left(\mathrm{CaSO}_{4} \cdot \mathrm{nH}_{2} \mathrm{O}\right)$. Although pure anhydrite would be stable at elevated pressures and temperatures, the presence of impurities requires the development of additional data about stability of anhydrite in the presence of carbonate, silicate, and evaporite minerals. Those sparse data that are available do suggest that significant stability problems will not be encountered (POTTER, in preparation). 
The processes of recrystallization and hydration to gypsum, or dehydration to anhydrite, occur on a continuous but slow basis in the subsurface. Physical and chemical evidence of these transformations has been summarized by Murray (1964), and he shows that the following sequence of events is common for calcium sulfate minerals: deposition of gypsum as the primary minera1, followed by dehydration of the gypsum to anhydrite during deep burial (apparently at depths exceeding $600 \mathrm{~m}$ ), followed in turn by hydration of anhydrite back to gypsum at shallow depths (1ess than 100 to $200 \mathrm{~m}$ ) when overlying strata are eroded due to uplift.

Thus, the anhydrite in most subsurface anhydrock units is a replacement of earlier formed gypsum. Replacenent of gypsum by anhydrite or of anhydrite by gypsum is not always complete; gypsum locally occurs as deep as $1000 \mathrm{~m}$, and, elsewhere, lenses of anhydrite are exposed at the surface in the midst of gypsum outcrops. Where gypsum and anhydrite are both present in the same rock mass, the gypsum commonly occurs at places where groundwater has had grcatcr access to the sulfatc rock, such as at the top and bottom of the bed and along fractures and other discontinuities within the rock.

Anhydrite exhibits retrograde solubility; thus, fluid inclusions that may be present within anhydrite migrate away from a nearby heat source, rather than toward the heat source as is the case with rock salt (POTTER, in preparation). Anhydrite also appears to have a higher sorptive capacity for radionuclides than does halite and has a thermal conductivity as high as that of halite (POTTER, in preparation). Various chemical properties of anhydrite, including thermochemistry, phase equilibria, kinetics, and radionuclide sorption, are summarized by Potter (in preparation).

\section{E.6.4.1.2 Texture}

Texture, as used in this report, refers to the size, shape, and spatial relationship of the individual anhydrite crystals within the rock mass. Laminations, nodules, and other, larger-scale characteristics are discussed below in Section E.6.4.2.

Anhydrite crystals in bedded anhydrocks generally range from microcrystalline to coarse-crystalline in size, although the more common grain sizes range from 25 to $500 \mu \mathrm{m}(0.025$ to $0.5 \mathrm{~mm})$ in diameter. Such textural variations result from adjustments of calcium sulfate to a variety of pressure, temperature, and hydrologic conditions since original deposition of the sulfate rock. Discussion of anhydrock textures is presented by several investigators (HAM 1962; MAIKLEM 1969; HOLSER 1979).

Anhydrite crystals typically are equidimensional or elongate in shape. The elongate crystals commonly are large, lath-shaped, or bladed in a finely crystalline matrix, or they are a mesh of fine laths that are said to have a felted texture (MAIKLEM 1969).

\section{E.6.4.1.3 Latera1 and Vertical Homogeneity}

Anhydrock beds deposited in several environments are characterized by significant lateral and vertical homogeneity. Basin-center and 
basin-margin anhydrocks generally extend over areas of at least several thousand square kilometers. Individual laminae and sequences of beds and laminae within some anhydrock units of the Castile Formation have been correlated and traced for more than $100 \mathrm{~km}$ in the Delaware Basin (ANDERSON 1966; KIRKLAND 1970). Also, the general lithology and the reasonably uniform chemical quality of basin-center and basin-margin anhydrocks commonly are persistent for distances of tens of kilometers to more than $100 \mathrm{~km}$.

Basin-center and basin-margin anhydrocks are also generally homogeneous through their full thickness of $30 \mathrm{~m}$ or more. Although the basal and uppermost meter or so of anhydrock may be transitional with underlying and overlying sediments, the major part of these anhydrocks was formed under essentially similar depositional conditions, and the resultant rock is generally quite homogeneous. Vertical variations that do exist in a given thick anhydrock generally result from variations in water depth, rate of marine-water influx, climatic conditions, and transgressiveregressive shoreline positions during deposition of the anhydrock.

Anhydrocks deposited in shelf, sabkha, or playa environments

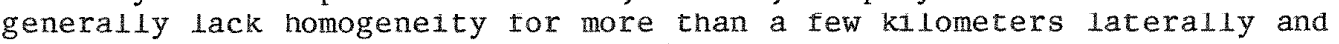
a few meters vertically, because the spatial and/or temporal conditions favorable for anhydrite precipitation were more restricted in those environments than in basin-center and basin-margin environments.

\section{E.6.4.2 BEDDING AND OTHER PRIMARY STRUCTURES}

Primary structures in anhydrock are malnly bedding-plane characteristics, although some nonbedding structures also are discussed here as primary features. Anhydrock is most commonly laminated or nodular, or locally may be massive and without apparent bedding. These primary structures are discussed by several authors (MURRAY 1964; MAIKLEM 1969; ANDERSON 1972; SCHREIBER 1978b; HOLSER 1979).

Laminated anhydrock consists of laminae (chin layers) of whice, nearly pure anhydrock that alternate with laminae of impure anhydrock that is gray, brown, or black, and which generally contain dolomite, calcite, or organic matter. The laminar pair is commonly 0.2 to $2 \mathrm{~mm}$ thick but may be as much as $10 \mathrm{~mm}$ thick, with the dark portion comprising about 10 to $20 \%$ of the aggregate thickness. Many laminae are perfectly planar and parallel and have sharp contacts; others are wavy and micro-nodular and may have gradational contacts. It is assumed that each laminar pair represents one complete cycle of evaporationprecipitation; most investigators feel that a cycle lasted one year (ANDERSON 1972). A remarkable aspect of laminated anhydrock is that sequences of laminae, even the individual laminae, can be accurately correlated for up to $100 \mathrm{~km}$ or more across basin-center and some basinmargin anhydrocks (ANDERSON 1966, ANDERSON 1972).

Nodular anhydrock, the other major structure, consists of white, nearly pure, nodular masses of anhydrite surrounded by dark streaks of dolomitic, calcitic, or organic material. The anhydrite nodules commonly 
range in size from 1 to $5 \mathrm{~cm}$, whereas the dark streaks are typically less than $1 \mathrm{~mm}$ wide. The dark material commonly is anastomosing or crisscrossing, leading to the terms "chicken-wire" or "mosaic" anhydrock (MAIKLEM 1969). These nodules are believed to result from displacive growth of anhydrite with unconsolidated muds, either on the floor of a body of water or in supratidal sabkhas (DEAN 1975).

Other bedding structures in anhydrock, such as cross-bedding, climbing ripples, oscillation ripples, desiccation chips, and massive bedding, are much less common (SCHREIBER 1978b). However, dissolution breccias in anhydrocks are important locally because they attest that a soluble mineral (commonly halite) has been dissolved to allow collapse and settling of overlying anhydrock (ANDERSON 1978). The dissolution may be contemporaneous with anhydrock deposition (primary feature), or it may have occurred well after deposition of the anhydrock (secondary feature).

\section{E.6.4.3 NATURE OF NON-ANHYDROCK INTERBEDS}

Non-anhydrock interbeds are of two types: (1) laminae of dolomite, calcite, or organic matter within laminated anhydrock; and (2) discrete layers or beds of salt, dolomite, limestone, gypsum, or shale that are interbedded with laminated, nodular, or massive anhydrock. The first type actually represents a particular bedding characteristic that is common to many anhydrock deposits (see Sect. E.6.4.2). Individual "non-anhydrock" laminae may contain on1y 5 to $10 \%$ of the impurity (dolomite, etc.), combined with 90 to $95 \%$ of anhydrite, or they may contain nearly $100 \%$ of the impurity. However, analysis of a composite sample through the full thickness (perhaps 5 to $30 \mathrm{~m}$ ) of a laminated anhydrock unit commonly yields only 2 to $10 \%$ non-anhydrock material. Therefore, although laminated anhydrock contains impure laminae, the rock mass is predominantly anhydrite, and its characteristics and behavior tend to be rather uniform and to approximate those of purer anhydrock.

Discrete interbeds (salt, etc.) within anhydrock are a result of temporary changes in the climate, tectonics, sea level, or relative influx of marine versus fresh water in the anhydrock-forming environment. As a result of these changes, evaporation and precipitation may have ceased temporarily, or may have advanced to the halite stage, thus allowing another type of sediment to accumulate over the depositional surface. The range of non-anhydrock interbeds that are present in major anhydrocks of the United States is described by Johnson (JOHNSON, in preparation). Interbeds of salt, dolomite, limestone, or shale are prone to be laterally persistent and somewhat uniform in thickness in basincenter or basin-margin anhydrocks, owing to the more uniform and stable conditions of those environments. These non-anhydrock layers tend to be sheet-like in in their distribution, and thus are likely to be bounded above and below by anhydrock for a considerable distance in all directions. Non-anhydrock interbeds are of variable thicknesses in various deposits, but thicknesses from 0.1 to $1 \mathrm{~m}$ are fairly common in those deposits where interbeds are present. For anhydrocks formed in shelf, sabkha, or playa environments, the nature, thickness, and lateral persistence of the non-anhydrork interheds is much mnre erratic and unpredictable. 
Interbeds of gypsum are a special case because, in most areas, they are not a result of original deposition but are due to the hydrationdehydration relationships of anhydrite and gypsum. Gypsum, therefore, may be irregularly distributed as layers, veins, or irregular masses within an anhydrock bed, and its distribution is controlled by the past and/or present pathways followed by percolating groundwater.

\section{E.6.4.4 SECONDARY STRUCTURES}

Secondary structures in anhydrock result mainly from tectonic/ structural events, from dissolution activities, or from hydration/ dehydration processes. The principal resultant structures are joints, faults, folds, dissolution breccias, veins, and distorted bedding. This discussion does not deal with the complex structures associated with anhydrock in the cap rock of salt domes.

The presence or absence of joints, faults, or folds in anhydrock in a particular area is primarily dependent upon the tectonic/structural history of the area. There is no inherent property of anhydrock that favors development of joints; if anything, the moderate plasticity and solubility of anhydrock would appear to promote nonbrittle deformation and healing of joints formed far below the land surface. Joints that remain open for a while may become filled and sealed with salt or gypsum, owing to plastic flowage of these materials from nearby deposits, or filled with gypsum owing to hydration of the anhydrite. Quantitative data on the spacing and/or frequency of joints in anhydrock units within the United States are not available. Thordarson (in preparation) has, however, summarized information on fractures in anhydrock beds and water inflow encountered in tunnels, mines, we11s, and springs in Europe and North America (Table E.6.4.1).

The data reported by Thordarson (in preparation) indicate that joints are present in some anhydrocks and appear to be lacking in others. Rockfal1s in tunnels and mines excavated in anhydrock are not reported, except where water is present and the rock has expanded during gypsification. Edie (EDIE 1958) states that fractures are common in limestone units in some of the oil fields of southern Saskatchewan, Canada, but that fractures are absent or rare in the associated anhydrock beds.

Faults in anhydrock result mainly from tectonic/structural events in the area or from collapse due to dissolution of an underlying soluble rock unit. As with joints, faults in anhydrock tend to become sealed and appear as veins filled with anhydrite, salt, gypsum, or other evaporite minerals. Folds result mainly from tectonic/structural events, but they may also result from arching over underlying dissolution zones or from plastic flow associated with diapirism and salt/evaporite flowage.

Dissolution breccias are zones of broken rock that result from collapse due to dissolution of soluble minerals within or below the breccia zone; they are fairly common in some of the anhydrock units that are interbedded with, or are underlain by, salt or other highly soluble 
Table E.6.4.1. Data on anhydrock from tunnels, mines, wells, and springs ${ }^{a}$

\begin{tabular}{|c|c|c|}
\hline Location & $\begin{array}{l}\text { Formation, age, } \\
\text { and rock type }\end{array}$ & Comments \\
\hline $\begin{array}{l}\text { Railway tunne1, } \\
\text { Lechere, France }\end{array}$ & $\begin{array}{l}\text { Unknown age; } \\
\text { anhydrock }\end{array}$ & $\begin{array}{l}\text { Walls and ceiling have not } \\
\text { expanded and no rockfalls } \\
\text { have occurced in } 10 \text { years. } \\
\text { In one place, water seeps } \\
\text { through sandy beds in } \\
\text { anhydrock and hydrates it to } \\
\text { gypsim. }\end{array}$ \\
\hline $\begin{array}{l}\text { Railway tunnel, } \\
\text { Braus, France }\end{array}$ & $\begin{array}{l}\text { Unknown age; } \\
\text { anhydrock }\end{array}$ & $\begin{array}{l}100 \mathrm{~m} \text { from the entrance, } \\
\text { abundant flow of water } \\
\text { streams down wall, but no } \\
\text { expansion has occurred. } \\
\text { other places have permeable } \\
\text { interbeds of sand or clay. } \\
\text { and gypsification of } \\
\text { anhydrite has formed slabs } \\
\text { of raised crust on wall. In } \\
40 \text { years, walls arched inward } \\
\text { or caved in, floor raised or } \\
\text { lowered } 0.5 \mathrm{~m} \text {, and pillars } \\
\text { dislocated. }\end{array}$ \\
\hline $\begin{array}{l}\text { Drifts, } \\
\text { Tignes, France }\end{array}$ & $\begin{array}{l}\text { Unknown age; } \\
\text { anhydrock } \\
\text { and shale }\end{array}$ & $\begin{array}{l}\text { Anhydrock appears perfectly } \\
\text { dry and dense without visible } \\
\text { fractures but contains } \\
\text { numerous veins of gypsum. } \\
\text { Shale surrounding anhydrock } \\
\text { is very fractured and has } \\
\text { abundant inflows of water. }\end{array}$ \\
\hline $\begin{array}{l}\text { Drift of the } \\
\text { Courbaisse, France }\end{array}$ & $\begin{array}{l}\text { Unknown age; } \\
\text { anhydrock }\end{array}$ & $\begin{array}{l}\text { Anhydrock has marked schistos- } \\
\text { 1ty and a necwork of numerous } \\
\text { open fractures. Gypsum growing } \\
\text { in fractures pushes blocks off } \\
\text { wall. Wall looks wet in } \\
\text { photographs. }\end{array}$ \\
\hline $\begin{array}{l}\text { Water-diversion } \\
\text { tunnel of factory } \\
\text { of the Courbaisse, } \\
\text { between Nice and } \\
\text { Puget-Theniers, } \\
\text { France }\end{array}$ & $\begin{array}{l}\text { Triassic; } \\
\text { anhydrock } \\
\text { and gypsum }\end{array}$ & $\begin{array}{l}\text { Anhydrock is dense and } \\
\text { completely dry for } 750 \mathrm{~m} \text {. } \\
\text { Gypsum in a pulverized, } \\
\text { chaotic zone } 80 \mathrm{~m} \text { long has } \\
\text { inflows of water in roof. } \\
\text { Rock bursts in anhydrock may } \\
\text { be due to expansion during } \\
\text { gypsification. }\end{array}$ \\
\hline
\end{tabular}


Table E.6.4.1 (Continued)

\begin{tabular}{|c|c|c|}
\hline Location & $\begin{array}{l}\text { Formation, age, } \\
\text { and rock type }\end{array}$ & Comments \\
\hline $\begin{array}{l}\text { Water-diversion } \\
\text { tunnel of the Arvan, } \\
\text { River Saint-Jean-de- } \\
\text { Maurienne, Savoie, } \\
\text { France }\end{array}$ & $\begin{array}{l}\text { Triassic; } \\
\text { anhydrock, } \\
\text { gypsum, lime- } \\
\text { stone in } \\
\text { in diapir }\end{array}$ & $\begin{array}{l}\text { Trias is completely dry; } \\
\text { impervious cover of shales of } \\
\text { Lias protected Trias from } \\
\text { infiltration of water. }\end{array}$ \\
\hline $\begin{array}{l}\text { Hauenstein tunne1, } \\
\text { Germany }\end{array}$ & $\begin{array}{l}\text { Triassic; } \\
\text { anhydrock }\end{array}$ & $\begin{array}{l}\text { Heaving of rock up to } 80 \mathrm{~cm} \text {, } \\
\text { owing to inflows of water. }\end{array}$ \\
\hline $\begin{array}{l}\text { Kappelisberg tunne1, } \\
\text { Caildorf, Cermany }\end{array}$ & $\begin{array}{l}\text { Triassic; } \\
\text { anhydrock }\end{array}$ & $\begin{array}{l}\text { Heaving of rock up to } 80 \mathrm{~cm} \text {, } \\
\text { owing to inflows of water. }\end{array}$ \\
\hline $\begin{array}{l}\text { Potash mines, } \\
\text { Germany }\end{array}$ & $\begin{array}{l}\text { Permian; } \\
\text { anhydrock in } \\
\text { salt diapir }\end{array}$ & $\begin{array}{l}\text { Flows of brine as much as } 30 \\
\text { L/min and some gas. Flows } \\
\text { decreased over periods of } \\
\text { days or years. }\end{array}$ \\
\hline $\begin{array}{l}\text { Mine of Grozon, } \\
\text { Arbois, Jura Mtns., } \\
\text { France }\end{array}$ & $\begin{array}{l}\text { Not reported; } \\
\text { anhydrock }\end{array}$ & $\begin{array}{l}\text { 8-m-wide mine with flat ceil- } \\
\text { ing; never had rockfalls dur- } \\
\text { ing period of more than } 100 \\
\text { years, despite abundant conden- } \\
\text { sation from air that coats } \\
\text { anhydrock with film of water. } \\
\text { Thin film of gypsum only. }\end{array}$ \\
\hline $\begin{array}{l}\text { We11, ERDA No. 6, } \\
\text { New Mexico }\end{array}$ & $\begin{array}{l}\text { Castile Forma- } \\
\text { tion, } \\
\text { Permian; } \\
\text { anhydrock }\end{array}$ & $\begin{array}{l}\text { Significant flow of brine con- } \\
\text { taining } \mathrm{Na}_{2} \mathrm{SO}_{4} \text { and } \mathrm{H}_{2} \mathrm{~S} \text {-rich gas } \\
\text { at depth of } 826 \mathrm{~m} \text {; no observed } \\
\text { decrease in flow during first } \\
10 \mathrm{~d} \text {; possibly a brine pocket. } \\
\text { Associated with salt anticline. } \\
\text { Core contained laminated } \\
\text { anhydrock and anhydrite-filled } \\
\text { fractures. }\end{array}$ \\
\hline $\begin{array}{l}\text { Well, ERDA No. } 8, \\
\text { New Mexico }\end{array}$ & $\begin{array}{l}\text { Castile Forma- } \\
\text { tion, } \\
\text { Pernian; } \\
\text { anhydrock }\end{array}$ & $\begin{array}{l}\text { No flow of fluid in dril1- } \\
\text { stem test }\end{array}$ \\
\hline $\begin{array}{l}\text { We11, ERDA No. } 9 \\
\text { New Mexico }\end{array}$ & $\begin{array}{l}\text { Castile Forma- } \\
\text { tion, } \\
\text { Permian; } \\
\text { anhydrock }\end{array}$ & $\begin{array}{l}\text { No flow of fluid in drill- } \\
\text { stem test }\end{array}$ \\
\hline $\begin{array}{l}\text { Relon nil we } 11 \text {, } \\
\text { New Mexico }\end{array}$ & $\begin{array}{l}\text { Castile Forma- } \\
\text { tion, } \\
\text { Permian; } \\
\text { anhydrock }\end{array}$ & $\begin{array}{l}\text { Significant flnw of hrine and } \\
\mathrm{H}_{2} \mathrm{~S} \text { gas decreased over } 1-\text { to } \\
2-\mathrm{d} \text { flow period, indicating } \\
\text { brine was in pocket. }\end{array}$ \\
\hline
\end{tabular}


Table E.6.4.1 (Continued)

\begin{tabular}{|c|c|c|}
\hline Location & $\begin{array}{l}\text { Formation, age, } \\
\text { and rock type }\end{array}$ & Comments \\
\hline $\begin{array}{l}\text { She11 Bootleg we11, } \\
\text { New Mexico }\end{array}$ & $\begin{array}{l}\text { Castile Forma- } \\
\text { tion, } \\
\text { Permian; } \\
\text { anhydrock }\end{array}$ & $\begin{array}{l}\text { Flow of brine decreased over } \\
\text { several days, indicating } \\
\text { brine was in pocket. }\end{array}$ \\
\hline $\begin{array}{l}011 \text { we } 11, \text { Sec. } 23 \\
\text { T. } 24 \text { S., R. } 29 \text { E. } \\
\text { New Mexico }\end{array}$ & $\begin{array}{l}\text { Castile Forma- } \\
\text { tion, } \\
\text { permian; } \\
\text { anhydrock }\end{array}$ & $\begin{array}{l}\text { Slight show of gas and hole } \\
\text { full of salt water at depth } \\
\text { of } 35 y \text { to } 561 \mathrm{~m} \text {. }\end{array}$ \\
\hline $\begin{array}{l}011 \text { we11, Sec. 3, } \\
\text { T. } 24 \text { S., R. } 29 \text { E. } \\
\text { New Mexico }\end{array}$ & $\begin{array}{l}\text { Castile Forma- } \\
\text { tion, } \\
\text { Permian; } \\
\text { anhydrock }\end{array}$ & $\begin{array}{l}\text { Fxceptinnally large yield of } \\
\text { brine at depth of } 526 \mathrm{~m} .\end{array}$ \\
\hline $\begin{array}{l}\text { Dillon No. } 91 \text { oil } \\
\text { wel1, Pine Island } \\
\text { oil field, Caddo } \\
\text { Parish, Louisiana }\end{array}$ & $\begin{array}{l}\text { Ferry Lake; } \\
\text { anhydrock: } \\
\text { Cretaceous; } \\
\text { anhydrock and } \\
\text { limestone }\end{array}$ & $\begin{array}{l}14 \mathrm{~m}^{3} / \mathrm{d} \text { of oil from we11 } \\
\text { completed in anhydrock; } \\
\text { anhydrock. }\end{array}$ \\
\hline $\begin{array}{l}\text { Hole No. } 3 \text {, sec. } 26 \text {, } \\
\text { T. } 20 \text { S., R. } 26 \text { E., } \\
\text { New Mexico }\end{array}$ & $\begin{array}{l}\text { Castile Forma- } \\
\text { tion, Permian; } \\
\text { gypsum, anhy- } \\
\text { drite, clay, } \\
\text { cave breccia }\end{array}$ & $\begin{array}{l}\text { Injection tests in } 62-\mathrm{m} \text {-deep } \\
\text { well indicated very low to } \\
\text { low transmissivity; hydraulic } \\
\text { conductivity greatest in cave } \\
\text { breccia. }\end{array}$ \\
\hline $\begin{array}{l}\text { Castile Springs, } \\
\text { culberson Councy, } \\
\text { Texas }\end{array}$ & $\begin{array}{l}\text { Castile Forma- } \\
\text { clon, Permian; } \\
\text { anhydrock and } \\
\text { gypsum }\end{array}$ & $\begin{array}{l}\text { May be artesian water from } \\
\text { velaware Mouncain Group } \\
\text { aquifer that underlies } \\
\text { Castile Formation. }\end{array}$ \\
\hline $\begin{array}{l}\text { Stinking Spring, } \\
\text { Culberson County, } \\
\text { Texas }\end{array}$ & $\begin{array}{l}\text { Castile Forma- } \\
\text { tion, Permian; } \\
\text { anhydrock and } \\
\text { gypsum }\end{array}$ & $\begin{array}{l}\text { May be artesian water from } \\
\text { Delaware Mountain Group } \\
\text { aquifer that underlies } \\
\text { Castile Formation. }\end{array}$ \\
\hline $\begin{array}{l}\text { Salt springs, western } \\
\text { Kansas and Oklahoma }\end{array}$ & $\begin{array}{l}\text { Permian; red } \\
\text { beds, salt, an- } \\
\text { hydrice }\end{array}$ & $\begin{array}{l}\text { Salt springs, from dissolved } \\
\text { salt and anhydrock, flow from } \\
\text { red beds. }\end{array}$ \\
\hline $\begin{array}{l}\text { Springs, Axel Heiberg } \\
\text { Island, Canada }\end{array}$ & $\begin{array}{l}\text { Permian; } \\
\text { anhydrock }\end{array}$ & $\begin{array}{l}\text { Saline springs in center of } \\
\text { Base Camp Diapir. }\end{array}$ \\
\hline
\end{tabular}

a Source: THORDARSON (in preparation). 
minerals (ANDERSON 1972, 1978; DEAN 1982). Typically the brecciated rock fragments are recemented into a wel1-1ithified rock mass by anhydrite or by other minerals precipitated from groundwater. Breccias either occur as laterally continuous beds that are lateral equivalents of salt beds in other parts of evaporite basins or as vertical chimneys or pipes where rock has collapsed into a deep-seated cavern system created by the stopping-dissolution of an underlying salt unit. Both these types of breccias are known from the Delaware Basin of New Mexico and West Texas (ANDERSON 1978).

Veins are tabular or sheet-like deposits of a mineral that fills fractures in a rock. In anhydrock, veins typically consist of anhydrite, gypsum, halite, or carbonate minerals, and they commonly are $0.5-$ to $50-\mathrm{mm}$ thick. Veins are formed as the openings fill that may have originally been present in anhydrock as joints, faults, or dissolution-induced features. Thus, they are evidence that these earlier openings have undcrgonc some ocaling and/or hcaling.

Distorted bedding in anhydrocks includes a wide range of undulatory, folded, and disrupted bedding features that result mainly from hydration/dehydration transformations, slumping, nonuniform compaction, or growth of non-anhydrite minerals within and around anhydrock layers. The bedding may be mildly to highly contorted, ropy, or even ruptured and discontinuous in places (MAIKLEM 1969; DEAN 1982).

\section{E.6.4.5 PLASTICITY}

Anhydrock is a moderately plastic rock, particularly at elevated pressures and temperatures. Data collected by Diehl (DIEHL, in preparation) show that the ultimate strength of anhydrock increases with increasing confining pressure at room temperature and that the ultimate strength generally decreases and ductility increases with increasing temperature. They also observed that anhydrock is brittle at or below $50 \mathrm{MPa}$ of confining pressure and at small strains of 1 to $3 \%$. At 100 to $300 \mathrm{MPa}$ of confining pressure, the elastic limit is reached at 1 to $3 \%$ strain, and beyond the elastic limit there is no change in strength with continuing flow (DIEHL, in preparation). At still higher pressures of 300 to $100 \mathrm{MPa}$, work hardening is evident, and, thus, anhydrock can undergo a large permanent deformation without fracturing at high confining pressures.

Grain size also exerts an influence upon the strength of anhydrock (DIEHL, in preparation). Fine-grained anhydrock is stronger at room temperature than is coarse-grained anhydrock, although the reverse is true at temperatures $>400^{\circ} \mathrm{C}$.

\section{E.6.4.6 POROSITY AND HYDRAULIC CONDUCTIVITY}

Data concerning porosity and hydraulic conductivity of anhydrock are sparse, owing to the general lack of interest in these properties of the rock. Thordarson (THORDARSON, in preparation) compiled data on hydraulic characteristice of bedded anhydrock and categorized them as those properties related to intercrystalline porosity and those related to fracture 
porosity. The geologic sources and the purity of samples reported by Thordarson are not well described by the original authors, and some samples may be from the cap rock of salt domes. The mean intercrystalline porosity of 38 samples of anhydrock from the United States, Switzerland, and Iran is $1.1 \%$, and the range is from zero to $4.7 \%$ (Table E.6.4.2).

The intercrystalline hydraulic conductivity of bedded anhydrock is very low, and bedded anhydrock acts as an effective, impermeable seal in many oil fields (THORDARSON, in preparation). Blazenko (BLAZENKO 1964) described a dolomitic anhydrock from the Permian Wellington Formation of southwestern 0klahoma as having a hydraulic conductivity of nearly zero. Also, Ibrahim and Katz (IBRAHIM 1972) reported a sample of anhydrock with a hydraulic conductivity of zero, as indicated by unsuccessful injection of mercury in a porosity test.

Hydraulic conductivity through fractured anhydrock is quite variable, depending upon the size, spacing, and extent of the fractures. Unfortunately, quantitative laboratory measurements are not available on fracture porosity (THORDARSON, in preparation). The fact that anhydrock beds act as effective, impermeable seals in many oil fields indicates that fracture porosity and resultant hydraulic conductivity of anhydrocks generally are very low to nil (EDIE 1958; THORDARSON, in preparation). In Florida, the Cedar Keys Limestone consists of nearly equal amounts of anhydrock and limestone, but the hydraulic conductivity of neither rock type could be determined during hydraulic injection tests in a single wel1 (WILSON 1973).

Several wells have encountered brine and gas in fractured anhydrock units of the Castile Formation in southeastern New Mexico (Table E.6.4.1).

Table E.6.4.2 Intercrystalline porosity of bedded anhydrocka

\begin{tabular}{lccc}
\hline & $\begin{array}{c}\text { Number } \\
\text { of } \\
\text { samples }\end{array}$ & \multicolumn{2}{c}{ Porosity (\%) } \\
\cline { 4 - 4 } Anhydrock, United States & 2 & 3.4 & $2.8-4.0$ \\
Anhydrock, United States & 1 & 0.0 & Range \\
Dolomitic anhydrock, Oklahoma & Wel1 log & & $1.0-3.0$ \\
Dolomitic anhydrock, Switzerland & 13 & 0.7 & $0.1-1.3$ \\
Anhydrock, Iran & 21 & 1.1 & $0.1-4.7$ \\
\hline
\end{tabular}

aSource: TIIORDARSON (in preparation). 
These wells include several petroleum tests and two government test holes (ERDA-6 and WIPP-12) drilled in the vicinity of the Waste Isolation Pilot Plant (WIPP) site (LAMBERT 1977; POWERS 1978). In two petroleum tests, the brine flow decreased within two days, indicating that the brine was contained within a confined system of fractures or solution cavities in the vicinity of the boreholes. In the ERDA-6 and WIPP-12 boreholes, brine and gas were encountered at depths of about $800 \mathrm{~m}$, with the yield dropping in conjunction with a decrease in the original pressure. Data from the WIPP area indicate that these brines and gases probably occur in a network of fractures formed during localized structural deformation of the anhydrock and that the fracture system in each case is like an isolated "pocket" that contains a limited quantity of brine and/or gas (SPIEGLER 1982; FAITH 1983). The fracture systems or "pockets" are not interconnected, and thus the fractures are quite localized.

In Germany, France, and Switzerland, anhydrock has been excavated in tunnels and mines (GIGNOUX 1955; LOTZE 1957; SAHORES 1962; LAUBSCHER 1975; BAAR 1977), and major observations by these investigators with regard to hydraulic conductivity of anhydrock have been summarized (THORDARSON, in preparation; Table E.6.4.1 of this report). Experience

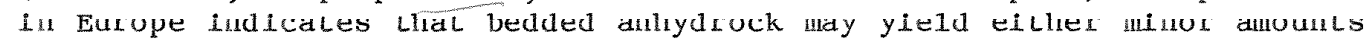
of water or no flowing water from fractures; therefore, the hydraulic conductivity and transmissivity of fractured anhydrock are 10w to very 1ow. Since measurements of water flows are not available, no estimates of the hydraulic conductivity or transmissivity values can be made (THORDARSON, in preparation). 


\section{E.6.5 LITHOLOGIES OF BOUNDING ROCK TYPES}

In gathering information on anhydrock deposits of the United States, Johnson et al. (JOHNSON, in preparation) also compiled data on the bounding rock types for most deposits. The principal lithologies associated with anhydrocks are shales, carbonates, and salts, and these lithologies commonly are $30 \mathrm{~m}$ to more than $300 \mathrm{~m}$ thick. Each of these lithologies is commonly, but not exclusively, formed in basin-center, basin-margin, and shelf environments undergoing epeirogenic subsidence, and thus they occupy the same settings as thick beds of anhydrock. Whether the sediment being deposited is shale, carbonate, salt, or anhydrock depends upon the salinity of the water and the influx of clays and ocher fine-grained clastics inco the deposicional area. Sandstones, conglomerates, and other sediments that generally are representative of cectonic activity and abrupt changes in source areas and depositional environments are not commonly associated with thick and extensive anhydrock deposits.

Most of the major anhydrock deposits in the United States are partly ui Lulally bunided by slides (JOHNSON, in pLeparaliun). Tluse Lulally bounded by shale include the Salina in the Appalachian Basin, the Ferry Lake in the Gulf Coast, the Stone Corral in the northern Denver Basin, the Gypsum Springs in the Wyoming basins, and the Miocene in the picacho Basin (Figure E.6.1.1). Anhydrock deposits bounded by shale and salt include the Werner in the Gulf Coast and the Eagle in the Eagle Basin, whereas those bounded by shale and limestone include the Buckner in the Gulf Coast, the Wolfcamp in the northern Denver Basin, and the Potlatch on the Sweetgrass Arch of Montana.

Major anhydrock deposits bounded mainly by rock salt are the Castile in the Delaware Basin and the Salina in the Michigan Basin (JOHNSON, in preparation). Carbonates are the principal bounding 1ithologies for the San Andres in the Permian Basin and the Madison in the Williston Basin. 


\section{E.6.6 REACTION OF ANHYDROCK TO EXTERNAL EVENTS}

\section{E.6.6.1 TECTONICS AND SEISMTC EVENTS}

Anhydrock deposits in the United States typically are located in regions of low tectonic and/or seismic activity. Most of the major anhydrocks were deposited during various episodes of epeirogenic downwarping on the craton in the central part of the country, and almost all parts of the craton (except the upper Mississippi Valley area centered near New Madrid, Missouri) have low levels of seismic activity and are in seismic-risk zones 0 or 1 (no earthquake damage expected, or minor earthquake damage expected) (ESSA/COAST AND GEODETIC SURVEY 1969). Therefore, the likelihood that tectonic or seismic activity will affect the major anhydrock deposits of the United States is low.

If a thick anhydrock bed ohould be cubjected to slow application of stress through tectonic or seismic activity, the plastic properties of anhydrock at high pressure and temperature should cause it to tend to deform plastically, according to the data discussed in Sect. E.6.4.5 of this report. In case of rapid application of stress, the anhydrock bed may rupture and be either faulted or fractured. Such a fault or fracture should heal or seal in a short time, owing to the plastic or ductile nature of anhydrock at high pressures and temperatures. It is also possible that the fault or fracture may become filled with salt and/or shale, which are two highly plastic rock types commonly associated with anhydrock. Or, if the fault or fracture remains open for a while, water that might enter the opening can cause gypsification, which will both remove some of the free water molecules and aid in sealing the opening through expansion.

\section{E.6.6.2 DISSOLUTION AND BRECCIATION}

Anhydrite is a soluble mineral. It is about two orders of magnitude less soluble than is rock salt, but anhydrock dissolution and related brecciation are important in evaluating anhydrock as a potential repository host rock. It is clear that anhydrock deposits can be, and have been, generally wcll protected from dissolution; this is attested to by the fact that anhydrock and associated salt beds of Cretaceous and older ages generally have remained intact and undissolved beneath overlying sediments in thousands of square kilometers of such major basins as the Michigan, Appalachian, Gulf Coast, Permian, Williston, and Paradox. Evaporites in these basins, and those of other basins as well, have survived for more than 100 million years, a time span well beyond that of the hazardous period during which radionuclides must be isolated from the biosphere.

Dissolution of anhydrock would occur chiefly at the top or base of a bed, along faults or fractures, or along any more permeable bed or zone within the anhydrock, providing there was a source of groundwater (unsaturated with respect to calcium sulfate) that could flow against and/or through the anhydrock. Dissolution is more 1ikely to occur, however, in salt beds that may be interbedded with, or beneath, the 
anhydrock unit. Dissolution of anhydrock, gypsum, or salt is mainly a near-surface phenomenon, but it can occur locally down to depths of 150 to $550 \mathrm{~m}$ (THORDARSON, in preparation).

The effect of dissolution of anhydrock (or salt) may be the collapse and brecciation of overlying rock layers. These brecciated zones may form channels for groundwater movement, as long as the voids in the breccia are not plugged subsequently with precipitated mineral deposits. Beds of dissolution breccia in the Castile anhydrock deposit of the Delaware Basin are composed of anhydrock fragments that collapsed after salt beds were dissolved from beneath the anhydrock beds (ANDERSON 1978; ANDERSON 1980). Vertical breccia zones represent rock that collapsed in a nearcylindrical pipe when a large cavern was dissolved in an underlying soluble rock unit, typically composed of salt (LANDES 1959; KIRKLAND 1976).

\section{E.6.6.3 HYDRATION AND GYPSIFICATION}

Basic anhydrite-gypsum relationships were described earlier in Sect. E.6.4.1.1, but here the discussion will focus on the mechanism and results of hydration and gypsification. Hydration of anhydrite to gypsum is likely to occur where groundwater encounters the anhydrite by means of a fault, a fracture, or a permeable stratum that is interbedded with or bounds the anhydrite. On a microscopic scale, cleavage planes within the anhydrite crystals are potential channels for hydration (DEER 1962). The depth at which hydration occurs varies with the local hydrology, the nature and thickness of confining beds and interbeds, the thermal gradient (temperature at various depths), and other geologic factors. In general, however, the depth of hydration commonly is 100 to $200 \mathrm{~m}$ below the land surface.

Theoretically, if all the calcium sulfate molecules of an anhydrock mass were hydrated, the resultant gypsum would represent an increase of about 1.6 times the original volume. If, however, the confining stress of the overburden is great enough, and if excess calcium sulfate is removed in solution, gypsification can occur without volumetric expansion.

The results of hydration from some tunnels and mines, mainly in Europe, are described in Table E.6.4.1. From these observations, it is clear that, in underground openings and in unconfined spaces, hydration and gypsification generally involve an expansion of the rock mass. In turn, this may cause buckling or heaving of the rock or may give rise to rock bursts. Thordarson (THORDARSON, in preparation) sumnarizes data showing that gypsification can be accompanied by large bulging shells or spalling in quarries, tunnels, and outcrops, and even sometimes by violent explosions. He also points out that some investigators have not found evidence for expansion during gypsification.

If expansion were to occur during gypsification, it is possible that overlying or other nearby portions of an anhydrock bed would be buckled, fractured, or otherwise disturbed, and this could compromise the integrity of a repository located within that anhydrock bed near the zone of gypsiftcation. 


\section{E.6.6.4 WEATHERING AND EROSION}

Anhydrock and gypsum are soltible rocks, and thus they weather and erode quite readily in subhumid or humid climates. Therefore, in eastern parts of the United States (i.e., east of approximately the $98 \mathrm{th}$ meridian, where the average annual precipitation is $>80 \mathrm{~cm}$ ), anhydrock and gypsum rarely are found in outcrops. In these areas, calcium sulfate rocks are readily dissolved and eroded, leaving topographic lows or depressions where the sulfates should crop out.

West of the 98th meridian (excluding the West coast area), where the average annual precipitation is typically $<80 \mathrm{~cm}$, anhydrock and gypsum are relatively resistant rock units that tend to cap mesas and escarpments. In these low-rainfall areas, dissolution activity is at a minimum, and, therefore, anhydrock and gypsum resist weathering and exosion quite effectively. 
Important non-anhydrock mineral resources, such as salt, potash, gypsum, and sulfur, are present in or near anhydrock beds in various parts of the United States (JOHNSON, in preparation). Most of the evaporitebearing basins also are important petroleum provinces, and, in some of these basins, anhydrock beds or associated shales and evaporites are the seals that hold petroleum in underlying reservoir rocks.

Salt, potash, and gypsum are evaporite minerals, and sulfur in most deposits is produced by biogenic breakdown of sulfates in anhydrock or gypsum. Thus, all these minerals are intimately associated with evaporite deposits and may be in close proximity to thick anhydrock beds. Whereas salt and outcropping gypsum are common and are associated with almost all the major anhydrock deposits, potash and sulfur are restricted to only a few places in the United States. Therefore, it is more critical to be aware of potash and sulfur distribution in order to reduce possible conflict between present or future use of these rarer resources and the use of a nearby anhydrock bed as a waste repository.

Major potash resources in the United States are in the Carlsbad district of southeastern New Mexico and in the Moab area of Utah. Only the potash deposits of the Salado Fornation near Carlsbad are in an area of thick anhydrock beds. These potash beds, the most prolific in the United States, are about $300 \mathrm{~m}$ above the top of the anhydrocks in the Castile Formation (POWERS 1978).

Sulfur deposits occur mainly in the cap rocks of certain Gulf Coast salt domes, and these would represent no conflict, since the anhydrock masses in cap rock are not currently considered as viable host rocks. Other sulfur deposits occur in the Delaware Basin in the Castile Formation, usually near the base, or in the overlying salado saltdissolution residuum (SMTTH 1978). Continued mining of these deposits

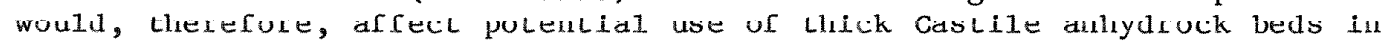
the vicinity of the sulfur deposits. 


\section{E.6.8 SUMMARY OF ANHYDROCK PROPERTIES}

The five depositional environments for the principal anhydrock deposits in the United States include the basin-center, basin-margin, shelf, sabkha, and playa environments. The basin-center and basin-margin environments contain the thickest and most laterally extensive anhydrocks, with homogeneous deposits commonly at least 30 to $105 \mathrm{~m}$ thick and extending for distances of 10 to $100 \mathrm{~km}$, or more. Shelf anhydrocks also are as much as $30 \mathrm{~m}$ thick in some areas, but they generally lack lateral homogeneity for more than a few kilometers. The properties of anhydrocks in al1 three of these depositional environments are sumarized in Table $\mathrm{E} .6 .8 .1$.

Properties and characteristics of anhydrocks deposited in sabkha and playa environments are not presented in the table and are not discussed further, since these anhydrocks generally lack homogeneity for more than a few kilometers laterally and a few meters vertically. 
Table $E_{*} 6.8 .1$ Properties of anhydrock related to depositional environments

\begin{tabular}{|c|c|c|c|}
\hline \multirow[b]{2}{*}{ Property of host rock } & \multicolumn{3}{|c|}{ Depositional environments of anhydrock } \\
\hline & Basin-center & Basinmargin & Shelf \\
\hline $\begin{array}{r}\text { Geometry } \\
\text { Shape }\end{array}$ & $\begin{array}{l}\text { Laterally extensive, } \\
\text { sheet-like, thick }\end{array}$ & $\begin{array}{l}\text { Laterally extensive, } \\
\text { sheet-like, thlck }\end{array}$ & $\begin{array}{l}\text { Laterally moderately } \\
\text { extensive, thick }\end{array}$ \\
\hline $\begin{array}{l}\text { Dimensions } \\
\text { Thlickness, range } \\
\text { Thlckness, common } \\
\text { Extent, range } \\
\text { Extent, common }\end{array}$ & $\begin{array}{c}3-105 \mathrm{~m} \\
30-105 \mathrm{~m} \\
100-20,000 \\
2,500-20,000\end{array}$ & $\begin{array}{c}3-30 \mathrm{~m} \\
10-30 \mathrm{~m} \\
100-30,000 \mathrm{~km}^{2} \\
2,500-30,000 \mathrm{~km}^{2}\end{array}$ & $\begin{array}{c}3-30 \mathrm{~m} \\
10-30 \mathrm{~m} \\
100-5,000 \mathrm{~km}^{2} \\
2,500-5,000 \mathrm{~km}^{2}\end{array}$ \\
\hline $\begin{array}{l}\text { Lithology } \\
\text { Mineralogy \& } \\
\text { geochenistry } \\
\text { Texture } \\
\text { Homogeneity (lateral } \\
\text { and vertical) }\end{array}$ & $\begin{array}{l}90-98 \% \text { anhydrite; minor } \\
\text { carbonates, clays, } \\
\text { quartz, gypsum } \\
\text { Equant, } 0.025-0.5 \mathrm{~mm} \\
\text { Lateral }(10-100 \mathrm{~km}) \\
\text { vertical }(30-105 \mathrm{~m})\end{array}$ & $\begin{array}{l}\text { Same } \\
\text { (same as data to } \\
\text { the left) } \\
\text { Same } \\
\text { Lateral }(10-100 \mathrm{~km}) \text {, } \\
\text { vertlcal }(10-30 \mathrm{~m})\end{array}$ & $\begin{array}{l}\text { Same } \\
\text { Same } \\
\text { Few km laterally, \& } \\
\text { few m vertically }\end{array}$ \\
\hline $\begin{array}{l}\text { Bedding characteristics } \\
\text { Thickness, range } \\
\text { Thlckness, common } \\
\text { Type of bedding } \\
\text { other pt imory } \\
\text { structures }\end{array}$ & $\begin{array}{l}\quad 0.2-10 \mathrm{~mm} \\
0.2-2 \mathrm{~mm} \\
\text { Laminated or nodular } \\
\text { Rare, } \text {, copt dissol. } \\
\text { breccla }\end{array}$ & $\begin{array}{l}\text { Same } \\
\text { Same } \\
\text { Same } \\
\text { Same }\end{array}$ & $\begin{array}{l}\text { Same } \\
\text { Same } \\
\text { Same } \\
\text { Same }\end{array}$ \\
\hline $\begin{array}{l}\text { Nature of interbeds } \\
\text { Lithology } \\
\text { Thl ckness } \\
\text { Uniformity }\end{array}$ & $\begin{array}{l}\text { Salt, carbonates, } \\
\text { gypsum, shale } \\
\text { Commonly } 0.1-1 \mathrm{~m} \\
\text { More than several km }\end{array}$ & $\begin{array}{l}\text { Same } \\
\text { Same } \\
\text { More than several } \mathrm{km}\end{array}$ & $\begin{array}{c}\text { Same } \\
\text { Same } \\
\text { Less than } 1 \mathrm{~km}\end{array}$ \\
\hline $\begin{array}{l}\text { Secondary structures } \\
\text { Joints, describe } \\
\text { Joints, frequency } \\
\text { Others? }\end{array}$ & $\begin{array}{l}\text { Probably few joints: } \\
\text { plastlcity causes non- } \\
\text { brittle deform. at depth } \\
\text { No data } \\
\text { Dissolution breccla }\end{array}$ & $\begin{array}{l}\text { Same } \\
\text { Same } \\
\text { Same }\end{array}$ & $\begin{array}{l}\text { Same } \\
\text { Same } \\
\text { Same }\end{array}$ \\
\hline $\begin{array}{l}\text { Plasticity } \\
\text { (describe) }\end{array}$ & $\begin{array}{l}\text { Moderate plasticity at } \\
\text { hlgh temp. and pressure }\end{array}$ & Same & Same \\
\hline $\begin{array}{l}\text { Porosity } \\
\text { Nature } \\
\text { Percent, range } \\
\text { Percent, common }\end{array}$ & $\begin{array}{c}\text { Intercrystalline } \\
0-4.7 \% \\
1.1 \%\end{array}$ & $\begin{array}{l}\text { Same } \\
\text { Same } \\
\text { Same }\end{array}$ & $\begin{array}{l}\text { Same } \\
\text { Same } \\
\text { Same }\end{array}$ \\
\hline $\begin{array}{l}\text { Permeabllity } \\
\text { Lateral, range } \\
\text { Lateral, common } \\
\text { Vertical, range } \\
\text { Vertical, common }\end{array}$ & $\begin{array}{l}\text { No data } \\
\text { No data } \\
\text { No data } \\
\text { No data }\end{array}$ & $\begin{array}{l}\text { Same } \\
\text { Same } \\
\text { Same } \\
\text { Same }\end{array}$ & $\begin{array}{l}\text { Same } \\
\text { Same } \\
\text { Same } \\
\text { Same }\end{array}$ \\
\hline $\begin{array}{c}\text { Bounding IIthologles } \\
\text { Vertical, II thology } \\
\text { Vertical, thickness } \\
\text { Lateral, IIthology } \\
\text { Lateral, thickness }\end{array}$ & $\begin{array}{c}\text { Shales, carbonates, salt } \\
30-300 \mathrm{~m} \\
\text { Shales, carbonates, salt } \\
30-300 \mathrm{~m}\end{array}$ & $\begin{array}{l}\text { Same } \\
\text { Same } \\
\text { Same } \\
\text { Same }\end{array}$ & $\begin{array}{l}\text { Same } \\
\text { Same } \\
\text { Same } \\
\text { Same }\end{array}$ \\
\hline $\begin{array}{l}\text { Reaction to external } \\
\text { events } \\
\text { Earthquakes } \\
\text { Water, dissolution } \\
\text { Water, brecclation } \\
\text { Weathering } \\
\text { Erosion }\end{array}$ & $\begin{array}{l}\text { Plastic deformation at } \\
\text { hlgh temp. \& pressure. } \\
\text { Moderately soluble rock } \\
\text { Locally comnon } \\
\text { High in E. USA, low in } W \\
\text { High in E. USA, low in } W .\end{array}$ & $\begin{array}{l}\text { Same } \\
\text { Same } \\
\text { Same } \\
\text { Same } \\
\text { Same }\end{array}$ & $\begin{array}{l}\text { Same } \\
\text { Same } \\
\text { Same } \\
\text { Same } \\
\text { Same }\end{array}$ \\
\hline $\begin{array}{l}\text { Rosourcos } \\
\text { Contalned in host } \\
\text { Assoclated with host }\end{array}$ & $\begin{array}{l}\text { Anhydrock, sulfur, gypsum } \\
\text { Petroleum, potash, salt }\end{array}$ & $\begin{array}{l}\text { Same } \\
\text { Same }\end{array}$ & $\begin{array}{l}\text { Same } \\
\text { Same }\end{array}$ \\
\hline
\end{tabular}




\section{E.6.9 REFERENCES}

ADAMS 1944. J. E. Adams, "Upper Permian Ochoa Series of Delaware Basin, and Southeastern New Mexico," Am. Assoc. Pet. Geol. Bul1., 28,

1596-25 (1944).

ANDERSON 1972. R. Y. Anderson, W. E. Dean, Jr., D. W. Kirkland, and H. I. Snider, "Permian Castile Varved Evaporite Sequence, West Texas and New Mexico," Geol. Soc. Am. Bul1., 83, 59-86 (1972).

ANDERSON 1978. R. Y. Anderson, K. K. Kietzke, and D. J. Rhodes, "Development of Dissolution Breccias, Northern Delaware Basin, New Mexico and Texas," in G. S. Austin, compiler's, Geology and Mineral Deposits of Ochoan Rocks in Delaware Basin and Adjacent Areas, New Mexico Bureau of Mines and Mineral Resources Circular 159, 1978, pp. 47-52.

ANDERSON 1966. R. Y. Anderson and D. W. Kirkland, "Intrabasin Varve Correlation," Geo1. Soc. Am. Bul1., 77(3), 241-56 (1966).

ANDERSON 1980. R. Y. Anderson and D. W. Kirkland, "Dissolution of Salt Deposits by Brine Density Flow," Geol., 8, 66-69 (1980).

BAAR 1977. C. A. Baar, Applied Salt-Rock Mechanics, Elsevier, New York, 1977, p. 294.

BLAZENKO 1964. E. J. Blazenko, "Geology of the South Erick Gas Area, Beckham and Greer Counties, Oklahoma," Shale Shaker, 15(4), 53-78 (1964).

BUTLER 1970. G. P. Butler, "Holocene Gypsum and Anhydrite of the Abu Dhabi Sabkha, Trucial Coast: An Alternative Explanation of Origin," in J. L. Rau and L. F. Dellwig, eds., Proceedings of the Third Symposium on Salt, Vol. 1, pp. 120-52, Northern Ohio Geological Society, Cleveland, $\overline{1970 .}$

BUTLER 1982. G. P. Butler, M. Harris, and C. G. St. C. Kenda11, "Recent Evaporites from the Abu Dhabi Coastal Flats," in C. R. Hanford, R. G. Loucks, and G. R. Davies, eds., Depositional and Diagenetic Spectra of Evaporites - A Core Workshop, Society of Economic Paleontologists and Mineralogists, Core Workshop No. 3, Calgary, Canada, June $26-27,1982$, pp. 33-64.

DEAN 1978. W. E. Dean and R. Y. Anderson, "Salinity Cycles - Evidence for Subaqueous Deposition of the Castile Formation and Lower Part of Salado Formation, Delaware Basin, Texas and New Mexico," in G. S. Austin, compiler's, Geology and Mineral Deposits of Ochoan Rocks in Delaware Basin and Adjacent Areas, New Mexico Bureau of Mines and Mineral Resources Circular 159, 1978, pp. 15-20. 
DEAN 1982. W. E. Dean and R. Y. Anderson, "Continuous Subaqueous Deposition of the Permian Castile Evaporites, Delaware Basin, Texas and New Mexico," in C. R. Hanford, R. G. Loucks, and G. R. Davies, eds., Depositional and Diagenetic Spectra of Evaporites - A Core Workshop, Society of Economic Paleontologists and Mineralogists, Core Workshop No. 3, Calgary, Canada, June 26-27, 1982, pp. 324-53.

DEAN 1975. W. E. Dean, G. R. Davies, and R. Y. Anderson, "Sedimentological Significance of Nodulax and Laminated Anhydrite," Geol., 3, 367-72 (1975).

DEER 1962. W. A. Deer, R. A. Howie, and J. Zussman, Rock-Forming Minerals, Vol. 5, Lowe and Brydone, London, 1962, p. 371 .

DIEHL, in preparation. S. F. Dieh1 and W. Z. Savage, "Physical Properties of Anhydrite, Sect. 3 in W. E. Dean and K. S. Johnson, eds., Anhydrite Deposits of the United States and Characteristics of Anhydrite Important for Storage of Radioactive Wastes, U. S. Geological Survey Professional Paper (in preparation).

DZENS-LITOVSKIY 1962. A. I. Dzens-Litovskiy and G. V. Vasi1'yev, "Geologic Conditions of Formation of Bottom Sediments in Karabogax-Gol in Connection with Fluctuations of the Caspian Sea Level," American Geological Institute's Translation of Isvestiya Academy of Science, USSR, Geological Series 3, (1962), pp. 79-86.

EDIE 1958. R. W. Edie, "Mississippian Sedimentation and Oil Fields in Southeastern Saskatchewan," Am. Assoc. Pet. Geo1. Bul1., 42(1), 94-126 (1958).

ESSA/COAST AND GEODETIC SURVEY 1969. ESSA/Coast and Geodetic Survey, Seismic Risk Map of the United States, U.S. Department of Commerce Map, 1969.

FAITH 1983. S. Faith, P. Spiegler, and K. R. Rehfeldt, The Geochemistry of Two Pressurized Brines from the Castile Formation in the Vicinity of the Waste Isolation Pilot Plant (WIPP) Site, Environmental Evaluation Group, Health and Environment Department, State of New Mexico, EEG-21, p. 69 .

FRIEDMAN 1978. G. M. Friedman, "Depositional Environments of Evaporite Deposits," in W. E. Dean and B. C. Schreiber, eds., Marine Evaporites, Society of Economic Palentologists and Mineralogists, Lecture Notes for Short Course No. 4, Oklahoma City, Oklahoma, Apri1 8, 1978, pp. 177-84.

GIGNOUX 1955. M. Gignoux and R. Barbier, Geologie des Barrages et des Amenagements Hydrauliques, Masson et Cie, Paris, (1955) p. 343.

GONZALES 1982. S. Gonzales, "Host Rocks for Radioactive-Waste Disposal, Amer. Sci., 70, (March-Aprii) 191-200 (1982). 
GONZALES 1980. S. Gonzales and K. S. Johnson, "International

Investigations of Geologic Media for the Disposal of Radioactive Wastes," in M. Bergman, ed., Subsurface Space: Proceedings of the International Symposium, Rockstore 80, Vol. 3, pp. 1339-44, Stockholm, Sweden, June $23-27,1980$.

HAM 1962. W. E. Ham, "Economic Geology and Petrology of Gypsum and Anhydrite," Part II in R. O. Fay, W. E. Ham, J. T. Bado, and L. Jordan, eds., Geology and Mineral Resources of Blaine County, Oklahona, Oklahoma Geological Survey Bulletin 89, 1962, pp. 100-51.

HOLSER 1979. W. T. Holser, "Mineralogy of Evaporites," Chapt. 8 in R. G. Burns, ed., Marine Minerals, Mineralogical Society of America, Short Course Notes, Vo1. 6, November 1979, pp. 211-94.

IBRAHIM 1972. M. A. Ibrahim and D. Lo Katz, "Evaluation of Capillary propcrtics of Cap Rocks," in Vol. 1 of procccdings of the Sccond Symposium on Fundamentals of Transport Phenomena in Porous Media, University of Guelph, Ontario, August 7-11, 1972, Huddleston and Barney Ltd., Woodstock, Ontario, 1972, pp. 137-54.

JOHNSON, in preparation. K. S. Johnson, S. Gonzales, and W. E. Dean, "Distribution and Geologic Characteristics of Anhydrite Deposits in the United States," Sect. 2 in W. E. Dean and K. S. Johnson, eds., Anhydrite Deposits of the United States and Characteristics of Anhydrite Important for Storage of Radioactive Wastes, U.S. Geological Survey Professional Paper (in preparation).

KING 1947. R. H. King, "Sedimentation in Permian Castile Sea," Amer. Assoc. Petr. Geo1. Bu11., 31, 470-77 (1947).

KINSMAN 1966. D. J. J. Kinsman, "Gypsum and Anhydrite of Recent Age, Trucial Coast Persian Gulf," in J. L. Rau, ed., Vol. 1 of Proceedings of the Second Symposium on Salt, Northern Ohio Geological Society, Cleveland, 1966, pp. 302-26.

KIRKLAND 1970. D. W. Kirkland and R. Y. Anderson, "Microfolding in the Castilc and Todilto Evaporitco, Texas and New Mexico," Gcol. Soc. Am. Bu11., 81, 3259-82 (1970).

KIRKLAND 1976. D. W. Kirkland and R. Evans, "Origin of Limestone Buttes, Culberson County, Texas," Amer.Assoc. Petr. Geol. Bu11., 60(11), 2005-18 (1976).

KRUMBEIN 1963. W. C. Krumbein and L. L. Sloss, Stratigraphy and Sedimentation, Sec. Ed., W. H. Freeman and Co., San Francisco, 1963, p. 660 .

LAMBERT 1977. S. J. Lambert and J. W. Mercer, Hydrologic Investigations of the Los Medanos Area, Southwestern New Mexico, Sandia Laboratories Report 77-1401, 1977, p.63. 
LANDES 1959. K. K. Landes, "The Mackinac Breccia," in Geology of Mackinac Island and Lower and Middle Devonian South of the Straits of Mackinac, Annual Geological Excursion Guidebook, Michigan Basin Geological Society, 1959, pp. 19-34.

LAUBSCHER 1975. H. P. Laubscher, "Viscous Components in Jura Folding," Tectonophysics, 27, 239-54 (1975)。

LOTZE 1957. Franz Lotze, Gebruder Borntraeger, Steinsalz und Kalisalze, Berlin, 1957 , p. 465 .

MADISON 1970. R. J. Madison, "Effects of a Causeway on the Chemistry of the Brine in Great Salt Lake, Utah," Utah Geol. and Mineral, Surv. Water Resour. Bul1., 14, 1970, p. 52.

MAIKLEM 1969. W. R. Maiklem, D. G. Bebout, and R. P. Glaister, "Classtfication of Anhydrite - A Practical Approach," Bu1l. Cane Pet. Geol., 17(2), 194-233 (1969).

MORRIS 1957. R. C. Morris and P. A. Dickey, "Modern Evaporite Deposition in Peru," Am. Assoc. Pet. Geol. Bul1., 41, 2467-74 (1957).

MURRAY 1964. R. C. Murray, "Origin and Diagenesis of Gypsum and Anhydrite," J. Sed. Pet., 34, 512-23 (1964).

POTTER, in preparation. R. W. Potter and M. A. Clynne, "Chemical Properties of Anhydrite," Sect. 5 in W. E. Dean and K. S. Johnson, eds., Anhydrite Deposits of the United States and Characteristics of Anhydrite Important for Storage of Radioactive Wastes, U.S. Geological Survey Professional Paper (in preparation).

POWERS 1978. D. W. Powers, S. J. Lambert, S. Shaffer, L. R. Hill, and W. D. Weart, eds., Geological Characterization Report, Waste Isolation Pilot Plant (WIPP) Site, Southeastern New Mexico, SAND 78-1596, 2 vols.. prepared for the U.S. Department of Energy by Sandia Laboratories, 1978 .

SAHORES 1962. J. Sahores, "Contribution a 1'Etude des Phenomenes Mecaniques Accompagnant 1'Hydration de 1'Anhydrite," Paris, Centre d'Etudes et Recherches de 1'Industrie des Liants Hydrauliques, Technical Publication 126, 1962, p. 230 .

SCHREIBER 1978a. B. C. Schreiber, "Introduction - Classification of Marine Evaporites," in W. E. Dean and B. C. Schreiber, eds., Marine Evaporites, Society of Economic Paleontologists and Mineralogists, Lecture Notes for Short Course No. 4, Oklahoma City, April 8, 1978, pp. 1-5.

SCHREIBER 1978b. B. C. Schreiber, "Environments of Subaqueous Gypsum Deposition" in W. E. Dean and B. C. Schreiber, eds., Marine Evaporites, Society of Economic Paleontologists and Mineralogists, Lecture Notes for Short Course No. 4, Oklahoma City, April 8, 1978, pp. 43-73. 
SCHRETBER 1982. B. C. Schreiber, M. S. Roth, and M. L. Helman, "Recognition of Primary Facies Characteristics of Evaporites and the Differentiation of These Forms from Diagenetic Overprints," in

C. R. Hanford, R. G. Loucks, and G. R. Davies, eds., Depositional and Diagenetic Spectra of Evaporites - A Core Workshop, Society of Economic Paleontologists and Mineralogists, Core Workshop No. 3, Calgary, Canada, June $26-27,1982$, pp. 1-32.

SCRUTON 1953. P. C. Scruton, "Deposition of Evaporites," Am. Assoc. Pet. Geol. Bull., 37, 2498-2512 (1953).

SHEARMAN 1978. D. J. Shearman, "Evaporites of Coastal Sabhkas," in W. E. Dean and B. C. Schreiber, eds., Marine Evaporites, Society of Economic Paleontologists and Mineralogists, Lecture Notes for Short Course No. 4, Oklahoma City, April 8, 1978, pp. 6-42.

SMITH 1978. A. R. Smith, "Sulfur Deposits in Ochoan Rocks of Southeast New Mexico and West Texas," in G. S. Austin, compiler, Geology and Mineral Deposits of Ochoan Rocks in Delaware Basin and Adjacent Areas, New Mexico Bureau of Mines and Mineral Resources Circular 159, 1978, pp. 71-77.

SPIEGLER 1982. P. Spiegler, "Hydrologic Analyses of Two Brine Encounters in the Vicinity of the Waste Isolation Pilot Plant (WIPP) Site," EG-17 Environmental Evaluation Group, Health and Environment Department, State of New Mexico, 1982, p. 64.

THORDARSON, in preparation. W. Thordarson, "Hydrogeology of Anhydrite," Sect. 4 in W. E. Dean and K. S. Johnson, eds., Anhydrite Deposits of the United States and Characteristics of Anhydrite Important for Storage of Radioactive Wastes, U. S. Geological Survey Professional Paper (in preparation).

WHELAN 1972. J. A. Whelan, "Ochsenius Bar Theory of Saline Deposition Supported by Quantitative Data, Great Salt Lake, Utah," Sect. 10, Geochemistry, 24th International Geological Congress, Montreal, 1972, pp. 296-303.

WILSON 1973. W. E. Wilson, J. S. Rosenhein, and J. D. Hunn, "Hydrologic Evaluation of Industrial Waste Injection at Mulberry, Florida" in Underground Waste Management and Artificial Recharge, Vo1. 1, American Association of Petroleum Geologists, Tulsa, Oklahoma, 19/3, pp. 352-64. 
This page intentionally left blank 
APPENDIX E.7

\section{SUMMARY}

S. H. STOW

OAK RIDGE NATIONAL LABORATORY

OAK RIDGE, TENNESSEE 37830 
This page intentionally left blank 


\section{E.7 SUMMARY}

Appendixes E.2 to E.6 have provided information that constitutes the geologic data base supporting evaluation of the five sedimentary rock types as to their geologic potential as host rocks for an HLW repository. Although the primary use of this data base is to provide input to other aspects of the rock evaluation effort, there is one rock evaluation discriminator (Appendix A, Sects. A.4 and B.3.2) directly relevant to the evaluation: the dimensions and homogeneity typical of the various rock types and the depositional environments for each. A qualitative summary of this information is given in Table E.7.1.

The data presented in these appendixes and summarized in Table E.7.1 support the conclusion that there are facies of each lithology (rock type) that satisfy minimal requirements for possible siting. Thus, none of the rock types can be differentiated or rejected on this basis. A summary of the more promising depositional environments for each rock type is contained in Table E.7.2. However, when data on (a) the relative abundance of the facios representing a depositional environment within a rock type and (b) the absolute abundance of the rock type (see last two columns of Table E.7.1) are taken into account, it is possible to differentiate between the rock types with respect to the discriminator concerning dimensions and homogeneity. Specifically, it is clear that shales are the most promising rock types with respect to these attributes. Sandstone and the carbonates (1imestone/dolostone) are also plentiful but clearly less so than shales. Chalk and anhydrock both occur to a very limited extent and are ranked third on this basis. 
Table E.7.1. Summary of geologic informationa

\begin{tabular}{|c|c|c|c|c|c|c|}
\hline \multirow{2}{*}{$\begin{array}{l}\text { Rock type and } \\
\text { depositional } \\
\text { environment }\end{array}$} & \multirow{2}{*}{$\begin{array}{l}\text { Thick- } \\
\text { ness }\end{array}$} & \multirow[b]{2}{*}{ Extent } & \multicolumn{2}{|c|}{ Homogeneity } & \multirow{2}{*}{$\begin{array}{l}\text { Depositional } \\
\text { environment } \\
\text { abundance }\end{array}$} & \multirow{2}{*}{$\begin{array}{l}\text { Absolute } \\
\text { abundance }\end{array}$} \\
\hline & & & Vertical & LateraI & & \\
\hline Anhydrock & & & & & & $\mathrm{L}$ \\
\hline Basin - center & $\mathrm{H}$ & $\mathrm{H}$ & $\mathrm{H}$ & $\mathrm{H}$ & $\mathrm{H}$ & \\
\hline Basin - margin & $\mathrm{M}-\mathrm{H}$ & $\mathrm{H}$ & H & $\mathrm{H}$ & $\mathrm{H}$ & \\
\hline Playa & $\mathrm{L}$ & $\mathrm{L}$ & $\mathrm{L}$ & $\mathrm{L}$ & $\mathrm{L}-\mathrm{M}$ & \\
\hline Sabkha & $\mathrm{L}$ & $\mathrm{L}$ & $\mathrm{L}$ & $\mathrm{L}$ & $\mathrm{L}$ & \\
\hline Shelf & M & M & L & L & L & \\
\hline Chalk & & & & & & $\mathrm{L}$ \\
\hline Shallow water & $\mathrm{L}$ & M & $\mathrm{H}$ & $\mathrm{M}-\mathrm{H}$ & $\mathrm{M}-\mathrm{H}$ & \\
\hline Decp water & $\mathrm{H}$ & $\mathrm{H}$ & $\mathrm{M}-\mathrm{H}$ & $\mathrm{H}$ & $\mathrm{H}$ & \\
\hline Carbonate rocks & & & & & & M \\
\hline Supratidal & $\mathrm{H}$ & H & $\mathrm{H}$ & н & $\mathrm{H}$ & \\
\hline Peritidal & $\mathrm{L}$ & $\mathrm{L}$ & $\mathrm{L}$ & $\mathrm{L}$ & $\mathrm{H}$ & \\
\hline Open shelf & M & M & $\mathrm{L}$ & $\mathrm{L}$ & $\mathrm{H}$ & \\
\hline Back-bank-edge & $\mathrm{M}-\mathrm{H}$ & M & $\mathrm{H}$ & $\mathrm{H}$ & M & \\
\hline Bank-edge & $\mathrm{H}$ & M & $\mathrm{L}$ & $\mathrm{L}$ & M & \\
\hline Slope & $\mathrm{H}$ & H & $\mathrm{L}$ & $\mathrm{H}$ & L & \\
\hline Sandstone & & & & & & M \\
\hline Open marine & H & н & M & $\mathrm{M}$ & M & \\
\hline Terrestrial & M & M & M & $\mathrm{M}$ & $\mathrm{H}$ & \\
\hline Transitional & $M-L$ & M & $\mathrm{L}$ & M & M & \\
\hline Shale & & & & & & $\mathrm{H}$ \\
\hline Continental & M & $\mathrm{L}$ & $\mathrm{L}$ & $\mathrm{L}$ & $L-M$ & \\
\hline Marine & $\mathrm{H}$ & $\mathrm{H}$ & $\mathrm{H}$ & $\mathrm{H}$ & $\mathrm{H}$ & \\
\hline Transitional & $\mathrm{M}-\mathrm{H}$ & $\mathrm{M}-\mathrm{H}$ & M & $\mathrm{M}-\mathrm{H}$ & M & \\
\hline
\end{tabular}

a Rankings (other than for absolute abundance) are relative for each rock type separately and are based on: H (high-most favorable), M (moderate), and L (least favorable). The specific data upon which these rankings are based are found in Appendixes E.2 through E.6. 
Table E.7.2. Sumnary of more promising depositional environments

\begin{tabular}{ll} 
Rock type & Promising depositional environment(s) \\
\hline Shale & Marine, transitional \\
Sandstone & Open marine, terrestrial \\
Carbonate rocks & Supratidal, open shelf, back band edge, bank edge, slope \\
Chalk & Shallow water, deep water \\
Anhydrock & Basin center, basin margin
\end{tabular}


This page intentionally left blank 


\section{Evaluation of Five Sedimentary Rocks Other than Salt for Geologic Repository Siting Purposes}

Volume 3: Appendixes $\mathrm{F}$ through $\mathrm{K}$

\section{November 2003}

Prepared by

A. G. Croff

T. F. Lomenick

R. S. Lowrie

S. H. Stow

OFFICIAL USE ONLY

May be exempt from public release under the Freedom of Information Act (5 U.S.C. 552), exemption number and category:

Exemption 5 - Privileged Information

Department of Energy review required before public release

Name/Org: Allen G. Croff, ORNL Date: October 10, 2003

Guidance (if applicable)

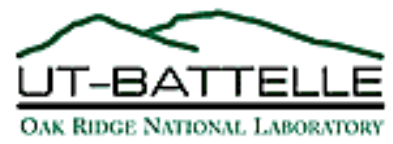


This page intentionally left blank 
EVALUATION OF FIVE SEDIMENTARY ROCKS

OTHER THAN SALT FOR GEOLOGIC REPOSITORY SITING PURPOSES

VOLUME 3: APPENDIXES F THROUGH $\mathrm{K}$

\author{
A. G. Croff \\ T. F. Lomenick \\ R. S. Lowrie \\ S. H. Stow \\ Date Published: November 2003 \\ PREPARED FOR THE \\ UNITED STATES DEPARTMENT OF ENERGY \\ OFFICE OF CIVILIAN RADIOACTIVE WASTE MANAGEMENT

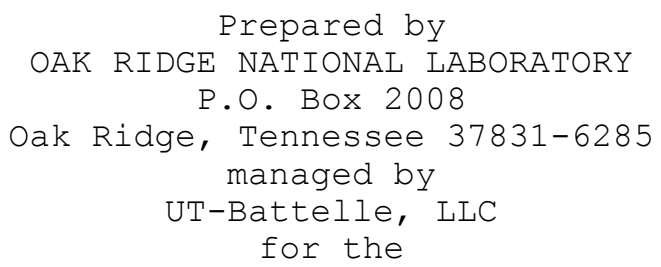


This page intentionally left blank 
CONTENTS

VOLUME 3

Page

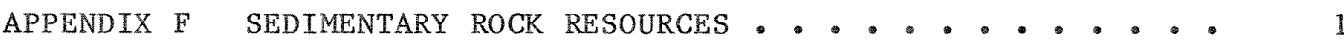

APPENDIX G DESIGN ANALYSIS FOR A HIGH-LEVEL WASTE REPOSITORY

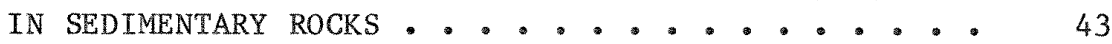

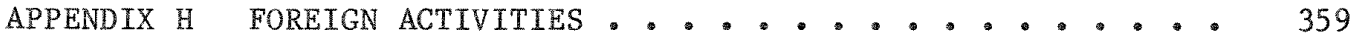

APRENDIX I ASSESSMENT OF SYGTEMS ANALYGIS FOR SEDIMENTARY

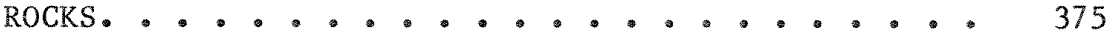

APPENDIX J REPOSITORY COST COMPARISONS FOR FIVE SEDIMENTARY

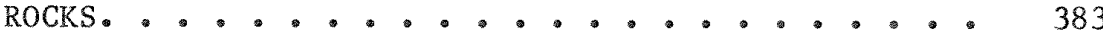

APPENDIX $\mathrm{K}$ BEHAVIOR OF METALLIC WASTE PACKAGES IN DEEP

SEDIMENTARY ROCKS. . . . . . . . . . . . . 399 
This page intentionally left blank 
APPENDIX F

SEDIMENTARY ROCK RESOURCES

NETHERLAND, SEWELL, AND ASSOCIATES, INC.

4500 THANKSGIVING TOWER

DALLAS, TEXAS 75201

AND

SERGE GONZALES

CONSULTING GEOLOGIST

295 E. DOUGHERTY STREET

ATHENS, GEORGIA 30601 
This page intentionally left blank 
F.1 INTRODUCTION. . . . . . . . . . . ........ 5

F.1.1 PURPOSE AND SCOPE . . . . . . ........... 5

F.1.2 VALUE OF SEDIMENTARY ROCK RESOURCES . . . . . . . 6

F.2 CRUde Otl AND NATURAL GAS . . . . . . . . . . . . 11

F.2.1 GENERAL DISCUSSION . . . . . . . . . . . . . 11

F.2.2 FORMATION/ACCUMULATION OF PETROLEUM. . . . . . . . 13

F.2.3 ASSOCIATION OF PETROLEUM WITH FTVE ROCK TYPES. . . . 14

F.2.4 RELATIVE VALUE OF FIVE ROCK TYPES AS OIL AND

GAS HABTTATS .................... 17

F.3 OTHER ENERGY AND MINERAL RESOURCES. . . . . . ....... 19

F.3.1 ORIGIN, ACCUMULATION, AND ASSOCIATION. . . . . . 19

F.3.1.1 Coal..................... 19

F.3.1.2 Uranium ................... 22

F.3.1.3 Metallic Resources............ 23

F.3.1.4 Nonmetal1ir Resnurres........... . 24

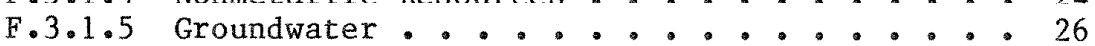

F.3.2 RELATIVE VALUE OF FIVE ROCK TYPES AS HABITAT FOR

OTHER RESOURCES. . . . . . . . . . . . . 32

F.3.2.1 Coa1................. 32

F.3.2.2 Uranium ............ 32

F.3.2.3 Metallic Resources .......... 32

F.3.2.4 Nonmetallic Resources.......... 33

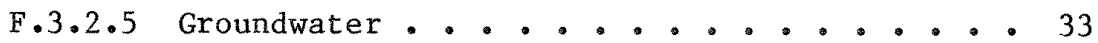

F.3.2.6 Ranking of Rock Types as Habitat for other

Resources........... 34

F.4 SUMMARY ........................ 35

F.5 RFFFRFNCFS. . . . . . . . . . . . . . . . . 37 
This page intentionally left blank 


\section{F.1 INTRODUCTION}

\section{F.1.1 PURPOSE AND SCOPE}

The value of resources associated with rocks is an important consideration in the evaluation of five sedimentary rocks (carbonate rocks, chalks, anhydrocks, sandstones, and shales) to determine their relative utility as repositories for the storage or disposal of high-level radioactive waste. The storage or disposal of such waste should be in those types of rocks that have relatively low potential as hosts for significant resources.

As used in this report, the term "resources" refers to, or includes, geologic materials that (1) can be used to produce energy, (2) are a source of metals, and (3) serve as essential raw materials tor industry. Thus, energy, metallic, nonmetallic, and water resources are considered.

Petroleum, represented hy crude nil and natural gas, and mal constitute this country's most significant energy resources, both historically and currently. For the past three decades, these three energy resources have accounted for more than $90 \%$ of all the direct energy produced in the United States (EXXON COMPANY 1979). Important metallic resources that are domestically produced in sizable tonnages include iron, copper, and lead. Precious metals such as gold and silver are also noteworthy in value, even if their production weight is only measured in ounces. Some representative nonmetallic resources of value are sand and gravel, crushed stone, limestone for lime and cement, sulfur, salt, phosphate, and clays.

The purpose of this report is to ascertain the genetic and/or spatial relationships that exist between resources and the five rock types that are currently being evaluated as potential hosts for a high-level waste repository. The discussion is limited to the conterminnus $4 R$ states. One way of approaching this objective is to ceverse-rank the five rock types relative to their likelihood to host or to contain valuable resources. Without considering site-specific data per se, the rock type least likely to contain resources is conceivably the most suitable from a generic perspective tor further consideration as a repository host rock.

It is recognized that mineral resources may be contained within one sedimentary rock type that is overlain and/or underlain by other types of sedimentary rock. Furthermore, boreholes and mining shafts may penetrate the nonmineral-bearing rocks to recover these materials and thereby diminish somewhat the capabilities of these rocks to contain high-level radioactive wastes. In these cases, rocks that are devoid of mineral resources but lie in close proximity to ore bodies in other rocks may be adversely affected for waste repository purposes by such associations. These conditions are, therefore, recognized but not dealt with in this report because of the site-specific nature of such occurrences and the complexities of treating such events in this generic study of five sedimencary rocks. 
Many valuable deposits of resources will not necessarily be found hosted within and/or immediately adjacent to the five subject rock types. Thus, some consideration must also be given to those deposits that occur within sedimentary sequences, yet generally at depths greater than $1000 \mathrm{~m}$. These deeper, but associated, resources lie below the maximum depth proposed for a repository and, therefore, are the subject of boreholes and/or shafts that pass (or would pass) through the potential host rock.

A final, and possibly the most difficult or nebulous, consideration is that of future resource potential. Connotations of significance here include (1) undiscovered deposits; (2) lower-grade resources that become viable production targets in the future; (3) future production from deposits that currently are not exploited, not because they are low grade, but rather because they cannot eronomically compete due to other factors (better located or more economical deposits exist); and (4) development of new markets or new products that, in turn, create a demand for certain resources that heretofore have not been recovered.

Finally, this report briefly discusses the origins of various resources. Such discussions, by design, are brief and make no effort to inclusively cover all hypotheses or thonghts in this suhjert area. Rather, the interested reader is referred to the voluminous literature on economic geology for more detailed discussions about the genesis of metallic ores, petroleum fields, coal seams, and industrial-mineral deposits. Some selected literature sources in this regard are: (1) metallic resources (RIDGE 1968; SKINNER 1981); (2) petroleum (LEVORSEN 1967; HALBOUTY 1970a, 1981; BRAUNSTEIN 1976; HUNT 1979); (3) COAl (DONALDSON 1979; FERM 1979; CRELLING 1980); and (4) industrial minerals (LEFOND 1975; HARBEN 1984). In addition, the report by Brobst and Pratt (BROBST 1973) contains information on all these resource categories as compiled by various U.S. Geological Survey authors relative to domestic deposits. Periodicals such as Economic Geology, American Association of Petroleum Geologists Bulletin, Mineralium Deposita, Mining Engineering, and Industrial Minerals also contain much useful information on the origin of particular mineral resources. Where appropriate in the roport, howevor, current specific literature is cited.

\section{F.1.2 VALUE OF SEDTMENTARY ROCK RESOURCES}

Sedimentary rocks are collectively the most valuable rock type with regard to resources in the United States. With the exception of certain vein and pegmatite uranium deposits, all domestic energy resonres of significance are found in such rocks. Most of the industrial rocks and minerals, especially several higher-value commodities, are either sediments or sedimentary rocks, or they occur in sedimentary host rocks. Some notable exceptions are granite and basalt (both as sources of crushed stone), asbestos, feldspar and spodumene (source of lithium), and talc. By comparison with even these important resources, however, both the tonnages and production values of sedimentary nonmetallic minerals are much greater.

It is only in the area of metallic resources that igneous and metamorplific tucks assune a grealer culleclive lmportance chan sedimentary 
rocks. With the exceptions of placers (gold, titanium), base metals (lead, zinc) hosted in carbonate rocks, micron-size gold deposits, and banded iron ores (deposited originally in stratigraphic sequences that have been slightly metamorphosed), most metallic deposits in the United States are hydrothermal in origin and/or are hosted within intrusive, metamorphic, or volcanic rock sequences. Thus, most of the major domestic deposits rich in copper, gold, silver, and molybdenum do not occur in sedimentary rocks.

Table F.1.1 compares the production values of the most significant resources produced in the United States during 1981. Because of its rather unique nature and the difficulty in assigning economic value in exact comparable terms, groundwater is tabulated separately here. A total annual recource production valuc of $\$ 300$ million, whilc arbitrary, was chosen as a cutoff for inclusion in the table. Nevertheless, the commodities listed in the table account for about $93 \%$ of the total value of such comnodities produced in 1981. Purposefully excluded are a number of important nonmetallic resources which, while meeting the selected economic value ( $\$ 300$ million), are exclusively recovered from surface mines. Additional explanation of these points may be found in the footnotes to Table F.1.1.

The economic importance of the energy resources, particularly oil, gas, and coal, is evident from the data contained in Table F.1.1. These three fuels account for $90 \%$ of the total value of all the resources listed, or nearly $86 \%$ of the entire resource value for that year (see footnote $j$ ).

Casual observation of the values shown in Table F.1.1 for metallic and nonmetallic resources might give the impression that the former are more significant than the latter in terms of production value. Actually, the converse holds because most of the unaccounted productive value ( $\$ 13.156$ billion) from 1981 is assignable to the seemingly less glamorous, but more diverse, nonmetallic mineral resources such as sand, gravel, etc. Al1 of these resources are excluded from the table. Thus, although more metallic resources of greater collective value are shown in the table, the nonmetallic resource actually rank eccond bchind the cncrgy reoourcco in terms of collective economic significance.

Because a sizable proportion of nonmetallic resources are sedimentary, it stands to reason that the resources listed may occur in some, or all, of the five rocks under consideration. With the exception of native sulfur, the other resources listed are typically tabular deposits interbedded with stratified rock units.

Thus, energy resources are not only the most important mineral-resource category from an economic production viewpoint, but are also more widespread and numerous in their occurrences relative to sandstones, carbonate rocks, shales, chalks, and anhydrocks. Nonmetallic mineral resources, while ranking collectively second in production value, definitely would appear (based upon those listed in Table F.1.1) to be very widely associated with the candidate rock types. In summary, with the notable exception of leadzinc ores and carbonate rocks, metallic resources seem to exhibit a lower incidence of either genetic or spatial involvement with these five rock types of interest. 
Table F.1.1. Comparison of domestic resources whose production values exceeded $\$ 300$ million in $1981^{a}, b$

\begin{tabular}{|c|c|c|c|c|}
\hline \multirow[b]{2}{*}{ Resource } & \multirow{2}{*}{\multicolumn{2}{|c|}{ Production quantity }} & \multicolumn{2}{|c|}{ Production value } \\
\hline & & & $\begin{array}{l}\text { Individual value } \\
\quad\left(\$ 10^{6}\right)\end{array}$ & $\begin{array}{l}\text { Percent } \\
\text { of total }\end{array}$ \\
\hline \multicolumn{5}{|l|}{ Energy } \\
\hline Crude oil & $3,129.00 \mathrm{x}$ & $10^{6} \mathrm{bbl}$ & 99,400 & 56.91 \\
\hline Natural gas & $20.18 \mathrm{x}$ & $10^{12} \mathrm{ft}^{3}$ & 39,950 & 22.87 \\
\hline Coal (a11 ranks) & $823.00 \mathrm{x}$ & $10^{6}$ short tons & 21,750 & 12.45 \\
\hline Uraniumc & $38.50 \mathrm{x}$ & $10^{6} \mathrm{Ib}$ & 1,539 & 0.88 \\
\hline \multicolumn{5}{|l|}{ Metallic } \\
\hline Iron ore ${ }^{d}$ & $77.20 \mathrm{x}$ & $10^{6}$ long tons & 2,919 & 1.67 \\
\hline Copperc & $1.70 \mathrm{x}$ & $10^{6}$ short tons & 2,886 & 1.65 \\
\hline Molybdenume & $119.00 \times$ & $10^{6} 1 \mathrm{~b}$ & 945 & 0.54 \\
\hline Gold $c$ & $1.38 \mathrm{x}$ & $10^{6}$ fine oz. & 634 & 0.36 \\
\hline Silverc & $40.70 \times$ & $10^{6}$ fine oz. & 428 & 0.25 \\
\hline Leadc & $0.49 \times$ & $10^{6}$ short tons & 359 & 0.21 \\
\hline Zinc ${ }^{c}$ & $0.34 \mathrm{x}$ & $10^{6}$ short tons & 307 & 0.18 \\
\hline \multicolumn{5}{|l|}{ Nonmeta11ic } \\
\hline Phosphatef & $59.10 x$ & $10^{6}$ short tons & 1,438 & 0.82 \\
\hline Sulfurg & $5.82 \mathrm{x}$ & $10^{6}$ long tons & 716 & 0.41 \\
\hline Salt & $38.90 \mathrm{x}$ & $10^{6}$ short tons & 636 & 0.37 \\
\hline Tronah & $6.01 \mathrm{x}$ & $10^{6}$ short tons & 420 & 0.24 \\
\hline Potash ${ }^{i}$ & $2.10 \mathrm{x}$ & $10^{6}$ short tons & 329 & 0.19 \\
\hline Totals & & & $174,656^{j}$ & 100.00 \\
\hline Groundwater $^{k}$ & $32.12 \mathrm{x}$ & $10^{9} \mathrm{gal}$ & 19,272 & \\
\hline
\end{tabular}

a Data are from the U.S. Department of Commerce (U.S. DEPARTMENT OF COMMERCE 1983) except for trona whole figures, which are derived by extrapolation (from KOSTICK 1979 and LEFOND 1984).

bPurposefully excluded are resources such as sand and grave1, crushed slone, dimension sloue, clays, cement raw malerials (shale, 11mestone), boron minerals, and limestone (1ime) that individually meet the economic cutoff value ( $\$ 300 \mathrm{million})$ but which are exclusively, or nearly so, recovered from surface mines. Value of groundwater utilized domestically not included here; see subsequent discussion in text.

$c_{\text {Based }}$ on recoverable metal content of ores.

diased on gross weight of ore mined.

eBased on metal content of processed concentrate.

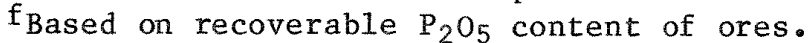

Includes only sulfur produced by Frasch recovery method.

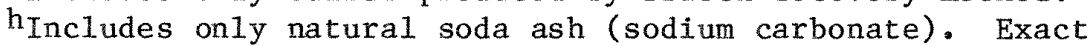
production and value data for 1981 withheld to protect individual producer firms; thus, values are extrapolated.

$i_{\text {Based upon }} \mathrm{K}_{2} \mathrm{O}$ equivalent value of ores. 
Table F.1.1 (Continued)

jTotal value of all domestic resources (exclusive of groundwater) produced in 1981 was $\$ 187,812 \mathrm{mi11i}$ in; thus, the resources 1isted here accounted for $93.0 \%$ of that production value.

$k_{\text {Data }}$ are from U.S. Geological Survey, Estimated Use of Water in the United States in 1980, Circular 1001 (SOLLEY 1983).

Because fresh water is essential to 1 ife, it is obviously a precious natural resource; in turn, groundwater, which is an integral part of the hydrologic cycle, is correctly viewed as a highly valuable resource. production-value data are not tabulated for groundwater, largely because of the many variables and unknowns involved. A major consideration is that much groundwater, particularly supplies used for nonmunicipal purposes iucluding agricultural irrigation, is recovered at essentially no resource cost. In other words, the only costs involved are the initial expenses for drilling boreholes and installing well-production equipment plus the ongoing cost of pumping the water to the surface (where the aquifers are not selfflowing). Thus, no water-right costs, user fees, or charges by suppliers are incurred.

Estimates about the volumes of surface waters and groundwaters that are used in the United States are summarized at the end of each decade by the U.S. Geological Survey. According to the most recent survey (SOLLEY 1983), data for 1980 suggest that daily withdrawals of groundwater for all uses amounted to 88 billion gallons. This is equivalent to slightly more than 32 trillion gallons consumed in that single year.

In an effort to assign a reasonable and comparable value (to those nonwater mineral resources previously discussed) for groundwater, data summarized by probstein and Gold in relating water costs to the emerging synfuels industry were utilized (PROBSTEIN 1978). These authors suggest $\$ 0.60$ per thousand gallons as a minimum value to reflect costs of water rights and pumpage expenses from the subsurface. If transportation and/or purification expenses are also to be considered, an upper cost around $\$ 2.00$ pet thousand gallons would be derived. Inasinuch as aust groundwaler is consumed near the underlying point where it is recovered and rarely needs appreciable treatment, the lower of the above values was selected for calculational purposes. Multiplication of 32.12 trillion gallons by $\$ 0.60$ per thousand gallons produces a total value of $\$ 19.272$ bil1ion. This figure means that groundwater ranks only behind crude oil, natural gas, and coal in annual production value (even though the groundwater figure is for 1980 and the others are for 1981). The magnitude of this economic value clearly supports the concept that groundwater is a resource which is both essential and valuable.

The trend in the United States for the past several years has been for the value of oil and gas production to increase relative to that of other resources. A hiatus has occurred in this trend during recent years; however, on a lung-natue basis, cuncent surpluses are expected lo be depleled, whlch 
would probably cause a resumption of this upward trend. Coal production has also increased for the past several years, but the value of this production has not changed appreciably in relation to that of other resources. In recent years, a hiatus in the upward trend of coal production has occurred similar to that of oil and gas; however, it is anticipated that the long-term trend of coal production is upward due to depletion of current surpluses. The current lack of demand for other resources, such as oil shale and heavy metals, may change in the future because of shortages. Such shortages could result in these currently unexploited resources becoming much more valuable, but they are not considered in the present discussion. 


\section{F.2 CRUDE OIL AND NATURAL GAS}

\section{F.2.1 GENERAL DISCUSSION}

According to statistics released by the U.S. Department of Energy for the period July 1983 through June 1984, crude oil and natural gas accounted for $67 \%$ of all the energy consumed in the United States. Figures issued by the American Petroleum Institute for the first nine months of 1984 reveal, however, that imported petroleum (principally crude oil) was needed to supply slightly more than one-third of this nation's total demand for this product. Even though domestic oil and gas fields are no longer able to meet national requirements and many such fields are displaying declining production trends, the petroleum recovered from fields in the continental 48 states will represent an impressive resource value.

The principal U.S. oil and gas fields are shown in Fig. F.2.1. Because of the long history of the domestic petroleum industry, which began in 1859, the United States is the most extensively explored and drilled petroleumproducing country in the world. As such, many of the nation's productive fields and/or trends are very mature; in most observers' minds, this also means that most of the large fields present on land within the conterminous United States have already been discovered.

To the converse, the prolific fields found in the so-called western overthrust Belt of Wyoming and Utah are relatively recent discoveries. Likewise, the onshore Tuscaloosa trend in Louisiana and Mississippi and the Smackover successes in Mississippi and Alabama are recent discoveries in the Gulf Coast province, and they clearly indicate that hydrocarbons in sizable volumes remain to be discovered. of course, it must be admitted that all these examples entail deeper drilling under commonly difficult circumstances (hydrogen sulfide gas, high pressures, high bottom-hole temperatures). In fact, the Gulf Coast discoveries occur between 12,000 and $18,000 \mathrm{ft}$ in depth.

Based roughly on total production and proven reserves still contained within fielda, most of the world's petroleum is from rocks of Mesozuic age (Triassic through Cretaceous); the Cenozoic era (Tertiary-Neogene) ranks second, and the paleozoic era (Cambrian-Permian) is a distant third. In the United States, however, Paleozoic- and Cenozoic-age petroleum production figures are about equal, whereas Mesozoic-age accumulations rank a very distant third. Most of our Paleozoic-age oil and gas comes from mature (in the sense of petroleum exploration) basins such as the Appalachian, Michigan, Illinois, Williston, and the several prolific subbasins (i.e., Anadarko, Midland) of the Permian Basin. The vast volumes of Cenozoic-age petroleum are found in two regions, namely the Gulf coast and various smaller basins such as San Joaquin, Ventura, and Los Angeles in California. Both regions have established production from onshore and offshore areas, but this is more pronounced within the Gulf Coast of Texas and Louisiana. Major Mesozoic-age accumulations are found in Alaska, the onohorc Gulf Coast of Tcxas through Florida, and some of the Western Overthrust Belt. Even though Mesozoic-age oil and gas are less significant 

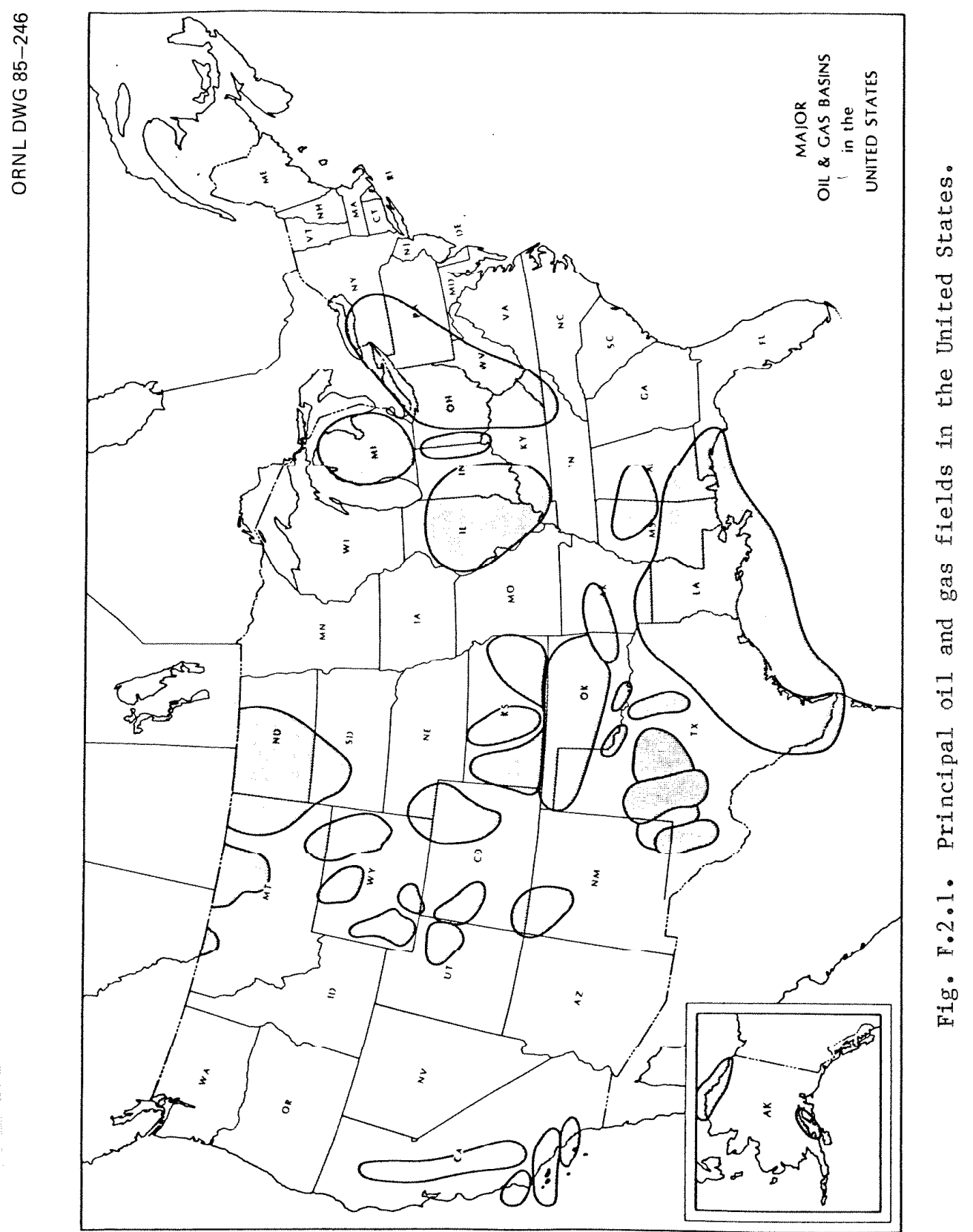
from a total volume-contribution standpoint, it is interesting to observe that this country's two largest oil fields (Prudhoe Bay in Alaska and East Texas in Texas) involve Mesozoic-age reservoirs.

\section{F.2.2 FORMATION/ACCUMULATION OF PETROLEUM}

In order for hydrocarbons to form and become concentrated in sufficient volumes to constitute calling the resulting accumulations oil and gas fields, the following natural, noneconomic circumstances must be present in the sedimentary basin(s):

1. Adequate source beds must be available. Studies by Tissot and Welte indicate that algal and amorphous organic matter or kerogen, with varying contributions from herbaceous kerogen when deposited with generally fine-grained sediments (muds $\rightarrow$ shales; 1ime oozes $\rightarrow$ marls), produce the basic beginning point; most such indurated source beds contain between 2 and $8 \%$ organic carbon (TISSOT 1978).

2. These source beds must be sufficiently buried and the basin must have a sufficient heat flow (or other point sources of heat) to permit adequate thermal maturation of the above accumulated organic matter to take place. Most crude-oil hydrocarbons are formed under temperatures between 60 and $150^{\circ} \mathrm{C}$, whereas most gaseous hydrocarbons are formed around $150^{\circ} \mathrm{C}$ (HUNT 1979).

3. The thermally maturated hydrocarbons must be expelled along with formational fluids (brines) from the compacting fine-grained sediments and undergo either short-distance or long-distance migration (in some cases, oil and gas will migrate more than once) within porous-permeable carrier beds which, in many cases, eventually become the reservoir rocks in the fields. There are many divergent views on the question of migration; the volume by Roberts and Corde11 summarizes the different arguments (ROBERTS 1980).

4. Somewhere within the course of the migrating hydrocarbon molecules there must be a barrier to their continued movement; if not, they will eventually escape at or near the land surface, and numerous oil (tar) seeps are evidence of this. These barriers to continued hydrodynamic flow are called traps and, for the sake of simplicity, are described as structural, stratigraphic, or a combination thereof. Levorsen provides a good general discussion about petroleum traps (LEVORSEN 1967). In more recent years, a greater awareness of the importance of stratigraphic traps has been gained; references by Busch (BUSCH 1974), Payton (PAYTON 1977), and Mazzullo (MAZZULLO 1980) provide very detailed information on these in sandstones and carbonate rocks and how exploration geophysics can be used to explore for them.

5. Combined with any trap must be an overlying rock unit whose low porosity and permeability prevent the escape of the hydrocarbons that have accumulated in the trap. These final barriers to flow are termed seals. Although several different rock types act as 
seals, the most common are evaporites (salt and anhydrock) and shales. Evaporites are actually involved with petroleum accumulations from several perspectives (relation to organic-matter accumulations in basins, brines, diapirs that cause various traps, and seals). A paper by Buzzalini and others reviews these important relationships (BUZZALINI 1969).

With regard to specific traps, the major structural types involve anticlinal closures; also important, but far less so than anticlines, are faults and structural closures caused by faults. Important stratigraphic traps include a large number of subtypes collectively termed here as unconformity traps; reefs and lateral permeability pinchouts represent oller very inportant stratigraphle traps. The most widely described combination traps are salt domes; however, it should be noted that many fields have been created by an interaction of both stratigraphic and structural elements. Strictly speaking, these should be called combination traps, but such a judgment depends on the viewpoint of the investigator.

\section{F.2.3 ASSOCIATION OF PETROLEUM WITH FIVE ROCK TIPES}

The two most common petroleum reservoir rocks are sandstones (which include semiconsolidated Tertiary sands) and carbonate rocks (1imestones and dolostones). Fractured-jointed rocks, which include shales and cherts, and uncommonly various igneous rocks are known to be locally significant but collectively do not constitute major reservoirs in this country. Normally, chalks would be included with carbonate rocks; however, since they are being considered separately in this evaluation, they would be classed as reservoirs similar to shales, etc., because fracturing-faulting is needed to produce adequate porosity and permeability in them. Anhydrocks are not known to be important hydrocarbon reservoirs.

Agaill, vecause of Lle linbalance Limposed by Llie excensive Middie East occurrences, carbonate rocks are more significant as reservoir rocks on a worldwide basis than they are in the United States. A review of the wor1d's 50 largest oil fields (HALBOUTY 1970c) reveals that carbonate rocks are the main reservoir rock in 19 of them and are involved as one of two reservoir rocks in another 8. These 50 fields contain 496 billion barrels of recoverable oil, and those with carbonate rocks as reservoirs account for 230 billion barrels, or $46 \%$. By contrast, if the ten largest oil fields in the United States are considered, carbonate rocks account for only about one-third of the reservoir rocks.

Major trends or fields where sandstones are the significant reservoir rock include (1) the largest oil field outside Alaska, or the famous East Texas field; (2) all the really significant oil and gas fields in the Tertiary sequences of the Gulf Coast (both onshore and offshore) and several California basins; (3) many fields in the older Paleozoic sequences of the Appalachian and Illinois basins, including the original field that began the U.S. petroleum industry; (4) individual fields of significance such as Rangely (Uinta-Piceance Basin), Salt Creek and Be11 
Creek (Powder River Basin), Burbank (Cherokee Basin), Bluebe11-Altamount and Red Wash (Uinta Basin), and Painter Reservoir (Wyoming Overthrust Belt); and (5) numerous fields in Pennsylvanian-Permian rocks of the midcontinent and Southwest and Cretaceous strata of the Denver and San Juan basins. Another we11-known gas-prone sandstone is the deep Tuscaloosa trend throughout Louisiana and Mississippi.

Important carbonate rock reservoirs are involved in the following fields or trends: (1) Abo reef trend, New Mexico; (2) the vast KellySnyder, Slaughter, and Yates fields in the Permian of West Texas; (3) numerous sma11, but collectively very productive, reef fields in the Michigan Basin; (4) Smackover oil and gas-condensate fields that extend across the onshore Gulf Coast from eastern Texas to western F1orida; (5) the famous Lima-Trenton dolostone field in Ohio and Indiana; and (6) many of the Paleozoic units involved in fields of the Anadarko Basin in Oklahoma, the Illinois Basin in Illinois, the Paradox Basin in Utah, and the Williston Basin in North Dakota and Montana. Two of the nation's must significant gas flelds are conlalned in carbonate rock reservolrs, namely the widespread Panhandle-Hugoton complex that extends from West Texas through Oklahoma into Kansas and the more localized Monroe field in northern Louisiana. Permian strata are involved in the former. while Tertiary and Cretaceous units are present in the latter.

Chalks are important oil reservoirs under the North Sea (HANCOCK 1975); but, while locally significant, they are not major reservoir rocks in the United States in spite of some noteworthy production (SCHOLLE 1977). Hattin has succinctly summarized the petroleum reservoir nature of American chalks as follows (HATTIN 1984): (1) the most noteworthy example (oil) is the Austin Chalk in South Texas; (2) other Gulf Coast chalks locally contain fairly large volumes of oil and gas, with those in northern Louisiana (Saratoga-Annona Chalks) appearing more productive than the Selma Group in Alabama and Mississippi; and (3) the shallow, and therefore economically attractive, gas deposits within the Niobrara Chalk of Colorado and Kansas are currently receiving a modest degree of exploration effort.

Gonzales and others have reviewed the petroleum-reservoir characteristics of shales and report the following (GONZALES 1984b):

1. Fractured-jointed Devonian shales of the Appalachian, Michigan, and Illinois basins are noteworthy gas reservoirs (some oil) for both past and current production; these shale intervals, especially in the Appalachian Basin, also exhibit a good resource potential for the future.

2. Fractured Upper Cretaceous shales, such as the Pierre and Mancos, are moderately significant oil reservoirs located in the Denver and San Juan Basins.

3. The fractured, highly siliceous Monterey Formation (shales and cherts) of onshore and offshore California has been an important heavy-oil reservoir and is gaining greater importance as the result of large recent discoveries offshore. 
4. The most significant contribution of petroleum accumulations is not their normal function as a reservoir but rather their ability to serve as a seal in numerous different traps.

In reference to the final point above, shales act as seals in most of the Tertiary fields of the Gulf Coast that are not sealed by salt; the Tertiary fields of California and the Rocky Mountain basins are similarly sealed predominantly by shales. In nearly all other geologic settings within the petroliferous basins of the United States that are not sealed by either salt, anhydrock, or a combination of these two evaporites, shales are the principal sealing lithology present. Areas where evaporites are more significant as seals include the Michigan and Delaware basins as well as certain trends in other basins. Dense, lowpermeability sandstones and carbonate rocks uncommonly act as seals, but a reasonable number of examples are known. Chalks can also serve as seals, as evidenced by the role of the Austin Chalk in the classic East Texas field; however, on a national basis, these rocks are a distant third behind shales and evaporites.

In certain special environments, oil and gas deposits can occur in sandstone and carbonate rocks overlain by a layer of shale which serves to trap the hydrocarbons in the aforementioned rocks. Such shale formations, to be useful as a repository host rock, would have to meet conditions such as depth, thickness, and lateral extent specified in the siting guidelines. In such a formation, boreholes to facilitate the recovery of the oil and gas from the underlying rocks, would penetrate the shale layer. Since shale does not readily undergo dissolution as do salt and carbonate rocks, it would be feasible, using state-of-the-art plugging techniques, to effectively seal the boreholes. Moreover, given the relative abundance of shale formations, it is doubtful that such shale formations would be seriously considered as the host rock for an HLW repository.

Johnson and Gonzales do not report any cases where anhydrock functions as a reservoir; rather, they indicate that anhydrock, particularly where associated with either salt beds or shales in evaporite sequences, can serve as a seal to entrap oil and gas within deeper reservoirs (JOHNSON 1984). Petroleum-bearing areas where anhydrocks are present include the northern Gulf Coast of Arkansas and Louisiana, the Permian Basin of southwest Texas and southeast New Mexico, and the Williston Basin of North Dakota and Montana.

As discussed by Gonzales and others, a number of shale- or marlstonerich sequences qualify as "oil shales," in which the "oil" is actually kerogen that can be destructively retorted into syncrude by either surface or in situ methods (GONZALES 1984b). The most noteworthy, extensive, and resource-rich sequence is the Tertiary Green River Formation found within several basins of Colorado, Utah, and Wyoming. These thick, kerogen-rich marlstones, which are lacustrine deposits, represent collectively one of (if not the) greatest accumulations of shale oil in the world. Ae long ao conventional petroleum io conomically more attractive to produce, however, it appears unlikely that these, or any 
other of the many potential syncrude-resource shales, will ever undergo appreciable production. In fact, it is probably safe to state that serious commercial development will have to be established in the Green River shales first, before any other deposits can be considered in similar economic terms.

Thus, one rather unique shale sequence in three western states clearly exhibits an important future petroleum resource implication that does not relate to conventional oil fields (reservoir rock) or seals. All other shales sufficiently rich in kerogen to be called "oil shales" may have some similar resource potential, but it is decidedly less than the Green River shales.

Tar- or oil-impregnated sandstones are not considered here inasmuch as the major deposits (Utah, California, Kentucky, and Texas) are contained in sandstones at or near the land surface. Another potential resource (to a degree it is already a current resource) is the so-called "tight gas sands." This term was originally phrased to describe various Cretaceous and Tertiary sandstones within the San Juan Basin and several Rocky Mountain hasins that contain appresiahle volumes of gas he1d in low-permeability sandstone reservoirs such as the Mesaverde Formation. In recent years, the U.S. Department of Energy (DOE) has extended this designation to include other similar low-permeability, gas-bearing units in the Gulf Coast, Appalachian Basin, and elsewhere that can apply for special pricing under current natural-gas legislation. These rather unique reservoirs have been included with the Devonian shales under a DOE program on unconventional gas resources. As such, the tight-gas sandstones appear more appropriately viewed with other future resource categories.

\section{F.2.4 RELATIVE VALUE OF FIVE ROCK TYPES AS OIL AND GAS HABITATS}

Fields producing from sandstone reservoirs are generally larger, more prolific, and more numerous than those producing from carbonate reservoirs. Based on a review of the ultimate production of the major oil and gas fields in the United States, it is estimated that the composite of all fields producing from sandstone reservoirs will account for about twice as much oll and gas recovery as all fields producing from carbonate reservoirs. However, many of the prolific oil and gas fields produce from carbonate rocks, which often have the porosity and permeability needed to provide excellent petroleum reservoir rock. Such properties are not inherent in chalk but, in some instances, are formed when bending and faulting cause sufficient stress to fracture the chalk. It is estimated that the oil and gas recovery for all fields producing from chalk is about $1 \%$ of the total recovery in the United States.

Under normal conditions, shale and anhydrock lack the permeability needed in petroleum reservoir rock; however, under rather unique conditions, commercial oil and gas production can be established from these rock types. However, the oil and gas recoveries from shale and anhydrock are normally quite low, and it is estimated that they constitute substanclally less chan $1 \%$ of the cocal recovery in che uniced states. Anhydrock, like shale, normally lacks the permeability and porosity needed to serve as a host rock for hydrocarbons. 
In summary, almost all of the petroleum reservoir rocks in the United States are sandstones and carbonate rocks. Some oil and gas are produced from chalks and a very limited amount from shales and anhydrock.

Based on the data discussed above, the following relative-value ranking has been developed for the five rock types as habitats for oil and gas:

\begin{tabular}{lr}
\multicolumn{1}{c}{ Rock } & Value ra \\
\cline { 2 - 2 } Sandstone & 1 \\
Carbonate rock & 2 \\
Chalk & 3 \\
Shale & 4 \\
Anhydrock & 5
\end{tabular}

aRankings are reported numerically:

1 is most favorable, 5 is least favorable. 


\section{F.3 OTHER ENERGY AND MINERAL RESOURCES}

\section{F.3.1 ORIGIN, ACCUMULATION, AND ASSOCIATION}

$\mathrm{F} \cdot 3 \cdot 1.1 \quad \underline{\mathrm{Coal}}$

Coal, in general terms, refers to a combustible solid matter that consists of at least $50 \%$ by weight (or $70 \%$ by volume) of carbonaceous material that was formed by compaction and induration of variously altered plant remains (DONALDSON 1979). Every geologic period since the Silurian (when land plants emerged) has seen the development of coal within sedimentary sequences.

The ranks of coal, in order of increasing carbon and increased thermal oucput (Btu/Ib) are 11gnite, subbltuminous, bltumimous, and anthracite. While more specific differentiation can be made on other properties, these ranks are adequate for this discussion. Peat, the progenitor of all coals, is however not truly a coal and thus is not designated as a rank. It is merely a mildly altered, woody vegetation. Figure F.3.1 illustrates the geographic distribution of coals by rank in the United States. As shown, the coal within the eastern half of the nation is largely bituminous, whereas the coals of the western states are principally lignite and subbituminous. Averitt indicates that more than $80 \%$ of the domestic bituminous coal lies in the eastern half, whereas some $99 \%$ of the other two ranks is located in the western states (AVERITT 1975).

Although coals of several different geologic ages are known, the majority of American coal is of three ages: Pennsylvanian, Lace Cretaceous, and Tertiary. Almost all of the eastern bituminous coal is Pennsylvanian; the western coals are Cretaceous and Tertiary in age, with the latter being the more dominant. The 1ignites along the Gulf coast region are also Tertiary in age.

A comparison of Figs. F.2.1 and $F .3 .1$ reveals that many basins are important surces or producers of both petroleum and coal. The Appalachian, Illinois, Williston, Unita, Powder River, and San Juan basins are good examples of this dual-energy-resource relationship. other petroleum-productive basins are, however, not important coal producers, even if the information given in Fig. F.3.1 appears to depict the opposite in some cases. For example, the Michigan and Gulf Coast Basins are much greater producers of oil and gas than of coal, even though considerable tonnages of lignites are currently mined in Texas. Certain other basins, most notably the Permian Basin, the San Joaquin Basin, and the other Tertiary basins of California, are prolific petroleum regions but contain no coal of any significance.

The United States possesses an immense amount of coal, most of which is bituminous. In compiling data now a decade old, but still quite

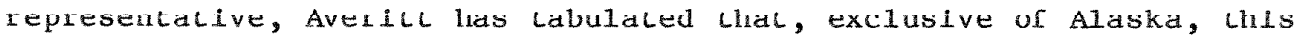
country has approximately 1.6 trillion short tons of identified coal 
0
$\stackrel{N}{1}$
1
0
0
0
$\vdots$
0
1
2
0
0

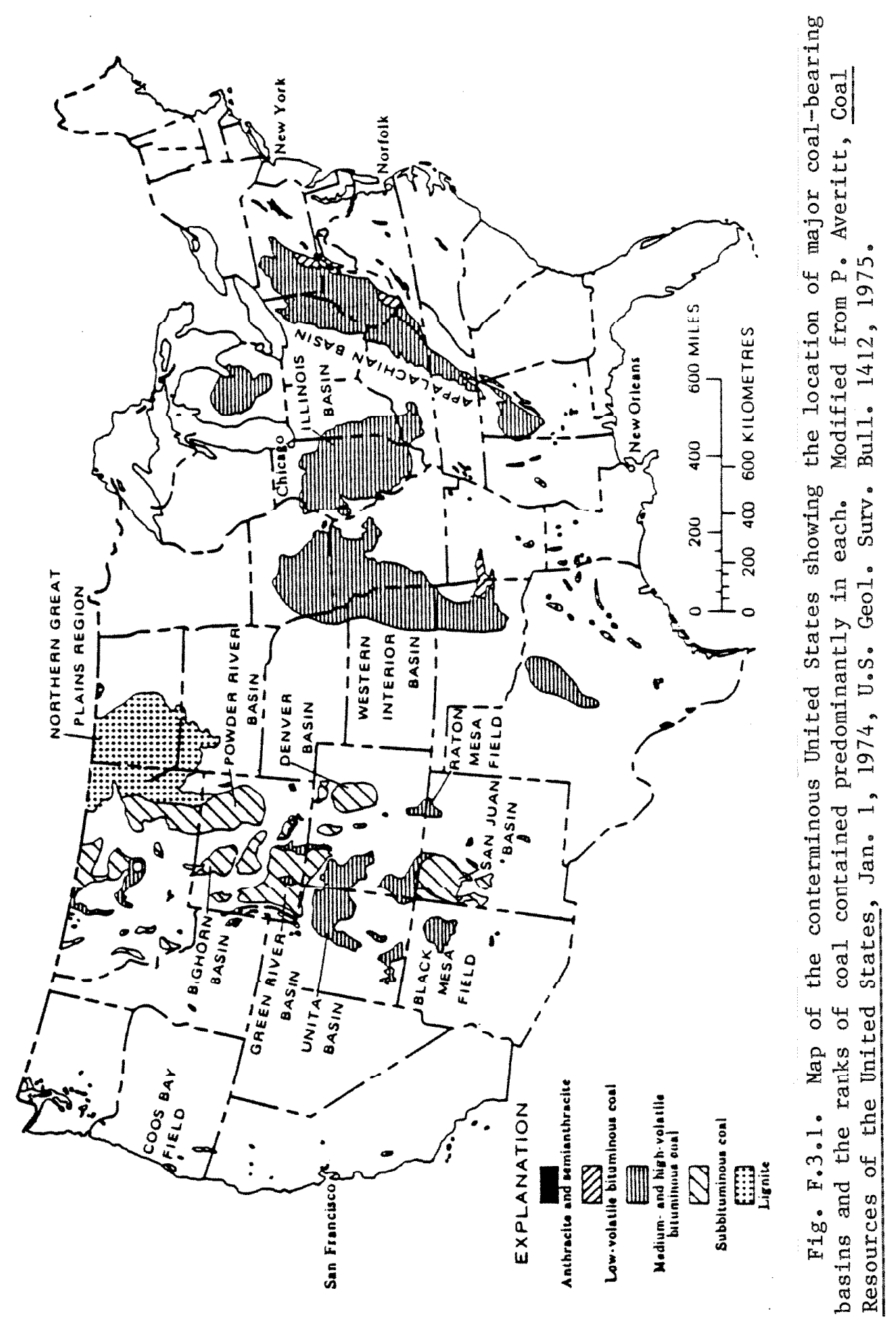


resources (AVERITT 1975). The foregoing term is used in place of proven reserves (as used to describe oil and gas) because (1) the figures only reflect coals down to $1000 \mathrm{~m}$ of depth; (2) only coal seams of 14 in. for bituminous and $30 \mathrm{in}$. for other ranks are included; and (3) variable recovery efficiencies will be experienced in mining. If coal deeper than $1000 \mathrm{~m}$ is considered, additional tonnages are calculated to the point that the entire United States has nearly 4 trillion tons of coal in the ground.

Major centers of producible coal resources from the 1.6 trillion-ton figure are: (1) Appalachian Basin - nearly 270 billion tons of bituminous and anthracite; (2) Illinois Basin - 210 billion tons of bituminous coal; (3) Williston Basin - 465 billion tons of 1ignite; and (4) the several basins of Wyoming, Colorado, and Montana (outside the Williston Basin) 320 billion tons of subbituminous and 125 billion tons of bituminous. It should be emphasized that all this coal, plus the sizable tonnages available in many other states (or basins), lies between 0 and $1000 \mathrm{~m}$ from the land surface, or wilhin lie anticipaled deplli range of a reposilory planned for any of the five sedimentary rock types.

Based on studies of modern depositional systems and a comparison of features found in ancient coal measures, it is well accepted that coals principally form in swamps, coastal marshes, and various locations within several different types of deltaic systems (DONALDSON 1979). Much of the influence on where ancient coal seams formed and how persistent and/or thick they became is attributable to such parameters as (1) rate of subsidence and input of nonorganic sediment relative to source area (near or distant); (2) shifting of subenvironments due to progradation of the deltaic system and changes in the positions of channels; (3) sea-level changes that resulted in temporal marine transgressions; (4) relative organic-matter productivity versus rate of nonorganic sediment influx, especially the amount and distribution of temporal deposits of such coarser-grained material as sand; and (5) the relative influence of marine versus fluvial processes (DONALDSON 1979).

Because of these and other factors, coal seams are clearly variable with regard to (1) thickness, (2) lateral extent/continuity, (3) content of noncoal lithologies as expressed in splits or washouts, (4) ash content, (5) oulfur and tracc-clement contenta, and (6) the spccific naturc of the different organic components (called coal macerals) that comprise coals. The formation of coal-bearing sequences can also be cyclic, as evidenced by the wel1-studied Pennsylvanian cyclotherms in the I1linois Basin and other midcontinent areas (WANLESS 1964). Certain coal seams can attain appreciable thicknesses. For example, the Wyodak seam in the Powder River Basin varies between 50 and $100 \mathrm{ft}$ generally throughout a large area, making it the single largest deposit from a reserves standpoint in the country (AVERITT 1975). Its appreciable thickness indicates the continuous and persistent coal-forming conditions existent in Tertiary times in several Rocky Mountain basins. While many (and probably most) seams are not greatly persistent in the lateral dimension, the Pittsburgh seam of the Appalachian Basin is a notable exception. It generally varies between 4 and $14 \mathrm{ft}$ in thickness over some 6000 square milce within the northern part of the baoin (AVERITT 1975). Theoc characteristics clearly reveal the long-term stability of coal-forming conditions in that area. 
There is a very decided association between coal and the five rock types. In essence, shales and sandstones are common to abundant lithologic associates; carbonate rocks (in this case, principally limestones) are moderately present in coal-measure sequences, and chalks and anhydrocks are not genetically linked with coals at all. Clastic rock types are thus found both within coal-bearing sequences and immediately adjacent to coal seams. However, many such sandstone and shale units will be too thin and/or too restricted laterally to be considered as appropriate for a repository.

Limestones are generally thin and poorly developed and are typically composed of a small proportion of cyclothermic sequences, but whether any of these carbonate rocks would meet the thickness-extent criteria established for HLW repositories is questionable. Pennsylvanian-age coal measures in the Appalachian Basin commonly overlie reasonably persistent and moderately thick limestones (FERM 1974).

The most persistent lithologic relationship is that several rock types are spatially associated to differing degrees within the principal basins where coal seams are present. Thus, shales, sandstones, and carbonate rocks both overlie and underlie coal-bearing sequences. Only chalk and anhydrocks appear to depart largely from this pattern by being deeper than any adjacent coal seams (JOHNSON 1985).

\section{F.3.1.2 Uranium}

Uranium is, of course, the fuel source for U.S. nuclear power plants. The most common ore minerals are the oxide, uranite, and the vanadate, carnotite. Ores of these and other minerals with a grade of $0.1 \% \mathrm{U}_{3} \mathrm{O}_{8}$ or better are typically mined. In addition to various igneous (pegmatitic), hydrothermal vein, and a few other types of deposits, the most significant sources of domestic uranium ore are the peneconcordant, or socalled "rollfront," deposits that are exclusively found in sandstones.

Rollfront-uranium sandstone ores are found in three principal districts in the United States: (1) Grants, New Mexico; (2) several areas in Wyoming, best illustrated by the Shirley Basin; and (3) along the south Texas coastal plali. The Uravan, Colorado discrict, which was an important producer of uranium and vanadium until recent years, also yielded ore from similar sandstones. The host sandstones in the Grants district are Jurassic in age, whereas Tertiary units are involved in both the Wyoming and the Texas trends. Articles by Finch (FINCH 1967), Fischer (FISCHER 1968), Eargle (EARGLE 1975), and Rackley (RACKLEY 1976) discuss the various concepts and unanswered questions about the genesis of these sandstone-hosted uranium deposits. It is further noteworthy that the principal associated lithologies in these deposits are shales and mudstones.

Two other types of sedimentary rocks exhibit enrichment in uranium; however, recovery of acceptable uranium values is marginal in one case and economically unlikely for the present (and possibly also for the future) in the otliex. Sedimentaly pliuspliatic rock, such as that which 
is mined as ore in Idaho, Montana, and Florida, may contain as much as $0.07 \% \mathrm{U}_{3} \mathrm{O}_{8}$, although most values are five to six times less. Certain widespread, black, marine shales also are enriched in uranium, but the value is one-tenth that of the richest phosphate occurrences. A good American example is the Chattanooga Shale of the southern Appalachian Basin, which is of Devonian-Mississippian age (SWANSON 1961). Other black shales display an enhanced response to gamma-ray logging as a result of similar, but lower, concentrations of uranium. Thus, it appears unlikely that any recovery of uranium will be made in the near future from black shales because of the very low concentrations involved.

Carbonate rocks, anhydrocks, and chalks are not genetically involved in any of the sandstone ores and are only remotely present in the basins where these sandstone ores are mined. Nash and others present data indicating that the United States possesses more than $30 \%$ of the uranium reserves of the free world (NASH 1981). Nearly all Lhese doneslic reserves are hosted in sandstones.

\section{F.3.1.3 Meta1lic Resources}

of the metallic resources included in Table $\mathrm{F} .1 .1$, only lead and zinc show any strong affinity or relationship to sedimentary rocks. This statement is predicated on the fact that the major source of domestic iron ore, namely the banded iron formations of terraines, while deposited under sedimentary conditions (JAMES 1966), have undergone differing degrees of metamorphism, and as such would not be included in this sedimentary rock program. The only significant nonbanded iron deposits in the United States are the Clinton ores near Birmingham, Alabama. Other domestic iron-ore deposits do not occur in sedimentary sequences.

Copper and molybdenum are recovered primarily from porphyry-copper and "climax-type" or porphyry-molybdenum deposits. Both of these deposits are genetically associated with igneous intrusions and attendant hydrothermal alteration relative to the sulfide ores involved (TITLEY 1966; WHITE 1981). Other domestic copper sources include various veinreplacement deposits and massive sulfide ores that are either hydro thermal or volcanogenic in origin (RIDGE 1968; HUTCHINSON 1973). Unlike the major sedimentary copper deposits in several south-central African nations, domestic occurrences of copper in sedimentary settings are rather limited. Aside from the native copper ores (nearly depleted) in the Precambrian Nonesuch Shale (ENSIGN 1968), no significant copper ores are mined from sedimentary terranes. Some production of copper from Permian red beds (Flowerpot Shale) has been undertaken (JOHNSON 1976), but it is extremely minor compared to that recovered from porphyry bodies and districts such as Butte, Montana. Shales similar to the Flowerpot, however, may be prospective throughout many of the other southwestern Permian subbasins. The Macimiento, New Mexico, copper district also is of small productive significance; its copper mineralization is associated with red-bed sandstones of Triassic age (KAUFMAN 1072 ). 
Silver and gold are largely produced from igneous, hydrothermal, and volcanogenic deposits (RIDGE 1968; LEWIS 1982). Typically, both are coproducts of the production of other metals, such as copper, lead, and zinc (the reverse involving these same metals is also known). A significant exception is the disseminated or so-called Carlin-type or micron-size gold deposits made attractive by the success of the Carlin, Nevada, deposit. These gold deposits generally illustrate an affinity for impure limestones and calcareous shales, even though the original source of the gold appears to be Tertiary-aged volcanics (LEWIS 1982). To date, these deposits seem confined primarily to the Great Basin region, or Nevada and Utah.

For all these metallic resources (namely copper, molybdenum, gold, and silver), deposits formed by igneous, hydrothermal, and volcanogenic processes are clearly more important. For the relatively few (and comparably stnall in mining-economic terms) occurrences involving sedimentary rocks, shales, and carbonate rocks seem to be the only rock types involved. The association of red-bed copper and some llicion-size yuld in shales might seemingly give more significance to that lithology; however, micron-size gold is basically more prone to be found in impure carbonate rocks. Also, many important replacement deposits that are hydrothermal in origin are hosted in carbonate rocks. One classic example of this is the famous Tintic district in Utah (JAMES 1984), where Paleozoic-age carbonate rocks host ores whose mineralizing fluids were introduced as a result of Tertiary igneous activity. Sandstones, even though they may have served as the conduits for ore-forming solutions in various deposits, are not significantly involved as ore hosts.

Lead and zinc ores (galena and sphalerite) from the often-described "Mississippi-type" stratiform and stratabound deposits show a definite relationship to carbonate rocks (BROWN 1970). Deposits in the Missouri lead belt, the Tri-State district, the central and eastern Tennessee zinc districts, and the Upper Mississippi district are hosted largely in dolostones and secondarily in limestones. Although they involve only lead and zinc as coproducts, the deposits in the Illinois and western Kentucky fluorite (an important nonmetallic resource) districts also exhibit the same characteristic.

F.3.1.4 Nonmetallic Resources

Phosphate, salt, potash, and trona (natural sodium carbonate) all are important nonmetallic resources that occur as thick, laterally extensive, stratified deposits interbedded with other sedimentary rocks. only sedimentary sulfur is different in that it occurs as a discrete ore mineral (native or pure sulfur) hosted within certain sedimentary rocks or in unusual zones (caprocks) that occur on some salt domes. Because sulfur is found as a discrete ore mineral in deposits hosted in another rock, it exhibits similarities to metallic ores.

Phosphate is principally produced from four main districts whose ores have three different genetic associations (GURR 1979). The largest deposits are the centra1-Florida, land-pebble ores that occur in unconcolidated Tertiary-age ocdimenta; likewise, Tertiary ores in North 
Carolina occur in poorly indurated strata. For this reason (unconsolidated sediments), these very large and important deposits are not being considered in our evaluation of the five rock types. Other phosphate ores come from residual and weathering-enriched deposits in Tennessee, where the host-rock association mainly involves Ordovician limestones. The large, western-U.S., phosphate deposits are found in the Meade Peak Member of the Permian Phosphoria Formation of Idaho, Montana, and Wyoming. The phosphatic ore (phosphorite) is principally associated with shales and mudstones, although 11mestones and chert beds are also abundant.

As long as the Florida and western phosphate deposits remain productive, it is very unlikely that various smaller occurrences of lower-grade ore will ever be placed into commercial extraction by the fertilizer and chemical industry. These occurrences are found mainly in shales and 1imestones. Other pocenc1al deposics occur chroughour the Aclantic Coastal Plain and, if economic and environmental matters can be overcome, would go into production prior to these smaller shale/1imestone deposits.

Sandstones, chalks, and anhydrocks are not genetically associated with the major U.S. phosphate deposits. Sandstones do, however, occur in the stratigraphic sequences adjacent to both the Tennessee and western phosphate ore districts. Chalks and anhydrocks are generally not closely involved.

Salt and potash are both evaporite deposits; as resources, the formex is very important to the chemical industry while the latter is an essential fertilizer component. Salt is produced from several basins, whereas potash (as solid ore) is only mined to any appreciable degree in the Carlsbad district of southeastern New Mexico. Potash is, however, solution-mined from the Paradox Basin in Utah. Salt is recovered in large quantities by underground- and solution-mining methods from the Michigan, Appalachian, Gulf Coast, Permian (several subbasins), and Supai (Arizona) Basins. Deposits in all these trends are extensive and thick, and the reserves are considerable. Johnson and Gonzales reported other thick sa1ts of a recoverable nature from several other bastns (JOHNSON 1978).

Adams reports that other potash occurrences are known from the deep (below $2500 \mathrm{~m}$ ) Michigan Basin, from the Eagle Basin of Colorado, and from the Williston Basin of North Dakota and Montana (ADAMS 1975). Note that the Canadian portion of the Williston Basin (called Elk Point Basin there) contains the dominant potash deposits in the free world. The influence of the Canadian export markets will probably determine whether other U.S. potash occurrences can be mined economically.

Lithologic associates of these extensive salt beds and the more restricted potash deposits (in the order of their abundance within these evaporite sequences) are: (1) anhydrocks, (2) carbonate rocks, (3) shales, (4) saldstunts, and (5) clalks. The rirsh three are tnvolved born generically and spatially, while the last two are considerably less common and only spatially associated. 
Other than some unique brines, all of the domestic trona or natural sodium carbonate (an important resource for the glass and chemical industries) produced in the United States comes from the huge deposits in the Wilkins Peak Member of the Green River Formation in southwestern Wyoming (CULBERTSON 1966). Historically, all the mines there have been of the large-volume, underground-shaft type (JACKSON 1981). Trona competes with man-made sodium carbonate made by the Solvoy process; over the last two decades, Wyoming trona has attained a dominant position.

The trona occurs interbedded within the unique Tertiary Green River oil shales (or marlstones); some 25 different layers are present, mainly near the town of Green River, Wyoming (JACKSON 1976). This deposit is possibly the world's largest, with some 50 billion tons of reserves; it is unlikely that the United States will need to tap other trona sources in the foreseeable future, given the established significance of the Wyoming deposit. Rock types associated with this trona are: shale (or marl), limestone (to a much lesser degree), and sandstones in the general stratigraphic sequences. Given the extremely site-specific nature of this unusual lacustrine evaporite deposit, its relationship to the five rock types would yield a biased response. Thus, trona is not being considered further in this evaluation of nonmetallic resources.

Sulfur is a resource of major importance to the production of chemical fertilizers and many other basic industries because of the role of sulfuric acid in many processes. Sulfur is derived from many sources. other than by-product sulfur recovered from "sour" petroleum, the only recovery of significance to this report is that by the Frasch process, where heated water is used to mine native sulfur. Such sulfur deposits are present in the caprocks of Gulf Coast salt domes and are not pursued further in this discussion. The major productive district entails vuggy limestones of Permian age beneath Culbertson County in southwest Texas. Thus, native sulfur recovered by the Frasch method from bedded sequences has a definite association with evaporites and carbonate rocks (DAVIS 1970). Specifically, anhydrock may have provided some of the sulfate for the genesis of the sulfur, and the host rocks are always limestones. This association is known from other evaporite basins; none currently appear commercially exploitable. Thus, the west-Texas deposits share oome of the characteristics of the Wyoming trona in being very silespecific. Nevertheless, native sulfur (if ever mined elsewhere) is going to exhibit the anhydrock-carbonate rock association and is considered in our evaluation. Shales and sandstones occur within adjacent stratigraphic sequences, but chalks do not appear to be present.

\section{F.3.1.5 Groundwater}

Two general approaches are used to describe aquifers or those subsurface geologic materials that are porous and permeable enough to contain groundwater and to yield it to wells. The first method considers the nature of the aquifer itself; the second method views the hydrodynamic condition of the water within the aquifer. Relative to the second point, aquifers are termed or described as either unconfined (watcr-tablc aquifers) or confined (artesiau). In llue former case, the 
water is not under a hydraulic head or pressure, and recharge occurs simply by gravity-induced percolation. Conversely, confined aquifers contain water under a hydraulic head that is the result of recharge entering the aquifer at a higher elevation and the presence of confining beds (aquitards) above and below the aquifer. For purposes of this discussion, whether groundwater is confined or unconfined is really not of significance; thus, the identification of various geologic materials that can serve as aquifers is the point of interest in the following discussion.

Beyond the presence of adequate to appreciable effective porosity and the resulting permeability, aquifers can either be unconsolidated sediments or bedrock. Examples of the former have heon summarized (MILLER 1980) and include: (1) sand and gravel (alluvium) in and along stream valleys; (2) sands, gravels, and shell beds within the coastal plains that border the Gulf Coast and Atlantic coastlines; (3) sands and gravels in numerous intermontane valleys or basins in several western and southwestern states; (4) alluvium (1argely sands and gravels) in the High Plains; and (5) glacial deposits (also typically sands and gravels) that are distributed throughout northern states from New England to the northern Great Plains. Bedrock aquifers, as considered by Miller, can be divided into the following: (1) basalts of the Pacific Northwest; (2) granites and other igneous-metamorphic ("crystalline") rocks found throughout New England, the Appalachians, the Canadian Shield (Lake Superior Uplands), the Sierra Nevadas, and various ranges that comprise the Rocky Mountains; and (3) sandstones and carbonate rocks that are distributed through many areas in the country from the Rocky Mountains (including areas within this trend) eastward to the eastern seaboard (MILLER 1980).

Thus, two of the five candidate rock types (and, in fact, the same two that were leading petroleum reservoirs) are important groundwater aquifers. Sandstones and carbonate rocks are important aquifers largely hecanse many units are porous, permeahle, and extensive so that they contain large volumes and benefit from appreciable recharge areas. Shales, chalks, and anhydrocks (unless fractured, jointed, or faulted) are generally not aquifers (certainly not high-volume, regionally significant aquifers).

Figure F.3.2 shows the generalized distribution of important sandstone aquifers; Fig. F.3.3 illustrates the geographical locations of significant carbonate rock aquifers. Although the general patterns shown on these two maps may not appear marked1y different, the sandstone aquifers are greater in number and in overall geohydrologic significance. This situation exists largely because most of the effective porosity (which ultimately influences permeability) is intergranular in sandstones. Also, because of the general size of the grains, the pore spaces between them tend to be generally large and thereby create higher porosities.

By contrast, many carbonate rock aquifers have developed as such only because they have been fractured or jointed, and/or have been partially dissolved by circulating, slightly acidic groundwaters. Flow rates and 


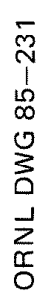

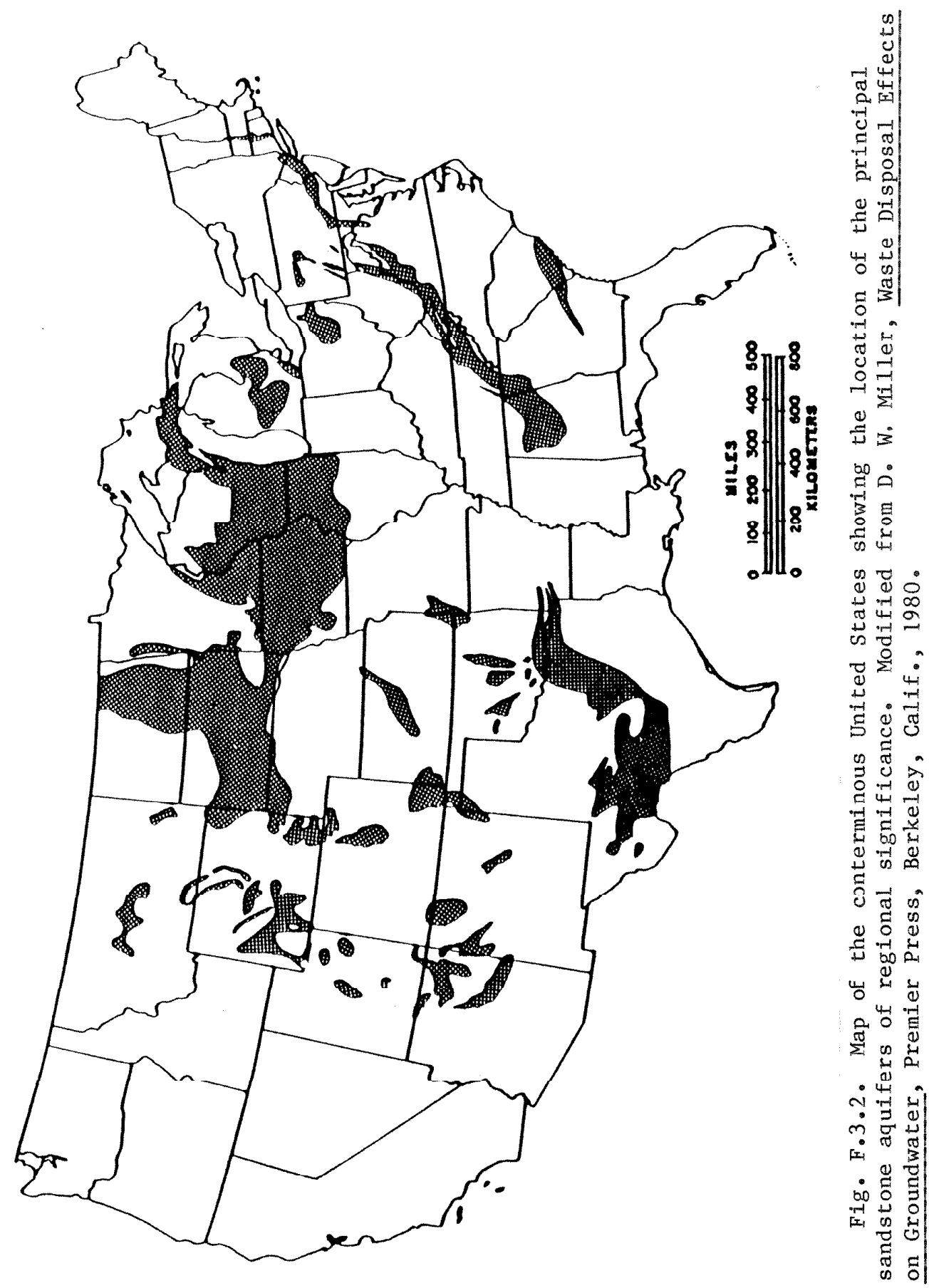




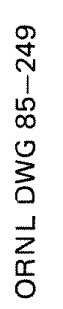

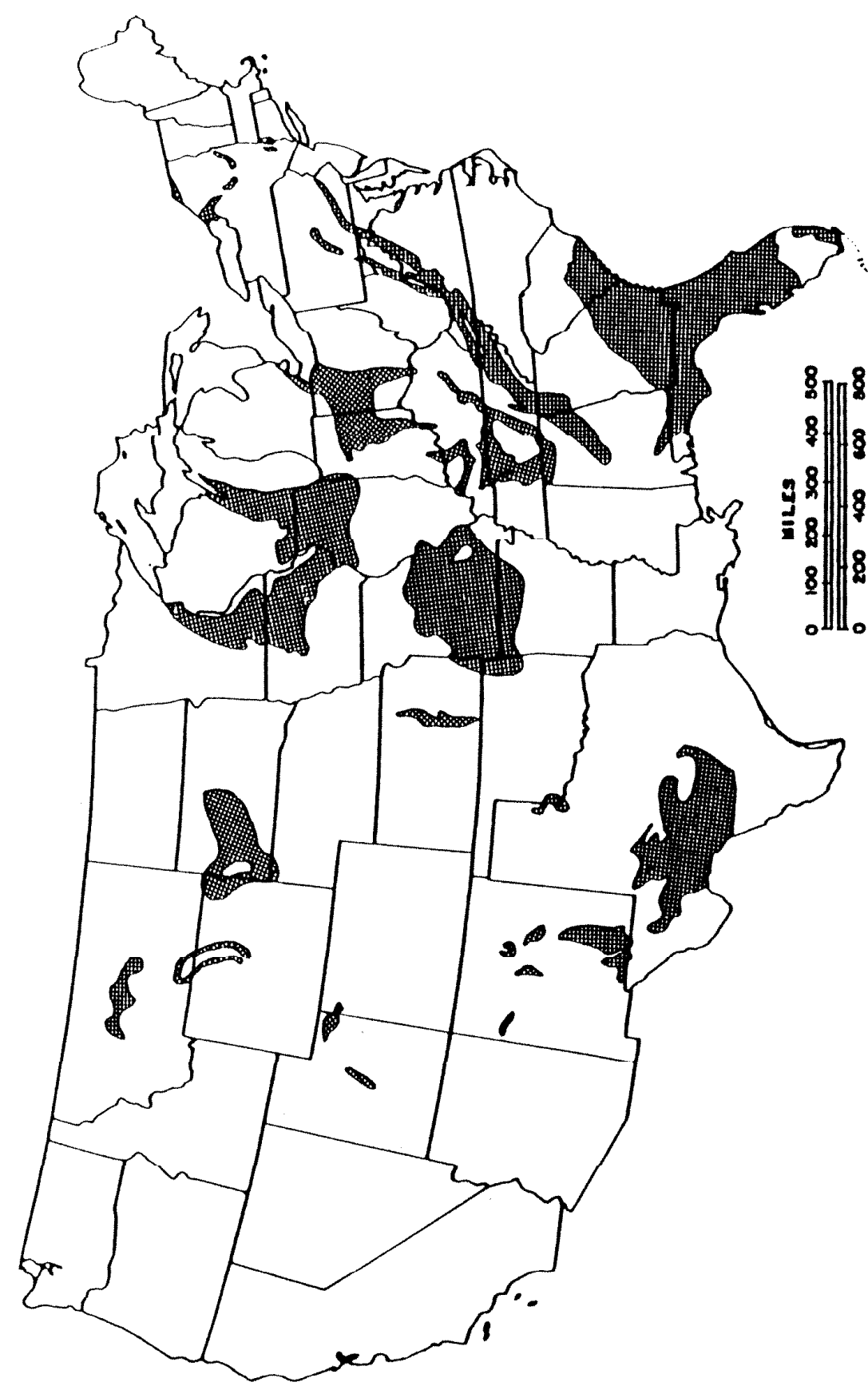

离

运苟

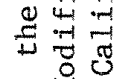

茨之

동

步苟

건

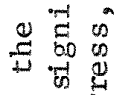

की

त्र

क्षे

of

苋出敌

के क口

분

氙豆

웜

응

署范苛

表

8 워

ฮ है न

¿

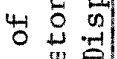

论讨

馬落

$\because 3$

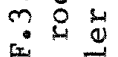

. 过

我范

这 
hydrologic properties of certain carbonate rock aquifers make several such aquifers prolific producers. A good example is the Tertiary Limestone Aquifer (also called the Floridan or Principal Artesian Aquifer) of the southeast United States. Transmissivities as high as $134,000 \mathrm{ft}^{2} / \mathrm{d}$ and well yields that range from 2000 to in excess of $10,000 \mathrm{gPm}$ have been reported (STRINGFIELD 1966; CEDERSTROM 1979). Many of the higher values are from intervals or zones of cavernous limestone or where intersecting fractures have markedly increased the permeability. Given these unusual hydrologic properties, it is little wonder that this aquifer system is one of the most prolific suppliers of fresh groundwater in the United States.

Despite the impressive hydrologic characteristics and productive capabilities of carbonate rock aquifers such as described above, there are more sandstone aquifers of regional significance. Possibly the most noteworthy is the Lower Cretaceous Dakota Sandstone, which furnishes large volumes of groundwater throughout the northern Great plains and the western Great Lakes states. Schoon (SCHOON 1971) and Taylor (TAYLOR 1978) discuss the importance of this regionally extensive sandstone aquifer.

Other selected carbonate rock aquifers of regional importance include the following: (1) Lower Cretaceous Edwards Limestone (BAKER 1976); (2) Mississippian Madison Limestone (SWENSON 1976); and (3) Upper Cambrian Potosi-Eminence and Lower Ordovician Gasconade-Roubidoux dolostones (TAYLOR 1978). Some additional, representative, sandstone aquifers include: (1) the Lower Cretaceous Tuscaloosa Group (CEDERSTROM 1979); (2) the Tertiary Carrizo-Wilcox Aquifer (BAKER 1976); and (3) the Upper Cambrian Mount Seimon-Hinckley Sandstone (BLOYD, 1975).

As discussed by Hattin, chalks where locally faulted and fractured may provide reasonable quantities of potable groundwater (HATTIN 1984); however, by and large, chalks in the Alabama-Mississippi-Louisiana-Texas Gulf Coast and the Western Interior Region are not aquifers. Throughout much of the former trend, the Selma and Austin Chalks typically lie stratigraphically below the principal fresh water sources. Within the latter region, the Niobrara Chalk lies deeper than the Ogallalla aquifer of the High Plains and other Tertiary sandstone aquifers in the Northern Great Platns. It, in turn, is underlain by the Dakota aquifer and other sandstone, as well as deeper carbonate, aquifers in the Northern Great plains and adjacent areas.

Gonzales and Johnson (GONZALES 1984a) and Gonzales and others (GONZALES 1984b) report that shales are rarely good sources of fresh groundwater but common1y serve as the aquitards for aquifers, especially a number of artesian sandstone systems. Miller discusses briefly the same relationship (MILLER 1980). Bloyd also indicates that many shales are associated with both sandstone and carbonate aquifers in the extensive Paleozoic sequences that underlie the Upper Mississippi region (BLOYD 1975). Gonzales and others also describe several selected shale formations, such as the Mississippian Coldwater and Upper Cretaceous Pierre Shales, that are spatially associated with regionally significant 
sandstone aquifers (GONZALES 1984b). Schoon points out, in his treatment of the Lower Cretaceous Dakota Sandstone, that this we11-known artesian system is bounded and confined by the Mancos or Graneros Shales (SCHOON 1971). Thus, while shales represent very poor aquifers for the most part, they are closely linked to many sandstone (and some carbonate) aquifers. Many shales, and/or many large tracts, have some of the shales cited above in the subsurface, with no association with important aquifers. The same type of statement can be made about sandstones and carbonate rocks [i.e., many examples of these rock types are not aquifers (fresh or saline water)].

Anhydrocks, like chalks and shales, rarely occur in nature as aquifers. Because of their generally deep locations, distribution, and association with evaporites, any formational fluids that they might contain are typically highly mineralized brines, and may even be under appreciable pressures (THORDARSON 1985). These pockets of brines in fact strongly suggest long-term isolation. Except where they are partially dissolved in the shallow subsurface, anhydrocks are very impermeable, and hence serve as aquitards.

To this point in the discussion, the focus has heen on fresh groundwater, the types of rocks that serve as aquifers and aquitards, and the relationships of the five candidate sedimentary rocks in that context. Four other aspects are of more than passing significance: (1) many aquifers (both sandstone and carbonate rock) contain saline groundwater, either throughout the entire aquifer system or in a saltwater leg that underlies the freshwater column; (2) many salaquifers (sandstone and carbonate rock aquifers that contain saline waters to highly saline fluids or brines) are utilized as disposal media through injection wells designed to handle a large array of toxic, corrosive, or otherwise highly contaminated industrial effluents; (3) in petroleum-producing states, there are thousands of disposal wells designed to inject oil-field brines (produced with, and separated from, the recovered oil and gas) back into the generally shallow salaquifers; and (4) some brine-bearing aquifers in solected areas serve as the sources for highly minoralized fluids important as chemical-industry feedstock.

The first point above alludes to the fact that not all sandstone and carbonate rock aquiters contain and/or yield valuable tresh groundwater. Just as there are large areas of low-porosity/low-permeability sandstones and carbonate rocks that do not function as aquifers, there are large areas where the contained saline fluids do not possess any economic value and are unlikely to ever demonstrate any economic value.

The second and third points cited above share three general observations: (1) the application of this disposal technique tends to be site-specific, (2) the aquifers that serve as the host media contain saline to very saline waters, and (3) the only economically significant utilization of these aquifers does not involve withdrawal of groundwater, but rather entails the injection of fluids. Based upon data acquired through the mid-1970s, 25 states contained waste-injection we11 systems and, of the more than 320 projects originally installed, slightly more than 200 were in operation (MLLLEK 1980). The states of Texas, Louisiana, Kansas, and Michigan account for more than two-thirds of these disposal we11s. 
The fourth point outlined above relates to a few localized areas in Ohio, West Virginia, Arkansas, Oklahoma, and Michigan, where relatively deep brines are extracted for the commercial recovery of chemicals (PRICE 1949; COLLINS 1974; SORENSEN 1974; COTTEN 1978). In the case of Arkansas and Michigan, carbonate rocks are the aquifers involved, whereas sandstone aquifers are the sources in the other states. The possibility certainly exists that other brine-producing aquifers might be tapped in the future, but speculation on this point is too uncertain to be of value to this discussion.

\section{F.3.2 RELATIVE VALUE OF FIVE ROCK TYPES AS HABITAT FOR OTHER RESOURCES}

\section{F.3.2.1 Coal}

Coal seams are principally associated with sandstones and shales; however, the depositional environments that are responsible for most of these associations do not typically yield shale and sandstone bodies which are both latera11y and vertically extensive. Carbonate rocks are infrequently associated with coal deposits; chalks and anhydrocks, however, are not genetically associated with coal deposits and, to a large degree, lie deeper than coal seams found in the same sedimentary basins. Sandstones and shales are, theretore, ranked highest from the coal-resource perspective (lowest for repository purposes) and are followed by carbonate rocks, chalks, and anhydrocks.

\section{F.3.2.2 Uranium}

Uranium occurs in hydrothermal veins and igneous (pegmatite) masses in addition to sandstone bodies. A few carbonate rocks have yielded uranium ore, while some shales show geochemical, but uneconomical (from a current ore-recovery perspective) enrichment. Neither chalks nor anhydrocks are known to host uranium ore, but may be spatially associated with other ore-bearing rocks in certain regions. From their uranium resource associations (low repository ranking), the five rock types would be ranked as follows: (1) sandstone, (2) carbonate rocks, (3) shales, (4) chalks, and (5) annydrocks.

\section{F.3.2.3 Metallic Resources}

Despite the fact that most of the important ore-supplying deposits for the metallic resources chosen on the basis of their relative economic value are not within sedimentary rocks, some tendencies can be summarlzed here relative to the flve rock types. Chalks and anhydrocks are not known to be associated genetically with any of these ore deposits, except possibly for anhydrock and its proximity in the evaporite sequences associated with the rather limited red-bed copper of this country. Both of these rocks would therefore rank lowest in the metallic resource sense (but highest for repository purposes). Chalks would rank slightly higher than anhydrocks because they are more extensive within the criteria of depth thickness used in this program and thus more prone to be spatially involved with metallic-resource deposits in other rock types (especially undiscovered cases). 
Sandstones would be ranked next, followed by shales (both are spatially associated with some of the carbonate rock-hosted deposits, and some, albeit minor, ores are formed within shales. Because carbonate rocks are (1) very important host rocks for both stratiform lead-zinc (and some fluorite) ore deposits, and (2) hosts for various multi-metal veins and replacement bodies of hydrothermal origin, these rocks rank highest from the metallic-resource perspective (but lowest for repository purposes).

\section{F.3.2.4 Nonmetallic Resources}

of the nonmetallic resources considered here, the carbonate rocks and shales are principally involved with phosphate deposits; the anhydrocks and carbonate rocks are involved with native sulfur ores; and the anhydrocks, carbonate rocks, and shales are involved with bedded-salt resources and the limited domestic occurrences of potash. Trona has been disregarded because of its site-specific nature.

Based upon the above, the nonmetallic-resource ranking (reverse of the ranking for repository utility) of the five rock typos appoare to be: (1) carbonate rocks; (2) anhydrocks; (3) shales; (4) chalks; and (5) sandstones. The first three are, however, considerab1y nore associated with nonmetallic resources than are the last two rock types.

\section{F.3.2.5 Groundwater}

of the five rock types under consideration, sandstones and carbonate rocks constitute the most numerous, widespread, and important sources of fresh groundwater in the United States. On a nationwide basis, it is further felt that sandstone aquifers are somewhat more numerous and widespread than are carbonate rock aquifers. These rock types are also the most widely utilized injection horizons for the disposal of industrial effluents and oil-field brines and also provide the chemical industry with brines for use as feedstorks. Ry rnmparisnn, chalks and shales are uncommonly found as aquifers and are not known to be extensive sources of either fresh or saline waters in any region of the country. Anhydrocks rarely serve as aquifers and, because of their general depth of occurrence, are associated with isolated brines and/or evaporites.

Shales, on the other hand, are the most important seals or aquitards for many regionally extensive artesian, freshwater aquifers and are associated with many other stratigraphic sequences that contain sandstone and/or carbonate rock aquifers. Chalks rank appreciably below shales, relative to their likelihood of being aquitards, but are known to occur both deeper and shallower than other aquifers of regional importance. Anhydrocks make good aquitards; however, as noted above, they are generally deep and are associated with evaporites. In some regions, dense impermeable carbonate rocks can serve either as confining beds or as associated strata adjacent to or interbedded with other aquifers. Tightly cemented sandstones can fit this designation also, but probably to a lower degree ot incidence. 
Based upon their occurrence as sources of fresh water, as disposal horizons for waste fluids, as aquitards within important confined aquifer systems, as sources of chemically rich brines, and as strata associated with other aquifers, the following ranking (reverse of, the ranking repository purposes) has been determined: (1) sandstones, (2) carbonate rocks, (3) shales, (4) anhydrocks, and (5) chalks.

\section{D.3.2.6 Ranking of Rock Types as Habitat for Dther Resources}

Each of the five sedimentary rock types of interest has been evaluated with regard to its importance and spatial-genetic relationships with coal, nonmetallic resources, metallic resources, and groundwater. The results of theac subcvaluations arc summarizcd bclow into a relative ranking for the five rock types as habitats for these resources:

\begin{tabular}{lc}
\multicolumn{1}{c}{$\begin{array}{c}\text { Value ranking as habitats } \\
\text { for coal, nonmetallic resources, } \\
\text { Roclk }\end{array}$ mctallic rcoourcco, and groundwatcra } \\
\hline Sandstone & 1 \\
Carbonate rocks & 2 \\
Chalk & 3 \\
Anhydrock & 4 \\
Shale & 5
\end{tabular}

aRankings are reported numerically: 1 is most favorable, 5 is least favorable.

From the perspective of evaluation as repository host rocks, therefore, chalks, anhydrocks, and shales are more highly ranked, whereas carbonate rocks and sandstones are decidedly less highly ranked, according to the data discussed in this section. 


\section{F.4 SUMMARY}

This Appendix has discussed each of the five sedimentary rock types of interest with regard to its relative importance to, and spatialgenetic relationships with, energy resources, nonmetallic resources, metallic resources, and groundwater. This investigation has found that oil and gas account for about $79 \%$ of the value of mined resources included in this report. The investigation also revealed that sandstones and carbonate rocks provide the reservoir rock or habitat for $~ 98 \%$ of the oil and gas expected to be ultimately recovered from oil and gas fields in the United States. The review indicates that fields producing from sandstones are generally larger, more prolific, and more numerous than are those producing from carbonate rocks. It is estimated that the ultimate oil and gas recovery from all fields producing from sandstones will be about twice as much as from those producing from carbonate rocks. It is also estimated that chalk will account for only $\sim 1 \%$ of the total oil and gas recovery in the United States and that shale and anhydrock wi11 account for $<1 \%$.

of the other resources, coal and fresh water account for most of the production value. Sandstones are normally associated with coal deposits, and they provide the most favorable aquifers for fresh water. Carbonate rocks are sometimes associated with coal deposits and provide the second most favorable aquifer for fresh water. Sandstones and carbonate rocks are also favorable host rocks for some metals and other resources.

In summary, the following relative-value ranking has been developed for the five rock types as hosts for oil, gas, coal, fresh water, and the other resources included in this investigation:

Rock

Value ranking as host for

$\begin{array}{lr}\text { Rock all energy and } \\ \text { Sandstone } & 1 \\ \text { Carbonate rocks } & 2 \\ \text { Chalk } & 3 \\ \text { Anhydrock } & 4 \\ \text { Shale } & 5\end{array}$

Generally, the rocks that rank lowest as resource hosts rank highest in regard to their potential for use as a host rock for a repository. Because shale has a negligible value as a host for energy and other resources and has relatively great abundance, it is considered to be the most favorable rock type to be considered as a repository for the storage or disposal of high-level radioactive waste. Considering the relative values of the other rocks as hosts for energy and other resources, the following ranking has been developed for the five rock types according to their potential utility for the storage or disposal of high-level radioactive waste: 


\section{Rock}

Shale

Anhydrock

Chalk

Carbonate rocks

Sandstone
Utility ranking as potential repository for radioactive waste

It is recognized that mineral resources may be contained within one sedimentary rock type that is overlain and/or underlain by other types of sedimentary rock and that boreholes and mining shafts may penetrate the nonmineral bearing rocks to recover these materials with concomitant altering of the local geohydrology. However, shale remains the least likely host for resources and would probably be the rock type least affected by penetration due to its less permeable nature. These conditions are, therefore, recognized but not dealt with in this report because of the site-specific nature of such occurrences and the complexities of treating such events in this generio study of five sedimentary rocks. 
ADAMS 1975. S. S. Adams, "Potash," in S. J. Lefond et al., eds., Industrial Minerals and Rocks, 4th Ed., Amer. Inst. Mining, Meta11. Pet. Eng., New York, 1975, pp. 963-90.

AVERITT 1975. P. Averitt, Coal Resources of the United States, January 1, 1974, U.S. Geol. Surv. Bul1. 1412, 1975.

BAKER 1976. E. T. Baker, Jr. and J. R. Wa11, Summary Appraisals of the Nation's Groundwater Resources - Texas - Gulf Region, U.S. Geol. Surv. Prof. Pap. 813-F, 1976.

BLOYD 1975. R. M. Bloyd, Jr., Summary Appraisals of the Nation's Groundwater Resources - Upper Mississippi Region, U.S. Geol. Surv. Prof. Pap. 813-B, 1975 .

BRAUNSTEIN 1976. J. Braunstein, ed., North American Oil and Gas Fields, Amer. Assoc. Pet. Geol. Mem. 24, 1976.

BROBST 1973. D. A. Brobst and W. r. Pratt, United States Mineral Resources, U.S. Geol. Surv. Prof. Pap. 820, 1973.

BROWN 1970. J. S. Brown, "Mississippi Valley Type Lead-Zinc Ores - A Review and Sequel to the 'Behre Symposium'," Miner. Deposit. 5, 103-19 (1970).

BUSCH 1974. D. A. Busch, Stratigraphic Traps in Sandstone Exploration Techniques, Amer. Assoc. Pet. Geol. Mem. 21, 1974.

BUZZALINI 1969. A. D. Buzzalini, F. J. Adler, and R. L. Jodey, Evaporites and Petroleum, Amer. Assoc. Pet. Geol. Bul1. 53, 775-1011 (1969).

CEDERSTROM 1979. D. J. Cederstrom, E. H. Boswe11, and G. K. larver, Summary Appraisals of the Nation's Groundwater Resources - South Atlantic-Gulf Region, U.S. Geol. Surv. Prof. Pap. 813-0, 1979.

COLLINS 1974. A. G. Collins, Geochemistry of Liquids, Gases, and Rocks from the Smackover Formation, U.S. Bur. Mines Rep. Inv. 7897, 1974.

COTTEN 1978. H. M. Culleil, "Iudine In Northwestern Oklahoma," In K. S. Johnson and J. A. Russe11, eds., Thirteenth Annual Forum on the Geology of Industrial Minerals, Okla. Geol. Surv. Circ. 79, 1978, pp. 89-94.

CRELLING 1980. J. C. Crelling and R. F. Dutcher, "Principles and Applications of Coal Petrology," Soc. Econ. Mineral. Paleont. Short-Course Notes, No. 8, 1980.

CULBERTSON 1966. W. D. Culbertson, Trona in the Wilkins Peak Member of the Green River Formation, Southwestern Wyoming. U.S. Geol. Surv. Prof. Pap. 550-B, 1966, pp. B159-B164. 
DAVIS 1970. J. B. Davis and D. W. Kirkland, "Native Sulfur Deposition in the Castile Formation, Culbertson County, Texas," Econ. Geo1. 65, 107-21 (1970).

DONALDSON 1979. A. C. Donaldson, M. W. Presley, and J. J. Renton, eds., Carboniferous Coal Guidebook, Vol. 3, West Virginia Geol. and Econ. Surv. Bull. B37, 1979 .

EARGLE 1975. D. H. Eargle, K. A. Dickinson, and B. O. Davis, South Texas Uranium Deposits, Amer. Assoc. Pet. Geol. Bull, 59, 766-779 (1975).

ENSIGN 1968. C. O. Ensign, W. S. White, J. C. Wright, J. L. Patrick, R. J. Leone, D. J. Hathaway, J. W. Tramme1, J. J. Fritts, and T. L. Wright, "Copper Deposits in the Nonesuch Shale, White Pine, Michigan," in J. D. Ridge, Ed., Ore Deposits of the United States, 1933-1967, Vol. 1, Amer. Inst. Mining Metall. Pet. Eng., New York, 1968, pp. 460-488.

EXXON COMPANY 1979. Exxon Company, U.S.A.'s Energy Outlook 1980-2000, Houston, 1979.

FERM 1974. J. C. Ferm, Carboniferous Environmental Models in the Eastern United States and Their Significance, Geol. Soc. Amer. Spec. Pap. 148, 1974, pp. 79-95.

FERM 1979. J. C. Ferm and J. C. Horner, Carboniferous Depositional Environments in the Appalachian Region, Univ. South Carolina Dept. Geo1., Coal Group Rep., Columbia, 1979 .

FINCH 1967. W. I. Finch, Geology of Uranium Deposits in Sandstone in the United States, U.S. Geol. Surv. Prof. Pap. 538, 1967.

FISCHER 1968. R. P. Fischer, "The Uranium and Vanadium Deposits of the Colorado Plateau Region," in J. D. Ridge, ed., Ore Deposits of the United States, 1933-1967, Vo1. 1, Amer. Inst. Mining, Metall. Pet. Eng•, New York, 1968, pp. 735-746.

GONZALES 1984a. S. Gonzales and K. S. Johnson, Shales and Other Argillaceous Strata in the United States, ORNL/Sub/84-6479/1, Oak Ridge National Laboratory Report, March 1985.

GONZALES 1984b. S. Gonzales, K. S. Johnson, and P. E. Potter, Geologic Characteristics of Shale, Oak Ridge National Laboratory Report, (Draft), 1984.

GURR 1979. T. M. Gurr, "Geology of U.S. Phosphate Deposits," Mining Eng. 31 (6) , 682-91 (1979).

HALBOUTY 1970a. M. T. Halbouty, ed., Geology of Giant Petroleum Fields, Amer. Assoc. Pet. Geol. Mem. 14, 1970.

HALBOUTY 1970b. M. T. Halbouty, "Giant Oil and Gas Fields in the United States," in M. T. Halbouty, ed., Geology of Giant Petroleum Fields, Amer. Assoc. Pet. Geol. Mem. 14, 1970, pp. 91-127. 
HALBOUTY 1970c. M. T. Halbouty, A. A. Meyerhoff, R. E. King, R. H. Dott, H. D. Klemme, and T. Shabad, "World's Giant 0il and Gas Fields, Geologic Factors Affecting Their Formation, and Basin Classification," in M. T. Halbouty, ed., Geology of Giant Petroleum Fields, Amer. Assoc. Pet. Geo1. Mem. 14, 1970, pp. 502-556.

HALBOUTY 1981. M. T. Halbouty, Giant Oil and Gas Fields of the Decade 1968-1978, Amer. Assoc. Pet. Geol. Mem. 30, 1981 .

HANCOCK 1975. J. M. Hancock and P. A. Scholle, "Chalk of the North Sea," in A. W. Woodland, ed., Petroleum and the Continental Shelf of Northwest Europe, Vo1. 1, John Wiley and Sons, New York, 1975, pp. 413-25.

HARBEN 1984. P. W. Harben and R. L. Bates, Geology of the Nonmetallics, Metal Bulletin, Inc., Surrey, England, 1984.

HATTIN 1984. D. E. Hattin, Chalk, Oak Ridge National Laboratory Report (DrafL), 1984.

HUNT 1979. J. M. Hunt, Petroleum Geochemistry and Geology, W. Ho Freeman and Co., San Francisco, 1979.

HUTCHINSON 1973. R. W. Hutchinson, "Volcanogenic Sulfide Deposits and Their Metallogenic Significance," Econ. Geol. 68, 1223-46 (1973).

JACKSON 1976. D. Jackson, Jr., "Wyoming Trona: Unbroken and Orderly Growth," Eng. Mining J. 177 (4), 67-76 (1976).

JACKSON 1981. D. Jackson, Jr., "Trona Solution Mining: FMC Goes After Deep Wyoming Deposits," Eng. Mining J. 182 (12), 68-69 (1981).

JAMES 1966. H. L. James, Chemistry of the Iron-Rich Sedimentary Rocks, U.S. Geo1. Surv. Prof. Pap. 440-W, 1966.

JAMES 1984. L. P. James, "The Tintic Mining District," Utah Geol. Miner. Surv. Notes, 18 (2) p. 1 and pp. 4-13 (1984).

JOHNSON 1976. K. S. Johnson, "Permian Copper Shales of Southwestern Oklahoma," in K. S. Johnson and R. L. Croy, eds., Stratiform Copper Deposits of the Mid-Continent Region, A Symposium, OkIa. Geol. Surv. Circ. 77, 1976, pp. 3-14.

JOHNSON 1978. K. S. Johnson and S. Gonzales, Salt Deposits in the United States and Regional Geologic Characteristics Important for the Storage of Radioactive Wastes, Y/OWI/Sub-7414/1, consultant's report to Oak Ridge National Laboratory, 1978.

JOHNSON 1984. K. S. Johnson and S. Gonzales, Geologic Characterization of Anhydrite, consultant's report to Oak Ridge National Laboratory (Draft), 1984. 
JOHNSON 1985. K. S. Johnson, S. Gonzales, and W. E. Dean, "Distribution and Geologic Characteristics of Anhydrite Deposits in the United States," in W. E. Dean and K. S. Johnson, eds., Anhydrite Deposits of the United States and Characteristics of Anhydrite Important for Storage of Radioactive Wastes, U.S. Geol. Surv. Prof. Pap. (in preparation).

KAUFMAN 1972. W. H. Kaufman, O. L. Schumacher, and L. A. Woodward, Stratiform Copper Mineralization in the Nacimiento Region, New Mexico, New Mexico Bur. Mines and Miner. Resource Dept. E-1, 1972.

KOSTICK 1979. D. S. Kostick and R. J. Foster, Soda Ash (Sodium Carbonate), Sodium Sulfate, and Sodium, U.S. Bur. Mines Miner. Commod. Prof. Pap., 1979 .

LEFOND 1975. S. J. Lefond, et al., eds., Industrial Minerals and Rocks, 4th Ed., Amer. Inst. Mining, Meta11. Pet, Eng., New York, 1975.

LEFOND 1984. S. J Lefond, "Industrial Minerals Activity is Improving," Mining Eng. 36 (5), 503-37 (1984).

LEVORSEN 1967. A. I. Levorsen, Geology of Petroleum, 2nd Ed., W. H. Freeman and Co., San Francisco, 1967.

LEWIS 1982. Alvin Lewis, "Gold Geology Basics," Eng. Mining J., 185 (2), 66-72 (1982).

MEYER 1968. C. Meyer, E. P. Shea, and C. C. Goddard, Jr., "Ore Deposits at Butte, Montana," in J. D. Ridge, ed., Ore Deposits of the United States, 1933-1967, Vo1. 2, Amer. Inst. Mining, Meta11. Pet. Eng., New York, 1968, pp. 1373-1416.

MAZZULLO 1980. S. J. Mazzu110, Stratigraphic Traps in Carbonate Rocks, Amer. Assoc. Pet. Geol. Reprint Series No. 23, 1980.

MILLER 1980. D. W. Miller, Waste Disposal Effects on Groundwater, Premier Press, Berkeley, 1980.

NASH 1981. J. T. Nash, H. C. Granger, and S. S. Adams, "Geology and Concepts of Genesis of Important Types of Uranium Deposits," in B. J. Skinner, ed., Economic Geology - Seventy-Fifth Anniversary Volume, Econ. Geo1. Pub. Co., New Haven, Conn., 1981, pp. 63-116.

PAYTON 1977. C. E. Payton, Seismic Stratigraphy - Applications to Hydrocarbon Exploration, Amer. Assoc. Pet. Geol. Mem. 26, 1977.

PRICE 1949. P. H. Price and J. P. Nolting, "Salt Resources of West Virginia," Amer. Inst. Min., Meta11. Pet. Eng. Trans. 184, 259-263 (1949).

PROBSTEIN 1978. R. F. Probstein and H. Gold, water in Synthetic Fuel Production: The Technology and Alternatives, MIT Press, Cambridge, Mass., 1978. 
RACKLEY 1976. R. I. Rackley, "Origin of Western States' Uranium Mineralization," in K. H. Wolf, ed., Handbook of Stratabound and Stratiform Ore Deposits, Vo1. 7, Elsevier, Amsterdam, The Netherlands, $1976, \mathrm{pp} .89-156$.

RIDGE 1968. J. D. Ridge, Ore Deposits of the United States, 1933-1967, Amer. Inst. Mining, Metall. Pet. Eng., New York, 1968 .

ROBERTS 1980. W. H. Roberts and R. J. Corde11, Problems of Petroleum Migration, Amer. Assoc. Pet. Geol. Stud. Series No. 9, 1980.

SCHOLLE 1977. P. A. Scholle, Current 0il and Gas Production from North American Upper Cretaceous Chalks, U.S. Geol. Surv. Circ. 767, 1977.

SCHOON 1971. R. A. Schoon, Geology and Hydrology of the Dakota

Formation in South Dakota, South Dakota Geol. Surv. Rep. Inv . 104, 1971.

SHERIFF 1980. R. E. Sheriff, Seismic Stratigraphy, Int, Hum. Dev.

Corp., Boston, Mass., 1980.

SKINNER 1981. B. J. Skinner, ed., Economic Geology - Seventy-Fifth Anniversary Volume, Econ. Geol. Publ. Co., New Haven, Conn., 1981 .

SOLLEY 1983. W. B. Solley, E. B. Chase, and W. B. Mann, Estimated Use of Water in the United States in 1980, U.S. Geol. Surv. Circ. 1001, 1983.

SORENSEN 1974. H. O. Sorensen and R. T. Sega11, "Natural Brines of the Detroit River Group, Michigan Basin," in A. H. Coogan, ed., Proc. of the Fourth Symposium on Salt, Northern Ohio Geol. Soc., Cleveland, 1974, pp. 91-99.

STRINGFIELD 1966. V. T. Stringfield, Artesian Water in Tertiary Limestone in the Southeastern States, U.S. Geol. Surv. Prof. Pap. 517 , 1966.

SWANSON 1961. V. E. Swanson, Geology and Geochemistry of Uranium in Marinc Black Shales, A Revicw, U.S. Geol. Surv. Prof. Pap. 356-C, 1961, pp. $67-110$.

SWENSON 1976. F. A. Swenson, W. R. Miller, W. G. Hodson, and F. N. Visher, Map from Water in the Madison Group, Powder River Basin, Wyoming and Montana, U.S. Geol. Surv. Misc. Inv. Ser. I-847C, 1976.

TAYLOR 1978. O. J. Taylor, Sumnary Appraisals of the Nation's Groundwater Resources - Missouri Basin Region, U.S. Geol. Surv. Prof. Pap. 813-Q, 1978.

THORDARSON 1985. W. Thordarson, "Hydrogeology of Anhydrite," in W. E. Dean and K. S. Johnson, eds., Anhydrite Deposits of the United States and Characteristics of Anhydrite Important for Storage of Radioactirc Wastca, U.S. Gcol. Surv. Prof. Pap. (in preparation). 
TISSOT 1978. B. Tissot and D. H. Welte, Petroleum Formation and Occurrence, Springer-Verlag, Berlin, Germany, 1978.

TITLEY 1966. S. R. Titley and C. L. Hicks, Geology of the porphyry Copper Deosits, Southwestern North America, Univ of Arizona Press, Tucson, 1966.

U.S. DEPARTMENT OF COMMERCE 1983. U.S. Department of Commerce, Statistical Abstract of the United States, 1984, Washington D.C., 1983.

WANLESS 1964. H. R. Wanless, "Local and Regional Factors in Pennsylvanian Cyclic Sedimentation," in D. F. Merriam, ed., Proc. of the Symposium on Cyclic Sedimentation, Vol. 2, Kansas Geol. Surv. Bull. 169, 1964, pp. 593-606.

WHITE 1981. W. H. White, A. A. Bookstrom, R. J. Hami11i, M. W. Ganster, R. P. Smith, D. E. Ranta, and R. C. Steininger, "Character and Origin of C11max-Type Mo1ybdenum Deposits," in B. J. Skinner, ed., Economic Geology - Seventy-Fifth Anniversary Volume, Econ. Geol. Pub. Co., New Haven, Conn., 1981, pp. 270-316. 
ARTENDIX G

DESIGN ANALYSIS FOR A HIGH-LEVEL WASTE REPOSITORY IN SEDIMENTARY ROCK

$\mathrm{RE} / \mathrm{SPEC}$ INC.

P. O. BOX 725

RAPID CITY, SOUTH DAKOTA 57709 
This page intentionally left blank 


\begin{abstract}
Thermal and mechanical analyses of five sedimentary rock types have been performed to determine their suitability to host a high-level waste repository. These sedimentary rocks include anhydrock, chalk, carbonate rocks (limestone/dolostone), sandstone, and shale. The repository was assumed to contain commercial high-level waste or spent fuel. The expected ranges in the material properties and initial conditions of these rock types that were required to perform these analyses were generated by an extensive literature survey also reported herein. The performance of the repository was evaluated using thermal and merhanical constraints developed herein to address the overall Sedimentary Rock Program (SRP) evaluation criteria regarding rock mechanics. On the basis of both thermal and mechanical considerations before and after repository closure, lie carbunate rocks were determined to be the most favorable of the five sedimentary rocks considered for the disposal of high-level nuclear waste. Shale was ranked as the second most favorable sedimentary rock, followed by anhydrock and sandstone on a more-or-less equal basis and finally chalk.
\end{abstract}


This page intentionally left blank 


\title{
FOREWORD
}

This report was prepared under a subcontract with Oak Ridge National Laboratory (ORNL), a U.S. Department of Energy (DOE) contractor. This subcontract is an integral part of the Sedimentary Rock Program (SRP). The principal objective of the SRP is to identify suitable sites and provide facilities in various deep sedimentary formations within the United States that will enable safe disposal of commercially generated high-level radioactive wastes.

This report was prepared with contributions from the following RE/SPEC Inc. employees:

\author{
Ar1o F. Fossum \\ Paul F. Gnirk \\ Marc C. Loken \\ Danny P. Nelson \\ Joe L. Ratigan \\ Tim J. Vogt \\ Henry Waldman
}


This page intentionally left blank 


\section{ACKNOWLEDGMENTS}

The technical contents of this report have been reviewed by Dr. Gary D. Callahan and Mr. Darrell K. Svalstad. The editorial review was provided by Ms. Julie S. Annicchiarico. The authors wish to thank Mr. H. Clyde Claiborne of ORNL and Dr. James E. Russell of Texas AdM University for their helpful suggestions in performing the thermal and mechanical analysis reported herein. The authors also wish to acknowledge Dr. Thomas L. Lomenick of ORNL for his guidance in this project and Mr. Robert S. Lowrie of ORNL for providing the necessary details to complete this project. The authors are alsn grateful to Ms. Lora A. Fargen and Ms. Fay L. Swenson for the typing and careful attention to the manuscript. The excellent drafting was done by Mr. Terry L. Hall. The computer plots were generated with the assistance of Ms. Karen M. Linde. 
This page intentionally left blank 


\section{CONTENTS}

Page

G.1 EXECUTIVE SUMMARY. . . . . . . .......... 69

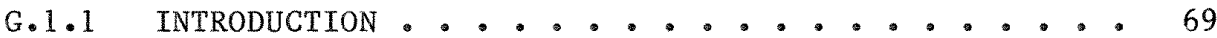

G.1.2 DESCRIPTION OF GENERIC REPOSITORY. . . . . . . 69

G.1.3 EVALUATION CRITERIA. . . . . . . . . . 70

G.1.4 REPOSITORY PERFORMANCE CONSTRAINTS ........ 70

G.1.5 ROCK PROPERTIES. ......................... 71

G.1.6 MODELING CONSIDERATIONS.............. 71

G.1.7 THERMAL RESULTS.................71

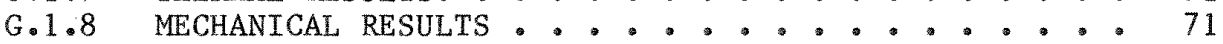

G.1.9 PERFORMANCE ASSESSMENT ........... 72

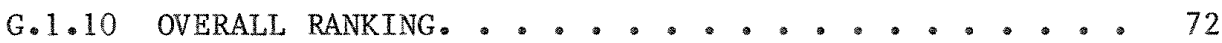

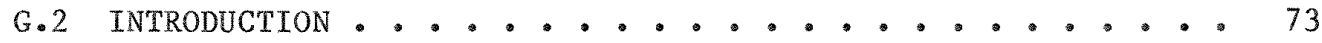

G.2.1 BACKGROUND AND OBJECTIVES ............ 73

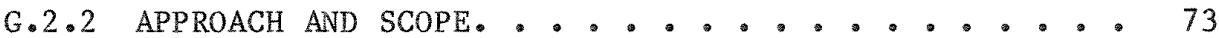

G.2.3 REPORT ORGANIZATION ......... 74

G.2.4 RANKING ASSESSMENT. .............. 74

G.3 DESCRTPTION OF GENERIC REPOSITORY. . . . . ...... 75

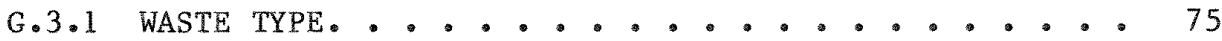

G.3.1.1 Commercial High-Level Waste........ 75

G.3.1.2 Spent Fuel ........... 76

G.3.2 ENGINEERED DESIGN PARAMETERS. . . . . . . . 78

G.3.2.1 Design Materials............ 79

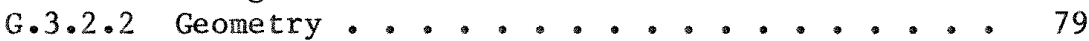

G.3.2.3 Material Properties.......... 86

G.3.3 STRATIGRAPHY. . . . ............ 88

G.3.3.1 Generic Stratigraphic Section: Anhydrock. 88

G.3.3.2 Generic Stratigraphic Section: Chalk. . . 88

G.3.3.3 Generic Stratigraphic Section: Carbonate

G.3.3.4 Rocks (Limestone/Dolostone). $\cdot \cdot \cdot \cdot \cdot 88$

G.3.3.5 Generic Stratigraphic Section: Sha1e. . 92

G.3.4 DESCRIPTION OF SEDIMENTARY ROCK TYPES . . . . . 92

G.3.4.1 Anhydrock............. 92

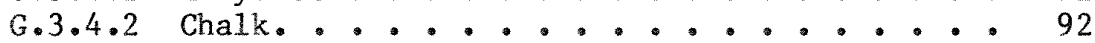

G.3.4.3 Carbonate Rocks (Limestone/Dolostone). . . 95

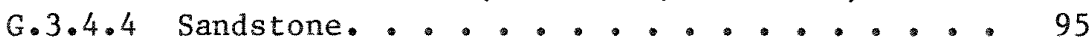

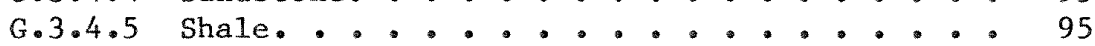

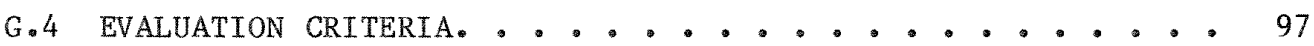


G.5 REPOSITORY PERFORMANCE CONSTRAINTS . . . . . . . . . 98

G.5.1 WASTE FORM TEMPERATURE.................. 101

G.5.1.1 Commercial High-Level Waste........ 101

G.5.1.2 Spent Fue1............... 102

G.5.2 OVERPACK TEMPERATURE. .............. 103

G.5.3 BOREHOLE (ROCK) TEMPERATURE ............ 104

G.5.4 DISPOSAL ROOM BACKFILL TEMPERATURE. . . . . . . 104

G.5.5 MINEABILITY ................... 105

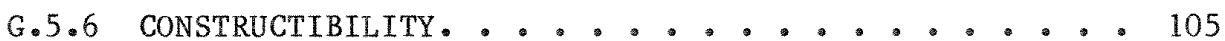

G.5.7 ORERATIONAL STABILITY ........... . 105

G.5.8 SITE GEOLOGY TEMPERATURES . . . . . . . . . 105

G.5.9 NEAR-SURFACE TEMPERATURE RISE ......... 106

G.6 ROCK PROPERTIES. . . . . . . . . . . . . . 108

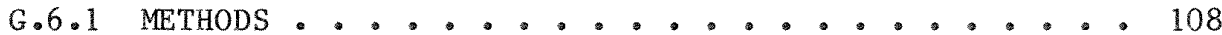

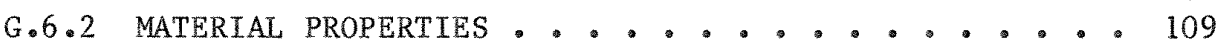

C.6.2.1 Mcchanical................ 109

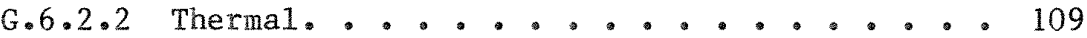

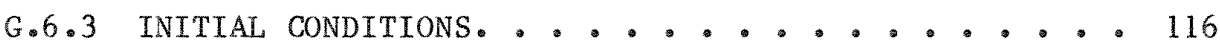

G.6.3.1 Surface Temperature and Geothermal Gradient. 116

G.7 MODELING CONSTDERATIONS. . . ............. 122

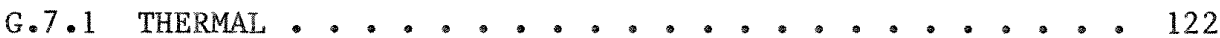

G.7.1.1 Very-Near Field................ 122

G.7.1.2 Near Field............... 126

G.7.1.3 Far Field.............. 126

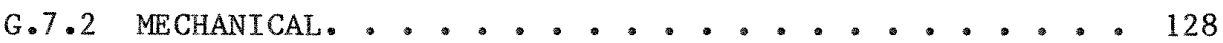

G.8 THERMAL RESULTS. . .................. 132

G.8.1 EVALUATION PROCEDURE. . . . . . . . . . 132

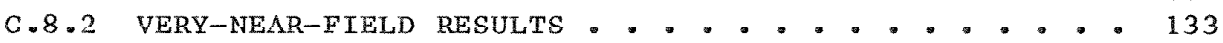

G.8.2.1 Waste Form Temperature.......... 135

G.8.2.2 Overpack Temperature .......... 135

G.8.2.3 Host Rock Maximum Temperature...... 138

G.8.3 NEAR-FIELD RESULTS. . . . . ......... 138

G.8.3.1 Average Backfill Temperature . . . . . 140

G.8.3.2 Near-Field/Far-Field Interface Temperature . 140

C.8.3.3 Hoct Rock Temperature (Isolation Period). . 143

G.8.4 FAR-FIELD RESULTS . . . . . . . . . . 143

G.8.4.1 Temperature at 595-m Depth....... . 145

G.8.4.2 Shaft Temperature.......... 145

G.8.4.3 Near-Surface Temperature Rise.... . . 148

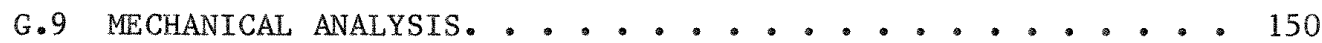

G.9.1 METHODS .................. 150

G.9.2 RESULTS .................. 155

G.10 PERFORMANCE ASSESSMENT .......................... 157 
Page

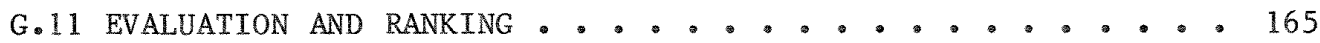

G.11.1 EVALUATTON PROCEDURE. . ............ 165

G.11.2 THERMAL EVALUATION. . . . ........... 165

G.11.3 MECHANICAL EVALUATION.$\cdot \cdot \cdot \cdot \cdot \cdot \cdot \cdot \cdot \cdot \cdot \cdot \cdot 166$

G.11.3.1 Mineability............... 168

G.11.3.2 Constructibility............. 168

G.11.3.3 Operational Stability........ 168

G.11.3.4 Stability Under Postclosure Conditions. . 170

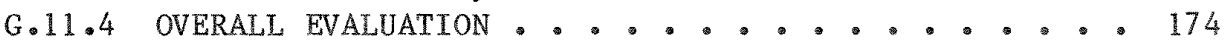

G.12 SUPPLEMENTAL INFORMATION * . . . . . . . . . . . 177

G.12.1 DETAILED MODEL RESULTS FROM THE VERY-NEAR-FIELD

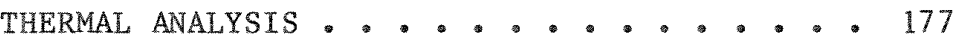

G.12.2 DETAILED MODEL RESULTS FROM THE NEAR-FIELD

THERMAL ANALYSIS . . . . . . . . . 208

G.12.3 DETAILED MODEL RESULTS FROM THE FAR-FIELD

TIERMAI ANALYSIS . . . ........ 239

G.12.4 COMPARISON OF EXPECTED VALUES OF THE THERMAL,

RESULTS FOR FIVE SEDIMENTARY ROCK TYPES. . 270

G.12.5 GENERIC ROCK TYPE MECHANICAL PROPERTIES . . 289

G.12.6 GENERIC ROCK TYPE THERMAL PROPERTIES . . . 326

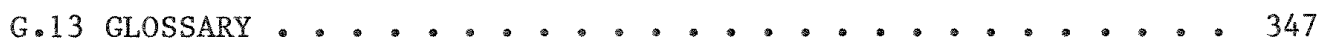

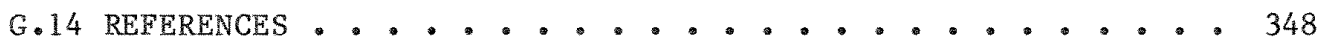


This page intentionally left blank

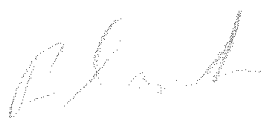


Figure

G.3.1. Normalized thermal power for commercial high-level (CHLW) waste and spent fuel (SF) . . . . . . . . . . . .

G.3.2. Reference commercial high-level waste package conceptual design for borehole emplacement . . . . . . . . . . .

G.3.3. Reference spent fuel (Form 2) package for borehole emplacement ...........................

G.3.4. Emplacement geometry for reference commercial high-

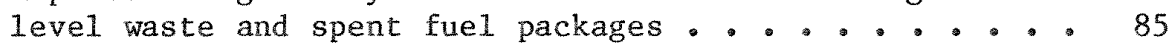

G.3.5. Generic stratigraphic section: anhydrock. . . . . 89

G.3.6. Generic stratigraphic section: chalk.........990

G.3.7. Generic stratigraphic section: carbonate rocks

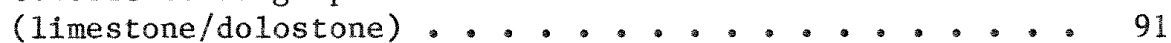

G.3.8. Generic stratigraphic section: sandstone ...... . 93

G.3.9. Generic stratigraphic section: shale (argillaceous

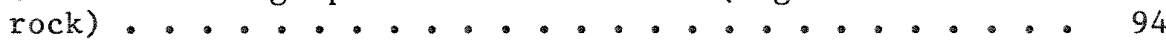

G.6.1. Unconfined compressive strength: mean, standard deviation, and extreme range................ 111

G.6.2. Young's modulus: mean, standard deviation, and extreme range ..................... 112

G.6.3. Poisson's ratio: mean, standard deviation, and extreme range........................ 113

G.6.4. Internal friction angle: mean, standard deviation and extreme range .................. 114

G.6.5. Thermal conductivity: mean, standard deviation, and extreme range .................. 117

G.6.6. Temperature dependence of thermal conductivity: mean, standard deviation, and extreme range . . . . . . . 118

G.6.7. Heat capacity: mean, standard deviation, and extreme

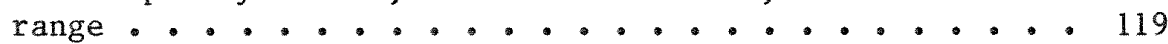

G.6.8. Coefficient of linear thermal expansion: mean, atandard deviation, and cxtreme range..... . . . 120 
G.6.9. Mass density: mean, standard deviation, and extreme range ................... 121

G.7.1. Axisymmetric unit-ce11 model for very-near-field analysis of commercial high-level waste and spent fuel emplacement in sedimentary rock..............

G.7.2. Geometric configuration for the emplacement of commercial high-level waste and spent fuel in sedimentary rock. .

G.7.3. General description of two-dimensional model used in the near-field analyses for commercial high-level waste and spent fuel emplacement in sedimentary rock. . . . . . 127

Q.7.4. Physical model used in far-field thermal analysis for spent fuel and commercial high-level waste emplacement in acdimentary rock................... 129

G.7.5. Boundary element mode1 used in mechanical analysis. . . 130

G.8.1. Expected range in waste centerline maximum temperature for five sedimentary rock types . . . . . . . . . 136

G.8.2. Expected range in overpack maximum temperature for five sedimentary rock types . . . . . . . . . . 137

G.8.3. Expected range in host rock maximum temperature for five sedimentary rock types . . . . . . . . . . 139

G.8.4. Expected range in room backfill maximum temperature for fivo oodimontary rock typoe . . . . . . . . . 111

G.8.5. Expected range in near-field/far-field interface maximum temperature for five sedimentary rock types . . 142

G.8.6. Expected range in host rock maximum temperature at 1000 years for five sedimentary rock types. . . . . 144

G.8.7. Expected range in maximum temperature at 595-m depth for five sedimentary rock types........... 146

G.8.8. Expected range in shaft maximum temperature for five sedimentary rock types. . . . . . . . . . . . 147

G.8.9. Expected range in near-surface maximum temperature rise for five sedimentary rock types. . . . . . . . 149

G.9.1. Penetration rate versus strength (modified from ROBBINS

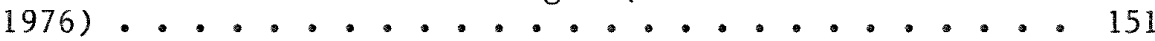


G.9.2. Approximation of effect of RQD on advance rate. . . 152

G.9.3. Relative excavation costs versus unconfined compressive strength. . . . ............... 154

G.11.1. Heat transfer capability ranking of five sedimentary rock types ....................... 167

G.11.2. Ranges in unconfined compressive strength of five sedimentary rocks used to evaluate constructibility. . 169

G.12.1.1. Expected range in waste form temperature for commercial high-level waste emplacement in anhydrock...... 178

G.12.1.2. Expected range in waste form temperature for comnercial high-level waste emplacement in chalk........ 179

G.12.1.3. Expected range in waste form temperature for commercial high-level waste emplacement in carbonate rocks . . . 180

G.12.1.4. Expected range in waste form temperature for commercial high-level waste emplacement in sandstone . . . . . 181

G.12.1.5. Expected range in waste form temperature for commercial high-level waste emplacenent in shale . . . . . .

G.12.1.6. Expected range in waste form temperature for spent fuel emplacement in anhydrock. ................

G.12.1.7. Expected range in waste form temperature for spent fuel omplarement in chalk. . . . . . . . . . . . . 184

G.12.1.8. Expected range in waste form temperature for spent fuel emplacement in carbonate rocks. . . . . . . . . 185

G.12.1.9. Expected range in waste form temperature for spent fuel emplacement in sandstone. . . . . ....... 186

G.12.1.10. Expected range in waste form temperature for spent fuel emplacement in shale................ 187

G.12.1.11. Expected range in overpack temperature for commercial high-level waste emplacement in anhydrock . . . . . 188

G.12.1.12. Expected range in overpack temperature for commercial high-level waste emplacement in chalk . . . . . . 189

G.12.1.13. Expected range in overpack temperature for commercial high-level waste emplacement in carbonate rocks . . . 190

G.12.1.14. Expected range in overpack temperature for commercial high-level waste emplacement in sandstone ........ 
G.12.1.15. Expected range in overpack temperature for commercial high-level waste emplacement in shale . . . . . . . 192

G.12.1.16. Expected range in overpack temperature for spent fue1 emplacement in anhydrock. .............. 193

G.12.1.17. Expected range in overpack temperature for spent fuel emplacement in chalk. . . . . . . . . . . . 194

G.12.1.18. Expected range in overpack temperature for spent fuel emplacement in carbonate rocks (1imestone/dolostone).

G.12.1.19. Expected range in overpack temperature for spent fuel emplacement in sandstone. ............... 196

G.12.1.20. Expected range in overpack temperature for spent fuel emplacement in shale...................

G.12.1.21. Expected range in host rock temperature for commercial high-level waste emplacement in anhydrock . . . . 198

G.12.1.22. Expected range in host rock temperature for comercial high-level waste emplacement in chalk....... 199

G.12.1.23. Expected range in host rock temperature for commercial high-level waste emplacement in carbonate rocks (1imestone/dolostone) . . . . . . . . . . 200

G.12.1.24. Expected range in host rock temperature for commercial high-level waste emplacement in sandstone . . . . . 201

G.12.1.25. Expected range in host rock temperature for commercial high-level waste emplacement in shale . . . . . . 202

G.12.1.26. Expected range in host rock temperature for spent fuel emplacement in anhydrock. . . . . . . . . . . 203

G.12.1.27. Expected range in host rock temperature for spent fuel emplacement in chalk. . . . . . . . . . . . . 204

G.12.1.28. Expected range in host rock temperature for spent fuel emplacement in carbonate rocks (1imestone/dolostone). . 205

G.12.1.29. Expected range in host rock temperature for spent fuel emplacement in sandstone. . . . . . . . . . . . 206

G.12.1.30. Expected range in host rock temperature for spent fuel emplacement in shale............... 207

G.12.2.1. Expected range in average backfill temperature for commercial high-level waste emplacement in anhydrock. . 209 
G.12.2.2. Expected range in average backfill temperature for commercial high-level waste emplacement in chalk . . . 210

G.12.2.3. Expected range in average backfill temperature for commercial high-level waste emplacement in carbonate rocks (1imestone/dolostone)... . . . . . . . . 211

G.12.2.4. Expected range in average backfill temperature for commercial high-level waste emplacement in sandstone. 212

G.12.2.5. Expected range in average backfill temperature for commercial high-level waste emplacement in shale . . . 213

G.12.2.6. Expected range in average hackfill temperature for spent fuel emplacement in anhydrock. . . . . . . . 214

G.12.2.7. Expected range in average backfil1 temperature for spent tuel emplacement in chalk. ................

G.12.2.8. Expected range in average backfill temperature for spent fuel emplacement in carbonate rocks (limestone/ dolostone) .....................

G.12.2.9. Expected range in average backfill temperature for spent fuel emplacement in sandstone... . . . . . . . .

G.12.2.10. Expected range in average backfill temperature for spent fuel emplacement in shale. . . . . . ..........

G.12.2.11. Expected range in near-field/far-field interface temperature for commercial high-level waste emplacement in anhydrock

G.12.2.12. Expected range in near-field/far-field interface temperature for commercial high-level waste emplacement in chalk....................... 220

G.12.2.13. Expected range in near-field/far-field interface temperature for commercial high-level waste emplacement in carbonate rocks (1imestone/dolostone) . . . . . 221

G.12.2.14. Expected range in near-field/far-field interface temperature for commercial high-level waste emplacement in sandstone ..........................

G.12.2.15. Expected range in near-field/far-field interface temperature for commercial high-level waste emplacement in shale .........................

G.12.2.16. Expected range in near-field/far-field interface temperature for spent fuel emplacement in anhydrock. . 224 
G.12.2.17. Expected range in near-field/far-field interface temperature for spent fuel emplacement in chalk. . . 225

G.12.2.18. Expected range in near-field/far-field interface temperature for spent fuel emplacement in carbonate rocks (1imestone/dolostone)......... 226

G.12.2.19. Expected range in near-field/far-field interface temperature for spent fuel emplacement in sandstone. . 227

G.12.2.20. Expected range in near-field/far-fleld interface temperature for spent fuel emplacement in shale. . . 228

6.12.2.21. Fxpected range in maximum rock temperature for commercial high-level waste emplacement in anhydrock . 229

G.12.2.22. Expected range in maximum rock temperature for commercial nigh-level wasce emplacement lil clialk . . . 230

G.12.2.23. Expected range in maximum rock temperature for commercial high-level waste emplacement in carbonate rocks (1imestone/dolostone). . . . . . . . . 231

G.12.2.24. Expected range in maximum rock temperature for commerclal high-level waste emplacement in sandstone . 232

G.12.2.25. Expected range in maximum rock temperature for commercial high-level waste emplacement in shale . . 233

G.12.2.26. Expected range in naximum rock temperature for spent fuel emplacement in anhydrock. . . . . . . . . . 234

G.12.2.27. Expected range in maximum rock temperature for spent fuel emplacement in chalk... . . . . . . . 235

G.12.2.28. Expected range in maximum rock temperature for spent fuel emplacement in carbonate rocks (1imestone/ dolostone) .................... 236

G.12.2.29. Expected range in maximum rock temperature for spent fuel emplacement in sandstone. . .......... 237

G.12.2.30. Expected range in maximum rock temperature for spent fuel emplacement in shale. . . . . . . . . . . 238

G.12.3.1. Expected range in temperature at 595-m depth for commercial high-level waste emplacement in anhydrock . 240

G.12.3.2. Expected range in temperature at 595-m depth for commercial high-level waste emplacement in chalk . . . 241 
G.12.3.3. Expected range in temperature at 595-m depth for commercial high-level waste emplacement in carbonate rocks (1imestone/dolostone)........... 242

G.12.3.4. Expected range in temperature at $595-\mathrm{m}$ depth for commercial high-level waste emplacement in sandstone. . 243

G.12.3.5. Expected range in temperature at 595-m depth for commercial high-level waste emplacement in shale . . . 244

G.12.3.6. Expected range in temperature at $595-\mathrm{m}$ depth for spent fuel emplacement in anhydrock. . . . . . . . . 245

G.12-3.7. Fxperted range in temperature at 595-m depth for spent fuel emplacement in chalk. .......... 246

G.12.3.8. Expected range in temperature at 595-m depth for spent tuel emplacement in carbonate rocks (11mestone/

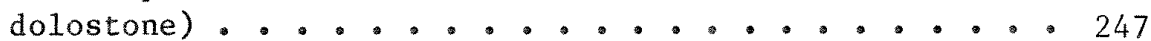

G.12.3.9. Expected range in temperature at 595-m depth for spent fuel emplacement in sandstone. . . . . . . . . 248

G.12.3.10. Expected range in temperature at 595-m depth for spent fuel emplacement in shale. . . . . . . . . . . . 249

G.12.3.11. Expected range in shaft temperature for commercial high-1evel waste emplacement in anhydrock. . . . . 250

G.12.3.12. Expected range in shaft temperature for comercial high-level waste emplacement in chalk. . . . . . . 251

G.12.3.13. Expected range in shaft temperature for commercial high-level waste emplacement in carbonate rocks (1imestone/dolostone). . . . . . . . . . . . 252

G.12.3.14. Expected range in shaft temperature for commercial high-level waste emplacement in sandstone. . . . . . 253

G.12.3.15. Expected range in shaft temperature for commercial high-level waste emplacement in shale. . . . . . . 254

G.12.3.16. Expected range in shaft temperature for spent fuel emplacement in anhydrock .......... 255

G.12.3.17. Expected range in shaft temperature for spent fuel emplacement in chalk . . . . . . . . . . . 256

6.12.3.18. Fxperted range in shaft temperature for spent fue1 emplacement in carbonate rocks (1imestone/dolostone). 
G.12.3.19. Expected range in shaft temperature for spent fuel

emplacement in sandstone . . . . . . . . . . 258

G.12.3.20. Expected range in shaft temperature for spent fue1 emplacement in shale .............. 259

G.12.3.21. Expected range in near-surface temperature for commercial high-level waste emplacement in anhydrock. 260

G.12.3.22. Expected range in near-surface temperature for commercial high-level waste emplacement in chalk . . . 261

G.12.3.23. Expected range in near-surface temperature for commercial high-level waste emplacement in carbonate rocks (1imestone/dolostone)............ 262

C.12.3.24. Expcetcd ronge in near-ourface tomporaturo for commercial high-level waste emplacement in sandstone . 263

G.12.3.25. Expected range in near-surface temperature for commercial high-level waste emplacement in shale . . 264

G.12.3.26. Expected range in near-surface temperature for spent fuel emplacement in anhydrock. . . . . . . . . . 265

G.12.3.27. Expected range in near-surface temperature for spent fuel emplacement in chalk. . . . . . ...... 266

G.12.3.28. Expected range in near-surface temperature for spent fuel emplacement in carbonate rocks (limestone) dolostone) . . . . . . . . . . . . . . . 267

G.12.3.29. Expected range in near-surface temperature for spent fuel emplacement in sandstone. . . . . . . . . . . 268

G.12.3.30. Expected range in near-surface temperature for spent fuel emplacement in shale............. 269

G.12.4.1. Expected waste centerline temperature for commercial high-level waste emplacement in five sedimentary rock types........................ 271

G.12.4.2. Expected waste centerline temperature for spent fuel emplacement in five sedimentary rock types.......

G.12.4.3. Expected overpack temperature for commercial high-leve1 waste emplacement in five sedimentary rock types . . .

G.12.4.4. Expected overpack temperature tor spent tuel emplacement in five sedimentary rock types . . . . . . . . . 274 
G.12.4.5. Expected host rock temperature for commercial high-level waste emplacement in five sedimentary rock types . . . 275

G.12.4.6. Expected host rock temperature for spent fuel emplacement in five sedimentary rock types ........ 276

G.12:4.7. Expected room backfill temperature for commercial highlevel waste emplacement in five sedimentary rock types $\cdot 277$

G.12.4.8. Expected room backfill temperature for spent fuel emplacement in five scdimentary rock types . . . . 278

G.12.4.9. Expected near-field/far-field interface temperature for commercial high-level waste emplacement in five

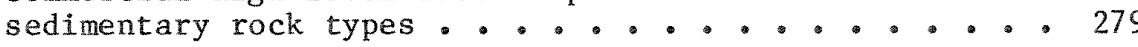

G.12.4.10. Expected near-field/far-field interface temperature for opent fucl omplacoment in five sedimentary rock types. - 280

G.12.4.11. Expected isolation period host rock temperature for commercial high-level waste emplacement in five sedimentary rock types ........... 281

G.12.4.12. Expected isolation period host rock temperature for spent fuel emplacement in five sedimentary rock types. . 282

G.12.4.13. Expected temperature at 595-m depth for commercial high-level waste emplacement in five sedimentary rock

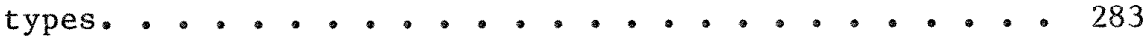

G.12.4.14. Expected temperature at 595-m depth for spent fuel emplacoment in five sedimentary rock types ...... 284

G.12.4.15. Expected shaft temperature for commercial high-level waste emplacement in five sedimentary rock types . . 285

G.12.4.16. Expected shaft temperature for spent fuel emplacement in five sedimentary rock types ........ 286

G.12.4.17. Expected near-surface temperature rise for commercial high-level waste emplacement in five sedimentary rock types................. 287

G.12.4.18. Expected near-surface temperature rise for spent fuel emplacement in five sedimentary rock types .... 288

G.12.5.1. Distribution of data points: unconfined compressive

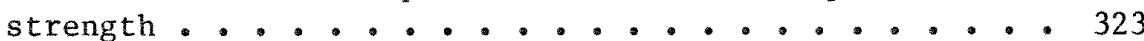


G.12.5.2. Distribution of data points: Young's modulus. . . . 324

G.12.5.3. Distribution of data points: Poisson's ratio. . . . 325

G.12.6.1. Distribution of data points: therma1 conductivity . . 346 


\section{LIST OF TABLES}

Table

Page

G.3.1. Reference sedimentary rock repository characteristics . . 76

G.3.2. Relative heat-generation decay characteristics . . . . 78

G.3.3. Waste package characteristics . . . . . . . . 80

G.3.4. Thermal properties for the waste package materials . . 87

G.4.1. Rock characteriscics evaluation criceria . . . . . 97

G.5.1. Qualitative performance constraints for a nuclear waste repository in sedimentary rock . . . . . . . . . . . 99

G.5.2. Quantitative performance constraints for a nuclear waste repository in sedimentary rock . . . . . . . 100

G.5.3. Sedimentary rock repository responses.......... 102

G.6.1. Summary of mechanical property values ......... 110

G.6.2. Ranges in thermal properties and initial conditions... 115

G.8.1. Permutation of input parameters for maximum thermal response ........................ 134

G.9.1. Boundary element computer code input data..... . 155

G.9.2. Strength-to-stress ratios and main effects . . . . . 156

G.10.1. Sumnary of expecled value (mean) resulls for a lifgllevel waste repository in anhydrock . . . . . . . . 158

G.10.2. Summary of expected value (mean) results for a highlevel waste repository in chalk........ . . 159

G.10.3. Summary of expected value (mean) results for a highlevel wasle repusilury in carbunale rocks........ 160

G.10.4. Summary of expected value (mean) results for a highlevel waste repository in sandstone . . . . . . 162

G.10.5. Summary of expected value (mean) results for a highlevel waste repository in shale........... 163

G.11.1 Average room periphery temperature $\left({ }^{\circ} \mathrm{C}\right)$ at time of backfill (5 years). . . . . . . . . . . . . . 
Table

Page

G.11.2. Operational stability indices for five sedimentary rock types ..................

G.11.3. Brittle to ductile transition pressures for rocks (at room temperature) ................ 172

G.11.4. Ranking of rock types on basis of favorable rock properties during postclosure ............

G.11.5. Postclosure stability indices for five sedimentary rock

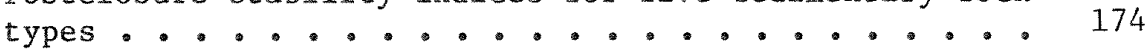

G.11.6. Preclosure ranking of five sedimentary rock types . . 176

G.11.7. Postclosure ranking of five sedimentary rock types. . 176

G.12.1. Generic rock type mechanical properties for anhydrock. 290

6.12.2. Generic rock type mechanical properties for chalk . . 293

G.12.3. Generic rock type mechanical properties for dolostone . 296

G.12.4. Generic rock type mechanical properties for limestone. 299

G.12.5. Generic rock type mechanical properties for sandstone - 310

G.12.6. Generic rock type mechanical properties for shale . 318

G.12.7. Unconfined compressive strength ......... 321

G.12.8. Young's modulus .............. 321

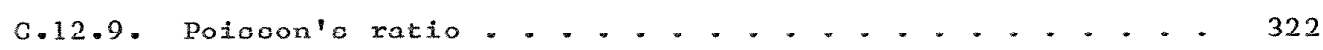

G.12.10. Angle of internal friction (phi)......... 322

G.12.11. Generic rock type thermal properties for anhydrock. - 327

G.12.12. Generic rock type thermal properties for chalk. . . 328

G.12.13. Generic rock type thermal properties for dolostone. - 329

G.12.14. Generic rock type thermal properties for limestone. • 332

G.12.15. Generic rock type thermal properties for sandstone. . 336

G.12.16. Generic rock type thermal properties for shale. . . 340

G.12.17. Thermal conductivity. . . . . . . . 344 


\section{Table}

Page

G.12.18. Temperature dependence of thermal conductivity . . 344

G.12.19. Heat capacity. . . . . . . . 345

G.12,20. Coefficient of linear thermal expansion. . . . . 345 
This page intentionally left blank 


\section{G.1 EXECUTIVE SUMMARY}

\section{G.1.1 INTRODUCTION}

This study attempts to rank five sedimentary rock types according to their thermal/rock mechanics suitability to serve as a host rock type for a high-level nuclear waste repository. To achieve this ranking it was necessary to collect as much information as possible from the literature on such things as thermal properties, elastic and strength properties, and "rock mass" properties. By "rock mass" properties is meant those properties or conditions that are of concern on a large scale (relative to an opening). Such properties or conditions include rock quality designation (RQD), joint spacing, condition of joints, and groundwater, for example. It was found that while an abundance of information was available for most of the rock types on thermal, elastic, and strength properties, such was not the case for the "rock mass" properties. The rock mass properties found in the literature for the five rock types were spotty at best and highly site specific. The intent of this study is to remain generic and, thus, even the information available from the literature on rock mass properties is not appropriate for a nonsite-specific evaluation.

It was also necessary in this study to identify evaluation criteria, performance criteria, and the appropriate responses for ranking the five rock types. By using well-defined responses, the authors tried to be as objective as possible in ranking the five rock types. However, it became apparent that such an approach could be misleading if the results were taken strictly at face value. There are a number of considerations that should be taken into account in an overall ranking scheme for these rock types that are not necessarily objective. For example, a rock type that is very strong may also be relatively stiff, and, while strength is certainly a desirable feature in constructibility, the rock, because of its greater stiffness, may be fractured to an extent that renders it less favorable from a constructibility standpoint than a rock type with lower strength and greater ductility. Thus, it is important for the reader to be aware that there are other factors that have not been considered here llat could lave been crilical in lle rankings delermined in lins sludy.

\section{G.1.2 DESCRIPTION OF GENERIC REPOSITORY}

The five rock types under consideration are anhydrock, shale (argillaceous rock), carbonate rocks (1imestone/dolostone), chalk, and sandstone. Generic stratigraphies for each of these rock types were provided by ORNL. The following assumptions were made at the outset of the study:

1. The repository depth will be between 300 and $1000 \mathrm{~m}$.

2. Waste types will be commercial high-level waste or spent fuel. 
3. Waste canisters will be placed in vertical holes in the floor of a single-1evel, room-and-pillar-type repository.

4. Backfilling of storage rooms for ground control will be permitted if it does not prevent retrievability.

5. Applicable NRC regulations and DOE guidelines will be followed.

For commercial high-level waste, the local thermal loading was taken to be $25 \mathrm{~W} / \mathrm{m}^{2}$, while for spent fuel it was assumed to be $20 \mathrm{~W} / \mathrm{m}^{2}$. These thermal loadings were adopted by the Reference Repository Conditions Interface Working Group (RRCIWG 1982a,b,c,d) as baseline values for repository design studies in granite, salt, tuff, and basalt. An $80 \%$ emplacement efficiency factor was applied to the thermal loading in performing far-field modeling to account for passive zones of the repository.

\section{G.1.3 EVALUATION CRITERIA}

The criteria used as the basis for ranking the rock types involve mincability, crscavation otability, and mechanical and thermal charac teristics of the host rock. These criteria were derived from the DOE Site Screening Guidelines in Title 10, Part 960 of the U.S. Code of Federal Regulations (CFR-1984). The criteria are addressed with the use of repository performance constraints.

\section{G.1.4 REPOSITORY PERFORMANCE CONSTRAINTS}

Repository performance constraints are given for operational, containment, and isolation periods. The operational period covers the time that the repository is open following construction. Its duration is taken to be $\sim 40$ years. The containment period follows closure and decommissioning of the repository and extends through the time that radioactivity levels and heat production in the waste are dominated by fiocion product decay. The containment duration is defined here as 1000 years. The isolation period is characterized by decay of actinides and their daughters and extends for a minimum period of 10,000 years.

Qualitative interim performance constraints were established in this study that encompass the presently perceived range of repositoryinduced responses that could be detrimental to the functional performance of the waste package, the engineered workinge, the eite geology, and the surrounding accessible environment.

The repository responses identified for the purpose of ranking the specific rock types are given for the very-near-field, near-field, and far-field regions of a repository. In the very-near-field region, the responses include the waste form temperature, overpack temperature, and the host rock temperature. In the near-field region, the responses include the volume averaged room backfill temperature, the near-field/ far-field interface temperature, the host rock temperature, mineability, constructibility, and thermomechanical stability. In the far-field region, the responses include the temperature at $85 \%$ of repository depth, the shaft temperature, and the near-surface temperature rise. 
Quantitative constraints are also established that represent numerical limits (or ranges) imposed on the above responses for specific sedimentary rock types and sites and identified repository designs where existing technology permits.

\section{G.1.5 ROCK PROPERTIES}

A literature search was made to determine rock properties for each of the rock types using computerized data bases where possible. Properties of all of the rock types, except chalk, were represented in the data bases available. Of the thermal properties of interest, only thermal conductivity has been well examined. Data were collected for unconfined compressive strength, Young's modulus, Poisson's ratio, angle of intcrnal friction, thermal conductivity, specific heat capacity, coefficient of thermal expansion, and mass density.

The literature was also used to establish site-specific initial surface temperature and geothermal gradients for use in determining the ambient temperature of the host rock at the repository depth. These initial conditions were developed for areas where the reference stratigraphic occtions might occur.

\section{G.1.6 MODELING CONSIDERATIONS}

A11 of the thermal responses in this study were made with the use of axisymmetric and two-dimensional finite element models. Separate models were developed for each of three geometric regions of interest, that is, the very-near-field encompassing the waste package and the emplacement borehole, the near-field encompassing the room-and-pillar system of the repository, and the far-field encompassing mainly the overlying rock of the repository. All of the mechanical responses were examined with the use of a two-dimensional boundary element computer program. This program was used for calculating the underground stress states around the repository disposal rooms.

\section{G.1.7 THERMAL RESULTS}

Anhydrock appeared to be the most favorable rock type and chalk the least favorable for all but one of the thermal responses. The one exception was the near-surface temperature rise response in which sandstone and shale were the most favorable and anhydrock the least favorable. Shale, carbonate rocks, and sandstone generally compared similarly, being somewhat less favorable than anhydrock and more favorable than cha1k.

\section{G.1.8 MECHANICAL RESULTS}

overa11, carbonate rocks appear to be the most favorable rock type based on mechanical performance. Generally, sandstone and shale exhibit similar mechanical behavior and can be ranked second, along with anhydrock. Chalk is the least favorable rock type based on mechanical performance. 


\section{G.1.9 PERFORMANCE ASSESSMENT}

The thermal and mechanical responses were compared with a set of quantitative performance constraints to determine the suitability of each of the rock types to serve as the host rock type for a high-level nuclear waste repository. For the repository designs used in this study, it was found that anhydrock satisfied all of the performance constraints with the possible exception of the operational stability of the disposal room. On the other hand, chalk violated nearly all of the performance constraints. Shale satisfied nearly all of the performance constraints with the exception of the borehole (rock) temperature. Carbonate rocks satisfied the mechanical performance constraints for high-level waste emplacement but violated several thermal conotrainto, copccially for spent fuel. Sandstone nearly paralleled the performance assessment of the carbonate rocks. In genera1, all rock types appeared to violate more constraints related to spent fuel (SF) than to commercial highleve1 waste (CHLW).

\section{G. 1.10 OVERALL RANKING}

On the basis of constructibility and operational stability considerations, the carbonate rocks are ranked the most favorable as repository host rocks for the preclosure time period, with sandstone ranked second, anhydrock and shale ranked third, and chalk ranked fourth. For postclosure, based on thermal performance and rock stability considerations, the carbonate rocks and shale are ranked first, with anhydrock, sandstone, and chalk ranked second, third, and fourth, respectively. From an overall viewpoint, considering postclosure and preclosure collectively, the carbonate rocks are ranked first, with shale ranked second, anhydrock and sandstone ranked third, and chalk ranked fourth. 


\section{G.2 INTRODUCTION}

\section{G.2.1 BACKGROUND AND OBJECTIVES}

Oak Ridge National Laboratory (ORNL), operated by Martin Marietta Energy Systems, Inc., is determining the suitability of five sedimentary rocks to serve as host rocks for a potential high-level nuclear waste repository under Contract No. DE-ACO5-840R21400 with the U.S. Department of Energy (DOE). RE/SPEC Inc. was selected by ORNL to provide a generic evaluation of five sedimentary rocks with the objective of ranking these rock types for their thermal/rock mechanics suitability to serve as the host rock for a nuclear waste repository.

\section{G.2.2 APPROACH AND SCOPE}

The work described in this report was performed in close coordination with personnel trom ORNL and supplements the work of ORNL personnel and other subcontractors concerned with the geologic, hydrologic, and nuclide transport aspects of the overall rock evaluation.

The technical approach involves a study program including rock mechanics and thermal analyses directed toward the generic evaluation of five sedimentary rocks as potential host rocks for a high-level nuclear waste repository. The rock types considered are anhydrock, shale, carbonate rocks (limestone/dolostone), chalk, and sandstone. A ranking is made of these rock types for their suitability to serve as the repository host rock. The analyses involve no new laboratory or field tests. A11 data on these rock types were collected from the 1iterature. The following assumptions were made at the onset of the analyses:

1. The repository depth will be between 300 and $1000 \mathrm{~m}$.

2. Waste types will be commercial high-level waste or spent fuel.

3. Waste canisters will be placed in vertical holes in the floor of a single-leve1, room-and-pillar type repository.

4. Backfilling of storage rooms for ground control will be permitted if it does not prevent retrievability.

5. Applicable NRC regulations and MOF guidelines wil1 he foll nwed.

6. Information on hydrology and geology will be available from the respective ORNL subcontractors.

Evaluation criteria, performance constraints, and the appropriate responses were established for thermal and rock mechanics ranking of the potential repository host rocks. A comprehensive literature review was made using computerized data bases to estimate ranges and mean values for strength, deformation, and thermal properties from laboratory and field tests. Constructibility and operational stability of a repository 
are determined for each rock type based on the properties collected from the literature. Thermal analyses were performed for the very-near-field (canister scale), near-field (room scale), and far-field (repository scale) regimes using generic geologic sections provided by ORNL. Ranking of the rock types is made based on properties, mechanical, and thermal performance.

\section{G.2.3 REPORT ORGANIZATION}

The remainder of this report presents: (1) the generic repository description including waste type, design parameters, stratigraphic columns, and a description of the sedimentary rock types; (2) a discussion of the evaluation criteria; (3) a discussion of repository performance constraints used for evaluation of repository designs; (4) a summary of the rock properties collected in the literature survey; (5) a discussion of the modeling considerations for the thermal and mechanical analyses; (6) the results of the thermal analyses for the three regimes of interest; (7) the mechanical results; (8) a ranking and evaluation of the five rock types; and (9) a number of conclusions and discussion of the results. More detailed results from the analyses are given in sect. G.12.

\section{G.2.4 RANKING ASSESSMENT}

By using well-defined responses, the authors tried to be as objective as possible in ranking the five rock types. However, it became apparent that such an approach could be misleading if the results were taken strictly at face value. There are a number of considerations that should be taken into account in an overall ranking scheme for these rock types that are not necessarily objective. For example, a rock type that is very strong may also be relatively stiff, and, while strength is certainly a desirable feature in constructibility, the rock, because of its greater stiffness, may be fractured to an extent that renders it less favorable from a constructibility standpoint than a rock type with lower strength and greater ductility. Thus, it is important for the reader to be aware that there are other factors that have not been considered here that could have been critical in the rankings determined in this study. 


\section{G.3 DESCRIPTION OF GENERIC REPOSITORY}

The reference sedimentary rock repository characteristics are summarized in Table G.3.1. The characteristics of the high-level nuclear waste repository required in this study include the waste description, the engineered design parameters, and the stratigraphy. These characteristics are discussed in the following sections, followed by a description of the five sedimentary rock types considered in this study.

\section{G.3.1 WASTE TYPE}

Three waste types are currently being considered for emplacement in a high-level waste repository, namely: commercial high-level waste (CHLW); spent fuel (SF); and defense high-level waste (DHLW). Because of the relatively low thermal output and large radius of the DHLW package, the maximum cemperatures in this package can be anticipated to be much less than the CHLW package. In addition, the DHLW accounts for $<5 \%$ of the total nuclear waste existing, including reprocessed waste. For those reasons, only the CHLW and SF packages were evaluated in this study. The thermal decay characteristics of these two waste types are shown in Fig. G.3.1. Descriptions of these two waste types follow.

\section{G.3.1.1 Commercial High-Level Waste}

The CHLW considered in this study was assumed to result from the reprocessing of the above-mentioned pressurized-water reactor (PWR) spent fuel (Sect. B.1), even though there are no such reprocessing plants currently operating in the United States. This reprocessing was assumed to occur immediately out-of-reactor and was assumed to last $\sim 150 \mathrm{~d}(0.4$ year). This reprocessing removes $99.5 \%$ of the uranium from the SF, that would be reused in the nuclear reactors. In contrast to the SF waste form, the CHLW form is a homogeneous matrix of borosilicate glass that is poured in its molten state into waste canisters and allowed to solidify before emplacement. Each waste canister is surrounded by a corrosion-resistant overpack. Emplacement of the CHLW was assumed to occur 10 years after reprocessing.

The decay characteristics for the assumed CHLW (i.e., reprocessed PWR spent fuel in a $3: 1 \mathrm{mix}$ of fresh $\mathrm{UO}_{2}$ and $\mathrm{MOX}$ fuels) are based on an average burnup of 33,000 MWd/MTU* (KISNER 1978). The normalized CHLW decay characteristics are presented in tabular form in Table G.3.1. After 10,000 years, the CHLW thermal power has diminished by nearly three orders of magnitude from its emplaced (i.e., 10 years after reprocessing) power, primarily because of the absence of the dominant long half-1ived plutonium isotope. The CHLW repository was assumed to contain the equivalent of $70,000 \mathrm{MTU}$.

\footnotetext{
*metric ton uranium $(1000 \mathrm{~kg})$.
} 
Table G.3.1. Reference sedimentary rock repository characteristicsa

\begin{tabular}{|c|c|c|}
\hline Waste type & SF-PWR & CHLW \\
\hline Repository configuration area, $\mathrm{km}^{2}$ & 5 & 5 \\
\hline Thermally loaded area, $\mathrm{km}^{2} \mathrm{~b}$ & 4 & 4 \\
\hline Depth below surface, $\mathrm{m}^{\mathrm{c}}$ & 700 & 700 \\
\hline Capacity, MTUC & 70,000 & 70,000 \\
\hline Number of waste packages & - & - \\
\hline \multicolumn{3}{|l|}{ Thermal loading (at emplacement) } \\
\hline Areal thermal loading, $\mathrm{W} / \mathrm{m}^{2}$ & 20 & 25 \\
\hline Global thermal loading, $\mathrm{W} / \mathrm{m}^{2 \mathrm{~b}}$ & 16 & 20 \\
\hline Canister thermal power, $\mathrm{kW}$ & 3.30 & 2.21 \\
\hline \multicolumn{3}{|l|}{ Roon description } \\
\hline Length, $\mathrm{m}^{\mathrm{d}}$ & NA & $\mathrm{NA}$ \\
\hline Width, m & 5.5 & 5.5 \\
\hline Height, m & 5.5 & 5.5 \\
\hline Adjacent pillar thickness, m & 18 & 18 \\
\hline \multicolumn{3}{|l|}{ Canister emplacement holes } \\
\hline Rows per room & 1 & 1 \\
\hline Pitch, $\mathrm{m}^{\mathrm{e}}$ & 7.02 & 3.76 \\
\hline Depth, m & 5.57 & 4.90 \\
\hline Dianeter, $\mathrm{m}$ & 0.64 & 0.52 \\
\hline Canisters per hole & 1 & 1 \\
\hline
\end{tabular}

aTaken from SAI 1980.

$\mathrm{b}_{80 \%}$ emplacement efficiency.

cSee Sect. G.3.2.2.8.

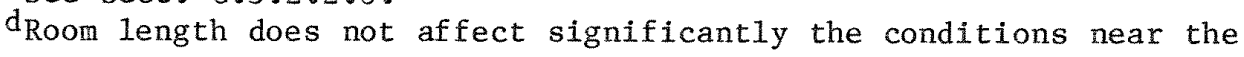
repository center.

epitch = canister spacing along the length of the room.

$\mathrm{NA}=$ not applicable.

\section{G.3.1.2 Spent Fue1}

The SF considered in this study was assumed to be from a PWR and was selected because of its higher thermal power in comparison with boilingwater reactor spent fuel. The spent fuel waste package contains several different materials and exhibits a complex geometry, which makes modeling the canister interior extremely difficult. The SF waste form consists of uranium dioxide fuel pellets inserted in a circular fuel rod by means of a Zircaloy cladding. These Zircaloy rods are grouped together in a square assembly (17 by 17 array) by means of a separator grid. Before emplacement, these arrays are disassembled, and the fuel rods are consolidated into a smaller volume. Subsequent emplacement of the SF waste packages in boreholes in the repusitory was assunted lo vecur at 10 years out-of-reactor. 
ORNL DWG 85-61

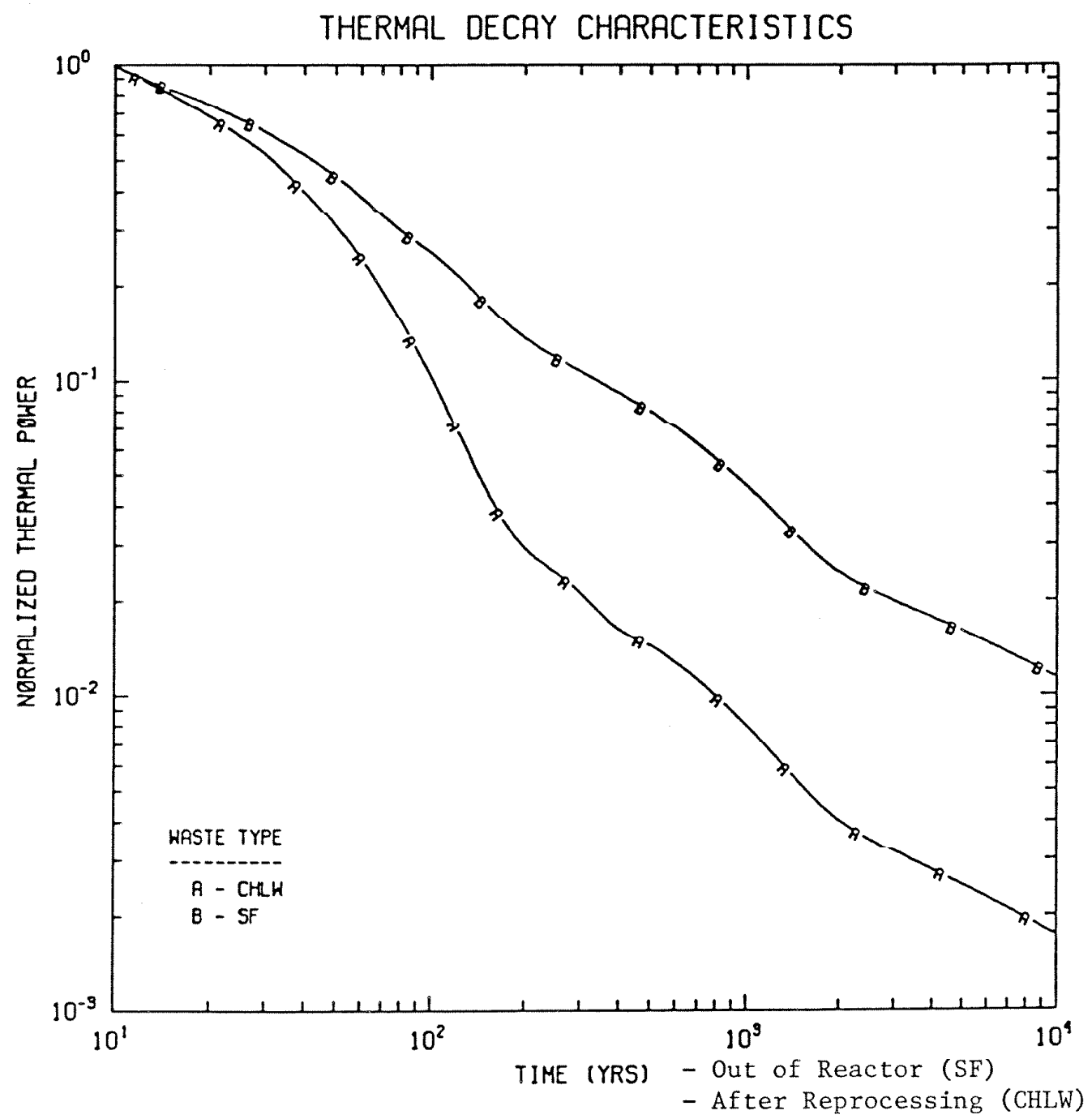

Fig. G.3.1. Normalized thermal power for commercial high-1eve1 (CHLW) waste and spent fuel (SF). 
The decay characteristics for PWR spent fuel are based on an average burnup of $33,000 \mathrm{MWd} / \mathrm{MTU}$ (KISNER 1978). For this study, the thermal decay characteristics were required in tabular form, expressing the digitized normalized thermal power at discrete times from time of emplacement to 10,000 years, as required input for SPECTROM-41 (SVALSTAD 1983). The normalized SF decay characteristics are presented in tabular form in Table G.3.2. After 10,000 years, the spent fuel thermal power has diminished by approximately two orders of magnitude from its emplaced (i.e., 10 years out-of-reactor) power. The spent fuel repository was assumed to contain the equivalent of $70,000 \mathrm{MTU}$.

\section{G.3.2 ENGINEERED DESIGN PARAMETERS}

Design parameters considered in this study can be classified under three general categories, namely: (1) design materials; (2) geometry; and (3) material properties. Geometry includes the dimensions of the waste package and borehole, the dimensions and location of the disposal rooms, and the location and size of the repository. The design parameters are discussed separately in detail below.

Table G.3.2. Relative heat-generation decay characteristics

\begin{tabular}{cll}
\hline $\begin{array}{l}\text { Year after } \\
\text { emplacement }\end{array}$ & $\mathrm{SF}^{\mathrm{a}}$ & CHLW \\
\hline 0 & 1.0 & 1.0 \\
5 & 0.838 & 0.810 \\
10 & 0.750 & 0.692 \\
15 & 0.681 & 0.600 \\
20 & 0.622 & 0.529 \\
30 & 0.525 & 0.402 \\
40 & 0.449 & 0.313 \\
50 & 0.387 & 0.246 \\
70 & 0.301 & 0.157 \\
100 & 0.238 & 0.0864 \\
190 & 0.131 & 0.0296 \\
290 & 0.108 & 0.0215 \\
390 & 0.0919 & 0.0163 \\
490 & 0.0806 & 0.0145 \\
990 & 0.0466 & 0.00810 \\
1990 & 0.0247 & 0.00404 \\
5990 & 0.0148 & 0.00230 \\
9990 & 0.0114 & 0.00175 \\
\hline
\end{tabular}

aTaken from SAI 1980.

bTaken from KTSNER 1978. 


\section{G.3.2.1 Design Materials}

The design materials that were considered in this study are the waste package (including the waste form and overpack) and the disposal room backfi11. Currently, these are the only engineered barriers under consideration in the Sedimentary Repository Program (SRP). No packing is provided for in the annulus surrounding the waste packages.

\section{G.3.2.1.1 Waste Packages}

Two kinds of waste packages were considered in this study (i.e., CHLW and SF). Waste package characteristics are summarized in Table $\mathrm{G} \cdot 3 \cdot 3$.

The CHLW package used in this analysis is shown in Fig. G.3.2. This reference CHLW package conceptual design for borehole emplacement has been used previously in salt (WESTINGHOUSE 1983b) and tuff (WESTINGHOUSE 1983a). The SF waste package used in this analysis is shown in Fig. G.3.3. This waste package contains 1584 PWR SF rods in a consolidated array. This design is known as the reference SF (Form 2) waste package for borehole emplacement and has been used as the reference design in both salt (WESTINGHOUSE 1983b) and tuff (WESTINGHOUSE 1983a). Note that this consolidated SF package does not include a stainless steel canister as does CHLW.

Each waste package also includes an overpack that has been designed to limit the corrosion of the waste canister. This overpack has been included to maintain the waste package as an intact barrier throughout the operational and containment periods (i.e., 1000 years after emplacement). The overpack was assumed to be composed of carbon steel surrounded by a Titanium-50A outer shell.

\section{G.3.2.1.2 Backfi11}

The room backf111 matertal was assumed to be a mixcure of benconite and crushed host rock in equal proportions by weight. The backfil1 porosity was assumed to be 0.30 . The time of backfill was assumed to occur at 5 years after emplacement. At the time of backfill, the disposal room was assumed to be completely and instantaneously backfilled.

\section{G.3.2.2 Geometry}

The geometry consists of the dimensions and locations of the waste package, the borehole, the emplacement drift, and the repository. Each aspect of the geometry is discussed separately in detail below.

\section{G.3.2.2.1 Waste Packages}

Two waste types were considered in this study, namely, unreprocessed $\mathrm{SF}$ and the CHLW that results from reprocessing domestic commercial power reactor fuel. The specifications for the waste packages which are essential for this study are given in Table G.3.3. 
Table G.3.3. Waste package characteristics ${ }^{a}$

\begin{tabular}{|c|c|c|}
\hline Waste type & $\mathrm{SF}-\mathrm{PWR}$ & CHLW \\
\hline \multicolumn{3}{|l|}{ Waste description } \\
\hline Active length, m & 3.85 & 2.63 \\
\hline Diameter, m & 0.432 & 0.311 \\
\hline Active volume, $\mathrm{m}^{3}$ & 0.56 & 0.20 \\
\hline Waste age at emplacement, years & 10 & 10 \\
\hline Canister thermal loading, $\mathrm{kW}$ & 3.30 & 2.21 \\
\hline Mass loading, W/MTU & 1,189 & 1,063 \\
\hline Power density, $\mathrm{W} / \mathrm{m}^{3}$ & 5,591 & 11,062 \\
\hline \multicolumn{3}{|l|}{ Canister dimensions } \\
\hline Outer diameter, m & NA & 0.324 \\
\hline Thickness, mm & NA & 9.5 \\
\hline Length, m & NA & 3.05 \\
\hline \multicolumn{3}{|l|}{ Overpack dimensions } \\
\hline Outer diameter, m & 0.589 & 0.475 \\
\hline Thickness, m & 0.079 & 0.063 \\
\hline Length, $\mathrm{m}$ & 4.20 & 3.38 \\
\hline \multicolumn{3}{|l|}{ Emplacement hole plug dimensions } \\
\hline Diameter, m & 1.2 & 1.0 \\
\hline Length, m & 1.3 & 1.5 \\
\hline \multicolumn{3}{|l|}{ Materials } \\
\hline Waste & $\mathrm{b}$ & Glass \\
\hline Filler in canister & $\mathrm{NA}$ & Air \\
\hline Canister & NA & ss \\
\hline Overpack & $\mathrm{CS} / \mathrm{T}$ & $\mathrm{CS} / \mathrm{T}$ \\
\hline Filler in overpack & Air & Air \\
\hline Emplacement hole plug & Concrete & Concrete \\
\hline
\end{tabular}

aTaken from WESTINGHOUSE 1983b.

bConsolldaced $\mathrm{UO}_{2}$ fuel rods.

$\mathrm{NA}=$ Not applicable.

$\mathrm{SS}=304 \mathrm{~L}$ stainless steel.

CS $=$ Carbon steel.

$\mathrm{T}=$ TICODE-50A (Titanium alloy). 
ORNL DWG 85-62

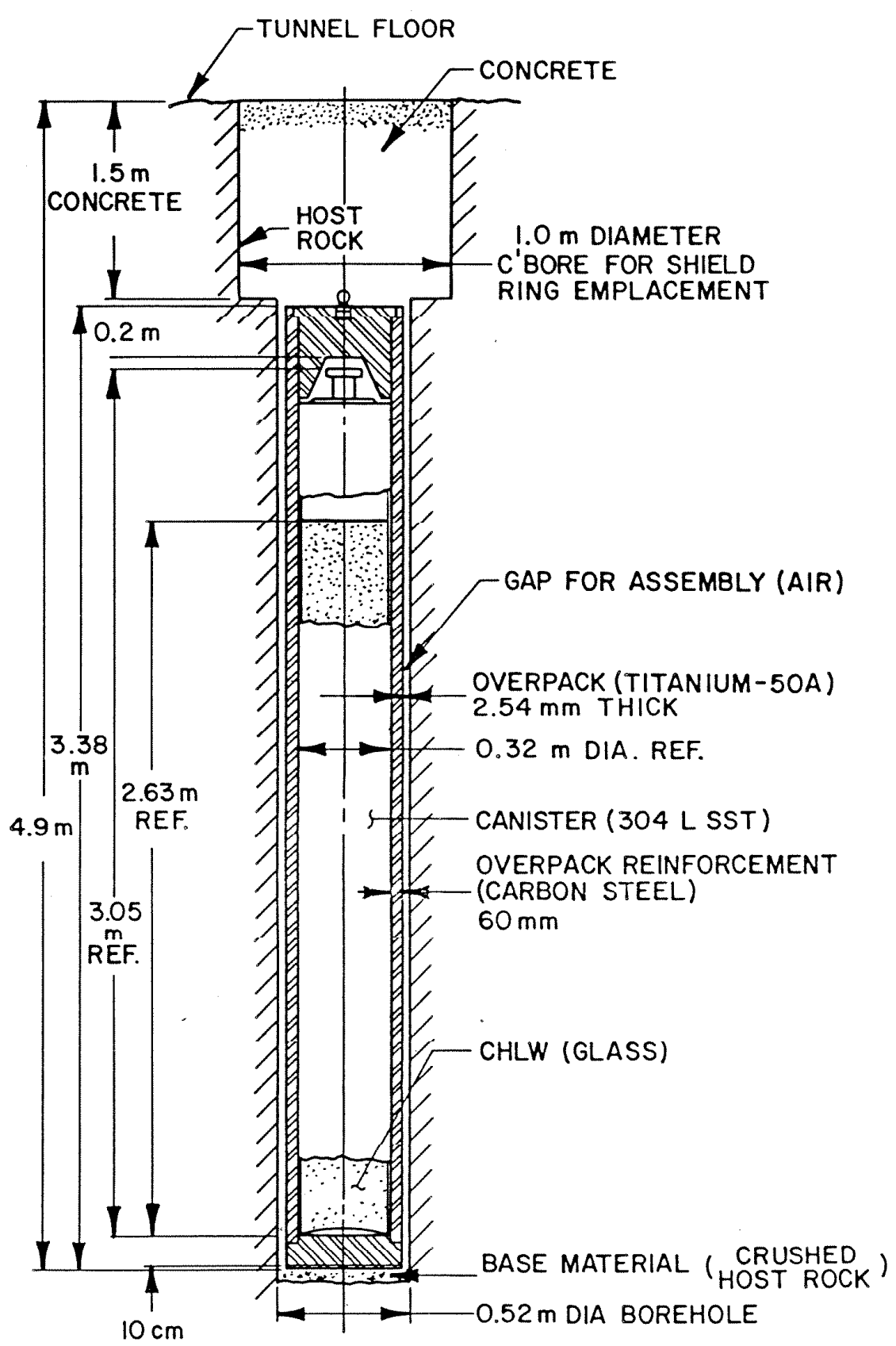

Fig. G.3.2, Reference comnercial high-level waste package conceptual design for borehole emplacement. 
ORNL DWG 85-63

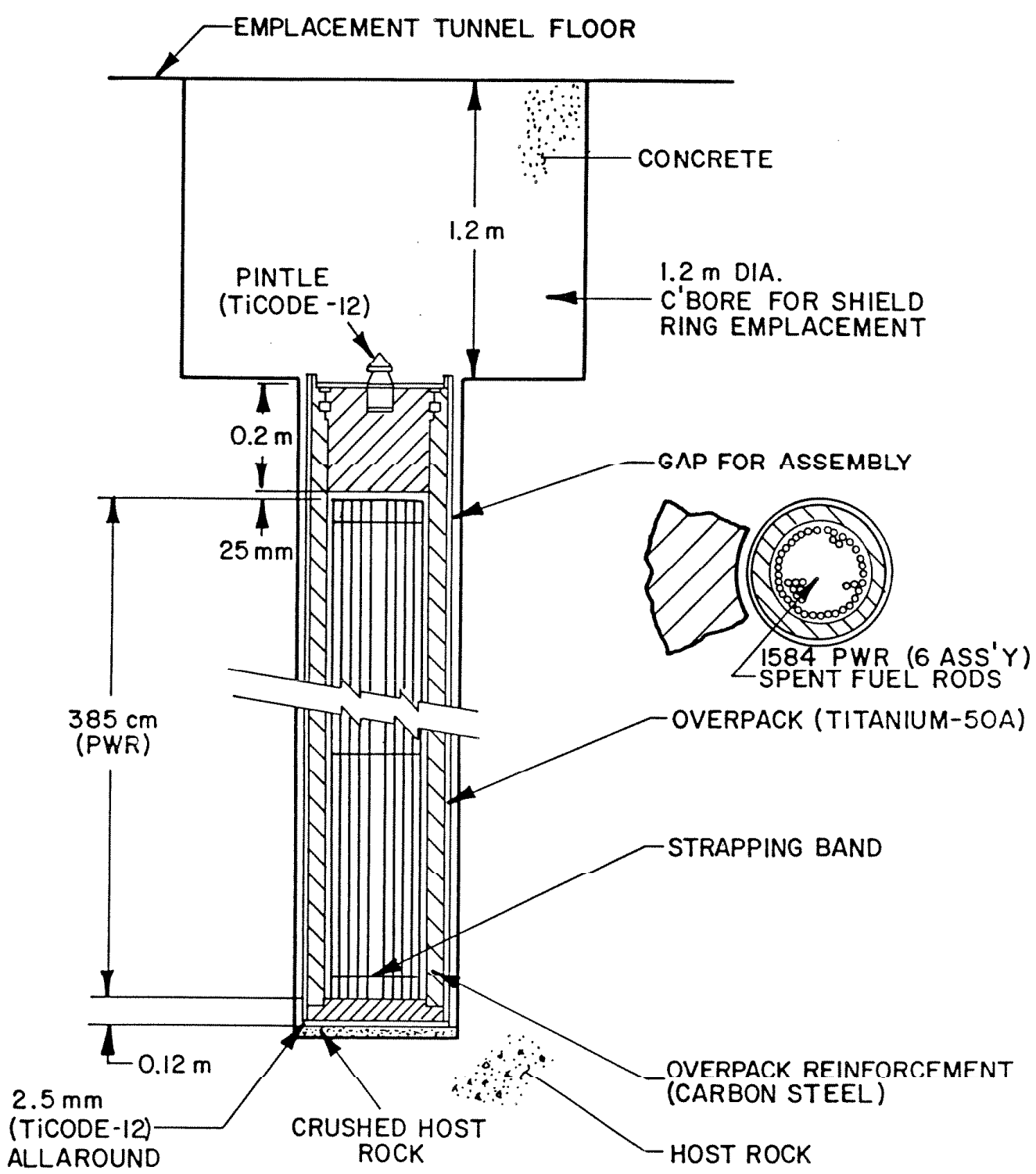

Fig. G.3.3. Reference spent fuel (Form 2) package for borehole emplacement. 
The total length of the waste package was assumed to be $4.20 \mathrm{~m}$ for $\mathrm{SF}$ and $3.38 \mathrm{~m}$ for CHLW. Each waste package includes an "active length" to represent the location of the heat-generating waste within the package accurately. The "active length" of the SF waste package is $3.85 \mathrm{~m}$, which represents the length of an individual PWR fuel rod. Similarly, the "active length" of the CHLW package is $2.63 \mathrm{~m}$, which represents the height of the CHLW borosilicate glass required for the initial canister thermal power. This "active length" was modeled as a homogeneous heat-generating material with thermal decay characteristics of SF or CHLW (Fig. G.3.1). The CHLW package also includes a "passive length," representing the air void directly above the waste within each canister.

The diameter of the waste package includes both the diameter of the waste form and the thickness of the overpack. The diameter of the waste form ranges from $0.31 \mathrm{~m}$ for CHLW to $0.43 \mathrm{~m}$ for SF. The overpack thickness was assumed to be $63 \mathrm{~mm}$ for CHLW and $79 \mathrm{~mm}$ for SF.

\section{G.3.2.2.2 Emplacement Borehole}

For the purpose of this study, the emplacement borohole was assumed to be unlined, with an internal diameter of $0.64 \mathrm{~m}$ for $\mathrm{SF}$ and $0.52 \mathrm{~m}$ for CHLW. A single waste package is contained within each borehole. A concrete plug was assumed to be used in the borehole above each waste package. In this study, no engineered barrier is provided between the waste package and the host rock since the assurance of a 1000-year package is placed on the overpack alone. In addition, the packages must remain retrievable during the operational period. An air annulus of $51 \mathrm{~mm}$ is provided for the SF waste package, whereas, a 45-mm annulus exists between the borehole surface and the CHLW package. The length of the borehole is related to the height of the waste package and the required length of the concrete plug. For CHLW the borehole length is $4.9 \mathrm{~m}$, while for $\mathrm{SF}$ it is $5.6 \mathrm{~m}$.

\section{G.3.2.2.3 Canister Pitch}

The canister pitch is defined as the borehole spacing along the length of the disposal room. For both waste types a single row of waste packages was assumed along the length of the room. The pitch was calculated to maintain a desired thermal loading for each waste type. For CHLW, the pitch was calculated to be $3.76 \mathrm{~m}$, while for SF it was calculated to he $7.02 \mathrm{~m}$.

\section{G.3.2.2.4 Emplacement Drifts}

The emplacement drift is one of the key elements in the repository design. Reviews of repository designs in other media indicate that there are two major factors contributing to the shape and size of the drift: (1) package size and (2) emplacement equipment and emplacement scheme. From a rock mechanics standpoint, one desires to construct the drift so that the tangential stress on the periphery of the room opening is nearly uniform along the entire periphery. Thus, using this 
criterion, one would only excavate a drift with equal width and height in a situation when one of the horizontal stresses was equal to the vertical stress. The ratio of the drift width to height should change as the ratio of the horizontal stress (perpendicular to the axis of the drift) to the vertical stress changes. The size of the drift should also be established with considerations of the spacing of any joint or fracture sets in the country rock. If possible, the drift size should be such that the support required for the blocks formed by the joint sets is minimized. The other major factor affecting the size and shape of the drift relates to the waste emplacement operation. Obviously, one dimension of the drift must be at least as great as the length of the waste package. Additional requirements will also be placed upon the drift size by the size of the emplacement equipment.

The emplacement drifts that are considered in this study are summarized in Fig. G.3.4. A room height to width ratio of 1.0 was used for both waste types. It was assumed that the emplacement equipment will necessitate a drift dimension equal to the package length plus $\sim 1 \mathrm{~m}$. No consideration has been given to joint set spacing in determining these cross sections, since this type of information is yet to be determined. These room sizes were taken from a previous similar analysis in shale (SAI 1980).

\section{G.3.2.2.5 Extraction Ratio}

Based on the ranges in the room dimensions and spacings, the range in extraction ratio can be calculated. The extraction ratio is the ratio of the area excavated to the total planar area and can be expressed as the quotient of disposal room width and room spacing. For both waste types, the extraction ratio was calculated to be 0.23 .

\section{G.3.2.2.6 Thermal Loading}

The thermal loadings that were used for each waste type in the very-near-field and near-field regions are known as the areal thermal loadings and were assumed to be the same for all rock types in this analysis. The thermal loading is the amount of thermal energy emplaced per unit area and is a measure of the efficiency of the repository in Lerms of use of avallable area. The thermal loading can also be used to calculate the horizontal extent of the repository that is required to emplace a given amount of waste. The areal thermal loading is directly related to the waste package thermal power and the number of packages per borehole and inversely related to the pitch and room spacing.

For CHLW, the areal thermal loading was taken to be $25 \mathrm{~W} / \mathrm{m}^{2}$, while for $\mathrm{SF}$ it was assumed to be $20 \mathrm{~W} / \mathrm{m}^{2}$. These thermal loadings were adopted by the Reference Repository Committee-Interface Working Group as baseline values for repository design studies in granite (RRCIWG 1982b), salt (RRCIWG 1982a), tuff (RRCIWG 1982c), and basalt (RRCIWG 1982d). An $80 \%$ emplacement efficiency factor was applied to the thermal loading in performing far-field modeling to account for passive zones of the 
ORNL DWG 85-64
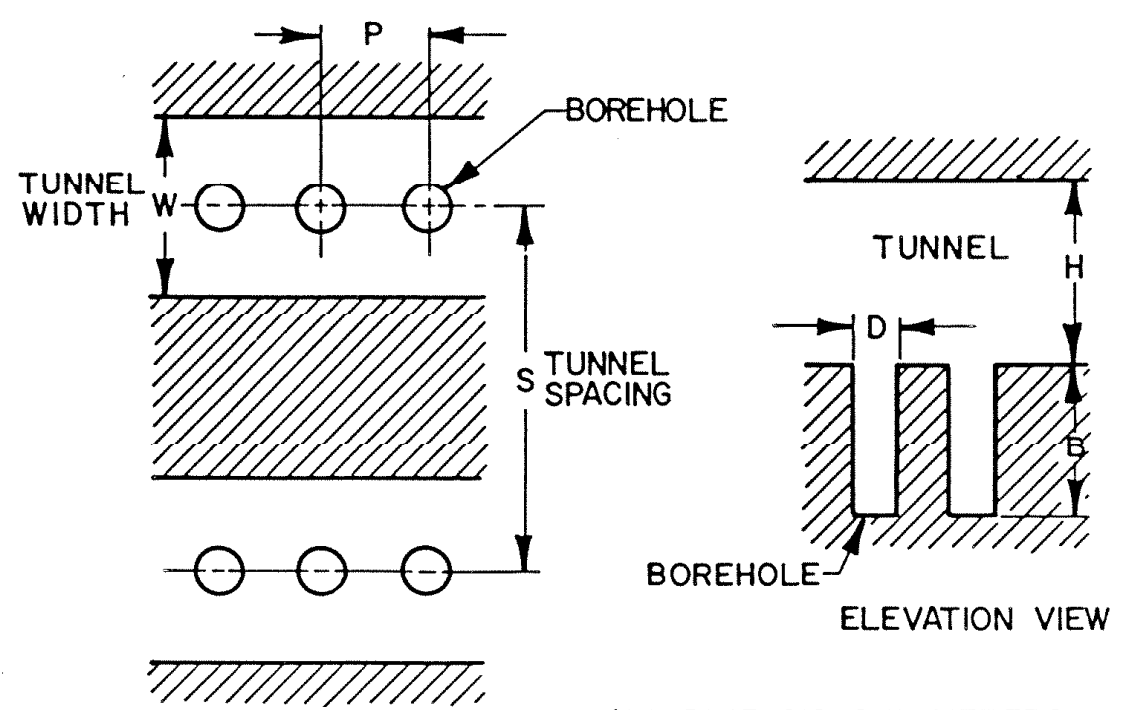

PLAN VIEW

ALL DIMENSIONS IN METERS

\begin{tabular}{|c|c|c|c|c|c|c|}
\hline & $\underline{B}$ & $\underline{D}$ & $\underline{H}$ & $\underline{P}$ & $\underline{s}$. & $\underline{w}$ \\
\hline $\mathrm{CHIS}$ & 4.9 & .52 & 5.5 & 3.76 & 23.5 & 5.5 \\
\hline & 5.6 & .64 & 5.5 & 7.02 & 23.5 & \\
\hline
\end{tabular}

Fig. F.3.4. Fmplacement genmetry for reference commersial highlevel waste and spent fuel packages. 
repository (i.e., nonheat-generating waste, connecting corridors, and drifts). These reduced thermal loadings used in the far-field region analysis are known as the global thermal loadings.

\section{G.3.2.2.7 Repository Layout}

The horizontal dimensions of the repository are directly related to the amount of waste that is to be emplaced and inversely related to the thermal loading. For this study, it was assumed that 70,000 MTU of SF or CHLW were to be emplaced in separate repositories. For 10-year-o1d waste, the conversion from MTU to thermal power is 1189 W/MTU for SF and 1063 W/MTU for CHLW (KISNER 1978). For an 80\% emplacement efficiency factor, the size of each repository is $\sim 5 \mathrm{~km}^{2}$.

\section{G.3.2.2.8 Repository Depth}

The repository depth considered in this study was assumed to be $700 \mathrm{~m}$. This depth is consistent with the depths considered for repositories in salt, 600 to $900 \mathrm{~m}$ (e.g., WAGNER 1984), tuff, 400 to $1000 \mathrm{~m}$ (e.g., BRANDSHAUG 1983), and crystalline rock, 300 to $500 \mathrm{~m}$ (e.g•, RATIGAN 1984).

\section{G.3.2.2.9 Shaft Location}

The final aspect of the repository layout, which was considered in this study, is the shaft facilities location. In this regard, the shaft was assumed to be located at a horizontal distance of $250 \mathrm{~m}$ from the repository emplacement panels. This minimum shaft pillar thickness has been used in previous repository design analyses in salt (WAGNER 1984) and crystalline rock (RATIGAN 1984). This distance is sufficient to allow negligible temperature rise in the region of the shaft.

\section{G.3.2.3 Material Properties}

The thermal material properties of the engineered design parameters are summarized in Table G.3.4. The values of these properties were assumed to remain constant for every case examined in the thermal analysis.

The properties of concrete were taken from Holman (HOLMAN 1979) and are representative of normal strength (i.e., $3000 \mathrm{psi}$ ) concrete. The properties of carbon steel are consistent with those used in similar analyses (RE/SPEC INC. 1984a,b,c) and were taken from Lynch (LYNCH 1975). The density and specific heat of air were taken from Chapman (CHAPMAN 1967) for standard conditions (i.e., atmospheric pressure and $\left.20^{\circ} \mathrm{C}\right)$. The effective thermal conductivity assumed for this disposal room air (i.e., $24 \mathrm{~W} / \mathrm{m} \cdot \mathrm{K}$ ) accounts for combined modes of heat transfer (i.e., conduction, convection, and radiation) across the room and has been validated in a previous study in crystalline rock which considered similar room designs (RATTGAN 1984). The assumed effective thermal conductivity of the annulus air (i.e., $1.0 \mathrm{~W} / \mathrm{m} \cdot \mathrm{K}$ ) has been used in a previous study which considered similar waste package designs in salt (RATIGAN 1984) and accounts primarily for the radiation from the waste 


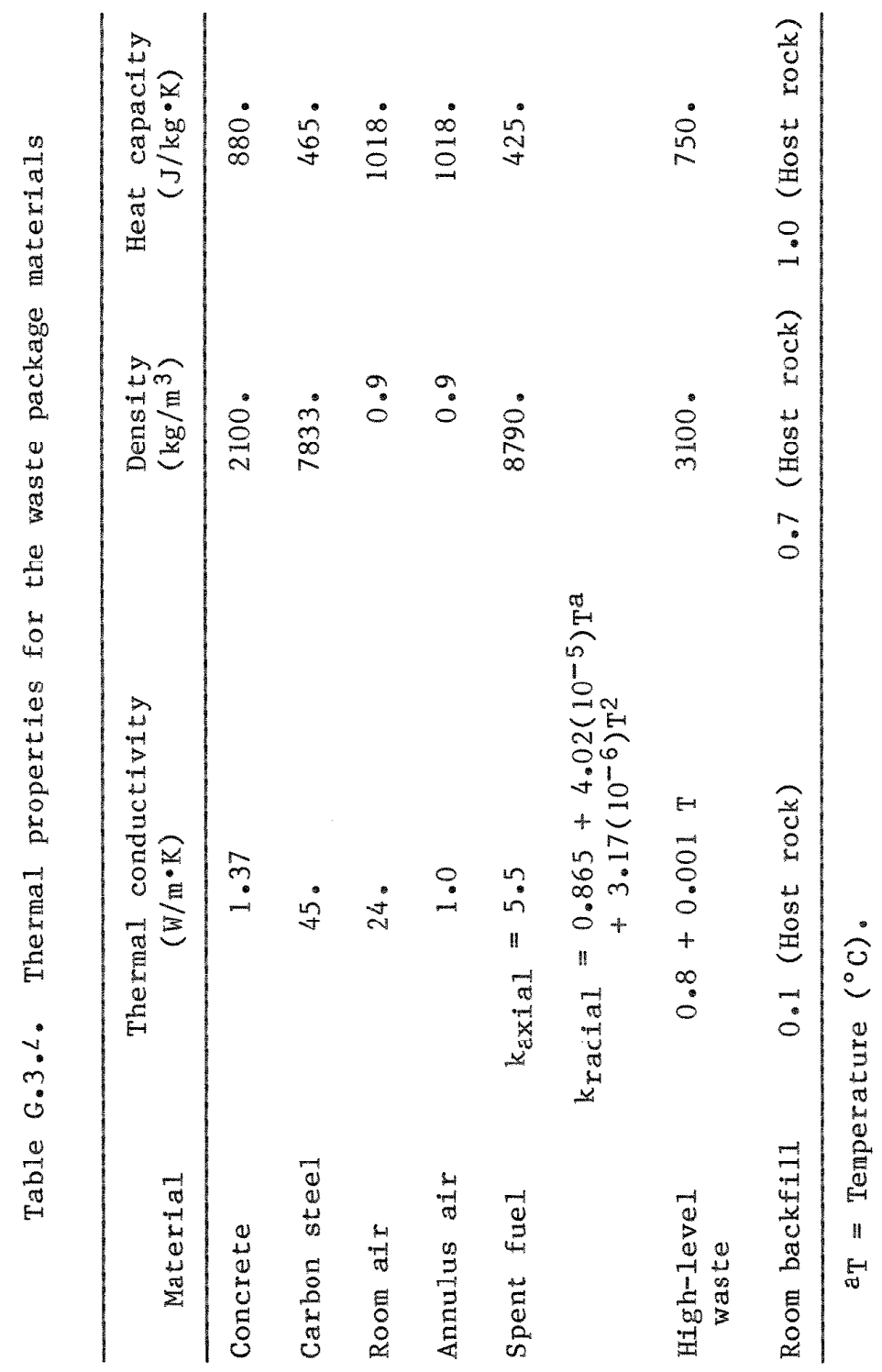


package to the borehole surface. The thermal properties of the two waste forms (i.e., CHLW and SF) were taken from Westinghouse Electric Corporation (WESTINGHOUSE 1983b). The thermal properties of the room backfill were estimated using an approach documented in Osnes et al. (OSNES 1984) for an emplaced porosity of $30 \%$. A therma1 conductivity of $10 \%$ of the intact rock has been used in numerous similar studies (e.g., RICKERTSON 1981).

\section{G.3.3 STRATIGRAPHY}

The reference data provided for this study included generic stratigraphic columns that place each host rock type in a typical or representative setting.* The subsequent modeling must consider the hehavior and effects of the overlying strata and to a lesser degree the strata underlying the host rock type. The repository depth is $700 \mathrm{~m}$ for each stratigraphic column. This section briefly describes the stratigraphic columns used for this scudy.

\section{G.3.3.1 Generic Stratigraphic Section: Anhydrock}

Anhydrock may occur as thick, bedded units with halite (rock salt) in evaporitic sequences. The generic stratigraphic section given in Fig. G.3.5 includes anhydrock within this type of setting.

The uppermost $15 \mathrm{~m}$ of the section is made up of sand, silt, and gravel representative of recent surface deposits. Underlying this is a thick evaporitic sequence of anhydrock and rock salt with one shale unit occurring in the 76- to 107-m-depth interval. The host interval is an anhydrock unit $183 \mathrm{~m}$ thick. The evaporite sequence continues below the anhydrock repository horizon.

\section{G.3.3.2 Generic Stratigraphic Section: Chalk}

Chalk may be deposited in an open marine, pelagic environment (PETTIJOHN 1975) or in a shallow water shelf environment (CORBETT 1982). Associated sedimentary rocks will consist of fine-grained detrital material forming shales or mudstones. The generic stratigraphic section for chalk, Fig. G.3.6, depicts thls assoctation of fine-grained rocks and cha1k.

The uppermost unit, $152 \mathrm{~m}$ in thickness, is made up of shale and sandstone. Underlaying this is $153 \mathrm{~m}$ of clay-shale and marl. The next unit is $305 \mathrm{~m}$ thick and is composed of shale, marl, and chalk with some sandstone. The repository horizon is thick-bedded chalk mixed with cha1ky limestones and limey chalks.

\section{G.3.3.3 Generic Stratigraphic Section: Carbonate Rocks (Limestone/ Dolostone)}

Carbonate rocks are deposited in a great variety of environments commonly associated with fine-grained sedimentary rock types. The generic statigraphic section for carbonate rocks is given in Fig. G.3.7.

\footnotetext{
* See Appendix B.3.
} 
ORNL OWG $84-998 R 2$

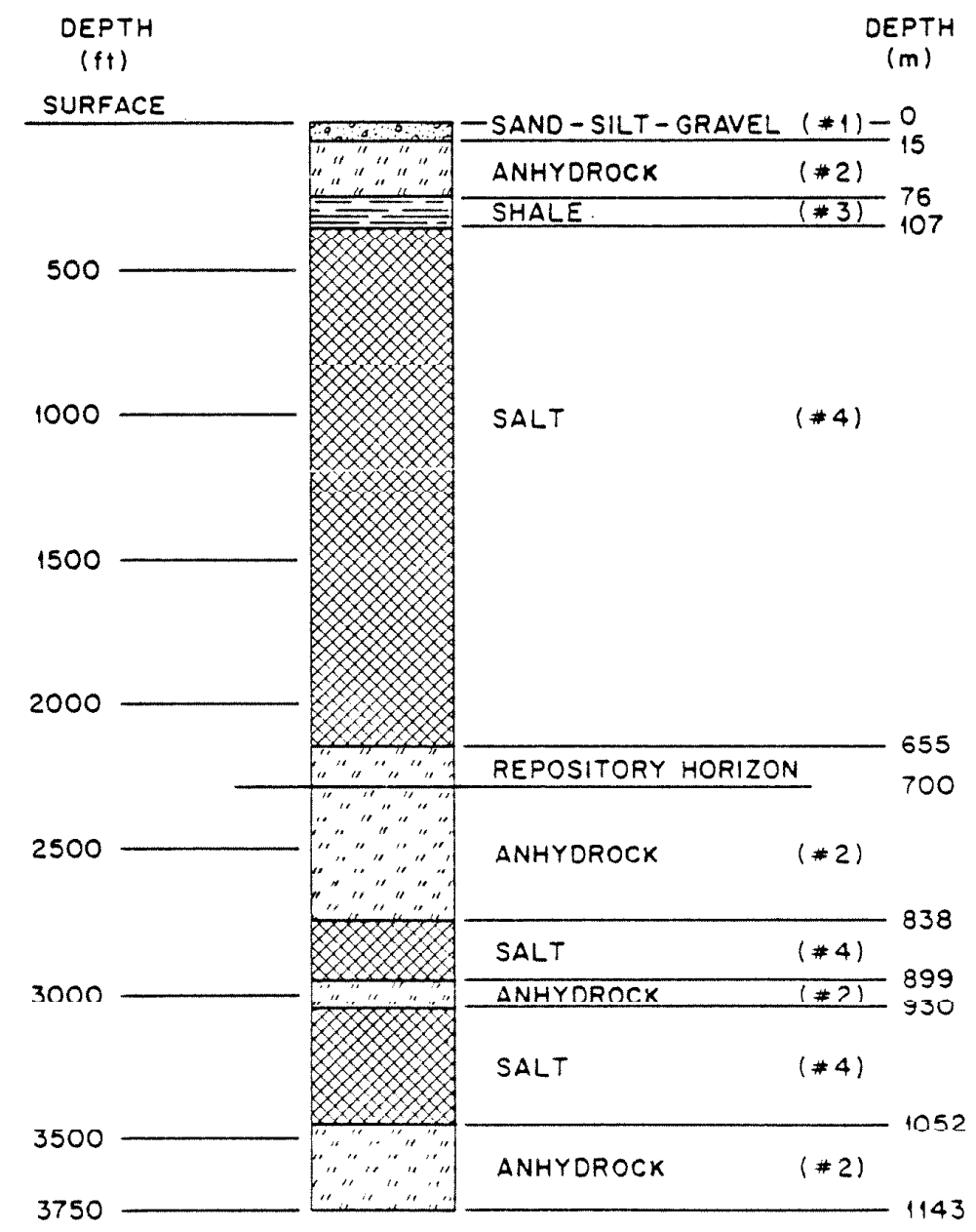

Hig. G.3.5. Generic stratigraphic section: anhydrock. 
ORNL OWG $84-994 R$

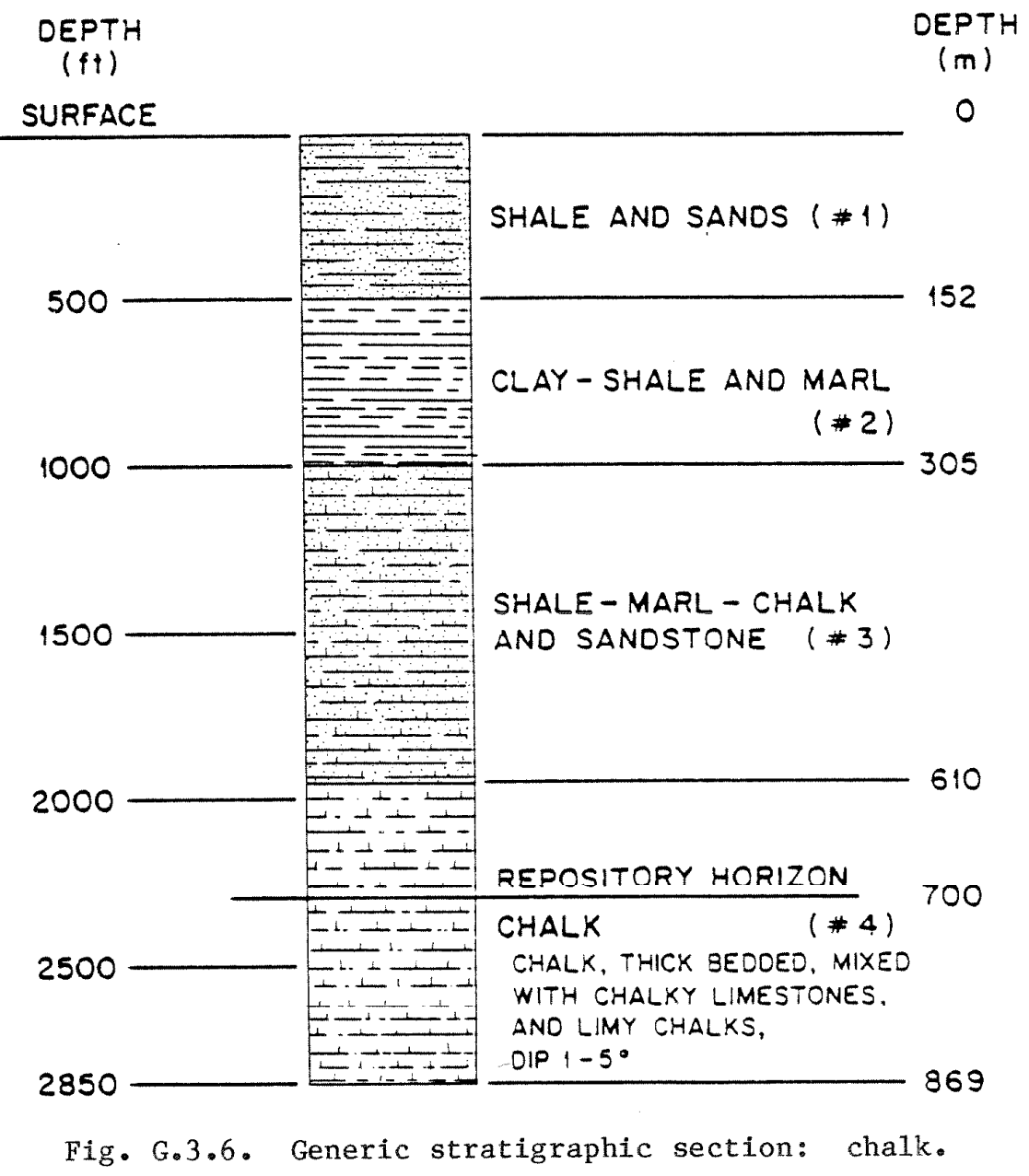


ORNL DWG $84-996 R 2$

DEPTH

( $f$ i)

DEPTH

(m)

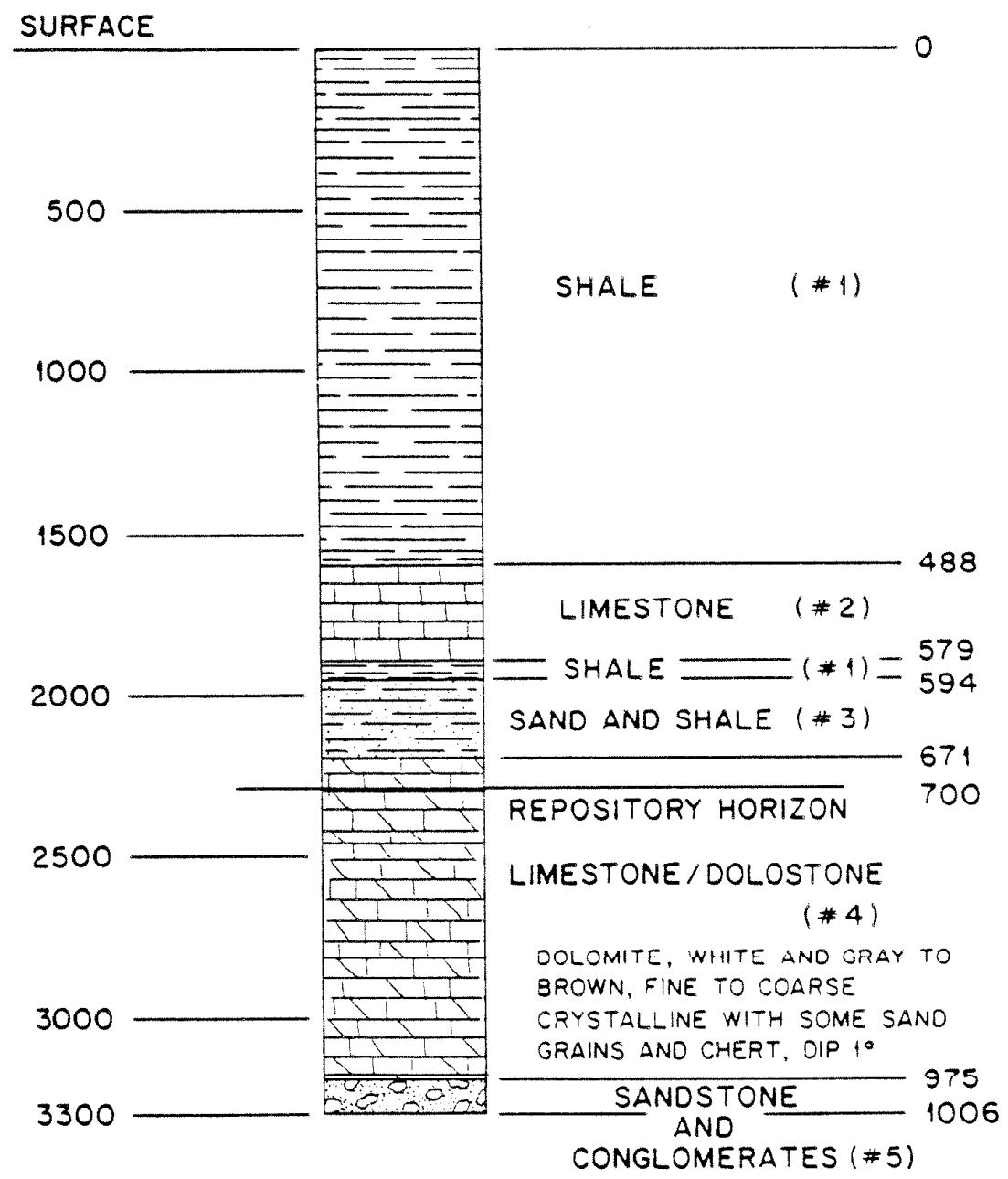

Fig. G.3.7. Generic stratigraphic section: carbonate rocks (limestone/dolostone). 
The uppermost $488 \mathrm{~m}$ is made up of shale underlain by $91 \mathrm{~m}$ of limestone. A thin, 15-m-thick shale unit is below the limestone followed by $77 \mathrm{~m}$ of sand and shale. The repository horizon is made up of $275 \mathrm{~m}$ of fine to coarse crystalline carbonate rocks with some sand grains and chert. The lowermost unit illustrated is made up of sandstone and conglomerate.

\section{G.3.3.4 Generic Stratigraphic Section: Sandstone}

Sandstone also occurs in a variety of enviroments, most often with finer-grained detrital material. Figure 6.3 .8 gives the generic stratigraphic section for sandstone. Shale, $610 \mathrm{~m}$ thick, overlies the repository host unit. The host unit is made up of very fine to medium-grained sandstone interbedded with layers of shale and siltstone.

\section{C.3.3.5 Generic Stratigraphic Section: Shale}

Shales, like carbonate rocks and sandstone, are common, occurring in a great number of depositional environments. The reference generic stratigraphic section for shale is given in Fig. G.3.9.

The uppermost $30 \mathrm{~m}$ is made up of sand, silt, and clay followed by $122 \mathrm{~m}$ of shale with some silt and sand. The repository host unit is $610 \mathrm{~m}$ of gray to dark gray, low carbon, illitic shale with minor silt and limestone. Underlying the repository host shale is limestone.

\section{G.3.4 DESCRIPTION OF SEDIMENTARY ROCK TYPES}

The five sedimentary rock types considered in this study are anhydrock, chalk, carbonate rocks (1imestone/dolostone), sandstone, and shale (argillaceous rock). One of the requirements of this study is to consider the generic properties of the rock types, that is, to be nonsite-specific and to use values representative of the entire rock type. This section describes the five sedimentary rock types.

\section{G.3.4.1 Anhydrock}

Anhydrock is a sedimentary rock composed chiefly of the mineral anhydrite that commonly occurs in finely granular masses and sometimes in fibrous or coarsely crystalline masses. It is typically uniformly bedded with a dense saccharoidal texture (GARY 1974). Anhydrock is found in massive to banded or thinly laminated beds often forming large beds associated with halite in evaporites. Limestone may be present in secondary amounts, and clastic materials are notably absent (POWERS 1978; PETTIJOHN 1975). Anhydrite is a mineral consisting of anhydrous calcium sulfate $\left(\mathrm{CaSO}_{4}\right)$. (The terms "anhydrock" and "anhydrite" are used interchangeably in the figures in Appendix G.)

\section{G.3.4.2 Cha1k}

Chalk occurs most commonly interbedded with or aceociated with limcy chalks and chalky limestones. The Glossary of Geology (GARY 1974) defines chalk as "a soft, pure, earthy, fine textured, usually white to 
ORNL DWG $84-997 R$

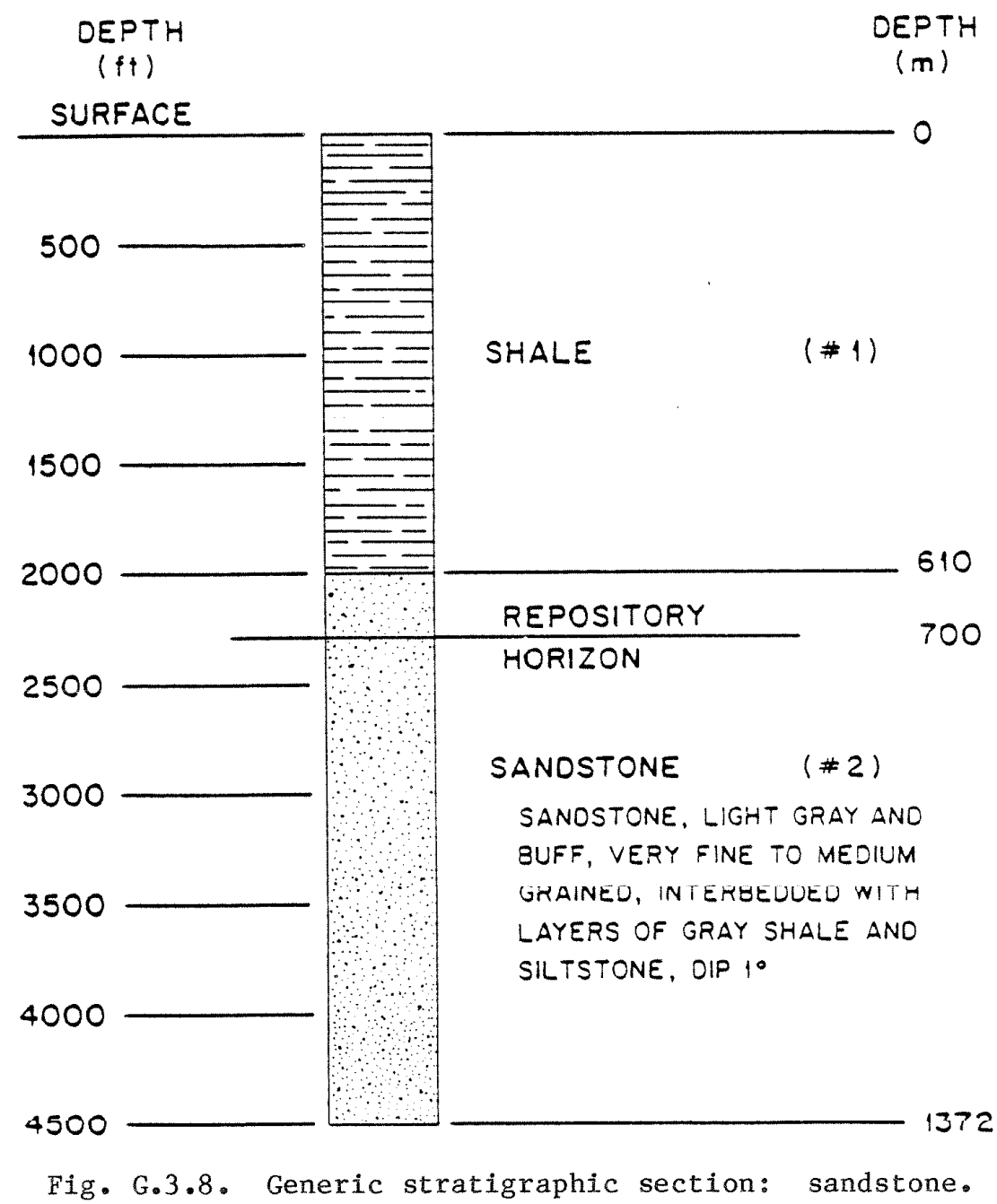


ORNL OWG 84-995R

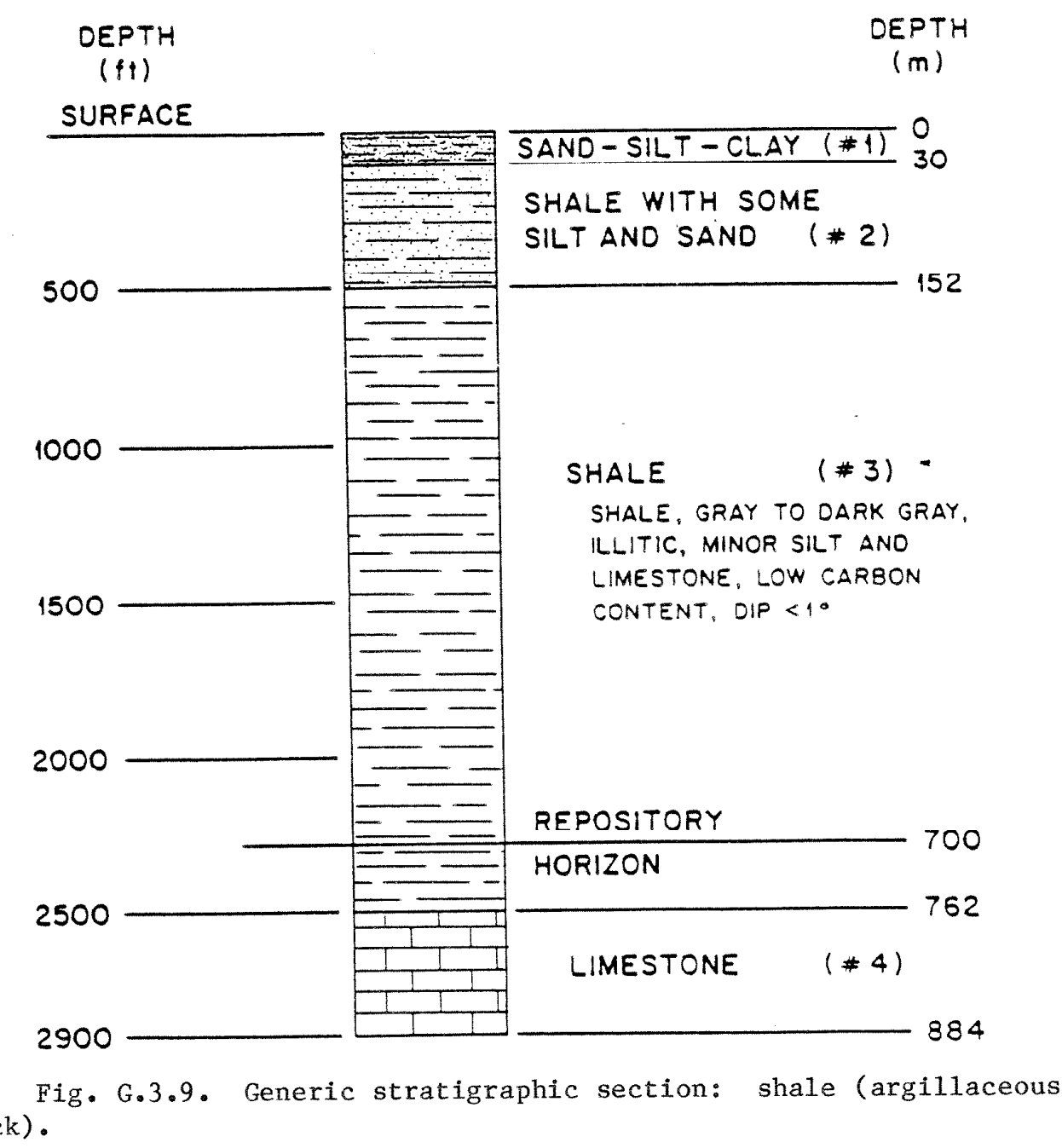


light gray or buff limestone of marine origin, consisting almost wholly ( 90 to $99 \%$ ) of calcite formed mainly by shallow water accumulation of calcareous tests of floating microorganisms (chiefly foraminifers) and of comminuted remains of calcareous algae (such as coccoliths and rhabdoliths) set in a structureless matrix of very finely crystalline calcite (some of which may have been chemically precipitated), and marked by a porous, somewhat friable, and indurated or slightly coherent character." Chalky limestones differ from true chalks in being less friable, harder, and more competent (GONZALES 1975). However, the chalky limestones are not nearly so dense or hard as the micritic limestones. Most of the chalk units that are of sufficient thickness to be considered for a repository host also contain appreciable amounts of shaley chalk or chalk with some fine-grained clastic materials.

\section{G.3.4.3 Carbonate Rocks (Limestone/Dolostone)}

Limestones and dolostones represent a very large category of sedimenlary rucks of very diverse fabric and origin. In general, the term limestone is applied to those rocks in which the carbonate fraction, calcite or dolomite (dolostone), exceeds the noncarbonate fraction. More specifical1y. the term limestone may be used for those rocks in which the carbonate fraction is composed primarily of the mineral calcite $\left(\mathrm{CaCO}_{3}\right)$, and the term dolostone is reserved for those rocks that are composed primarily of the mineral dolomite $\left[(\mathrm{Ca}, \mathrm{Mg})\left(\mathrm{CO}_{3}\right)_{2}\right]$.

Limestones are formed by inorganic and organic processes. They may be detrital, chemical precipitates, or recrystallized. Dolostone is clearly associated, and often interbedded, with limestone and usually represents a postdepositional replacement of limestone. For the purpose of this report, this category of carbonate rocks will be referred to as carbonate rocks (1imestone/dolostone). (The rock-type chalk is actually a subset of the carbonate group but is distinct in being made up chiefly of the tests of microorganisms.)

\section{G.3.4.4 Sandstone}

"Sandstone is a medium-grained, clastic sedimentary rock composed of abundant and rounded or angular fragments of sand-size set in a fine grained matrix (silt or clay) and more or less firmly united by a cementing material. - : The sand particles usually consist of quartz, and the term 'sandstone," when used without qualification, indicates a consolidated clastic rock containing 85 to $90 \%$ quartz sand" (GARY 1974).

\section{G.3.4.5 Shale}

Shale is a very general term commonly applied to almost any fine to very fine-grained sedimentary rock. The Glossary of Geology (GARY 1974) defines shale as "a fine-grained, indurated, detrital sedimentary rock formed by the consolidation (as by compression or cementation) of clay, silt, or mud, and characterized by finely stratified (laminae 0.1 to $0.4 \mathrm{~mm}$ thick) structure and/or fissility that is approximately parallel to bedding (along which the rock breaks readily into layers) and that is commonly 
most conspicuous on weathered surfaces, and by a composition with an appreciable content of clay minerals or derivatives from clay minerals and with a high content of detrital quartz; a thinly laminated or fissile claystone, siltstone, or mudstone. . . Shale is generally soft but sufficiently indurated so that it will not fall apart on wetting; it is less firm than argillite and slate, commonly has a splintery fracture and a smooth feel and is easily scratched."

As an aid to understanding what is commonly considered shale, the following definitions are also included from the Glossary of Geology (GARY 1974):

Clay: A rock or mineral fragment or a detrital particle of any composition (often a crystalline fragment of a clay mineral) smaller than a very fine silt grain, having a diameter $<1 / 256 \mathrm{~mm}$ (4 $\mathrm{\mu m})$. ..

Silt: A rock fragment or detrital particle smaller than very fine sand and larger than coarse clay having a diameter in the range of $1 / 256 \mathrm{~mm}$ to $1 / 16 \mathrm{~mm}(4$ to $62 \mu \mathrm{m})$.

Claystone: An indurated clay having the texture and composition, but lacking the fine lamination or fissility of shale; a massive mudstone in which clay predominates over silt. . .

Siltstone: An indurated or somewhat indurated silt having the texture and composition, but lacking the fine lamination or fissility, of shale; a massive mudstone in which silt predominates over clay....

Mudstone: (a) An indurated mud having the texture and composition, but lacking the fine lamination or fissility of shale; a blocky or massive, fine-grained sedimentary rock in which the proportions of clay and silt are approximately the same. . ( (b) a general term that includes clay, silt, claystone, siltstone, shale, and argillite and that should be used only when the amounts of clay and shale are not known or cannot be precisely identified. . . 


\section{G.4 EVALUATION CRITERIA}

This section summarizes the criteria used to evaluate the rock types that are the subject of the Sedimentary Rock Program. These criteria were derived from the DOE Site Screening Guidelines in Title 10, Part 960 of the U.S. Code of Federal Regulations (CFR 1984) and are discussed in detail by the Sedimentary Rock Program staff.

The evaluation criteria used in this study involve only the rock characteristics aspects; namely, the thermal characteristics of the host rock and mineability and excavation stability. These criteria are a subset of the overall evaluation criteria presented in Table G.4.1 and represent only those items currently addressed in the SRP. These overall criteria are organized into three major sections reflecting their relative importance to site screening, namely:

- expccted postelosure repooitory performance,

- processes and events potentially disruptive to repository performance, and

- preclosure repository performance.

As noted above, the analyses presented in this study address only two of these criteria; namely, the thermal characteristics of the host rock (weight factor $=3.0$ ) and mineability and excavation stability (weight factor $=1.0$ ). These criteria are addressed further in the development of repository performance constraints (Sect. G.5).

Table G.4.1. Rock characteristics evaluation criteria

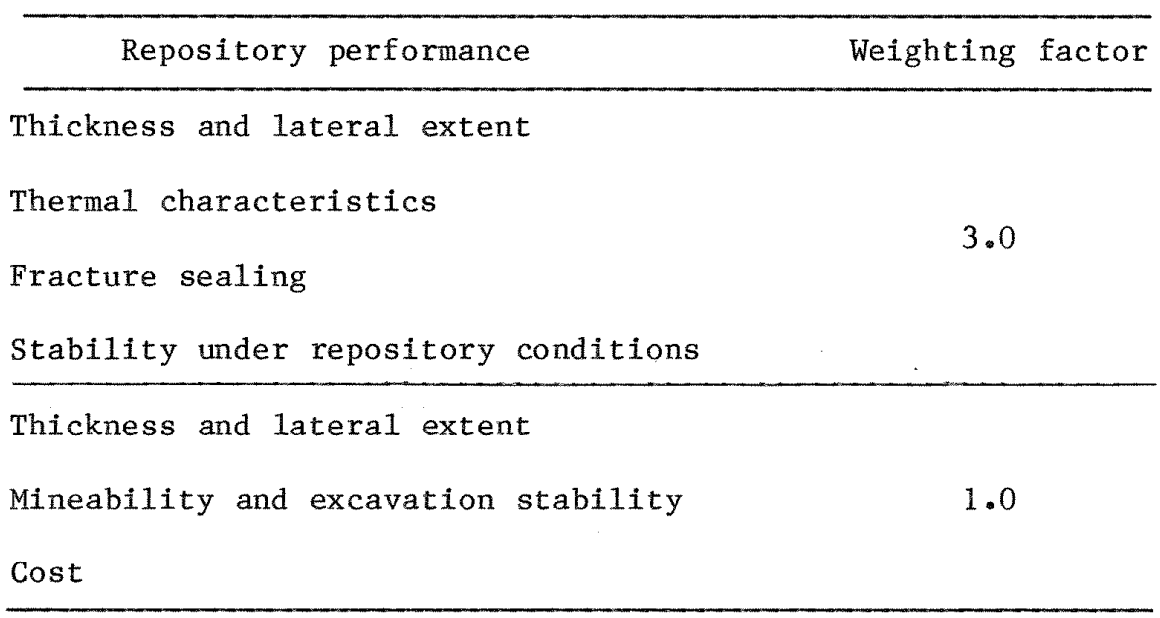




\section{G.5 REPOSITORY PERFORMANCE CONSTRAINTS}

Performance constraints have been used extensively in the Civilian Radioactive Waste Management (CRWM) Program for evaluation of repository designs in various geologic media. The NWTS Far-Field Performance Constraints Working Group was established to identify the performance limits on the far-field response for repositories in salt, basalt, granite, and tuff. More recent1y, Johnstone and Gnirk (JOHNSTONE 1982) established performance constraints for nuclear waste disposal in tuff. Finally, performance constraints have been specified for repositories in salt (BSPCWG 1984) and crystalline rock (CRPCWG 1984). The specific manner in which performance constraints were applied to sedimentary rock and how they relate to the evaluation criteria (Sect. G.4) is given below.

Three time periods have been previuusly derined (U.S. NRC 1983) in evaluating the performance of a nuclear waste repository. These three are the operational, the containment, and the isolation periods. The operational period covers the time that the repository is open following construction. Its duration, without retrieval, is taken to be 40 years (i.e., 30 years for waste emplacement and repository demonstration, 5 years for room backfilling, and 5 years for repository closure and decommissioning). For this study, it was assumed that the demonstration period for a given disposal room is 5 years; (i.e., each room is to remain open for 5 years before it is backfilled). The containment period follows closure and decommissioning of the repository and extends through the time that radioactivity levels and heat production in the waste are dominated by fission product decay. Containment duration, as defined by NRC regulations (U.S. NRC 1983), can range from 300 to 1000 years after emplacement, depending upon thermal conditions resulting from fission product heating. For the purposes of this analysis, the waste package was assumed to have a design life of 1000 years. Thus, containment duration is defined as 1000 years. The isolation period is characterized by decay of actinides and their daughters and extends for a minimum period of 10,000 years, during which geologic isolation must be demonstrated.

Constraints on repository performance can be expressed both qualitatively and quantitatively. While determination of performance constraint values in the form of numerical limits is highly desirable, several factors tend to prevent quantification, namely: (1) the constraint may arise from a variety of phenomena that individually or collectively may not be fully understood; (2) the constraint may arise from site-specific conditions and properties; and (3) the constraint may result from a specific design choice.

Consequently, interim performance constraints have been established at the qualitative leve1 (Table G.5.1) and, where possible, at the quantitative level (Table G.5.2). The qualitative constraints are fairly consistent among the various geologic media and have been applied to odimentary rock in this study. The qualitative constraints encompass 


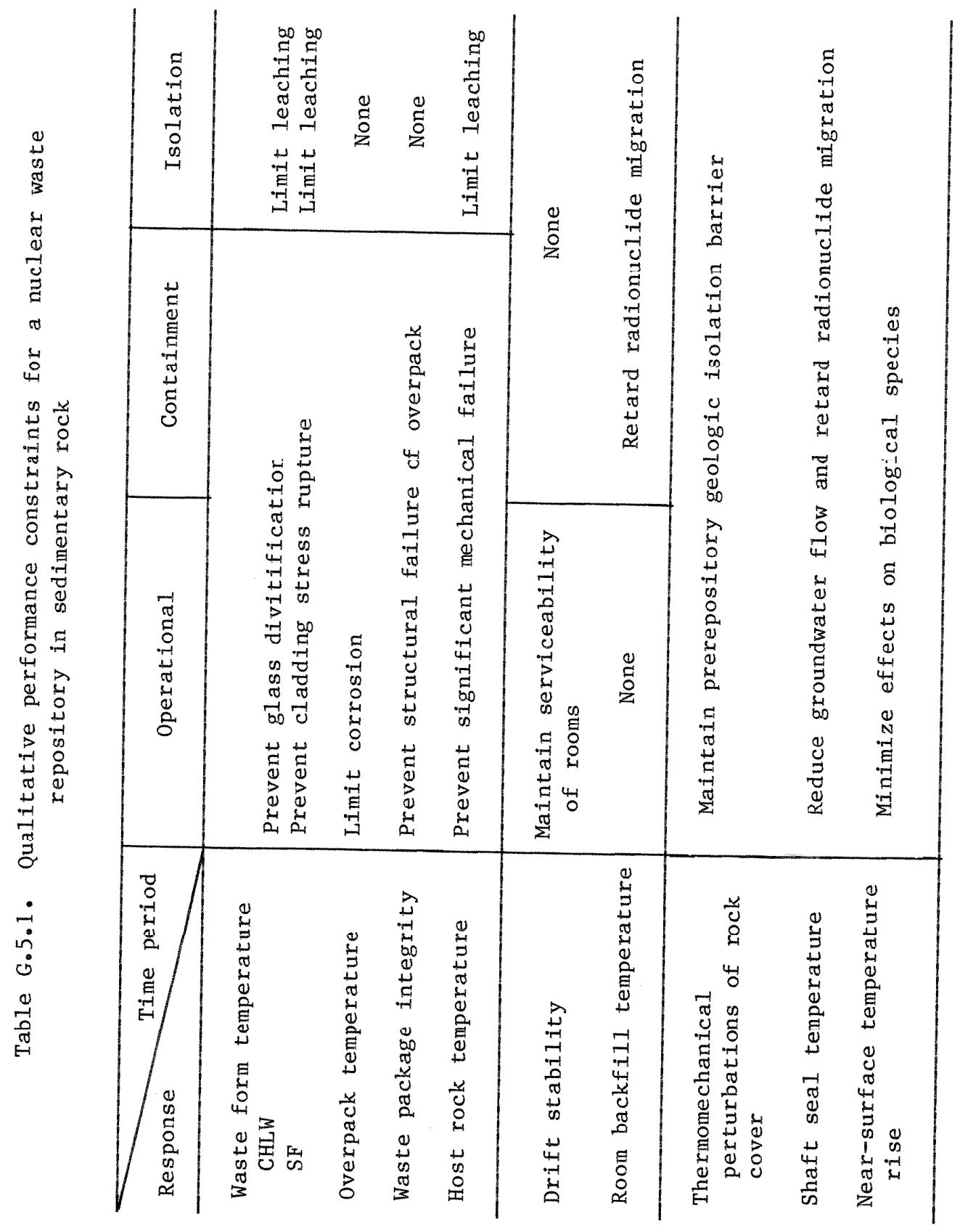


Table G.5.2. Quantitative performance constraints for a nuclear waste repository in sedimentary rock

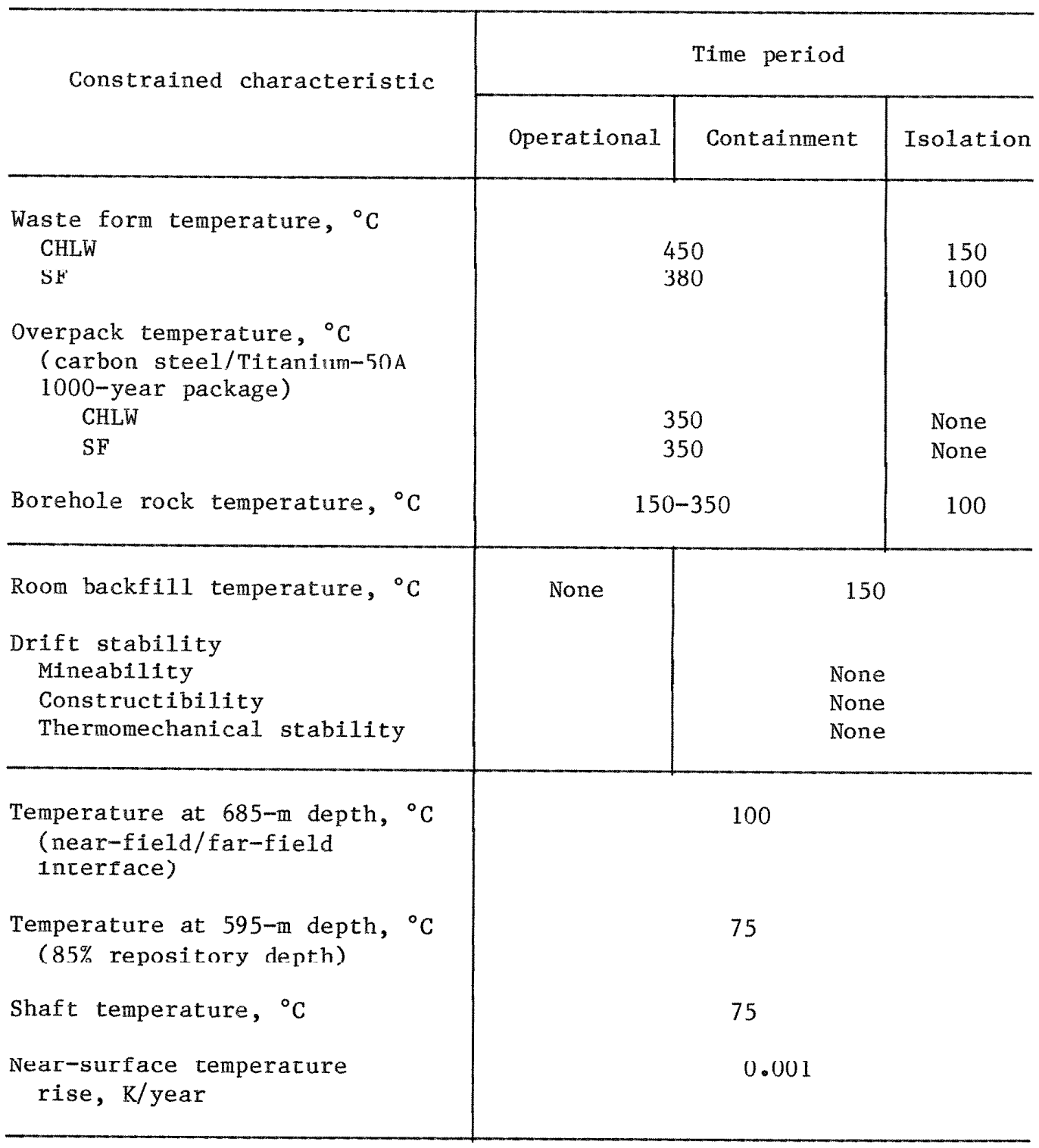


the presently perceived range of repository-induced responses that could be detrimental to the functional performance of the waste package, the engineered workings, the site geology, and the surrounding accessible environment. The qualitative constraints in this table are an abbreviated list from the nore extensive compilations given by The Crystalline Repository Performance Constraints Working Group (CRPCWG 1984) and The Far-Field Performance Constraints Working Group. Only those constraints that are applicable to sedimentary rock and are specifically addressed in the modeling efforts of this current study are included in Table 6.5 .1 . The quantitative constraints represent numerical limits (or ranges) imposed upon the above responses for specific sedimentary rock types and sites and identified repository designs. The quantiative limits shown in Table 6.5 .2 specifically address the rock types and the conceptual repository designs presented in Sect. G.3.

The responses that were examined in this study are summarized in Table G.5.3. Thermal responses of the waste package, the disposal room, and the site were examined using finite element models (described in Sect. G.7.1). Mineability, constructibility, and operational stability of the disposal room were examined using boundary element techniques in conjunction with an established empirical method (HOEK 1980) described in Sect. G.7.2. These responses are consistent with the quantitative performance constraints. Each response was examined only during the time period it is expected to be of concern.

These responses were used to compare the five sedimentary rocks qualitatively for CHLW and SF emplacements. The overall thermal performance of each rock type was evaluated based on a weighted average of al1 the thermal responses. This thermal performance is one of the evaluation criteria (Table G.4.1) examined in this study. The mineability, constructibility, and operational stablity mechanical rankings are used to evaluate the preclosure mechanical criteria (Table G.4.1). Background information concerning the selection of the quantitative limits shown in Table G.5.2 follows.

\section{G.5.1 WASTE FORM TEMPERATURE}

For the sake of technical conservat1sm, a waste form temperature constraint was specified for both CHLW and SF. This constraint was established to ensure the integrity of the waste form and, thus, to assist in providing a "reasonable assurance" that the NRC-defined performance criteria regarding the waste package are satisfied (U.S. NRC 1983). Specifica11y, those criteria require substantial containment of all radionuclides within the waste package throughout the operational and containment periods. This constraint on the waste form temperature is to be applied to all repository designs, independent of site.

\section{G.5.1.1 Commercial High-Level Waste}

The waste form temperature limits in Table G.5.2 for the case of CHLW are based on the potential for devitxification of borosilicate glass. Comsquenly, a temperabure limil of $450^{\circ} \mathrm{C}$ lias betu applied lo 
Table G.5.3. Sedimentary rock repository responses

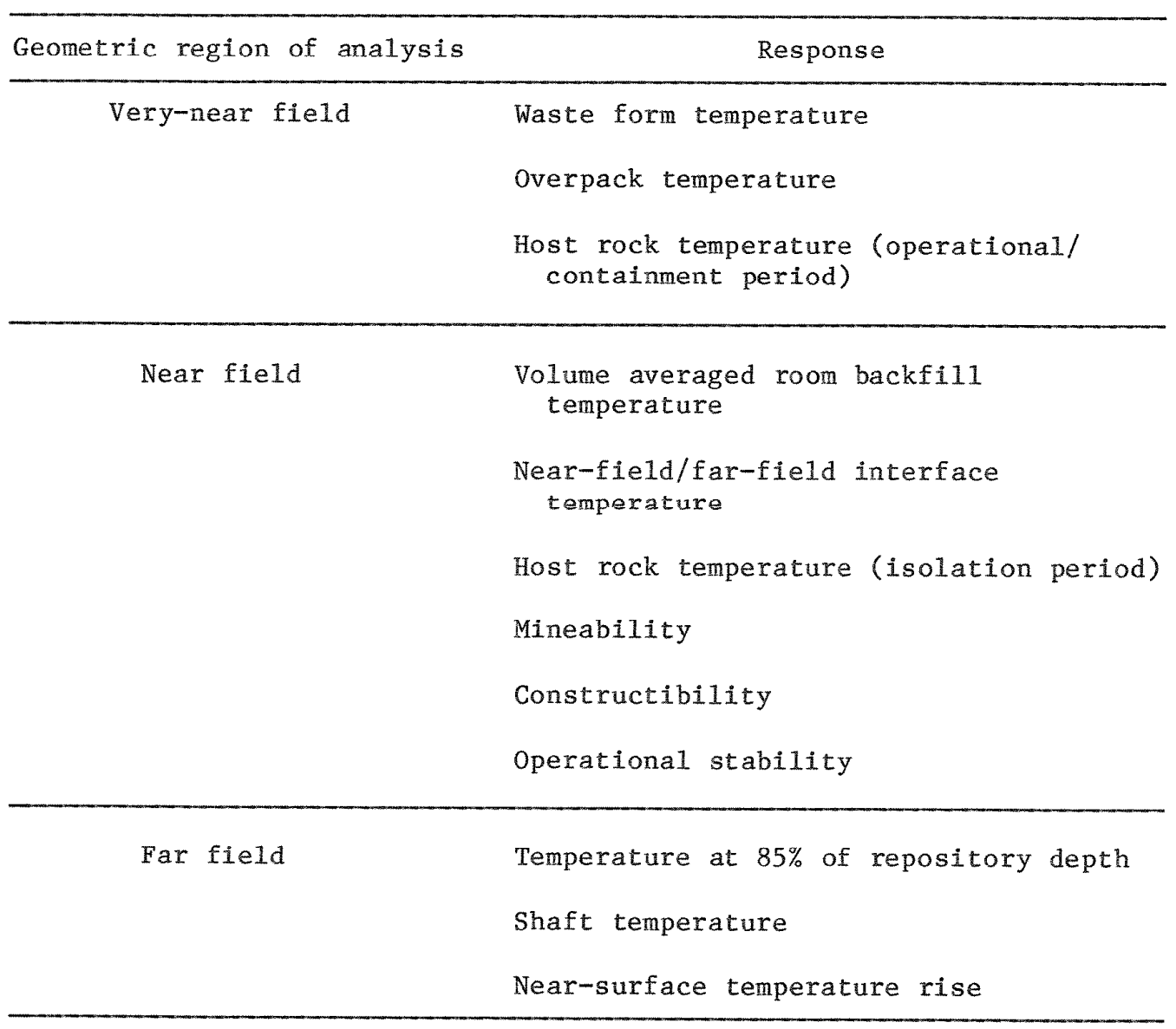

CHLW during the operational and containment periods. The objective of the isolation perind waste form temperature constraint is to limit the leaching and dissolution rates once the waste package has been breached. A temperature 1 imit of $150^{\circ} \mathrm{C}$ has been established for CHLW during the isolation period. For this study, the transition from containment to isolation period is defined as 1000 years (i.e., the waste package is assumed to have a design life of 1000 years). These limits are consistent with the recommendations of The Crystalline Repository Performance Constraints Working Group (CRPCWG 1984).

\section{G.5.1.2 Spent Fue1}

A temperature 1 imit of $380^{\circ} \mathrm{C}$ for the $\mathrm{SF}$ waste form is applicable during the operational and containment periods. This limit is based 
upon the potential for stress rupture of Zircaloy cladding (BLACKBURN 1978). The isolation period temperature 1 imit of $100^{\circ} \mathrm{C}$ is based upon the concern for potential oxidation of $\mathrm{UO}_{2}$, in the oxidizing atmosphere created by self-generated alpha radiation, that could lead to increased $\mathrm{JO}_{2}$ solubility and dissolution rates. As with the CHLW, these SF temperature limits are consistent with the recommendations of The Crystalline Repository Performance Constraints Working Group (CRPCWG 1984).

\section{G.5.2 OVERPACK TEMPERATURE}

Overpack temperature limits have been set to limit the corrosion of the waste package to within the overpack throughout the operational and containment periods (i.e., to prevent the groundwater from contacting the waste form during the first 1000 years following emplacement). Uverpack temperature constraints were calculated previous to this study for similar repository designs in crystalline rock (RATIGAN 1984) assuming that the corrosion rate is independent of corrosion product accumulation ( $i \ldots .$, pitting) and the overpack remains continuous ( $i . e .$, no cracking). Corrosion is assumed to be governed by an equation of the form:

$$
R(T)=A \exp (-B / T)
$$

where:

$$
\begin{aligned}
& \mathrm{R}=\text { corrosion rate, } \mathrm{mm} / \text { year, } \\
& \mathrm{A}=\text { constant determined from laboratory experiments, mo/year, } \\
& \mathrm{B}=\text { constant determined from laboratory experiments, } \mathrm{K}^{-1}, \\
& \mathrm{~T}=\text { temperature, } \mathrm{K} .
\end{aligned}
$$

In the current study, one type of overpack was considered for both waste types, namely, carbon steel with an outer she11 of Titanium-50A. The Titanium-50A was assumed to be 3.2 and $4.0 \%$ of the total overpack thickness of the $\mathrm{SF}$ and CHI,W parkages, respectively. These percentages are based on the titanium thickness suggested by Westinghouse Electric Corporation (WESTINGHOUSE 1983b), $0.25 \mathrm{~cm}$, compared with the carbon steel overpack thicknesses of the reference waste package designs discussed in sect. G.3.

For both waste forms, the use of Titanium-50A permits a maximum overpack temperature much greater than $350^{\circ} \mathrm{C}$. Thus, a maximum overpack temperature of $350^{\circ} \mathrm{C}$ appears reasonable as a conservative limit for sedimentary rock types considered in this study and reflects uncertainties in the waste package design, initial conditions, material properties, and corrosion formulation. 
A borehole surface temperature limit has been established to preserve the structural integrity of the host rock surrounding the waste package throughout the operational and containment periods. For sedimentary rock types, this integrity considers phenomena such as chemical conversion of the mineral structure of the host rock, decrepitation (or disintegration), and thermal spalling, which are all considered undesirable since they reduce the thermal conductivity of the host rock and, consequently, reduce the heat dissipation from the waste package, increase the potential for water inflow into the emplacement borehole, and increase the rock pressure exerted along the waste package.

The temperatures that produce these results depend on many factors, such as in situ stresses, borehole geometry, and particularly rock type and mineralogy. For argillaceous rock, the chemical conversion from smectite to illite usually occurs at temperatures ranging from 125 to $150^{\circ} \mathrm{C}$ (IOHNSTON 1983), while for crystalline rock spalling would not occur until the borehole surface is heated to $350^{\circ} \mathrm{C}$, based on the Stripa experience (HOOD 1979). Decrepitation of some halites can occur at temperatures as $10 \mathrm{w}$ as $250^{\circ} \mathrm{C}$ (BRADSHAW 1971). The disaggregation of sulfates (anhydrock) and carbonate rocks (limestone or dolostone) occurs, in all probability, at temperatures bounded by the above-mentioned limits for argillaceous and crystalline rocks. Thus, a range in this constraint seems most appropriate at present to encompass all sedimentary rock types in a generic sense (i.e., 150 to $350^{\circ} \mathrm{C}$ ). Future quantification of this constraint should consider the mineralogy of each rock type on a site-specific basis. This constraint is applicable during the operational and containment periods.

A temperature limit of $100^{\circ} \mathrm{C}$ has been established as a performance constraint for repository designs in crystalline rock (CRPCWG 1984) and bedded salt (BSPCWG 1984). The primary concern during the isolation period is waste leaching because of expected contact between the waste form and the groundwater. A temperature limit of $100^{\circ} \mathrm{C}$ means that the groundwacer in contact with the waste torm should be below its boiling point.

\section{G.5.4 DISPOSAL ROOM BACKFTT.T. TFMPFRATIIRF.}

The disposal room backfill temperature constraint of $150^{\circ} \mathrm{C}$ is based on the concern for conversion of smectite to illite. For sedimentary rock reposicory designs, this constraint is applicable since the assumed backfill is 50 wt \% bentonite (see Sect. G.3). This chemical conversion is expected to result in (1) an increase in permeability, (2) a decrease in the swelling capability of the backfill, and (3) a decrease in the absorptive capacity of the backfill. This conversion process can begin at temperatures as $10 \mathrm{w}$ as $85^{\circ} \mathrm{C}$, but usually occurs at temperatures between 125 and $150^{\circ} \mathrm{C}$ (JOHNSTON 1983). This constraint is applicable only during the contalnment period, since the rooms are assumed to be open during the operational period. 


\section{G.5.5 MINEABILITY}

Mineability involves the evaluations of the relative ease of excavation in a rock mass and subsurface conditions that may adversely affect personnel and equipment during excavation operations. The relative ease of excavation is based principally on the unconfined compressive strength and joint characteristics of a particular rock unit. In general, as the compressive strength increases, the method of excavation proceeds from the use of a continuous mining machine to conventional drilling and blasting, although the mineability of a rock relates somewhat to its fracture resistance and structural/textural variability. Required ventilation, dehumidifying, and water removal systems are related to temperature increase with depth and the existence of groundwater. Additionally, an increase in overburden stress follows directly with increasing depth and generally leads to increasing mining difficulties in the context of worker safety during the excavation and roof stabilization processes.

\section{G.5.6 CONSTRUCTIBILITY}

Constructibility involves evaluations of pillar and room stabilities on the basis of rock matrix properties and root span stability and necessary support requirements on the basis of rock mass classification. For the evaluation of pillar and room stabilities on the basis of rock matrix properties, unconfined compressive strength, Poisson's ratio, and Young's modulus are considered. In this regard, these rock matrix properties are used in the boundary element model to determine to what degree each property can be used as a ranking criterion for constructibility over the entire range of in situ stresses considered possible in the rock types under examination. Rock mass classification methods are not used in this study because of the lack of the specific data required for their application.

\section{G.5.7 OPERATIONAI STABILITY}

In the context of this study, operational stability relates to the ability of the opening to remain serviceable during the first 5 years of the repository operational period when the rock is undergoing heating and the rooms are not backfilled. For the purpose of this study, the rooms were assumed to be backfilled at 5 years. Thus, the constraint on operational stability is appropriate at 5 years, even though $10 \mathrm{CFR} 60$ specifies a 50-year room serviceability since the backfill material is assumed to provide structural stability to the rooms at times between 5 and 50 years. Evaluation of operational stability requires consideration of the thermally induced stresses.

\section{G.5.8 SITE GEOLOGY TEMPERATURES}

The far-field constraints are associated primarily with the thermal and hydrogeological environments of the overlying strata during the containment and isolation periods. For technical conservatism, the far-field constraints were required to provide a "reasonable assurance" 
that the site satisfies the current recommended U.S. Nuclear Regulatory Commission (U.S. NRC 1983) criteria. The criterion regarding the site specifies a minimum groundwater transit time of 1000 years from the repository horizon to the accessible environment. Recently, The NWTS Far-Field Performance Constraints Working Group recommended that this criterion could best be met by ensuring that the thermomechanical perturbations or disturbances to the site be minimized. In this regard, they have chosen to establish a constraint relative to the amount of thermomechanical damage or disturbance to the rock cover. This approach implicitly assumes that one is capable of selecting a site with an in situ travel time of 1000 years before repository construction and operation.

This constraint encompasses both a thermal and a mechanical response of the ovcrlying otrata. Howcver, only the thermal aspecte (which consider the thermal disturbance to the site immediately surrounding the repository) were considered in this analysis. It is hoped that future studies consider the mechanical aspects that address the near-surface mechanical disturbance.

Enhanced temperatures may lead to a number of chemical effects in the far-ficld rogion. Mincrale may become unetable, and reactions may occur that reduce their volume or reduce the radionuclide retention capability of fracture-filling minerals. For nuclear waste disposal in bedded stratigraphies, the primary thermochemical concern is the stability of the overlying aquitards.

Clay minerals occur widely in sedimentary sequences, as clay seams in salt strata and as secondary minerals in igneous rocks. Clay minerals can undergo dehydration and other changes on heating, and these changes may commence at relatively lower temperatures, $\sim 100$ to $200^{\circ} \mathrm{C}$ (GRIM 1953 ).

To minimize the thermochemical perturbations in the far-field rock mass, The Far-Field Performance Constraints Working Group recommended the following thermal performance constraints: (1) temperatures do not exceed $100^{\circ} \mathrm{C}$ for all sedimentaxy rock types anyrhere in the region that extend outward from the repository near-field to a distance equal to $15 \%$ of the repository depth; and (2) temperatures do not exceed $75^{\circ} \mathrm{C}$ anywhere outside of the region defined above.

Thus, for a repository depth of $700 \mathrm{~m}$ for all sedimentary rock types, a maximum temperature of $100^{\circ} \mathrm{C}$ is to be applied at a depth of $685 \mathrm{~m}$ (i.e., approximately one-half pillar width above the disposal room) and a temperature limit of $75^{\circ} \mathrm{C}$ is to be applied at a depth of $595 \mathrm{~m}$ (i.e., $85 \%$ of the repository depth). The $75^{\circ} \mathrm{C}$ temperature constraint is also applicable to the shaft seal at the shaft bottom along the repository horizon (see Fig. G.7.4). These thermal constraints for the site are applicable throughout the life of the repository (i.e., 10,000 years) for all sedimentary rock types.

\section{G.5.9 NEAR-SURFACE TEMPERATURE RISE}

The near-surface thermal constraints are established to ensure negligible perturbation of the near-surface environmental regime. The 
thermal perturbation of the near-surface environment (defined to a depth of $5 \mathrm{~m}$ ) should be less than the thermal variation that occurs naturally. This depth, although arbitrarily selected, should be sufficient to encompass most biological species. The mean natural surface temperature variation for the North American continent ranges from 0.001 to 0.005 $\mathrm{K}$ /year (NATIONAL RESEARCH COUNCIL 1983), the minimum of which has been included as a performance constraint for a repository in sedimentary rock applied at an assumed depth of $5 \mathrm{~m}$. This constraint is applicable throughout the life of the repository. 


\section{G.6 ROCK PROPERTIES}

\section{G.6.1 METHODS}

The evaluation of the five sedimentary rock types requires a knowledge of representative values of various physical, mechanical, and thermal properties for each rock type. Relevant literature was examined to compile a list of intact rock properties as determined by laboratory experiments. This literature search was aided by using the computeraccessed data bases of Infoline by Pexgamon International Information Corporation and Knowledge Index by Dialog Information Services, Inc. Rock properties of interest for this study include:

- unconfined compressive strength,

- Young's modulus,

- Poisson's ratio,

- angle of internal friction,

- thermal conductivity,

- heat capacity,

- coefficient of thermal expansion, and

- mass density.

The physical and mechanical properties of all rock types, except chalk, have been extensively investigated and are well represented in the 1iterature. of the thermal properties, only thermal conductivity has been well examined. The mechanical and thermal property values compiled in this literature search are included as Sect. G.13.

These data 1ists and summaries must be used with prudence. As in any compilation from published literature, the integrity of the compiled data depends on the methods and descriptions of the original researcher. For the data compilation, every attempt was made to reference the original published work and to ascertain that the data are in fact, appropriate. Petrographic descriptions of most of the tested rocks are absent or incomplete. As stated above, these values represent intact rock properties for laboratory tests. Rock mass properties are inherently different than intact rock properties because of the naturally occurring joints, fractures, and other planes of weakness within the rock mass. These data lists and summaries are intended to be used to compare the broad rock types relative to each other.

Each of the five sedimentary rock types encompasses a very wide range of variability in composition and fabric. Similarly, the physical, mechanical, and thermal properties show very wide ranges. A 
summary of the statistics of each property examined is given in Sect. G.12. Tables G.12.7 through G.12.10 summarize the values for the mechanical properties and Tables G.12.17 through G.12.20 summarize the values for the thermal properties. The distributions of data points for each property are also included as Figs. G.12.5.1 through G.12.5.3. and Fig. G.12.6.1. These frequency plots are presented where the number of data points permitted.

\section{G.6.2 MATERIAL PROPERTIES}

\section{G.6.2.1 Mechanical}

Table G.6.1 gives the mean values and standard deviations of unconfined compressive strength, angle of internal friction, Poisson's ratio, and Young's modulus for each of the five rock types. Only those tests that were conducted at room temperature on dry sperimens are included in this tabulation. Carbonate rocks (1imestone and dolostone), as indicated in the literature, are listed in individual tables in Sect. G.12.5, but are combined here. The range from the mean value minus one standard deviation to the mean value plus one standard deviation is taken to represent the plausible range of values for a typical rock type. The range of unconfined compressive strength values for each rock type is illustrated in Fig. G.6.1. Carbonate rocks show the highest mean value, 107.3 MPa, with anhydrock second highest, 92.6 MPa. Shale and sandstone fall close together at $69.4 \mathrm{MPa}$ and $65.9 \mathrm{MPa}$, respectively, and chalk has the lowest mean value of $17.5 \mathrm{MPa}$.

The ranges of values for Young's modulus and Poisson's ratio are shown in Figs. G.6.2 and G.6.3. Anhydrock shows the highest mean value of Young's modulus at $64.1 \mathrm{GPa}$, and chalk has the lowest value of $6.8 \mathrm{GPa}$. Anhydrock has the highest mean values of Poisson's ratio at 0.34 , while shale and sandstone show the lowest mean values of 0.21 and 0.20 , respectively. Some values of Poisson's ratio $>0.50$ are reported in the 1iterature. These are included in the daca lists buc excluded from the tabulation of statistics. Reported values of the internal angle of friction are included in sect. G.12.5. The ranges are shown in Fig. 6.6.4. The highest mean value is $44.8^{\circ}$ for anhydrock and chalk has the lowest, $17.0^{\circ}$. Carbonate rocks, sandstone, and shale have mean values of $41.9^{\circ}, 41.0^{\circ}$ and $32.6^{\circ}$, respectively.

\section{G.6.2.2 Therma1}

The thermal rock property values and initial conditions used for the thermal modeling are given in Table G.6.2. Generally, the values given for each property represent the mean, mean minus one standard deviation, and mean plus one standard deviation of the total data set. Some exceptions are noteworthy: (1) anhydrock has been most extensively studied in southeast New Mexico at the Waste Isolation Pilot Plant (WIPP) site. Most of the values used in the modeling of anhydrock are extracted from a set of accepted values from that location (KREIG 1983); (2) similarly, the shale values used in the thermal modeling are drawn chiefly from Kibbe and Boch (KIBBE 1978), for a "typical" illite shale. The summary 


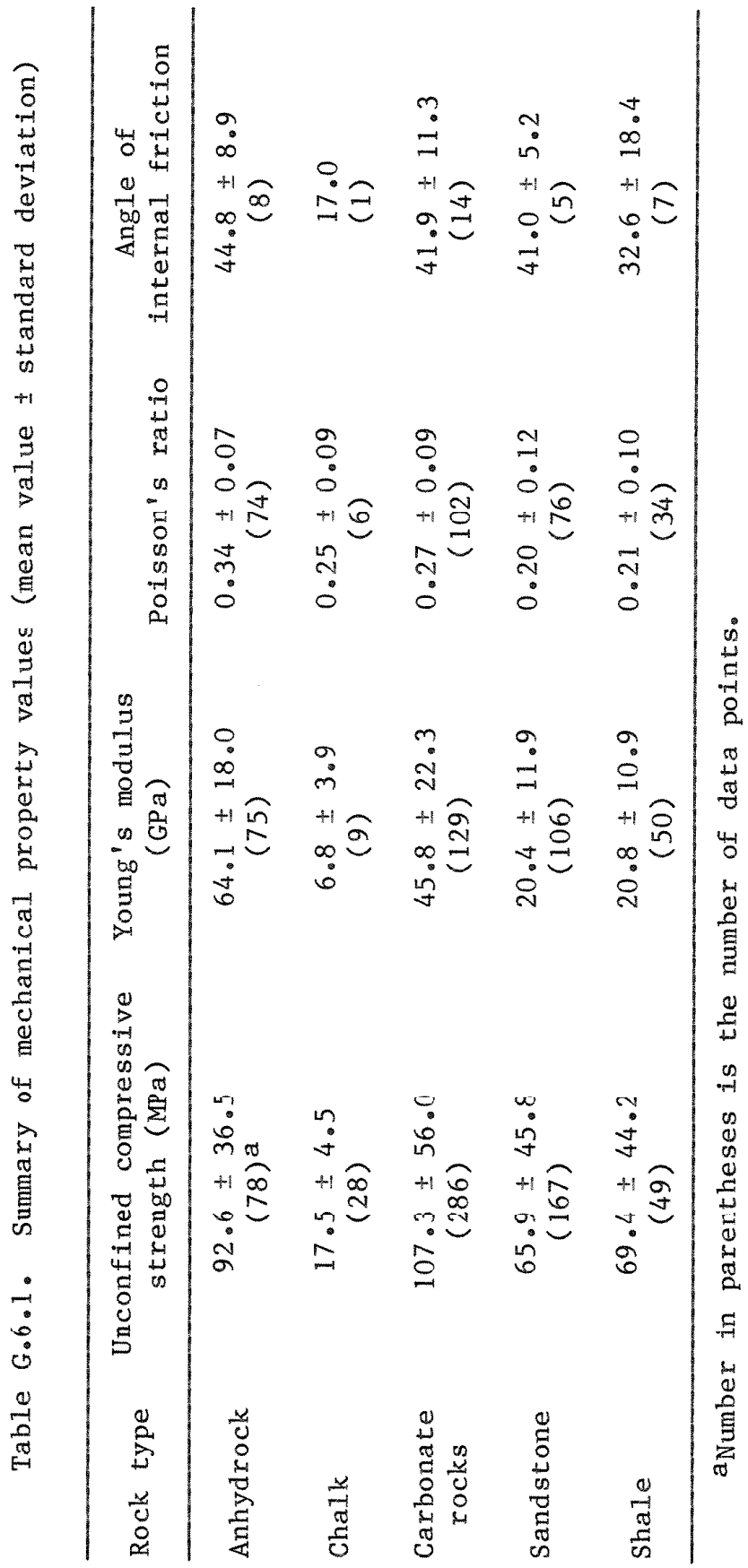



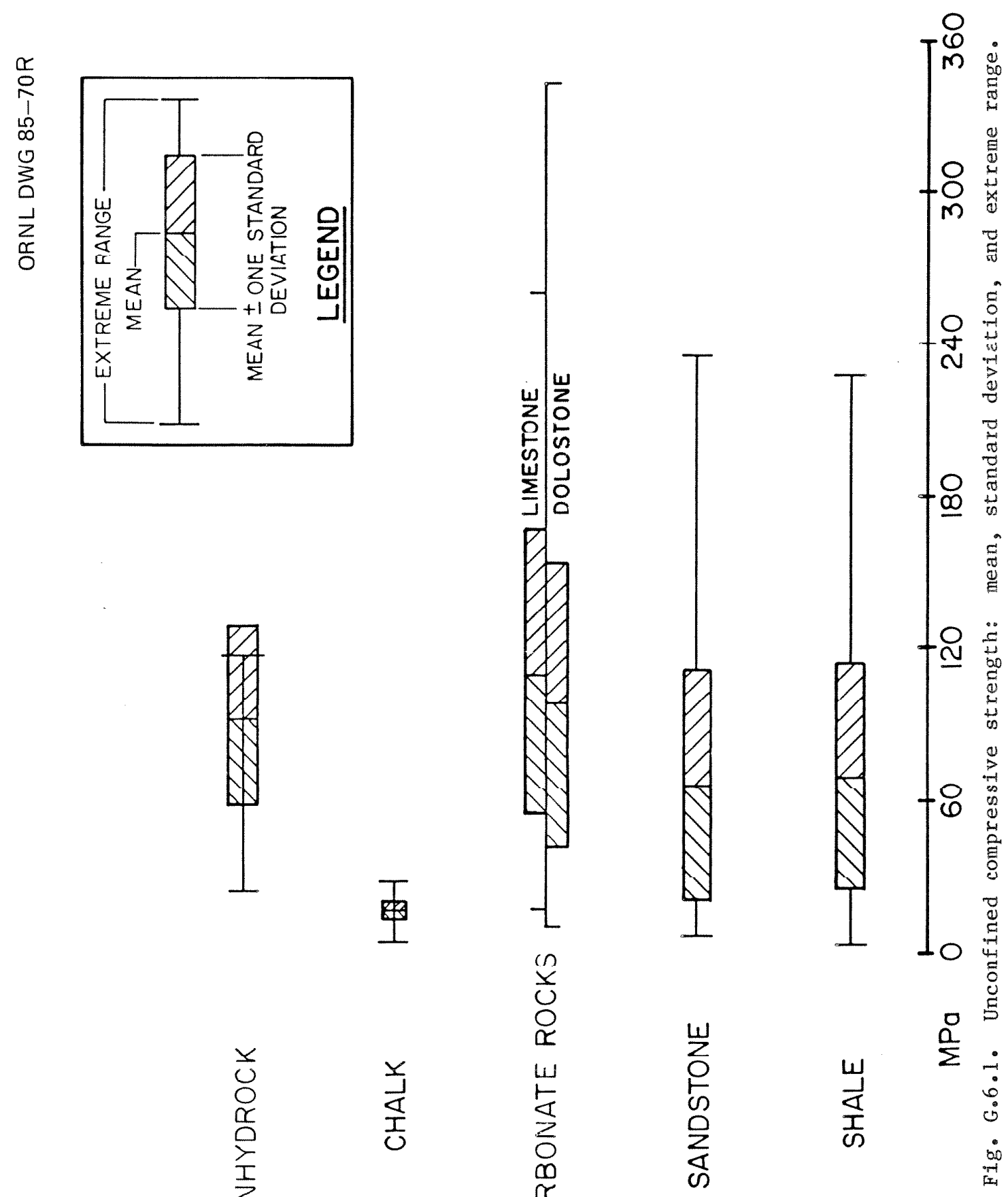


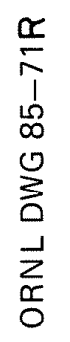
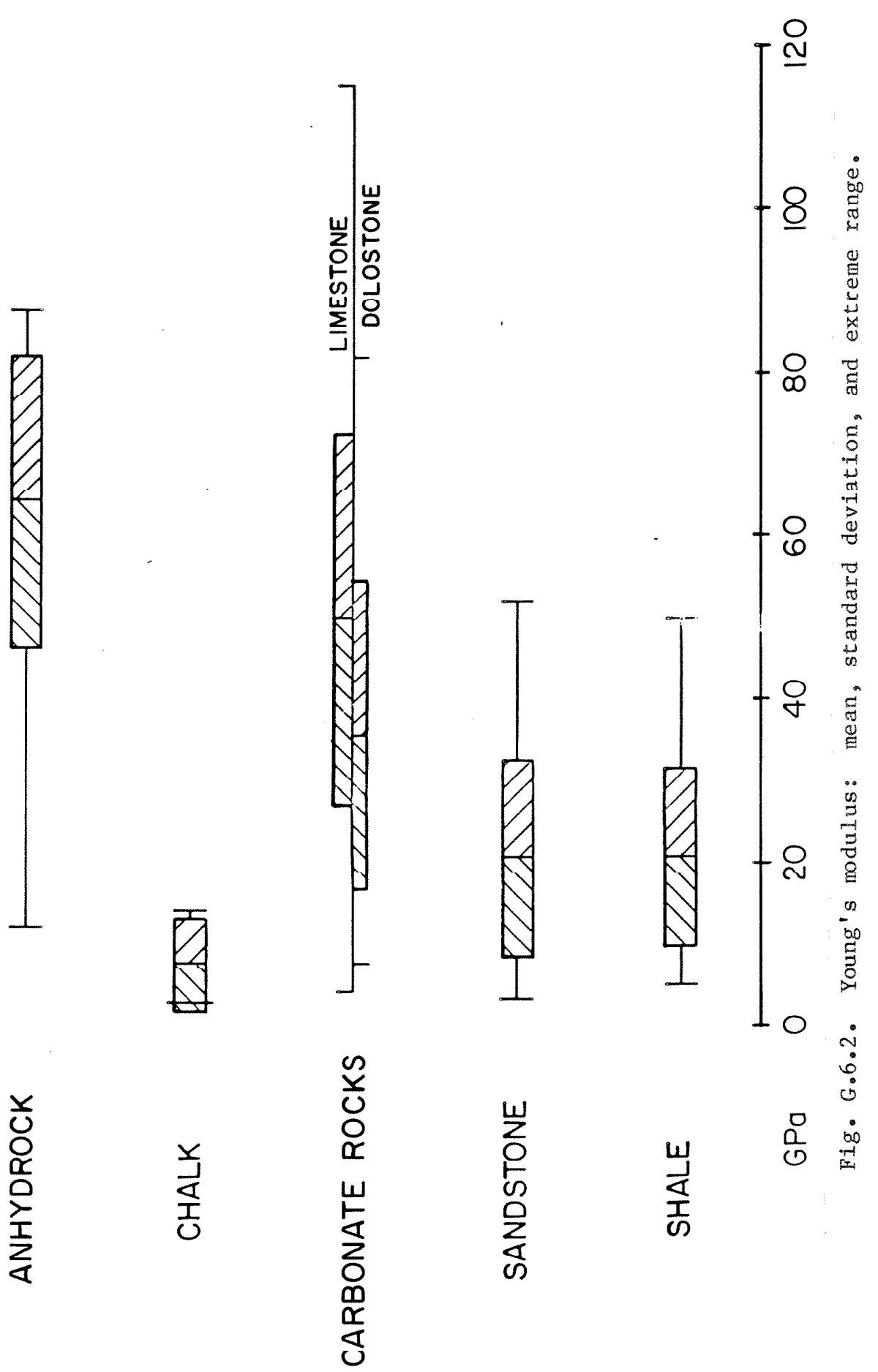

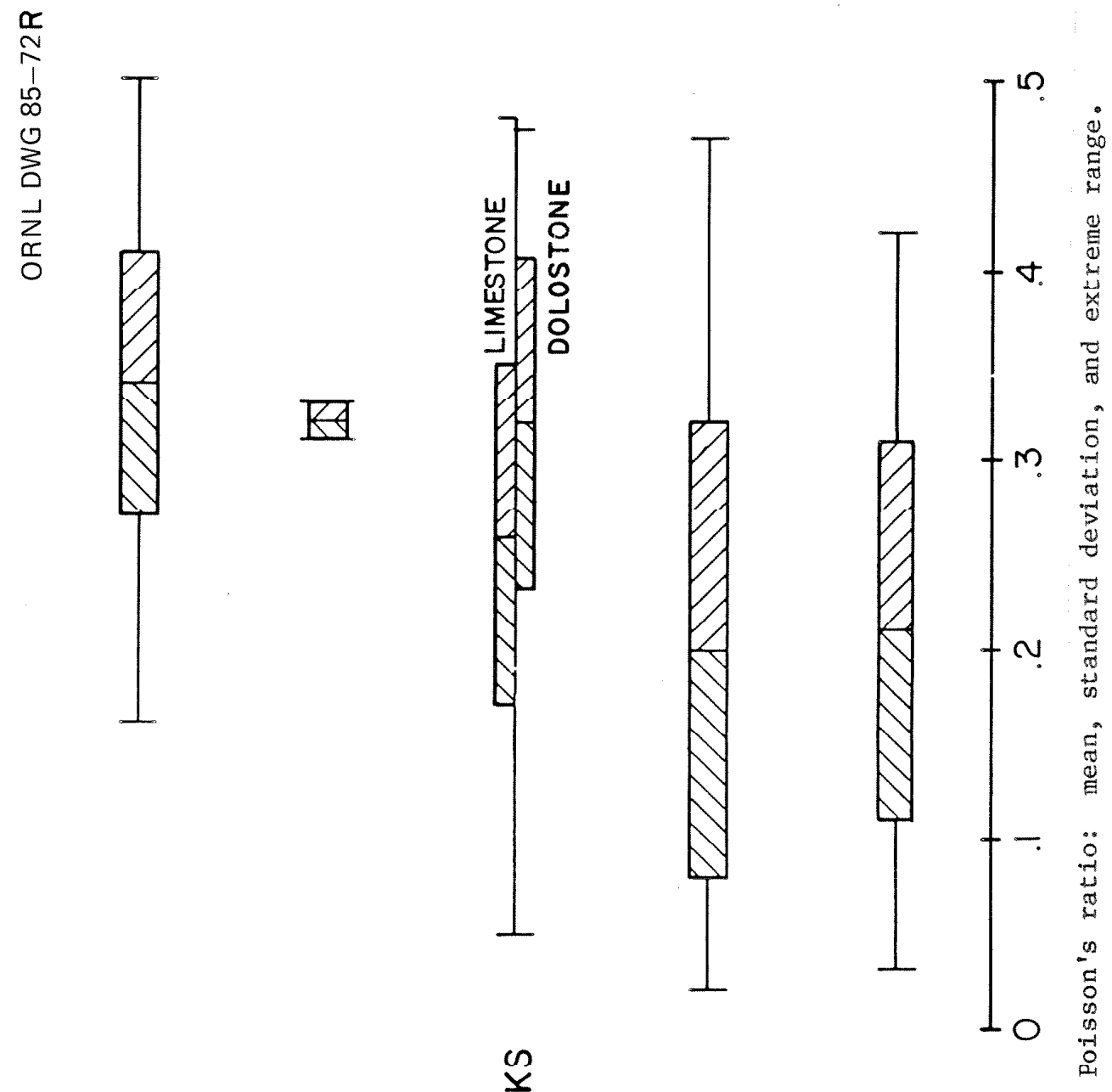

$\frac{y}{0}$
ฯ
$\frac{1}{2}$
$\frac{1}{2}$

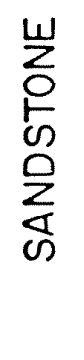

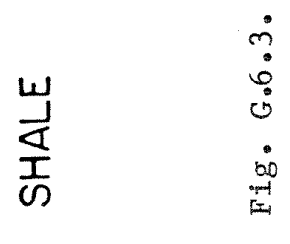


0
0
0
1
0
0
0
$z$
0
2
20
0

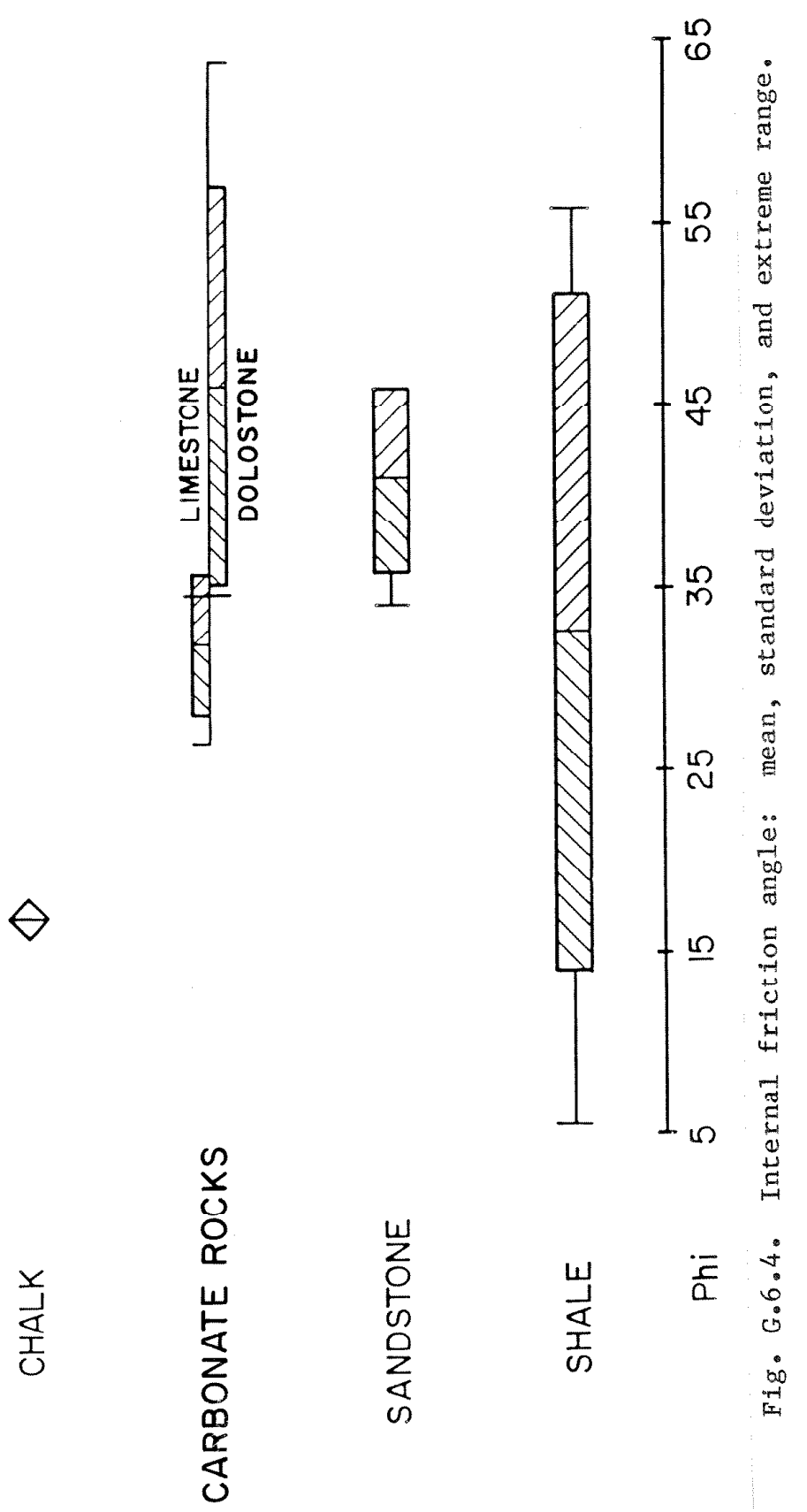




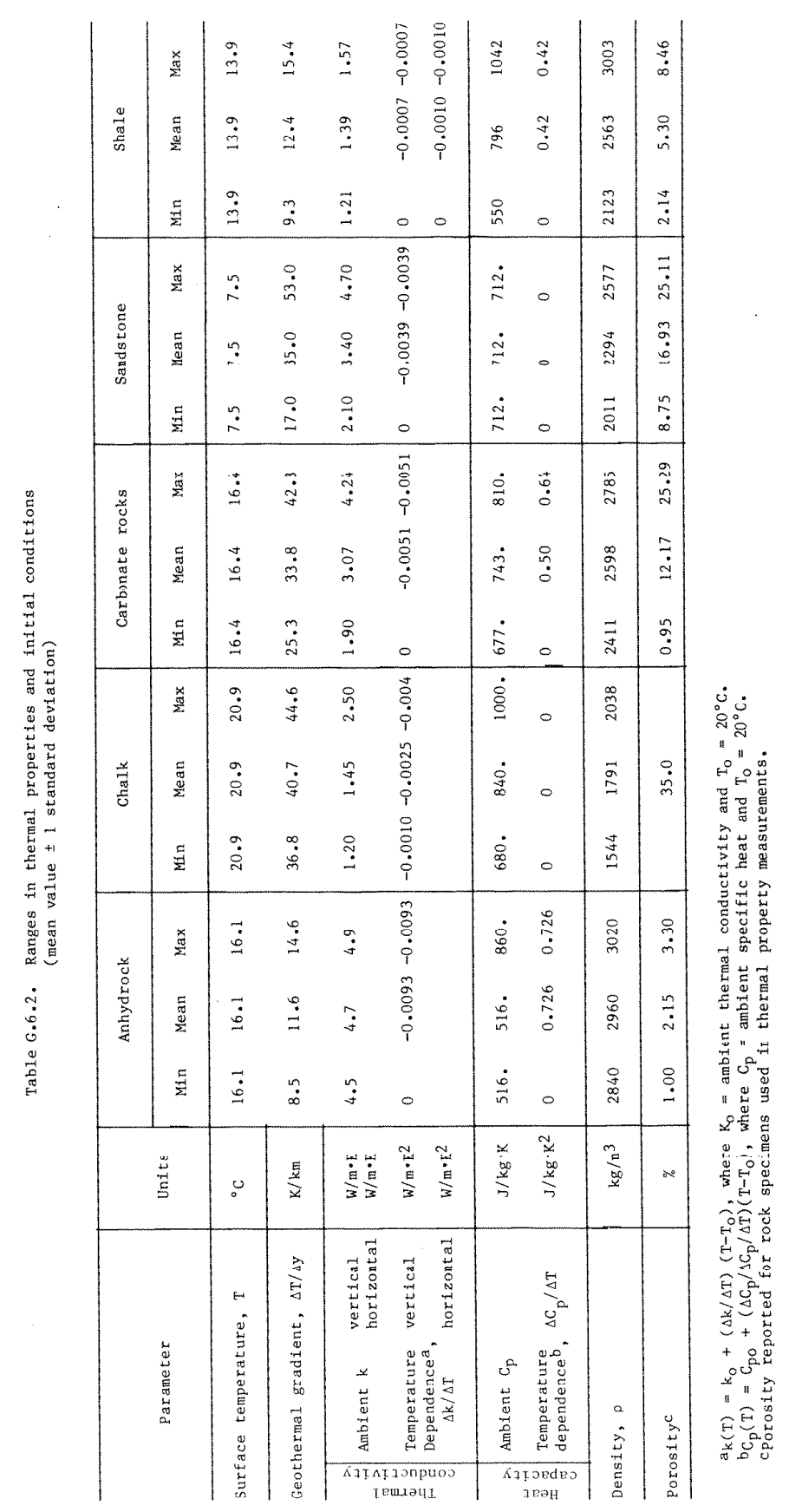


values for thermal properties include tests on both saturated and dry specimens. Limestone and dolostone are listed separately in Sect. G.12.6 but are combined into one category here.

The ranges of the property values used in the thermal analysis are illustrated in Figs. G.6.5 through G.6.8. The mean thermal conductivity value for anhydrock is highest at $5.0 \mathrm{~W} / \mathrm{m} \cdot \mathrm{K}$, and the chalk value is lowest at $1.5 \mathrm{~W} / \mathrm{m} \cdot \mathrm{K}$. The thermal conductivity of shale parallel to bedding is about 1.4 times as great as perpendicular to bedding (KIBBE 1978).

Thermal conductivity values for most sedimentary rocks tend to decrease as temperature increases (e.g., ROBERTSON 1979). Shale, however, may show an increase in thermal conductivity with increasing temperature (RHINES 1977). The ranges of the temperature dependence of llerillal conduclivily uslug a linear fil co available data are slluwn. Although not reported, the temperature dependence of chalk is probably very similar to the reported values for limestone of similar porosity. Published values for the specific heat of these rock types are very limited. Shale has the highest mean value of $879 \mathrm{~J} / \mathrm{kg} \cdot \mathrm{K}$ and anhydrock the lowest of $688 \mathrm{~J} / \mathrm{kg} \cdot \mathrm{K}$. Specific heat also shows a temperature dependence, increasing slightly with increasing temperature. Values for the temperature dependence of specific heat are available only for carbonate rocks $\left(0.50 \mathrm{~J} / \mathrm{kg} \cdot \mathrm{K}^{2}\right)$ and for shale $\left(1.15 \mathrm{~J} / \mathrm{kg} \cdot \mathrm{K}^{2}\right)$. [Note: Values shown in Table G.6.2 were used for the thermal modeling (see p. 109) and do not necessarily agree with these values.]

The coefficient of linear thermal expansion is neither a purely mechanical or thermal property. It has been investigated to a limited degree for limestone/dolostone and shale, while sandstone and anhydrock are each represented by a single value. Anhydrock has the highest mean value, $20 \mathrm{~K}^{-1} \times 10^{-6}$, and carbonate rocks have the lowest mean value, $6.65 \mathrm{~K}^{-1} \times 10^{-6}$.

The range of values for the physical property, mass density, are given in Fig. G.6.9. Anhydrock has the highest mean density, $2851 \mathrm{~kg} / \mathrm{m}^{3}$, and chalk has the lowest mean value, $1791 \mathrm{~kg} / \mathrm{m}^{3}$.

\section{G.6.3 INITIAL CONDITIONS}

\section{G.6.3.1 Surface Temperature and Geothermal Gradient}

In addition to the rock thermal properties, the site-specific initial surface temperature and geothermal gradients are needed to establish the ambient temperature of the host rock at the repository depth. The values given for these initial conditions were developed for areas where the reference stratigraphic section may occur. Surface temperature values are the average of monthly data given for each type locality from Climatic Atlas of the United States (U.S. DOC 1983). The surface temperature values range from $7.5^{\circ} \mathrm{C}$ for the typical sandstone location to $20.9^{\circ} \mathrm{C}$ for the typical chalk location. The goothermal gradient for each area was determined using the well temperature data of Kron and Stix (KRON 1982). The geothermal gradient is greatest for the typical chalk location, with a mean value of $40.7 \mathrm{k} / \mathrm{km}$, and least for the typical anhydrock location, with a mean value of $11.6 \mathrm{~K} / \mathrm{km}$. 
\begin{tabular}{l}
0 \\
\multirow{1}{r}{} \\
1 \\
0 \\
0 \\
0 \\
$\vdots$ \\
0 \\
$\vdots$ \\
2 \\
0 \\
0 \\
0
\end{tabular}

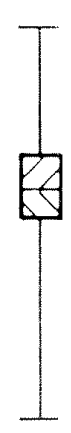

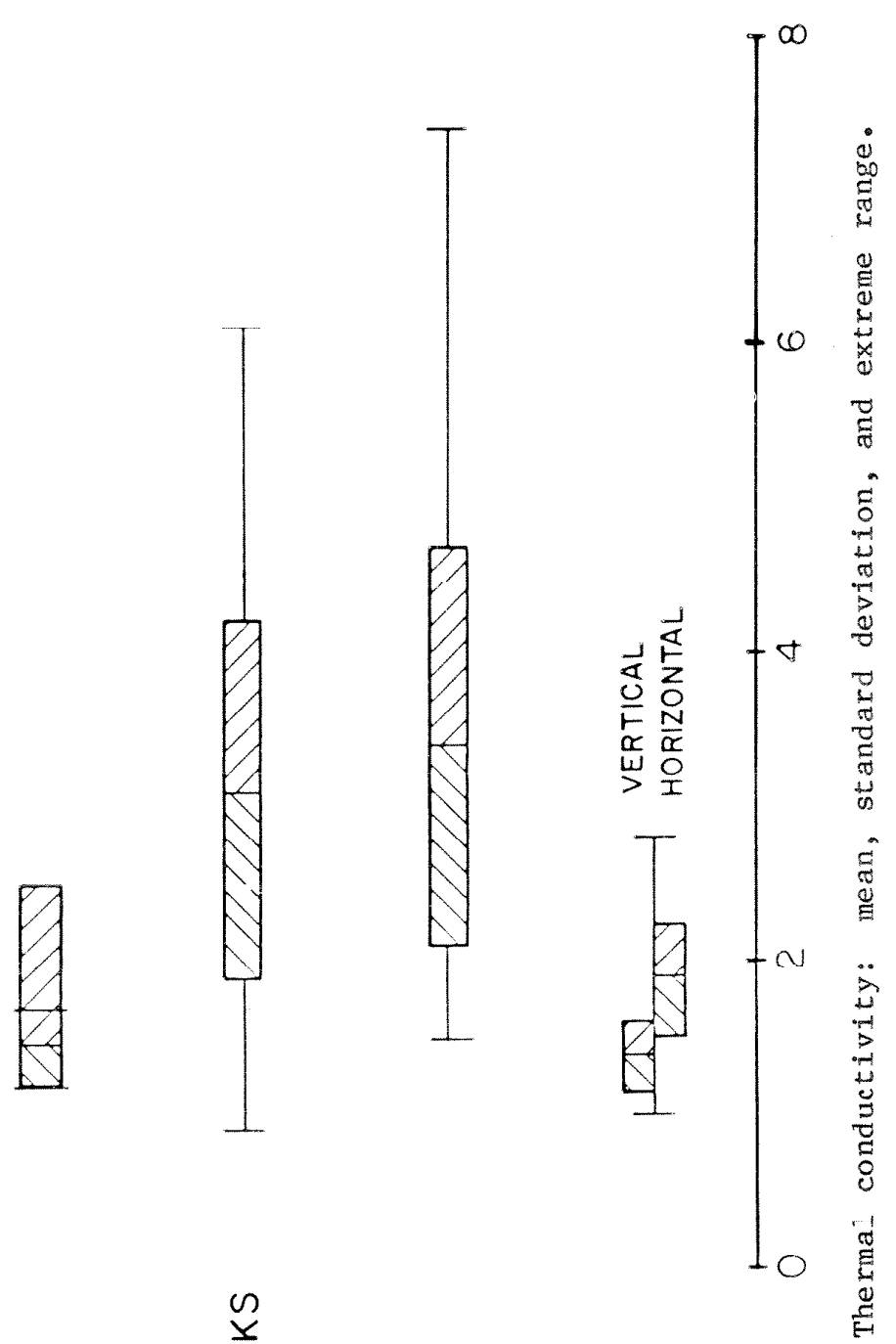

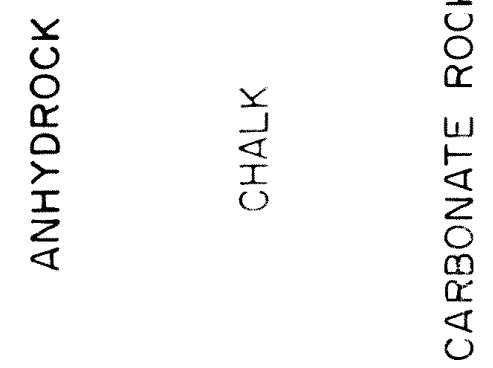

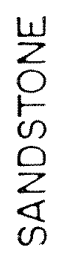

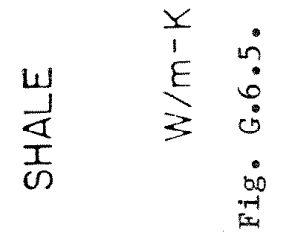



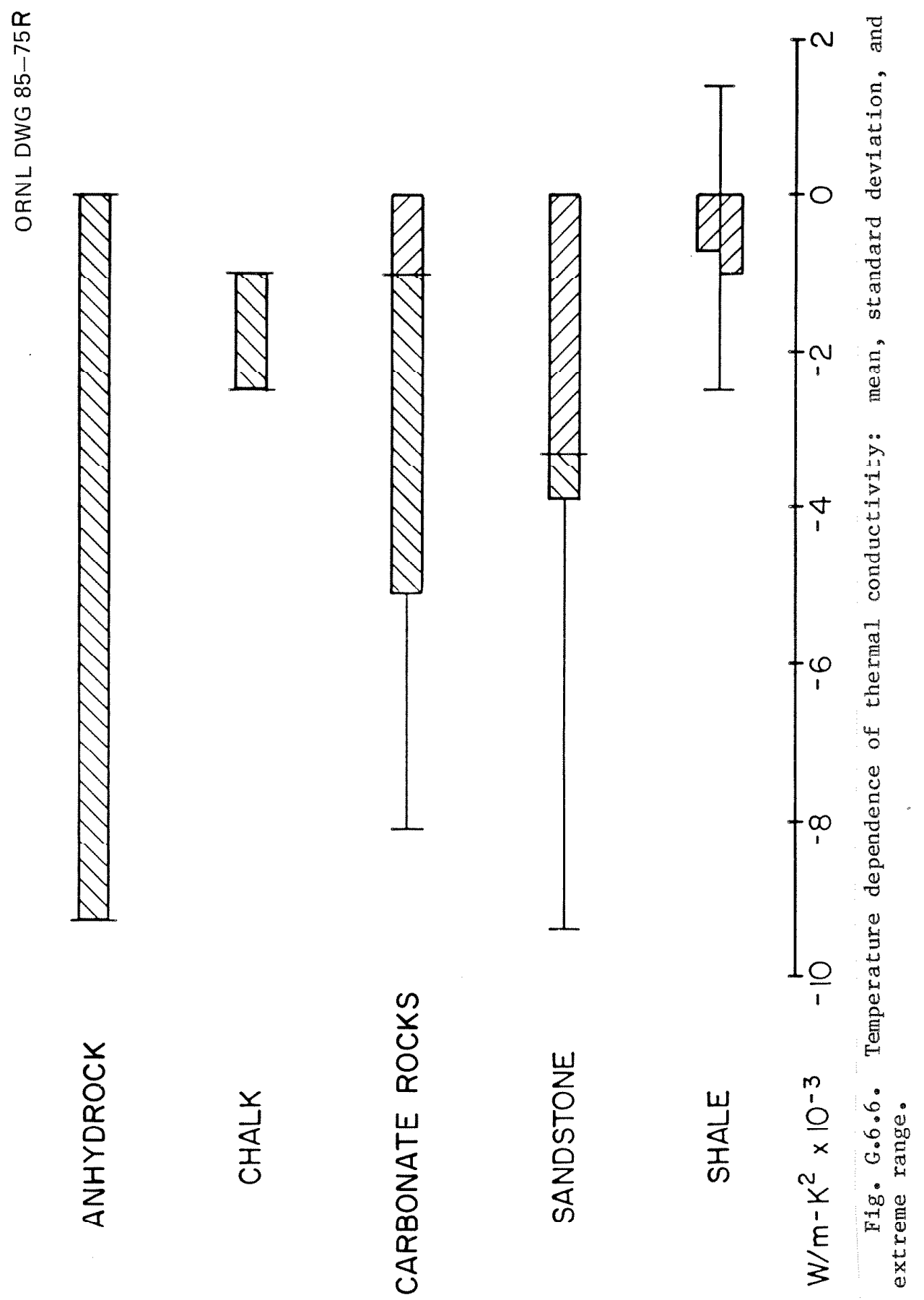
0
0
1
1
0
0
0
3
0
$\vdots$
0
0
0

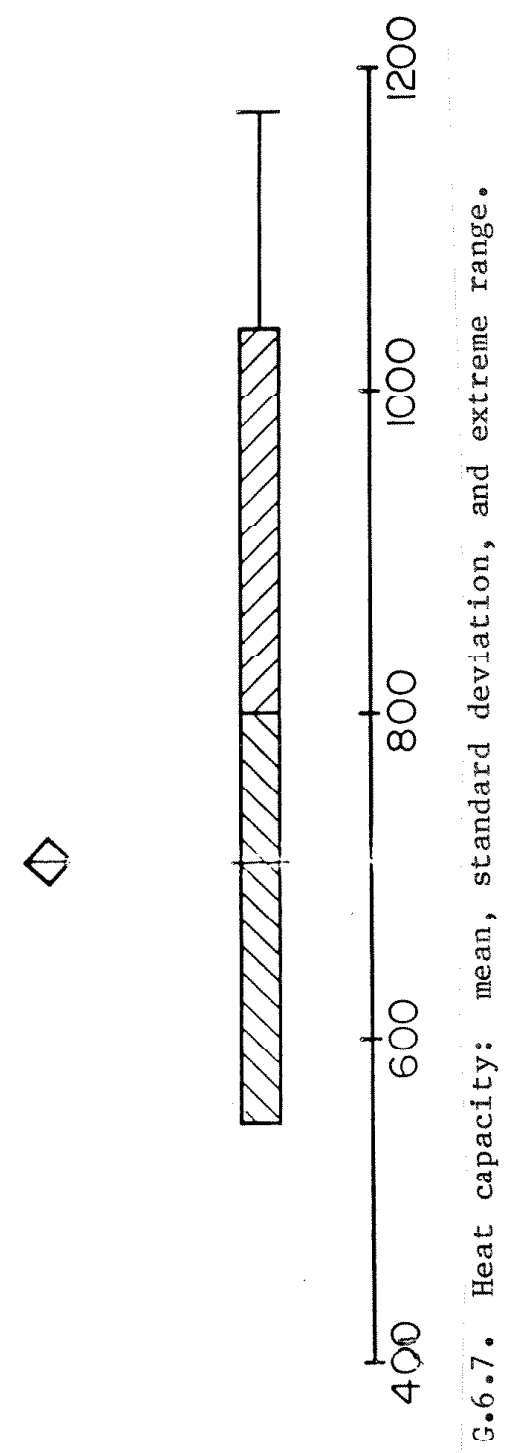

\begin{tabular}{l}
$\frac{x}{0}$ \\
0 \\
\hdashline \\
0 \\
$\frac{1}{2}$ \\
$\frac{1}{4}$
\end{tabular}

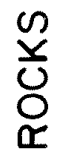

w
잉
en
交
on

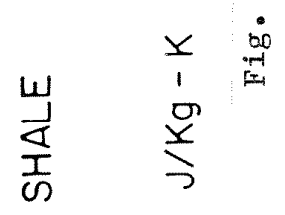

亗 

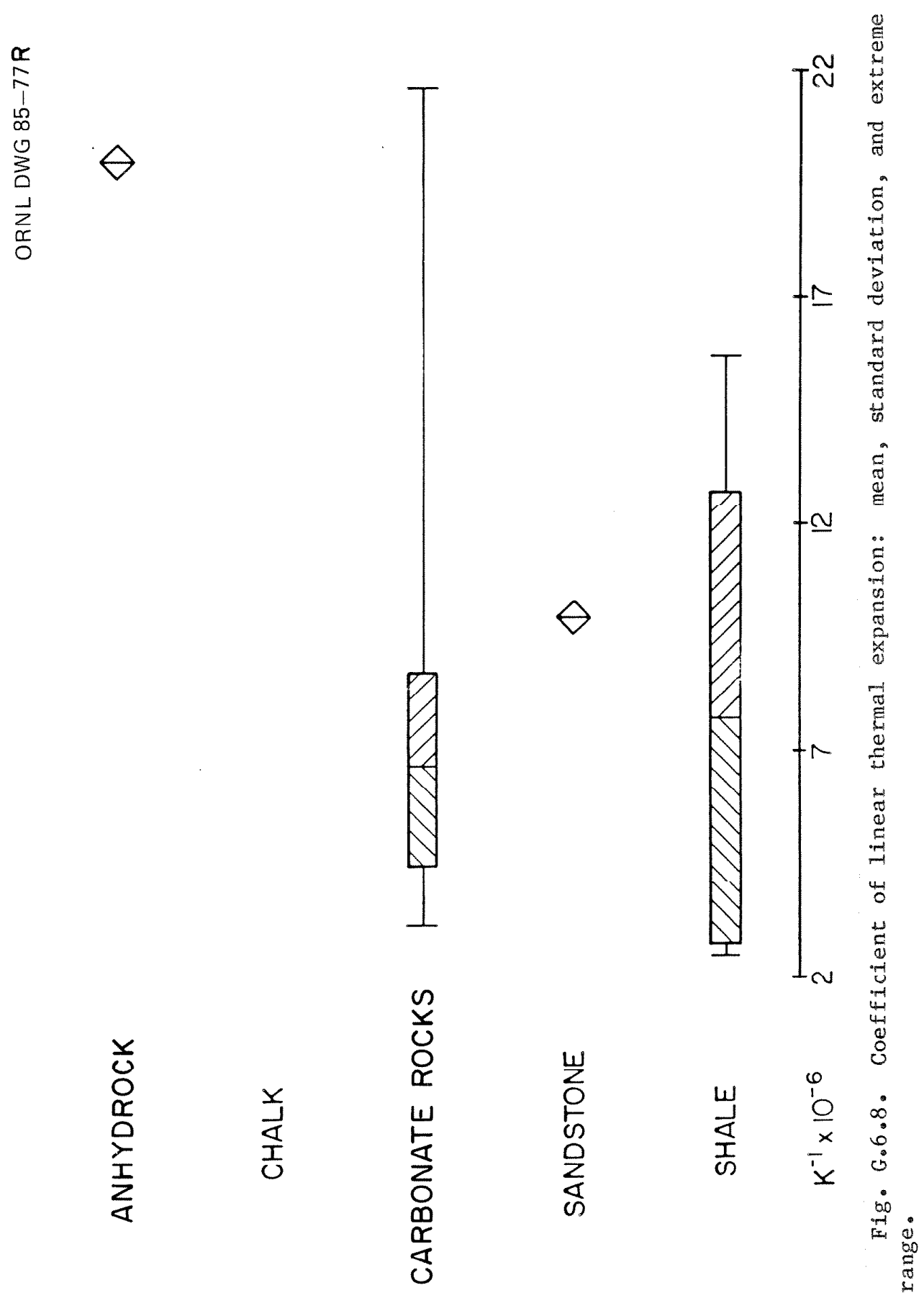

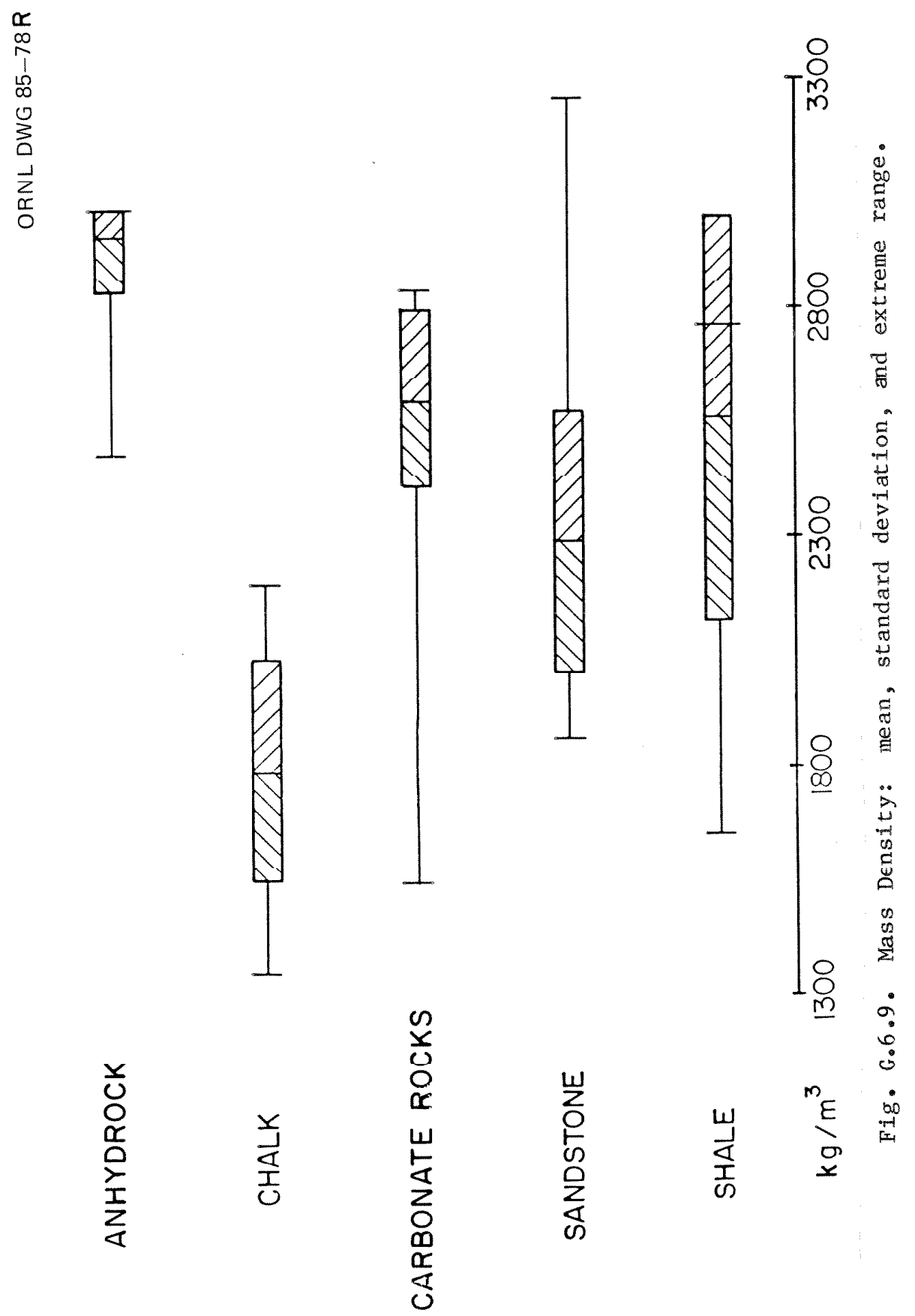


\section{G.7 MODELING CONSIDERATIONS}

This section discusses in detail the modeling characteristics required to address the repository performance constraints identified in Sect. G.5. The thermal models are discussed in Sect. G.7.1, whereas, the mechanical aspects are presented in Sect. G.7.2.

\section{G.7.1 THERMAL}

The thermal responses are addressed with numerical (finite element) models of the underground repository physical system. Each of the thermal responses requires a particular degree of detail in the geometric region for which the particular responses are to be determined. For example, the maximum centerline temperature of the waste form requires a high degree of modeling detail in the vicinity of the waste package. For a comprehensive application of the thermal responses, the underground repository has been divided into three different geometric regions:

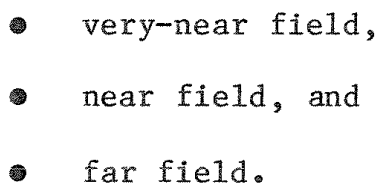

The very-near field encompasses the waste package and the emplacement borehole as the primary area of investigation and modeling detail. The near field relates to the room-and-pillar system of the repository, while the far-field model primarily addresses the behavior of the overlying rock. This differentiation of geometric regions has been used extensively in the modeling of underground radioactive waste repositories. More extensive definitions and explanations of the extent of the different regions appear in numerous references (e.g., CRPCWG 1984).

The assumpliums used in lie develupment of models in eacli of linese geometric regions differ. The particular aspects of the numerical models are discussed separately below. In certain instances, the models designed to address the thermal response in a certain region may also be used to address a thermal response in another region. For example, even though the near-field model is not of adequate detail to address the operational period response in the waste package region, it is sufficient for addressing the isolation period response in the waste package regiun.

\section{G.7.1.1 Very-Near Field}

The thermal responses that are addressed with the very-near-field model are: (1) the waste form maximum temperature; (2) the overpack maximum temperature; and (3) the maximum temperature of the borehole surface (rock). The very-near-field modeling only addresses the operational and containment period magnitudes of these responses. Since the temperature gradients in the vicinity of the waste package decrease to a very low magnitude by the end of the containment period, the isolation period waste package temperatures will be addressed in the near-field modeling. 
The very-near-field model for both CHLW and SF is illustrated in Figs. G.7.1 and G.7.2. This axisymmetric unit-ce11 mode1 encompasses a single waste package and associated emplacement borehole. The radial extent of the model is such that the horizontal areal extent of the model is equivalent to that for each waste package in the actual repository. Mathematically, the radius of this model is calculated as:

$$
r_{\mathrm{m}}=\sqrt{\frac{\text { waste package pitch } \mathrm{x} \text { room spacing }}{\pi}} .
$$

The radius of the cylindrical "room region" of this model is calculated in a similar manner. Mathematically:

$$
r_{x}=\sqrt{\frac{\text { waste package pitch } \times \text { room width }}{\pi}}
$$

The height of the room in this model is equal to that in the repository design. Thus, the volume of the room in this model is equivalent to the total room volume in the repository divided by the total number of waste packages in the repository.

The axisymmetric unit-cel1 model has been used extensively in previous analyses for predicting the thermal response of the waste package components (WAGNER 1984). Use of this unit cell is appropriate for repository designs that consider a single row of canisters along the length of the room and for numerical simulations of less than 50 years in duration.

All of the exterior boundaries of the model are considered adiabatic. The left vertical boundary, passing through the waste package center, is a line of symmetry. Application of the adiabatic boundary condition to the outside radius of the model is done to account for the effects of the other waste packages in the repository. An adiabatic boundary condition implies that an infinite number of waste packages exist at the same depth as the particular package being explicitly modeled. The horizontal boundaries are meant to approximate an infinite extent in the vertical direction. The validity of such an approximation can easily be determined by monitoring whether or not these boundaries experience any temperature rise during the time of interest. The extent of these models was found to be sufficient to preclude any significant temperature rise at the upper and lower boundaries throughout the simulation period of 50 years. A uniform initial temperature representative of the repository level undisturbed rock temperature was applied to the model. This assumption is appropriate for this modeling since all the temperatures of interest are at the repository level temperature initially. 
ORNL DWG 85-79

MODEL GEOMETRY

\begin{tabular}{|l|l|l|}
\hline \multirow{2}{*}{ DIMENSION } & \multicolumn{2}{|c|}{ WASTE TYPE } \\
\cline { 2 - 3 } & CHLW & \multicolumn{1}{|c|}{ SF } \\
\hline$r_{\mathrm{m}}(\mathrm{m})$ & 3.51 & 7.25 \\
$r_{r}(\mathrm{~m})$ & 2.57 & 5.30 \\
$h^{2}$ & 5.5 & 6.4 \\
\hline
\end{tabular}

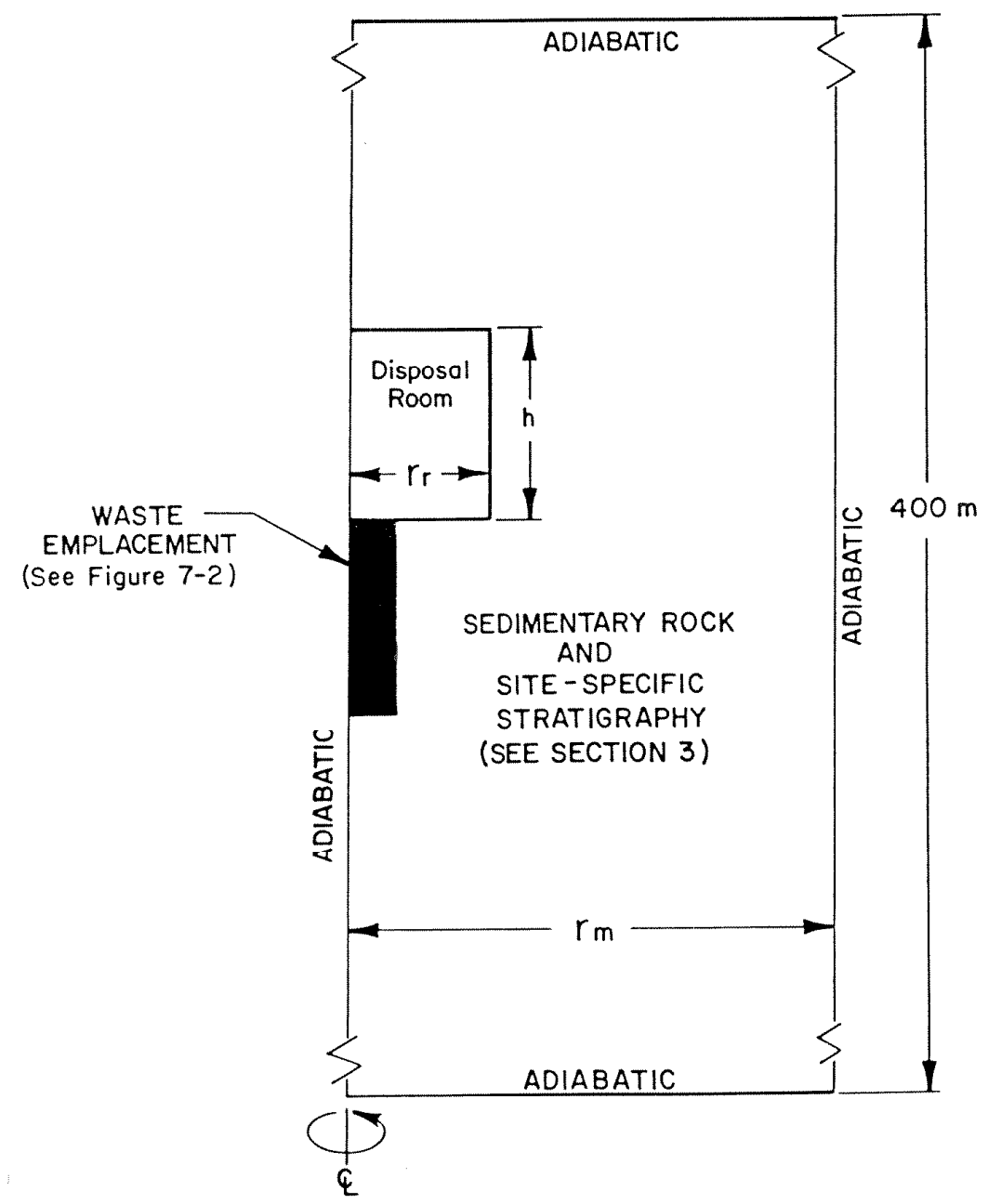

Fig. G.7.1. Axisymmetric unit-cell model for very-near-field analysis of commercial high-level waste and spent fuel emplacement in sedimentary rock. 


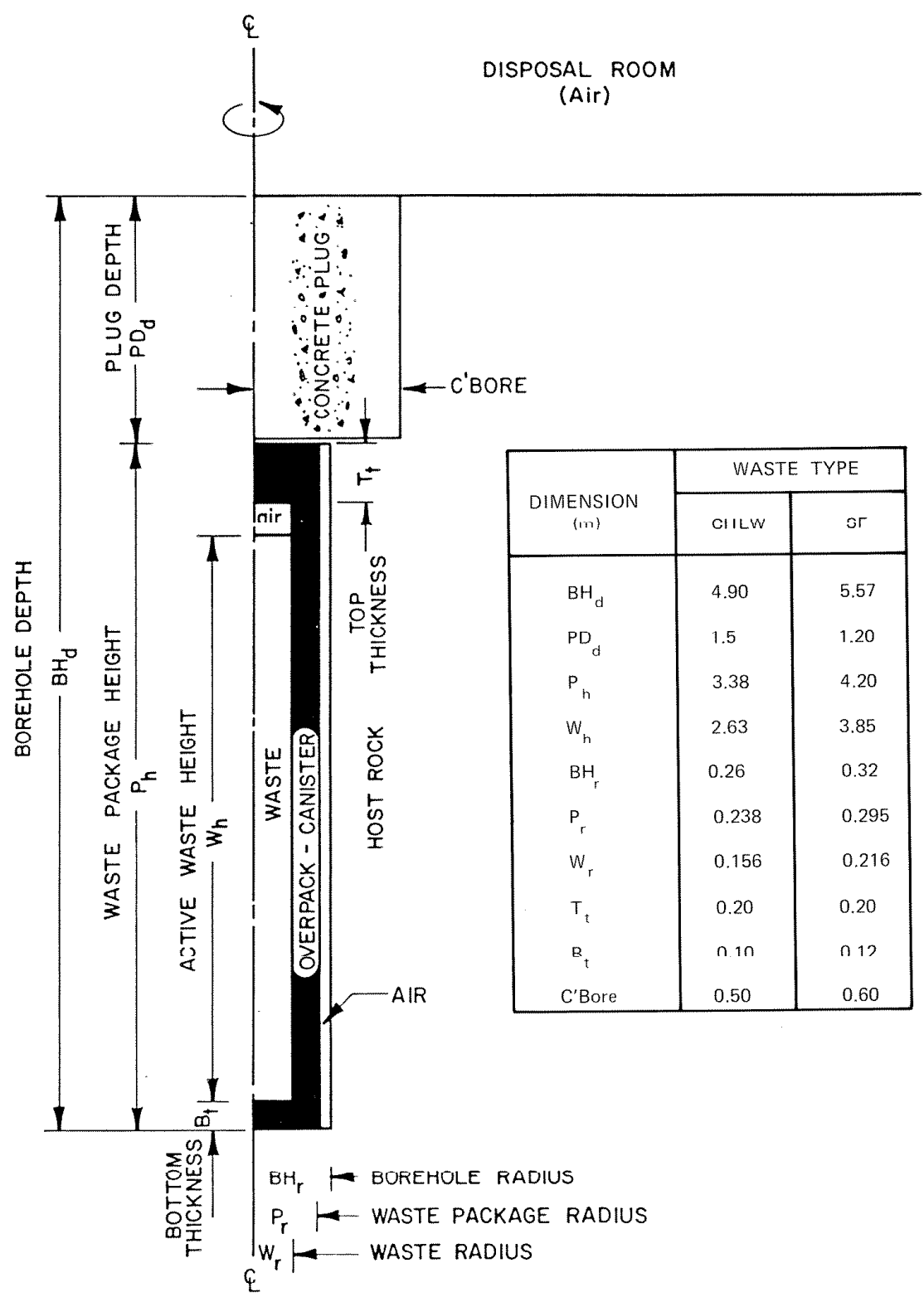

Fig. G.7.2. Geometric configuration for the emplacement of commercial high-level waste and spent fuel in sedimentary rock. 


\section{G.7.1.2 Near Field}

The specific responses that are addressed in the near field are: (1) the room backfill maximum temperature; (2) the maximum temperature at the near-field/far-field interface; and (3) the maximum borehole (rock) temperature during the isolation period (at 1000 years). The room hackfill temperature is calculated by taking a volume average of the temperatures within the room. This calculated temperature is representative of the room backfill temperature at any location, since the thermal gradients in the room are very low. The near-field/far-field interface temperature is calculated at a depth of $685 \mathrm{~m}$, or approximately one-half pillar width above the disposal room. The maximum borehole (rock) temperature was addressed only during the isolation period (i.e., at 1000 years after emplacement). The uce of a ncar-field model for the calculation of borehole (rock) temperatures does not give conservative results; however, the small temperature differences when compared to the results of a very-near-field model simulation are of no practical signiticance.

The near-field model is illustrated in Fig. G.7.3. This model is develoned assiming an infinito number of rooms in the ropooitory of essentially infinite direction along the axis of the emplacement roon. Because of the assumption of infinite extent, planes of symmetry exist through the center of the pillar and through the center of the emplacement room. Because of the two-dimensional character of this model, the line of distinct emplacement boreholes containing the waste packages is actually modeled as a heat-generating parallelepiped having material properties of each sedimentary rock type. The vertical boundaries are assumed to be adiabatic, and a time-dependent convective coefficient is specified along the upper and lower boundaries. These upper and lower boundary conditions provide approximately the same heat removal rate as an infinitely long model. A discussion of this approximation and its validity has been published previously (WAGNER 1980). A uniform initial temperature representative of the repository horizon undisturbed rock temperature was applied to the near-field model.

Before and after backfill (at 5 years), the room is modeled as air and crushed rock, respectively. The magnitude of the thermal conductivity used in modeling these materials is presented in Sect. G.3 of this report and discussed in detail in a previous report (RATIGAN 1984).

\section{G.7.1.3 Far Field}

The far-field model is constructed to address the following repository responses: (1) shaft seal maximum temperature; (2) maximum nearsurface cemperature rise; and (3) maximum temperature at $\sim 85 \%$ of the repository depth. The maximum shaft temperature is assumed to occur at its bottom (i.e., along the repository horizon $250 \mathrm{~m}$ from the nearest heat-generating waste). The latter two responses were both assumed to occur directly above the repository center at depths of $5 \mathrm{~m}$ and $595 \mathrm{~m}$, respectively. 
ORNL DWG $85-81$

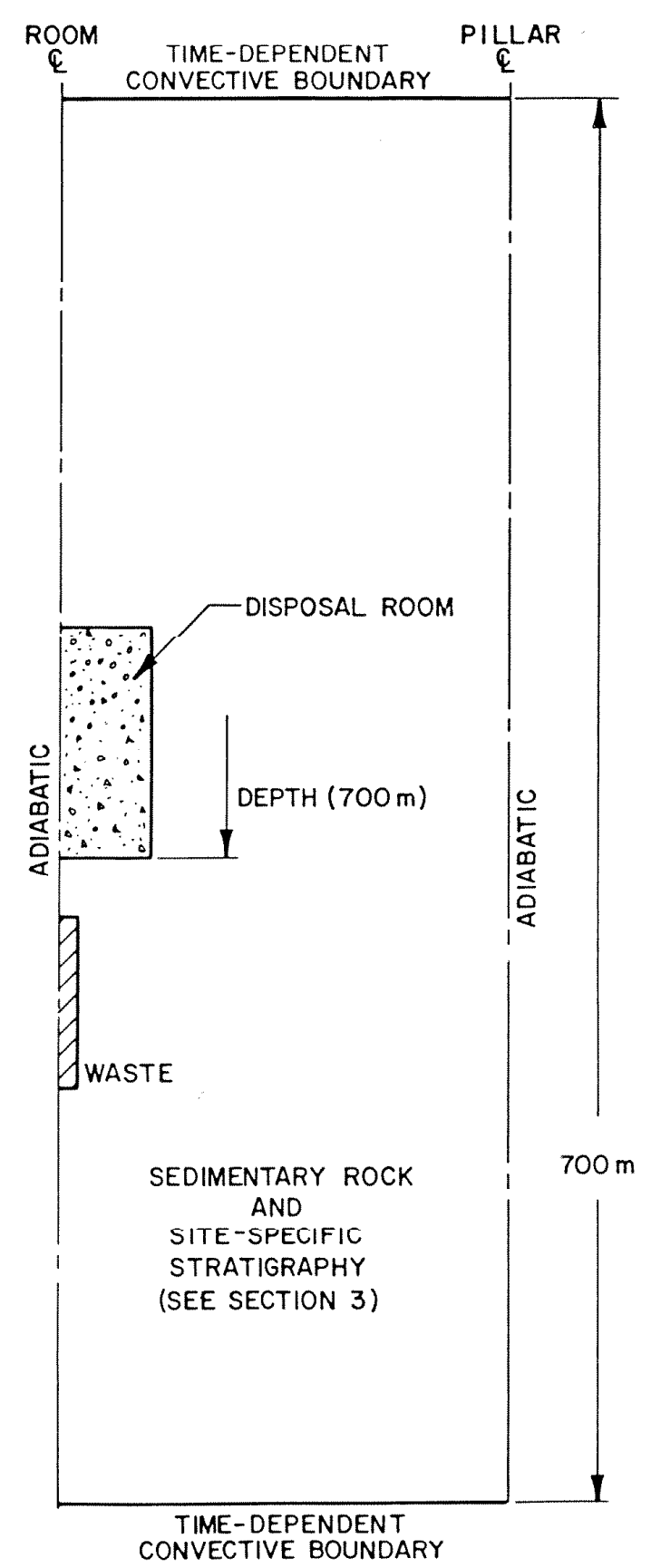

Fig. G.7.3. General description of two-dimensional model used in the near-field analysis for commercial high-level waste and spent fuel emplacement in sedimentary rock. 
The far-field axisymmetric model is illustrated in Fig. G.7.4. The repository was modeled as a heat-generating circular disk having the same thermal properties as the host sedimentary rock. No refinement is provided for the room-and-pillar configuration in the far-field model. The radius of the repository $(1250 \mathrm{~m})$ closely approximates the planar area required to emplace the quantity of each waste type (70,000 MTU) at an emplacement efficiency of $80 \%$. The height of the heat-generating repository was assumed to be $10 \mathrm{~m}$, which approximates the combined height of the disposal room and emplacement borehole. The shaft is assumed to be located at a depth of $700 \mathrm{~m}$ and $250 \mathrm{~m}$ horizontally from the nearest heat-generating waste.

The vertical boundaries are considered adiabatic. The left boundary is a line of symmetry; whereas, the right boundary is meant to approximate an infinite extent throughout the simulation time (10,000 years). The boundary at the earth's surface is modeled as a convective boundary. A convective heat transfer coefficient of $2.84 \mathrm{~W} / \mathrm{m}^{2} \cdot \mathrm{K}$ was applied at the surface. The ambient air temperature was taken to be the initial surfacc temperature. The comparative effect of the applied convective surface boundary condition vs a constant temperature condition on the near-surface temperature perturbation has been shown previously to be negligible (RATIGAN 1983). The initial far-field temperature distribution was based on the estimated geothermal gradient and surface temperature for each rock type (Sect. G.6.3).

\section{G.7.2 MECHANICAL}

A boundary element computer code is used for modeling of the underground stress states around the repository disposal rooms. This particular boundary element computer code is adapted from that given in Hoek and Brown (HOEK 1980). Use of this boundary element computer code requires several significant assumptions:

1. all deformation is linear elastic,

2. the entire rock mass is homogeneous and isotropic, and

3. excavation of the disposal rooms is simultaneous and instantanenus.

Although these assumptions are not rigorously appropriate for the majority of rock types considered in this study, the boundary element results provide qualitative guidance for ranking of the rock types with respect to excavation stability during the excavation and operational phases of the repository.

The discretized model used with the boundary element computer code is illustrated in Fig. G.7.5. The mechanical symmetry that exists about the center of a disposal room in the center of a repository results in the requirement for only modeling half of the physical configuration. Further, since the stress state around a single excavation will be studied in detail, only the first few rooms adjacent to the central disposal room need he considered in the houndary element model. plane strain is assumed in the direction parallel to the axis of the disposal room. 
ORNL DWG 85-82

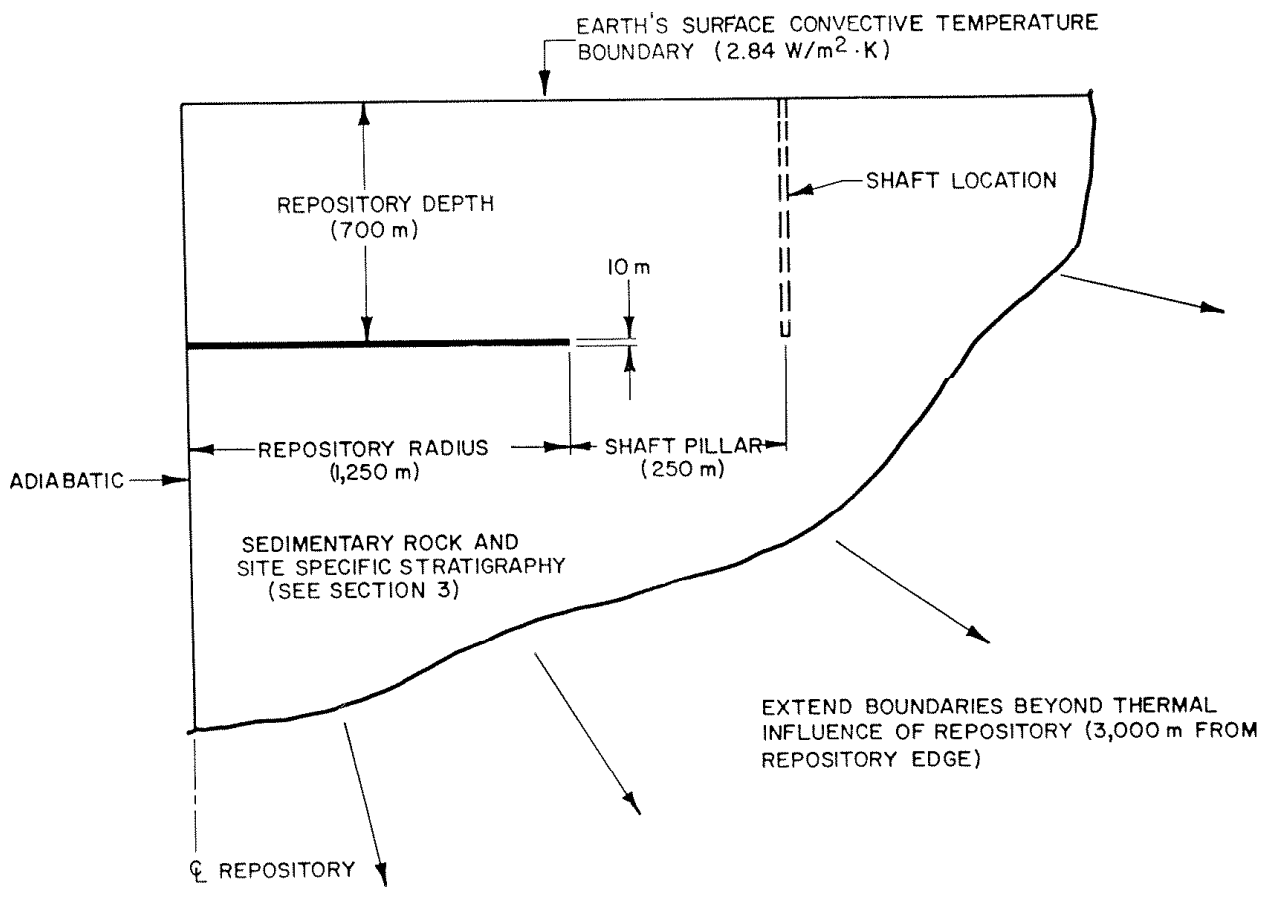

Fig. G.7.4. Physical model used in far-field thermal analysis for spent fuel and commercial high-level waste emplacement in sedimentary rock. 
ORNL DWG $85-83$

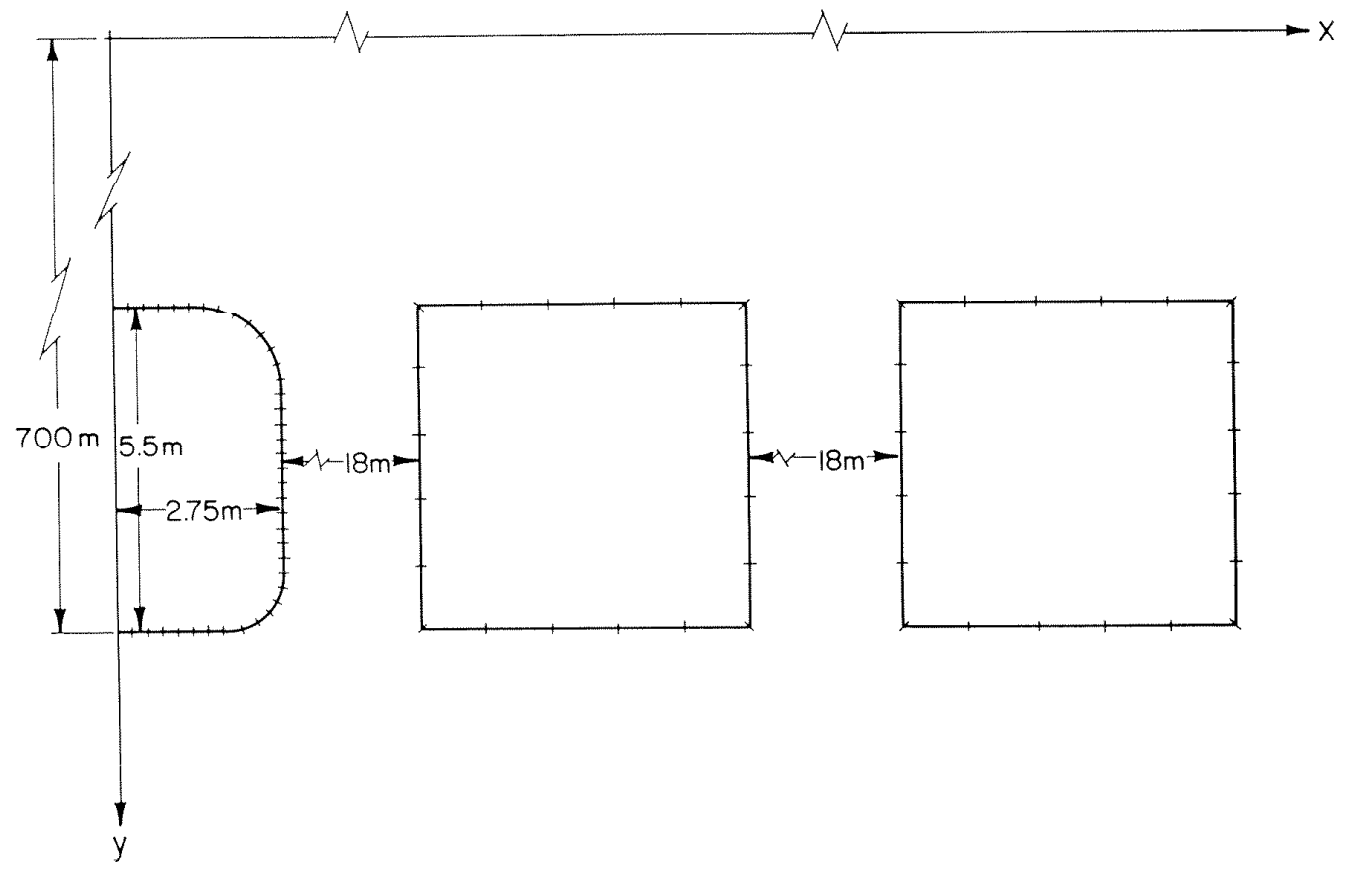

Fig. G.7.5. Boundary element model used in mechanical analysis. 
The vertical stress before excavation is assumed to be that due to the weight of the overburden. This stress is estimated to be:

$$
\begin{aligned}
\sigma_{z} & =-p g z, \\
\sigma_{z} & =-0.027 \mathrm{MPa} / \mathrm{m} \times 700 \mathrm{~m} \text { (at the repository level), } \\
& =-18.9 \mathrm{MPa},
\end{aligned}
$$

where

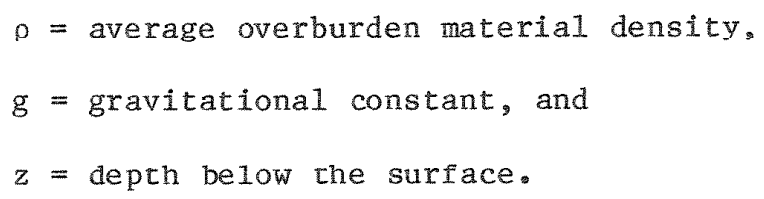

Compressive stresses are taken to be negative. The initial horizontal stress in the direction perpendicular to the axis of the disposal room is taken to be a multiple of the vertical stress at the same depth. In these analyses, multiple values for in situ stress ratios of 0.5 , 1.0 , and 1.5 are considered. In situ stress ratios of these magnitudes have been measured (e.g., HOER 1980). 


\section{G.8 THERMAL RESULTS}

This section presents in detail the evaluation procedure and results of the thermal analyses. These analyses encompassed:

- Three distinct geometric regions

- very-near field

- near field

- far field

- Two waste types

- commercial high-level waste

- spent fuel

- Five rock typeo

- anhydrock

- chalk

- carbonate rocks (1imestone/dolostone)

- sandstone

- shale (argillaceous rock)

Section G.8.1 presents the procedure for evaluating the results of the analyses used in determining the expected range in the outputs for each of the geometric regions considered. Sections G.8.2 through G.8.4 discuss the thermal results of the very-near-field, near-field, and far-field regions, respectively. Section G.10.2 provides an overall summary of the thermal performance of each rock type, both individually and collectively. Supplemental information related to this thermal analysis is contained in Sects. G.12.1 through G.12.4 for each analytic region.

\section{G.8.1 EVALUATION PROCEDURE}

As discussed in Section G.7.1, three geometric regions (models) were used to evaluate the thermal performance of the repository for each waste type and rock type. These regions of analysis and associated thermal responses include:

- Very-near field

- waste form temperature

- overpack temperature

- host rock temperature (operational/containment period)

- Near field

- volumetric averaged room backfill temperature

- near-field/far-field interface temperature

- host rock tomperature (isolation period) 
- temperature at 595-m depth

- shaft temperature

- near-surface temperature rise

Each of these analytic regions reflects the geometric detail required to calculate the associated responses.

The range in the output for each thermal response was determined based on the range of initial conditions and material properties for each rock type presented in Sect. G.6. These input parameters were permuted to result in the minimum, mean, and maximum outputs associated with each thermal response. The term "minimum" is used here to denote the output based on a permutation of all the input parameters (i.e., one standard deviation above or below the mean) that results in the minimum response. Similarly, the term "maximum" refers to the maximum response based on the range of al1 the input parameters. This pernutation of input parameters is presented in Table G.8.1 for each response considered. For example, the maximum waste form temperature results from the minimum values of the material properties (i.e., thermal conductivity, specific heat, and density) and the maximum values tor the initial thermal conditions (i.e., surface temperature and geothermal gradient). This permutation of parameters has been verified by the plackett-Burman statistical method used in a previous similar study (RATIGAN 1984).

The calculated range in output represents the range in each thermal response under the extremes expected for the site conditions. For this analysis the minimum response is taken to be the most favorable condition, while the maximum response is taken to be the least favorable condition. The difference in these extreme responses is the range. The mean response is taken to be the output based on the (mean) values of all the input parameters. In addition, the range in output reflects the uncertainty in the magnitude of each response, based on the uncertainty in the material properties and initial conditions. Conceivably, one is able to decermine an approximate probability distribution associated with each output, since the probability distribution for each input parameter is assumed to be known. Unfortunately, the data base upon which the input range is based is insufficient at present to justify such an analysis. Therefore, the present analysis will concentrate on comparing the rock types with the associated thermal responses and commenting qualitatively on the uncertainty in making such a comparison at present.

\section{G.8.2 VERY-NEAR-FIELD RESULTS}

The thermal responses evaluated with very-near-field models (see Sect. G.7 for theoretical background for thermal models) include the waste form temperature, the overpack temperature, and the host rock temperature. The location of the occurrence of the maximum values of these responses is known a priori (i.e., along the midplane of the waste height). These responses were calculated only to 50 years following emplacement. This period encompasses the time required to reach maximum values for every response. waste type, and rock type. Each of these responses is discussed separately below. 
Table G.8.1. Permutation of input parameters for maximum thermal response $e^{a, b}$

\begin{tabular}{|c|c|c|c|c|c|c|c|c|c|}
\hline \multirow[b]{2}{*}{ Input parameter } & \multicolumn{9}{|c|}{ Thermal responsec } \\
\hline & 1 & 2 & 3 & 4 & 5 & 6 & 7 & 8 & 9 \\
\hline Surface temperature & + & + & + & + & + & + & + & + & + \\
\hline Geothermal gradient & + & + & + & + & + & + & + & + & + \\
\hline Ambient temperature & - & - & - & - & - & - & - & - & - \\
\hline Temperature dependence & + & + & + & + & + & + & + & + & + \\
\hline Anisotropy & - & - & - & + & + & + & + & - & + \\
\hline Ambient temperature & - & - & - & - & - & - & - & - & - \\
\hline Temperature dependence & - & - & - & - & - & - & - & - & - \\
\hline Density & - & - & - & - & - & - & - & - & - \\
\hline
\end{tabular}

aThe symbol " + " indicates maximum value of input parameter, while "- indicates minimum value of input parameter.

$b_{T h e}$ permutation of input parameters for the minimum thermal response is naturally the converse of the above table.

crhermal response:

1 waste form temperature

2 overpack temperature

3 host rock maximum temperature

4 volume averaged room backfill temperature

5 near-field/far-field interface temperature

6 host rock temperature at 1000 years

7 temperature at 595-m depth

8 shaft temperature

9 near-surface cemperature rise 


\section{G.8.2.1 Waste Form Temperature}

A summary of the range in the maximum waste form temperatures is shown in Fig. G.8.1. Displayed in this figure are the minimum, mean, and maximum waste form temperature for CHLW and SF emplacement for each of the five sedimentary rock types.

The magnitude and range of the maximum waste form temperature are the lowest for anhydrock and the highest for chalk for both CHLW and SF emplacement. The maximum CHLW temperatures range from 183 to $224^{\circ} \mathrm{C}$ in anhydrock with an expected value of $213^{\circ} \mathrm{C}$. In contrast, the maximum CHLW temperatures in chalk range from 256 to $559^{\circ} \mathrm{C}$ with an expected value of $406^{\circ} \mathrm{C}$. Similarly, the minimum, mean, and maximum SF temperatures for anhydrock are 170,199 , and $210^{\circ} \mathrm{C}$, respectively, while the $\mathrm{SF}$ temperatures range from 246 to $565^{\circ} \mathrm{C}$ in chalk with a mean value of $409^{\circ} \mathrm{C}$. Thus, anhydrock appears to be the most favorable rock type and chalk the least favorable for the waste form temperature.

The magnitude and range of the waste form temperature for the remaining three rock types, carbonate rocks (1imestone/dolostone), sandstone, and shale (argillaceous rock) are similar for both waste types and fall within the range encompassed by anhydrock and chalk. The maximum CHLW temperature in carbonate rocks ranges from 206 to $433^{\circ} \mathrm{C}$ with a mean value of $257^{\circ} \mathrm{C}$. Similarly, the minimum, mean, and maximum CHLW in sandstone are 192,241 , and $344^{\circ} \mathrm{C}$, respectively, and in shale are 243,289 , and $366^{\circ} \mathrm{C}$, respectively. Finally, the SF temperatures range from 193 to $435^{\circ} \mathrm{C}$ in carbonate rocks, from 178 to $337^{\circ} \mathrm{C}$ in sandstone, and 233 to $357^{\circ} \mathrm{C}$ in shale, with mean values of 245,228 , and $280^{\circ} \mathrm{C}$, respectively. Thus, these three rock types compare similarly for this response, which is much more favorable than chalk and somewhat less favorable than anhydrock.

\section{G.8.2.2 Overpack Temperature}

A summary of the range in the overpack temperatures is shown in Fig. G.8.2. Displayed in this figure are the minimum, mean, and maximum overpack temperatures for CHLW and SF emplacement for each of the five sedimentary rock types.

The magnitude and range of the overpack temperature are the lowest for anhydrock and the highest for chalk for both CHLW waste and SF emplacement. The maximum CHLW temperature ranges fron 119 to $169^{\circ} \mathrm{C}$ in anhydrock with a mean value of $155^{\circ} \mathrm{C}$. In comparison, the maximum CHLW temperature range in chalk is from 197 to $514^{\circ} \mathrm{C}$, with a mean value of $356^{\circ} \mathrm{C}$. Similarly, the maximum SF temperature ranges from 117 to $166^{\circ} \mathrm{C}$ in anhydrock and 199 to $542^{\circ} \mathrm{C}$ in chalk, with mean values of 153 and $375^{\circ} \mathrm{C}$, respectively. Thus, anhydrock appears to be the most favorable rock type for the overpack temperature response and chalk the least favorable.

The magnitude and range of the overpack temperature for the remaining three rock types are similar for both waste types and fall within 


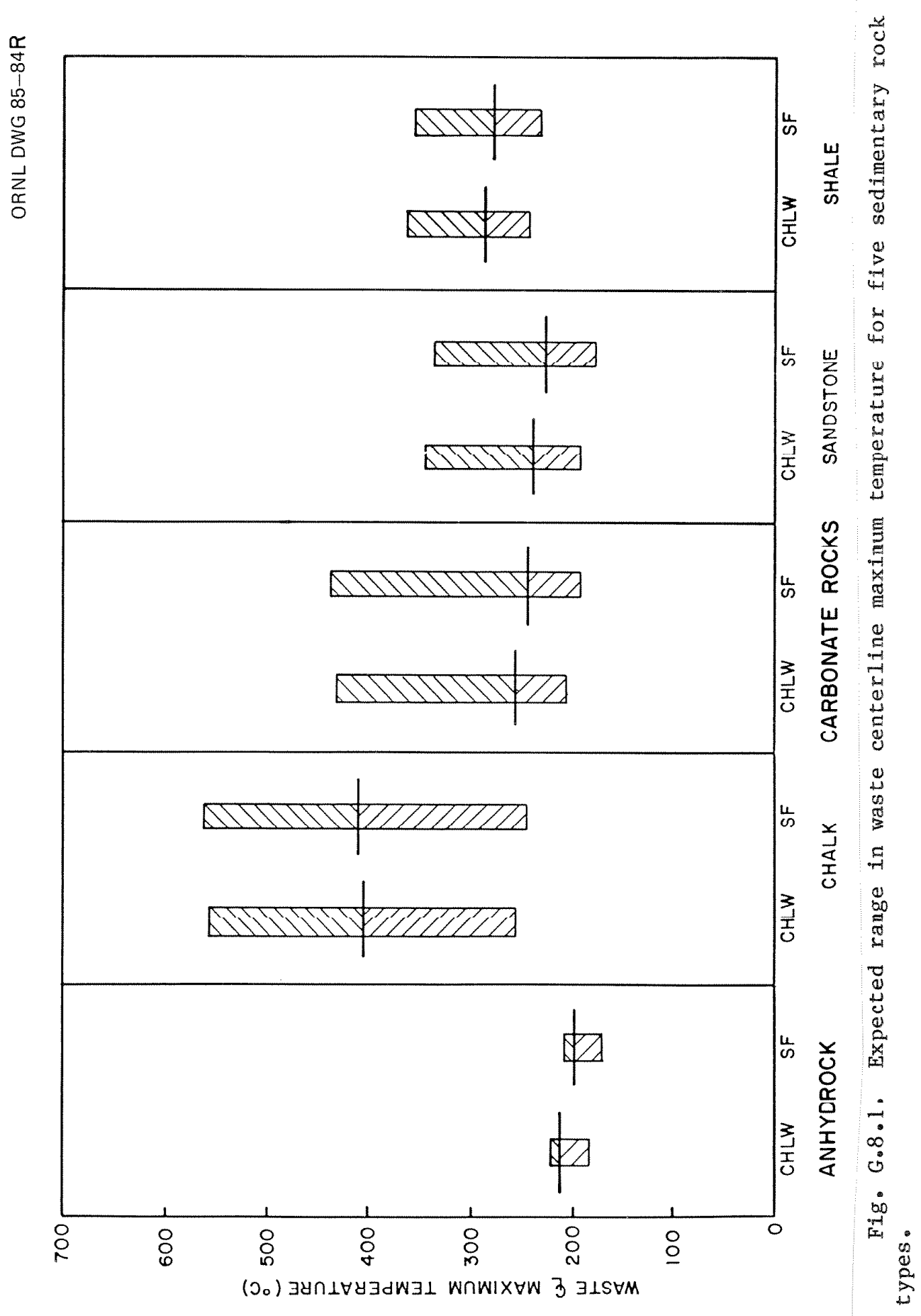




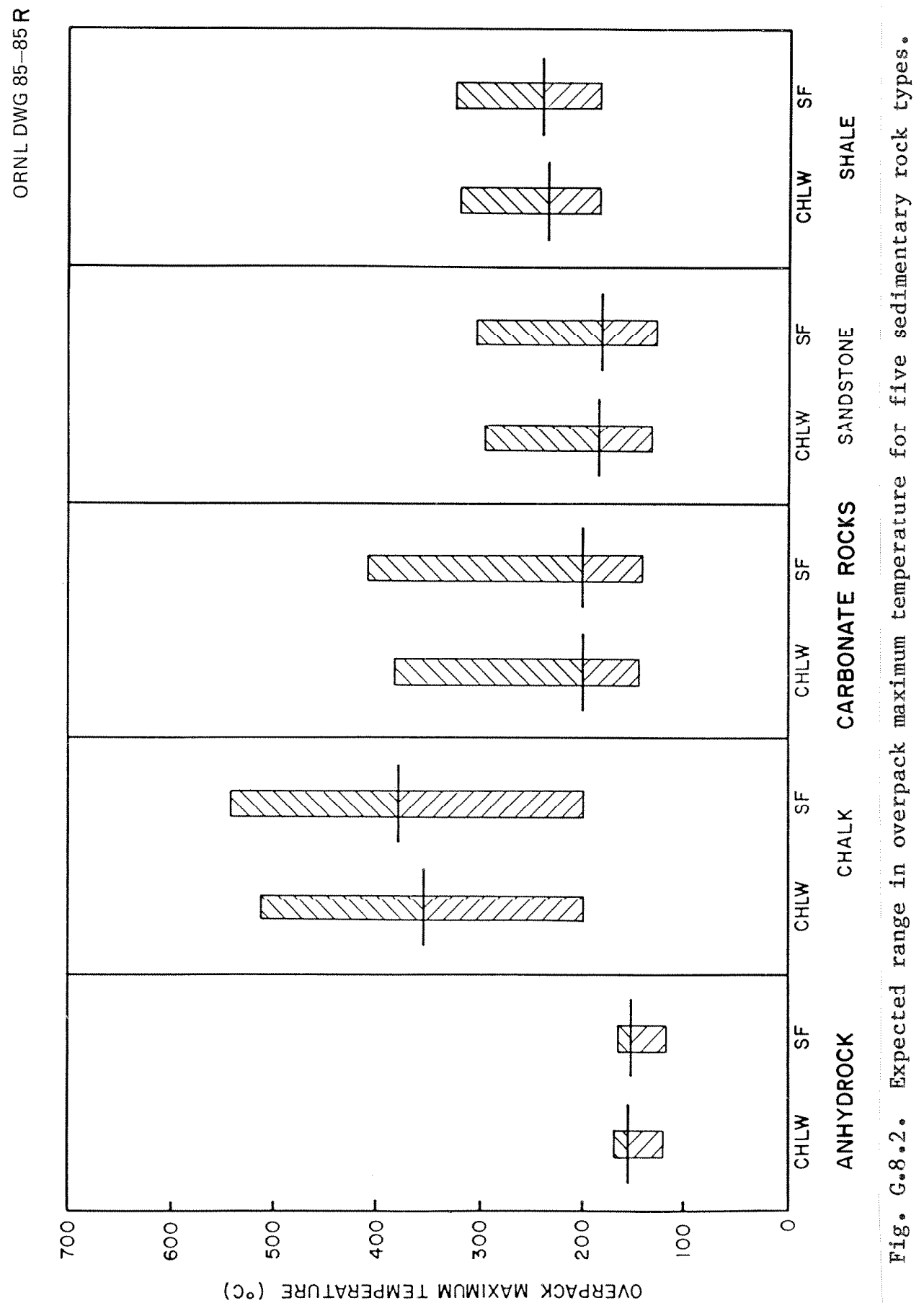


the range encompassed by anhydrock and chalk. The maximum CHLW temperature in carbonate rocks ranges from 144 to $383^{\circ} \mathrm{C}$, in sandstone from 131 to $294^{\circ} \mathrm{C}$, and in shale from 184 to $319^{\circ} \mathrm{C}$, with mean values of 200,184 , and $235^{\circ} \mathrm{C}$, respectively. Similarly, the SF temperature ranges from 142 to $409^{\circ} \mathrm{C}$ in carbonate rocks, 129 to $302^{\circ} \mathrm{C}$ in sandstone, and 186 to $323^{\circ} \mathrm{C}$ in shale, with mean values of 202,183 , and $239^{\circ} \mathrm{C}$, respectively. Thus, these three rock types compare similarly for this response and are more favorable than chalk and less favorable than anhydrock.

\section{G.8.2.3 Host Rock Maximum Temperature}

Shown in Fig. G.8.3 is a summary of the range in the host rock maximum temperature. Displayed in this figure are the minimum, mean, and maximum temperature ranges for CHLW and SF emplacement for each of the five sedimentary rock types.

The magnitude and range of the maximum host rock temperature are the lowest for anhydrock and the highest for chalk for both waste emplacements. The maximum CHLW temperature ranges from 110 to $161^{\circ} \mathrm{C}$ in anhydrock with a mean value of $147^{\circ} \mathrm{C}$. In contrast, the maximum CHLW temperatures in chalk range from 188 to $505^{\circ} \mathrm{C}$, with a mean value of $347^{\circ} \mathrm{C}$. Similarly, the minimum, mean, and maximum $\mathrm{SF}$ temperatures for anhydrock are 111,148 , and $161^{\circ} \mathrm{C}$, respectively. The minimum, mean, and maximum $\mathrm{SF}$ values are 193,373 , and $538^{\circ} \mathrm{C}$, respectively, for chalk. Thus, anhydrock appears to be the most favorable rock type and chalk the least favorable rock type for the host rock maximum temperature response.

The magnitude and range of the host rock maximum temperature for the remaining three rock types are similar for both waste types and fall within the range encompassed by anhydrock and chalk. The maximum CHLW temperature in carbonate rocks ranges from 135 to $375^{\circ} \mathrm{C}$, with a mean value of $191^{\circ} \mathrm{C}$. Similarly, the minimum, mean, and maximum CHLW temperature for sandstone are 123,176 , and $287^{\circ} \mathrm{C}$, respectively, and in shale are 175,227 , and $312^{\circ} \mathrm{C}$, respectively. Finally, the SF temperatures range from 136 to $404^{\circ} \mathrm{C}$ in carbonate rocks, from 124 to $297^{\circ} \mathrm{C}$ in sandstone, and 181 to $318^{\circ} \mathrm{C}$ in shale, with mean values of 196,178 , and $233^{\circ} \mathrm{C}$, respectively. Thus, these three rock types compare similarly for this response and are less favorable than anhydrock but somewhat more favorable than chalk.

\section{G.8.3 NEAR-FIELD RESULTS}

The thermal responses evaluated with near-field models include the average backfill temperature, the near-field/far-field interface temperature, and the maximum rock temperature. These responses were calculated to 1000 years after emplacement, that is, to the beginning of the isolation period. Depending on rock types, the average backfill temperature reaches a maximum value between 30 and 40 years after emplacement for CHLW and between 75 and 100 years after emplacement for SF. The near-field/far-field interface temperature reaches a maximum between 40 and 80 years after emplacement for CHLW and between 100 and 200 years after emplacement for SF. The maximum rock temperature calculated from the near-field model is given at 1000 years. Fach of these responses are discussed separately below. 


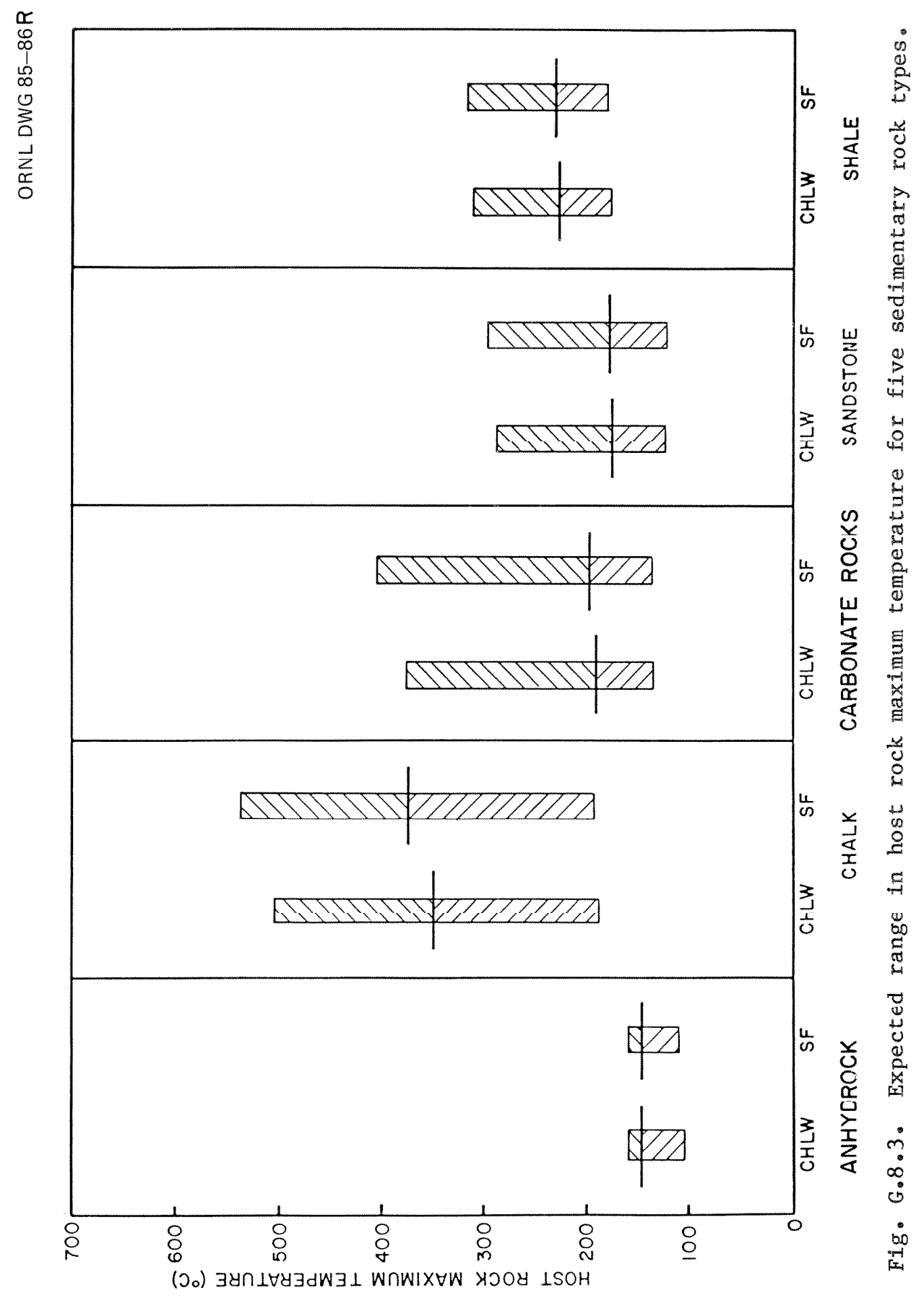




\section{G.8.3.1 Average Backfill Temperature}

A summary of the range of the average backfill temperatures is shown in Fig.G.8.4. The minimum, mean, and maximum average backfill temperatures are displayed in this figure for CHLW and SF emplacement for each of the five sedimentary rock types.

The magnitude and range of the average backfill temperature are the lowest for anhydrock and the highest for chalk for both CHLW and SF emplacement. The maximum CHLW temperature ranges from 82 to $117^{\circ} \mathrm{C}$ in anhydrock, with a mean value of $107^{\circ} \mathrm{C}$. In contrast, the maximum CHLW temperatures in chalk range from 129 to $279^{\circ} \mathrm{C}$, with a mean value of $194^{\circ} \mathrm{C}$. Similarly, the minimum, mean, and maximum SF temperatures for anhydrock are 82,105 , and $113^{\circ} \mathrm{C}$, respectively, while the $\mathrm{SF}$ temperatures range from 129 to $280^{\circ} \mathrm{C}$ in chalk, with a mean value of $194^{\circ} \mathrm{C}$. Thus, anhydrock appears to be the most favorable rock type and chalk the least favorable for the average backfill temperature.

The magnitude and range of the average backfill temperature for the remaining three rock types are similar for both waste types and fall within the range encompassed by anhydrock and chalk. The maximum CHLW temperature in carbonate rocks ranges from 111 to $186^{\circ} \mathrm{C}$, with a mean value of $137^{\circ} \mathrm{C}$. Similarly, the minimum, mean, and maximum CHLW temperatures in sandstone are 94,129 , and $185^{\circ} \mathrm{C}$, respectively, and in shale are 110,144 , and $206^{\circ} \mathrm{C}$, respectively. Finally, the SF temperatures range from 114 to $181^{\circ} \mathrm{C}$ in carbonate rocks, 95 to $184^{\circ} \mathrm{C}$ in sandstone, and 110 to $198^{\circ} \mathrm{C}$ in shale with mean values of 138,129 , and $142^{\circ} \mathrm{C}$, respectively. Therefore, these three rock types compare similarly for this response and are more favorable than chalk and somewhat less favorable than anhydrock.

\section{G.8.3.2 Near-Field/Far-Field Interface Temperature}

A summary of the range of the interface maximum temperature is shown in Fig. G.8.5. This figure shows the minimum, mean, and maximum interface temperature for CHLW and SF emplacement for each of the five sedimentary rock types.

The magnitude and range of the interface temperature is the lowest for anhydrock and the highest for chalk for both CHLW and SF emplacement. The maximum CHLW temperature ranges from 72 to $96^{\circ} \mathrm{C}$ in anhydrock with a mean of $92^{\circ} \mathrm{C}$. In contrast, the maximum range for CHLW in chalk is from 110 to $210^{\circ} \mathrm{C}$, with a mean value of $151^{\circ} \mathrm{C}$. Similarly, the $\mathrm{SF}$ temperature for anhydrock ranges from 76 to $102^{\circ} \mathrm{C}$, with a mean value of $95^{\circ} \mathrm{C}$, while the SF temperature for chalk ranges from 118 to $233^{\circ} \mathrm{C}$, with a mean value of $169^{\circ} \mathrm{C}$. Thus, anhydrock appears to be the most favorable rock type and chalk the least favorable with respect to the interface temperature response.

The magnitude and range of the near-field/far-field interface temperature for the remaining three rock types are similar for both waste types and fall within the range encompassed by anhydrock and chalk. The 


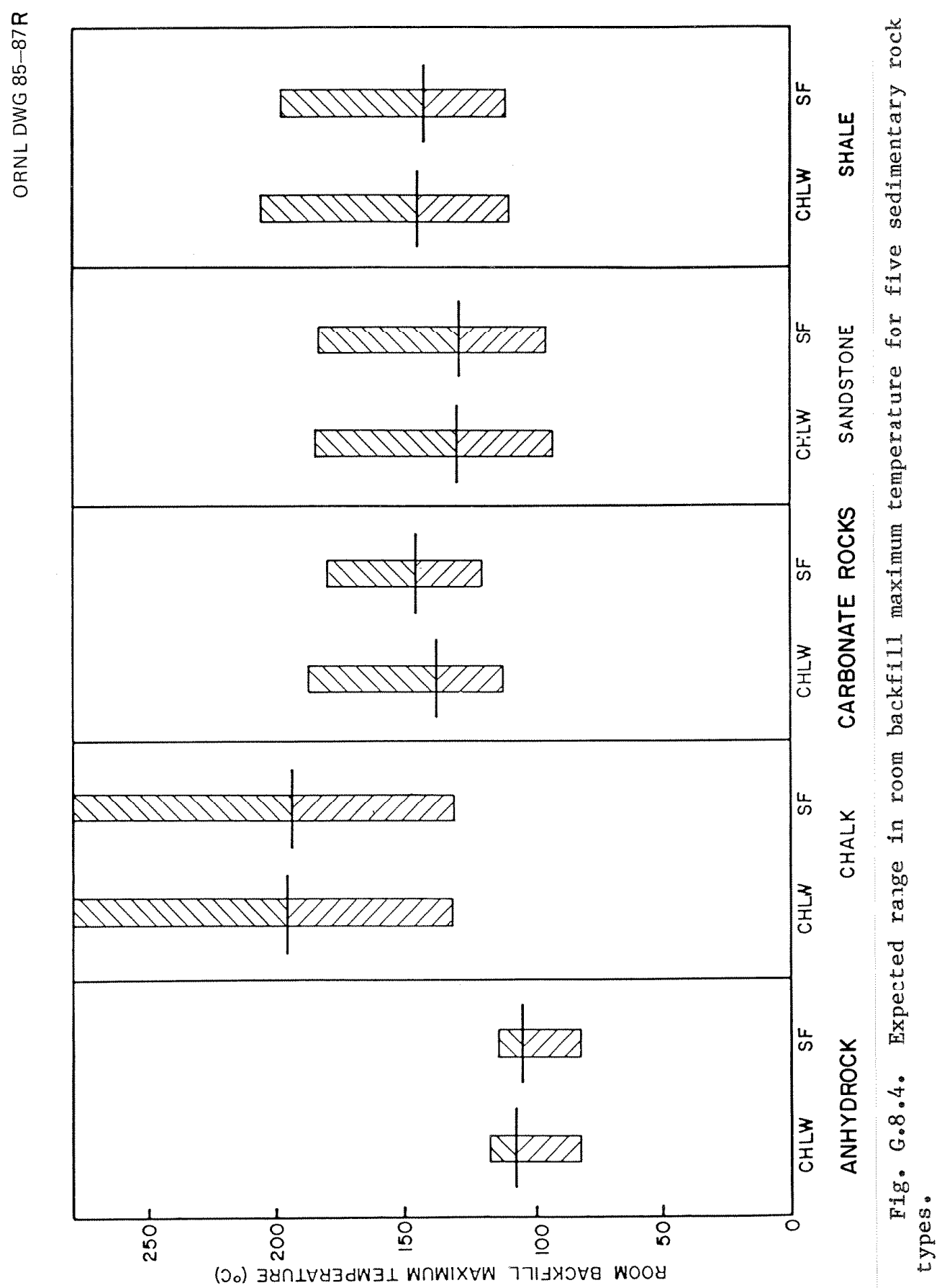




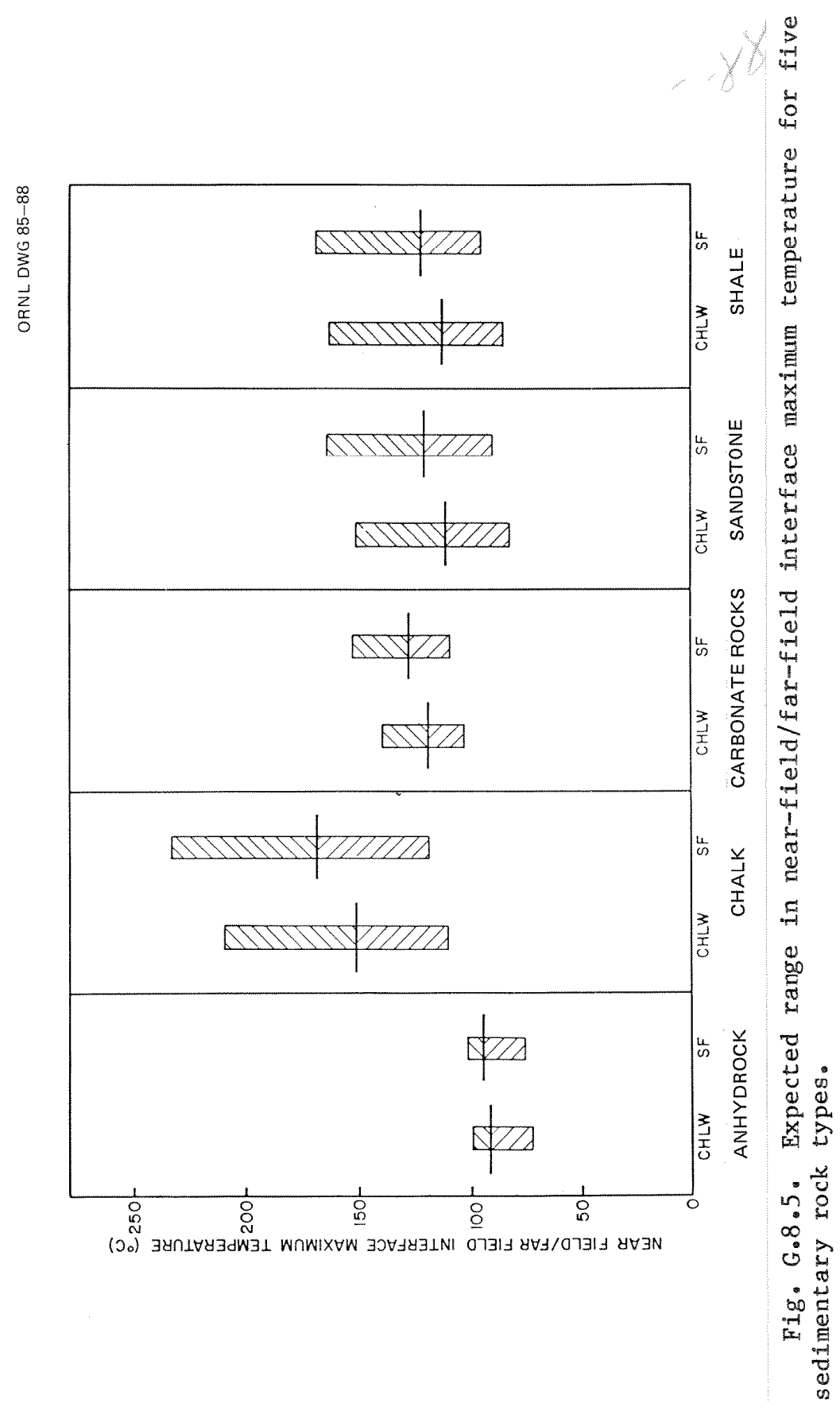


maximum CHLW temperature in carbonate rocks ranges from 102 to $139^{\circ} \mathrm{C}$, with a mean value of $119^{\circ} \mathrm{C}$. Similarly, the minimum, mean, and maximum CHLW temperatures in sandstone are 82,111 , and $151^{\circ} \mathrm{C}$, respectively, and in shale are 85,111 , and $162^{\circ} \mathrm{C}$, respectively. Finally, the SF temperatures range from 109 to $153^{\circ} \mathrm{C}$ in carbonate rocks, from 90 to $164^{\circ} \mathrm{C}$ in sandstone, and from 94 to $169^{\circ} \mathrm{C}$ in shale, with mean values of 128,120 , and $121^{\circ} \mathrm{C}$, respectively. Thus, these three rock types compare similarly for this response and are more favorable than chalk, but slightly less favorable than anhydrock.

\section{G.8.3.3 Host Rock Temperature (Isolation Period)}

A summary of the range in the maximum rock temperature is shown in Fig. G.8.6. This figure illustrates the minimum, mean, and maximum host rock temperature at 1000 years for CHLW and SF emplacement in each of the five sedimentary rock types.

In general, the GF temperatures for this response are somewhat higher than the corresponding CHLW temperatures. In addition, differences among the five rock types reflect differences in initial thermal conditions, as well as differences in material properties, in particular, thermal conductivity.

The magnitude and range of the host rock temperature are the lowest for anhydrock and the highest for chalk for both waste emplacements. The host rock temperature for $\mathrm{CHLW}$ ranges from 43 to $49^{\circ} \mathrm{C}$ in anhydrock with a mean value of $47^{\circ} \mathrm{C}$. In contrast, the host rock CHLW temperature in chalk ranges from 77 to $113^{\circ} \mathrm{C}$, with an expected value of $96^{\circ} \mathrm{C}$. The minimum, mean, and maximum SF temperatures for anhydrock are 75, 84, and $88^{\circ} \mathrm{C}$, respectively, while the $\mathrm{SF}$ temperatures for chalk range from 128 to $226^{\circ} \mathrm{C}$, with a mean value of $172^{\circ} \mathrm{C}$. Therefore, for the host rock isolation period temperature, anhydrock appears to be the most favorable and chalk the least favorable.

The magnitude and range of the host rock temperature for the remaining three rock types vary for each waste type with SF temperatures being considerably higher than CHLW temperatures. The maximum CHLW temperature in carbonate rocks ranges from 64 to $88^{\circ} \mathrm{C}$, with a mean value of $74^{\circ} \mathrm{C}$. Similarly, the minimum, mean, and maximum CILW temperatures in sandstone are 48,66 , and $89^{\circ} \mathrm{C}$, respectively, and in shale are 50,57 , and $64^{\circ} \mathrm{C}$, respectively. Finally, the SF temperatures range from 121 to $189^{\circ} \mathrm{C}$ in carbonate rocks, from 89 to $160^{\circ} \mathrm{C}$ in sandstone, and 94 to $130^{\circ} \mathrm{C}$ in shale, with mean values of 146,117 , and $111^{\circ} \mathrm{C}$, respectively. These three rock types are all more favorable than chalk but somewhat less favorable than anhydrock.

\subsection{FAR-FIELD RESULTS}

The thermal responses evaluated with far-field models include the maximum temperature at $85 \%$ of the repository depth $(595 \mathrm{~m})$, the maximum shaft temperature, and the maximum near-surface ( $5 \mathrm{~m}$ depth) temperature rise. The location of the occurrence of these responses is known a 


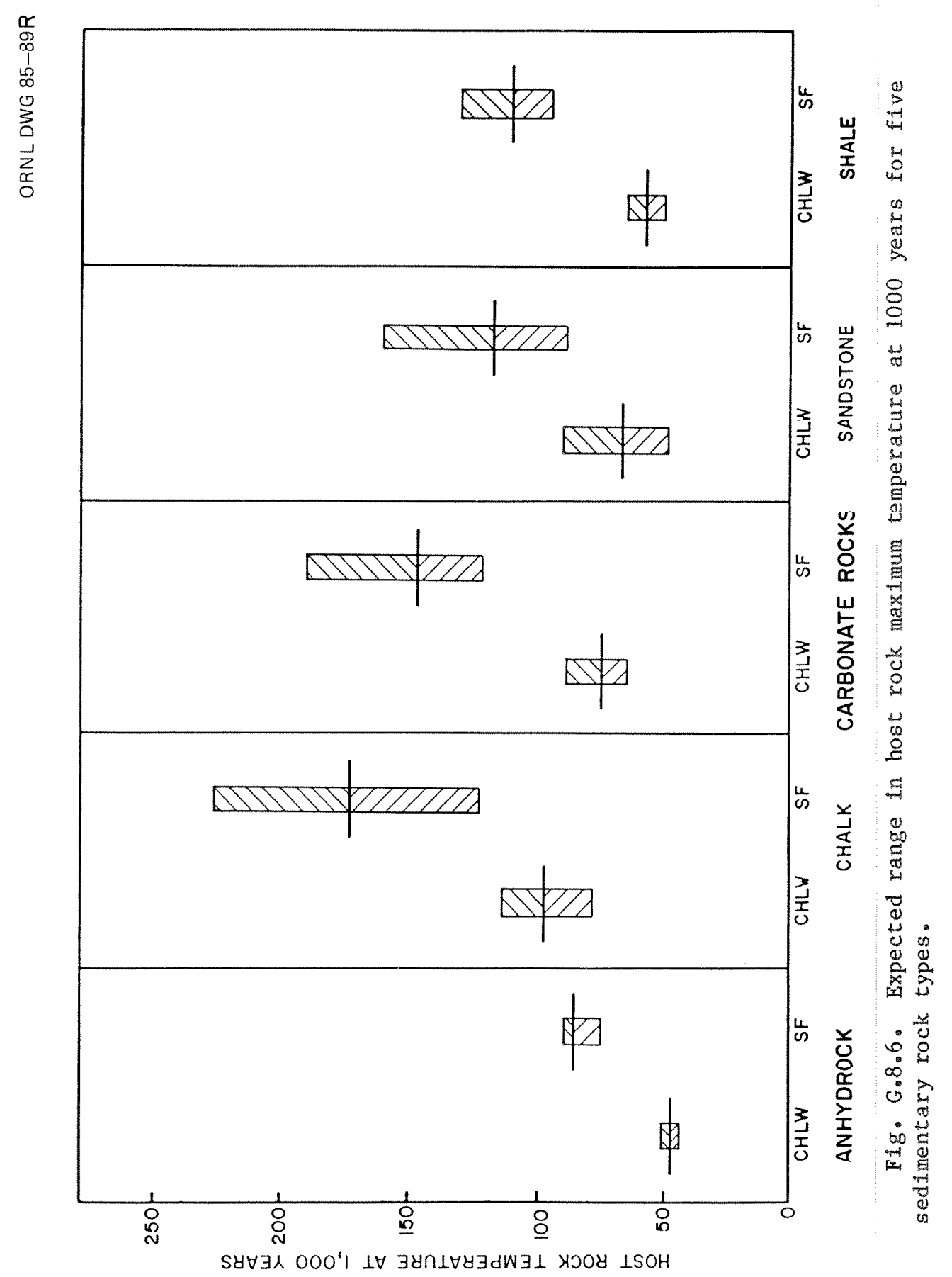


priori. The maximum temperature at $85 \%$ of the repository depth and the maximum near-surface temperature rise occur directly above the repository center at depths of $595 \mathrm{~m}$ and $5 \mathrm{~m}$, respectively. The maximum temperature of the shaft occurs at its base (i.e., at a depth of $700 \mathrm{~m}$ ) $250 \mathrm{~m}$ from the repository edge. These responses were calculated from time of emplacement to 10,000 years, which encompasses the time required to reach maximum values for each response, waste type, and rock type. Each of these responses is discussed separately below.

\section{G.8.4.1 Temperature at 595-m Depth}

A summary of the range in the maximum temperature at a depth of 595 $\mathrm{m}$ is shown in Fig. G.8.7. The minimum, mean, and maximum temperatures are displayed in this figure for CHLW and SF emplacement in each of the five sedimentary rock types.

In general, the SF temperatures at this location are somewhat higher Lhan the corresponding CHLW temperatures. In addition, differences among the five rock types reflect differences in initial thermal conditions, as well as differences in material properties, in particular thermal conductivity.

The magnitudes and ranges for the 595-m depth temperature are the lowest for anhydrock and the highest for chalk for both waste emplacements. The maximum CHLW temperature ranges from 40 to $49^{\circ} \mathrm{C}$ in anhydrock with a mean value of $47^{\circ} \mathrm{C}$. In contrast, the maximum CHLW temperatures in chalk range from 65 to $80^{\circ} \mathrm{C}$, with a mean value of $71^{\circ} \mathrm{C}$. Similarly, the minimum, mean, and maximum SF temperatures for anhdyrock are 54 , 60 , and $62^{\circ} \mathrm{C}$, respectively, while the $\mathrm{SF}$ temperatures range from 101 to $125^{\circ} \mathrm{C}$ in chalk, with a mean value of $112^{\circ} \mathrm{C}$.

The magnitude and range of the 595-m depth temperature for the remaining rock types fall within the range encompassed by anhydrock and chalk. The maximum CHLW temperature in carbonate rocks ranges from 55 to $63^{\circ} \mathrm{C}$. with a mean value of $59^{\circ} \mathrm{C}$. Similarly, the minimum, mean, and maximum CHLW temperatures in sandstone are 48,61 , and $74^{\circ} \mathrm{C}$, respectively, and in shale are 38,43 , and $61^{\circ} \mathrm{C}$, respectively. Finally, the $\mathrm{SF}$ temperatures range from 76 to $86^{\circ} \mathrm{C}$ in carbonate rocks, 68 to $102^{\circ} \mathrm{C}$ in sandstone, and 58 to $85^{\circ} \mathrm{C}$ in shale, with wean values of 81,86 , and $69^{\circ} \mathrm{C}$, respectively. Thus, anhydrock appears to be the most favorable rock type and chalk the least favorable with respect to this response, with the remaining rock types falling somewhere in between and comparing similarly.

\section{G.8.4.2 Shaft Temperature}

A sumnary of the range in the maximum shaft temperatures is shown in Fig. G.8.8. Displayed in this figure are the minimum, mean, and maximum shaft temperatures for both CHLW and SF emplacement in each of the five rock types.

In general, the spent fuel maximum shaft temperatures are somewhat higher than similax temperatures fur CHLW. In didilium, difrenemces 


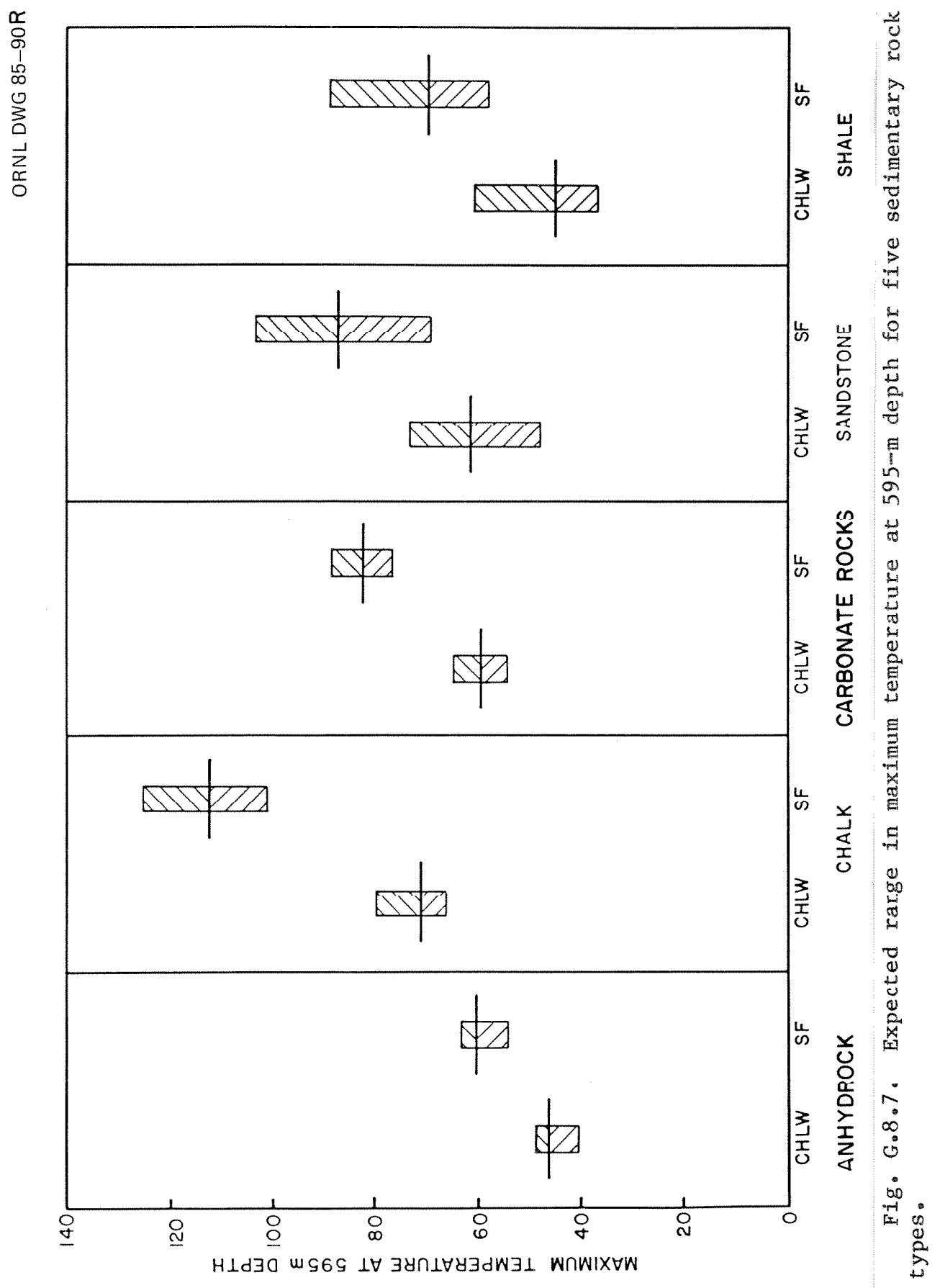




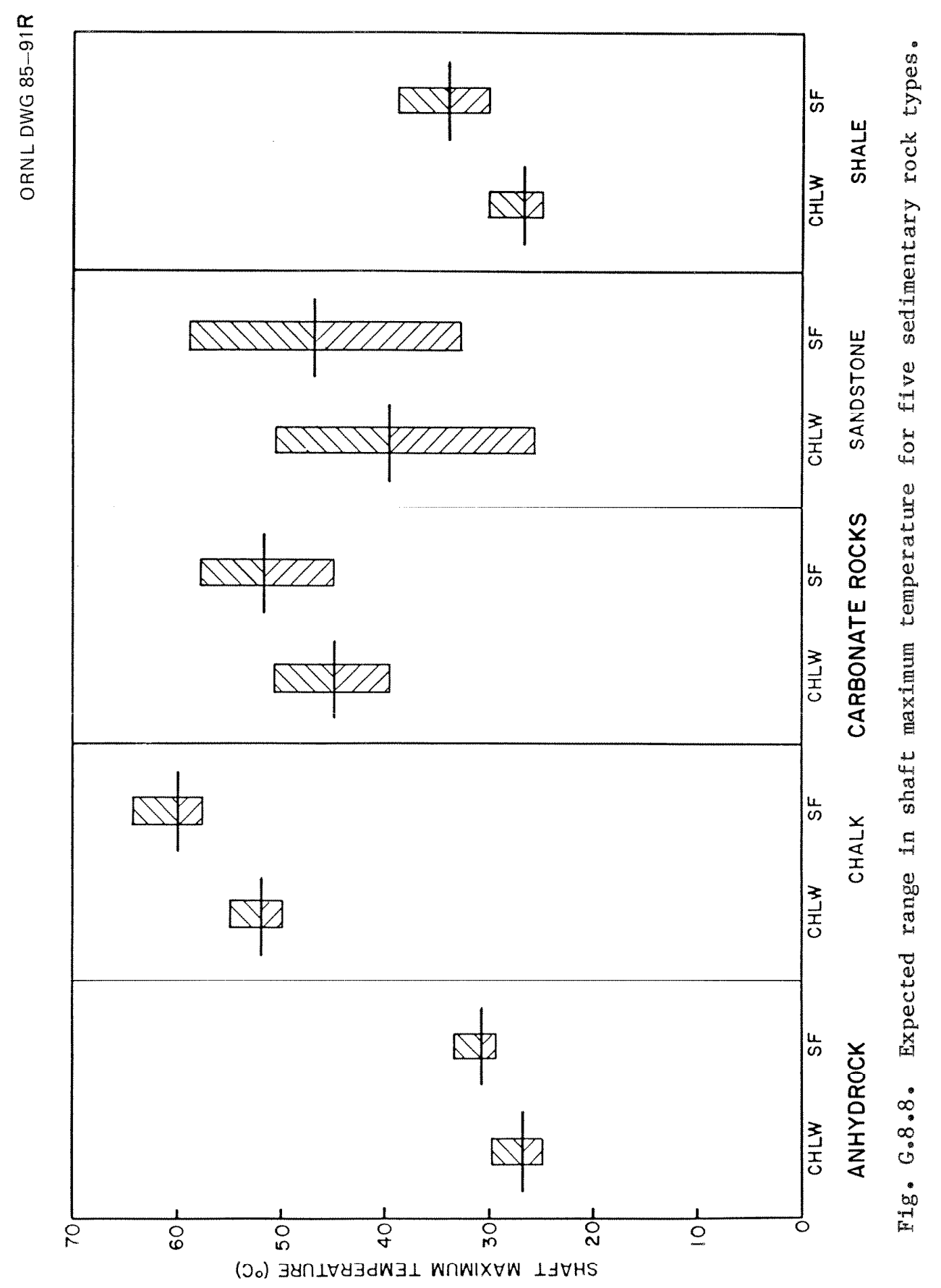


in shaft temperatures among the five rock types are caused by the differences in the initial temperature conditions almost exclusively.

The magnitude and range of the maximum shaft temperatures are the lowest for anhydrock and shale. The highest shaft temperatures are observed in chalk for both waste types. The maximum CHLW temperatures range from 25 to $29^{\circ} \mathrm{C}$ in anhydrock and 24 to $30^{\circ} \mathrm{C}$ in shale, with mean values of $26^{\circ} \mathrm{C}$ for both rock types. In contrast, the maximum CHLW temperatures in chalk range from 49 to $54^{\circ} \mathrm{C}$, with a mean value of $52^{\circ} \mathrm{C}$. The minimum, mean, and maximum SF temperatures for anhydrock are 29,31 , and $33^{\circ} \mathrm{C}$, respectively, and 30,34 , and $38^{\circ} \mathrm{C}$, respectively, for shale. In contrast, the maximum spent fuel temperatures in chalk range from 57 to $64^{\circ} \mathrm{C}$, with a mean value of $60^{\circ} \mathrm{C}$.

The magnitude and range of the maximum shaft temperature for carbonate rocks and sandstone exhibit the highest range in response, with magnitudes somewhat lower than chalk. The CHLW temperatures in carbonale rucks range rrou $39 \mathrm{Lo} 50^{\circ} \mathrm{C}$, with a mean value of $44^{\circ} \mathrm{C}$, while sandstone ranges from 25 to $49^{\circ} \mathrm{C}$, with a mean value of $38^{\circ} \mathrm{C}$. Finally, the $\mathrm{SF}$ temperatures range from 44 to $57^{\circ} \mathrm{C}$ in carbonate rocks and 32 to $58^{\circ} \mathrm{C}$ in shale. with mean values of 51 and $46^{\circ} \mathrm{C}$, respectively. Thus, anhydrock and shale appear to be the most favorable rock types with respect to this response and chalk the least favorable. The range in the shaft temperatures for carbonate rocks and sandstone are the greatest.

\section{G.8.4.3 Near-Surface Temperature Rise}

A summary of the range in the maximum near-surface temperature rise is shown in Fig. G.8.9. The minimum, mean, and maximum near-surface temperature rises for both CHLW and SF emplacement are displayed in this figure for each of the five sedimentary rock types.

In genera1, the near-surface temperature rise is negligible for all rock types and waste types. However, the near-surface thermal perturbation for spent fuel emplacement is somewhat higher than for CHLW emplacement. Differences in the magnitude of this response among the five rock types reflect differences in the material properties, primarily thermal conductivity.

The magnitude and range of the near-surface temperature rise are the lowest in sandstone and shale for both waste types. Anhydrock yields the highest near-surface thermal perturbation. The magnitude and range for chalk and carbonate rocks are similar and somewhat less than anhydrock. Thus, sandstone and shale appear to be the most favorable rock types compared with this response, whereas, anhydrock is the least favorable. 


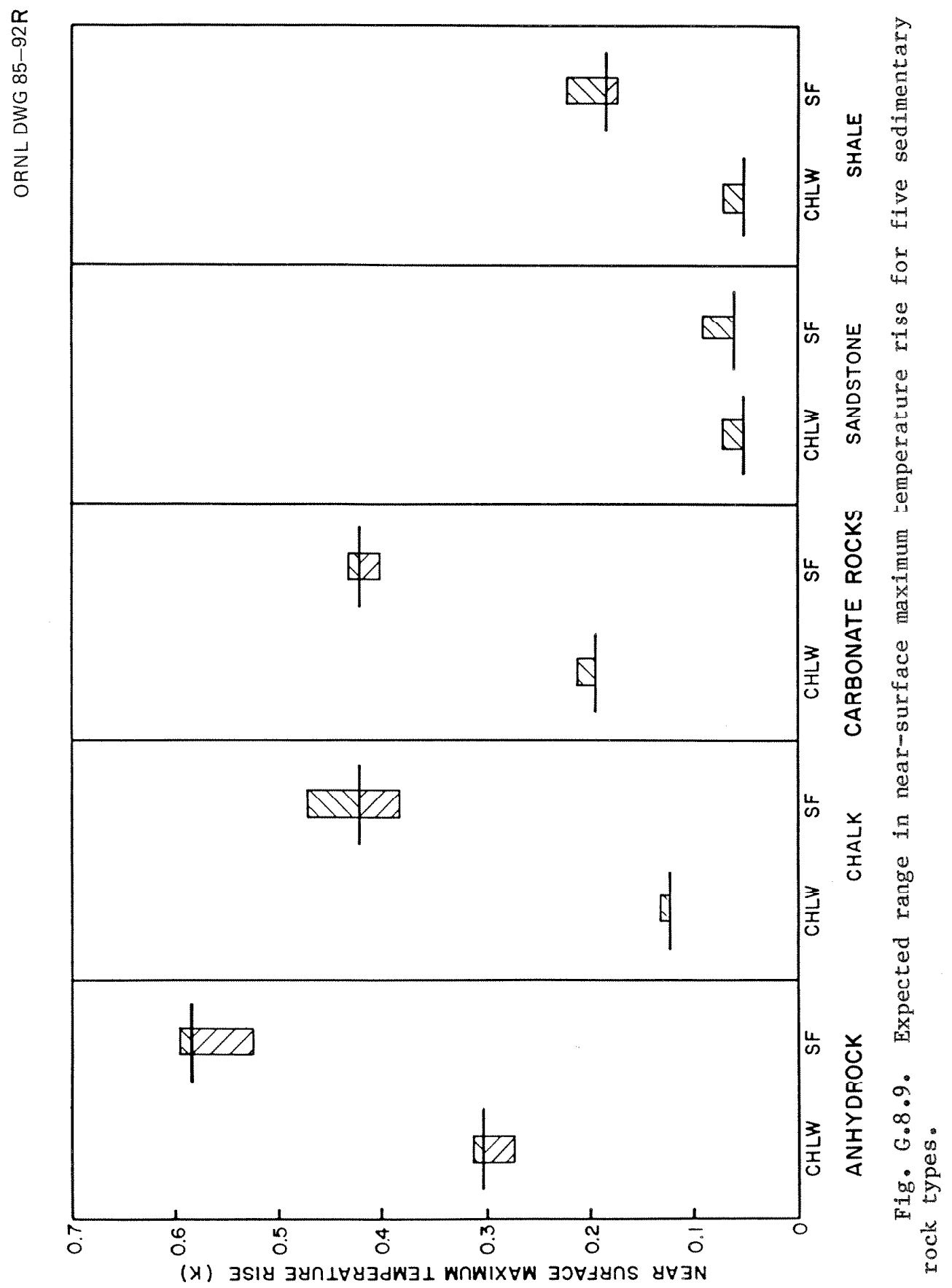




\section{G.9 MECHANICAL ANALYSIS}

\section{G.9.1 METHODS}

Three features of the rock mechanics aspects of the disposal room are considered in this analysis:

1. mineability,

2. constructibility, and

3. operationa1 stability.

For purposes of this report, mineability is defined as the evaluation of the relative ease of excavation in a rock mass and subsurface conditions that may adversely affect personnel and equipment during excavation operations. Intuitively, one would expect that strong rocks would be more difficult co excavace than weak rocks and that the fracture spacing would also adversely affect the excavation process, particularly when highly mechanized methods are used. The data herein relate to tunnel-boring machines (TBMs) and are probably the most recent data available to assess the mineability of sedimentary rocks considered in this report.

The influence of rock strength on penetration rates of TBMs has been addressed by Robbins (ROBBINS 1976) as reported by Clark et al. (CLARK 1980). As of 1976, the influence of rock strength on penetration rate of TBMs is shown in Fig. G.9.1. As expected, the penetration rate declines with increasing strength. The most dramatic drop in penetration rate occurs in going from the low-to-intermediate-strength rocks ( $\sim 50 \mathrm{MPa}$ ) to the medium-to-high-strength rocks ( 100 MPa). These rates are expected to increase over the years as TBM technology increases with the rate approaching $\sim 8.5 \mathrm{~m} / \mathrm{h}$ by mid-to-late $1980 \mathrm{~s}$ for rock with a strength of $50 \mathrm{MPa}$.

The influence of fracture frequency on mineability is illustrated in Fig. G.9.2 where percent of maximum advance rate is plotted vs the RQD. Rock Quality Designation is a modified core recovery index which represents the percentage of 54-mm-d1am core recovered incact that has a length-to-diameter ratio $>2$. Rock masses with RQDs approaching 100 are considered to be excellent while those with RQDs less than $\sim 35$ are essentially rubble.

Note that Fig. G.9.2 refers to "advance rate" while Fig. G.9.1 refers to "penetration rate." In this context, penetration rate refers to the instantaneous rate of forward progress while advance rate refers to the rate of progress averaged over some period of time $\left(e_{. g} ., 1\right.$ d) or over some length of the tunnel. Thus, one could expect advance rates approaching the penetration rate only for rock that would be classified as excellent. As shown in Fig. G.9.2, the quality of the rock has an extremely important influence on the advance rate and therefore the mineability. 


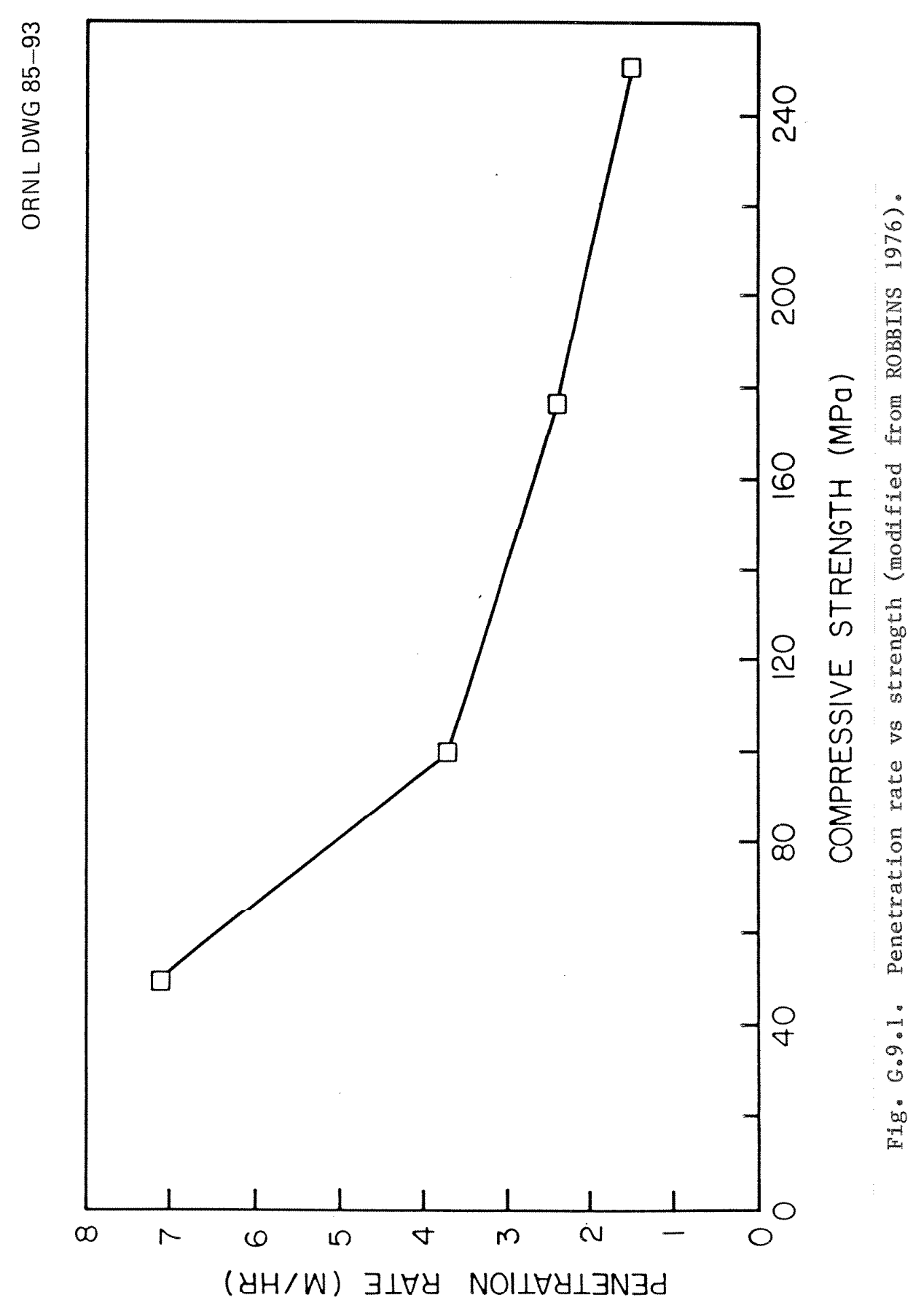


ORNL DWG 85-95

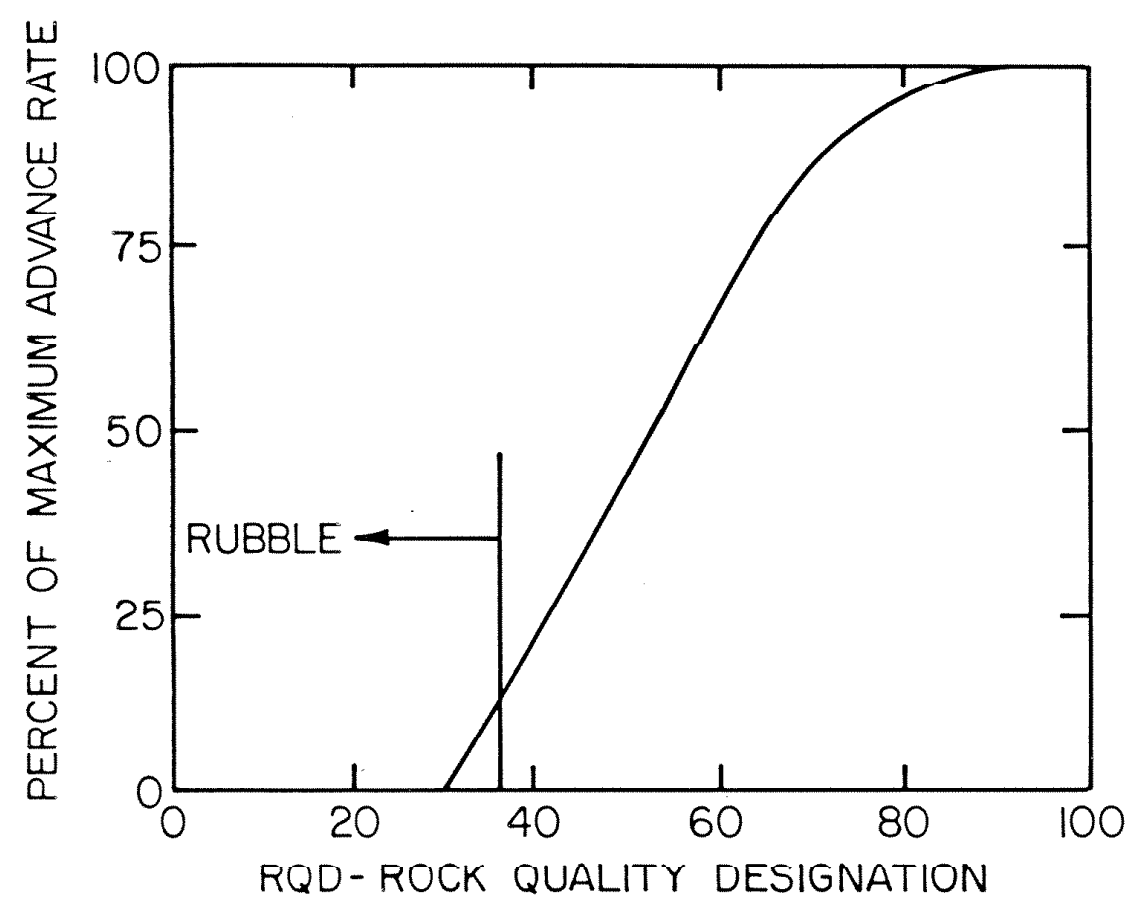

Fig. G.9.2. Approximation of effect of RQD on advance rate. 
Tunneling costs have been divided into three categories by Clark et al. (CLARK 1980), excavation, water, and lining. Figure G.9.3 shows data adapted from Clark and coworkers (CLARK 1980) in the form of relative excavation costs vs rock strength for various values of RQD. Excavation costs are a good measure of mineability of the various rock types and Fig. G.9.3 combines the effects shown separately on Figs. G.9.1 and G.9.2. If we use the mean values of compressive strength and their one standard deviation values from Table G.6.1, it is apparent that variations in $R Q D$, which are site specific, have a much greater influence on mineability than variations in compressive strength.

Constructibility involves evaluations of pillar and room stabilities on the basis of rock matrix properties and numerical models and pillar and roof stability and necessary support requirements on the basis of rock mass classification. For the evaluation of pillar and room stabilities on the basis of rock matrix properties, using a numerical model, unconfined compressive strength, Poisson's ratio, and Young's modulus are considered. In this regard, these rock matrix properties are used in the boundary element model to determine to what degree each property can be used as a ranking criterion for constructibility over the entire range of in situ stresses considered possible for the rock types under examination. Many empirical guidelines or formulae are available for evaluating or designing pillars in underground excavations [e.g., see Abe1 and Hoskins (ABEL 1976) for a review of methods]. Typically, these formulae involve one or more of the quantities: pillar size, in situ stress, unconfined compressive strength, angle of internal friction for the rock or joints, and a term for relating rock mass strength to laboratory determined rock strength. These formulae will not be used in the evaluation or ranking of the five rock types because of a lack of appropriate information. However, the implications of the formulae will be discussed later.

In the context of this study, operational stability relates to the ability of the opening to remain serviceable during the first 5 years of the repository operational period when the rock is undergoing heating and the rooms are not backfilled. Evaluation of operational stability requires consideration of the thermally induced stresses.

The mean values and standard deviations of unconfined compressive strength, Poisson's ratio, and Young's modulus for all five of the rock types are given in Table G.6.1. This table also shows the range for each of these rock properties (the range is considered to be the mean plus or minus one standard deviation) for all of the five rock types. These ranges are used in the boundary element mode1 to determine which of the three rock properties should be used in the ranking of the rock types with respect to constructibility. The criterion or index used in this study for ranking with respect to constructibility is the average ratio of the rock unconfined compressive strength to the tangential stress around the room periphery from the midheight of the rib to the center of the roof. Such a criterion neglects the differences in frictional properties of the five rock types. The frictional character of rock enables a rock mass to mobilize greater shear strength as the 


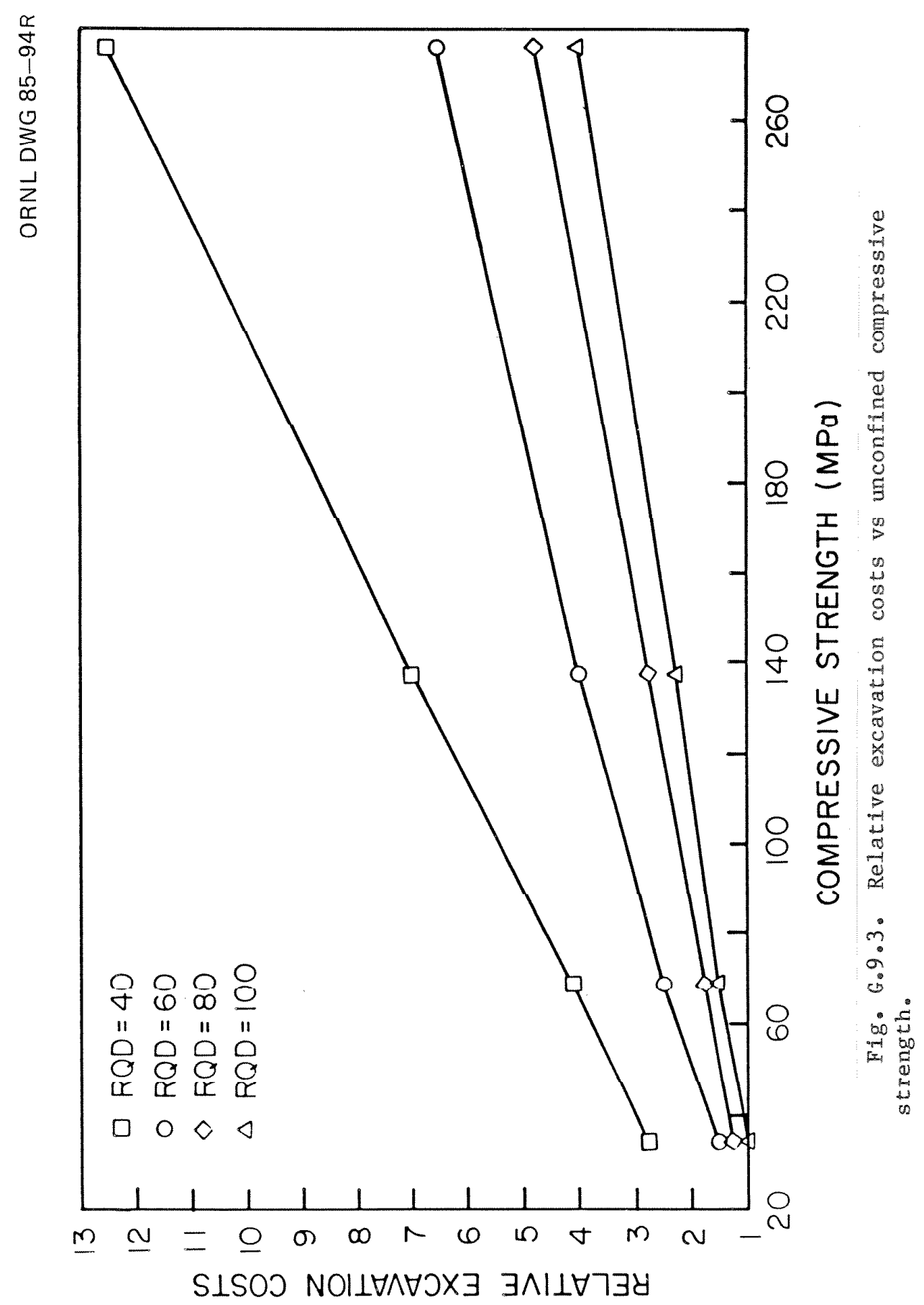


mean stress or pressure in the rock increases. Thus, a portion of the rock mass slightly removed from the room periphery (into the pillar) would have a greater shear strength than the rock directly on the room periphery, assuming that the mean stress is greater. From observation of the information in Tables 6.6 .1 , it is clear that the greater the compressive strength, the greater the angle of internal friction for these five rock types. Based on this observation, the unconfined compressive strength and angle of internal friction do not appear to be independent properties and either can be used to rank the rock types with respect to constructibility.

Table G.9.1. Boundary element computer code input data

\begin{tabular}{cccc}
\hline Run & $\begin{array}{c}\text { Young's } \\
\text { modulus (MPa) }\end{array}$ & $\begin{array}{c}\text { Poisson's } \\
\text { ratio }\end{array}$ & $\begin{array}{c}\text { Unconfined compressive } \\
\text { strength (MPa) }\end{array}$ \\
\hline 1 & 87 & 0.409 & 163 \\
2 & 1.6 & 0.409 & 163 \\
3 & 82 & 0.09 & 163 \\
4 & 1.6 & 0.09 & 163 \\
5 & 82 & 0.409 & 13 \\
6 & 1.6 & 0.409 & 13 \\
7 & 82 & 0.09 & 13 \\
8 & 1.6 & 0.09 & 13 \\
\hline
\end{tabular}

\section{G.9.2 RESULTS}

A11 possible combinations of the "maximum" and "minimum" values of the three rock properties considered in this analysis (unconfined compressive strength, Poisson's ratio, and Young's modulus) result in eight boundary element evaluations for each of the three different initial in situ stress states. These different computer code evaluations are given in Table G.9.1. The average strength-to-stress ratios along the room periphery from the rib midheight to the roof center for each of the computer code evaluations are shown in Table G.9.2. The change in the average strength-to-stress ratio resulting from a change in any one of the three input parameters (rock properties) is called the main effect of that input parameter. The main effects of each of the three rock properties are also shown in Table G.9.2. 
The main effect of each of the rock properties is calculated by subtracting the sum of the strength-to-stress ratio for all of the computer runs with the minimum value of the particular parameter from the sum of the strength-to-stress ratio for all of the computer runs with the maximum value of the particular parameter. This quantity is then divided by 4 .

The range of the mechanical properties for all five rock types has been examined. The results show that the unconfined compressive strength contributes 96 to $99 \%$ of the range in the possible strengthto-stress ratios along the room periphery for any particular rock type. Thus, the unconfined compressive strength is used as the mechanical rock propercy to rank the variuus rucks presented in sect. G.11.

Table G.9.2. Strength-to-stress ratios and main effects

\begin{tabular}{|c|c|c|c|c|}
\hline \multirow[b]{2}{*}{ Run } & \multicolumn{4}{|c|}{ 3trength-to-stress ratios } \\
\hline & & $k_{0}=0.5$ & $\mathrm{~K}_{0}=1$ & $k_{0}=1.5$ \\
\hline 1 & & 15.59 & 5.44 & 5.02 \\
\hline 2 & & 15.59 & 5.44 & 5.02 \\
\hline 3 & & 14.45 & 5.37 & 4.96 \\
\hline 4 & & $14 \cdot 45$ & 5.37 & 4.96 \\
\hline 5 & & 1.24 & 0.435 & 0.400 \\
\hline 6 & & 1.24 & 0.435 & 0.400 \\
\hline 7 & & 1.155 & 0.435 & 0.395 \\
\hline 8 & & 1.155 & 0.435 & 0.395 \\
\hline & & & Effects & \\
\hline $\mathrm{c}_{0}$ & + & $13.81(96 \%)$ & $+4.97(99 \%)$ & $+4.59(99 \%)$ \\
\hline E & & 0 & 0 & 0 \\
\hline$v$ & + & $0.6125(4 \%)$ & $+0.035(1 \%)$ & $+0.033(1 \%)$ \\
\hline Range & & 14.435 & 5.005 & 4.625 \\
\hline
\end{tabular}

aThe average stress concentration factor along the room periphery from the rib midheight to the roof center, on the basis of the integration of the point-wise stress concentration factors over the peripheral distance, is 1.38 for $K_{0}=0.5$, 1.8 for $K_{0}=1$, and 2.2 for $K_{0}=1.5$. 


\section{G.10 PERFORMANCE ASSESSMENT}

The performance of the repository designs for each of the five sedimentary rock types is evaluated in this section. The thermal and mechanical responses reported in sects. G.8 and G.9, respectively, are compared to a set of quantitative performance constraints developed in Sect. G.5. The performance of the repository (for each of the five sedimentary rock types) is evaluated using the results.

A summary of the thermal and mechanical results presented in Sects. G.8 and G.9, respectively, are shown in Tables G.10.1 through G.10.5 for each sedimentary rock type. Each table presents the expected (mean) responses for both waste types and a comparison to the performance constraints presented in Sect. G.5. The values footnoted with an "*" indicate possible violation of each respective constraint.

Anhydrock satisfies all of the performance constraints with the possible exception of the operational stability of the disposal room (Table G.10.1). This indicates that anhydrock offers very favorable site conditions and thermal characteristics for high-level waste emplacement, since all of the thermal constraints are easily satisfied. In addition, the strength characteristics of anhydrock are also more than adequate, since the mineability and constructibility of the disposal roons appears to be satisfactory. However, possible violation of the thermomechanical criterion indicates that anhydrock may exhibit undesirable mechanical characteristics (particularly the elastic modulus) relative to highlevel waste emplacement. Thus, for anhydrock, one desires a site with an in situ modulus as low as possible to increase the thermomechanical stability of the disposal rooms.

Unlike anhydrock, chalk violates nearly all of the performance constraints for both CHLW and SF emplacement. The performance constraints that are satisfied are the shaft temperature and near-surface thermal perturbations (which are easily satisfied for all rock types) and the operational stability of the disposal rooms (Table G.10.2). This indicates that chalk exhibits favorable site conditions and mechanical characteristics. Violation of nearly all of the thermal constraints indicateo that chalk has undecirable thermal characterietice, primarily thermal conductivity. In addition, the strength characteristics of chalk are unsatisfactory since the mineability and constructibilty of the disposal rooms are questionable. Thus, it may be impossible to locate a chalk site for the repository designs considered in this analysis. In addition, severe reductions in the thermal loadings and modifications to the disposal room geometry are required for emplacement of both waste types in chalk.

Carbonate rocks (1imestone/dolostone) satisfy the mechanical performance constraints for high-level waste emplacement, but violate several thermal constraints especially for SF (Table G.10.3). This indicates that carbonate rocks exhibit very favorable site conditions and mechanical and strength charactgeristics. The thermal characteristics 
Table G.10.1. Summary of expected value (mean) results for a high-level waste repository in anhydrock

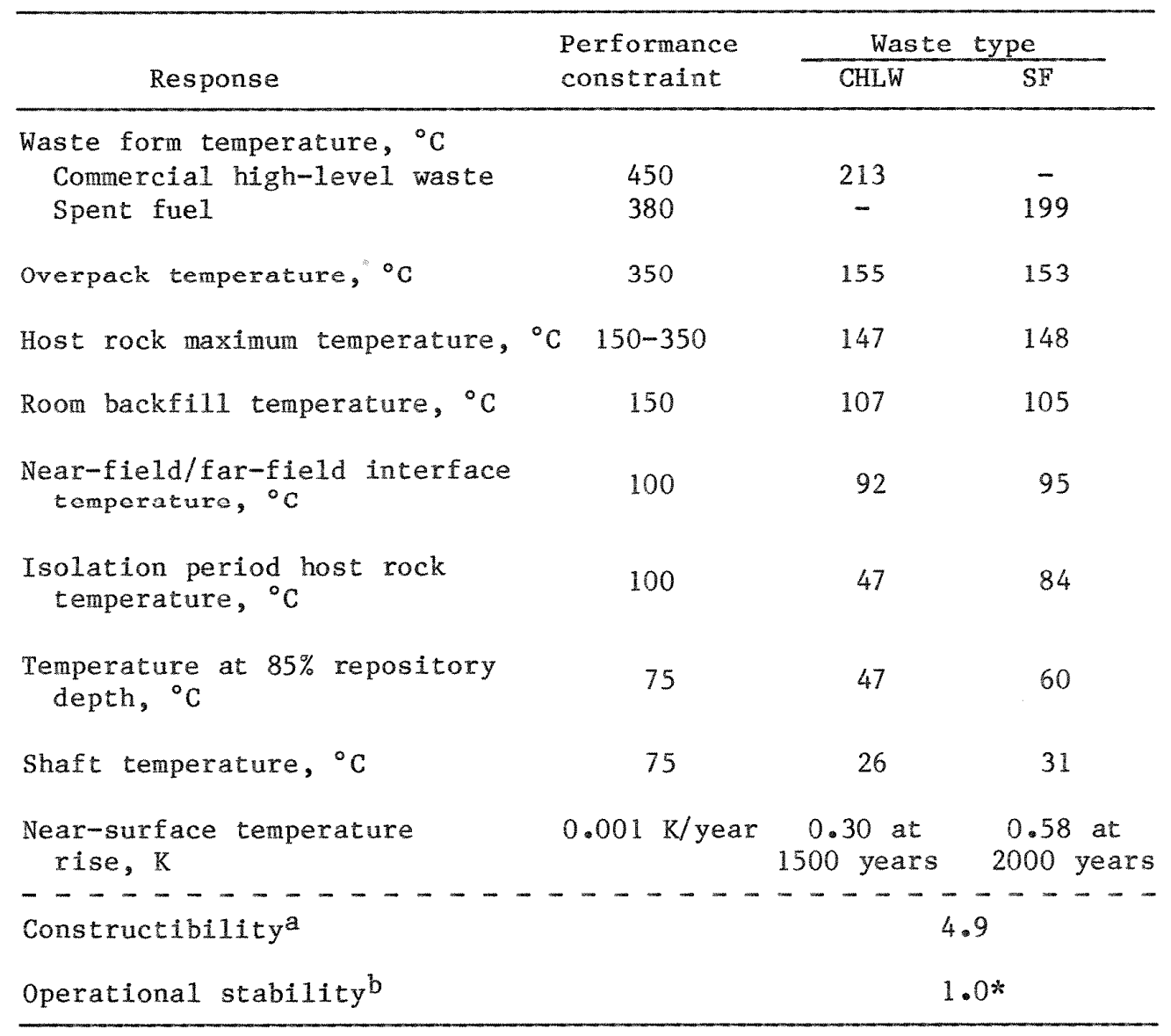

abefined as $\begin{aligned} \frac{\mathrm{C}_{\mathrm{O}}}{\sigma_{\mathrm{v}}}, \text { where } \mathrm{C}_{\mathrm{O}} & =\text { compressive strength and } \\ \sigma_{\mathrm{v}} & =\text { in situ vertical stress. }\end{aligned}$

bDefined as $\frac{C_{O}(1-\nu)}{E \alpha \Delta T}$ (see Sect. G.11.3.3, p. 168).

* Possible constraint violation. 
Table G.10.2. Summary of expected value (mean) results for a high-level waste repository in chalk

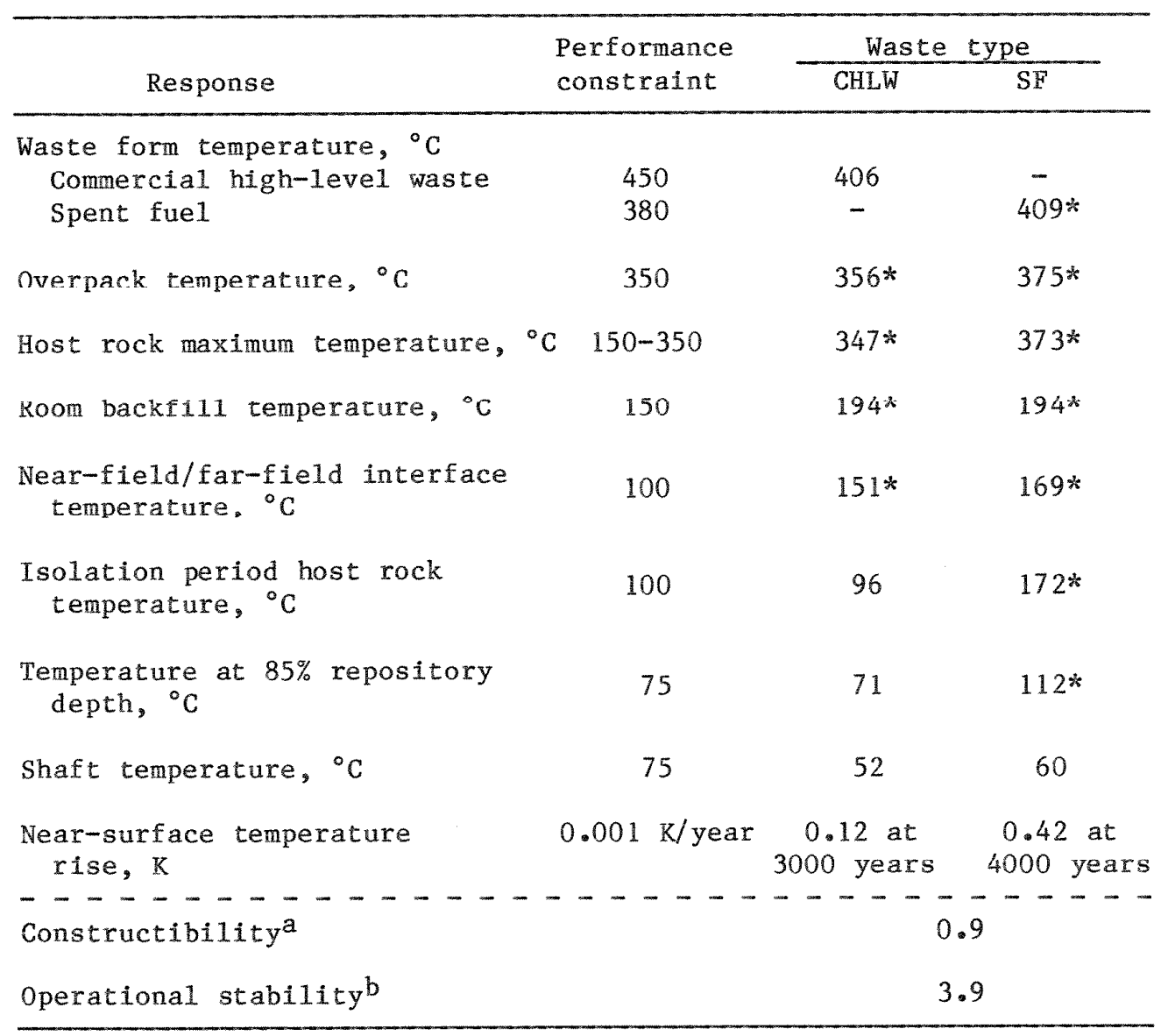

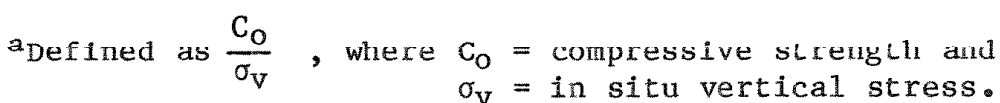

$b_{\text {Defined as }} \frac{C_{0}(1-\nu)}{E \alpha \Delta T}$ (see sect. G.11.3.3, p. 168).

* Possible constraint violation. 
Table G.10.3. Summary of expected value (mean) results for a high-level waste repository in carbonate rocks

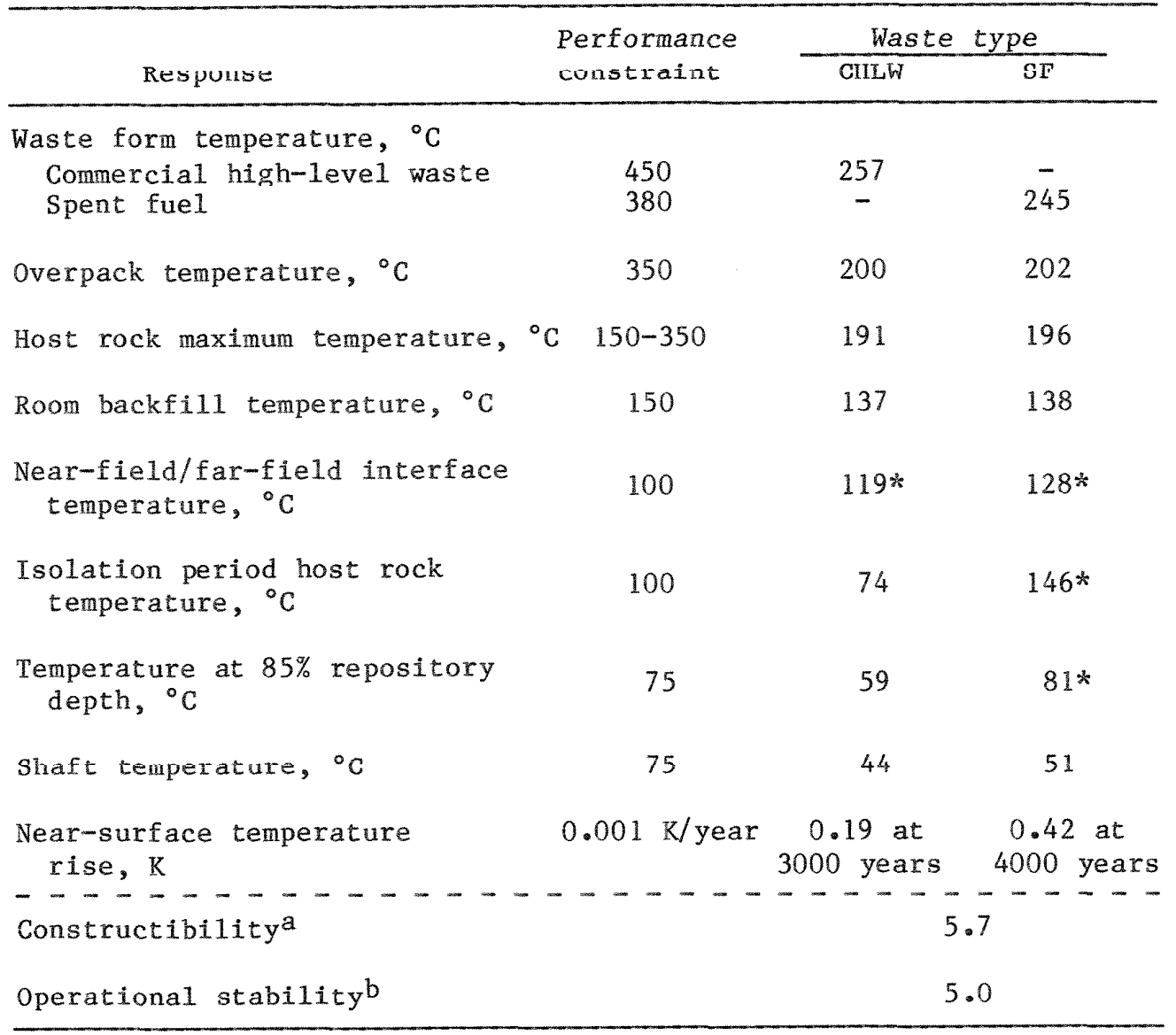

a Defined as $\frac{\mathrm{C}_{\mathrm{O}}}{\sigma_{\mathrm{v}}}$, where $\begin{aligned} \mathrm{C}_{\mathrm{O}} & =\text { compressive strength and } \\ \sigma_{\mathrm{v}} & =\text { in situ vertical stress. }\end{aligned}$

$b_{D e f i n e d}$ as $\frac{C_{0}(1-v)}{E \alpha \Delta T}$ (see Sect. G.11.3.3, p. 168).

* Possible constraint violation. 
of carbonate rocks appear to be more favorable for CHLW emplacement than for SF emplacement, since the long-term thermal responses for SF may be questionable. This indicates that modifications to the spent fuel design (reduction of the thermal loading) may be more desirable than locating a site with thermal characteristics favorable to both waste types. In addition, one desires a carbonate rock type generally free of argillaceous minerals so that a high temperature limit for the maximum rock temperature can be applied.

Sandstone nearly parallels the carbonate performance assessment (Table G.10.4). The site conditions for sandstone appear to be satisfactory for high-level waste emplacement. The strength and mechanical characteristics of sandstone appear to be satisfactory, since the mechanical responses of the disposal room are relatively high in comparison to the other rock types. The thermal characteristics are more sensitive to spent fuel emplacement than to CHLW emplacement. Thus, one desires a sandstone site with a thermal conductivity as possible to improve the SF thermal performance. Otherwise, reductions in the SF themal loadings may be required for sandstone.

Shale (argillaceous rock) satisfies nearly all of the performance constraints for the CHLW and SF designs used in this study, with exception of the borehole (rock) temperature (Table G.10.5). This indicates that shale exhibits favorable site conditions, mechanical characteristics, and strength characteristics for high-level waste emplacement. However, one desires a shale with a thermal conductivity as high as possible to improve the thermal performance of the borehole surface (rock), since the performance constraint for the maximum shale temperature probably lies near the lower end of the range presented $\left(1 . e ., 150^{\circ} \mathrm{C}\right)$. Reductions in the thermal loadings may be required for both waste types to satisfy this constraint.

A number of significant conclusions can be made from this performance assessment. Simply stated:

- For the repository designs used in this study, anhydrock appears to be the most favorable sedimentary rock for high-level waste emplacement.

- Similarly, chalk appears to be the least favorable.

- The remaining rock types [carbonate rocks (1imestone/dolostone), sandstone, and shale (argillaceous rock)], have similar characteristics and compare more closely to anhydrock than to chalk.

- For the repository designs considered in this study, a11 rock types in general appear to violate more constraints when SF is considered than with CHLW Thus, reductions in the SF thermal loading may be more desirable than locating a site with more favorable thermal characteristics. 
Table G.10.4. Summary of expected value (mean) results for a high-level waste repository in sandstone

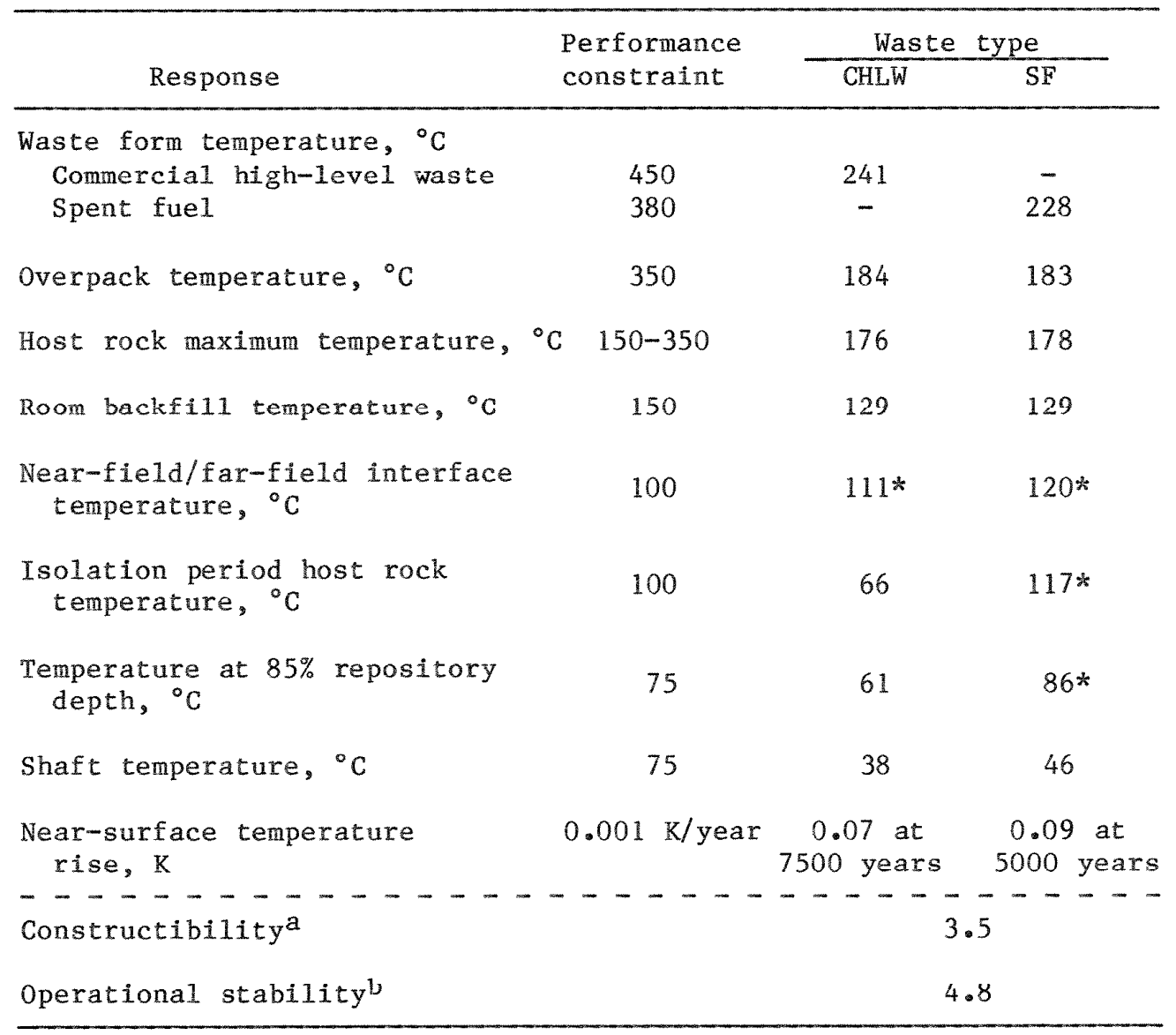

apefined as $\frac{\mathrm{C}_{\mathrm{O}}}{\sigma_{\mathrm{v}}}$, where $\begin{aligned} \mathrm{C}_{\mathrm{o}} & =\text { compressive strength and } \\ \sigma_{\mathrm{v}} & =\text { in situ vertical stress. }\end{aligned}$

${ }^{b}$ Defined as $\frac{C_{O}(1-\nu)}{E a \Delta T}$ (see Sect. G.11.3.3, p. 168).

* Possible constraint violation. 
Table G.10.5. Summary of expected value (mean) results for a high-level waste repository in shale

\begin{tabular}{|c|c|c|c|}
\hline \multirow[b]{2}{*}{ Response } & \multirow{2}{*}{$\begin{array}{l}\text { Performance } \\
\text { constraint }\end{array}$} & \multicolumn{2}{|c|}{ Waste type } \\
\hline & & CHLW & $\mathrm{SF}$ \\
\hline \multicolumn{4}{|l|}{ Waste form temperature, ${ }^{\circ} \mathrm{C}$} \\
\hline Commercial high-level waste & 450 & 289 & - \\
\hline Spent fuel & 380 & - & 280 \\
\hline Overpack temperature, ${ }^{\circ} \mathrm{C}$ & 350 & 235 & 239 \\
\hline Host rock maximum temperature, ${ }^{\circ} \mathrm{C}$ & C $150-350$ & $227 *$ & $233^{*}$ \\
\hline Room backfill temperature, ${ }^{\circ} \mathrm{C}$ & 150 & 144 & 142 \\
\hline $\begin{array}{l}\text { Near-field/far-field interface } \\
\text { temperature, }{ }^{\circ} \mathrm{C}\end{array}$ & 100 & $111 *$ & $121 *$ \\
\hline $\begin{array}{l}\text { Isolation period host rock } \\
\text { temperature, }{ }^{\circ} \mathrm{C}\end{array}$ & 100 & 57 & 111 \\
\hline $\begin{array}{l}\text { Temperature at } 85 \% \text { repository } \\
\text { depth, }{ }^{\circ} \mathrm{C}\end{array}$ & 75 & 43 & 69 \\
\hline Shaft temperature, ${ }^{\circ} \mathrm{C}$ & 75 & 26 & 34 \\
\hline $\begin{array}{l}\text { Near-surface temperature } \\
\text { rise, } \mathrm{K} \\
\text { Constructibility }\end{array}$ & $0.001 \mathrm{~K} /$ year & $\begin{array}{c}0.05 \text { at } \\
3000 \text { years } \\
-----\frac{-}{3}\end{array}$ & $\begin{array}{l}0.18 \text { at } \\
5000 \text { years } \\
------\end{array}$ \\
\hline Operational stahilityb & & & \\
\hline
\end{tabular}

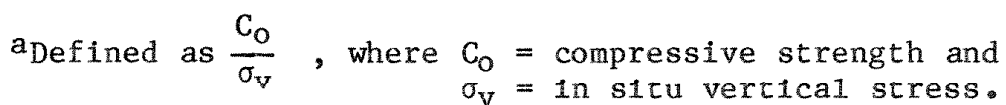

$b_{\text {Defined as }} \frac{C_{o}(1-\nu)}{E \alpha \Delta T}$ (see Sect. G.11.3.3, p. 168).

* Possible constraint violation. 
- For anhydrock, one desires a site with an elastic modulus as low as possible. The thermal and strength characteristics, as well as the site conditions, for anhydrock are the most favorable of the rock types considered.

- For chalk, it may be impossible to locate a site with favorable characteristics that satisfy all of the performance constraints, In fact, reducing the thermal loadings (and, hence, increasing the land area required) may be the only practical solution for locating a repository in chalk.

- For the remaining rock types (i.e., shale, sandstone, and carbonate rocks, one desires to locate a site with rock types that have a high thermal conductivity and are capable of tolerating a high temperature 1imit. Nevertheless, it may be more practical to reduce the thermal loadings, especially for spent fuel. The strength and mechanical characteristics of these rock types are satisfactory. 


\section{G.11 EVALUATION AND RANKING}

The five sedimentary rock types are evaluated in this section, based on the thermal and mechanical evaluation criteria presented in Sect. G.4. These criteria are addressed using the performance constraints identified in Sect. G.5 for an assumed high-level waste repository (Sect. G.3.1). This section evaluates the five rock types in a comparative fashion based on their thermal and mechanical performance (Sects. G.8 and G.9, respectively) relative to high-level waste emplacement. Section G.11.1 presents the methods used in performing this evaluation. The thermal and mechanical evaluations are presented separately in Sects. G.11.2 and G.11.3, respectively. This evaluation is concluded with rankings of the five rock types for preclosure and postclosure pertormance separately, and for overall repository performance.

\section{G.11.1 FVAT.ITATTON PROCFNTIRF}

The thermal and mechanical evaluations were performed separately, based on the expected ranges of the various responses reported in sects. G.8 and G.Y. Ine most tavorable rock type for each thermal response was assigned a ranking of one. The ranking of each of the remaining rock types was expressed as a percentage of its response to the response of the most favorable rock type. For example, the lowest waste form temperature can be expected in anhydrock. Thus, anhydrock was assigned a ranking of one. The waste form temperatures in chalk are approximately double those in anhydrock. The chalk ranking for this thermal response is thus 0.5 . In this fashion, these rankings are normalized (i.e., their numerical values lie between 0 and 1 for all responses). Thermally, the most favorable response was taken to be the lowest mean temperatures.

The mechanical evaluation was separated into four parts dealing with mineability, constructibility, operational stability, and stability under postclosure conditions. Whthin each of these parts, the five rock types were ranked in terms of favorability as a repository host rock.

Subsequently, the five rock types were ranked on the basis of preclosure repository performance by considering collectively the rankings for constructibility and operational stability. Postclosure rankings were established on the basis of thermal performance and stabi1ily cousiderations for the rocks after repostcory closure. Final1y, by use of the preclosure and postclosure rankings, an overall ranking of the five rock types was established.

\section{G.11.2 THERMAL EVALUATION}

The thermal results of this study are summarized in sect. G.12.4. Each figure in sect. G.12.4 presents the transient behavior of a single response and waste type, comparing the five rock types at their mean values. A number of significant conclusions regarding these mean value results are summarized below: 
- Anhydrock appears to be the most favorable sedimentary rock type with respect to high-level waste (CHLW and SF) emplacement since all of the resultant temperatures in the very near field, near field, and far field are consistently the lowest compared to the remaining rocks.

- Conversely, chalk appears to be the least favorable rock type with respect to high-level waste emplacement since the resultant temperatures are the highest.

- The range in each thermal response is consistently the lowest for anhydrock and the highest for chalk.

- The remaining three rock types (i.e., carbonate rocks, sandstone, and shale) compare somewhat more closely to anhydrock than to chalk and exhibit similar thermal characteristics.

- Material properties (particularly thermal conductivity) account for nearly all of the differences in the verynear-field and near-field temperatures. For example, chalk exhibits the lowest thermal conductivity and the highest waste form and room backfill temperatures.

- The range in the far-field thermal responses are more sensitive to the initial conditions than the verynear-field and near-field responses. For example, the differences in shaft temperatures directly are caused by the differences in the initial temperature distribution at each site.

- Spent fuel emplacement has a greater thermal impact in the far-field and very-near-field regions than CHLW because of its longer transients and higher canister loadings, respectively; however, CHLW has a greater impact in the near-field region, primarily because of the higher thernal loadings than SF.

The ability of the rock types to transfer heat is shown on a relative basis in Fig. G.11.1. This figure presents the range in the thermal ranking of all five rock types for both waste types. Overall, anhydrock is the most favorable rock type, based on thermal performance. Conversely, chalk is the least favorable. Shale and sandstone compare similarly but somewhat less favorably than anhydrock. Carbonate rocks closely follow shale and sandstone in thermal performance.

\section{G.11.3 MECHANICAL EVALUATION}

The five rock types are ranked with regard to rock mechanics performance in three categories:

1. mineabilily,

2. constructibility, and

3. operational stability. 
ORNL DWG 85-96

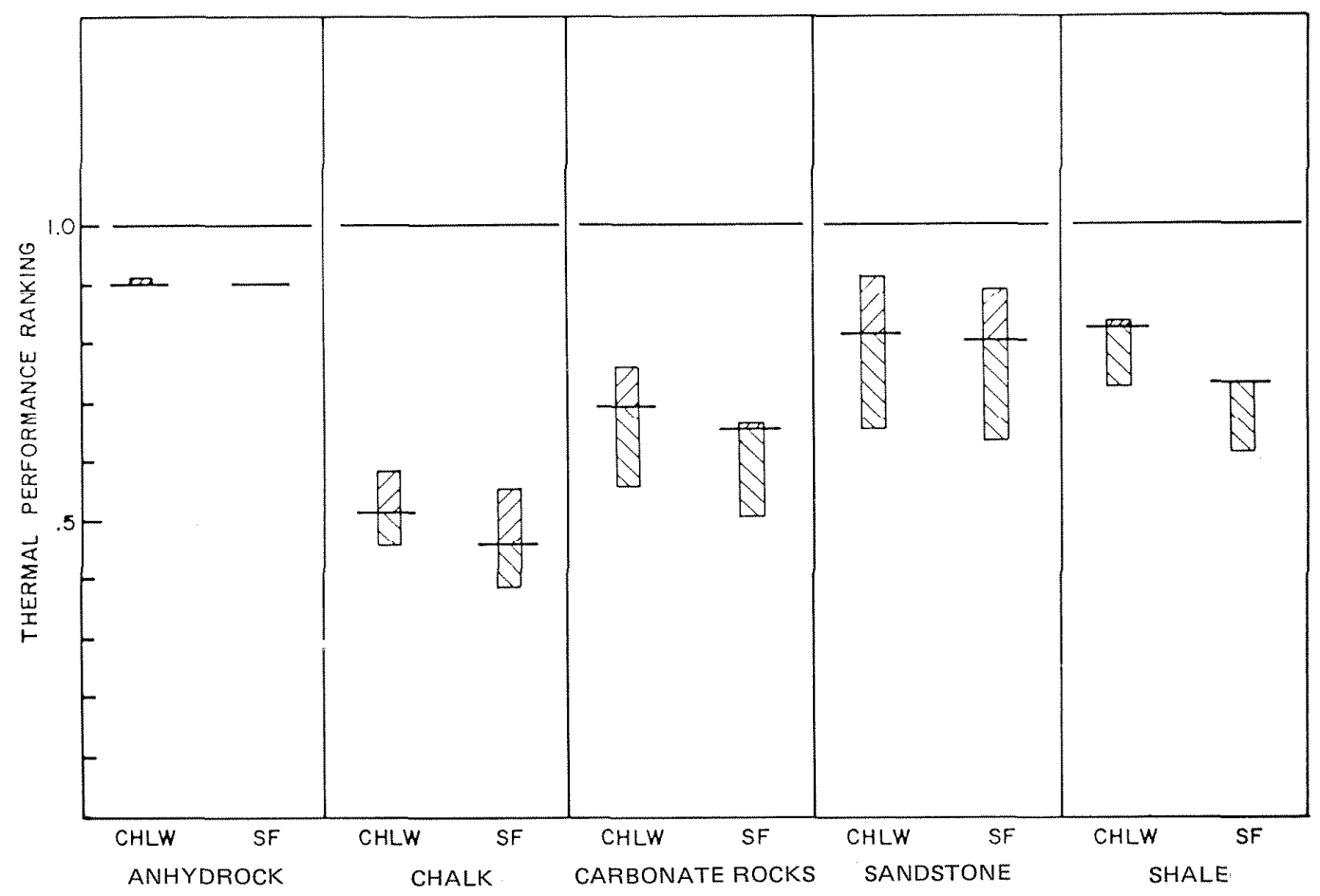

Fig. G.11.1. Heat transfer capability ranking of five sedimentary rock types. 


\section{G.11.3.1 Mineability}

Mineability is not used for ranking since insufficient information is available to differentiate among the five rocks.

\section{G.11.3.2 Constructibility}

In Sect. G.9.2 of this report, the unconfined compressive strength was show to be the primary rock characteristic affecting the constructibility of disposal rooms in the five rock types. Therefore, the unconfined compressive strength should be used in ranking the rock types with respect to constructibility.

The five rock types are ranked in Fig. G.11.2 on the basis of laboratory-determined unconfined compressive strength. This ranking could be altered based on the in situ rock strength. Although the relationship between the laboratory and in situ compressive strength is not known for all of these rocks, it may be estimated. Obert and Duval1 (OBERT 1973) suggest the following reduction factors:

Reduction factor

2

4
Rock description

Laminated, foliated, or essentially unjointed rock.

Jointed rock with relatively tight joint planes.

One possible set of strength reduction factors is:

Rock type

Anhydrock

Carbonate rocks (1imestone/dolostone)

Shale (argillaceous rock)

Sandstone

Chalk

\section{Reduction factor}

Use of these reduction factors would result in a ranking based on conotructibility with the carbonatc rocks and anhydrock ranked first, sandstone and shale ranked second, and chalk ranked third.

\section{G.11.3.3 Operational Stability}

Operational stability relates to the stability of the pillars and rooms during repository operation when the rocks will be subjected to thermal stresses. During this phase, consideration must be given to the magnitude of the thermal stresses in relation to the strength of the rock. The stresses induced in an ideal confined rock mass (assumed to be elastic) because of heating can be shown to be proportional to the quantity: 
ORNL. DWG $85-98$

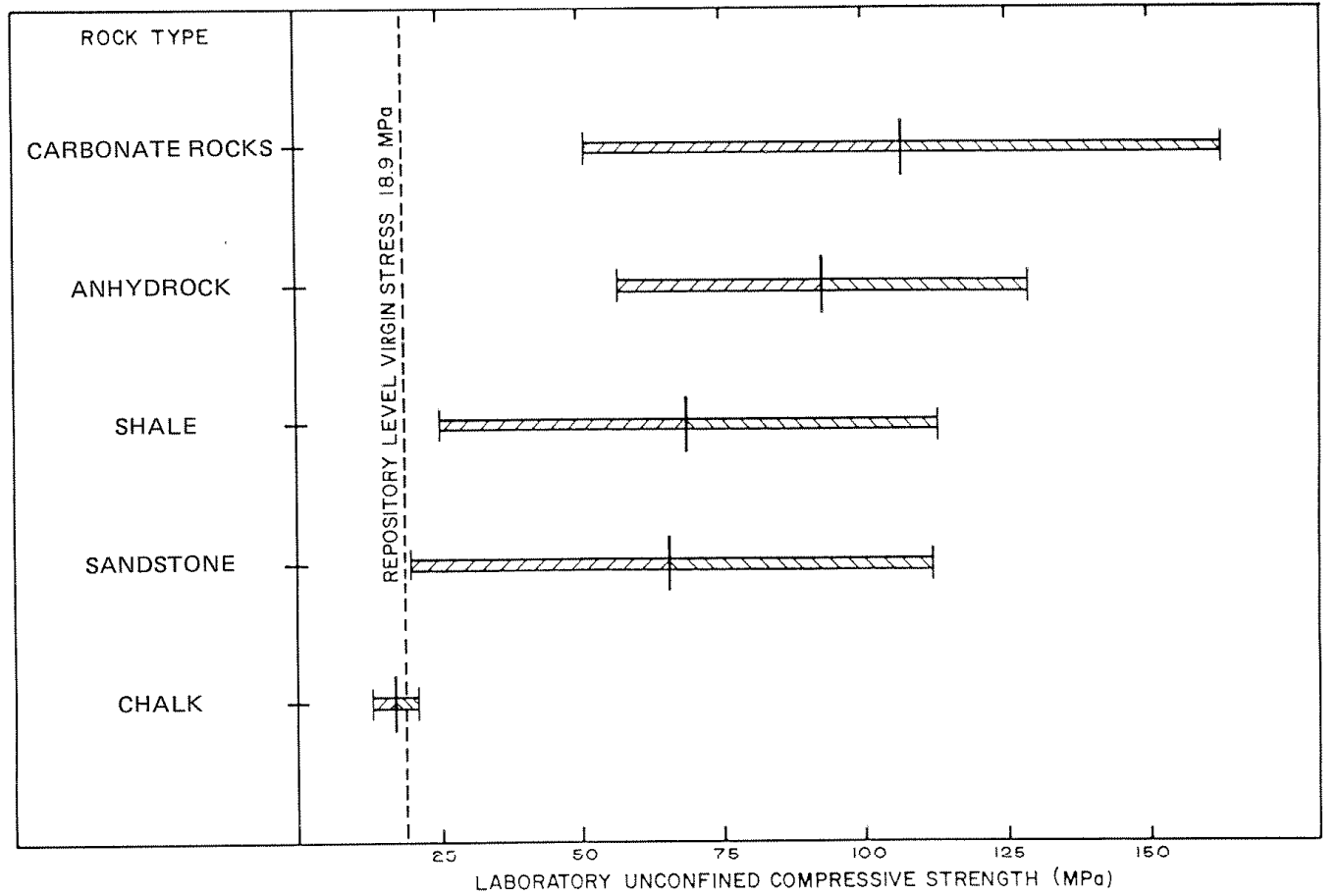

Fig. G.11.2. Ranges in unconfined compressive strength of five sedimentary rocks used to evaluate constructibility. 
where

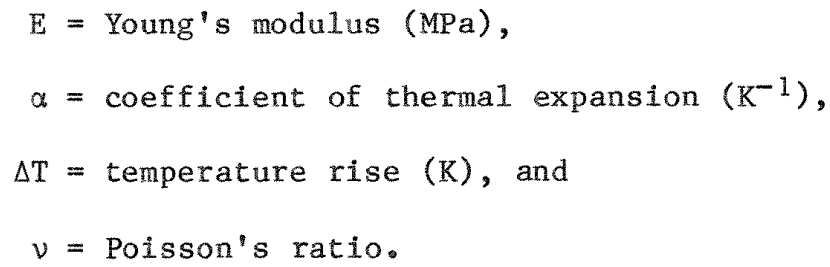

A strength-to-stress index can be obtained by dividing the unconfined compressive strength by the quantity in $\mathrm{Eq} \cdot(11-1)$. This ratio is defined as the operational stability index. The low catimatc (minimum), mean, and high estimate (maximum) room periphery temperatures at 5 years for the five rock types are given in Table G.11.1. Using these temperatures and the rock property ranges in Table G.6.1, the approximate operational strength-to-stress indices can be calculated. The resulting ranking for operational stability, as given in Table G.11.2, is shale, carbonate rocks, sandstone, chalk, and anhydrock, in descending order.

\section{G.11.3.4 Stability Under Postclosure Conditions}

The most important rock mechanics considerations during postclosure are related to the potential for creating fractures and/or opening existing fractures in the host rock and surrounding rock units. These fractures could conceivably act as conduits for the transport of radionuclides from the emplaced waste to the accessible environment. The creation of new fractures is related to thermally induced stresses in the rock mass, rock ductibility, and rock strength, including the increase in strength with an increase in confinement stress. Thermally induced stresses in a confined elastic material are proportional to the modulus of elasticity, the coefficient of thermal expansion, and the temperature rise.

Table G.11.1. Average room periphery temperature $\left({ }^{\circ} \mathrm{C}\right)$ at time of backfill ( 5 years)

\begin{tabular}{cccccc}
\hline & Anhydrock & Chalk & $\begin{array}{c}\text { Carbonate } \\
\text { rocks }\end{array}$ & Sandstone & Shale \\
\hline $\begin{array}{c}\text { Low estimate } \\
\text { (minimum) }\end{array}$ & 56 & 91 & 74 & 62 & 63 \\
Mean & 72 & 122 & 91 & 86 & 83 \\
$\begin{array}{c}\text { High estimate } \\
\text { (maximum) }\end{array}$ & 79 & 161 & 118 & 118 & 120 \\
\hline
\end{tabular}


Table G.11.2. Operational stability indices for five sedimentary rock types

\begin{tabular}{|c|c|c|c|c|}
\hline \multirow[b]{2}{*}{ Rock type } & \multicolumn{2}{|c|}{ Temperature rise $\left({ }^{\circ} \mathrm{C}\right)$} & \multicolumn{2}{|c|}{ Stability indices } \\
\hline & Mean & Range & $\overline{\text { Mean }}$ & Range \\
\hline Shale & 61 & $41-98$ & 5.5 & $2.5-14.8$ \\
\hline Carbonate rocks & 51 & $34-78$ & 5.0 & $2.9-8.7$ \\
\hline Sandstone & 54 & $30-86$ & 4.8 & $2.3-8.8$ \\
\hline Chalk & 73 & $42-112$ & 3.9 & $1.8-14.8$ \\
\hline Anhydrock & 48 & $32-55$ & 1.0 & $0.7-1.8$ \\
\hline
\end{tabular}

Opening of existing fractures is related to the amount of thermally induced uplift, or doming, of the rocks above the repository. No largescale thermomechanical analyses of the host rock and surrounding units has been made because of the site-specific nature of the required data. A first approximation of the vertical movement of the rocks in the center of a repository is the integral over depth of the product of the coefficient of thermal expansion, which varies with lithology and therefore depth, and the temperature rise, which also varies with depth. Because the temperature distribution changes with time, the amount of vertical uplift will change with time and will reach a maximum at a time that depends on the decay characteristics of the waste and the thermal properties of the rocks. In general, the temperature rise will be inversely related to the thermal conductivity (i.e., rocks with high thermal conductivities will be associated with lower temperature rises).

Most rocks behave in a brittle manner when loaded uniaxially. The plasticity domain of such rocks and, thus, their plastic deformation and degree of plasticicy are very small. For most rocks, the seress-stra1n diagrams take an approximately linear path, like that of an ideally elastic solid where stress is proportional to strain. Generally, igneous rocks and some sedimentary rocks behave in this manner.

If a confining pressure is applied to a rock specimen while it is being loaded in the axial direction, the stress-strain diagram will not necessarily be 11near. In fact, as the confining pressure is increased, the stress-strain diagram becomes less and less linear. The reason for this departure from linearity is that the mode of internal deformation is changing. Examination of the deformed rock that has exhibited this nonlinear behavior will show intracrystalline twin gliding, intercrystal slip, and rupture.

The confining pressure at which the deformation mode changes from brittle to ductile is referred to as the brittle-to-ductile transition 
pressure. The lower the transition pressure, the greater the ductility that the rock will exhibit. Generally, the transition pressure is defined as that confining pressure at which a rock will exhibit 3 to $5 \%$ axial strain under differential stress before fracture. The brittle-toductile transition pressures for the five sedimentary rocks are given in Table G.11.3. Chalk and shale would receive the highest relative ranking of the five rock types with respect to ductility, followed by 1imestone. The two rock types that would receive the lowest ranking are anhydrock and sandstone. If dolostone were to be considered separately, it would also be included in this lowest ranking.

The above considerations indicate that the most favorable rock type should have, in a relative sense, a high thermal conductivity, a low coefficient of thermal expansion, a low modulus of elasticity, a high unconfined compressive strength, a high angle of internal friction, and a low brittle-to-ductile transition pressure. Table G.11.4 gives a ranking of the five rock types for each of these rock properties, as we11 as an overall ranking. On the basis of the compilation of rankings by rock properties, shale, the carbonate rocks, and anhydrock are ranked first overa11, on balance, with sandstone ranked second and chalk ranked third.

An additional measure of postclosure stability can be developed on the basis of the concept used to comparatively evaluate preclosure operational stability for the five rock types. This concept involves consideration of the ration of unconfined compressive strength to thermally induced stress in the host rock. This ratio is defined here as the postclosure stability index. The maximum temperature rise in the host rock is assumed to be the arithmetic mean of the peak temperature

Table G.11.3. Brittle to ductile transition pressures for rocks (at room temperature)

\begin{tabular}{lcc}
\hline \multicolumn{1}{c}{ Rock type } & $\begin{array}{c}\text { Transition pressure } \\
(\mathrm{MPa})\end{array}$ & $\begin{array}{c}\text { Reference } \\
\text { (psi) }\end{array}$ \\
\hline Chalk & $<10$ & COODMAN 1980 \\
$\begin{array}{l}\text { Compaction shale } \\
\begin{array}{l}\text { Medium- to high- } \\
\text { porosity shales }\end{array}\end{array}$ & GOODMAN 1980 \\
$\begin{array}{l}\text { Limestone } \\
\text { Dolostone }\end{array}$ & $<100$ & HANDIN 1957 \\
Anhydrock & $20-100$ & \\
Sandstone & $100-200$ & PATERSON 1978 \\
\hline
\end{tabular}




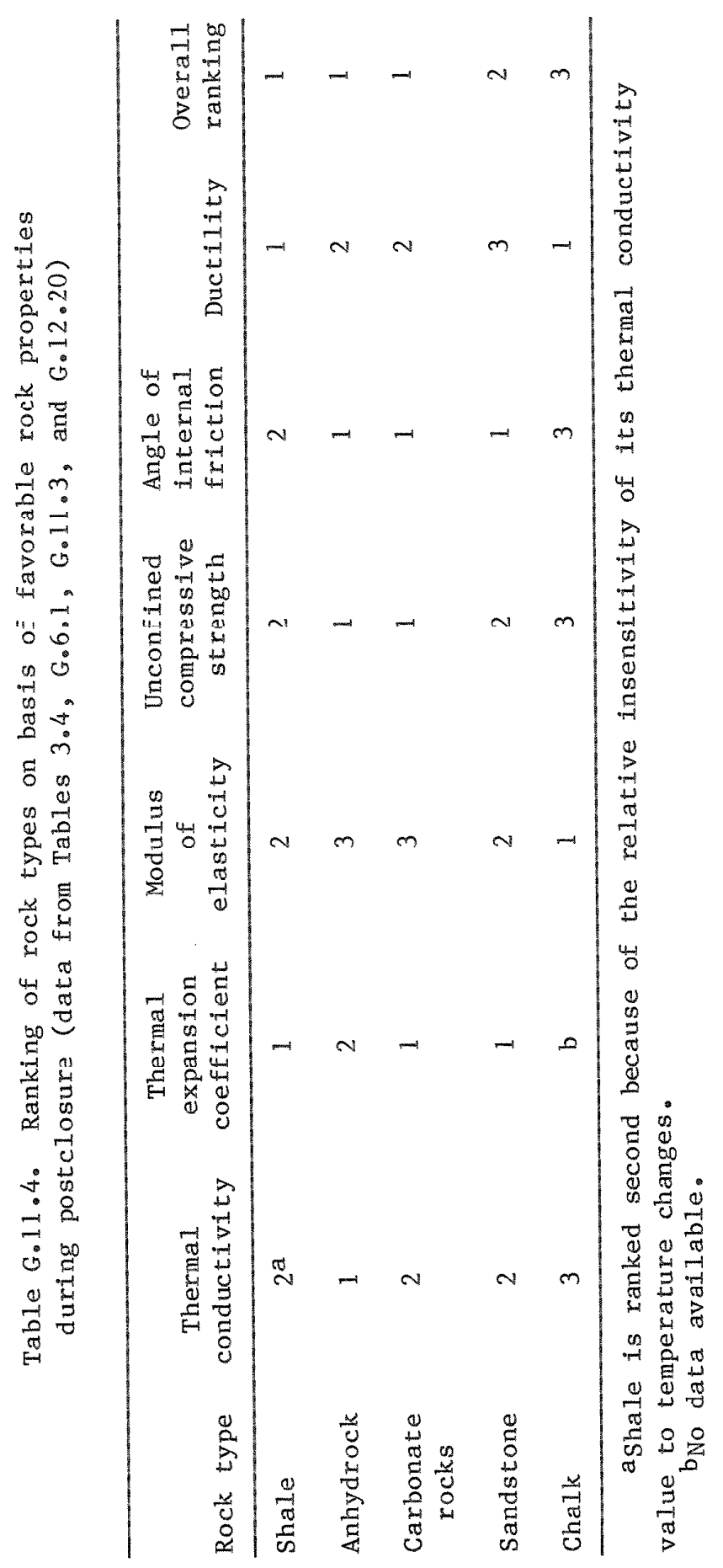


rises in the rock around the emplacement borehole, in the backfilled room, and in the rock at a distance of one room height above the room (i.e., the near-field/far-field interface temperature), for both SF and CHLW disposal configurations. Because these peak temperature rises occur at different times after emplacement, the value of the maximum "mean" temperature rise should be conservative. The temperature data used in this calculation are given in Tables G.10.1-G.10.5.

The mean values and range of postclosure stability indices for the five rock types are given in Table G.11.5. The rock properties data were taken from Tables G.6.1 and G.6.10, with the coefficient of thermal expansion for chalk assumed to be equal to that for the carbonates. As in the evaluation of preclosure operational stability, the range of rock properties corresponds to plus and minus one standard deviation from the mean values. On the basis of the stability indices given in Table G.11.5, sandstone, shale, and the carbonates are ranked first, with chalk ranked second and anhydrock ranked a distinct third.

Table G.11.5. Postclosure stability indices for five sedimentary rock types

\begin{tabular}{|c|c|c|c|c|}
\hline \multirow[b]{2}{*}{ Rock type } & \multicolumn{2}{|c|}{$\begin{array}{l}\text { Peak host rock } \\
\text { temperature rise }\left({ }^{\circ} \mathrm{C}\right)\end{array}$} & \multicolumn{2}{|c|}{ Stability indices } \\
\hline & Mean & Range & Mean & Range \\
\hline Sandstone & 108 & $69-155$ & 2.4 & $1.3-3.8$ \\
\hline Shale & 141 & $104-206$ & 2.4 & $1.2-5.8$ \\
\hline Carbonate rock & 112 & $78-200$ & 2.3 & $1.1-3.8$ \\
\hline Chalk & 189 & $96-292$ & 1.5 & $0.6-6.5$ \\
\hline Anhydrock & 92 & $63-101$ & 0.5 & $0.4-0.9$ \\
\hline
\end{tabular}

\section{G.11.4 OVERALL EVALUATION}

The preceding analyses have considered the expected thermal performance, mineability, constructibility, operational stability, and postclosure stability of five sedimentary rock types as related to the development of a repository facility for SF and CHLW disposal at a common depth of $700 \mathrm{~m}$. The performance of the repository facility from a rock mechanics viewpoint before closure is related to considerations of mineability, constructibility, and operational stability. At this time, no clear distinction among rock types was evident for the mineability consideration. However, it was possible to rank the five rock types on 
the basis of constructibility and operational stability. These rankings are reproduced in Table G.11.6, along with an overall ranking which indicates, on balance, the relative favorabilities among the five rock types for these two considerations. For preclosure, the carbonate rocks rank first overall and sandstone ranks second. Although anhydrock and shale are each ranked third, shale is probably more favorable in a relative sense because of its significantly higher ranking from the viewpoint of operational stability. Overall, chalk is clearly ranked fourth on a relative basis to the other four sedimentary rock types.

For the time period after closure, the performance of a repository is related to the thermal and thermonechanical responses of the host rock and surrounding rock units. For the tive sedimentary rock types, particular attention has been given to the evaluation of these responses within the host rock, coupled with consideration of the favorability of the rock properties for achieving relatively low temperature increases and high rock stability under conditions of thermally induced stresses. For purposes of ranking, the three consideration include thermal performance, a combination of favorable rock properties, and a measure of rock stability under thermally induced stresses. These three considerations do overlap in scope, but in an indirect way because of the relative focus of each. The rankings of the five rock types for the three considerations are given in Table G.11.7, along with an overall ranking which indicates, on balance, the relative favorabilities of the rocks from a composite point of view. For postclosure, the carbonate rocks and shale are ranked first, with anhydrock, sandstone, and chalk ranked second, third, and fourth, respectively.

For determining an overall ranking of the five sedimentary rock types, on the basis of thermal and rock mechanics considerations, primary significance must be given to the postclosure results in accordance with the provisions of 10 CFR Part 960, Subpart B. On this basis, the carbonate rocks would rank first overall and shale would rank second. That is, the results for preclosure permic a discriminacion becween the carbonate rocks and shale under postclosture. By similar reasoning, anhydrock and sandstone would be ranked third overall. Finally, chalk is ranked the lowest in terms of expected overall repository performance. 
Table G.11.6. Preclosure ranking of five sedimentary rock types

\begin{tabular}{lccc}
\hline Rock type & Constructibility & $\begin{array}{c}\text { Operational } \\
\text { stability }\end{array}$ & $\begin{array}{c}\text { Overal1 } \\
\text { ranking }\end{array}$ \\
\hline Carbonate rock & 1 & 1 & 1 \\
Sandstone & 2 & 1 & 2 \\
Anhydrock & 1 & 4 & 3 \\
Shale & 2 & 2 & 3 \\
Chalk & 3 & 3 & 4 \\
\hline
\end{tabular}

Table G.11.7 Postclosure ranking of five sedimentary rock types

\begin{tabular}{lcccc}
\hline $\begin{array}{c}\text { Rock } \\
\text { type }\end{array}$ & $\begin{array}{c}\text { Thermal } \\
\text { performance }\end{array}$ & $\begin{array}{c}\text { Favorable } \\
\text { rock } \\
\text { properties }\end{array}$ & $\begin{array}{c}\text { Stability } \\
\text { indices }\end{array}$ & $\begin{array}{c}\text { Overall } \\
\text { ranking }\end{array}$ \\
\hline $\begin{array}{c}\text { Carbonate } \\
\text { rocks }\end{array}$ & 2 & 1 & 1 & 1 \\
Shale & 2 & 1 & 1 & 1 \\
Anhydrock & 1 & 1 & 3 & 2 \\
Sandstone & 2 & 2 & 1 & 3 \\
Chalk & 3 & 3 & 2 & 4 \\
\hline
\end{tabular}




\section{G.12 SUPPLEMENTAL INFORMATION}

G.12.1 DETAILED MODEL RESULTS FROM THE VERY-NEAR-FIELD THERMAL ANALYSIS

This section presents the detailed very-near-field thermal results that supplement the information presented in Sect. G.8.2. The figures in this section encompass (Figs. G.12.1.1 through G.12.1.30):

- Three responses

- waste form temperature

- overpack temperacure

- host rock temperature (operation/containment period)

- Two waste types

- commercial high-level waste

- spent fuel

- Hive rock rypes

- anhydrock

- chalk

- carbonate rocks (1imestone/dolostone)

- sandstone

- shale (argillaceous rock)

Each figure presents the expected range in the transient behavior for each response, waste type, and rock type. 
ORNL DWG 85-101

ANHYDR I TE

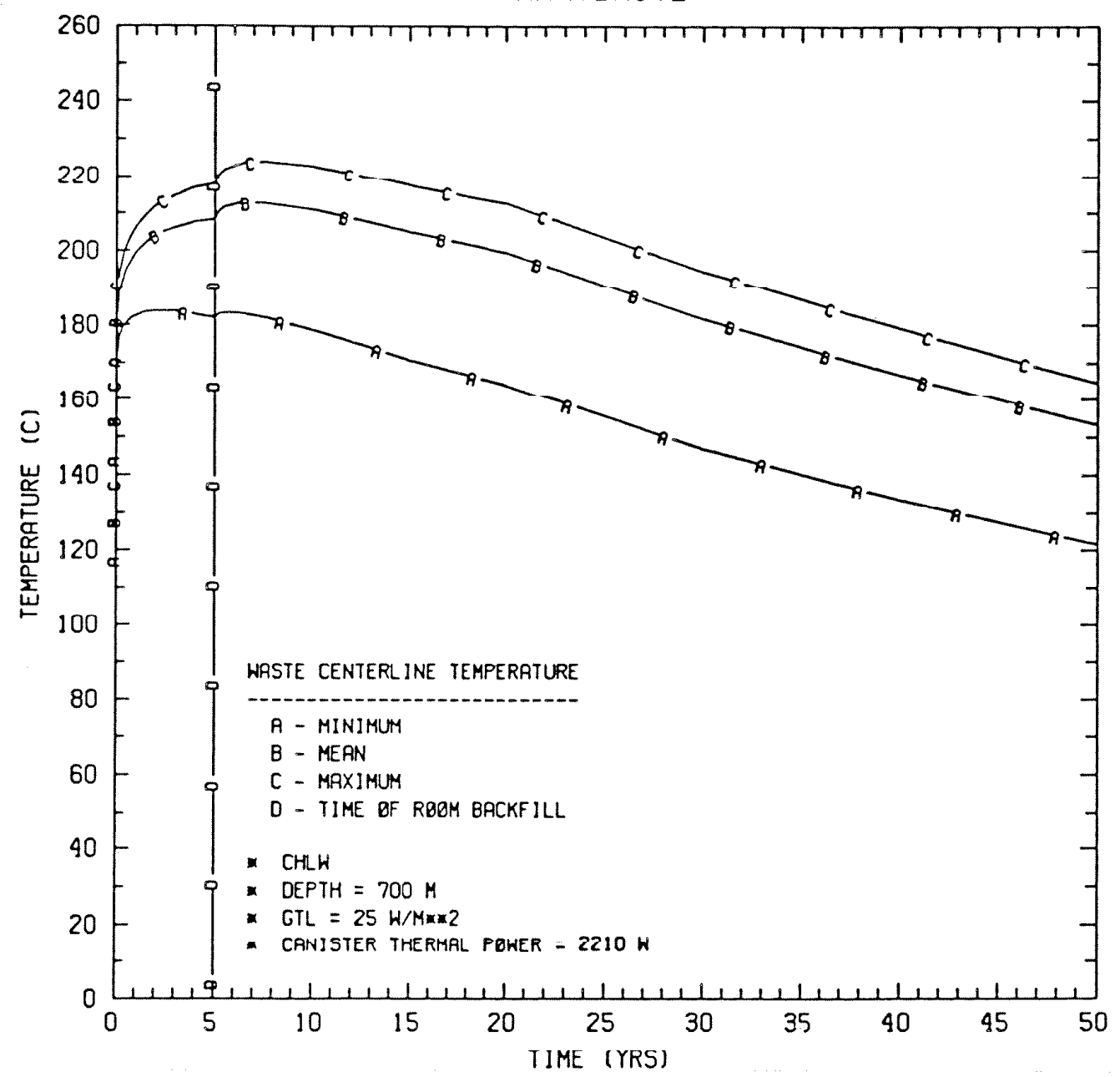

Fig. G.12.1.1. Expected range in waste form temperature for commercial high-level waste emplacement in anhydrock. 
ORNL DWG 85-102

CHALK

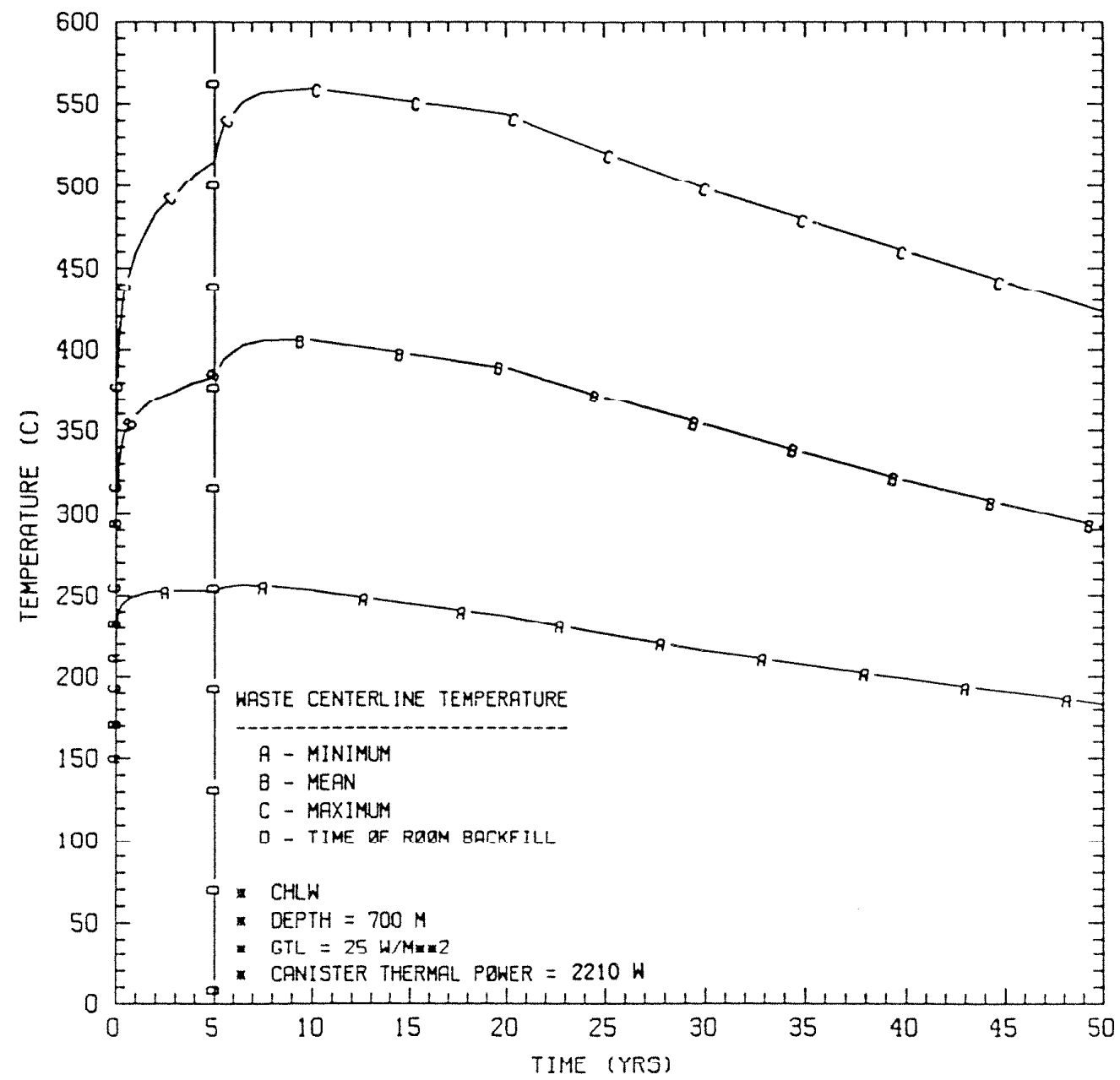

Fig. G.12.1.2. Expected range in waste form temperature for commercial high-level waste emplacement in chalk. 
ORNL DWG 85-103

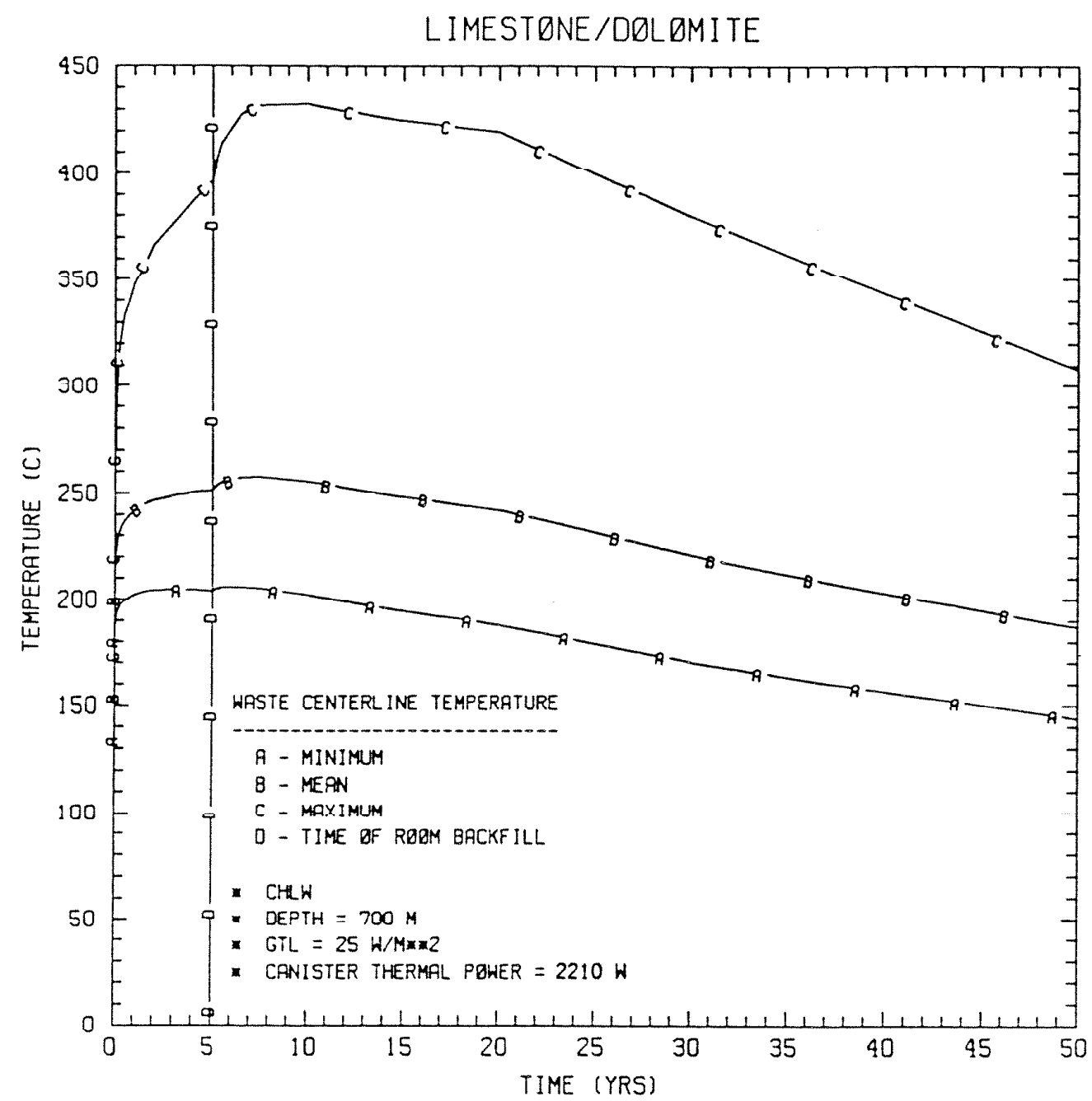

Fig. G.12.1.3. Expected range in waste form temperature for commercial high-level waste emplacement in carbonate rocks. 
ORNL DWG 85-104

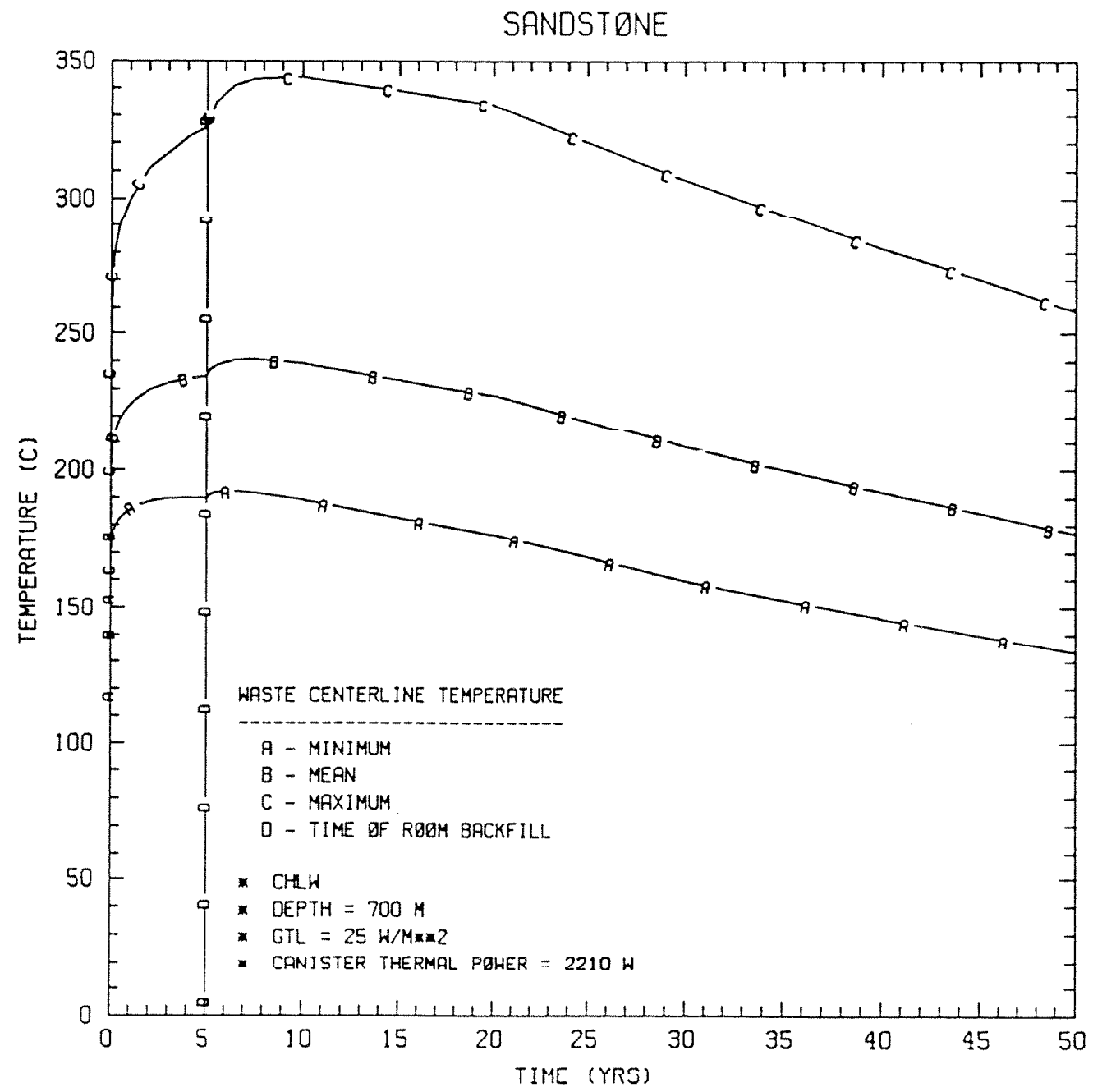

Fig. G.12.1.4. Expected range in waste form temperature for commercial high-level waste emplacement in sandstone. 
ORNL DWG 85-105

SHALE

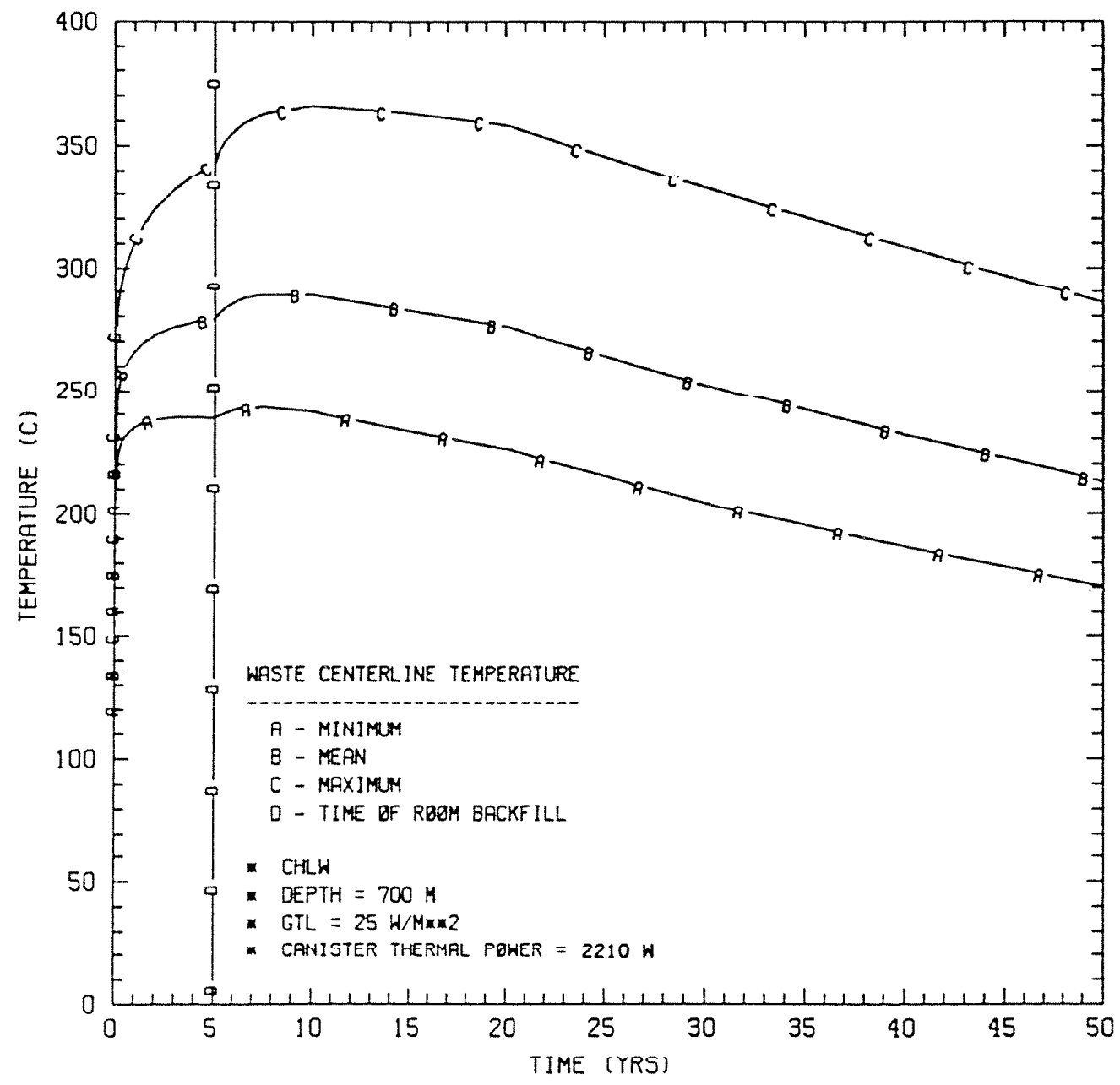

Fig. G.12.1.5. Expected range in waste form temperature for commercial high-level waste emplacement in shale. 
ORNL DWG 85-106

\section{ANHYDR ITE}

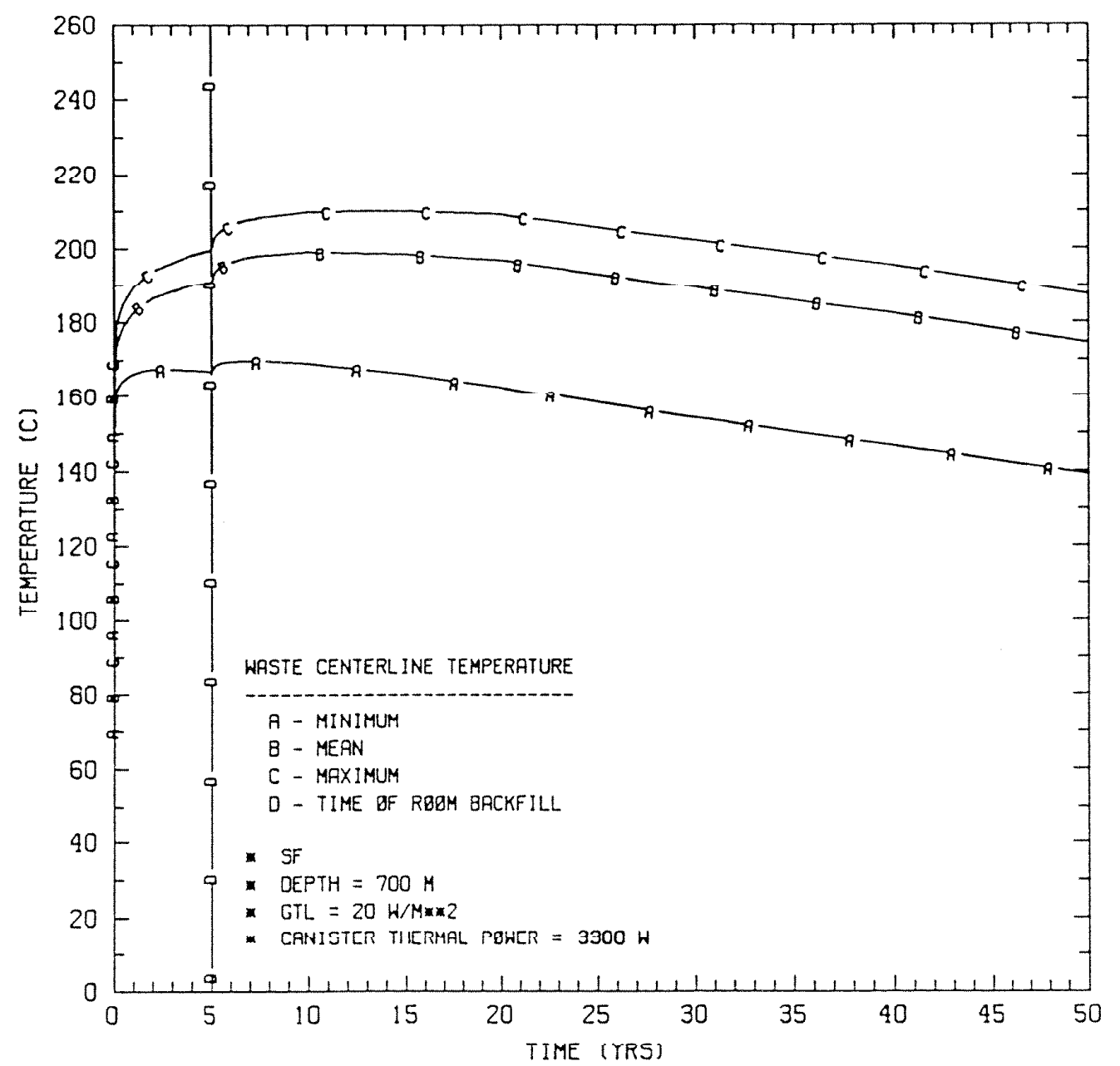

Fig. G.12.1.6. Expected range in waste form temperature for spent fuel emplacement in anhydrock. 
ORNL DWG 85-107

CHALK

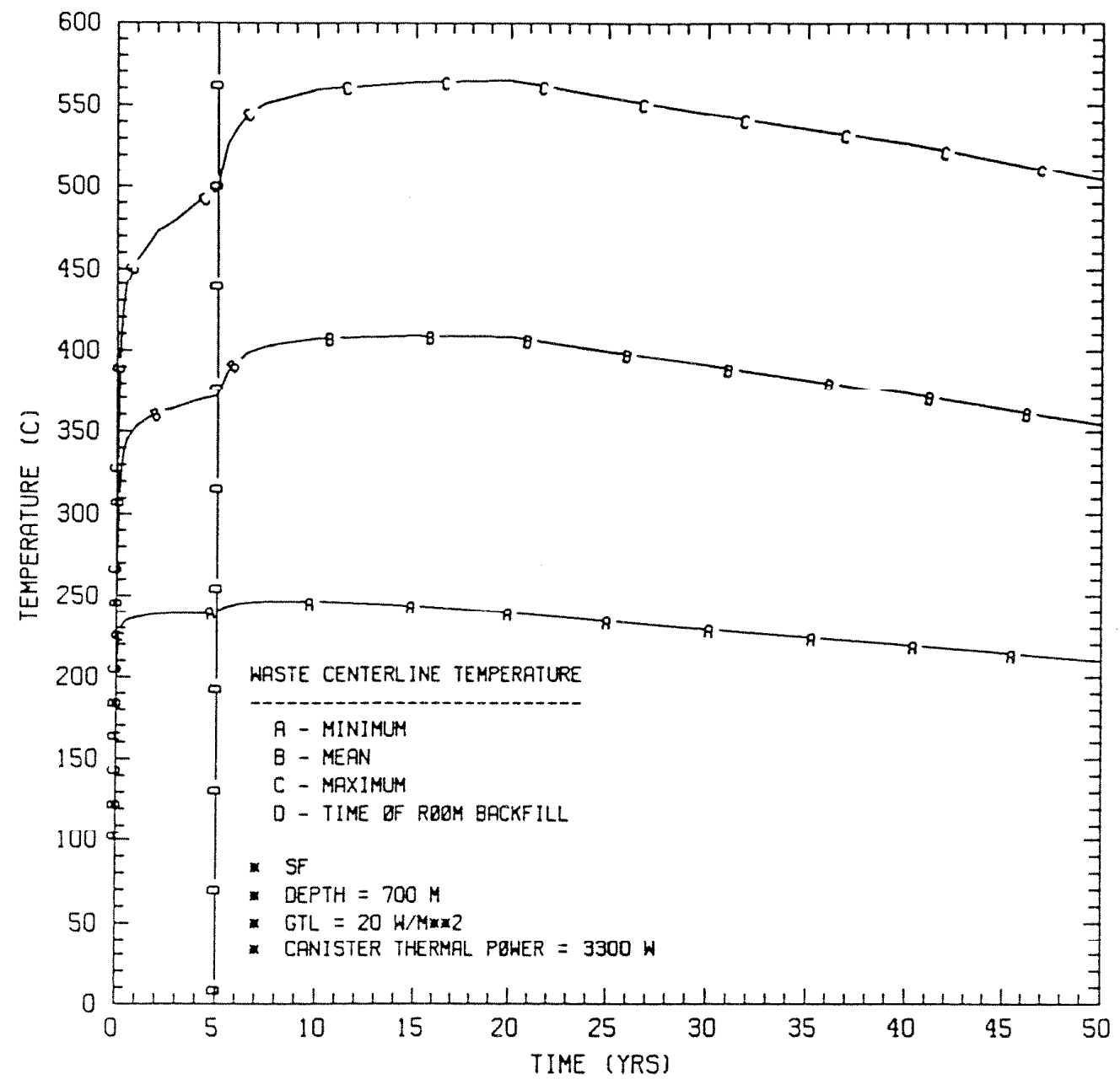

Fig. G.12.1.7. Expected range in waste form temperature for spent fuel emplacement in chalk. 
ORNL DWG 85-108

LIMESTONE/OOLOMITE

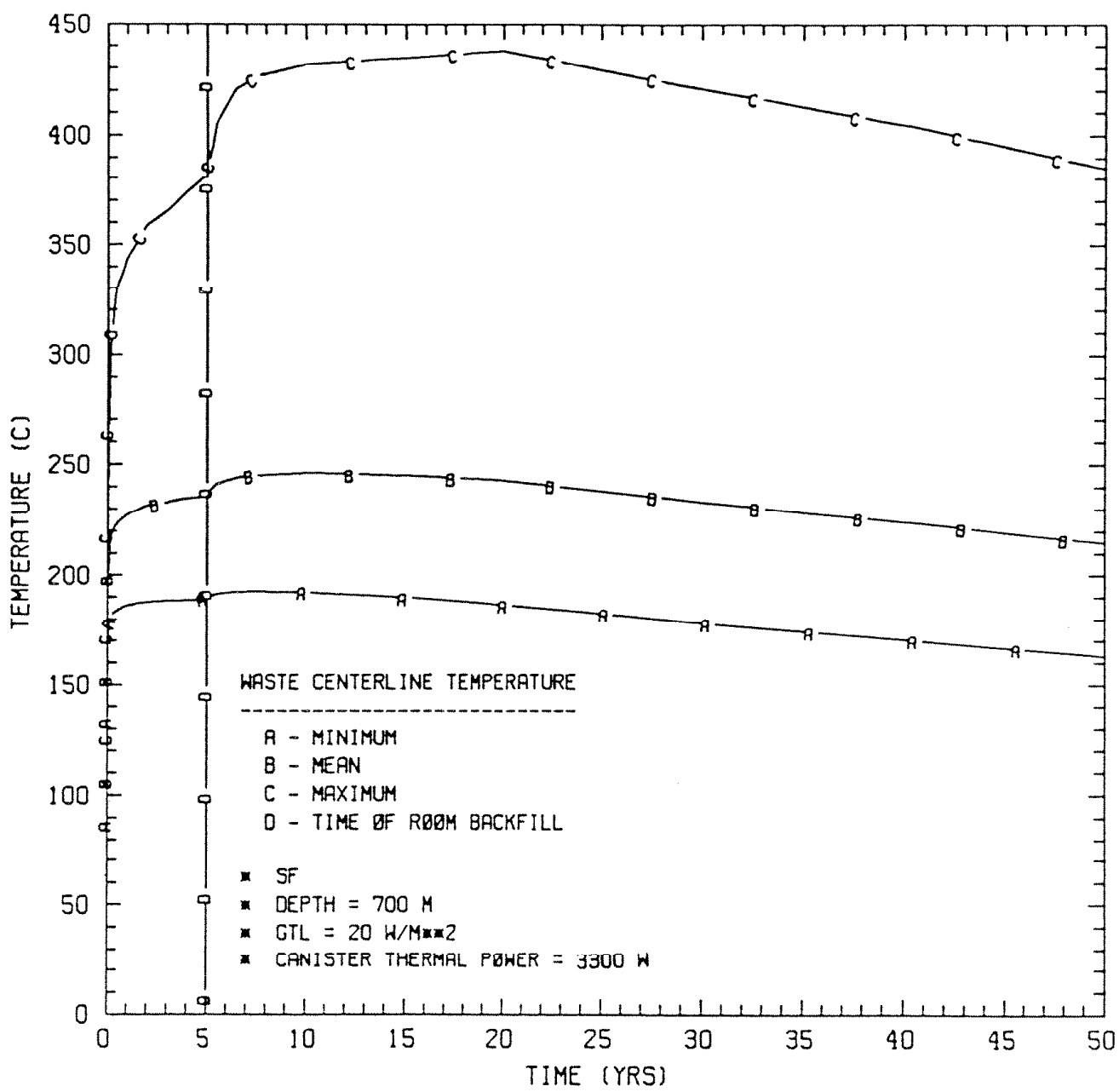

Fig. G.12.1.8. Expected range in waste form temperature for spent fuel emplacement in carbonate rocks. 
ORNL DWG 85-109

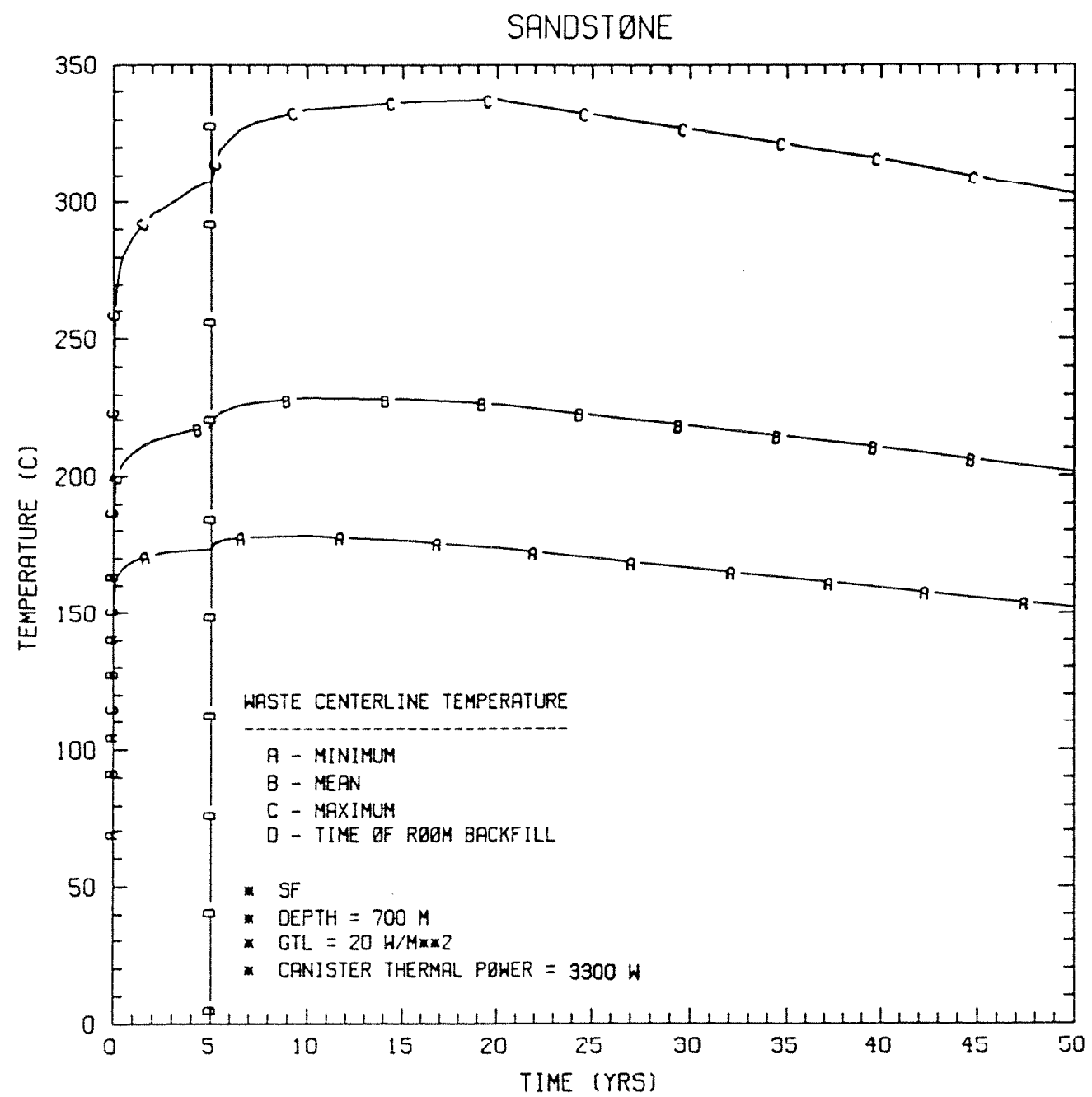

Fig. G.12.1.9. Expected range in waste form temperature for spent fuel emplacement in sandstone. 
ORNL DWG 85-110

SHALE

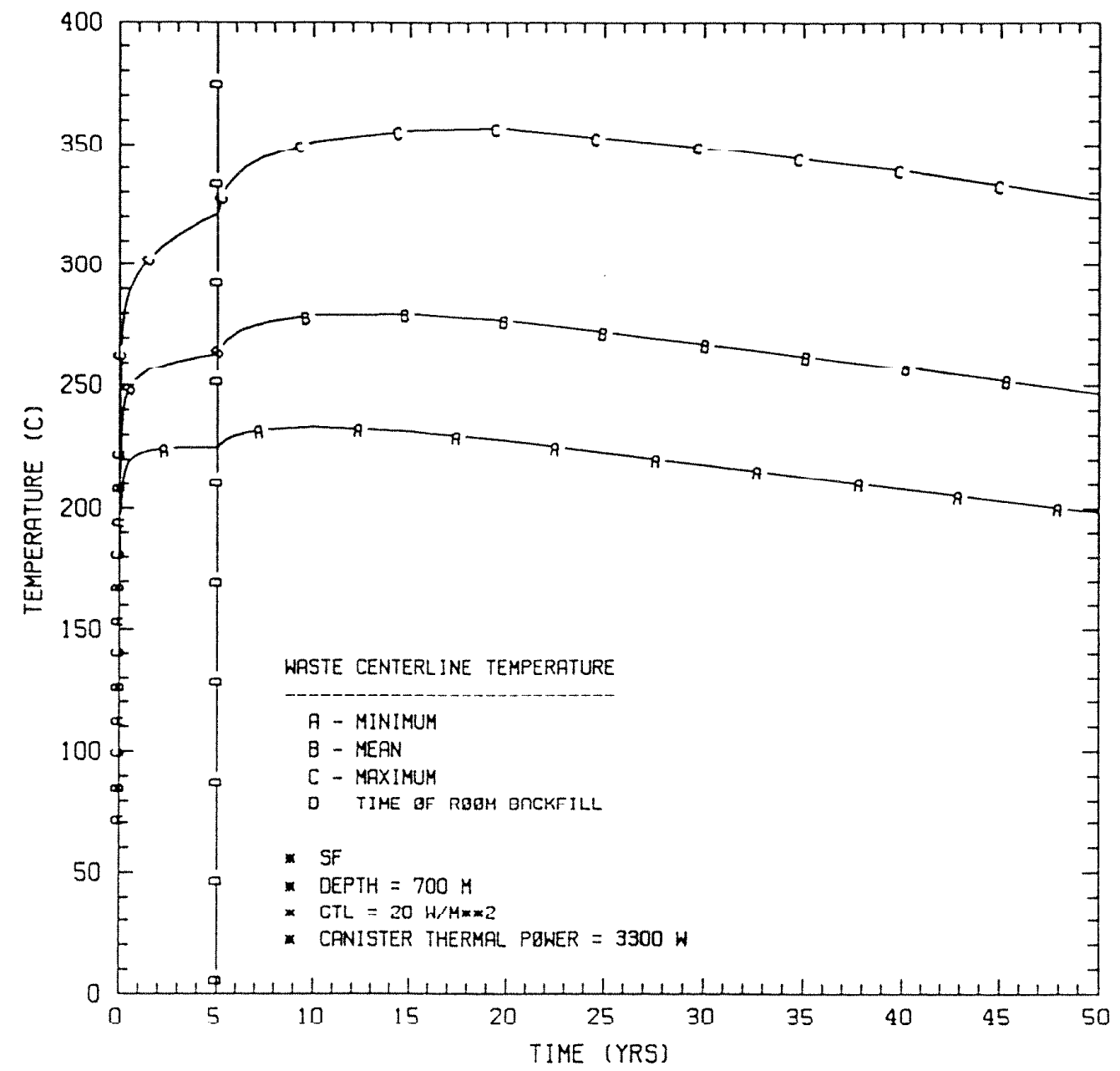

Fig. G.12.1.10. Expected range in waste form temperature for spent fuel emplacement in shale. 
ORNL DWG 85-111

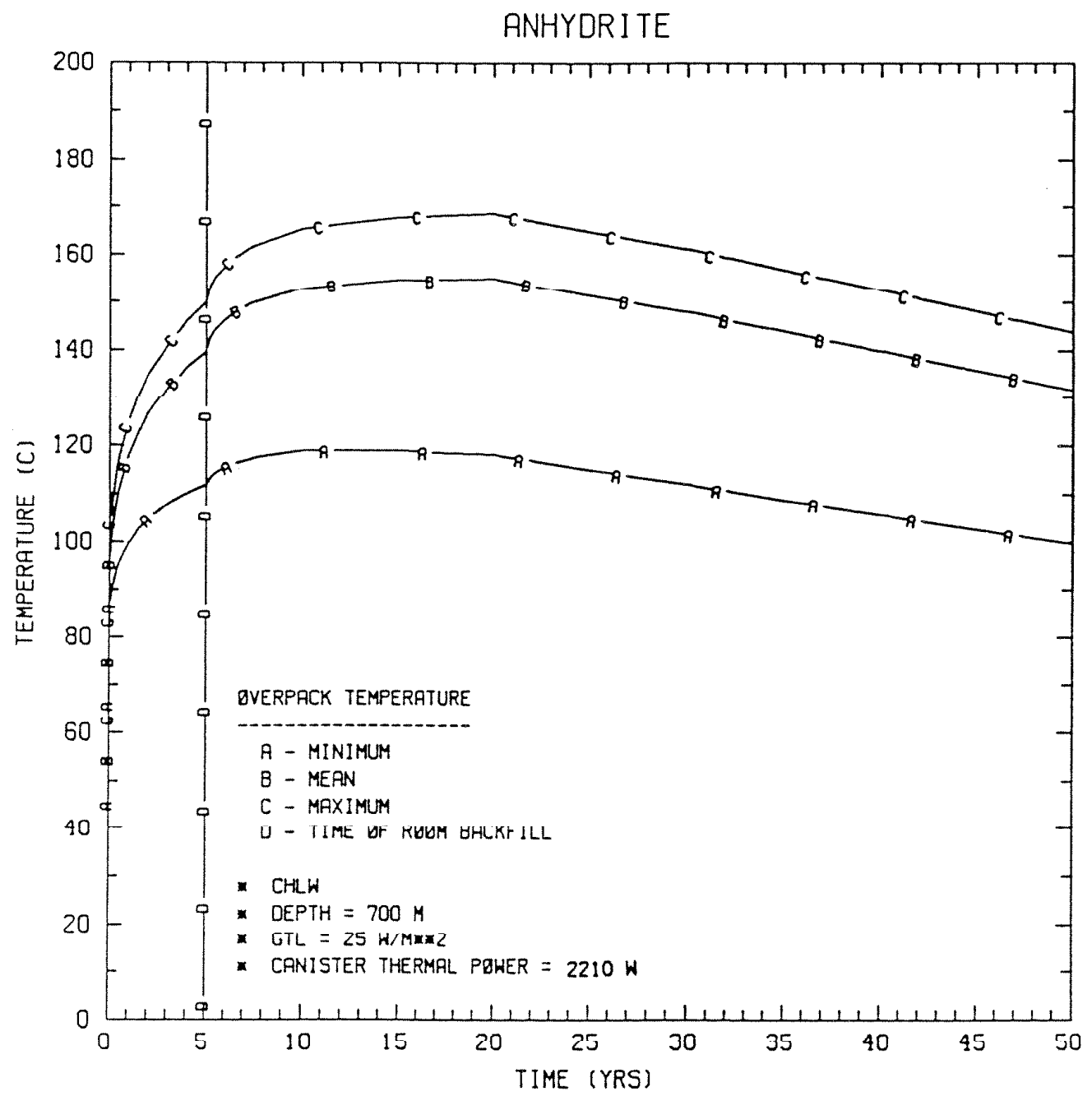

Fig. G.12.1.11. Expected range in overpack temperature for commercial high-level waste emplacement in anhydrock. 
ORNL DWG 85-112

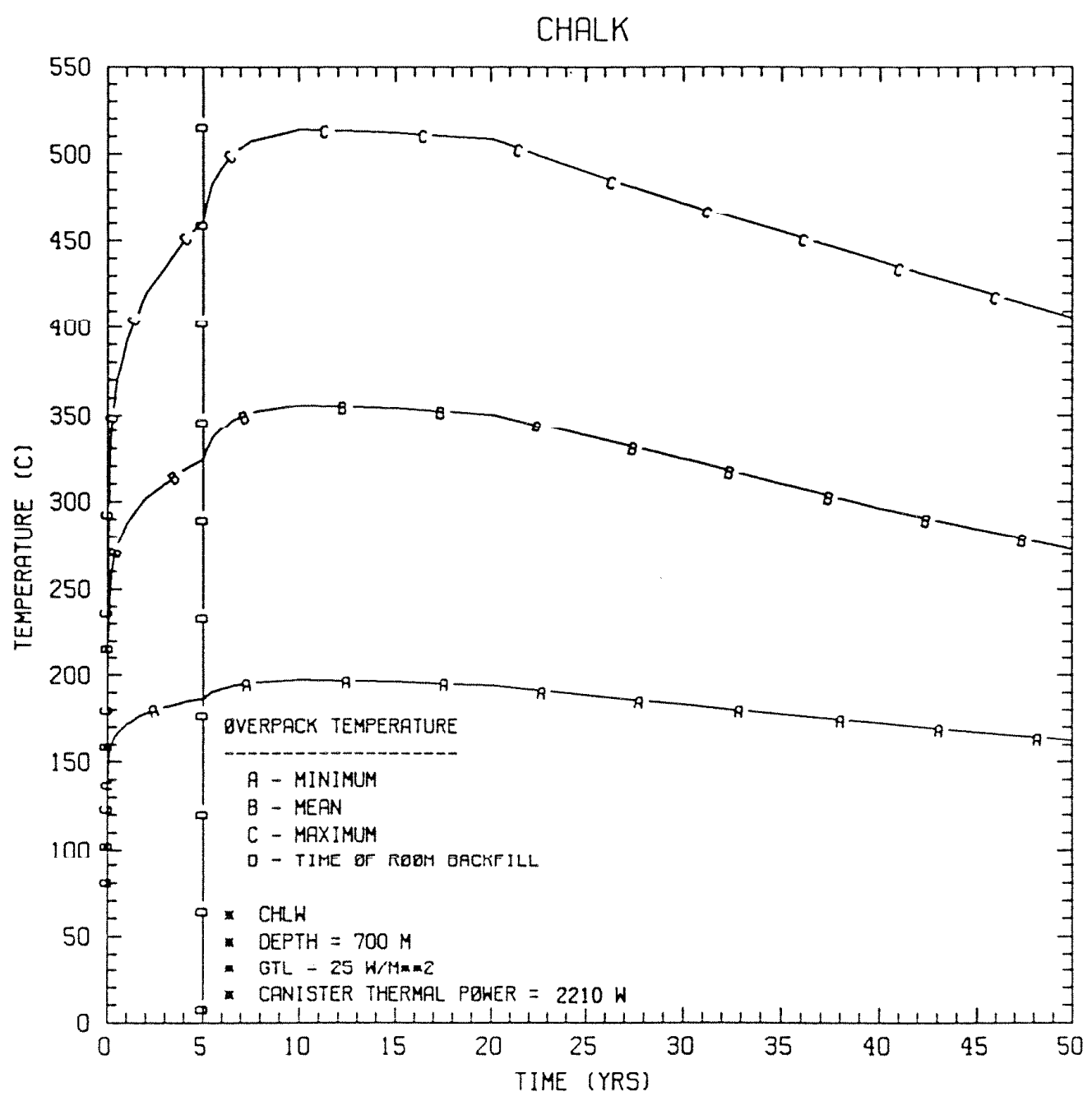

Fig. G.12.1.12. Expected range in overpack temperature for commercial high-level waste emplacement in chalk. 
ORNL DWG 85-113

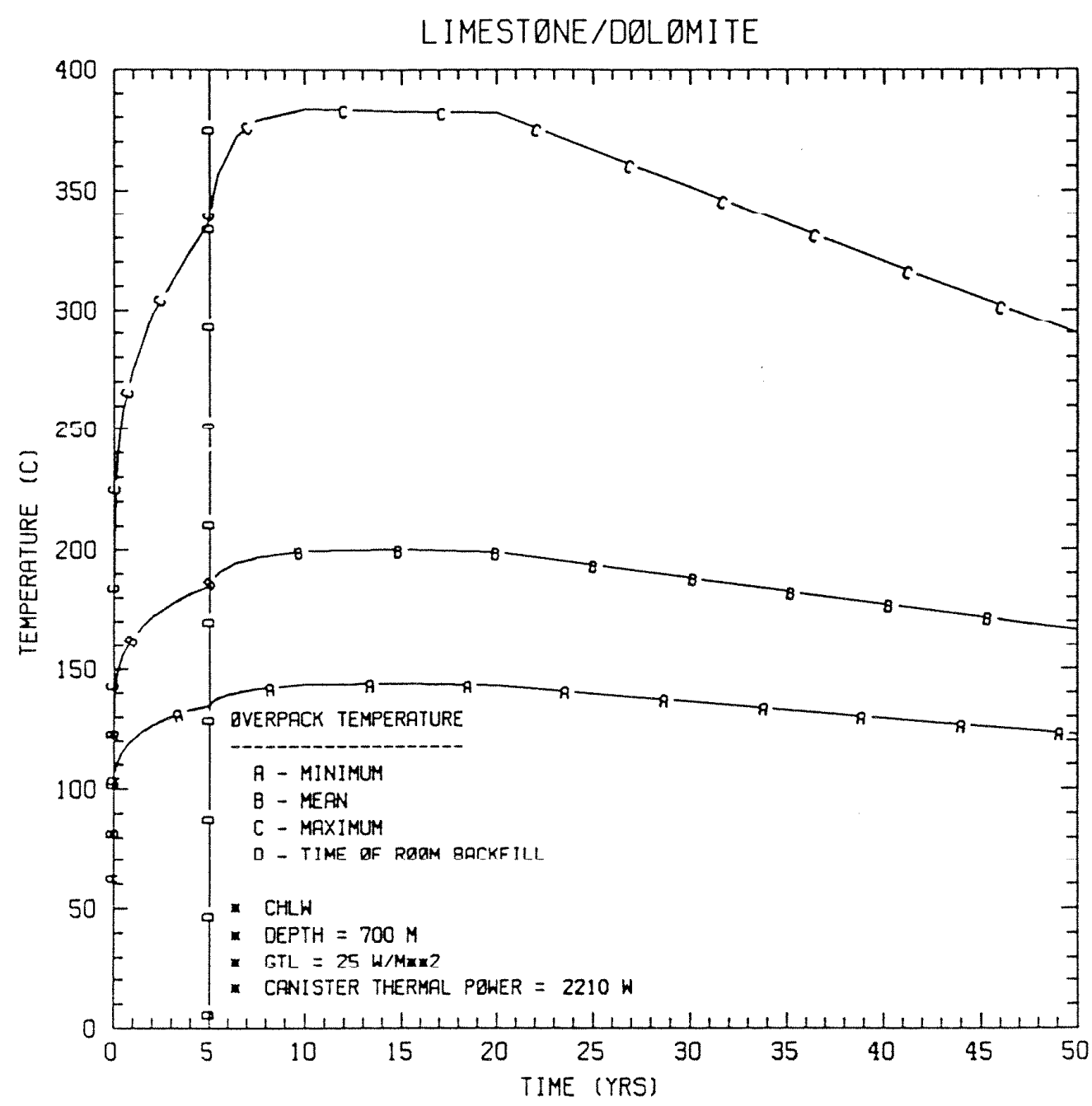

Fig. G.12.1.13. Expected range in overpack temperature for commercial high-level waste emplacement in carbonate rocks. 
ORNL DWG 85-114

SANDSTONE

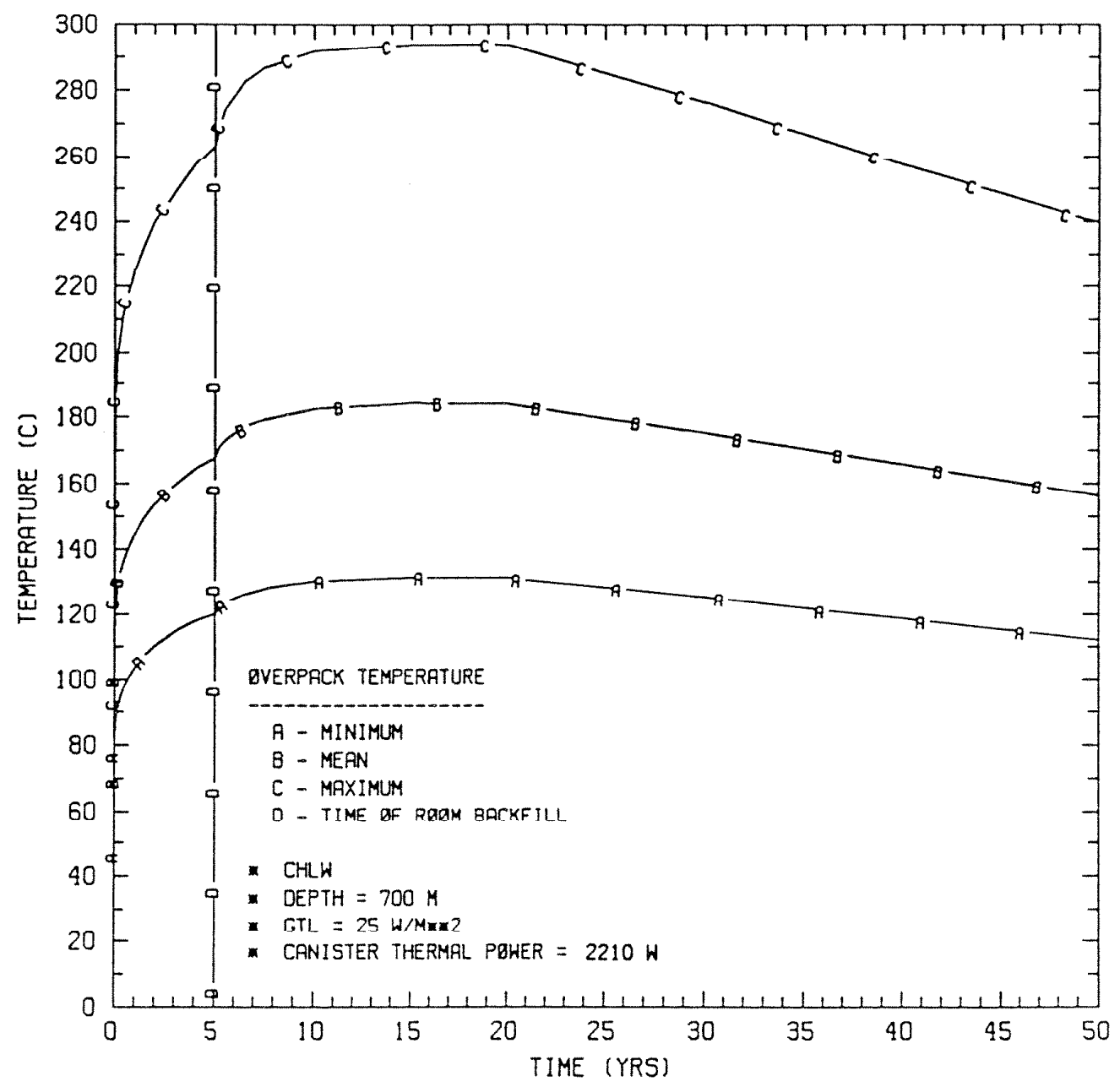

Fig. G.12.1.14. Expected range in overpack temperature for commercial high-level waste emplacement in sandstone. 
ORNL DWG 85-115

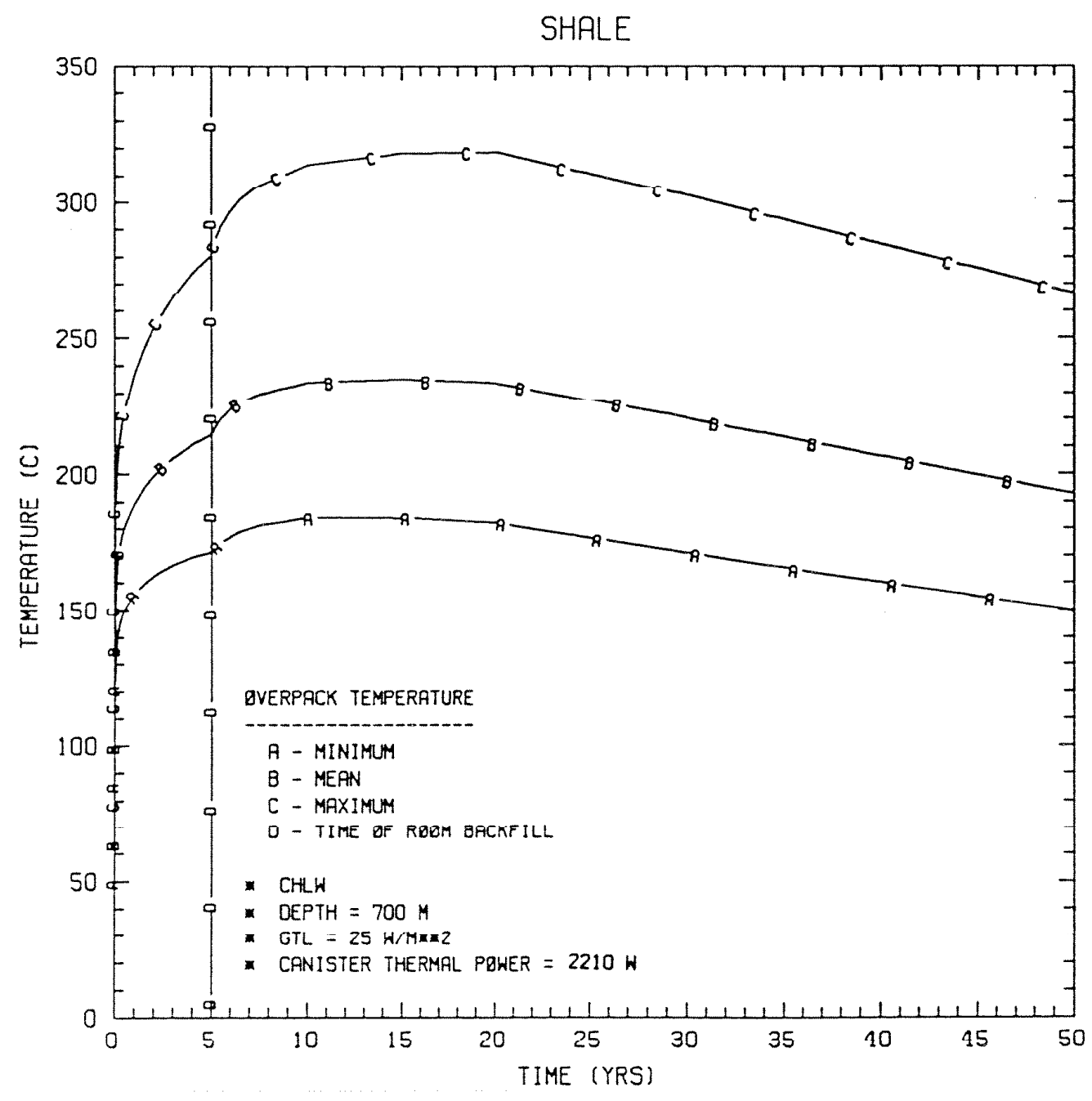

Fig. G.12.1.15. Expected range in overpack temperature for commercial high-level waste emplacement in shale. 
ORNL DWG 85-116

ANHYDRITE

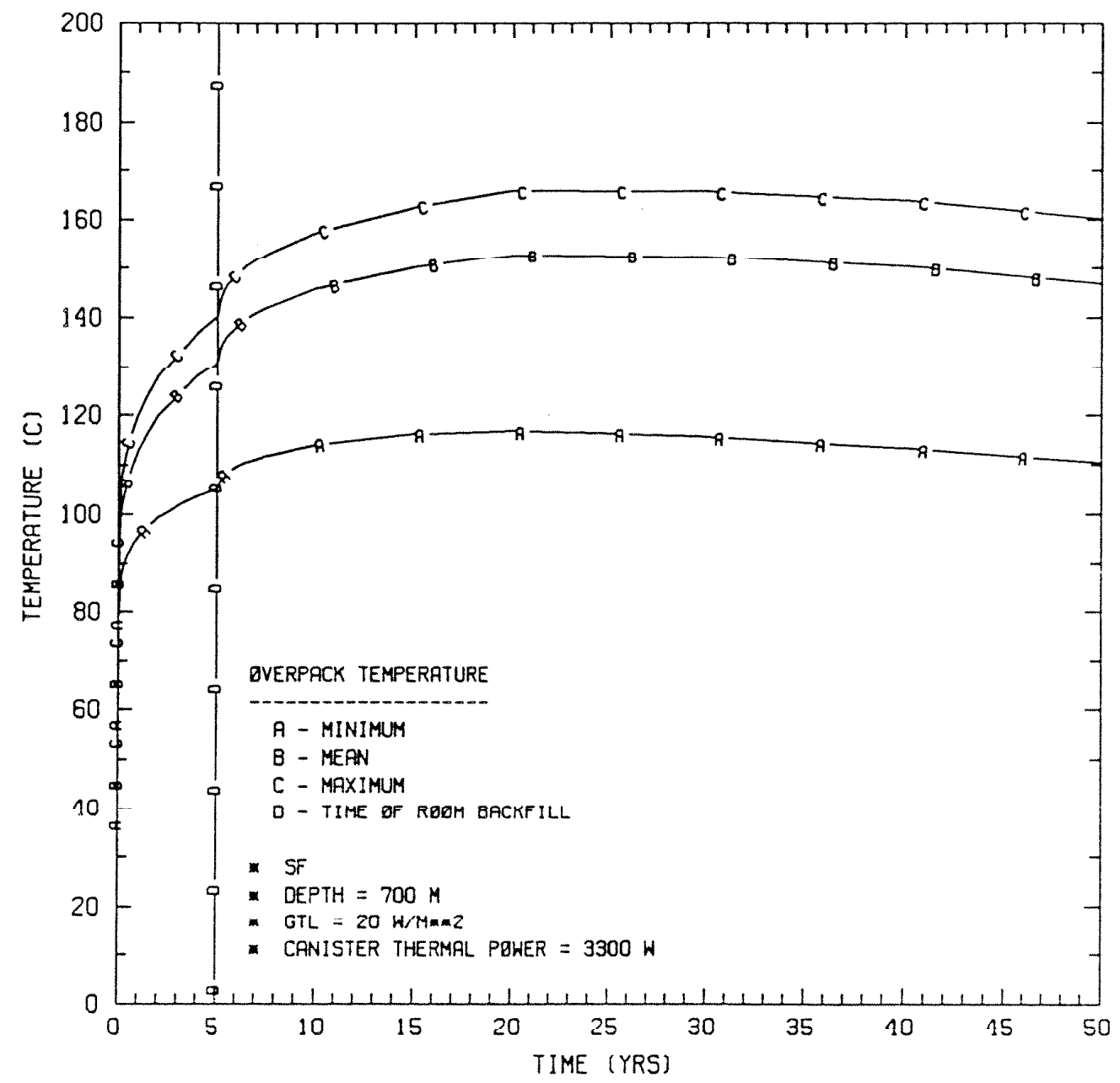

Fig. G.12.1.16. Expected range in overpack temperature for spent fuel emplacement in anhydrock. 
ORNL DWG 85-117

CHALK

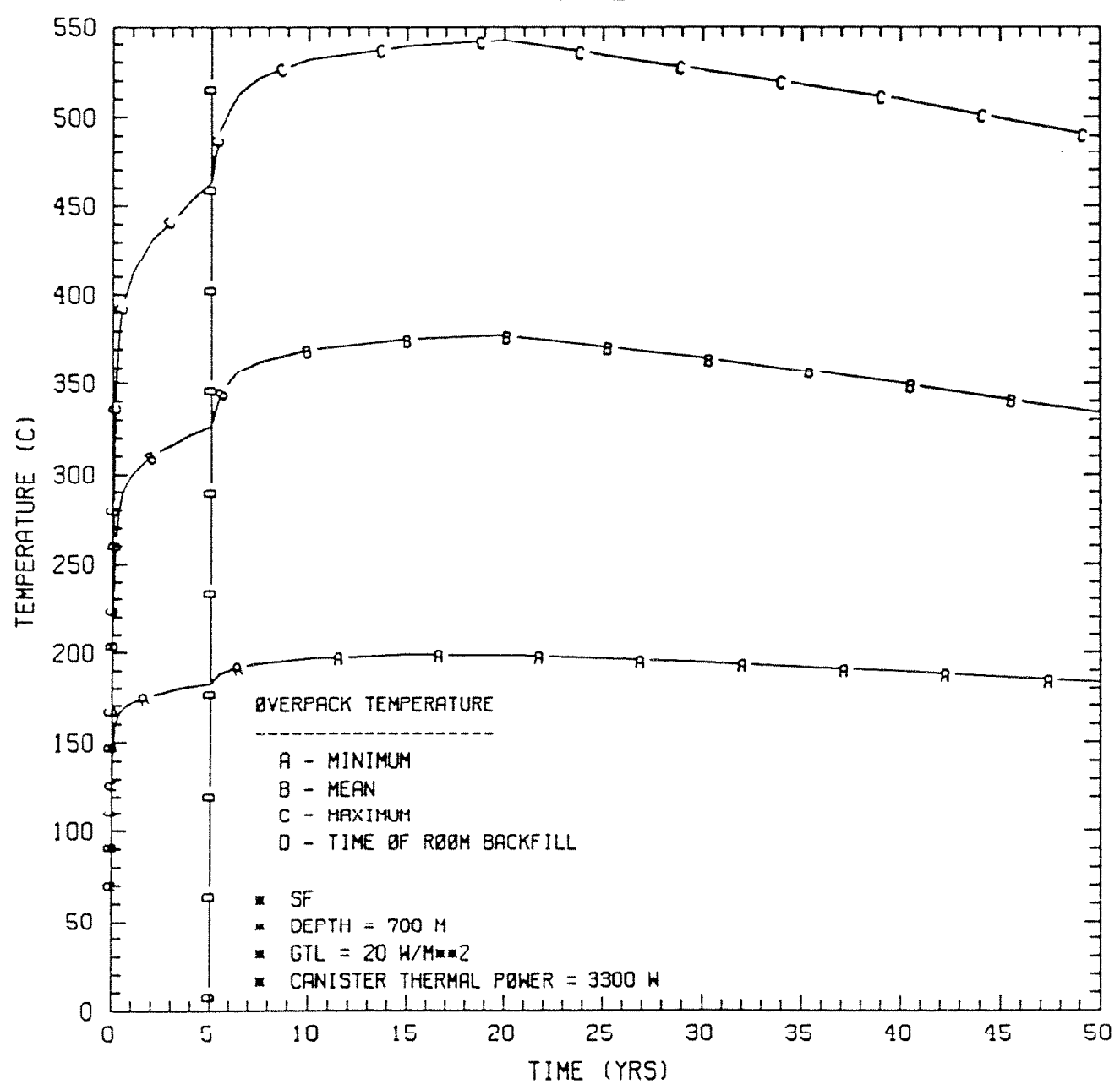

Fig. G.12.1.17. Expected range in overpack temperature for spent fuel emplacement in chalk. 
ORNL DWG 85-118

LIMESTONE/DOLOMITE

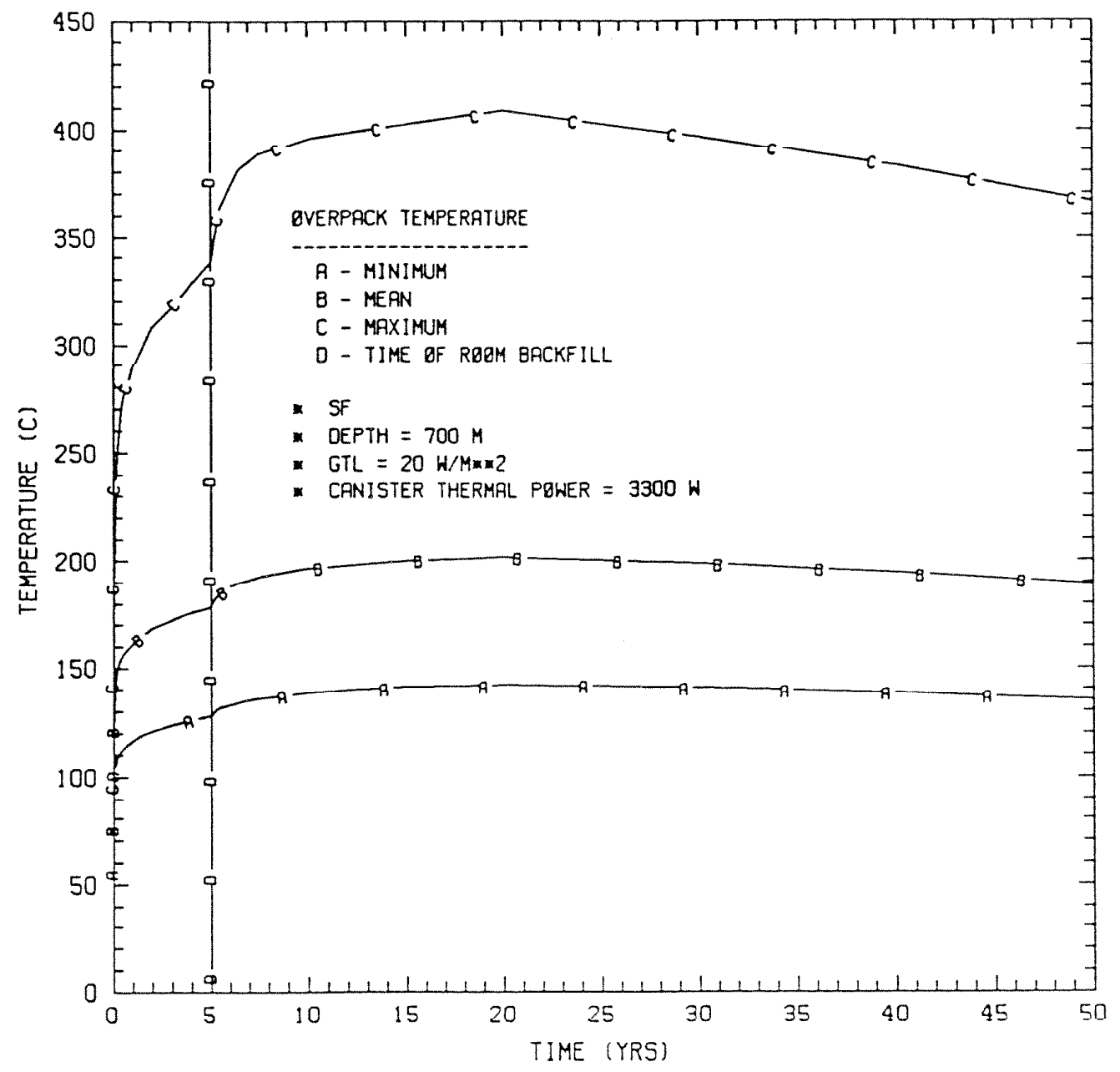

Fig. G.12.1.18. Expected range in overpack temperature for spent fuel emplacement in carbonates (1imestone/dolostone). 
ORNL DWG 85-119

SANDSTDNE

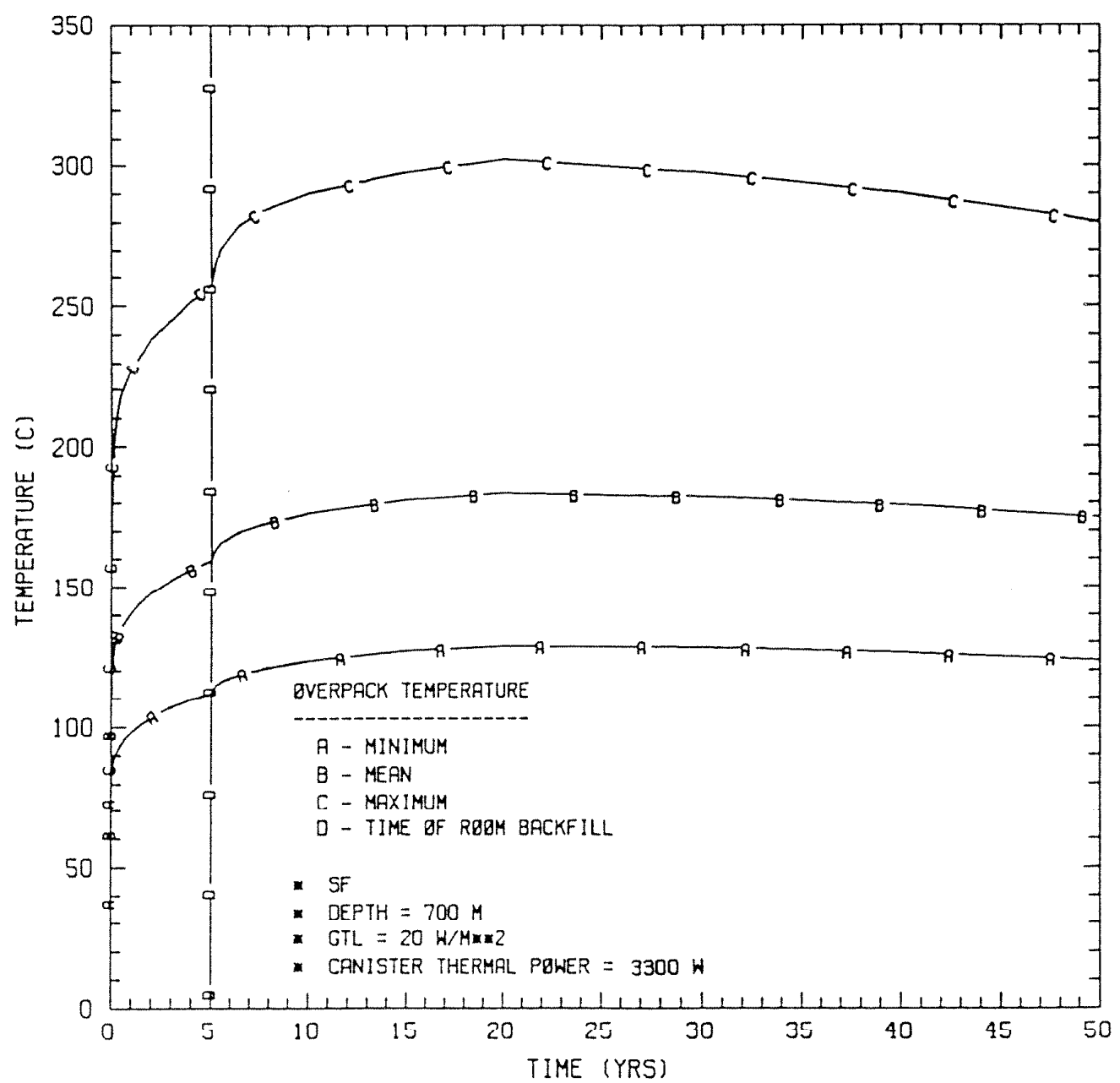

Fig. G.12.1.19. Expected range in overpack temperature for spent fuel emplacement in sandstone. 
ORNL DWG $85-120$

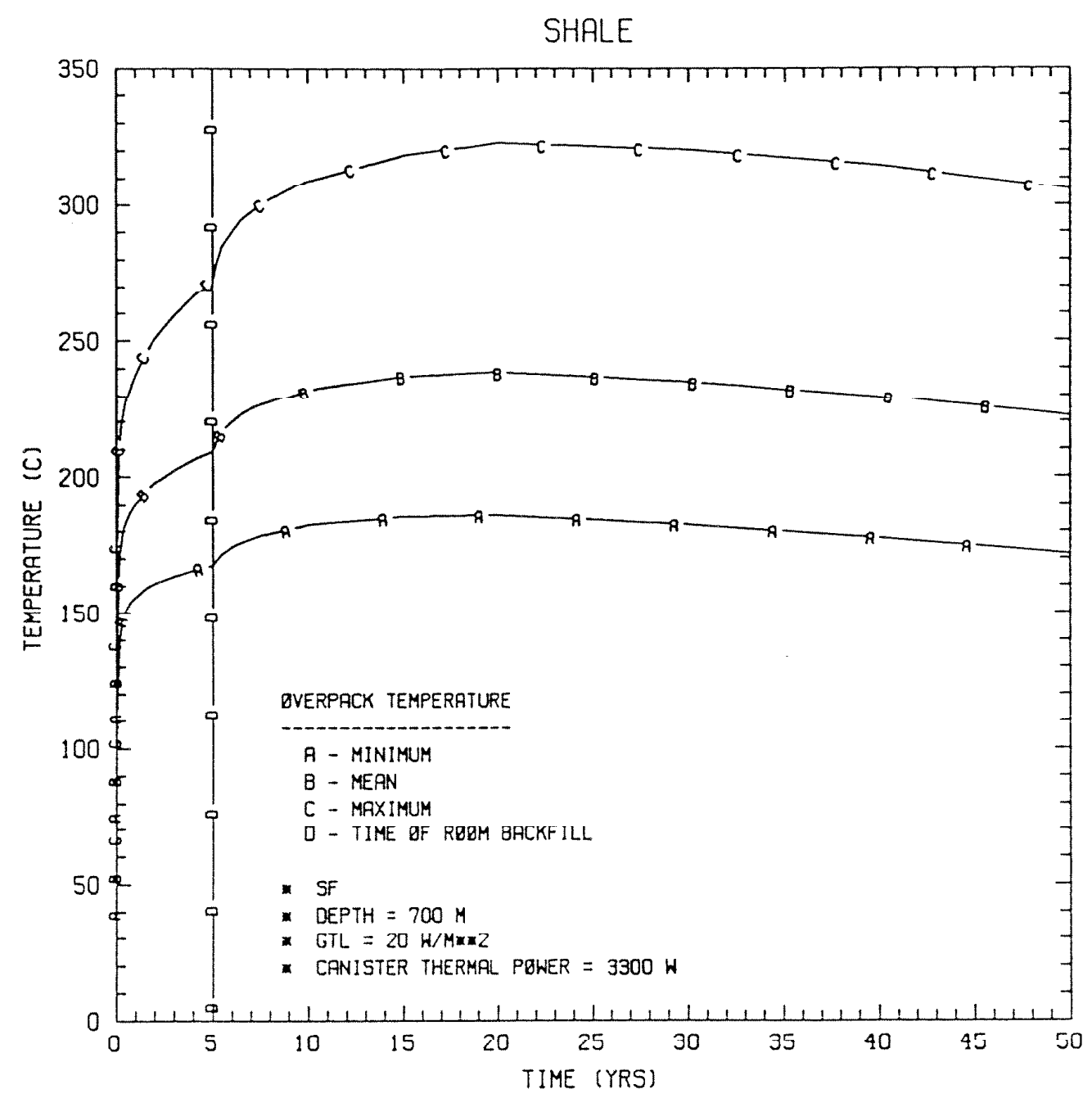

Fig. G.12.1.20. Expected range in overpack temperature for spent fuel emplacement in shale. 
ORNL DWG 85-121

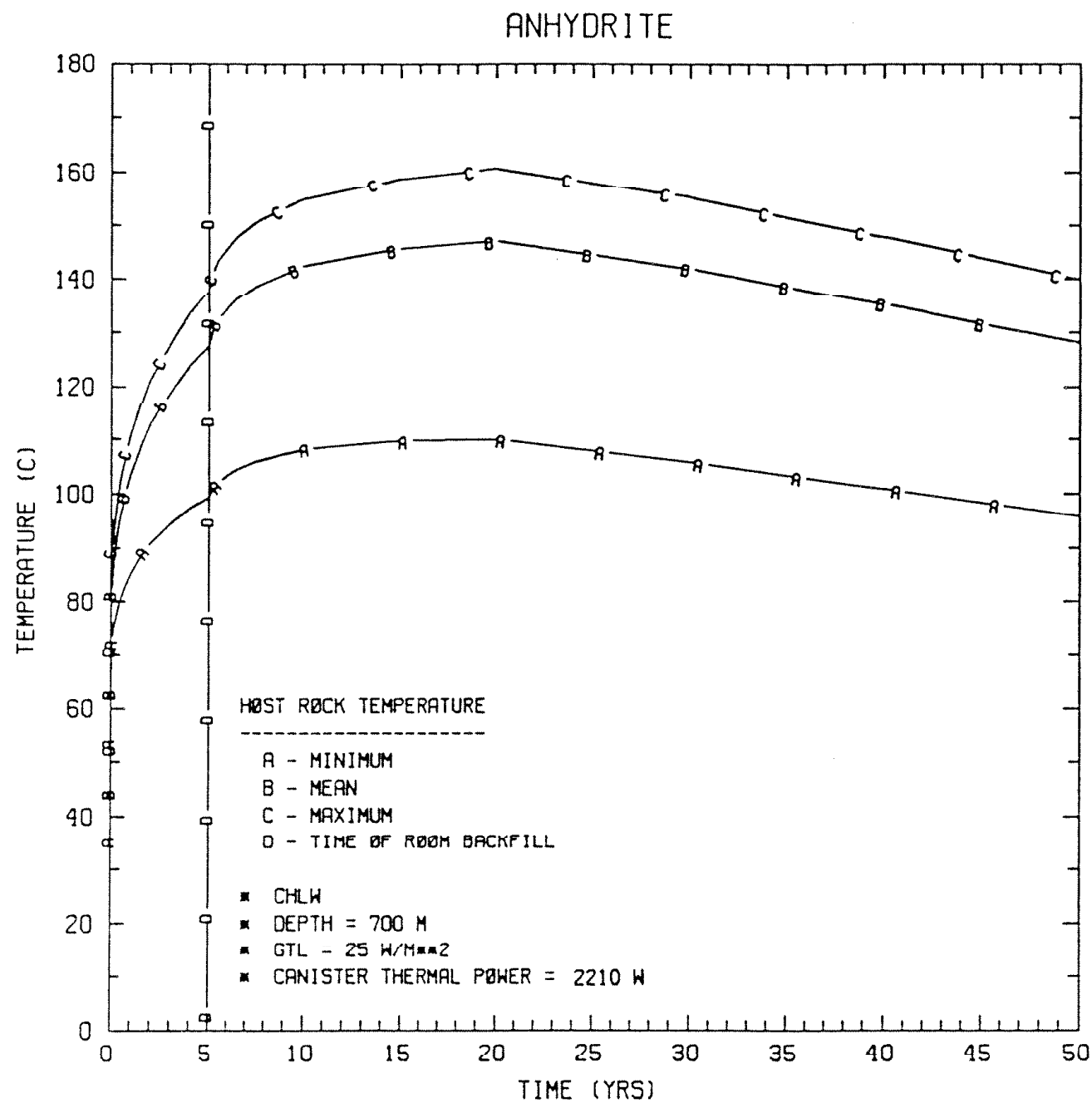

Fig. G.12.1.21. Expected range in host rock temperature for commercial high-level waste emplacement in anhydrock. 
ORNL DWG 85-122

\section{CHALK}

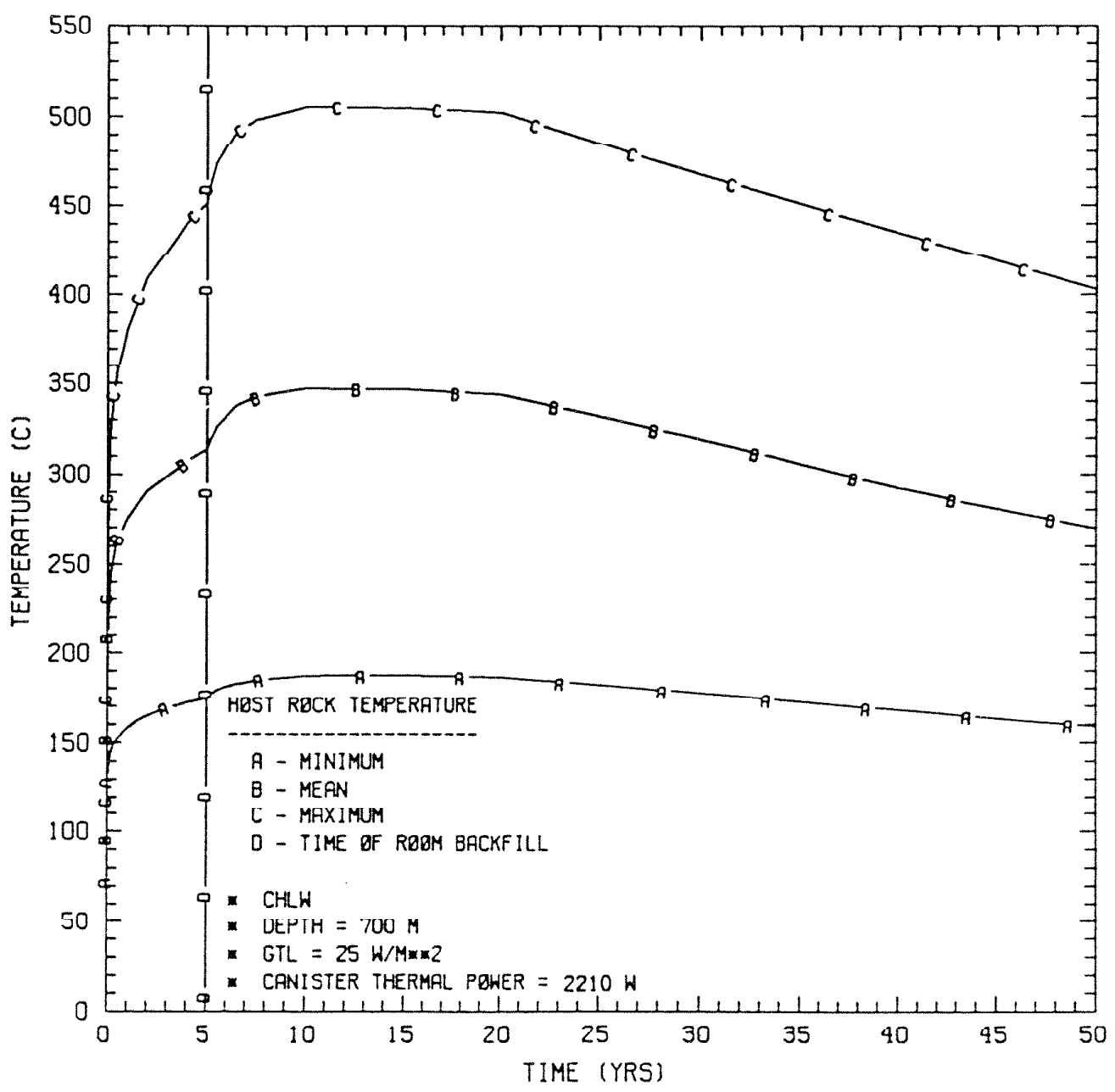

Fig. G.12.1.22. Expected range in host rock temperature for commercial high-level waste emplacement in chalk. 
ORNL DWG 85-123

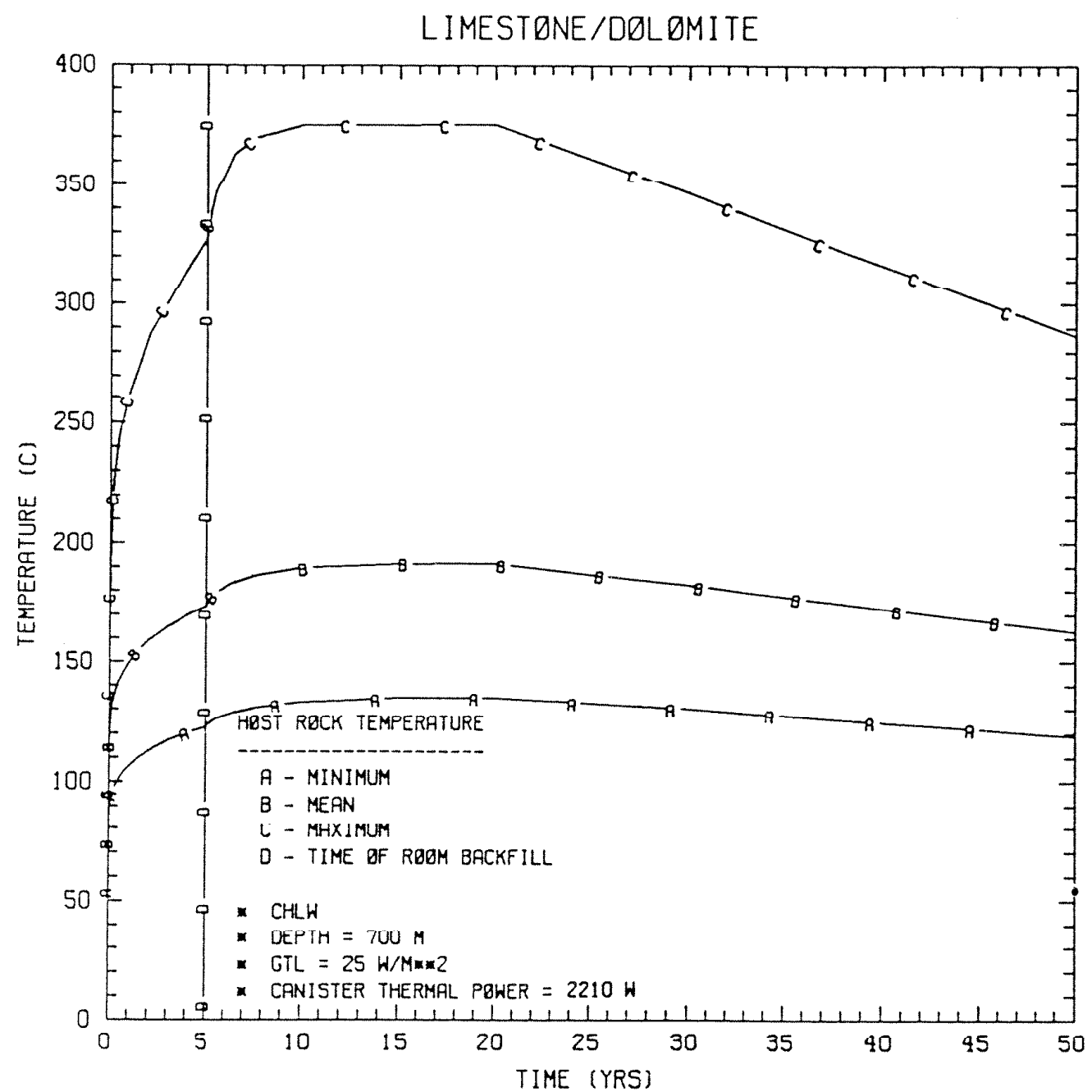

Fig. G.12.1.23. Expected range in host rock temperature for commerclal high-level waste emplacement in carbonate rocks (limestone/ dolomite). 
ORNL DWG 85-124

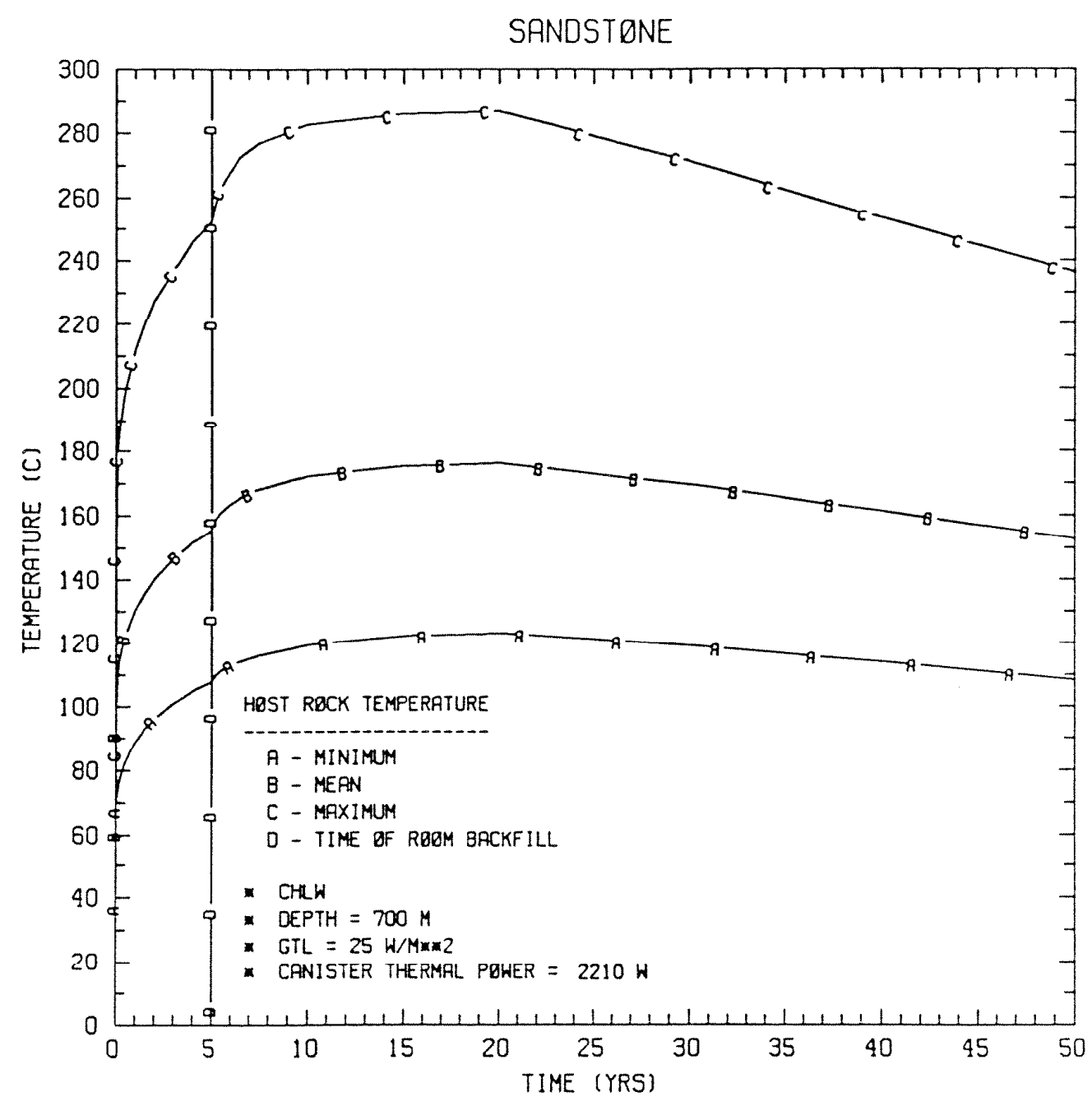

Fig. G.12.1.24. Expected range in host rock temperature for commercial high-level waste emplacement in sandstone. 
ORNL DWG 85-125

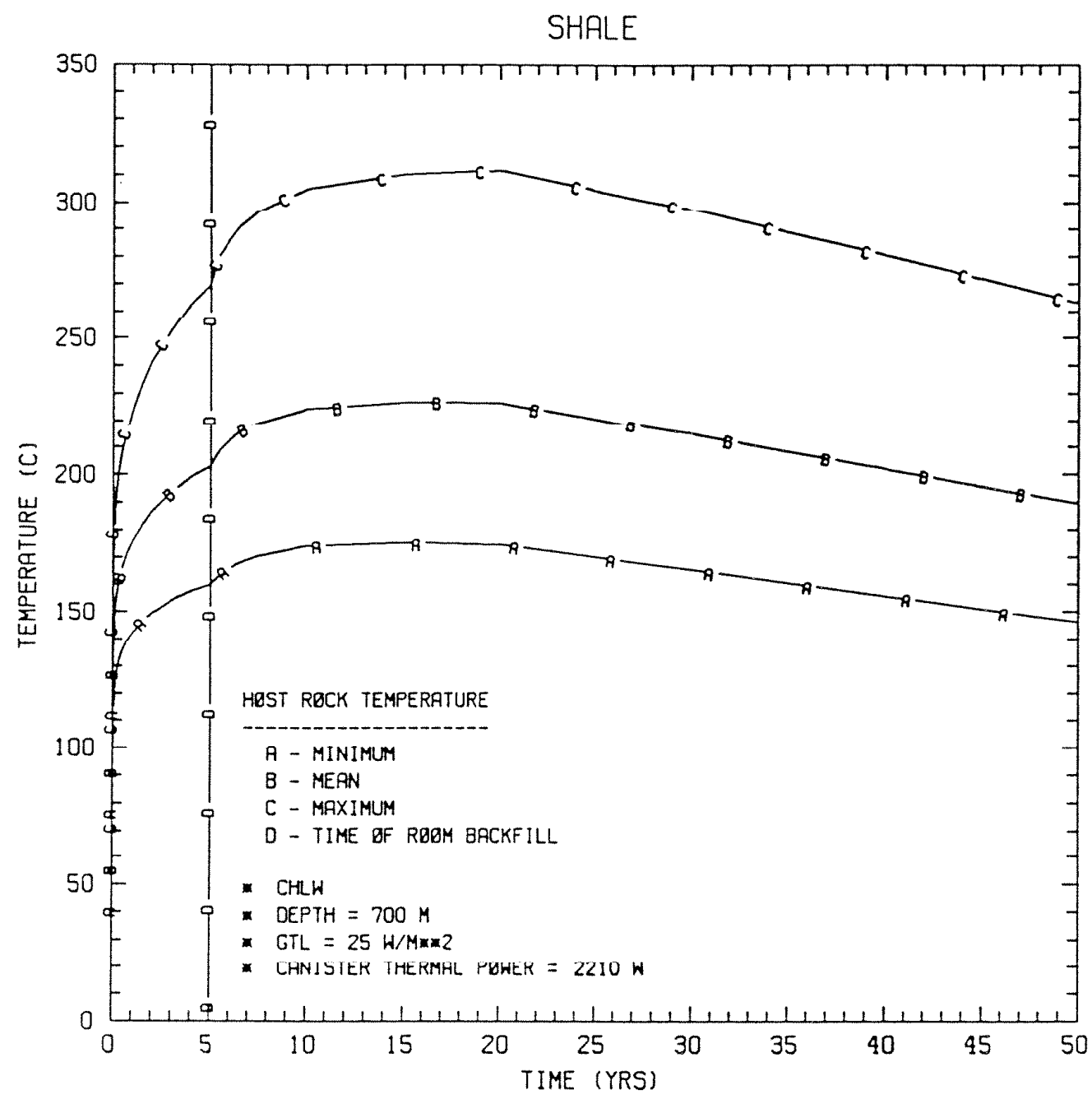

Fig. G.12.1.25. Expected range in host rock temperature for commercial high-level waste emplacement in shale. 
ANHYDRITE

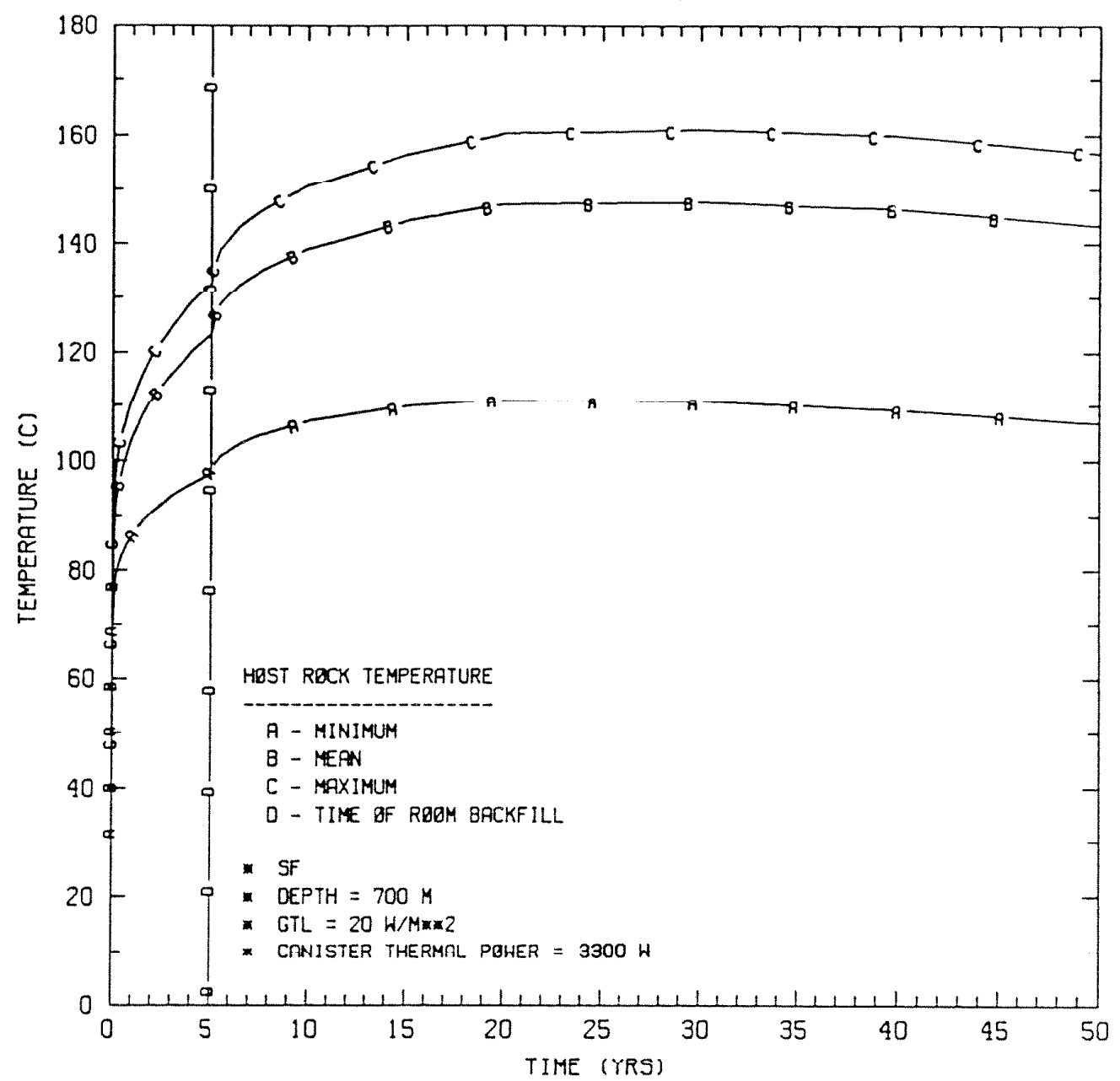

Fig. G.12.1.26. Expected range in host rock temperature for spent fuel emplacement in anhydrock. 
ORNL DWG 85-127

CHALK

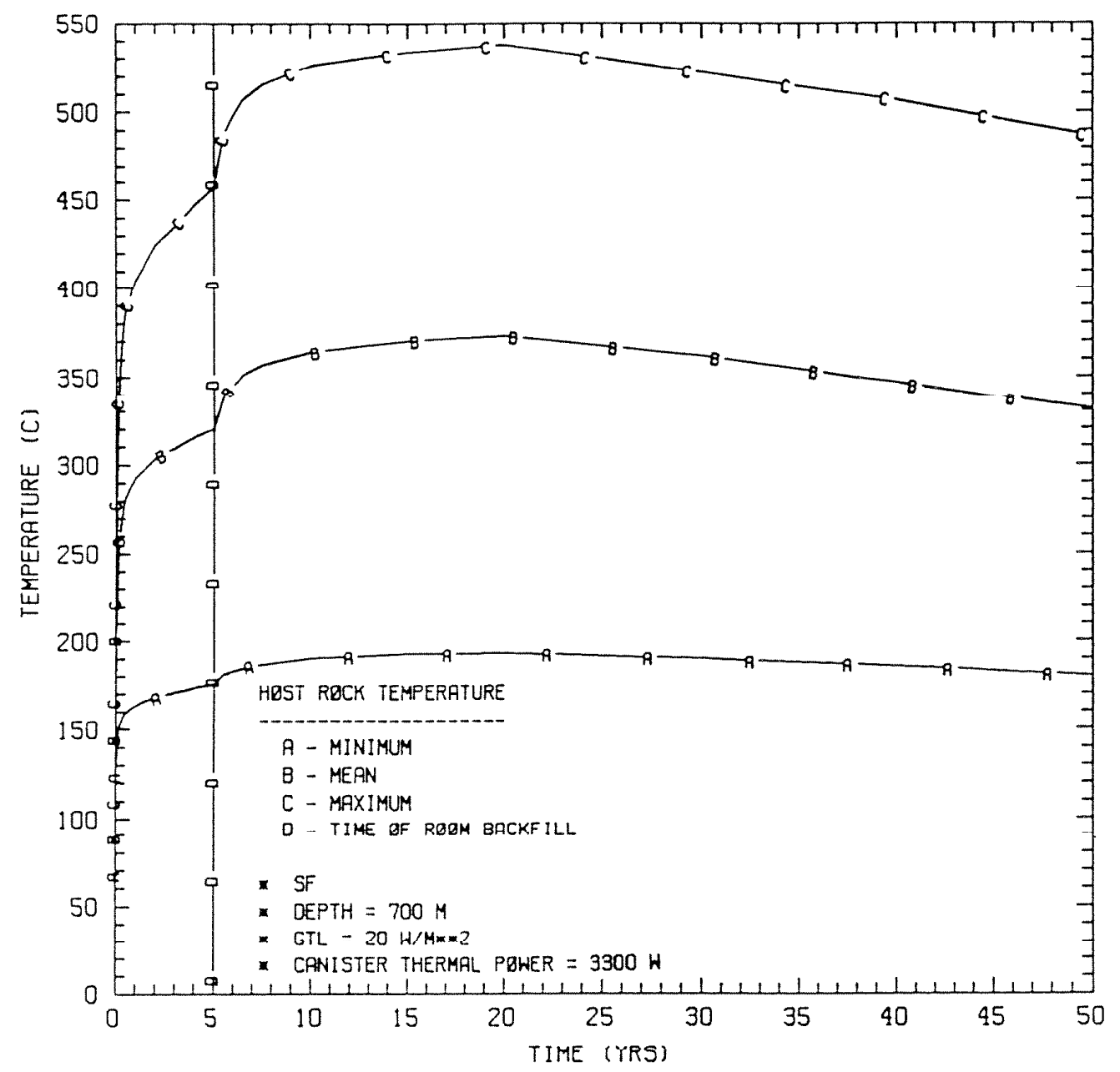

Fig. G.12.1.27. Expected range in host rock temperature for spent fuel emplacement in chalk. 
ORNL DWG 85-128

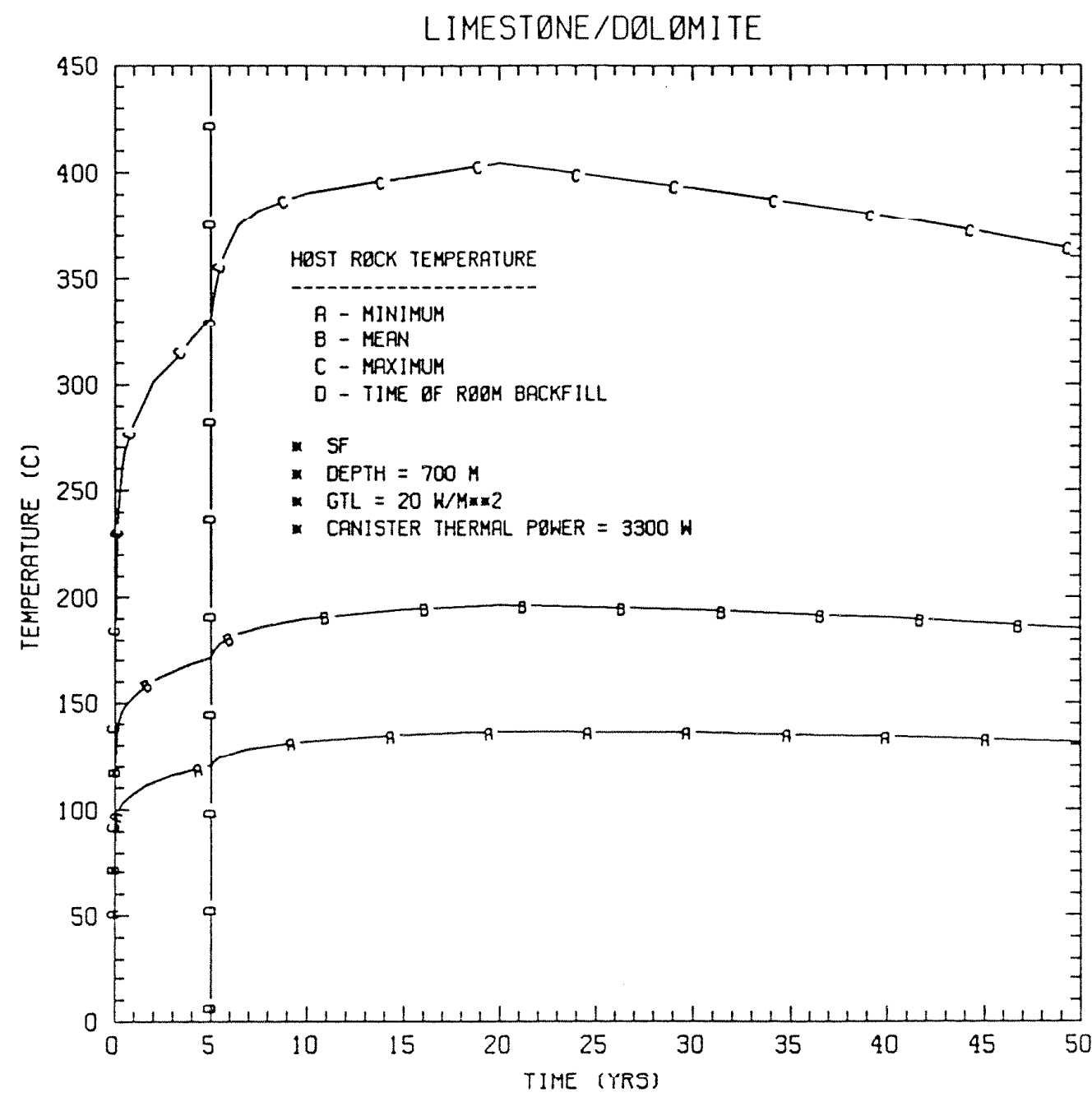

Fig. G.12.1.28. Expected range in host rock temperature for spent fuel emplacement in carbonate rocks (1imestone/dolostone). 
ORNL DWG 85-129

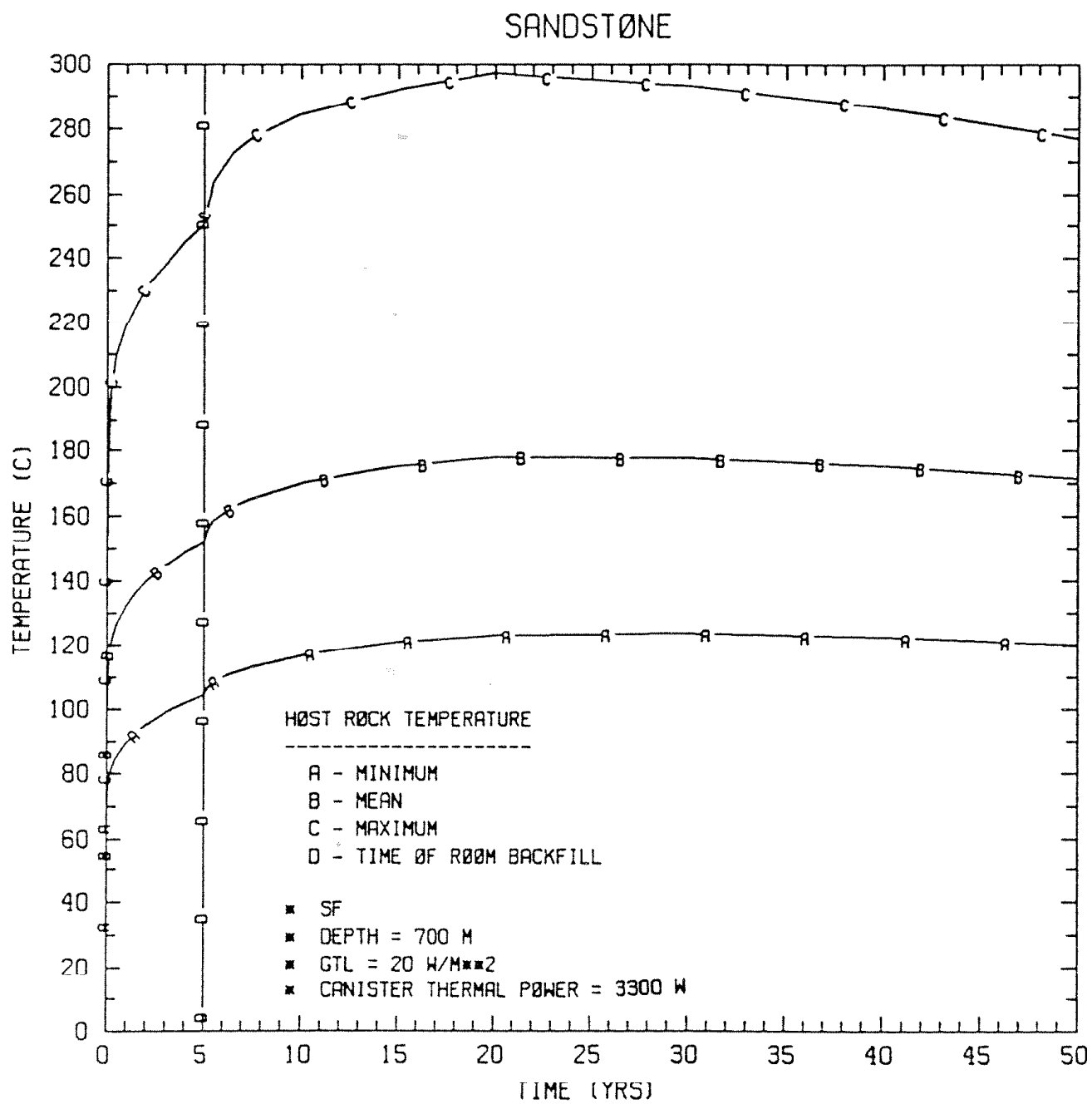

Fig. G.12.1.29. Expected range in host rock temperature for spent fuel emplacement in sandstone. 
ORNL DWG 85-130

SHALE

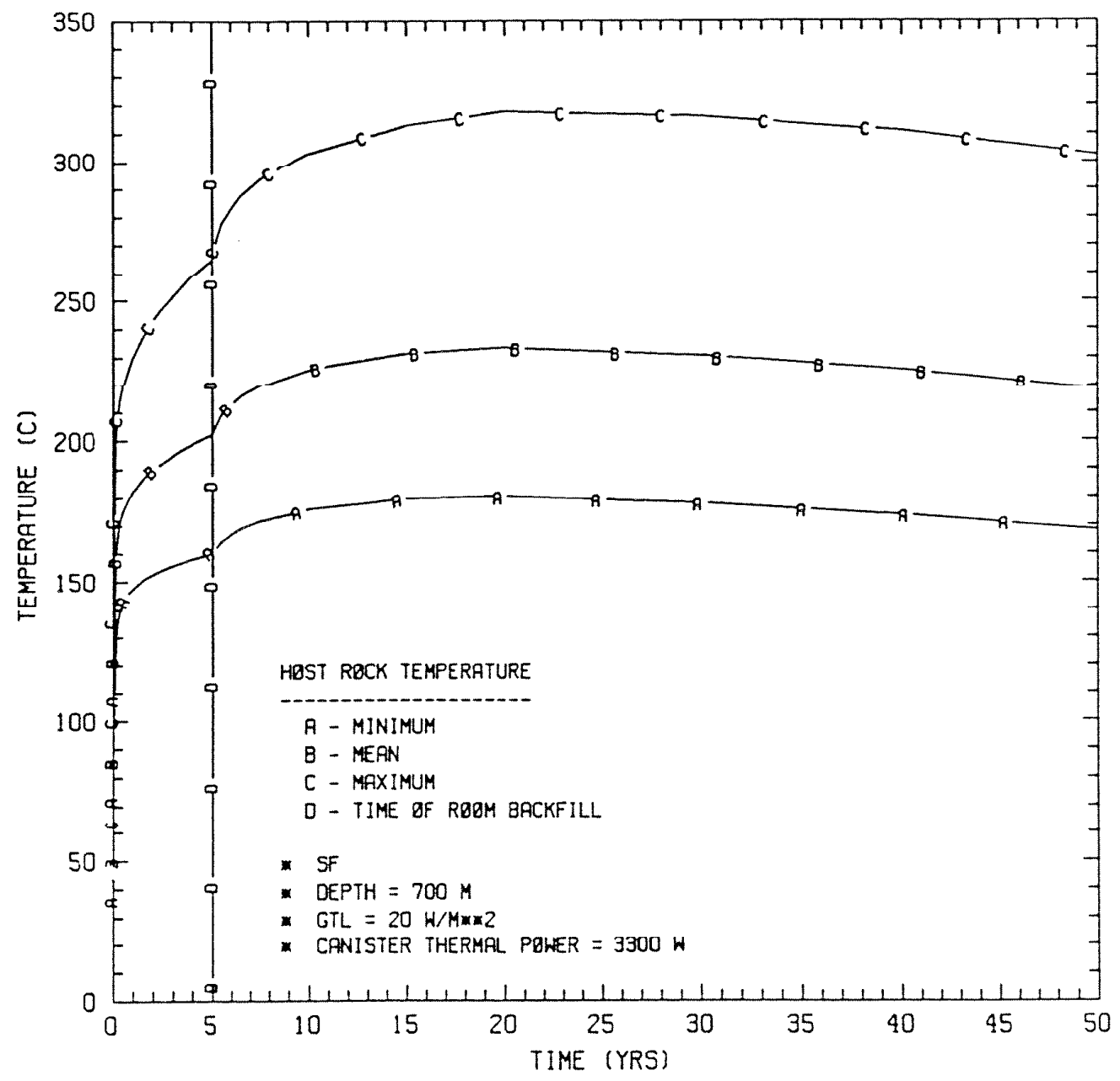

Fig. G.12.1.30. Expected range in host rock temperature for spent fuel emplacement in shale. 
G.12.2 DETAILED MODEL RESULTS FROM THE NEAR-FIELD THERMAL ANALYSIS

This section presents the detailed near-field thermal results that supplement the information presented in Sect. G.8.3. The figures in this section encompass (Figs. G.12.2.1 through G.12.2.30):

- Three responses:

- volume averaged backfill temperature

- near-field/far-field onterface temperature

- host rock temperature (isolation period)

- Two waste types

- commercial high-level waste

- spent fuel

- Five rock types

- anhydrock

- chalk

- carbonate rocks (1imestone/dolostone)

- sandstone

- sliale (argillaceuus luck)

Each figure presents the expected range in the transient behavior for each response, waste type, and rock type. 


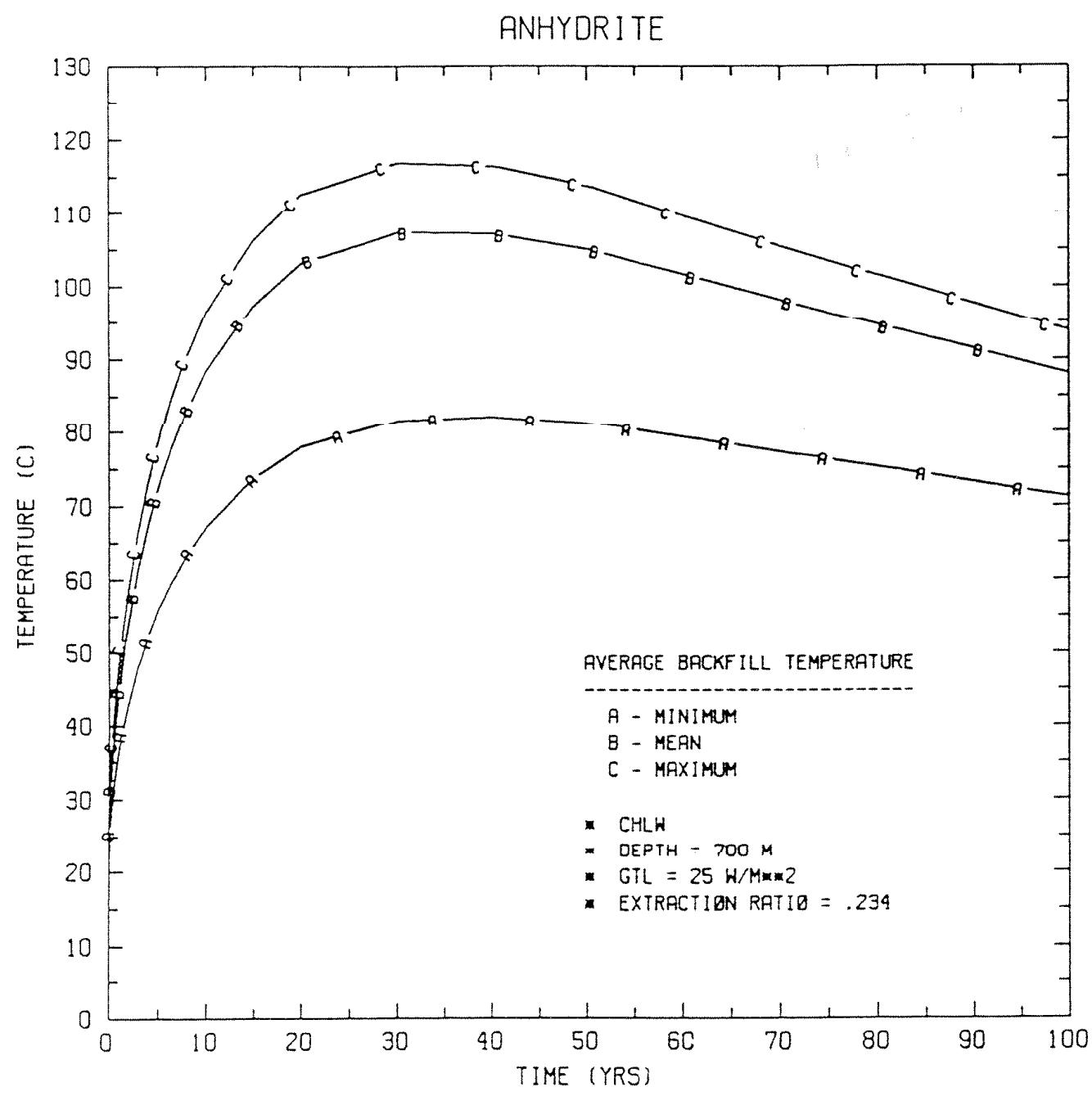

Fig. G.12.2.1. Expected range in average backfil1 temperature for commercial high-level waste emplacement in anhydrock. 
ORNL DWG 85-132

CHALK

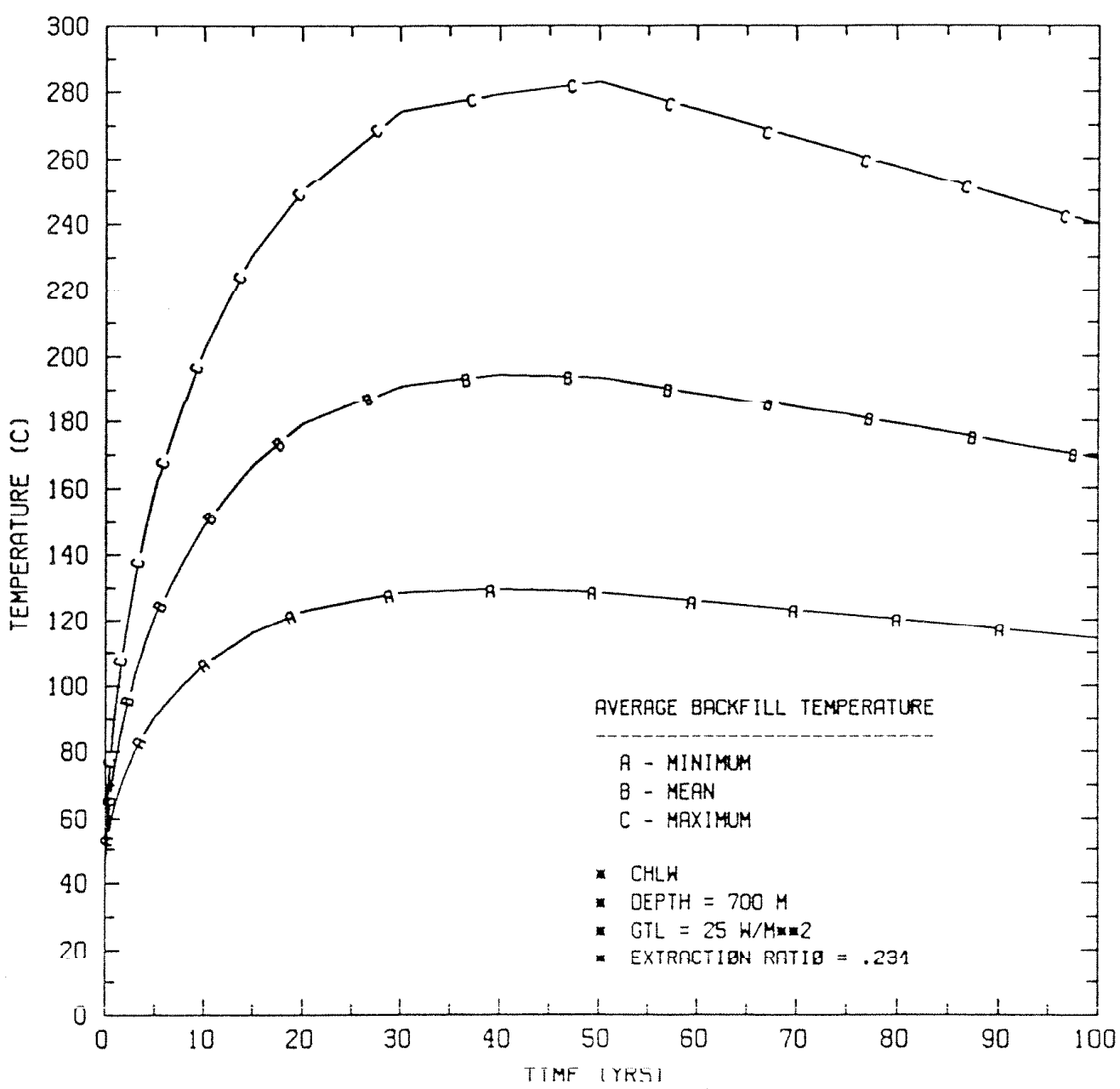

Fig. G.12.2.2. Expected range in average backfill temperature for commercial high-level waste emplacement in chalk. 
ORNL DWG 85-133

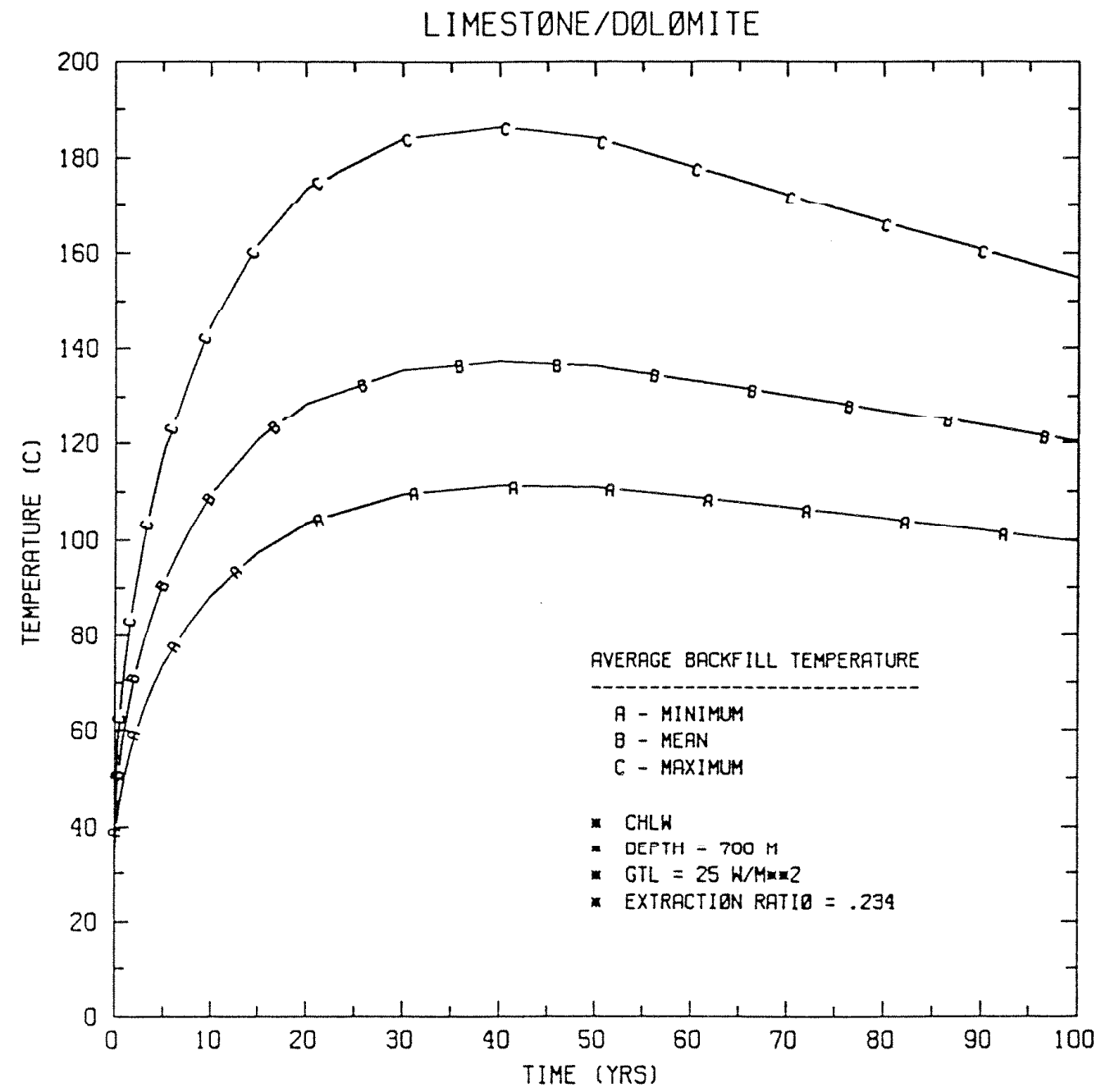

Fig. G.12.2.3. Expected range in average backfill temperature for commercial high-level waste emplacement in carbonate rocks (1imestone/ dolostone). 
ORNL DWG 85-134

SANDSTONE

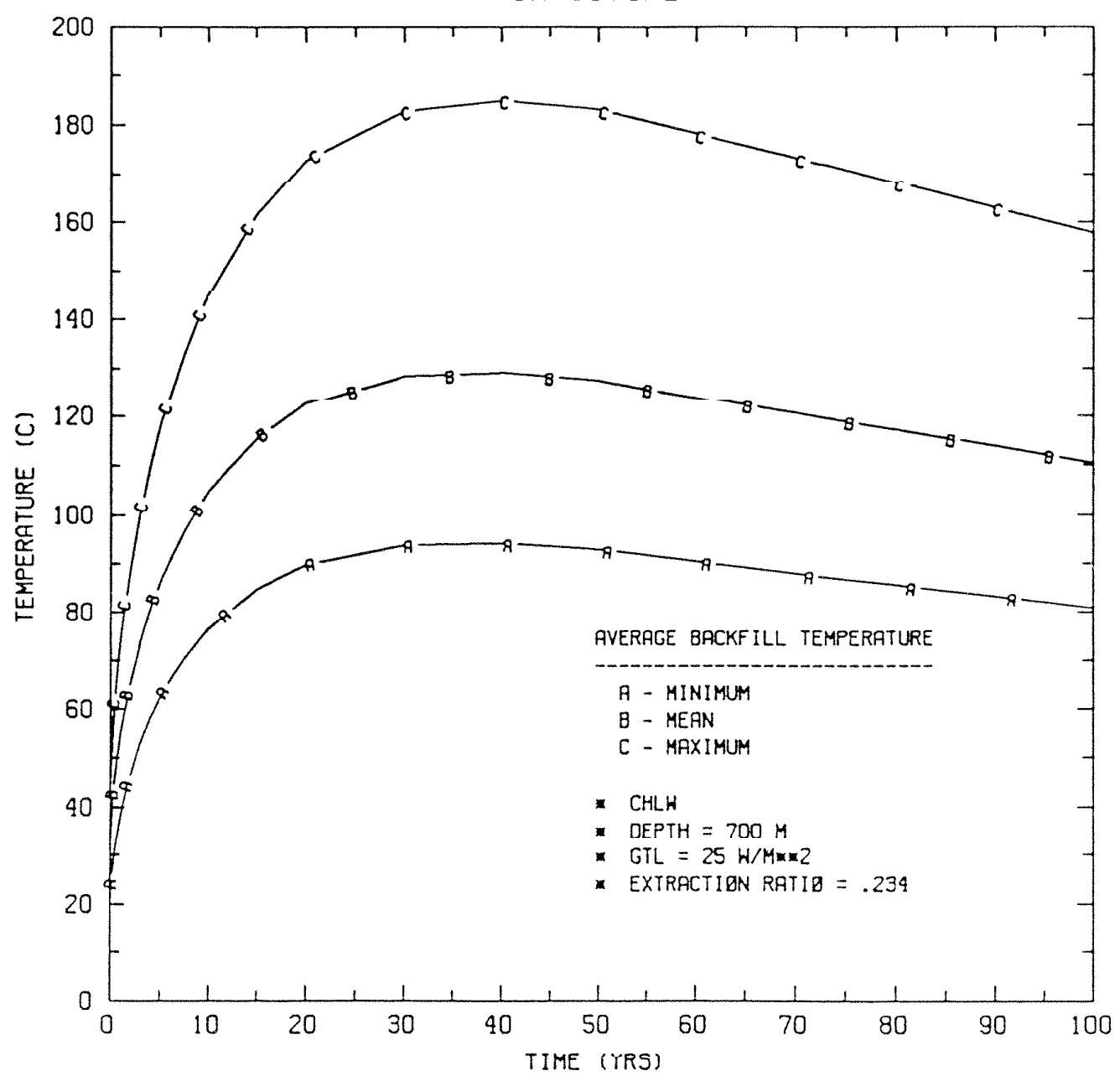

Fig. G.12.2.4. Expected range in average backfill temperature for commercial high-level waste emplacement in sandstone. 
ORNL DWG 85-135

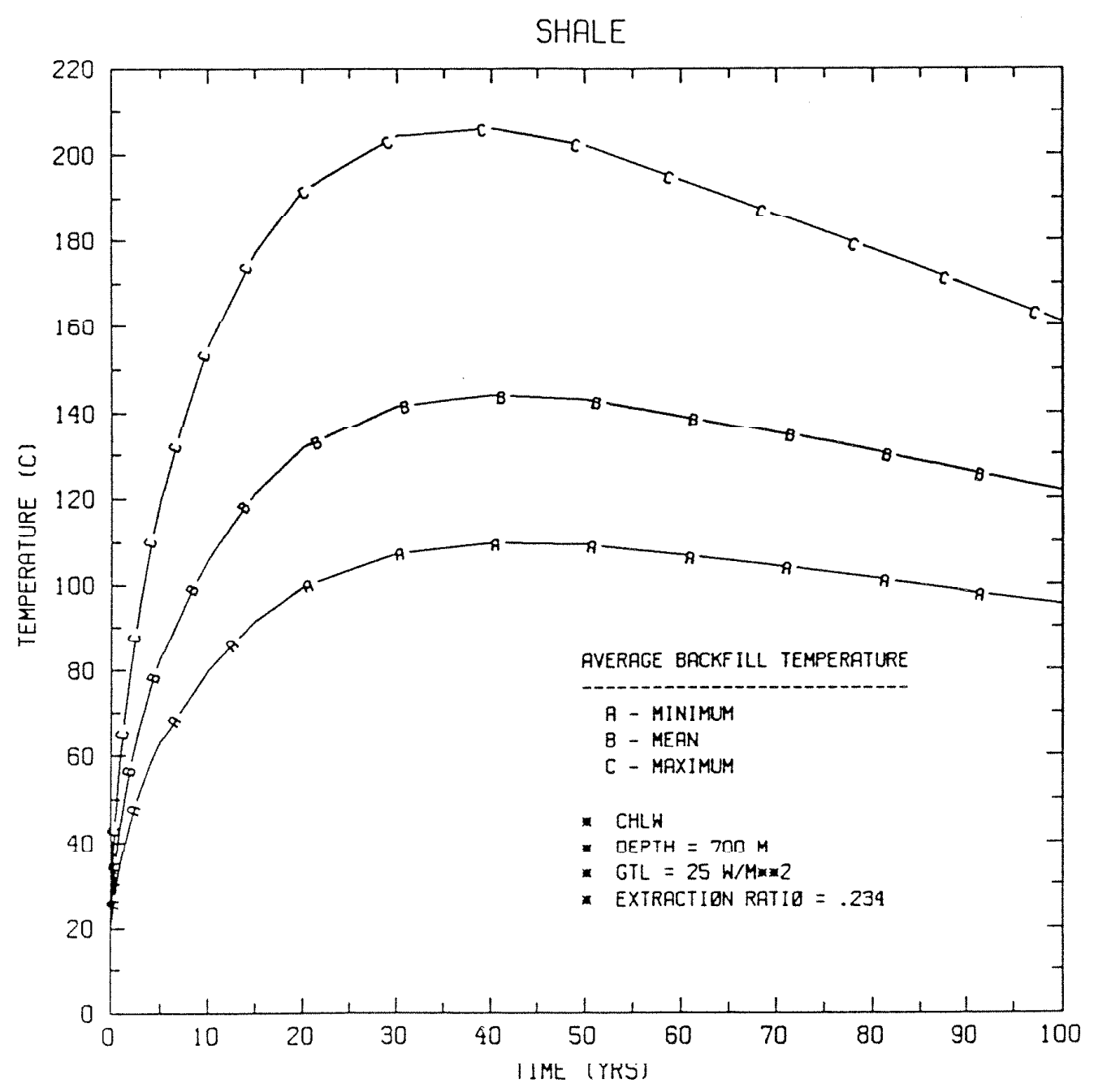

Fig. G.12.2.5. Expected range in average backfill temperature for commercial high-level waste emplacement in shale. 
ORNL DWG 85-136

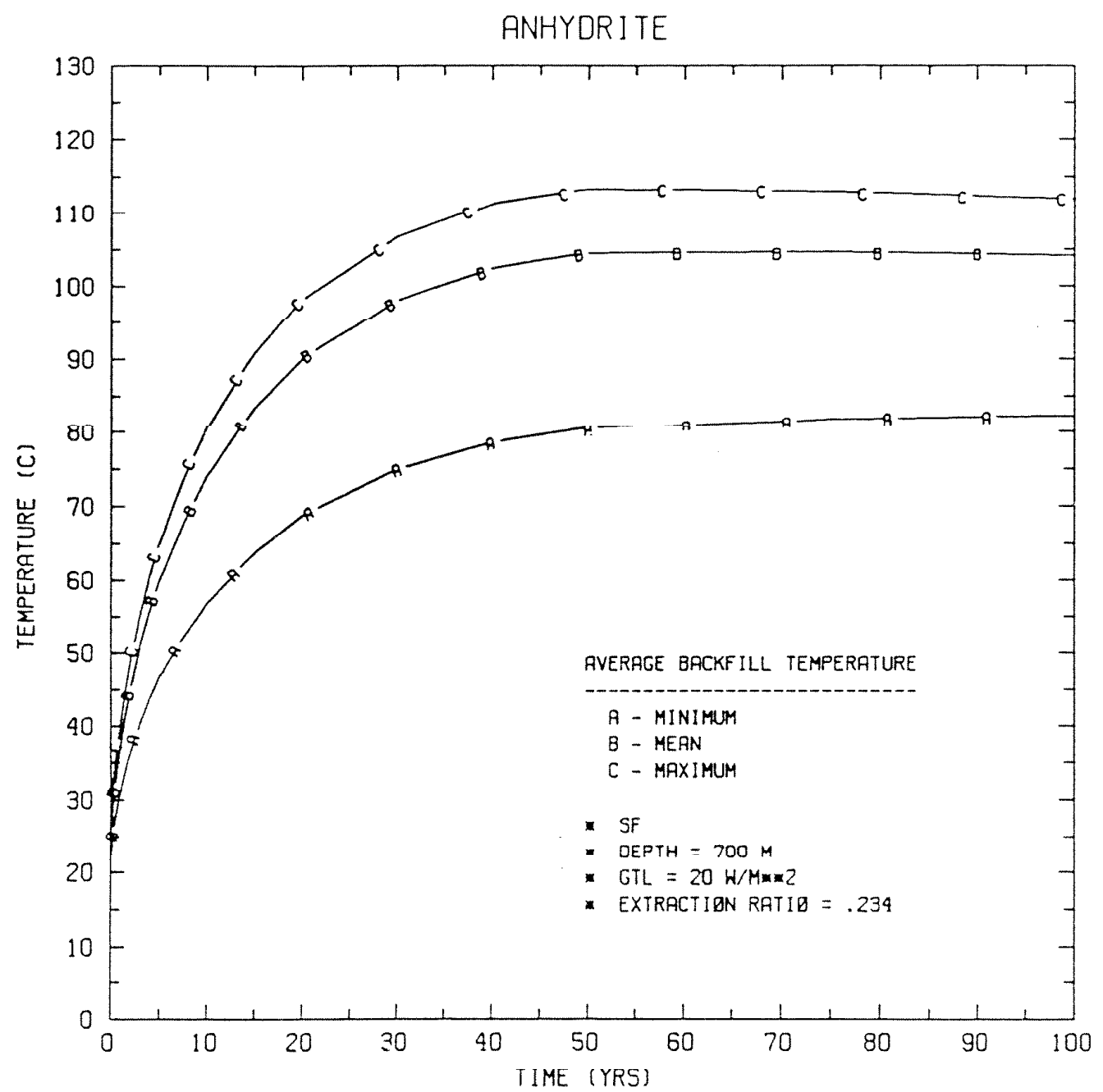

Fig. G.12.2.6. Expected range in average backfill temperature for spent fuel emplacement in anhydrock. 
ORNL DWG 85-137

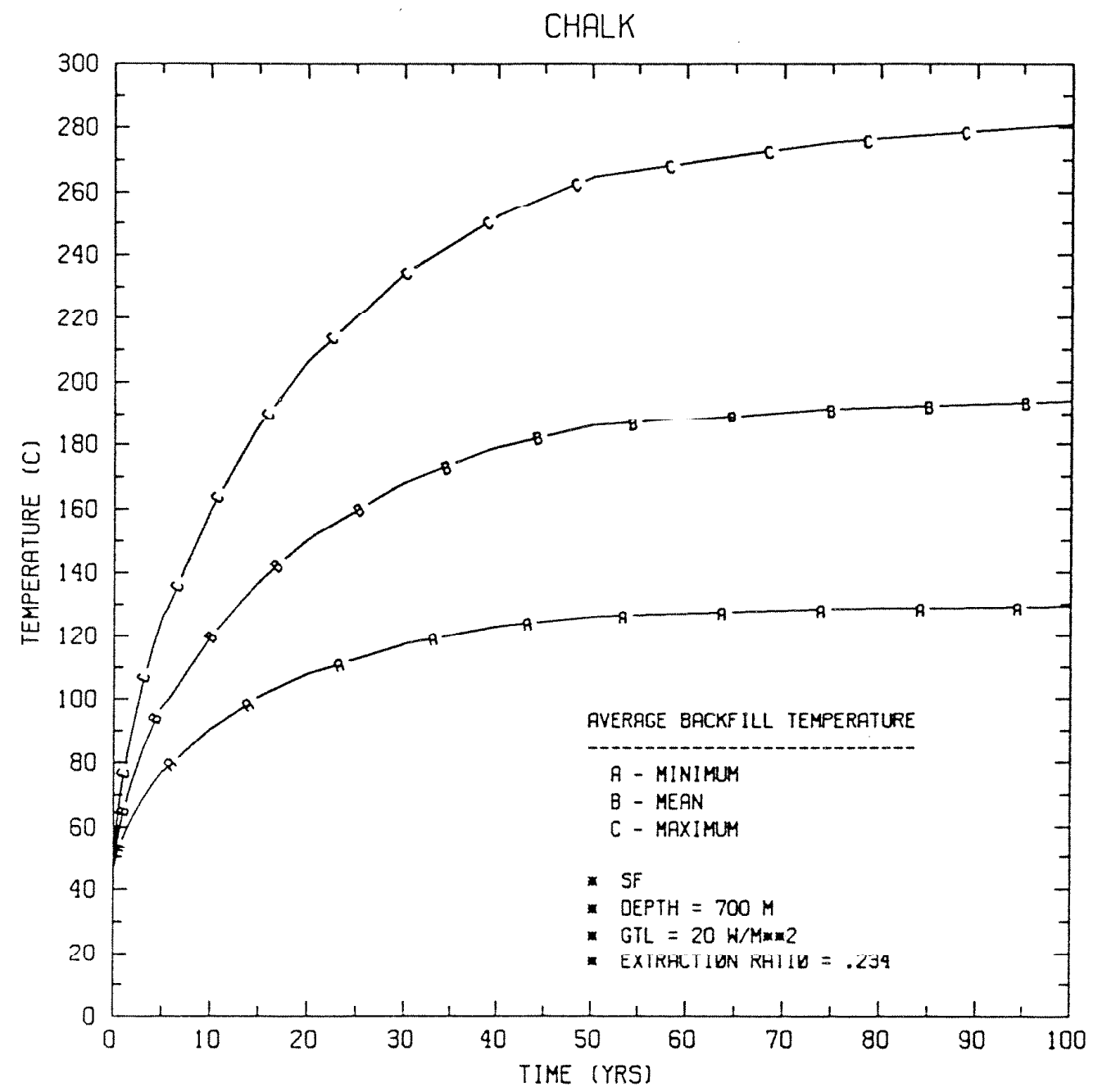

Fig. G.12.2.7. Expected range in average backfill temperature for spent fuel emplacement in chalk. 


\section{LIMESTONE/DOLOMITE}

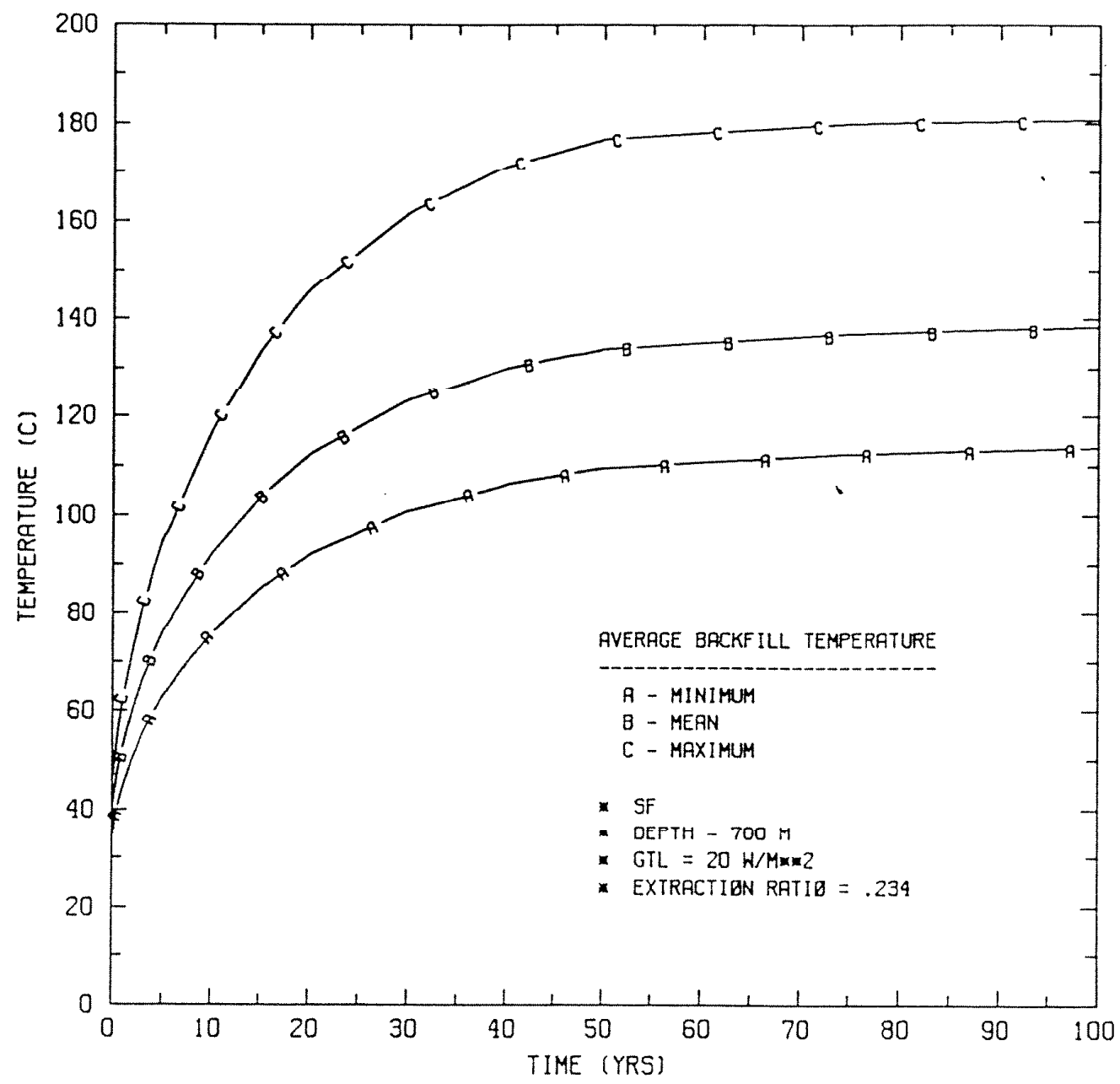

Fig. G.12.2.8. Expected range in average backfill temperature for spent fuel emplacement in carbonate rocks (limestone/dolostone). 
ORNL DWG 85-139

SANDSTONE

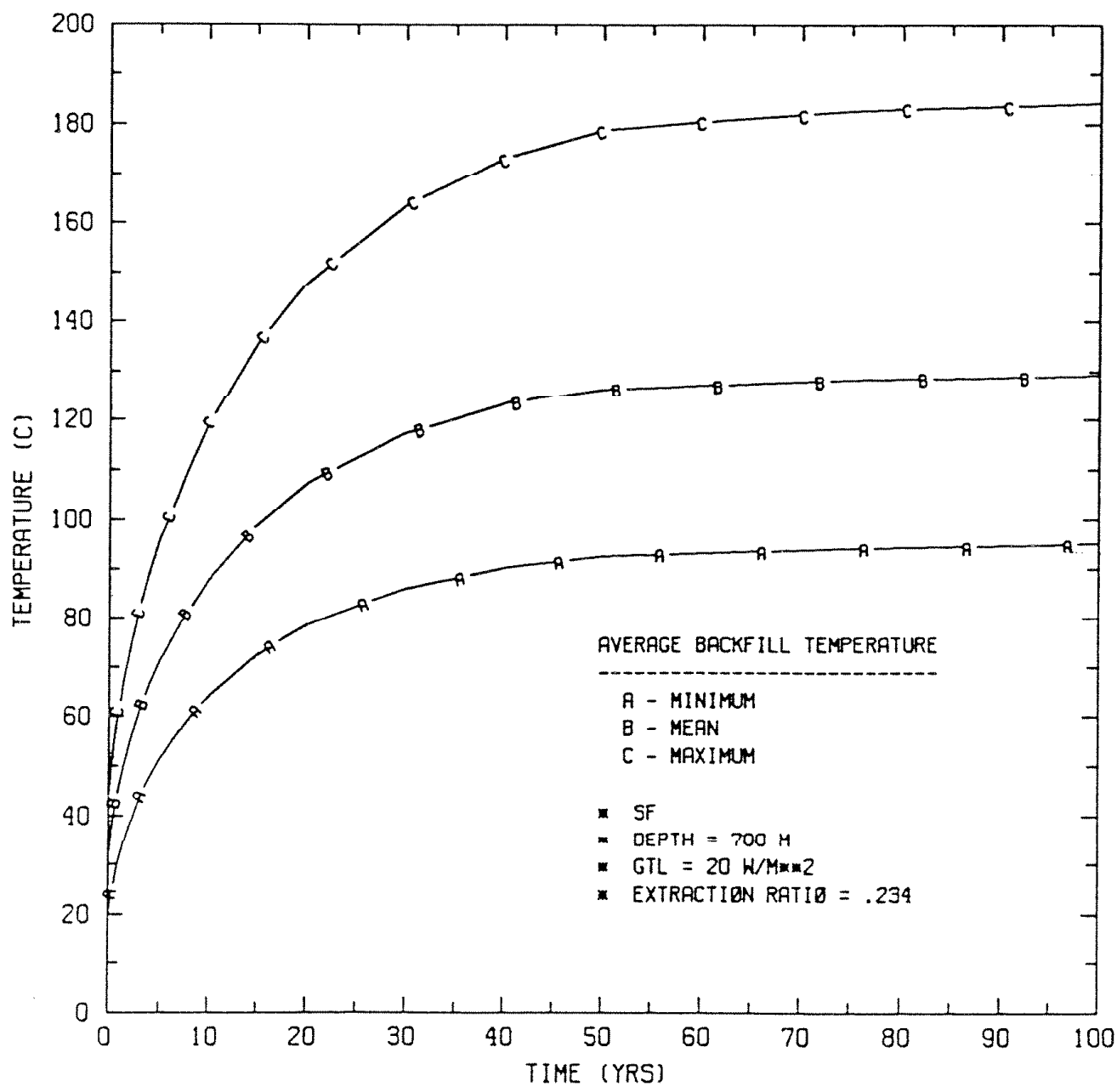

Fig. G.12.2.9. Expected range in average backfill temperature for spent fuel emplacement in sandstone. 
ORNL DWG 85-140

SHALE

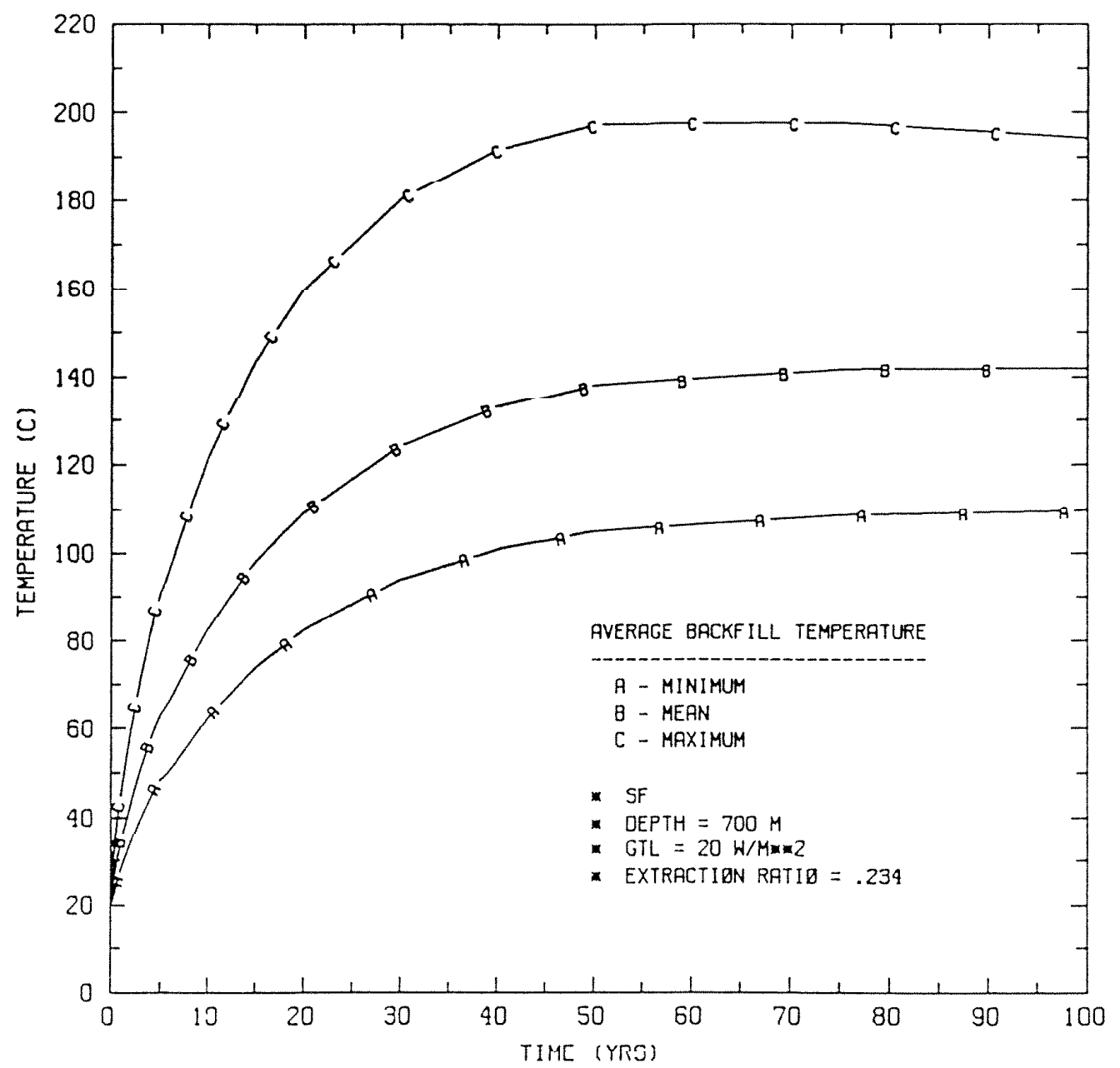

Fig. G.12.2.10. Expected range in average backfill temperature for spent fuel emplacement in shale. 
ORNL DWG 85-141

ANHYDRITE

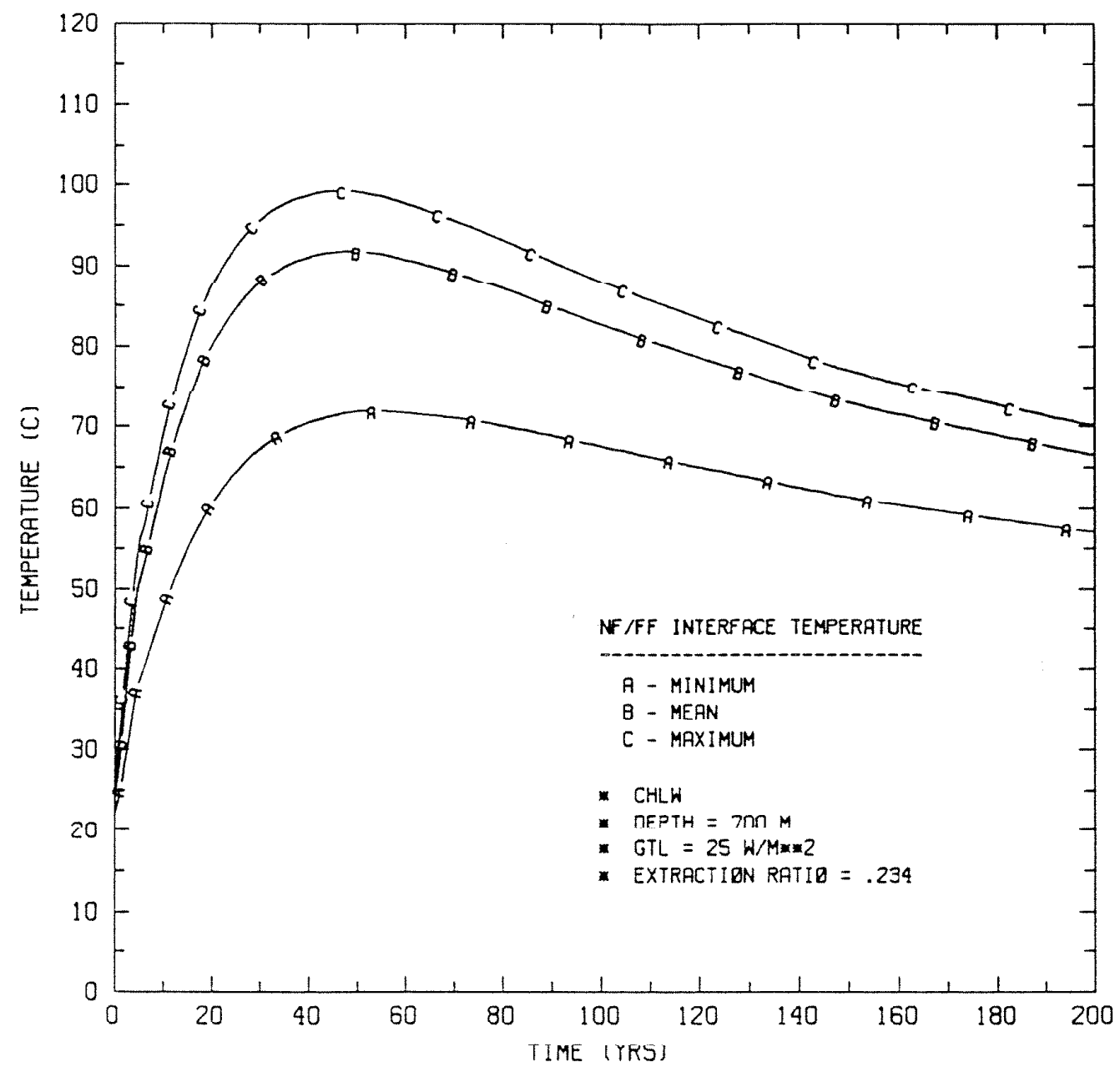

Fig. G.12.2.11. Expected range in near-field/far-field interface temperature for commercial high-level waste emplacement in anhydrock. 
ORNL DWG 85-142

CHALK

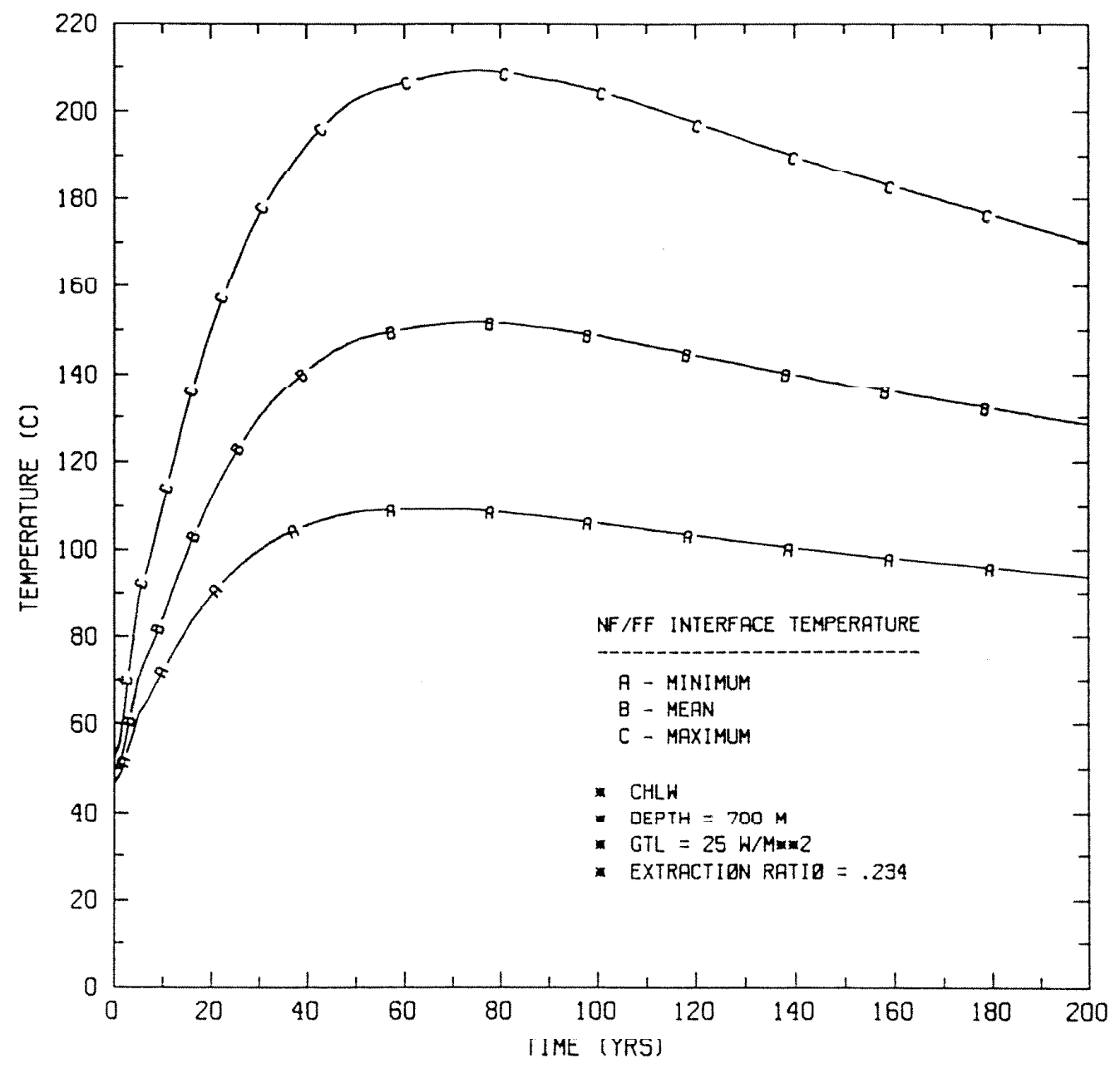

Fig. G.12.2.12. Expected range in near-field/far-field interface temperature for commercial high-level waste emplacement in chalk. 


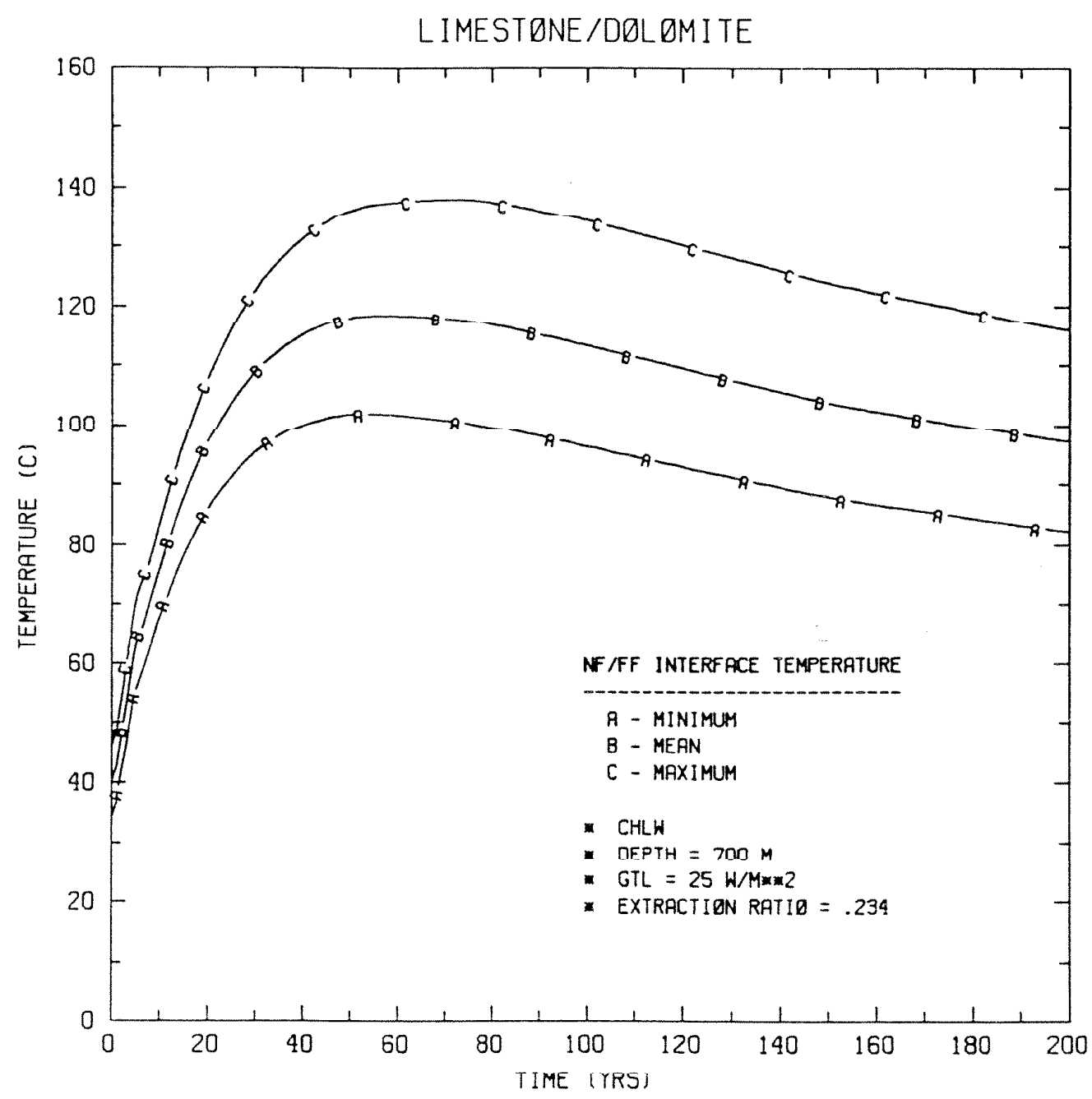

Fig. G.12.2.13. Expected range in near-field/far-field interface temperature for commercial high-level waste emplacement in carbonate rocks (1imestone/dolostone). 
ORNL DWG 85-144

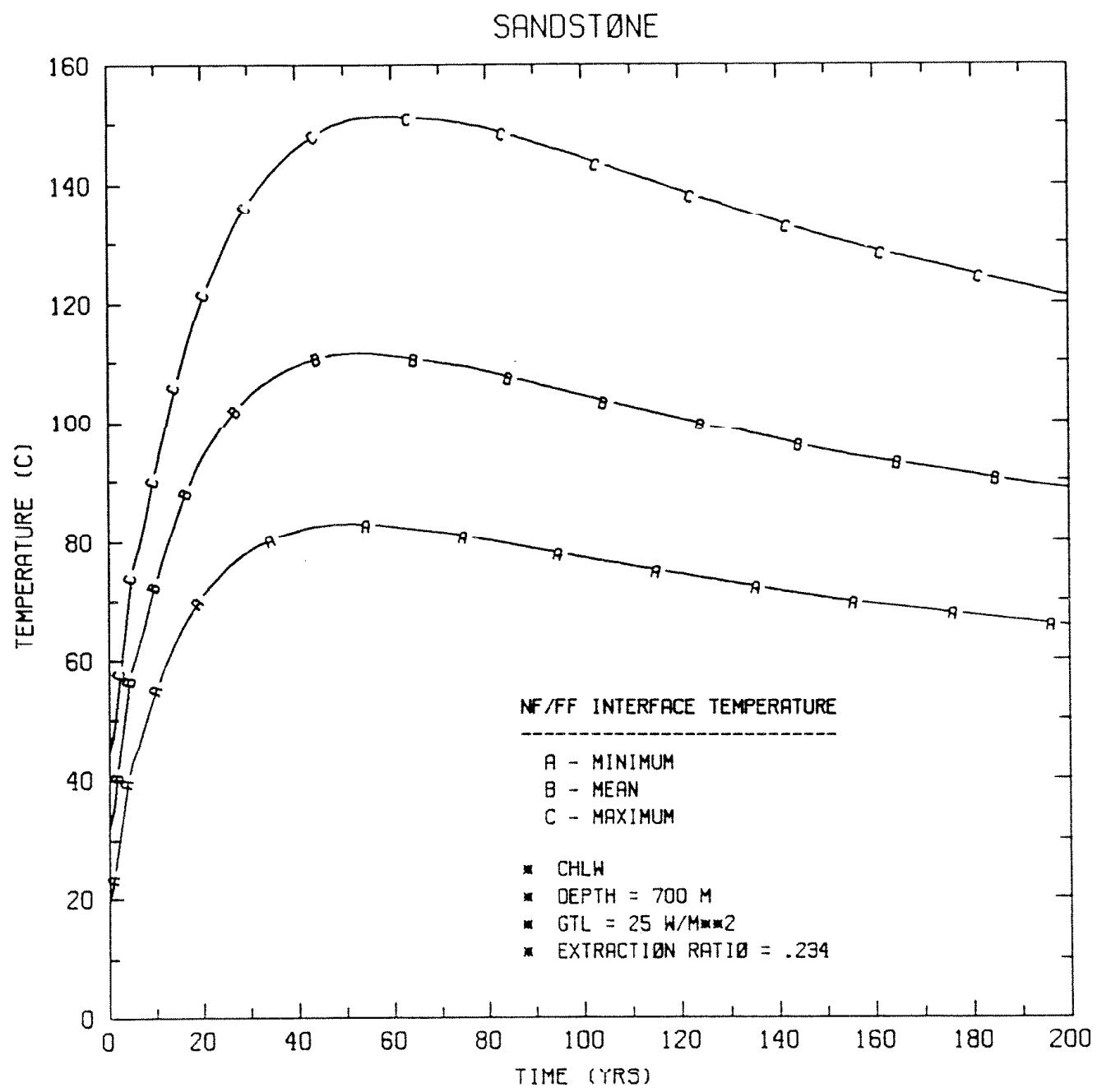

Fig. G.12.2.14. Expected range in near-field/far-field interface temperature for commercial high-level waste emplacement in sandstone. 
ORNL DWG $85-145$

SHALE

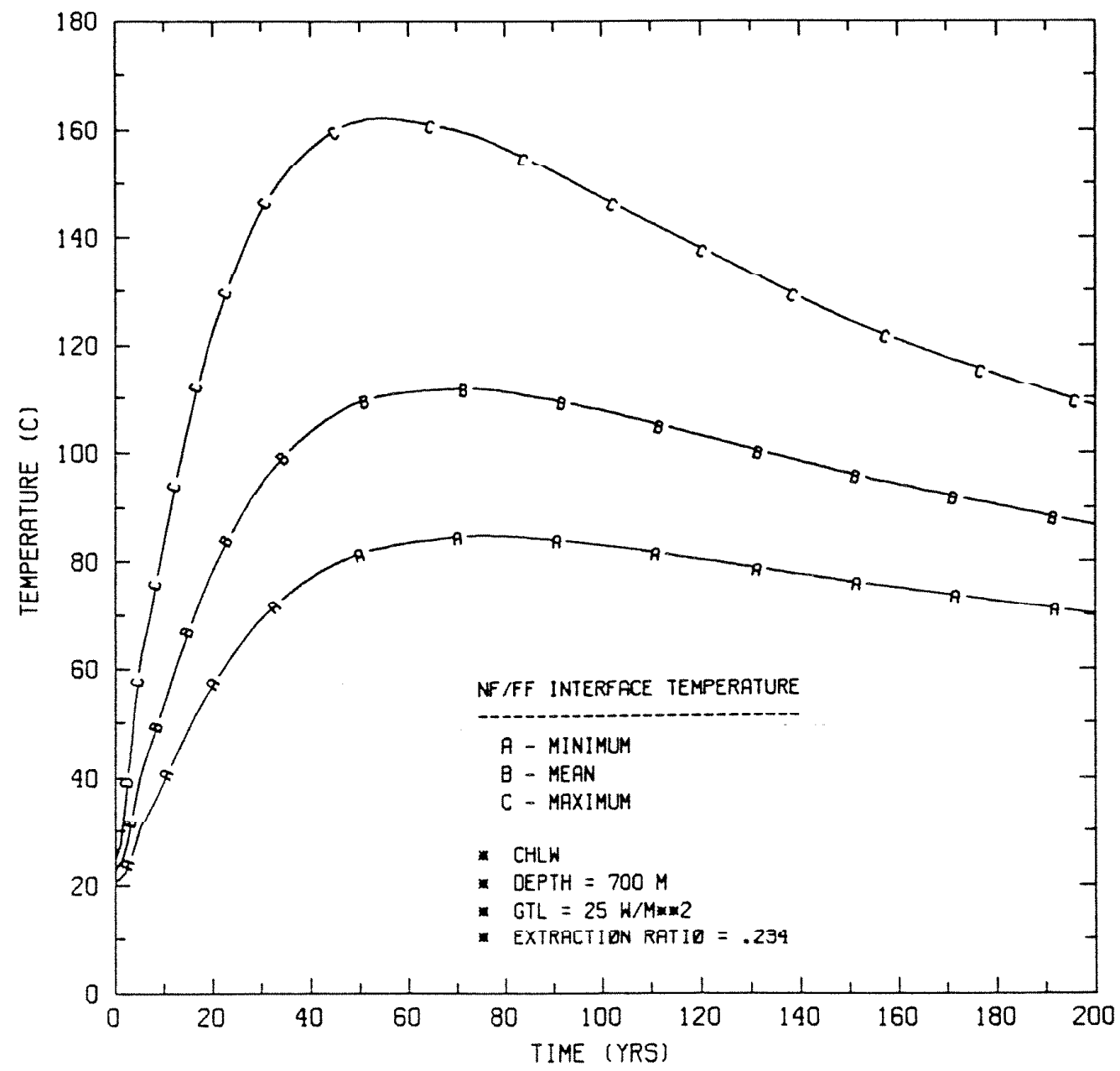

Fig. G.12.2.15. Expected range in near-field/far-field interface temperature for comercial high-level waste emplacement in shale. 
ORNL DWG 85-146

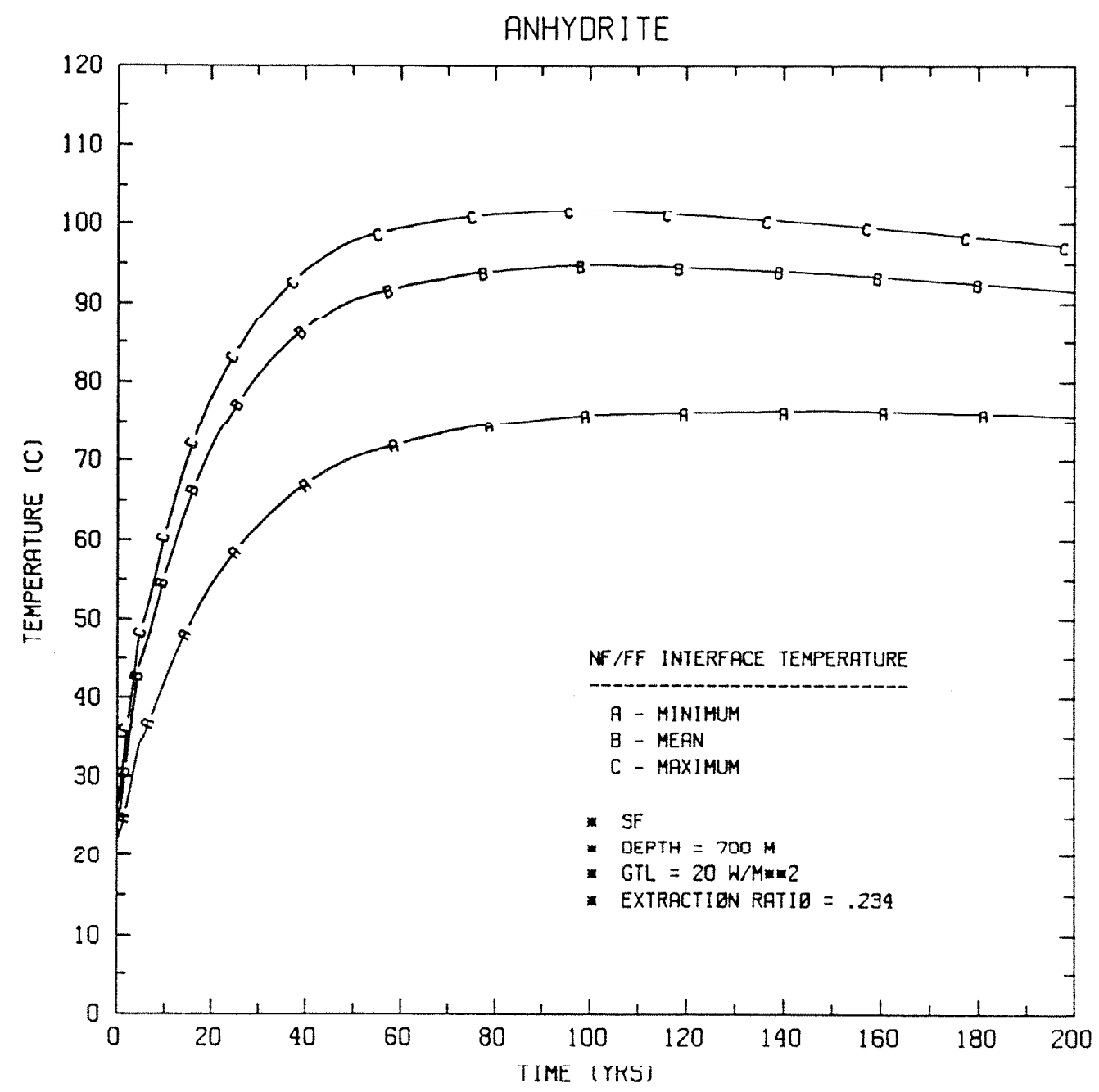

Fig. G.12.2.16. Expected range in near-field/far-field interface temperature for spent fuel emplacement in anhydrock. 
ORNL DWG 85-147

CHALK

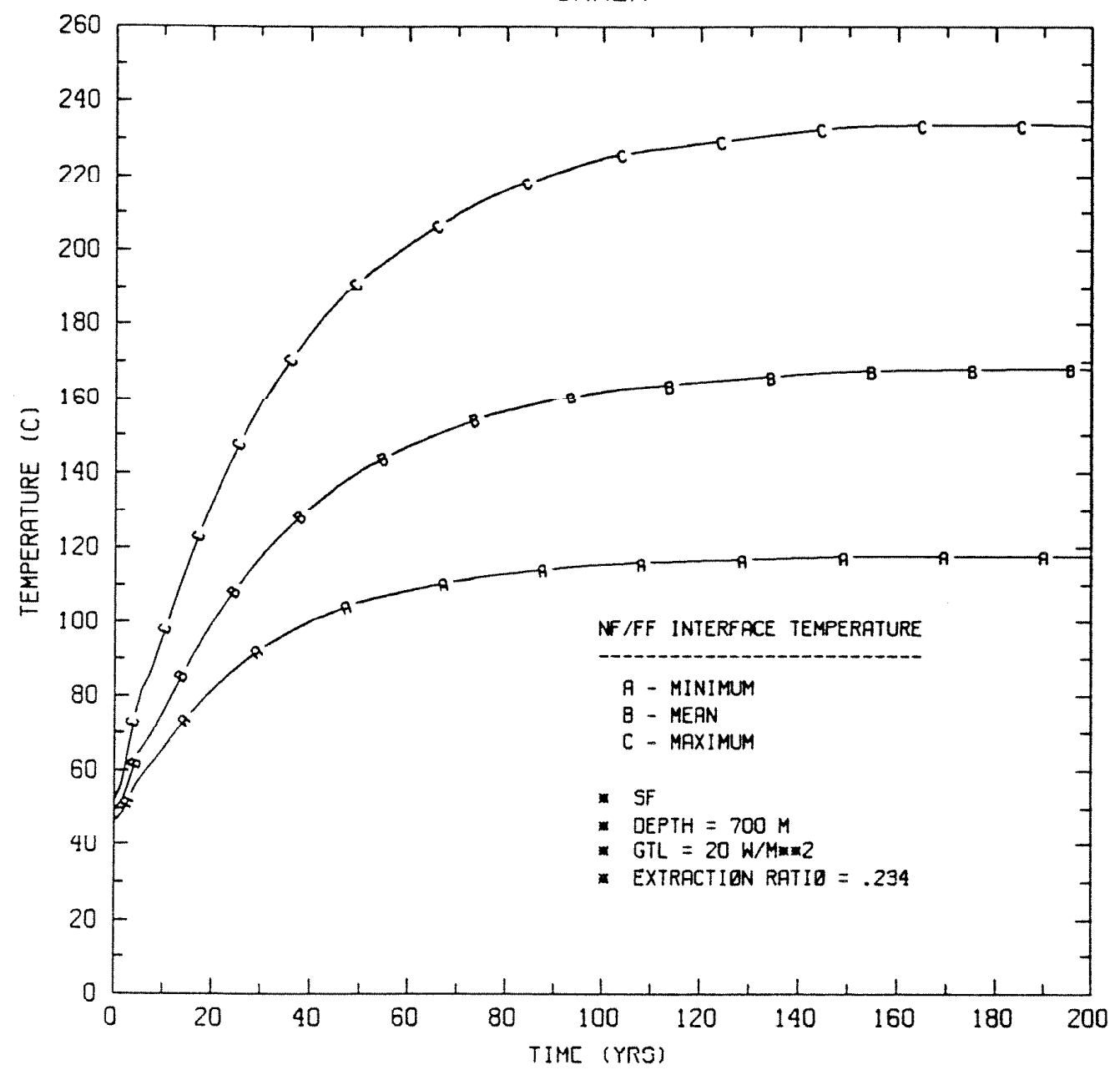

Fig. G.12.2.17. Expected range in near-field/far-field interface temperature for spent fuel emplacement in chalk. 
ORNL DWG 85-148

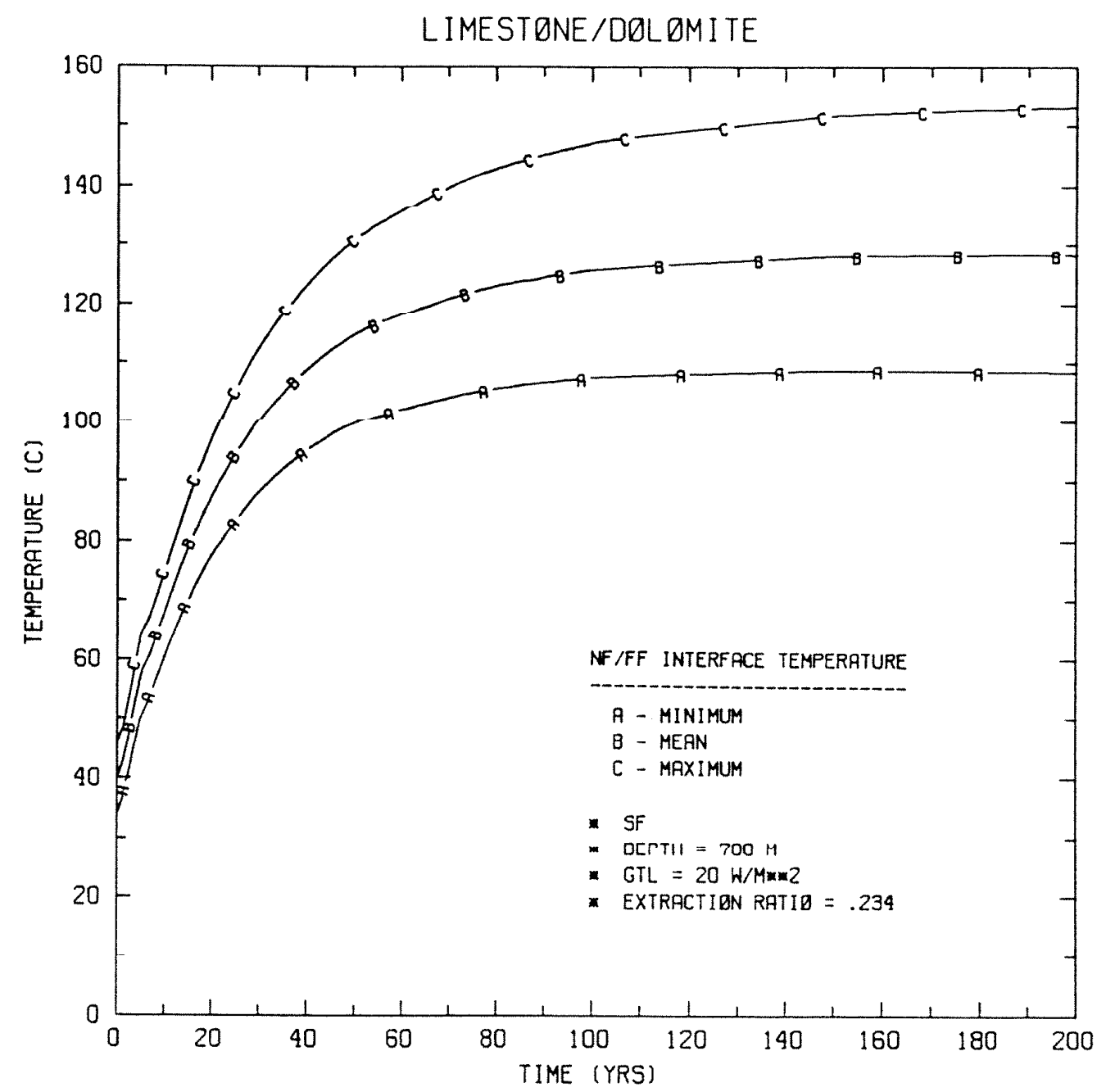

Fig. G.12.2.18. Expected range in near-field/far-field interface temperature for spent fuel emplacement in carbonate rocks (1imestone) dolostone). 
ORNL DWG 85-149

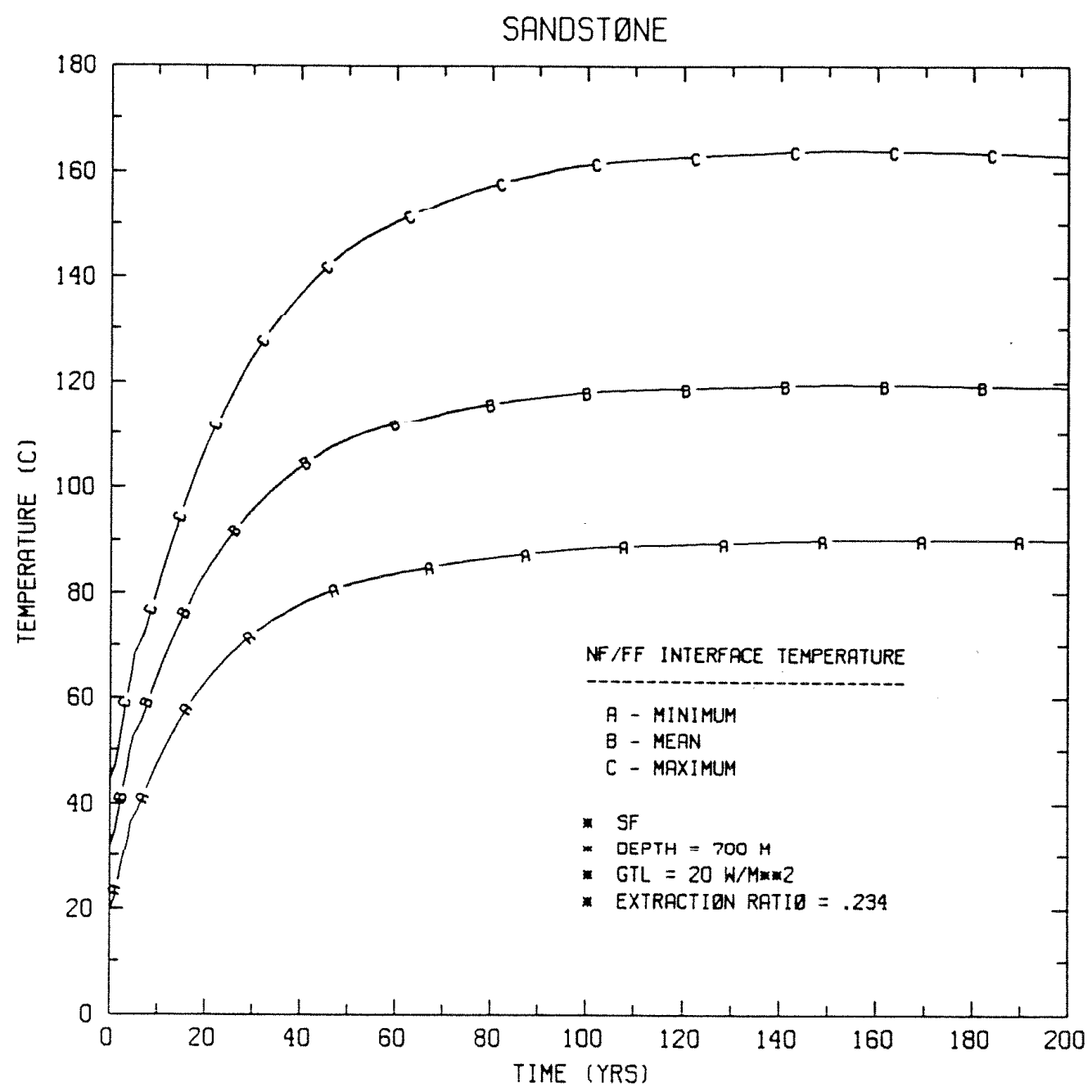

Fig. G.12.2.19. Expected range in near-field/far-field interface temperature for spent fuel emplacement in sandstone. 
ORNL DWG 85-150

SHALE

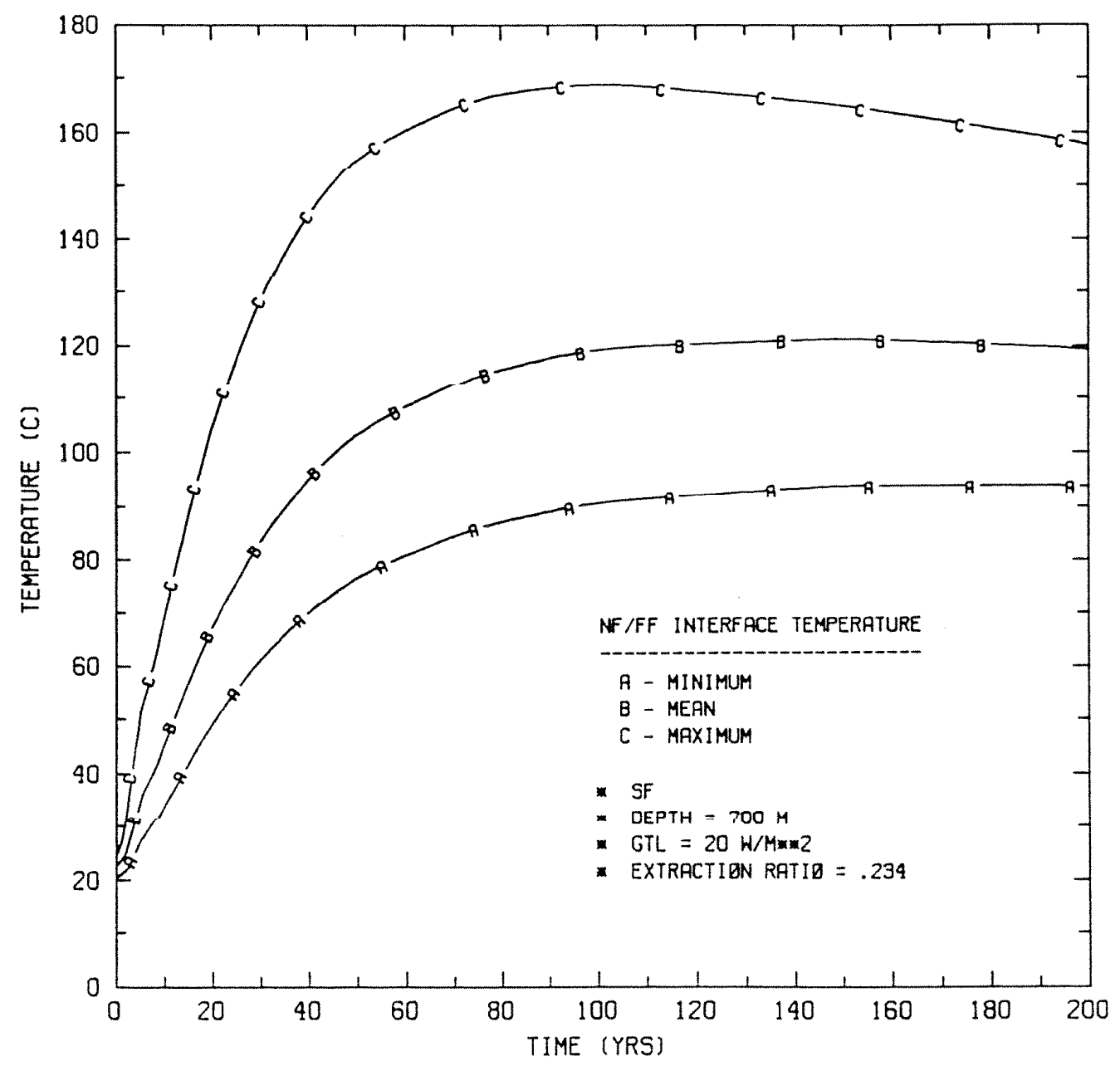

Fig. G.12.2.20. Expected range in near-field/far-field interface temperature for spent fuel emplacement in shale. 
ORNL DWG 85-151

ANHYDRITE

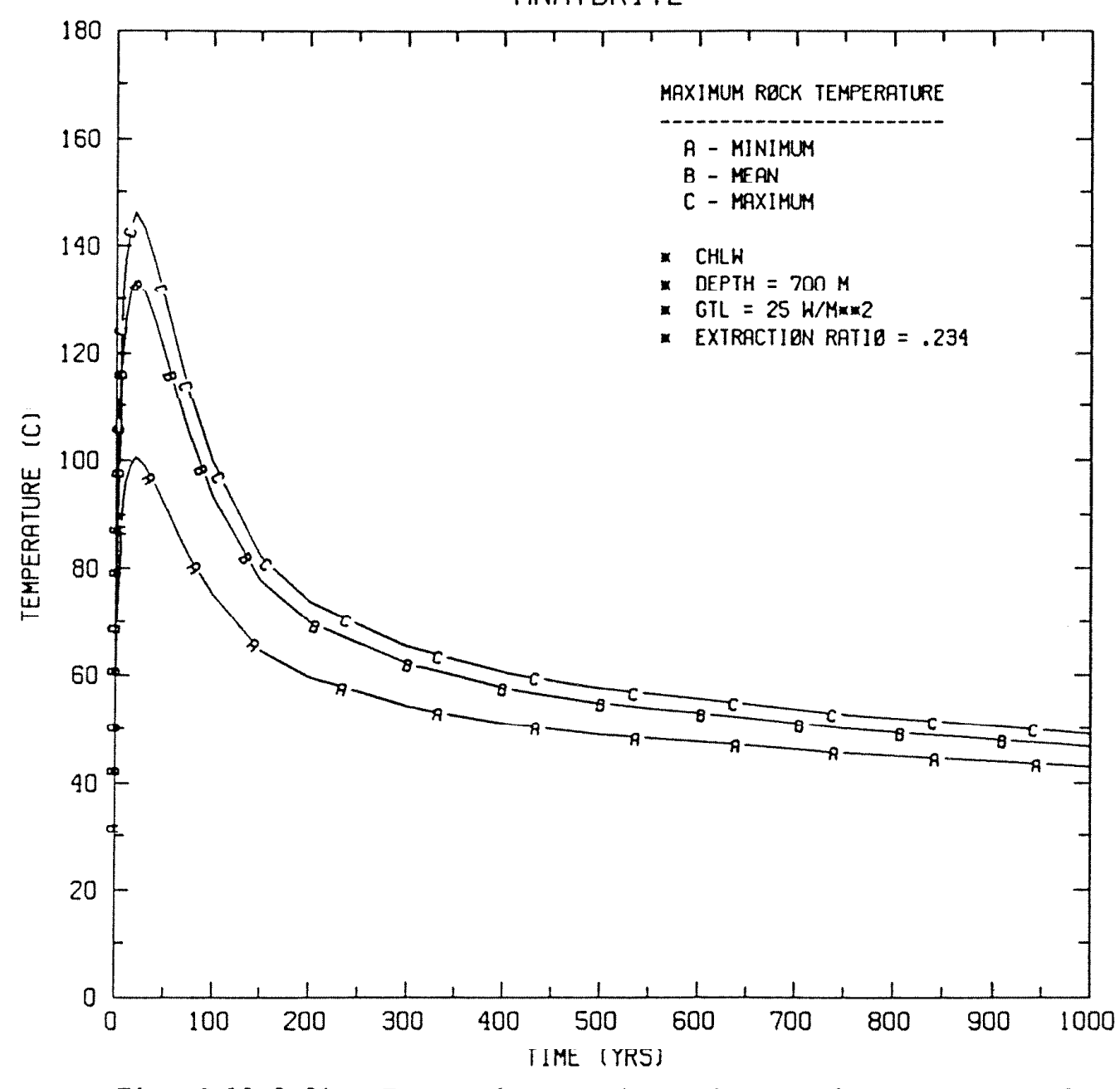

Fig. G.12.2.21. Expected range in maximum rock temperature for commercial high-1eve1 waste emplacement in anhydrock. 
ORNL DWG 85-152

CHALK

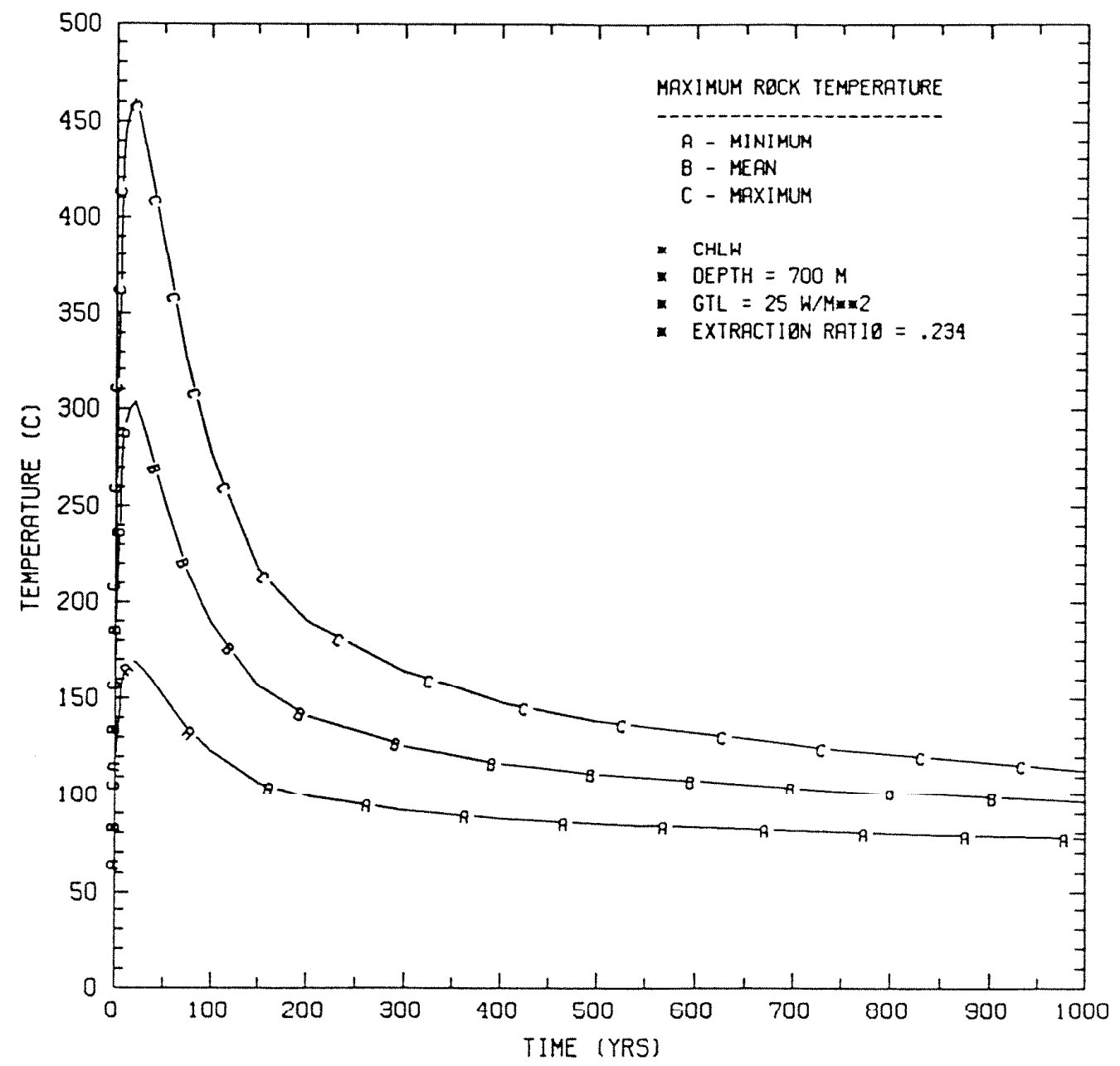

Fig. G.12.2.22. Expected range in maximum rock temperature for commercial high-level waste emplacement in chalk. 
ORNL DWG 85-153

LIMESTONE/OØLOMITE

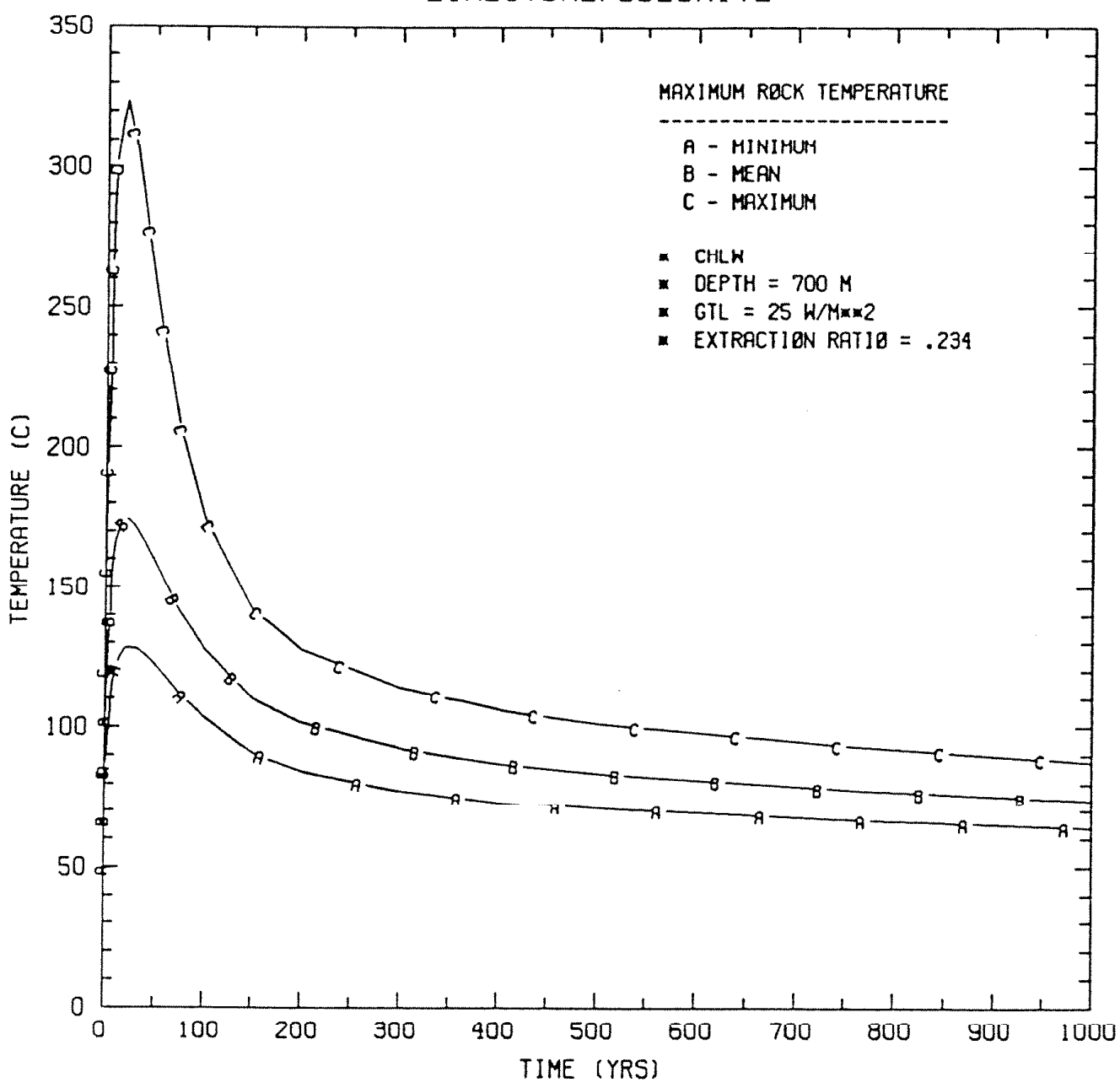

Fig. G.12.2.23. Expected range in maximum rock temperature for commercial high-level waste emplacement in carbonate rocks (1imestone/dolostone). 
SANDSTONE

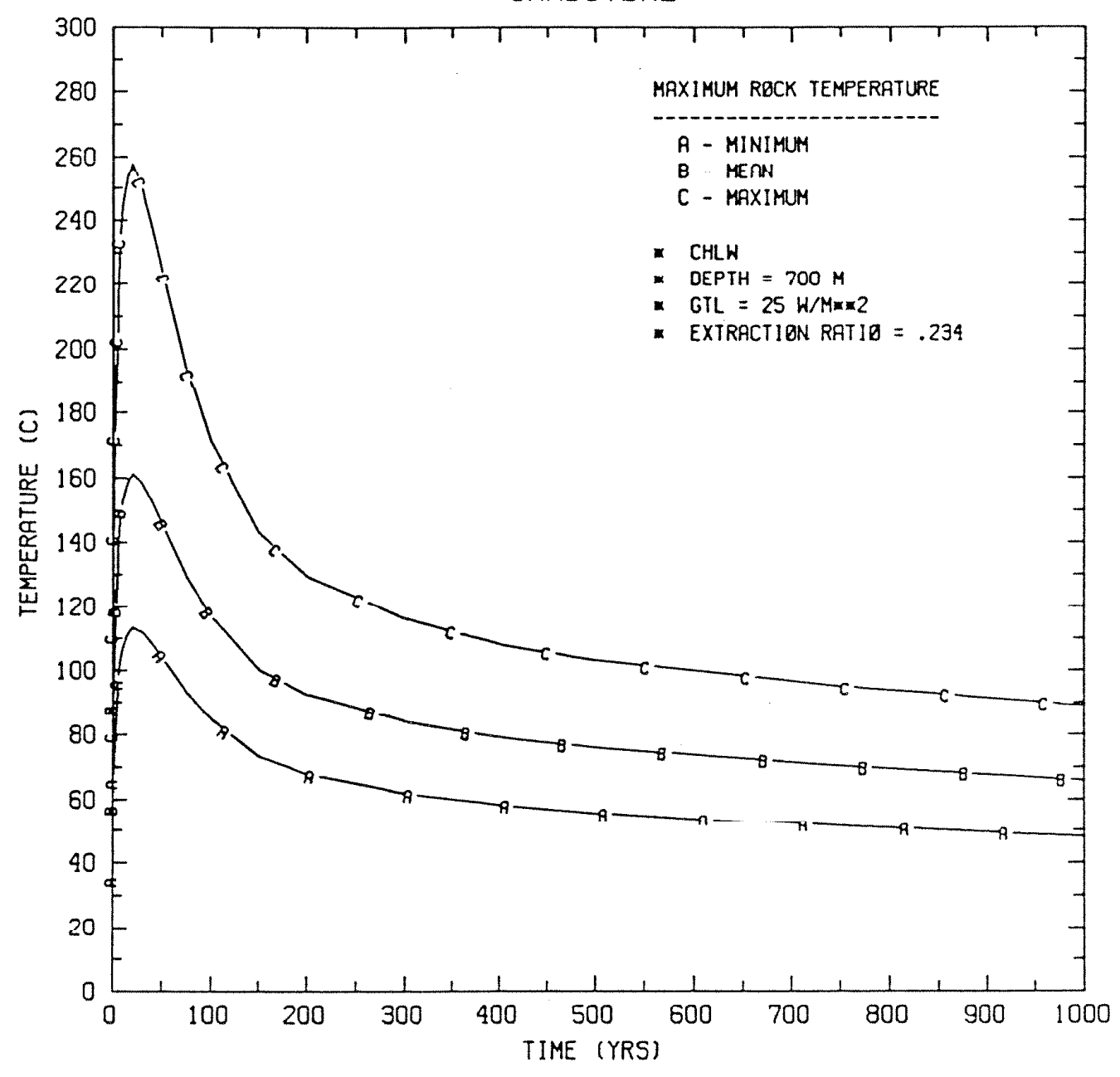

Fig. G.12.2.24. Expected range in maximum rock temperature for commercial high-level waste emplacement in sandstone. 
ORNL DWG 85-155

SHALE

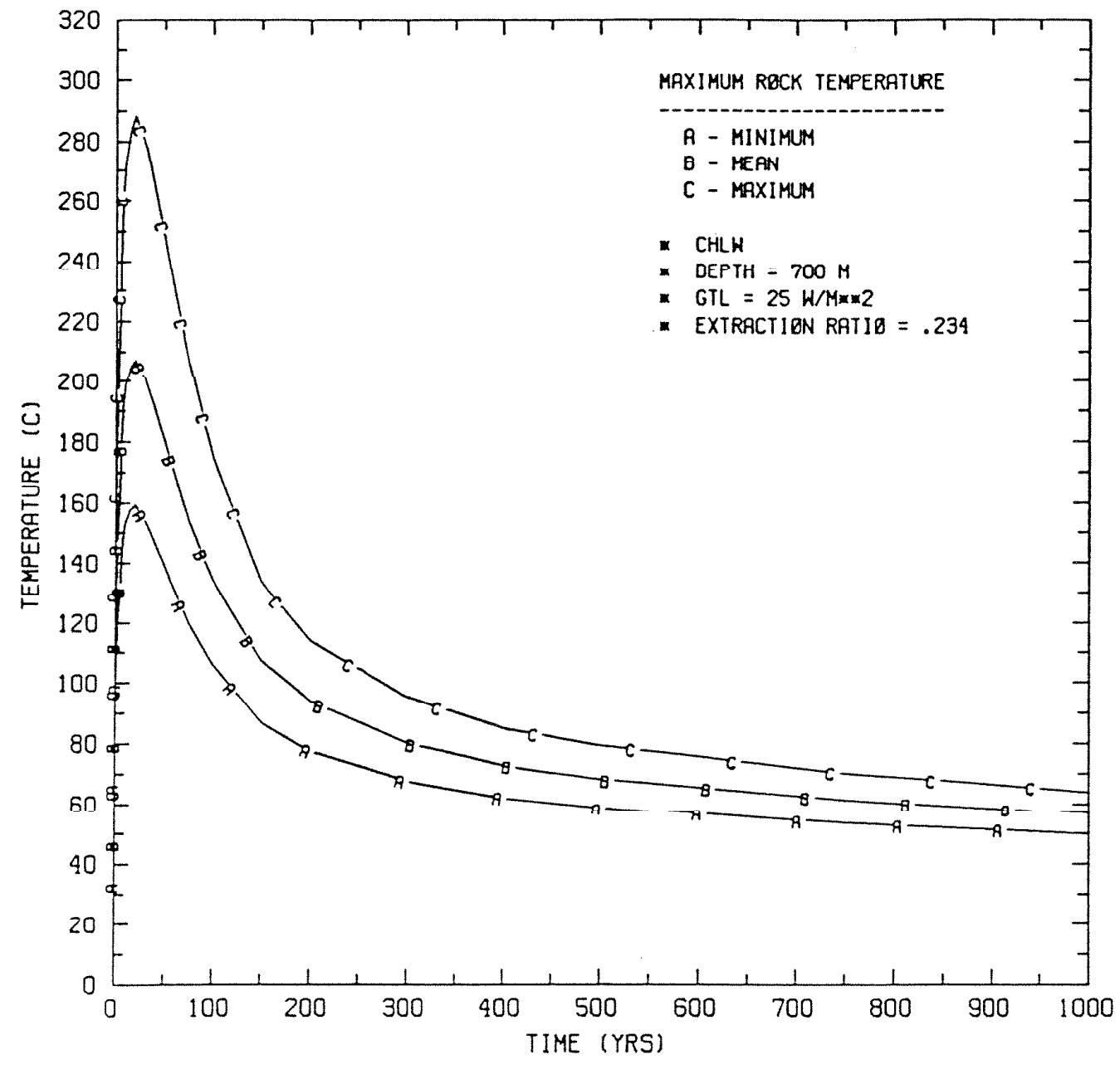

Fig. G.12.2.25. Expected range in maximum rock temperature for commercial high-level waste emplacement in shale. 
ORNL DWG 85-156

ANHYDR ITE

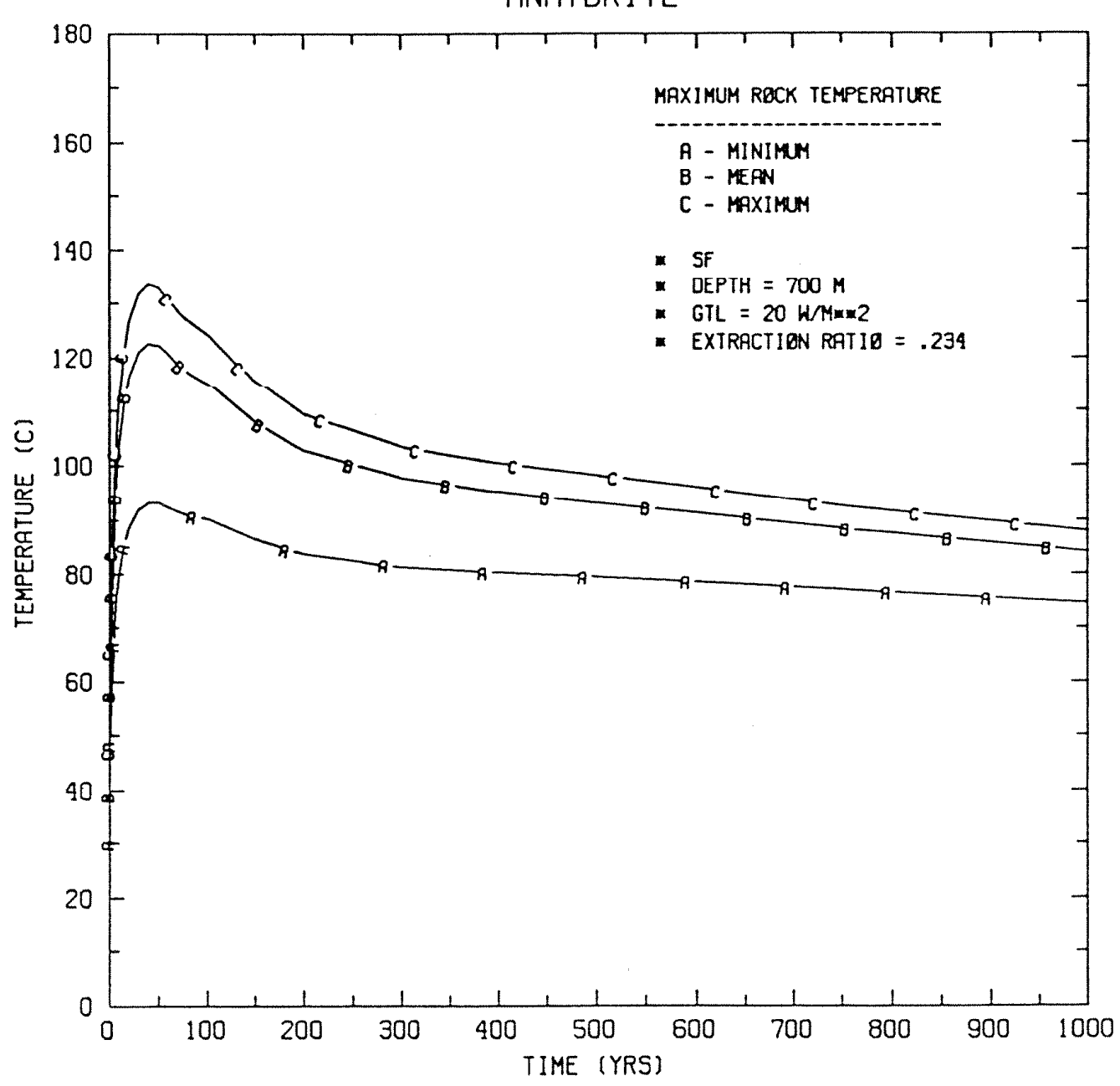

Fig. G.12.2.26. Expected range in maximum rock temperature for spent fuel emplacement in anhydrock. 
ORNL DWG 85-157

CHALK

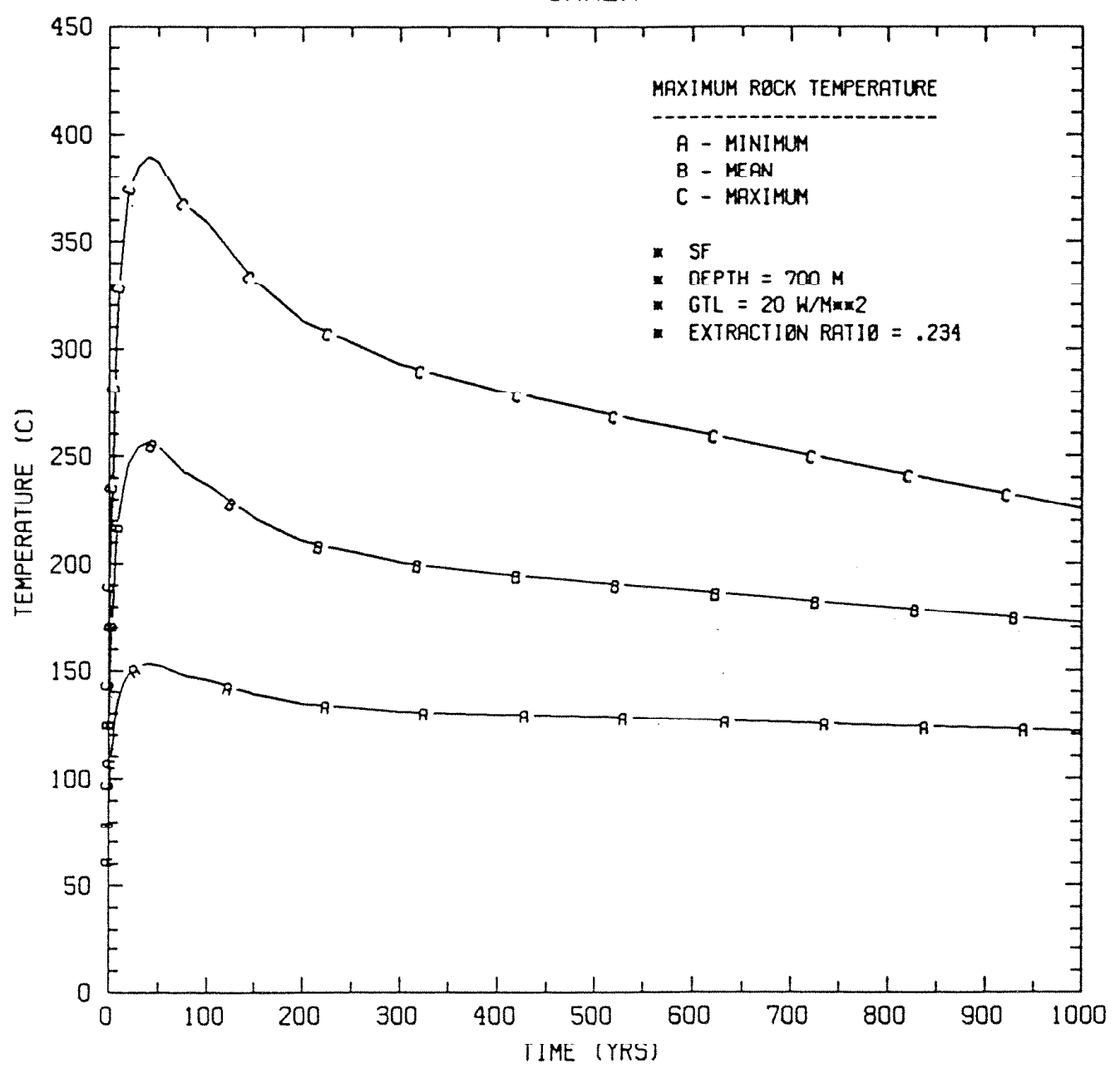

Fig. G.12.2.27. Expected range in maximum rock temperature for spent fuel emplacement in chalk. 
ORNL DWG 85-158

LIMESTONE/DOLOMITE

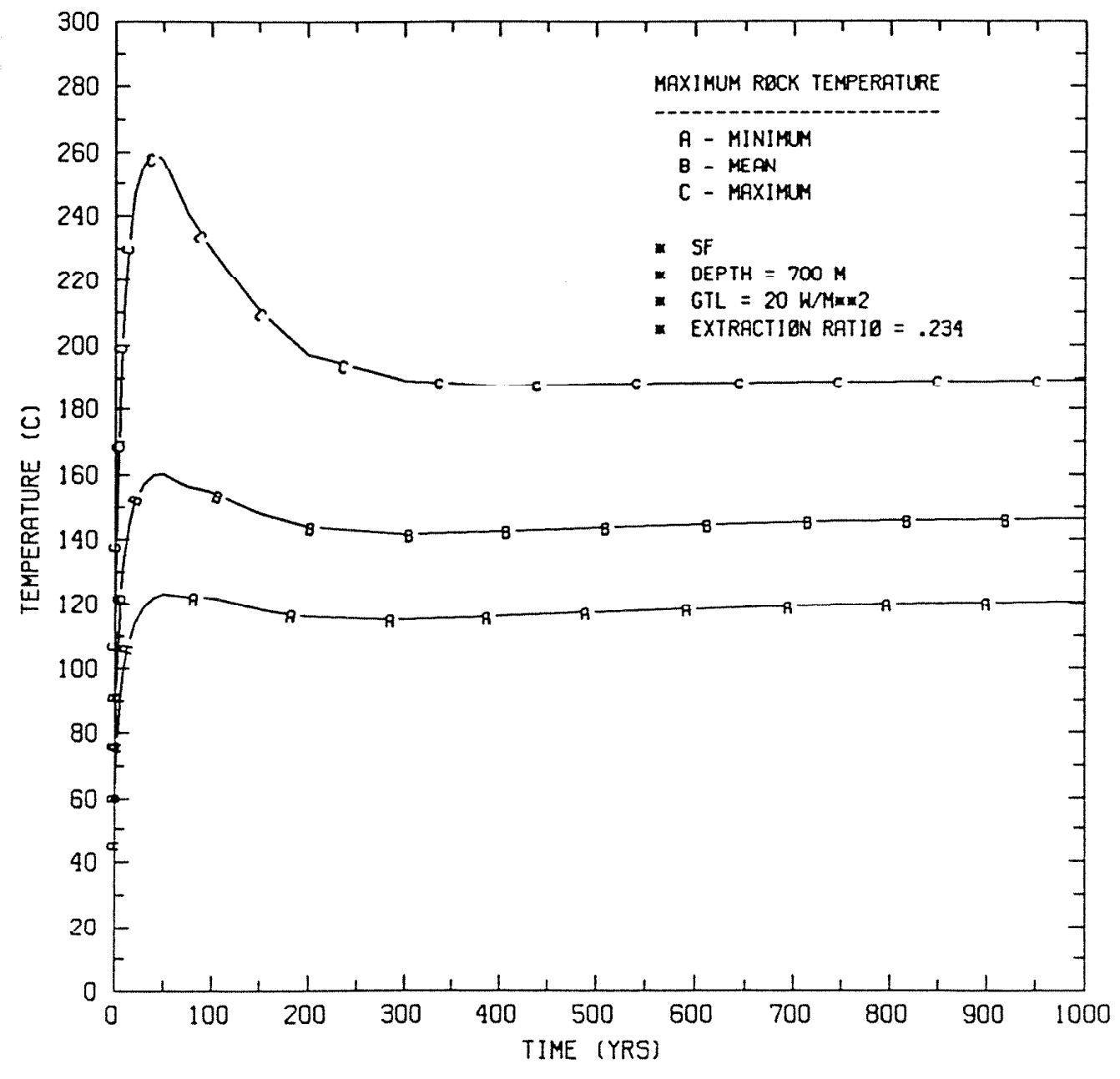

Fig. G.12.2.28. Expected range in maximum rock temperature for spent fuel emplacement in carbonate rocks (1imestone/dolostone). 
ORNL DWG 85-159

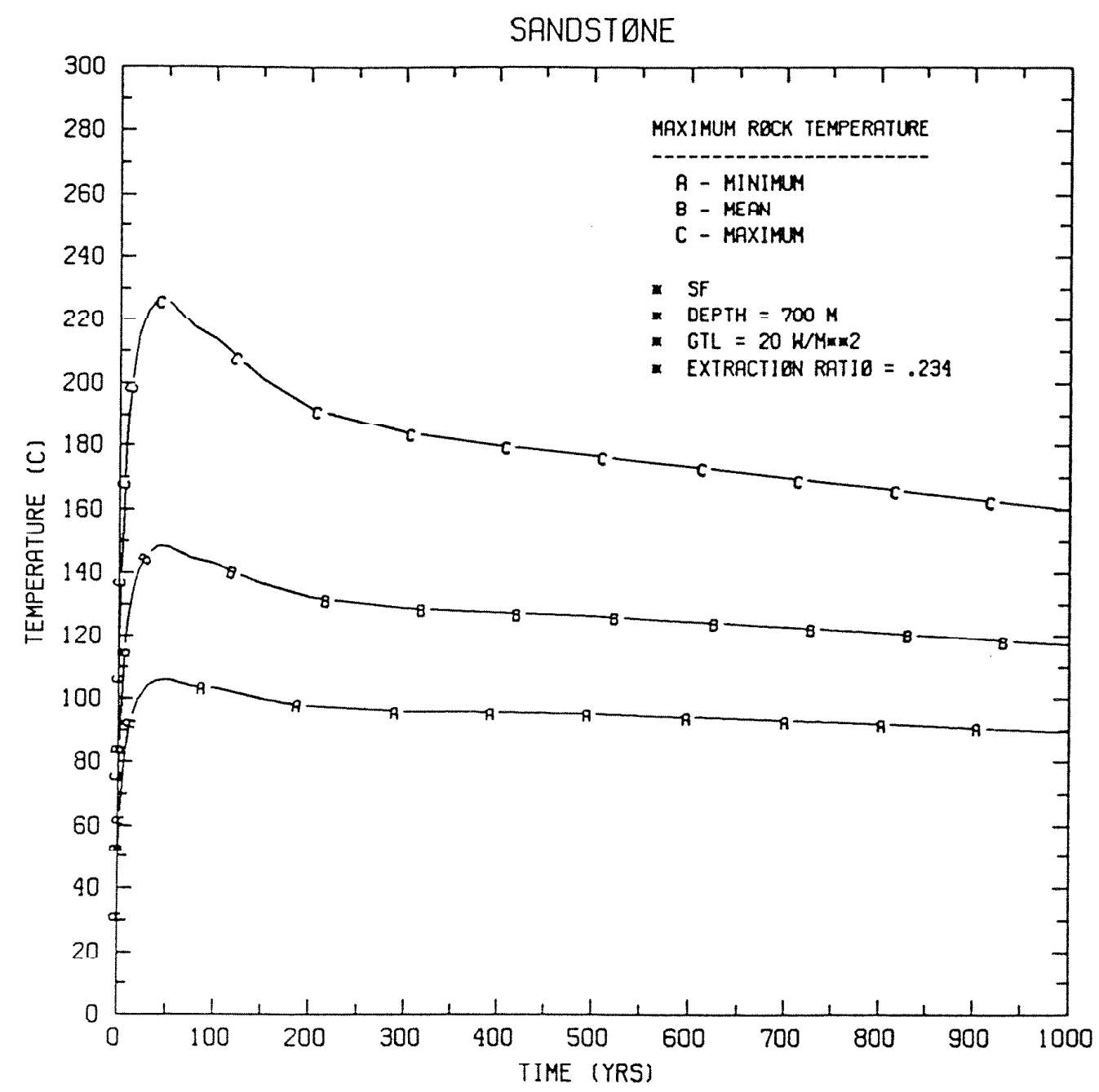

Fig. G.12.2.29. Expected range in maximum rock temperature for spent fuel emplacement in sandstone. 
ORNL DWG 85-160

SHALE

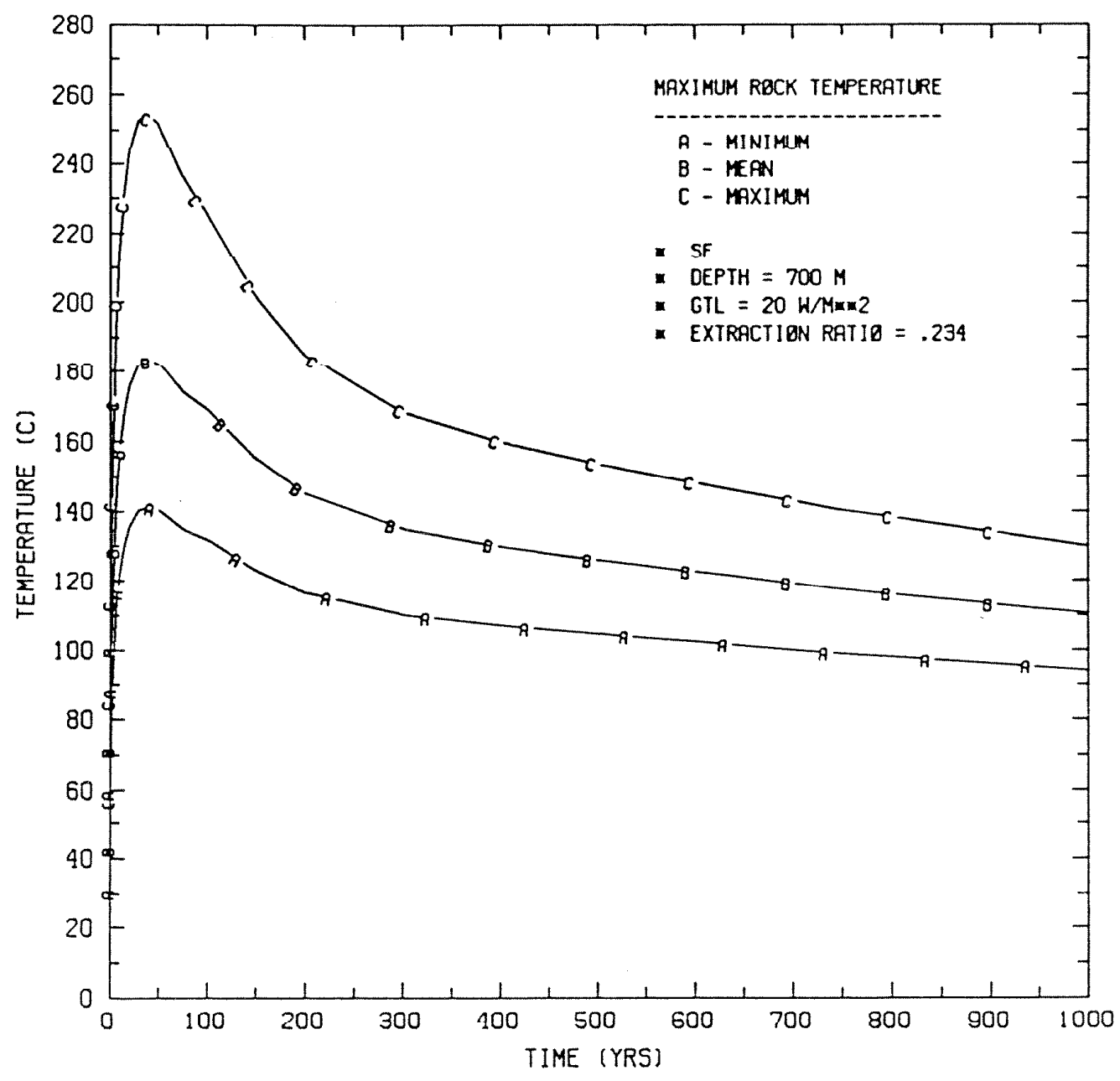

Fig. G.12.2.30. Expected range in maximum rock temperature for spent fuel emplacement in shale. 
G.12.3 DETAILED MODEL RESULTS FROM THE FAR-FIELD THERMAL ANALYSIS

This section presents the detailed far-field thermal results that supplement the information presented in Sect. G.8.4. The figures in this section encompass (Figs. G.12.3.1 through G.12.3.30):

- Three responses

- temperature at 595-m depth

- shaft temperature

- near-surface temperature

- Two waste types

- commercial high-level waste

- spent fuel

- Five rock types

- anhydrock

- chalk

- carhonate rocks (1imestone/dolostone)

- sandstone

- shale (argillaceous rock)

Each figure presents the expected range in the transient behavior for each response, waste type, and rock type. 
ORNL DWG 85-161

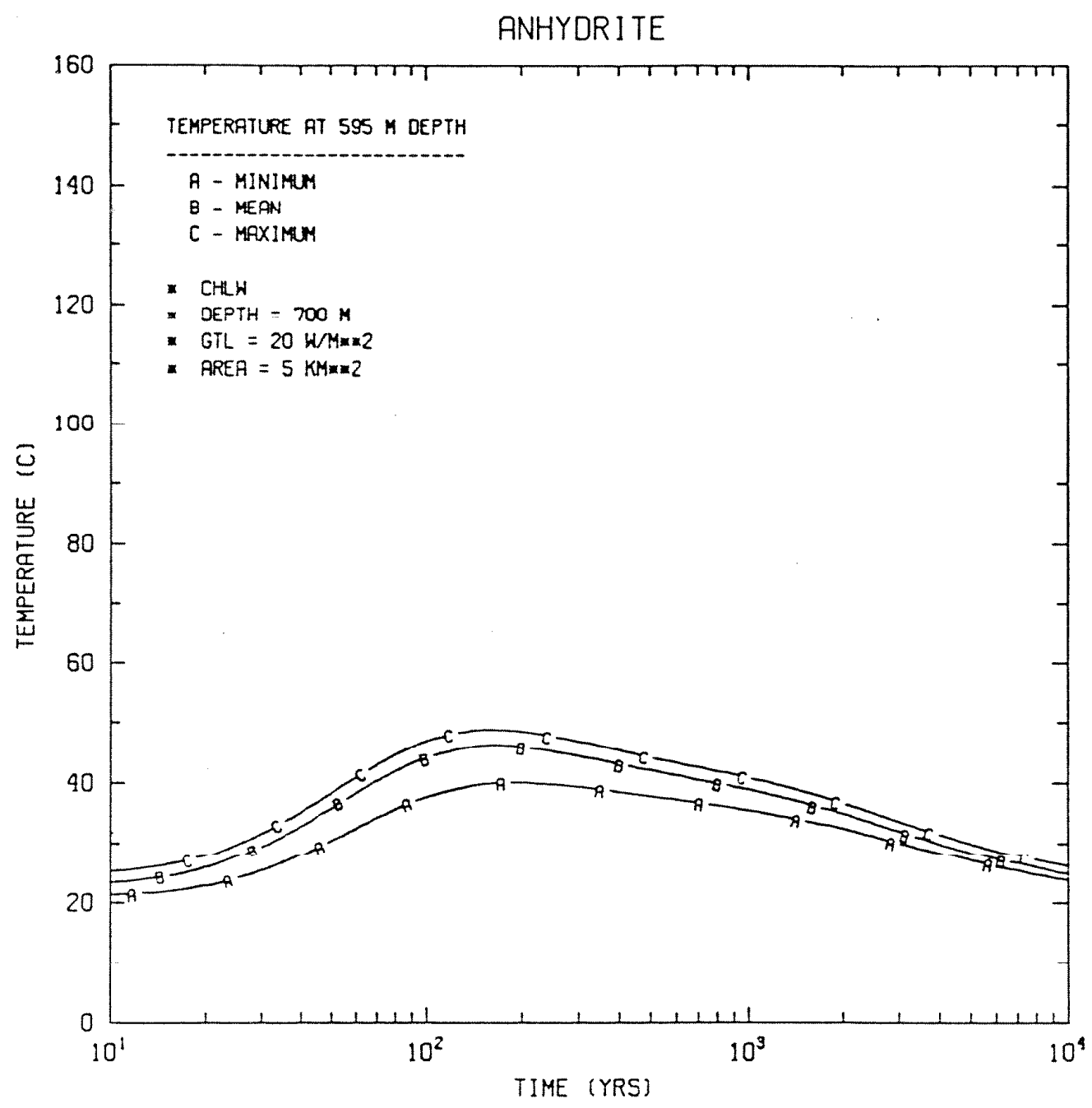

Fig. G.12.3.1. Expected range in temperature at 595-m depth for commercial high-level waste emplacement in anhydrock. 
ORNL DWG 85-162

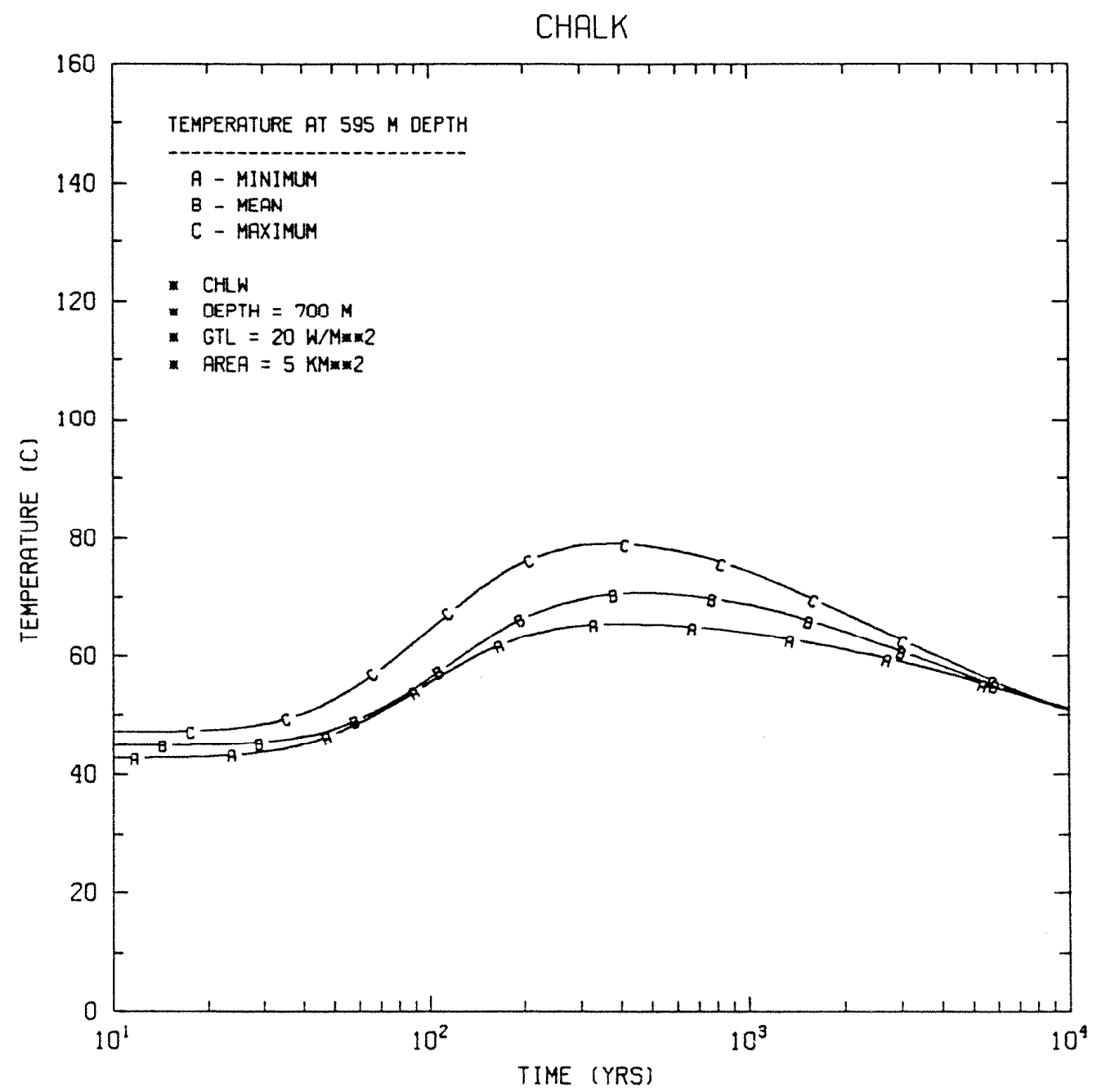

Fig. G.12.3.2. Expected range in temperature at 595-m depth for commercial high-level waste emplacement in chalk. 
ORNL DWG 85-163

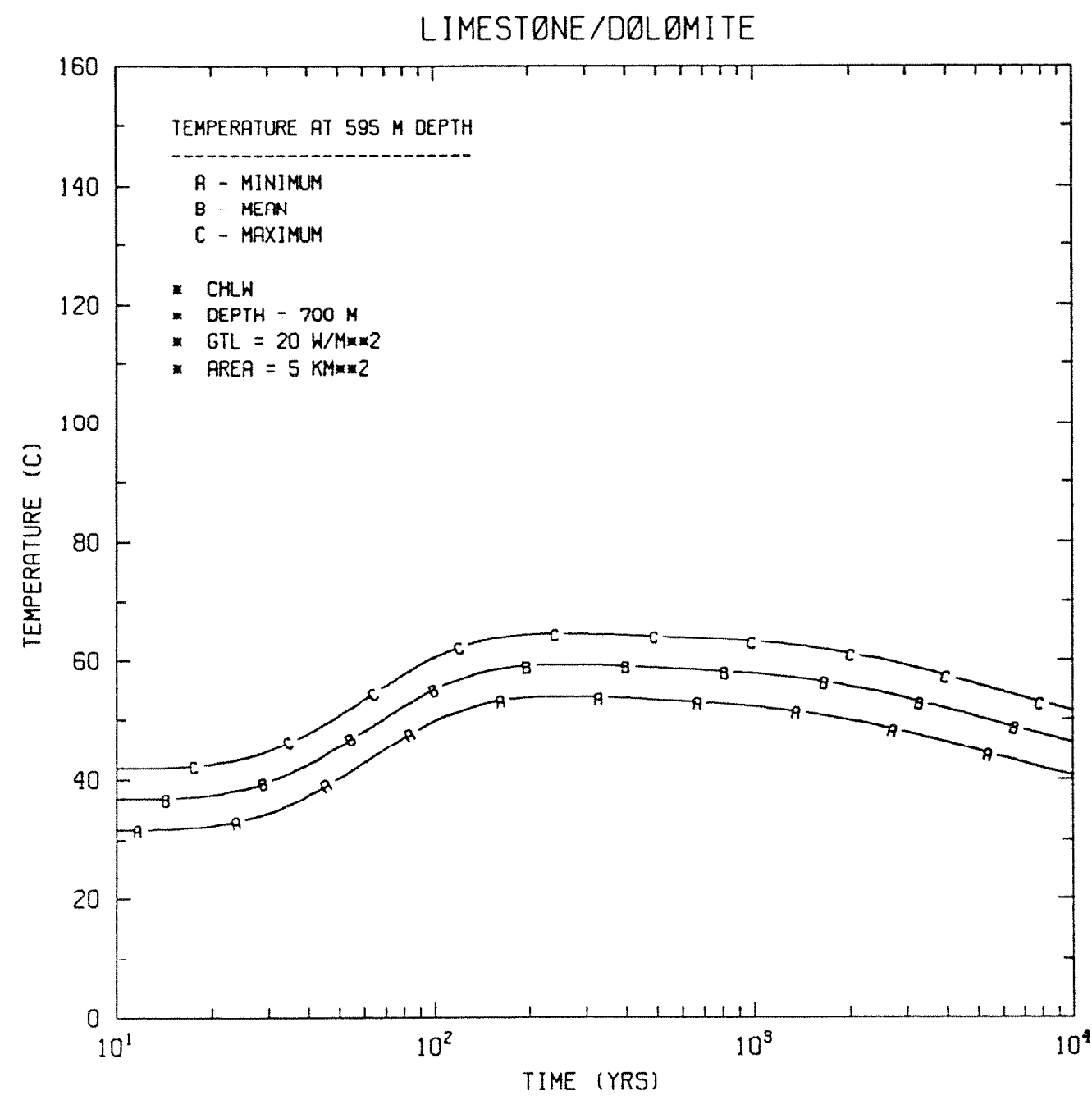

Fig. G.12.3.3. Expected range in temperature at 595-m depth for commercial high-level waste emplacement in carbonate rocks (1imestone/ dolostone). 
ORNL DWG 85-164

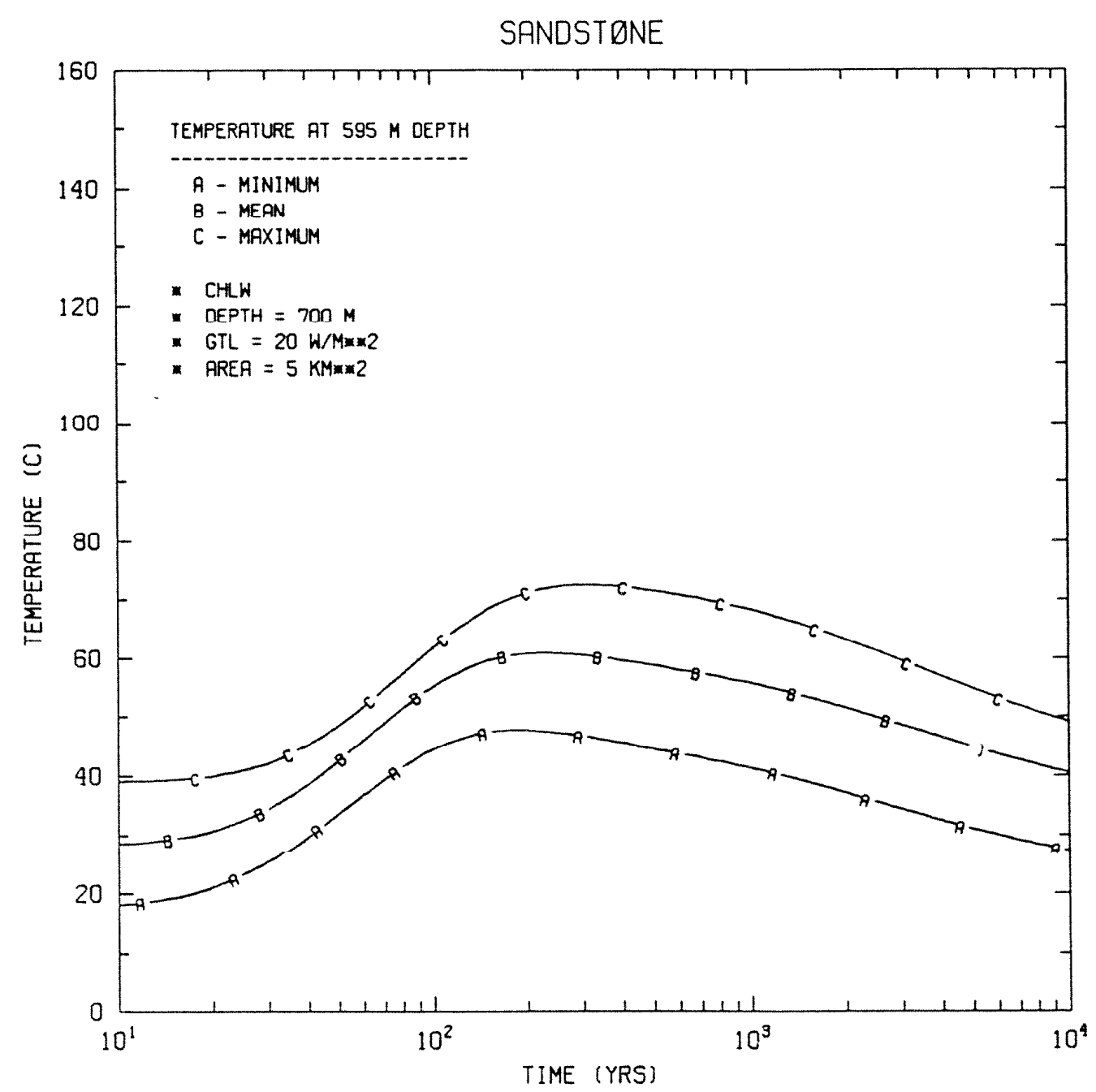

Fig. G.12.3.4. Expected range in temperature at 595-m depth for commercial high-level waste emplacement in sandstone. 
ORNL DWG 85-165

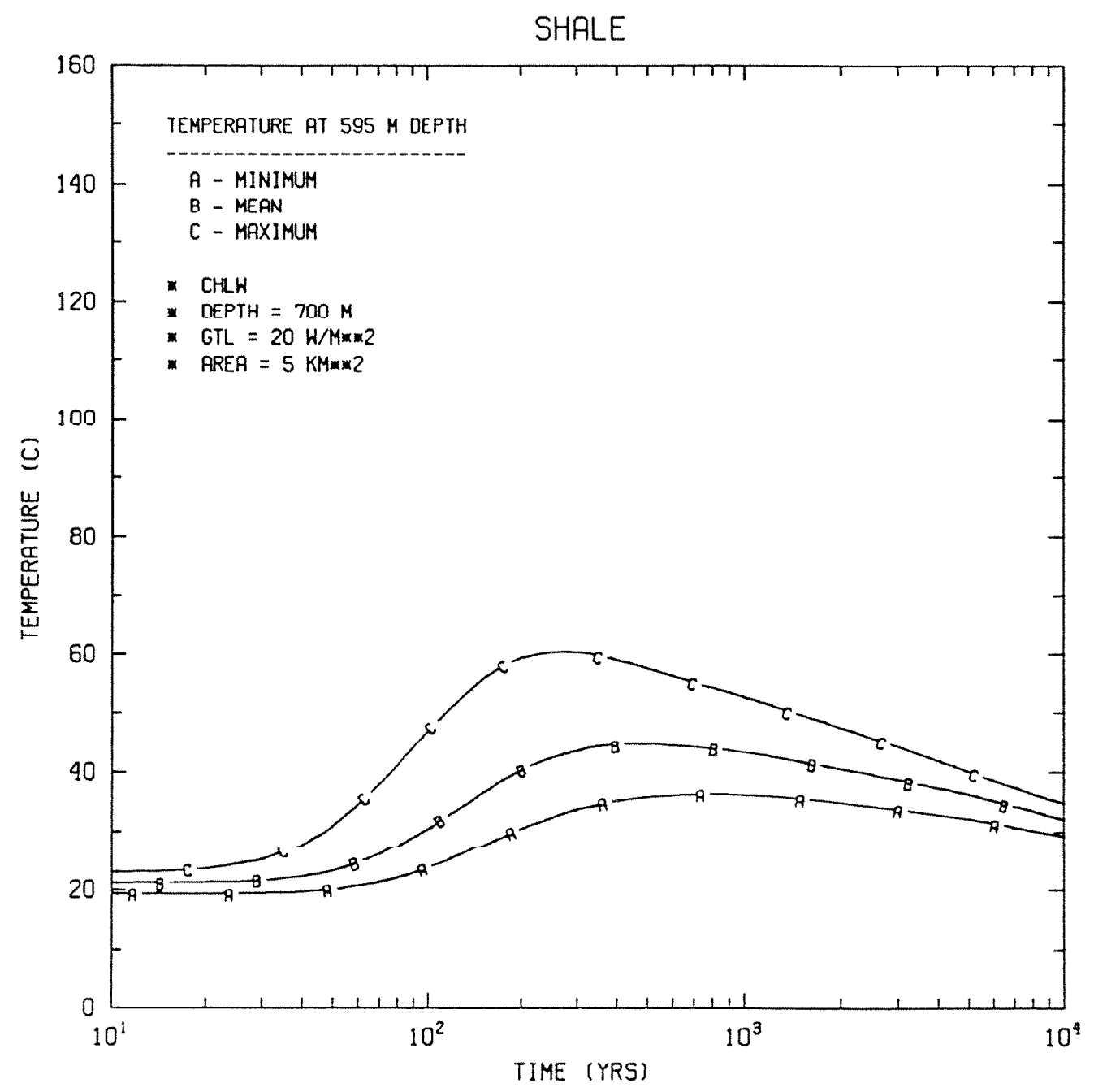

Fig. G.12.3.5. Expected range in temperature at 595-m depth for commercial high-level waste emplacement in shale. 
ORNL DWG 85-166

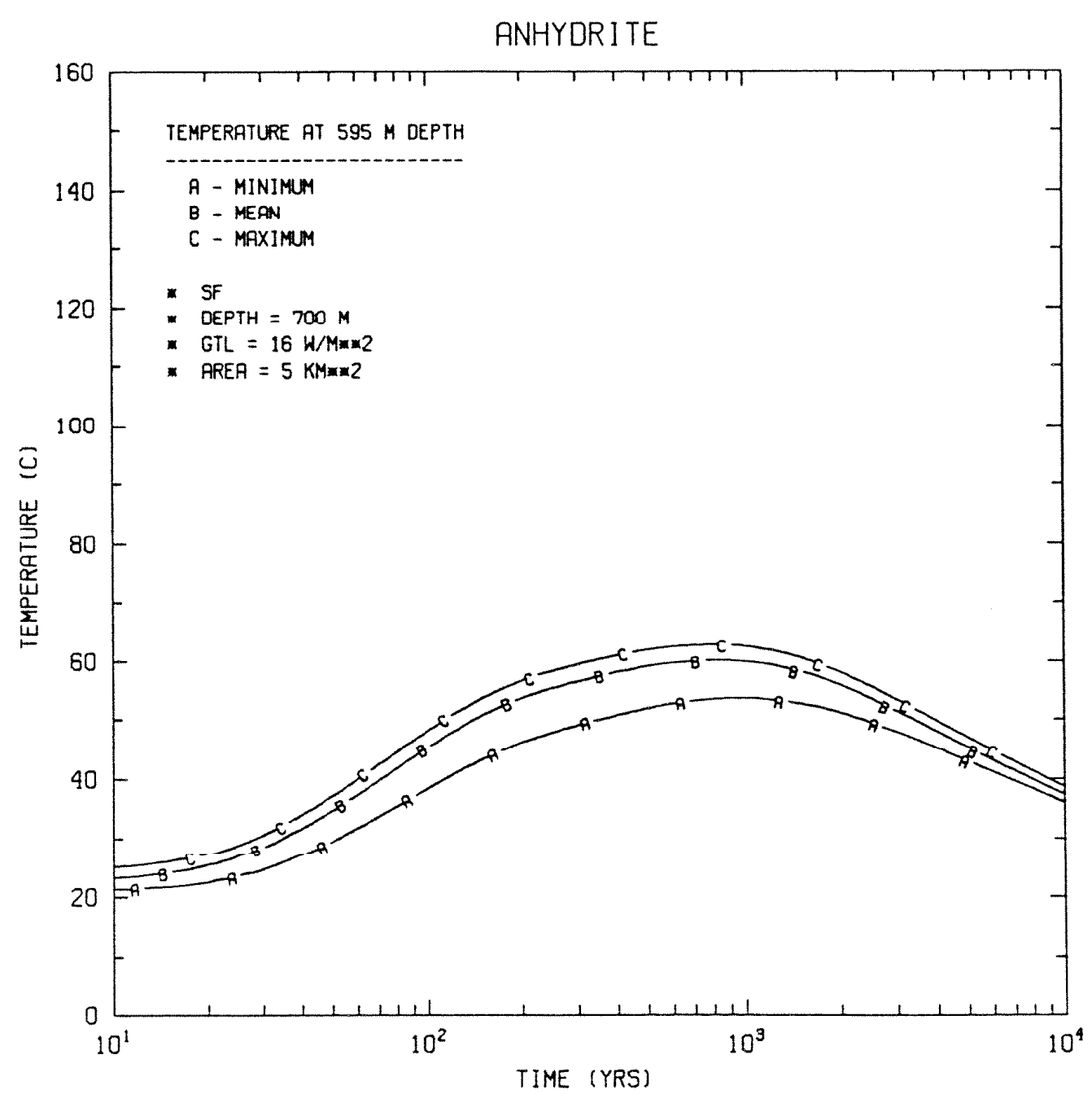

Fig. G.12.3.6. Expected range in temperature at 595-m depth for spent fuel emplacement in anhydrock. 
ORNL DWG 85-167

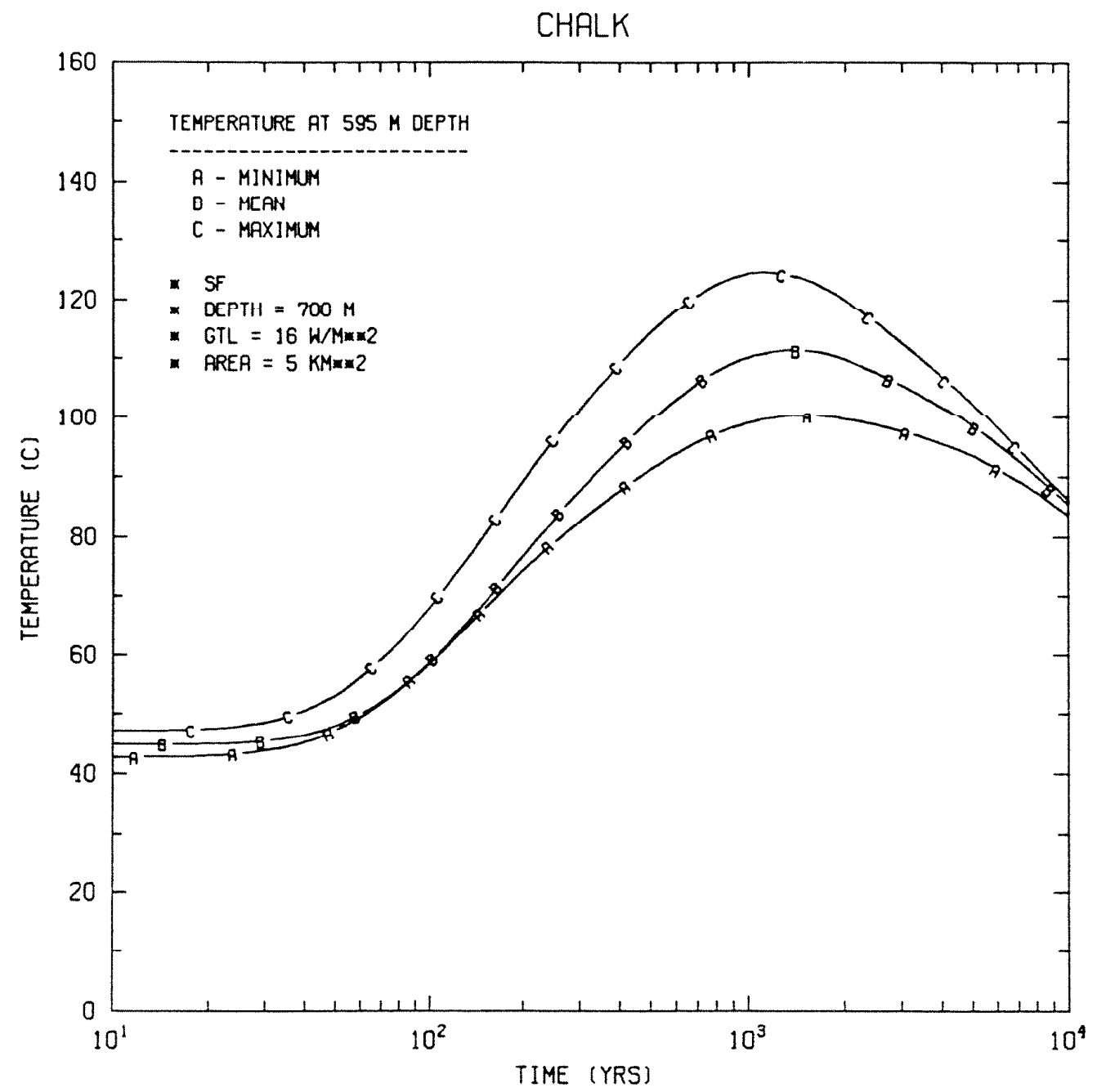

Fig. G.12.3.7. Expected range in temperature at 595-m depth for spent fuel emplacement in chalk. 
ORNL DWG 85-168

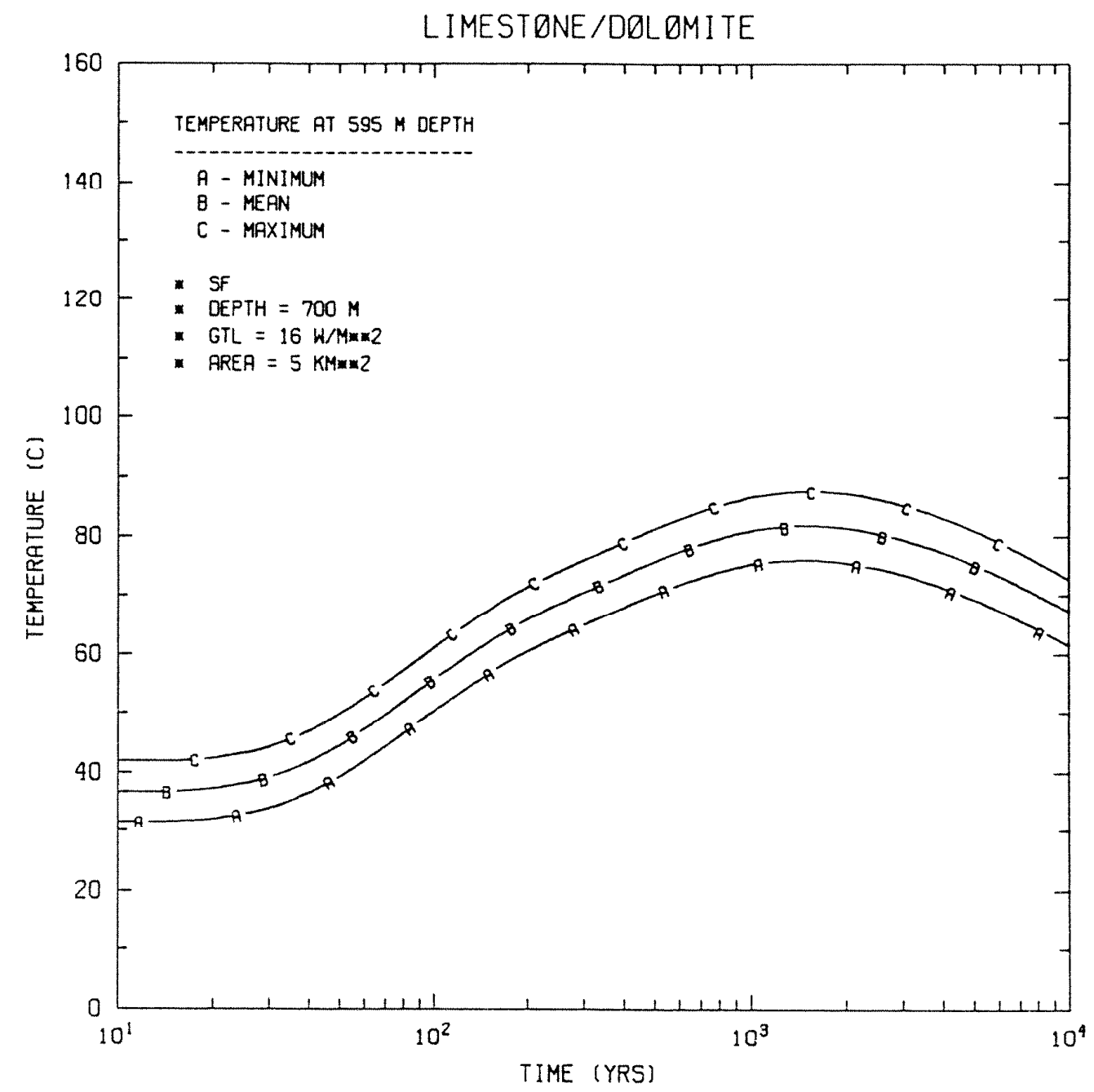

Fig. G.12.3.8. Expected range in temperature at 595-m depth for spent fuel emplacement in carbonate rocks (11mestone/dolostone). 
ORNL DWG 85-169

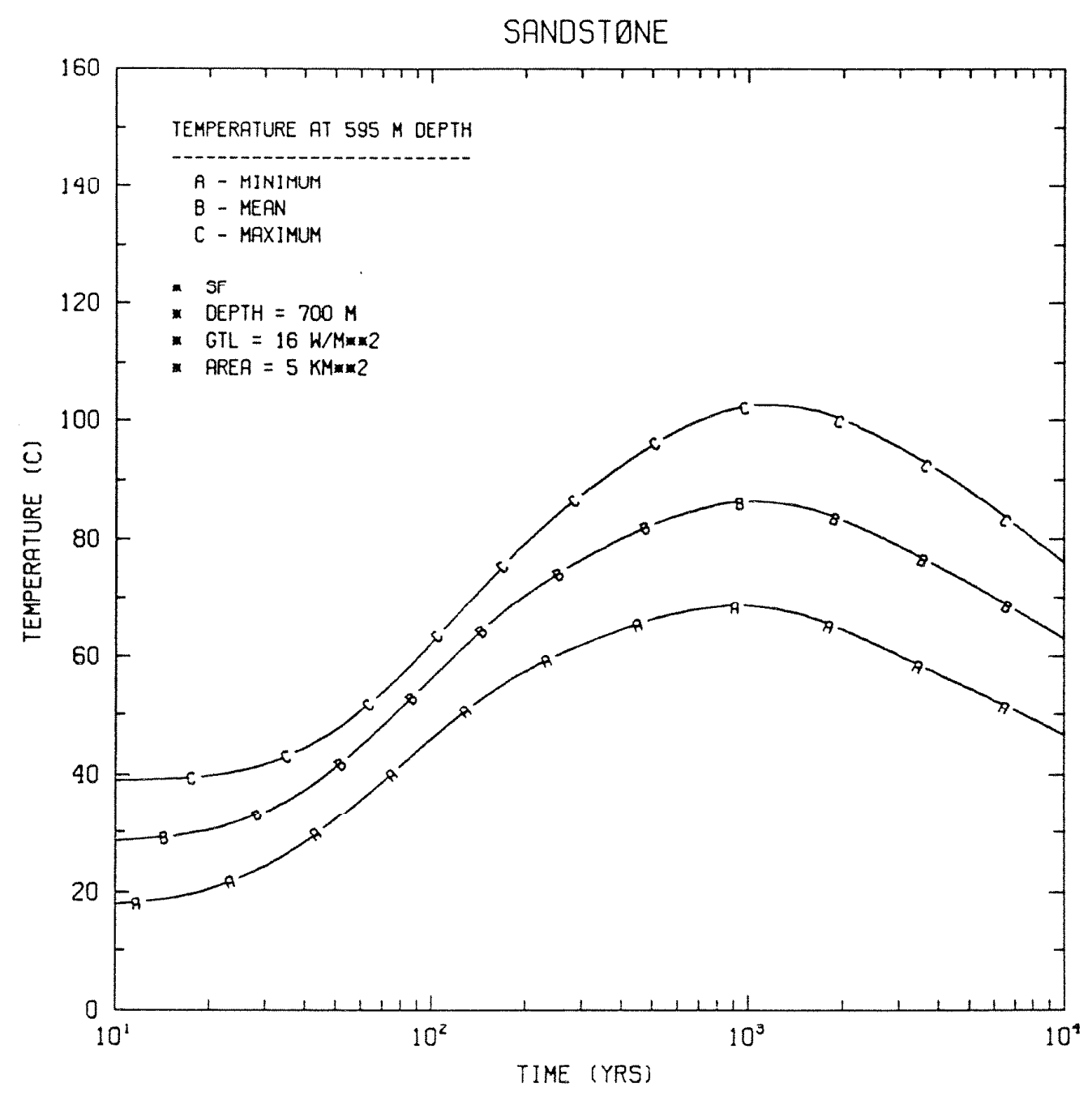

Fig. G.12.3.9. Expected range in temperature at 595-m depth for spent fuel emplacement in sandstone. 
ORNL DWG 85-170

SHALE

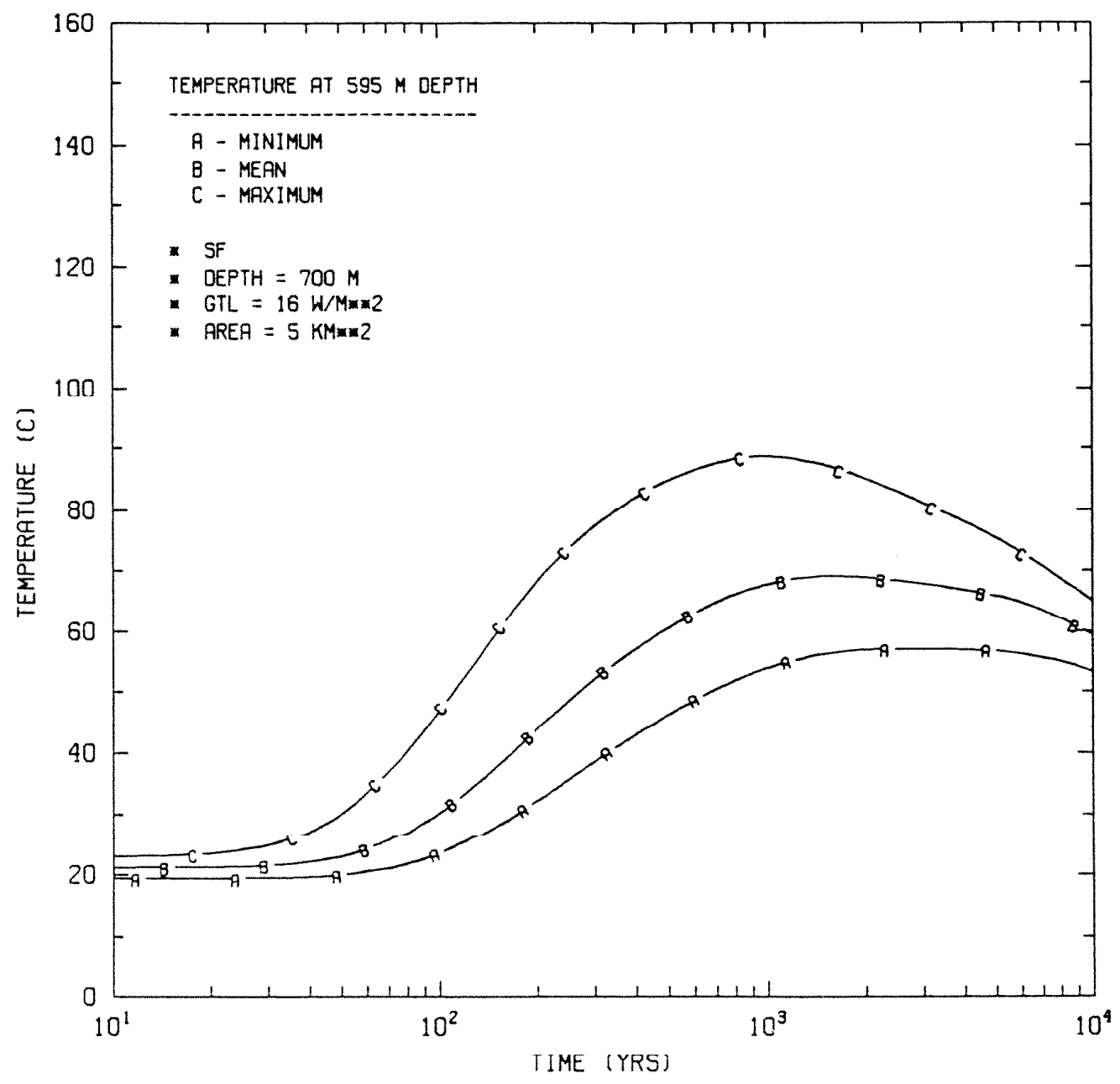

Fig. G.12.3.10. Expected range in temperature at 595-m depth for spent fuel emplacement in shale. 
ORNL DWG 85-171

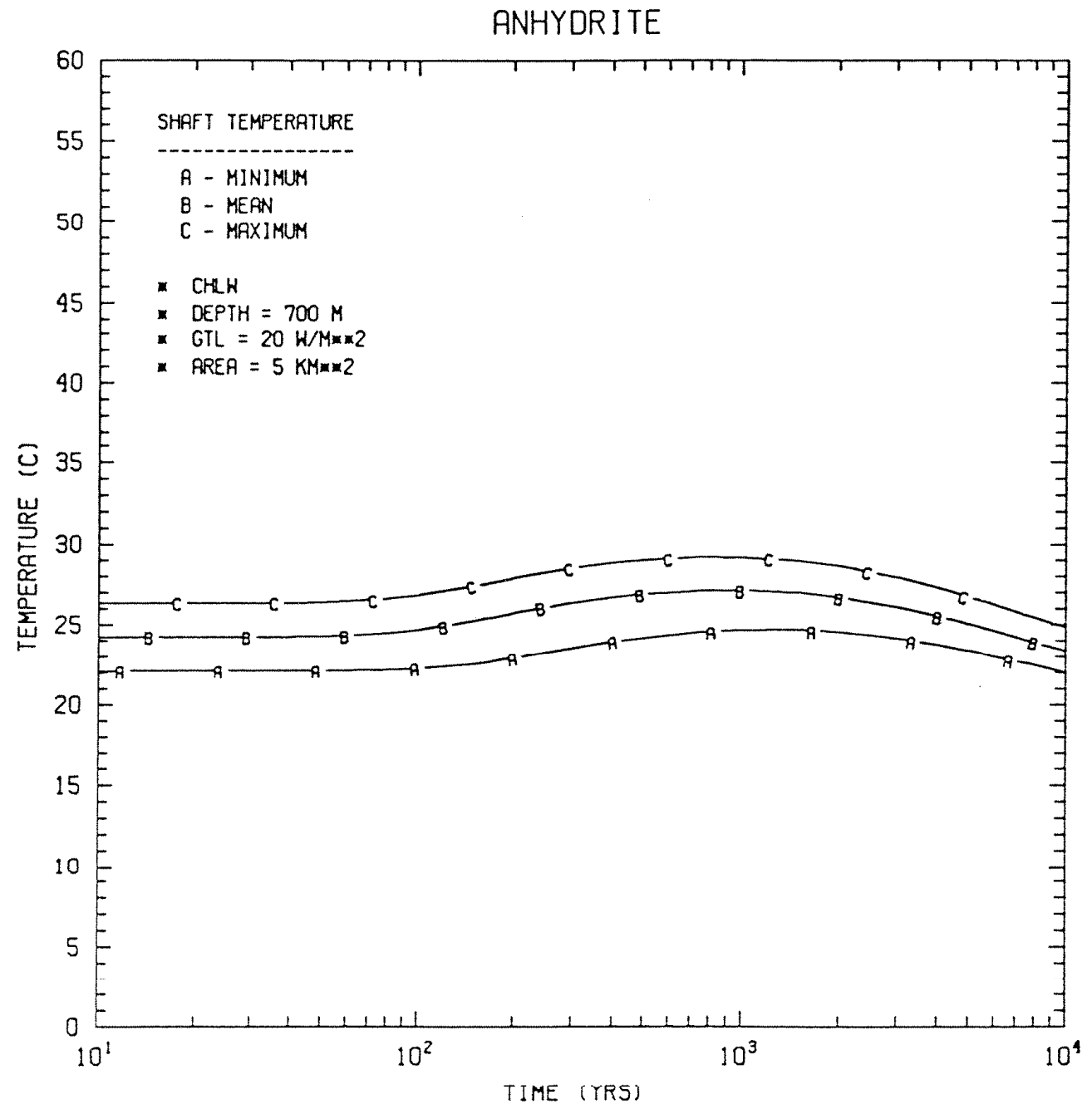

Fig. G.12.3.11. Expected range in shaft temperature for commercial high-level waste emplacement in anhydrock. 
ORNL DWG 85-172

CHALK

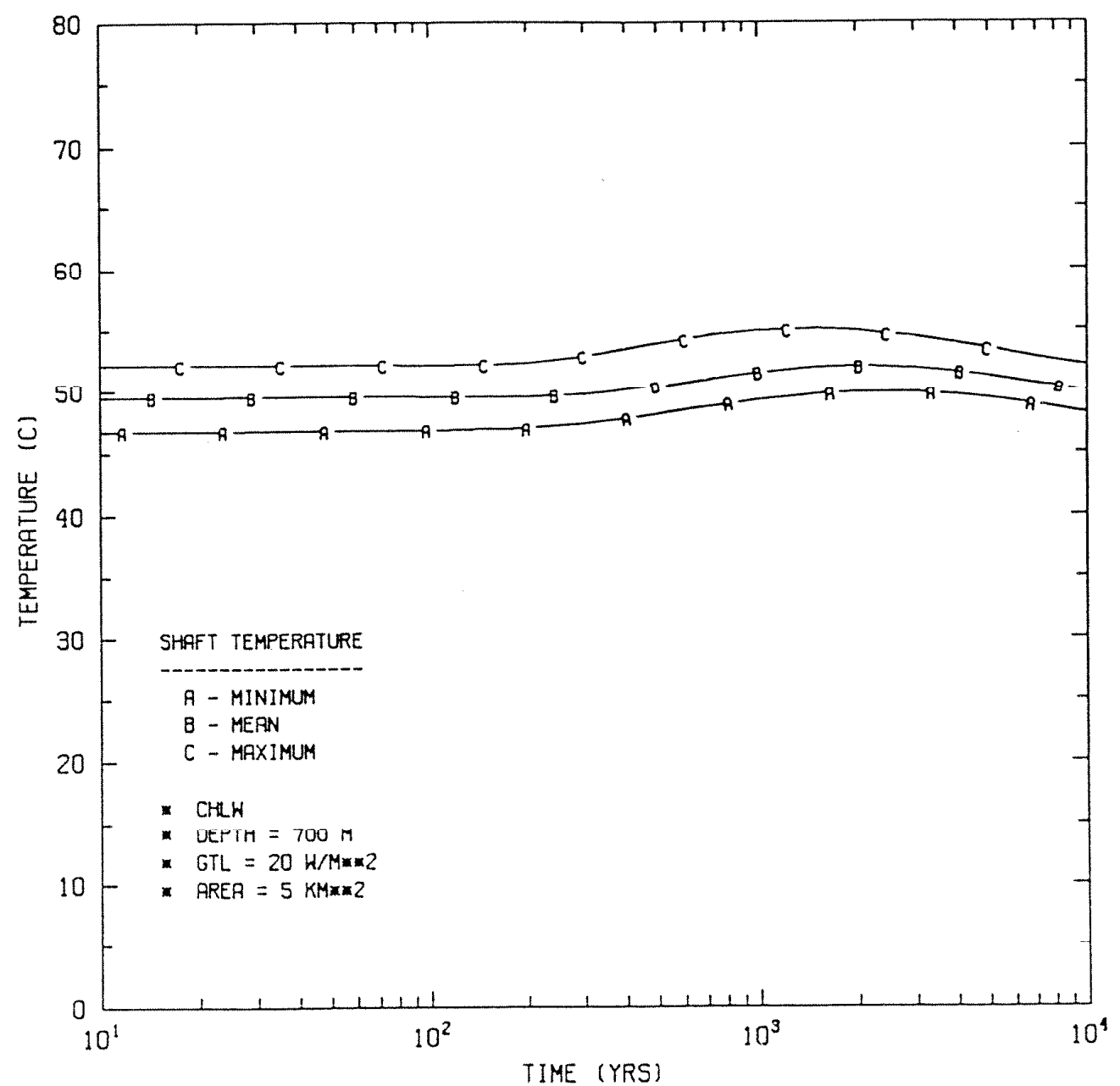

Fig. G.12.3.12. Expected range in shaft temperature for commercial high-level waste emplacement in chalk. 
ORNL DWG 85-173

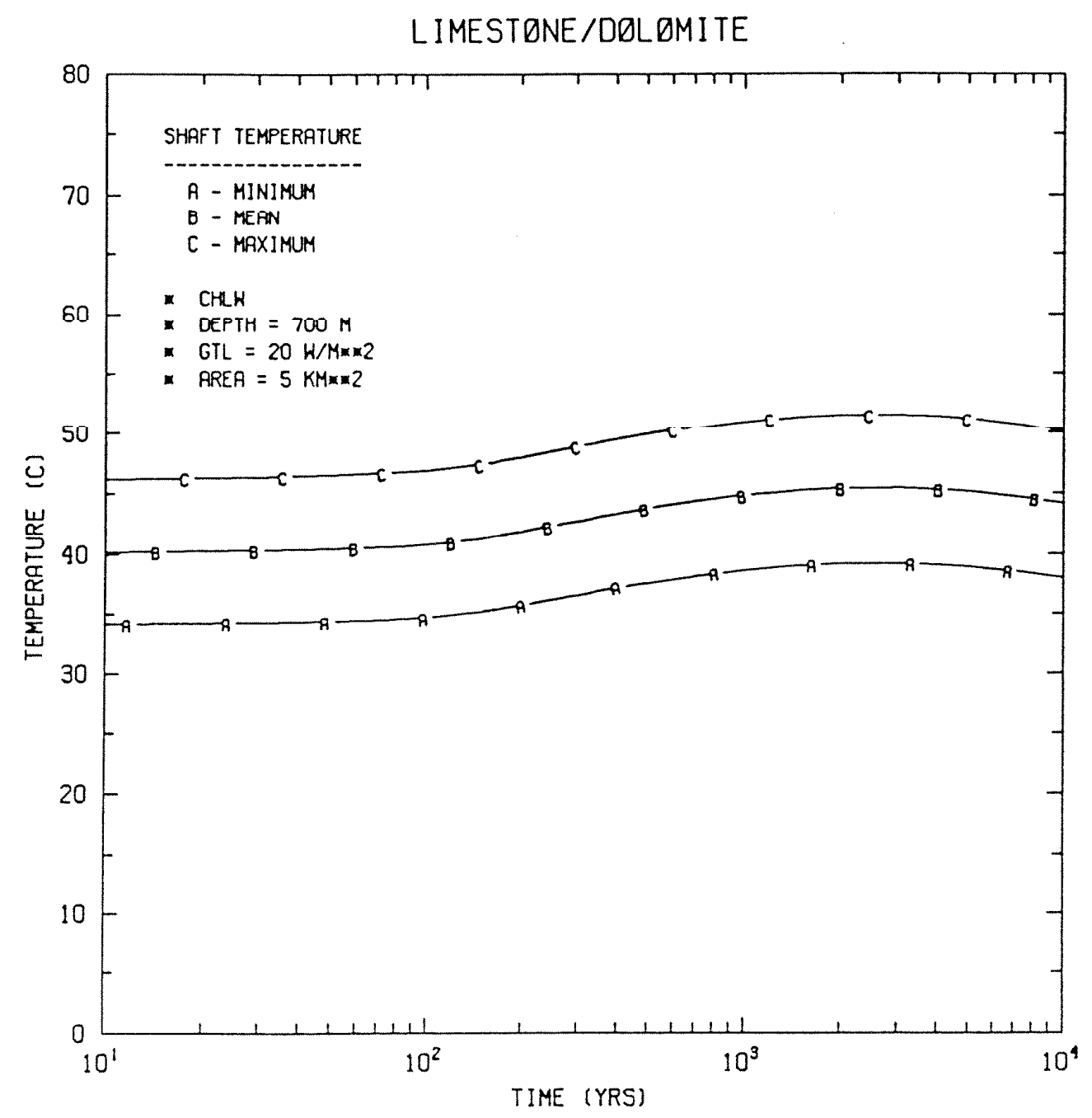

Fig. G.12.3.13. Expected range in shaft temperature for commercial high-level waste emplacement in carbonate rocks (1imestone/dolostone). 
ORNL DWG 85-174

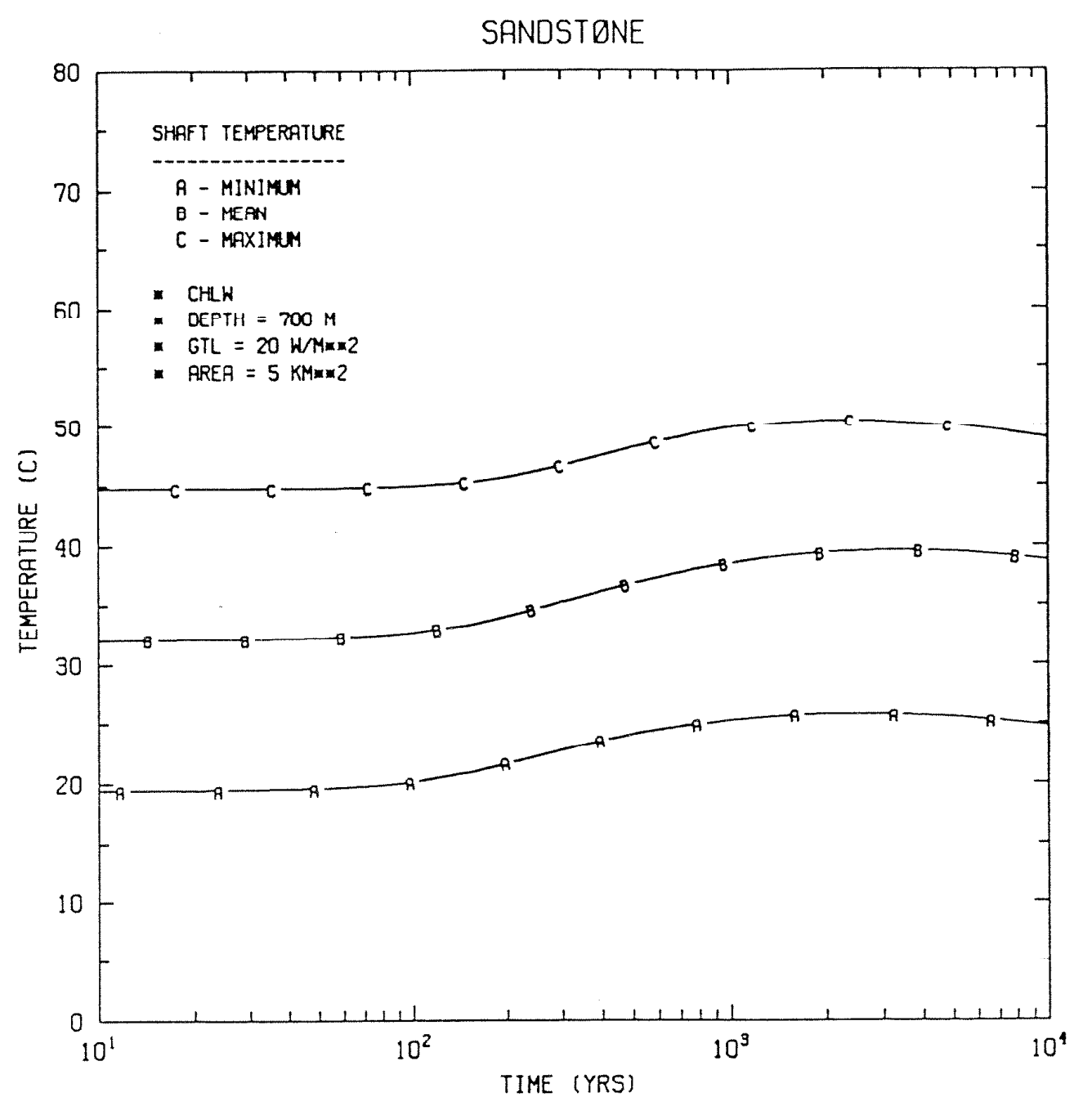

Fig. G.12.3.14. Expected range in shaft temperature for commercial high-level waste emplacement in sandstone. 
ORNL DWG 85-175

SHALE

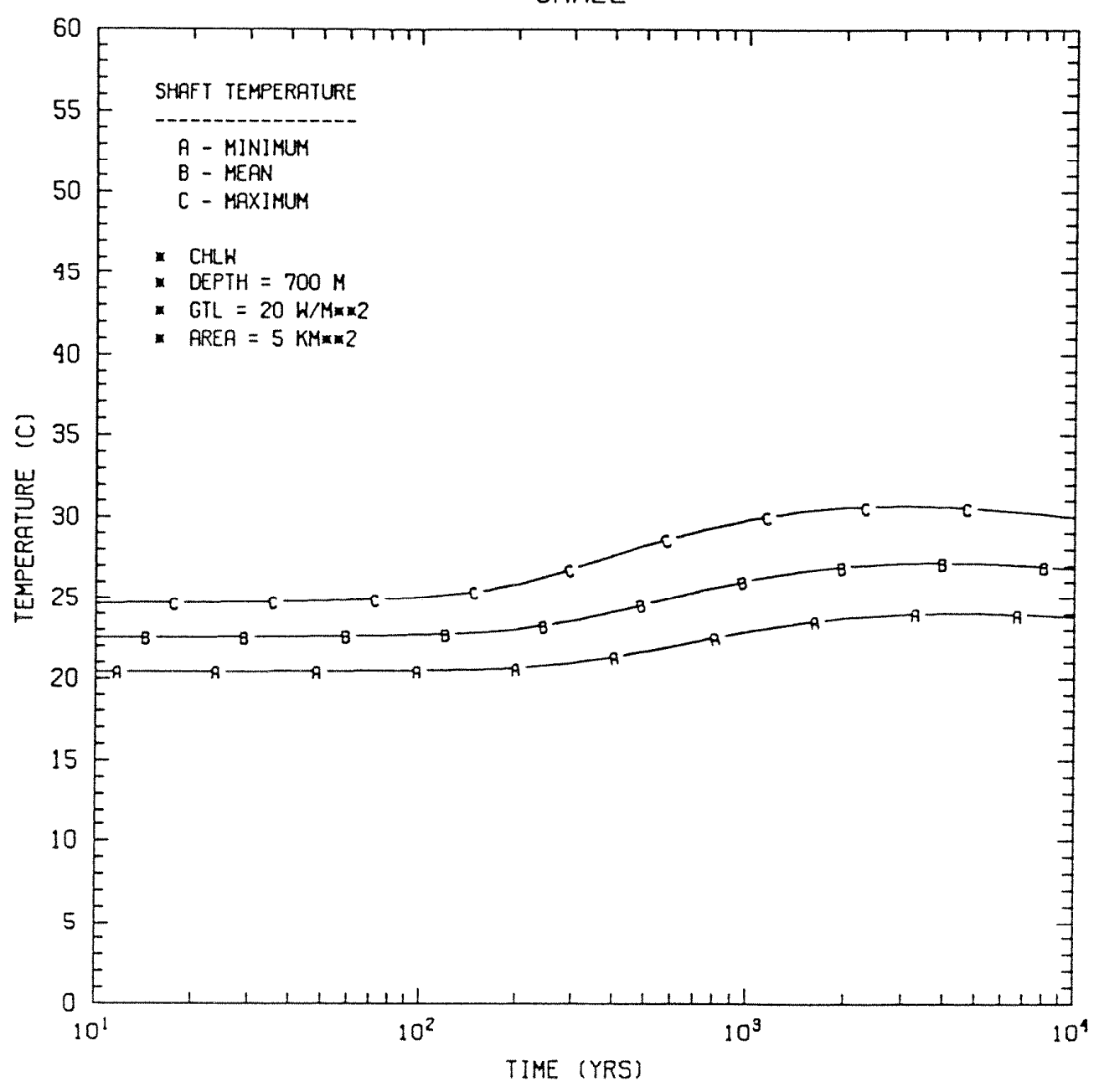

Fig. G.12.3.15. Expected range in shaft temperature for commercial high-level waste emplacement in shale. 
ORNL DWG 85-176

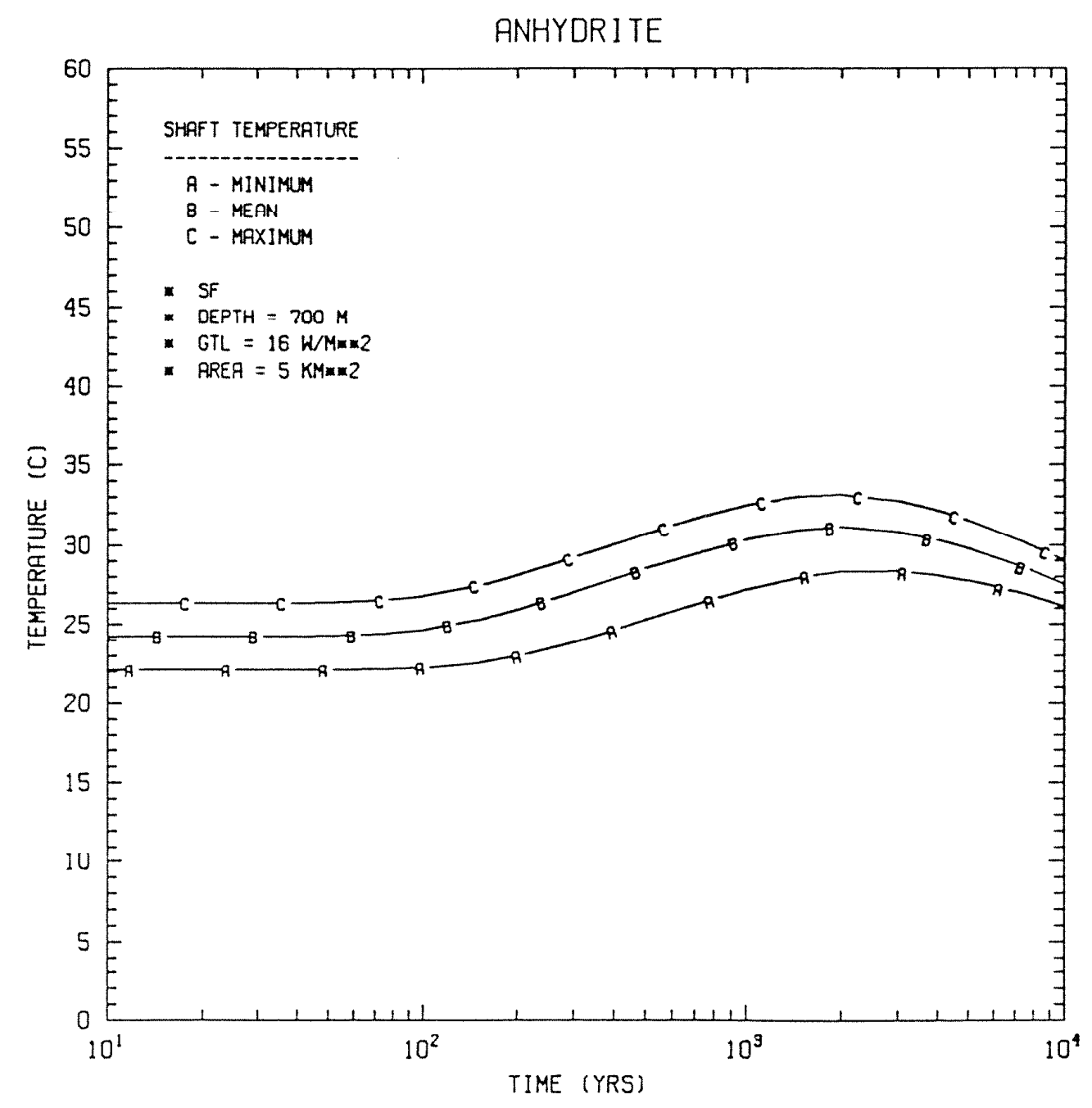

Fig. G.12.3.16. Expected range in shaft temperature for spent fuel emplacement in anhydrock. 
ORNL DWG 85-177

CHALK

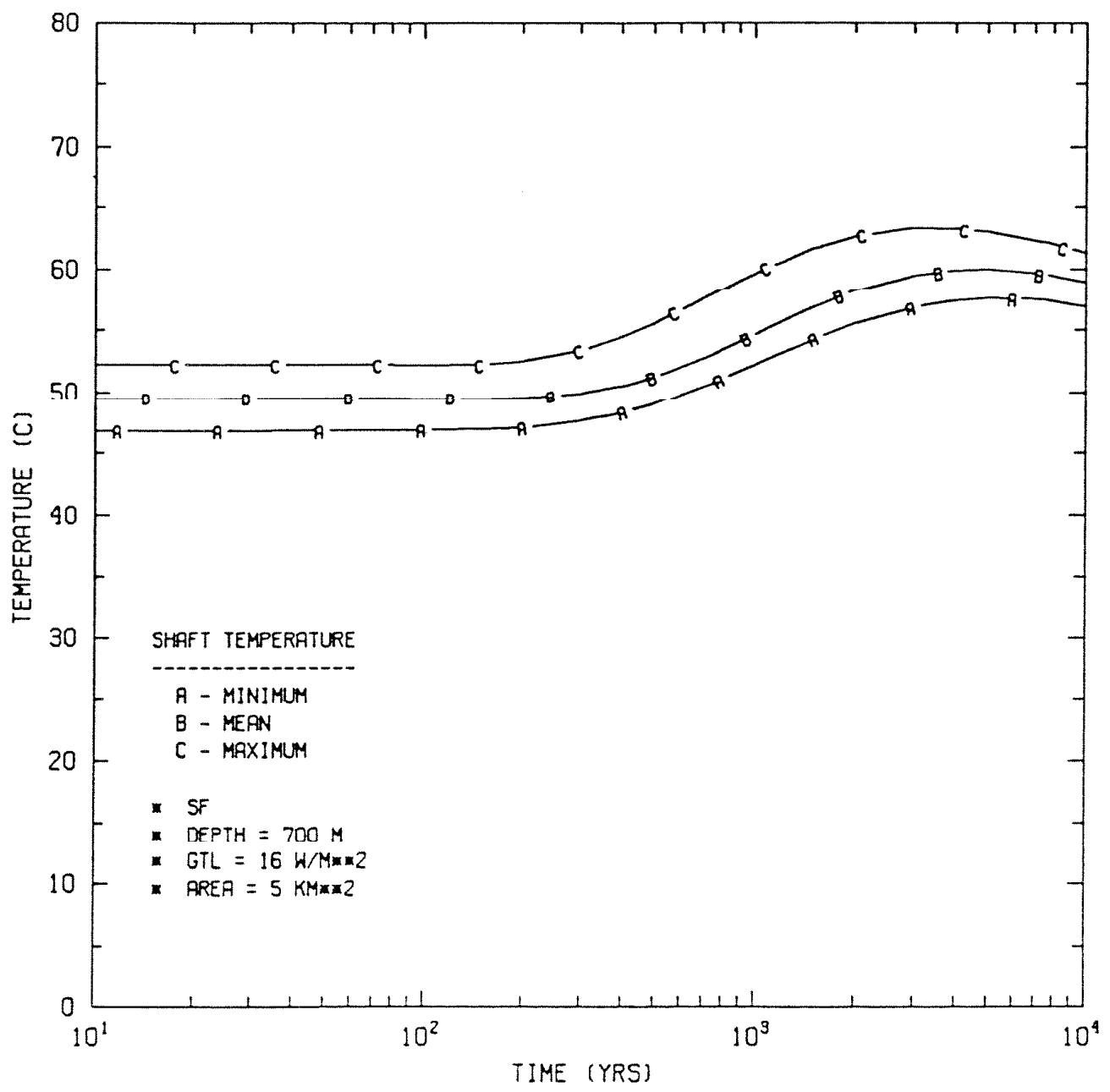

Fig. G.12.3.17. Expected range in shaft temperature for spent fuel emplacement in chalk. 
ORNL DWG 85-178

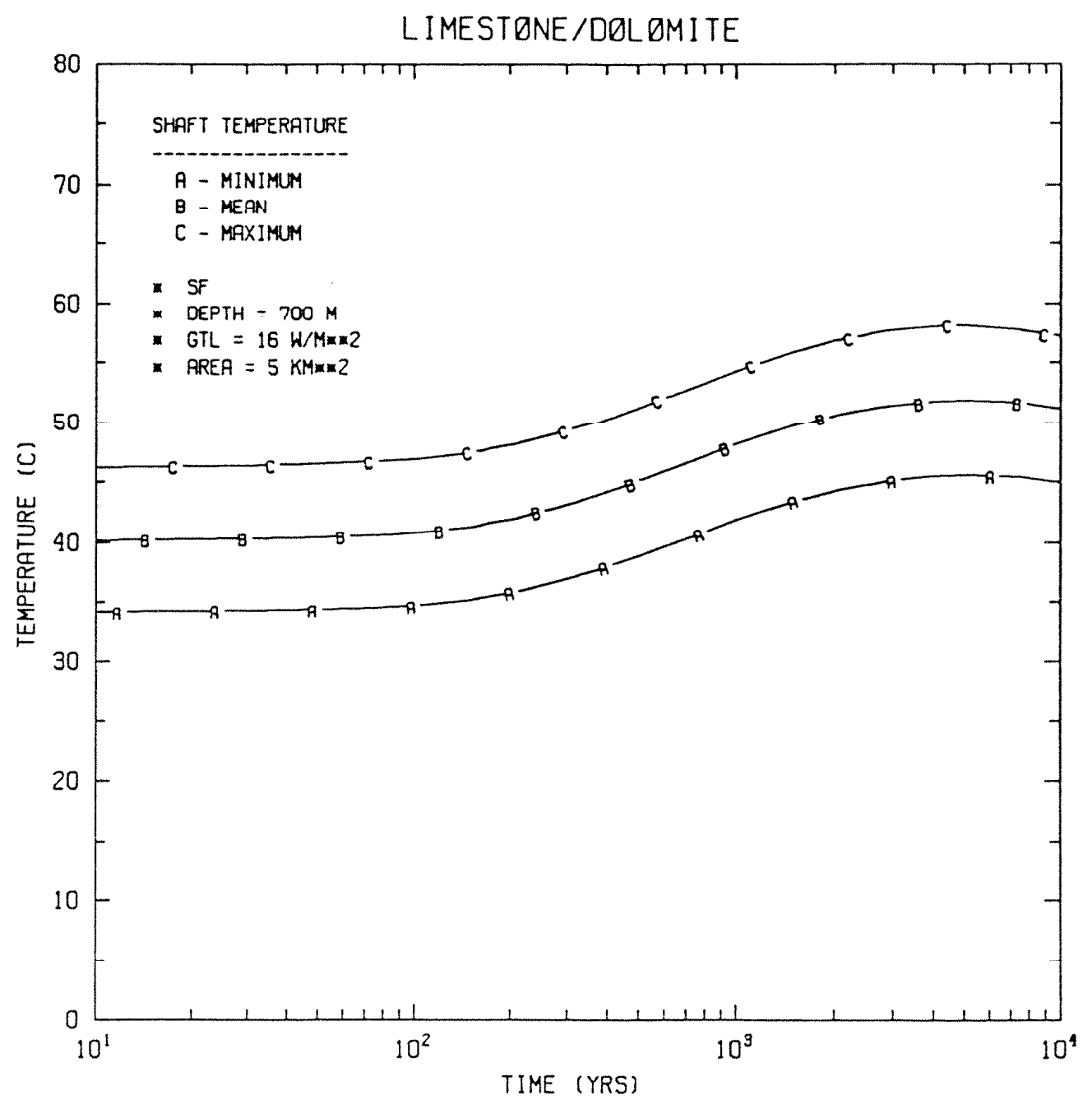

Fig. G.12.3.18. Expected range in shaft temperature for spent fue1 emplacement in carbonate rocks (limestone/dolostone). 
ORNL DWG 85-179

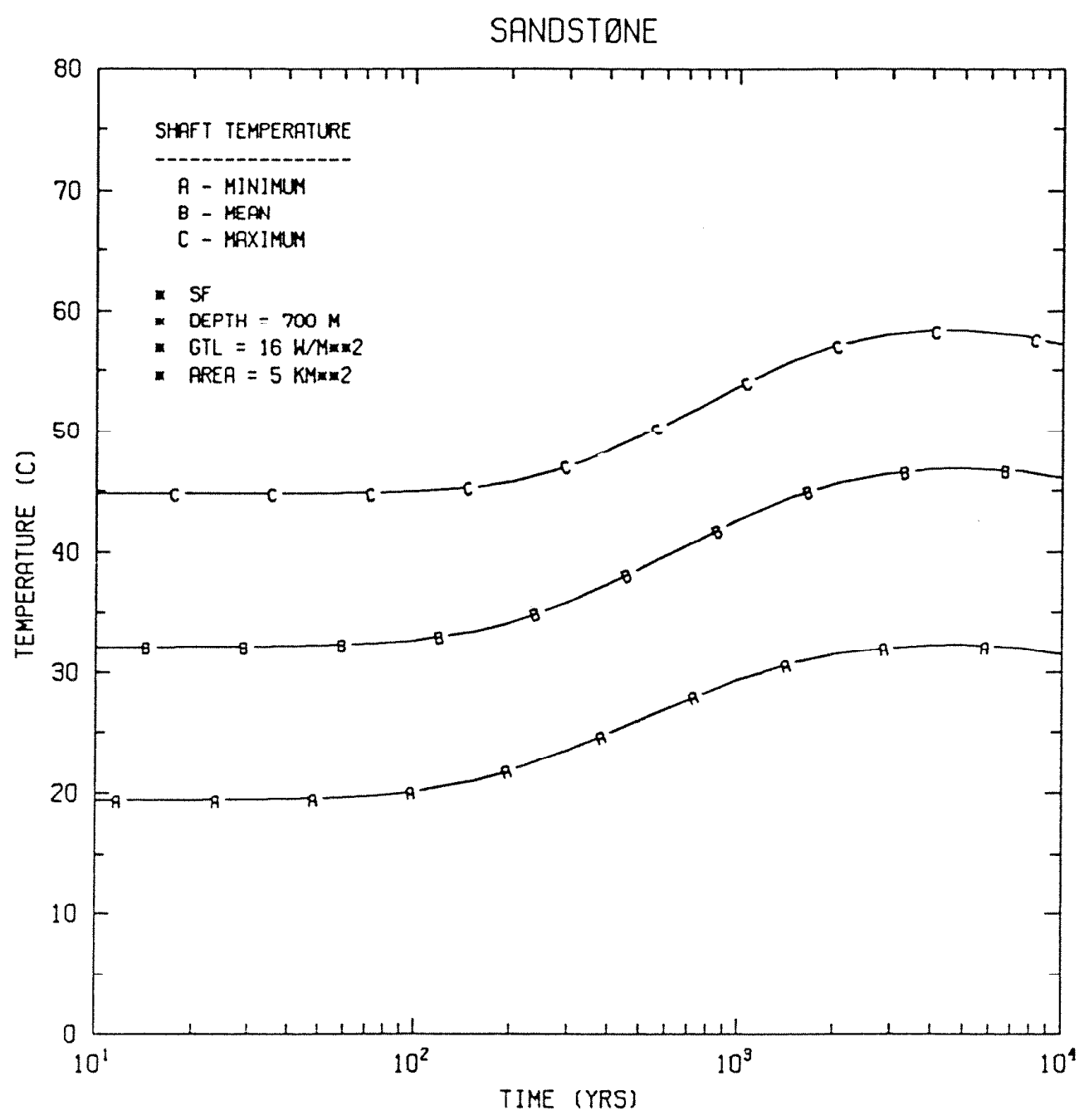

Fig. G.12.3.19. Expected range in shaft temperature for spent fuel emplacement in sandstone. 
ORNL DWG 85-180

SHALE

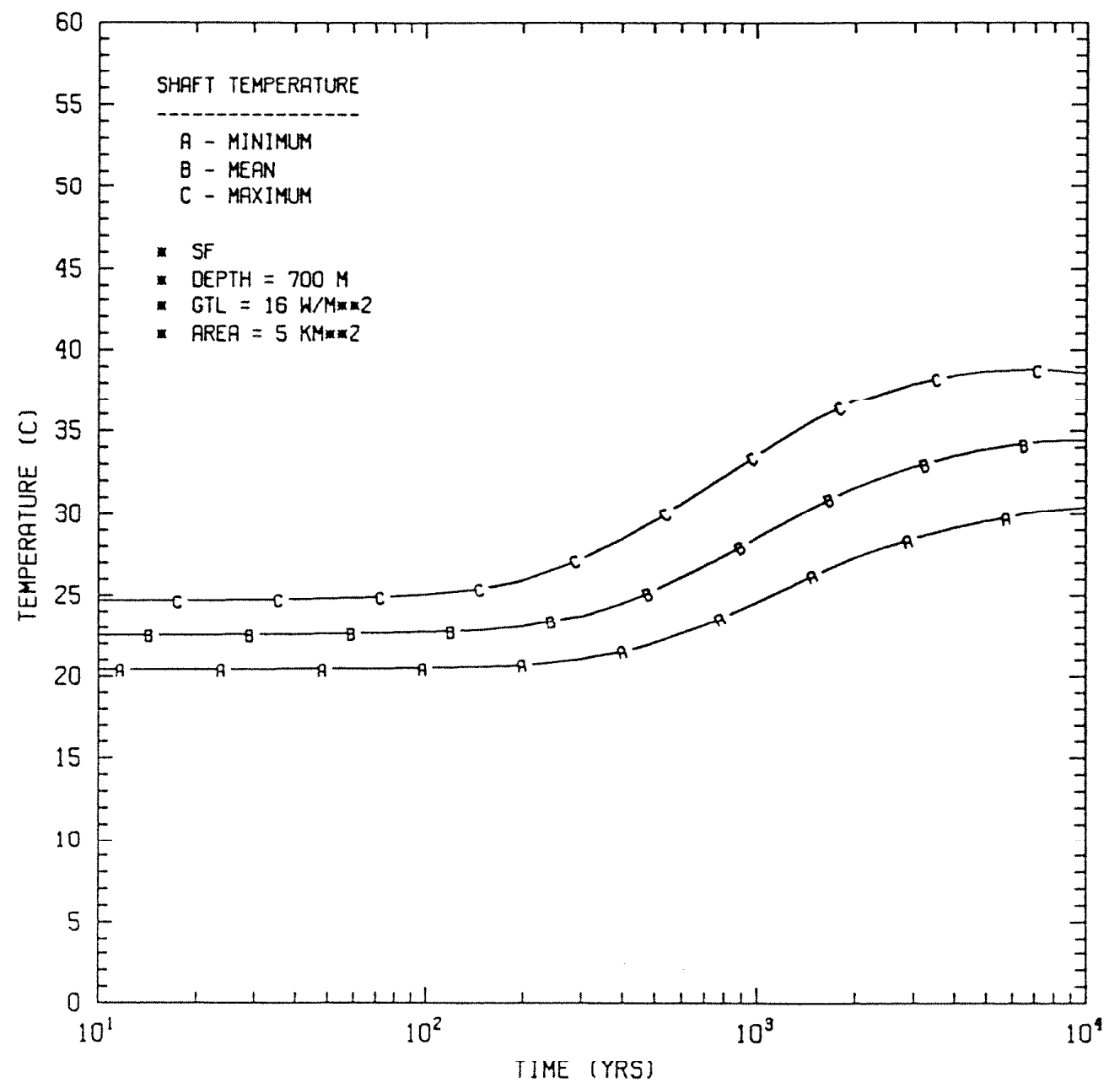

Fig. G.12.3.20. Expected range in shaft temperature for spent fue1 emplacement in shale. 


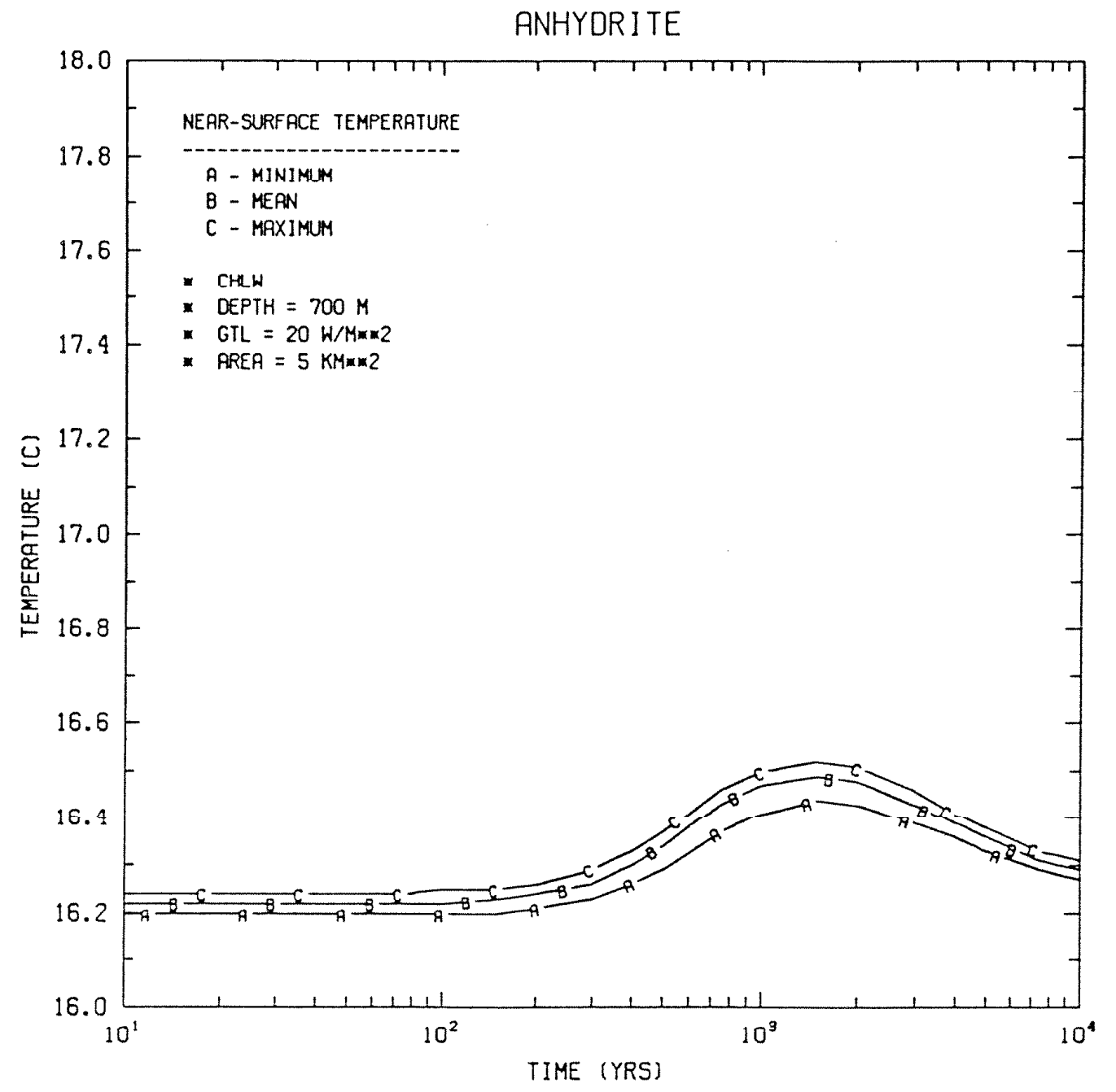

Fig. G.12.3.21. Expected range in near-surface temperature for commercial high-level waste emplacement in anhydrock. 
ORNL DWG 85-182

CHALK

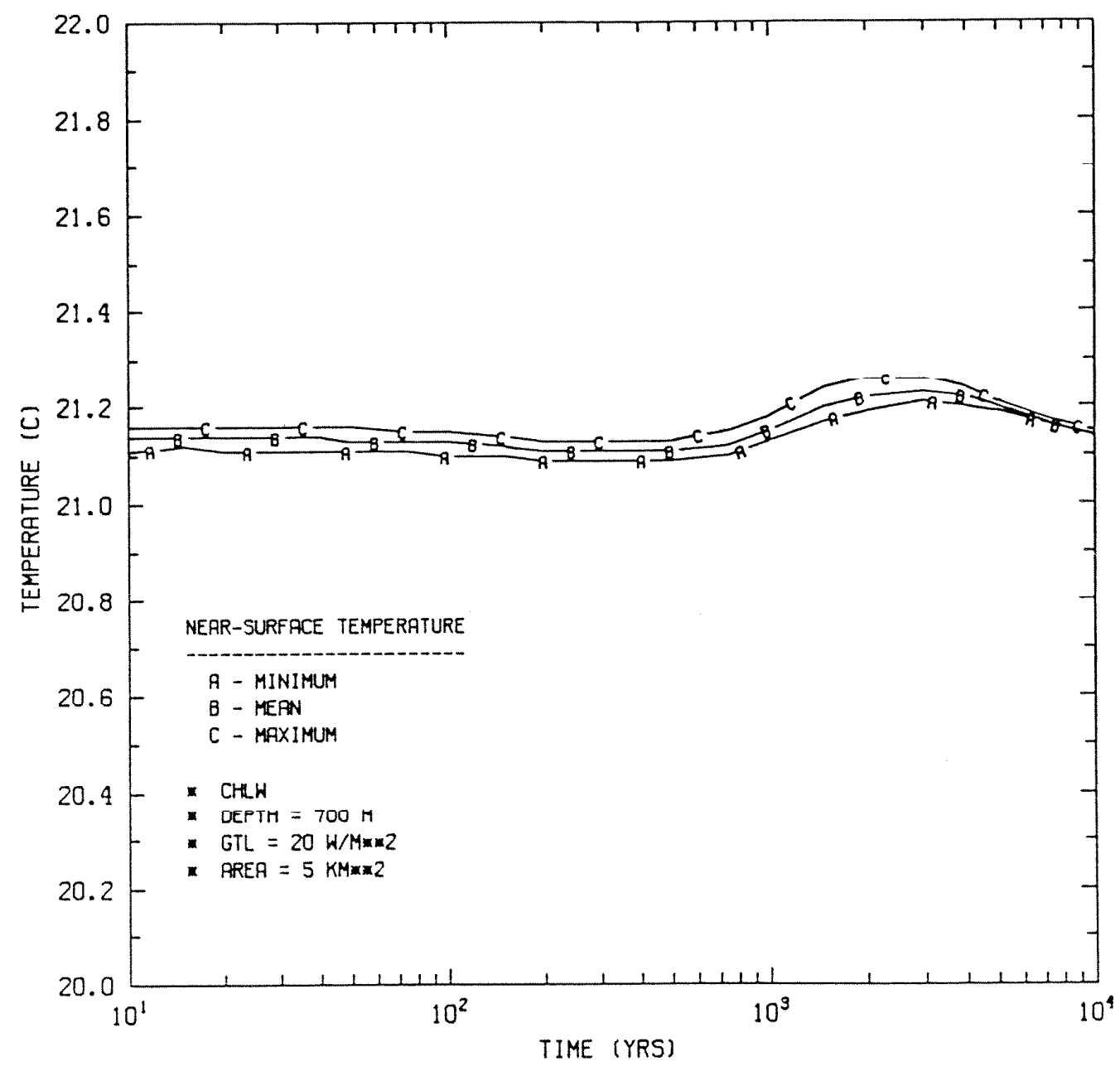

Fig. G.12.3.22. Expected range in near-surface temperature for commercial high-level waste emplacement in chalk. 
ORNL DWG 85-183

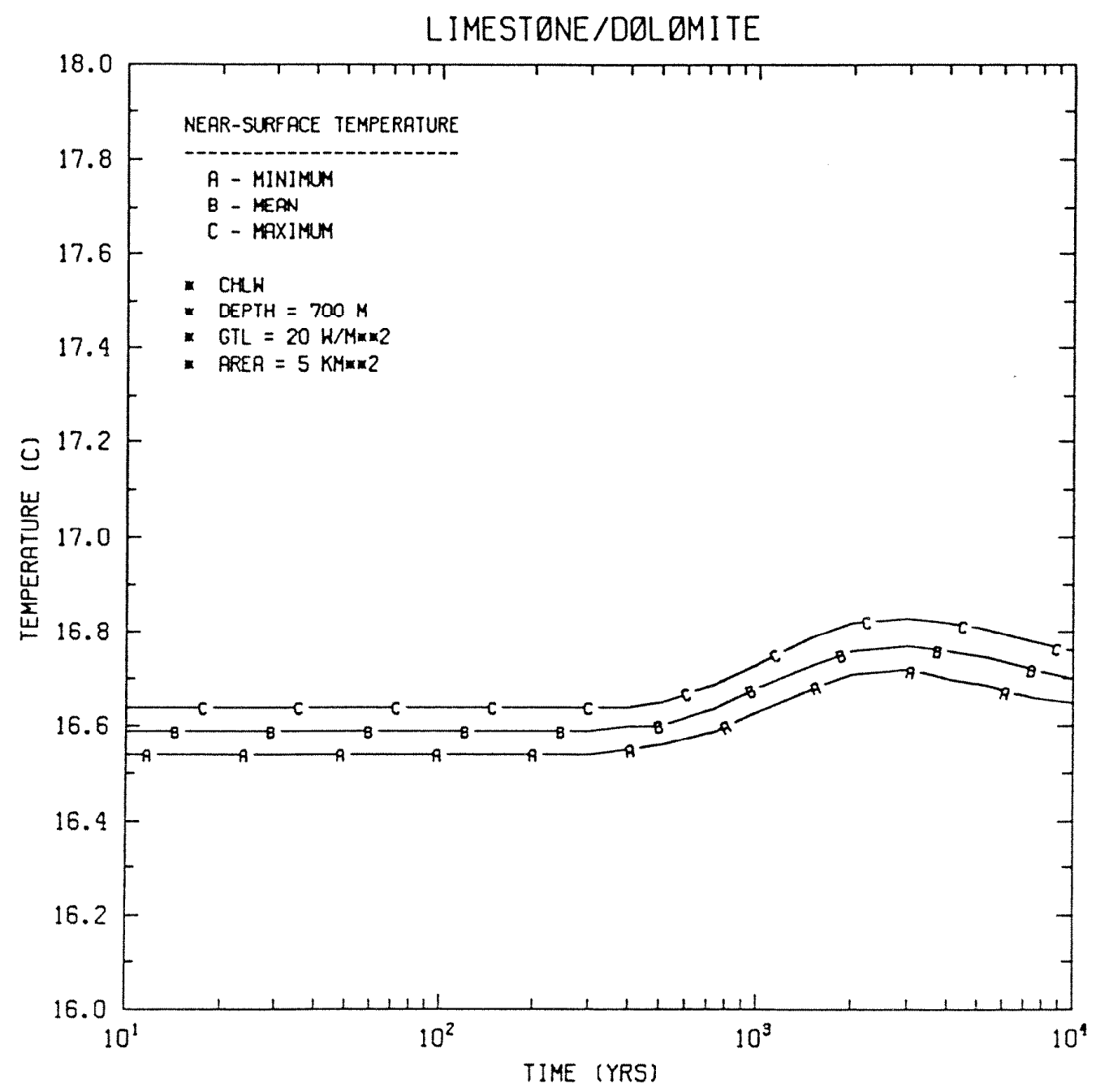

Fig. G.12.3.23. Expected range in near-surface temperature for commercial high-level waste emplacement in carbonates (limestone/ dolostone). 
ORNL DWG 85-184

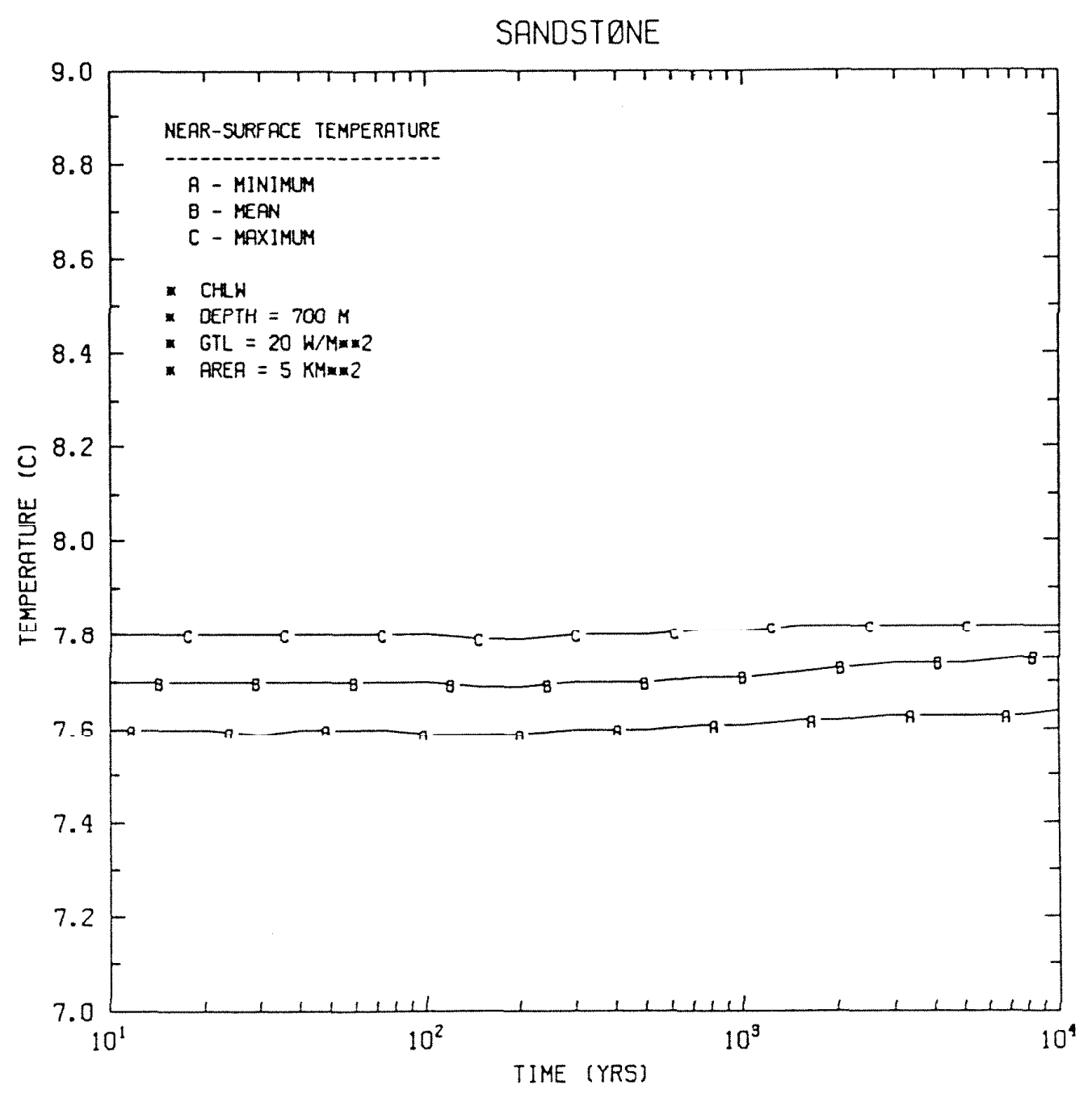

Fig. G.12.3.24. Expected range in near-surface temperature for commercial high-1evel wasto amplacoment in sandstone. 
ORNL DWG 85-185

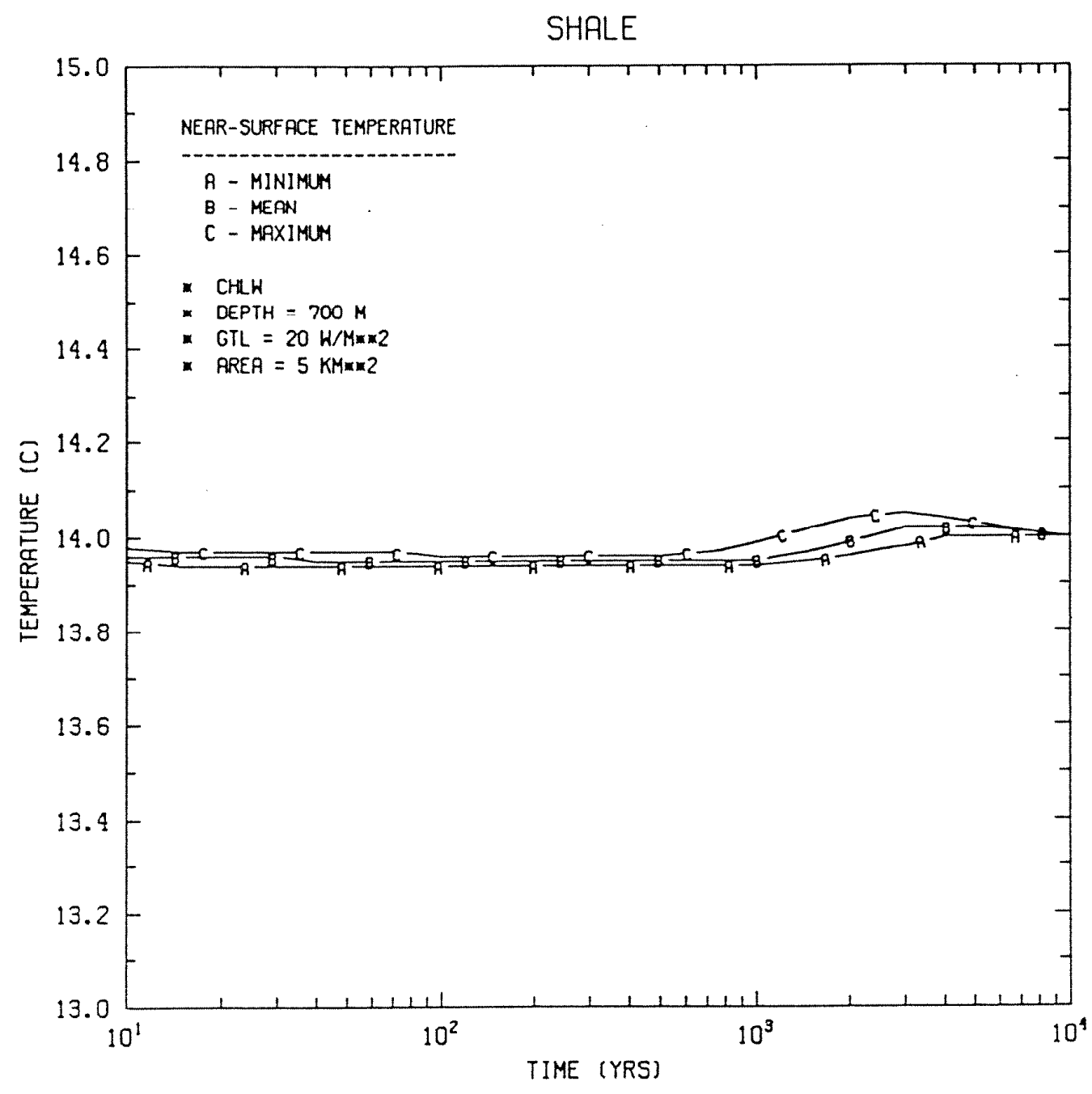

Fig. G.12.3.25. Expected range in near-surface temperature for commercial high-level waste emplacement in shale. 
ORNL DWG 85-186

ANHYDRITE

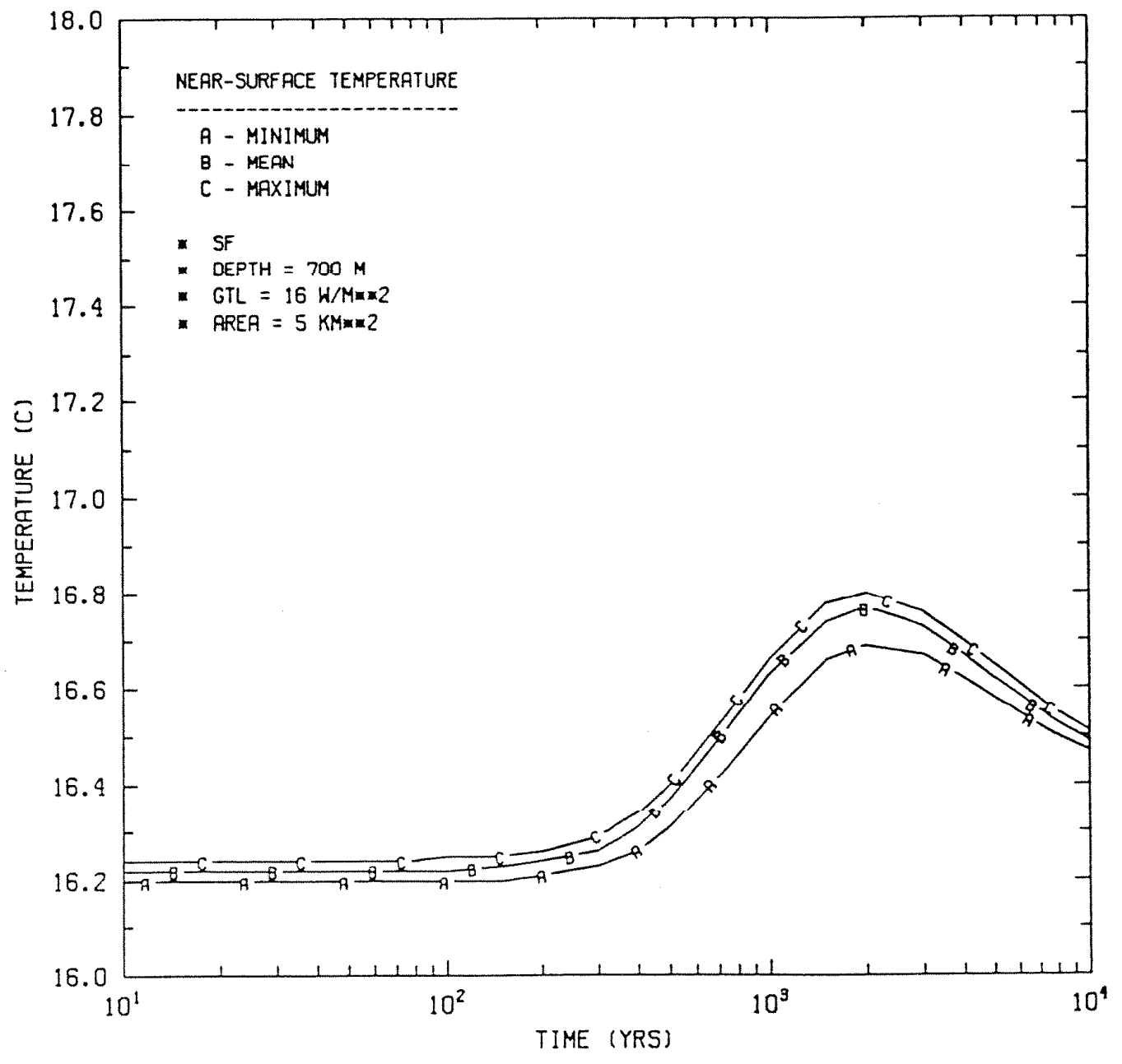

Fig. G.12.3.26. Expected range in near-surface temperature for spent fuel emplacement in anhydrock. 
ORNL DWG 85-187

CHALK

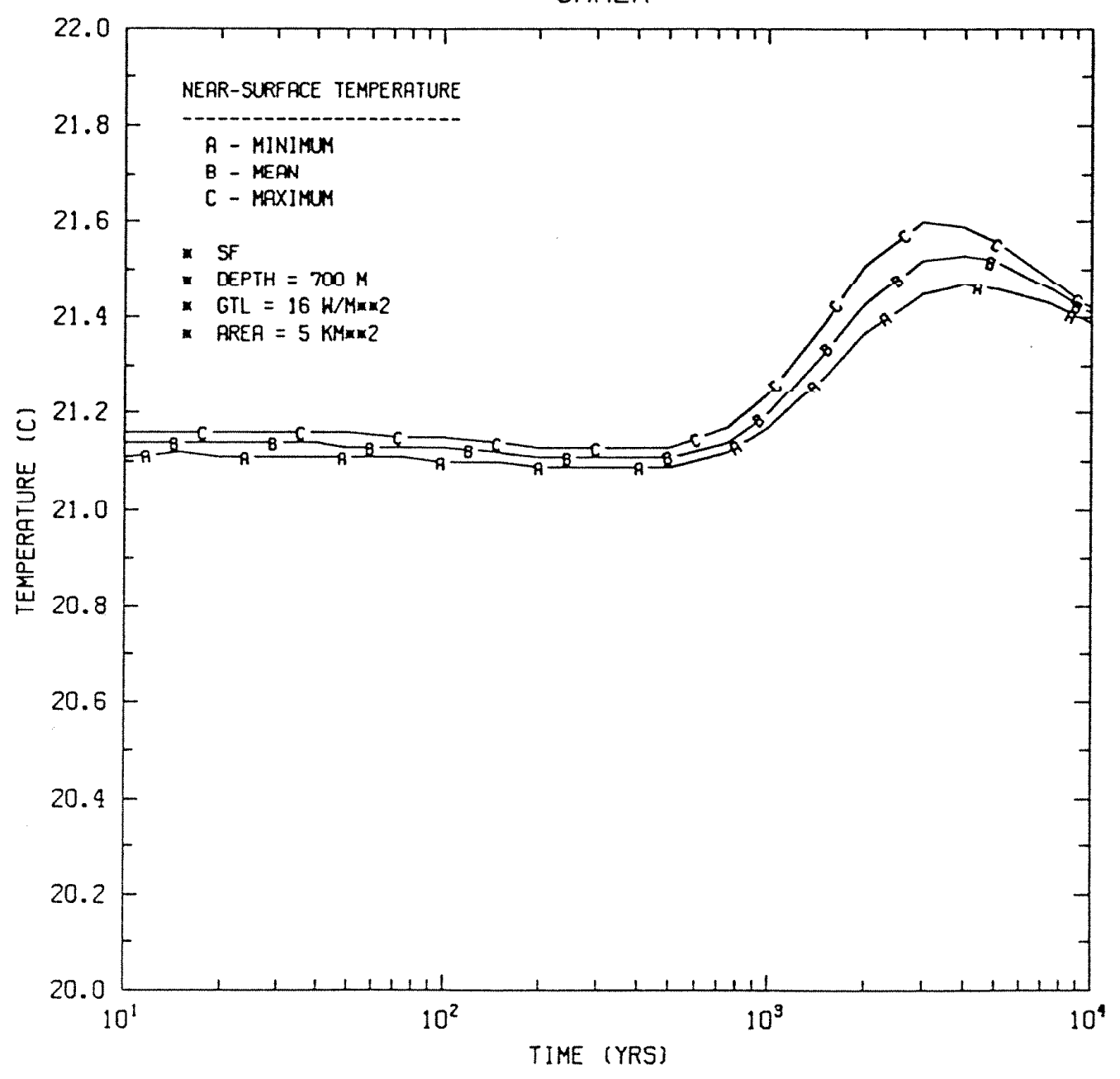

Fig. G.12.3.27. Expected range in near-surface temperature for spent fuel emplacement in chalk. 
ORNL DWG 85-188

LIMESTONE/DØLØMITE

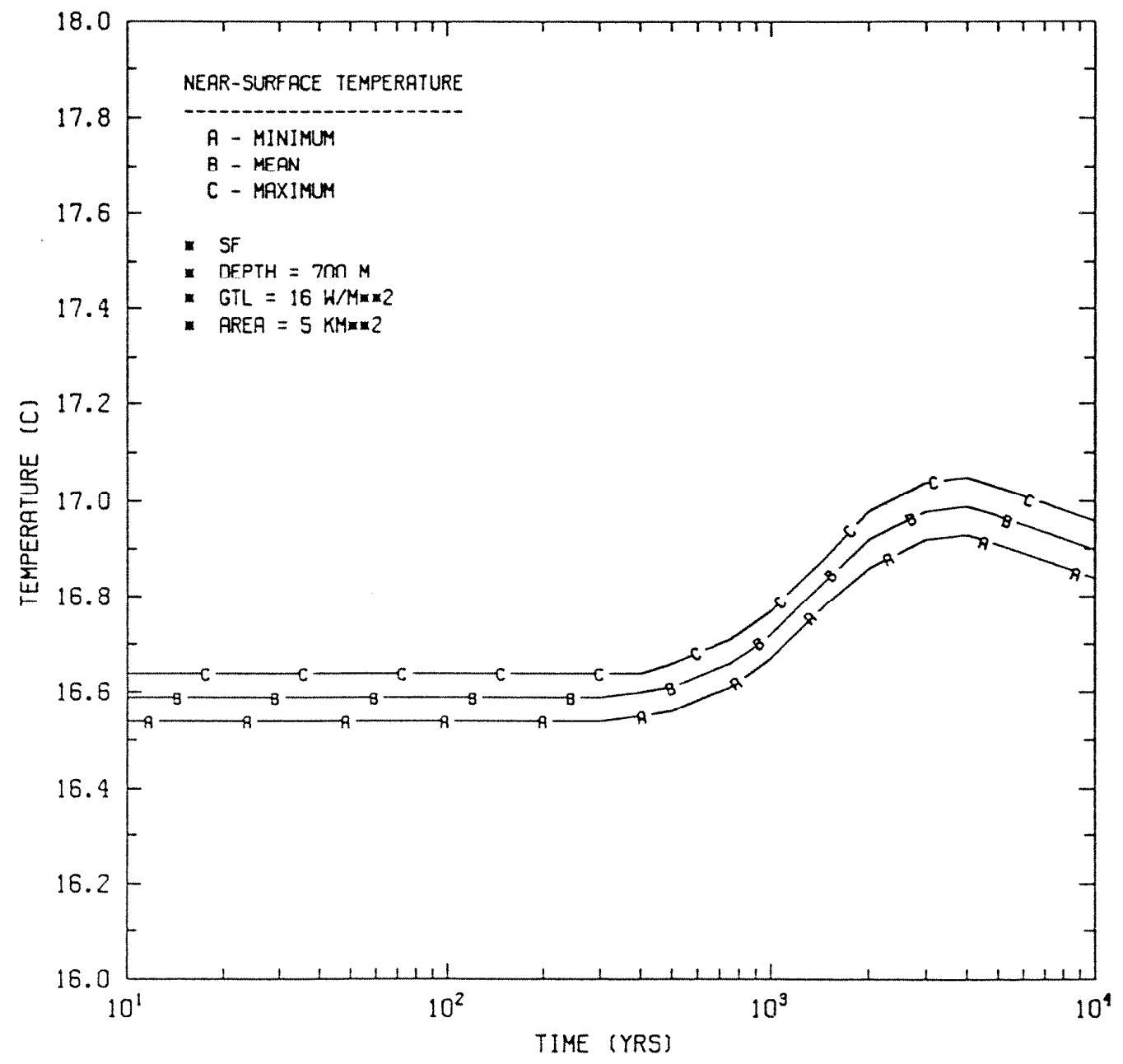

Fig. G.12.3.28. Expected range in near-surface temperature for spent fuel emplacement in carbonate rocks (1imestone/dolostone). 
ORNL DWG 85-189

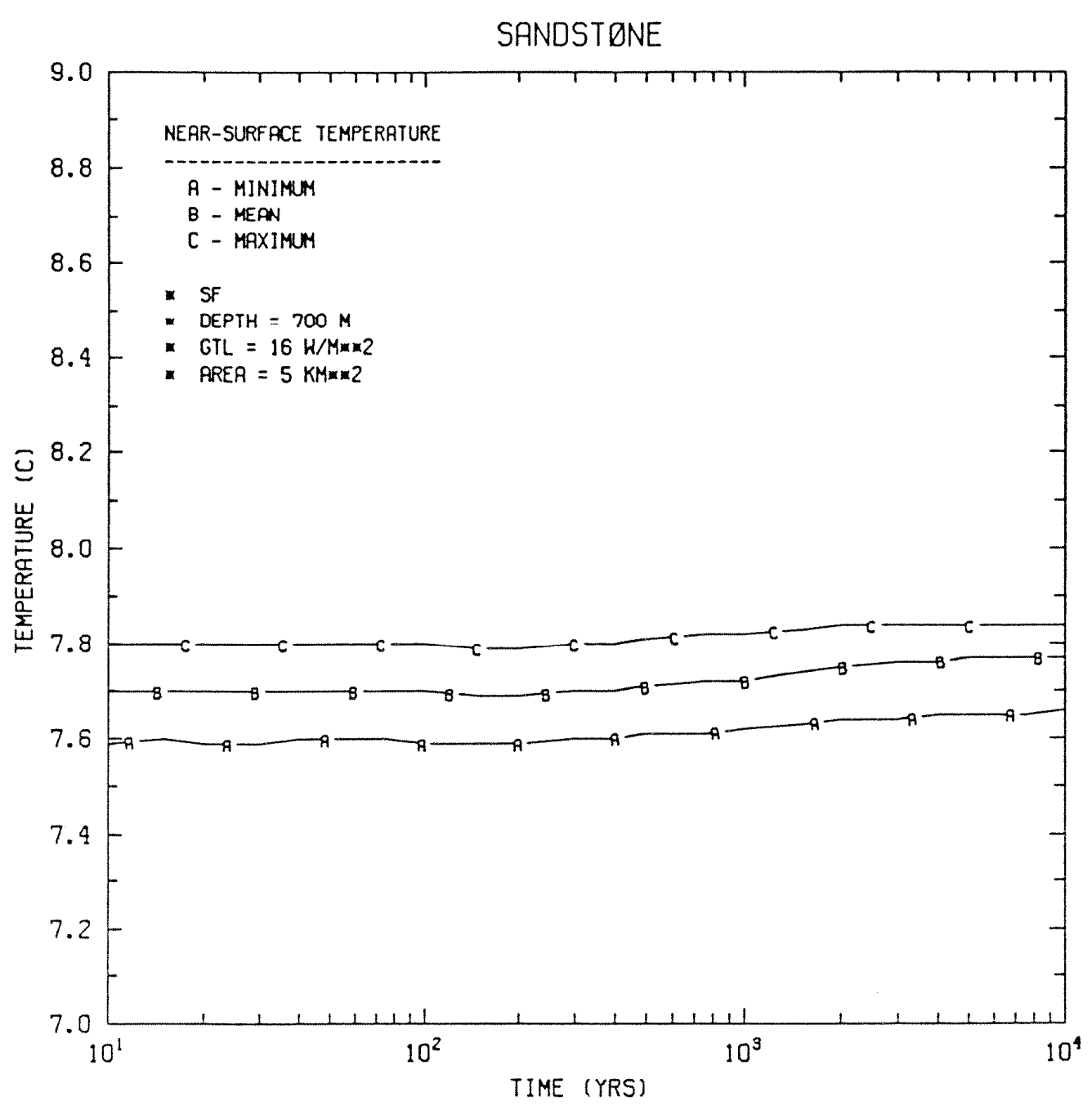

Fig. G.12.3.29. Expected range in near-surface temperature for spent fuel emplacement in sandstone. 
ORNL DWG 85-190

SHALE

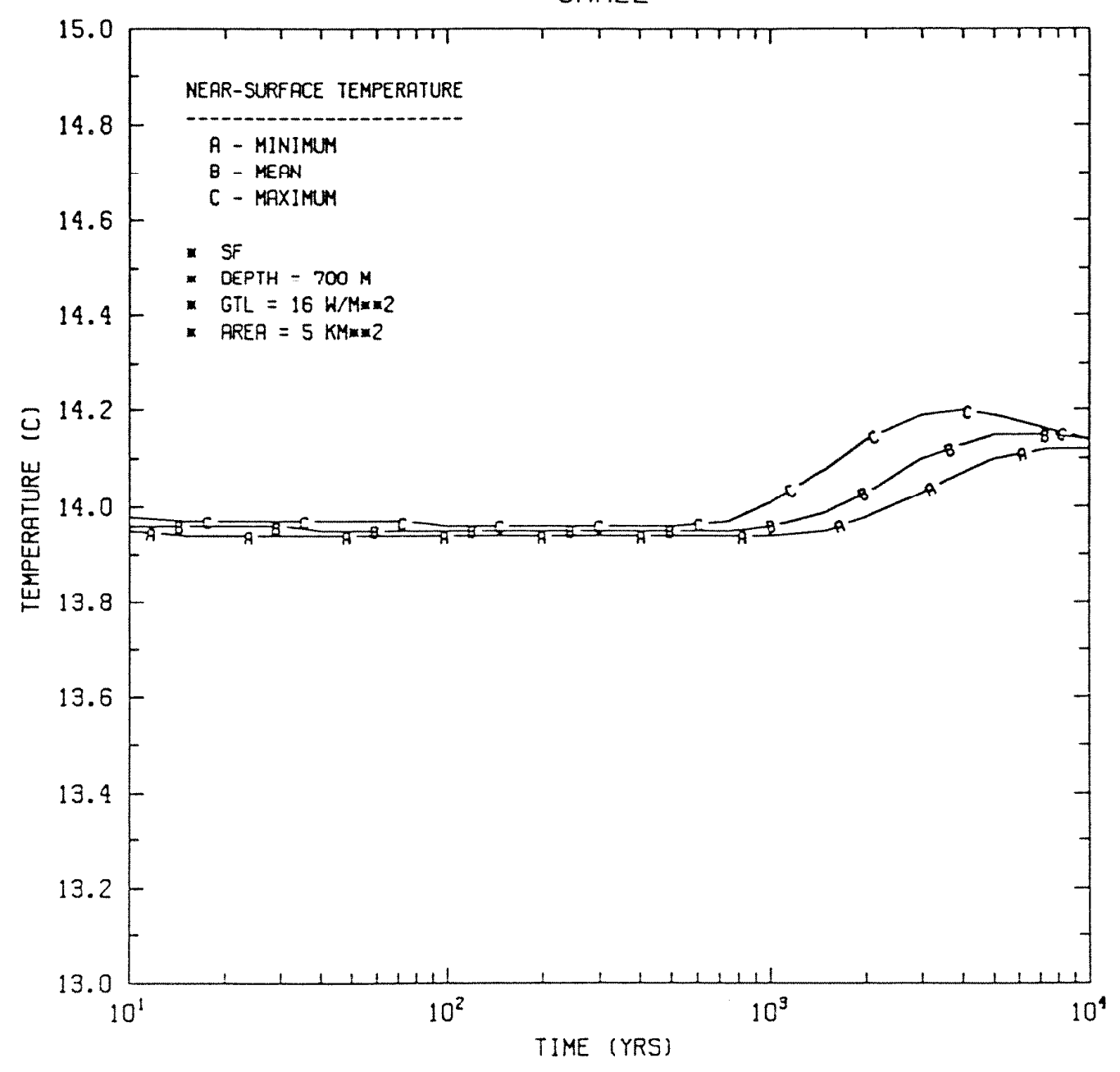

Fig. G.12.3.30. Expected range in near-surface temperature for spent fuel emplacement in shale. 
G.12.4 COMPARISON OF EXPECTED VALUES OF THE THERMAL RESULTS FOR FIVE SEDTMENTARY ROCK TYPES

This section presents a comparison of the five rock types at their mean values for each thermal response. This comparison supplements the Information presented in Sects. G.8 and G.11.2. The figures in this section encompass (Figs. G.12.4.1 through G.12.4.18):

- Nine responses

- waste form temperature

- overpack temperature

- host rock temperature (operational/containment period)

- volune-averaged backfill temperacure

- near-field/far-field interface temperature

- host rock temperature (isolation period)

- temperature at 595-m depth

- shaft temperature

- near-surface temperature rise

- Two wasce cypes

- commercial high-level waste

- spent fuel

- Five rock types

- anhydrock

- chalk

- carbonate rocks (1imestone/dolostone)

- sandstone

- shale (argillaceous rock)

Each figure presents the transient behavior of a single response and waste type, comparing the five rock types at their expected values. 
ORNL DWG 85-191

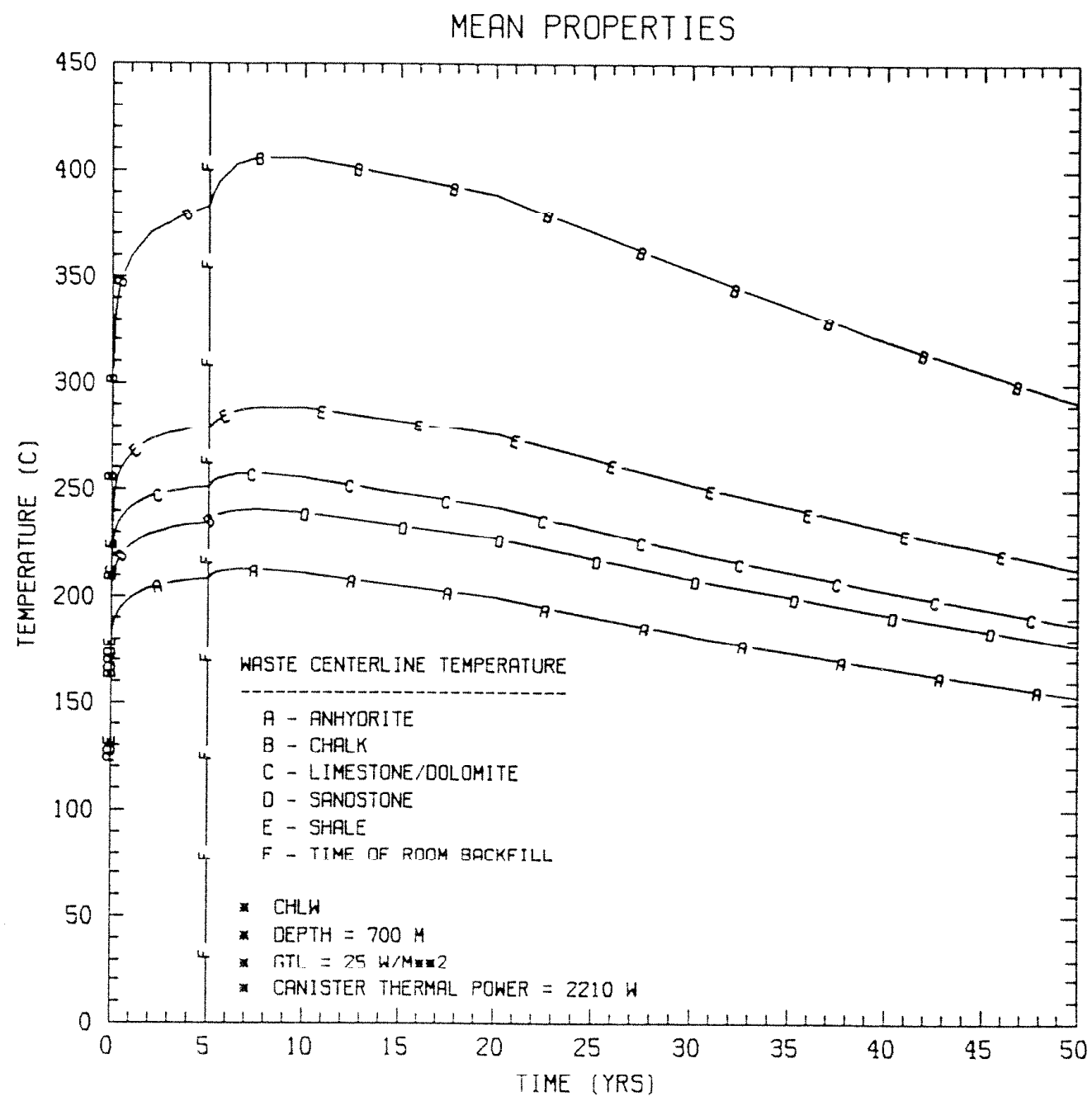

Fig. G.12.4.1. Expected waste centerline temperature for commercial high-level waste emplacement in five sedimentary rock types. 
ORNL DWG $85-192$

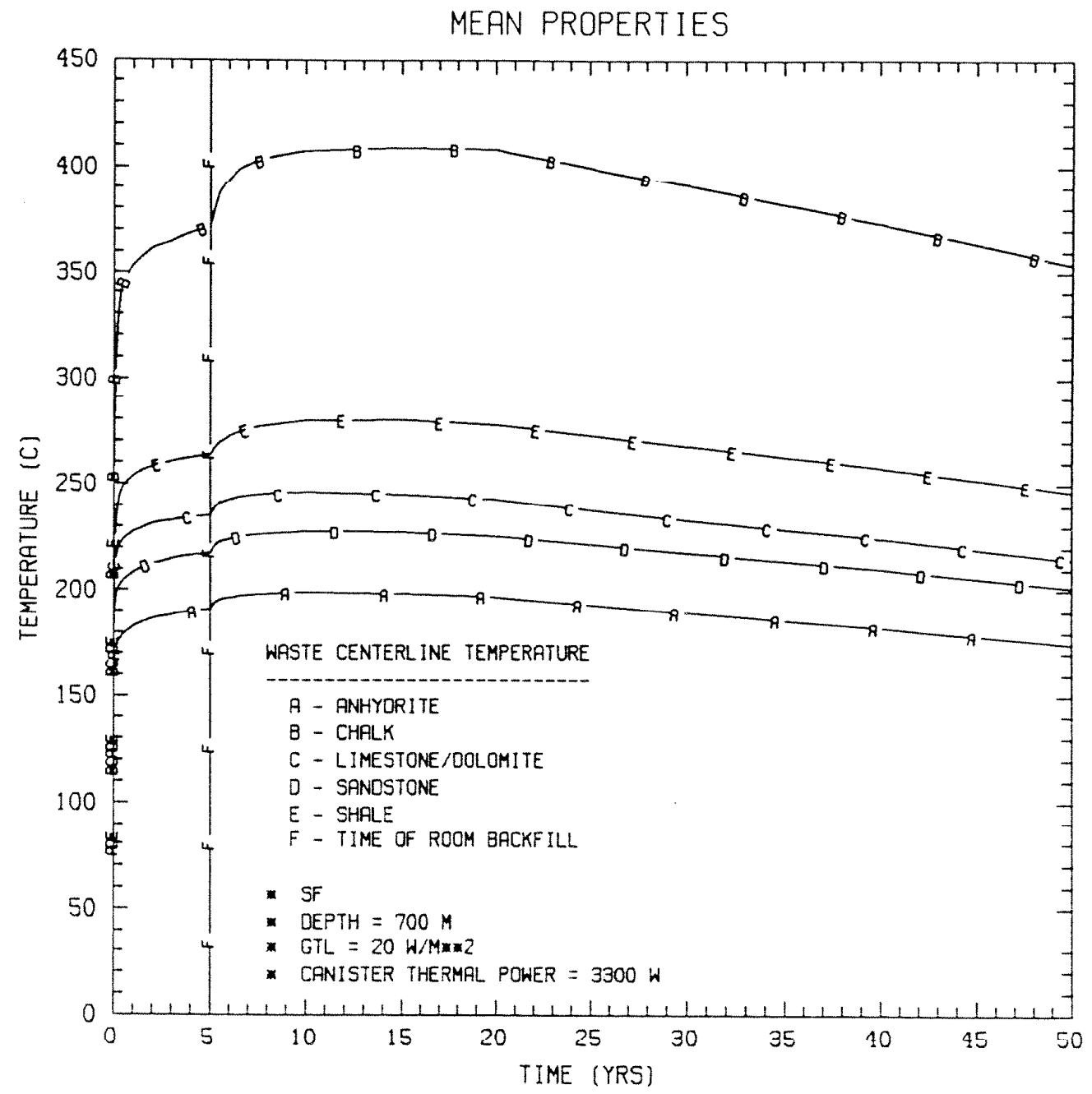

Fig. G.12.4.2. Expected waste centerline temperature for spent fuel emplacement in five sedimentary rock types. 
ORNL DWG 85-193

MEAN PROPERTIES

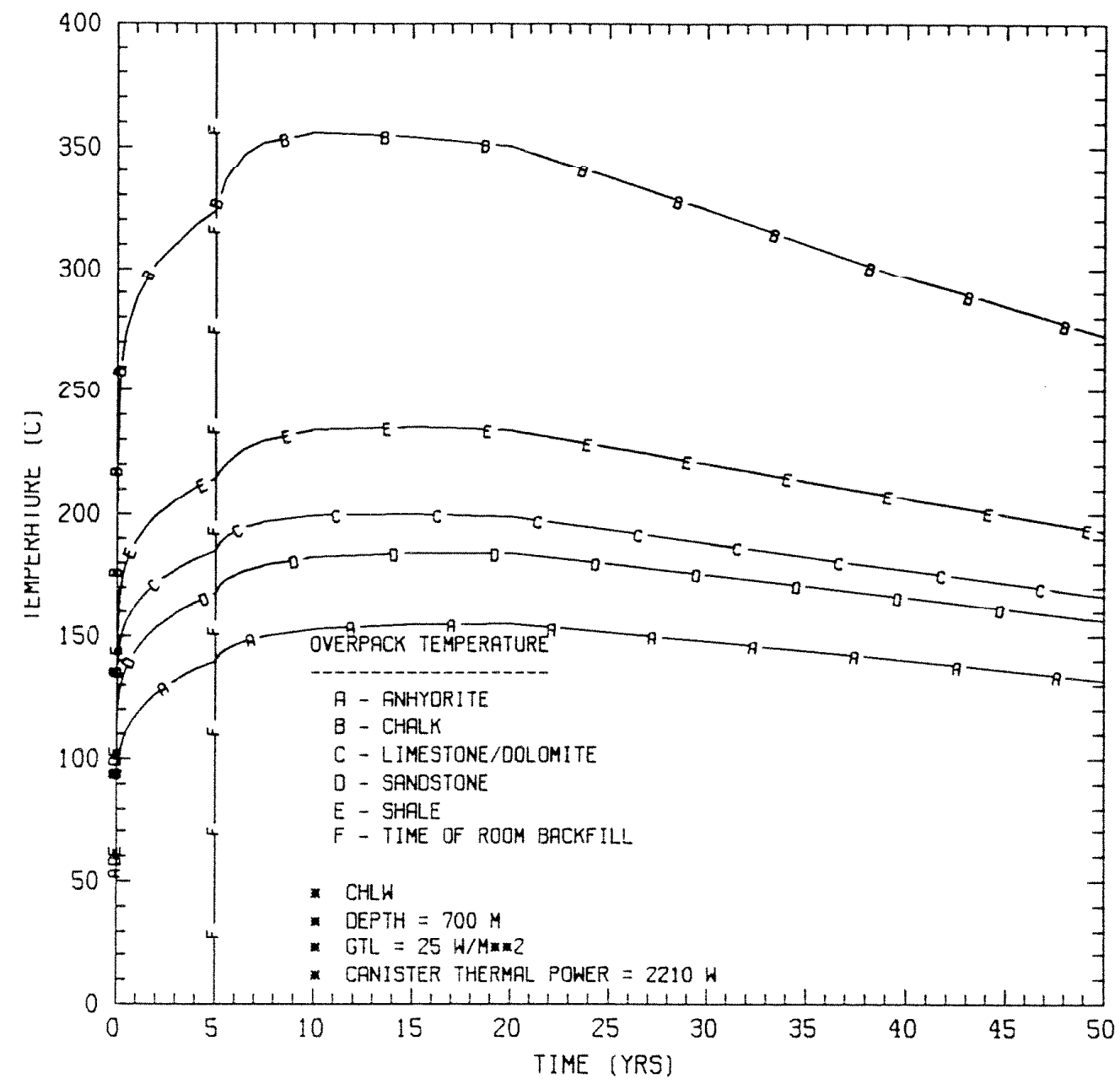

Fig. G.12.4.3. Expected overpack temperature for commercial highlevel waste emplacement in five sedimentary rock types. 
ORNL DWG 85-194

MEAN PROPERTIES

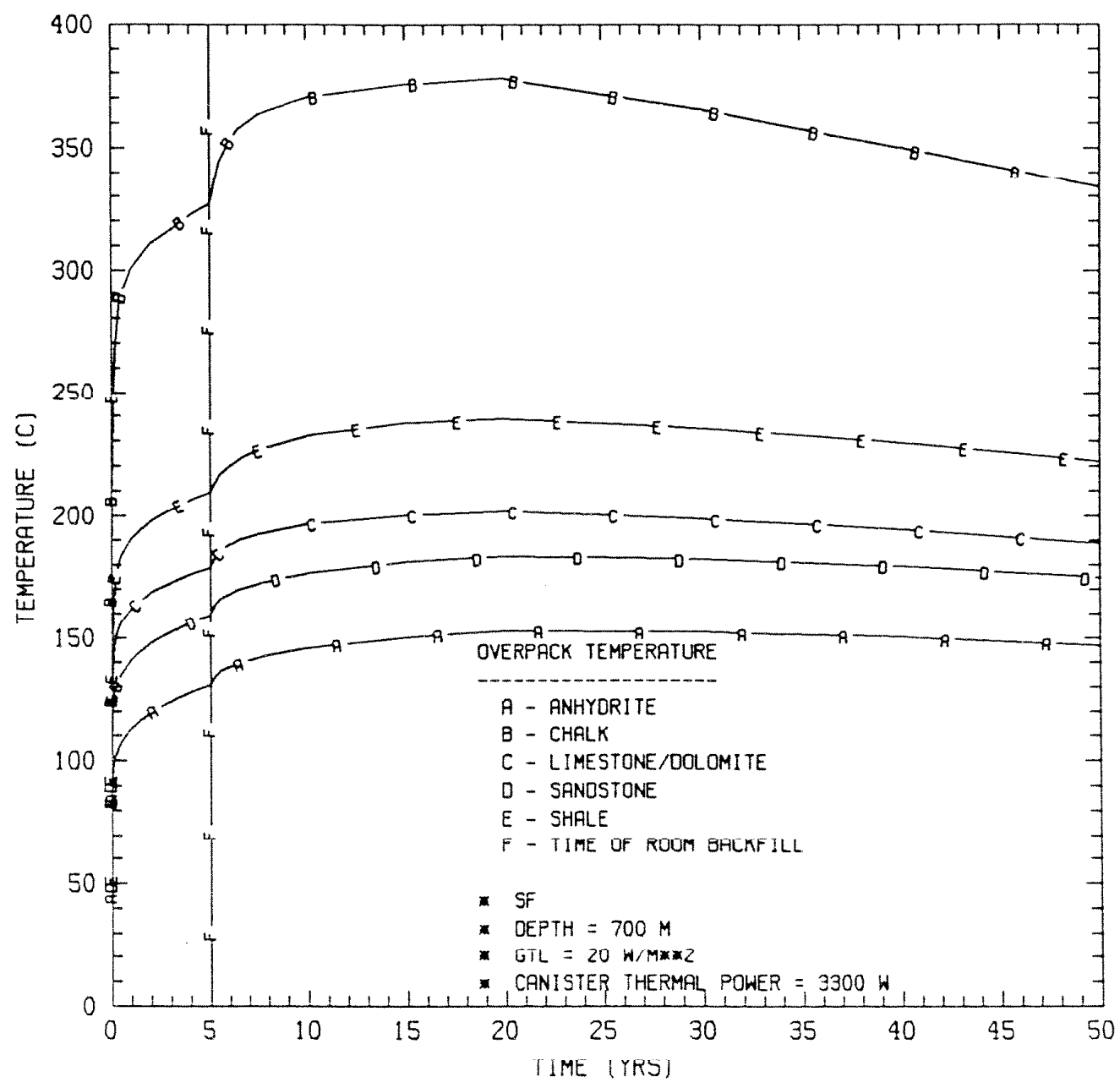

Fig. G.12.4.4. Expected overpack temperature for spent fuel emplacement in five sedimentary rock types. 
ORNL DWG 85-195

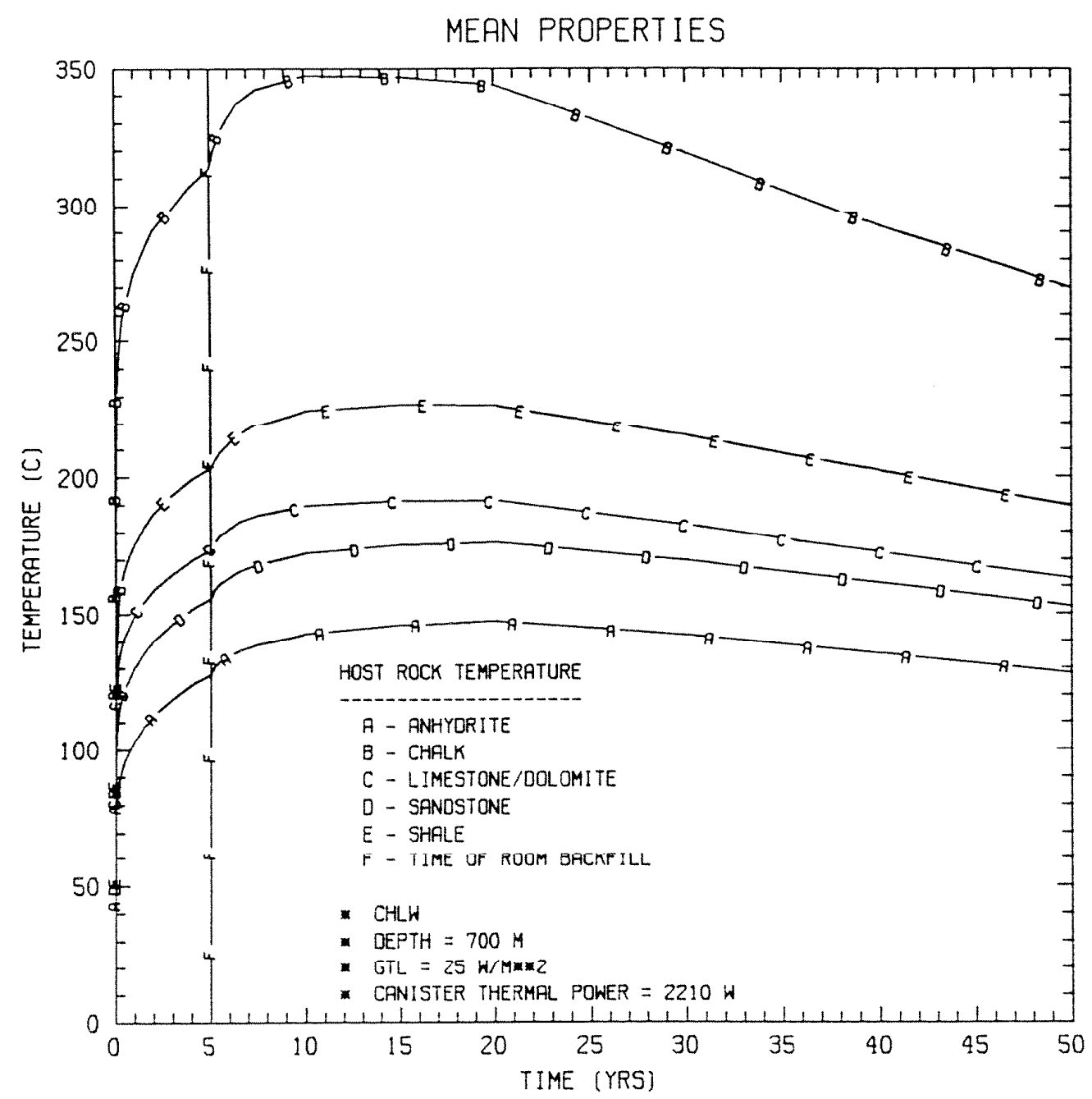

Fig. G.12.4.5. Expected host rock temperature for commercial highlevel waste emplacement in five sedimentary rock types. 
ORNL DWG 85-196

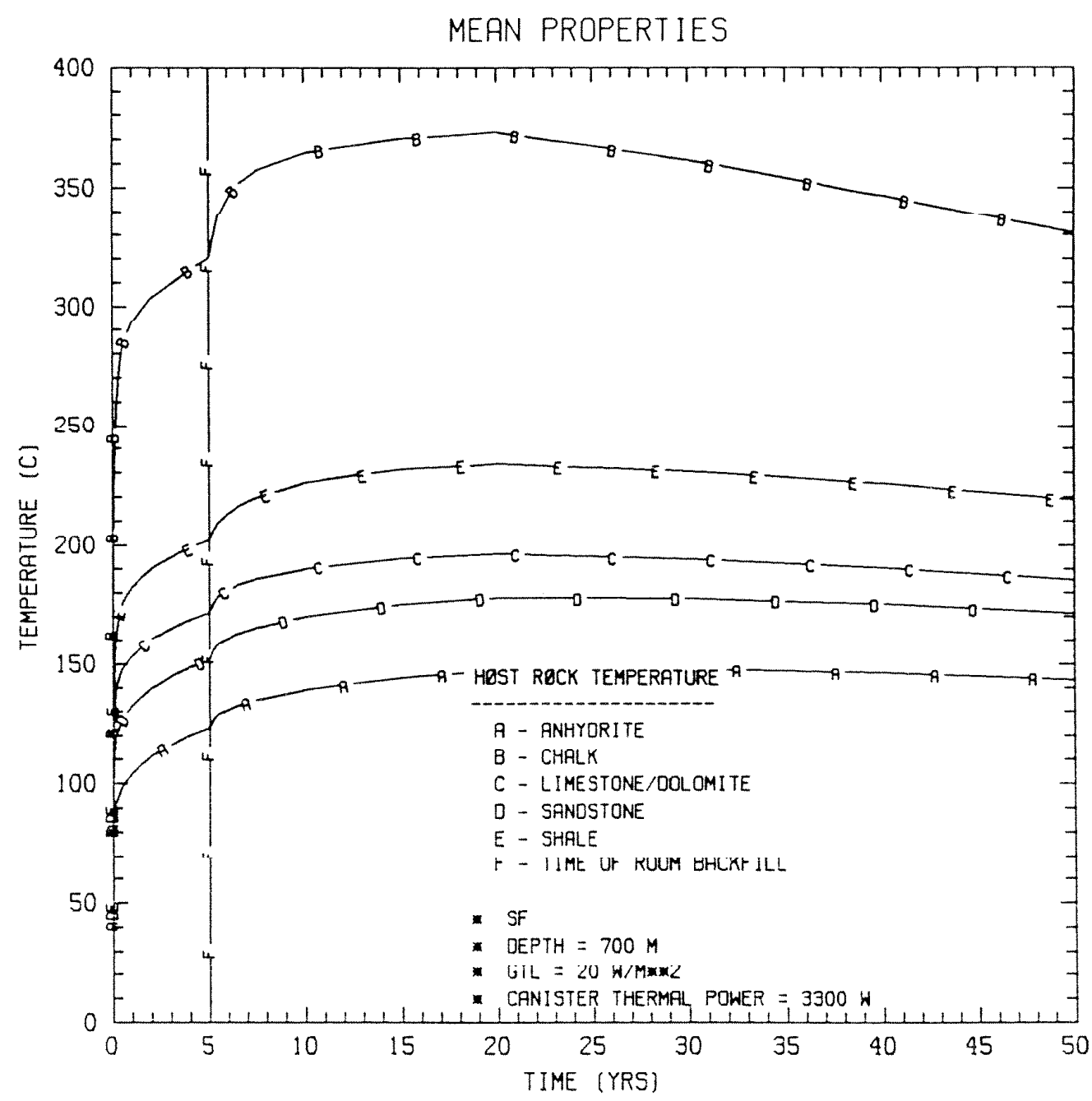

Fig. G.12.4.6. Expected host rock temperature for spent fuel emplacement in five sedimentary rock types. 
ORNL DWG 85-197

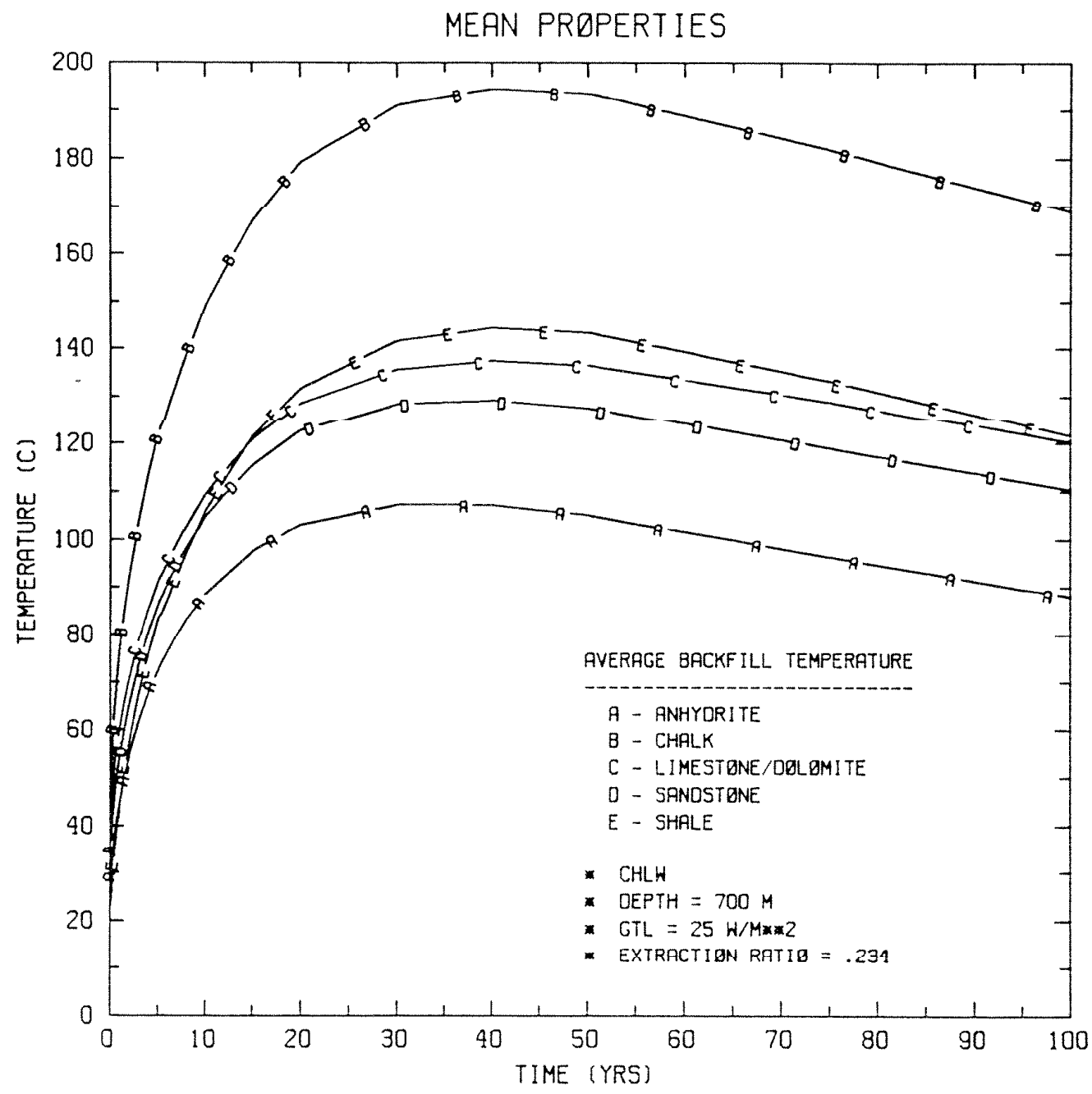

Fig. G.12.4.7. Expected room backfill temperature for commercial high-level waste emplacement in five sedimentary rock types. 
ORNL DWG 85-198

MEAN PROPERTIES

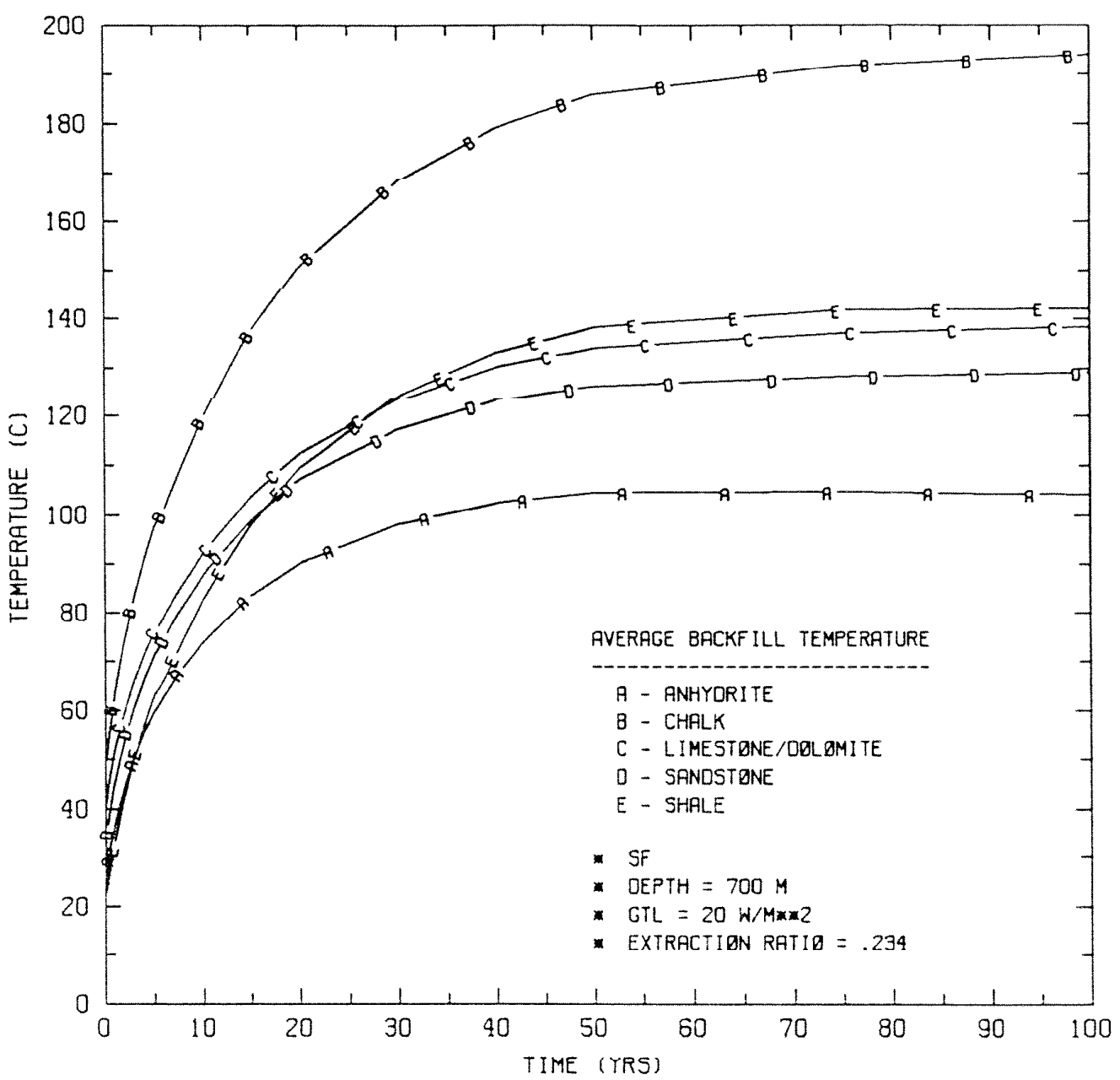

Fig. G.12.4.8. Expected room backfill temperature for spent fuel emplacement in five sedimentary rock types. 
ORNL DWG 85-199

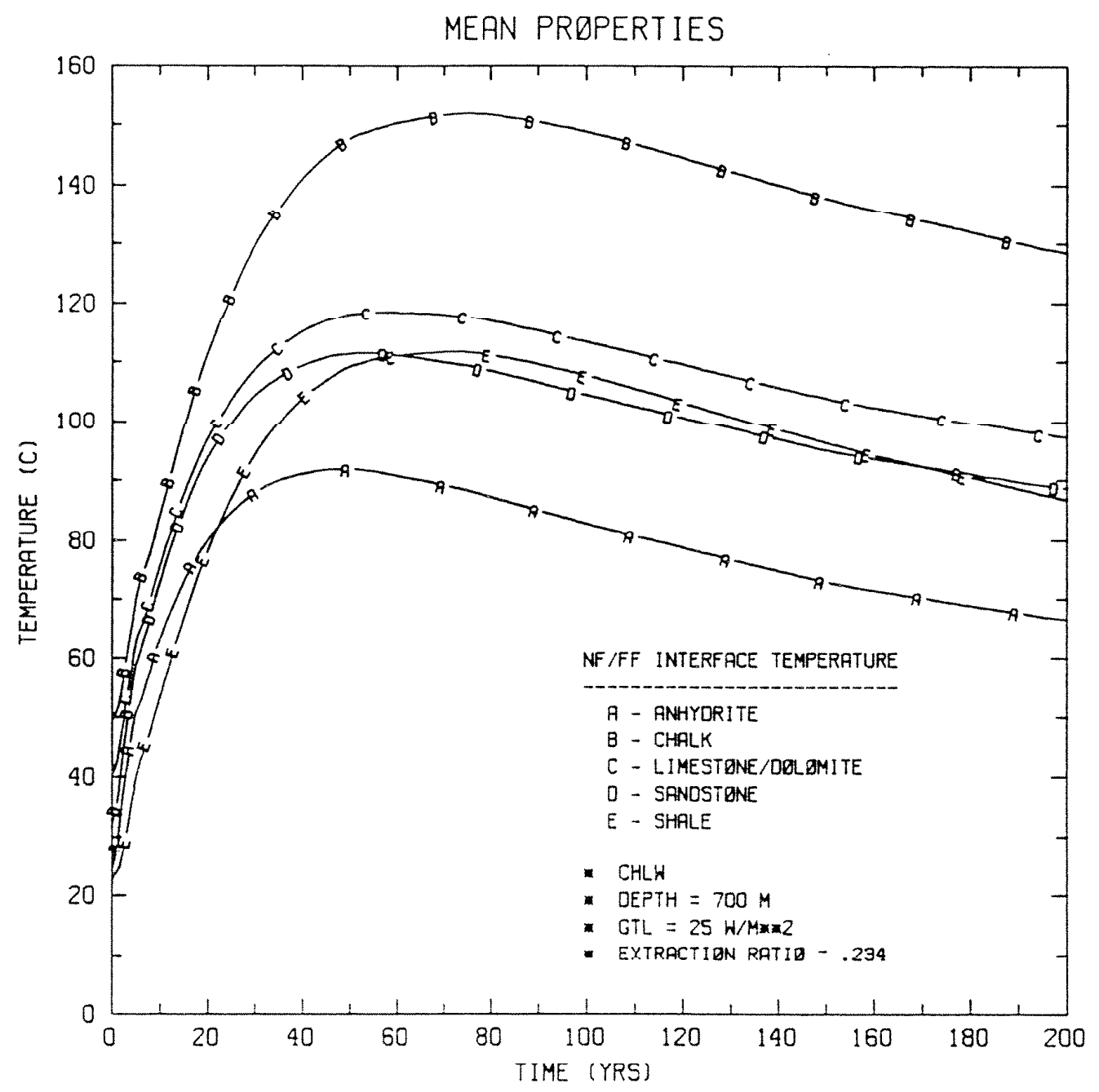

Fig. G.12.4.9. Expected near-field/far-field interface temperature for commercial high-level waste emplacement in five sedimentary rock types. 
ORNL DWG 85-200

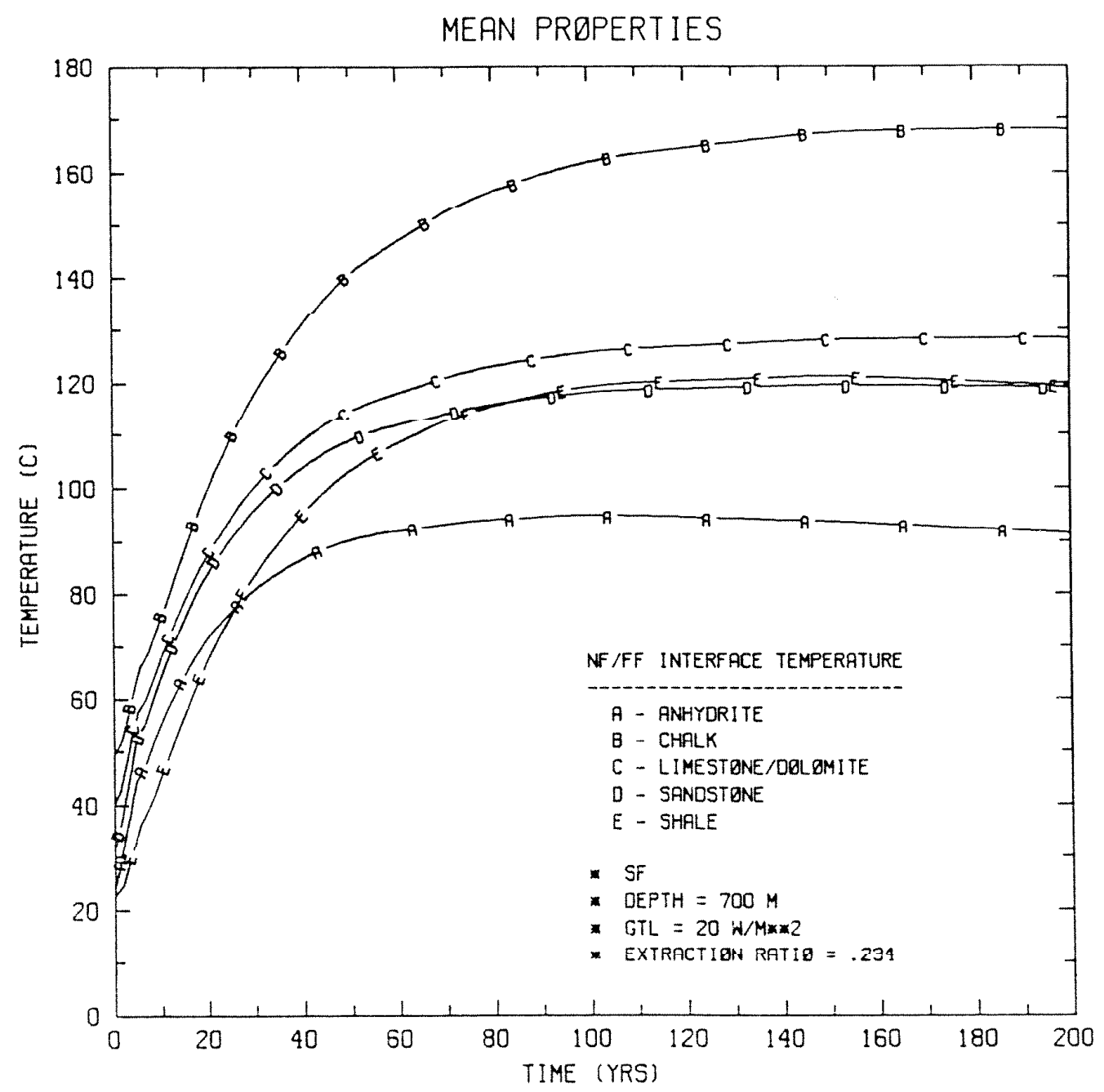

Fig. G.12.4.10. Expected near-field/far-field interface temperature for spent fuel emplacement in five sedimentary rock types. 
MEAN PROPERTIES

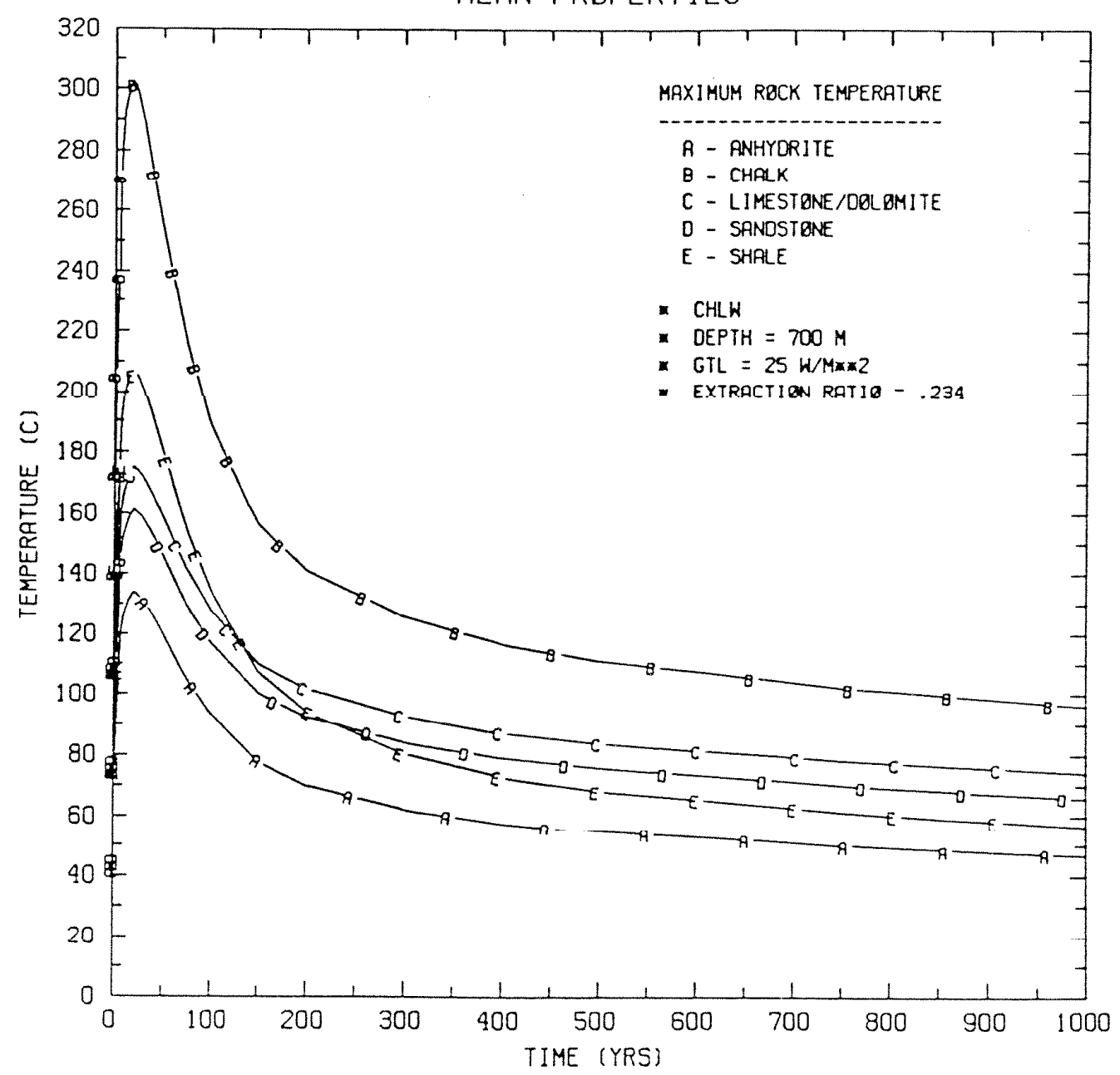

Fig. G.12.4.11. Expected isolation period host rock temperature for commercial high-1evel waste emplacement in five sedimentary rock types. 


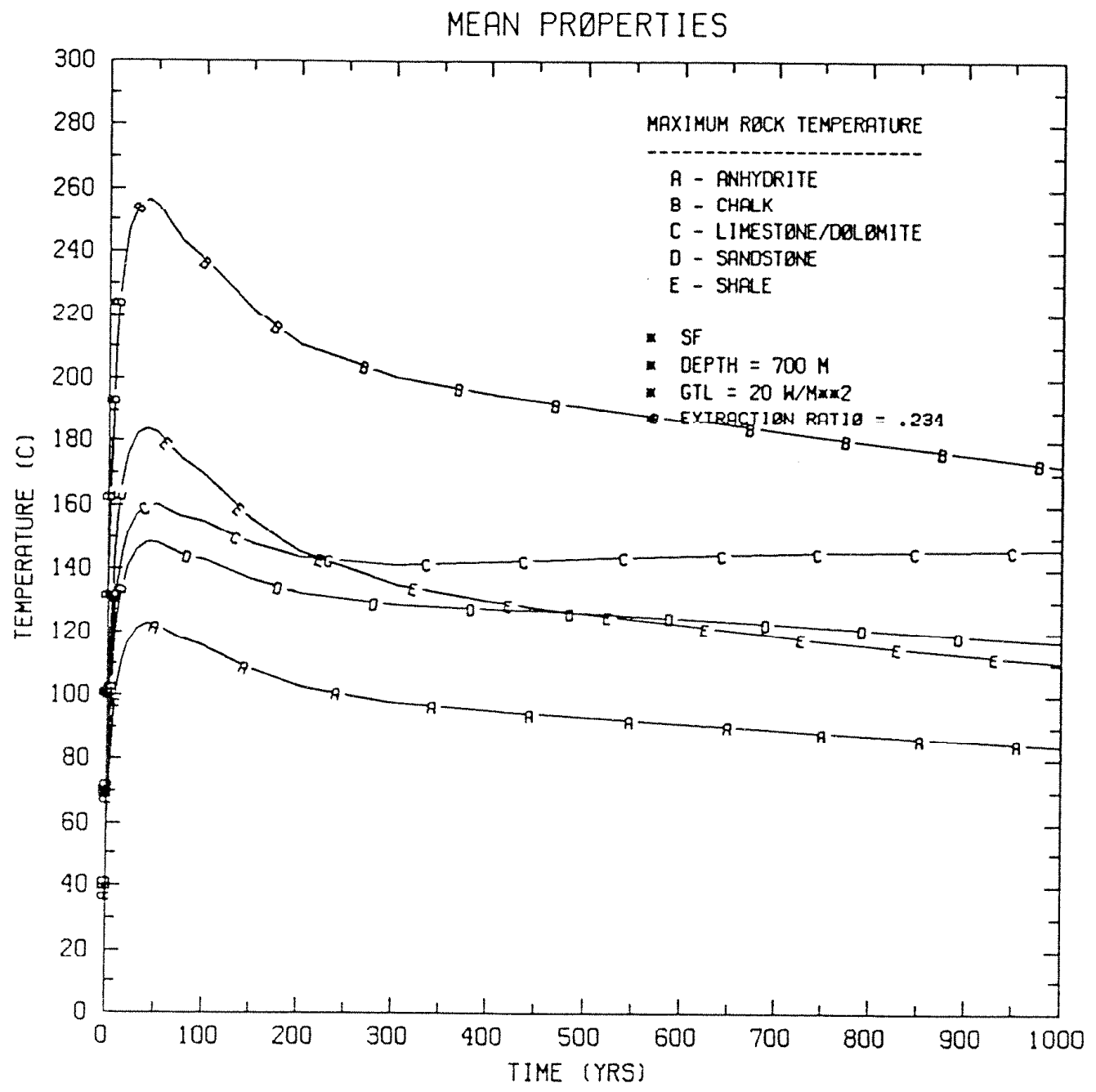

Fig. G.12.4.12. Expected isolation period host rock temperature for spent fuel emplacement in five sedimentary rock types. 


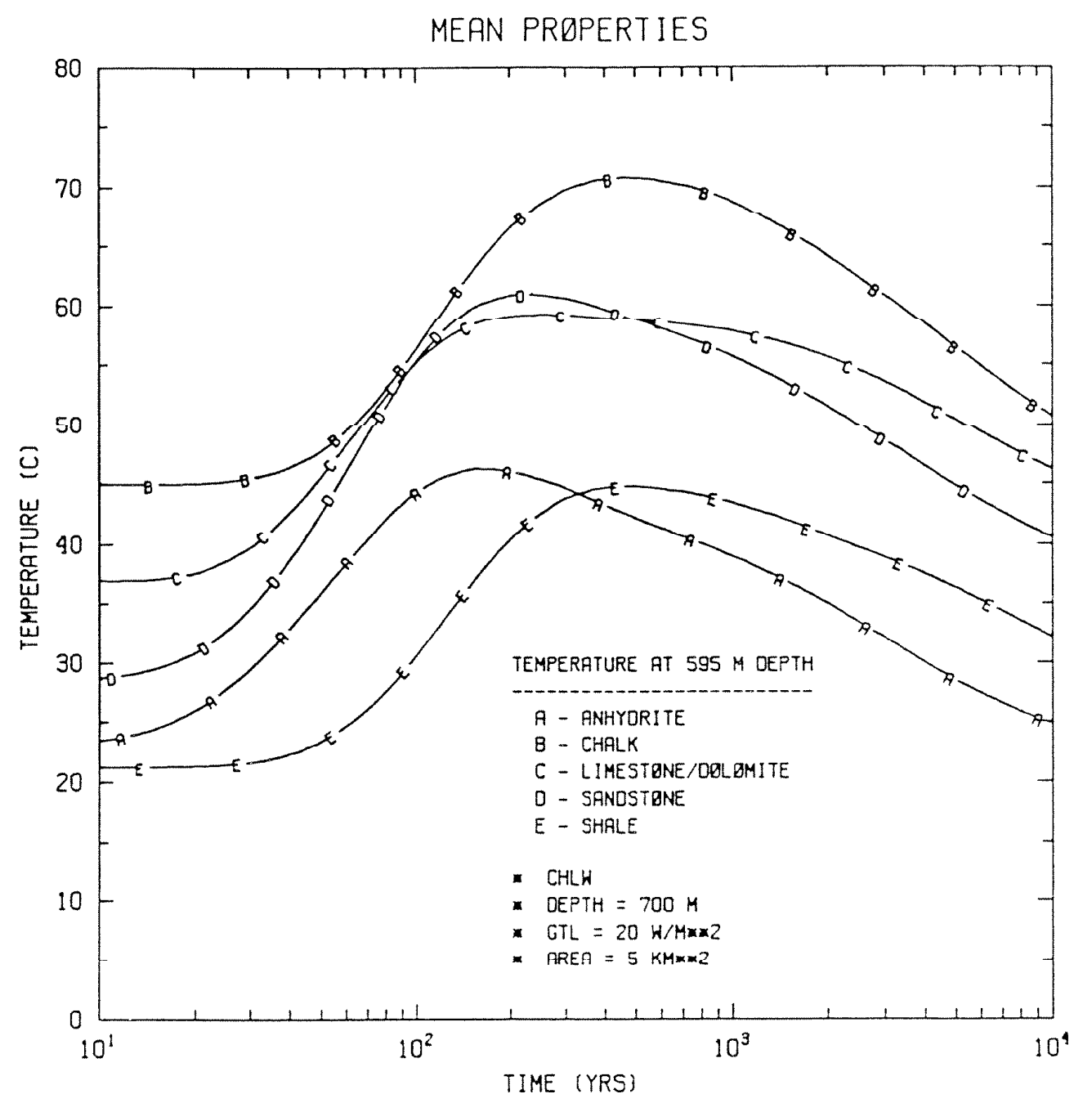

Fig. G.12.4.13. Expected temperature at 595-m depth for commercial high-level waste emplacement in five sedimentary rock types. 
ORNL DWG $85-205$

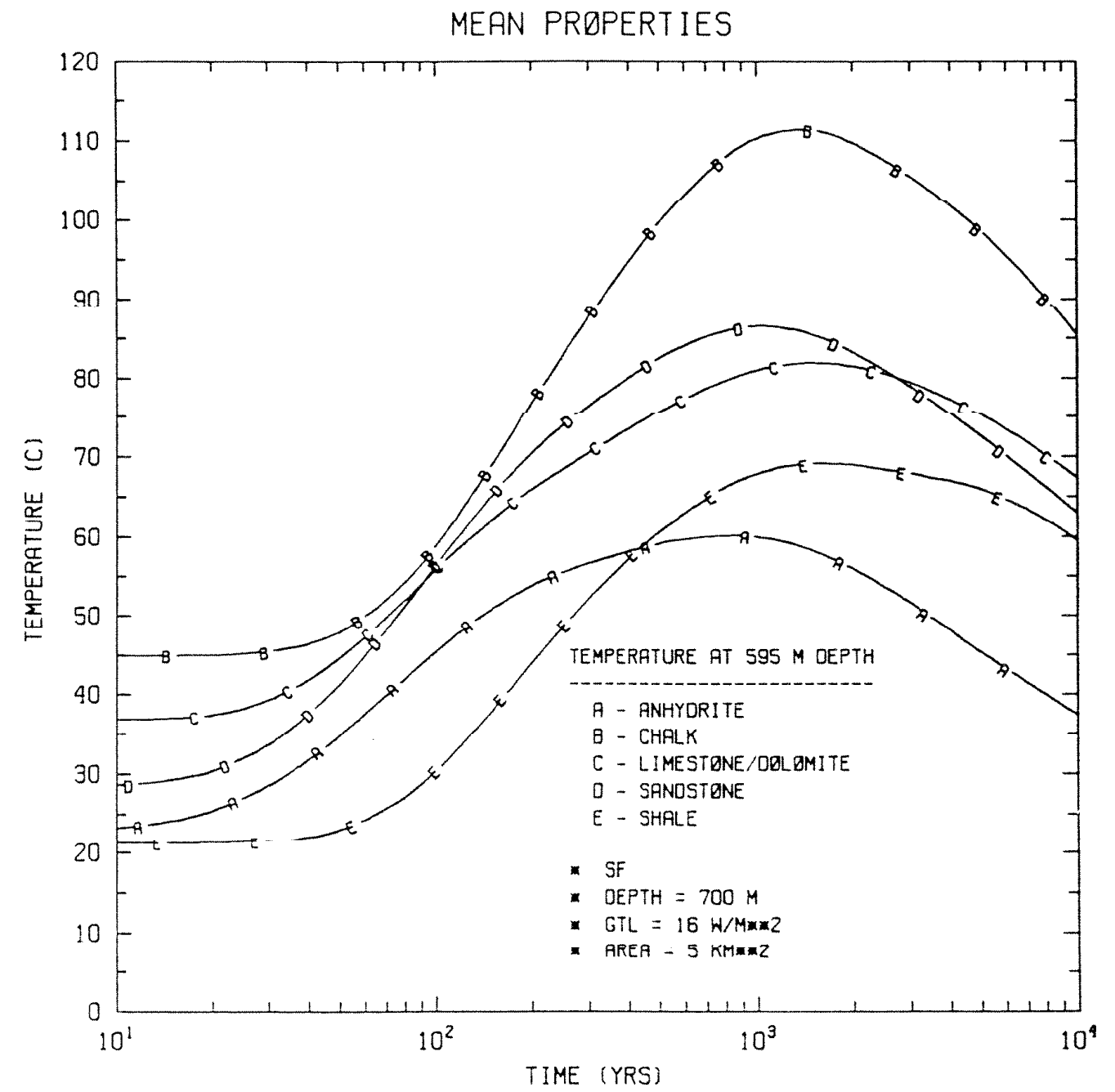

Fig. G.12.4.14. Expected temperature at 595-m depth for spent fue1 emplacement in five sedimentary rock types. 
ORNL DWG $85-206$

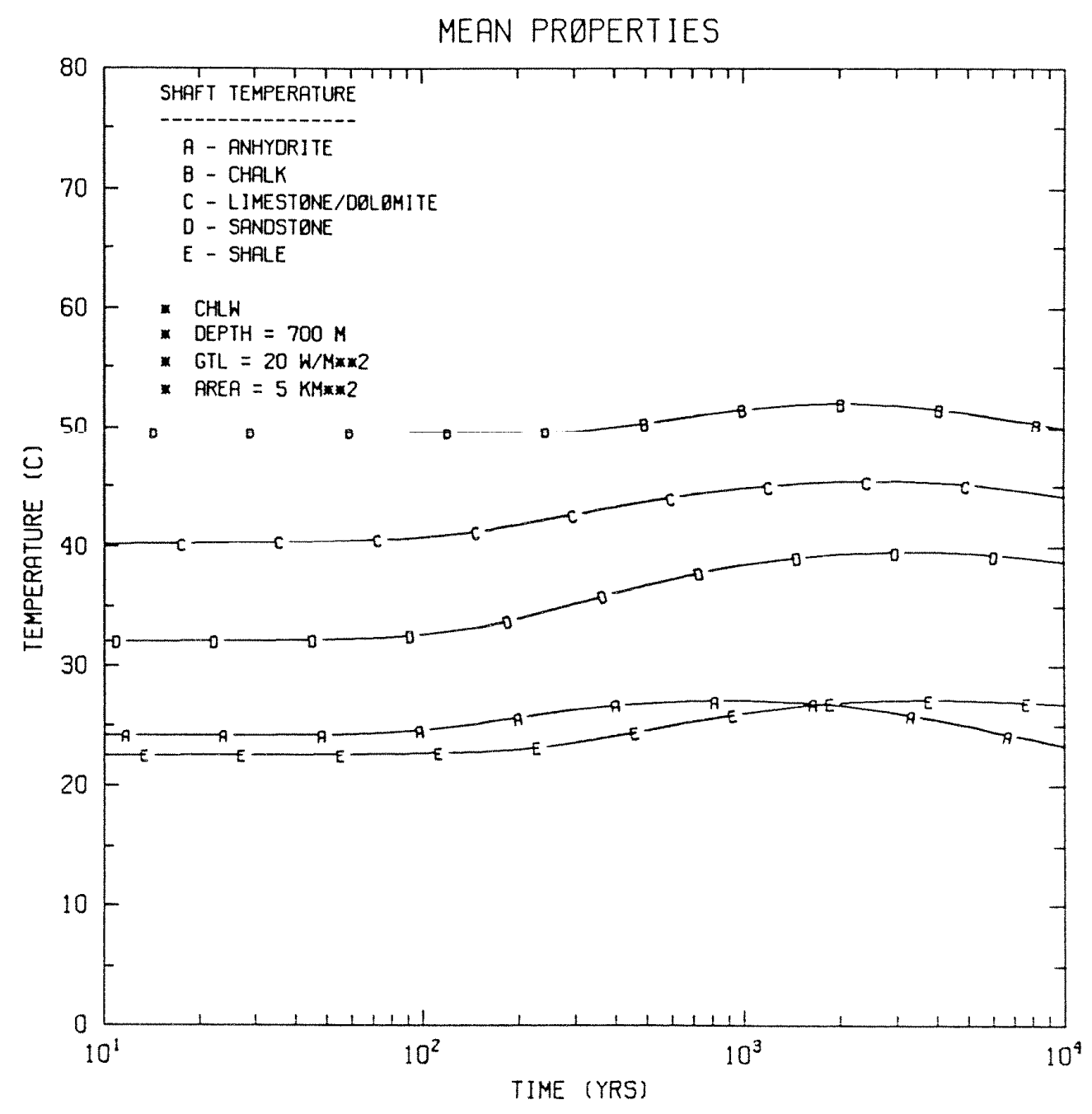

Fig. G.12.4.15. Expected shaft temperature for commercial highlevel waste emplacement in five sedimentary rock types. 
ORNL DWG $85-207$

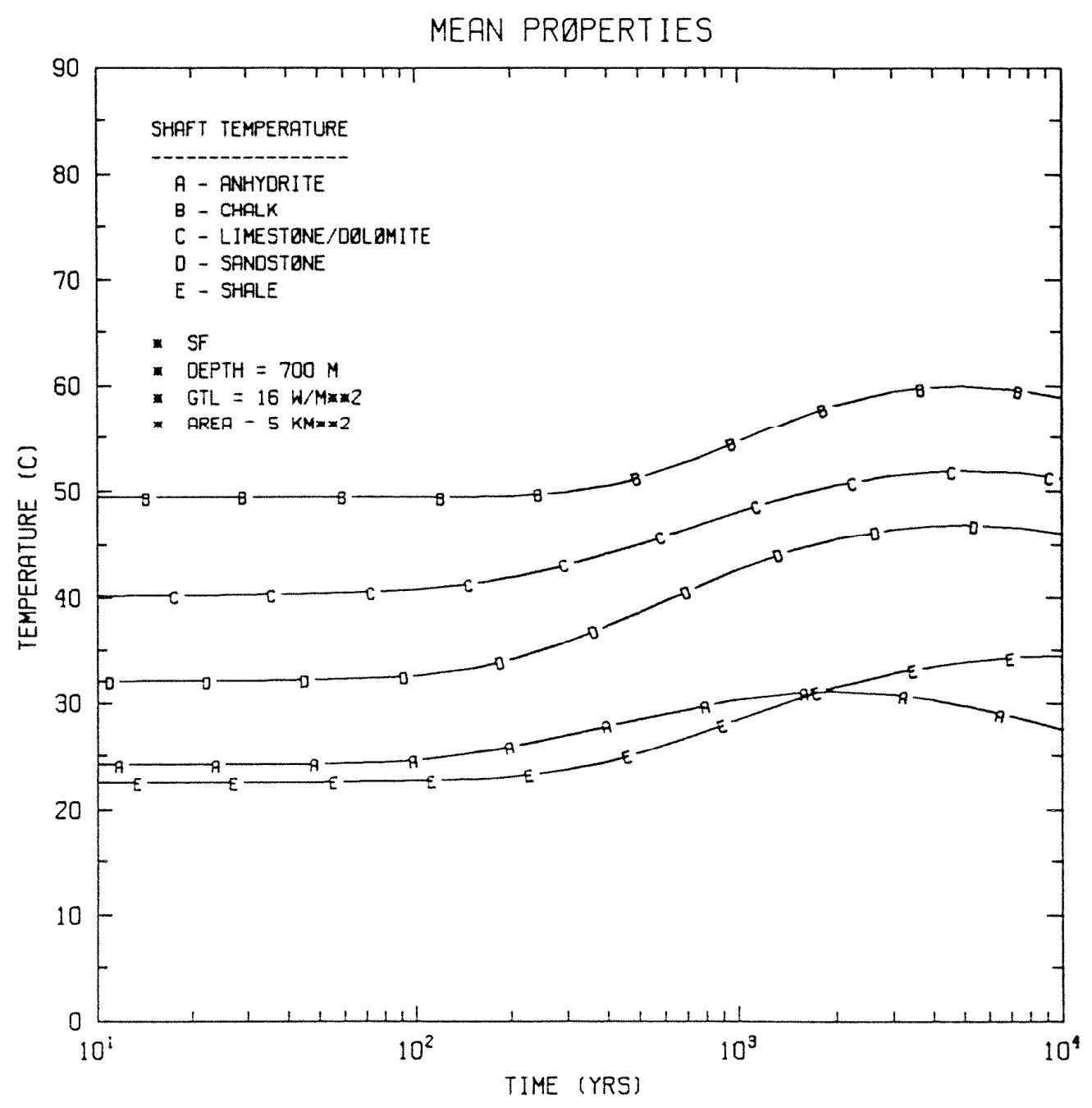

Fig. G.12.4.16. Expected shaft temperature for spent fuel emplacement in five sedimentary rock types. 
ORNL DWG $85-208$

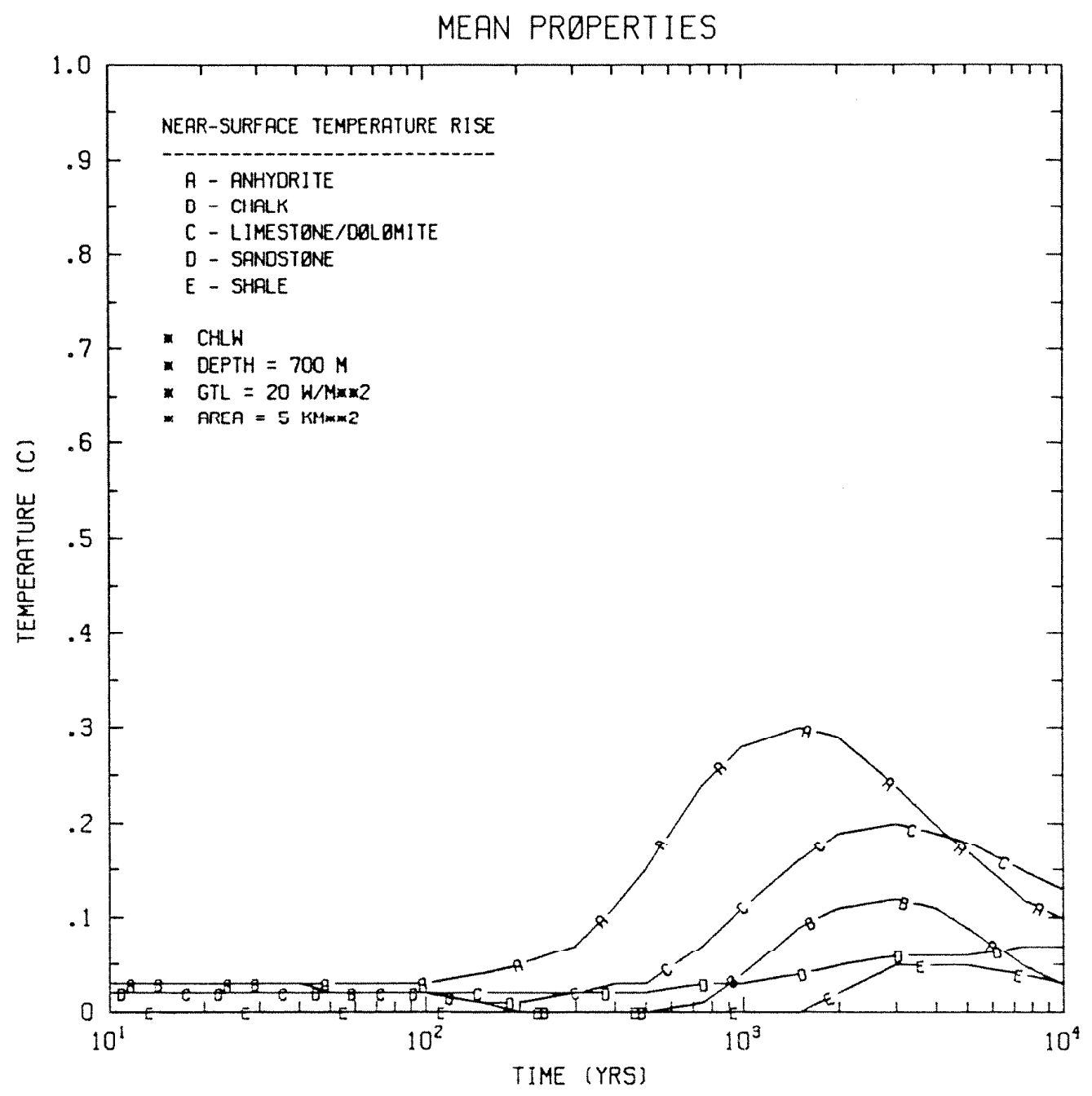

Fig. G.12.4.17. Expected near-surface temperature rise for commercial high-level waste emplacement in five sedimentary rock types. 
ORNL DWG $85-209$

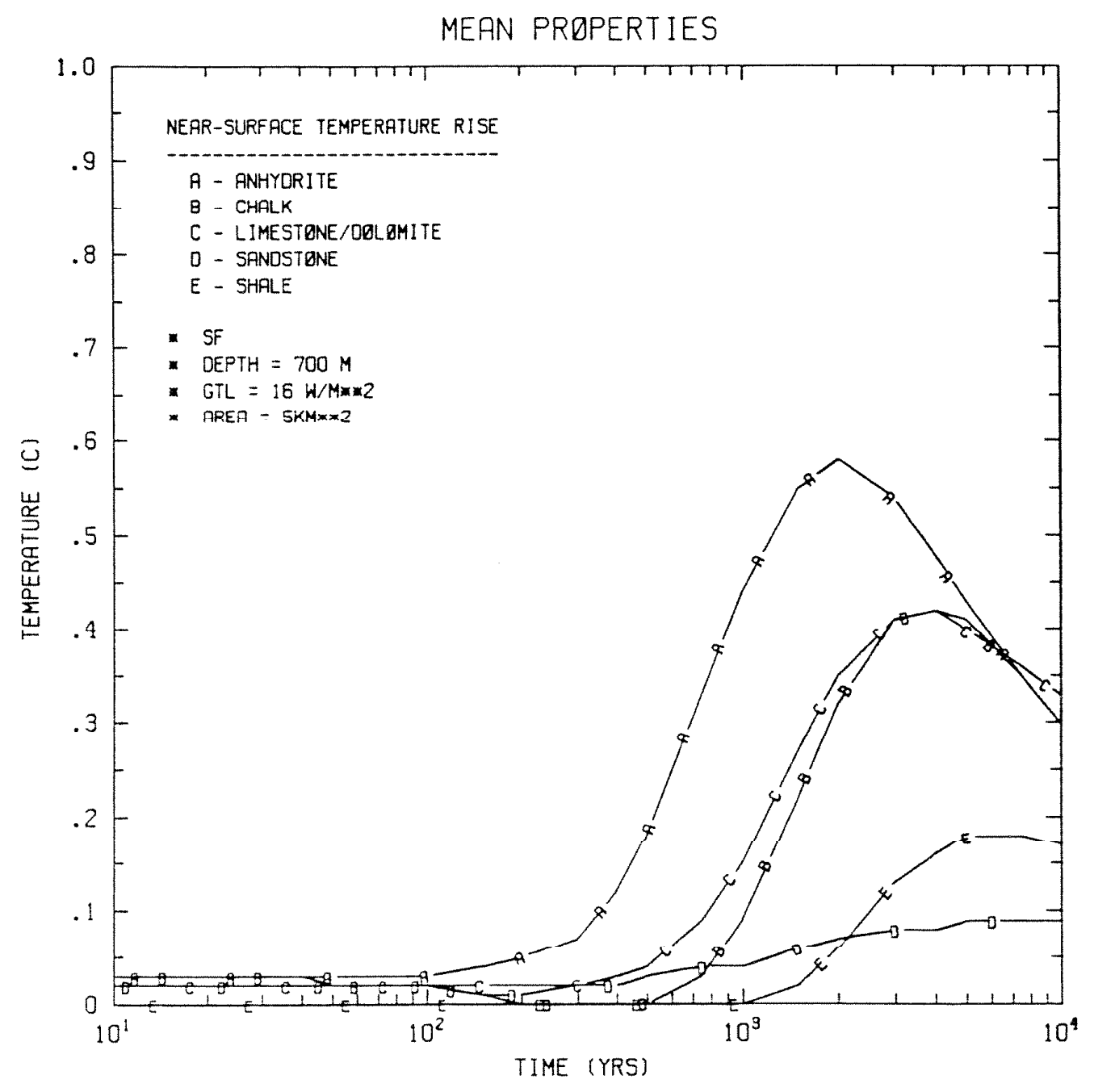

Fig. G.12.4.18. Expected near-surface temperature rise for spent fuel emplacement in five sedimentary rock types. 


\section{G.12.5 GENERIC ROCK TYPE MECHANICAL PROPERTIES}

This section presents the results of the literature search for mechanical properties of anhydrock, chalk, carbonate rocks (limestone/ dolostone), sandstone, and shale (argillaceous rock). Tables G.12.1 through $G .12 .6$ consist of data essentially taken from unconfined compressive strength tests performed on samples at room temperature. The statistics calculated for Tables 6.12 .7 through G.12.10 do not include data resulting from the saturated or partly saturated test samples. These data, in addition to specimen size and loading rate, were not used in the mechanical analyses. This additional information was available from the literature survey and is included in the tables for the sake of completeness and pussible future reference. Included in the section are:

- Data 1ists for each rock type (Tables G.12.1 through G.12.6.

- A summary of statistics for each mechanical property (Tables G.12.7 Lirough G.12.10).

- Frequency histograms illustrating the distribution of data points for each property (Figs. G.12.5.1 through G.12.5.3).

- References for Tables G.12.1 through G.12.6. 


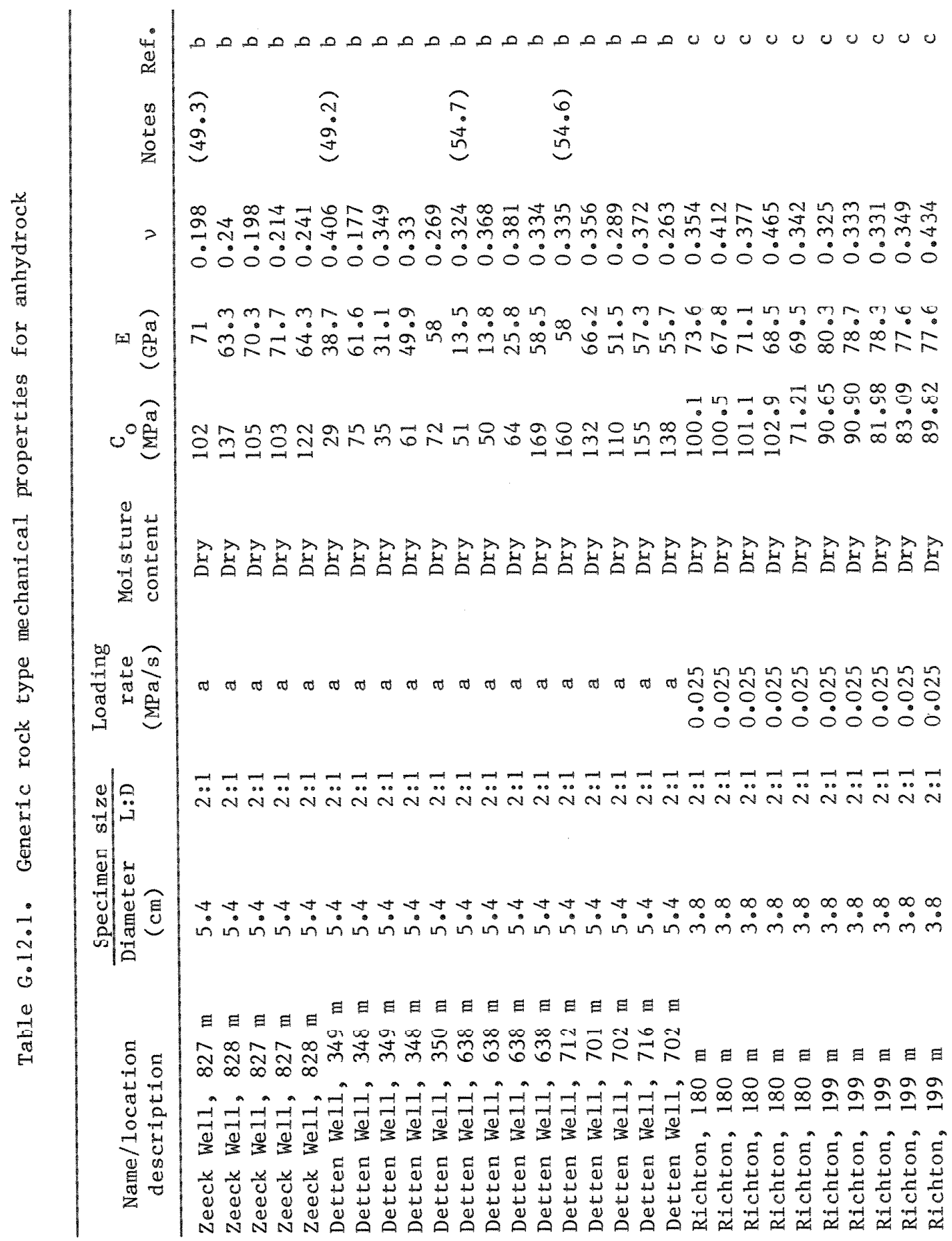




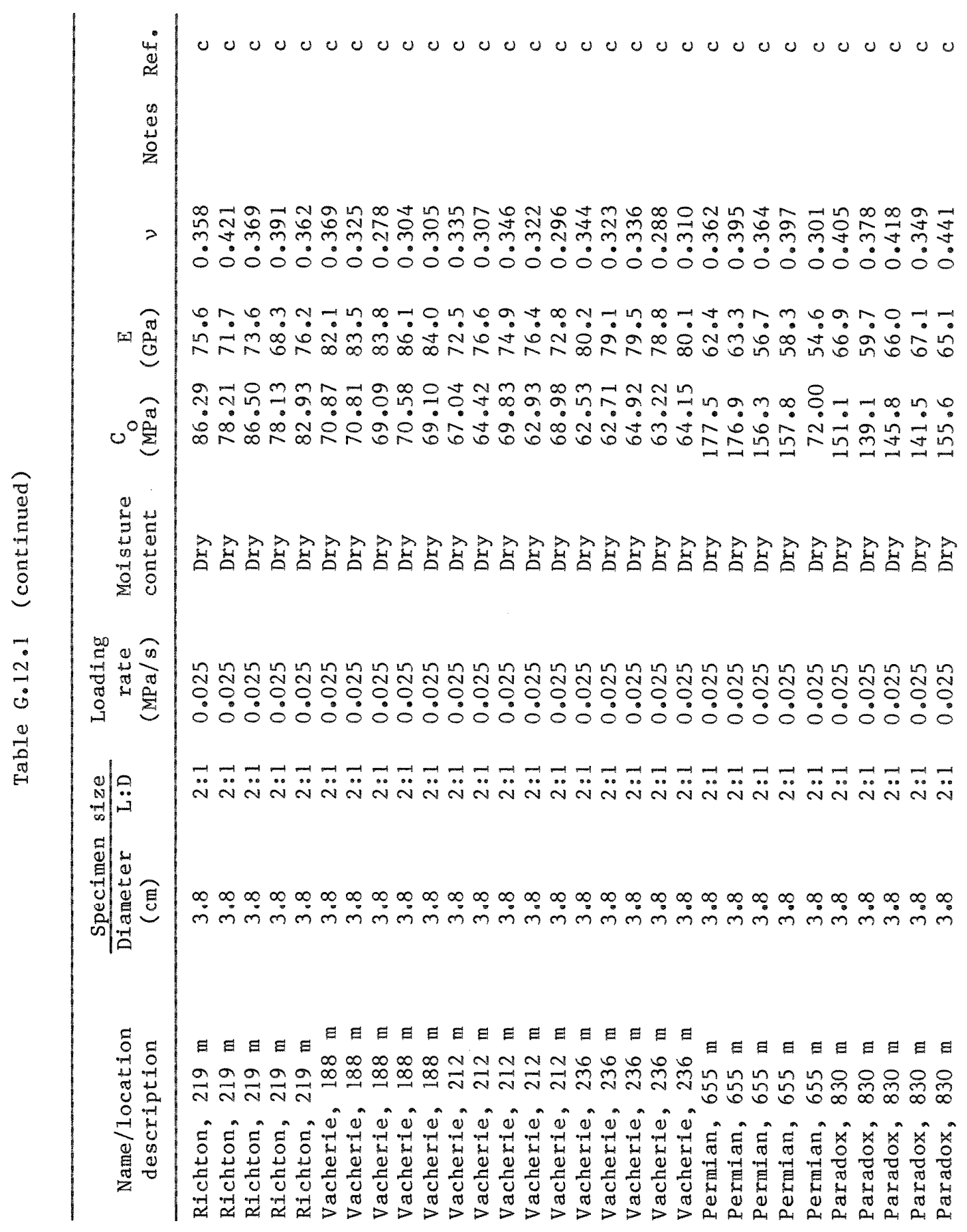




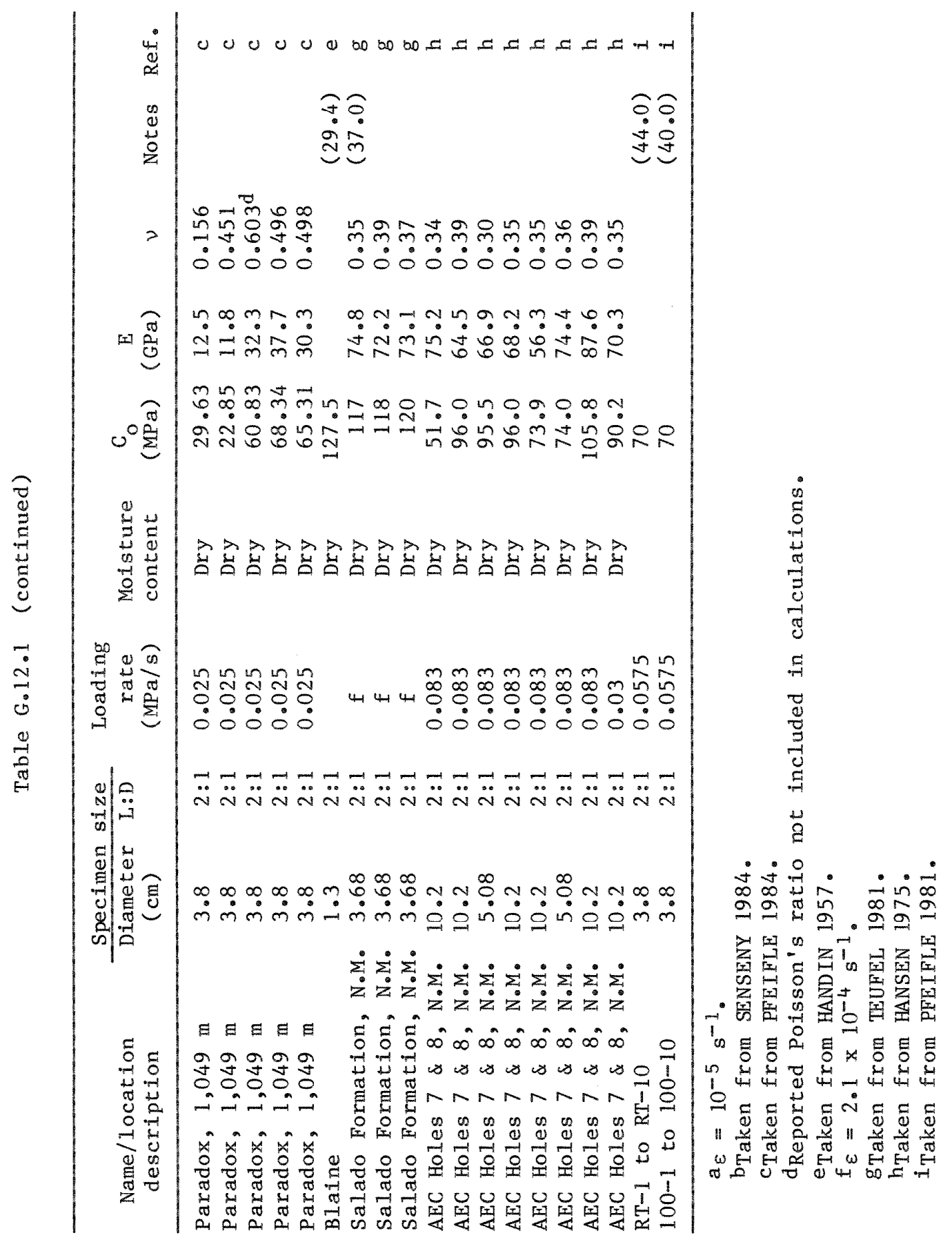




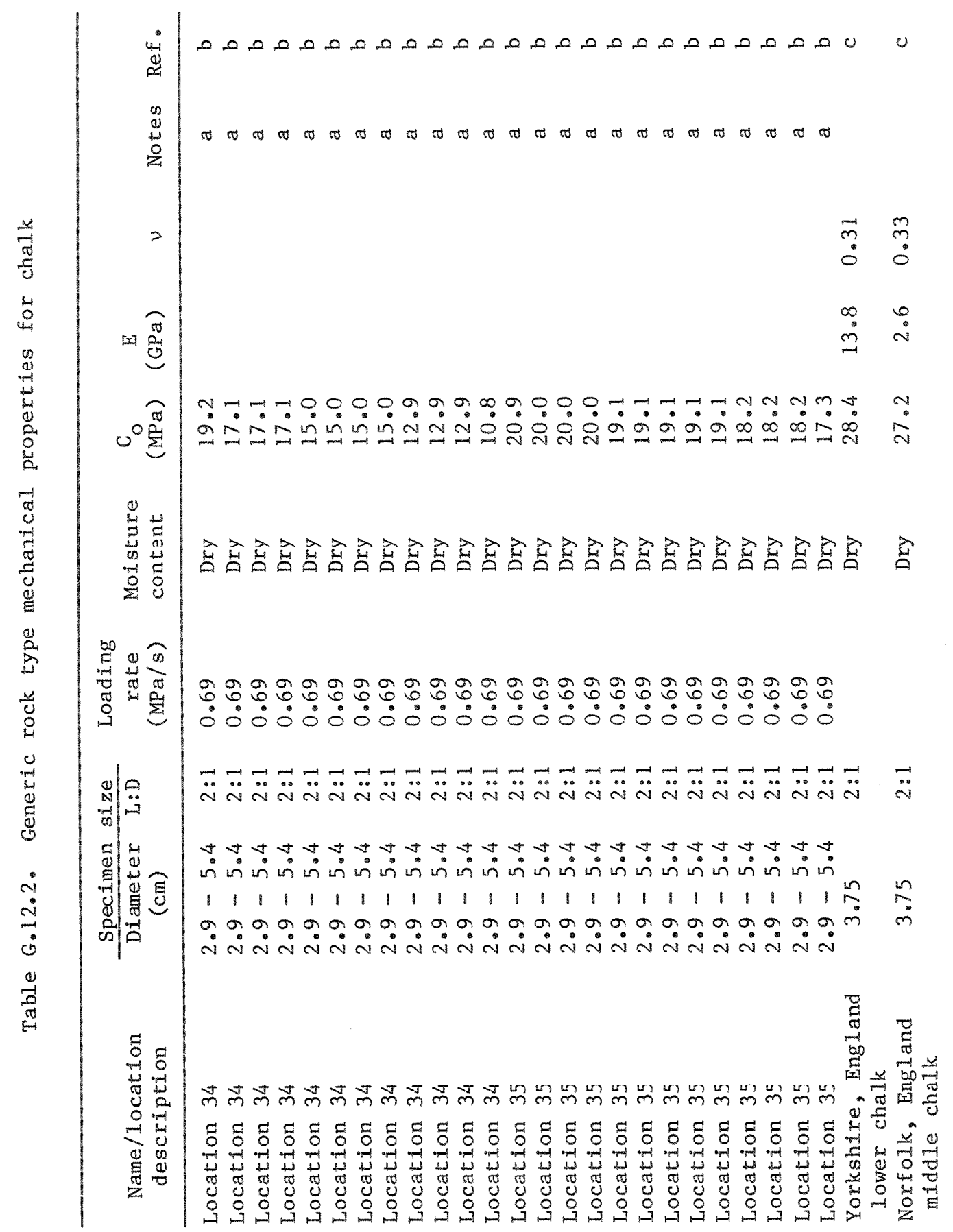




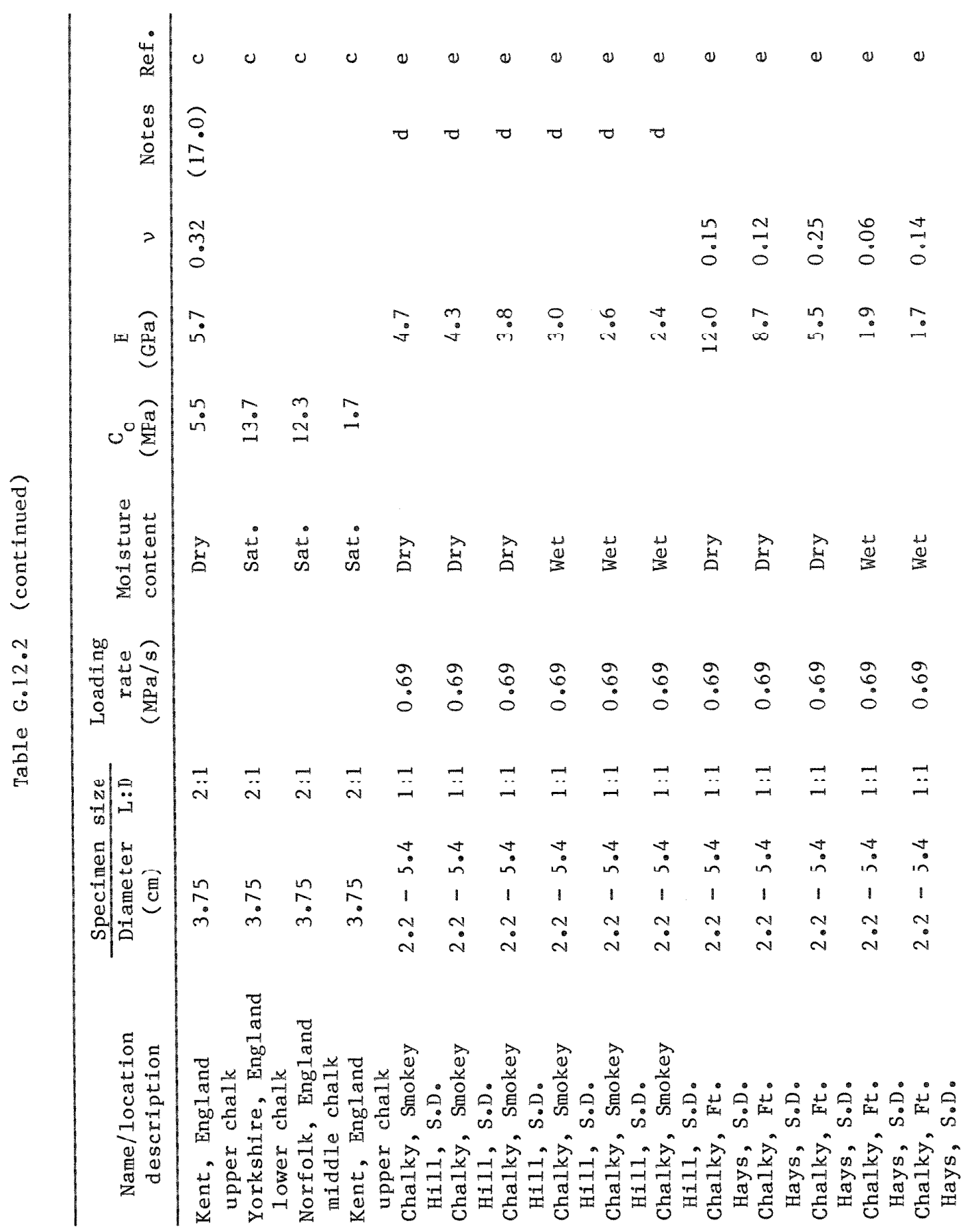




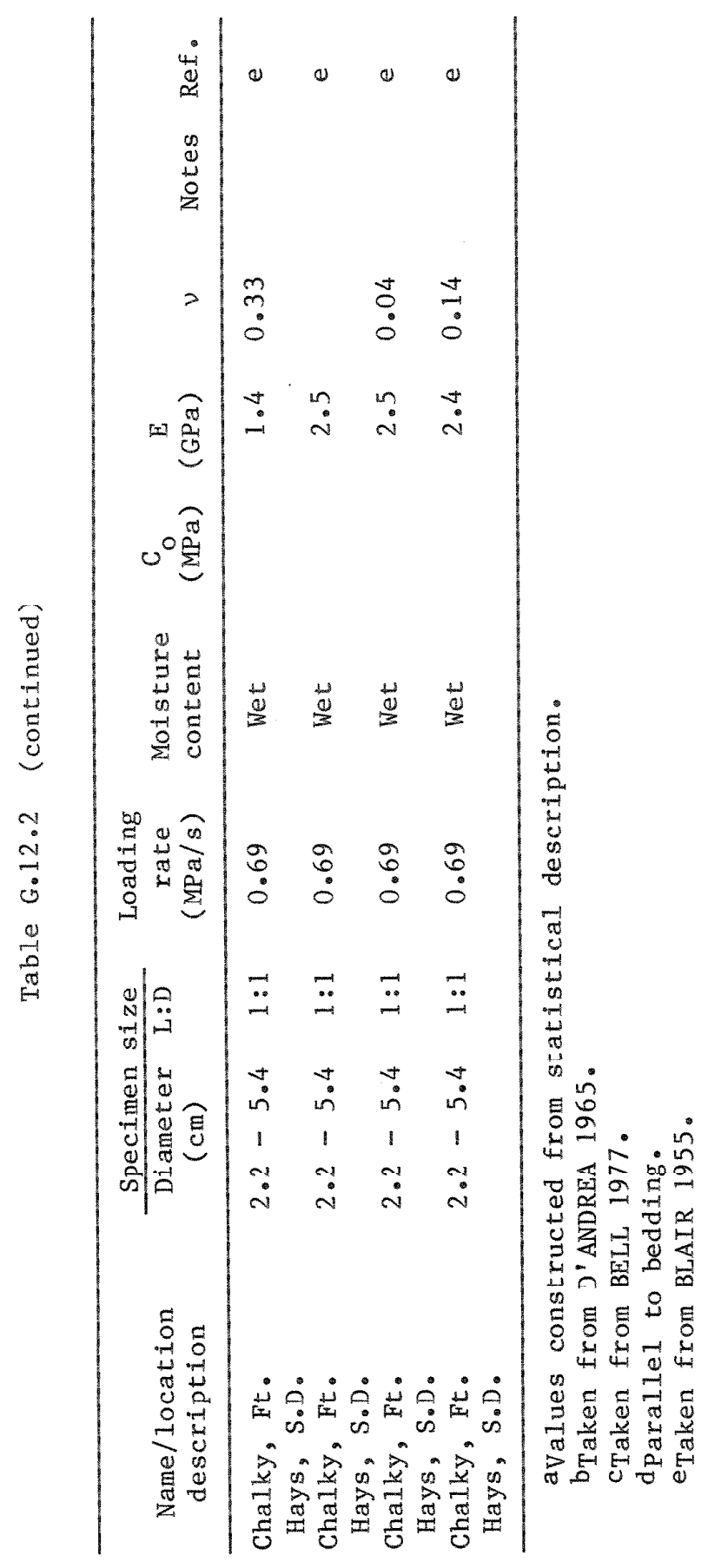




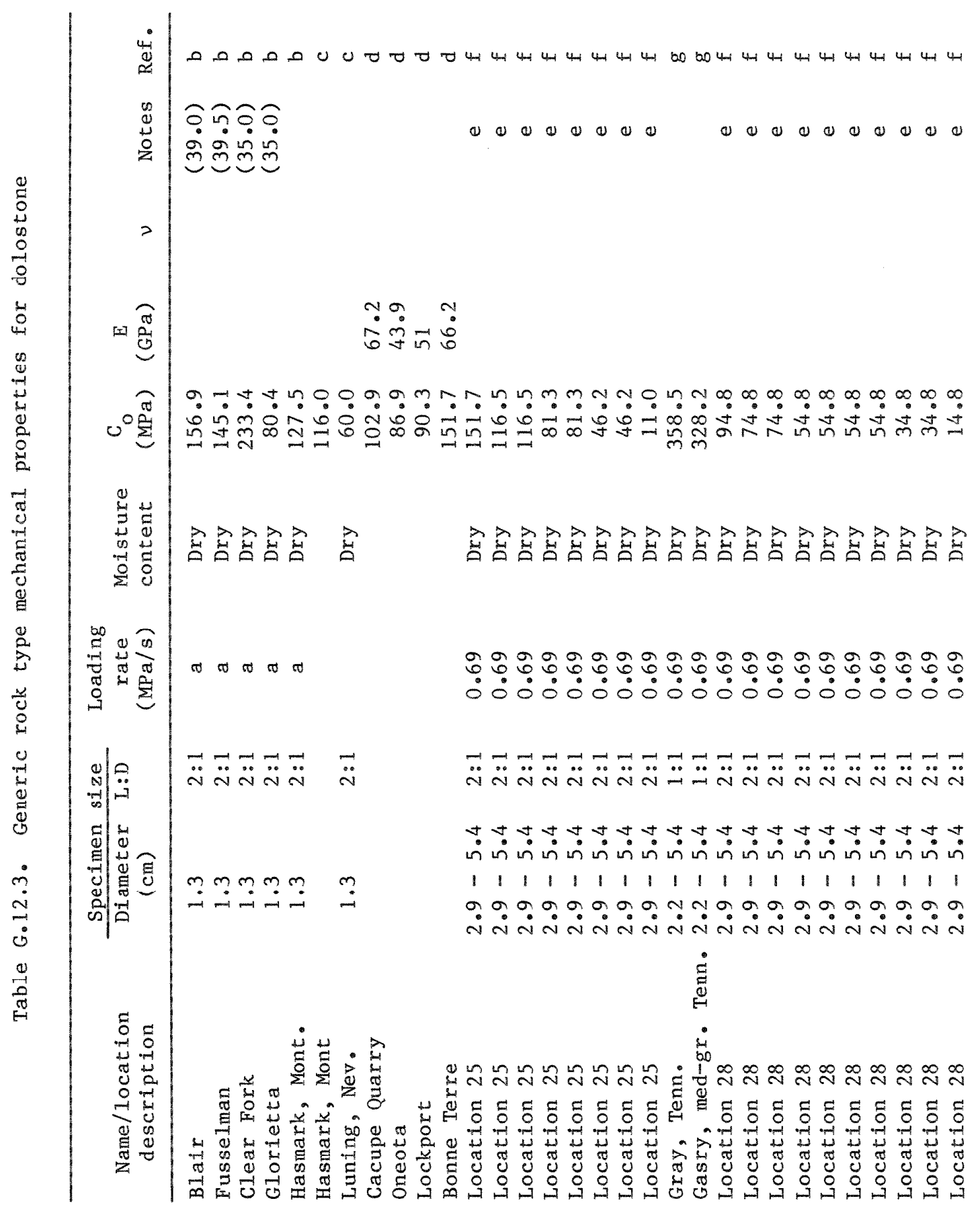




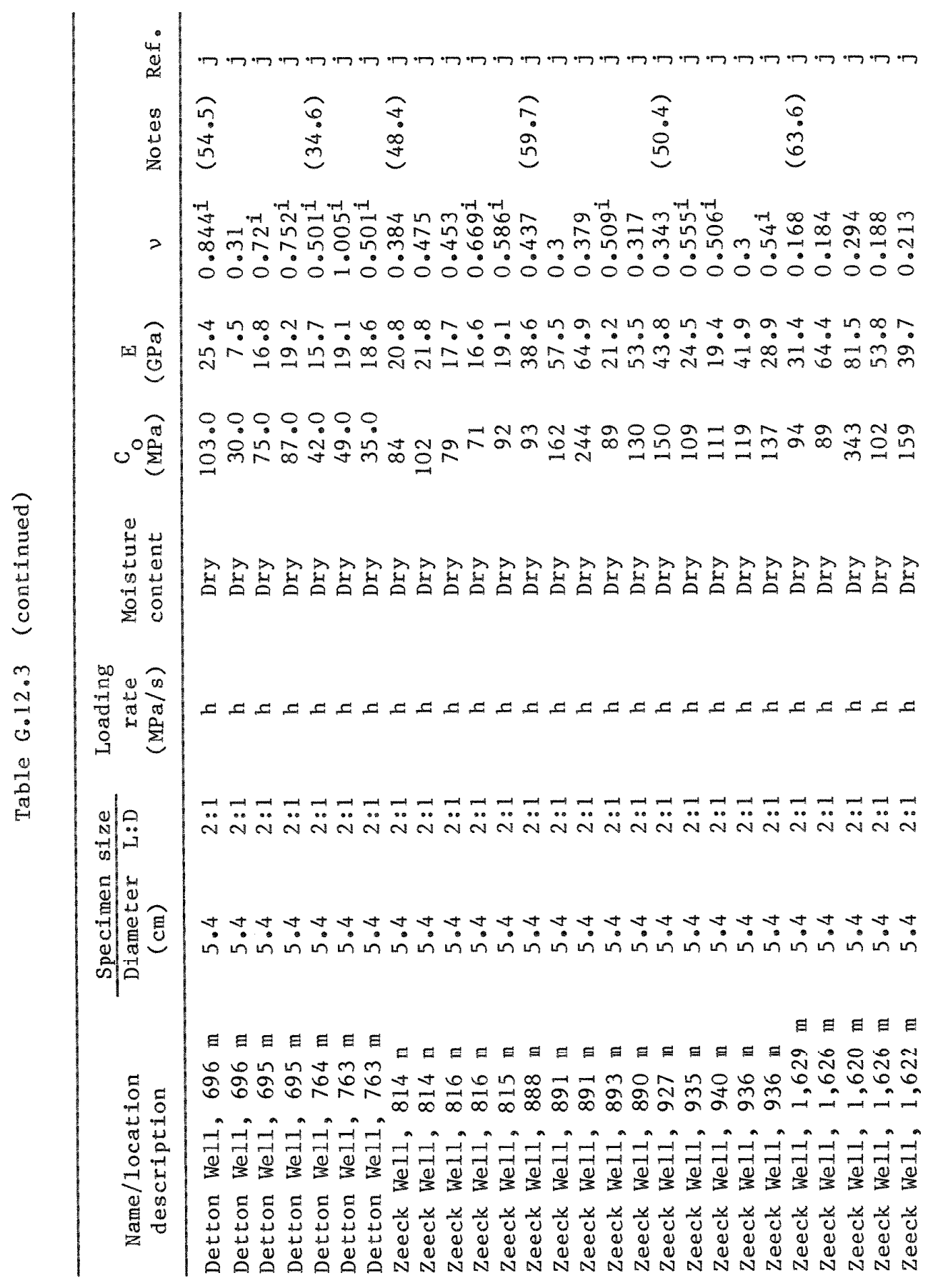




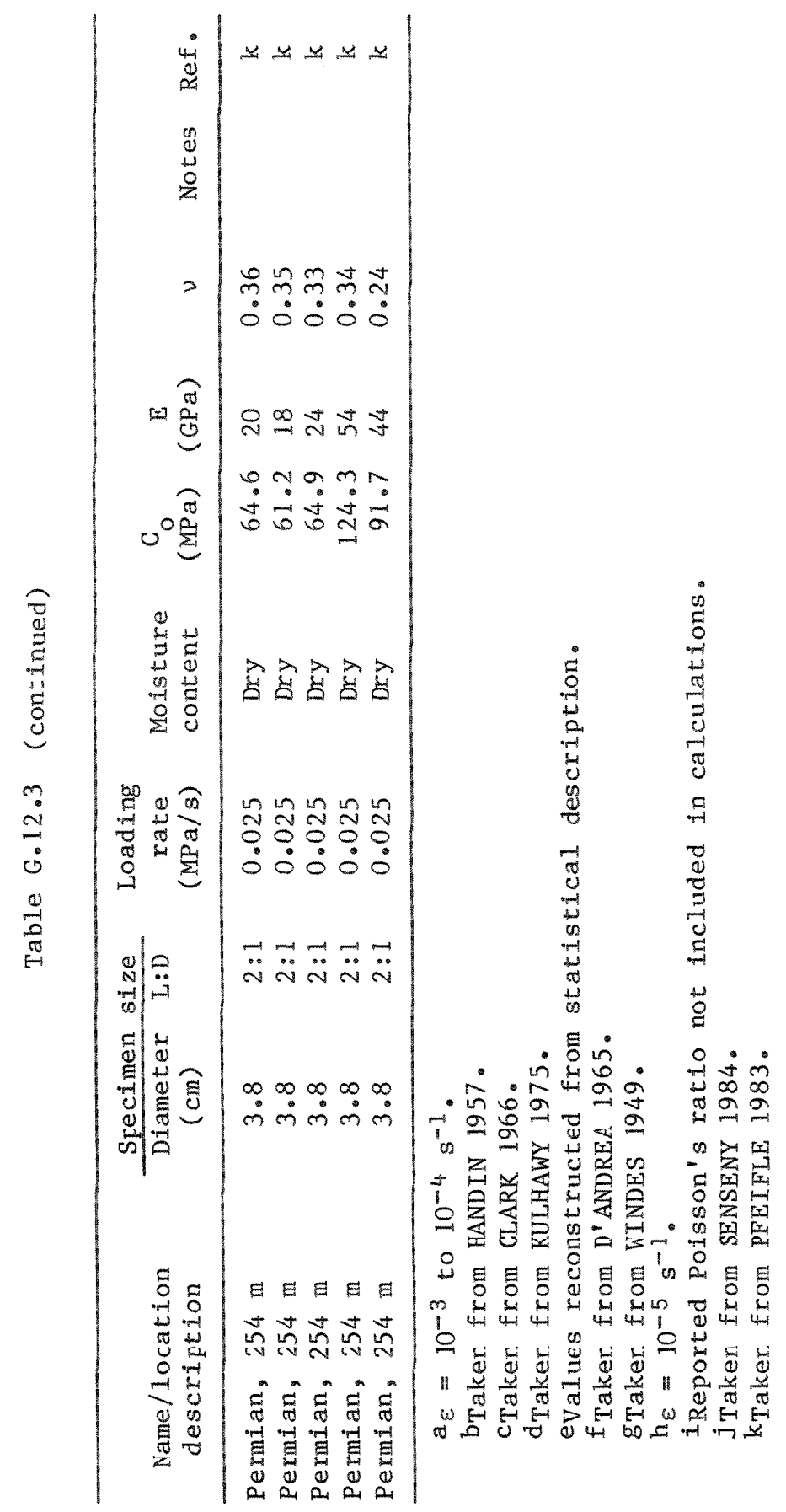




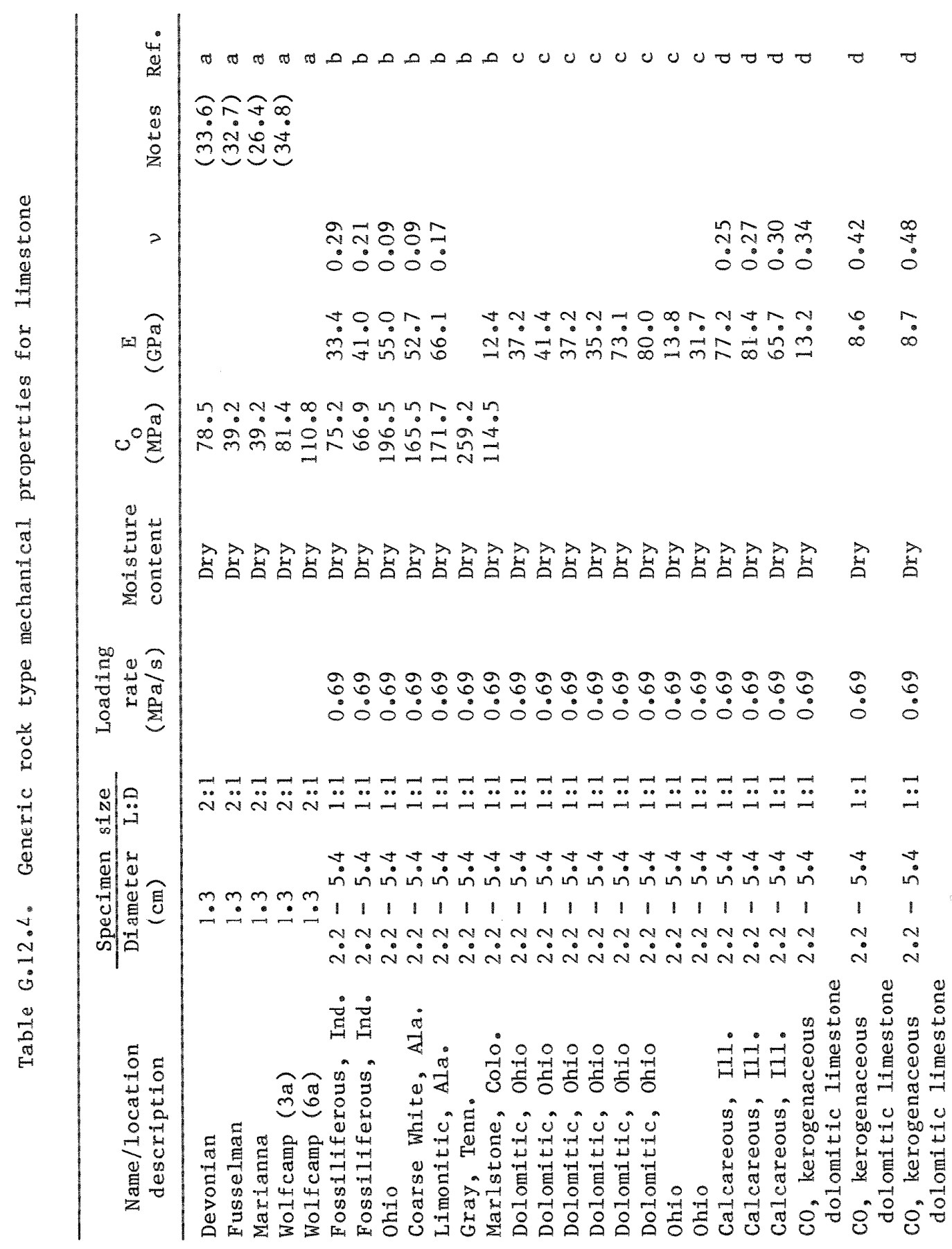




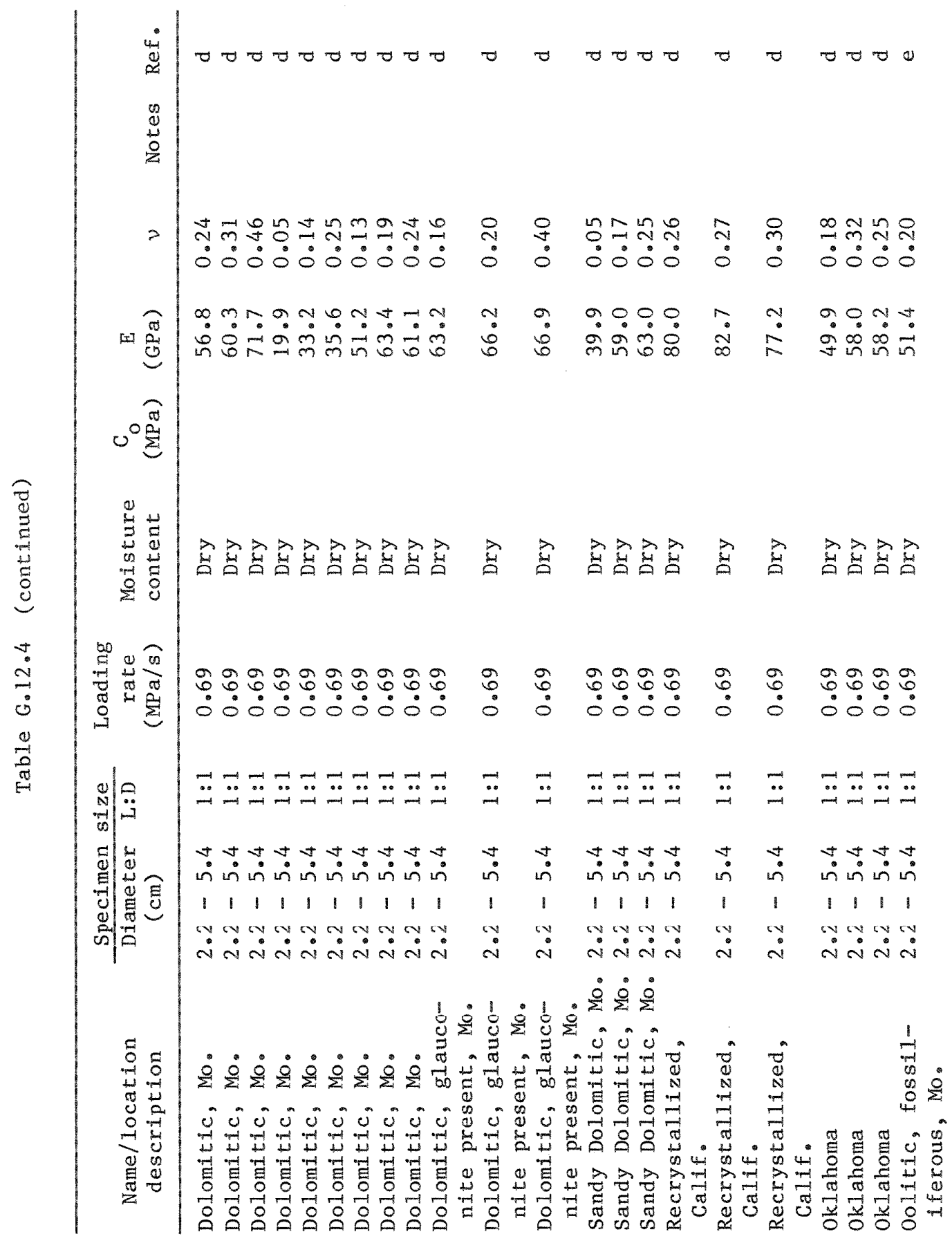




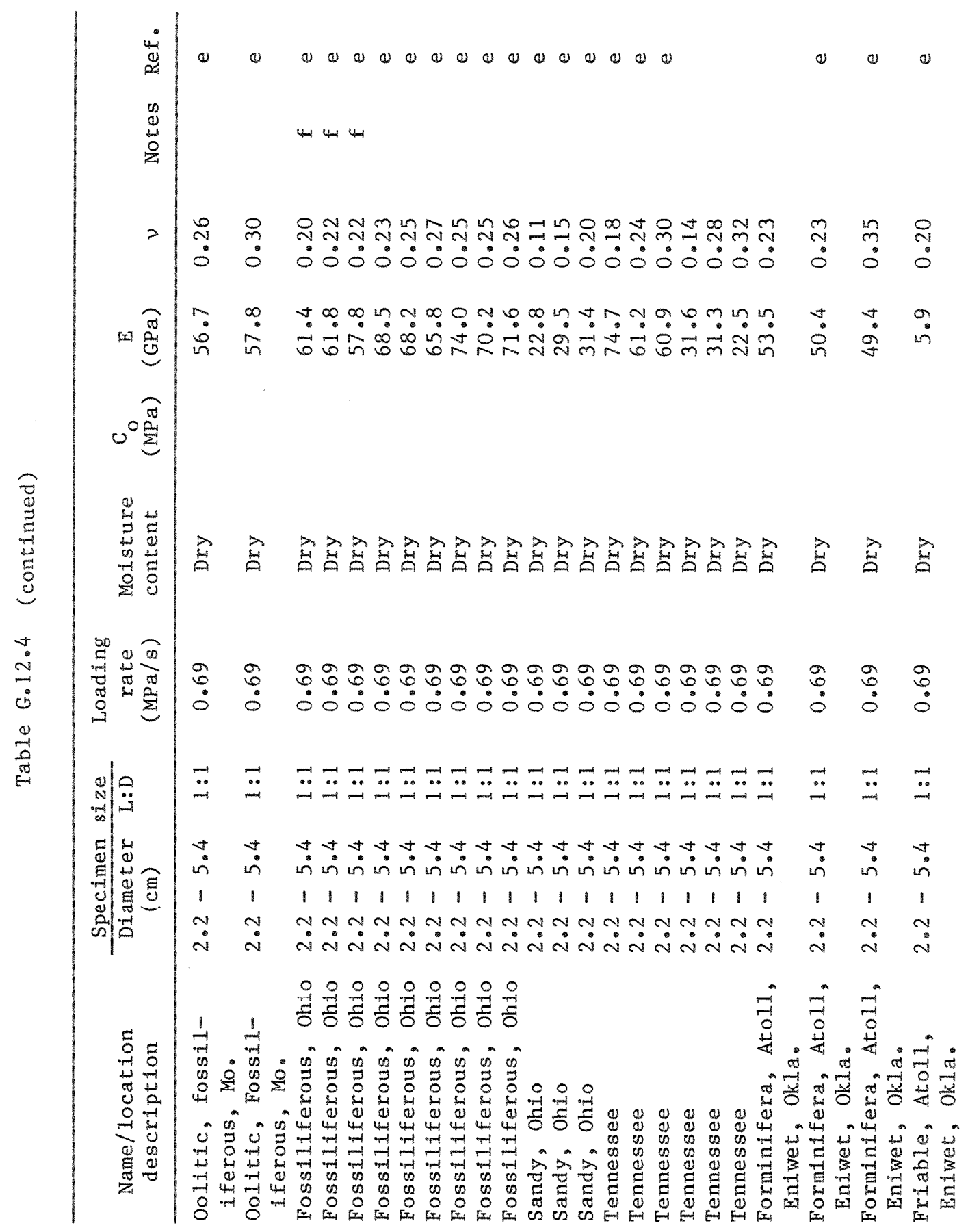




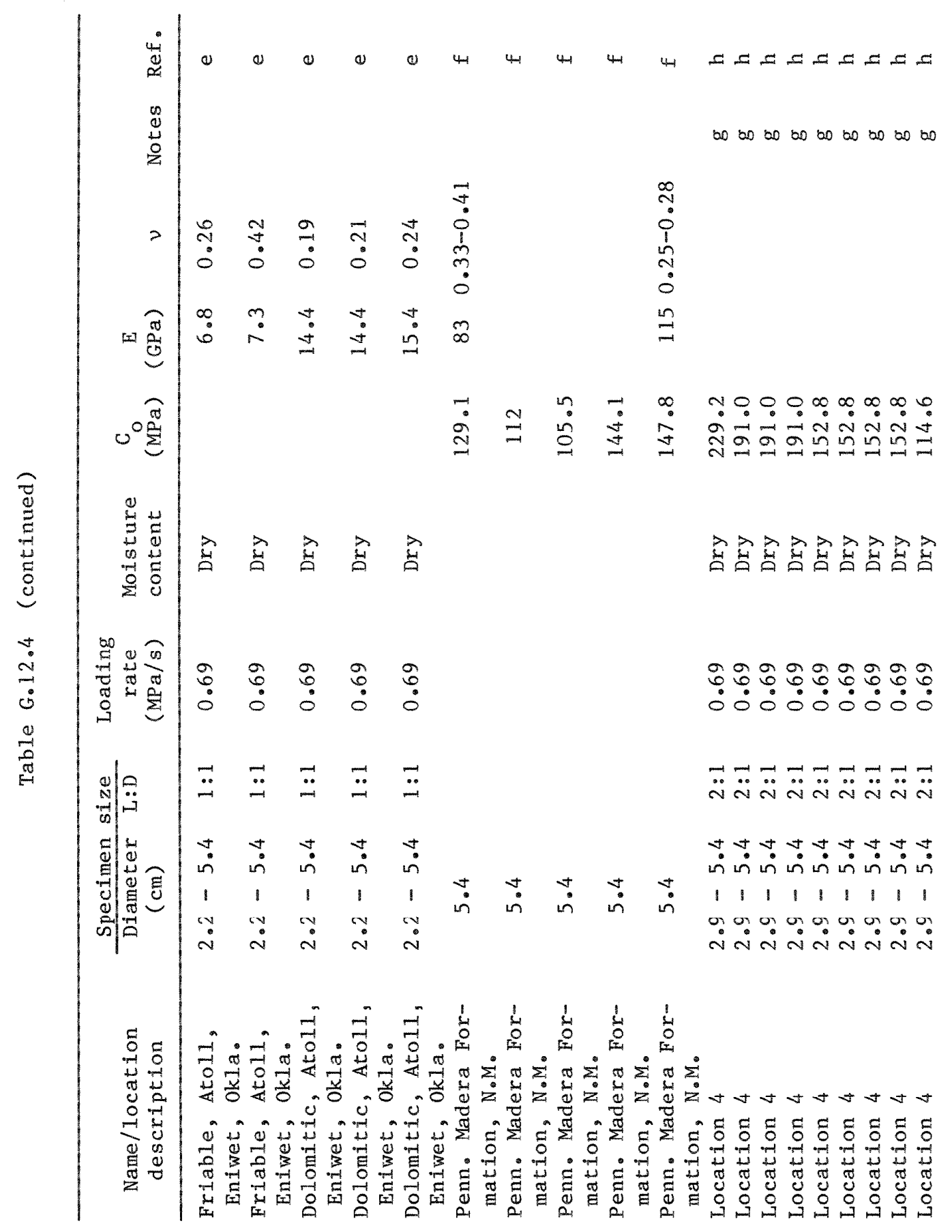




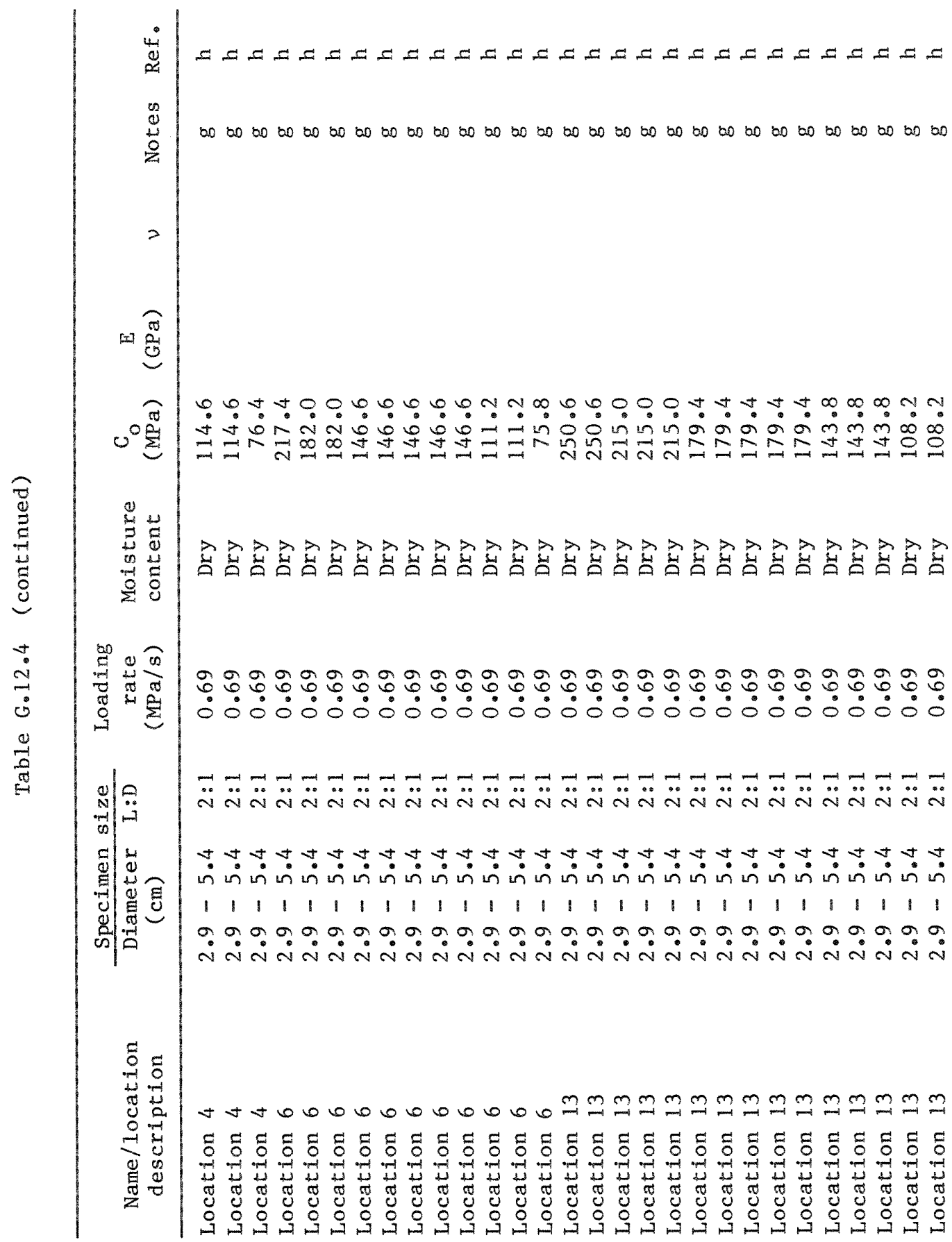




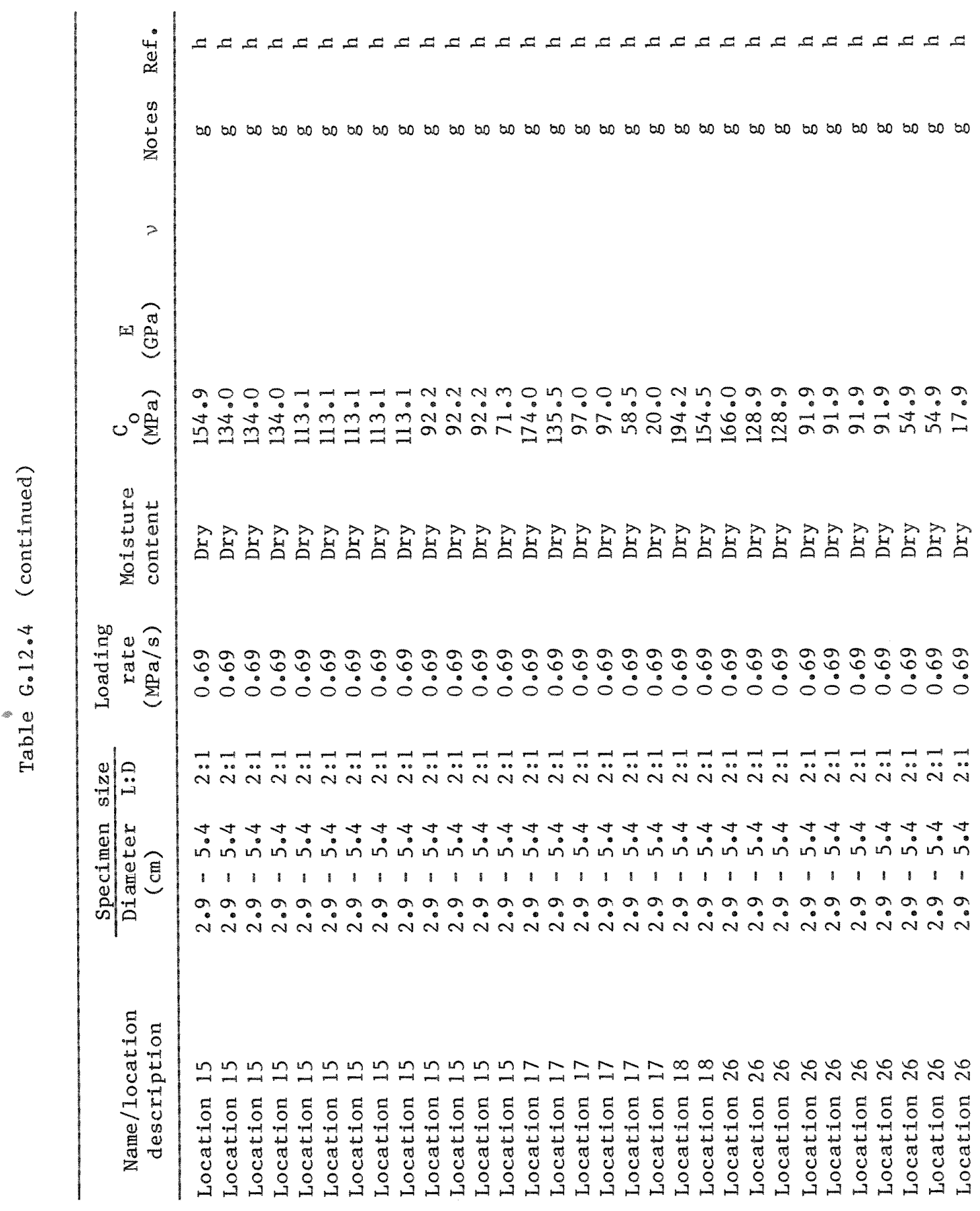




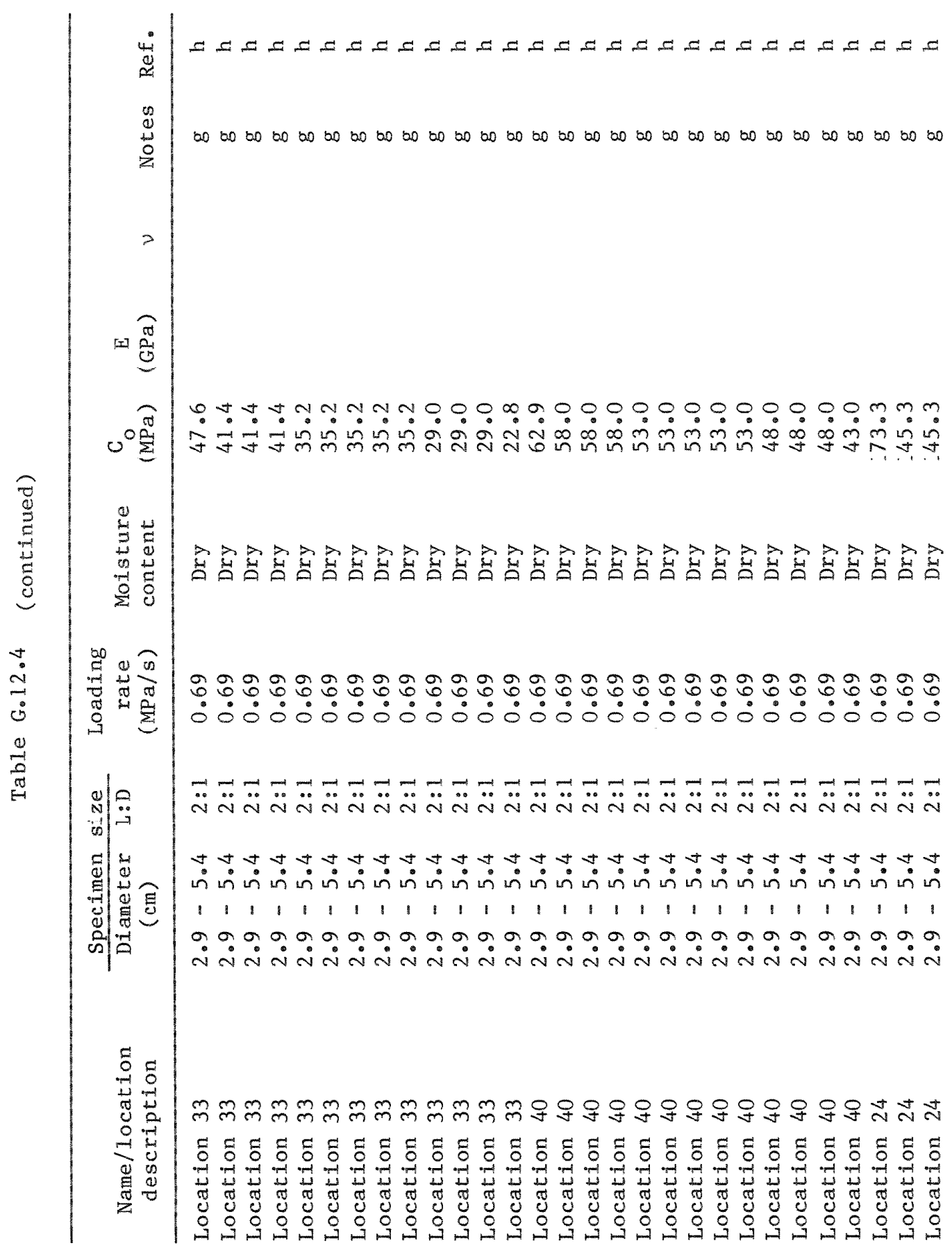




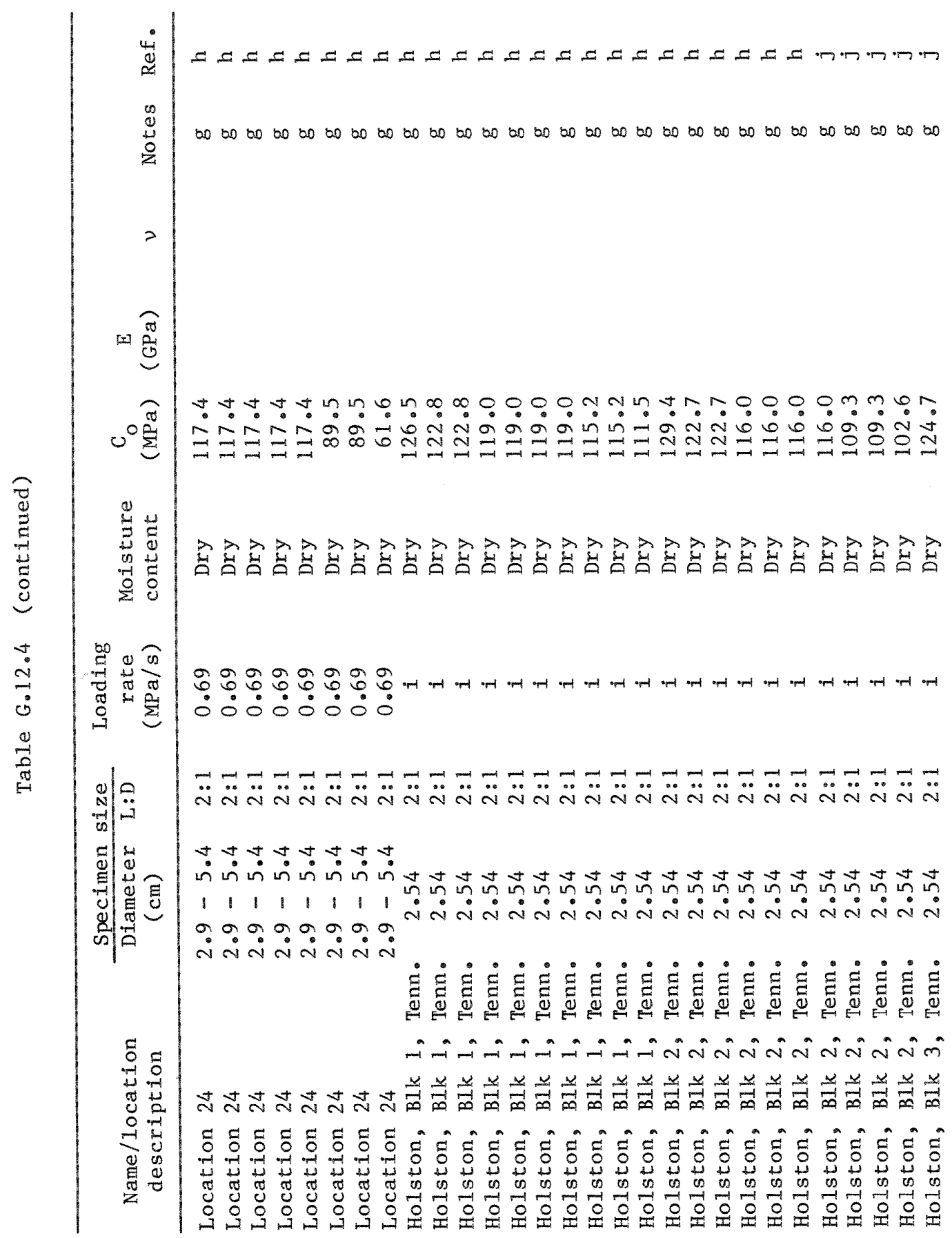




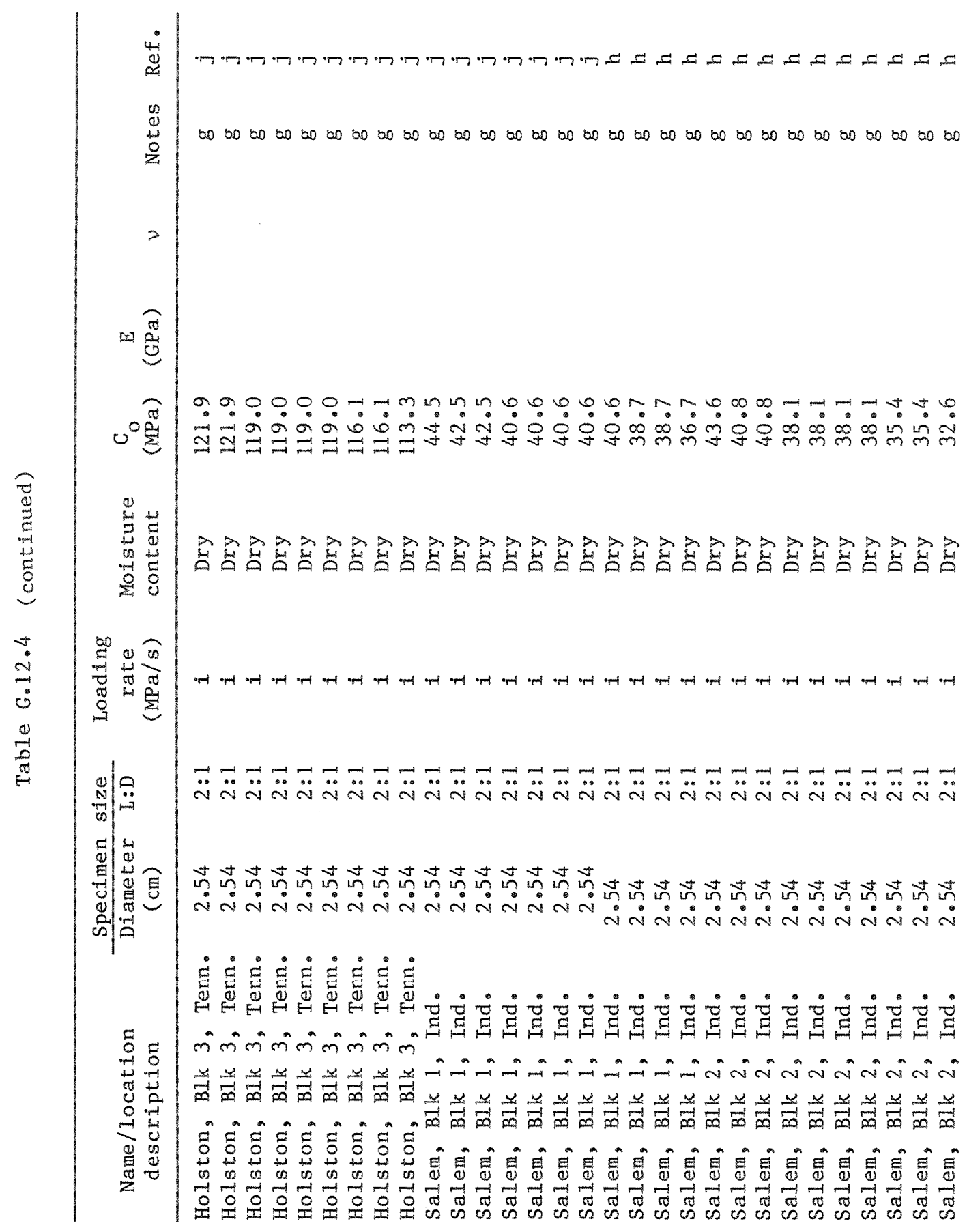




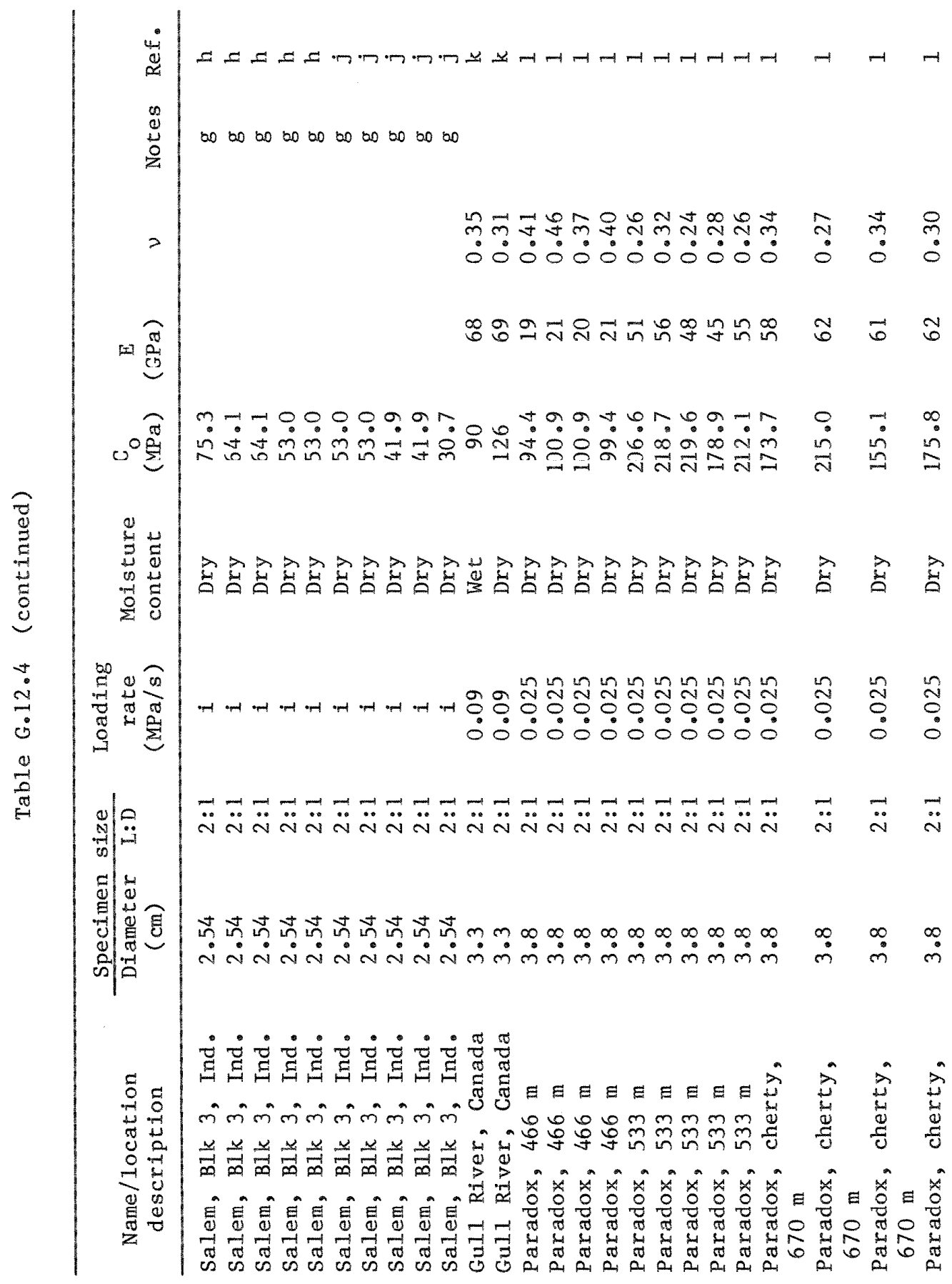




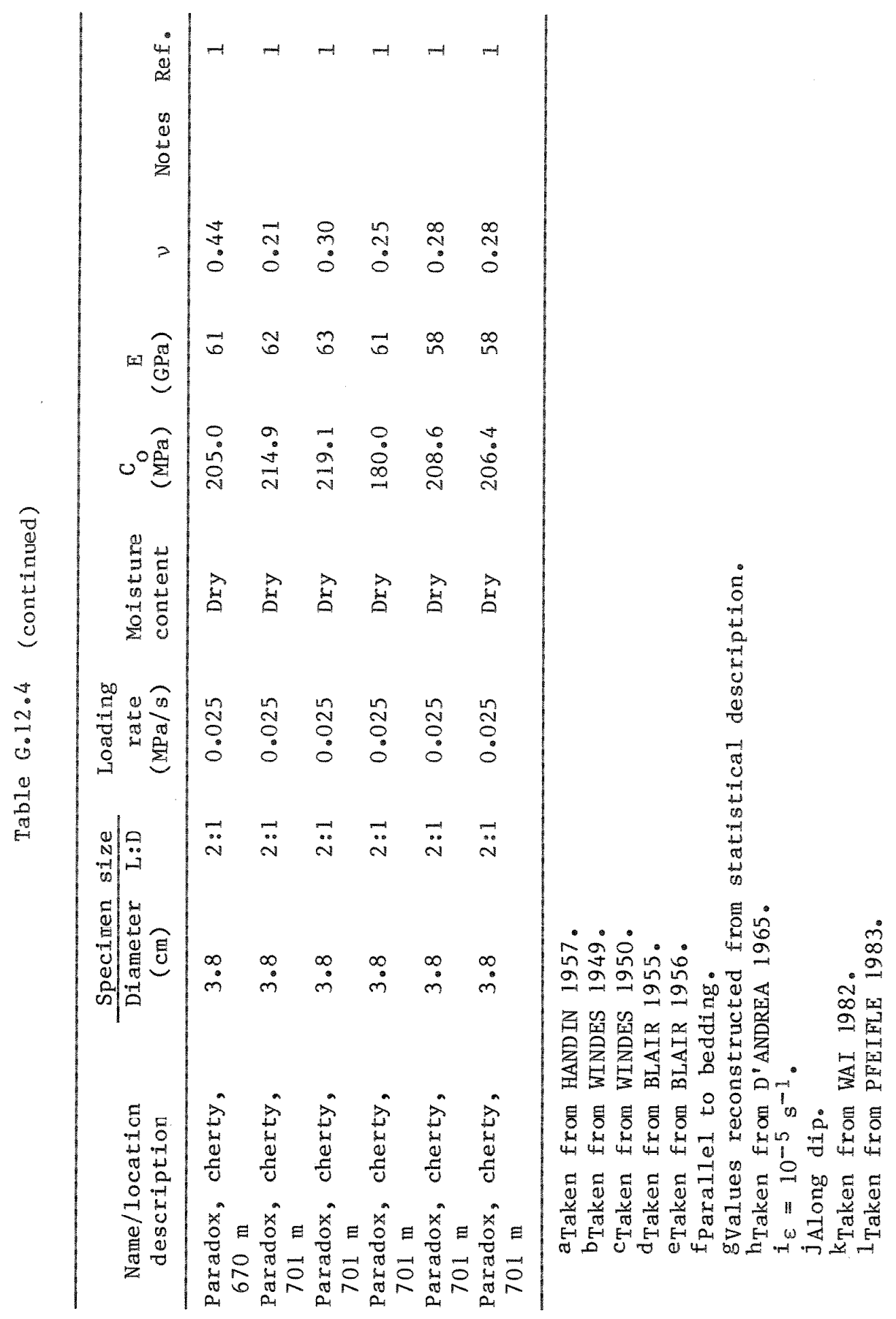




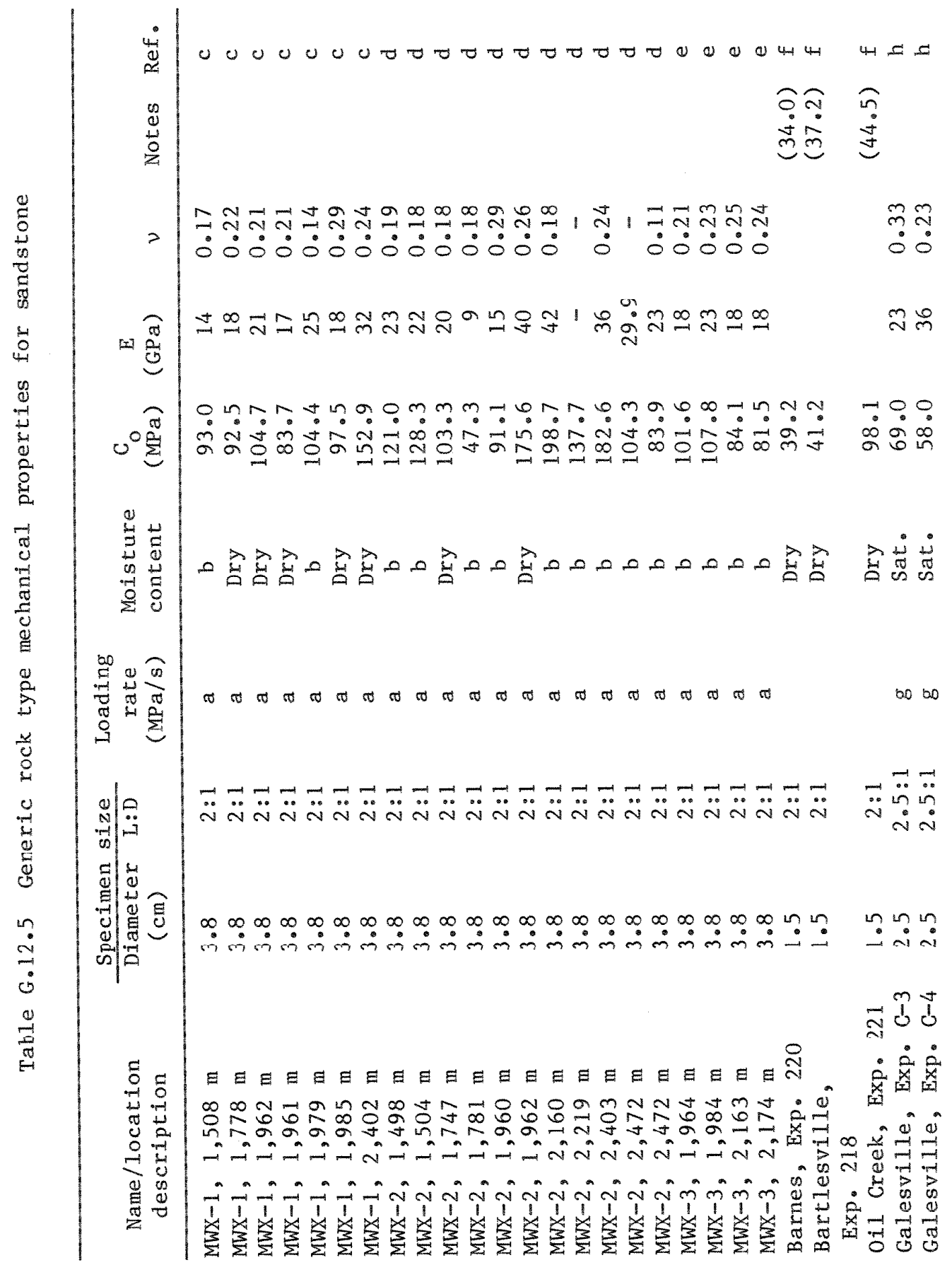




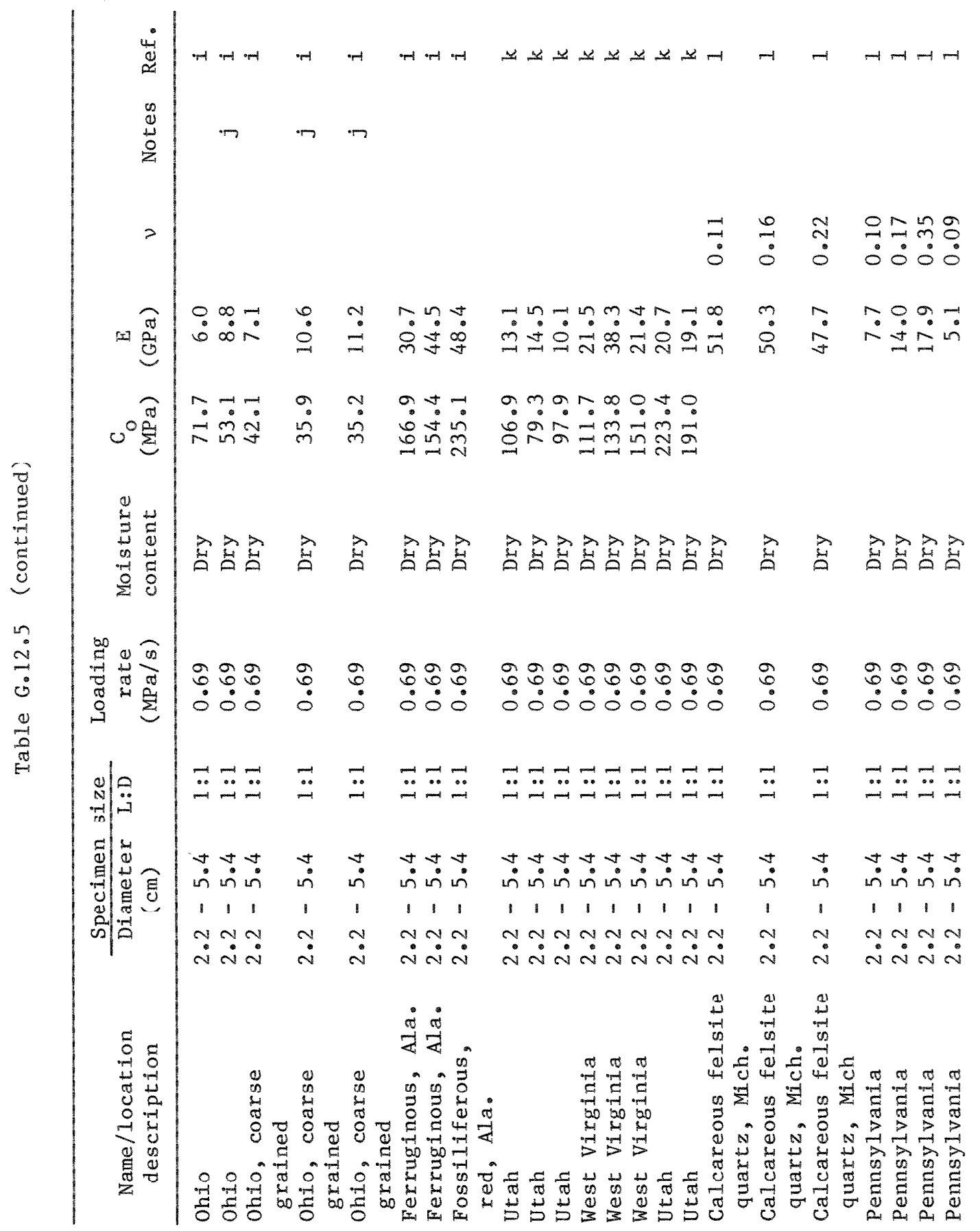




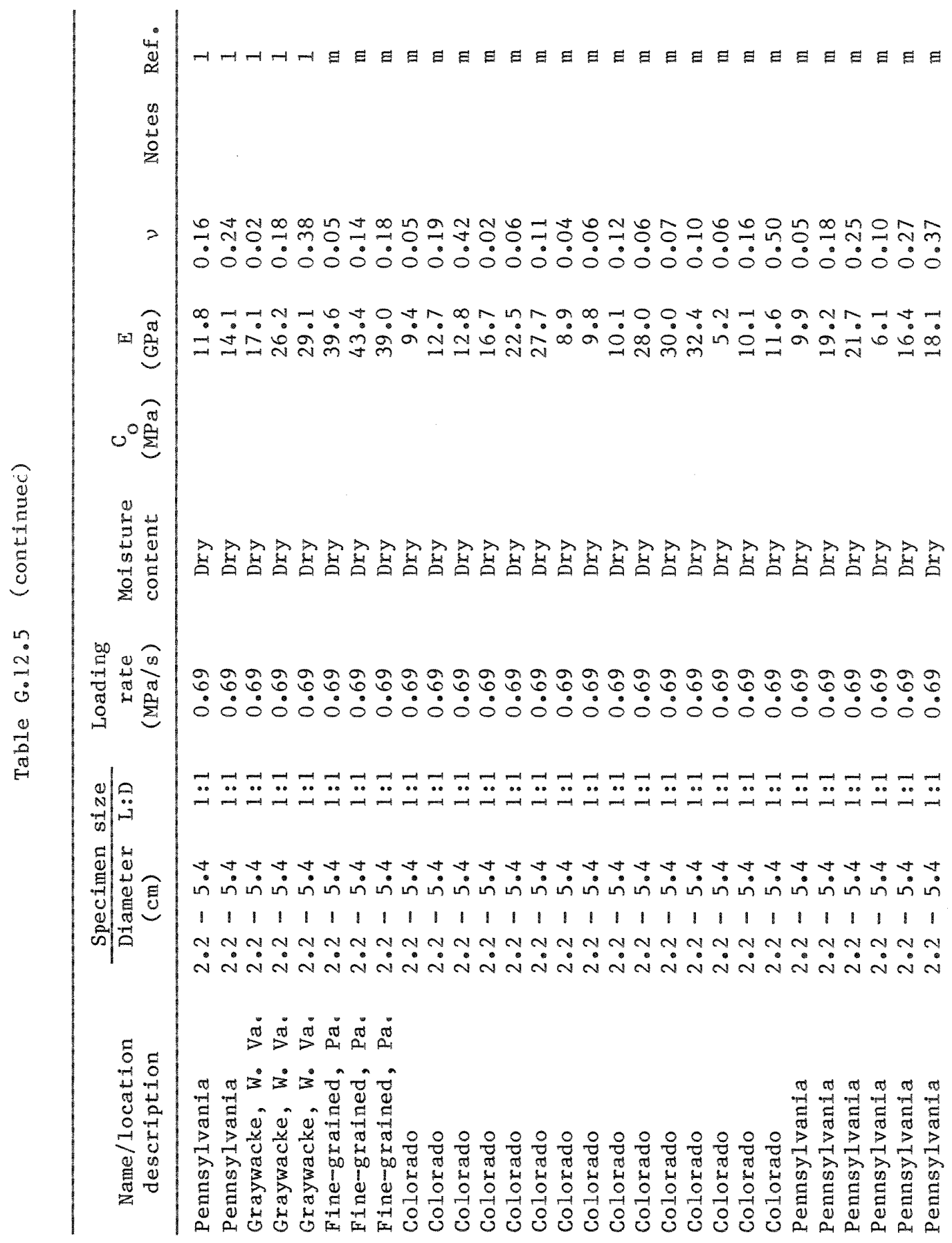




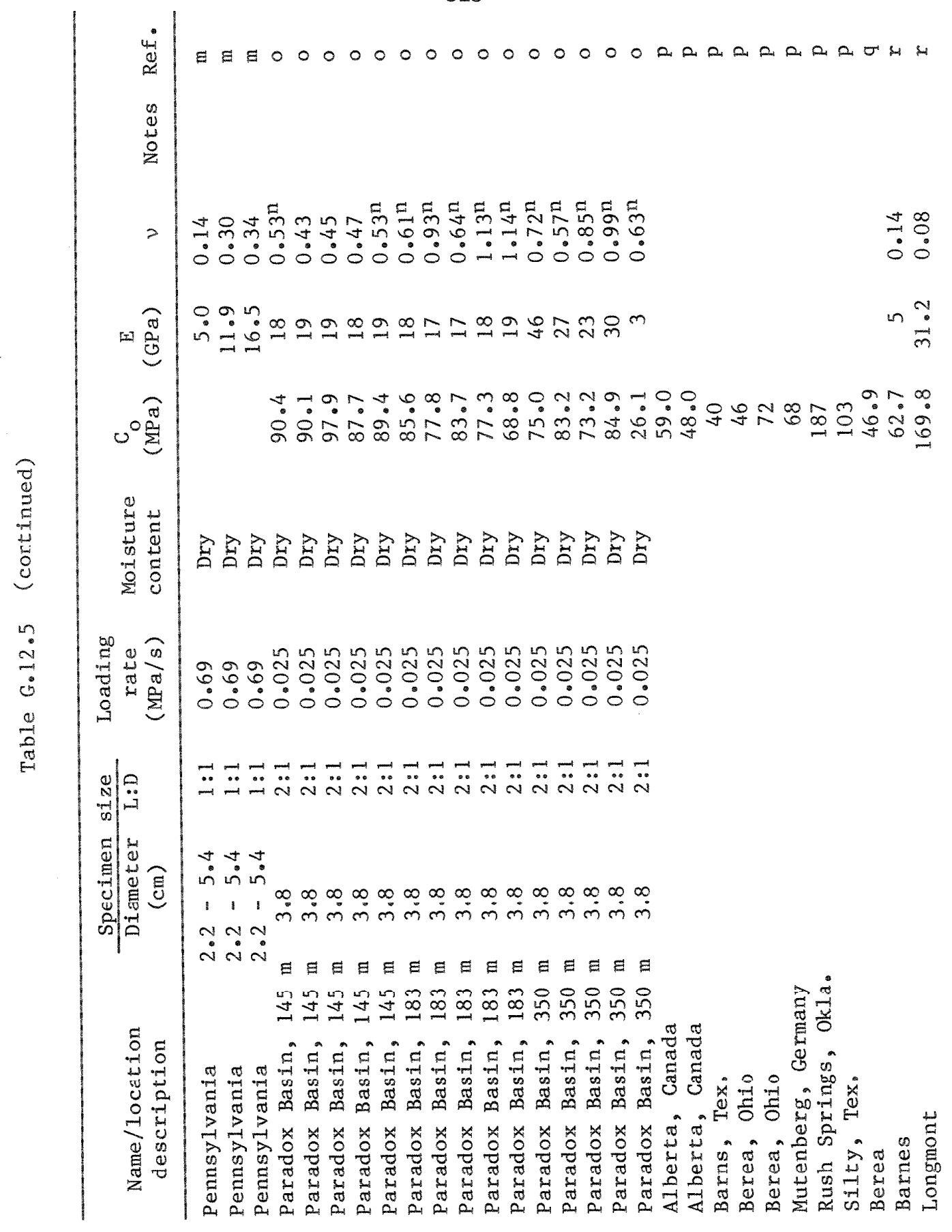




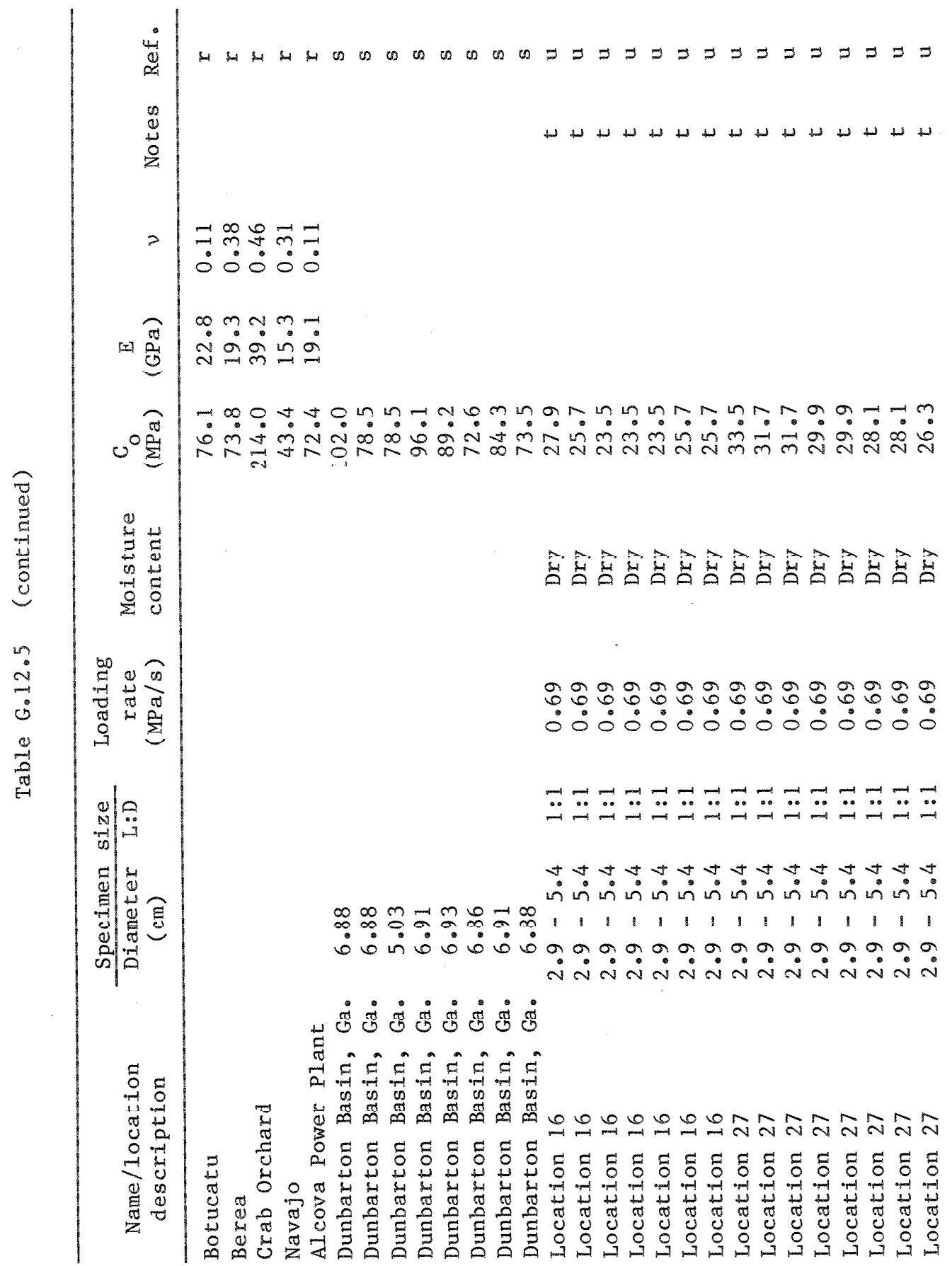




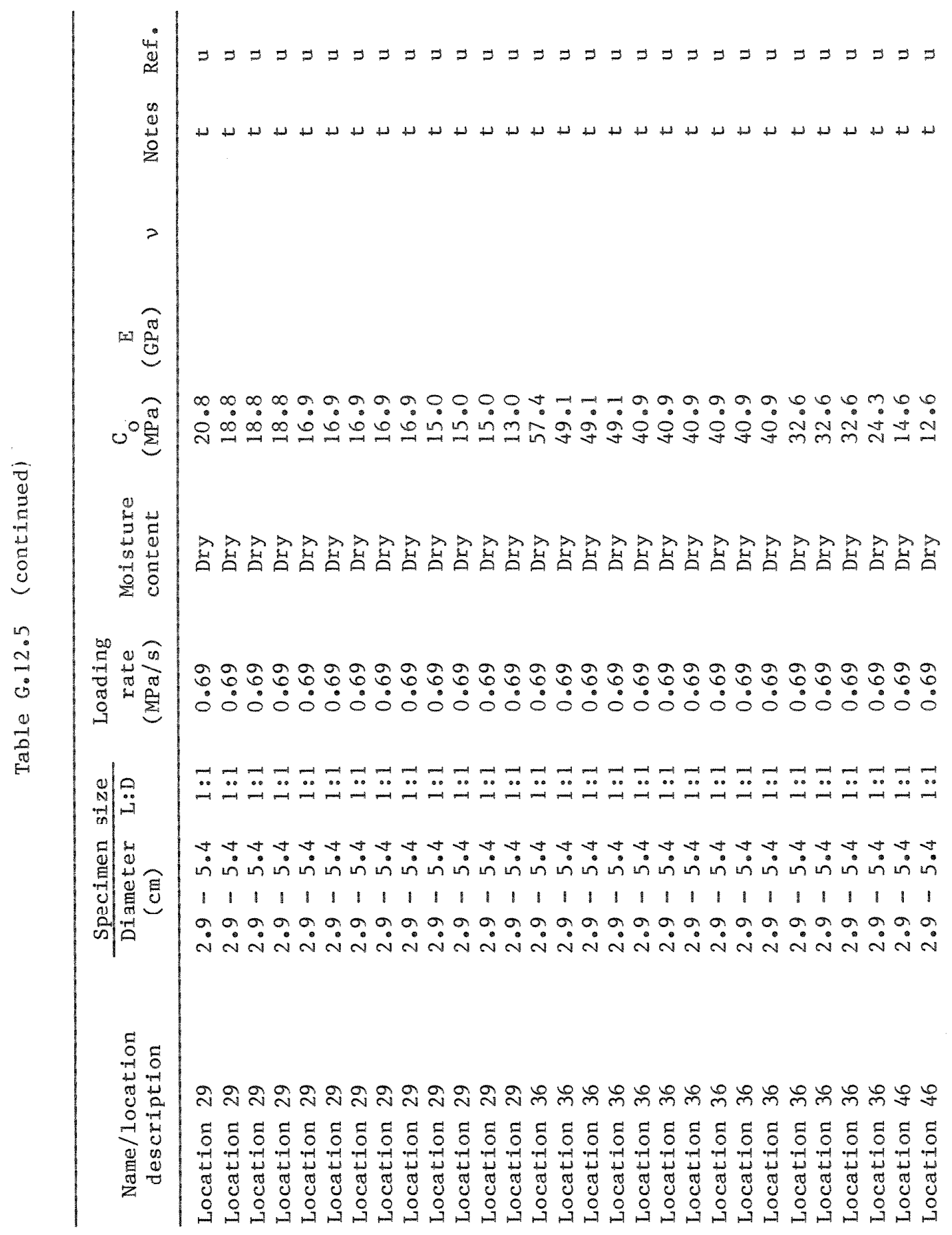




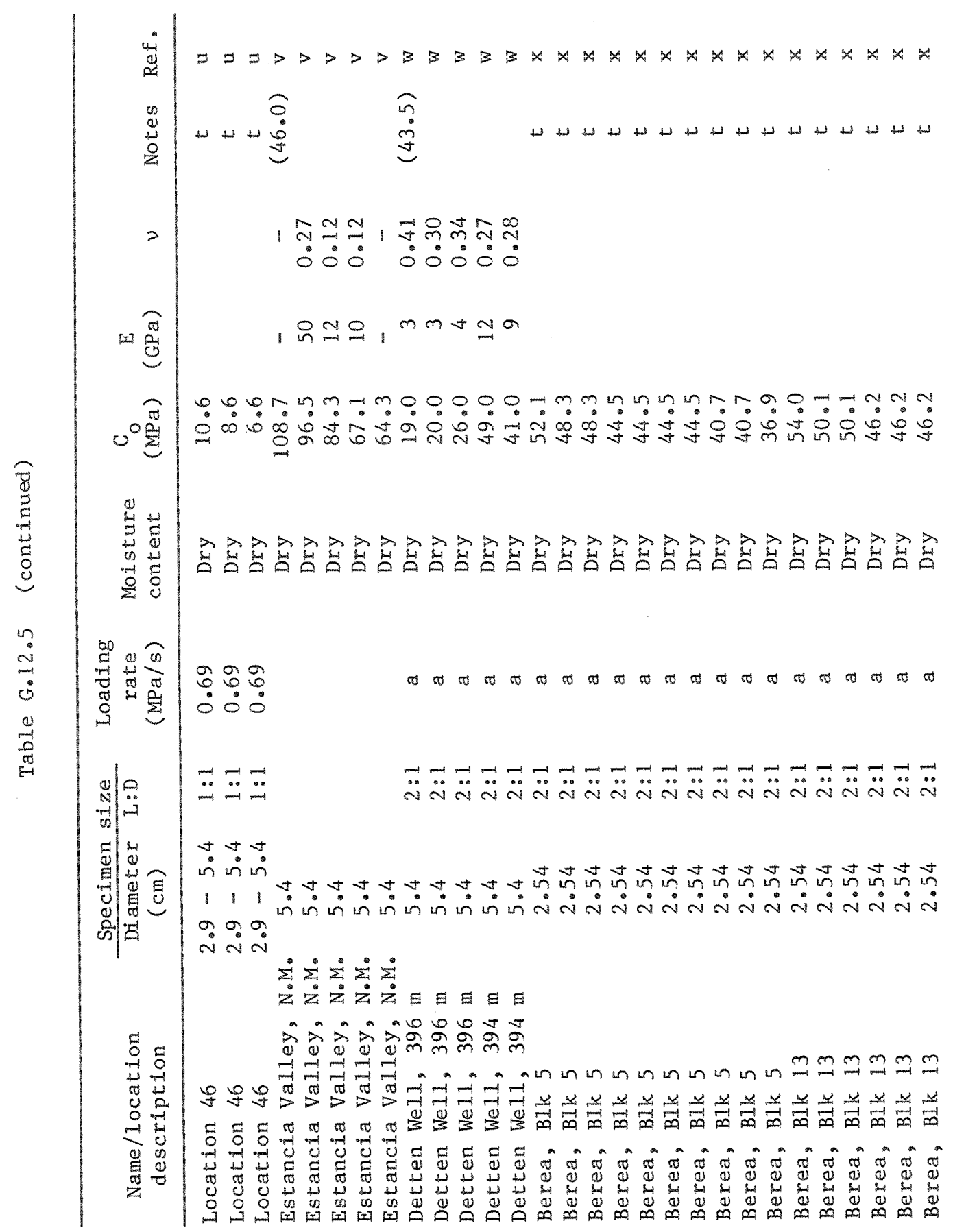




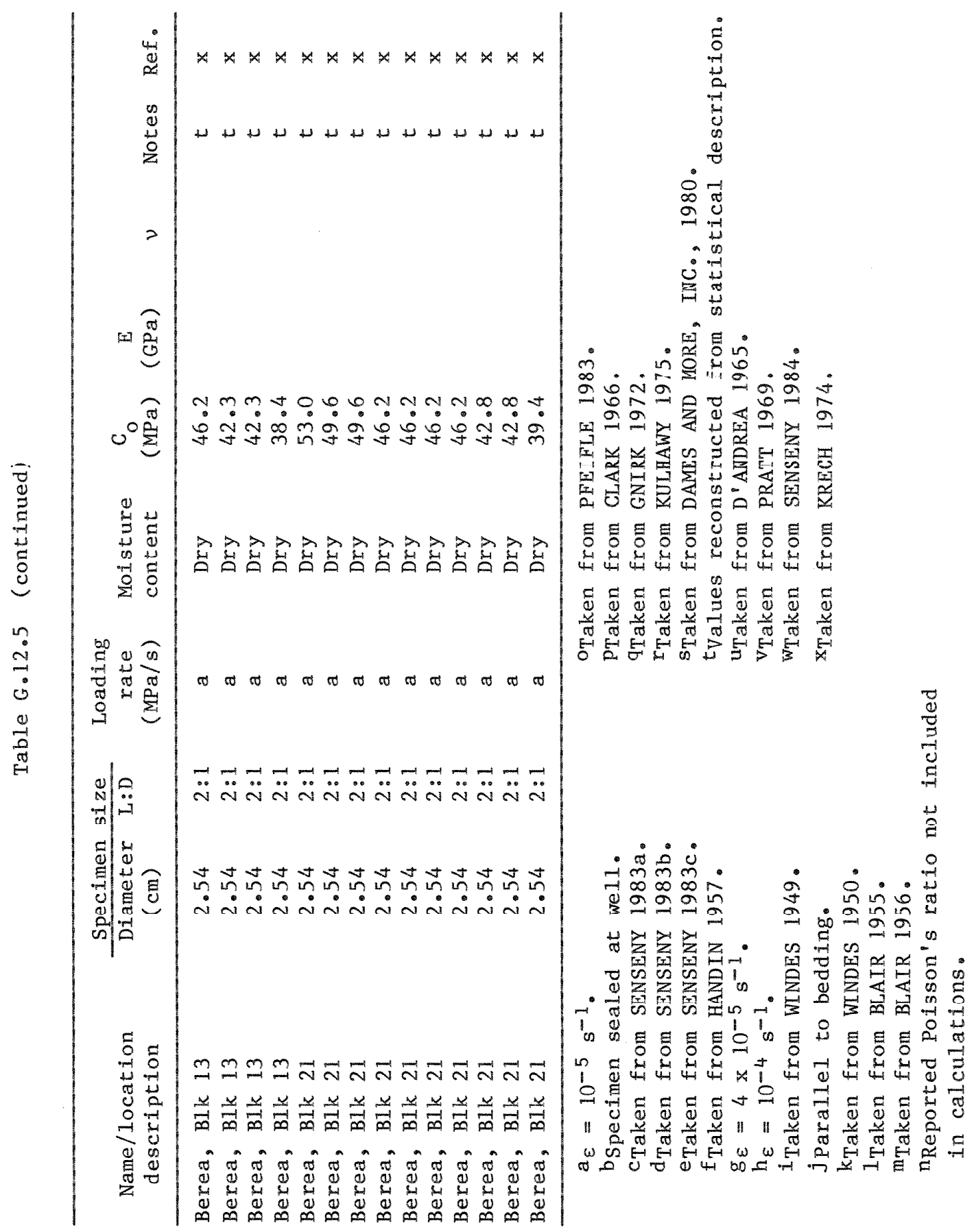




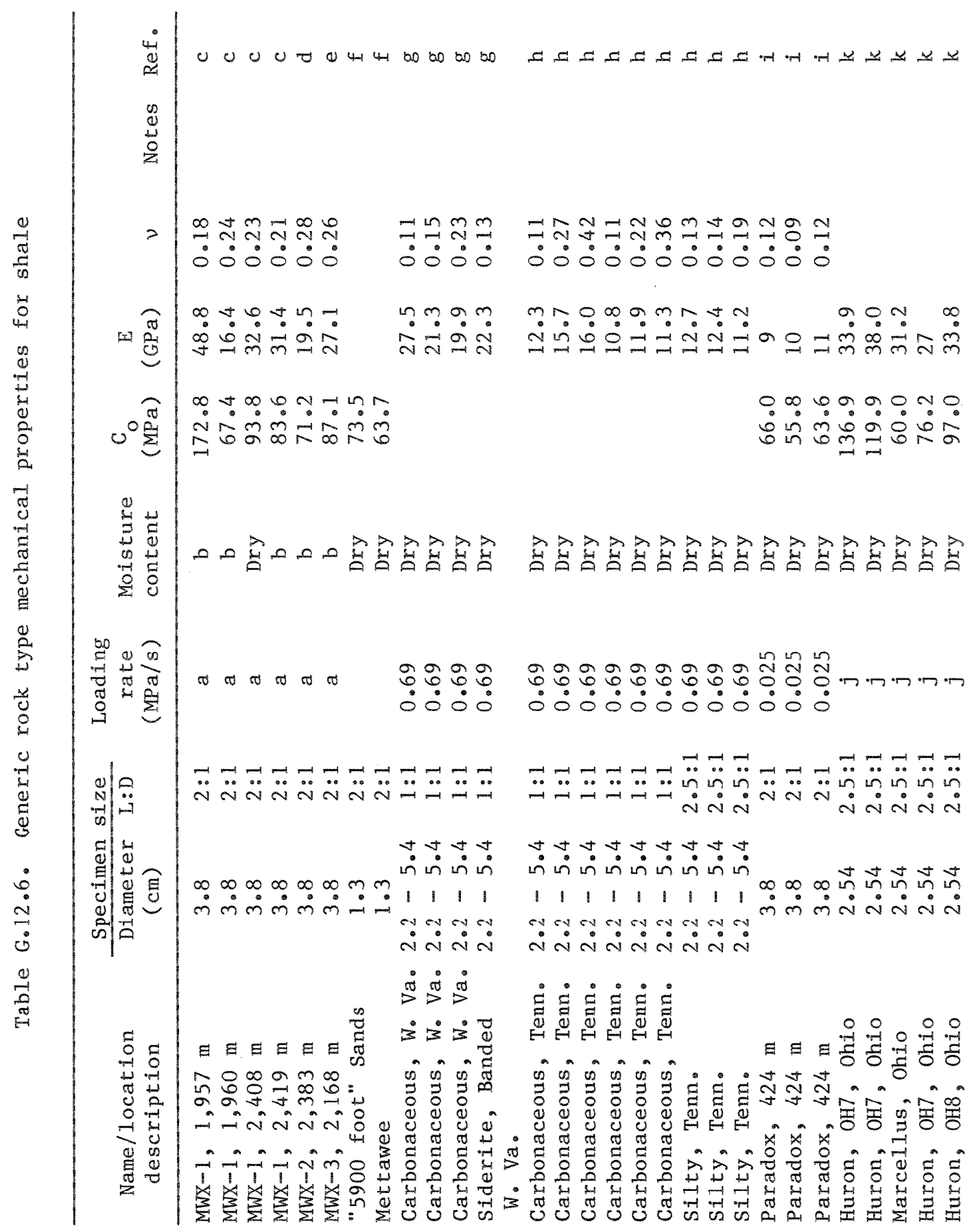




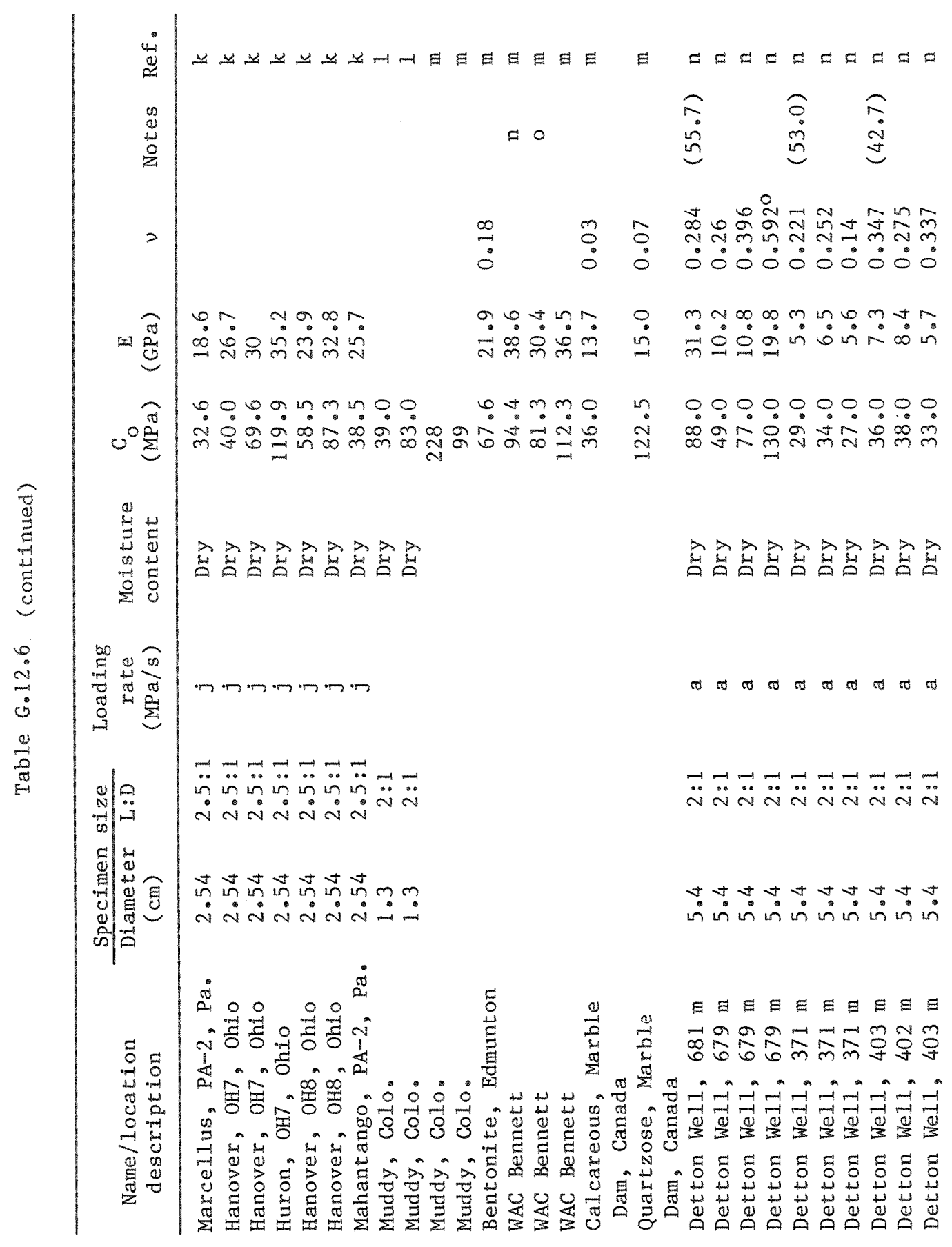




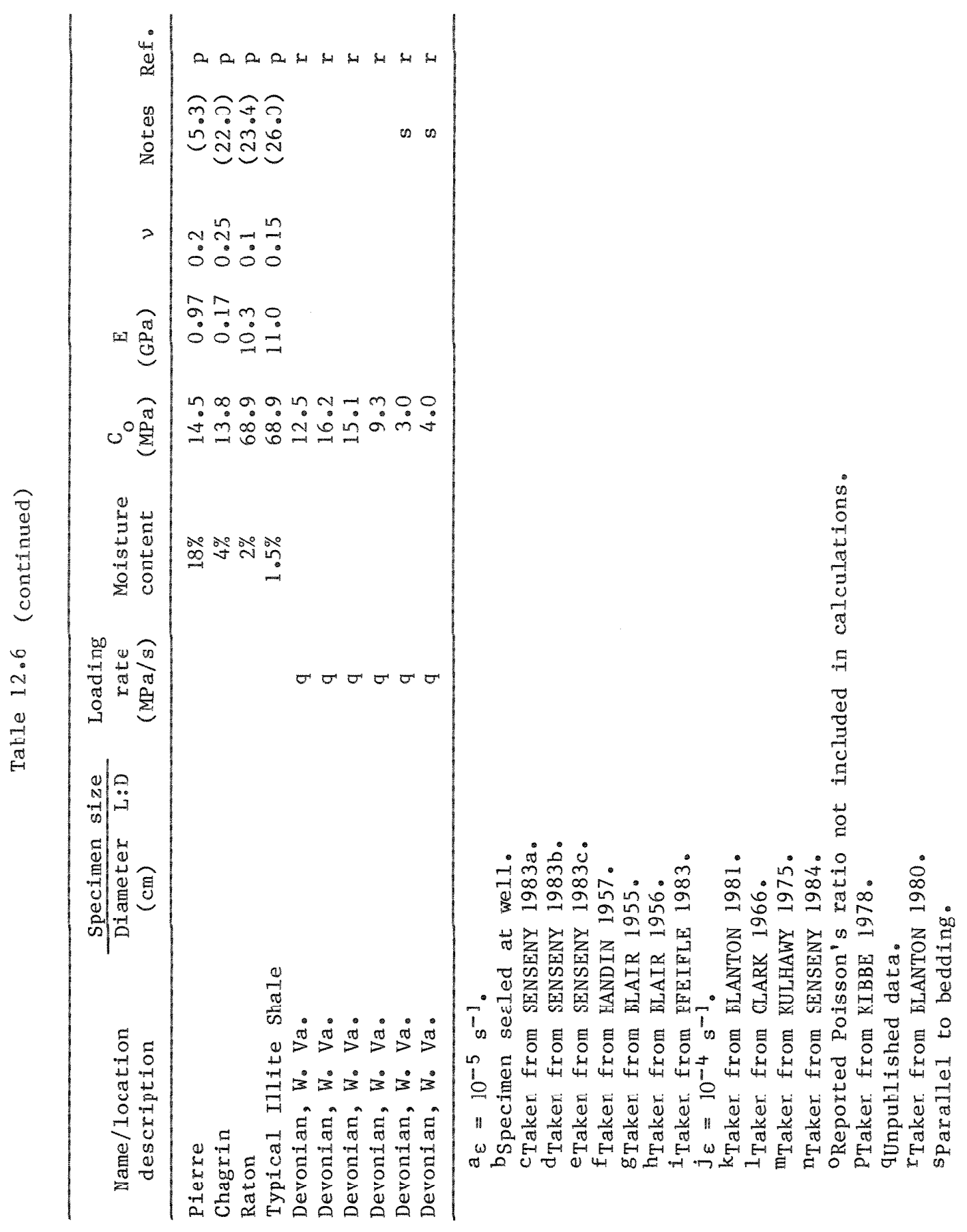


Table G.12.7. Unconfined compressive strength (MPa)

\begin{tabular}{lccccc}
\hline Rock type & $\mathrm{n}$ & Maximum & Minimum & Mean & $\begin{array}{l}\text { Standard } \\
\text { deviation }\end{array}$ \\
\hline Anhydrock & 78 & 177.5 & 22.9 & 92.6 & 36.5 \\
Chalk & 28 & 28.4 & 5.5 & 17.5 & 4.5 \\
Limestone & 225 & 259.2 & 17.9 & 110.1 & 55.9 \\
Dolostone & 63 & 358.5 & 11.0 & 97.3 & 55.7 \\
Sandstone & 167 & 235.1 & 6.6 & 65.9 & 45.8 \\
Shale & 49 & 228 & 3 & 69.4 & 44.2 \\
\hline
\end{tabular}

Table G.12.8. Young 's modulus (GPa)

\begin{tabular}{|c|c|c|c|c|c|}
\hline Rock type & $\mathrm{n}$ & Maximum & Minimum & Mean & $\begin{array}{l}\text { Standard } \\
\text { deviation }\end{array}$ \\
\hline Anhydrock & 75 & 87.6 & 11.8 & 64.1 & 18.0 \\
\hline Chalk & 9 & 13.8 & 2.6 & 6.8 & 3.9 \\
\hline Limestone & 93 & 115.0 & 5.9 & 49.9 & 22.2 \\
\hline Dolostone & 36 & 81.5 & $7 \cdot 5$ & 35.3 & 12.2 \\
\hline Sands tone & 106 & 51.8 & 3.0 & 20.4 & 11.9 \\
\hline Shale & 50 & 48.8 & $5 \cdot 3$ & 20.8 & 10.9 \\
\hline
\end{tabular}


Table G.12.9 Poisson's ratio

\begin{tabular}{lccccc}
\hline Rock type & $\mathrm{n}$ & Maximum & Minimum & Mean & $\begin{array}{c}\text { Standard } \\
\text { deviation }\end{array}$ \\
\hline Anhydrock & 74 & 0.50 & 0.16 & 0.34 & 0.07 \\
Chalk & 6 & 0.33 & 0.12 & 0.25 & 0.09 \\
Limestone & 82 & 0.48 & 0.05 & 0.26 & 0.09 \\
Dolostone & 20 & 0.18 & 0.17 & 0.32 & 0.09 \\
Sandstone & 76 & 0.47 & 0.02 & 0.20 & 0.12 \\
Shale & 34 & 0.42 & 0.03 & 0.21 & 0.10 \\
\hline
\end{tabular}

Table G.12.10. Angle of internal friction (phi)

\begin{tabular}{lccccc}
\hline \multicolumn{1}{c}{ Rock type } & $\mathrm{n}$ & Maximum & Minimum & Mean & $\begin{array}{c}\text { Standard } \\
\text { deviation }\end{array}$ \\
\hline Anhydrock & 8 & 54.7 & 29.4 & 44.8 & 8.9 \\
Chalk & 1 & & & 17.0 & \\
Carbonate rock & 14 & 63.6 & 26.4 & 41.9 & 11.3 \\
Sandstons & 5 & 46.0 & 34.0 & 41.0 & 5.2 \\
Shale & 7 & 55.7 & 5.3 & 32.6 & 18.4 \\
\hline
\end{tabular}




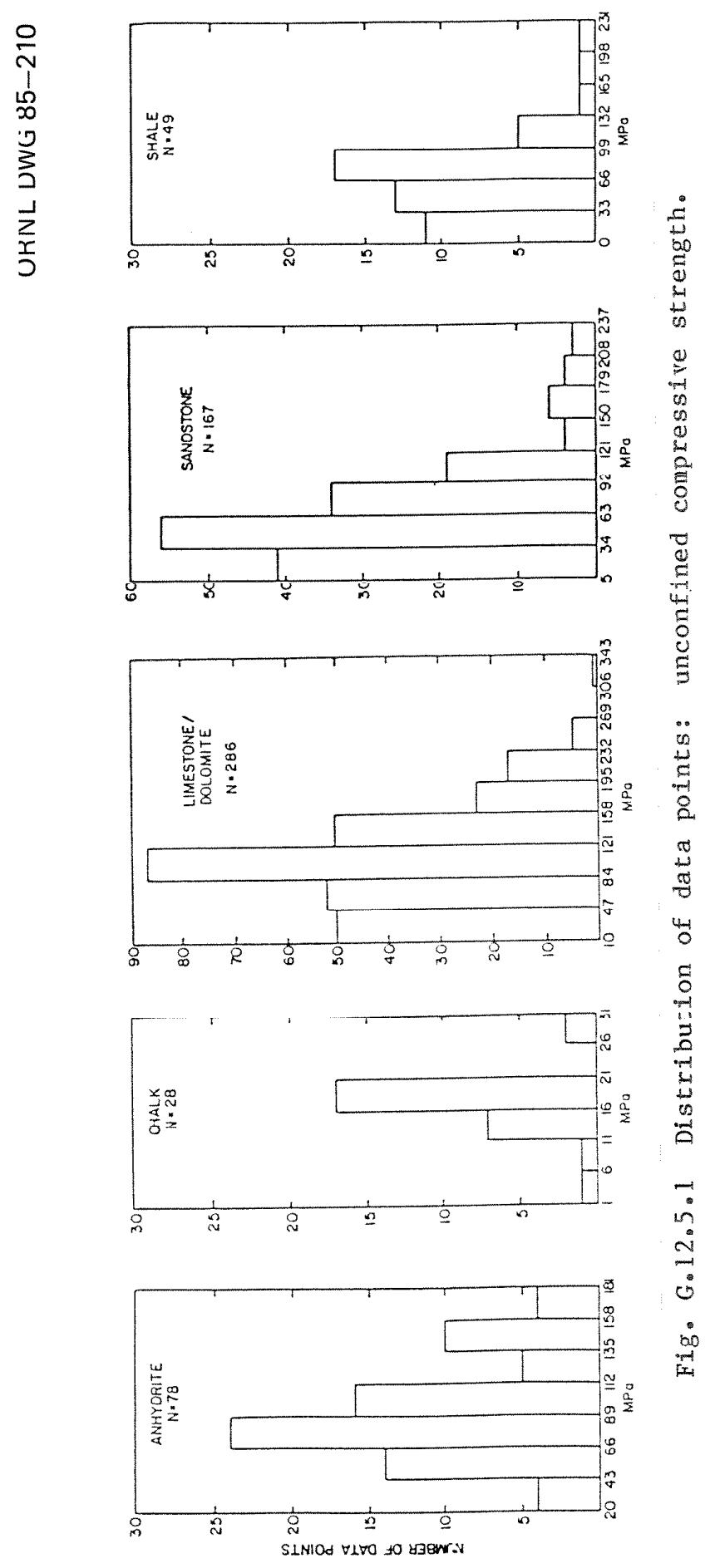



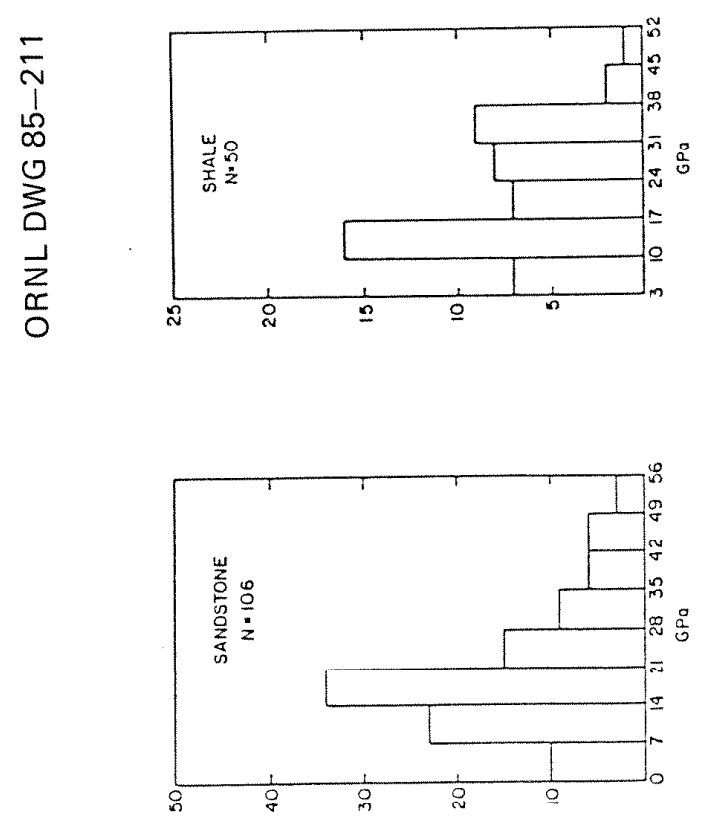

$\stackrel{8}{3}$

品

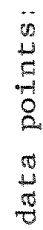

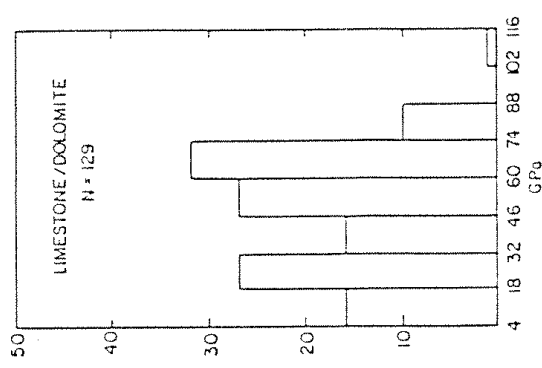

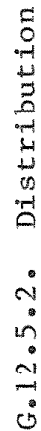

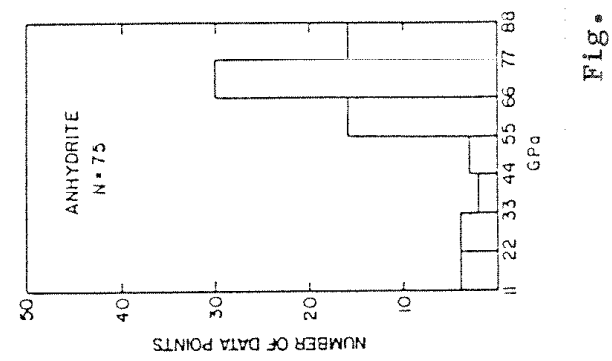




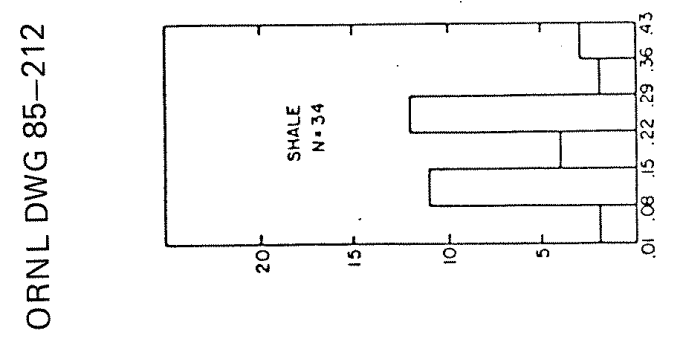

$\stackrel{\circ}{\stackrel{3}{\sharp}}$

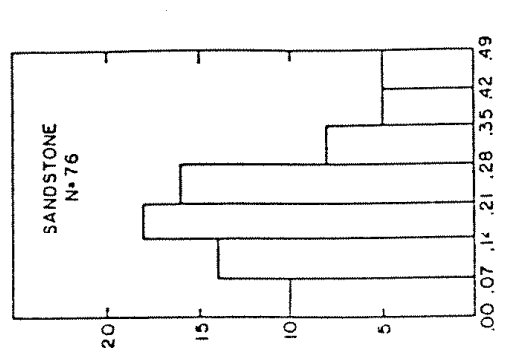

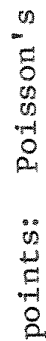

苕

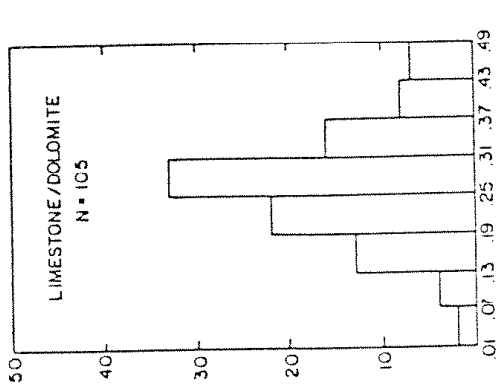

प्येㅇ

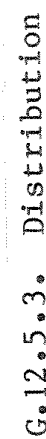

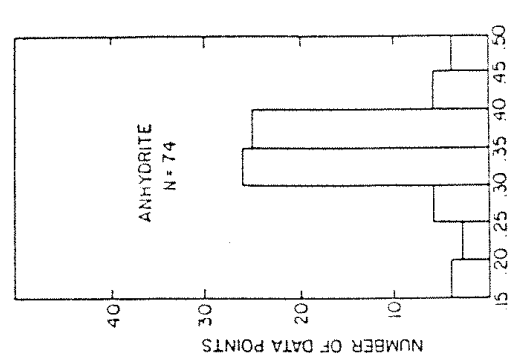

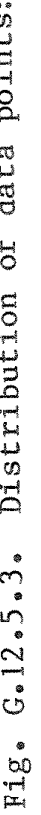




\section{G.12.6 GENERIC ROCK TYPE THERMAI PROPERTIES}

This appendix presents the results of the literature search for thermal properties of anhydrock, chalk, carbonate rocks (1imestone/ dolostone), sandstone, and shale (argillaceous rock). Included in the section are:

- Data lists for each rock type (Tables G.12.11 through G.12.16).

- A sumary of statistics for the thermal properties (Tables G.12.17 through G.12.20).

- A frequency histogram illustrating the distribution of data points for thermal conductivity (Fig. G.12,6.1).

- References for Tables G.12.11 through G.12.16.

Tables G.12.11 through G.12.16 represent the data present in the illelaluie. Several tests for one rock type and tompcraturc condition may be represented by only one entry in the tables, with a mean value and standard deviation or range given. Tables G.12.16 through G.12.20 are summaries of the values given in Tables G.12.11 through G.12.16. 


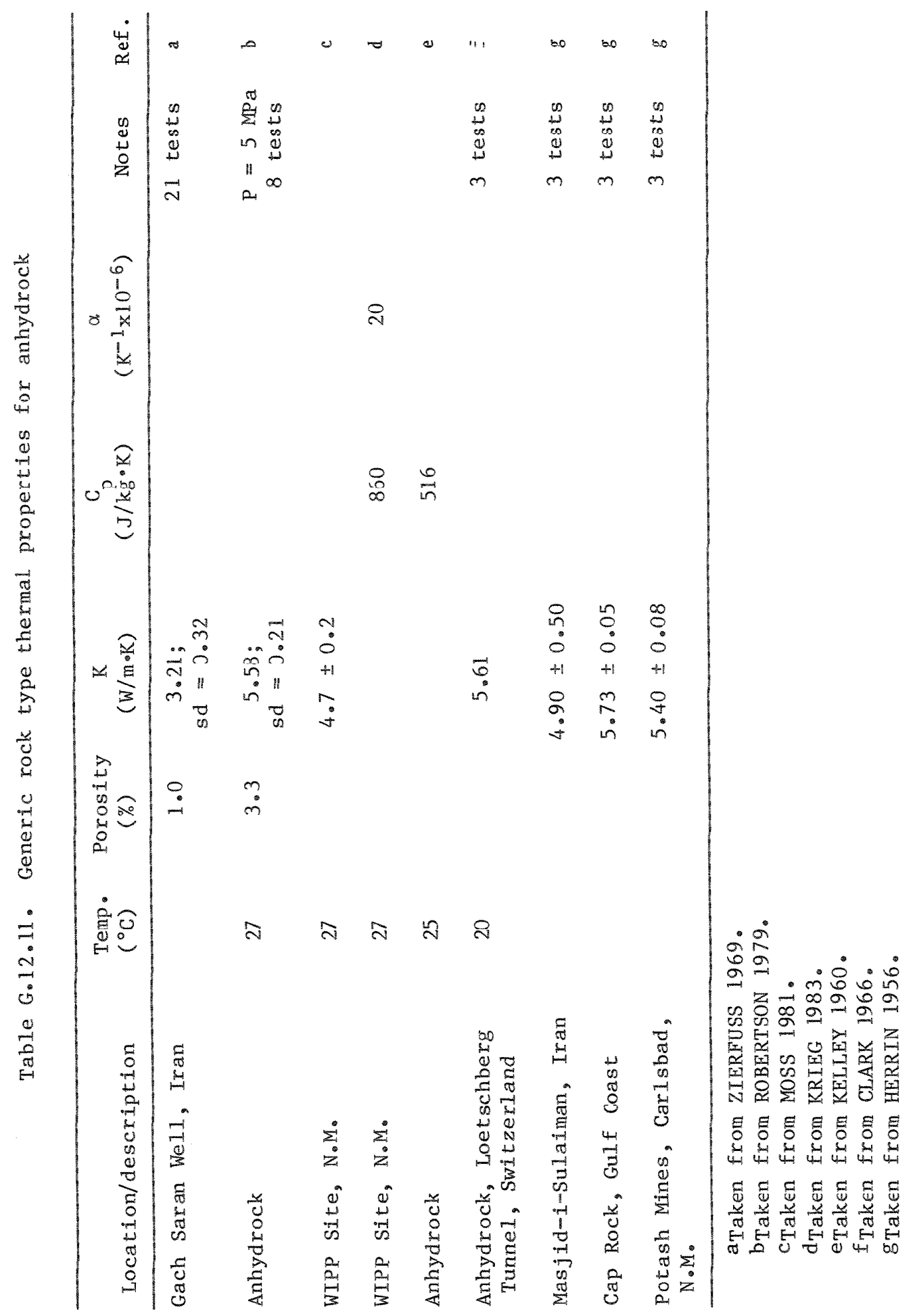




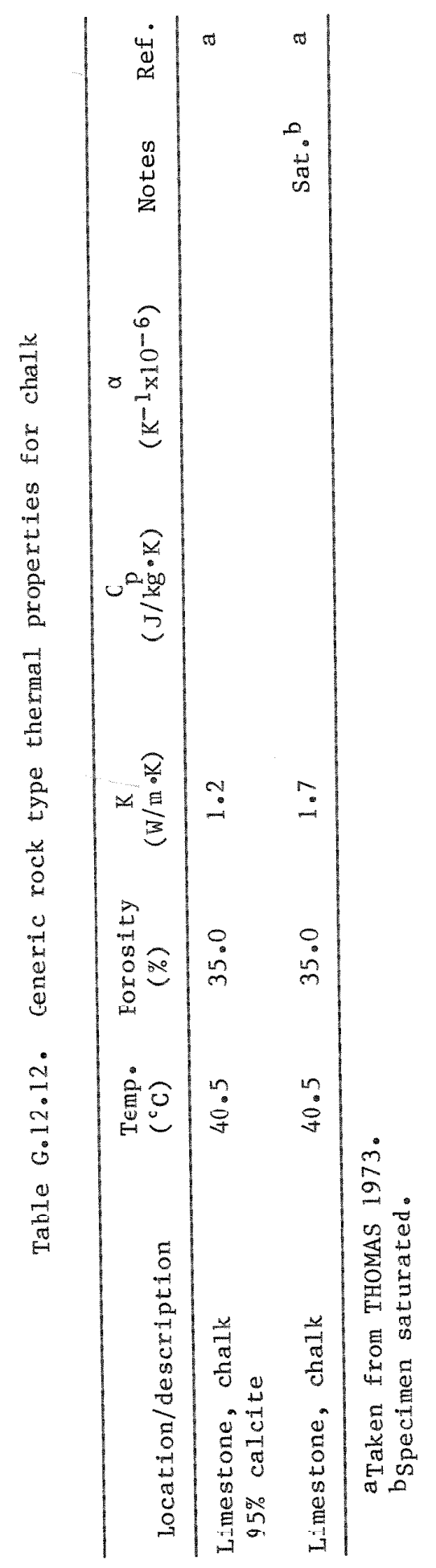




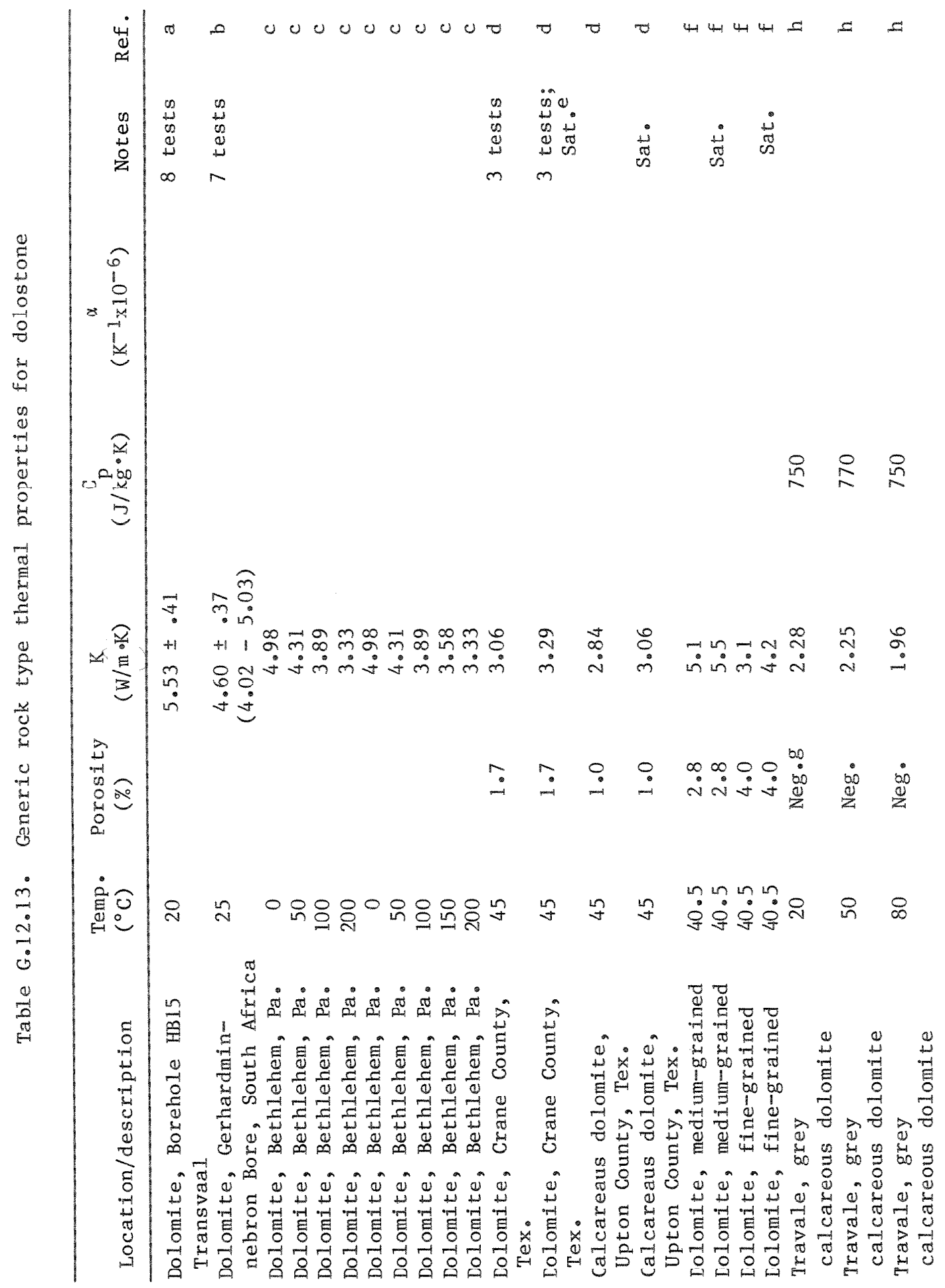




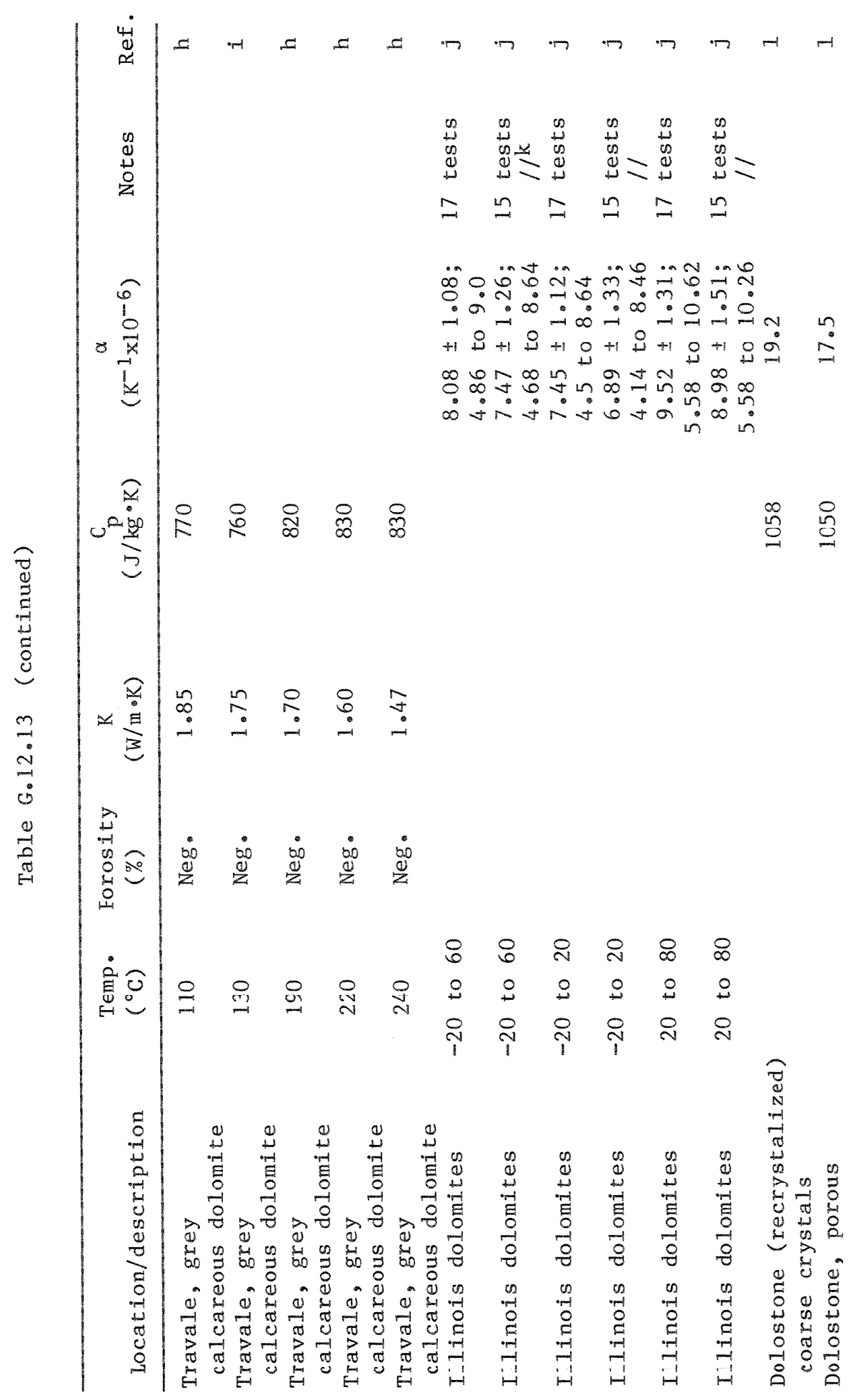




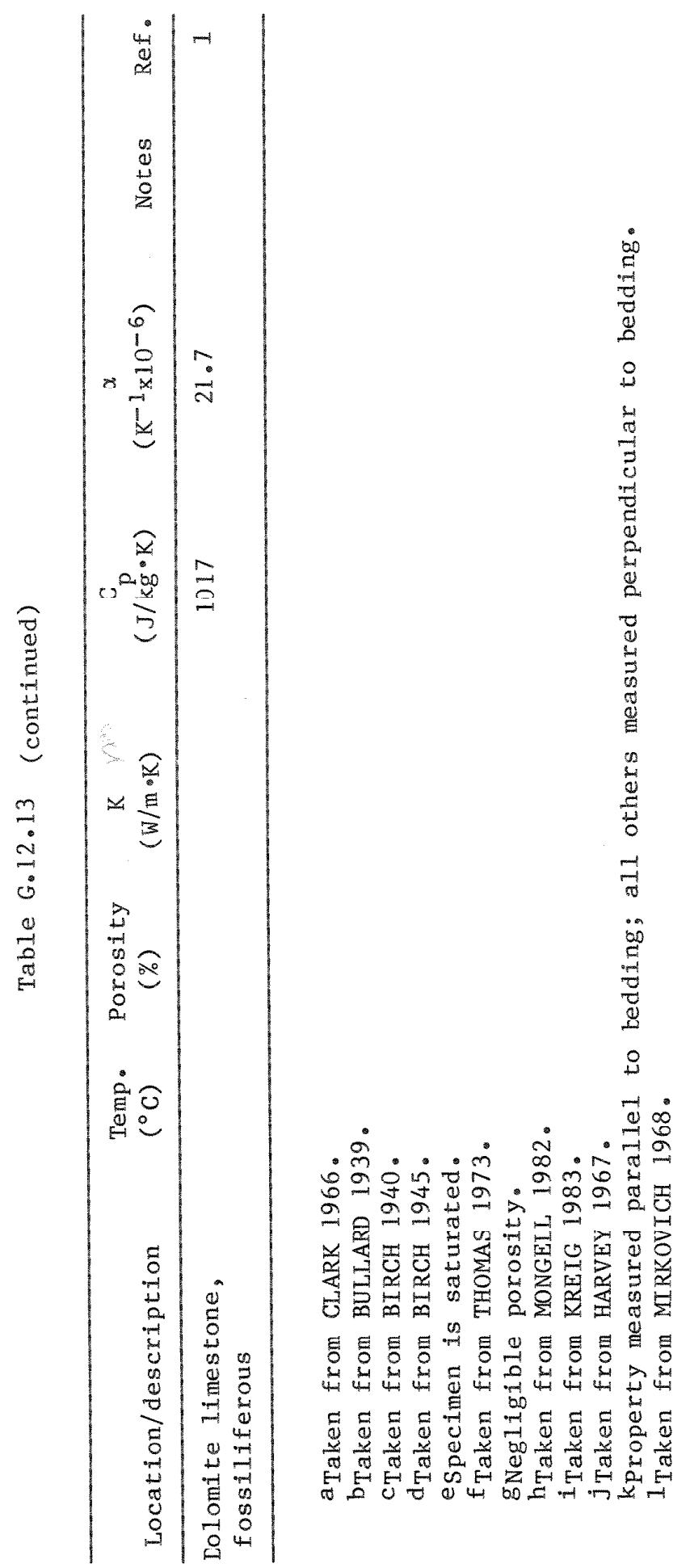




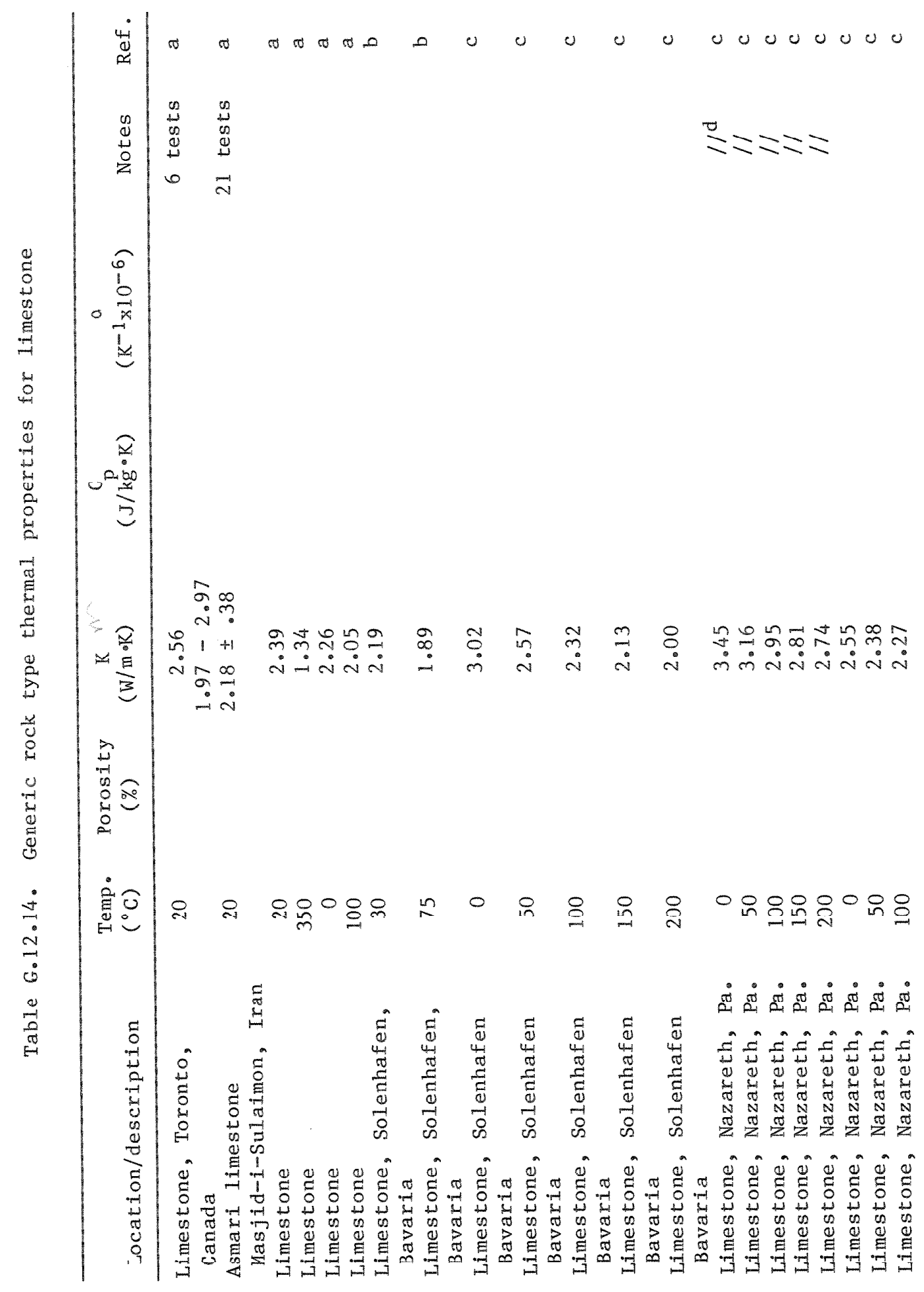




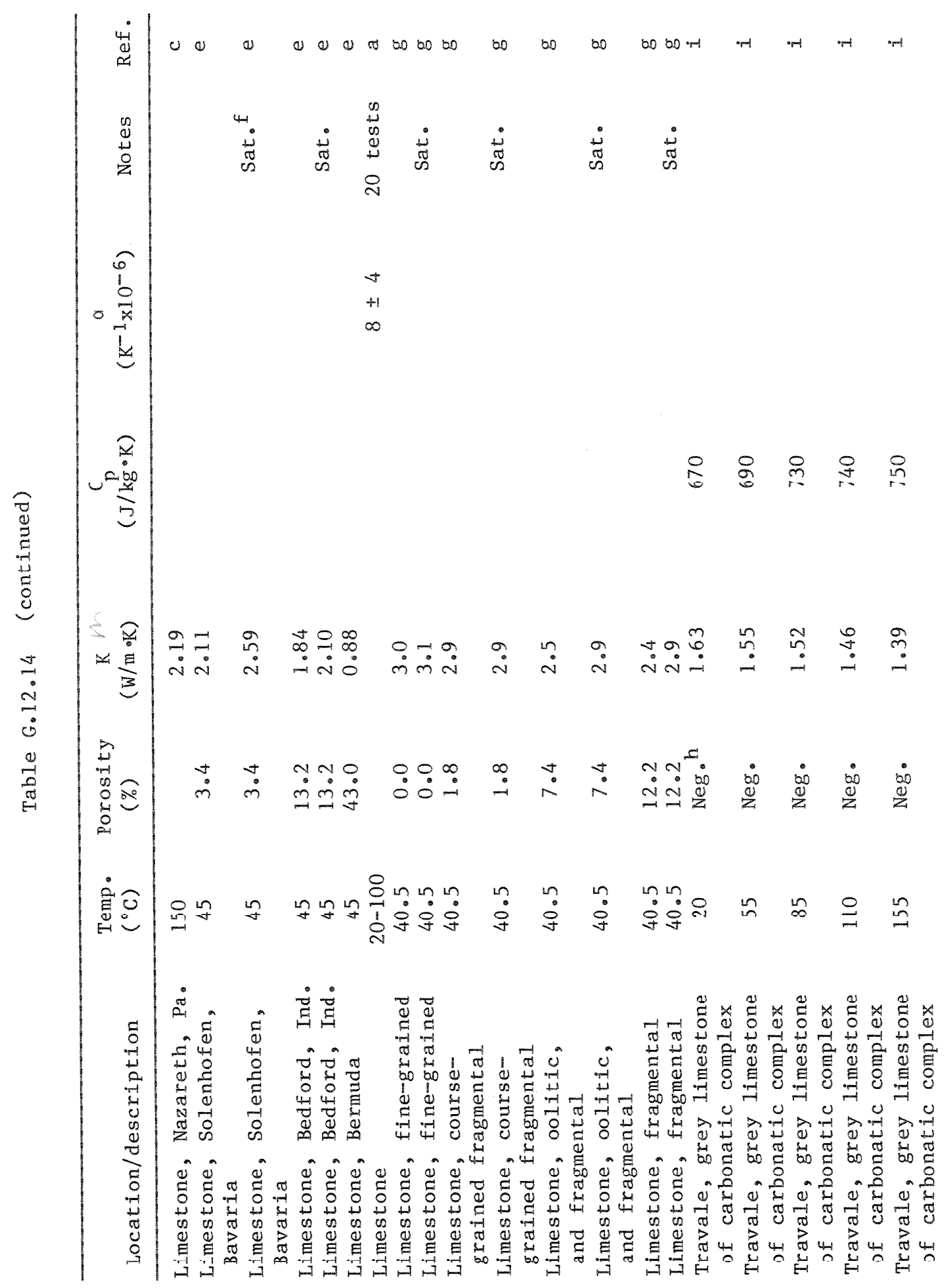




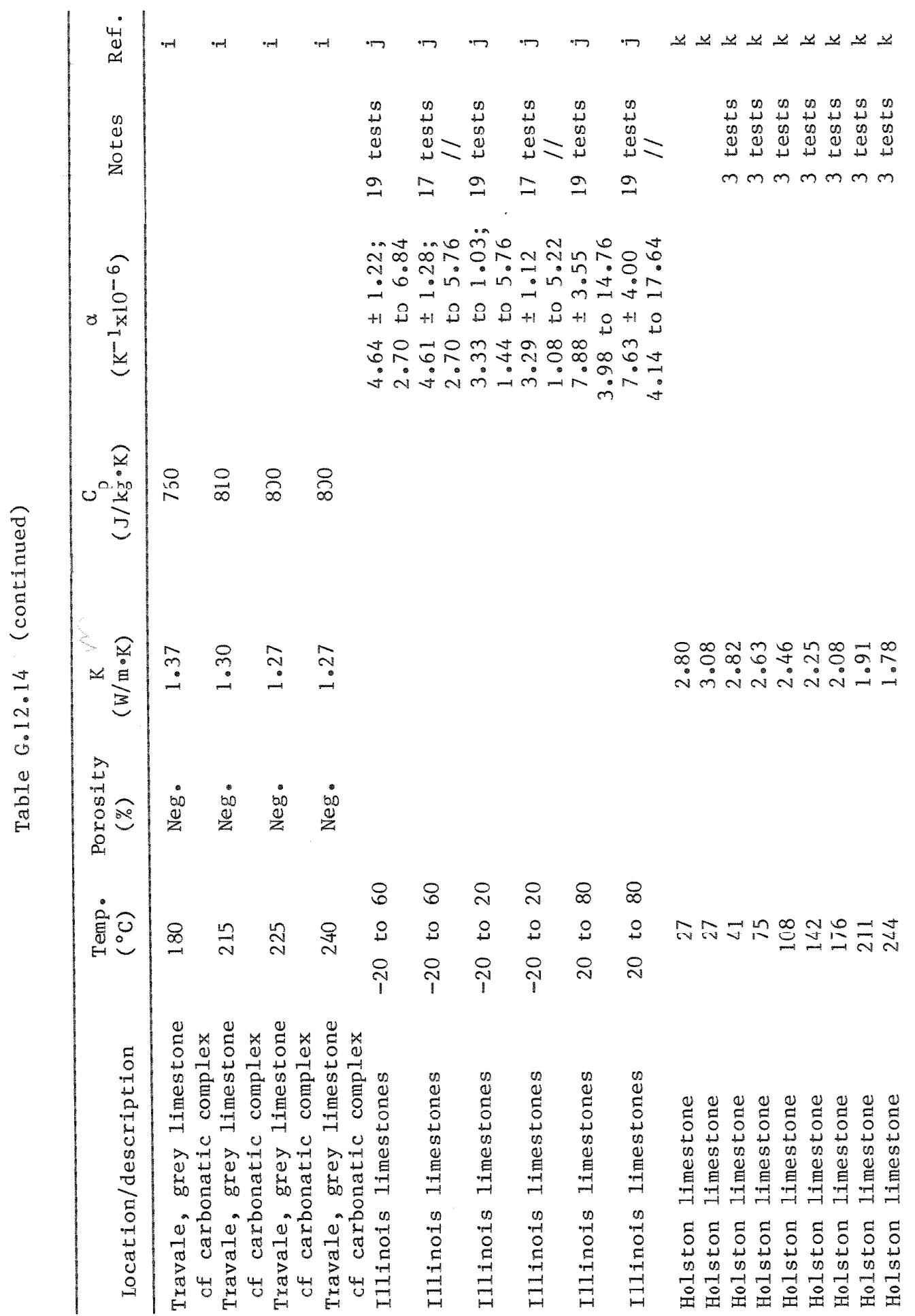




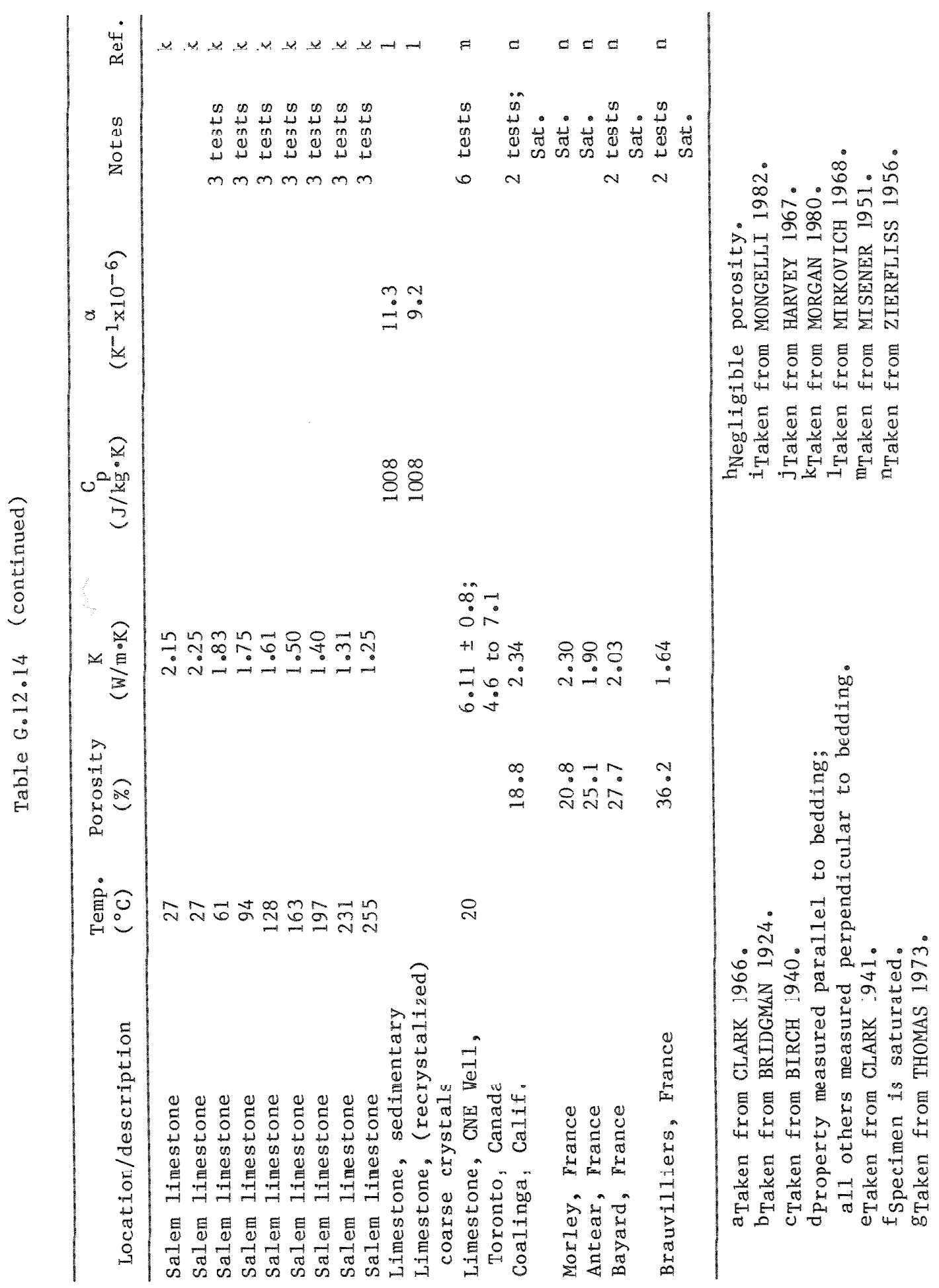




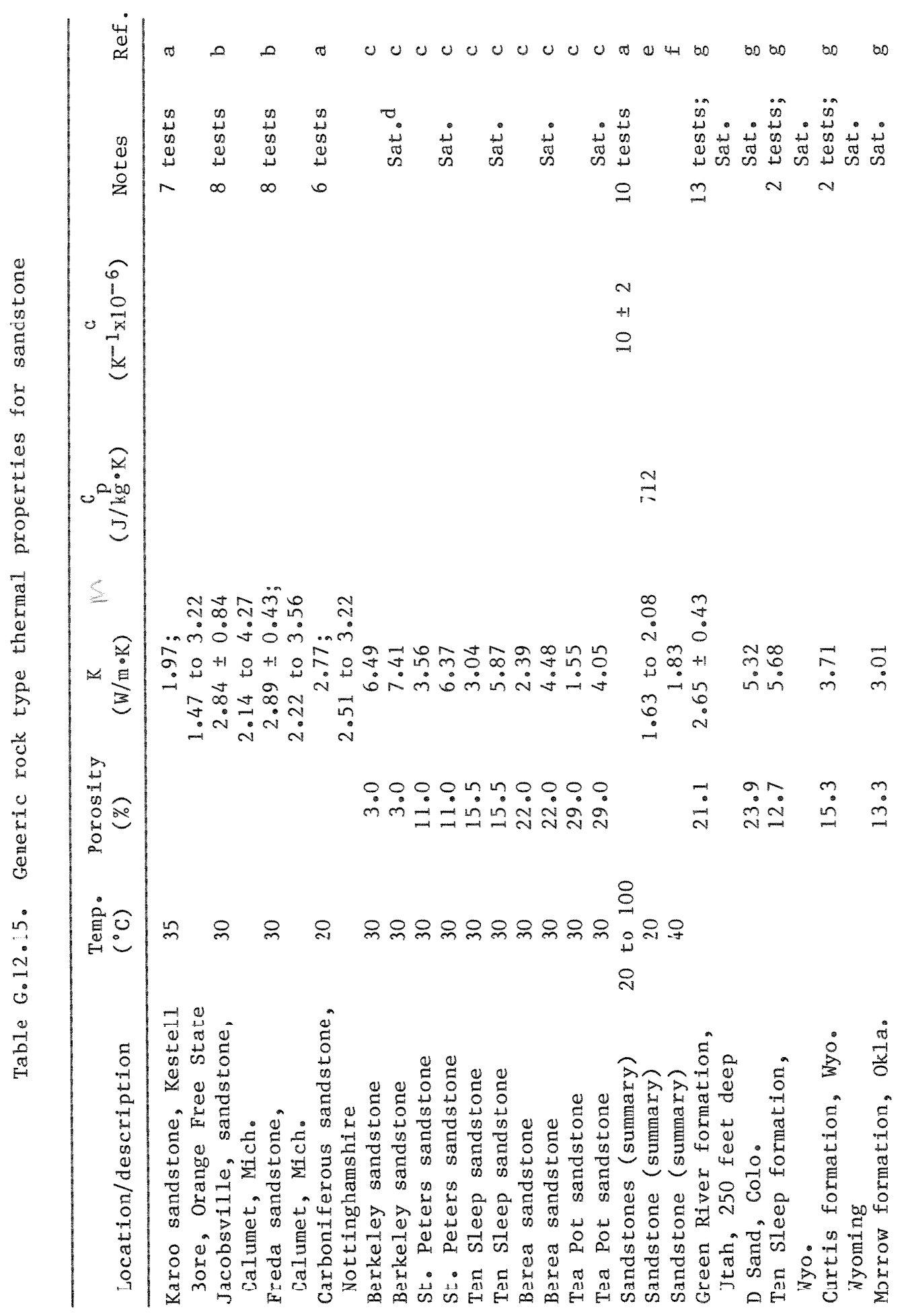




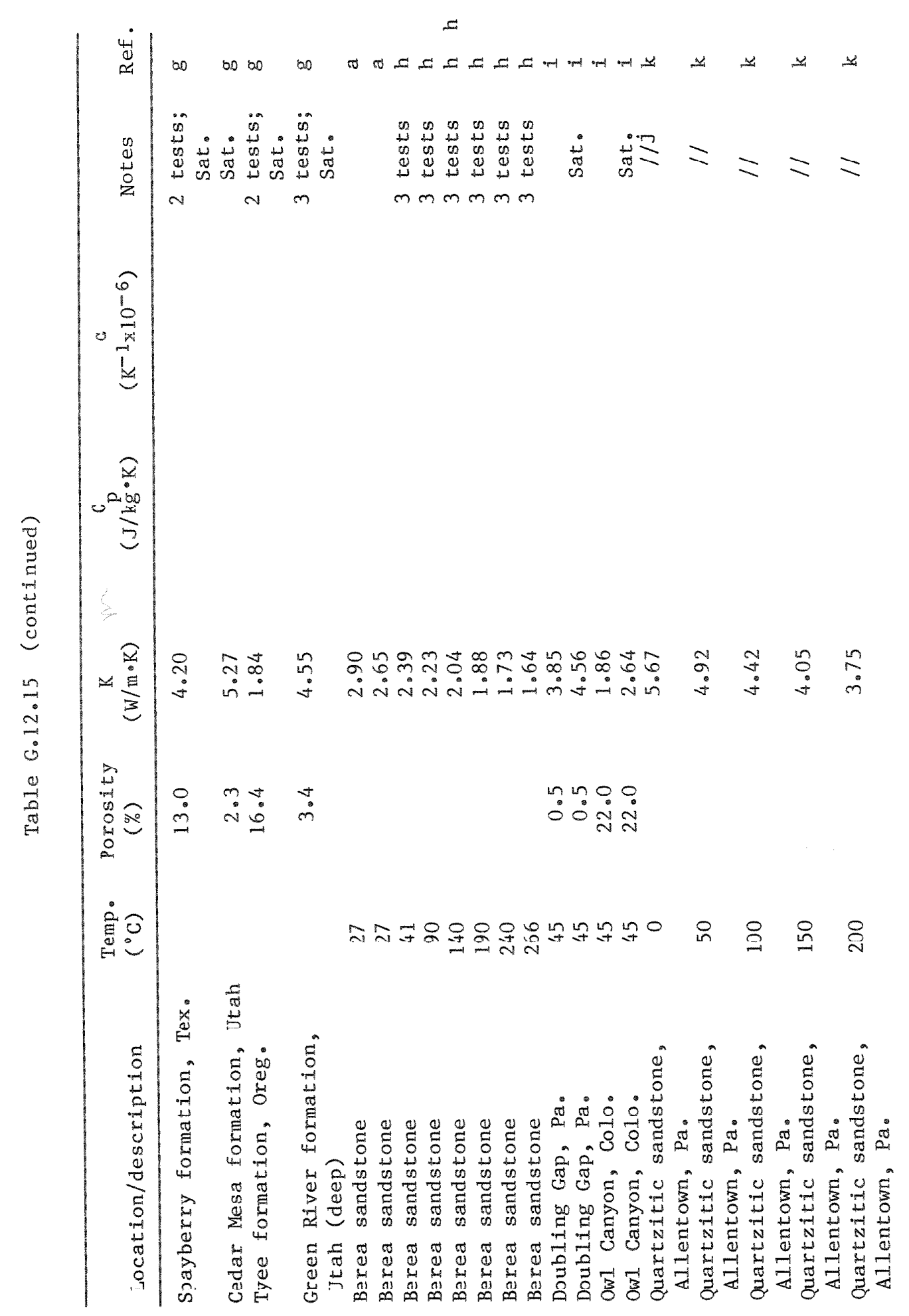




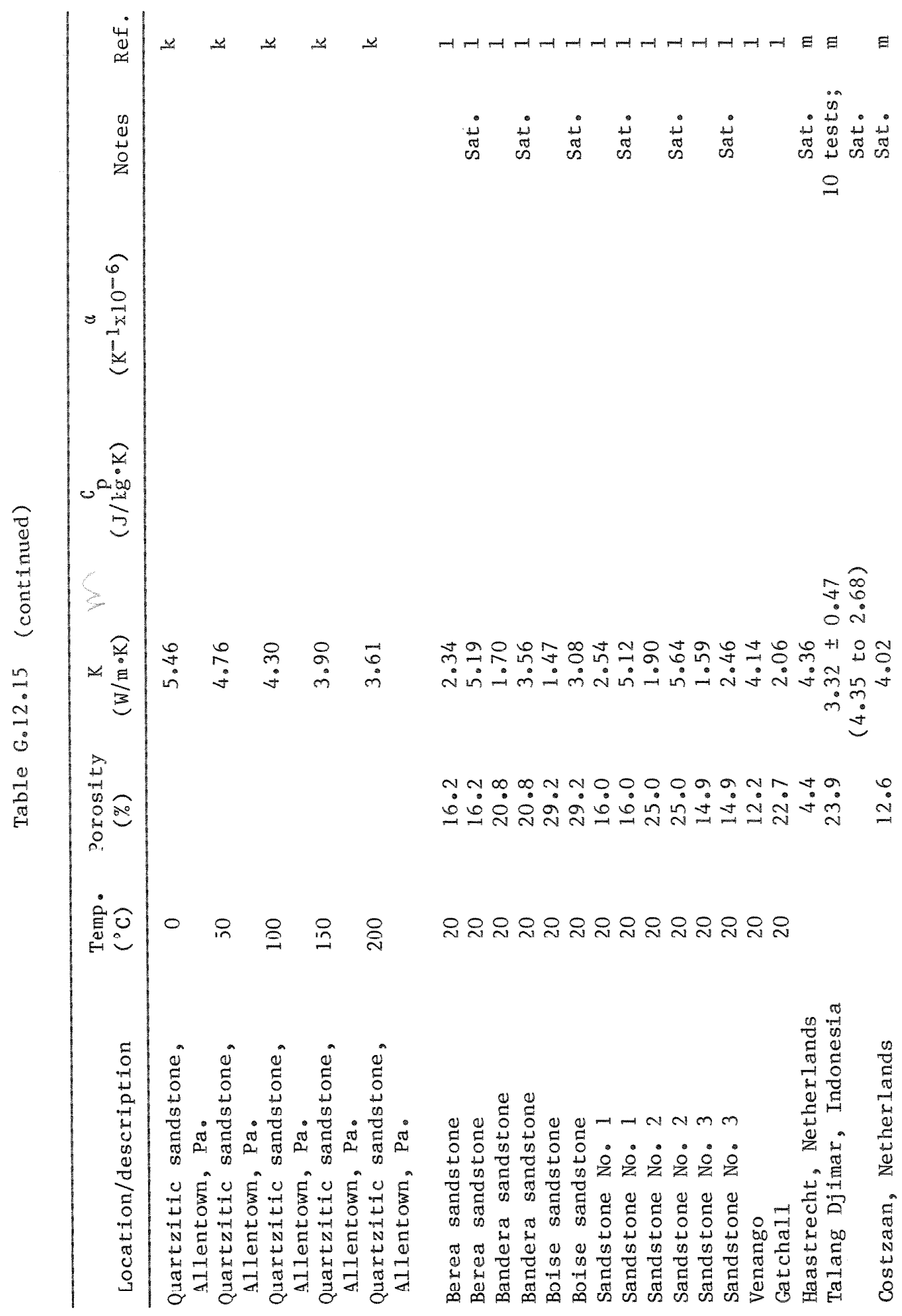




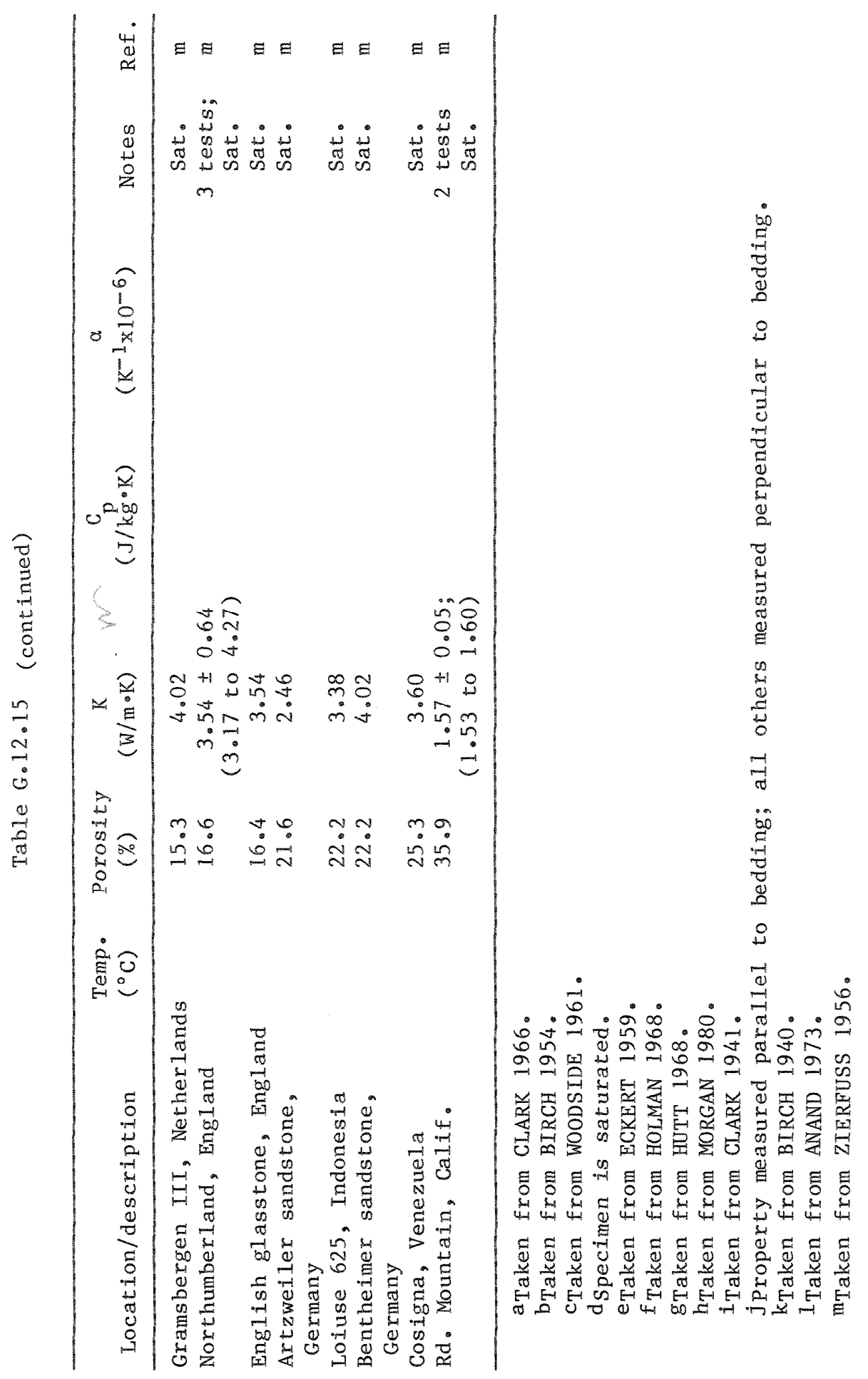




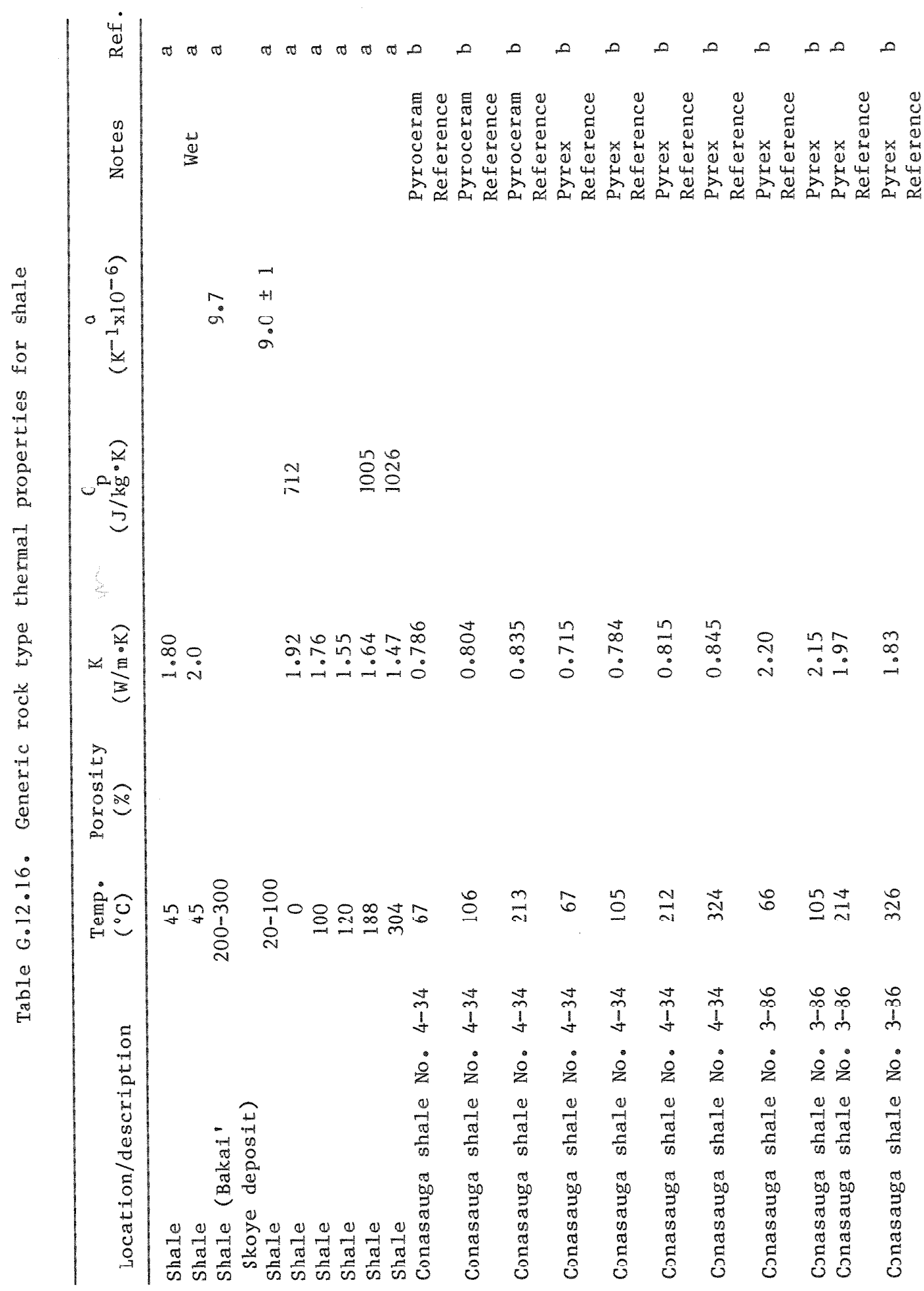




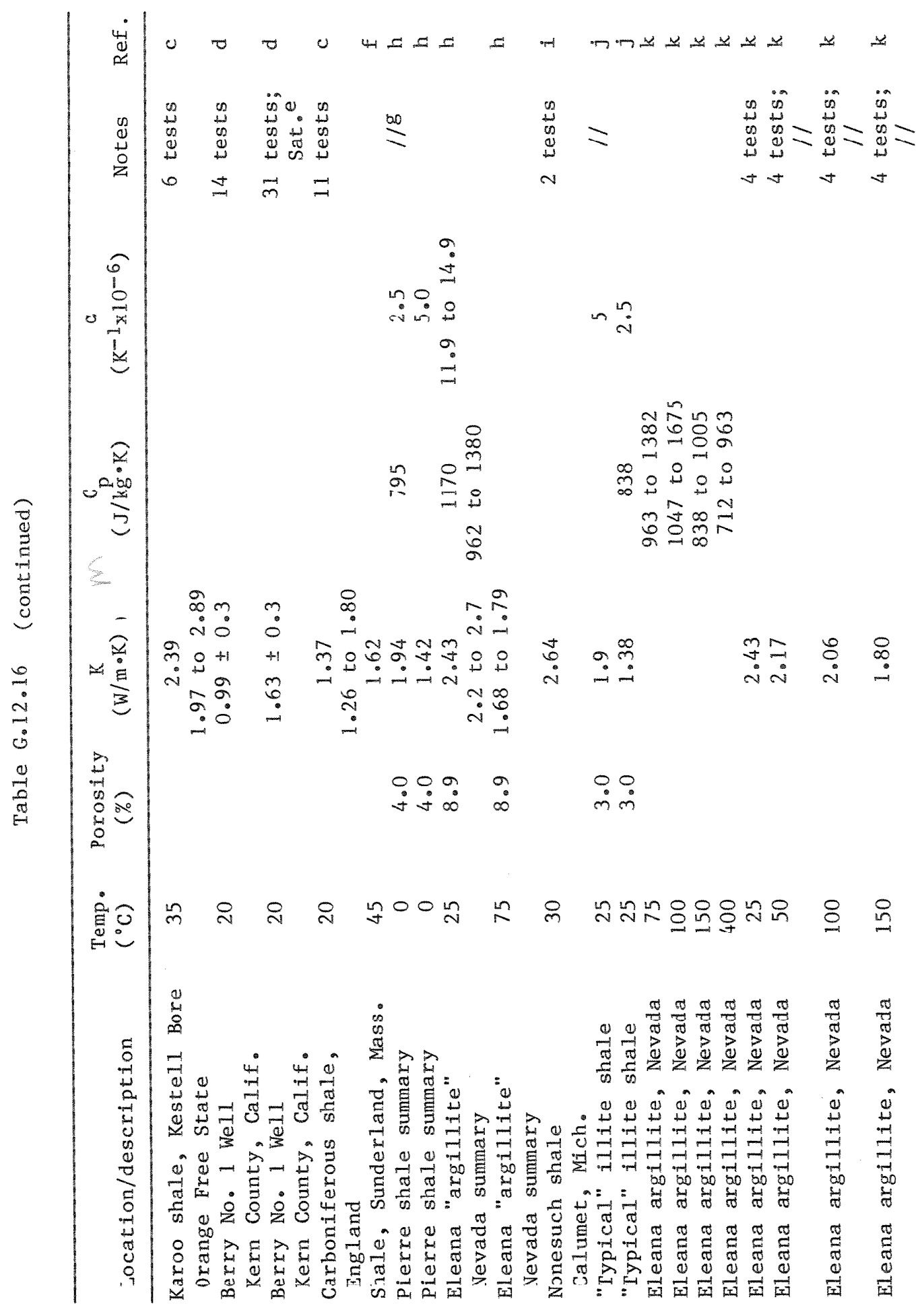




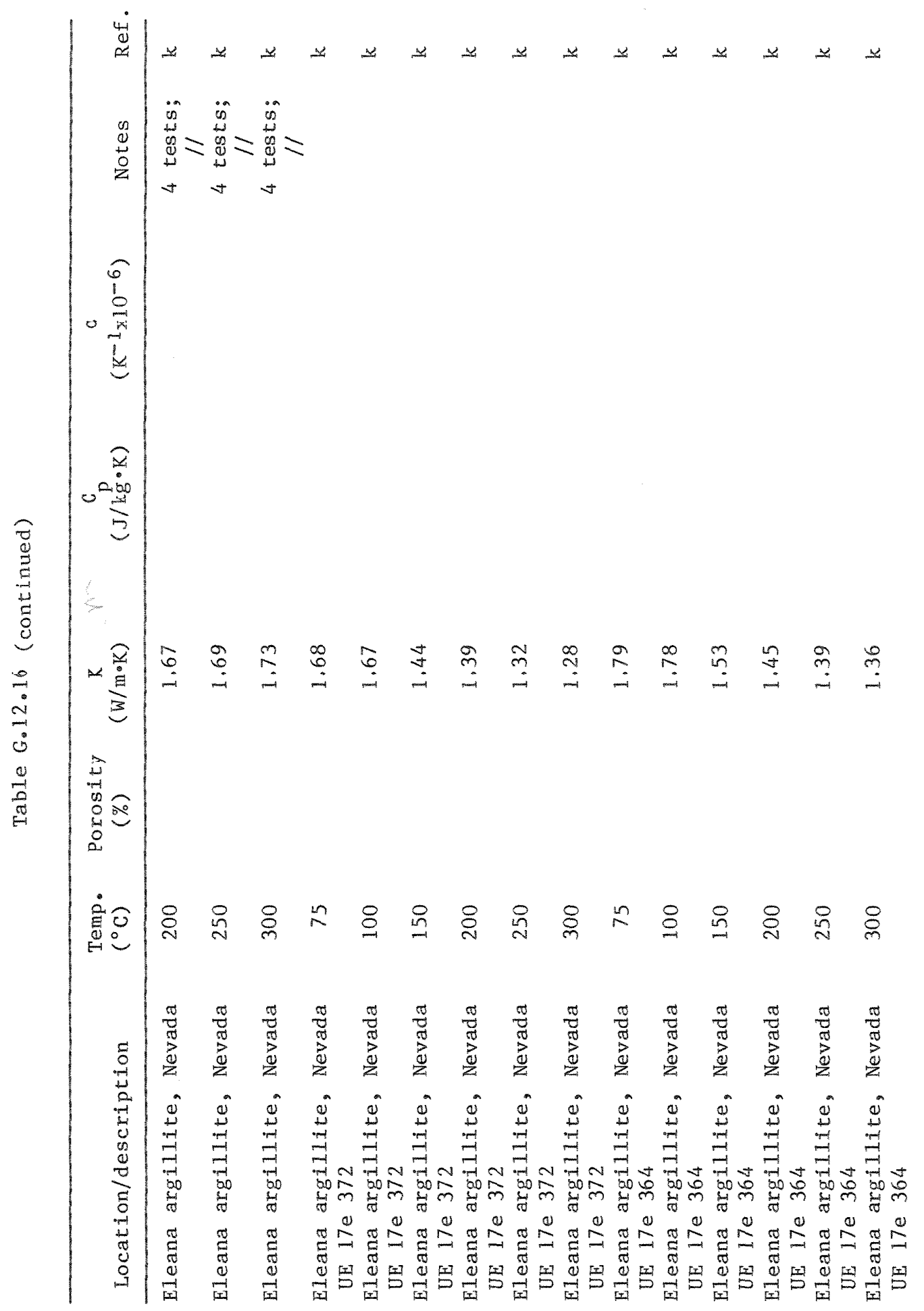




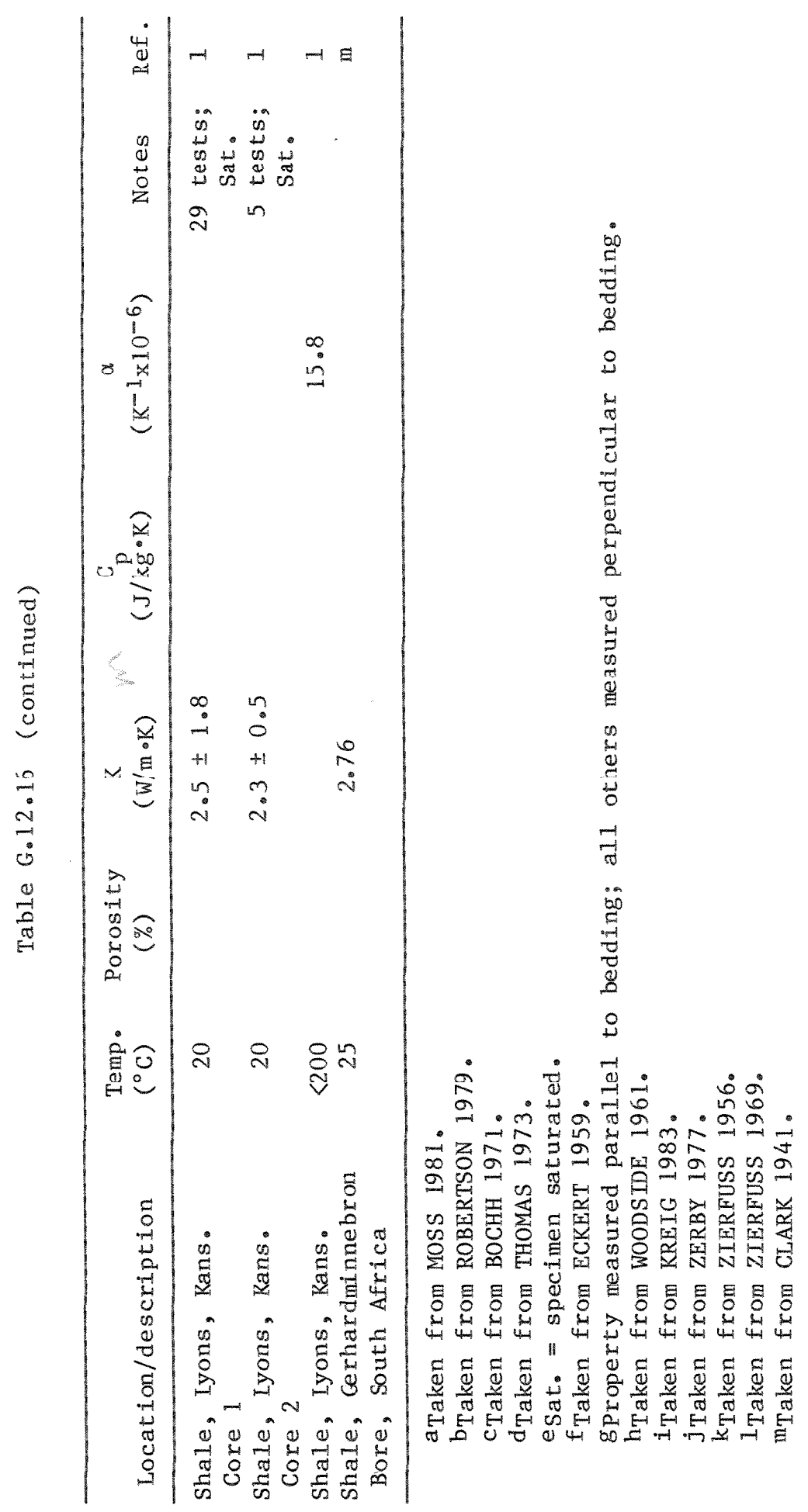


Table G.12.17. Therma1 conductivity, $\mathrm{W} / \mathrm{m} \cdot \mathrm{K}$

\begin{tabular}{lccccc}
\hline \multicolumn{1}{c}{ Rock type } & $\mathrm{n}$ & Maximum & Minimum & Mean & $\begin{array}{c}\text { Standard } \\
\text { deviation }\end{array}$ \\
\hline Anhydrock & 7 & 5.7 & 3.2 & 5.0 & 0.9 \\
Chalk & 2 & 1.2 & 1.7 & 1.5 & 1.1 \\
Carbonate rocks & 52 & 6.1 & 0.9 & 3.0 & 1.4 \\
Sandstone & 61 & 7.4 & 1.5 & 3.6 & 0.5 \\
Shalea & 14 & 2.8 & 1.0 & 2.0 & \\
\hline
\end{tabular}

ashale values given are measured perpendicular to bedding. The value of thermal conductivity parallel to bedding is about

1.4 times that perpendicular to beding.

Table G.12.18. Temperature dependence of thermal conductivity, $\left.\left[\mathrm{K} / \mathrm{m} \cdot \mathrm{K}^{2}\right)\right] \times 10^{-3}$

\begin{tabular}{lccccc}
\hline \multicolumn{1}{c}{ Rock type } & $n$ & Maximum & Minimum & Mean & $\begin{array}{c}\text { Standard } \\
\text { deviation }\end{array}$ \\
\hline Carbonate rocks & 11 & -1.0 & -8.1 & -4.5 & 2.3 \\
Sandstone & 3 & -3.3 & -9.4 & -6.3 & 4.2 \\
$\begin{array}{l}\text { Shale } \\
\text { Shan }\end{array}$ & 1 & +1.39 & -2.54 & -1.23 & 1.2 \\
\hline
\end{tabular}


Table G.12.19. Heat capacity, J/kg $\cdot \mathrm{K}$

\begin{tabular}{lccccc}
\hline \multicolumn{1}{c}{ Rock type } & $\mathrm{n}$ & Maximum & Minimum & Mean & $\begin{array}{c}\text { Standard } \\
\text { deviation }\end{array}$ \\
\hline Anhydrock & 2 & 860 & 516 & 688 & \\
Carbonate rocks & 6 & 770 & 670 & 727 & 39 \\
Sandstone & 1 & & & 712 & \\
Shale & 1 & 1170 & 712 & 879 & 201 \\
\hline
\end{tabular}

Table G.12.20. Coefficient of linear thermal expansion, $\mathrm{K}^{-1} \times 10^{-6}$

\begin{tabular}{lccccc}
\hline \multicolumn{1}{c}{ Rock type } & $\mathrm{n}$ & Maximum & Minimum & Mean & $\begin{array}{c}\text { Standard } \\
\text { deviation }\end{array}$ \\
\hline Anhydrock & 1 & & & 20 & \\
Carbonate rocks & 12 & 21.7 & 3.3 & 6.65 & 2.13 \\
Sandstone & 1 & & & 10 & 2 \\
Shale & 8 & 15.8 & 2.5 & 7.86 & 5.0 \\
\hline
\end{tabular}


$\overline{2}$
1
1
$\infty$
0
0
0
$\vdots$
$\vdots$
0
0
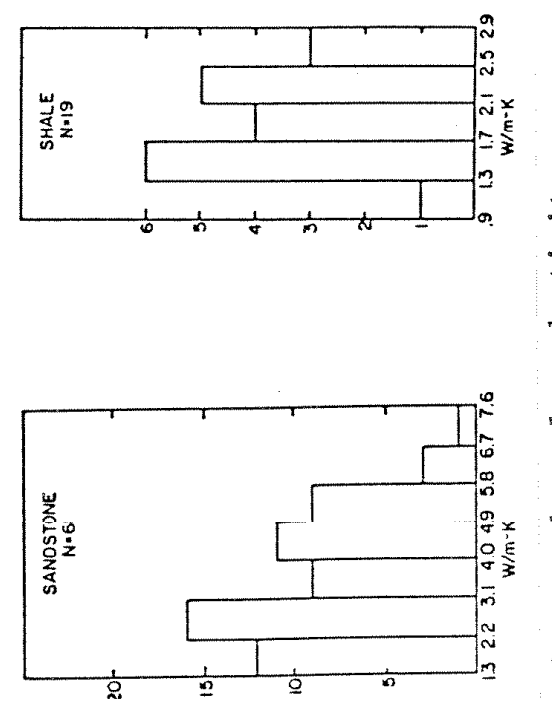

궁

$\frac{2}{2}$

苞

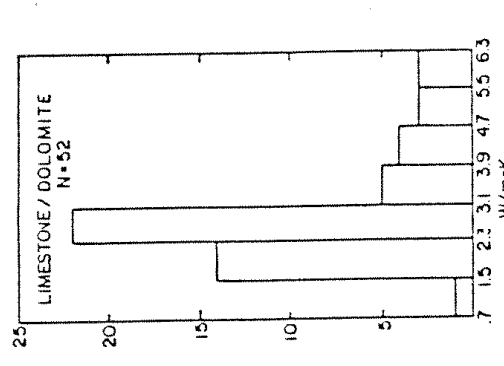

营

岁

:

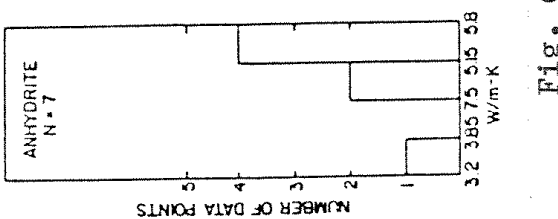




\section{G.13 GLOSSARY}

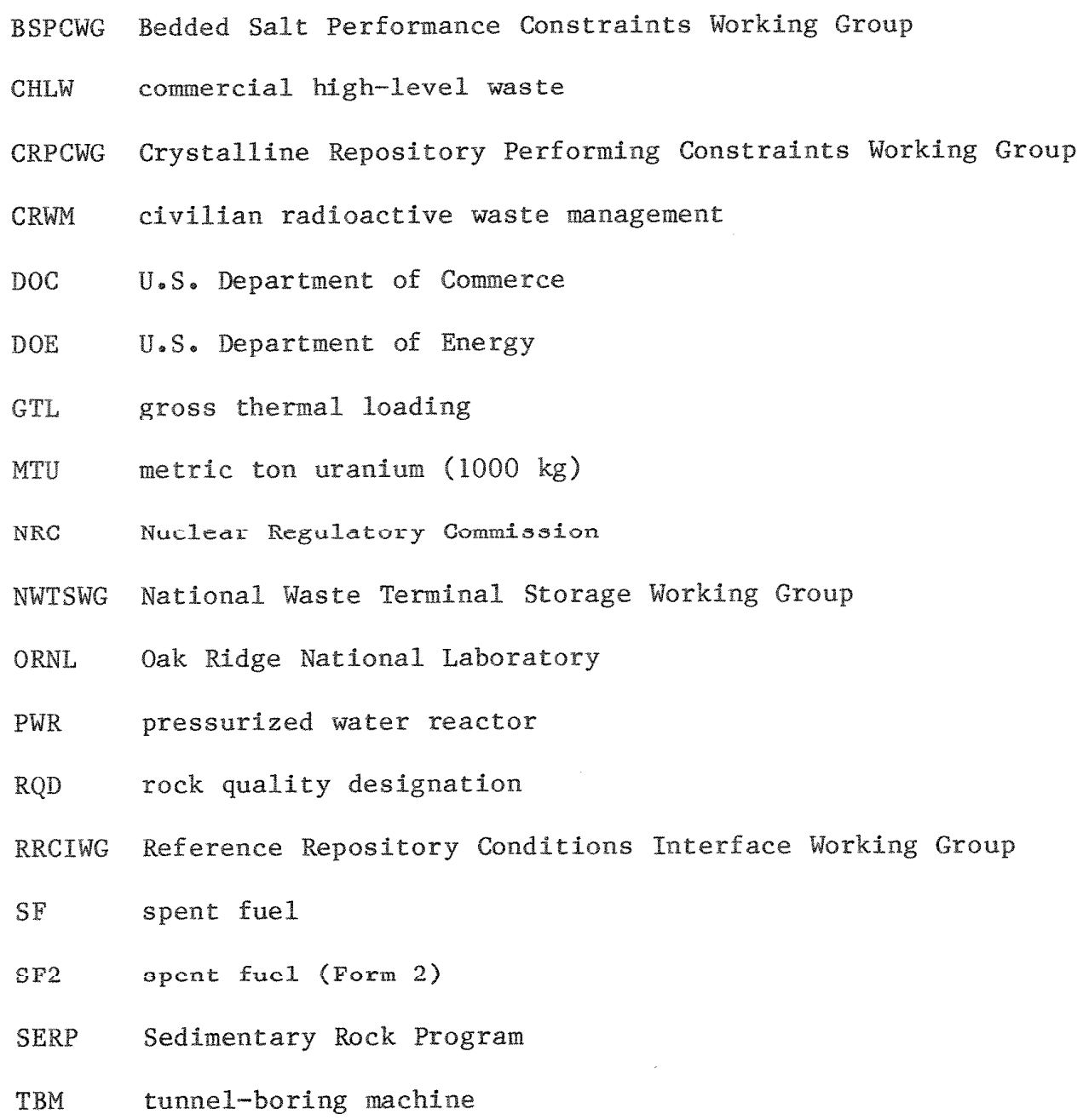




\section{G.14 REFERENCES}

ABEL 1976. J. F. Abel, Jr., and W. N. Hoskins, "Confined Core Pillar Design for Colorado Ofl Shale" (Proceedings of the Ninth oil Shale Symposium), Colorado School of Mines Quarterly, 71, October 1976.

ANAND 1973. J. Anand, W. H. Somerton, and E. Gomaa, "Predicting Thermal Conductivities of Formations From Other Known Properties," Soc. Pet. Eng. J., 13, pp. 267-273 (1973).

BELL 1977. F. G. Be11, "A Note on the Physical Properties of the Chalk," Engineering Geology, 11, pp. 217-225 (1977).

BENFIELD 1947. A. E. Benfield, "A Heat Flow Value for a well in California," Am. J. Sci., 2/5, pp. 1-18 (1947).

BIRCH 1940. F. Birch and H. Clark, "The Thermal Conductivity of Rocks and Its Dependence Upon Temperature and Composition," Am. J. Sci., 238, pp. 529-558 (1940).

BIRCH 1945. F. Birch and H. Clark, "An Estimate of the Surface Flow of Heat in the West Texas Permian Basin," Am. J. Sci., 243A, pp. 69-74 (1945).

BIRCH 1954. F. Birch, "Thermal Conductivity, Climatic Variation, and Heat Flow Near Calumet, Michigan," Am. J.Sci., 252, pp.1-25 (1954).

BLACIC 1981. J. D. Blacic, P. H. Halleck, P. D'Onfro, and R. E. Riecker, "Thermomechanical Properties of Galesville Sandstone," Mechanical Behavior of Crystal Rocks, American Geophysical Union, Washington, D.C., Geophysical Monograph 24, 1981, pp. 153-159.

BLACKBURN 1978. L. D. Blackburn, D. G. Farwick, S. R. Fields, L. A. James, and R. A. Moen, Maximum Allowable Temperature for Storage of Spent Nuclear Reactor Fuel - An Interim Report, HEDL-TMS 78-37, prepared by Hanford Engineering Development Laboratory, Westinghouse Electric Corporation, Pittsburgh, Pa., 1978.

BLAIR 1955. B. E. Blair, Physical Properties of Mine Rock, Part III, Investigation Report No. 5130 , U.S. Bureau of Mines, Washington, D.C., 1955.

BLAIR 1956. B. E. Blair, Physical properties of Mine Rock, Part IV, Investigation Report No. 5244, U.S. Bureau of Mines, Washington, D.C., 1956.

BLANTON 1980. T. L. Blanton, C. Young, and N. C. Patti, Material Properties of Devonian Shale for Stimulation Technology Development, DE83006484, prepared by Science Applications, Inc., Steamboat Springs, Colo., for U.S. Department of Energy. Margantown Finergy Terhnnlngy Center, Morgantown, W. Va., 1980. 
BLANTON 1981. T. L. Blanton, Dischler, and N. C. Patti, Mechanical Properties of Devonian Shales From the Appalachian Basin, DE83006477, prepared by Science Applications, Incorporated, Steamboat Springs, Colo., for U.S. Department of Energy, Morgantown Energy Technology Center, Morgantown, W. Va., 1981.

BOCH 1971. A. L. Boch, J. O. Blomeke, W. C. McClain, and

B. F. Bottenfield, Radioactive Waste Repository Project: Technical Status Report for Period Ending September 30, 1971, ORNL-4751, prepared by Oak Ridge National Laboratory, Union Carbide Corporation, Oak Ridge, Tenn., for U.S. Atomic Energy Commission, 1971.

BRADSHAW 1971. R. L. Bradshaw and W. C. McClain, project Salt Vault: A Demonstration of the Disposal of High Activity Solidified Wastes in Underground Salt Mines, ORNL-4555, prepared by Oak Ridge National Laboratory, Dak Ridge, Tenn., Apri1 1971.

BRANDSHAUG 1983. T. Brandshaug, NNWSI Unit Evaluation at Yucca Mountain, Nevada Test Site: Far-Field Thermal/Rock Mechanics Analyses, RSI(ALO) -0209, prepared by RE/SPEC Inc., Rapld City, S.D., for Sandia National Laboratories, Sandia Corporation, Albuquerque, N.M., April 1983.

BRIDGMAN 1924. P. W. Bridgman, "The Thermal Conductivity and Compressibility of Several Rocks Under High Pressures," Am. J. Sci., I, pp. 81-102 (1924).

BSPCWG 1984. The Bedded Salt Performance Constraints Working Group, Performance Constraints for a Repository in Bedded Salt, RSI-0197, prepared by RE/SPEC Inc., Rapid City, S.D., for Office of Nuclear waste Isolation, Battelle Memorial Institute, Columbus, Ohio, June 1984.

BULLARD 1939. E. C. Bullard, "Heat Flow in South Africa," Royal Society of London Proceedings, Series A, 173, pp. 474-502 (1939).

CFR 1984. Code of Federal Regulations, 10 CFR 960, Federal Register, 49 (236), 17714 (December 1984).

CHAPMAN 1967. A. J. Chapman, Heat Transfer, Second Edition, The MacMillan Company, New York, $\overline{1967 . ~}$

CLARK 1941. H. Clark, "The Effects of Simple Compression and Wetting on the Thermal Conductivity of Rocks," Trans. Am. Geophys. Union, Washington, D.C., pp. 543-544 (1941).

CLARK 1966. S. P. Clark, Jr., Handbook of Physical Constants, Memoir 97. The Geological Society of America, Inc., New York, 1966.

CLARK 1980. G. B. Clark, L. Ozdemir, and F. D. Wang, Tunnel Boring Machine Technology for a Deep1y Based Missile System, AFWL-TR-79-120, prepared hy the Colnradn Schnot of Mines for the Air Force Weapons Laboratory, Vols. I and II, 1980. 
CORBETT 1982. K. P. Corbett, Structural Stratigraphy of the Austin Chalk, M.S. Thesis, prepared for Graduate College of Texas A\&M University, College Station, December 1982.

CRPCWG 1984. The Crystalline Repository Performance Constraints Working Group, Interim Guidelines on Performance Constraints for Nuclear Waste Disposal in Crystalline Rock, RSI-0215, prepared for Office of Crystalline Repository Development, Battelle Memorial Institute, Columbus, Ohio, January 1984.

DAMES AND MOORE, INC., 1980. Review of Potential Host Rocks for Radioactive Waste Disposal in the Southeast United States - Triassic Basic Subregion, UC-70, prepared by E. I. du Pont dc Ncmours \& Co., Aiken, S.C., DP-1569, for U.S. Department of Energy, 1980.

D'ANDREA 1965. D. V. D'Andrea, R. L. Fischer, and D. E. Fogelson, Prediction of Compressive Strength from Other Rock Properties, Investigation Report No. 6702 , U.S. Bureau of Mines, Washington, D.C. 1965.

DMITRIYEV 1972. A. P. Dmitriyev, L. S. Kuzyayev, Yu. I. Protasou, and V. S. Yamshchikov, Physical Properties of Rocks at High Temperatures, NASA TT F-684, National Aeronautics and Space Administration, Washington, D.C., 1972 .

ECKERT 1959. E. R. G. Eckert, R. M. Drake, Heat and Mass Transfer, McGraw-Hi11, New York, 1959.

GARY 1974. M. Gary, R. McAfee, Jr., and C. L. Wolf, Glossary of Geology, Third Edition, American Geological Institute, Washington, D.C., 1974.

GNIRK 1972. P. F. Gnirk and W. H. Grams, "Rock Drilling With Pulsed High-Velocity Water Jets," Proceedings of the Fourteenth Symposium on Rack Mechanics, Univeraity Park, Po., 1972, pp. 589-612.

GONZALES 1975. S. Gonzales, Geologic Feasibility of Selected ChalkBearing Sequences Within the Conterminous United States With Regard to Siting of Radioactive-Waste Repositories, Y/OWI/SUB-4310/2, prepared by Union Carbide Corporation, Nuclear Division, Office of Waste Isolation, Oak Ridge, Tenn., for U.S. Energy Research and Development Administration, November 1975.

GOODMAN 1980. R. E. Goodman, Introduction to Rock Mechanics, John Wiley and Sons, New York 1980.

GRIM 1953. R. E. Grim, Clay Mineralogy, McGraw-Hill, New York, 1953.

HANDIN 1957. J. Handin and R. V. Hager Jr., "Experimental Deformation of Sedimentary Rocks Under Confining Pressure: Tests at Room Temperature on Dry Samples," Am. Assoc. Petro1. Geo1. Bull., 41, pp.1-50 (1957). 
HANSEN 1975. F. D. Hansen and P. F. Gnirk, Design Aspects of the Alpha Repository: III. Uniaxial Quasi-Static and Creep Properties of the Site Rock, ORNL-SUB-4269-10, RSI-0029, prepared by RE/SPEC Inc., Rapid City, S.D., for Dak Ridge National Laboratory, Union Carbide Corporation, Nuclear Division, Oak Ridge, Tenn., 1975.

HARVEY 1967. R. D. Harvey, Thermal Expansion of Certain Illinois Limestones and Dolomites, Illinois State Geological Survey, Urbana, I11., 1967, Circular 415.

HASWELL 1975. C. K. Haswell, "Problems of Tunnelling in Chalk," Tunnels and Tunnelling, 7 , pp. 40-43 (1975).

HERRIN 1956. E. Herrin and S. P. Clark, Jr., "Heat Flow in West Texas and Eastern New Mexico," Geophysics, 21, pp. 1087-1099 (1956).

HOEK 1980. E. Hoek and E. T. Brown, Underground Excavations in Rock, The Institution of Mining and Metallurgy, London, 1980 .

HOLMAN 1968. J. P. Holman, Heat Transfer, McGraw-Hill, New York, 1 Yb8.

HOLMAN 1979. J. P. Holman, Heat Transfer, Second Edition, McGraw-Hi11 Book Company, New York, 1979.

HOOD 1979. M. Hood, H. Carlsson, and P. H. Nelson, II. The Application of Field Data From Heater Experiments Conducted at Stripa, Sweden to Parameters for Repository Design, LBL-9392 SAC-26, Lawrence Berkeley Laboratory, Berkeley, Calif., 1979.

HUTT 1968. J. R. Hutt and J. W. Berg, Jr., "Thermal and Electrical Conductivities of Sandstone Rocks and Ocean sediments, "Geophysics, 33, pp. 489-500 (1968).

JOHNSTON 1981. R. G. Johnston and R. A. Palmer, Characteristics ofCandidate Geologies for Nuclear Waste Isolation! A Review, prepared by Rockwell Hanford Operations, Richland, Wash., for U.S. Department of Energy, Savannah River Operations office, 1981.

JOHNSTON 1983. R. M. Johnston, The Conversion of Smectite to Illite in Hydrothermal Systems: A Literature Review, AECL-7792, Atomic Energy of Canada, Limited, Pinawa, Manitoba, 1983.

JOHNSTONE 1982. J. K. Johnstone and P. F. Gnirk, Preliminary Technical Constraints for a Repository in Tuff, SAND82-2147, Sandia National Laboratories, Albuquerque, N.M., 1982.

KELLEY 1960. K. K. Kelley, Contributions to the Data on Theoretical Metallurgy, XIII. High-Temperature Heat-Content, Heat-Capacity and Entropy Data for the Elements and Inorganic Compounds, Bureau of Mines, Berkeley, Calif., 1960, Bulletin 584. 
KIBBE 1978. R. K. Kibbe and A. L. Boch, "Baseline Rock PropertiesShale," Technical Support for GEIS: Radioactive Waste Isolation in Geologic Formations, 6, Y/OWT/TM-36/6, prepared by Dames and Moore, White Plains, N.Y., for Union Carbide Corporation, Nuclear Division, Office of Waste Isolation, Oak Ridge, Tenn., 1978.

KISNER 1978. R. A. Kisner, J. R. Marsha11, D. W. Turner, and J. E. Vath, Nuclear Waste Projections and Source-Term Data for FY 1977, Y/OWI/TM-34, prepared by U.S. Department of Energy for office of Waste Isolation, Oak Ridge, Tenn. 1978.

KRECH 1974. W. W. Krech, F. A. Henderson, and K. E. Hjelmstad, A Standard Rock Suite for Rapid Excavation Reocarch, Investigation Report No. 7865, U.S. Bureau of Mines, Washington, D.C. 1974.

KRIEG 1983. R. D. Krieg, Reference Stratigraphy and Properties for the Waste Isolation Pilot Plant (WIPP) Project, SAND83-1908, Sandia National Laboratories, Albuquerque, N.M., 1983.

KRoN 1902. A. Kron and J. Stix, Gcothcrmal Cradient Map of the United States (Exclusive of Alaska and Hawaii), produced by National Geophysical Data Center, National Oceanic and Atmospheric Administration for Los Alamos National Laboratory, Los Alamos, NoM., University of California, 1982.

KULHAWY 1975. F. H. Kulhawy, "Stress Defomation Properties of Rock and Rock Discontinuties," Engineering Geology, 9, pp. 327-350 (1975).

LYNCH 1975. C. T. Lynch, CRC Handbook of Materials Science, II, (Metals, Composites, and Refractory Materials), CRC Press, Inc., Florida, 1975 .

MCVEX 1979. D. F. McVey, A. R. Lappin, and R. K. Thomas, "Test Results and Supporting Analyoilo of a Near Surface Heater Experiment in the Eleana Argillite," Proceedings of the Workshop on the Use of Argillaceous Materials for the Isolation of Radioactive Waste, Paris, France, September, 1979, pp. 93-113.

MIRKOVICH 1968. V. V. Mirkovich, "Experimental Study Relating Thermal Conductivity to Thermal Piercing of Rocks," Int. J. Rock Mech. Min. Sci., 5, pp. 205-218 (1968).

MISENER 1951. A. D. Misener, L. G. D. Thompson, and R. J. Uffen, "Terrestrial Heat Flow in Ontario and Quebec," Trans. Am. Geophys. Union, 32, pp. 729-738 (1951).

MONGELLI 1982. F. Monge11i, M. Loddo, and A. Tramacere, "Therma1 Conductivity, Diffusivity and Specific Heat Variation of Some Travale Field (Tuscany) Rocks Versus Temperature," Tectonophysics, 83, pp. 33-43 (1982). 
MORGAN 1980. M. T. Morgan and G. A. West, Thermal Conductivity of the Rocks in the Bureau of Mines Standard Rock Suite, ORNL/TM-7052, Oak Ridge National Laboratory, Union Carbide Corporation, Oak Ridge, Tenn., for the Office of Nuclear Waste Isolation, Battelle Memorial Institute, Columbus, Ohio, 1980.

Moss 1981. M. Moss and G. M. Haseman, Thermal Conductivity of Polyhalite and Anhydrite From the Site of the Proposed Waste Isolation Pilot plant, SAND 81-0856, prepared by Sandia National Laboratories, Albuquerque, N.M., for U.S. Department of Energy, 1981.

NAS 1983. National Academy of Sciences, Waste Isolation Systems Panel - Board of Radioactive Waste Management, Nac1onal Research Council, National Acadeny Press, Washington, D.C., 1983.

NATIONAL RESEARCH COUNCIL 1983. National Research Council, Changing Climate, Report of the Carbon Dioxide Assessment Committee, Board of Atmospheric Sciences and Climate Commission on Physical Sciences, Mathematics, and Resources, National Academic Press, Washington, D.C., 1983.

NRC 1983. U.S. Nuclear Regulatory Commission, "Disposal of High-Level Radioactive Wastes in Geologic Repositories Technical Criteria (10 CFR 60)," Federal Register, 48, No. 120, Washington, D.C., June $21,1983$.

NWTSWG 1981. The NWTS Working Group on Far-Field Performance Constraints, Repository Performance Constraints in the Far-Field Domain, July 1981.

OBERT 1973. L. Obert and W. Duva11, "Design and Stability of Excavations in Rock-Subsurface," SME Mining Engineering Handbook, 1 , pp. 7-10 to $7-49,1973$.

OSNES 1984. J. D. Osnes, G. K. Coates, K. B. yeJong, M. C. Loken, and R. A. Wagner, Expected Repository Environments in Granite: Thermal Envi conment, OCRD-7, RSI-0161, prepared by RE/SPEC Inc., Rapid City, S.D., for office of Nuclear Wate Tsolation. Battelle Memorial Institute, Columbus, Ohio, issued as an office of Crystalline Repository Development report with concurrence of the office of Nuclear Waste Isolation, September 1984 .

PATERSON 1978. M. S. Paterson, Experimental Rock Deformation: The Brittle Field, Springer-Verlag, Berlin, Heidelberg, New York, p. 166.

PETTIJOHN 1975. F. J. Pettijohn, Sedimentary Rocks, Third Edition, Harper \& Row, New York, 1975.

PFETFLE 1981. T. W. Pfeifle and P. E. Senseny, Elastic-Plastic Deformation of Anhydrite and Polyhalite as Determined From Quasi-Static Triaxial Compression Tests, SAND81-7063, RSI-0135, prepared by RE/SPEC Inc., Rapid city, S.n., for Sandia National Laboratories, Albuquerque, N.M., 1981 . 
PFEIFLE 1983. T. W. Pfeifle, K. D. Mellegard, and P. E. Senseny, Preliminary Constitutive Properties for Salt and Nonsalt Rocks From Four Potential Repository Sites, ONWI-450, RSI-0191, prepared by RE/SPEC Inc., Rapid City, S.D., for office of Nuclear Waste Isolation, Battelle Memorial Institute, Columbus, Ohio, 1983.

PLACKETT 1946. R. L. P1ackett and J. P. Burman, "The Design of Optimum Multifactorial Experiments," Biometrika 33, pp. 305-25 (1946).

POWERS 1978. D. W. Powers, S. J. Lambert, S. E. Shaffer, L. R. Hil1, and W. D. Weart, Geological Characterization Report, Waste Isolation pilnt p1ant (WTPP) Site, Southeastern New Mexico, I, SAND78-1596, prepared by Sandia National Laboratories, Albuquerque, N.M., and Livermore, Calif., for U.S. Department of Energy, 1978.

PRATl 1969. H. Pract, J. L. Bralcon, aud R. Zbur, Geology and Material Properties of the Estancia Valley Test Site, New Mexico, AFWL-TR-69-24, Air Force Weapons Laboratory, Kirtland Air Force Base, N.M., 1969.

RATIGAN 1984. J. L. Ratigan, M. C. Loken, K. M. Linde, and R. A. Wagner, Design Analysis for a Repository in Crystalline Rock, RSI-0237, prepared by RE/SPEC Inc., Rapid City, S.D., for Office of Nuclear Waste Isolation, Battelle Memorial Institute, Columbus, Ohio, May 1984.

RE/SPEC INC. 1984a. RE/SPEC Inc., Rock Mechanics Evaluation of Potential Repository Sites in the paradox Basin, RSI-0253, prepared by RE/SPEC Inc., Rapid City, S.D., for Office of Nuclear Waste Isolation, Battelle Memorial Institute, Columbus, Ohio, April 1984.

RE/SPEC INC. 1984b. RE/SPEC Inc., Rock Mechanics Evaluation of Potential Repository Sites in the Permian Basin, RSI-0254, prepared by RE/SPEC Inc., Rapid City, S.D., for Office of Nuclear Waste Isolation, Battelle Memorial Institute, Columbus, Ohio, May 1984.

RE/SPEC INC. 1984c. RE/SPEC Inc., Rock Mechanics Evaluation of Potential Repository Sites in the Gulf Coast Domes, RSI-0255, prepared by RE/SPEC Inc., Rapid CiLy, S.D., for Office of Nuclear Wostc Isolation, Battelle Memorial Institute, Columbus, Ohio, May 1984.

RHINES 1977. R. C. Rhines and J. M. Asher, office of Waste Isolation Progress Report, Y/OWI/TM-43/2, prepared by office of Waste Isolation, Union Carbide Corporation, Nuclear Division, Oak Ridge, Tenn., for U.S. Energy Research and Development Administration, November 1977.

RICKERTSEN 1981. L. D. Rickertsen and H. C. Claiborne, Expected Environments for a Defense High-Level Waste Repository in Salt, ORNL/TM-7597, prepared by Oak Ridge National Laboratory, Union Carbide Corporation, for Office of Nuclear Waste Isolation, Battelle Memorial Institute, Columbus, Ohio, March 1981.

ROBBINS 1976. R. S. Roluins, Development Trends in Tunncl Boring Machines for Hard Rock Application, lst U.S. - Sweden Underground Workshop, Stockholm, Sweden, 1976. 
ROBERTSON 1979. E. C. Robertson, Thermal Conductivities of Rocks, prepared by U.S. Geological Survey, Reston, Va., Open File Report 79-356, for the Division of Waste Management, U.S. Department of Energy, 1979.

RRCIWG 1982a. The Reference Repository Conditions Interface Working Group, Interim Reference Repository Conditions for Commercial and Defense High-Level Nuclear Waste and Spent Fuel Repositories in Salt, NWTS-3, Office of Nuclear Waste Isolation, Battelle Memorial Institute, Columbus, Ohio, September 1982.

RRCIWG 1982b. The Reference Repository Conditions Interface Working Group, Interim Reference Repository Conditions for Commercial and Defense Uligh-Leve1 Nuclcar Waote and Spent Fuel Repositories in Granite, NWTS-5, Office of Nuclear Waste Isolation, Battelle Memorial Institute, Columbus, Ohio, September 1982.

RRCIWG 1982c. The Reference Repository Conditions Interface Working Group, Interim Reference Repository Conditions for Spent Fuel and Commercial High-Level Nuclear Waste Repositories in Tuff, NWTS-12, Officc of Nuclcar Waotc Ioolation, Battello Mernorial Institute, Columbus, Ohio, September 1982.

RRCIWG 1982d. The Reference Repository Conditions Interface Working Group, Interim Reference Repository Conditions for a Nuclear Waste Repository in Basalt, NWTS-16, office of Nuclear Waste Isolation, Battelle Memorial Institute, Columbus, Ohio, September 1982.

SAI 1980. Science Applications, Inc., Expected Environments for a High-Level Waste Repository in Shale, prepared for Office of Nuclear Waste Isolation, Battelle Memorial Institute, Columbus, Ohio, September 1980.

SENSENY 1983a. P. E. Senseny, Triaxial Compression and Brazilian Test Resulte For Samples From MWX-1, RSI-0226, prepared hy RF/SPFC Tnr., Rapid City, S.D., for Sandia National Laboratories, Albuquerque, N.M॰, 1983.

SENSENY 1983b. P. E. Senseny, Triaxial Compression and Brazilian lest Results For Samples From MWX-2, RSI-0234, prepared by RE/SPEC Inc., Rapid City, S.D., for Sandia National Laboratories, Albuquerque, N.M., 1983.

SENSENY 1983c. P. E. Senseny, Triaxial Compression and Brazilian Test Results For Samples From MWX-3, RSI-0238, prepared by RE/SPEC Inc., Rapid City, S. D॰, for Sandia National Laboratories, Albuquerque, N.M॰, 1983.

SENSENY 1984. P. E. Senseny, T. W. Pfeifle, and K. D. Mellegard, Constitutive Parameters for Salt and Nonsalt Rocks From the Detten, G. Friemel, and Zeeck Wells in the Palo Duro Basin, BMI/ONWI-549, RSI-0221, prepared by RE/SPEC Inc., Rapid City, S.D., for office of Nuclear Waste Isolation, Battelle Memorial Institute, Columbus, Ohio, 1984 • 
SVALSTAD 1983. D. K. Svalstad, User's Manua1 for SPECTROM-41: A Finite Element Heat Transfer Program, ONWT-326, RSI-0152, prepared by RE/SPEC Inc., Rapid City, S.D., for Office of Nuclear Waste Isolation, Battelle Memorial Institute, Columbus, Ohio, June 1983.

TEUEEL 1981. L. W. Teufel, Mechancial Properties of Anhydrite and Polyhalite in Quasi-Static Triaxial Compression, SAND81-0858, prepared by Sandia National Laboratories, Albuquerque, N.M., for the U.S. Department of Energy, 1981 .

THOMAS 1973. J. Thomas, Jr., R. R. Frost, and R. D. Harvey, "Therma1 Conductivity of Carbonate Rocks," Eng. Geol., I, pp. 3-12 (1973).

U.S. DOC 1983. U.S. Department of Commerce, Environmental Science Services Administration, Environmental Data Service, Climatic Atlas of the United States, 1983.

WAGNER 1980. R. A. Wagner, Parametric Study Involving Therno/ Viscoelastic Analyses of a Room and Pillar Configuration, ONWI-115, RSI-0070, prepared by RE/SPEC Inc., Rapid City, S.D., for uffice of Nuclear Waste Isolation, Battelle Menorial Institute, Columbus, Ohio, July 1980.

WAGNER 1984. R. A. Wagner, M. C. Loken, and H. Y. Tammemagi, Preliminary Thermomechanical Analyses of a Conceptual Nuclear Waste Repository at Four Salt Sites, BMI/ONWI-512, RSI-0186, prepared by RE/SPEC Inc., Rapid City, S.D., for offlce of Nuclear Waste Isolation, Batte1le Menorial Institute, Columbus, Ohio, June 1984.

WAI 1982. R. S. C. Wai and K. Y. Lo, "Temperature Effects on Strength and Deformation Behaviour of Rocks in Southern Ontario," Can. Geotech. J., 19, pp. 307-319 (1982).

WESTINGHOUSE 1983a. Westinghouse Electric Corporation, Engineered Waste Package Conceptual Design: Defense High-Level Waste (Form 1), Commercial High-Level Waste (Form 1), and Spent Fuel (Form 2) Disposal in Salt, ONWI-438, prepared for office of Nuclear Waste Isolation, Battelle Menorial Institute, Columbus, Ohio, 1983.

WESTINGHOUSE 1983b. Westinghouse Electric Corporation, Conceptual Waste Package Designs for visposal of Nuclear Waste in Tuff, ONWI-439, prepared for office of Nuclear Waste Isolation, Battelle Memorial Institute, Columbus, Ohio, April 1983.

WINDES 1949. S. L. Windes, Physical Properties of Mine Rock, Part I, Investigation Report No. 4459, U.S. Bureau of Mines, Washington, D.C., 1949.

WINDES 1950. S. L. Windes, Physical Properties of Mine Rock, Part II, Investigation Report No. $472 \overline{7}$, U.S. Bureau of Mines, Washington, D.C., 1950 . 
WOODSIDE 1961. W. Woodside and J. H. Messmer, "Thermal Conductivity of Porous Media. II. Consolidated Rocks," J. Appl. Phys., 32 , pp. $1699-1706$ (1961).

ZERBY 1977. C. D. Zerby, Office of Waste Isolation Progress Report, $\mathrm{Y} / \mathrm{OWI} / \mathrm{TM}-43 / 2$, prepared by Office of Waste Isolation, Union Carbide Corporation, Nuclear Division, Oak Ridge, Tenn., for Department of Energy, 1977.

ZIERFUSS 1956. H. Zierfuss and G. van der V1iet, "Laboratory Measurements of Heat Conductivity of Sedimentary Rocks," Am. Assoc. Petrol. Geol. Bull., 40, pp. 2475-2488 (1956).

ZIERFUSS 1969. H. Zierfuss, "Heat Conductivity of Some Carbonate Rocks and Clayey Sandstones," Bul1. Am. Assoc. Petrol. Geol., 53, pp. 251-260 b1969). 
This page intentionally left blank 
APPENDIX H

FOREIGN ACTIVITIES

T. F. LOMENICK

OAK RIDGE NATIONAL LABORATORY

P. O. BOX X

OAK RIDGE, TENNESSEE 37831 
This page intentionally left blank 
CONTENTS

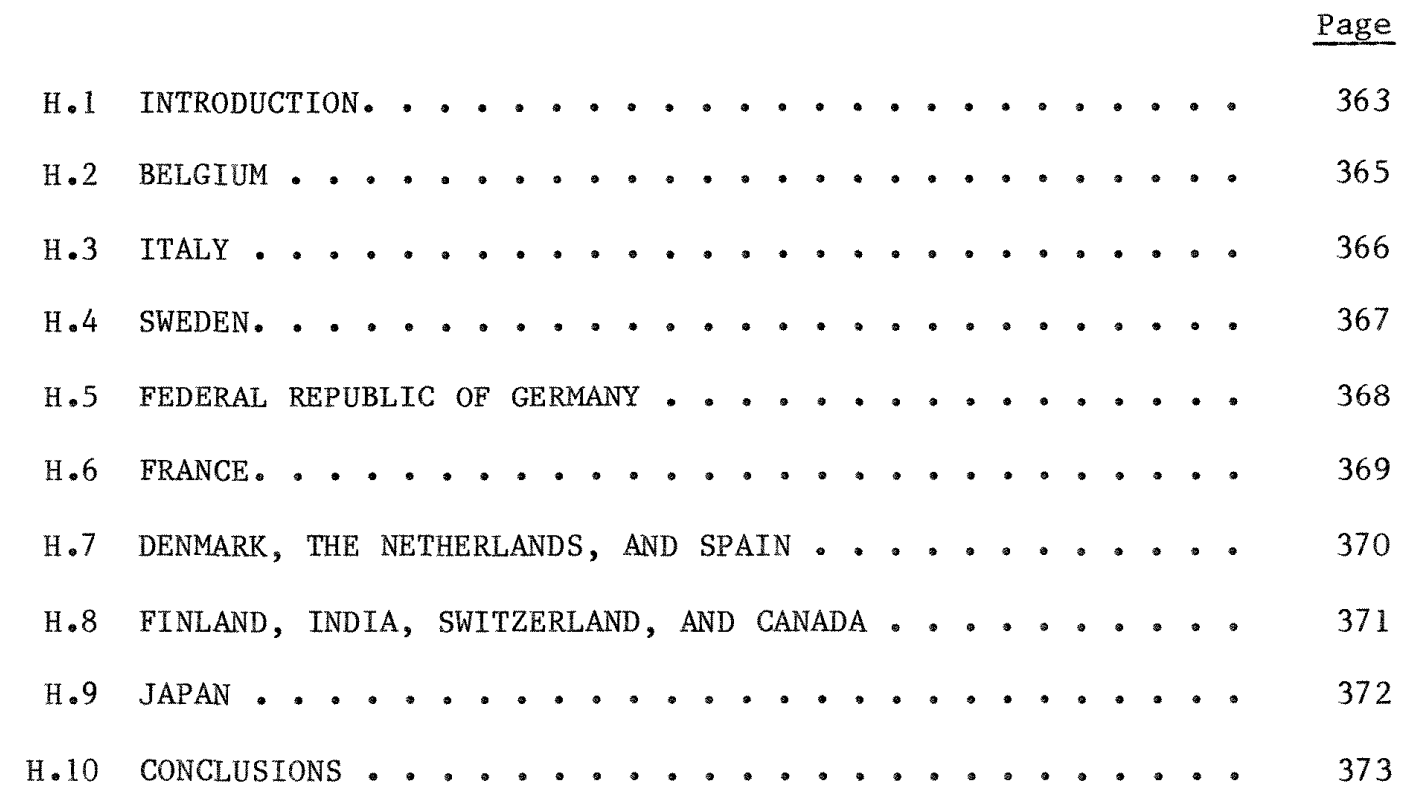


This page intentionally left blank 


\section{H.1 INTRODUCTION (HARMON 1983; OECD/NEA 1984)}

In accordance with national and international principles, high-level radioactive wastes must be isolated from man's environment for such periods of time that any releases of radionuclides would not result in unacceptable hazards to human populations. To meet this strategy, the waste management programs of other countries generally favor the interim storage of spent fuels in water pools at at-reactor (AR) facilities and/or dry storage in convection vaults or casks of iron, steel, or concrete at away-from-reactor (AFR) sites. After this interim storage period, which may range up to 100 years, the spent fuel and/or high-level waste canisters are to be placed in geologic tormations deep underground for final disposition. A generalized listing of the interim storage modes and disposal parameters of World Outside Centrally Planned Economies Areas (WOCA) countries is given in Tahle H.l. From this table it is noted that all countries are preparing for AR pool storage, while some plan supplemental storage in AFRs. Furthermore, some countries are committed to fuel reprocessing with the resulting canisters of vitrified high-level waste, while still others continue to evaluate their fuelcycle options. At least one country (Spain) has committed itself to disposal of spent fuel only without reprocessing. Because it is judged that spent fuel and/or vitrified high-level waste canisters can be stored safely for 50 or more years, most countries plan to store their waste upon removal from the reactors on an interim basis for several decades. This method would, of course, result in significant decay of many fission products with a corresponding reduction in thermal loading. Although the most common repository designs utilize the room and pillar methods for excavations on a single level with emplacement in boreholes drilled into the floor, other schemes, such as deep borehole emplacements, are envisaged for some countries with relatively small quantities of waste.

The magnitude of studies in foreign countries related to the storage/ disposal of high-level reduction wasce varies greatly. On the one liand, the Federal Republic of Germany (FRG) has committed to an extensive program of investigative work at potential repository sites with companion studies in repository development and safety, while on the other hand, the United Kingdom (UK) has suspended all site-specific work and is generally relying on the investigative work in other countries to develop a generic data base for geologic disposal. For the member states of the commission of European communities (CEC), a significant amounc of research and development (R\&D) work in high-level waste storage/disposal is funded by the parent organization. In order to promote studies on the rocks of interest to the member states of the CEC and to avoid duplication of individual states' efforts, all R\&D studies related to the disposal of high-level wastes in clay rocks are assigned to Belgium and Italy. Similarly, for work in rock salt deposits, the FRG and the Netherlands have the assigned funding and responsibilities, as do France and Great Britain in the study of granitic rocks. Supporting roles in the R\&D work are relegated to Denmark and Ireland. 


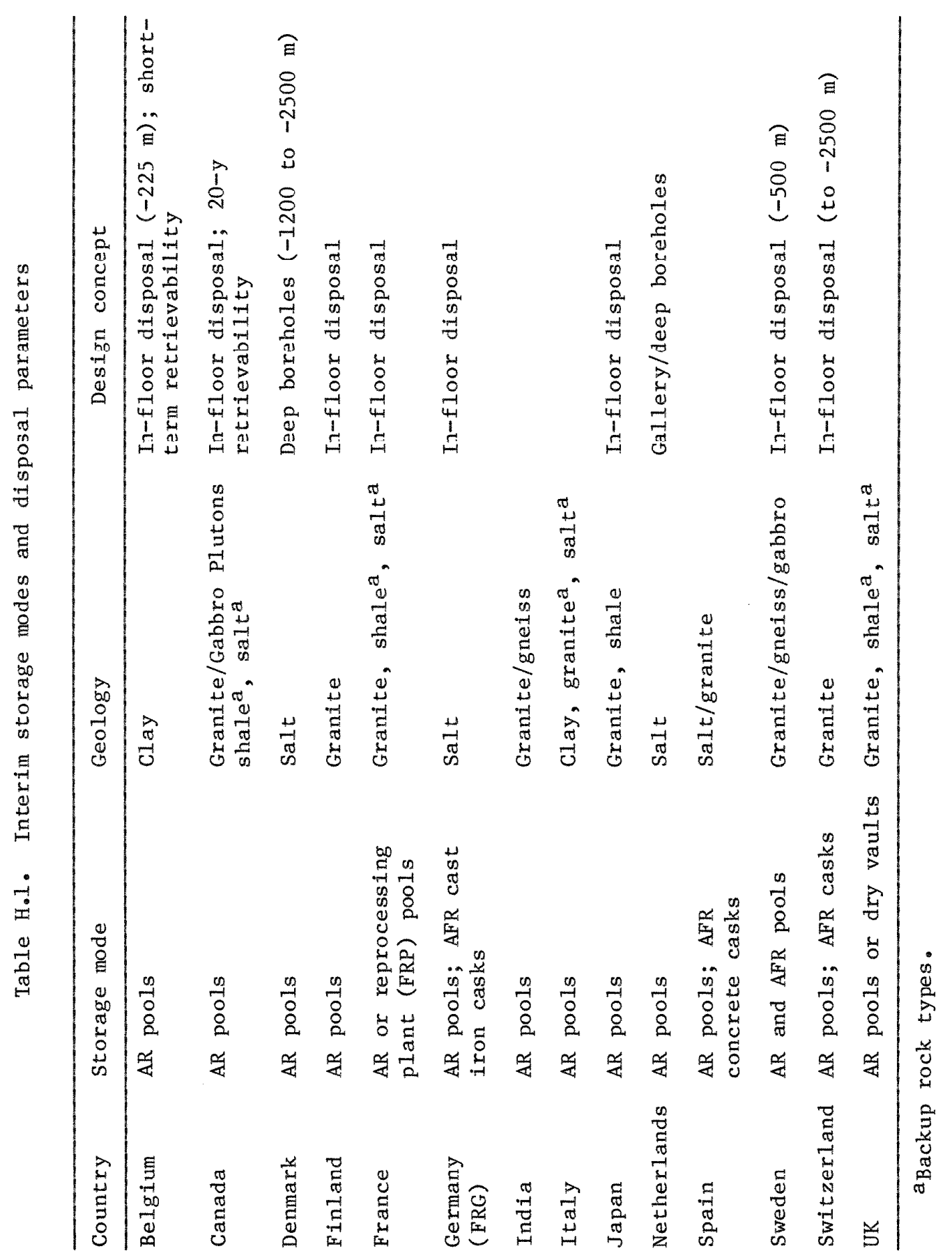


The Boom clay has been selected for study in Belgium to serve as a host rock for the storage/disposal of high-level wastes. This formation underlies a large part of the northeastern section of the country, including the Study Centre for Nuclear Energy (CEN/SCK) at Mo1. For the past few years, extensive investigations of the Boom clay have been carried out by the CEN/SCK at the Mol site, culminating in the establishment of an underground research laboratory (Hades) in the clay rocks at a depth of $225 \mathrm{~m}$. At this site the Boom clay was found to be about $110 \mathrm{~m}$ thick, with upper and lower boundaries of $160 \mathrm{~m}$ and $270 \mathrm{~m}$, respectively. The formation is of oligocene age (about 35 million years old) and dips to the northeast at about $1^{\circ}$. It is also 1 ithologically homogeneous, and because of its rather high plasticity, is free of cracks and fissures and exhibits low permeability. The underground research laboratory at Mol consists generally of a cast-iron-1ined, horizontal gallery that is $3.5 \mathrm{~m}$ in diameter and some $30 \mathrm{~m}$ in length. A second gallery that is involved and somewhat smaller than the first has also been excavated to study mine closure in these rocks. A single, 2.5-m-diam shaft leads to the underground workings where in situ tests are being performed that relate to groundwater movement, heat transfer, corrosion effects, and the deve1opment of techiques for underground drilling in the clay. It is planned to expand the laboratory into a full-scale repository, providing that the tests prove the clays to be suitable host rocks for the storage/disposal of wastes. Preliminary scheduling indicates that authorization proceedings may begin in the late 1980s, with limited use of the repository starting in the mid-1990s.

For design purposes the Belgians would assume a maximum allowable temperature elevation of $100^{\circ} \mathrm{C}$ for the host rock (Boom clay), with a projected increase of $5^{\circ} \mathrm{C}$ for the overlying rocks. A maximum thermal loading of $15 \mathrm{~kW}$ per hectare (ha) is planned, and a cooling period of 50 years is proposed before burial for the individual canisters of vitrified high-level wastes (HLW). In general, the layout for the repository shows a single level of lumels where secondary emplacement galleries are extended sideways from the head gallery. Each secondary gallery will be $1250 \mathrm{~m}$ in length and $3.5 \mathrm{~m}$ in diameter, with high-level canisters being emplaced in inclined or vertical boreholes centered at $10-\mathrm{m}$ intervals in the floor of the galleries. The emplacement holes will vary between 15 and $20 \mathrm{~m}$ in length and about $0.5 \mathrm{~m}$ in diameter. Fuel-cladding waste (hulls) and medium-level and alpha-bearing wastes may also be buried in the repository but in separate galleries.

To prevent groundwater from contacting the HLW for periods of up to 1000 years after burial, the Belgians are studying the possibility of encapsulating the canisters with materials having suitable cation sorptive properties and lining the emplacement holes with corrosionresistant metals. 


\section{H.3 ITALY (BRONDI 1980; TASSONI 1980; GERA 1984)}

Clay deposits are considered to be the best geological medium for the storage/disposal of high-level radioactive wastes in Ttaly. At this time full-scale commercial reprocessing of spent fuel in Italy is impractical because of the limited installation of nuclear generating capacity. However, long-term policies envisage domestic reprocessing and geological disposal of vitrified wastes. Regardless of the time table for reprocessing though, a 50-year cooling period is contemplated for spent fuel and/or high-level wastes which would delay the need for an operating repository intil the next rentury.

As part of a program funded by the CEC to identify and describe thick and extensive deposits of clay through western Europe, the Italians have compiled geotechnical data on clay formations that may be potentially suitable for the storage/disposal of high-level radioactive wastes. More recently, a drilling program has been initiated to characterize more fully the slays underlying several sedimentary hasins in that country. In addition to the drilling program, laboratory and field investigations were made at the Trisaia Centre in southern Italy to study such things as thermal and radiation effects, engineering, and risk assessment. Although the Trisaia site is no longer being considered as a potential repository site, the results of in situ tests conducted near that location are generally applicable to other sites in that country. The 380-m exploratory drill hole near Trisaia shows that the clays, which are representative of many of the deposits in that part of the country, are mostly illitic and rather homogeneous, except for an abundance of carbonaceous matter in the middle to upper part of the deposit.

In the geologic past, the clay deposits at Trisaia were deeply buried; thus, useful geotechnical data can be gleaned from test samples of this material to characterize much deeper deposits. Additionally, the physicochemical reducing conditions characterizing these clays not only provide an effective barrier to the migration of many radionuclides but also strong1y suggest that the clay is impermeable. Useful data have also been collected from an in situ heater test at Trisaia, where a $1.2-\mathrm{kW}$ heat source was emplaced in the clay at a depth of $25 \mathrm{~m}$.

At Ente Nazionale Energie Alternative's (ENCA's) Casaccia Centre, drilling and other investigations have been initiated to characterize the clay in a nearby quarry. Finally, thermal, rock mechanical, and hydrologic tests are planned in an underground laboratory, which will be excavated in early 1985 in clay deposits at Pasquasia in Sicily. 


\section{H.4 SWEDEN (CARLSSON 1984; RUNDQUIST 1984)}

Sweden's current policy on nuclear power calls for a limited number of reactors (12) that will all be decommissioned after only 25 years of operation. After a cooling period of 40 years, the spent fuel and/or vitrified waste canisters will be emplaced permanently in a crystalline rock repository that should be in operation around the year 2020 . Canisters of lead and titanium would be utilized to contain the vitrified wastes, while spent fuel would be encapsulated in lead- or copper-filled heavy-walled copper jackets. In general, the vitrified wastes would be emplaced in boreholes surrounded by compressed bentonite at a depth of about $500 \mathrm{~m}$ in granite. Drifts and rooms would be backfilled with a mixture of sand and bentonite. It is unclear whether Sweden will ever have a large enough quantity of both HLW and spent fuel to require separate repusiluries.

For the 10 to 15 potential repository sites that have been identified to date. the Swedes are currently conducting site-specific exploratory drilling, geophysical surveys, and other geological investigations. In addition, they are engaged in a variety of companion studies on such things as waste glass and canister materials, safety analysis, radionuclide sorption, groundwater movement, modeling, and engineered barriers. In situ test work is also continuing at the Stripa Mine in north-central Sweden, where cooperative work agreements have been established with the OECD/NEA and the United States. By the year 2000, it is expected that one or more sites will have been thoroughly evaluated and licensing can proceed that will lead to the operation of a high-level repository in the year 2020 . 


\section{H.5 FEDERAL REPUBLIC OF GERMANY (REUSE 1984; ROTHEMEYER 1984)}

Rock salt deposits and salt domes in particular are the preferred host rocks for high-level wastes in the Federal Republic of Germany. Although a final decision has not been made as to the final storage of spent fuel as an alternative to reprocessing, work is progressing rapidly on the evaluation of a salt dome near the town of Gorleben in Lower Saxony. Site investigations at Gorleben include deep borehole drilling, geologic mapping, and extensive hydrologic testing. To date, the results of this work have been favorable. Excavation of two 7.5-m-diam shafts, extending to depths of about $800 \mathrm{~m}$, is expected to start in 1984 . By 1988 it is expected that the shafts will be completed, and a 4-year underground exploration period will commence. A conceptual design for a repository in a salt dome has been formulated. In general, the repository whild contain one disposal zone for the disposal in boreholes of heat-generating wastes and a second area for the disposition of transuranic wastes having insignificant amounts of heat. In both cases, disposal would proceed from the far extremities of the repository toward the shatts. Rock salt would comprise the backfill in the mine, and clay and concrete would be used to seal the mine and shafts. A large amount of supporting $R \& D$ work is under way at various laboratories and research establishments in the country. In addition, important in situ tests are being conducted in the Asse II salt mine that may have far-reaching implications for demonstrating the suitability of high-level radioactive wastes in salt domes.

For the disposal of low-level radioactive wastes, the Germans plan to utilize an abandoned iron ore mine in sedimentary rock near the city of Salzgitter in the eastern part of Lower Saxony. In general, this mine (referred to as the Konrad Mine) is encapsulated by clay deposits which make it extremely dry and essentially free of circulating groundwater. 


\section{H.6 FRANCE (DeFONTREAUX 1984; OECD/NEA 1984)}

Although France continues to investigate rock salt, granite, as well as shale deposits as potential host rocks for high-level radioactive wastes, most studies are centered around granite because of its arrangements with the CEC. To develop methodology and test techniques, the French have utilized two formations in Brittany for this work. In addition, they have conducted deep drilling in granite within the Massif Central. Generic R\&D work includes numerous laboratory-scale studies and theoretical investigations related to radionuclide migration, artificial and natural geochemical barriers and to the potentialities for repository siting in western France.

Design studies for a repository in granite have been undertaken. In general, the repository would be constructed at a depth of $1000 \mathrm{~m}$ and would have a capacity for 30,000 canisters with a disposal rate of 1000 year. To achieve rock temperatures of no more than $150^{\circ} \mathrm{C}$ at the wall of the boreholes and $100^{\circ} \mathrm{C}$ in the remaining rock throughout the repository, canisters would be emplaced $30 \mathrm{~m}$ apart laterally and $20 \mathrm{~m}$ vertically.

The French plan to construct and operate a new storage facility for high-level radioactive wastes by 1992 . Although an underground test and evaluation facility that would serve for temporary storage is preferred, an interim aboveground storage facility is being considered along with a final underground repository. 


\section{H.7 DENMARK, THE NETHERLANDS, AND SPAIN (CADELLI 1984; OECD/NEA 1984)}

For Denmark, The Netherlands, and Spain, rock salt deposits are judged to be the most favorable host rocks for the storage/disposal of high-level radioactive wastes. In these countries, some feasibility and siting studies have been undertaken along with $R \& D$ work on such things as thermal effects, radionuclide transport, safety assessment, and modeling. In general, plans for future activities are not clear due to political as well as governmental uncertainties. 


\section{H.8 FINLAND, INDIA, SWITZERLAND, AND CANADA (PFISTER 1984; ROMETHSGH} 1984; SETHNA 1984; MAKIPENTTI 1984; NIEDERER 1984)

A rather large number of countries, including Canada, Finland, India, and Switzerland, have made commitments to utilize crystalline rocks for the storage/disposal of high-level waste. The Finns have made an inventory of possible storage/disposal sites within that country and are conducting supporting studies in radionuclide migration. They are also participants in the Organization for Economic Cooperation \& Development/ Nuclear Energy Agency (OECD/NEA) joint R\&D work at the Stripa Mine, Sweden.

In India, candidate sites for repositories in granitic rock are being investigated. Also, plans are being developed to establish an experimental research laboratory in an abandoned tunnel in the northern part of the country.

Switzerland's high-level waste storage/disposal work is predicated on fodcral law, which requirco a demonotration of the foacibility of tho safe disposal of these wastes by the end of 1985 . A recent design study envisions a mined repository for either vitrified waste or spent fuel in granitic rocks up to depths of $2500 \mathrm{~m}$. In order to select the most promising site(s) for detailed evaluation, a series of 12 deep boreholes are being drilled in the north and central parts of the country. Although the Swiss are parties to the OECD/NEA joint studies in the Stripa, Swedish mine, they are also constructing their own underground laboratory at Grimsel Pass in the Alps.

Like many other countries, Canada has not yet decided whether or not to process spent nuclear fuel and, therefore, is developing technology for both vitrified wastes and spent fuel. Apparently several potential repository sites in granitic rocks have been located, and work is continuing on a hoot of R\&D etudies. However, the principal offort in the Canadian program is directed toward the construction of an underground research laboratory near Whiteshe11. It is hoped that investigations and in situ tests at this facility can assess such things as the utility of state-of-the-art techniques for characterizing large bodies of granitic rocks from the surface to deep underground. The effects of excavation (blasting, drilling, etc.) on the rock mass may also be studied in the underground $1 a b$ along with the effectiveness of shaft and gallery seals. The underground lab should also provide a means for verification of various mathematical models that are used to predict groundwater flow, rock behavior, and other conditions in the subsurface. 


\section{H.9 JAPAN (OKUI 1984; SHIMOOKA 1984)}

Current policy in Japan calls for the as-soon-as-practical processing of spent fuel, followed by interim storage of vitrified waste and eventual disposal of the wastes into geological repositories. Development and demonstration work is continuing on waste vitrification technology, and plans have been formulated for the design of interim storage facilities. Japan is an active participant in the OECD/NEA joint R\&D studies in the Stripa, Swedish Mine. In addition, the Japanese are in the preliminary stages of a site-selection process for a geologic repository. Granite, shale, and basalt rocks are being studied in the field as well as in the laboralory. 


\section{H.10 CONCLUSIONS}

Although crystalline rocks, salt deposits, and clays are all being investigated as host rocks for the storage/disposal of high-level radioactive wastes in foreign countries, it is significant that one of the most advanced studies is in the Boom clay at Mol, Belgium. At this site, an exploratory shaft has been sunk to a depth of $225 \mathrm{~m}$, and chambers have been excavated laterally into the clay to study such things as mechanical closure, groundwater movement, heat transfer, and drilling and excavating techniques. Another underground laboratory in clay deposits is being developed by the Italians at Pasquasia in Sicily. In addition to the Belglans and Itallans, who consider clays to be the most promising host rocks for high-level wastes in these countries, the United Kingdom, France, Canada, and Japan are investigating clays and shales as backup rock types for repositories. In general, the clay deposits in these countries possess many of the same favorable characteristics (10w permeability, high ion-exchange capacity, and great thickness) for the contaimment of radioactive wastes, as do the clay-shale deposits in the Unlled states. However, the European clays contaln considerably more pore water and behave more plastically than do the indurated shales that are considered to be potentially suitable host rocks for high-level wastes in the United States. 
This page intentionally left blank 
APPENDIX I

ASSESSMENT OF SYSTEMS ANALYSES

FOR SEDIMENTARY ROCKS

R. S. LOWRIE

OAK RIDGE NATIONAL LABORATORY

P. 0. BOX X

OAK RIDGE, TENNESSEE 37831 
This page intentionally left blank 
CONTENTS

$\underline{\text { Page }}$

I.1 INTRODUCTION . . . . . . . . . . . 379

I.2 THE OFFICE OF WASTE ISOLATION STUDY. . . . . . . 380

I.3 THE ENVIRONMENTAL PROTECTION AGENCY STUDY. . . . . . . 381

I.4 REFERENCES ............................ 382 
This page intentionally left blank 


\section{I.1 INTRODUCTION}

System studies techniques are quite useful in assessing the performance of a given facility at a specific site under conditions expected during its lifetime. The accuracy and meaningfulness of such a study, however, particularly for a mined geologic disposal system, are directly proportional to the quality and extent of the site-specific data base used in the study. For this reason, it is very difficult to perform an accurate and meaningful systems study for a generic mined geologic disposal system utilizing only intrinsic rock properties and fictional site characteristics rather than site-specific data. Consequently, system study considerations were not developed and used by SERP in eval uating the potential for the five sedimentary rock types to serve as the host rock for a high-level waste disposal facility.

However, the literature search to develop the Sedimentary Rock Program (SERP) technical information base revealed that two system studies had been made for a generic shale formation prior to SERP, one by the office of Waste Isolation (OWI 1978a) and one for the Environmental Protection Agency (EPA 1982). [The quality and extent of the data for chalk, sandstone, anhydrock, and carbonate rocks precluded making system studies for these rocks.] These studies will be examined in this appendix to provide background information and perspective for the SERP studies. 


\section{I.2 THE OFFICE OF WASTE ISOLATION STUDY}

The Office of Waste Isolation published a series of reports in 1978 under the general title, Technical Support for GEIS: Radioactive Waste Isolation in Geologic Formations (OWI 1978a), which summarized the technical information developed by OWI for isolating commercial light-water reactor (LWR)-derived waste in an underground repository in salt, granite, basalt, and shale. The primary objective of this OWI study was to provide estimates of both the volume of and radionuclide concentration in effluent streams released at the boundary of an underground repository so that the impact of these releases on the public and environment could be evaluated for the Generic Environmental Impact Statement (GEIS) study. For its study, OWI utilized a stepwise methodology, starting from a literature review to determine host rock properties (OWI 1978b), progressing through developing the characteristics of a generic site (OWI 1978c), a preconceptual repository design (OWI $1978 \mathrm{~d}, \mathrm{e}$ ), the repository construction and operating costs (OWI 1978f), and finally, the radionuclide release to the accessiblo onvironment via groundwater transport (OWI 1978g). The study makes two major points: (1) that a mined geologic disposal facility can be designed, constructed, operated, and closed in selected shale formations; and (2) for the radionuclide release scenario used, the concentration of most radionuclides in groundwater released to the accessible environment $4.8 \mathrm{~km}$ ( 3 miles) from the center of the repository would be very low (the calculated activities would be $<10^{-2} 0_{\mu} \mathrm{Ci} / \mathrm{mL}$ ).

The values developed for the OWI study in 1978 for the chemical, physical, and thermal properties of shale, as well as the characteristics of a shale formation (thickness, depth, lateral extent, homogeneity), and used to evaluate the feasibility of constructing and operating an HLW underground repository in a generic shale formation, are either the same as, or very similar to, those developed for SERP based on current knowledge. Both studies use the same waste emplarement rechniques (wasto ranisters placed in boreholes drilled in the floor of the underground storage rooms), and both studies conclude that it is possible to design, construct, operate, and close a repository in shale.

The radionuclide release scenario developed for OWI assumes that, 50 years after decommissioning, the repository, containing high-level waste in glass matrix from reprocessed pressurized water reactor (PWR) fuel, is completely flooded, and the entire inventory of radionuclides is dissolved or suspended in the repository water. This leads to much higher verynear-field release rates than are currently used: release rates today are typically a small percentage $(0.3 \%)$ of the total inventory per year. The hydrologic transport model used by OWI calculates that, with the exception of ${ }^{99} \mathrm{Tc}$, the activity in water as it passes the repository boundary [4.88 $\mathrm{km}(16,000 \mathrm{ft})$ from center of the repository] for any isotope would be $<10^{-20} \mu \mathrm{Ci} / \mathrm{mL}$. These results are several orders of magnitude less than those calculated today, where peak concentrations typically range from $10^{-3}$ to $10^{-7} \mu \mathrm{Ci} / \mathrm{mL}$ after 10,000 years (DOVE 1982). W1 chout a careful analysis of the UWI model to compare it with today's modeling technique (which was not done and probably cannot be done due to inadequate documentation of the OWI work), the reasons for the apparently low groundwater radionurlide transport results in the nw study are unknown, and their implications for this study are not assessable. 


\section{I.3 THE ENVIRONMENTAL PROTECTION AGENCY STUDY}

The Environmental Protection Agency (EPA) reported the results of a study to determine Population Risks from the Disposal of High-Level Radioactive Waste in Geologic Repositories (SMITH 1982). The objective of the study was to provide enough information to judge the adequacy of geologic disposal in limiting release of radionuclides contained in radioactive waste to the environment. This report identified the important characteristics of mined geologic disposal systems in generic salt, granite, basalt, and shale formations as variables to study for effects on overall population risks. The study used relatively unsophisticated models which, deliberately, overestimated the risks. Their approach was to develop a generic or reference repository for each of the rock types, establish the physical, chemical, thermal, and hydrologic parameters for the repostitory, develop a racher decalled scenario describing the pathways by which the radionuclides are transported to the accessible environment, and then calculate the expected health effects over 10,000 years. For reference repositories in the different geologic media, the results indicated that the risks for basalt and shale are higher than for granite and salt (roughly one order of magnitude). This result apparently derives primarily from the calculated effects of intruder events (undetected boreholes), which were assumed to occur with a much higher frequency for a shale repository as compared to a basalt repository. Due to the problematic nature of human intrusion, and the differing associations of natural resources with various shales (see Appendixes E.2 and F), the validity of this assumption is uncertain. The EPA study also assumed that shale had the same mechanical and hydrologic properties as basalt, an assumption which may not be correct, depending on the type of shale used. For instance, the ductility of a candidate shale formation may be such as to assure that joints and fractures in undisturbed shale at depths of interest will be fairly well sealed and that the shale will tend to seal shafts, boreholes, and fractures resulting from construction and closure of the repository. This self sealing would greatly reduce groundwater flow through the repository, with a concomitant drop in health effects due to the release of radionuclides from the repository to the accessible envirument over the first 10,000 years after closure. Additionally, equating the hydraulic conductivity of massive shales with that of a relatively thin basalt having interbeds and flowtops with substantial permeability is at best a dubious assumption. As a result of these considerations, the calculated impacts of an HLW repository in shale, as given in the subject report, appear to be higher than expected.

The above observations serve to point out that calculating meaningful health effects for a repository located in shale necessitates the use of geologic data and modeling scenarios representative of the shale formations which might actually be utilized as the host rock for an HLW repository. 


\section{I.4 REFERENCES}

Dove 1982. F. H. Dove, C. R. Cole, M. G. Foley, F. W. Bond, R. E. Brown, W. J. Deutsch, M. D. Freshley, S. K. Gupta, P. J. Gutknecht, W. L. Kuhn, J. W. Lindberg, W. A. Rice, R. Schalla, J. F. Washburn, J. T. Zellmer, AEGIS Technology Demonstration for a Nuclear Waste Repository in Basalt, PNL-3632, Pacific Northwest Laboratory, Richland, Washington, 1982.

EPA 1982, U.S. Environmenta1 Protection Agency, C. B. Smith, D. J. Egan, Jr., W. A. Williams, J. M. Gruhlke, C. Y. Ilung, and B. L. Serinni, Population Risks from Disposal of High-Level Radioactive Wastes in Geologic Repositories, EPA 520/3-80-006, 1982.

OWI 1978a. Technical Support for GEIS: Radioactive Waste Isolation in Geologic Formations, Vols. 1-23, Y/OWI/TM-36/1-36/23, Union Carbide Corp. Nuclear Div., Office of Waste Isolation, Oak Ridge, Tenn., 1978.

OWI 1978b. Baseline Rock Properties-Shale, Vol. Y/OWI/TM-36/6, Dames \& Moore, White Plains, New York, 1978.

OWI 1978c. Stratigraphies of Salt, Granite, Shale, and Basalt, Vol. $\mathrm{Y} /$ OWI/TM-36/3, Dames \& Moore, White Plains, New York, 1978.

OWI 1978d. Repository Preconceptual Design Studies: Shale, Vol. Y/OWI/TM-36 12 , Parsons Brinckerhoff Quade \& Douglas, Inc., New York, New York, 1978 .

OWI 1978e. Drawings for Repository Preconceptual Design Studies: Shale, Vo1. Y/OWI/TM-36/13, Parsons Brinckerhoff Quade \& Douglas, Inc., New York, New York, 1978.

OWI 1978f. Facility Construction Feasibility and Costs by Rock Type, Vo1. Y/OWI/TM-36/18, Parsons Brinckerhoff Quade \& Douglas, Inc., New York, New York, 1978.

OWI 1978g. Groundwater Movement and Nuclide Transport, Vo1. $\mathrm{Y} /$ OWI $/ \mathrm{TM}-36 / 21$, Dames \& Moore, White Plains, New York, 1978.

SMITH 1982. C. B. Smith, D. J. Egan, Jr., W. A. Williams, J. M. Gruhlke, C. Y. Hung, B. L. Serini, Population Risks from Disposal of High-Leve1 Radioactive Wastes in Geologic Repositories, EPA 520/3-80-006, U.S. Environmental Protection Agency, 1982. 
APPENDIX $J$

REPOSITORY COST COMPARISON FOR FIVE SEDIMENTARY ROCKS

\author{
LEO L. VAN SAMBEEK \\ ARLO F. FOSSUM \\ RE/SPEC INC. \\ P. O. BOX 725 \\ RAPID CITY, SOUTH DAKOTA 57701 \\ AND \\ ALLEN G. CROFF \\ OAK RIDGE NATIONAL LABORATORY \\ P. O. BOX X \\ OAK RIDGE, TENNESSEE 37831
}


This page intentionally left blank 
CONTENTS

Page

J.l INTRODUCTION . . . . . . . . . . 387

J.2 Cost estimates . . . . . . . . . . . . 389

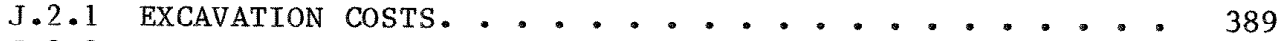

$\mathrm{J} .2 .2$ GROUND SUPPORT COSTS. ............ 391

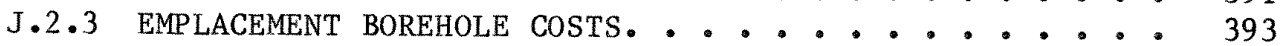

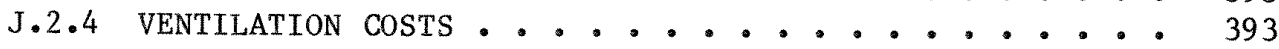

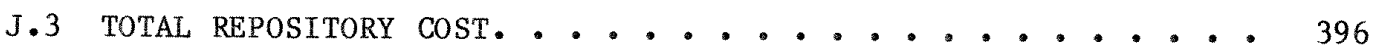

T.4 RFFFRFNCES . . . . . . . . . . . . 398 
This page intentionally left blank 


\section{$\mathrm{J} \cdot 1$ INTRODUCTION}

Predicting the cost of a high-level waste (HLW) repository is a complex task involving the acquisition of substantial quantities of data on the relevant $\operatorname{rock}(\mathrm{s})$, stratigraphy, and system requirements and then using this information to develop a detailed repository design which can be costed element by element. This approach is not feasible for the SERP because the required information is not available during the rock evaluation phase. Therefore, the approach adopted herein in performing a cost analysis for repositories in the five subject rocks is to analyze an existing cost estimate for a bedded-salt repository (DOE 1984), separate the cost elements into those that depend on the rock type being considered (e.g., excavation costs) and those that are substantially independent of rock type (e.g., surface facility cost), and then adjust the rock-typedependent costs leading to a repository cost estimate for each rock type.

The costs of an HLW repository can be divided into two categories: those for the waste preparation system and those for the repository system. The waste preparation system includes all facilities, equipment, packages, and operations required to prepare and package the spent fuel (SF) or commercial HLW (CHLW) form before emplacing it in the geologic repository. Waste preparation includes the following processes: atrepository SF disassembly and consolidation; HLW/SF packaging; packaging of transuranic waste generated on-site; and volume reduction and packaging of on-site generated low-leve1 waste. It is expected that the cost of the waste preparation system will be essentially independent of the rock type being considered for the repository. The waste preparation costs given in the Mission Plan for the Civilian Radioactive Waste Management program (DOE 1984) for a bedded-salt repository are adopted in this analysis for all of the subject rock types.

The repnsitory system includes a11 suhsystems designed to handle, transport, and emplace the waste packages in the repository; to develop underground disposal rooms, waste emplacement boreholes, shafts, and ventilation pathways; and to provide all other support, surface facilities, and utilities required. l'hese subsystems can be further divided into two components, one of which is essentially independent of the rock type under consideration and one that is strongly dependent on the rock type. Rock-type-independent costs include those for waste hand1ing, transportation, and emplacement; those for surface support, facilities, and utilities such as administration, maintenance, warehouses, sewage treatment, pump houses, and holding ponds; and those for electrical substations and standby power. The cost of shafts was also assumed to be independent of rock type, since their cost is heavily dependent on the site-specific stratigraphy, which is not available in the rock evaluation phase. These costs were assumed to be the same for all of the subject rock types, and their costs were obtained from the Mission Plan (DOE 1984). The rocktype-independent cost for each of the five subject rocks is the sum of the waste preparation costs and the invariant repository system costs, which gives a tocal of $\$ 2,847$ million. 
The second component of the repository system cost is dependent on the rock types because of variations in the volume of rock mined, the unit cost of excavating the rock, ventilation requirements (both equipment and operating), and ground support requirements. The remainder of this report will concentrate on developing cost estimates for those aspects of the repository system component by adjusting the costs of the bedded-salt repository given in the Mission Plan to account for variations in rock characteristics. 


\section{J.2 COST ESTIMATES}

\section{J.2.1 EXCAVATION COSTS}

The excavation costs for the repository system are for all underground openings. Included would be the disposal rooms and all interconnecting openings, such as haulageways and ventilation drifts, utilities' breakouts, and underground shops and warehouses. It is assumed that the disposal rooms represent $40 \%$ of the total excavation volume, and all other openings account for the remainder. An identical set of opening dimensions are assumed for all rock types.

The number and length of the disposal rooms are defined by the acceptable areal thermal loading. An identical thermal loading cannot be assuned for all rock bypes because of lleir varying chermal properties. Based on the calculated temperatures presented in Appendix G, the thermal loading for four of the five rock types was modified from the assumed thermal loading of $20 \mathrm{~W} / \mathrm{m}^{2}$ as follows:

\begin{tabular}{|c|c|c|}
\hline \multirow[b]{2}{*}{ Rock type } & \multicolumn{2}{|r|}{$\begin{array}{l}\text { Modified } \\
\text { thermal loading } \\
\left(\mathrm{W} / \mathrm{m}^{2}\right)\end{array}$} \\
\hline & SF & CHLW \\
\hline Anhydrock & 12.5 & 12.5 \\
\hline Chalk & 8.3 & 12.6 \\
\hline Carbonate rocks & 11.2 & 19.0 \\
\hline Sandstone & 15.5 & 21.5 \\
\hline Shale & 15.7 & 21.9 \\
\hline
\end{tabular}

The modifications were linear extrapolations to arrive at a lower calculated mean temperature that would satisfy either the near-field/far-field interface temperature constraint, the isolation period temperature constraint value, or that was low enough so that the index of operational stability (as defined in Appendix G) was at least 2.0, whichever was the mure restrictive constraint.

To accomplish these reductions in thermal loading, the pitch (spacing between canisters along the length of the room) was modified from the $7.02-\mathrm{m}$ value used in the Appendix $\mathrm{G}$ thermal analyses. The modified pitches, by rock type, are given below.

Rock type

Anhydrock

Chalk

Carbonate rocks

Sandstone

Shale

\begin{tabular}{cr}
\multicolumn{2}{c}{ Modified pitches $(\mathrm{m})$} \\
\hline \multicolumn{3}{c}{ SF } & CHLW \\
11.23 & 6.02 \\
16.92 & 7.46 \\
12.54 & 4.95 \\
9.06 & 4.37 \\
8.94 & 4.29
\end{tabular}


The volume of excavation required for disposal rooms is determined by

$$
V=(A)(p)(n),
$$

where

$$
\begin{aligned}
& \mathrm{V}=\text { disposal room volume, } \mathrm{m}^{3} ; \\
& \mathrm{A}=\text { cross-sectional area of the room, } \mathrm{m}^{2} ; \\
& \mathrm{p}=\text { pitch (canister spacing), } \mathrm{m} ; \\
& \mathrm{n}=\text { number of canisters in the repository }
\end{aligned}
$$

The number of canisters is calculaled based on a capacity of 70,000 metric tons of initial uranium (MTU) equivalent for the repository, with an individual canister containing 2.778 MTU of SF or 2.08 MTU of CHLW. The number of canisters per repository is 25,200 for SF and 33,650 for CHLW. The cross-sectional area for the disposal rooms is $30.25 \mathrm{~m}^{2}$, based on a $5.5-\mathrm{m}$ square geometry. The total excavation requirement for the repository is assumed to be 1.7 times the excavation required for

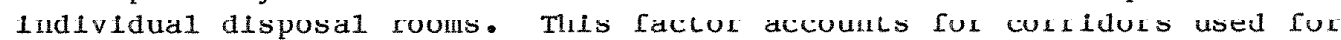
haulageways and ventilation flow paths. The total excavation volumes for the five rock types are given here.

\section{Rock type}

Anhydrock

Chalk

Carbonate rocks

Sandstone

Shale
Total repository

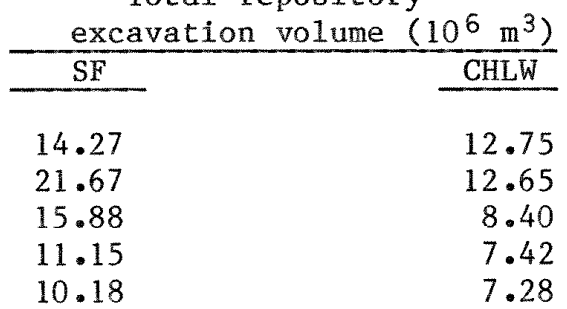

Une method considered for determining the unit rock excavation cost was by interpolation according to each rock's compressive strength. Two estimated costs for excavating repositories in other rocks are known: $\$ 29.79 / \mathrm{t}\left(\$ 70.96 / \mathrm{m}^{3}\right)$ for bedded salt and $\$ 44.50 / \mathrm{t}\left(\$ 171 / \mathrm{m}^{3}\right)$ for tuff (MONTGOMERY 1984). The compressive strengths for bedded salt and tuff are about $24.1 \mathrm{MPa}$ and $124.1 \mathrm{MPa}$, respectively.

Singh (SINGH 1982) presents comparisons for raise-boring coses as a function of raise diameter and the rock's compressive strength. That evaluation suggests that the cost of excavation is nearly linearly related to uniaxial compressive strength, particularly in the range of 68.9 to $138 \mathrm{MPa}$. In that range, the cost of excavation increases by $\sim 3.5 \%$ for each $6.9-\mathrm{MPa}$ increment in compressive strength. The evaluation also suggests that the unit volume excavation cost $\left(\$ / \mathrm{m}^{3}\right)$ is essentially constant when the face area exceeds $\sim 10 \mathrm{~m}^{2}$.

The costs of mining salt and tuff given above also correlate well using the results given by Singh (SINGH 1982). Therefore, it is assumed that the unit excavation cost for the five subject rocks can be determined 
by linearly interpolating between the unit excavation costs for salt and tuff, using the compressive strength as a basis. The compressive strengths of the subject rocks (taken from Appendix G) and the resulting unit costs are summarized below.

\begin{tabular}{lcc} 
Rock type & $\begin{array}{c}\text { Compressive } \\
\text { strength } \\
(\mathrm{MPa})\end{array}$ & $\begin{array}{c}\text { Unit excavation } \\
\text { cost } \\
\left(\$ / \mathrm{m}^{3}\right)\end{array}$ \\
\cline { 3 - 4 } Anhydrock & 93.1 & 139 \\
Chalk & 17.2 & 64 \\
Carbonate rocks & 103.4 & 150 \\
Sandstone & 66.2 & 113 \\
Shale & 68.9 & 116
\end{tabular}

Underground haulage, hoisting, and surface storage costs are an additional $\$ 10 / \mathrm{m}^{3}$ for all rock types.

\section{$\mathrm{J} \cdot 2 \cdot 2$ GROUND SUPPORI COSIS}

Some ground support costs are included in the excavation costs; however, special ground support considerations beyond those needed for salt or tuff must be used for some of the sedimentary rocks. Without site-specific information, ground support requirements are highly speculative, but the following requirements and costs are assumed based on mining experience and on inferences based on alternative ground support systems shown by Deere (DEERE 1969) and applied by the Army Corps of Engineers (ARMY 1978).

Rock type

Anhydrock

Cha1k

Carbonate rocks

Sandstone
Support requirements and cost

Only spot bolting will be required, and the cost is included in the excavation cost.

Wire mesh and rockbolting on a regular pattern (1-m spacing) will probably be required on the ribs and roof. This will require $16 \mathrm{~m}^{2}$ of wire mesh and 13 rock bolts for each meter of opening length (every $30 \mathrm{~m}^{3}$ of excavation). At an installed cost of $\$ 25 /$ bolt and $\$ 5 / \mathrm{m}^{2}$ for mesh, this results in a special ground support cost of $\$ 13.50 / \mathrm{m}^{3}$ of excavation.

Only spot bolting will be required, and this cost is included in the excavation cost.

Long rockbolts on a regular pattern will be required if significant jointing is present. A special ground support cost of $\$ 5.30 / \mathrm{m}^{3}$ is assumed, based on a rock bolt spacing of $1 \mathrm{~m}$ ( 4 bolts per meter of opening length), with an installed cost of $\$ 40 /$ bolt . 
Rock type

Shale
Shotcreting of all excavation surfaces will be required because of the lamination of the rock and to prevent environmental deterioration. Assuming a shotcrete volume of $1.7 \mathrm{~m}^{3}$ per meter of opening length, at an emplaced cost of $\$ 130 / \mathrm{m}^{3}$, results in a special ground support cost of $\$ 7.40 / \mathrm{m}^{3}$. Additionally, it is assumed that wire mesh and rockbolting on a regular pattern $(1-\mathrm{m}$ spacing) will probably be required on the ribs and roof. The cost would be the same as that developed above for chalk, namely, $\$ 13.50 / \mathrm{m}^{3}$. Thus, the total support requirements cost is $\$ 20.90 / \mathrm{m}^{3}$.

The costs presented for the above-ground support elements are engineering estimates of the installed costs, including drilling and installing labor, in addition to the material cost.

The costs presented to this point for excavation, haulage and hoisting, and special ground support do not include contractor fee or profit, quality assurance costs, or contingency. Montgomery (MONTGOMERY 1984) indicates that these costs are treated as a series of cost multipliers at the following rates:

- contractor fee or profit at $12 \%$

- quality assurance at $5 \%$

project contingency at $30 \%$

These factors have the combined effect of increasing the costs by $52.88 \%$. Therefore, the total excavation cost is given by:

Total Cost - (Unit Excavation Cost I Special Ground Bupport + Haulage, Hoisting, and Storage) $\times 1.529$

By rock type, these costs are shown below.

\begin{tabular}{|c|c|c|c|c|c|}
\hline Rock type & $\begin{array}{c}\text { Unit } \\
\text { excavation } \\
\text { cost } \\
\left(\$ / \mathrm{m}^{3}\right) \\
\end{array}$ & $\begin{array}{l}\text { Special } \\
\text { ground } \\
\text { support } \\
\left(\$ / \mathrm{m}^{3}\right) \\
\end{array}$ & $\begin{array}{l}\text { Haulage, } \\
\text { hoisting, } \\
\text { and storage } \\
\left(\$ / \mathrm{m}^{3}\right) \\
\end{array}$ & $\begin{array}{c}\text { Subtotal } \\
\left(\$ / \mathrm{m}^{3}\right) \\
\end{array}$ & $\begin{array}{l}\text { Total } \\
\left(\$ / \mathrm{m}^{3}\right)\end{array}$ \\
\hline Anhydrock & 139 & 0 & 10 & 149.0 & 227.8 \\
\hline Chalk & 64 & 13.50 & 10 & 87.5 & 133.8 \\
\hline Carbonate rocks & 150 & 0 & 10 & 160.0 & 244.6 \\
\hline Sandstone & 113 & $5 \cdot 30$ & 10 & 128.3 & 196.1 \\
\hline Shale & 116 & 20.90 & 10 & 146.9 & $224 \cdot 6$ \\
\hline
\end{tabular}




\section{J.2.3 EMPLACEMENT BOREHOLE COSTS}

The waste emplacement concept for the repositories in sedimentary rock is to place the canisters in vertical boreholes drilled into the floor along the length of the disposal rooms. The number and dimensions of the boreholes are:

\begin{tabular}{lll} 
& \multicolumn{1}{c}{ SF } & CHLW \\
Number of boreholes & 25,200 & 33,650 \\
Diameter & $0.64 \mathrm{~m}$ & $0.52 \mathrm{~m}$ \\
Depth (length) & $5.57 \mathrm{~m}$ & $4.90 \mathrm{~m}$
\end{tabular}

It was assumed that, for boreholes in a SF repository in chalk, the cost for drilling a single borehole was $\sim \$ 2,000$ ( $\$ 50 \mathrm{million}$ for the total repository). This cost is slightly less than the $\$ 55$ million cost for bedded salt (DOE 1984). For the CHLW repository in chalk, the cost was reduced to about $\$ 1,200$ per borehole ( $\$ 40 \mathrm{million}$ for the total repository) on the basis of the reduced diameter and length of the boxelioles required. The waste emplacement borehole drilling cost for the other rock types was determined by interpolation on the basis of compressive strength, as described earlier for the disposal room excavation costs.

\section{$\mathrm{J} \cdot 2.4$ VENTILATION COSTS}

The only adjustment of ventilation cost considered in this analysis is that for the difference in repository area. Possible cost differences for the various rock types because of differing construction costs for the shafts, the need for differing degrees of water sealing of the shafts, the need for cooling and dehumidifying intake air, and other factors are not speculated upon.

The area of the reposituries affects lle uperaliug vellilatiun cosls because of the increased flow path lengths and proportional quantities of air required to service the repository. The increased construction cost for the flow paths is included in the excavation cost because the total excavation volume was factored to include haulageways and ventilation drifts. The total quantity of ventilation air is proportional to the area of the repository, assuming that the repositories in various rock types each have the same emplacement life. Moreover, as the area of the repository increases, longer pathways result, which in turn calls for larger fan heads and power requirements. At this preliminary estimation stage, the operating cost of ventilation is assumed to be proportional to the cube of the area of a repository (fan power is proportional to the cube of air volume).

The areas of the repositories were calculated by:

$$
A=(w)(p)(n)(1 / e) \text {, }
$$


where

$A=$ repository area, $\mathrm{m}^{2}$;

$\mathrm{w}=$ width of the disposal room, $\mathrm{m}$;

$\mathrm{p}=$ pitch (distance between canisters), m;

$\mathrm{n}=$ number of canisters in the repository;

$e=$ areal emplacement efficiency ( $80 \%$, taken from Appendix G).

The capital construction costs will depend on the quantity of air required. A nonlinear cost-to-capacity (6/10) relationship is assumed:

$$
\text { Capital Construction Cost Factor }=\left(\frac{A}{\text { Abase }}\right)^{0.6} \text {, }
$$

where

Abase is the area of the base repository in $\mathrm{m}^{3}$.

To facilitate the comparison, the sandstone repository, because it has the same pitch as a documented bedded-salt repository (DOE 1984), will be chosen as the base repository. The ventilation costs will be factored from the base using the capital cost construction factor defined above. The construction costs and operating costs for a base repository are assumed to be the same as those for a bedded-salt $\mathrm{SF}$ repository (DOE 1984): $\$ 684 \mathrm{mil1ion}$ (construction) and $\$ 287 \mathrm{mi} 11$ ion (operating). The CHLW repository costs are factored from the SF costs, using the 0.6 rule for cost-to-capacity scaling. The repository areas and ventilation cost factors for each rock type are 1isted in Table J.1. 


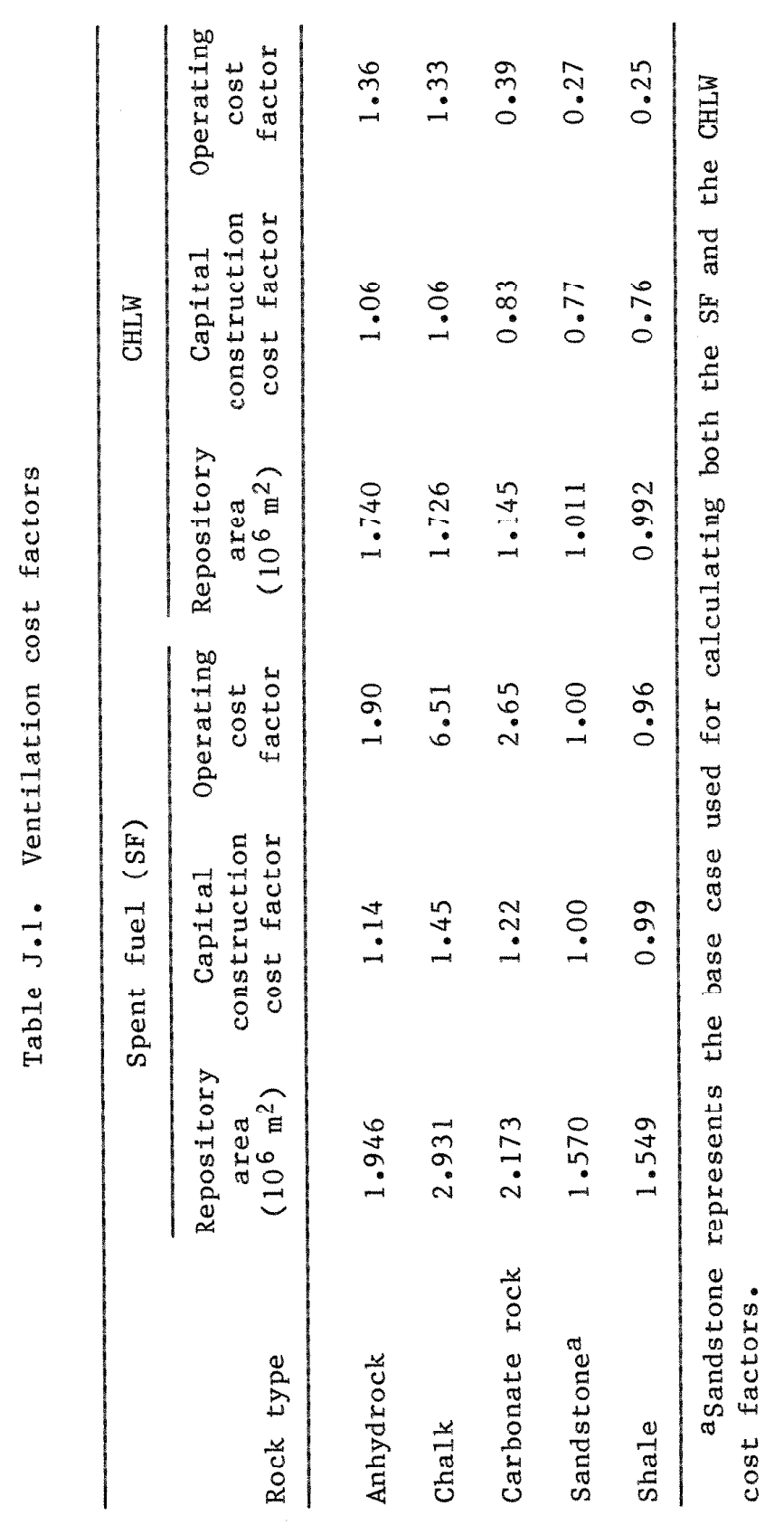




\section{J.3 TOTAL REPOSITORY COST}

Table J.2 presents a summary of the total expected cost for repositories in each of the five sedimentary rock types. A SF repository in shale is shown to have the lowest cost, but the difference between repository costs for sandstone and shale is insignificant when consideration is given to cost estimate uncertainties.

The cost estimates for a repository in anhydrock, sandstone, or shale were not initially expected to differ substantially from the DOE estimate ( $D O E$ 1984) for bedded salt, because of the relative trade-offs belween lierilal luading and rock mineability. The total sF repository costs for sandstone $(\$ 6,066$ million) and shale $(\$ 6,147$ million) are about the same as the DOE estimate (DOE 1984) for bedded salt $(\$ 5,610$ miliion) when the attendant uncertainties are considered. The cost for anhydrock was higher, due to the reduction in thermal loading necessary to achieve acceptable operational stability.

The cust estimates reported from this study are adequate for a relative ranking of the sedimentary rock types based on the cost of a repository. These cost estimates, however, are not totally comparable with those for other rocks (salt, tuff, basalt, etc.) because of their preliminary nature and subjective determination. The cost of a SF repository in anhydrock is significantly higher than for one in shale or sandstone due to a combination of somewhat higher excavation volumes and unit excavation costs. The costs of repositories in carbonate rocks and chalk are significantly higher than those for anhydrock. This results from the somewhat higher excavated volume and unit excavation cost in the case of carbonate rocks, and solely from the much higher estimated volume in the case of chalk.

In general, these same results are obtained in the case of a CHLW rcpooitory, with the notablc cxception of anhydrock, which has the highest cost. This is because the thermal loading, and thus the excavated volume, cannot be reduced as much for anhydrock as for the other rocks since it is dependent on the rock stability. The thermal loading for the other rocks is dependent only on temperature contraints. 


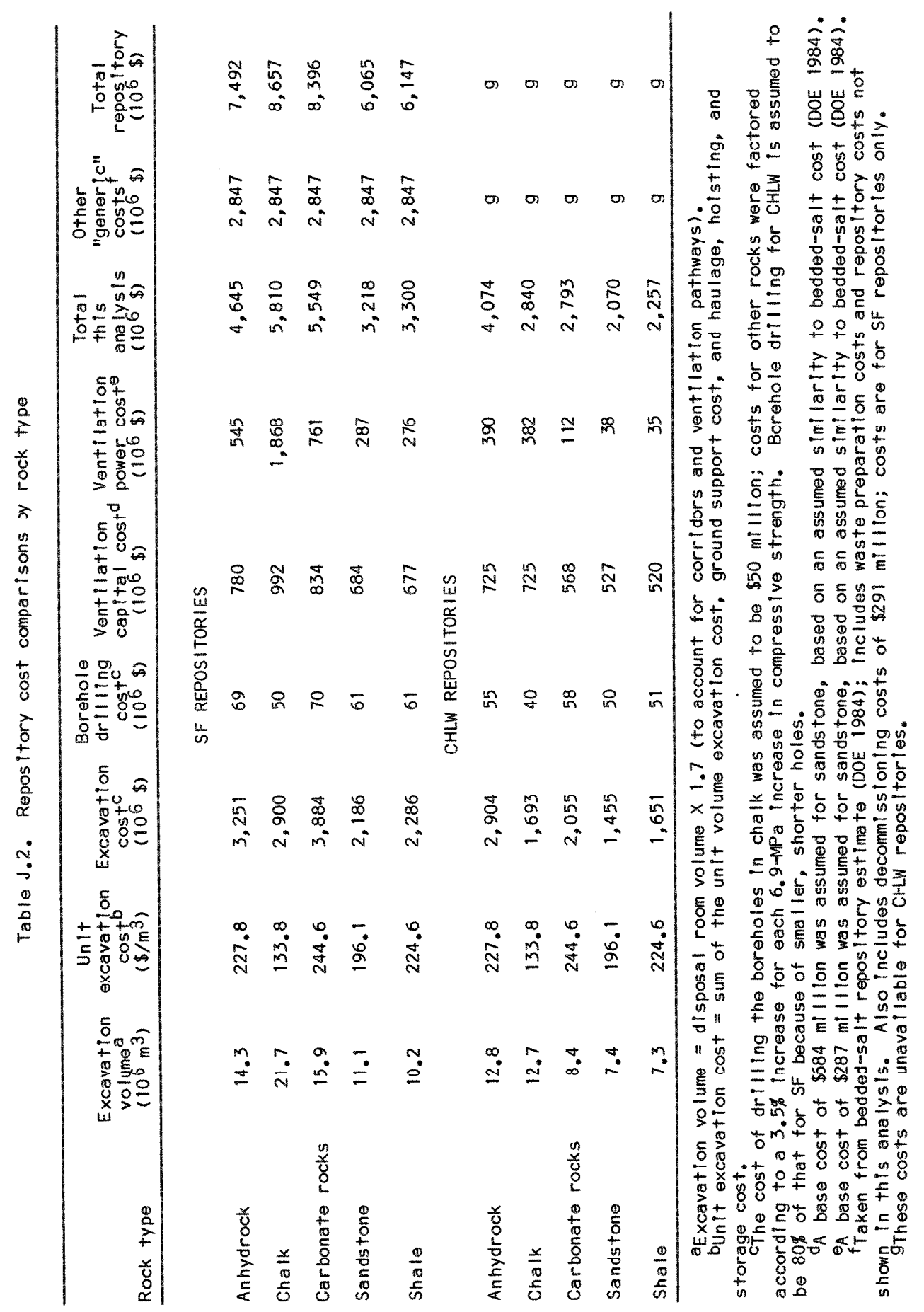




\section{J.4 REFERENCES}

ARMY 1978. Army Corps of Engineers, "Tunnels and Shafts in Rock," Engineer Manual, EM 1110-2-2901, Washington D.C., 1978 .

BROCKWAY 1982. J. E. Brockway, "Tunnel Boring Machine or Drill and Blast", Proceedings, 14th Canadian Symposium on Rock Mechanics, Vancouver, British Columbia, May 13-15, 1982 .

DEERE 1969. D. U. Deere et al., Design of Tunnel Lines and Support Systems, University of Illinois, for office of High-Speed Ground Transportation, U.S. Department of Transportation, Washington D.C., 1969.

DOE 1984. U.S. Department of Energy, A Mission Plan for the Civilian Radioactive Waste Management Program, DOE/RW-005 (Draft), U.S. Department of Energy, office of Civilian Radioactive Waste Management, washington D.C., 1984.

MONTCOMERY 1984. J. Montgomery, R. F. Weston, Tne., Gaithershirg, Maryland, telephone conversation on December 19, 1984, with Leo L. Van Sambeek, RE/SPEC, Inc., Rapid City, South Dakota.

SINGH 1982. M. M. Singh, D. F. Hambley, and F. S Kendorski, "Effect of Geological Conditions on Shaft Support Systems", presented at the Shaft Sinking and Boring Technology Symposium, Institute for Shaft Sinking, New Mexico School of Mines and Technology, Socorro, New Mexico, 1982. 
APPENDIX K

BEHAVIOR OF METALLIC WASTE PACKAGES IN DEEP SEDIMENTARY ROCKS

J. C. GRIESS

OAK RIDGE NATIONAL LABORATORY

P. 0. BOX X

OAK RIDGE, TENNESSEE 37831 
This page intentionally left blank 
CONTENTS

$\underline{\text { Page }}$

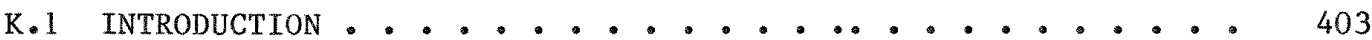

K.2 CHEMISTRY OF WATERS ASSOCIATED WITH SEDIMENTARY ROCKS . • . . 404

K.3 CORROSION OF METALS AND ALLOYS IN SEDIMENTARY ROCK WASTE

REPOSITORIES. . . . . . . . . . . . . 408

K.3.1 IRON-BASED ALLOYS. . . . . . ........ 408

K.3.2 COPPER-BASED ALLOYS. . . . . . . . . . . . . . 410

K.3.3 NTCKEL-BASED ALLOYS. . .............. 411

K.3.4 TITANIUM ALLOYS. ................. 411

K.4 RANKING THE CORROSIVITY OF SEDIMENTARY ROCK REPOSITORY. • • 413

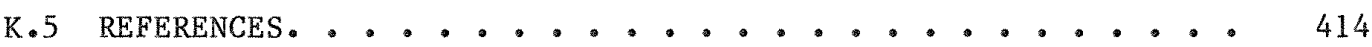


This page intentionally left blank 


\section{K.1 INTRODUCTION}

Present plans for the permanent disposal of nuclear wastes call for canning the waste in thin-walled metallic canisters that are then encased in heavy-walled metallic containers, usually referred to as overpacks. The waste packages are then placed in either horizontal or vertical holes in a geologic formation. The space between the overpack and the rock formation will likely be backfilled with a packing material. It is expected that this arrangement will completely isolate the waste from the repository environment for 300 to 1000 years.

Selection of matexials for waste containers represents a major challenge since all practical engineering materials are unstable in highlevel waste repositories and will sooner or later fail. Corrosion engineers can only hope to select materials on which the corrosion processes are slow enough so that the containers will last for the prescribed time. It is the purpose of this section to consider corrosion of metallic waste containers in sedimentary rock repositories. For a given material the rate and type of corrosion are largely determined hy the chemistry of the groundwater, which is influenced strongly by temperature and the presence of a radiation field. Therefore, before discussing corrosion, some general aspects of the chemistry of groundwaters and the effect of radiation on the solutions will be briefly presented. 


\section{K.2 CHEMISTRY OF WATERS ASSOCIATED WITH SEDIMENTARY ROCKS}

The compositions of representative groundwaters for the sedimentary rocks considered are shown in Table K.1. Although there are large variations in the salt content of the waters, even within the same rock type, most have high concentrations of chloride, magnesium, and calcium ions, and some contain ferrous ions. Excluding the low levels of hydrogen sulfide, ammonia, and flouride ions in some waters, these are the ions that most influence corrosion. The groundwaters associated with shale generally contain relatively large sulfate concentrations, but, on the average the molar concentration of sulfatc ia approximatcly cqual to that of chloride. Not shown in Table $\mathrm{K} .1$ is the fact that groundwaters frequently contain organic materials that may influence corrosion processes. Furthermore, sedimentary rocks often contain solid organic matter that may be degraded by heat and radiation to form additional soluble organic compounds. The effect of these materials on corrosion has not been taken into account because behavior patterns are not known with reaconable certainty.

When waters containing calcium, magnesium, and ferrous ions are heated in the absence of air, hydrolysis lowers the $\mathrm{pH}$ of the solution. Calcium and magnesium form basic salts, and ferrous ions form magnetite. At what temperatures these reactions take place will depend on the composition of the water, but in strong halite brines Jenks (JENKS 1972) noted that significant hydrolysis of magnesium chloride occurs at temperatures as $10 w$ as $180^{\circ} \mathrm{C}$. It seems probable, however, that there will be enough carbonate minerals associated with sedimentary rocks so that the waters will be buffered near the neutral point. In the absence of significant levels of hydrogen ions, the most aggressive ion in the groundwaters is the chloride ion.

After a repository is closed, the fixst groundwater to contact metal1ic waste packages is likely to be concentrated on the hot surfaces and may form a solid deposit on the metal (COUTURE 1984). As additional water enters the region of the package, any deposit may dissolve, and the concentrated solution will be diluted. How long a concentrated solution remains in contact with the metal depends on how readily the steam can escape during concentration and on the flow rate of the groundwater. The potential importance of the above scenario is that in the concentrated solution (although of only transitory existence) localized attack may initiate where it would not in more dilute solutions and continue to propagate once the natural groundwater is restored.

When one examines the ranges of concentrations of the ions in the groundwaters of the different types of rocks, particularly the chloride ion concentrations, it is apparent that they overlap in many cases. Furthermore, the chloride concentration can be regarded as being more than adequate to cause substantial corrosion of susceptible metals (i.e., the chloride concentration is "high" for most locations in all types of rocks). Since this assessment is generic in nature and not sitespecific, it, therefore, seems appropriate to treat all groundwaters as 


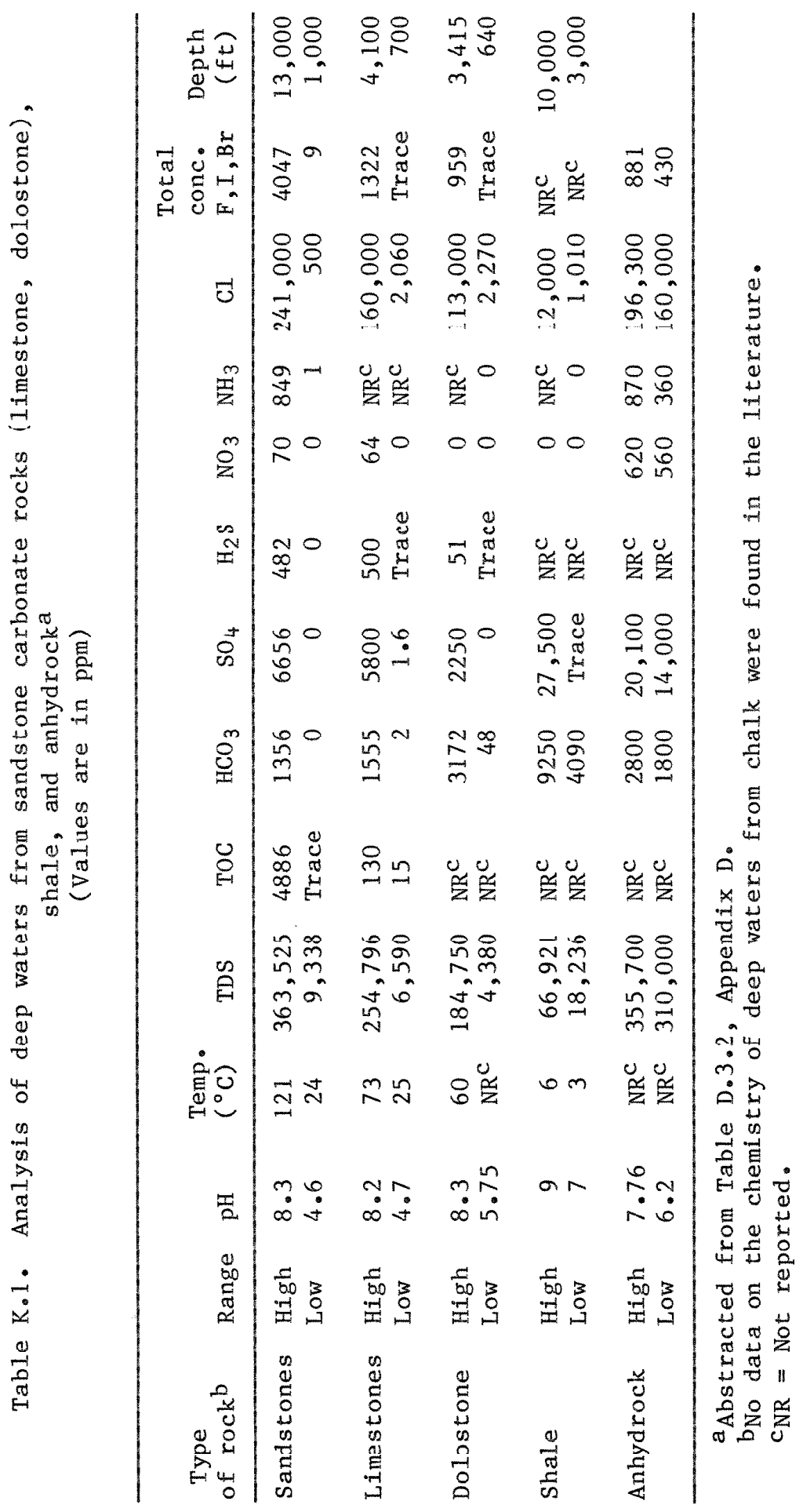


being about equally corrosive; for the present evaluation, this approach is taken. Further justification for this approach is the large number of unknowns that presently exist (effect of organics on redox potential of solutions, effect of radiation on organics and redox potential, permeability of formation to gas and liquids, etc.) which will have an important bearing on corrosion of materials in waste repositories. Once a site is selected, such unknowns can be evaluated, and their effects on corrosion can be determined.

Absorption of radiant energy will significantly alter the chemistry of groundwaters. In pure water under gamma-irradiation, the decomposition products that appear in homogeneous distribution are $\mathrm{e}^{-} \mathrm{aq}, \mathrm{OH}, \mathrm{H}_{2}$, and $\mathrm{H}_{2} \mathrm{O}_{2}$, although other species exist locally (JENKS 1972). The equilibrium concentrations of these products are small because of a large number of reactions that regenerate water. However, the presence of certain substances in solution, such as bromide and chloride ions, can increase the amount of $\mathrm{H}_{2}$ produced by reacting with radiolysis products that would normally react with $\mathrm{H}_{2}$ to reform water. Since most groundwaters are likely to contain substances that react with the products of radiolysis, cteady-ctate gae preseures will undoubtedly be higher than predicted on the basis of the behavior of pure water. Gray (GRAY 1983a), for example, irradiated a brine similar to that shown for anhydrock in Table K.l at $75^{\circ} \mathrm{C}$ and found that the steady-state pressure of $\mathrm{H}_{2}$ and $\mathrm{O}_{2}$ was $100 \mathrm{~atm}$ $\left(75 \% \mathrm{H}_{2}, 25 \% \mathrm{O}_{2}\right)$. In this brine with $\mathrm{Br}$ and $\mathrm{Cl}$ were scavengers, but the steady-state pressure was much greater than could be accounted for by the sum of the effects produced by the two ions; some sort of synergism was required to rationalize the results. This example suggests that the effects of radiation on multicomponent solutions such as groundwaters cannot presently be predicted with any degree of confidence. The effect will obviously be highly site-specific.

Already alluded to is the appearance of organic compounds, both as solubles in the groundwater and as solids in the rocks. The presence of these compounds will cextainly complicate the radiation chemistry. One example of how radiation affects organics in groundwaters is the recent observation that methane in basaltic groundwater is polymerized to a substance that resembles polyethylene (GRAY 1983b). The possibility that radiation will convert some organic materials to metal ion-complexing agents or to sulfides or ammonia that will influence corrosion may not be very great but neither can it be totally dismissed.

The redox potential of the groundwater can strongly influence the behavior of metals and alloys in solutions, but it is not clear how radiation will affect the redox potential of groundwaters in the immediate vicinity of the waste packages. Undisturbed groundwaters in these rocks are generally reducing in nature because of a lack of oxygen, and, in this case, the imposition of a gamma field should tend to raise the redox potential of the waters. On the other hand, the production of hydrogen by radiolysis and corrosion will tend to lower the redox potential. Thus, whether hydrogen can escape from the solution surrounding the waste package or is retained in it has a large bearing on the redox potential. The presence or absence of organics can also have a large 
effect. Consequently, as with most other aspects of repositories, the effect of radiation will depend on conditions at the specific site.

The importance of the redox potential of the solution on corrosion depends on the metal or alloy under consideration. Increasing the redox potential of chloride solutions generally makes them more corrosive to iron- and copper-based alloys, whereas it could be beneficial for titanium and some of its alloys.

Temperature generally increases the corrosion rate of materials, and, consequently, the thermal conductivity of the rocks is important. From a purely thermal consideration and assuming constant heat generation in the waste packages, corrosion would be least in anhydrock, followed in increasing order by sandstone, limestone, shale, and chalk (RE/SPEC 1984). However, since the temperature constraints are essentially the same for most rock types, the thermal loading would be adjusted to achieve this, and the temperatures would be about the same. In any case, increasing the temperature enhances the leaching of substance from surrounding rocks and increases the solubility of gases in the groundwater $\left(a b n v e \sim 100^{\circ} \mathrm{C}\right.$ ). Both of these factors will influence the radiation chemistry and the corrosiveness of the solution. Hence, changes in the groundwater chemistry produced by temperature may be more important from a corrosion standpoint than the temperature itself.

It is a well-established fact that radiation of moist air produces nitric acid and lesser amounts of other nitrogen oxides (LIND 1961). The steady-state concentration of nitric acid is very low, but if a process exists for the removal of the acid, such as by reaction with a metal susceptible to attack by nitric acid, there is a continuous production of nitric acid. Such a situation was first observed in beam tubes associated with a nuclear reactor (PRIMAK 1954). There appears to be a critical relative humidity below which the nitric acid formed in the vapor will not attack a metal. In view of the fact that the overpack will be at a much higher temperature than the surrounding atmosphere (during transportation to the site and before groundwater surrounds the overpack in the repository), the effective relative humidity at the surface will be very low, and it is unlikely lial significanl allack will vccur on malerials that may be susceptible to attack at lower temperatures.

In summary, the chemistry of the relevant groundwaters is complex and overlapping because of the large number of species present and wide variations in their concentrations, resulting from both preemplacement and alterations due to radiolysis and high temperature. Since corrosion of metallic materials in aqueous environments is closely related to the chemistry of the solution to which they are exposed, assessing corrosion damage in a sedimentary rock waste repository is not a simple task even for a specific site; the wide variations in water chemistries and the high concentrations of chlorides in these rocks make differentiation even more difficult and probably of very limited value. 


\section{K.3 CORROSION OF METALS AND ALLOYS IN SEDIMENTARY ROCK WASTE REPOSITORIES}

As indicated previously, within the uncertainties involved, it is probable that the corrosivity of the groundwaters will be the same for all sedimentary rock repositories. It should be recognized, however, that in any type of formation there will probably be locations where the groundwater will contain very low concentrations of salts, and corrosion rates at these sites could be very low for materials that would suffer extensive corrosion at other sites. However, since these considerations are site-specific, they cannot be addressed here, and the following discussion is general in nacure and involves the bellavior of classes of alloys rather than individual alloys.

\section{$\mathrm{K} .3 .1$ IRON-BASED ALLOYS}

Mild- and low-alloy steels experience relatively high corrosion rates in chloride solutions. For example, tests conducted in the United Kingdom in deaeraced seawalex al $90^{\circ} \mathrm{C}$ in a gamm field of $10^{5} \mathrm{rad} / \mathrm{h}$ indicated that a corrosion allowance of $115 \mathrm{~mm}$ would be needed for 1000 years (HAIJTINK 1984). In Germany, tests in irradiated concentrated brine solutions high in magnesium chloride at $90^{\circ} \mathrm{C}$ showed that mild steels experienced corrosion rates between 55 and $230 \mu \mathrm{m} /$ year $(55-230 \mathrm{~mm}$ in 1000 years) (HAIJTINK 1984). At higher temperatures, the rates in both environments would probably have been substantially higher.

The quantitative effect of temperature and $\mathrm{pH}$ on the corrosion of mild steel in $4 \mathrm{M} \mathrm{NaCl}$ up to $200^{\circ} \mathrm{C}$ was investigated by Posey et al. (POSEY 1977). They used a titanium autoclave equipped with a feed and letdown system so that the solution was constantly refreshed and gently stirred during the test. These results showed that at $\mathrm{pH}$ values between 5 and 8 (measured at $25^{\circ} \mathrm{C}$ ), the corrosion rate was independent of pH at all temperalures. In lils $\mathrm{jH}$ sallge, lle cuxiusion rate (CR) was described by the relationship

$$
\mathrm{CR}(\mu \mathrm{m} / \mathrm{y})=48.6 \exp \left(\frac{-3980}{\mathrm{~K}}\right)
$$

where $\mathrm{K}$ is temperature in degrees Kelvin. From this relationship, corrosion rates of $0.11,0.40,1.08$, and $2.41 \mathrm{~mm} /$ year are calculated for temperatures of $100,150,200$, and $250^{\circ} \mathrm{C}$, respectively. At these temperatures, the corrosion product was principally magnetite. It should be emphasized that these are short-time rates. As the volume of corrosion products increases, lower rates may be observed; however, the temperature dependence would probably remain the same.

Posey et a1. (POSEY 1977) also investigated the effect of chloride ion concentration on the corrosion of mild steel in pure, deaerated sodium chloride solution, at $25^{\circ} \mathrm{C}$. Their results, presented in Fig. $\mathrm{K} .1$, 


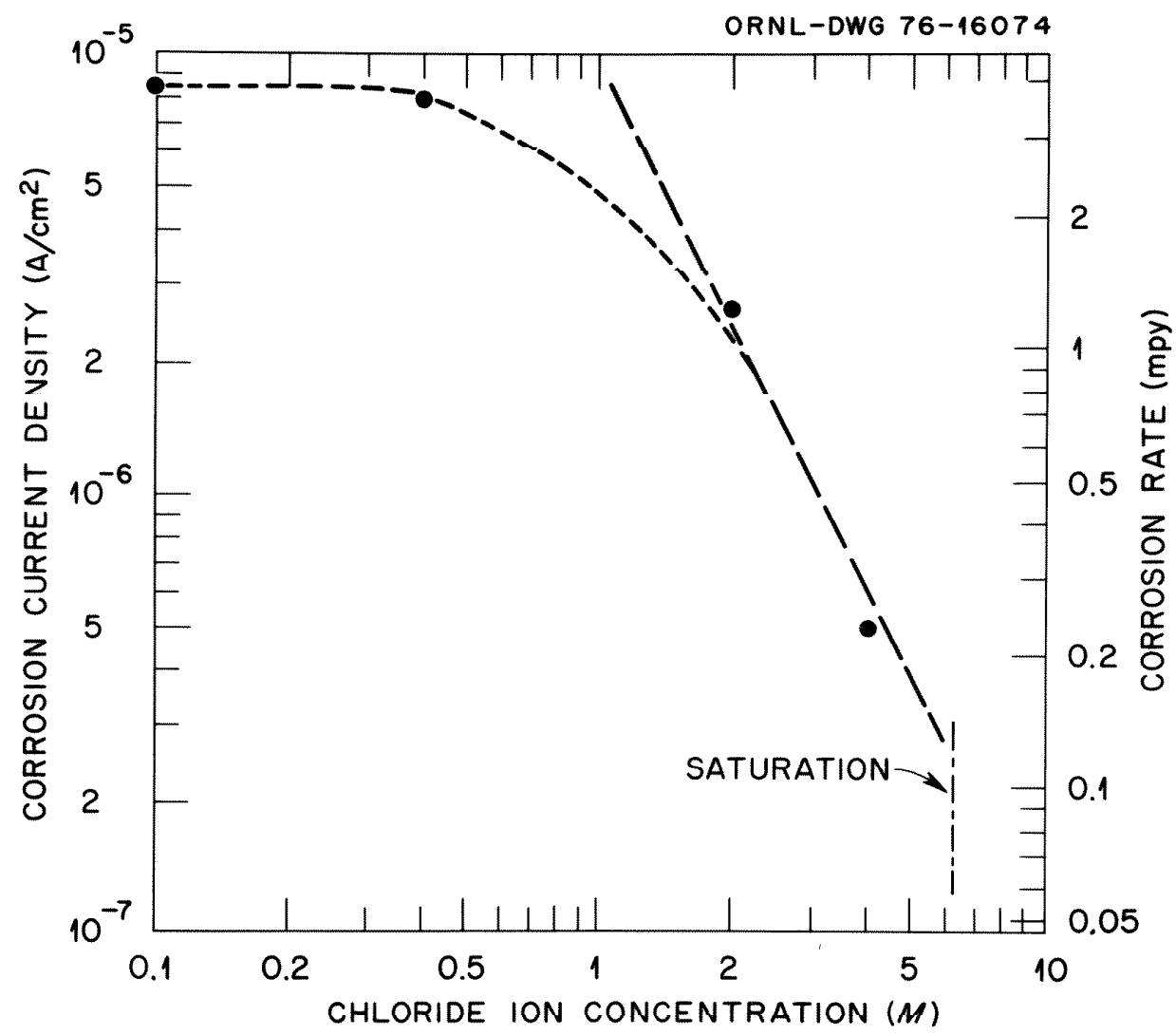

Fig. K.1. Effect of chloride ion concentration (as $\mathrm{NaCl}$ ) on the corrosion of mild steel, $\mathrm{T}=25^{\circ} \mathrm{C}, \mathrm{pH}=5.0$. 
show that the higher rates occurred in 0.1 and $0.5 \mathrm{M}$ solutions ( 3550 and $17,750 \mathrm{ppm}$ ) rather than in more concentrated solutions. They point out that chloride ions at high concentrations actually inhibit the corrosion of iron. Whether a similar situation occurs at higher temperatures and in solutions containing a multitude of different ions is not known, but the results make the assumption that "attack is greater with higher chloride ion concentration" of doubtful validity. There is obviously some level of chloride ions below $3550 \mathrm{ppm}$ where attack would decrease, but this value has not been determined.

Low-alloy steels, containing 1 to $9 \% \mathrm{Cr}$ and $1 \%$ Mo would be expected to experience lower rates than mild steels, but the rates may still be too high for use in a repository. For example, lin lypersaline geolliermal bines, acidified to $\mathrm{pH} 4.0$ to prevent scaling, corrosion rates of 380,200 , 180 , and $150 \mu \mathrm{m} /$ year were noted for mild stee1, $1 \% \mathrm{Cr}-0.5 \% \mathrm{Mo}, 2.25 \% \mathrm{Cr}-1 \% \mathrm{Mo}$, and $9 \% \mathrm{Cr}-1 \%$ Mo steels, respectively, at $125^{\circ} \mathrm{C}$ (McCRIGHT 1978).

The general corrosion of the conventional ferritic and austenitic stainless steels in sedimentary rocks would be modest, but in the presence of clllorlde lous dild a ladialiuil field, buth pits and/or stress corrosion cracks would most likely penetrate the overpack and canister in a few years. However, some of the more recently developed stainless steels, both austenitic and ferritic, that contain low concentrations of interstitial elements and high concentrations of molybdenum have very good corrosion resistance in chloride-containing environments and might be considered in this application.

In summary, the ferrous alloys as a class do not seem to be suitable materials for overpacks in most sedimentary rock repositories. There are, however, some recently developed stainless steels that may prove useful, but as of this date they have not been adequately tested.

\section{K.3.2 COPPER-BASED ALLOYS}

Copper alloys are used extensively in marine environments. Corrosion rates in ambient seawater are low, but as the temperature is increased, corrosion rates increase. For example, in deaerated seawater at $250^{\circ} \mathrm{C}$, copper and 90-10 CuNi were reported to corrode at $70 \mu \mathrm{m} /$ year (MAGNANI 1983). In both environments, rates would have undoubtedly been higher in the presence of a radiation field. In addition to the high chloride concentrations, at least some groundwaters contain low levels of hydrogen sulfide and/or ammonia; the former accelerates the general corrosion of copper alloys, whereas the latter is known for its ability to produce cracking in copper alloys. Although copper is suggested as a material for waste packages in granite repositories in Sweden (AHLSTRÖM 1980) where both the salt content of groundwaters and the radiation intensity at the metal-water interface are low, it is unlikely that copper or its alloys would be satisfactorily corrosion-resistant in a sedimentary rock highlevel waste repository.

It should be noted that even if a groundwater is corrosive to ironand copper-based alloys, corrosion damage could be moderate if the volume 
of solution reaching the package were very low, as might be the case in anhydrite. In such cases corrosion is limited by the total amount of water available to the metal, not by the corrosiveness of solution.

\section{$\mathrm{K} \cdot 3.3$ NICKEL-BASED ALLOYS}

Many nickel-based alloys have excellent general corrosion resistance to saline waters even at high temperatures. The most commonly considered alloys of this class for waste repositories are the Hastelloys* and the Incone1s.** Examples of their high resistance is illustrated by corrosion rates experienced in strong brine solution (similar to that under anhydrock in Table K.1); corrosion rates of $0.91,0.42$, and $0.12 \mu \mathrm{m} /$ year were noted for Incone1 600, Hastelloy $\mathrm{C}-276$, and Inconel 625 , respectively, at $250^{\circ} \mathrm{C}$ in the absence of radiation (PITMAN 1981). How much radiation would influence these rates is unknown, but even an increase by a factor of 5 would still yield very low corrosion rates. Because of their resistance to corrosion and their cost, these materials would most 1ikely be used in waste repositories as a relatively thin cladding on a base metal such as steel.

Nickel alloys are also highly resistant to localized attack, although pitting (BRAITHWAITE 1978 and HIBNER 1982) and stress corrosion cracking (KOLTS 1982) have been noted in chloride-containing environments. Generally, the higher the molybdenum content of the alloy, the better its resistance to localized attack.

This class of alloys appears to have adequate corrosion resistance to groundwaters associated with sedimentary rocks; however, choosing the most appropriate alloy (or whether an alloy as expensive as these is needed) will depend on the specific site. The major disadvantage with these alloys is the lack of experience with them; these alloys have been commercially available for very short times.

\section{K.3.4 TITANIUM ALLOYS}

Titanium and its alloys are highly resistant to chloride solutions at high temperatures (MOLECKE 1983), and alloys containing low concentrations of palladium or both molybdenum and nickel are resistant to solution even in slightly acid environments. Furthermore, titanium and its alloys resist pitting in chloride solutions except perhaps in very highly oxidizing solutions that will not exist in waste repositories.

Two forms of degradation that titanium may experience in waste repositories are crevice corrosion and stress corrosion cracking. In the absence of radiation, crevice corrosion of titanium and most of its alloys occurs readily in salt solutions; however, both the alloy containing low levels of palladium (GRIESS 1968) and the one containing nicke1 and molybdenum appear to be highly resistant to this form of attack (MOLECKE 1983). Evidence of crevice corrosion has been noted with the latter (AHN 1982).

*Trademark of Cabot Wrought Products Division of Cabot Corporation. **Trademark of Huntington Alloys, Inc. 
Both hydrogen embrittlement and active-path stress-corrosion cracking are possible failure modes for titanium alloys. Certainly, if the solubility of hydrogen in titanium is exceeded, a brittle hydride phase forms; but recently acquired evidence suggests that enough hydrogen to produce embrittlement can only be introduced into the titanium alloy containing nickel and molybdenum by cathodic charging at potentials much more negative than could possibly be achieved in a repository (MOLECKE 1983). Thus, with the data in hand, it appears that hydrogen embrittlement of titanium will probably not be a problem in waste repositories.

Similarly, tests in various solutions have shown that titanium and most alpha titanium alloys do not undergo active-path stress corrosion cracking, but precracked specimens will show crack growth in chloride solutions if the stress intensity at the tip of the crack is sufficiently high (BROWN 1972). Thus, all data available suggest that titanium, or preferably the titanium-nicke1-molybdenum alloy. would experience only slight corrosion, probably penetrating no more than $1 \mathrm{~mm}$ during 1000 years in a sedimentary rock waste repository. As with the nickel alloys, titanium would probably be used as a cladding on steel. The major disadvancage with cicantum alloys is the 1 imlced expertence with them in aqueous environments; titanium was first produced commercially shortly after World War II.

In summary, the relatively high levels of chloride ions in sedimentary rock groundwaters are likely to corrode most iron- and copper-based alloys at excessive rates, although some recently developed stainless steels may ultimately prove useful. Most types of rocks, however, have certain locations where the salt content of the groundwater is low; and in such waters, select alloys of both classes may be suitable if sufficient corrosion allowance is designed into the waste package. For all of the subject rocks, high-nickel alloys and titanium alloys would be expected to have very high resistance to corrosion and would probably be used as a thin cladding on steel. Obviously, the choice of material will depend on the composicion of the groundwater ac the spectfic location under consideration. 


\section{K.4 RANKING THE CORROSIVITY OF SEDIMENTARY ROCK REPOSITORY}

It has been noted previously that in all types of sedimentary rocks the groundwaters at most locations contain high enough concentrations of chloride ions to produce appreciable attack on most iron- and nicke1-based alloys. On the other hand, both titanium and high-nickel alloys appear to have corrosion resistance such that they would experience only minor attack during 300 to 1000 years at all locations. Therefore, it seems appropriate to rank all rocks, in terms of their corrosivity to waste packages, approximate1y equal.

Based on the thermal conductivities referred to in Sect. K.2, it may seem appropriate at first glance to rank the rocks on the basis of overpack temperatures of waste packages that generate equal amounts of heat. However, from consideration of thermal effects on the host rock, it is necessary that in rocks with poor thermal conductivity the waste package thermal loadings be less than those in rocks with greater thermal conductivities. Thus, the overpack temperatures will tend to be about the same in 111 rocks and do not provide a hasis for ranking the rocks in terms of corrosiveness. 


\section{K.5 REFERENCES}

AHLSTROM 1980. Per-Eric Ah1strom, "Ceramic and Pure-Metal Canisters in Buffer Material for High-Level Radioactive Waste," Nuc1. Chem. Waste Management $1,77-78(1980)$.

AHN 1982. T. M. Ahn and P. Soo, Container Assessment-Corrosion Study of HLW Container Material, Quart. Prog. Rept. October-December 1981, NUREG/CR-2317 (BNL NUREG-51449), Apri1 1982.

BRAITHWAITE 1978. J. W. Braithwaite and M. A. Molecke, High-Level Waste Cantster corrosion Studies Perlineut lo Geolugic Isolation, SAND 78-2111, December 1978 .

BROWN 1972. B. F. Brown, Stress-Corrosion Cracking in High Strength Steels and in Titanium and Aluminum Alloys, Naval Research Laboratory, Washington, 1972, pp. 245-353.

COUTURE 1984. R. A. Courure and M. G. Seltz, "Physical Response or Backfill Materials to Mineralogical Changes in a Basalt Environment," in Proceedings of the U.S. Nuclear Regulatory Commission, NRC Nuclear Waste Geochemistry 183, D. H. Alexander and G. F. Birchard eds., NUREG/CP-0052, May 1984.

GRAY 1983a. W. J. Gray, Gamma Radiolysis of Groundwaters Found Near Potential Radioactive Waste Repositories, PNL-SA-10928, May 1983.

GRAY 1983b. W. J. Gray, Gamma Radiolysis Effects on Basalt Groundwater, PNL-SA-11415, October $198 \overline{3}$.

GRIESS 1968. J. C. Griess, "Crevice Corrosion of Titanium in Aqueous Salt Solutions," Corrosion 24, 96-109 (1968).

HAIJTINK 1984. B. Haijtink and A. Accary, "The Joint European Testing Program on HLW Container Materials," pp. 603-606 in Waste Management/84, Proceedings of the Symposium on Waste Management at Tucson, Arizona, March 11-15, 1984, 1, R. G. Post ed., Arizona Board of Regents, 1984.

HIBNER 1982. E. L. Hibner and R. W. Ross, "Effect of pH, Chloride Concentration and Temperature on Localized Corrosion of Nickel Alloys in $\mathrm{SO}_{2}$-Scrubber Environments," Paper No. 196 presented at Corrosion/82, March 22-26, 1982, Houston, Texas.

JENKS 1972. G. H. Jenks, Radiolysis and Hydrolysis in Salt-Mine-Brines, ORNL/TM-3717, March 1972.

KOLTS 1982. J. Kolts, "Temperature Limits for Stress Corrosion Cracking of Selected Stainless Steels and Nicke1-Base Alloys in

Chloride-Containing Environments," Paper No. 241 presented at Corrosion/82, March 22-26, 1982, Houston, Texas. 
LIND 1961. S. C. Lind, Radiation Chemistry of Gases, Reinhold, New York, 1961, pp. 232-45.

MAGNANI 1983. N. J. Magnani, "Corrosion Resistant Canisters for Nuclear Waste Isolation," pp. 669-76 in Materials Research Society Proceedings, Scientific Basis for Nuclear Waste Management VI, 15, D. G. Brookine ed., North-Ho1land, New York, 1983.

McCRIGHT 1978. R. D. McCright and R. E. Garrison, "Corrosion in a Multiple-Stage Flash System," in Proceedings of Geothermal Systems Materials: A Workshop/Symposium, Austin, Texas, May 23-25, 1978, C00-3904-1, May 1978.

MOLECKE 1983. M. A. Molecke, J. A. Ruppen, and R. B. Diegle, "Materials for High-Level Waste Overpacks in Salt Formations," Nucl. Tech. 62, 476-506 (1983).

PITMAN 1981. S. G. Pitman, B. Griggs, and R. P. Elmore, "Evaluation of Metallic Materials for Use in Engineered Barrier Systems," pp. 523-30 in Materials Research Society Proceedings, Scientific Basis for Nuclear Waste Management, 3, J. G. Moore ed., Plenum Press, New York 1981.

POSEY 1979. F. A. Posey and A. A. Palko, "Corrosivity of Carbon Steel in Concentrated Chloride Solutions," Corrosion 35, 38-43 (1979).

POSEY 1977. F. A. Posey, A. A. Palko, and A. L. Bacarella, Corrosivity of Geothermal Brines Progress Report for Period Ending December 1976, ORNL/TM-5863, April 1977.

PRIMAK 1954. W. Primak and L. H. Fuchs, "Transportation of Matter and Radioactivity by Ionized Air," Phys. Today 7 , (9) 15-16 (1954). 
This page intentionally left blank 


\section{INTERNAL DISTRIBUTION}

1. A. G. Croff

2. S. H. Stow

3. Central Research Library

4. ORNL Laboratory Records-RC

5-6. ORNL Laboratory Records-OSTI

\section{EXTERNAL DISTRIBUTION}

7. Dr. R. J. Budnitz, RW-40E/Forrestal Building, U.S. Department of Energy, 1000 Independence Avenue S.W., Washington, DC 20585

8. Dr. M. S. Y. Chu, Director, Office of Civilian Radioactive Waste Management, RW-1/Forrestal Building, U.S. Department of Energy, 1000 Independence Avenue S.W., Washington, DC 20585

9. Dr. A. E. Van Luik, RW-40W, U.S. Department of Energy, Yucca Mountain Site Characterization Office, 1551 Hillshire Drive, Suite A, Las Vegas, NV 89134 
This page intentionally left blank 